UNITED STATES DEPARTMENT OF THE INTERIOR

Harold L. Ickes, Secretary

GEOLOGICAL SURVEY

w. C. Mendenhall, Director

Water-Supply Paper 843

\title{
FLOODS OF DECEMBER 1937 IN NORTHERN CALIFORNIA
}

BY

H. D. McGLASHAN AND R. C. BRIGgGS

Prepared in cooperation with the

FEDERAL EMERGENCY ADMINISTFATMO OF PUBLIC WORKS, BUREAU OF RECLIMATION

AND STATE OF CALIFORNIA
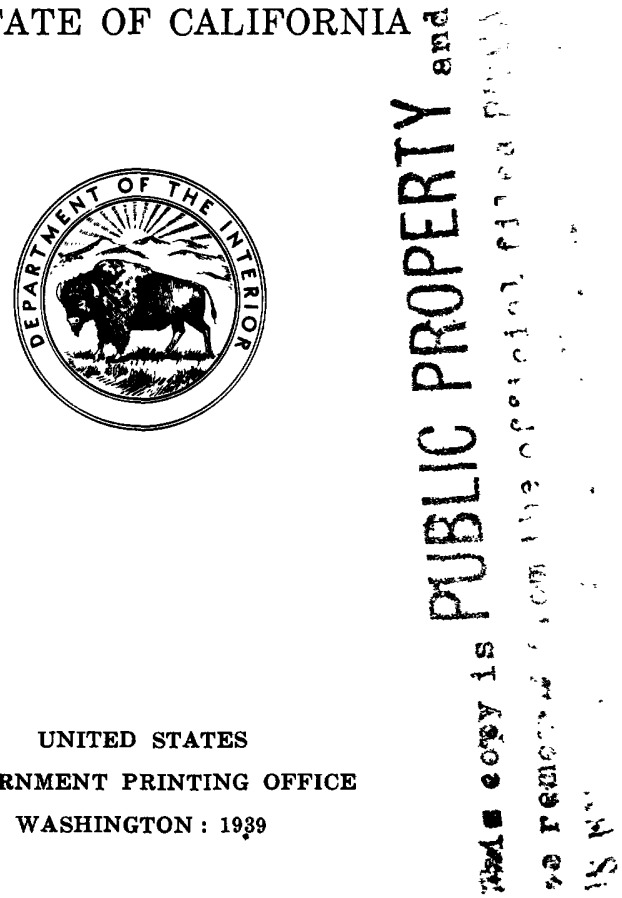

For sale by the Superintendent of Documents, Washington, D. C. - - - Price 60 cents (paper cover) 
Introduction $\ldots$

Administration and personnol ....................... . . . 4

Acknowledgments. . . . . . . . . . . . . . . . . . . . . 5

General features of the floods fo.................... . . . . . 6

Meteorologic and hydrologlc conditions................... 22

Precipltation

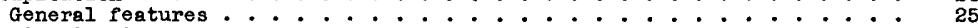

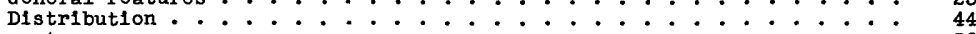

Temperature ......................... . . . . 56

Sierra Nevada slopes tributary to south half of Central Valley . . . . 68

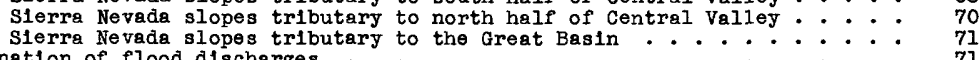

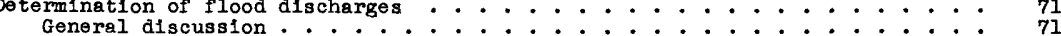

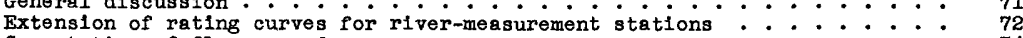

Computation of flow over dams .............................. 74

Computation of flow from slope-area observations . . . . . . . . . . 75

Computation of flow through contracted openings . . . . . . . . . . . 77

Stages and discharges at river-measurement stations......... .7979

Explanation of data stages on the san Joaquin River : : : : : : ${ }^{79}$

Salinas River Basin . . . . . . . . . . 97

Salinas River near Santa Margarita................. . . 97

Salinas River near Spreckels................... . . . . . 98

Arroyo Seco near soledad............................. 100

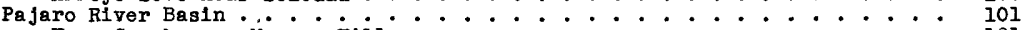

Uvas Creek near Morgan Hill .................... . . . 101

San Lorenzo River Basin

San Lorenzo Rlver at Blg Trees . . . . . . . . . . . . . . . : : 102

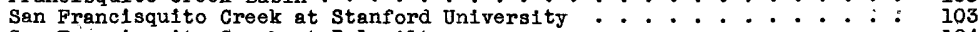

San Francisquito Creek at Palo Alto to.............. 104

Los Trancos Creek at Stanford Unlversity . . . . . . . . . . . . 105

Sterens Creek Basin

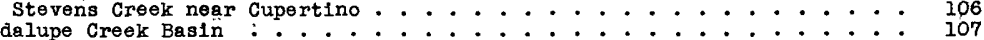

Guadalupe Creek at Guadalupe . . . . . . . . . . . . . . . . 107

Guadalupe Creek at San Jose ..................... 108

Alamitos Creek near Edenvale . . . . . . . . .......... 109

Los Gatos Creek at Los Gatos . . . . . . . . . . . . . . 110

Campbell Creek at Saratoga . . . : . : . : . : . : 111

Coyote Creek Basin

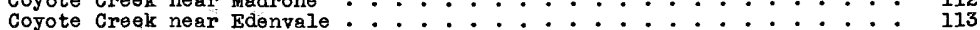

Alameda Croek Basin : . . : : : : : : : : : 114

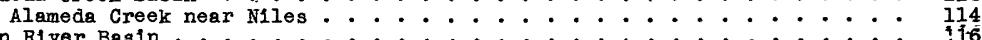

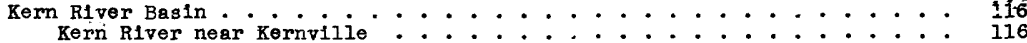

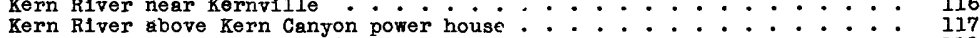

Kern River near Bakersfleld . . . . . . . . . . . . . . . . 118

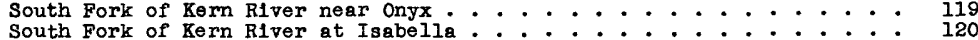

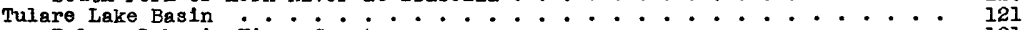

Tulare Lake in Kings County . . . . . . . . . . . . . . . . . 121

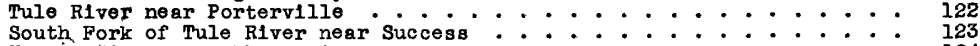

Kaweah River near Three RIvers . . . . . . . . . . . . 124

North Fork of Kaweah RIver at Kaweah : . : . : . : . . . 125

Klngs Rlver above North Fork . . . . . . . . . . . . . . . . 126

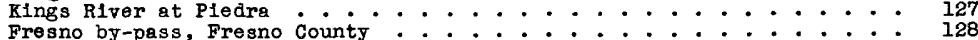

North Fork of Kings RIver near Cliff Camp : : : : : : 129

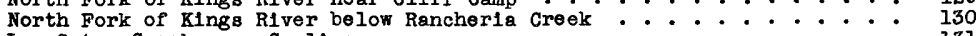

Los Gatos Creek near Coalinga .................... 131

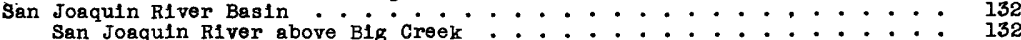

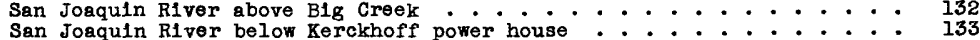

San Joaquin RIver near Frlant . . . . . . . . . . . 134

San Joqquin River below Skaggs Bridge ................ 135

San Joaquin R1ver near Neman . . . . . . . . . . . . . . . . 136

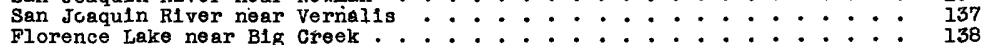

South Fork of San Joaquin Rlver near Plorence Lake : : : : : : ${ }_{139}$

Bear Greek near Vermilion Valley ................... 140

Mono Creek near vermllion Valley .................. 141

Huntington Lake near Blg Creek . . . . . . . . . . . . . . . . . 142

Big Creek below Huntington Lake . . . . . . . . . . . . . . 143

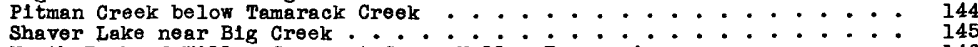

North Fork of W1llow Creek at Crane valiej Reservoli : : : : : : 146

B1g Sandy Creok near Auberry ................... 147 
Stages and discharges at river-measurement stations--Continued

San Joaquin River Basin--Continued

Fine Gold Creek near Friant

Greek near Friant.

Little Dry Creek near Friant.

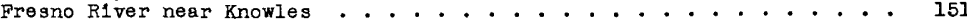

Fresno River near Daulton . . . . . . . . . . . . . . . . . . . . 15

Chowchilia River at Buchanan dam site . . . . . . . . . . . . . . . . 153

Bear Creek near Planada . . . . . . . . . . . . . . . . . . . . 154

Mar1posa Creok near Le Grand ....................... . . 155

Merced River at Happy Isles Bridge, near Yosemite . . . . . . . . . . 156

Merced R1ver at Pohono Bridge, near Yosem1te... . . . . . . . . . . . 157

Merced River at Kittridge . . . . . . . . . . . . . . . . . . . . 158

Lake McClure at Exchequer ............. 159

Merced Rlver at Exchequer ...... . . . . . . . . . . . . . . . . 160

Merced River near Livingston:. . . . . . . . . . . . . . . . . . . . 161

Tenaya Creek near Yosem1te... . . . . . . . . . . . . . . . . . . 162

Orestimba Creek near Newman . . . . . . . . . . . . . . . . . . . . 163

Hetch Hetchy Reservoir at Hetch Hetchy . . . . . . . . . . . . . . . 164

Tuolumne RIver near Hetch Hetchy . . . . . . . . . . . . . . . . . . . 165

Don Pedro Regervoir near La Grange . . . . . . . . . . . . . . . . . . 166

Tuolumne River above La Grange Dam, near La Grange.. . . . . . . . . . 167

Falls Creek near Hetch Hetchy . . . . . . . . . . . . . . . . . . . 168

Cherry Creek near Hetch Hetchy. . . . . . . . . . . . . . . . . . 169

Lake Eleanor near Hetch Hetchy . . . . . . . . . . . . . . . . . . . . . 170

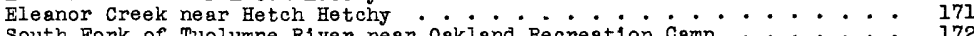

South Fork of Tuolumne River near Oakland Recreation Camp

M1ddle Tuolumne R1ver near Buck Meadows . . . . . . . . . . . . . . 173

Woods Creek near Jacksonv1lle . . . . . . . . . . . . . . . . . . . . . 174

Middle Fork of Stanlslaus River at Sand Bar Flat, near Avery . . . . . 175

Melones Reservolr at Melones Dam . . . . . . . . . . . . . . . . . 176

Stanislaus River below Melones power house. . . . . . . . . . . . . . . 177

North Fork of Stan1slaus River near Avery . . . . . . . . . . . . . . . 178

South Fork of Staniglaus River at Strawberry Reservoir . . . . . . . . . 179

South Fork of Stanislaus River below Lyons Dam . . . . . . . . . . . . 180

Calaveras River at Jeriny Lind . . . . . . . . . . . . . . . . . 181

Cosgrove Creok near Valiey Springs . . . . . . . . . . . . . . . . . . . 183

Salt Springs Reservoir near West Point . : . . . . . . . . . . . . . . . . . 184

North Fork of Mokelume River below Salt Springs Dam . . . . . . . . . . 185

Mokelumne River near Mokelumne Hill . . . . . . . . . . . . . . . 186

Mokelumne River at Lancha Plana . . . . . . . . . . . . . . . . . 187

Mokelumne R1ver near Clements . . . . . . . . . . . . . . . . . . . 188

Mokelumne R1ver at Woodbridge . . . . . . . . . . . . . . . . . . . 189

Cold Creek near Mokelumne Peak . . . . . . . . . . . . . . . . . . . . 190

Bear River at Pardoe Camp . . . . . . . . . . . . . . . 191

Middle Fork of Mokelumne River at West Point . . . . . . . . . . . . . 192

South Fork of Mokelumne R1ver near West Polnt . . . . . . . . . . . . . 193

Sutter Creek near Sutter Creek . . . . . . . . . . . . . . . . . . . . 194

North Fork of Cosumnes R1ver near El Dorado . . . . . . . . . . . . . . 195

Cosumnes River at Michlgan Bar . . . . . . . . . . . . . . . . . . 196

Sacramento River Balin... . . . . . . . . . . . . . . . . . . . . . 197

Sacramento River at Antier: . . . . . . . . . . . . . . . . . . 197

Sacramento R1ver at Kennett . . . . . . . . . . . . . . . . . . . 198

Sacramento Rlver negr Red Bluff:...................... . 199

Sacramento R1ver at Verona... . . . . . . . . . . . . . . . . . 200

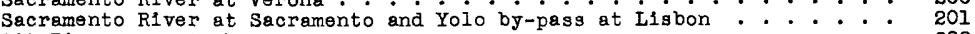

P1t R1ver near Canby . . . . . . . . . . . . . . . . . . . . . . 202

Pit R1ver at Fal1 River Milis . . . . . . . . . . . . . . . . . . . 203

Pit River below Plt No. 4 dam . . . . . . . . . . . . . . . . . . . 204

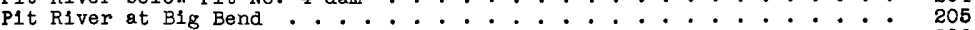

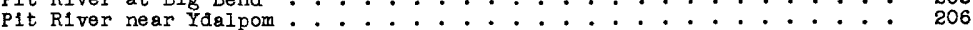

South Fork of P1t River near Likely . . . . . . . . . . . . . . . . 207

Hat Creok near Hat Creek . . . . . . . . . . . . . . . . . . . 208

McCloud River near McCloud . . . . . . . . . . . . . . . . 209

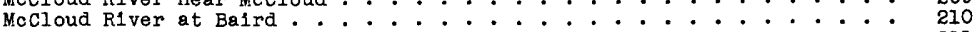

MIII Creek near Ios Molinos . . . . . . . . . . . . . . . . . . . 211

Elder Creek near Henleyville... . . . . . . . . . . . . . . . 212

Thomas Creek at Paskenta... . . . . . . . . . . . . . . . . . . 213

Deer Creek near Vina... . . . . . . . . . . . . . . . . . . . . . 214

Chlco Creok near Chlco... . . . . . . . . . . . . . . . . . . . . . 215

Stony Creok above Stony Gorge Reservoir . . . . . . . . . . . . . . . 216

Stony Gorge Regervoir near Elk Creek................... . . . 217

Butte Creek near Chlco............ . . 218

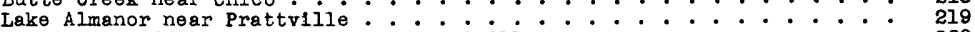

North Fork of Feather RIver near Prattvilie . . . . . . . . . . . . . . 220

Feather River near Orovilie . . . . . . . . . . . . . . . . . . . . 221

Indian Creok near Crescent M11ls........... . . . . . . . . . 222

Spanlsh Creek at Keddie . . . . . . . . . . . . . . . . . . . . . . 223

Bucks Creok storage reservoir near Bucks ranch : . . . . . . . . . . . . . 224

Bucks Creek at Buckg Creek storage reservolr . . . . . . . . . . . . . 225

Grizzly Creek near Storrie . . . . . . . . . . . . . . . . . . . 226

West Branch of Feather Rlver near Yankee Hilj . . . . . . . . . . . . . 227

Concow Creek near Yanke Hill . . . . . . . . . . . . . . . . . . . . . . 228

Middle Fork of Feather R1ver near Clio . . . . . . . . . . . . . . . . 229

M1ddle Fork of Feather R1ver at Bldwell Bar . . . . . . . . . . . . . . 230

South Fork of Feather R1ver at Enterprise . . . . . . . . . . . . . . . 231

Lost Creek near Clipper Mills . . . . . . . . . . . . . . . . . . . . 232

Middle Fork of Yuba River at Milton . . . . . . . . . . . . . . . . . . 233

M1ddle Fork of Yuba River near North San Juan . . . . . . . . . . . . . 234

Yuba R1ver at Smartville . . . . . . . . . . . . . . . . . . . ...

Oregon Creok near North San Juan. . . . . . . . . . . . . . . . . 236 
Stages and discharges at river-measurement stations--Continued Sacramento River basin--Continued

Lake Spaulding near Emlgrant Gap..................... 238

South Fork of Yuba Rlver at Lake spauiding $: \therefore .: \therefore .: 239$

Bowman Lake near Graniteville ..................... 240

Canyon Creek below Bowman Lake.................... 241

Deer Creek near Smartv1lle .................... 242

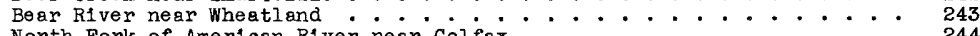

North Fork of Amerlcan R1ver near Colfax................ 244

American R1ver at Falr Oaks . . . . . . . . . . . . . .... 245

M1ddle Fork of Amer1can R1ver near Auburn . . . . . . . . . . 246

South Fork of Amerlcan River near Kyburz . . . . . . . . . . . 247

South Fork of Amerlcan River near Camino: : : : : : : : : : : : : ${ }_{249}^{248}$

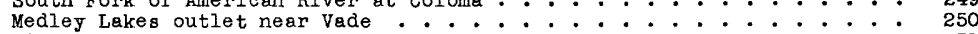

S1lver Lake outlet near k1rkwood : . . . . . . . . . . . . . . 251

S1lver Fork of South Fork of American River near Kyburz . . . . . 252

Twin Lakes outlet near Klrkwood .................... 253

Alder Creek near Wh1tehall ..................... . 254

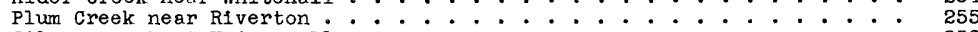

Sllver Creek at Unlon Valley . . . . . . . . . . . . . . 256

Sllver Creek near Placerville . . . . . . . . . . . . . . 257

South Fork of S1lver Creek near Ice House . . . . . . . . . . . . 258

Clear Lake at Lakeport ....................... . . . 259

Cache Creek at Yolo

North Fork of Cache Creek near Lower Lake

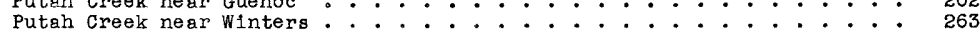

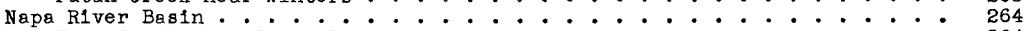

Conn Creek near St. Helena... . . . . . . . . . . . . . . . 264

Eel R1ver Basin . . . . . . . . . . . . . . . 265

Lake P1llsbury at Hullville . . . . . . . . . . . . . . . . 265

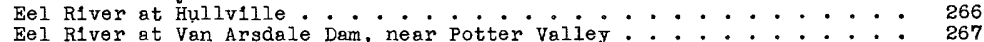

Eel River at Scot1a.

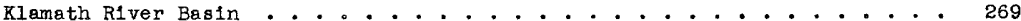

Klamath R1ver at Somesbar : : : : : : : : : 269

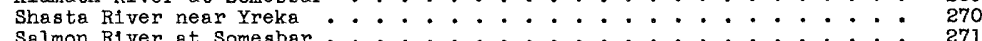

Salmon Rlver at Somesbar $: \therefore: \therefore: \therefore: \therefore 2^{272}$

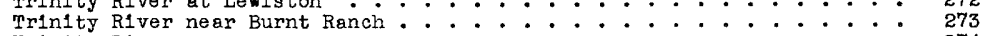

Trinity R1ver near Hoopa.................. . . . 274

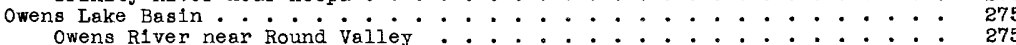

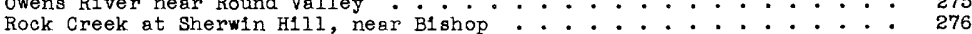

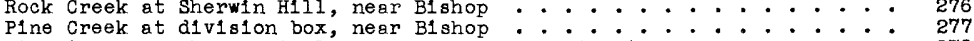

Big Pine Creek below Little Pine Creek, near Big Pline $. . \therefore . . . \quad 278$

Independence Creek at Independence o

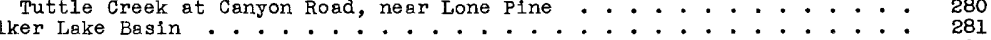

Brldgeport Reservolí near Bridgeport : . . . . . . . . . 281

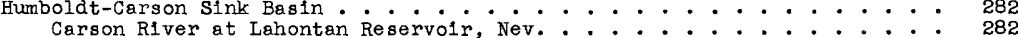

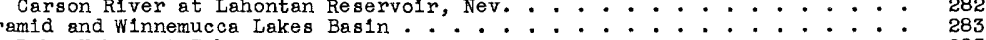

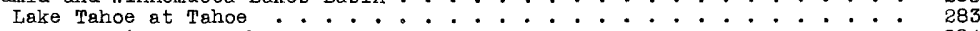

Truckee R1ver at Tohoe ....................... 284

Trucke Rlver at Iceland . : : : : : : : : : : : : : : : ${ }^{285}$

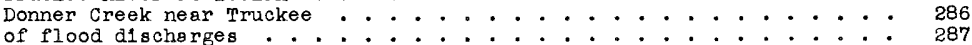

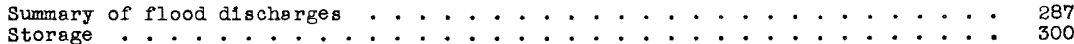

Examples of effect on storage ................... 302

San Joequin R1ver ........................ 302

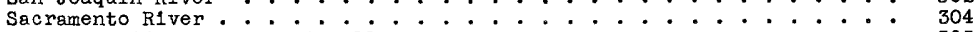

Areas outside the central valiey : : . : . : : : : : 305

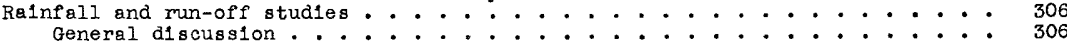

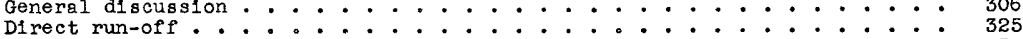

Residuals of rainfali and run-of conditions during floods of record: : 333

Comparison of rainfali and run-off conditions during floods of record $: .3_{341}$

Character1stics of peak discharge : : . : . : . : 344

Basin characteristics..................... . . . 346

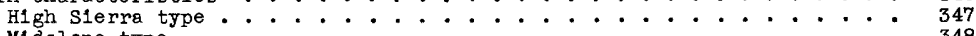

M1dslope type ........................ 348

Foothlil type froup : : : : : : : : : : : : : : : : : ${ }_{349}$

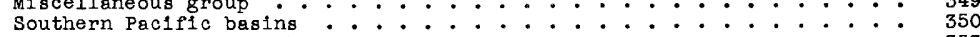

Los Gatos Creek Basin (near Coalinga) and Orestimba Creek Basin..... 353

Kern Rlver Basin

Tule and Kaweah R1ver Basins : : : : : : : : : : : : : : ${ }^{357}$

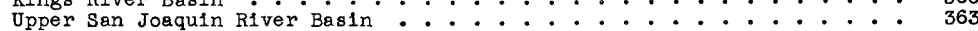

Fresno and Chowch1lla R1ver, Mariposa and Bear Creek Bas1ns ...... 367

Merced R1ver Basin....................... 370

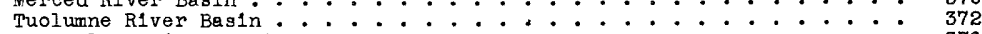

Stanlslaus R1ver Basin . . . . . . . . . . . . 376

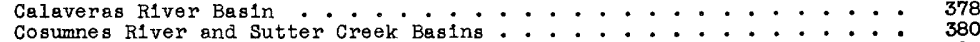

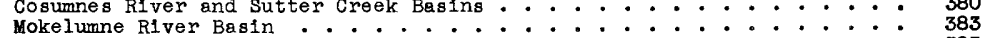

Opper Sacramento R1ver ana Mccloud River Basins : : : : : : 385

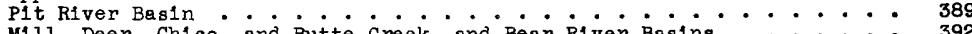

M111, Deer, Ch1co, and Butte Creek, and Bear River Basins ..... 392 
RaInfall and run-off studies--Cont1nued

Basin character1st1cs--Cont1 1nued
Elder, Thomas, Stony, Cache and Putah Creek Basins .......... Page

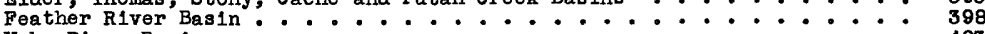

Yuba R1ver Basin ........................ 403

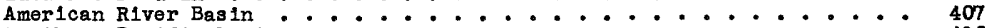

Northern Pac1f1c basins ..................... 410

San Francisco Bay bas1ns ..................... 413

Owens Lake basins .......................... 417

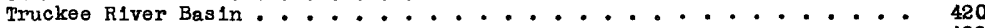

Flood crests bo

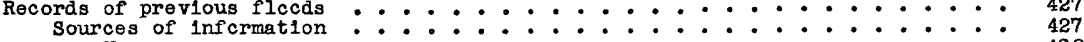

Newspapers ........................ 428

Historles

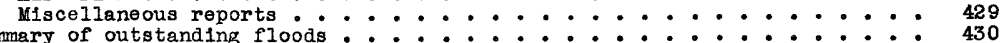

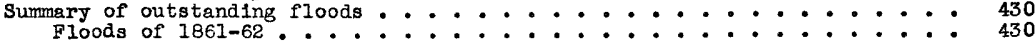

Flcods of $1867-68: \ldots$

Floods of 1881

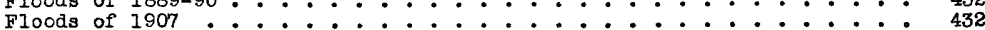

Southern Pacific basins........................ 433

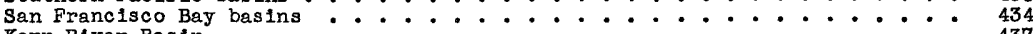

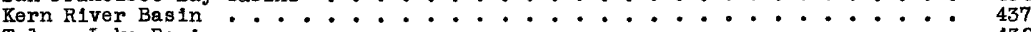

Tulare Lake Basin .......................... 439

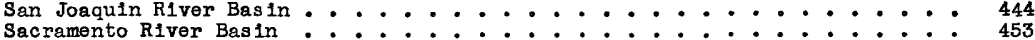

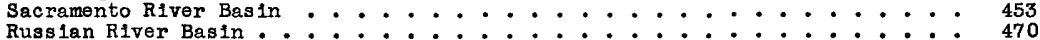

Eel River Basin . : : : : : : : : : : : : 471

Klamath R1ver Bas 1n ........................ 473

Smith R1ver Basin............................ . . . . . 475

Majer streams from the sierra Nevada tributary to the Great Basin : . : 476

Records of floods in 1938 . . . . . . . . . . . . . . . . 479

Sal1nas R1ver near Santa Margar1ta ................. 482

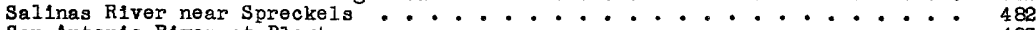

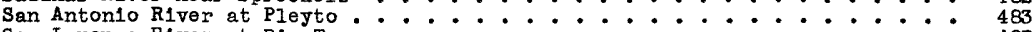

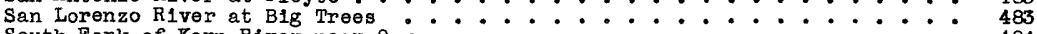

South Fork of Kern River near Onyx .................. 484

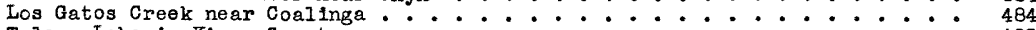

Tulare Lake In KIngs County : : : : : : : : : : 48

Fresno by-pass, Fresno County : : : : : : : : : : 486

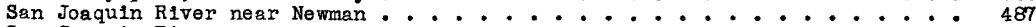

San Joaquin River near Vernalis . . . . . . . . . . . . . 487

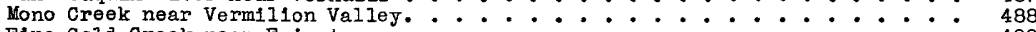

Fine Gold Creek near Friant..................... . . . 488

Fresno River near Knowles . : : : : : : : : : : : : 489

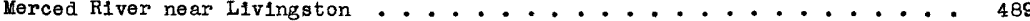

Wocds Creek near Jacksonville . . . . . . . . . . . . . . . . 490

Shasta River near Yreka. . : : : : : : : : : : : 490

$\operatorname{Irdex} \ldots$

\section{ILLUSTRATIONS}

Plate 1. Flood damage in Feather River Basin: A, Rock slide on Feather Rlver

highway at Butte-PIumas county line; B, Washout on Main Street,

Chester, Callf. ...................

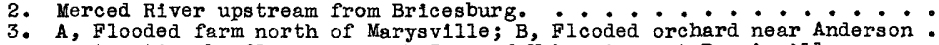

3. A, Flooded farm north of Marysville; B, Flcoded orchard near Anderson.

5. A, H1ghway flooded by Sacramento R1ver; B, Damaged highway bridge on Bear Creek south of Los Molinos.

6. Sacramento River overflow near Gerber

7. Flood scenes on Sacramento River . . . . . . . . .

8. Flooded areas in Butte Bas in In vicinity of Biggs $:$ : A, Inundated farmlands in Sacramento Valley; B, Town of Gllroy flooded

10. Flooded areas along Russian River in vicinity of Healdsburg: $: \ldots$

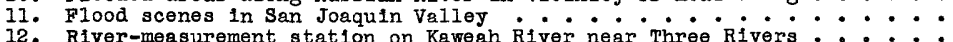

12. River-measurement station on Keweah River near Three Rivers $: \ldots$

Figure 1. Map showing location of area covered by this report : ${ }_{2}$. Map showing the principal river systems and cities mentioned in text:

3. Map showing areas flooded in lower Sacramento River Basin,

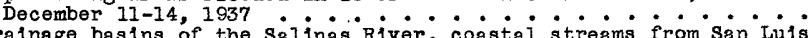

4. Drainage basins of the Salinas River, coastal streams from San Luis Oblspo Creek to San Francisco Bay, and streams tributary to San Francisco Bay from the south Lake and Tulare Lake : : : : :

5. Drainage basins of Buena Vista Lake and Tulare Lake ${ }^{6}$. Drainage bas in of the San Joaquin River above the mouth of the

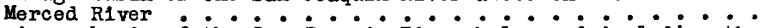

7. Drainage basin of the San Joaquin River below and including the

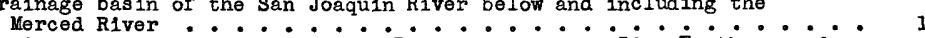

8. Dralnage basin of the sacramento River, except the Pit, Feather, and Amerlcan Rivers ......................

9. Drainage bas ins of the Pit, Feather, American, and Trucke Rivers: :

10. Drainage basins of the Mad and Eel Rivers, streams tributary to San Francisco Bay from the north, and coastal streams betweon San 
Figure 11. Dralnage basins of the Klamath River, Smith RIver, and Redwood

12. Dralnage basins from the carson River to Owens Lake, inclusive, along the westerm boundary of the Great Basin ......... 2I

13. Is ohyetal map of the dralnage basins of the Salinas River, coastal streams from San Luis Obispo Creek to San Francisco Bay, and streams tributary to San Francisco Bay from the south, showing the total precipitation, in inches, December 8-13, 1937. .

14. Isohyetal map of the drainage basins of Buena Vista Lake and Tulare Lake, showing the total precipitation, in inches,

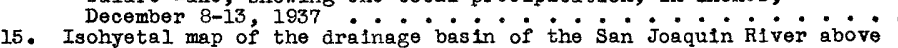
the mouth of the Merced River, showing the total preclpitation In Inches, December 8-13, 1937 . . . . . . . . . .

16. Isohyetal map of the drainage basin of the San Joaquin River below and including the Merced RIver, showing the total precipitation,

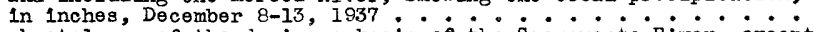

17. Isohyetal map of the drainage basin of the Sacramento River, except the Pit, Feather, and American Rivers, showing the total pre-

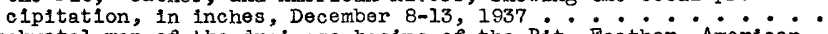

18. Isohyetal map of the drainage basins of the Pit, Feather, American, and Truckee Rivers, showing the total precipitation, in inches, December 8-13, 1937 ... . . . . . . . . . .

19. Isohyetal map of the drainage basins of the Mad and Eel Rivers, streams tributary to San Franclsco Bay from the north, and coastal streams between San Francisco Bay and Mad River, showing the total precipltation, in inches, December 8-13, 1937 ...

20. Isohyetal map of the drainage basins of the Klameth River, Smith River, and Redwood Creek, showing the total precipitation, in

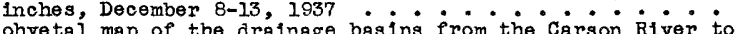

21. Is ohyetal map of the dralnage basins from the Carson River to
Orens Iake, inclusive, along the western boundary of the Great Basin, showing the total precipitation, in inches, December

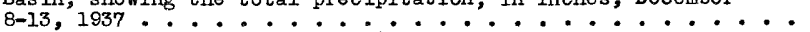

22. Section $A-B$; location shown on flgure $2 \ldots \ldots$

23. Section C-D; location shown on flgure $2 \ldots \ldots$

24. Section E-F; location shown on figure $2: \therefore . . . . .$.

25. Section G-H; location shown on flgure 2 - : Mount Shaste C1ty to Fiddletown, December 8-13, 1937 .

27. Hourly precipltation, in inches, at various precipitation stations,

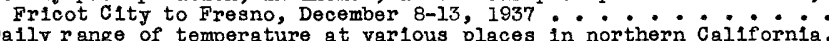

28. Daily $r$ ange of temperature at varlous places in northern california, November and December 1937 a a sections of the siope-area

29. Map, profile of high-water marks, and sectlions of the slope-area.

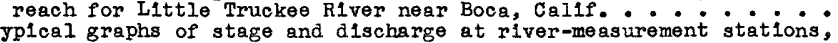
plotted from records in this report . . . . . . . . .

31. Graphs of mean da11y discharge at varlous river-measurement stations in northern Callfornla for the perlod November 1, 1937, to

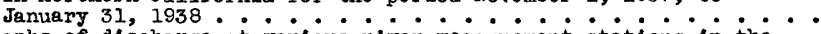

32. Graphs of discharge at various river-measurement stations in the Salinas River Basin and on nearby coastal and San Francisco Bay

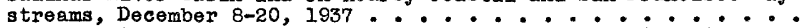

33. Graphs of discharge at varlous river-measurement stations in Buena V1sta and Tulare Lake Basins, December 8-20, $1937 \ldots . . . .$.

34. Graphs of discharge at various river-measurement stations on the San Joaquin River, December 8-20, 1937 ............

35. Graphs of discharge at varlous river-measurement stations on tributarles to the San Joaquin River, December 8-20, 1937 ......

36. Graphs of discharge at varlous river-measurement stations on the Secramento R1ver, December 8-20, 1937 .........

37. Graphs of discharge at various river-measurement stations in the PIt River Bas in, December 8-20, $1937 \ldots . . . . . . .$.

38. Graphs of discharge at varlous river-measurement stations in the Feather R1ver Basin, December 8-20, $1937 \ldots . . . . . .$.

39. Graphs of discharge at varlous river-measurement stations in the American River Basin, December 8-20, 1937 ...........

40. Graphs of discharge at varlous river-measurement stations on tributarles to the Sacramento RIver from the west, December 8-20, 1937 .

41. Graphs of discharge at varlous river-measurement stations in the Bel and Klamsth River Basins, December 8-20, 1937 .......

42. Graphs of stage at various river-stage stations on the san joaquin

43. Chart showing the maximum momentary discharge, in second-feet per square mile, for unregulated streams in California, December 1937,

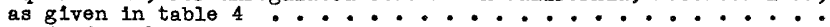

44. Wethod of analysis used in determining direct min-off associated with the storm perlod December 8-13, 1937 .........

45. Chart showing direct run-off, in inches, determined for various drainage areas in northern California during flood of December

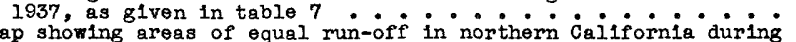

46. Map showing areas of equal run-off in northerm California during

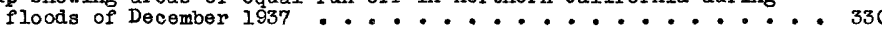

47. Koy map showing location of southern Pacific basins : : :

48. Key map showing location of Los Gatos Creok Basin (near Coainga)

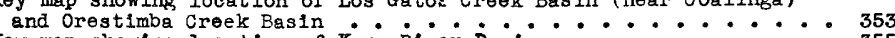

49. Key map showlng location of Kern River Basin $::_{0}::_{0} \quad 355$

50. Key map showing location of Thle and Kaweah River Basins..... 358

51. Key map showing location of Kings R1ver Basin . . . . . . 361

52. Key map showing location of upper San Joaquin River Basin .... 364

53. Key showing location of Fresno and Chowchilla Rivers, Mariposa and Bear Creok Basins 
Figure 54. Key map showing location of Merced R1ver Basin . . . * : * : * :

56. Key map show1ng location of Stanislaus R1ver Basin ... . . . . . 377

57. Key map showing location of Calaveras River Basin .......... 379

58. Key map showing location of Cosumes R1ver and Sutter Creok Basins. 381

59. Key map showing location of Mokelume River Basin . * * * * . . 383

60. Key map showing location of upper Sacramento River and Mccioud

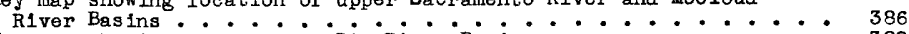

61. Key map showing iocation of Pit River Basin:

62. Key map showing location of Mill, Deer, Chico, and Butte Creok and

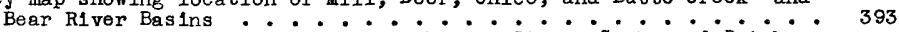

63. Key map showing location of Eider, Thomas, stony, Cache and Putah creek Basins. . . . . . . . . . 396

64. Key map showing location of Feather River Basin . . . . . . . . 399

65. Key map showing location of Yuba River Basin ............. . . 404

66. Key map showing location of Amerlcan R1ver Bas1n......... . 407

67. Key map showing location of northerm Pac1f1c bas1ns ....... . 411

68. Key map showing location of San Franc1sco Bay basins....... . . 4l4

69. Key map showing location of Owens Lake basins $\cdot{ }^{*} \cdot *_{*} \cdot *_{*}^{*} \cdot 418$

70. Key map showlng location of Truckee R1ver Basin (cailfornia part). : 421

71. Profile of crest stages on the San Joaquin R1ver during the flood

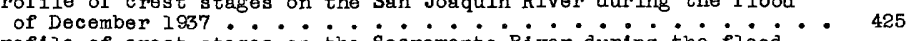

72. Profile of crest stages on the sacramento River during the flood

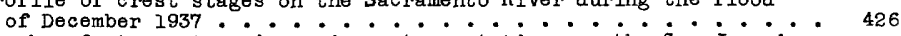

73. Graphs of stage at various river-stage stations on the San Joaquin R1ver, March 1-20, 1938 ...................

74. Proflle of crest stages on the san Jogquin ivive during the fiood of March 1938 .. . . . . . . . . . . . . . . . . . . .

\section{TABLES}

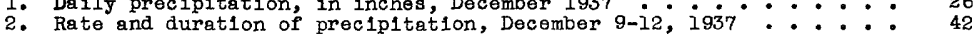

3. Snow conditions in November and during the storm of December i 1937 .

4. Summary of flood discharges in northern California. . . . . . . . 288

5. Total available storage capacity of reservoirs in northern califor-

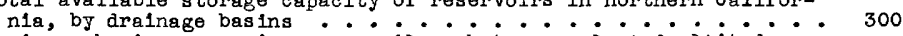

6. Drainage basin areas, in square miles, between selected altitudes along western slopes of the Slerra Nevada ............. 307

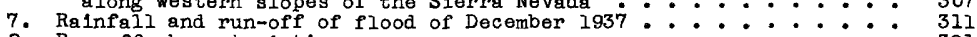

9. Run-off characteristics

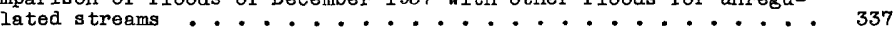

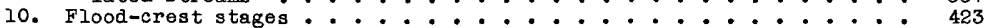

11. Maximum stage and discharge of recorded fioods at indicated places in Kerm RIver and Tulare Lake Basins................... 440

12. Maximum stage and discharge of recorded fiods at indicated places on the San Joaquin and Tuolume Rivers.............. 452

13. Maximum stage and discharge of recorded fioods at indicated places

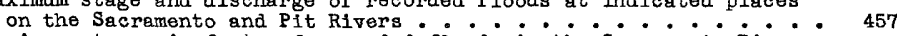

14. Maximum stage, in feet, of recorded floods in the sacramento River

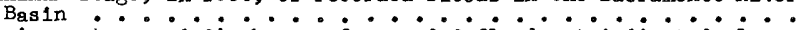

15. Maximm stage and discharge of recorded fiods at indicated places on the Feather, Yuba, and American R1vers * * * * * * . - .

16. Maximum stage and discharge of recorded floods at indicated piaces on Stony, Cache, and Putah Creeks ...............

17. Maximum amual stages, in feet, on the Sacramento River at Sacra-

18. Maximum stage, in feet, of recorded fiods at indicated piaces in
the northern pacific basing

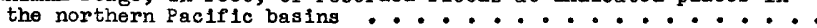


By H. D. McGlashan and R. C. Briggs

\section{ABSTRACT}

During the period December 9-12, 1937, streams in northern California were subjected to severe floods which, at 80 river-measurement stations, exceeded previously recorded maximum discharges. Flood stages prevailed from the Kaweah River Basin in the south to the Pit and Trinity River Basins in the north, and from the Pacific ocean to the Sierras. Farm lands, highways, bridges, and public utility systems were seriously damaged.

The floods were caused by an exceptionally intense rainstorn of wide extent, whioh formed over the Pacific Ocean and moved rapidly eastward into northern California on December 9. It was a well-defined single storm, and most of the precipitation fell within a 48-hour period. The storm was notable for the accompanyins warm temperature, which caused precipitation to have the form of rain, ratier than snow, up to high altitudes in the Sierras. Other distinctive features were the relatively small amounts of rainfall in the lower altitudes of the Central Valley, and the large amounts of rainfall in the middle altitudes of the Sierras where normally much of the precipitation during December storms is in the form of snow.

In general, there was little snow on the ground at the beginning of the storm period, and contribution from melting snow was not an important factor in the flood run-off.

An interesting characteristic of the floods was the absence of high water along the lower reaches of the San Joaquin River, in contrast to the flooded areas along the lower Sacramento River. Large volumes of flood waters were withheld by the many storage reservoirs on tributaries of the San Joaquin River, whereas much smaller volumes were detained by the comparatively few storage reservoirs in the Sacramento River Basin.

The extent to which the absorptive capacity of the soil had been utilized by antecedent precipitation at the time of the December storm had an important influence on the relative magnitude of the flood run-off from different areas. In general, this factor tended to make the floods in the northern part of the Central valley more severe than those in the southern part. A study of the conditions of antecedent precipitation and probable ground moisture associated with previous great floods supports the conclusion that the ground storage is generally a very critical factor in the development of floods in this region.

This water-supply paper presents, for the period that included the floods, records of stage and discharge at about 170 river-measurement stations and records of storage in all the larger reservoirs. It also presents a summary of peak discharges with comparative data for other floods at 74 measurement points, and tables and graphs showing crest stages along the Sacramento and San Joaquin Rivers.

The paper includes information about the weather associated with the floods; the results of studies of the rainfall and mun-off; discussions of flood characteristics; and other pertinent information about the meteorologic and hydrologic conditions prior to and during the flood period.

The main flood report is followed by a section on floods that occurred before the beginning of systematic stream-flow records. The early flood data, although lacking in quantitative information, indicate that the floods of the winter seasons of 1861-62 and 1867-68 were the most outstanding in magnitude. The peak discharges of the lower san Joaquin and Sacramento Rivers in January 1862 appear to have been the greatest since early in the nineteenth century at least; those in some localities, however, were closely approached in December 1867. In general, the floods of December 1937 were materially less in total volume than those just mentioned, but in some places they probably exceeded all other known floods in peak discharge.

The final section of the paper presents data on floods that brought record stages to some streams in 1938 . 


\section{INTRODUCTION}

The storm of December 9-12, 1937, in northerm Califormia, was notable both for its severity and for the extent of the area that it covered. Extreme storm conditions prevalled throughout the Central Valley, from the Kaweah River northward, and from the Salinas River Basin northward along the coast to Oregon. Figure 1 shows the location of the area covered by this report.

Since 1867 there has been no other major flood in northern California so early in the season as that of December 1937. The plentiful rainfall in October and especially heavy rains during November in Sacramento River Basin, associated with temperatures well above normal and an absence of snow-cover except at high altitudes, produced conditions favorable for high run-off rates at the time of the December storm.

The intensity and speed with which the storm swept across the State, and extended to forty-three of the fifty-eight counties, make it one of the outstanding storms of record. The precipitation lasted about two and one-half days in the affected area as a whole, but in general it lasted less than two days at any one place. It resulted in rates and volumes of run-off equalling or exceeding those for storms of 6 to 14 days duration in earlier years. The maximum rainfall record for the 2 -day period, December 10-11, was that of more than 18 inches in Feather River Basin.

In its swift passage across the state, the storm and resulting floods left an area of devastation marked by damaged highways, wrecked bridges, broken levees, and flooded homes and ranches. Transportation in many areas was intermpted or stopped entirely for varying periods, lines of communication as well as those for transmission of power were down, and many towns were thus isolated. The total damage was estimated by Edward Hyatt, State Engineer, at nearly $\$ 15,000,000$.

The outstanding flood period recorded in Califormia has long been considered as the one caused by the storms of 1861-62 which extended from Alaska to Mexico. In some sections of the Great Central Valley and especially in the southerm half of the San Joaquin Valley, the flood of 1867 exceeded that of 1861-62. Notable floods in 1881, 1907, 1909, and 1928 were confined to smaller areas.

Reliable evidence indicates that the highest river stages ever noted were reached in December 1937 at certain points on the Sacramento River and tributaries in the general vicinity of Red Bluff.

Maximum discharges were recorded in December 1937 on the sacramento, 


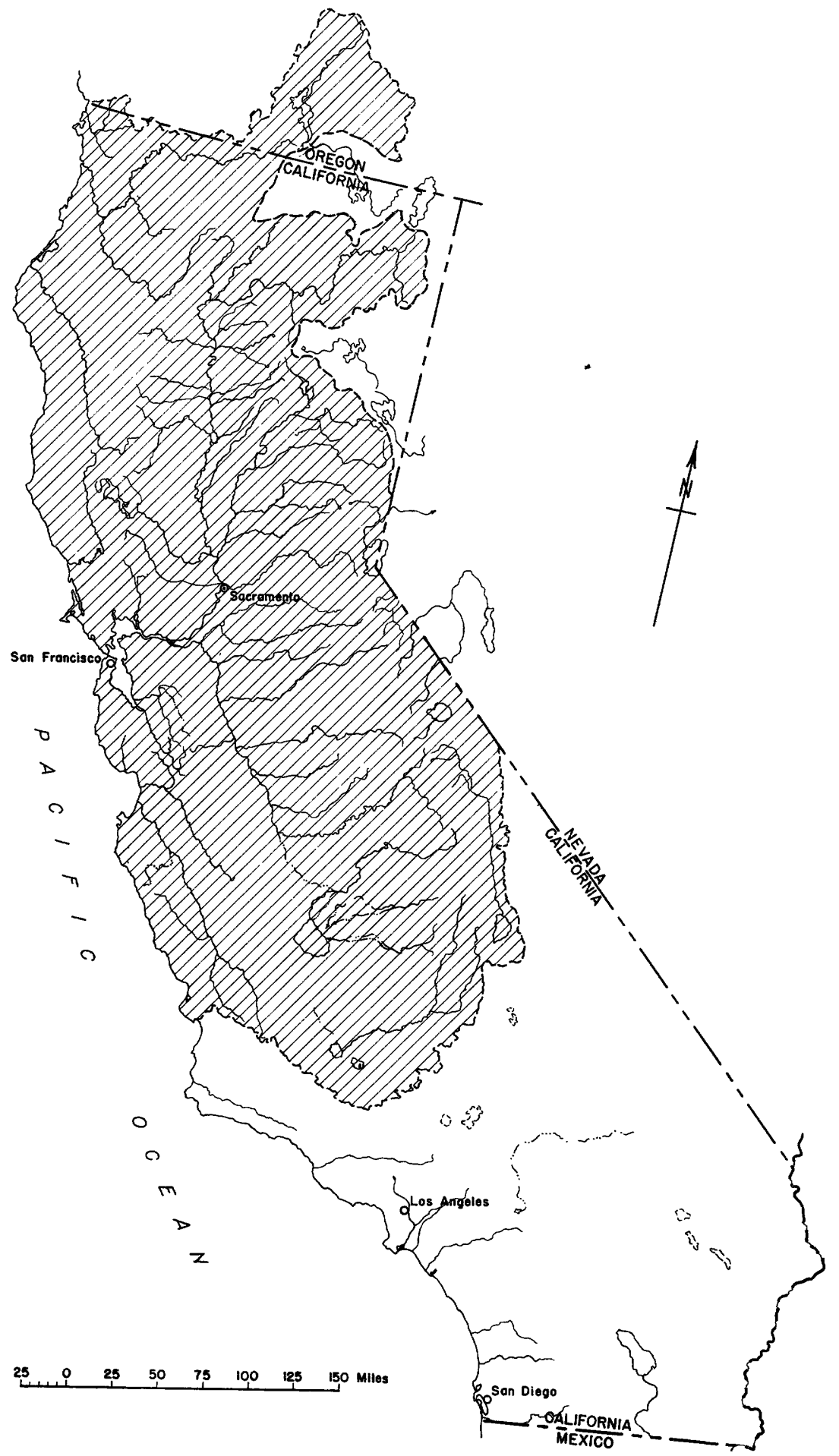

Figure 1.--Map showing location of area covered by this report. 
upper San Joaquin, Kings, and Kaweah Rivers, as well as on many tributaries. On the Feather River the peak discharge was approximately that of 1928, whereas on the American River it was considerably less than in that record year. The storm was much less severe in the extreme southern part of the San Joaquin Valley, and the crest discharge of the Kern River did not equal that of the flood of February 1937. As the storage reservolrs on the Mokelumne, Stanislaus, Tuolumne, and Merced Rivers were not filled in December 1937, there was no high water along the lower reaches of these streams or on the San Joaquin downstream from these tributaries.

As a part of 1 ts regular nation-wide stream-gaging program, the Geological Survey maintains about 185 river-measurement stations within the area covered by the flood of December 1937. These stations have been operated by the Geological Survey in cooperation with the State and many counties, cities, irrigation districts, public utilities, and other agencies, generally for periods beginning many years prior to the storm of December 1937. By this program the Survey has obtained continuous records of stage and rates and volumes of flow of the streams, covering the range from dry-season flows to major floods.

The records of stage, discharges, and other characteristics of the floods of December 1937 are of great interest and Importance, and furnish basic information needed in the design and construction of hydraulic works and in the study of flood control and land-use measures.

In addition to detalled data concerning the floods of December 1937, this report includes a section on floods prior to the beginning of stream-flow records, and a section on floods in 1938 .

\section{ADMINISTRATION AND PERSONNEL}

The field and office work incident to the preparation of this report was performed by the water-resources branch of the Geological Survey under the general administrative direction of N. C. Grover, chief hydraulic englneer, and C. G. Paulsen, chlef, division of surface water. The field work, the collection and tabulation of the basic information with respect to stages and discharges, and the many other tasks in the preparation of the report were done by the personnel of the san Francisco district office in the division of surface water, under the direction of H. D. McGlashan, district engineer, assisted by R. C. Briggs, hydraulic engineer, who were primarily responsible for the authorship. General supervision and coordination of the collection of data and the final 
assembling of the report were carried on in the division of water utilization, R. W. Davenport, chief. W. G. Hoyt, consulting engineer, conservation branch, has directed and prepared the presentation of information on rainfall and other climatologic features and is the author of the section on rainfall and run-off studies. He was aided by $H$. M. Orem, assistant engineer. Most of the data in the chapter concerning previous floods was collected by F. A. Johnson, assistant engineer. Many other members of the Geological Survey's staff have particlpated in important ways in the collection and preparation of the information in this report including Peter Alexander, Jesse Arnold, L. E. Bossen, B. C. Colby, C. J. Enerson, A. B. Goodwin, Charles Leidl, H. F. Mattha1, and H. J. Sexton in the San Francisco office. In carrying on all this work the permanent field and office staffs were assisted by temporary employees appointed by the Secretary of the Interior, a part of whom were furnished by the Public Works Administration. Office assistance was given by the Works Progress Administration.

\section{ACKNOWLEDGMENTS}

The Geological Survey, acting through its San Francisco district office, cooperates with the state and many municipal agencies in California. Acknowledgment is made to these cooperating agencies for participation in the collection of the systematic records of river discharge that form the broad base on which the specific flood information has been placed, also for furnishing a number of complete records of discharge at river-measurement stations which they maintain independently.

Information appearing in this report has been obtained from many sources, including individuals, corporations, and governmental organizations, local, State, and Federal. Financial cooperation in connection with the regular river-measurement program of the Geological survey in the areas in northern California covered by this report has been received from the Bureau of Reclamation, United States Department of the Interior; the State of California, through Edward Hyatt, State Engineer; the East Bay Municipal Utility District; the Santa Clara Valley Water Conservation District; Stanford University; and the cities of San Francisco, Santa Cruz, and San Luis Obispo. In addition to this regular cooperation, special allotments were made by Governor Frank F. Merriam through the State Director of Finance, by the United States Bureau of Reclamation, and by the Public Works Administration, to supplement the funds available for the preparation of this report. 
Federal agencies to whom acknowledgments are made for services rendered or data furnished include the United States Weather Bureau; the Corps of Engineers, United States Army; the United States Forest Service; the National Park Service; and the Works Progress Administration.

Other agencies in California that furnished data or rendered services are the following: Pacific Gas \& Electric Co.; San Joaquin Light and Power Corp.; Southern California Edison Co., Ltd.; City of Sacramento; Merced Irrigation District; Turlock \& Modesto Irrigation Districts; Emma Rose \& Hobart Estate Co.; and Thermalito and Table Mountain Irrigation District. The city of Los Angeles prepared the complete records for their stations in Owens River Basin. Where practicable, acknowledgments for individual contributions of information are given at appropriate places in the report.

\section{GENERAL FEATURES OF THE FLOODS}

The rivers and creeks over most of northern California, from the Kaweah on the south to the Pit and Prinity on the north, rose rapidy to very high stages as a result of the storm of December 9-12, 1937. From west to east the storm was severe from the coast of California to the State of Nevada, and many streams on both sides of the Coast Ranges and the Sierra Nevada exceeded previously recorded maximum flood discharges. Figure 2 is a map showing the principal river systems and cities mentioned in the text of this report.

A notable characteristic of the storm was the relatively small amount of rainfall on the floor of the Great central Valley. The rainfall was also of only moderate depth and intensity in the coastal areas south of the Salinas Basin, and in owens valley on the east side of the Sierra Nevada. Consequently, streams in those localities did not reach excessive stages.

South of the Kaweah River the intensity of the storm was much less, and the peak discharges did not equal those of February 1937. The discharge of the Kaweah and Kings Rivers and tributaries far exceeded previous long-period records. Excessive and record-breaking run-off rates were recorded in the foothill and mountain areas in the San Joaquin, Merced, Tuolumne, Stanislaus, and Mokelumne Basins but, because of available storage in Lake Mcclure, Hetch Hetchy, Don Pedro, Melones, Salt Springs, Pardee, and other, but smaller, reservoirs there was no heavy run-off along the lower reaches of these streams. 


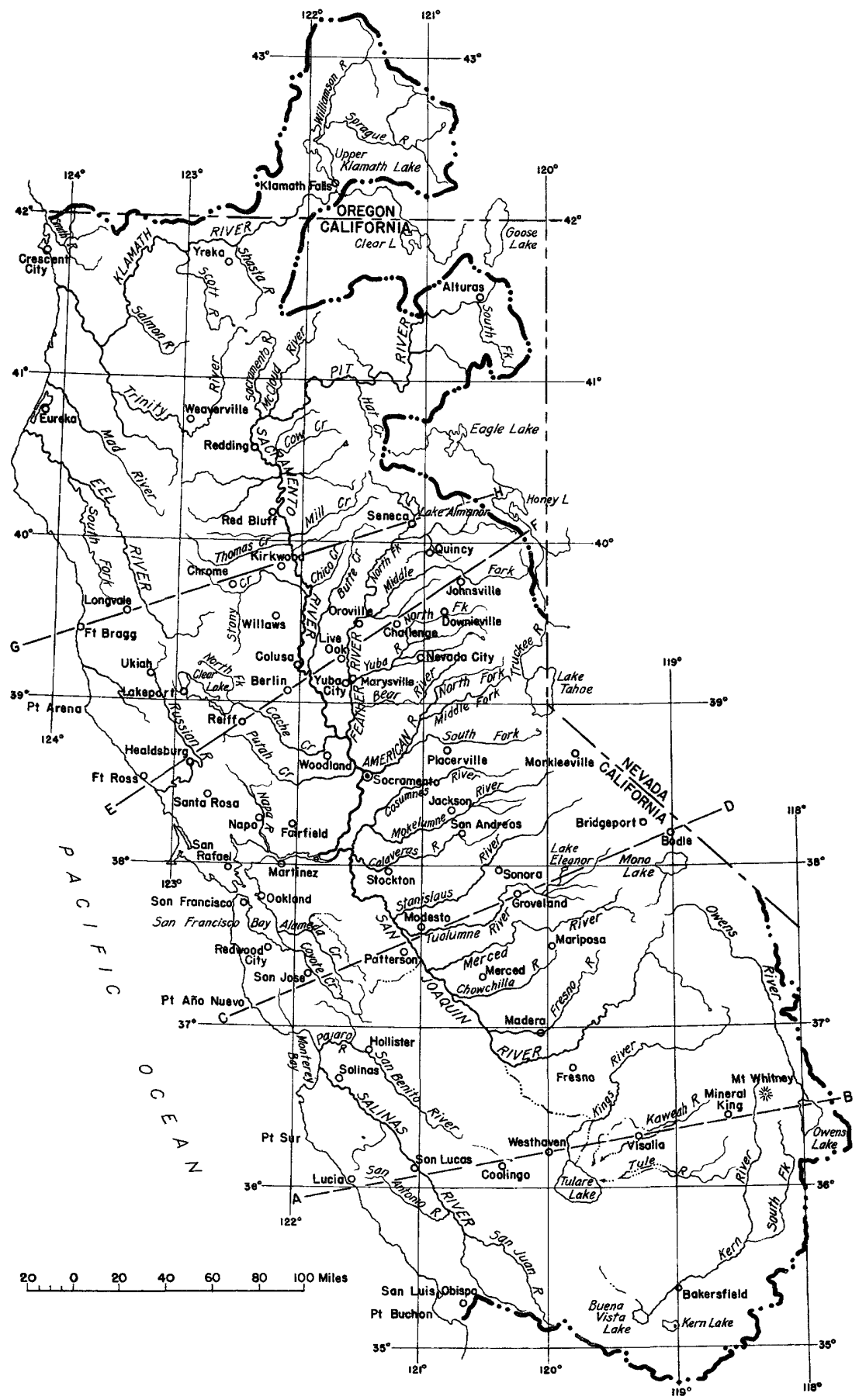

Figure 2.--Map showing the principal river systems and cities mentioned in text. 
From the headwaters of the sacramento downstream to and including the Feather River Basin major flood conditions prevalled. On the Sacramento River near Red Bluff the stage was 1.3 feet above that recorded in 1909, but owing to changes in the channel the discharge was only slightly greater than the revised maximum for that year.

On the Feather River near Oroville the discharge equalled the revised maximum for 1928 , but was less than the revised discharge for the record year 1907.

Along the coast from San Francisco Bay to Oregon many new maxima were established, but the length of record at these stations is relatively short. The storm was particularly heavy in the Russian River Basin and in the upper part of Putah Creek Basin.

The damage resulting from the flood of December 1937 has been estimated at nearly $\$ 15,000,000$. The principal items were about $\$ 4,500,000$ in damage to roads, bridges, and streets; $\$ 3,500,000$ classed as agricultural; $\$ 2,500,000$ for river protection works and debris removal; and $\$ 1,000,000$ for public utslities. The damage reported for Butte County was more than $\$ 2,000,000$; the next highest were for Sonoma and Tehama Counties, each with damages exceeding $\$ 1,000,000$. Most of the main highways were made passable in three or four days after the storm, but in some areas normal traffic was not restored for a week or more. There was heavy damage to Donner Highway, which was opened to normal traffic December 20; Walker Canyon Highway, south of Coleville, was opened January 3, 1938; and Feather River Highway was opened January 16, 1938. (See pl. I.) The All-year Yosemite Highway, in Merced Canyon, was reopened December 30, 1937, on a one-way schedule whlch was continued through 1938. The Yosemite Valley Railroad grade, on the opposite side of the canyon, was also severely damaged. (See pl. 2.)

In the coastal valleys and in parts of the Great Central Valioy many farms and orchards were damaged. (See pl. 3.) The rains and inundation of the land so saturated the soll that the heavy winds that followed the storm uprooted the trees.

In San Joaquin Valley the damage was largely limited to the foothill and mountain areas and to the lower lands along the Kings, Kaweah, and San Joaquin Rivers where large areas of farm lands were flooded. About 15,000 acres in Centerville Bottoms, on the Kings River at the edge of the foothills below Piedra, and 30,000 acres in Burris Park, Laton, and Lemoore areas were inundated. The "Bottoms" acted as a 


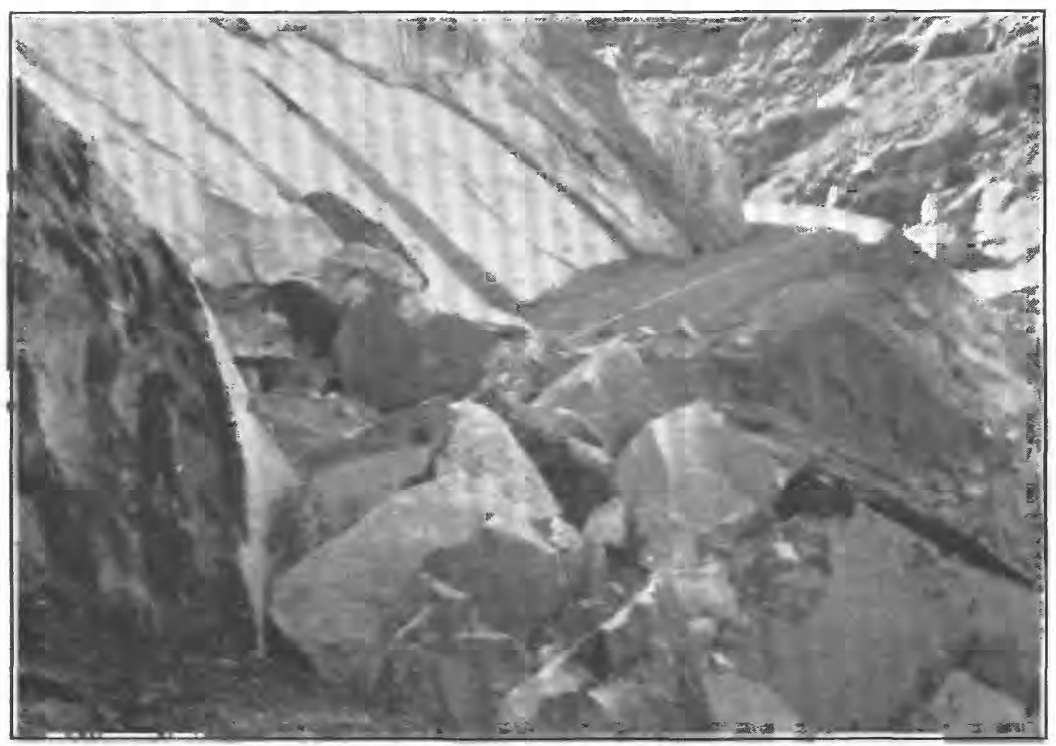

A. ROCK SLIDE ON FEATHER RIVER HIGHWAY AT BUTTE-PLUMAS COUNTY LINE. Courtesy of Division of Highways, State of California.

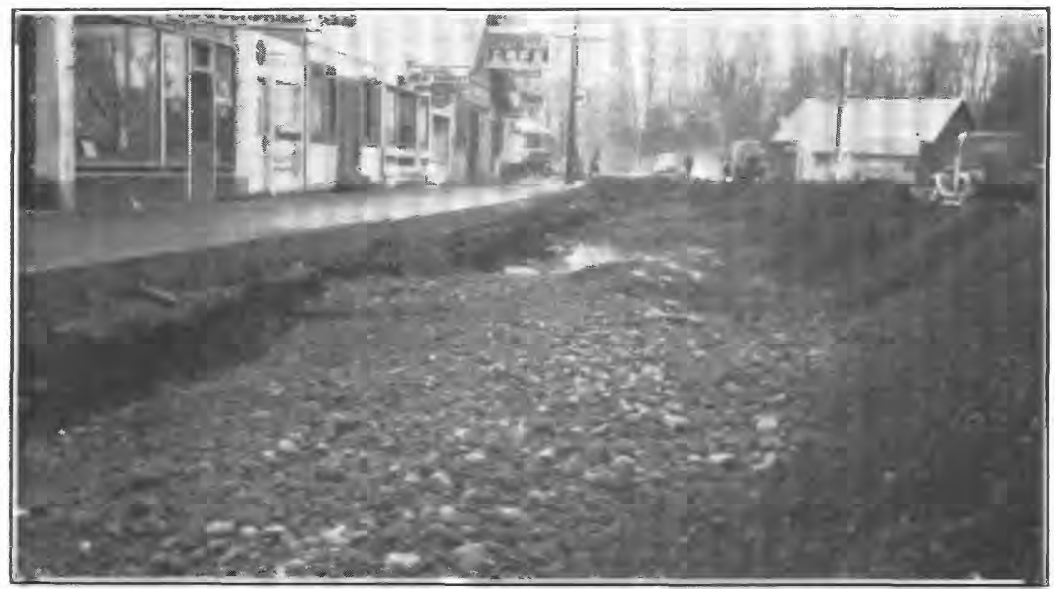

B. WASHOUT ON MAIN STREET, CHESTER, CALIF.

Caused by overflow from North Fork of Feather River. Courtesy of Division of Highways, State of California. 


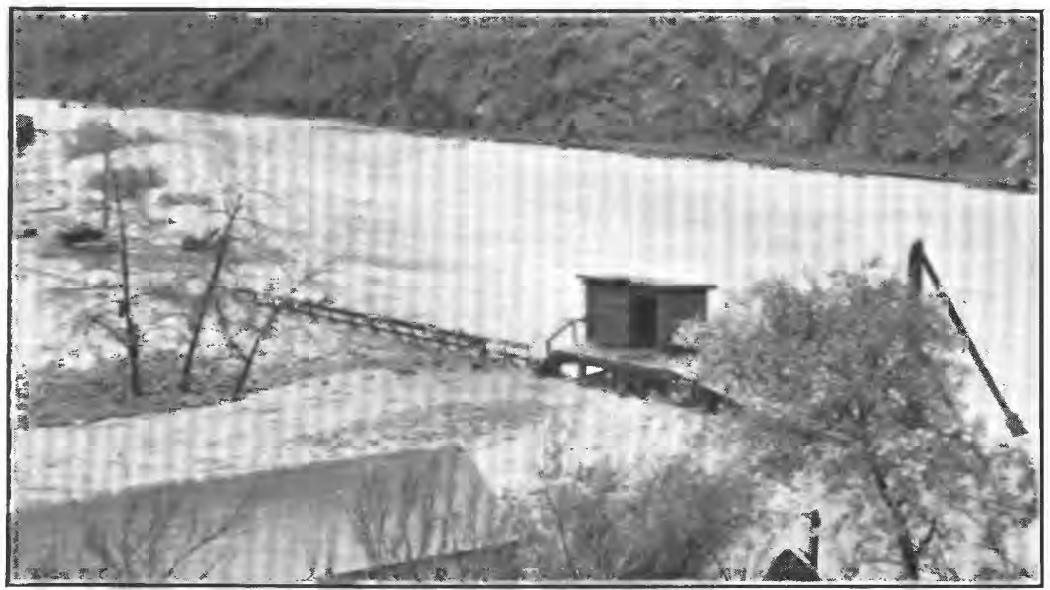

A. YOSEMITE VALIEY RAILWAY IN FOREGROUND AND HIGHWAY TO YOSEMITE VAILLEY ON OPPOSITE BANK.

Courtesy of Division of Highways, State of California.

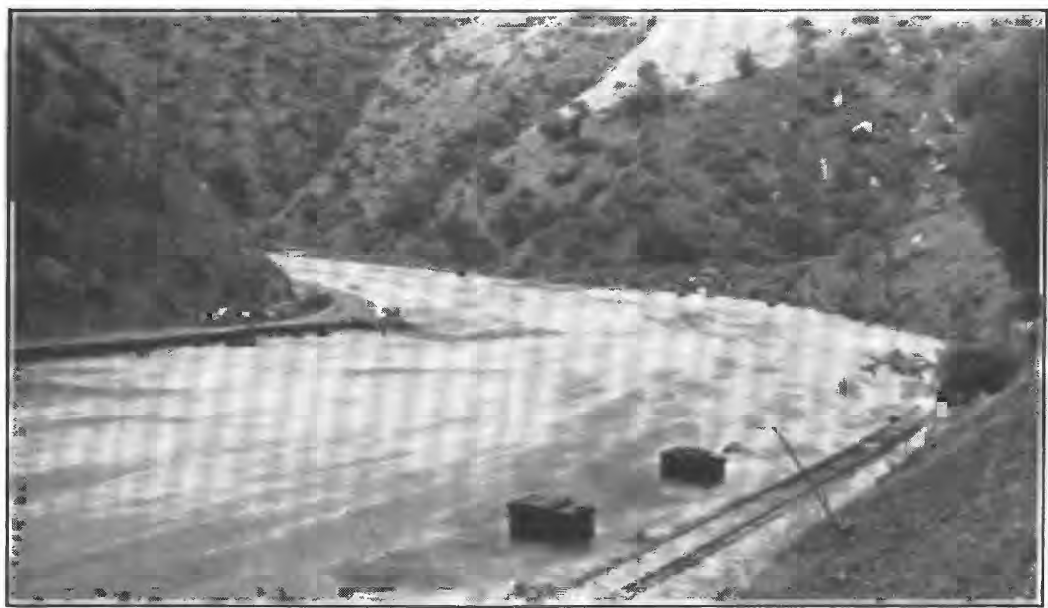

B. YOSEMITE VALLEY RAILWAY AT RIGHT AND HIGHWAY TO YOSEMITE VALLEY AT LEFT.

Courtesy of Division of Highways, State of California.

MERCED RIVER UPSTREAM FROM BRICEBURG DURING FLOOD OF 1937. 


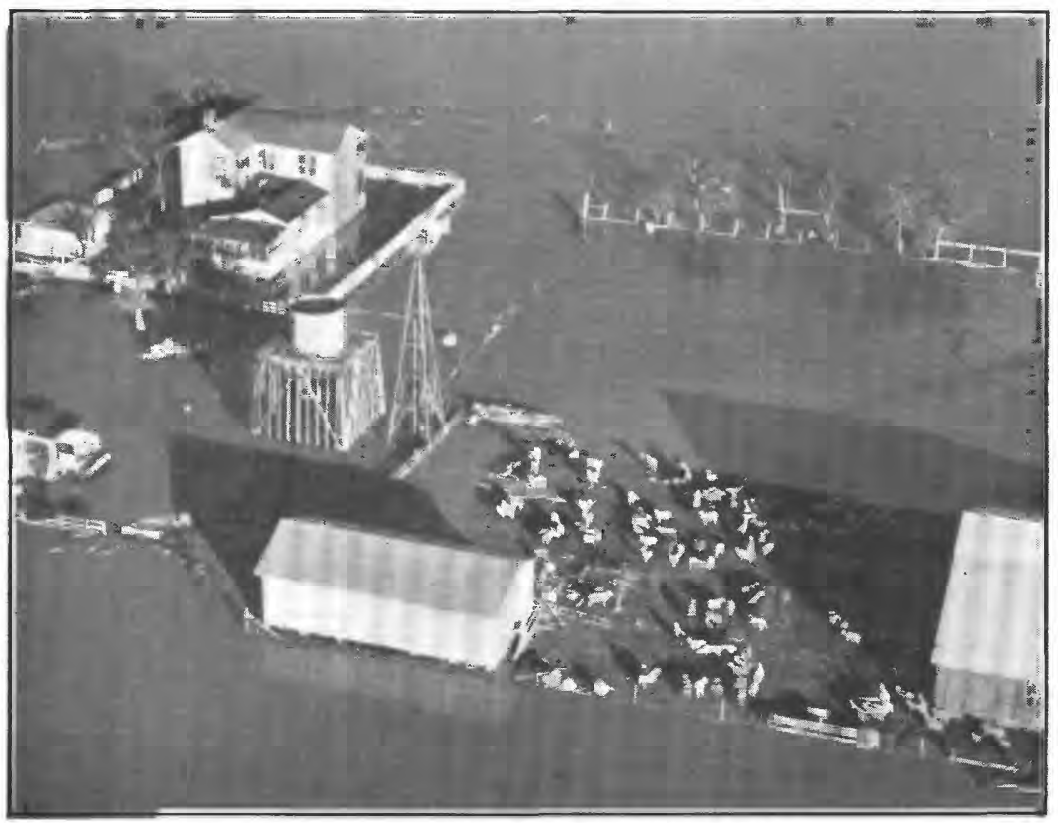

A. FLOODED FARM NORTH OF MARYSVILLE.

Overflow from Feather River, December 12, 1937. Courtesy of the Sacramento Bee.

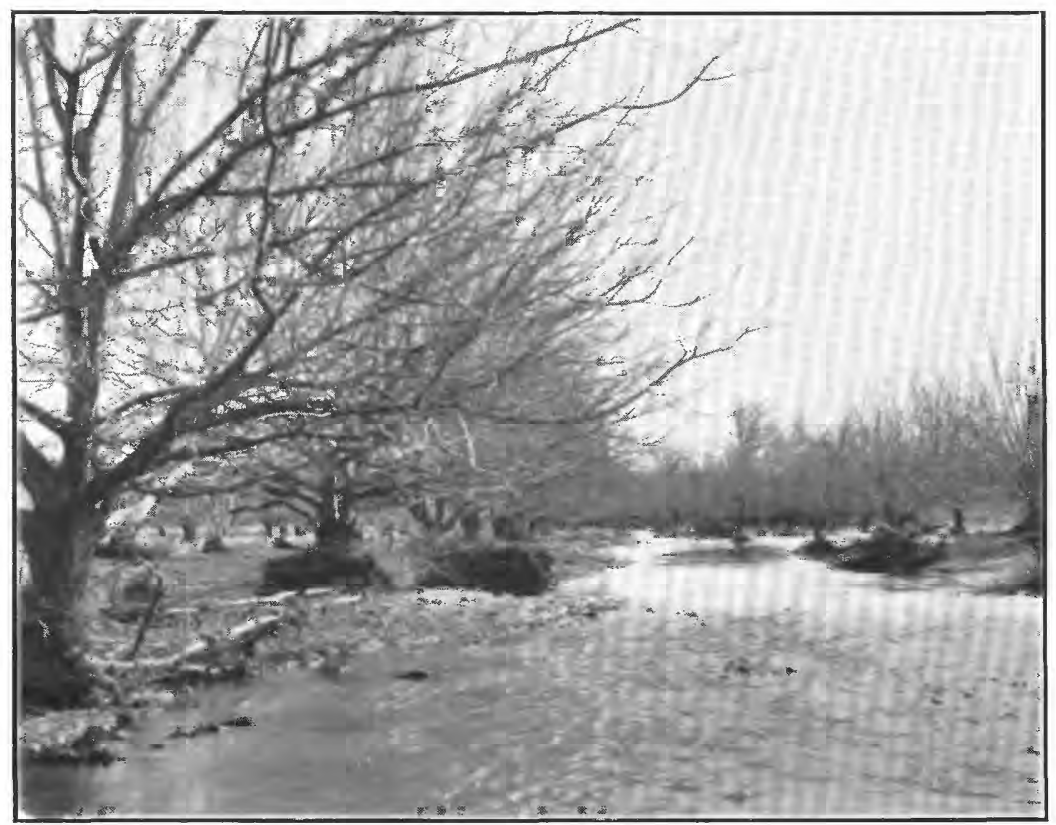

B. FLOODED ORCHARD NEAR ANDERSON.

New channel cut by Battle Creek. Courtesy of Department of Public Works, State of Californiag 


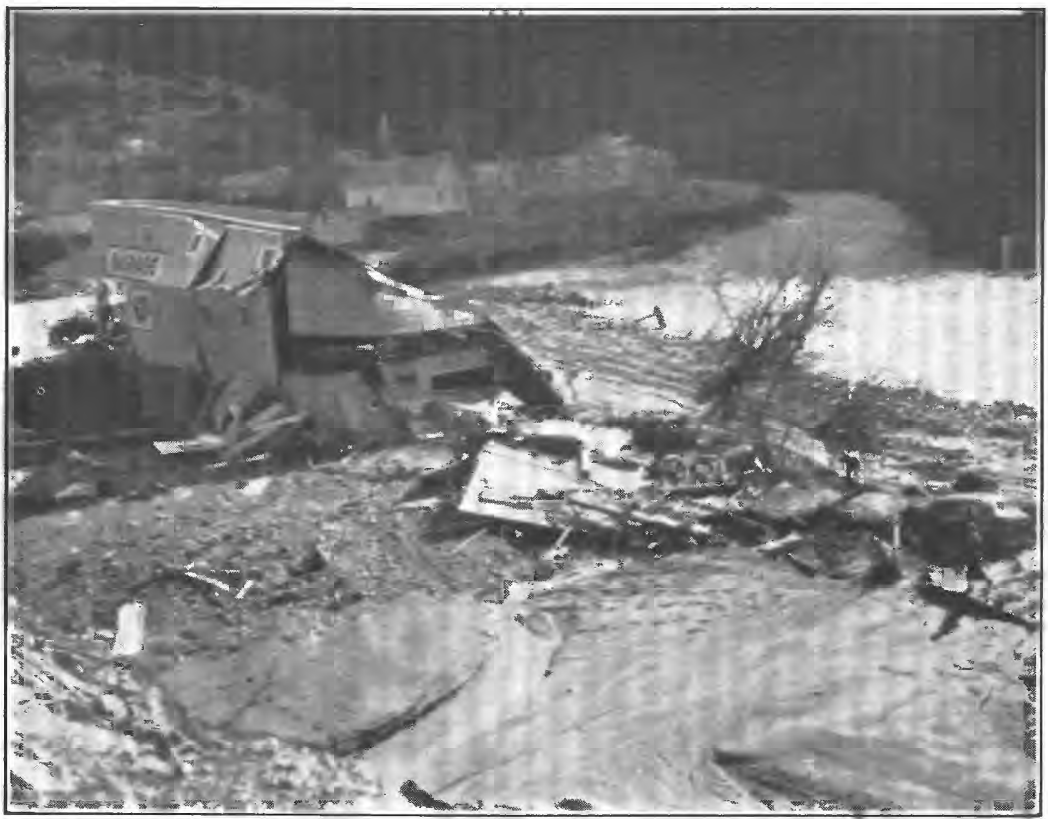

A. LOOKING UP NORTH FORK OF YUBA RIVER TO JUNCTION WITH THE NORTH FORK OF NORTH FORK.

Courtesy of United States Forest Service.

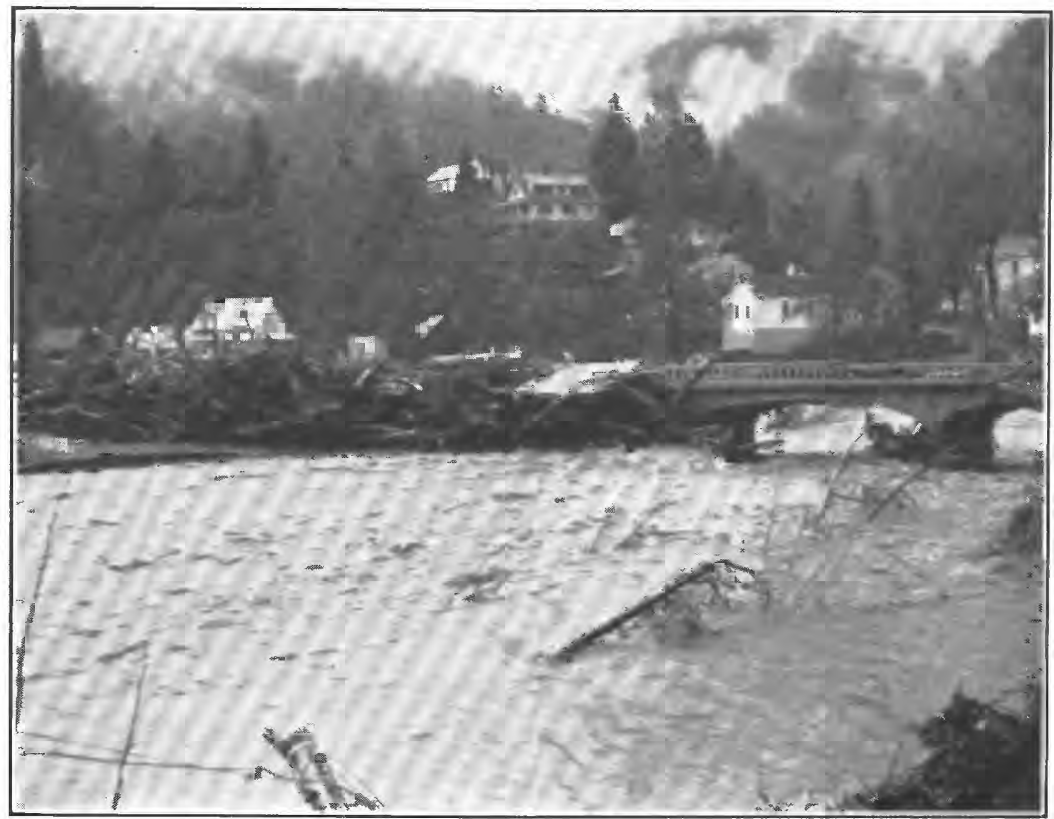

B. LOOKING DOWN NORTH FORK OF NORTH FORK OF YUBA RIVER TO WRECKED BRIDGE AND DEBRIS.

Courtesy of United States Forest Service. 
drained back into the Kings River and thus increased the flow in the lower reaches.

The discharge of the Merced River at Pohono Bridge near Yosemite was nearly four times the previous maximum recorded in 1922, and about one-half of the valley floor in Yosemite Valley was flooded.

From Alturas, on the upper Pit River, to Visalia in the Tulare Lake Basin several towns and cities suffered severe damage from overflow, and large areas of agricultural land were covered by flood water. At Chester the streets were flooded and seriously eroded, owing to debris jams that diverted water from the North Fork of the Feather River. (See pl. I, B.)

At the historic town of Downievile, at the junction of the North Fork of the North Fork of the Yuba River with the North Fork, there was severe damage to both the community and the highway. (See pl. 4.) Many homes and business bulldings were wrecked or moved from their foundations, but fortunately there was no loss of life. The loss of bridges and damage to highways greatly hampered and delayed relief parties that were bringing supplies to Downievilie, and retarded the rehabilitation of public utility services.

In the upper Sacramento Valley, mile after mile of highway was inundated, motor vehicles were trapped, and entire towns were isolated. (See pl. 5.) Of the 70 miles of State Highway between Gridley and Red Bluff, 45 miles were under water. Sacramento River overflowed its banks below Red Bluff and flooded the towns of Gerber and Tehama and lands in Tehama and Butte Counties. (See pl.6.)

The 48 gates of Sacramento weir, just above the mouth of the American River, were opened about 5 p.m. December 11. (See pl. 7, A..) The discharge of the flood waters at this point into Yolo By-pass materially reduced the flood height at Sacramento. The situation did not become serious in the Sacramento-San Joaquin Delta, outside the Yolo By-pass district, for the San Joaquin River was at relatively low stage owing to storage on the lower tributaries.

The Sacramento levee system, built to protect the city and agricultural land from floods, was overtaxed and falled at several points, (see pl. 7, B) allowing the flood waters to spread over many thousand acres of agricultural land in Glenn and Colusa Counties. (See fig. 3 and pl. 9, $\left.\underline{A}_{0}\right)$ From Knights Landing south the levee system held.

The Feather River broke through the levee at Hamilton Bend, below Oroville, and sent a large flow west across developed farm land into 


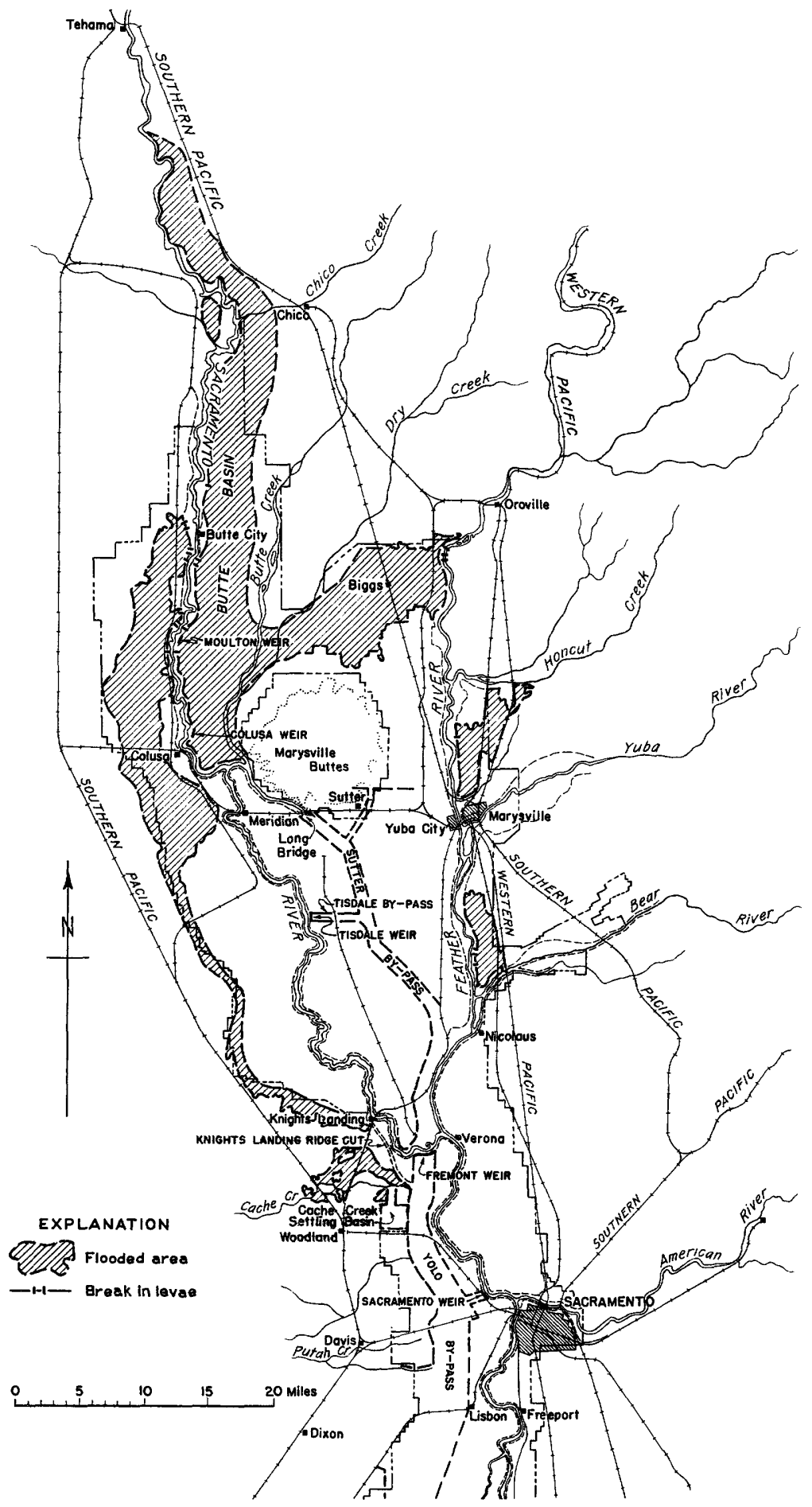

Figure 3.--Map showing areas flooded in the lower Sacramento River Basin, December 11-14, 1937. 
Butte Basin, north of Marysville Buttes, flooding settled areas including the city of Biggs. (See pl. 8.) There were also serious breaks north and south of Marysville that inundated a large acreage of diversifled ranch land.

Serious damage occurred in the smaller basins along and adjacent to the coast south and north of San Francisco Bay. Gilroy was flooded by water from Uvas Creek (see pl. $9, \underline{B}$ ) and the southern part of Watsonville by the overflow from the Pajaro River. The Russian River made practically a clean sweep of the resort areas and flooded part of Healdsburg and fertile farm lands in the vicinity. (See pl. 10.) The damage in Mendocino county was chiefly to roads and bridges, and in Lake and Humboldt Counties to agricultural developments.

High water at or near river-measurement stations is shown in plates 11 and 12. The latter shows the Kaweah River station at low stage (pl. 12, A) and at a high-stage (p1. 12, B) immediately preceding the peak of December 11, 1937 .

The momentary peak discharge in December 1937 was the maximum for the period of record, to December 31, 1937, at the following rivermeasurement stations:

Pajaro River Basin.--Uvas Creek near Morgan Hill.

Tulare Lake Basin.--Kaweah River near Three Rivers; North Fork of Kaweah River at Kaweah; Kings River above North Fork; Kings River at Piedra; North Fork of Kings River near Cliff Camp; North Fork of Kings River below Rancheria Creek; Los Gatos Creek near Coalinga.

San Joaquin River Basin.--San Joaquin River above Big Creek; San Joaquin River below Kerckhoff power house; San Joaquin River near Friant; Pitman Creek below Tamarack Creek.

Merced River Basin.--Merced River at Happy Isles Bridge, near Yosemite; Merced River at Pohono Bridge, near Yosemite; Merced River at Kittridge; Tenaya Creek near Yosemite.

Tuolumne River Basin.--Tuolumne River near Hetch Hetchy; Falls Creek near Hetch Hetchy; Cherry Creek near Hetch Hetchy; Eleanor Creek near Hetch Hetchy; South Fork of Tholumne River near Oakland Recreation Camp; Midale Tuolumne River near Buck Meadows.

Stanislaus River Basin.--Middle Fork of Stanislaus River at Sand Bar Flat, near Avery; North Fork of Stanislaus River near Avery. Mokelumne River Basin.--North Fork of Mokelumne River below Salt Springs Dam; Cold Creek near Mokelumne Peak; Bear River at Pardoe Camp. 
Sacramento River Basin.--Sacramento River at Kennett; Sacramento River near Red Bluff; Sacramento River at Verona.

Pit River Basin.--Pit River at Fall River Mills; Pit River below Pit No. 4 dam; Pit River at Big Bend; Pit River near Yalpom; Hat Creek near Hat Creek; McCloud River near McCloud; McCloud River at Beira.

Mill Creek Basin.--Mill Creek near Los Molinos.

Elder Creek Basin.--Elder Creek near Henleyville.

Deer Creek Basin.--Deer Creek near Vina.

Chico Creek Basin.--Chico Creek near Chico.

Stony Creek Basin.--Butte Creek near Chico.

Feather River Basin.--Spanish Creek at Keddie; Grizzly Creek near Storrie; West Branch of Feather River near Yankee Hill; South Fork of Feather River at Enterprise; Lost Creek near Clipper Mills; Midale Fork of Yuba River at Milton; North Fork of Yuba River near Sierra City; North Fork of Yuba River below Goodyears Bar; Canyon Creek below Bowman Lake; Deer Creek near Smartville.

American River Basin.--North Fork of American River at Rattlesnake Bridge; South Fork of American River near Kyburz; South Fork of American River near Camino; South Fork of American River at Coloma; Silver Lake outlet near Kirkwood; Silver Fork of South Fork of American River near Kyburz; Twin Lakes outlet near Kirkwood; Silver Creek at Union Valley; Silver Creek near Placerville; South Fork of Silver Creek near Ice House. Cache Creek Basin.--North Fork of Cache Creek near Lower Lake. Eel River Basin.--Eel River at Hullville.

Klamath River Basin.--Klamath River at Somesbar; Shasta River near Yreka; Salmon River at Somesbar; Trinity River at Lewiston; Trinity River near Burnt Ranch; Trinity River near Hoopa.

Smith River Basin.--Smith River near Crescent city.

Owens Lake Basin.--Owens River near Round Valley.

Walker Lake Basin.--West Walker River near Coleville.

Humboldt-Carson Sink Basin.--East Fork of Carson River near Markleeville; Markleeville Creek at Markleeville; West Fork of Carson River at Woodfords.

Pyramid and Winnemucca Lakes Basin.--Truckee River at Iceland; Donner Creek near Truckee; Little Truckee River near Boca.

The drainage basins of the various streams seriously affected by the storm and resulting floods are shown in figures 4 to 12 . 


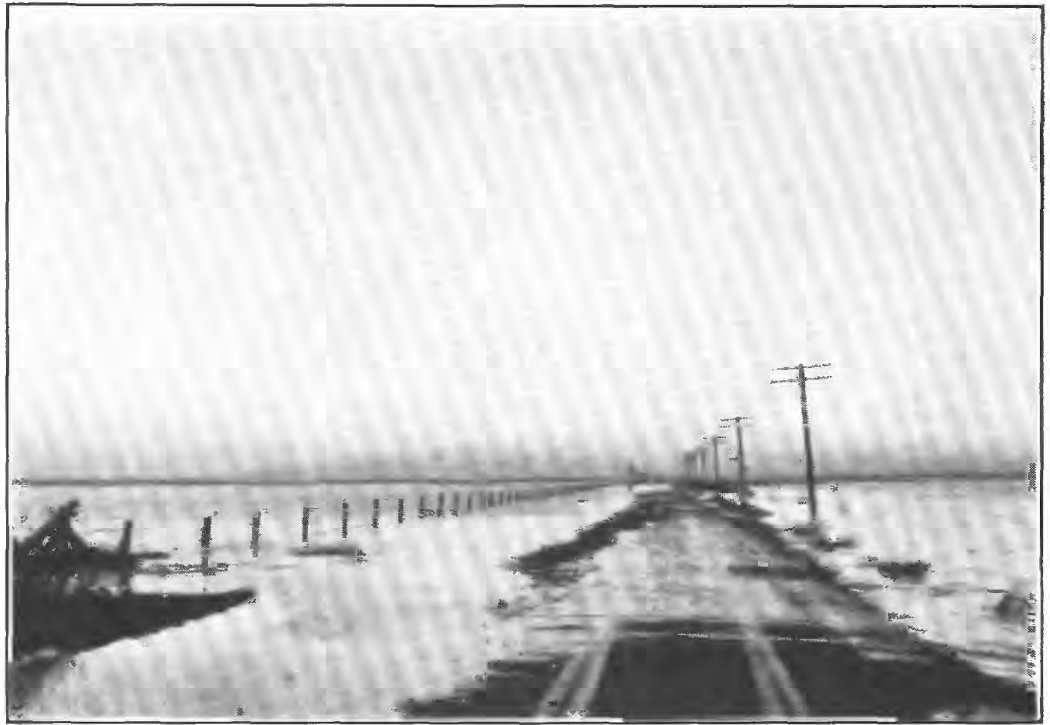

A. HIGHWAY FLOODED BY SACRAMENTO RIVER.

View on Williams-Colusa highway 61/2 miles east of Williams, December 14, 1937. Courtesy of United States Forest Service.

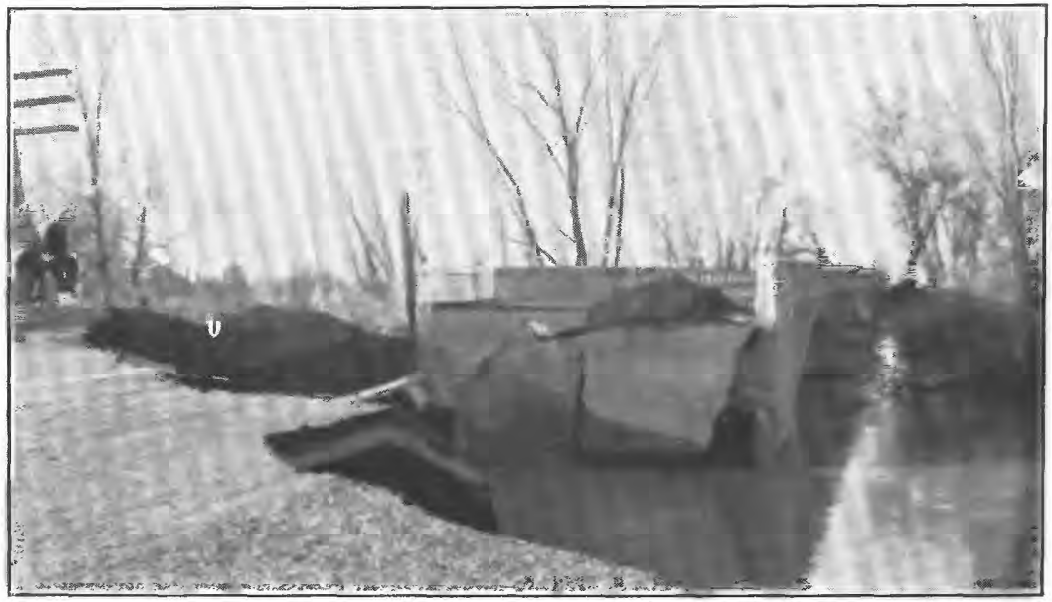

B. DAMAGED HIGHWAY BRIDGE ON BEAR CREEK SOUTH OF LOS MOLINOS. Courtesy of Division of Highways, State of California. 


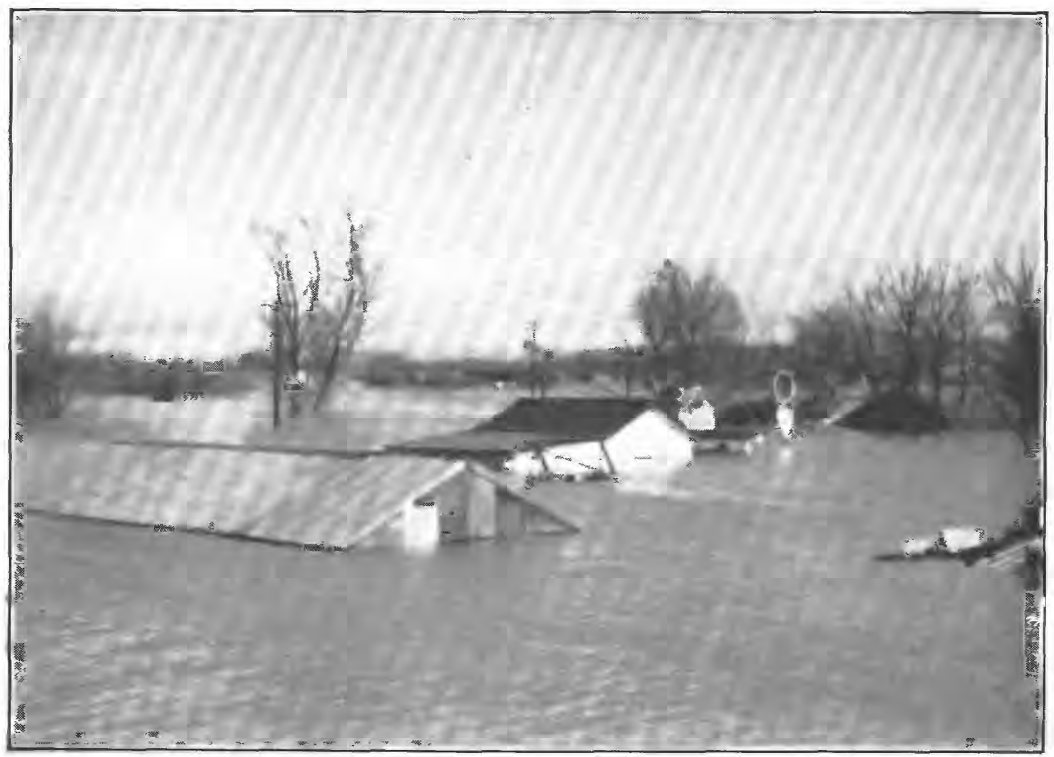

A. SUBMERGED BUILDINGS NEAR TOWN.

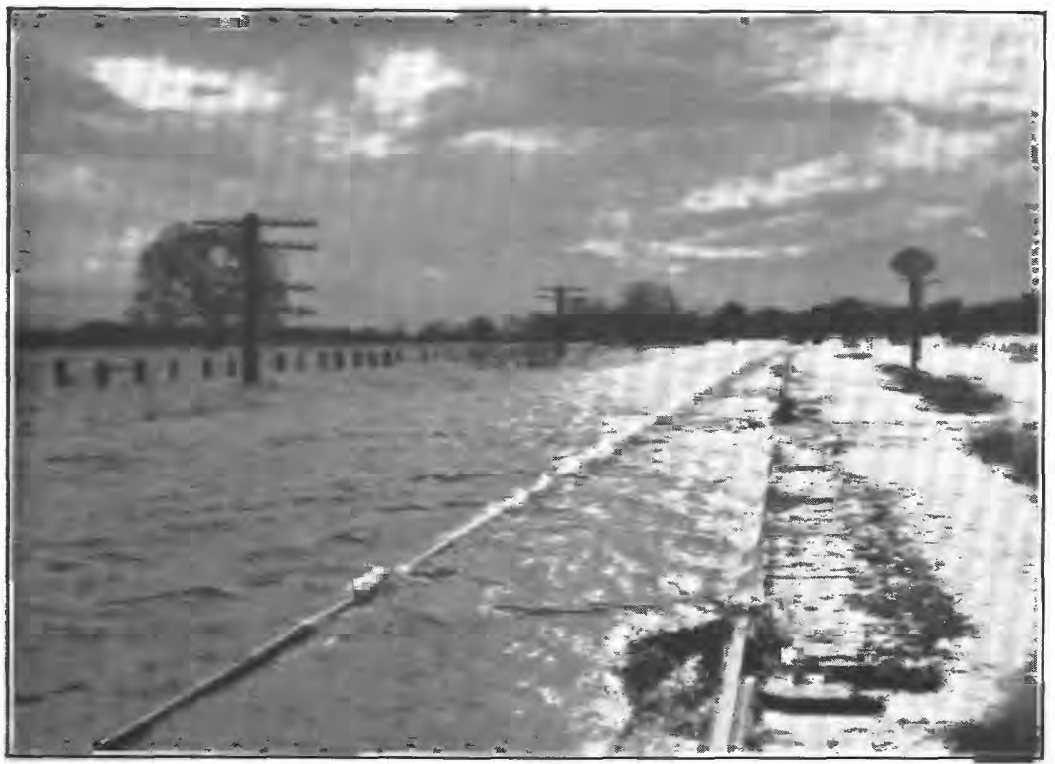

B. RIGHT-OF-WAY OF SOUTHERN PACIFIC LINES SOUTH OF TOWN. 


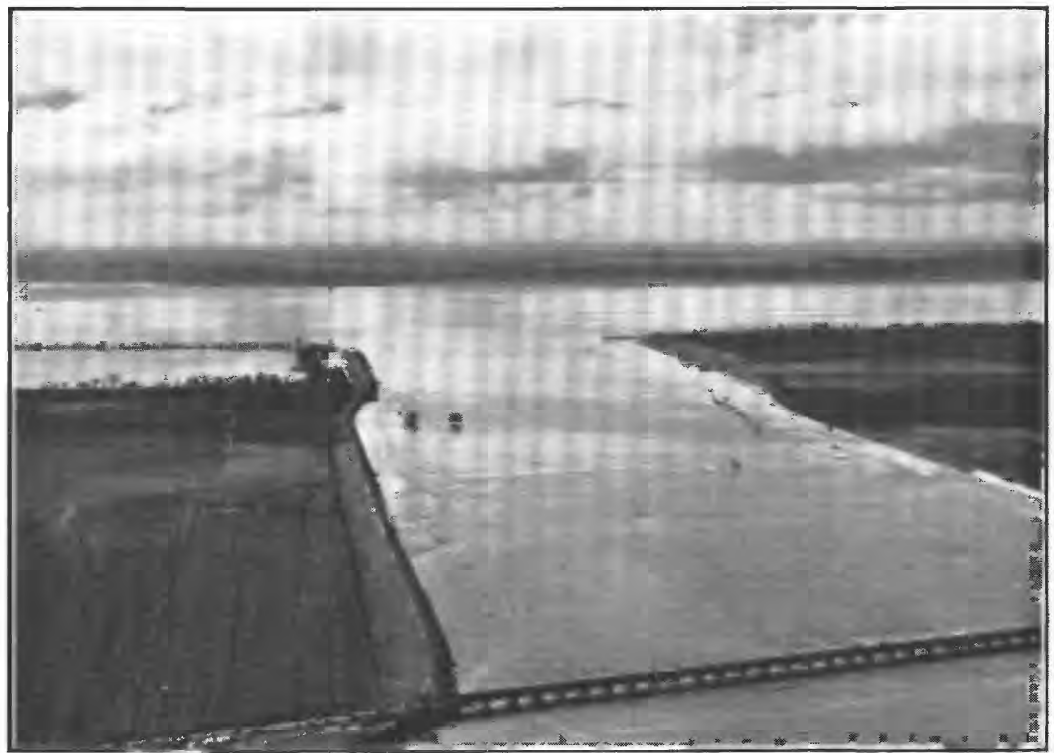

A. SACRAMENTO RIVER (IN FOREGROUND) DISCHARGING THROUGH WEIR INTO YOLO BYPASS.

Courtesy of the Sacramento Bee.

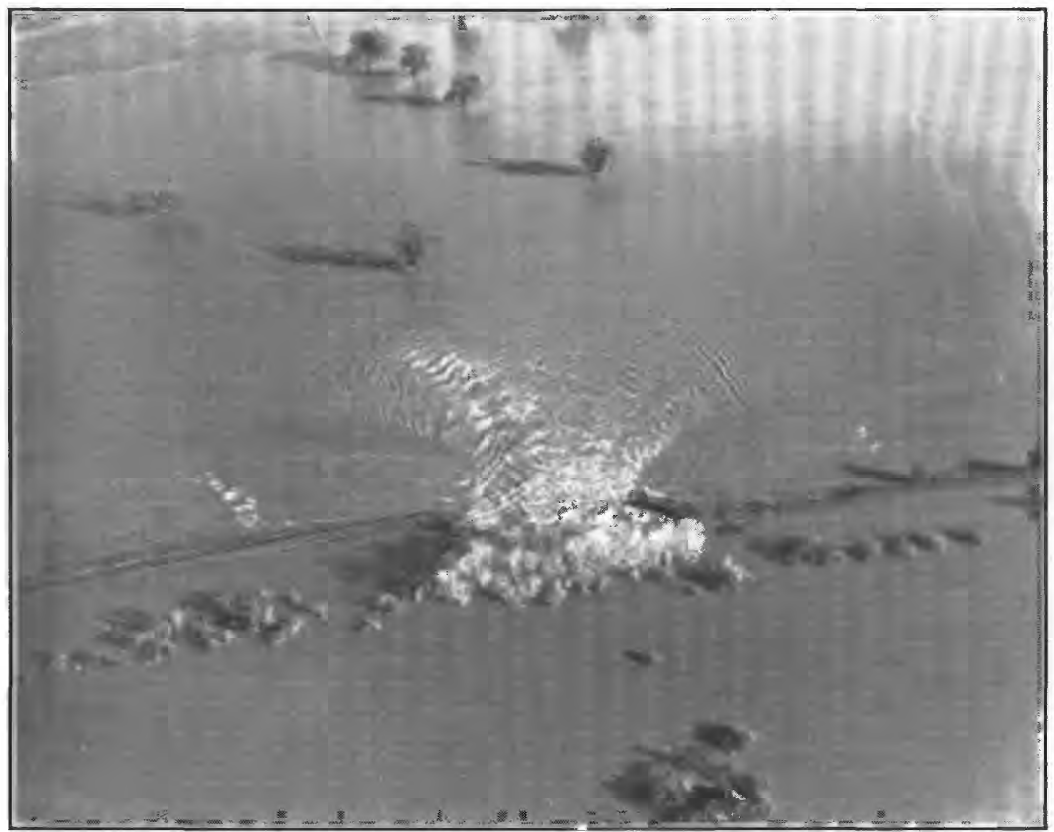

B. ONE OF MANY BREAKS IN RIVER LEVEE.

Courtesy of the Sacramento Union.

FLOOD SCENES ON SACRAMENTO RIVER, DECEMBER 12, 1937. 


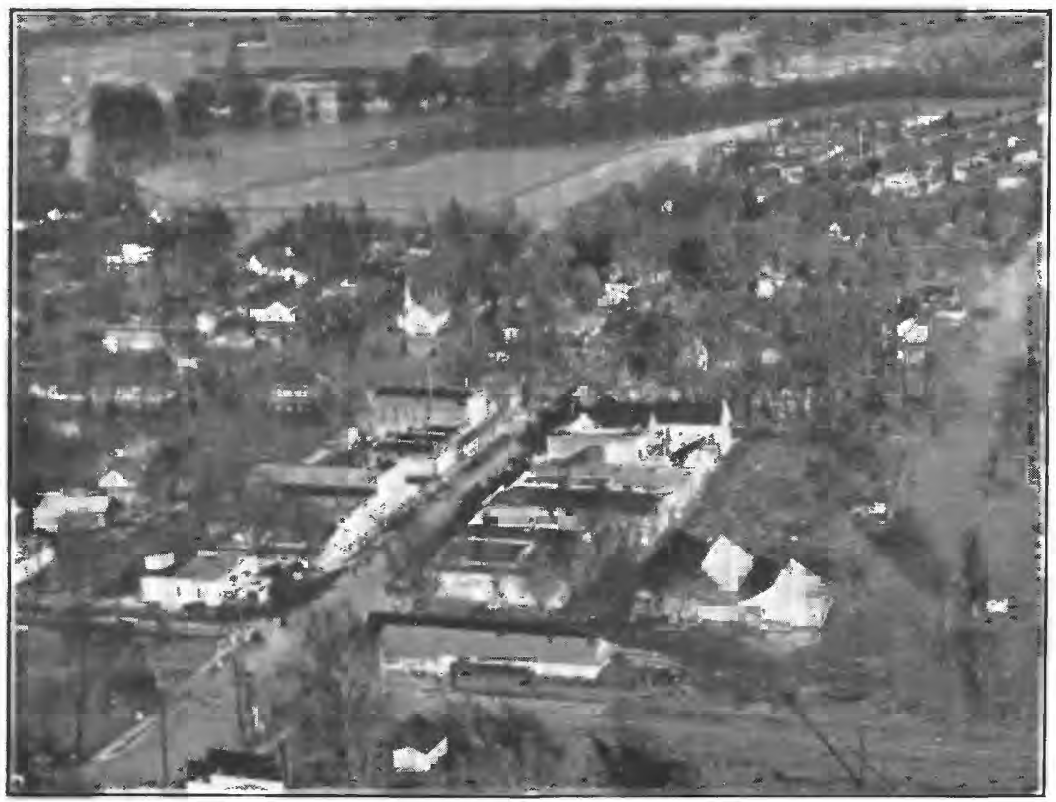

A. FLOODWATERS OF FEATHER RIVER IN TOWN OF BIGGS. Courtesy of the Sacramento Bee.

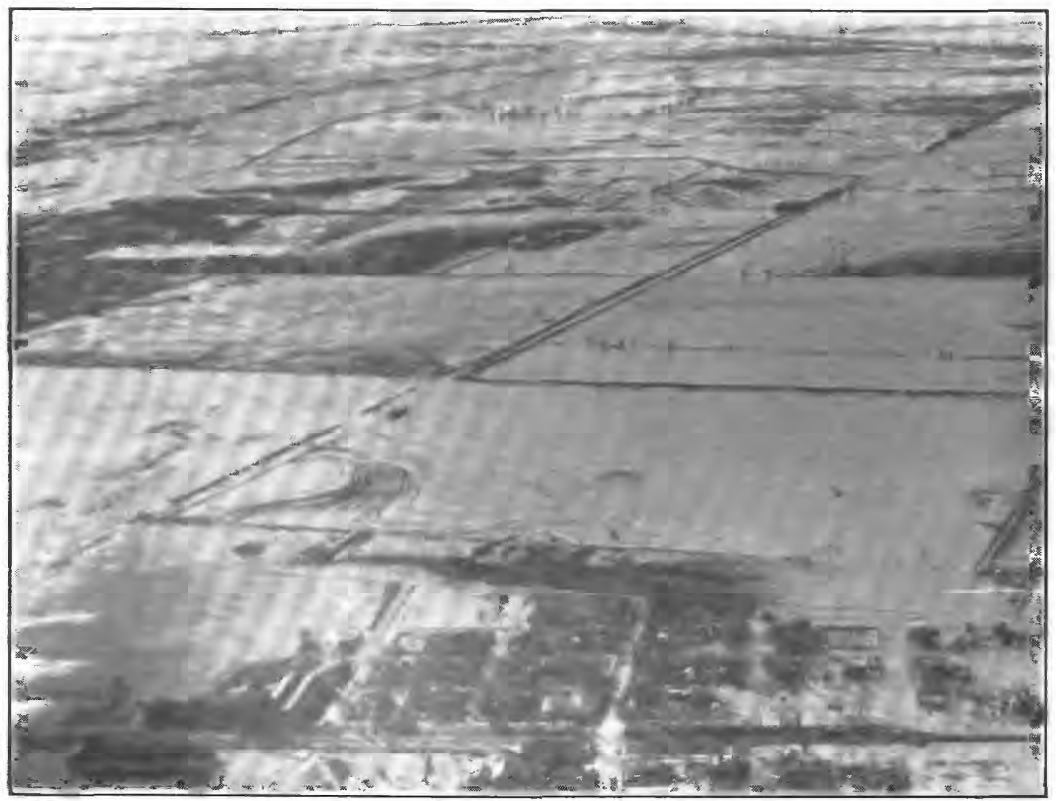

B. LOOKING WEST FROM BIGGS OVER BUTTE BASIN.

Courtesy of the Sacramento Bee. 


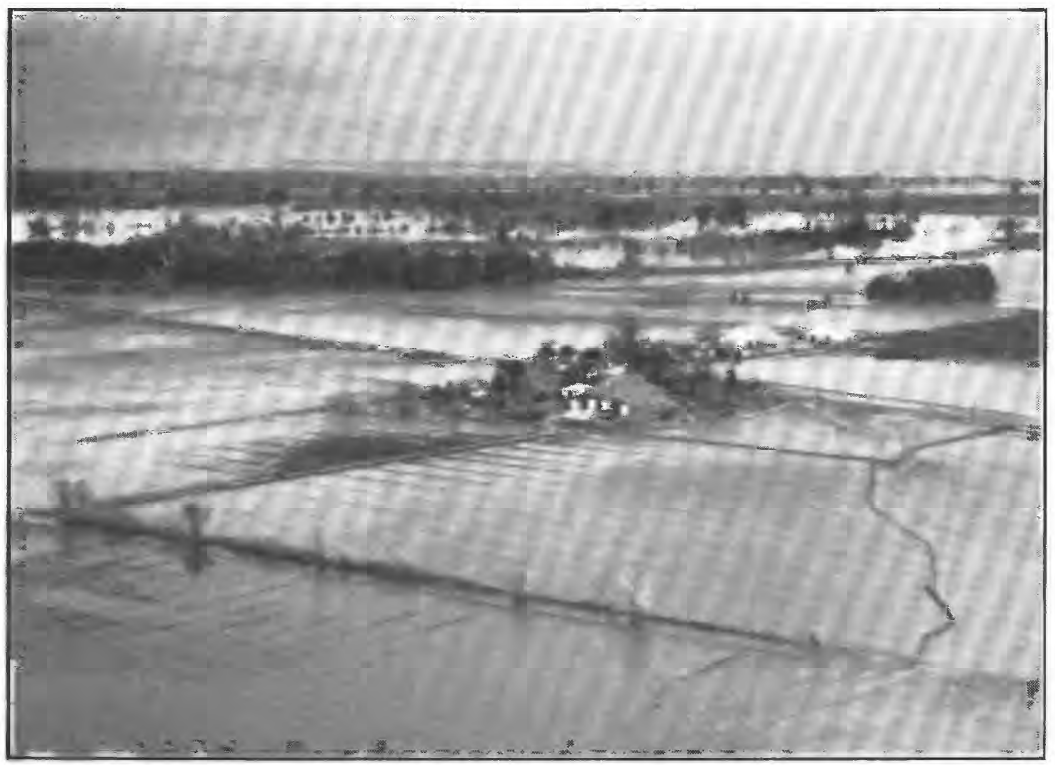

A. INUNDATED FARM LANDS IN SACRAMENTO VALLEY, DECEMBER 12, 1937. Area north of Colusa, flooded by Sacramento River. Courtesy of the Sacramento Union.

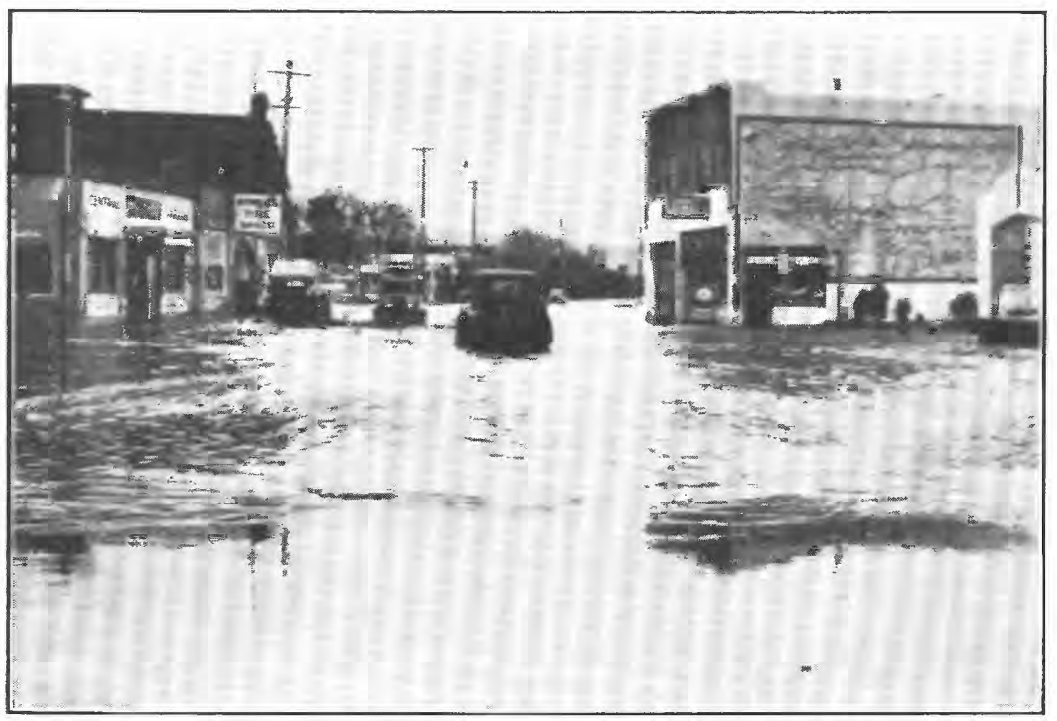

B. TOWN OF GILROY FLOODED BY WATER FROM UVAS GREEK. 


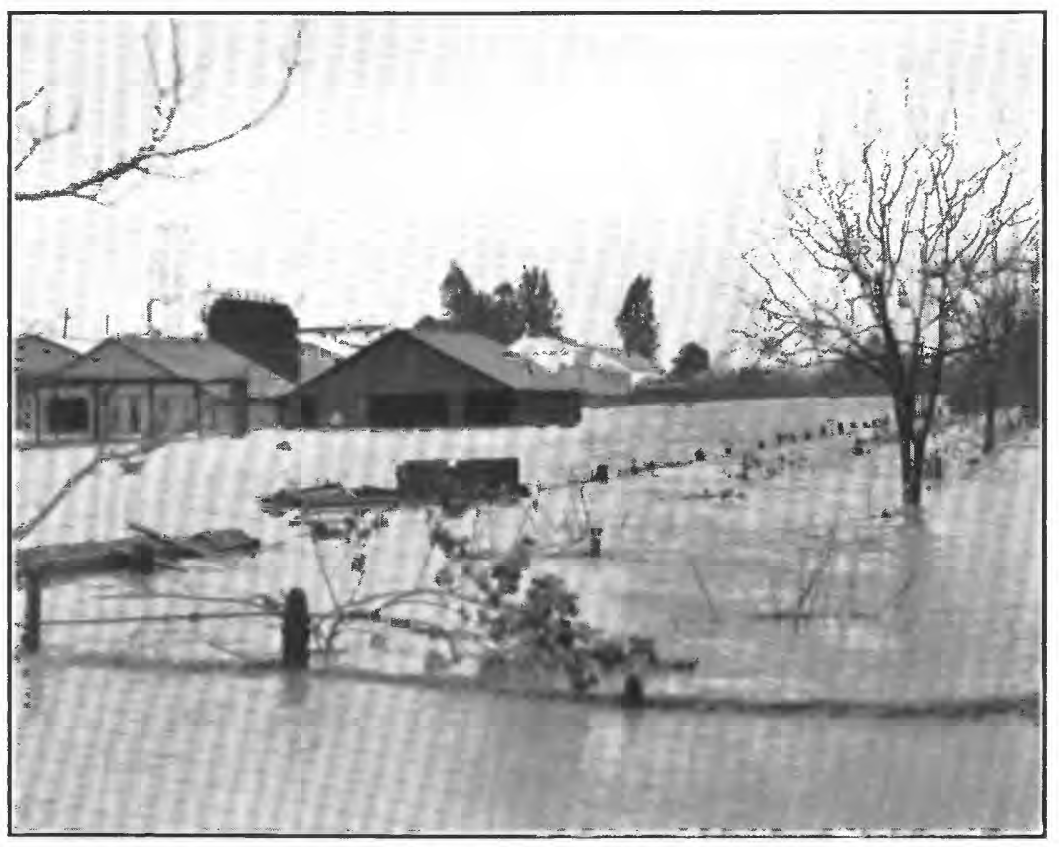

A. INDLSTRIAL DISTRICT IN NORTH SECTION OF HEALDSBURG.

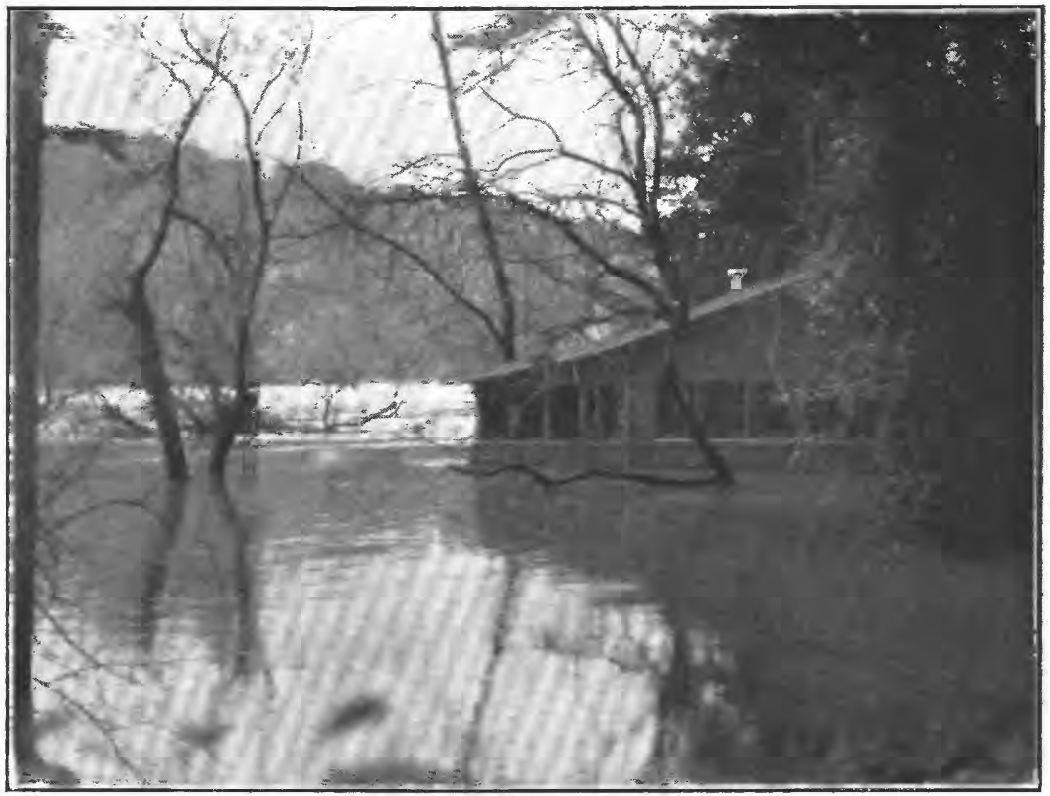

B. HOME NEAR FTTCH MOUNTAIN, EAST OF HEALDSBURG. 


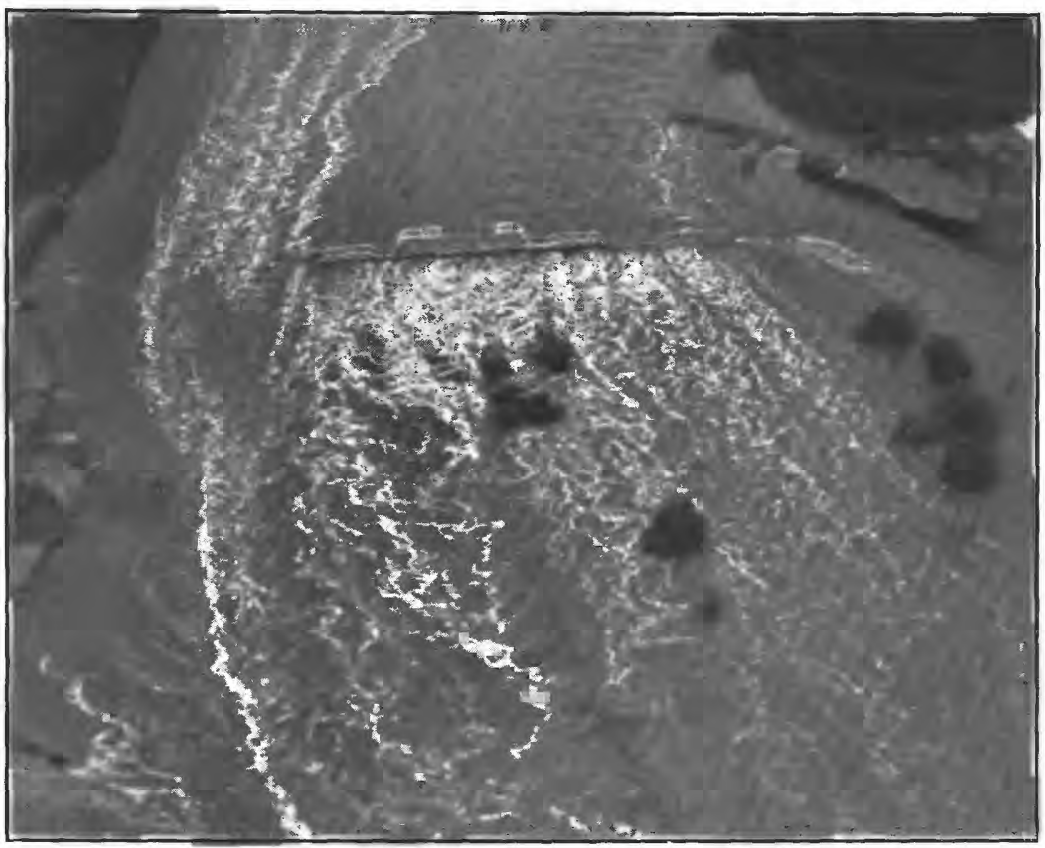

A. LOOKING UP KIVGS RIVER AT HIGHWAY BRIDGE AT PIEDRA.

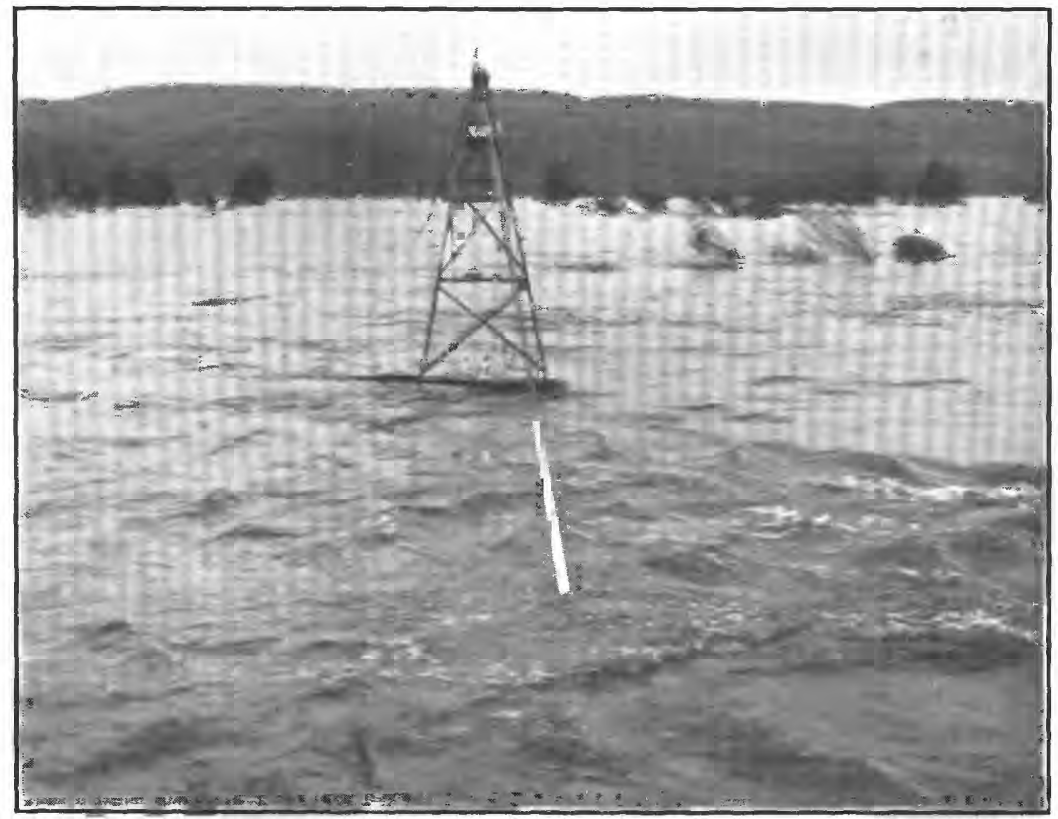

B. CABLEWAY AT RIVER-MEASUREMENT STATION ON SAN JOAQUIN RIVER BELOW FRIANT.

Stage about half a foot below peak, 


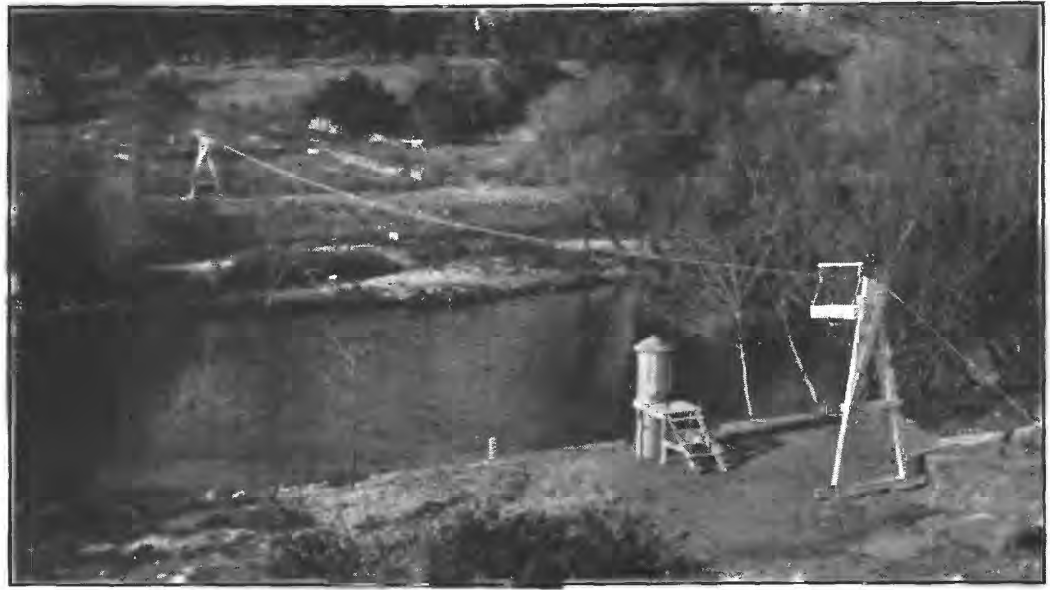

A. LOW-WATER STAGE PRIOR TO FLOOD OF DECEMBER 1937.

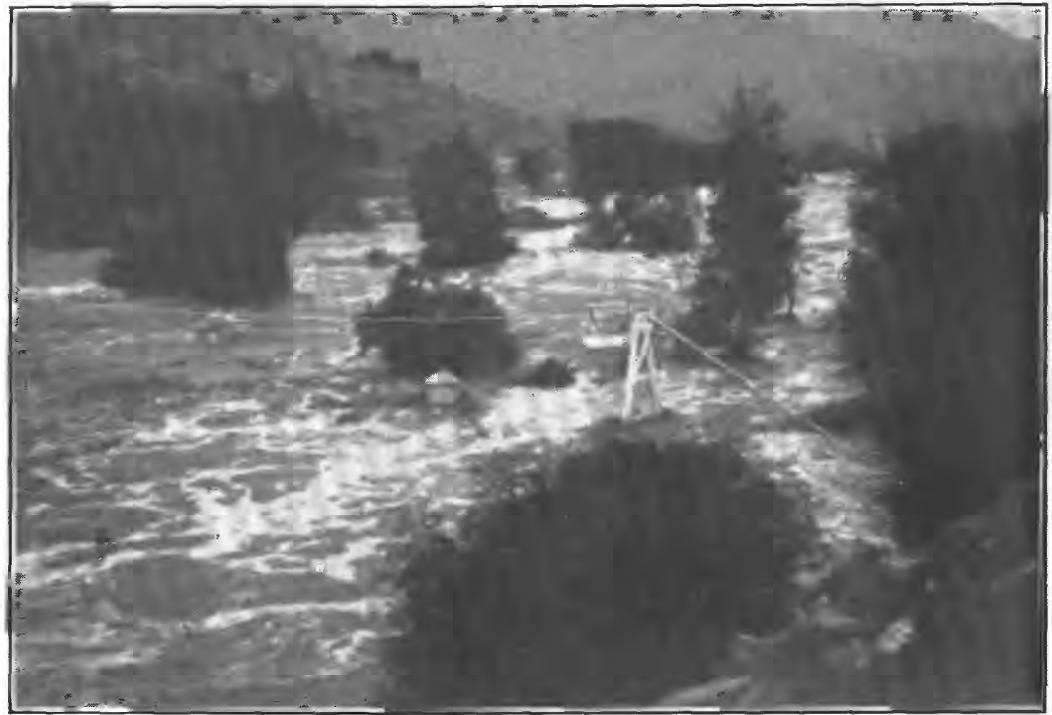

B. FLoOd STAGE IMMEdiately PRECEDING PEAK.

Courtesy of H. H. Holley. RIVERS. 

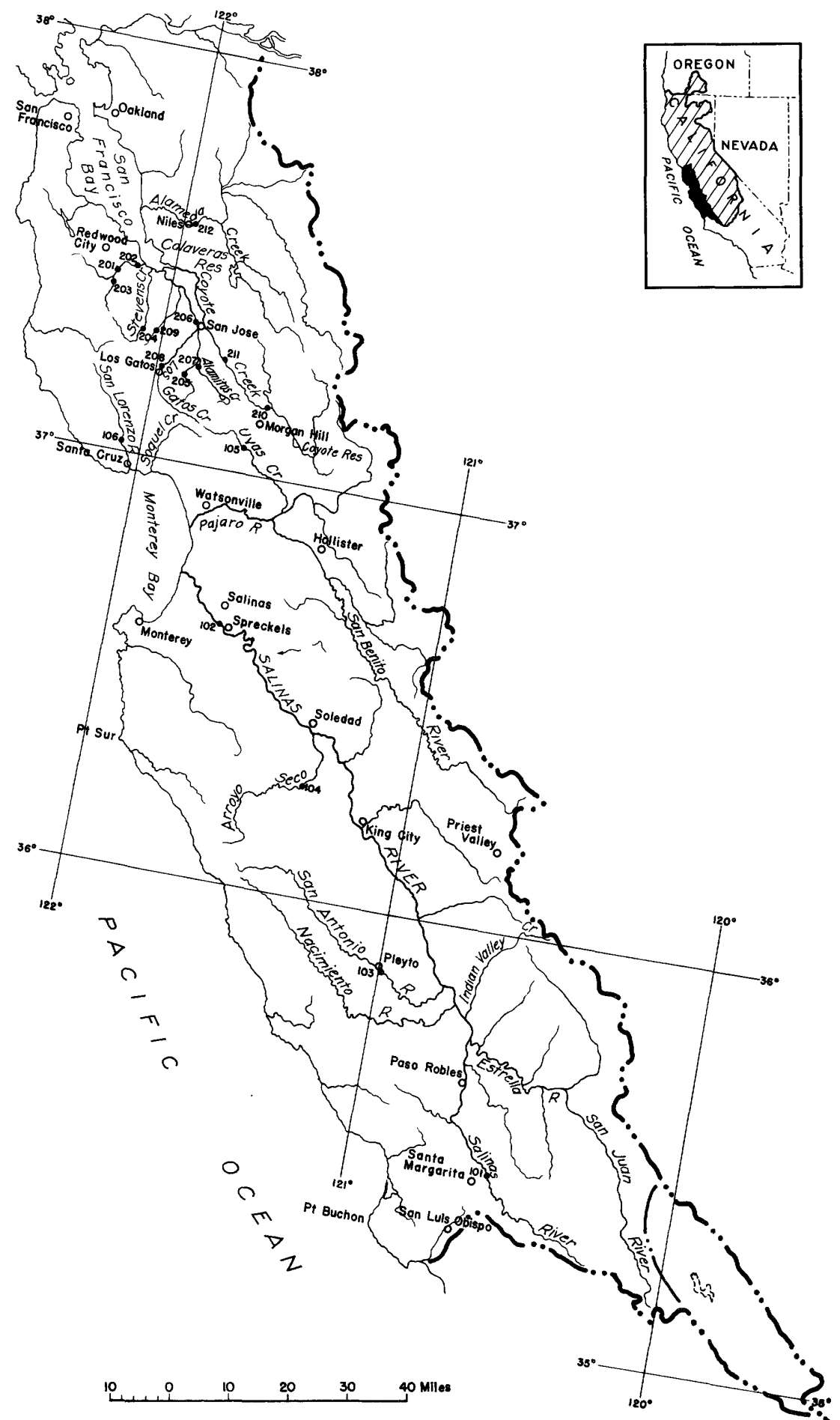

Figure 4.--Dralnage basins of the Salinas River, coastal streams from San Lu1s obispo Creek to San Franc1sco Bay, and streams tributary to San Francisco Bay from the south. 


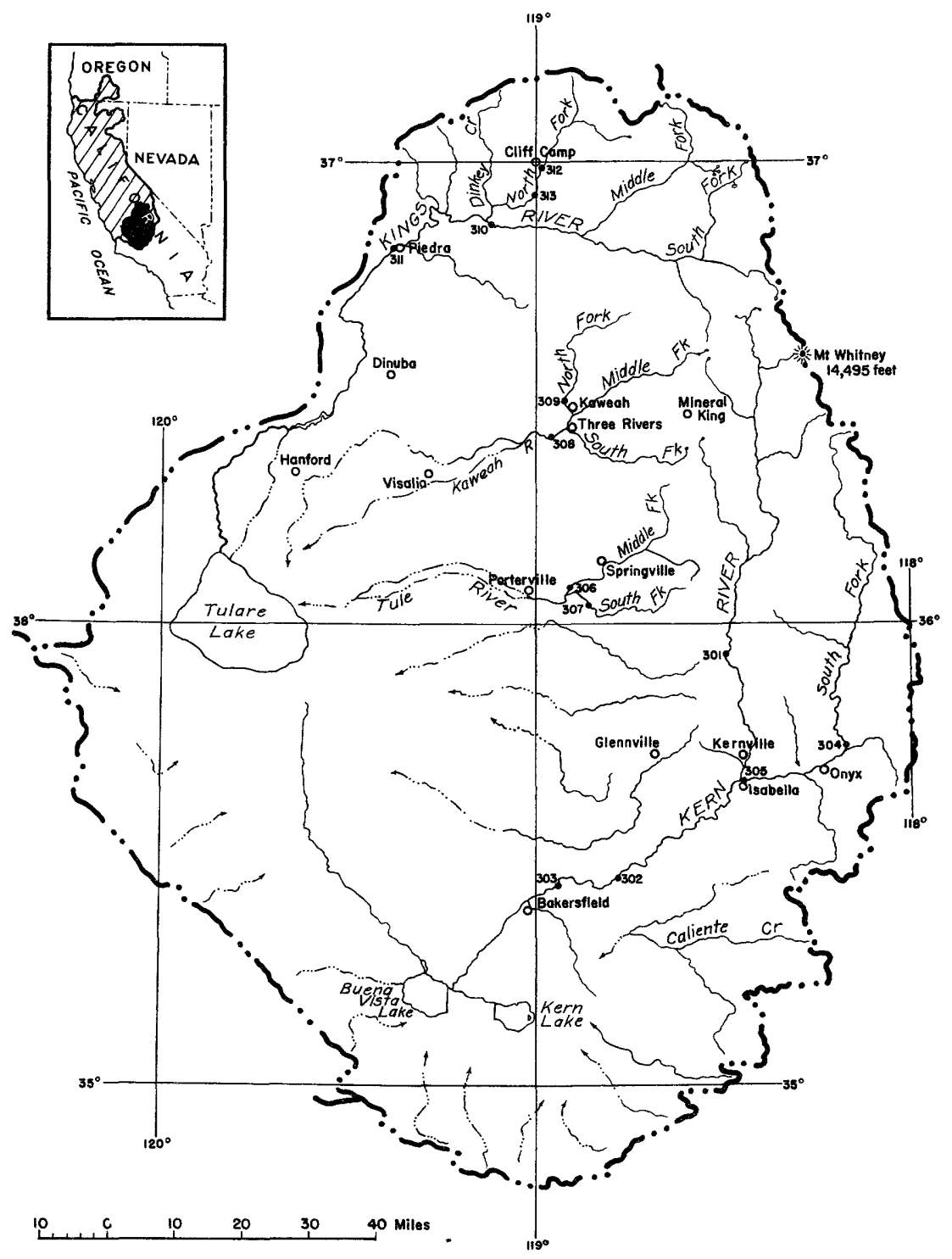




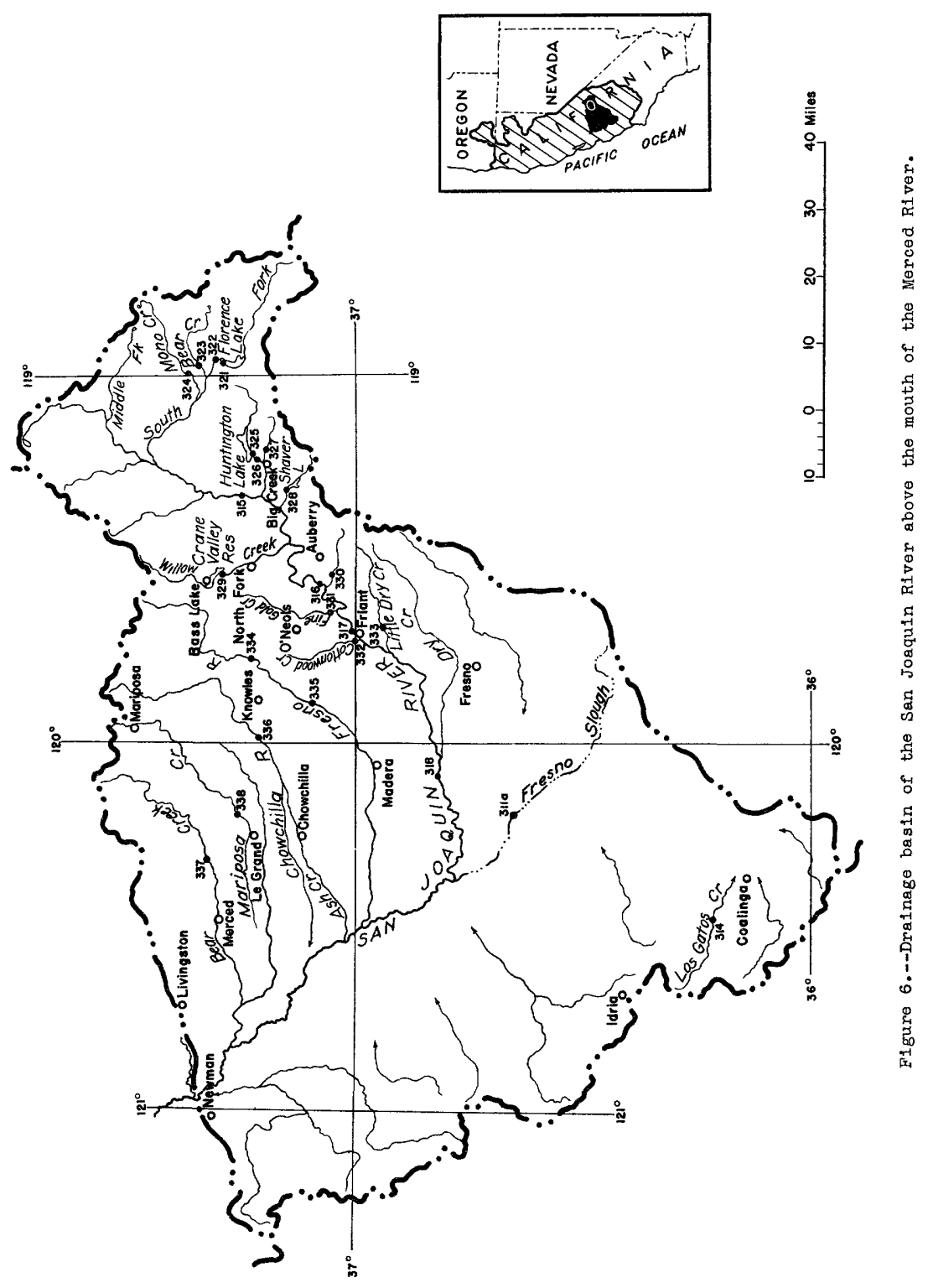



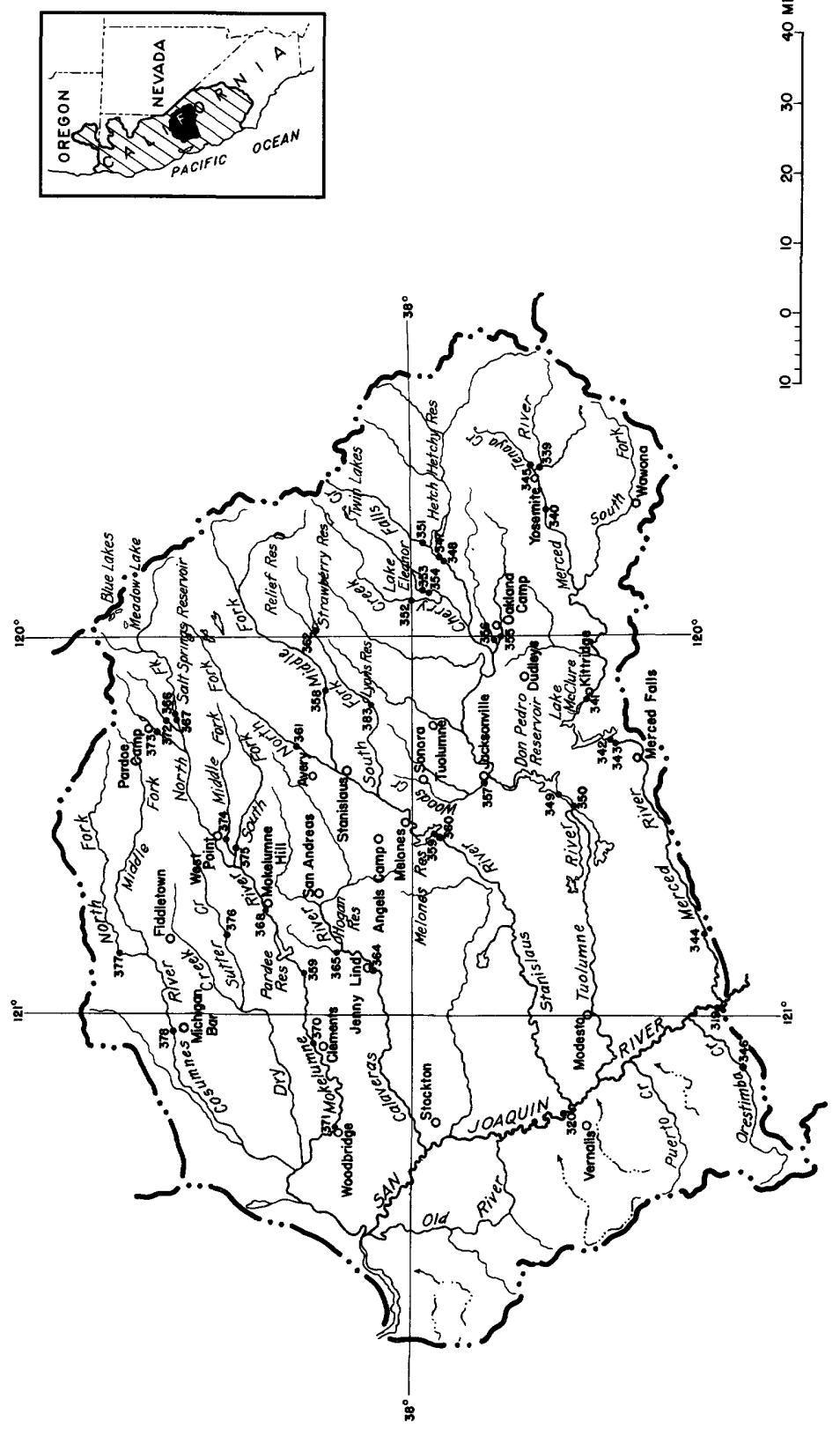

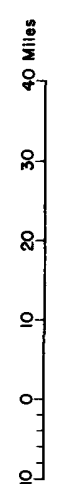




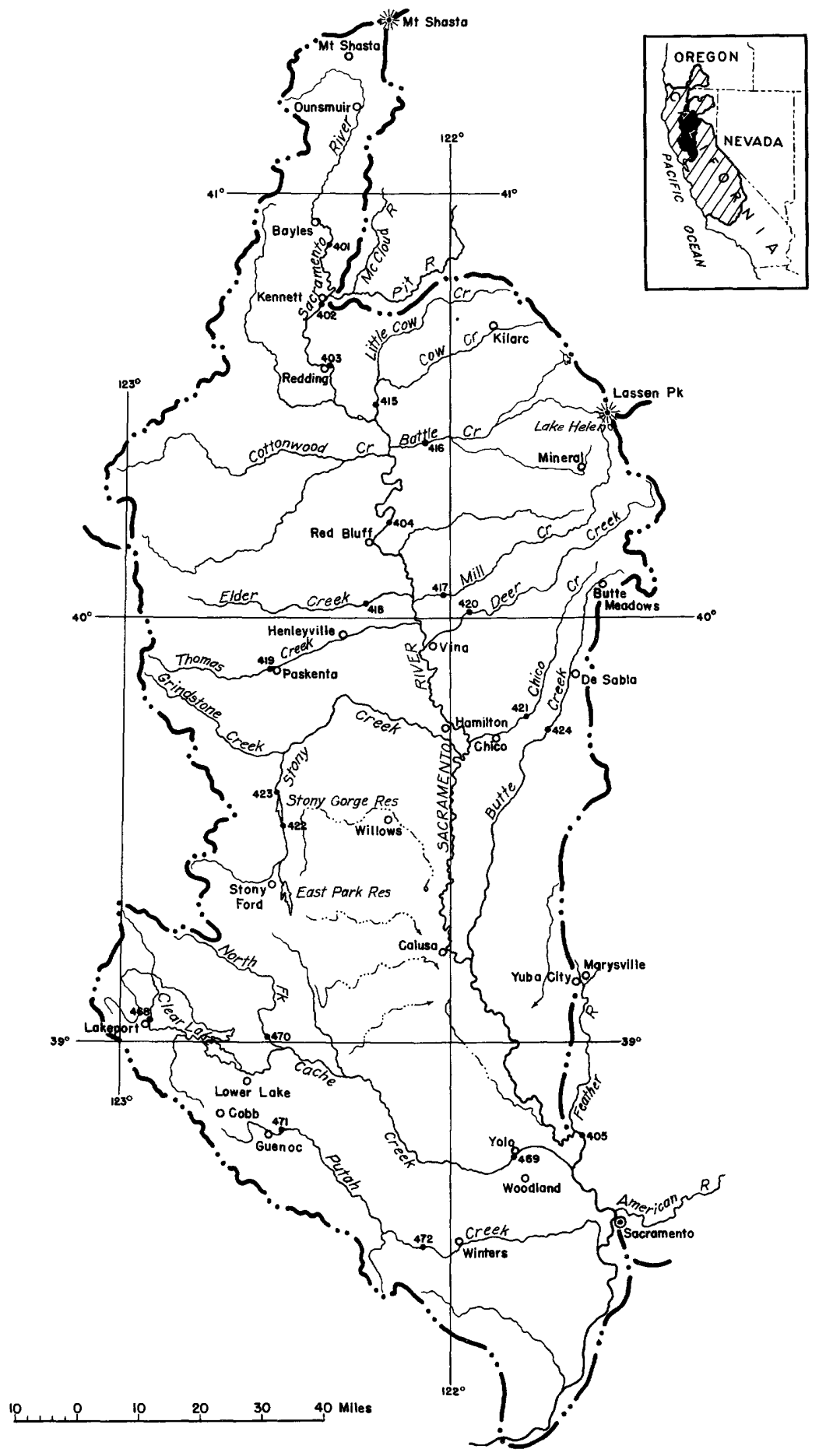

Figure 8.--Drainage basin of the Sacramento River, except the Pit, Feather, and American Rivers. 


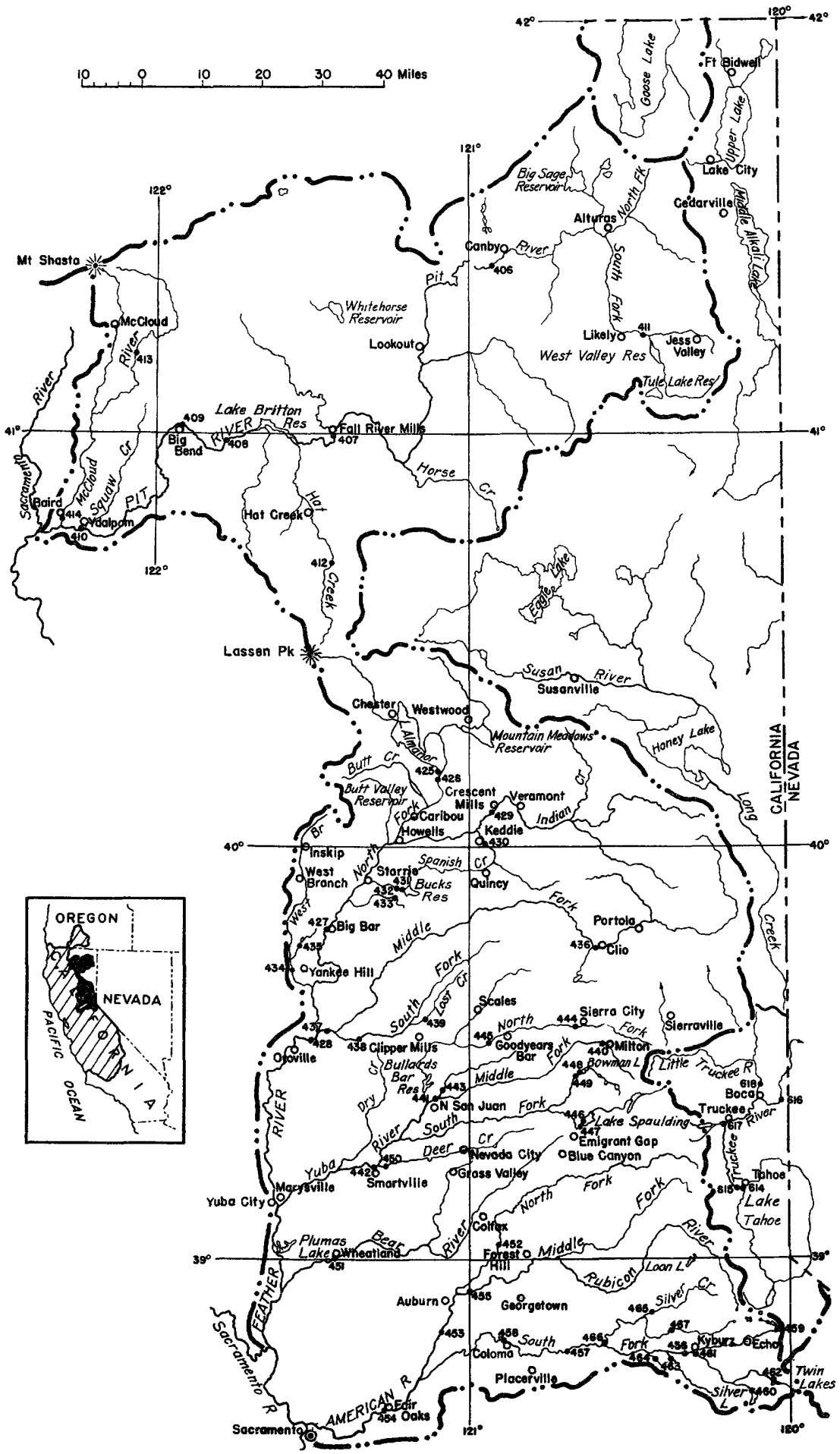

Figure 9.--Drainage basins of the P1t, Feather, American, and Truckee Rivers. 


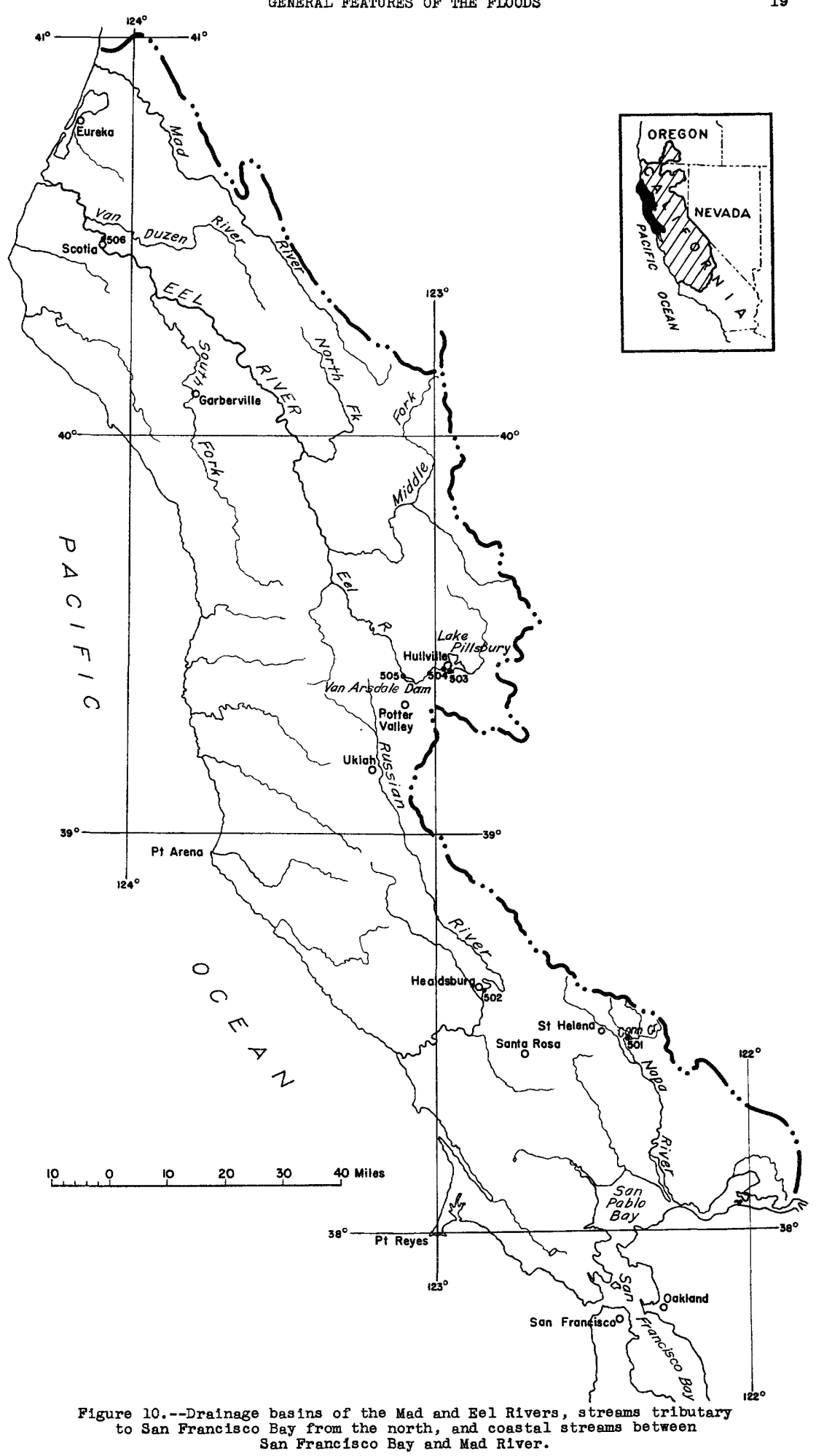




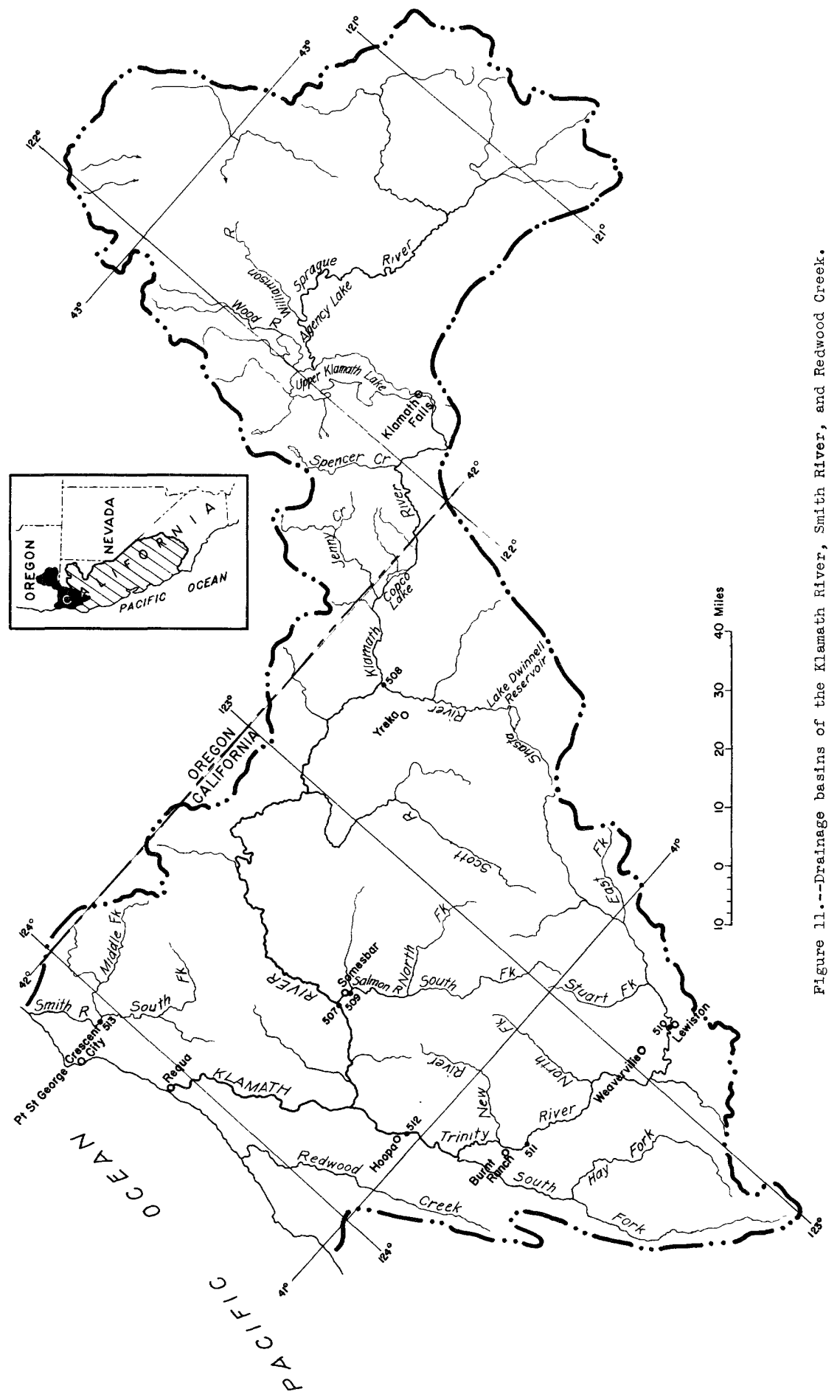




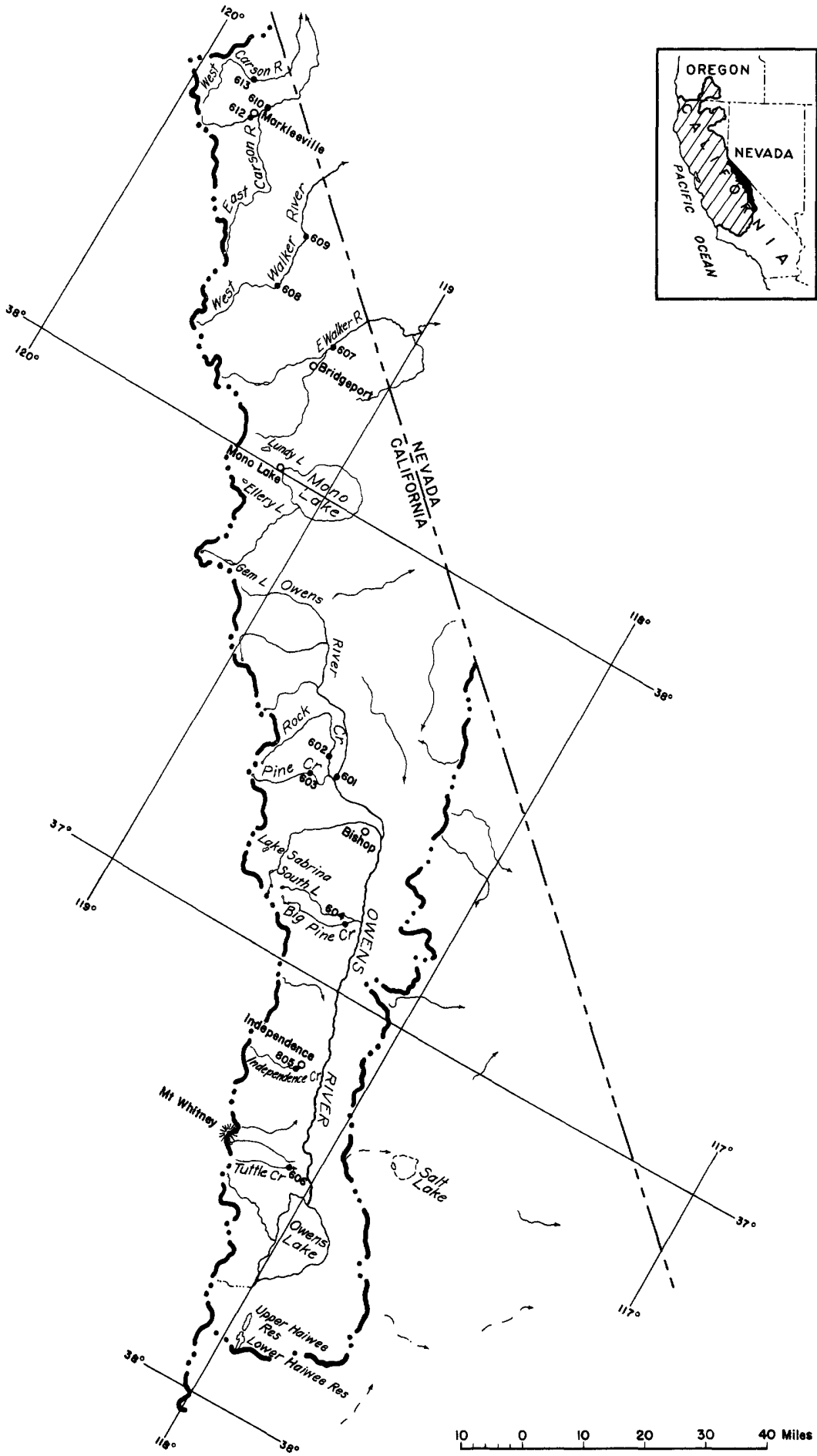




\section{METEOROLOGIC AND HYDROLOGIC CONDITIONS}

The outstanding characteristics of the storm of December 1937 were the speed with which it swept across the northern part of California, the relatively small amount of rainfall on the floor of the Great central Valley, and the excessive amount of rainfall and abnormally high temperature at high altitudes. The stomn was notable also for the time of its occurence, and for causing, during early winters, the largest floods in the Sacramento River Basin since 1861-62 and in the San Joaquin since 1867.

In view of these unusual aspects, special effort has been made to collect and to compile in this report all available basic information re lating to meteorologic conditions that may have had a bearing on the characteristics of the floods. The information is analyzed to a moderate extent, and the effects of meteorologic conditions on the run-off are discussed.

In connection with the discussion, however, it should be recognized that in most of the major and minor drainage basins in California there are pronounced and abrupt changes in altitude and in topographic aspect, which have a marked effect on the amount of precipitation and on its occurrence as rain or snow in different parts of the basin. These factors hamper the translation of limited observations into values that are representative of conditions over entire drainage basins. Although these factors exist in most drainage basins, they are more pronounced in the Western States than in the Central and Eastern States, and they are probably more pronounced in California than in Mountain States to the east, because of its proximity to the Pacific ocean and the varying ways In which the loast Ranges affect the moisture-laden winds from that ocean. A density of precipitation stations, which might be quite adequate for a study of flood characteristics in an area where meteorologic and topographic features are more uniform, may therefore be inadequate for most basins in California.

Briefly, the unusual meteorologic conditions that affected the floods of December 1937 were as follows: Preceding and during the 48-hour storm there were abnormally high temperatures that caused the precipitation in headwater areas to take the form of heavy warm rain instead of the snow that is usual with the normal December temperatures; there was a deficiency or a complete absence of snow cover in headwater areas where temperstures are normally such that snow melts but slowly even during periods of rain; and in the northern part of the area there was an excess of antecedent rainfall, which probably was reflected in an 
increased run-off by reason of a decreased infiltration capacity during the storm period.

The meteorologic and related data are here presented in detall, with a view to their usefulness to engineers and others who are studying the causes of floods and the measures that may be taken for protection against them.

\section{Antecedent conditions}

During october 1937 there was a tendency for the precipitation to be deficient in the San Joaquin River Basin and excessive in the Sacramento River Basin. However, departures from normal were small as compared with those of November 1937, when deficiencies in precipitation were recorded at practically all of the stations in the San Joaquin River Basin and excesses at all stations in the Sacramento River Basin.

In the northern areas, rains were more or less continuous from November $I 1$ to November 24, and the resulting run-off brought record November flood stages in many parts of the Sacramento River Basin. The mean discharge during November for the Sacramento River near Red Bluff was the third highest ever recorded for that month, and was more than two and a half times the 42-year average. The rainfall and run-off records in several basins in the northerm part of the area indicate that an average depth of 10 to 12 inches of water was retained in the basins during the November storm period by means of infiltration and surface and ground storage. This probably aggravated the December flood conditions in the Sacramento River Basin.

In contrast, the December flood run-off in the San Joaquin River Basin and southern Coast Ranges area was probably less than it would have been had the November precipitation been normal or excessive. Over much of the San Joaquin Basin the November precipitation was only onefourth to one-half of the normal. Mean discharge of the Kings River at Pledra, for November, was about half the 43-year average for that month.

A discussion of the meteorologic and hydrologic conditions during maximum floods of record as compared with the conditions during the flood of December 1937 is found in another part of this report. Comparisons taken up as a part of the discussion of each basin show qualitatively the very important part that antecedent precipitation plays in the flood mu-off in California. 


\section{Precipitation}

All available records of precipitation for the period from December 9 to 13 inclusive, which embraced the storm primarily causing the floods, are published in this report. (See table 1.) In addition, records are included for 14 places where recording precipitation reccras are avallable, showing duration and intensity of the rainfall. (See table 2.) The records of dally precipitation in table 1 are grouped by major basins covering the area in California where the storm reached significant magnitude.

Unfortunately, there were no recording precipitation stations in areas where the total storm precipitation was the heaviest. The duration of the storm period was probably nearly the same at all points in the area. The maximum recorded intensity was about one inch per hour at an experimental area maintained by United States Forest Service near o'Neals. The Intensity, at least near the outstanding storm centers, was probably greater than any shown by the recording precipitation graphs.

About half of the records of precipitation were obtained from the Weather Bureau, and the other half from numerous sources indicated in the tables. These additional records have been of great value in supplementing the Weather Bureau data. Many supplemental records are based on observations in 3-inch gages maintained by ranchers, irrigationists, and others who have a vital interest in rainfall. In using the observations, essentially the same welght has been given to each record regardless of 1 ts source and but few records have been discarded. In the valley areas, where the precipitation was relatively low and conditions were more or less uniform, less attempt was made to collect precipitation data than in headwater areas where the precipitation was heaviest and where at best there was, and still 1s, a scarcity of observational data. Such areas were falrly well canvassed to locate avallable records. In the valley areas, many more precipitation records could probably be located.

The figures in table 1 represent the amounts of precipitation as reported by observers and are not strictly comparable on individual days, because the observations at the various stations are not always made simultaneously. The amount recorded for a given day in most cases represents the rainfall for the 24-hour period preceding the time of observation. Rain falling during the daylight hours may be recorded under the date of fall when observations are made in the late afternoon or under the date of the next day when readings are made in the morning. 
General features $1 /$

On December 7, 1937, when the barometric pressures were relatively high in California and in the Pacific northwest, storm disturbances with accompanying low barometric observations were reported by ships in the Paciflc in the vicinity of lat. $30^{\circ}$ north, long. $140^{\circ}$ west, and in lat. $50^{\circ}$ north, long. $165^{\circ}$ west. By Wednesday morning, December 8 , when these disturbances were more defined, southwest winds accompanied by rains were forecast by the Weather Bureau for California. On the morning of December 9, when the disturbance was about 900 miles off the coast, storm warnings of gale intensity were being displayed between Cape Blanco and Point Conception, and the Sacramento office of the Weather Bureau forecast a general rise in all streams in the Sacramento river basin. By noon it was raining throughout the western half of the State, and by evening over all of the State north of Bakersfield.

The weather map of the next morning (December 10) showed the storm to be of record magnitude and almost of hurricane intensity (barometer, 28.1 inches at 1ts center) of $f$ the coast of Washington and Oregon, and the Weather Bureau issued additional flood warnings by means of the press, radio, and telegraph throughout the Central Valley. Durlng the day the maritime tropical air at a record-breaking high temperature for December was flowing rapidly across Califormia at gale velocity and converging agalnst the Coast Range and the slerra Nevada. The cooling of this molsture-laden air produced the heavy precipitation forecast for December 10. The precipitation continued with little interruption until late afternoon on December 11 , and there were occasional showers on December 12. In the northern part of the state, the rain was nearly continuous. In the southern part of the area, there was a tendency for the precipitation to be concentrated in two storm periods, apparently of about equal intensity and depth.

Bennett Swenson of the River and Flood Division, the Weather Bureau, Washington, D. C. describes the storm in part as follows:

The heavy rains of December 9-11, 1937, resulting in floods in the Sacramento River Basin, were almost entirely due to orographic effects and any fronts which passed over the region during this period played a very minor part in the causation of this precipitation. The situation was such that very strong southwesterly winds prevalied over northerm and central California from the 9 th to the lith importing warm moist air from the ocean areas. This molsture laden air was forced to rise rapidly over the steep slopes of the mountains forming the eastern and northern boundaries of the Sacramento River Basin and resulted in excessive precipitation. 


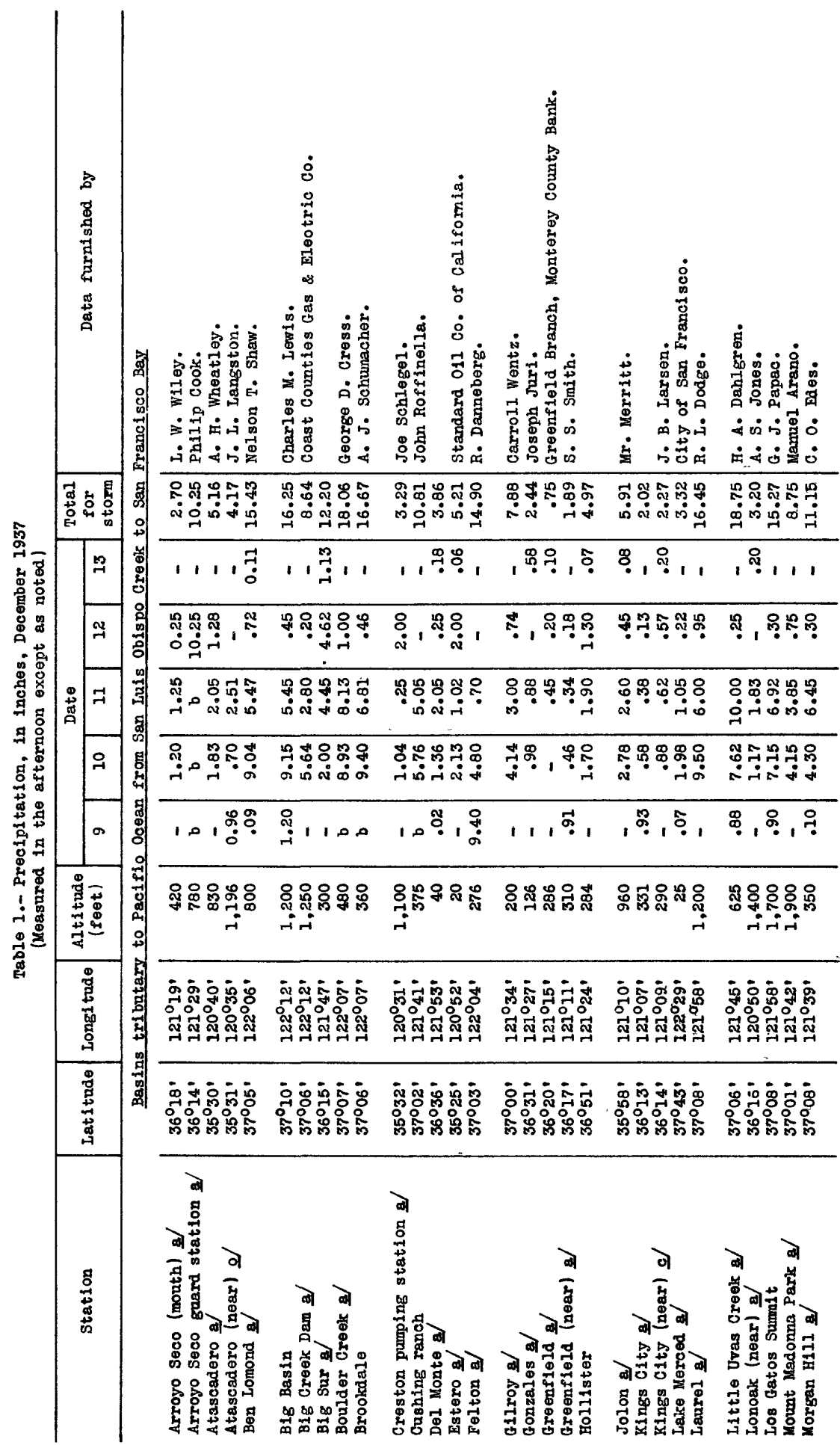




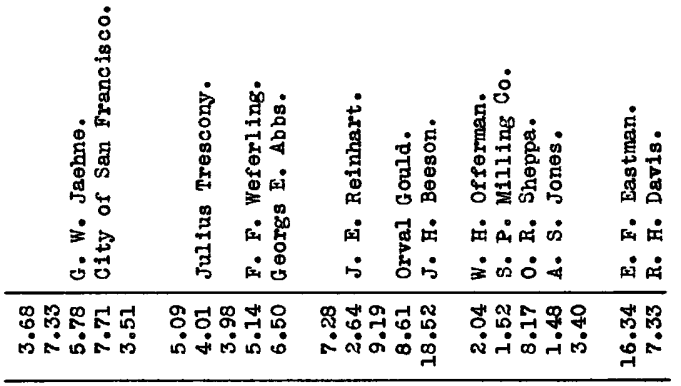

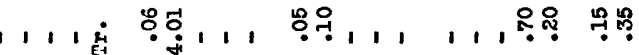

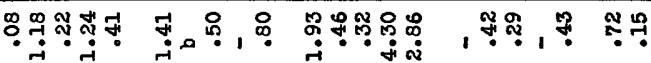

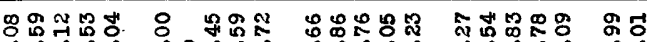

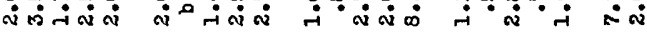

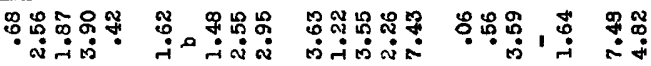

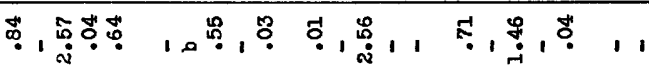

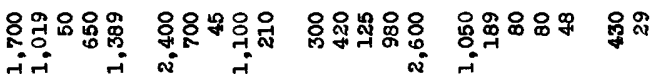

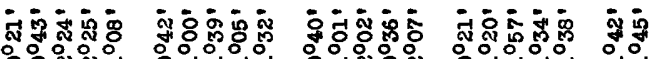

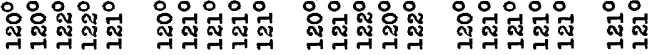

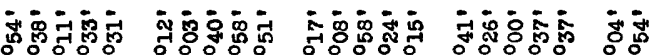

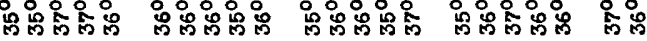

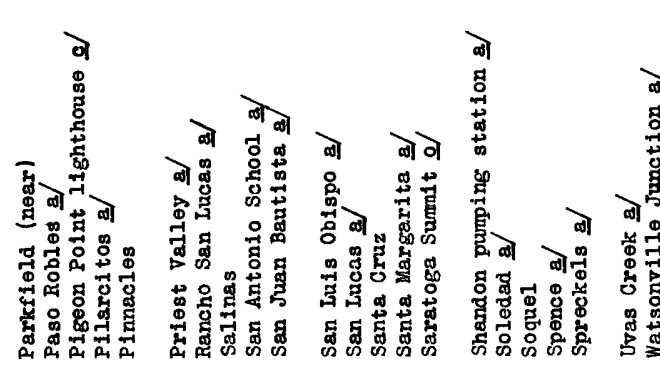

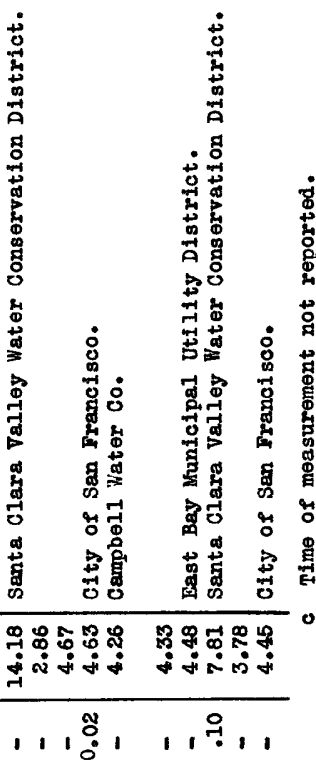

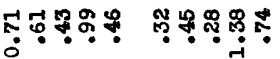

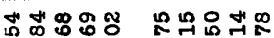

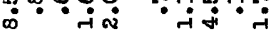

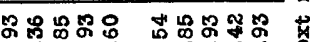

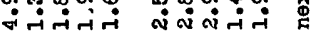

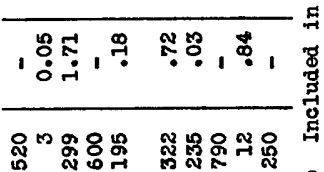

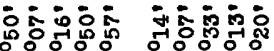

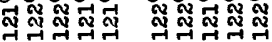

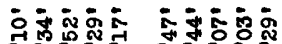

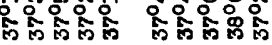

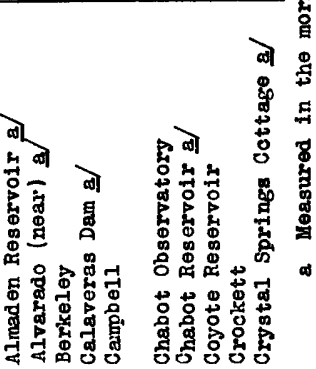




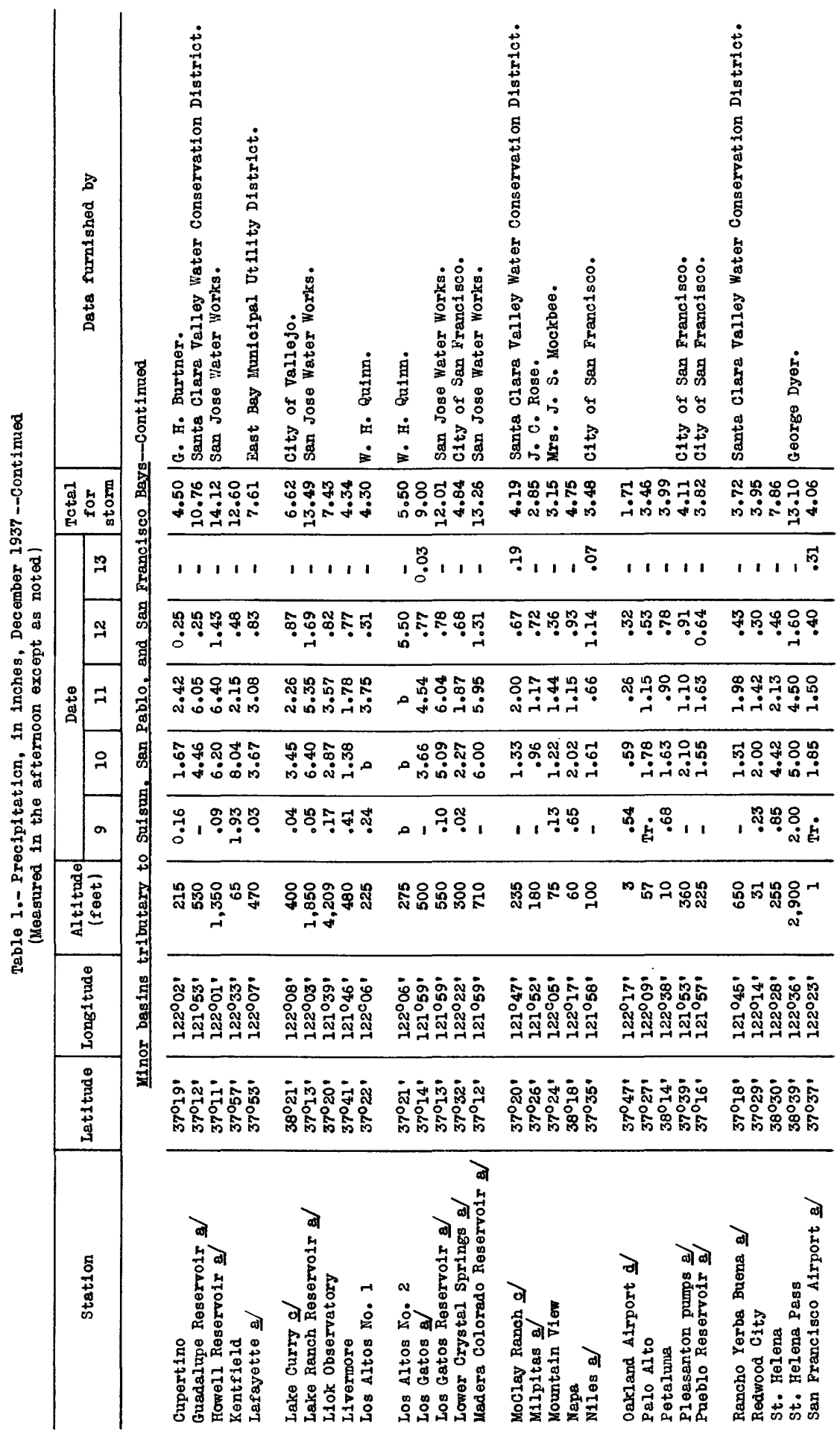




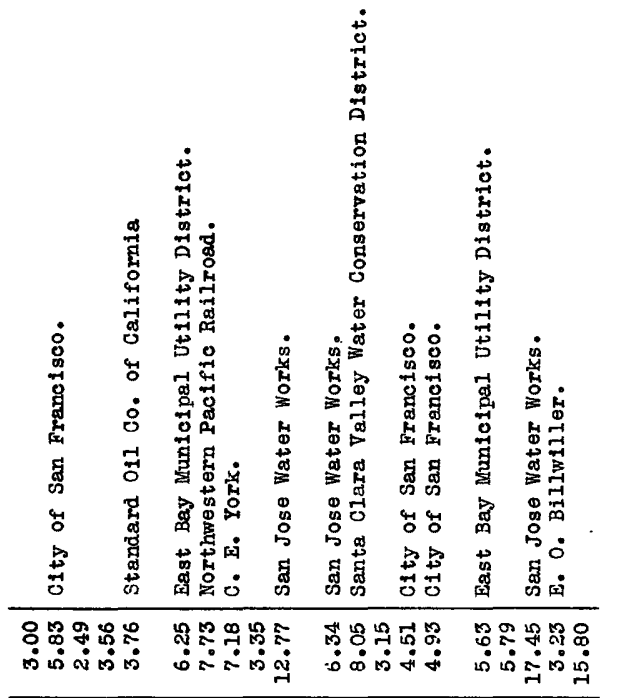

$1,1,1,0_{0}^{-} 11,1,1,1,1,1,11$

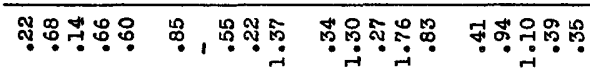

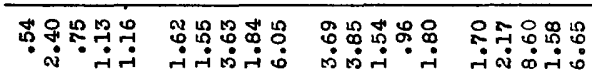

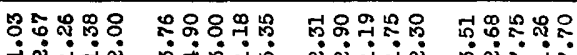

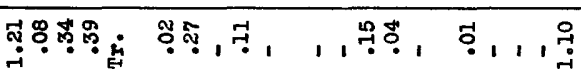

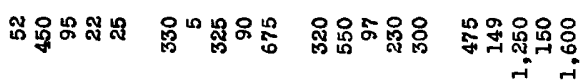

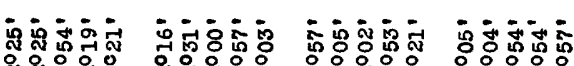

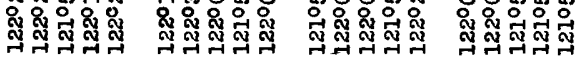

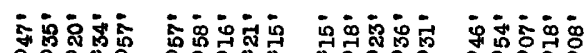

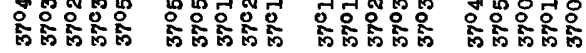

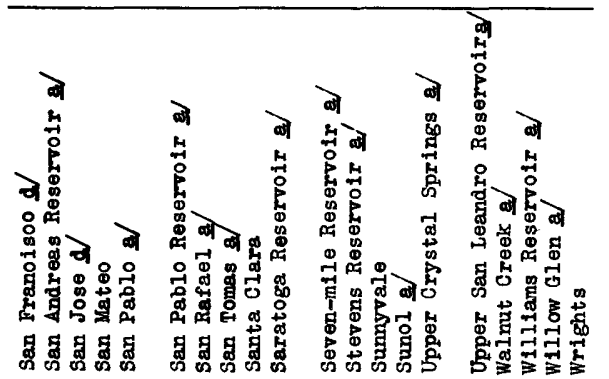

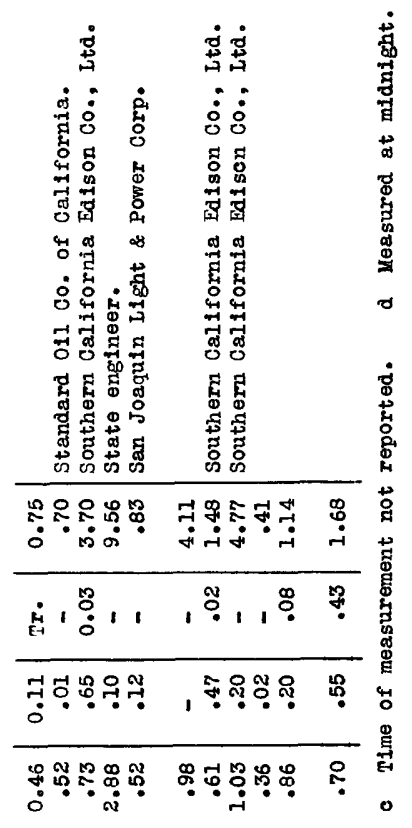

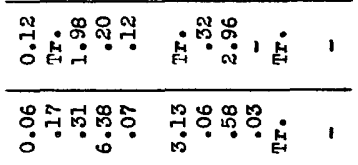

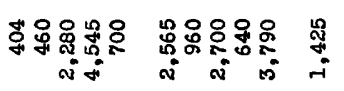

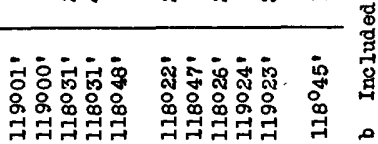

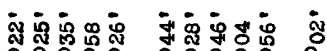
品品品品品 品品品品高 勋

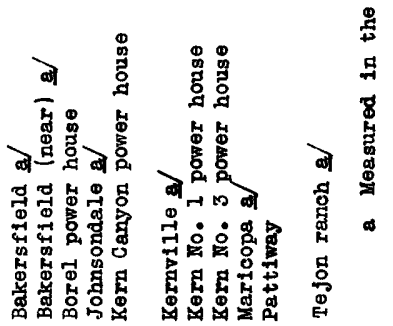




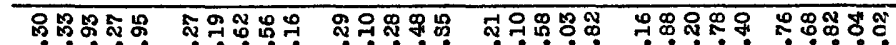

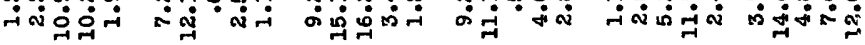

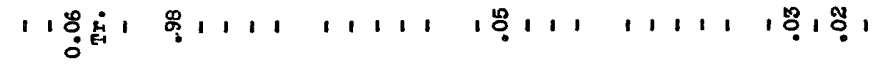

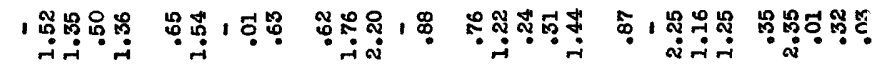

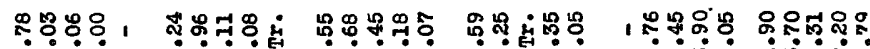

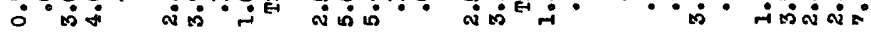

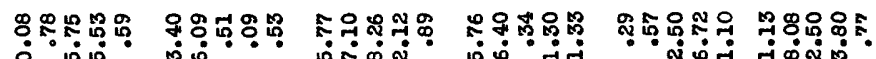

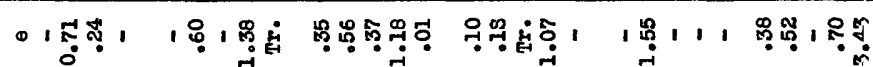

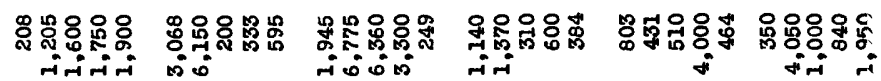

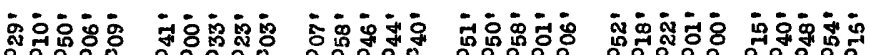

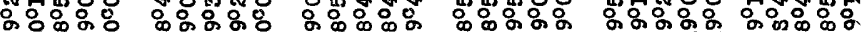

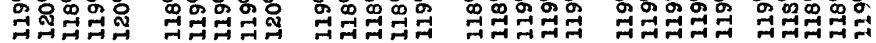

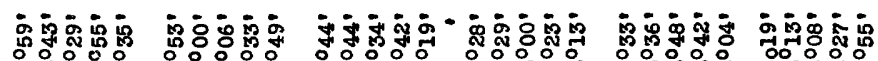

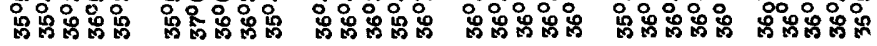

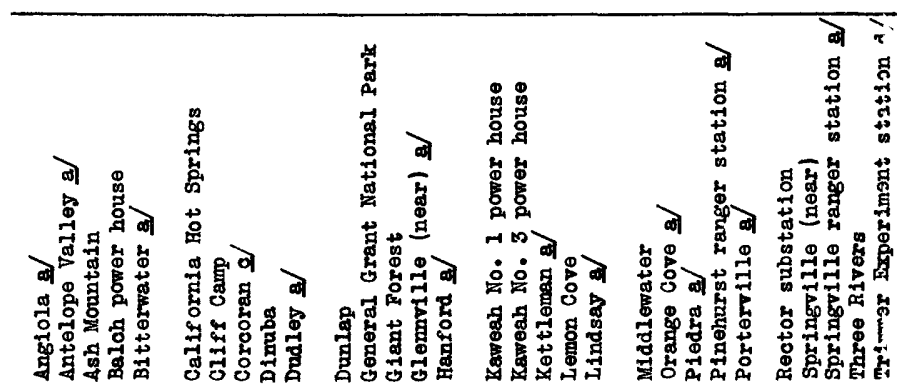




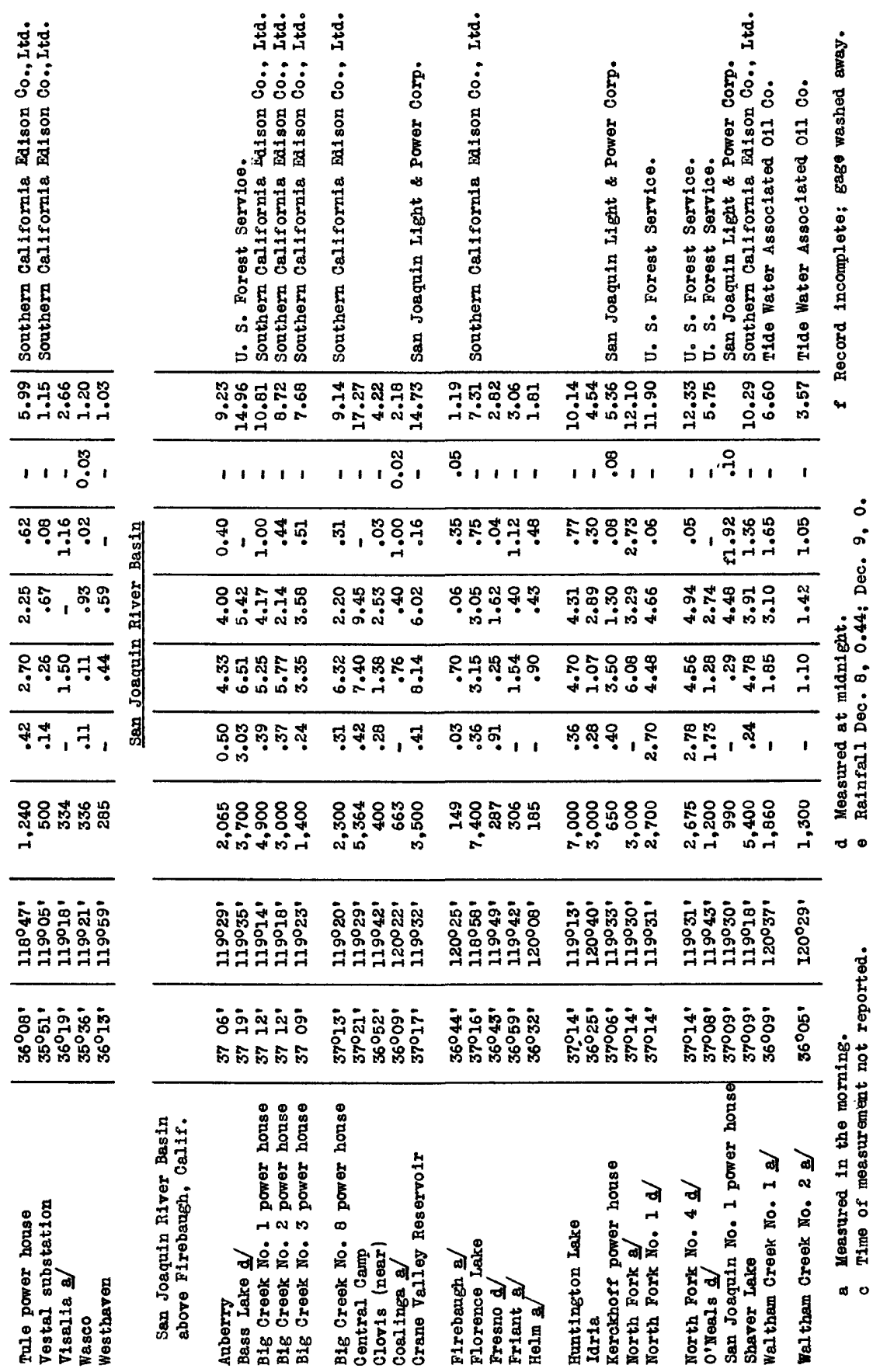




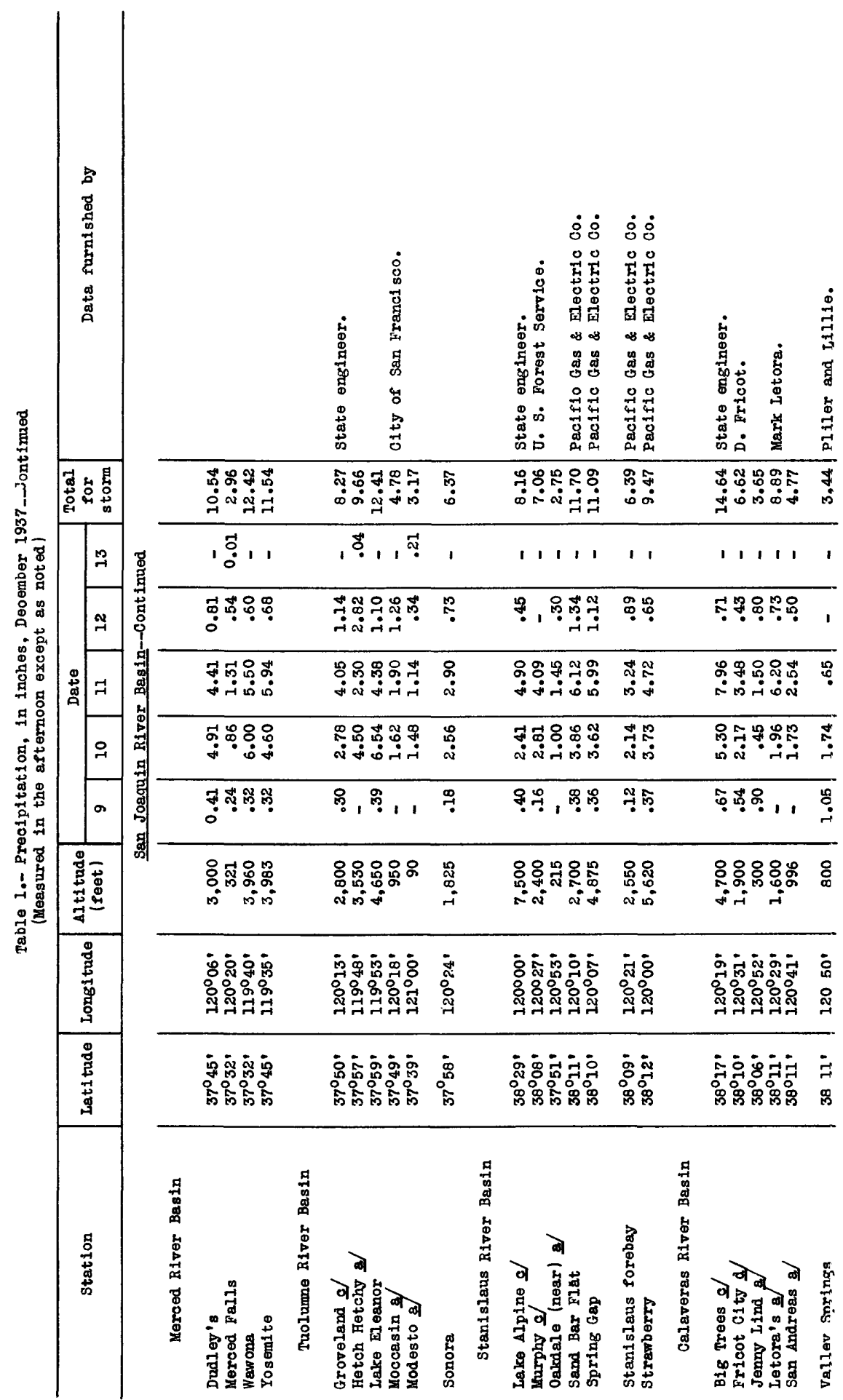




\begin{tabular}{|c|c|c|c|c|c|c|c|}
\hline & 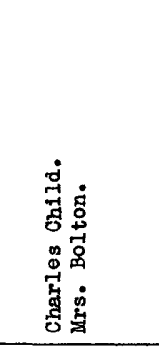 & 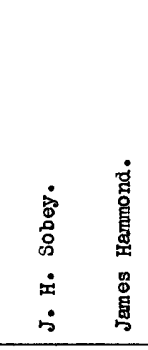 & 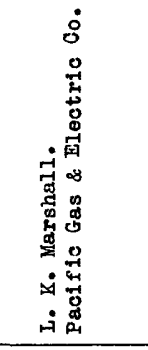 & 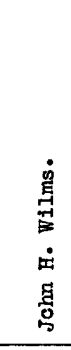 & & 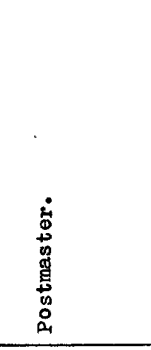 & 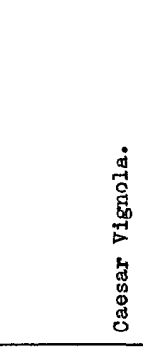 \\
\hline & 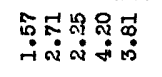 & 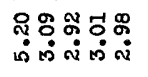 & 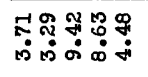 & 跑 & & 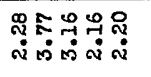 & 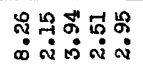 \\
\hline & $\stackrel{?}{?}, 1, \stackrel{\circ}{\circ}$ & $, \tilde{)}, \overline{0}, 1$ & ث̊ & $1 \stackrel{0}{0}$ & & 1,19 & , 웅 \\
\hline & 㝵 & 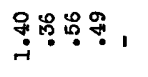 & 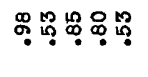 & ํํㅇ & & 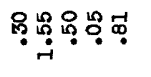 & 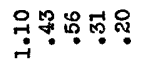 \\
\hline & 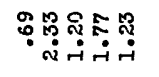 & 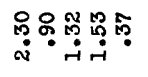 & 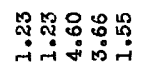 & 兽 & & 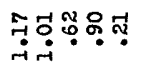 & 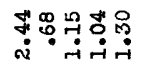 \\
\hline & "ִ. & 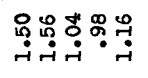 & 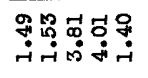 & 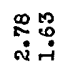 & & 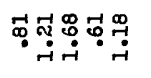 & 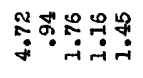 \\
\hline & ' & $1,1, \frac{9}{4}$ & $\stackrel{-1}{\circ}, \stackrel{0}{?}$, & $\stackrel{\infty}{0}$, & & , , $\stackrel{000}{\circ}:$ & 11111 \\
\hline & స怘吕哭 & 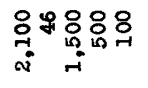 & 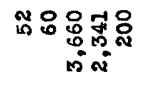 & $\begin{array}{l}\text { 电早 } \\
\text { 心 }\end{array}$ & & 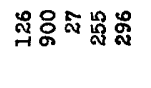 & 荅: \\
\hline & 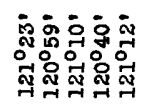 & 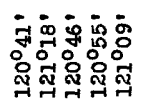 & 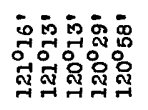 & 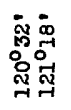 & & 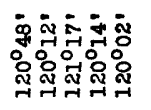 & 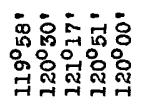 \\
\hline & 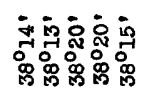 & 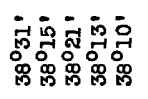 & 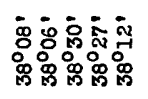 & 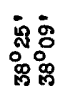 & & 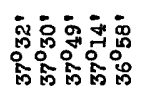 & 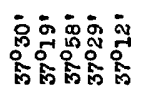 \\
\hline 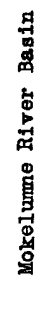 & 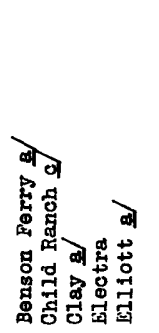 & 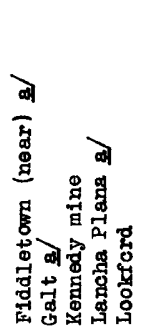 & 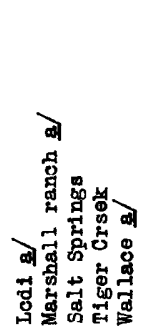 & 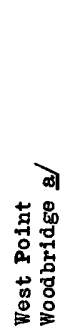 & 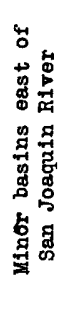 & 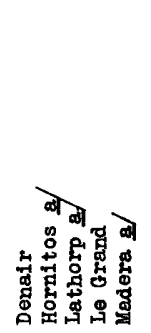 & 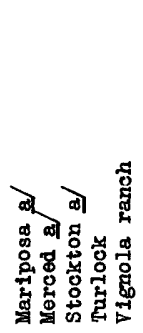 \\
\hline
\end{tabular}




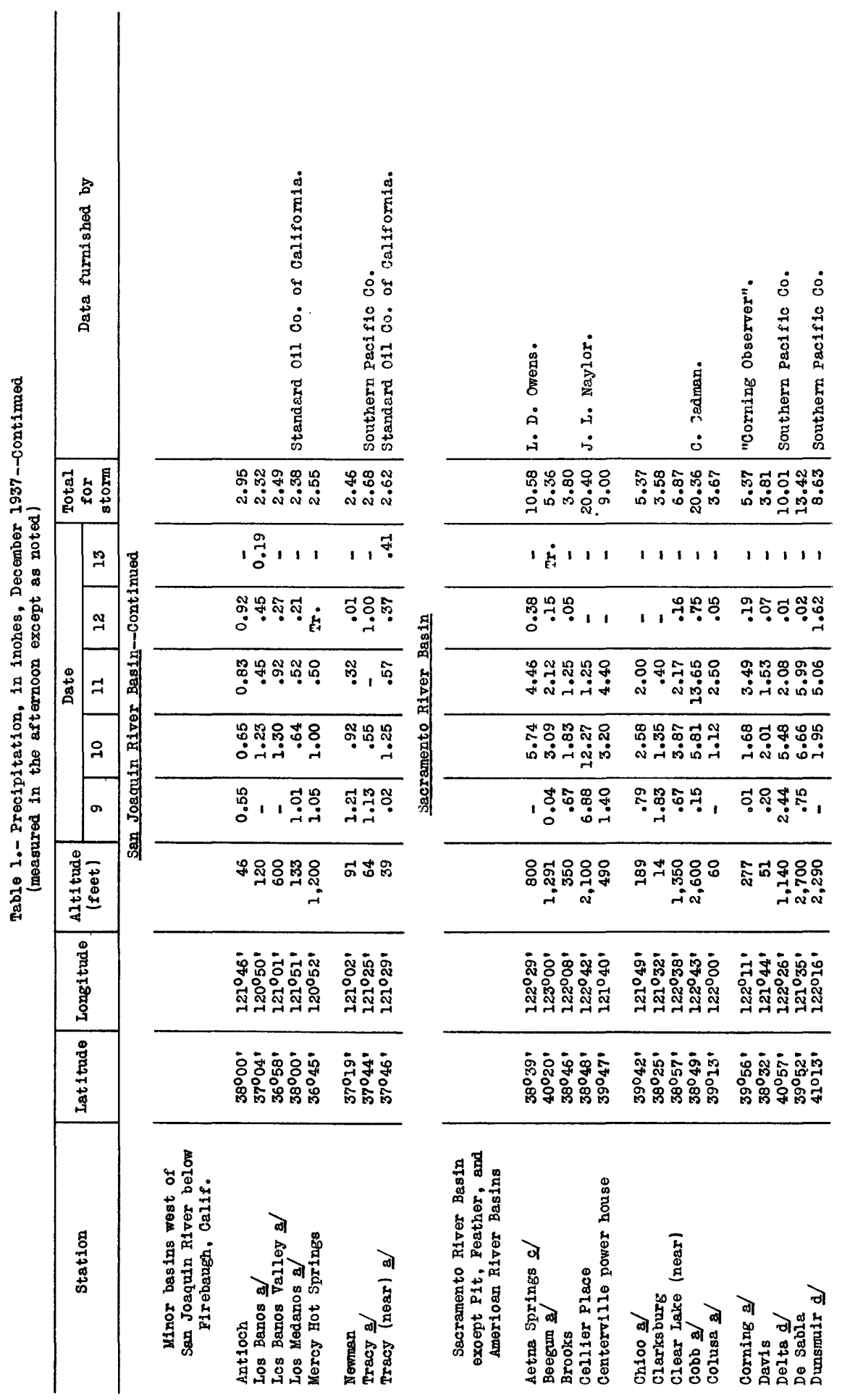




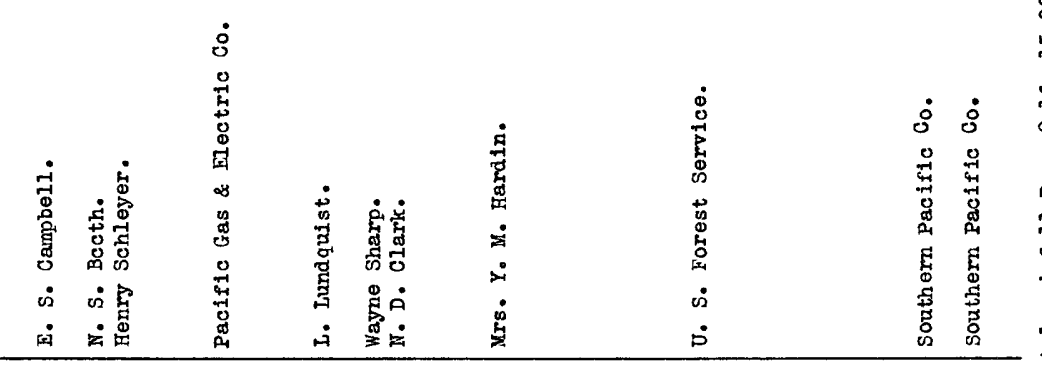

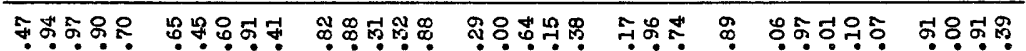

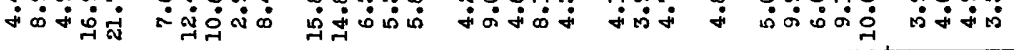
80.5

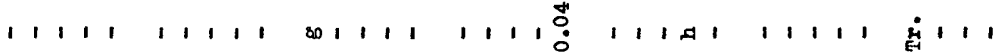

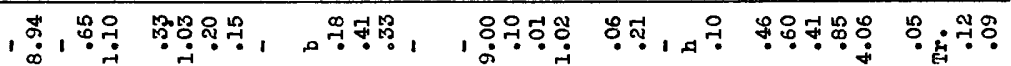

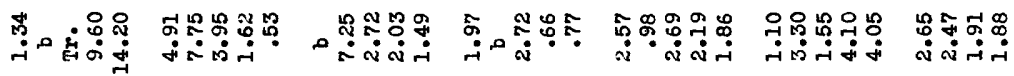

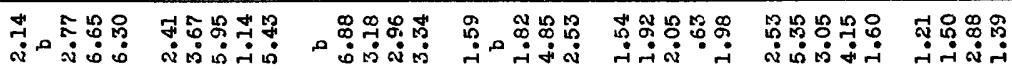
:

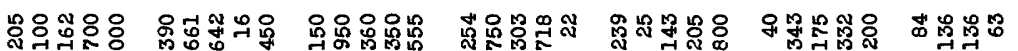

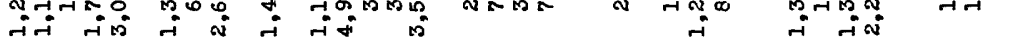

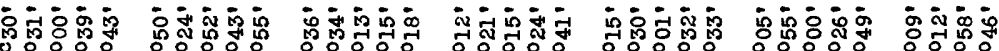

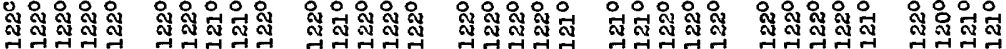

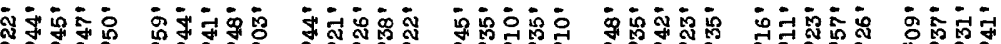

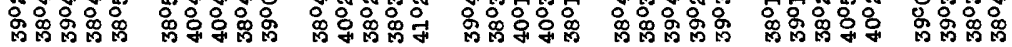

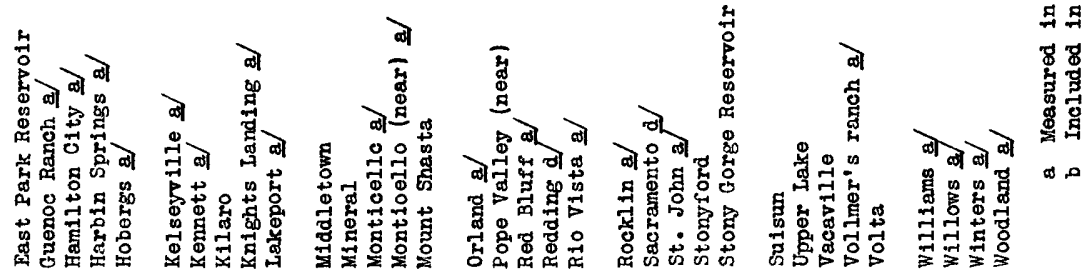




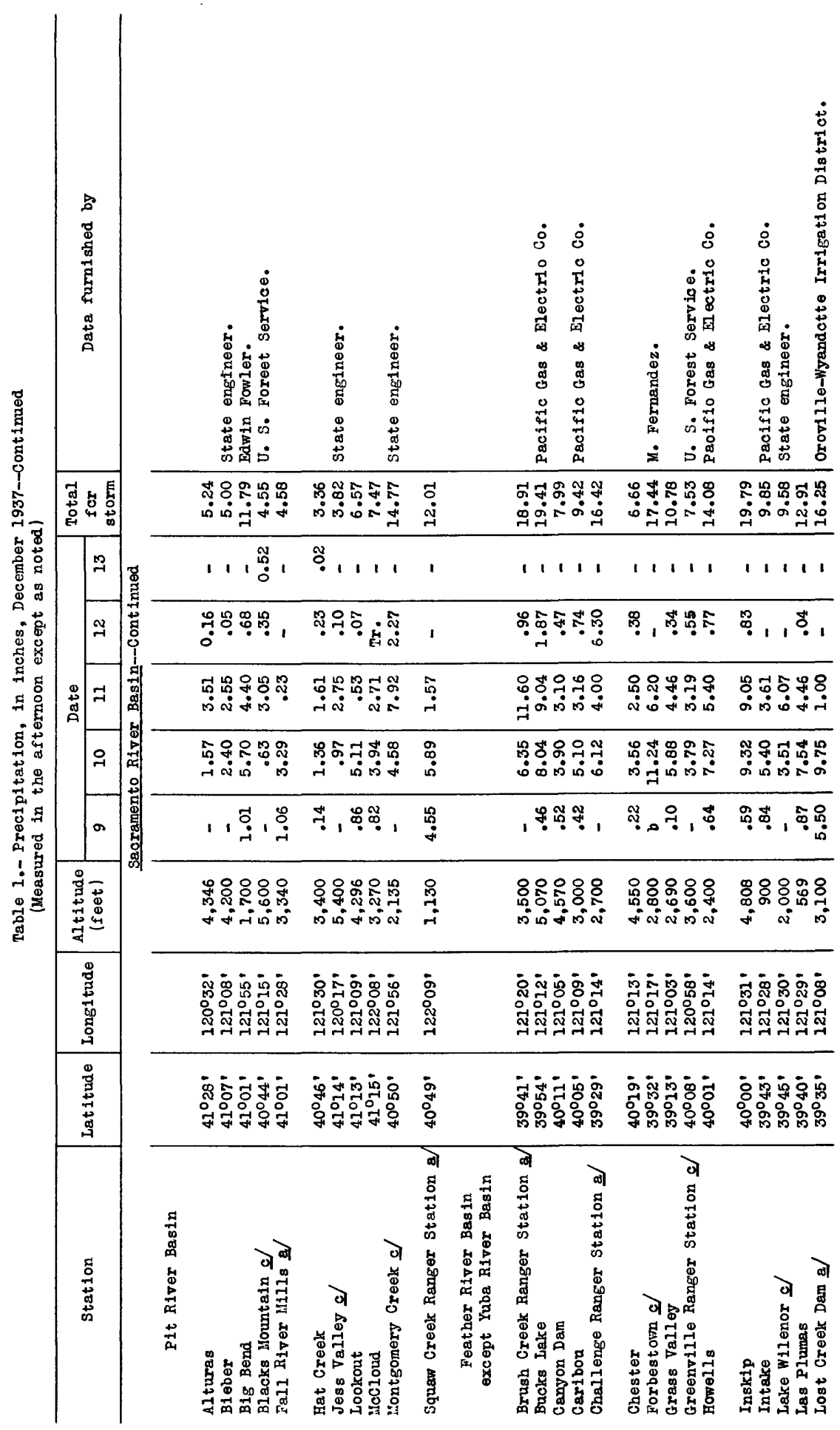




\begin{tabular}{|c|c|c|c|c|c|c|c|}
\hline 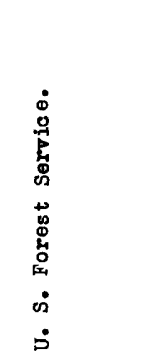 & 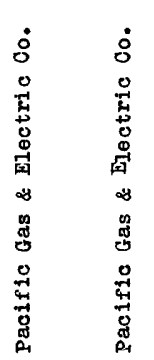 & 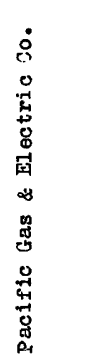 & & & $\begin{array}{l}\dot{4} \\
\stackrel{0}{0} \\
\stackrel{0}{0} \\
\dot{4} \\
\dot{4}\end{array}$ & & 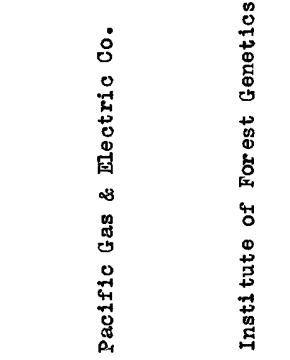 \\
\hline 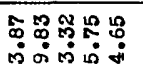 & 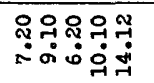 & 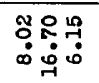 & & 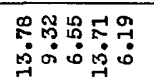 & 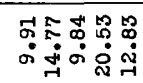 & & 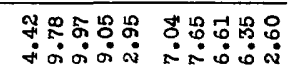 \\
\hline 1,11 & 1111 & 111 & & $1, \tilde{o}_{0}^{0}, 1$ & 11111 & & 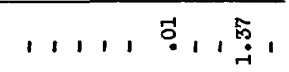 \\
\hline 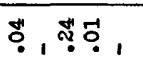 & 笣 & 우ำำำ & & 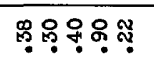 & , & & 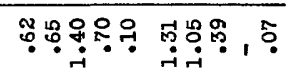 \\
\hline 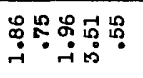 & 舟足 & 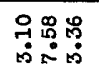 & & 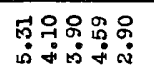 & 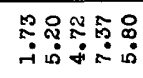 & & 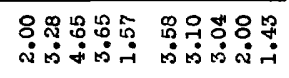 \\
\hline 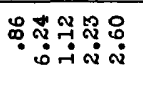 & 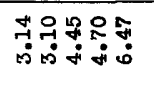 & T: & & 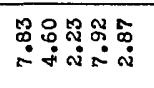 & 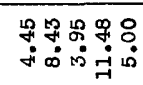 & & 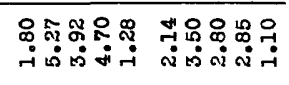 \\
\hline 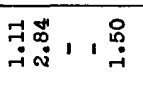 & 号 , & ํํำํํำ & & ঙ̊: & 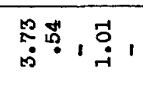 & & 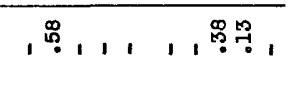 \\
\hline 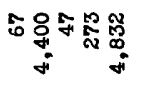 & 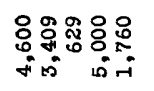 & 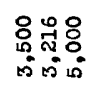 & & 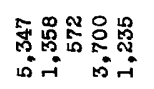 & 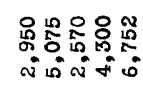 & & 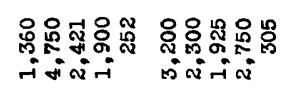 \\
\hline 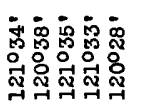 & 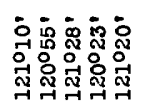 & 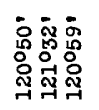 & & 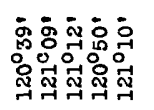 & 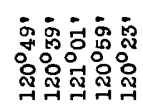 & & 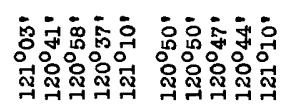 \\
\hline 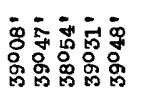 & 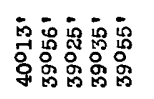 & 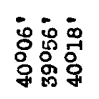 & & 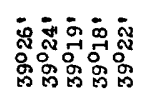 & 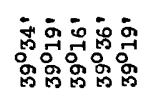 & & 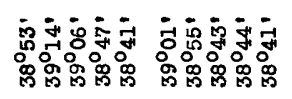 \\
\hline 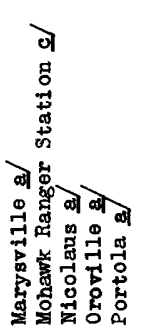 & 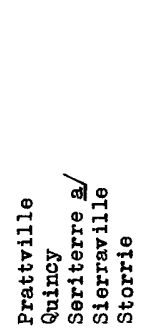 & 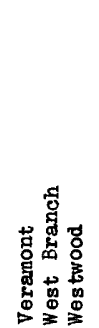 & 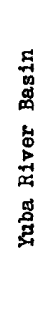 & 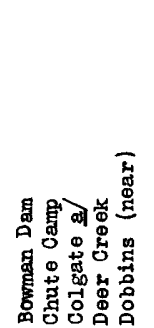 & 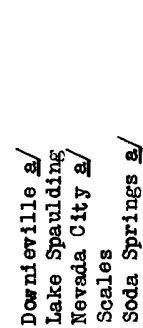 & 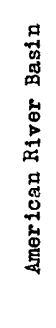 & 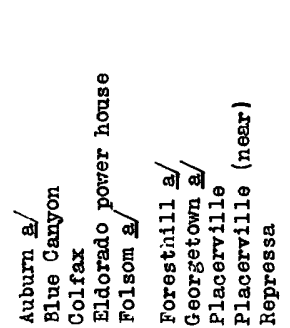 \\
\hline
\end{tabular}




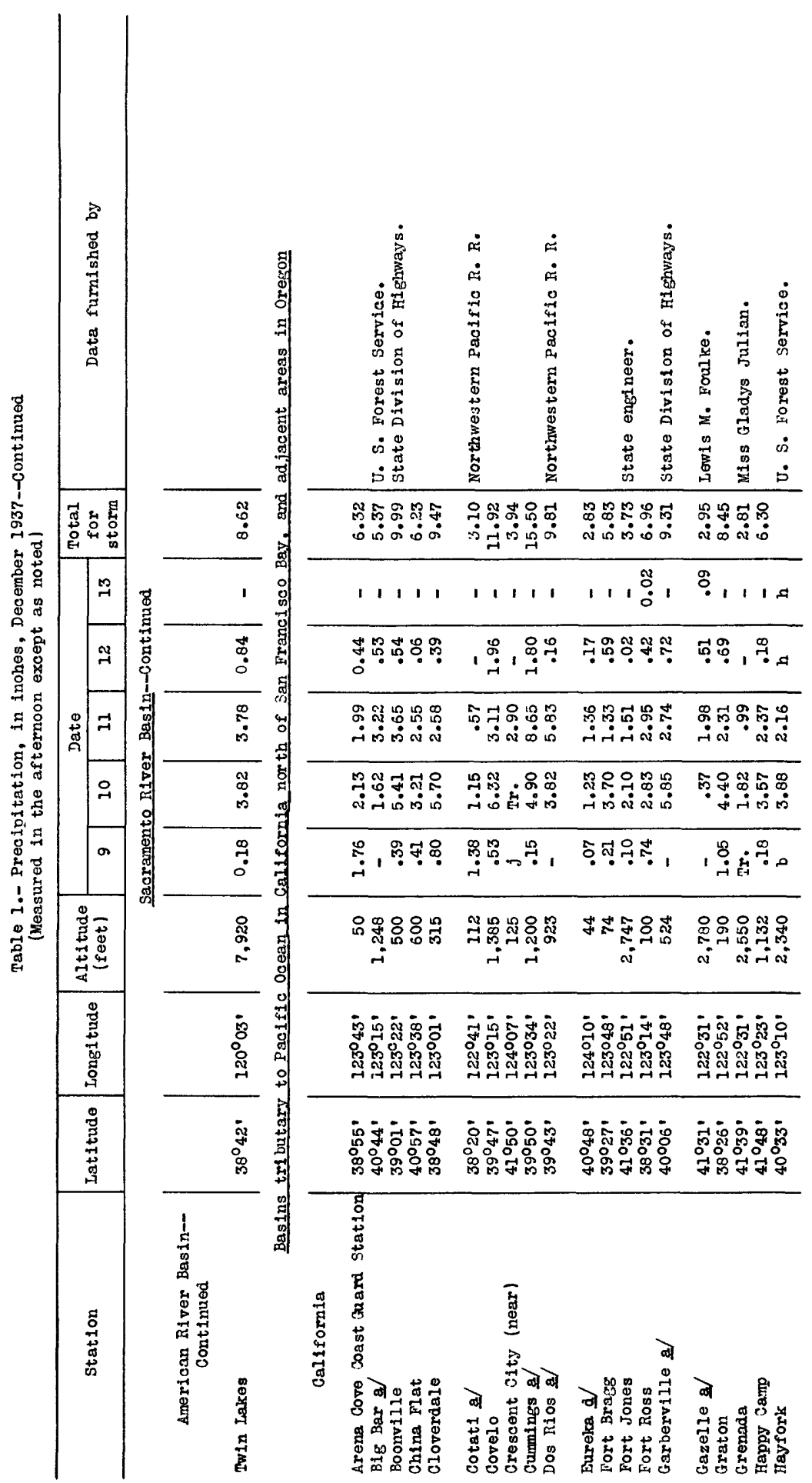




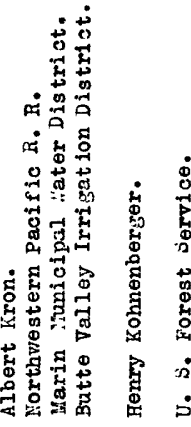

म

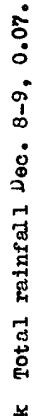

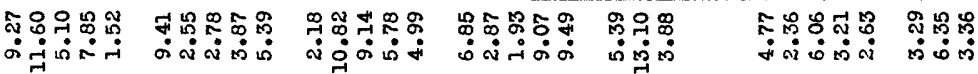

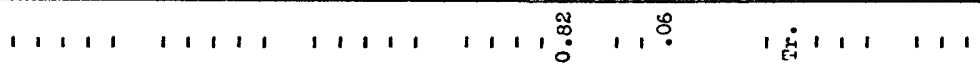

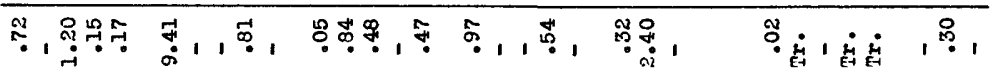

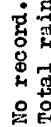

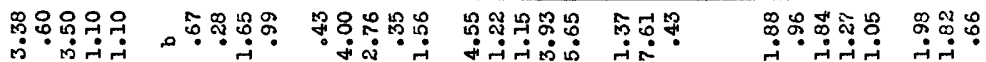

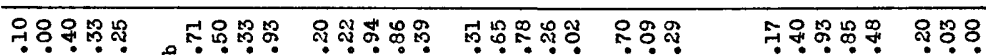
कि

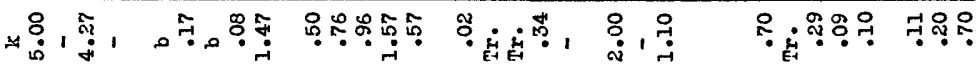

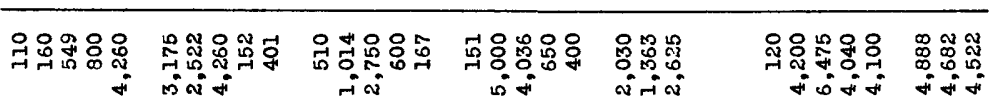

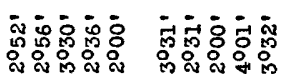
每

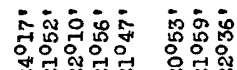
(1)

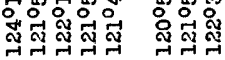




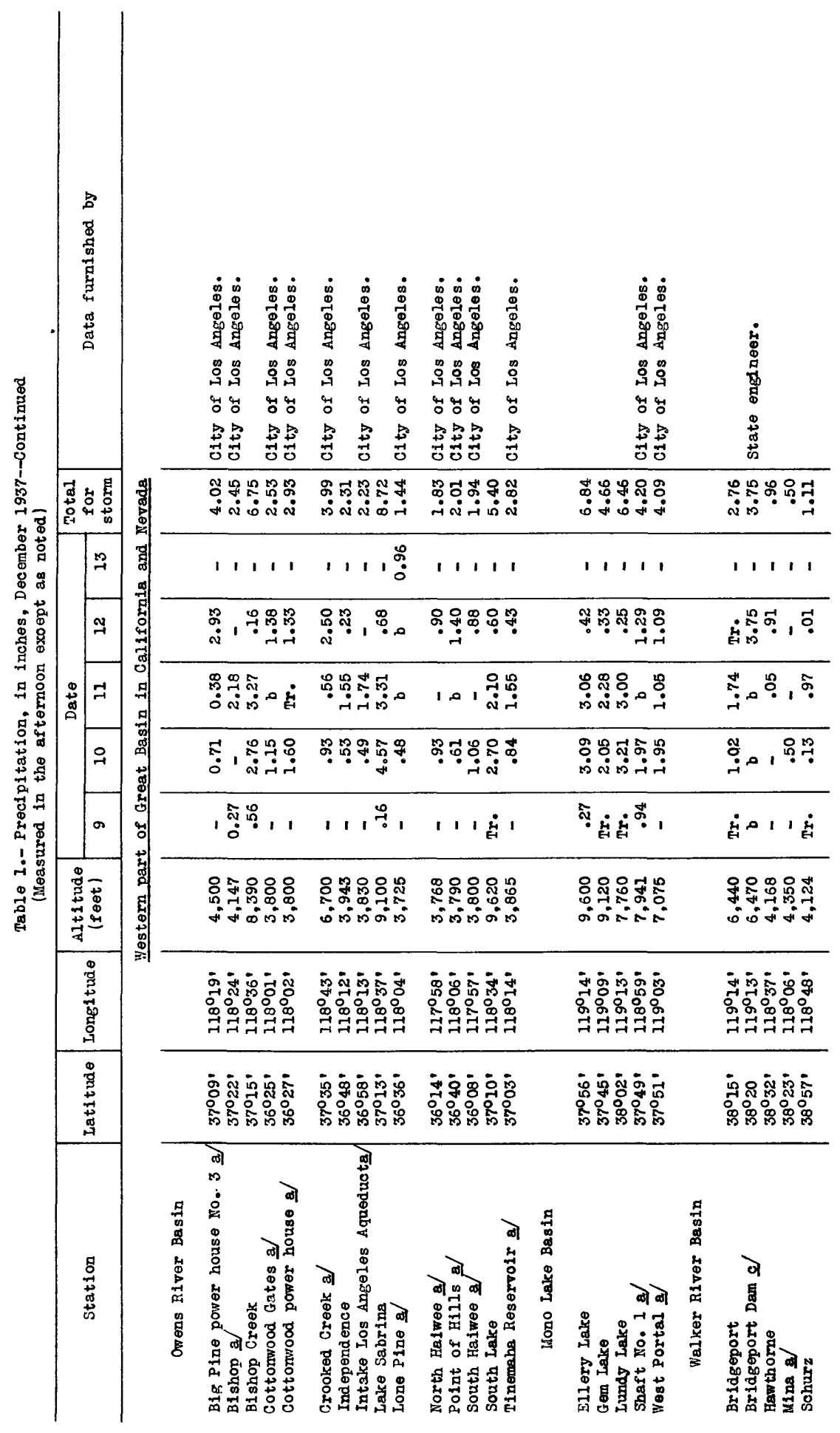




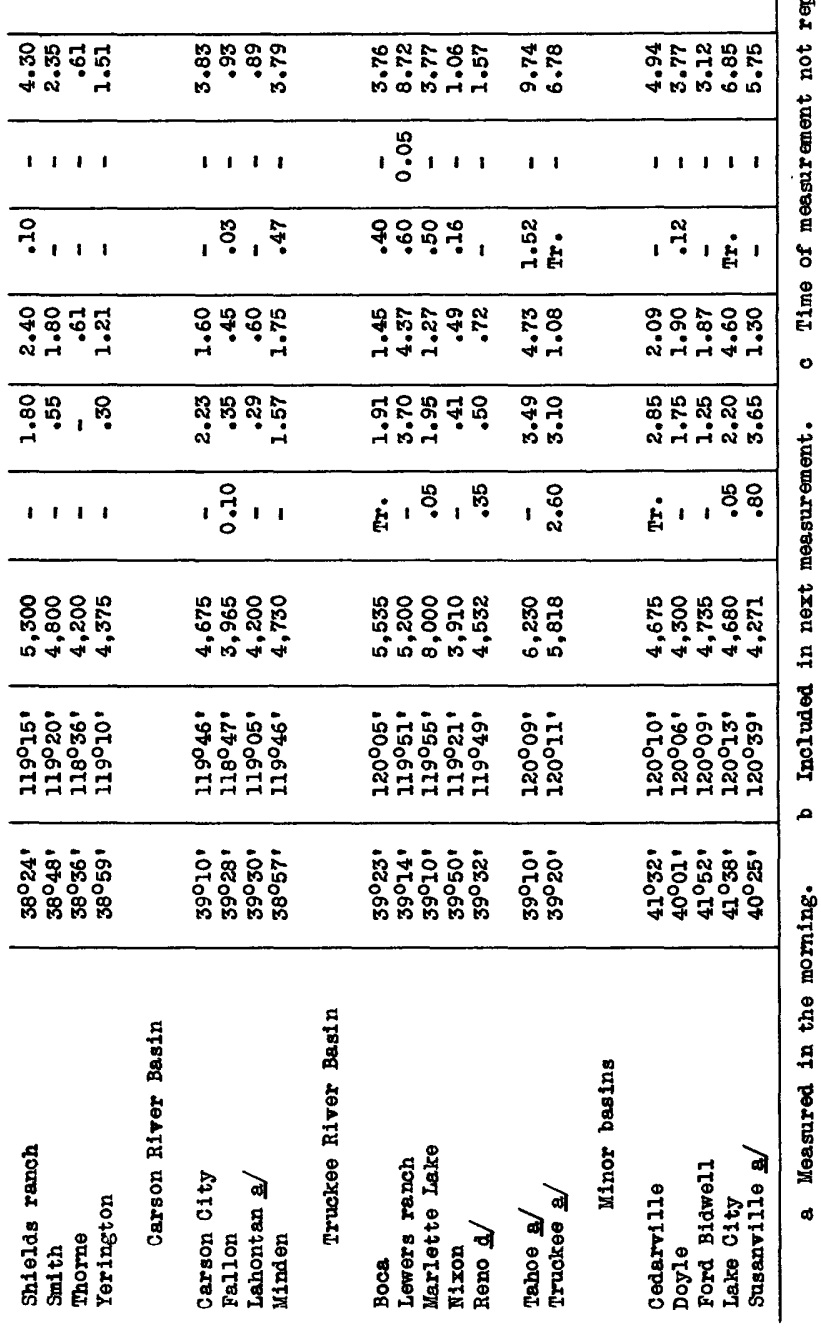




\begin{tabular}{|c|c|c|c|c|c|}
\hline & \multicolumn{2}{|c|}{ 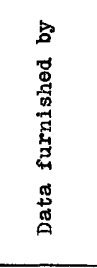 } & 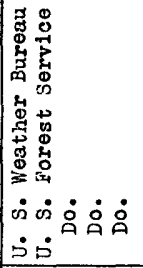 & 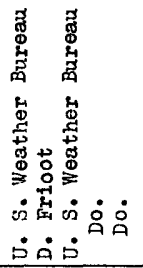 & 官宫宫宫 \\
\hline & \multicolumn{2}{|c|}{ 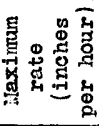 } & : & 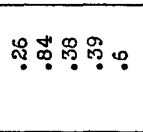 & 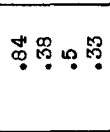 \\
\hline & \multirow{2}{*}{ 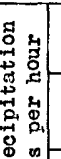 } & $\stackrel{8}{8}$ & ન-억월 & 0 O०Oन & momo \\
\hline & & $\begin{array}{l}\stackrel{8}{0} \\
\vdots\end{array}$ & 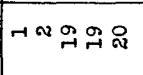 & O & $\forall N \infty N$ \\
\hline & 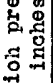 & $\stackrel{\substack{0 \\
0}}{0}$ & m엄 & $\rightarrow \infty \sin \theta$ & $\ddot{न}$ \\
\hline & تี & ণั) & 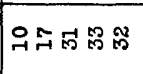 & 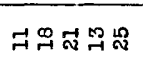 & 雨 ○品 \\
\hline & \multirow{4}{*}{ 焉 } & $\begin{array}{l}8 \\
\vdots \\
0\end{array}$ & 品怘品吢品 & 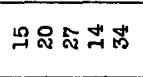 & 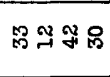 \\
\hline & & $\stackrel{0}{0}$ & 志怘志品的 & న & 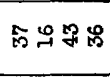 \\
\hline & & $\begin{array}{l}\dot{0} \\
\dot{0}\end{array}$ & 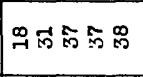 & ベ & タのずす \\
\hline & & $\stackrel{2}{\stackrel{0}{0}}$ & 怘品ず品 & స̊요요 & 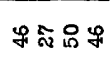 \\
\hline & \multicolumn{2}{|c|}{ 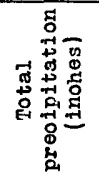 } & 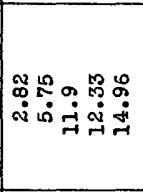 & 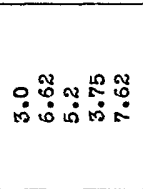 & 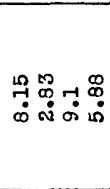 \\
\hline & \multirow{2}{*}{ 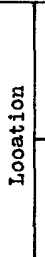 } & 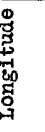 & 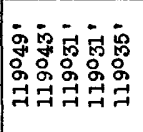 & 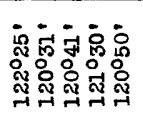 & 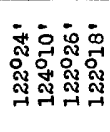 \\
\hline & & 离 & 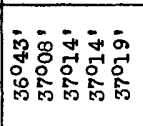 & 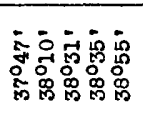 & 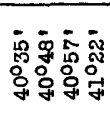 \\
\hline & \multicolumn{2}{|c|}{ 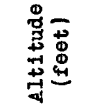 } & 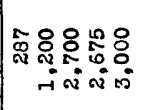 & 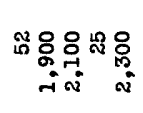 & 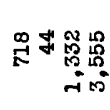 \\
\hline & \multicolumn{2}{|c|}{ 志 } & 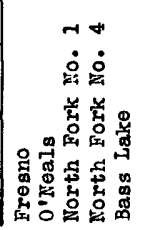 & 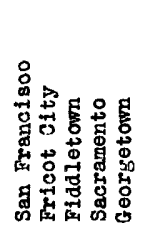 & 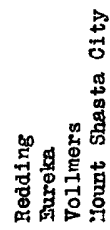 \\
\hline
\end{tabular}


The rather simple situation that existed may be illustrated by the following brief description: On December 9 an intense disturbance was centered about $900 \mathrm{miles}$ off the central California coast. This storm was of unusual extent, as well as intensity, covering most of the ocean area north of about latitude $20^{\circ} \mathrm{N}$. The strong westerly and southwesterly currents prevaling in the southern and southeastern portions of the disturbance resulted in extensive transport of a large mass of warm moist air which was originally Polar Paciflc air but had been modifled considerably in its trajectory over the warm ocean surface in the lower latitudes. The disturbance as it moved slowly northeastward, increased in intensity, the winds approaching hurricane force. On the morning of the loth it was centered off the coast of Washington and Oregon with lowest pressure about 28.10 inches and by December 11 it had reached the lower Alaskan Coast.

The warm molst alr mass began invading northern and central California on the morning of December 9, the flow of air from the Southwest reaching gale velocity at times. The air as it was forced to rise rapidly over the steep slopes of the mountains released its abundant moisture, mostly in the form of rain except at extremely high elevations. By the night of the lith the disturbance had moved far enough northward so that the western coast of the United States was out of the influence of the strong southwesterly winds and moderately high pressure prevalled over northern California, resulting in a cessation of the rains.

Based on the behavior of the streams as recorded at the rivermeasurement stations, the center of the storm seemed to progress across the state in about 48 hours, moving generally eastward and southeastward. Most of the streams in the northern part of the area reached peak stages beginning late in the evening of December 10 or early in the morning of December 11, whereas those along the western slope of the Sierra Nevada tributary to the southern part of the Central Valley reached their crest stages between three and four in the afternoon of December 11.

The total precipitation during the storm period from December 9 to 12 was heaviest along the Coast Ranges between the Central Valley and the Pacific Ocean, and at altitudes of 4,000 to 6,000 feet along the western slope of the Sierra Nevada. At altitudes above 9,000 feet, the precipitation was largely in the form of snow.

There were two distinct areas of exceptionaliy heavy rainfall along the Coast Ranges. One area was along the divide between Upper Putah Creek and Russian River, where three supplemental records furnished to the Geological Survey by private parties at Cobb (altitude, 2,600 feet), Cellier Place (altitude, 2,100 feet), and Hoberg's (alt1tude, 3,000 feet) indicate a total storm precipitation of 20 to 22 inches and maximum daily depths of $13.65,12.27$, and 14.20 inches respectively. Precipitation was unusually heavy also in the Santa Cruz mountains, the headwater areas of Los Gatos Creek, San Lorenzo River, and Uvas Creek. In this area, supplemental records indicate a total storm precipitation of 18 to 19 inches; a maximum of 18.75 inches was recorded at Little Uvas Creek (altitude, 625 feet), and 18.52 inches at Saratoga Summit (altitude, 2,600 feet). At several precipitation stations in this area, 
between 9 and 10 inches were recorded on December 10. These high preclpitation amounts are largely substantiated by the evidence of flood run-off, especially in the Uvas Creek Basin.

Preclpitation was heavy and general along the western front of the Slerra Nevada at altitudes of 4,000 to 6,000 feet. A storm total of 17.27 inches was recorded at Central Camp (alt1tude, 5,364 feet), of 18.91 Inches at Brush Creok (altitude, 3,500 feet), of 19.41 inches at Bucks Lake (alt1tude, 5,070 feet), of 19.79 at Inskip (altitude, 4,808 feet), and of 20.53 inches at scales (altitude, 4,300 feet). A maximum dally depth of 11.48 Inches was recorded at Scales on December 10, and many other stations recorded between 9 and 10 inches for approximately a 24-hour period.

In view of the sparsity of precipltation stations along parts of the Coast Ranges and in the high Sierra, it is probable that there were unrecorded variations of precipitation in addition to those defined and delineated on the precipitation maps included in this report (figs. 13 to 21 ).

On an areal basis, storm precipitation apparently ranged from 11 to 13 inches over considerable parts of headwater areas in Tulare Lake, Kings, San Joaquin, Fresno, Merced, Tuolumne, Stanislaus, American, Eel, and Russian River Basins; from 14 to 18 inches over considerable parts of Pajaro and Guadalupe River Basins; and from 12 to 19 inches in parts of the Feather, Yuba, and Putah Basins.

No figures on the area-depth characteristics of past great storms of California are avallable for comparison. However, the storm of December 1937 was unquestionably one of the great early-winter storms of which there is record for central and northern California.

\section{Distribution}

During the stomn period significant amounts of rain fell in an area extending from the California-Oregon boundary to the southern limits of the Central Valley and from the Paciflc Ocean to the eastern slopes of the Slerra Nevada. In the northern half of the area the precipitation was almost continuous from about 6 a.m. on December 9 to $1 \mathrm{p} . \mathrm{m}$. on December 11. In the southern part of the area the storm lasted from about noon on December 9 to $6 \mathrm{p} . \mathrm{m}$. on December 11 . In the northern part of the area there seemed to be more of a tendency for the precipitation to be continuous than in the southern part, where there was a lull in the storm during the afternoon of December 10 . 

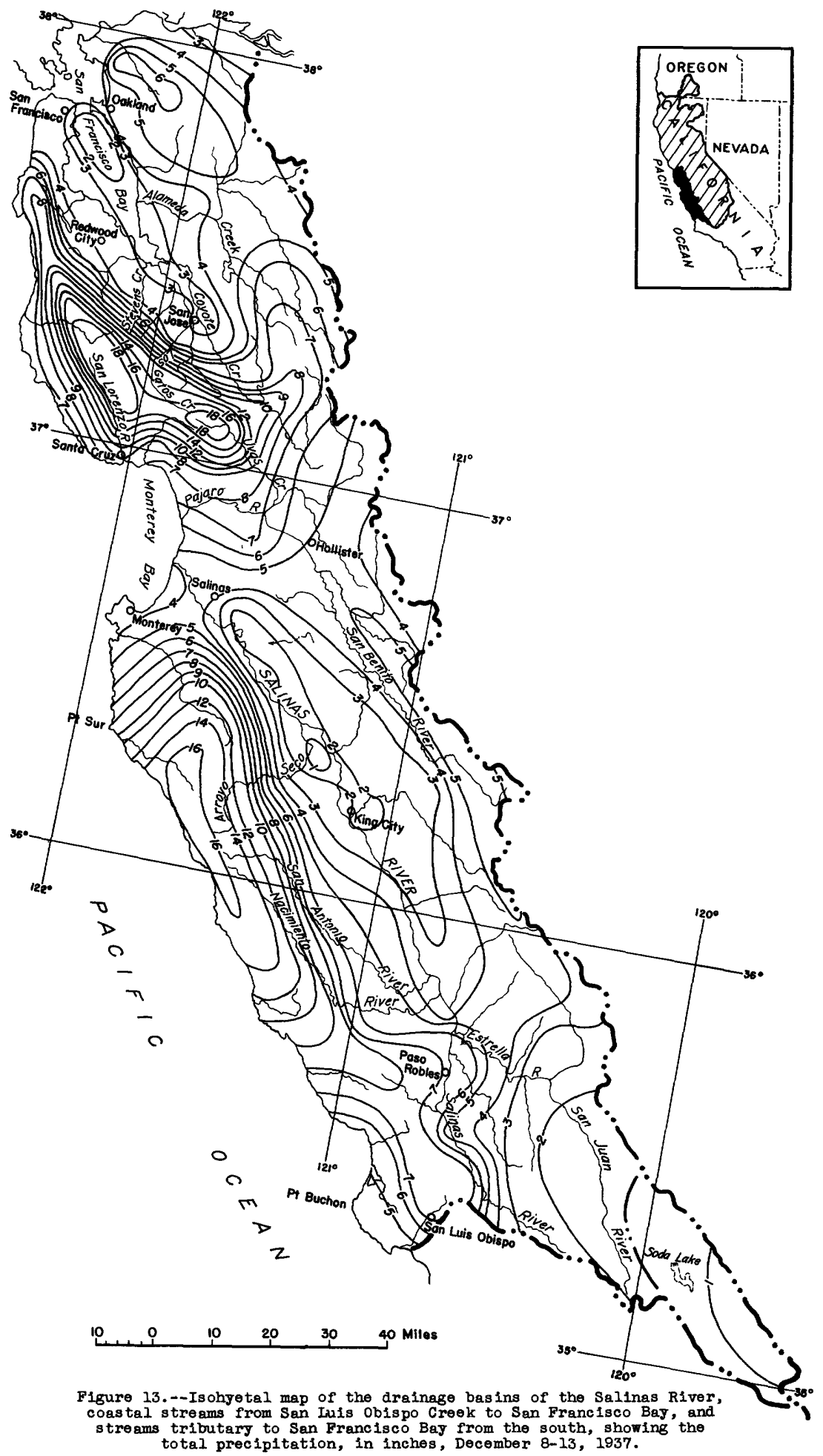


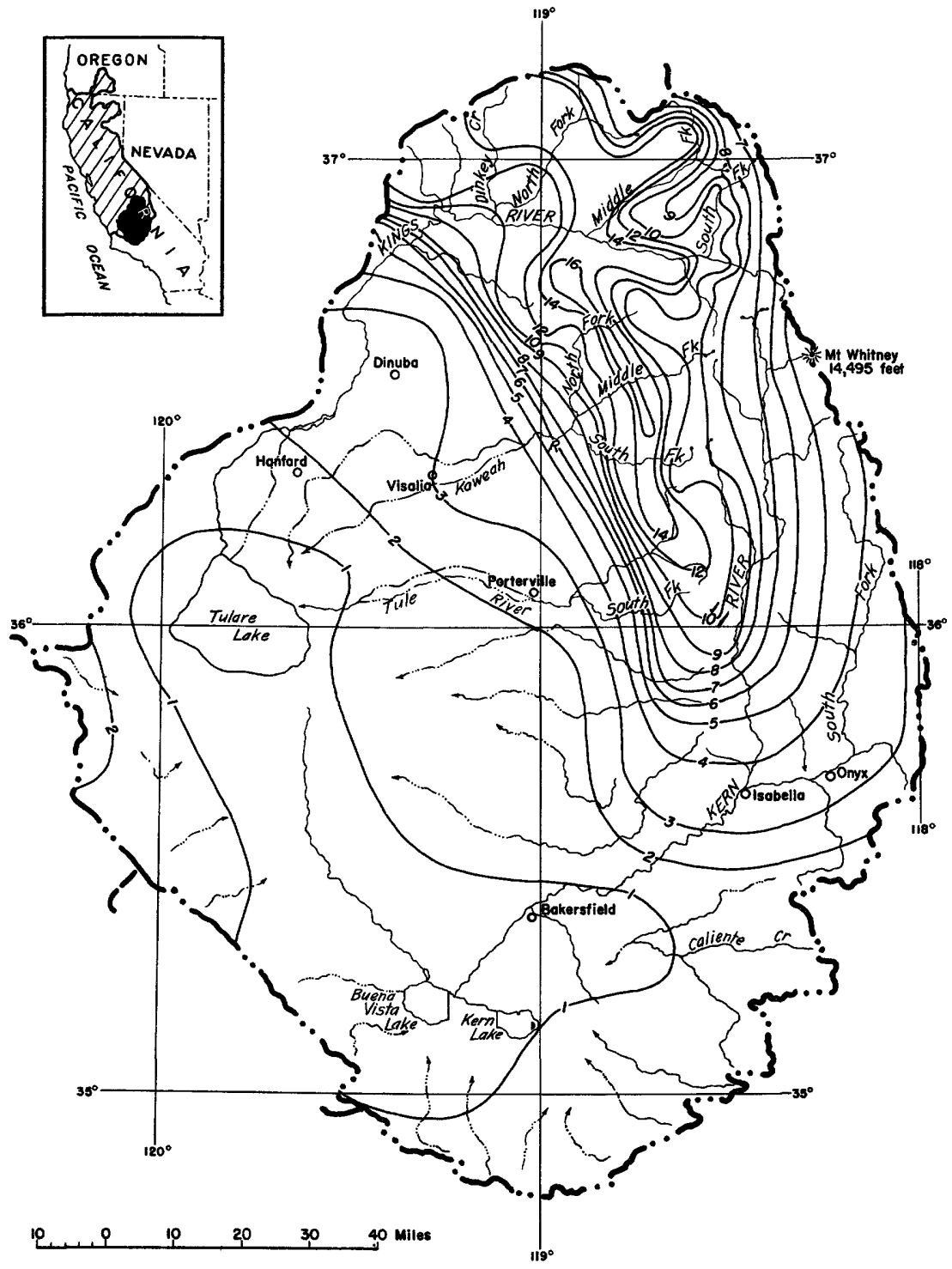
showing the total precipitation, in inches, December 8-13, 1937. 

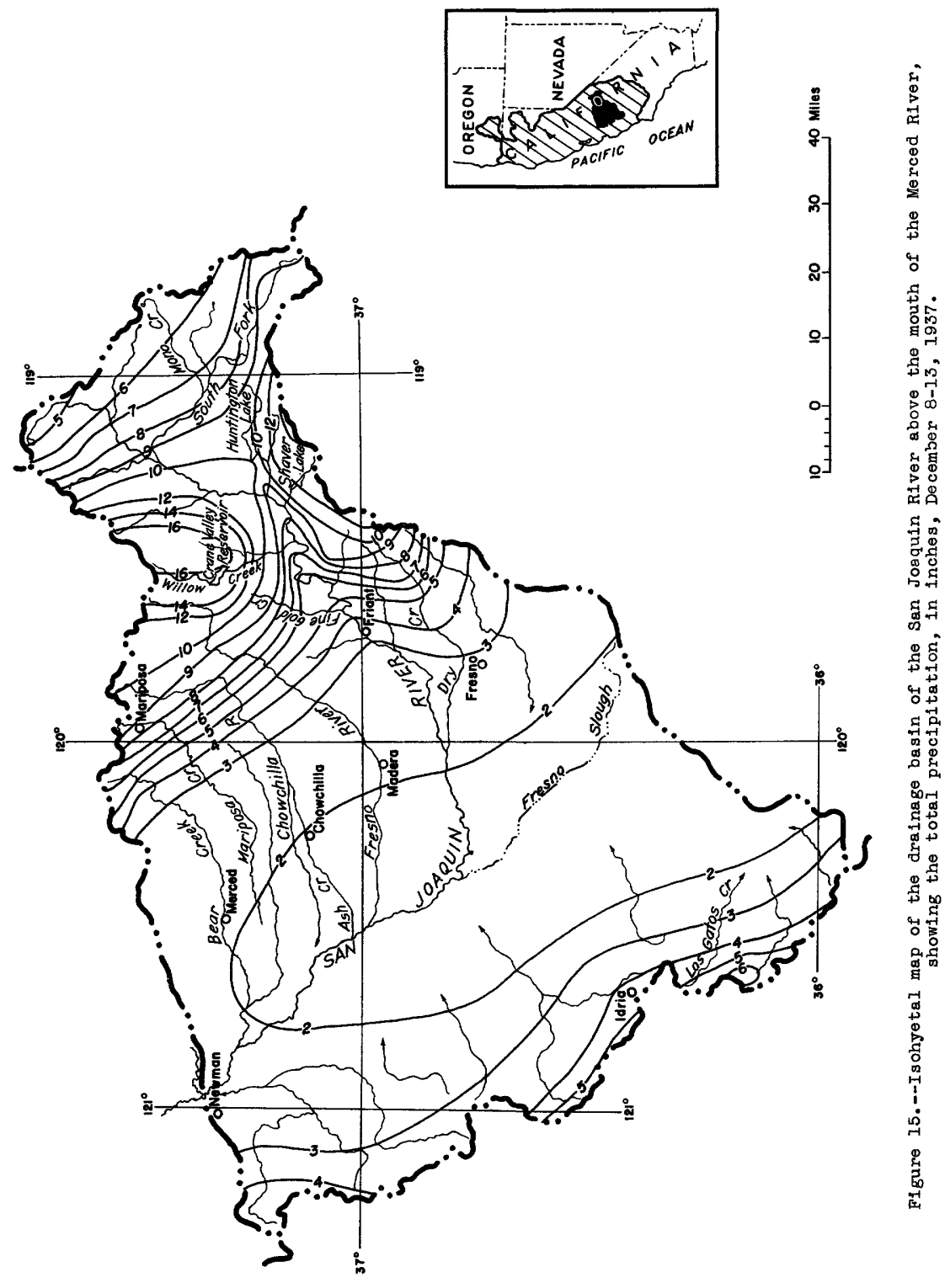

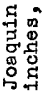

茄

兘

品- 


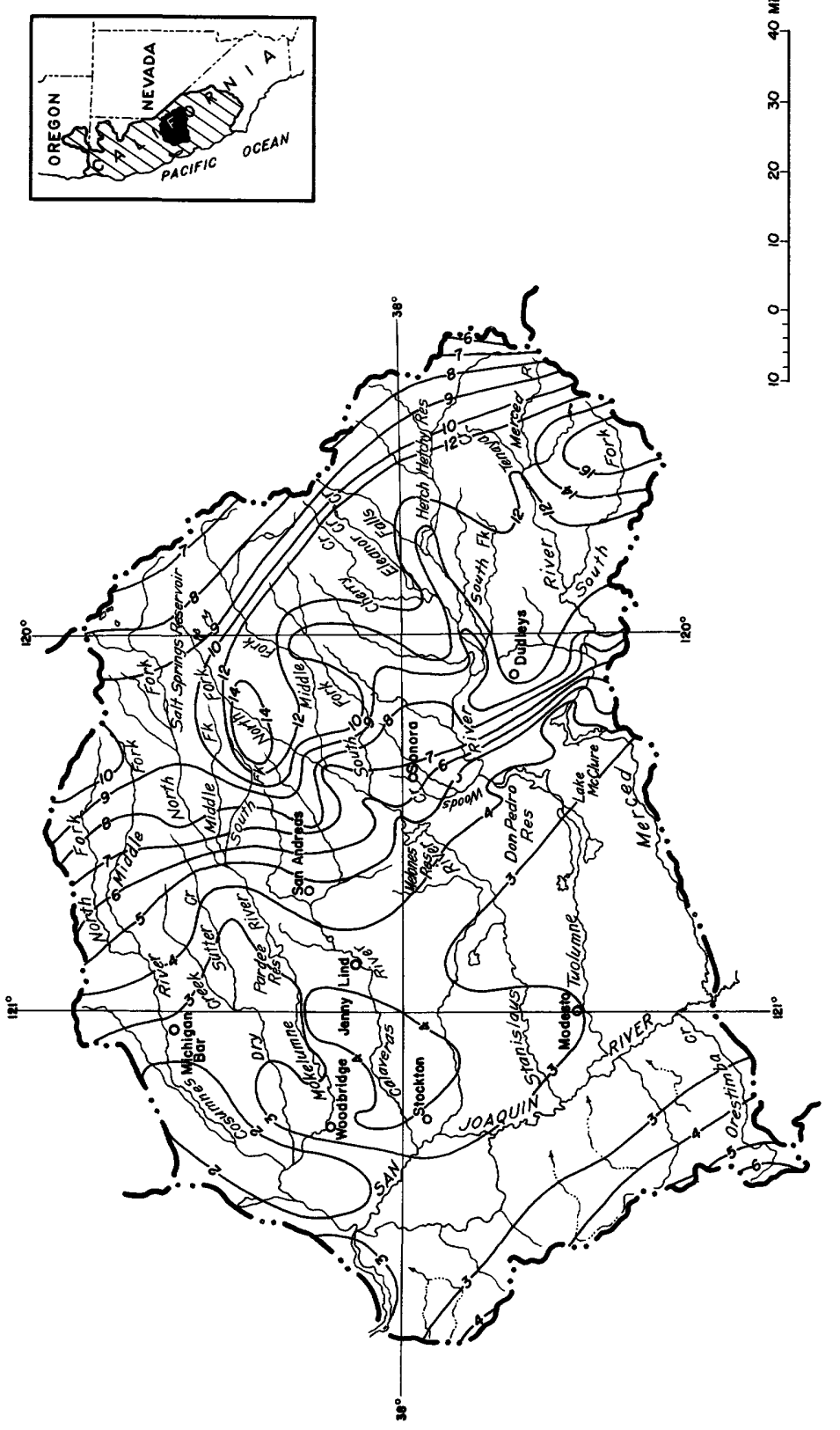

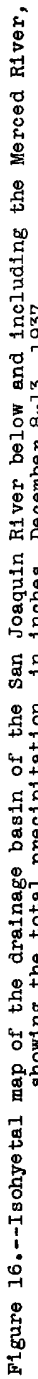



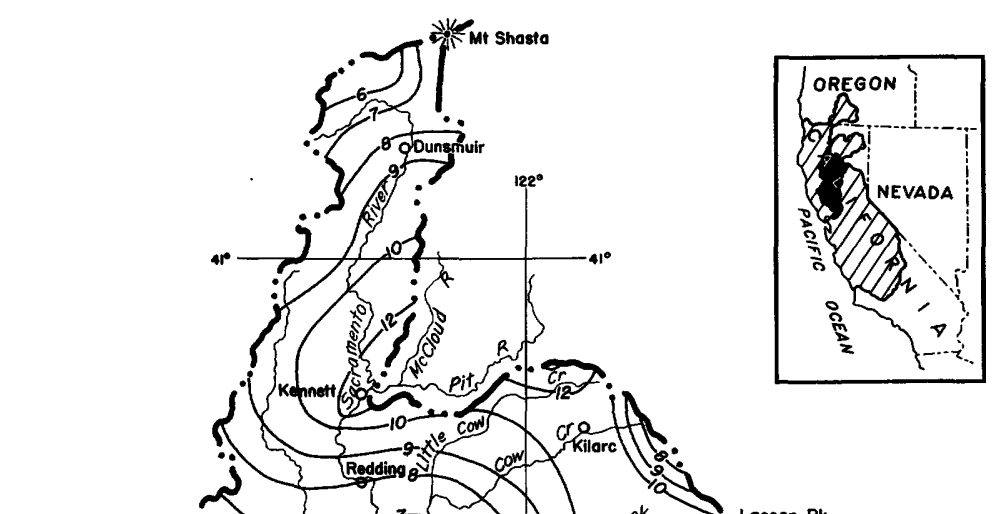

$10 \quad 10 \quad 20 \quad 30 \quad 40$ Miles $122^{\circ}$

Figure 17.--Isohyetal map of the drainage basin of the Sacramento R1ver, except the Pit, Feather, and American R1vere, showing the totel precipitation, in 1nches, December 8-13, 1937. 


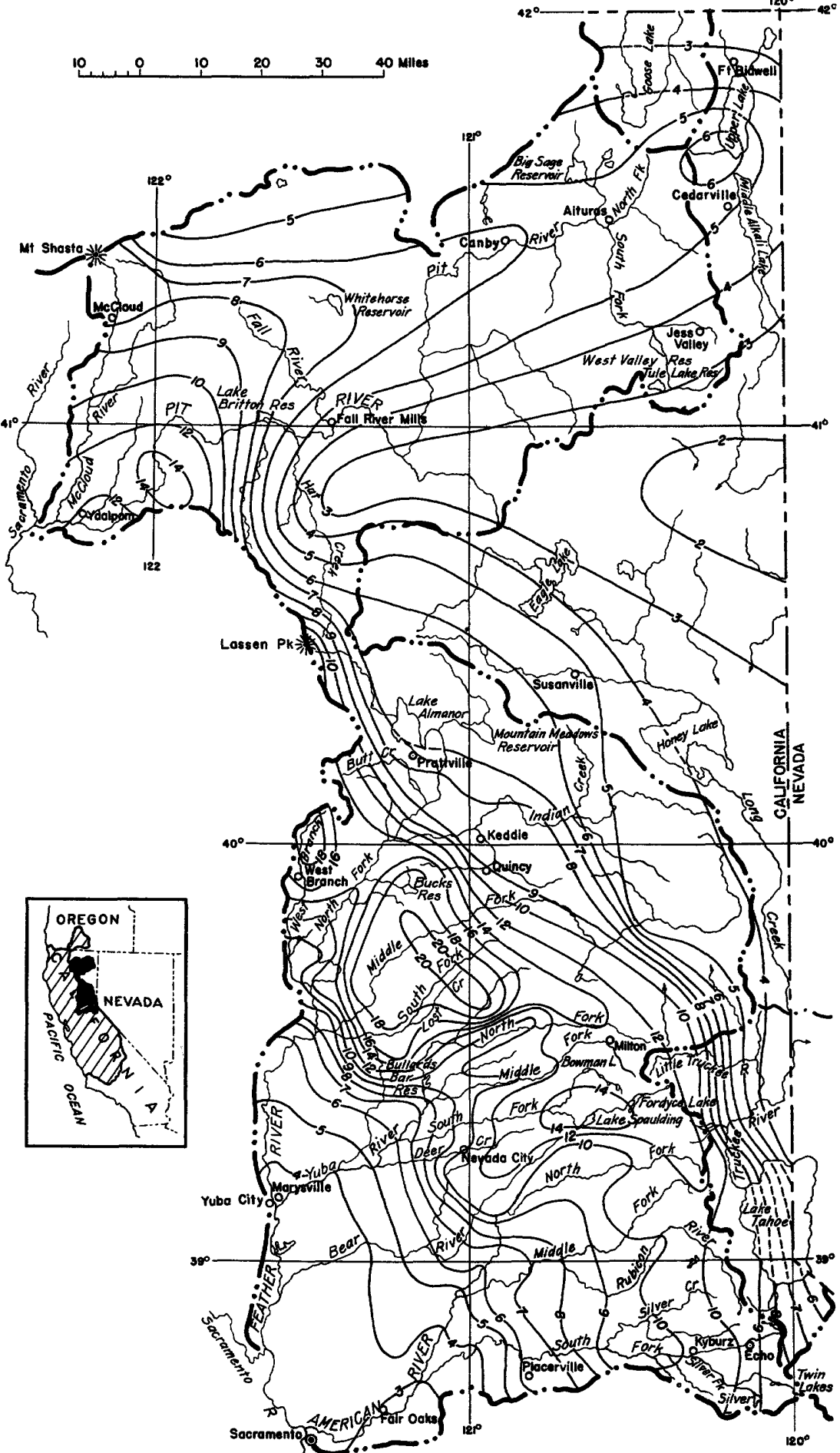

F1gure 18.--Inohyetal map of the dralnage basins of the P1t, Feather, American, and Trucke Rivers, showing the total precipitation, in inches, 

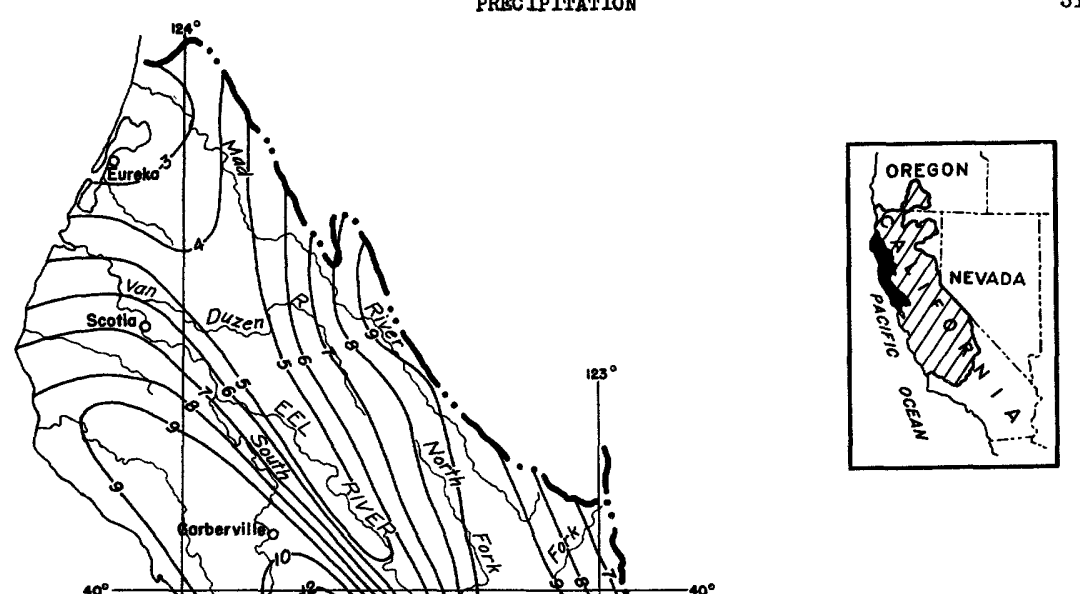

0
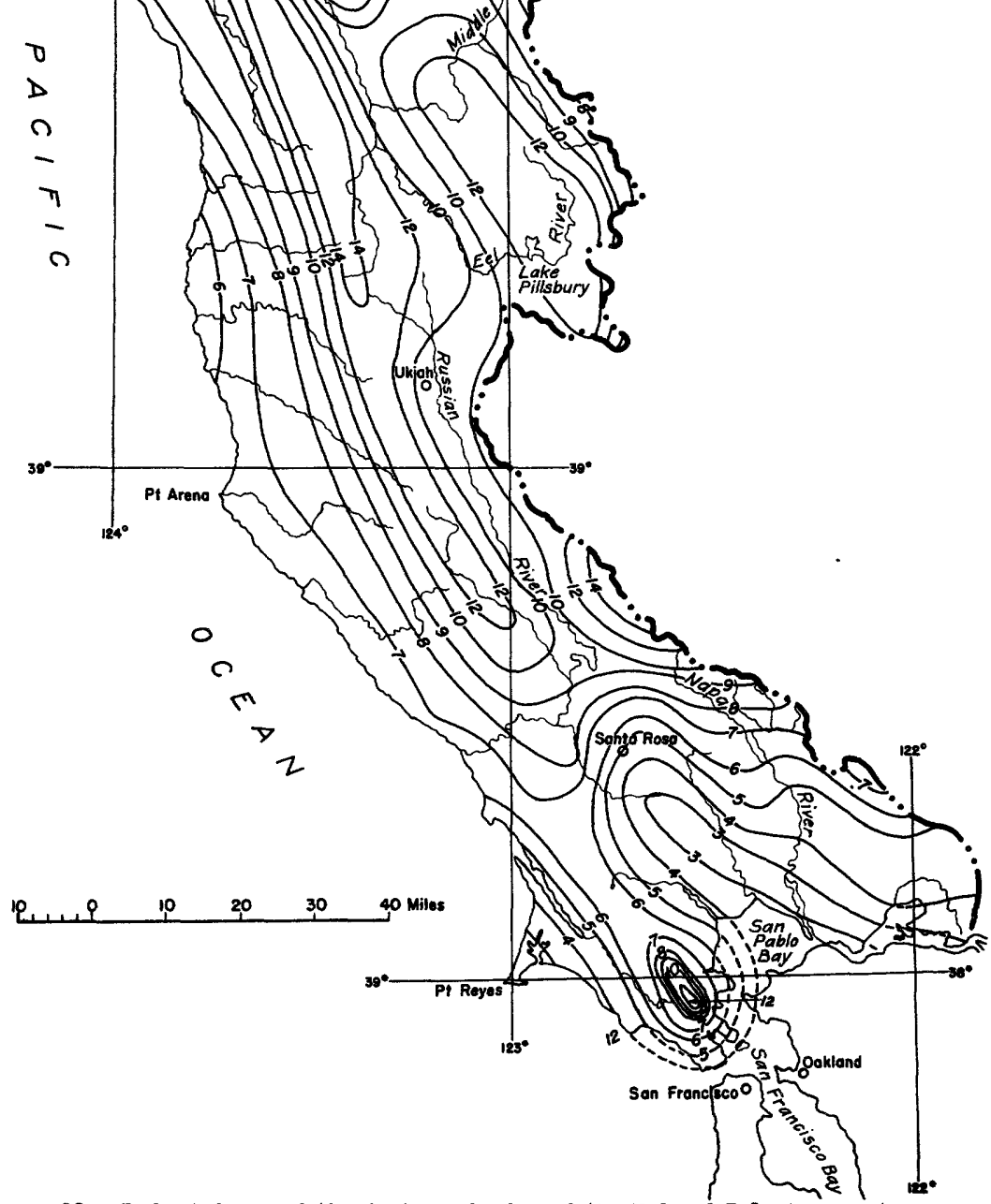

Figure 19.--Isohyetal map of the drainage basins of the Mad and Eel Rivers, streams tributary to San Francisco Bay from the north, and coastal streams between San Francisco Bay and Ked River, showing the total precipitation, in inches, December 8-13, 1937. 


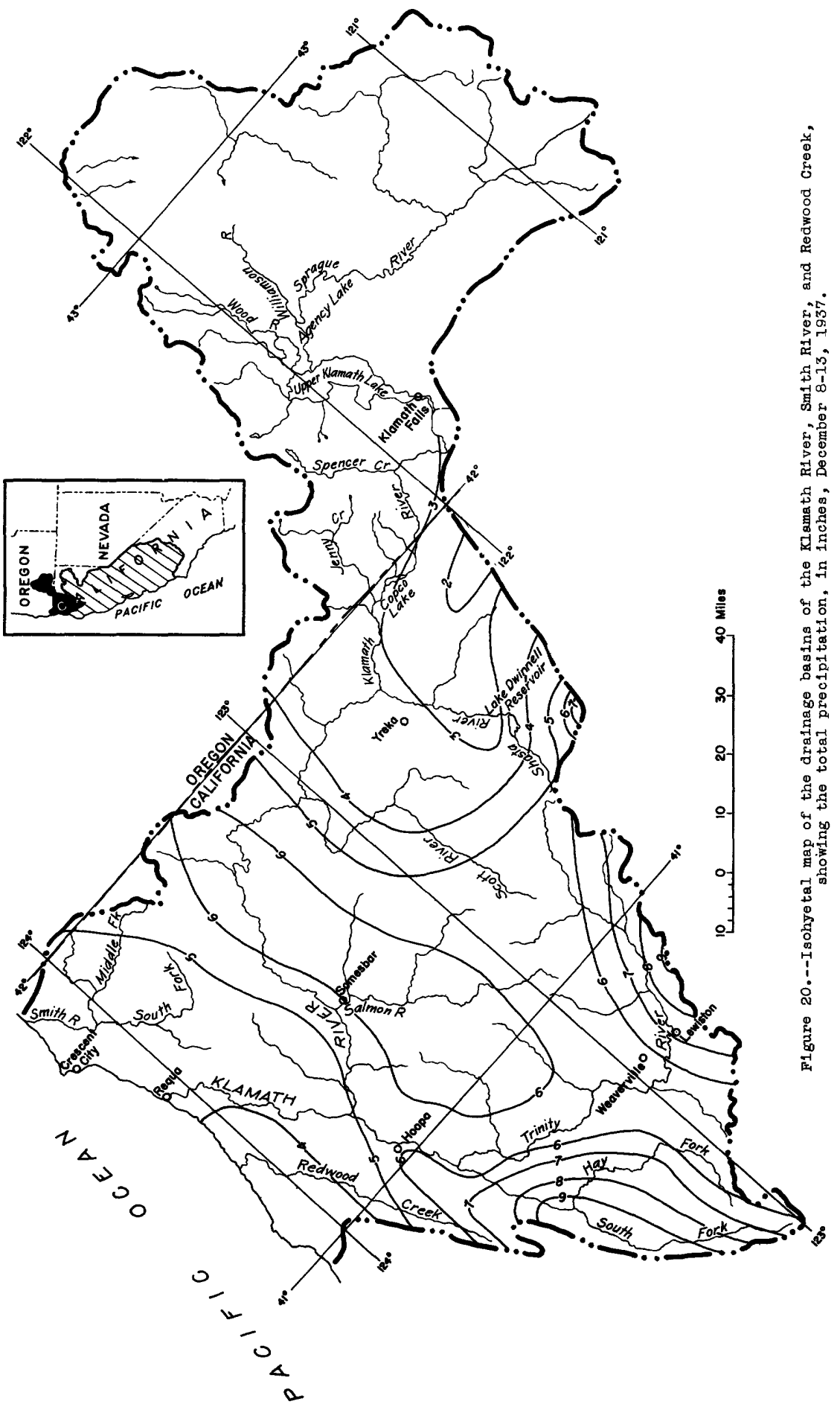




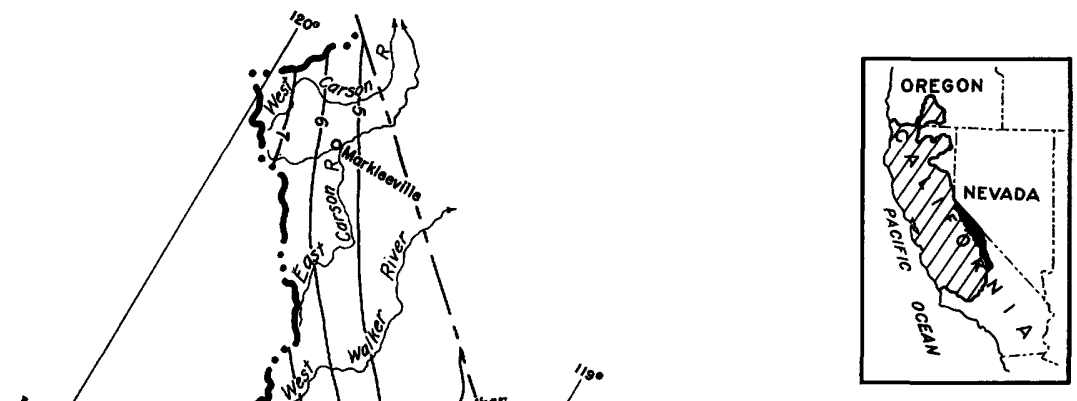


The entire period from December 9 to 12 has been treated as a unit in the preparation of a precipitation map, although, as indicated, most of the precipitation fell during 48 hours. The recorded precipitation for the period from December 9 to 12 has been plotted on Geological Survey base maps (scale 1:500,000), and an isohyetal map has been prepared. This base map has been transferred and reduced to appropriate scales for publication by major drainge basins (figs. 13 to 21 ).

The areas between the isohyetal lines on the original base map were measured by planimeter for the drainage basin upstream from each rivermeasurement station, and a value was obtained for the average total precipitation in each basin. The results of these determinations are given in the section on "Rainfall and run-off studies" in table 7 .

If the storm precipitation were accurately known at every point, an isohyetal map might reflect the influence of altitude and topographic aspect on the precipitation. In much of the area it would be hazardous to estinate the number of observations that would be required to construct an isohyetal map from which the average precipitation over widespread areas could be determined with ressonable accuracy. In parts of the area, especially along the valley floor, distribution of rainfall was relatively uniform and sufficient records are available to permit thê construction of a precipitation map that is fairly accurate. This applies also to a limited extent for portions of the Coast Ranges and in the foothill area of the Sferra Nevada where, although regular Weather Bureau stations are scattered, it has been possible to compile a considerable number of supplemental precipitation records and thereby f1ll in the gaps. But many of the Coast Ranges north of Clear Lake and 211 of the higher Sierra Nevada are sparsely inhabited, especially during winter months. In these areas there is a serious deficiency in basic meteorologic data, hence the isohyetals as drawn may not reflect actual conditions in every particular.

As an aid in constructing the isohyetals in areas where there were deficient observations, some attempt has been made to use such relations as could be determined between altitude and the total storm precipitation. The available data are sufficient to warrant only the most general conclusions. From south to north along the western slopes of the sierra Nevada, the observed precipitation was correlated with the altitude with results generalized as follows:

On a line between Visalia and Giant Forest there was an increase of 6.9 inches per thousand feet up to an altitude of 2,000 feet and an 
Increase of 1.1 inches per thousand feet between altitudes of 2,000 feet and 6,300 feet. Between Dinuba and General Grant National Park there was an increase of 4.3 inches per thousand feet up to an altitude of 2,000 feet and an increase of 1.2 inches per thousand feet between 2,000 and 6,700 feet. Between Friant and Big Creek No. 1 power house the increase was 3.4 inches per thousand feet up to 2,000 feet and 0.5 inch between 2,000 and 5,000 feet. There was an increase of 3.7 inches per thousand feet up to 4,300 feet on a line between Hamilton city and Downievilie, and of 2.6 inches up to 4,000 feet between Marysville and Lake Spaulding.

It seems evident that, in the storm of December 1937, altitude was a dominant but not wholly controlling factor in the determination of precipitation; and that, although there was a marked tendency for the rainfall to increase with altitude up to a certain limit, the relations were not anfform either in a north and south direction along the weistern front or vertically in the same vicinity. A part of the variations disclosed may be due to the location of the precipitation stations in relation to topographic features, or they may have resulted from the inherent meteorologic characteristics of the storm.

There seems to have been a tendency for the rate of increase of precipitation with altitude to be somewhat larger in the southern part of the area than in the northern, and a tendency for a decreased rate of increase at the higher altitudes. As drawn, the isohyetals ind1cate an average increase in precipitation of about 3 inches per thousand feet up to an altitude of 5,000 feet. What happened at the higher altitudes during the storm period is somewhat problematical. At an altitude of about 9,000 feet, at least a part of the precipitation took the form of snow, and it seems probable, from the avallable data, that at altitudes between 5,000 and 6,000 feet the water equivalent of the snow was considerably less than the depth of rainfall. Along the foot of the eastern slopes of the Sierra Nevada the total storm precipitation was between 3 and 4 inches. The isohyetals for areas in the high Sierra Nevada (figs. 14 to 16 and 21) have been constructed, without definite data, on the assumption that, with some possible exceptions, there was a general decrease in precipitation in those areas between an altitude of about 6,000 feet and the crest of the Slerra Nevada. This assumption apparently conforms with the observation and experience of those who are familiar with climatic conditions and life zones along the Slerra Nevada as a whole. Along the Coast Ranges, isohyetals have been 
constructed almost entirely from observed data.

Users of the precipitation maps (figs. 13 to 21 ) and of the precipitation values (see table 7 ) derived therefrom are referred to the discussion relating to "Rainfall and run-off studies" wherein there are comments on the probable accuracy of the maps as judged from an analysis of the measured run-off from individual drainage basins.

Figures 22 to 25 show graphically the relation of topography and altitude to precipitation during the storm of December 1937, on four generally east-and-west lines across California. (See fig. 2.) The land profiles on these figures are based on topographic maps, and the profile of precipitation is based on the isohyetal map of the storm.

Graphs indicating hourly precipitation at various precipitation stations between Mount Shasta City and Fresno are shown in figures 26 and 27.

\section{Temperature}

Temperature had a large influence on the characteristics and magnitude of the December floods. This feature has been noted by

E. H. Fletcher, meteorologist of the United States Weather Bureau at Sacramento, in his report previously cited, and by many others who are familiar with the meteorologic and hydrologic conditions.

At altitudes up to 3,000 feet or more, along the slopes of the Sierra Nevada tributary to the great Central Valley, mean temperatures were about $2^{\circ} \mathrm{F}$. above normal during November 1937 and nearly $5^{\circ} \mathrm{F}$. above normal during December. The temperatures did not follow the normal seasonal decline through November and December. Instead, as shown by daily maximum and minimum temperature for November and December at Fresno (altitude, 287 feet), Lake Sebrina (altitude, 9,100 feet), Marysville (altitude, 67 feet), and Soda Springs (altitude, 6,752 feet), there was a general tendency (see fig. 28) for the temperatures even to increase somewhat beginning about Novemuer 15. They culminated in an unusually warm period from December 5 to 8 , when minimum temperatures even at the higher altitudes were above freezing. During the storm period from December 9 to 12 , mean temperatures ranged from $55^{\circ} \mathrm{F}$. on the valley floor to $32^{\circ} \mathrm{F}$. at the higher altitudes, and averaged $7^{\circ}$ to $8^{\circ} \mathrm{F}$. above normal. The correlation of temperature and altitude along the western front of the Sierra Nevada indicates that the rate of decrease in tempereture per thousand feet increase in altitude during the December storm period corresponded with the rate of change indicated by the long-time 


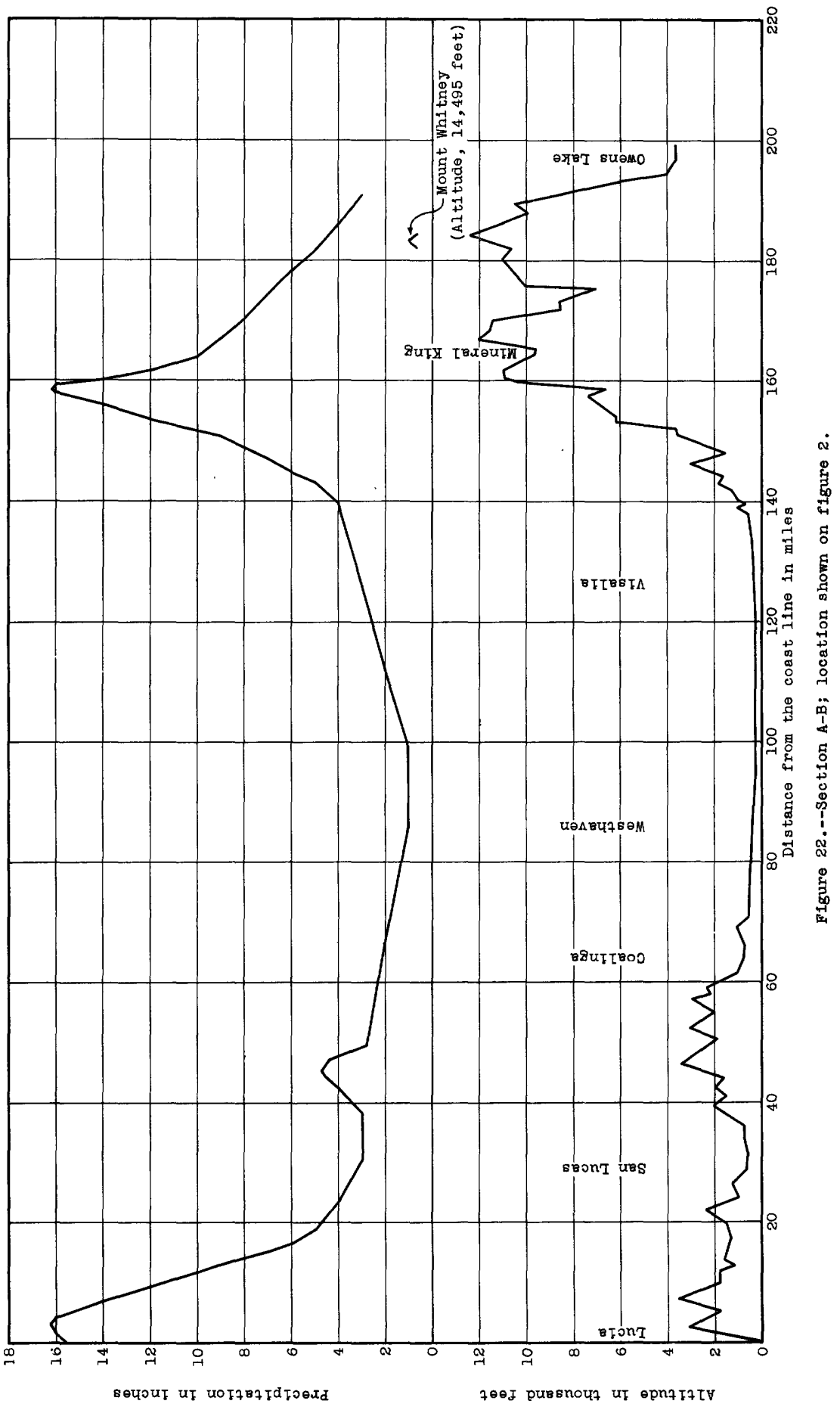




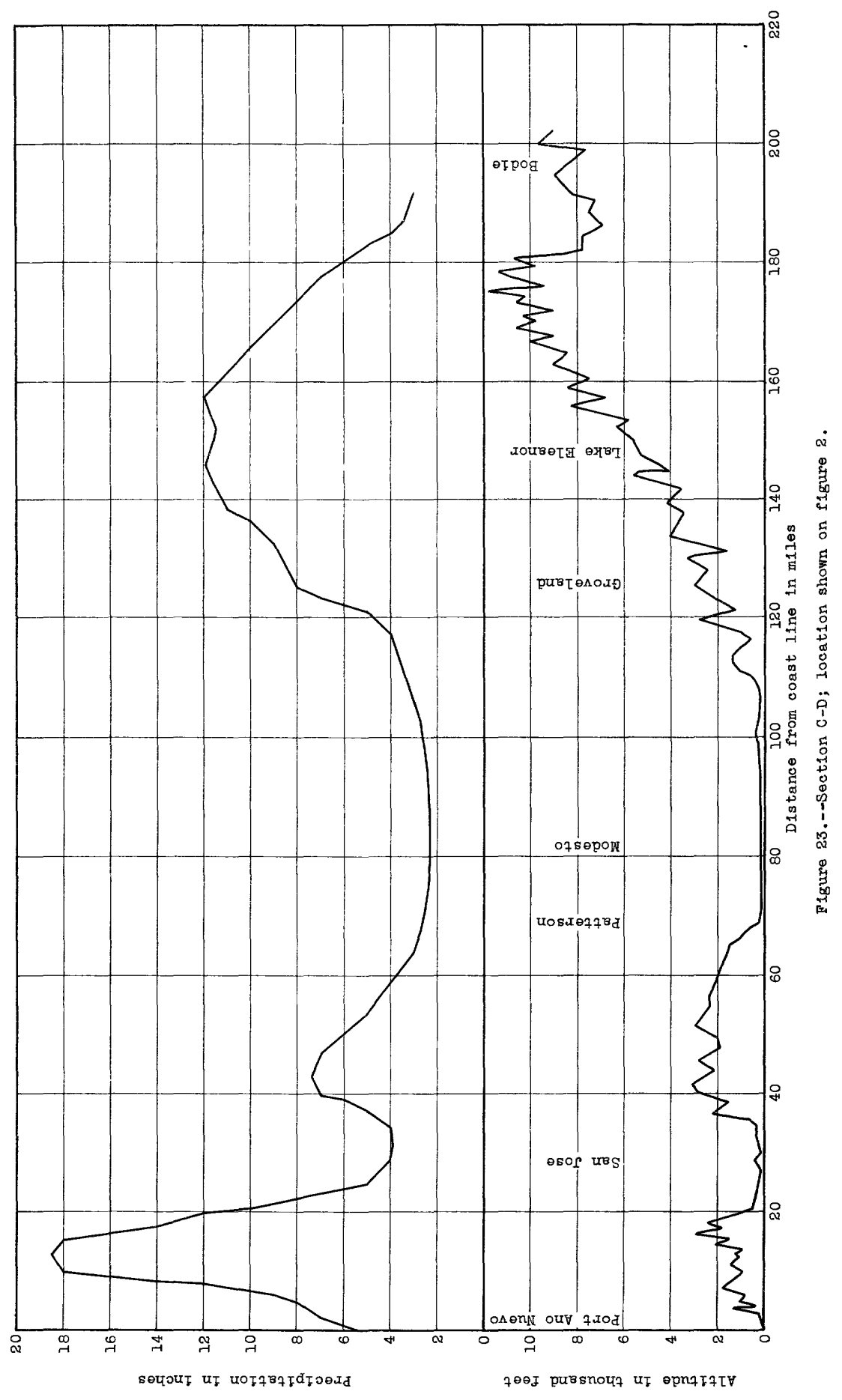




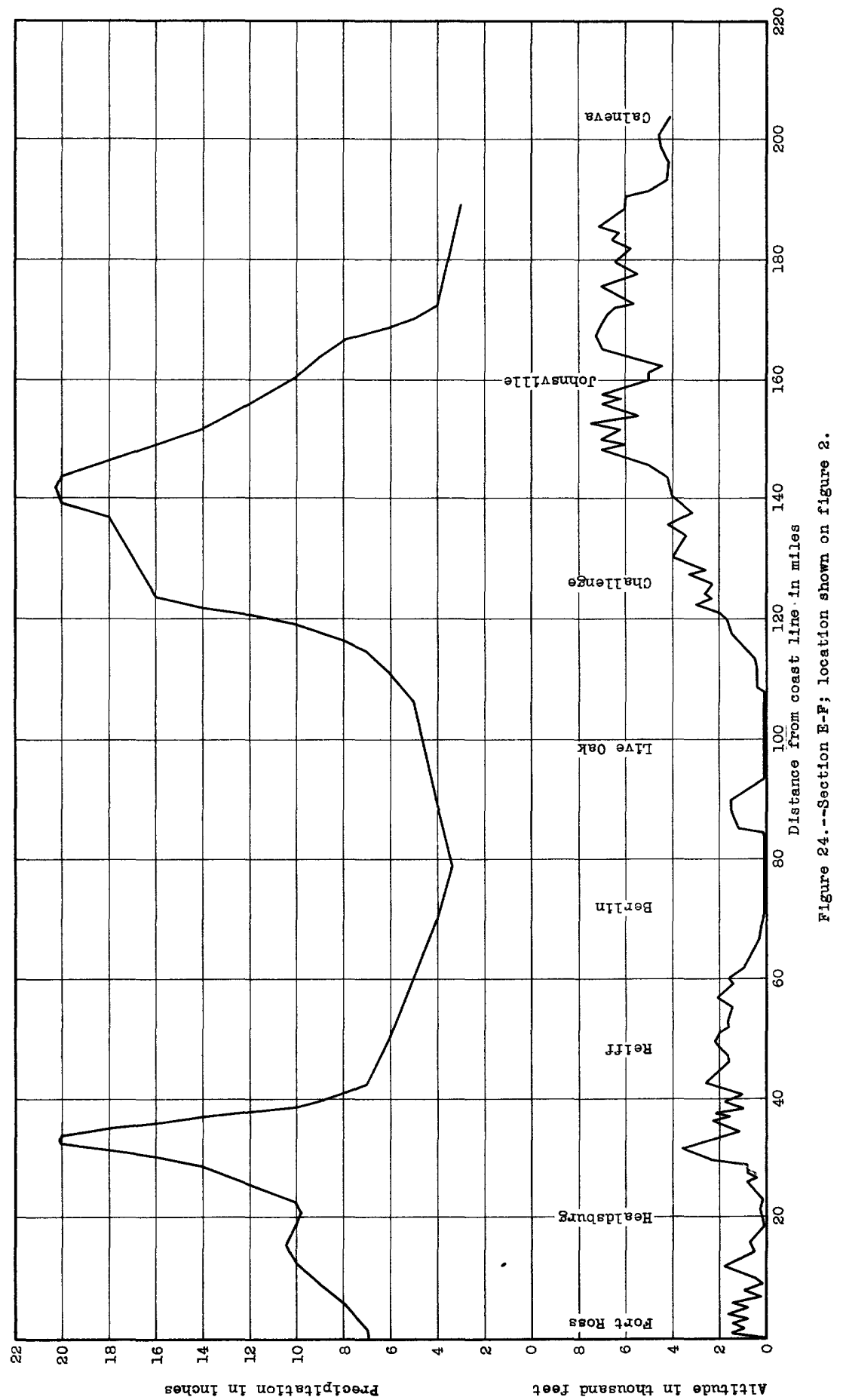




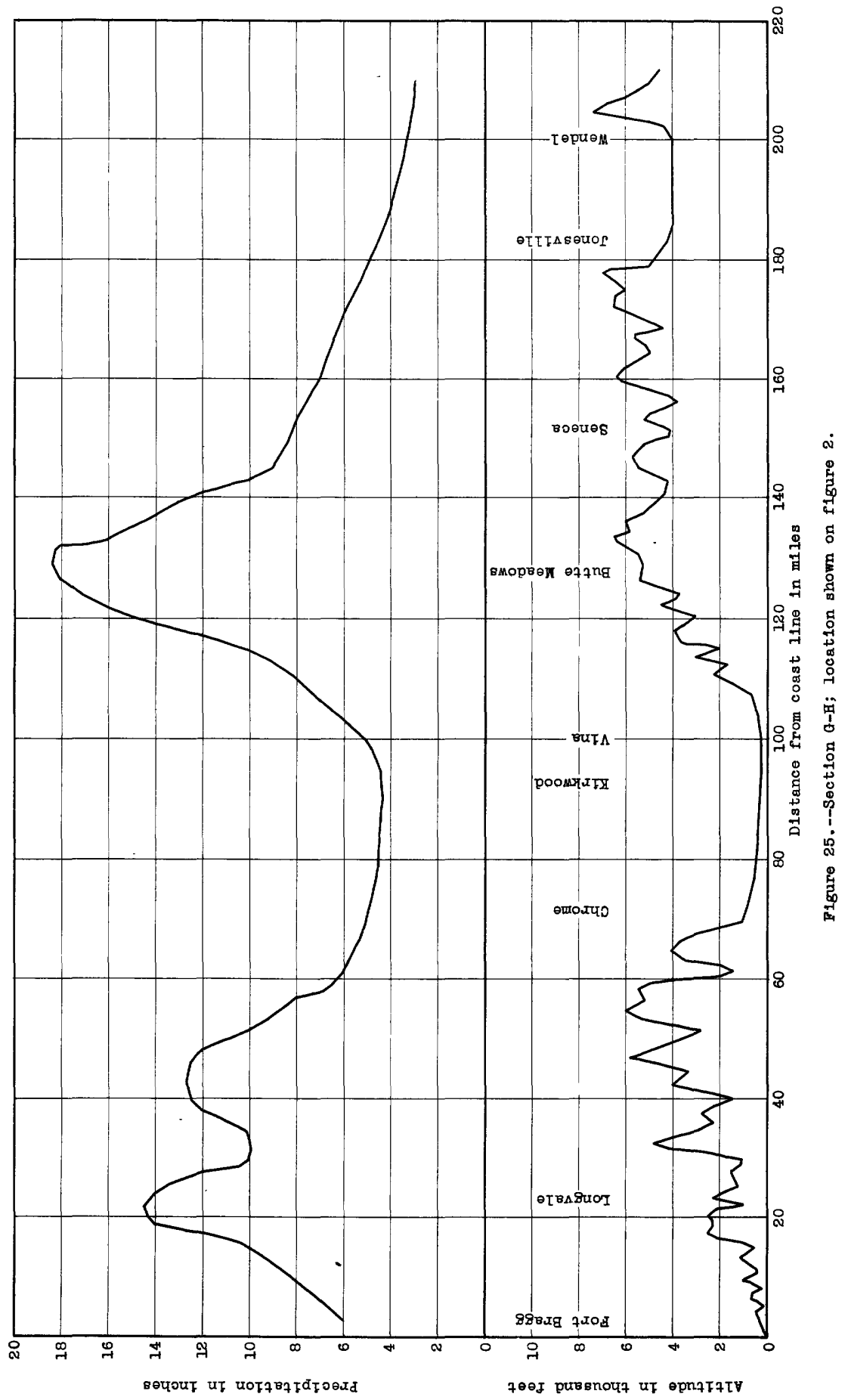




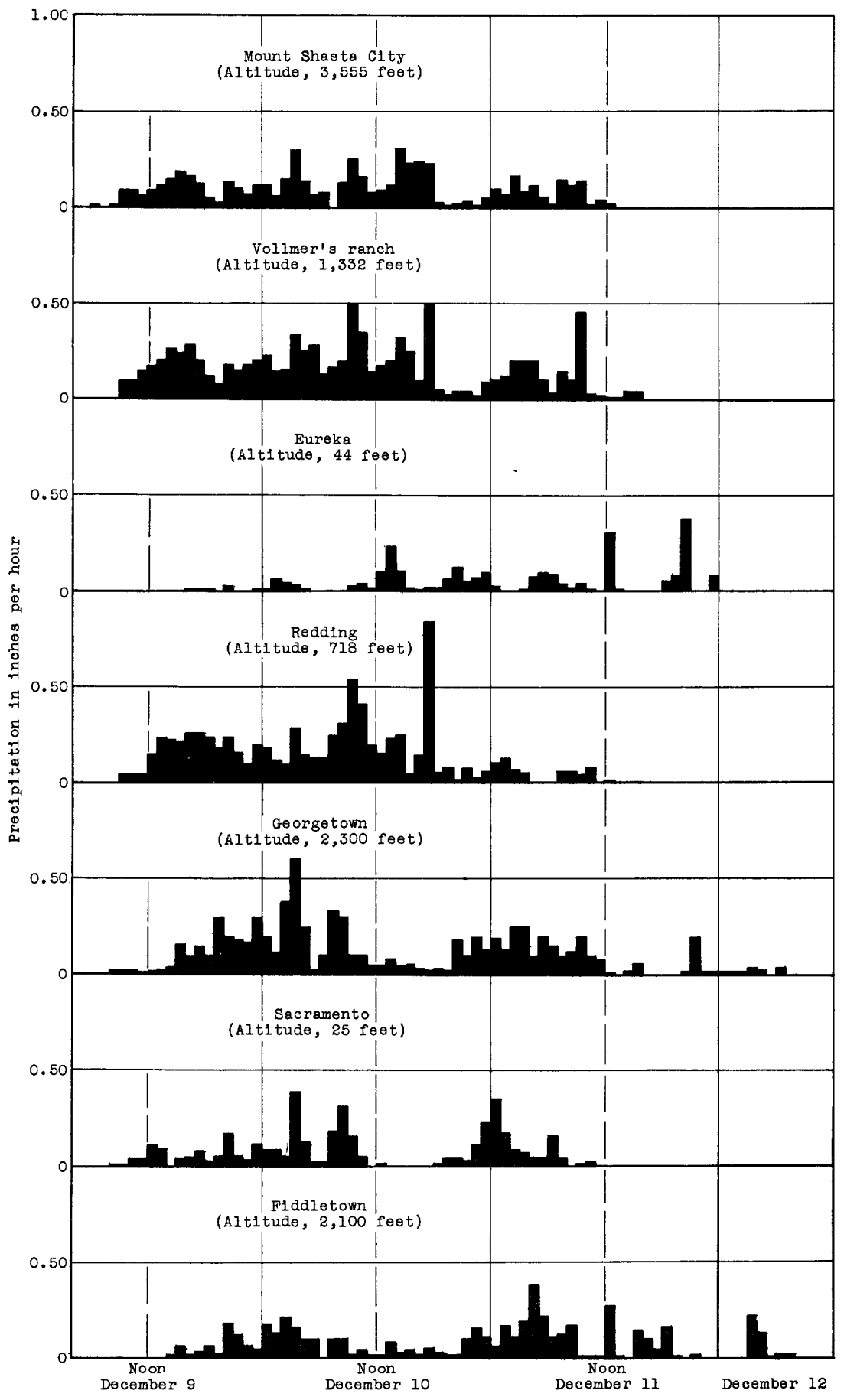

Pigure 26.--Hourly precipitation, in Inches, st varlous precipitation stations, Kount Shasta C1ty to Fiddletom December 8-13, 1937. 


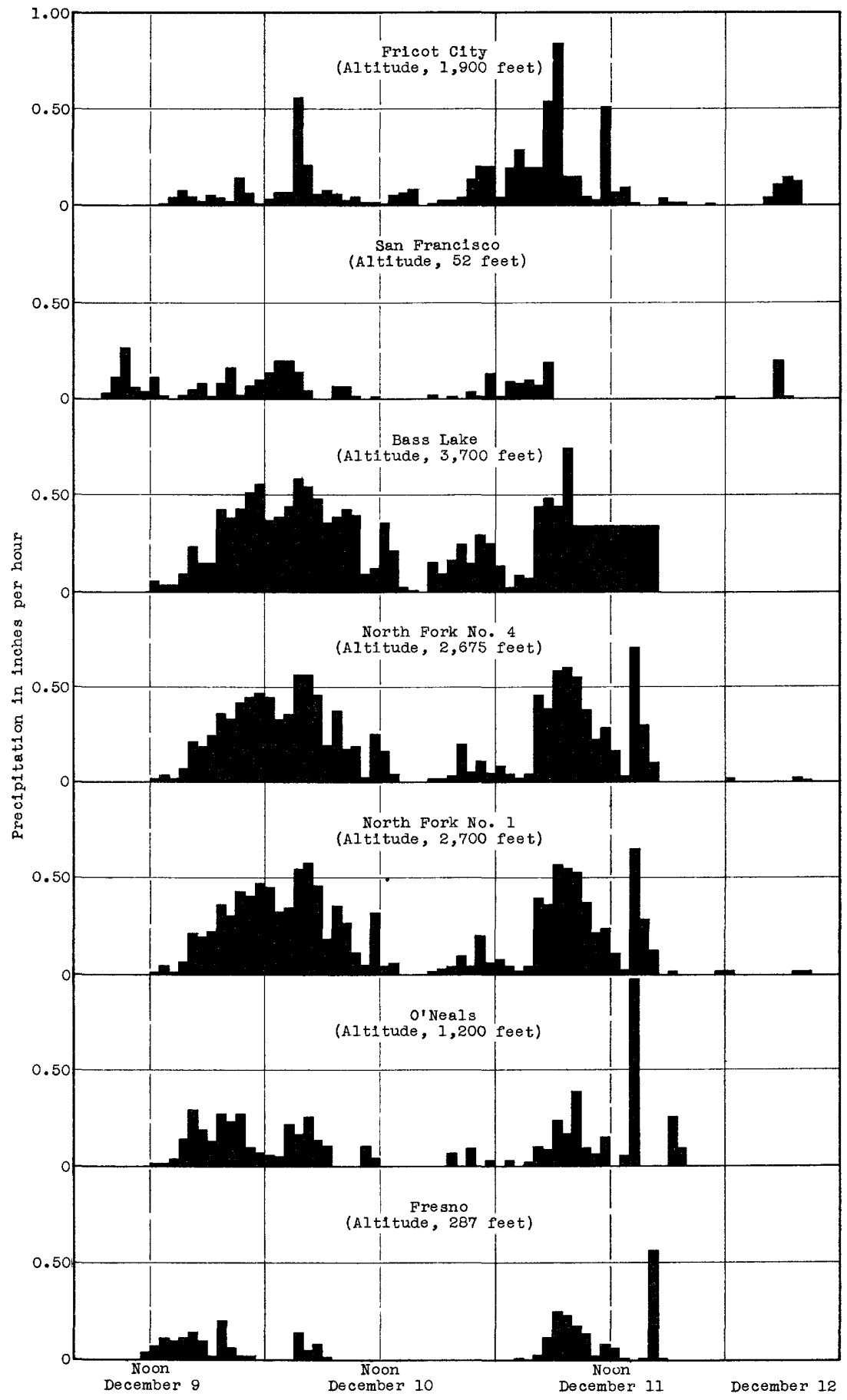

Figure 27.--Hourly precipitation, in inches, at various precipltation stations, Fricot City to Fresno December 8-13, 1937. 
December temperatures, namely, about $2^{\circ} \mathrm{F}$. decrease in maximum daily temperature, $2 \frac{1}{2}^{\circ} \mathrm{F}$. decrease in mean daily temperatures, and $3^{\circ} \mathrm{F}$. decrease in maximum temperature, for each increase of 1,000 feet in altitude.

One effect, therefore, of the high temperatures during the storm period from December 9 to 12 was to increase the area that contributed to the December flood run-off by raising the altitude limit at which the precipitation took the form of rain. Another effect was to increase greatly the amount of precipitation which fell as rain and which, in the absence of a deep snow cover, was an immediate source of run-off.

A study was made to determine the approximate number of square miles in the drainage area contributing to the central valley along the western front of the Sierra Nevada which lie between certain contours. These values were obtained by sketching the 5,000, 7,000 and 9,000 foot contours on the 1:500,000 base map from standard topographic maps where avaliable, and by measuring the area between each pair of contours. The values are only approximate, but the totals for any major basin should be reasonably correct. The results of these determinations are shown under "Rainfall and run-off studies" in table 6.

of the 12,300 square miles of the western front tributary to the San Joaquin system, upstream from the several gaging stations, nearly 2,000 square miles lie above an altitude of 9,000 feet; 2,500 square miles between altitudes of 7,000 and 9,000 feet; 2,300 square miles between altitudes of 5,000 and 7,000 feet; and about 5,500 square miles below an altitude of 5,000 feet.

In the area along the western slope, tributary to the Sacramento River and above the several gaging stations, only a negligible amount of the 16,900 square miles is above an altitude of 9,000 feet, and somewhat less than 500 square miles is above an altitude of 7,000 feet. About 5,200 square miles lie between altitudes of 5,000 and 7,000 feet, and about 11,200 square miles are below 5,000 feet.

The Sierra Nevada area contributing to the San Joaquin River contains about 4,500 square miles above an altitude of 7,000 feet whereas that tributary to the Sacramento River has only about 500 square miles above the 7,000 foot contour. The effect of this factor upon the runoff of the two basins is alscussed in other sections of this paper.

Considering the area upstream from gaging stations on the western slope as a whole, the areas between the several pairs of 1,000-foot contours average about 3,600 square miles each up to an altitude of about 


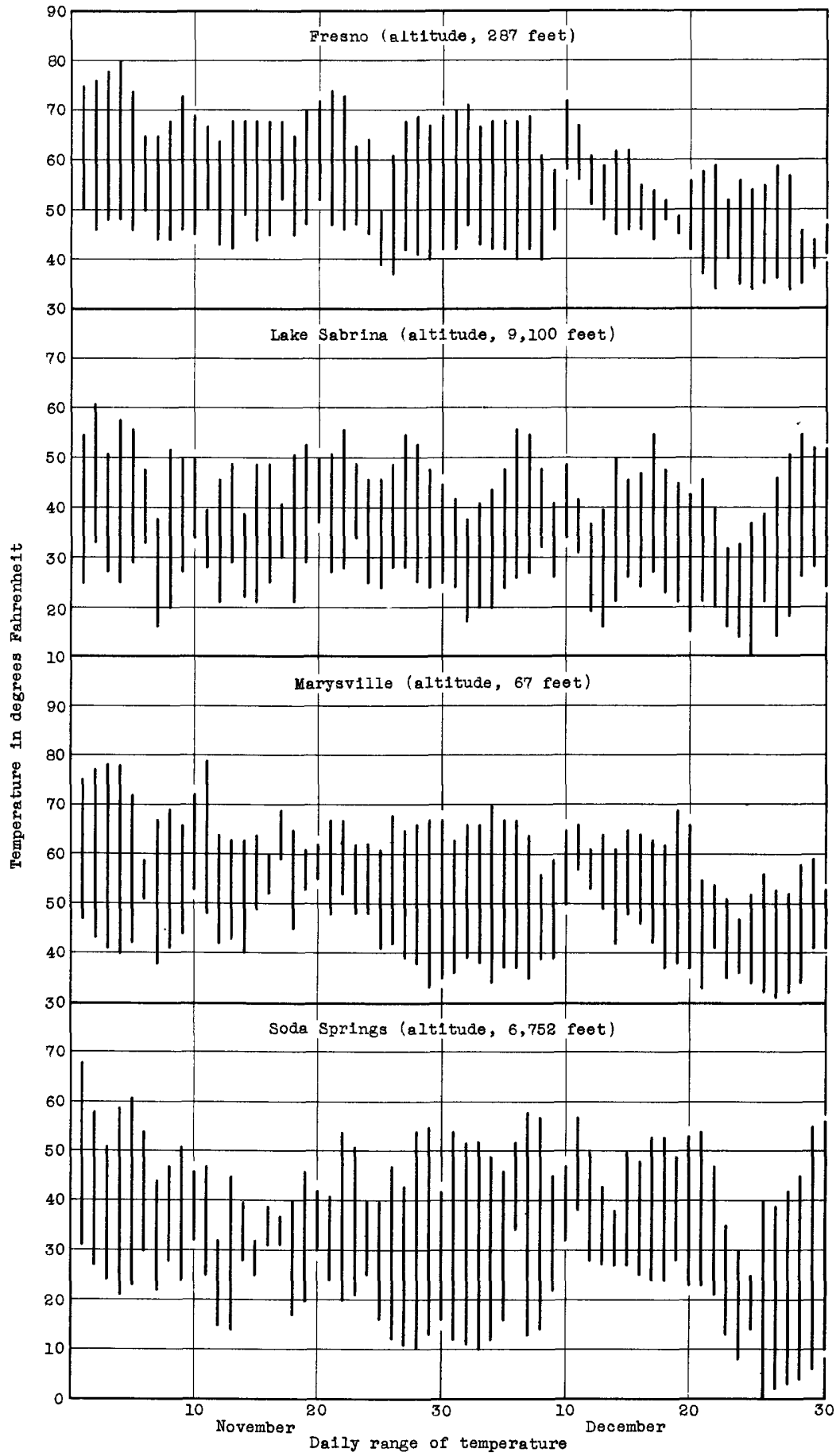

Figure 28.--Da1ly range of temperature at varlous places in northern Calirornia, November and December 1937. 
7,000 feet, and 1,200 square miles above 7,000 feet. At critical temperatures a change of $2^{\circ}$ F. might change the character of the precipitation from rain to snow or vice versa over more than 3,000 square miles; and an increase in temperature of $7^{\circ}$ or $8^{\circ} \mathrm{F}$, such as occurred during December 1937, might result in precipitation as rain instead of snow over an area of as much as 10,000 to 12,000 square miles, which is roughly 40 percent of the contributing area along the western front of the Sierra Nevada.

\section{Snow}

In California, as in other western states, snow surveys as an aid in forecasting probable spring and summer run-off are systematically carried on by State and Federal agencies in cooperation with irrigation, power, and other organizations which are vitally interested in the conservation and use of water. Thus, in California, the Division of Water Resources of the California Department of Public Works, in cooperation with the Bureau of Agricultural Engineering, the United States Weather Bureau, irrigation districts, and public utilities, makes observations of snow in headwater areas and issues monthly bulletins about snow conditions and forecasts of probable run-off. However, these observations are normally carried on only from January through May, hence at the time of the flood of December 1937 there was comparatively little information available about snow conditions. Even though data be avallable concerning the amount of snow on the ground there is relatively little quantitative information avaliable about the effect of snow on flood discharge and run-off.

Studies and observations made by the United States Weather Bureau (see report by E. H. Fletcher, previously cited) and by the State Engineer's office indicate that the abnomal occurrence of rain rather than snow was one of the princlpal aggravating factors in connection with the intensities of run-off in many of the streams draining the Sierra Nevada during the flood of December 1937. Special effort has therefore been made to collect and complie all readily available information about snow during November and December 1937. The data are summarized in table 3 .

The United States Weather Bureau also furnishes the following information:

Snowfall was negligible prior to November 10, and was generally subnormal thereafter (to the end of December). The average fall for 
Table 3.--Snow conditions in November and during storm of December 1937

\begin{tabular}{|c|c|c|c|c|c|c|c|c|c|}
\hline \multirow{3}{*}{ Station } & \multirow{3}{*}{ Sub-basin } & \multirow{3}{*}{$\begin{array}{c}\text { Alt1- } \\
\text { tude } \\
\text { (feet) }\end{array}$} & \multirow{3}{*}{$\begin{array}{l}\text { Total } \\
\text { snow- } \\
\text { fall } \\
\text { for Nov; } \\
\text { (Inches) }\end{array}$} & \multirow{3}{*}{$\begin{array}{l}\text { Type of } \\
\text { precip- } \\
\text { 1tation } \\
\text { Dec. } \\
9-12\end{array}$} & \multicolumn{3}{|c|}{$\begin{array}{l}\text { Snow on ground } \\
\text { (1nches) }\end{array}$} & \multirow{2}{*}{\multicolumn{2}{|c|}{\begin{tabular}{|c|c}
$\begin{array}{c}\text { Dally } \\
\text { snowfall } \\
\text { (inches) }\end{array}$ \\
December a
\end{tabular}}} \\
\hline & & & & & \multirow{2}{*}{$\begin{array}{c}\text { Nov. } \\
30\end{array}$} & \multicolumn{2}{|c|}{ December a / } & & \\
\hline & & & & & & 9 & 12 & 9 & 12 \\
\hline & & \multicolumn{3}{|c|}{ Kern River Bas in } & & & & & \\
\hline Johns ondale & Kern & \multicolumn{2}{|c|}{ Tulare Lake Bas in } & Ra1n & 0 & 0 & 0 & 0 & 0 \\
\hline $\begin{array}{l}\text { Glennvilie } \\
\text { Springvilie } \\
\text { CIIff Camp } \\
\text { Gen. Grant Nat. } \\
\text { Park }\end{array}$ & $\begin{array}{l}\text { Poso Creek } \\
\text { Tule } \\
\text { KIngs } \\
\text { do. }\end{array}$ & $\begin{array}{r}3,300 \\
4,050 \\
6,150 \\
6,775 \\
\\
\text { San Joa }\end{array}$ & $\begin{array}{c}0 \\
0 \\
\mathrm{Tr} . \\
1.5 \\
\end{array}$ & $\begin{array}{c}\text { Rain } \\
\text { do. } \\
b \\
b \\
\text { Bas in }\end{array}$ & $\begin{array}{l}0 \\
0 \\
0 \\
0\end{array}$ & $\begin{array}{l}0 \\
0 \\
0 \\
0\end{array}$ & $\begin{array}{l}0 \\
0 \\
- \\
-\end{array}$ & $\begin{array}{l}0 \\
0 \\
0 \\
0\end{array}$ & $\begin{array}{l}0 \\
0 \\
5 \\
\mathrm{~b}\end{array}$ \\
\hline $\begin{array}{l}\text { Sand Bar Flat } \\
\text { Dudleys } \\
\text { North Fork } \\
\text { Crane Valley } \\
\text { Hetch Hetchy }\end{array}$ & $\begin{array}{l}\text { Stanislaus } \\
\text { Merced Creak } \\
\text { W1llow Crea } \\
\text { do. } \\
\text { Tholumne }\end{array}$ & $\begin{array}{l}2,700 \\
3,000 \\
3,000 \\
3,500 \\
3,530\end{array}$ & $\begin{array}{l}0 \\
0 \\
0 \\
0 \\
0\end{array}$ & $\begin{array}{l}\text { Ra1n } \\
\text { do. } \\
\text { do. } \\
\text { do. } \\
\text { do. }\end{array}$ & $\begin{array}{l}0 \\
0 \\
0 \\
0 \\
0\end{array}$ & $\begin{array}{l}0 \\
0 \\
0 \\
0 \\
0\end{array}$ & $\begin{array}{l}0 \\
0 \\
0 \\
0 \\
0\end{array}$ & $\begin{array}{l}0 \\
0 \\
0 \\
0 \\
0\end{array}$ & $\begin{array}{l}0 \\
0 \\
0 \\
0 \\
0\end{array}$ \\
\hline $\begin{array}{l}\text { Salt Springs } \\
\text { Yosemite } \\
\text { Lake Eleanor } \\
\text { Big Trees } \\
\text { Spring Gap }\end{array}$ & $\begin{array}{l}\text { Moke lume } \\
\text { Merced } \\
\text { Tuolumne } \\
\text { Calaveras } \\
\text { Stanis laus }\end{array}$ & $\begin{array}{l}3,660 \\
3,983 \\
4,650 \\
4,700 \\
4,875\end{array}$ & $\begin{array}{l}0^{.5} \\
1 \\
1 \text { to } 2 \\
1.5\end{array}$ & $\begin{array}{l}\text { do. } \\
\text { do: } \\
\text { do. } \\
\text { do: } \\
\text { b }\end{array}$ & $\begin{array}{l}0 \\
0 \\
0 \\
0 \\
0\end{array}$ & $\begin{array}{l}0 \\
0 \\
0 \\
0 \\
0\end{array}$ & $\begin{array}{l}0 \\
0 \\
0 \\
0 \\
-\end{array}$ & $\begin{array}{l}0 \\
0 \\
0 \\
0 \\
0\end{array}$ & $\begin{array}{l}0 \\
0 \\
0 \\
0 \\
.5\end{array}$ \\
\hline $\begin{array}{l}\text { Big Creek No. I } \\
\text { Shaver Lake } \\
\text { Strawberry } \\
\text { Huntington Lake } \\
\text { Florence Lake }\end{array}$ & $\begin{array}{l}\text { Big Creek } \\
\text { Stevenson Cr } \\
\text { Stanis laus } \\
\text { B1g Creek } \\
\text { South Fork }\end{array}$ & $\begin{array}{l}4,900 \\
5,400 \\
5,620 \\
7,000 \\
7,400\end{array}$ & $\begin{array}{l}\mathrm{mr}_{\mathrm{r}} \\
\mathrm{Tr}_{\mathrm{r}} \\
4.5 \\
5 \\
4\end{array}$ & $\begin{array}{c}\text { Rain } \\
\text { do. } \\
b \\
b \\
b\end{array}$ & $\begin{array}{l}0 \\
0 \\
0 \\
0 \\
0\end{array}$ & $\begin{array}{c}0 \\
0 \\
0 \\
\text { Tr. } \\
-\end{array}$ & $\begin{array}{c}0 \\
0 \\
- \\
\operatorname{Tr} . \\
-\end{array}$ & $\begin{array}{c}0 \\
0 \\
0 \\
\operatorname{Tr} . \\
0\end{array}$ & $\begin{array}{l}0 \\
0 \\
2 \\
1 \\
5.5\end{array}$ \\
\hline Lake Alpine & Stan1s laus & 7,500 & $\begin{array}{l}27.4 \\
c 4.67\end{array}$ & $\mathrm{~b}$ & 13 & - & - & $\begin{array}{r}2.5 \\
c .46\end{array}$ & $\begin{array}{r}3.2 \\
0.45\end{array}$ \\
\hline $\begin{array}{l}\text { Badger Flats } \\
\text { Ka1ser Pass }\end{array}$ & $\begin{array}{l}\text { Big Creek } \\
\text { South Fork }\end{array}$ & $\begin{array}{l}8,300 \\
9,300\end{array}$ & $=$ & Snow & $\begin{array}{r}8 \\
12\end{array}$ & $\overline{-}$ & $\overline{-}$ & - & $\overline{-}$ \\
\hline & & \multicolumn{3}{|c|}{ Sacramento River Bas in } & & & & & \\
\hline $\begin{array}{l}\text { Vollmers ranch } \\
\text { Chute Camp } \\
\text { Storrle } \\
\text { Dunsmuir } \\
\text { Howells }\end{array}$ & $\begin{array}{l}\text { Sacramento } \\
\text { Yuba } \\
\text { Feather } \\
\text { Sacramento } \\
\text { Feather }\end{array}$ & $\begin{array}{l}1,332 \\
1,358 \\
1,760 \\
2,290 \\
2,400\end{array}$ & $\begin{array}{l}0 \\
0 \\
0 \\
0 \\
0\end{array}$ & $\begin{array}{c}\text { Rain } \\
\text { do. } \\
\text { do. } \\
\text { do. } \\
\text { do. }\end{array}$ & $\begin{array}{l}0 \\
0 \\
0 \\
0 \\
0\end{array}$ & $\begin{array}{l}0 \\
0 \\
0 \\
0 \\
0\end{array}$ & $\begin{array}{l}0 \\
0 \\
0 \\
0 \\
0\end{array}$ & $\begin{array}{l}0 \\
0 \\
0 \\
0 \\
0\end{array}$ & $\begin{array}{l}0 \\
0 \\
0 \\
0 \\
0\end{array}$ \\
\hline $\begin{array}{l}\text { Nevada C1ty } \\
\text { Kilare } \\
\text { Grass Valley } \\
\text { Challenge } \\
\text { De Sabla }\end{array}$ & $\begin{array}{l}\text { Yuba } \\
\text { Cow Oreek } \\
\text { Feather } \\
\text { do. } \\
\text { Butte Creek }\end{array}$ & $\begin{array}{l}2,570 \\
2,642 \\
2,690 \\
2,700 \\
2,700\end{array}$ & $\begin{array}{l}0 \\
0 \\
0 \\
0 \\
0\end{array}$ & $\begin{array}{l}\text { do. } \\
\text { do: } \\
\text { do. } \\
\text { do. } \\
\text { do. }\end{array}$ & $\begin{array}{l}0 \\
0 \\
0 \\
0 \\
0\end{array}$ & $\begin{array}{l}0 \\
0 \\
0 \\
0 \\
0\end{array}$ & $\begin{array}{l}0 \\
0 \\
0 \\
0 \\
0\end{array}$ & $\begin{array}{l}0 \\
0 \\
0 \\
0 \\
0\end{array}$ & $\begin{array}{l}0 \\
0 \\
0 \\
0 \\
0\end{array}$ \\
\hline $\begin{array}{l}\text { Car1bou } \\
\text { Forest H1ll } \\
\text { West Brench } \\
\text { McCloud } \\
\text { Fall River Mills }\end{array}$ & $\begin{array}{l}\text { Feather } \\
\text { Amerlcan } \\
\text { Feather } \\
\text { P1t } \\
\text { do. }\end{array}$ & $\begin{array}{l}3,000 \\
3,200 \\
3,216 \\
3,270 \\
3,340\end{array}$ & $\begin{array}{c}0 \\
0 \\
0 \\
\operatorname{Tr} . \\
\operatorname{Tr} .\end{array}$ & $\begin{array}{l}\text { do. } \\
\text { do: } \\
\text { do: } \\
\text { do: } \\
\text { do. }\end{array}$ & $\begin{array}{l}0 \\
0 \\
0 \\
0 \\
0\end{array}$ & $\begin{array}{l}0 \\
0 \\
0 \\
0 \\
0\end{array}$ & $\begin{array}{l}0 \\
0 \\
0 \\
0 \\
0\end{array}$ & $\begin{array}{c}0 \\
0 \\
0 \\
0 \\
\mathrm{Tr} .\end{array}$ & $\begin{array}{l}0 \\
0 \\
0 \\
0 \\
0\end{array}$ \\
\hline $\begin{array}{l}\text { Hat Oreek } \\
\text { Qulncy } \\
\text { Brush Creek } \\
\text { Veramount } \\
\text { Mount Shas ta }\end{array}$ & $\begin{array}{l}\text { do. } \\
\text { Feather } \\
\text { do. } \\
\text { do. } \\
\text { Sacramento }\end{array}$ & $\begin{array}{l}3,400 \\
3,409 \\
3,500 \\
3,500 \\
3,555\end{array}$ & $\begin{array}{l}0 \\
0 \\
0 \\
0 \\
0\end{array}$ & $\begin{array}{l}\text { do. } \\
\text { do. } \\
\text { do. } \\
\text { do. } \\
\text { do. }\end{array}$ & $\begin{array}{l}0 \\
0 \\
0 \\
0 \\
0\end{array}$ & $\begin{array}{l}0 \\
0 \\
0 \\
0 \\
0\end{array}$ & $\begin{array}{l}0 \\
0 \\
0 \\
0 \\
0\end{array}$ & $\begin{array}{l}0 \\
0 \\
0 \\
0 \\
0\end{array}$ & $\begin{array}{l}0 \\
0 \\
0 \\
0 \\
0\end{array}$ \\
\hline $\begin{array}{l}\text { Deer Croek } \\
\text { Lookout } \\
\text { Scales } \\
\text { Alturas } \\
\text { Chester }\end{array}$ & $\begin{array}{l}\text { Yuba } \\
\text { P1t } \\
\text { Yuba } \\
\text { P1t } \\
\text { Feather }\end{array}$ & $\begin{array}{l}3,700 \\
4,296 \\
4,300 \\
4,346 \\
4,550\end{array}$ & $\begin{array}{r}0 \\
0 \\
0 \\
0 \\
12\end{array}$ & $\begin{array}{l}\text { do. } \\
\text { do. } \\
\text { do. } \\
\text { do. } \\
\text { do. }\end{array}$ & $\begin{array}{l}0 \\
0 \\
0 \\
0 \\
0\end{array}$ & $\begin{array}{l}0 \\
0 \\
0 \\
0 \\
0\end{array}$ & $\begin{array}{l}0 \\
0 \\
0 \\
0 \\
0\end{array}$ & $\begin{array}{l}0 \\
0 \\
0 \\
0 \\
0\end{array}$ & $\begin{array}{l}0 \\
0 \\
0 \\
0 \\
0\end{array}$ \\
\hline $\begin{array}{l}\text { Canyon Dam } \\
\text { Prattvilie } \\
\text { Drum Forebay } \\
\text { Blue Canyon } \\
\text { Inskip }\end{array}$ & $\begin{array}{l}\text { do. } \\
\text { do. } \\
\text { Yuba } \\
\text { American } \\
\text { Feather }\end{array}$ & $\begin{array}{l}4,570 \\
4,600 \\
4,653 \\
4,750 \\
4,808\end{array}$ & $\begin{array}{c}\operatorname{Tr} . \\
3 \\
2 \\
3 \\
\operatorname{Tr}\end{array}$ & $\begin{array}{l}\text { do. } \\
\text { do: } \\
\text { do. } \\
\text { do: } \\
\text { do. }\end{array}$ & $\begin{array}{l}0 \\
0 \\
0 \\
0 \\
0\end{array}$ & $\begin{array}{l}0 \\
0 \\
0 \\
0 \\
0\end{array}$ & $\begin{array}{l}0 \\
0 \\
0 \\
0 \\
0\end{array}$ & $\begin{array}{c}0 \\
0 \\
0 \\
0 \\
\text { Tr. }\end{array}$ & $\begin{array}{l}0 \\
0 \\
0 \\
0 \\
0\end{array}$ \\
\hline
\end{tabular}

a Any anow on ground or additional snowfall on Dec. 10 or 11 is indicated by footnotes.

b Rain and snow.

c Water content in inches. 
Table 3.--Snow conditions in November and during storm of December 1937--Continued

\begin{tabular}{|c|c|c|c|c|c|c|c|c|c|}
\hline \multirow{3}{*}{ Station } & \multirow{3}{*}{ Sub-bas in } & \multirow{3}{*}{$\begin{array}{c}\text { Alti- } \\
\text { tude } \\
\text { (feet) }\end{array}$} & \multirow{3}{*}{$\begin{array}{c}\text { Total } \\
\text { snow- } \\
\text { fal1 } \\
\text { for Nov. } \\
\text { (Inches) }\end{array}$} & \multirow{3}{*}{$\begin{array}{l}\text { Type of } \\
\text { precip- } \\
\text { itation } \\
\text { Dec. } \\
9-12\end{array}$} & \multicolumn{3}{|c|}{$\begin{array}{c}\text { Snow on ground } \\
\text { (Inches) }\end{array}$} & \multicolumn{2}{|c|}{$\begin{array}{c}\text { Daily } \\
\text { gnowfall } \\
(\text { Inches })\end{array}$} \\
\hline & & & & & \multirow{2}{*}{$\begin{array}{c}\text { Nov. } \\
30\end{array}$} & \multicolumn{2}{|c|}{ December a } & \multicolumn{2}{|c|}{ December a } \\
\hline & & & & & & 9 & 12 & 9 & 12 \\
\hline & \multicolumn{5}{|c|}{ Sacramento River Basin--Cont inued } & & & & \\
\hline $\begin{array}{l}\text { Portola } \\
\text { Mineral } \\
\text { Sierraville } \\
\text { Westwood } \\
\text { Bucks Iake }\end{array}$ & $\begin{array}{l}\text { Feather } \\
\text { Battle Creek } \\
\text { Feather } \\
\text { do. } \\
\text { do. }\end{array}$ & $\begin{array}{l}4,832 \\
4,950 \\
5,000 \\
5,000 \\
5,070\end{array}$ & $\begin{array}{l}0 \\
2.5 \\
2 \\
4 \\
11\end{array}$ & $\begin{array}{l}\text { Rain } \\
\text { do. } \\
\text { do. } \\
\text { do. } \\
\text { do. }\end{array}$ & $\begin{array}{l}0 \\
0 \\
0 \\
0 \\
-\end{array}$ & $\begin{array}{l}0 \\
0 \\
0 \\
0 \\
0\end{array}$ & $\begin{array}{l}0 \\
0 \\
0 \\
0 \\
0\end{array}$ & $\begin{array}{c}0 \\
\mathrm{Pr} \\
0 \\
0 \\
0\end{array}$ & $\begin{array}{l}0 \\
0 \\
0 \\
0 \\
0\end{array}$ \\
\hline $\begin{array}{l}\text { Lake Spaulding } \\
\text { Bowman Dam } \\
\text { Jess Valley } \\
\text { Soda Springs } \\
\text { Tw1r Lakes }\end{array}$ & $\begin{array}{l}\text { Yuba } \\
\quad \text { do. } \\
\text { P1t } \\
\text { Yuba } \\
\text { American }\end{array}$ & $\begin{array}{l}5,075 \\
5,347 \\
5,400 \\
6,752 \\
7,920\end{array}$ & $\begin{array}{l}10 \\
18.3 \\
1 \\
70 \\
29.5 \\
c 4.44\end{array}$ & $\begin{array}{l}b \\
b \\
b \\
b\end{array}$ & $\begin{array}{r}\operatorname{Tr}_{1} \\
0 \\
20 \\
11\end{array}$ & $\begin{array}{r}0 \\
0 \\
0 \\
013 \\
88\end{array}$ & $\begin{array}{r}0 \\
1 \\
- \\
8 \\
8\end{array}$ & $\begin{array}{c}0 \\
\mathrm{Tr} . \\
\overline{0} \\
.5 \\
\mathrm{c.} \\
18\end{array}$ & $\begin{array}{c}1 \\
1 \\
-5 \\
\text { f5 } \\
\text { h6. } 0 \\
\text { c. } 84\end{array}$ \\
\hline Helen Lake & M111 Creek & $\begin{array}{r}8,300 \mid \\
\text { The }\end{array}$ & $\begin{array}{c}- \\
\text { Great Bas }\end{array}$ & $\mathrm{b}$ & $j 96 \pm$ & - & $60 \pm$ & - & - \\
\hline $\begin{array}{l}\text { Independence } \\
\text { Cedarvilie } \\
\text { Lake C1ty } \\
\text { Fort Bldwell } \\
\text { Boca }\end{array}$ & $\begin{array}{l}\text { Owens } \\
\text { Alka11 Iake } \\
\text { do. } \\
\text { do. } \\
\text { Truckee }\end{array}$ & $\begin{array}{l}3,943 \\
4,675 \\
4,680 \\
4,735 \\
5,535\end{array}$ & $\begin{array}{l}0 \\
8.5 \\
6 \\
8 \\
5.25\end{array}$ & $\begin{array}{l}\text { RaIn } \\
\text { do. } \\
\text { do. } \\
\text { do. } \\
\text { b }\end{array}$ & $\begin{array}{l}0 \\
0 \\
0 \\
0 \\
0\end{array}$ & $\begin{array}{l}0 \\
0 \\
0 \\
0 \\
0\end{array}$ & $\begin{array}{l}0 \\
0 \\
0 \\
0 \\
0\end{array}$ & $\begin{array}{l}0 \\
0 \\
0 \\
0 \\
0\end{array}$ & $\begin{array}{l}0 \\
0 \\
0 \\
0 \\
k .5\end{array}$ \\
\hline $\begin{array}{l}\text { Truckee } \\
\text { Tahoe } \\
\text { Bridgeport } \\
\text { Lundy Lake }\end{array}$ & $\begin{array}{l}\text { do. } \\
\text { do. } \\
\text { walker } \\
\text { Mono }\end{array}$ & $\begin{array}{l}5,818 \\
6,230 \\
6,440 \\
7,760\end{array}$ & $\begin{array}{l}10.5 \\
15 \\
5 \\
7\end{array}$ & $\begin{array}{l}\mathrm{b} \\
\mathrm{b} \\
\mathrm{b} \\
\mathrm{b}\end{array}$ & $\begin{array}{r}m \\
0 \\
0\end{array}$ & {$\left[\begin{array}{c}0 \\
\operatorname{Tr} . \underline{p} \\
0 \\
0\end{array}\right.$} & $\begin{array}{c}0 \\
2 \\
\operatorname{Tr} \cdot q \\
2\end{array}$ & $\begin{array}{l}0 \\
0 \\
0 \\
0\end{array}$ & $\begin{array}{l}\mathrm{Tr} \cdot \mathrm{n} / \\
\mathrm{Tr} \cdot \mathrm{q} / \\
\mathbf{r} 2\end{array}$ \\
\hline B1shop Creek & Owens & 8,390 & $\begin{array}{l}c .76 \\
1\end{array}$ & $\mathbf{b}$ & 0 & 0 & 83 & Tr. & $t^{c .20}$ \\
\hline Lake Sabrina & do. & 9,100 & $\begin{array}{l}5 \\
c, 35\end{array}$ & b & 0 & .5 & u7 & .5 & u6 \\
\hline Gem Leke & Kono & 9,120 & $\begin{array}{l}8.5 \\
c .04\end{array}$ & b & 1 & $\mathrm{pl}$ & จ7 & Tr. & \\
\hline $\begin{array}{l}\text { Bllery Lake } \\
\text { South Lake }\end{array}$ & $\begin{array}{l}\text { do. } \\
\text { Owens }\end{array}$ & $\begin{array}{l}9,600 \\
9,620\end{array}$ & $\begin{array}{l}27 \\
\mathrm{c} 3.13 \\
6 \\
\mathrm{c} .28\end{array}$ & $\begin{array}{l}\text { b } \\
\text { b }\end{array}$ & 0 & $\begin{array}{l}x \\
\mathrm{Tx}\end{array}$ & $\begin{array}{r}20 \\
212\end{array}$ & $\begin{array}{c}2 \\
\text { c. } 32 \\
T r .\end{array}$ & $\begin{array}{l}\text { y3 } \\
\text { c. } 44 \\
\text { aa5 } \\
\text { c. } 72\end{array}$ \\
\hline
\end{tabular}

a Snow on ground or additional snovfall on Dec. 10 or 11 is indicated by footnotes.

b Rain and anow.

c Water content in 1nches.

d. 19 inches Dec. I; 13 Inches Dec. 8.

e 10 inches Dec. 10; 5 Inches Dec. 11; 7 inches Dec. 13.

f 4 inohes Dec. 10 .

g 11 inches Dec. 1; 8 Inches Dec. 8 .

h 1 inch Dec. il (water content, 0.20 inch).

5 Snows of November accumalated to a depth of about 8 feet; warm rains of December reduced the snow to about 5 feet of slush, whlch eubsequently froze into gramular 1ce.

$k$ Disappeared same day.

$\mathrm{m}$ Patches of snow on ground.

n 1.5 Inches Dec. 11; melted by Dec. 12.

s Snow on ground for period Dec. 1-9.

q 2-inch snowfall Dec. 10; disappeared 1mmediately, as did trace Dec. 12.

I Disappeared by Dec. 14.

s 2 inches Dec. II; I Inch Dec. 15.

$t$ Trace Dec. 10; 2 1nches Dec. 11.

a 2 inches Dec. 11 .

$\checkmark 3$ Inches Dec. 10; 2 Inches Dec. 11; and 7 Inches Dec. 15.

- 2 Inches Dec. 10.

$x$ None Dec. 8; 19 inches Dec. 10; 18 inches Dec. 11; 14 inches Dec. 15.

y 17 inches Dec. 10 (water content, 3.75 inches); 4 inches Dec. 11 (water content, 1.92 inches).

z 6'inches Dec. 10; 11 inches Dec. 11; 7 inches Dec. 15.

aa 6 Inches Dec. 10 (water content, 3.07 1nches); 5 inches Dec. 11 (water content, 2.16 Inches). 
November was 52 percent and for December was 34 percent of the 41 -year mean (for those months). The November fall occurred over the Modoc Plateau, above the 4,500 foot level over the northern and middle Sierra Nevada, and above 6,500 foot level over the southern Sierra Nevada. The December fall exceeded the normal at low level stations in the Klamath basin, but was decidedly deficient elsewhere... .

The total seasonal snowfall to the close of December was 36 percent and the average depth of snow on the ground on the last day of December was 21 percent of normal. A large part of the November accumulation was melted by the warm rains of December 10-11, except over the high Sierra, and most of the snow on the ground at the end of December fell after the lith of that month... . The snow cover was deficient in all sections and at all levels on December 31 .

In compiling the data shown in table 3 , full use has been made of observations and records derived from the following sources:- the United States weather Bureau; the Division of Water Resources, California Department of Public Works; the United States Forest Service, in connection with operations at their experimental stations, and aiso the roports of forest supervisors and forest rangers to the regional forester; the Bureau of Water Works and Supply of the Los Angeles Department of Water and Power; public utility companies; postmasters; and others.

The snow observations herein recorded relate largely to conditions on the slopes of the Sierra Nevada. In the Coast Ranges to the west of the Central Valley there was apparently complete absence of snow, with the possible exception of drifts and patches on northern slopes in the relat:vely small areas lying above 6,500 feet north of Clear Lake. The records are discussed by major subdivisions of area: namely, the slopes of the Sierra Nevada tributary to the southern part of the Central Valley, the slopes tributary to the northern part of the Central Valley, and the slopes tributary to the Great Basin. The influence of snow, as reflected by stream flow records, is discussed to a limited extent by drainage basins in the section of this report relating to rainfall and run-off.

\section{Sierra Nevada slopes tributary to south half of Central Valley}

Under normal climatic conditions in San Joaquin River Basin, there may be precipitation in the form of snow from November to March at altitudes above 3,000 feet. During November 1937, mean daily temperatures at altitudes over 3,000 feet averaged from $1 \frac{1}{2}^{\circ}$ to $2 \frac{1}{2}^{\circ} \mathrm{F}$. above normal, and the precipitation, although of substantial amount, averaged from 1 to 3 inches below normal. Very little or no precipitation fell as snow below altitudes of about 4,500 feet, and there was considerably less than normal snowfall at altitudes above 4,500 feet.

At stations above 5,600 feet, much of the precipitation took the form of snow during four general storm periods, November 6, 11-14, 16-20, 
and 23-24; and at stations above 7,500 feet, snow was reported on the ground at the end of the month.

The fragmentary observations of snowfall given in table 3 indicate an apparent absence of snow on Sierra Nevada slopes tributary to the south half of Central Valley during November at altitudes up to 4,000 feet. Between a ltitudes of 4,000 and 5,500 feet, from a trace to $1 \frac{1}{2}$ inches of snow fell, with no snow on the ground at the end of the month. Between altitudes of 7,500 and about 9,000 feet, there were appreciable snowfalls, and at the end of November there was approximately one foot of snow on the ground.

Between November 30 and December 9, preceding the general storn period, there was iittle if any precipitation in the form of either rain or snow recorded in San Joaquin River Basin. Therefore, any snow on the ground at the beginning of the general storm period was a remnant of the November snowfall, the last of which fell on November 24. During the period from November 24 to December 9, maximum temperatures at altitudes up to 7,500 feet were well above freezing; and durine the period from December 4 to 8 the minimum temperatures also were above freezing, a condition unusual for December at these altitudes. Below an altitude of 8,000 feet there was apparently a marked recession in the extent of snow cover during the period just preceding the storm.

For the storm period, from December 9 to 12 , all the precipitation was reported as rain or as snow at certain localities shown in table 3 .

From the foregoing records it is indicated that, up to an altitude of about 7,500 feet in the south half of the Central Valley, little snow fell on December 10 and 11 during the greater part of the storm precipitation, but that in general above an altitude of 5,000 feet snow was associated with the rain on December 12, the last day of the storm. As to conditions at altitudes above 7,500 feet, the following observations have been furnished by W. A. Lang, chief hydrographer of the Southern CaIifornia Edison Co., Ltd., based on observations by an employee of that company:

December 9,10 , and 11, raining up to altitude of 8,500 feet, with storm ending on December 12, with $5 \frac{1}{2}$ inches of very wet snow at Florence Lake. General observations on December 18 in the vicinity of Kaiser Pass, altitude, 9,300 feet, indicate that 100 percent rainfall prevailed up to 8,500 feet during the storm period. From 8,500 to 9,000 feet, rain and snow combined, with 100 percent snow at altitudes of 9,000 feet and above. December 19,19 inches snow on ground at Kaiser Pass and 11 inches of snow on grouna at Badger Flats $(8,300$ feet). Road from Huntington Lake to Kaiser Pass badly washed out but passable to elevation 8,500 feet where it was closed by washouts. 
Mr. W. E. Bonnett, meteorologist, United States Weather Bureau, Fresno, concludes in the absence of definite observations that:

At some time near the middle of the storm period, it is highly probable that precipitation was rain to and even above the 9,000-foot level, although the storm began and ended with snow at those altitudes. Aside from the initial temperatures of the air mass, the condensation of the enormous quantities of moisture released additional heat which undoubtedly was effective in keeping temperatures above the freezing point to an unknown altitude above 9,000 feet about the time of maximum precipitation at the known levels. (Letter dated Sept. 19, 1938.)

Sierra Nevada slopes tributary to north half of Central Valley

From November to March in most years, in the Sacramento River Basin, precipitation in the form of snow may be expected at altitudes above 3,000 feet. During November 1937 there was apparently no outstanding abnormality with respect to temperatures above an altitude of 3,000 feet, for about as many stations recorded mean daily temperatures of $1^{\circ}$ to $2^{\circ}$ F. below normal as reported temperatures above normal. The monthly precipitation along the western slopes of the northern Sierra Nevada was from 3 to 10 inches above normal.

The records show that in general there was no snow in the north half of the Central Valley below an altitude of about 4,500 feet prior to or during the flood period from December 9 to 13. The records also show there was some snow between 4,500 and 5,500 feet prior to the flood period, but that it had generally disappeared before the heavy rains of December 10 and 11. The forest supervisor reports that in the Upper Pit Fiver Basin there was approximately 3 inches of snow between elevations of 5,000 and 6,000 feet which melted and ran off during the flood period. Above 6,000 feet there was snow on the ground at the beginning of the storm. Below an altitude of about 5,000 feet there was no snow assoclater with the precipitation during this stom. At 7,000 feet a part of the precipitation from December 9 to 12 was snow.

E. H. Fletcher, associate meteorologist, United States Weather Bureau, Sacramento, reports as follows with respect to snc.u depths:

The late November storms deposited about 3 feet of snow over the headwaters of the American River, but at the beginning of the December storm the snow cover above the 6,500-foot level had settled to about 12 inches. During the first day of the heavy rainfall, December 10, the old snow mostly melted, releasins (it is estimated) 2 or 3 inches of additional weter between 6,500 and 7,500 feet over the American River Basin.

The acting superintendent of Lassen Volcanic National Park reports as follows with respect to snow observations at an altitude of about 8,300 feet near Lake Helen at the foot of Lassen Peak.

March 14, 1938--The history of the great snow pack in the park is interesting. The first fall storm, october 1 to 5, put down three feet 
of heavy snow at Lake Helen. Most of this melted, but left some in hollows and between rocks. The storms of November built the snow pack at Lake Helen to about 8 feet. Then the warm rains of December packed it down to about five feet of slush, which subsequently froze into granular ice. The pack built up to about 10 feet again in January, settling to 8 feet by January 26. On January 30 , the big snow storm began.

Sierra Nevada slopes tributary to the Great Basin

Along the western margin of the Great Basin, to the east of the Sacramento and San Joaquin Basins, temperatures during November and the first part of December 1937 were definitely above normal. From Lake Tahoe northward the precipitation was materially above normal whereas to the south it was subnormal, corresponding with the precipitation characteristics in the San Joaquin River Basin. Snow normally accumulates to a considerable extent in this region throughout November. The following records indicate that, although there were several falls of snow during November 1937, there was also considerable depletion of the snow, and that by the end of the month there was appreciable snow cover only at the higher altitudes in the central and southern portions. In nearly all the area above an altitude of about 6,500 feet, snow was associated with the storm of December 9-12, and in general there was an accumulation of snow cover throughout this storm period above an altitude of about 9,000 feet. Below an altitude of 6,500 feet, some precipitation took the form of snow, but melted soon after it fell. A forest ranger reports that, in the vicinity of Truckee, southern slopes were bare prior to the storm, but that there was some snow on the northern slopes which melted and ran off toward the end of the storm period. Although some precipitation fell as rain above an altitude of 9,000 feet, it appears that much fell as snow.

\section{DETERMINATION OF FLOOD DISCHARGES}

\section{General discussion}

In the usual method of determining discharge at a river-measurement station, hydraulic engineers of the Geological Survey make current-meter measurements to establish a rating curve that will show the discharge for any given stage.

Obviously the rating curve can be well defined by measurements for the usual range of stage. Its definition is more difficult for high water stages, and increasingly difficult for flood stages of rare occurrence when conditions for obtaining measurements are most unfavorable. 
Complete definition of the rating curve to the highest peak can be obtained only by an adequate number of timely measurements and a record of channel conditions during the flood. This ideal is difficult to realize. Most California streams have very flashy floods and high momentary peaks. They usually carry large quantities of debris and suspended material, and many of their floods rise and pass almost simultaneously, and many of them take place during the night. The field engineer is further handicapped during flood periods by washed-out or obstructed routes of travel and at times by damage to bridges or cableways from which discharge measurements are made.

When a current-meter measurement of flood flow is lacking, one or more of four different methods is comonly used to determine the maximum discharge. The methods are: (1) extension of rating curves for rivermeasurement stations, (2) computation of flow over dams, (3) computation of flow from slope-area data, (4) computation of flow through contracted openings. The method used depends upon the physical conditions at the location and the availability of necessary information. Whenever practicable, the result obtained by one method is cnecked by another. often the results of two different methods may be combined so as to produce the most probable value.

The methods mentioned are described in standard textbooks and manuals concerning hydraulics and have been discussed in previous reports of the Geological survey

Extension of rating curves for river-measurement stations

When a rating curve is extended beyond the range of discharge measurements, proper consideration of all the factors involved is important. Knowledge of channel characteristics upstream and downstream from the river-measurement station is required. The changing influence of contracted sections downstream and the possibility of backwater from lower tributaries should not be overlooked. The channel conditions most favorable for the accurate extension of a rating curve consist of a pool, or stretch, with comparatively low velocity at the gage, and well-defined rapids, riffles, or stable control section not exceeding a few hundred feet downstream. If, also, the cross section of the channel increases uniformly with stage, then the hydraulic features of the familiar

3/ See Water-Supply Paper 773-E, The New York State flood of July 1935, pp. 251-254, 1936; Water-Supply Paper 798, The floods of March 1936, Part 1, New England Rivers, pp. 70-77, 1937; and Water-Supply Paper 816, Major Texas floods of 1936 , pp. 12-18, 1937 . 
rectangular or trapezoidal weir are roughly duplicated, and the shape of the extension of the rating curve can be determined within reasonable limits.

The cross section of the channel at flood stage, including all overflow and by-pass channels, should be determined by instrumental surveys. It may be advisable to obtain such a cross section at more than one point. If the measuring section is not at the station gage, rating curves for both locations should be extended and the results compared.

When the stream channel at the measuring section is permanent, plotting of both area and velocity curves for the measuring section is always advisable, using gage height as the ordinate. The area curve is developed from fleld observations. The velocity curve is drawn through values of mean velocity, as determined from current-meter measurements, and may be extended to peak stage on the basis of knowledge of channel conditions. A quantitative study of the variation of the slope and channel roughness, as computed from discharge measurements made at a standard cross section, will, for some measuring sections, furnish a dependable basis for the velocity curve extension. The product of the velocity and area at peak gage height gives a check upon peak discharge as determined by other methods. In the final result, the product of area and velocity, as taken from their respective curves for any gage height, must check the discharge indicated by the rating curve for the same gage height.

The construction and study of a curve showing the relation of the product of the cross-sectional area of the channel and the square root of the mean depth $(A \sqrt{d})$, to the corresponding discharge, may be helpful. The resulting curve will generally approach a straight line.

Plotting of both stage and discharge on logarithmic scales may also be useful in making the extension. Before plotting stage, the observed gage height should be adjusted, by the addition or subtraction of a constant, to the piysical conditions of the location. For example, at a gaging station with a stable control of uniform elevation across the channel, the gage height of zero flow should be subtracted from each observed gage reading. Most logarithmic rating curves tend to be very flat curves or straight lines. It is not safe to assume without confirmation that a short portion that may be defined as a straight Iine can be extended as a straight line throughout. A difference in the upper ends of two curves may appear slight on logarithmic scales and yet be surprisingly large in absolute amount. Experience and 
discrimination are essential to the effective use of the logarithmic method of extension.

Very often extreme floods will change the channel conditions at gaging stations. Discharge measurements made after a peak may define a rating curve that is very different from the one previously developed. Both curves must then be extended, and as it is generally assumed that the change occurred during the time of maximum flow, the curves are merged at or near the maximum stage.

Notwithstanding the application of the best available knowledge and experience, the results obtained by extension of the rating curve may be subject to considerable error, particularly if the extension is carried far beyond the range defined by current-meter measurements. Therefore, special efforts are made to obtain high water measurements and to check extensions of rating curves by one or more of the other methods of determining discharge.

It should be recognized that, even though the extreme high water portion of a rating curve may be somewhat uncertain, the effect upon the accuracy of the total measured mun-off for a certain storm may be relatively slight. This will be readily appreciated when it is considered that many flashy streams in California are at or near peak stage for a period of only one to three hours.

\section{Computation of flow over dams}

The computation of flow over dams often affords a reliable means of determining flood discharge. The common method is use of a weir formula, in which the principal factors are length of crest between abutments, head on the crest, and a coefficient (C) which varies with shape of the crest and the head. The basic formula is commoniy expressed as $Q=C L H^{n}$ where $Q$ is the discharge in second-feet; $C$, the coefficient for the dam; L, the effective length of the crest in feet; $H$, the head in feet on the crest, measured far enough upstream from the dam to avoid surface drawdown; and $n$, the exponent of $H$.

The exponent $\mathrm{n}$ is usually assumed as $I .5$ and then coefficient $\mathrm{C}$ w11l generally vary with the head and with different shapes of the crest. When several discharge measurements are avaliable, the rating may be determined for a sufficient range of stage to define both $n$ and $\mathrm{C}$ as constants. When $\mathrm{C}$ is constant, $\mathrm{n}$ will often be somewhat greater than 1.5. The velocity of approach in the channel above a dam has an influence on the discharge over the dam and in effect increases the 
head on the crest. The cross-sectional area just upstream from the dam should therefore be determined so that the velocity of approach may be computed.

Information as to the shape and profile of the crest and other essential features should be obtained from construction plans of the dam or by measurement of the dam itself. The head over the dam may be ascertained from gage readings made during the flood or from high water marks. Profiles of the high water marks above and below the dam may also be desirable.

Data concerning submergence, over-flow channels or other by-passes, and diversions through flood gates, sluice ways, and water-wheels should be collected. Discharge over a dam may also be affected by an accumulation of logs or other floating debris on the crest. This is especially likely to occur if the dam crest carries a bridge or other superstmucture, or gates with piers, or if it has equipment for the installation of flashboards.

A large number of dams in California have gates, auxiliary equipment, or superstructures of some kind, so that methods of determination required special adaptation to individual conditions. Wherever discharge over a dam was used, an effort was made to obtain all pertinent facts about the conditions during the flood period.

The exponent $n$ was in general taken as 1.5 and the values for the coefficient $\mathrm{C}$ were selected from data summarized in Water-Supply Paper 200 or from those contained in recent handbooks. For some dams tre coefficients were determined by Creager's method 4 for ogee sections, for which the coefficients depend on the ratio of the heads on the crest to the head for which the crest was designed. The results obtained are believed to be reliable, although many of the determinations were made for heads considerably greater than those for which coefficients are well established.

\section{Computation of flow from slope-area observations}

In the slope-area method, discharge is based upon measurements of the slope along a suitable reach of channel and of cross-sectional areas at representative points in the reach. The basic formula $V=C \sqrt{R S}$ is that of Chezy for the mean velocity of a stream, in which $\mathrm{R}$ is the hydraulic radius, $S$ the slope (energy gradient), and $C$ a coefficient whose value 
depends upon the roughness of the channel and the hydraulic radius. This coefficient may be determined by one of several well-known formulas. Manning's formula was used in computations for this report. In its simplified form the Chezy-Manning formula becomes $V=\frac{1.486}{n} \mathrm{R}^{2 / 3} \mathrm{~s}^{1 / 2}$. The coefficient $n$ is intended to express the degree of roughness of the channel. However, it conteins other elements that absorb the energy of flowing water. Among these elements are adverse bottom slope, and also irregularities of alinement in banks and stream bed and other physical factors thet cause cross currents, eddies, and turbulence.

The values of $\mathrm{n}$ chosen and used in this report were based upon ava1lable published data and the experience of engineers of the Geological Survey in preparing earlier flood reports, such as the series on the floods of March 1936 in the eastern part of the United States.

Many of the data from which the formulas and coefficients were derived were based on observation in stream channels with gentle slopes, little turbidity, and uniform beds and cross sections that were free from bends or other characteristics that would tend to produce irregular and turbulent flow. The applicability of formulas and coefficients thus derived, to streams of steep slope, great turbulence, high silt load, and perhaps a large volume of coarser material moving as a bed load, is somewhat doubtful. Unfortunately the flashy streams, which are very difficult to reach and measure by current meter at high stages, often have these unfavorable characteristics. Therefore, the slope-area method was used for such streams only in conjunction with some other method or, at a very few locations, because no other method was avallable.

Surveys to obtain slopes and areas were necessarily made after the flood had passed. The most favorable reach available was selected and the high water line was staked out on both banks, from observation of flood marks left by the stream, or as marked by reliable observers. Two or more cross sections were obtalned for all reaches. After the field notes were plotted, an allowance, based on field observation, was made for surge and splash of waves on the banks, and slope lines and cross sections were appropriately adjusted thereto. If the cross sections were not reasonably uniform and symmetrical, or if there was a noticable difference in the character of the two banks, the channel was divided into more than one section, each with its suitable value of $n$. By selecting a reach with nearly uniform area throughout, it was not necessary to compute the velocity head or to correct the surface slope 
to sliow the energy grade line. For the few locations where 1t was necessary to consider these factors the correction was very small.

As an example of the application of the slope-area method, the basic data used In the determination of discharge of the Little Truckee RIver near Boca, Cal1f., are shown in figure 29.

\section{Computation of flow through contracted openings}

Peak discharge may sometimes be computed from data obtalned where a stream passes through a contracted opening, such as the space between bridge abutments. There is an increase in velocity at the contraction, resulting from conversion of potential to kinetic energy. The velocity is determined from the increase in velocity head in entering the contractIon with appropriate allowance for the Influence of friction and velocity of approach. The velocity of approach is computed from the cross-sectional area of approach channel by using a kind of successive approximations unt11 the contracted-opening formula is satisfied. The determination, from flood marks, of the surface proflle through the contraction is generally subject to considerable error and in some cases is Impracticable. An accurate estimation of the friction loss, particularly when 1t is large, Is Iikewise subject to considerable error. In northern California, opportunities to use this method in a satisfactory way are limited.

only a few sultable contracted-opening sections were avallable for determining the discharge for inclusion in this report, and they were used only to verify the results obtalned by other methods. The following formula was applied:

$$
Q=k A \sqrt{2 g\left(H+\frac{V^{2}}{2 g}-h_{f}\right)}
$$

Where $Q=$ discharge in second-feet

$k=$ coefficient of contraction

$A=$ area, in square feet, of most contracted section

$H=$ surface drop, in feet, at entrance to the contracted section

$V=$ velocity of approach, in feet per second

$h_{f}=$ head loss, in feet, due to friction. 


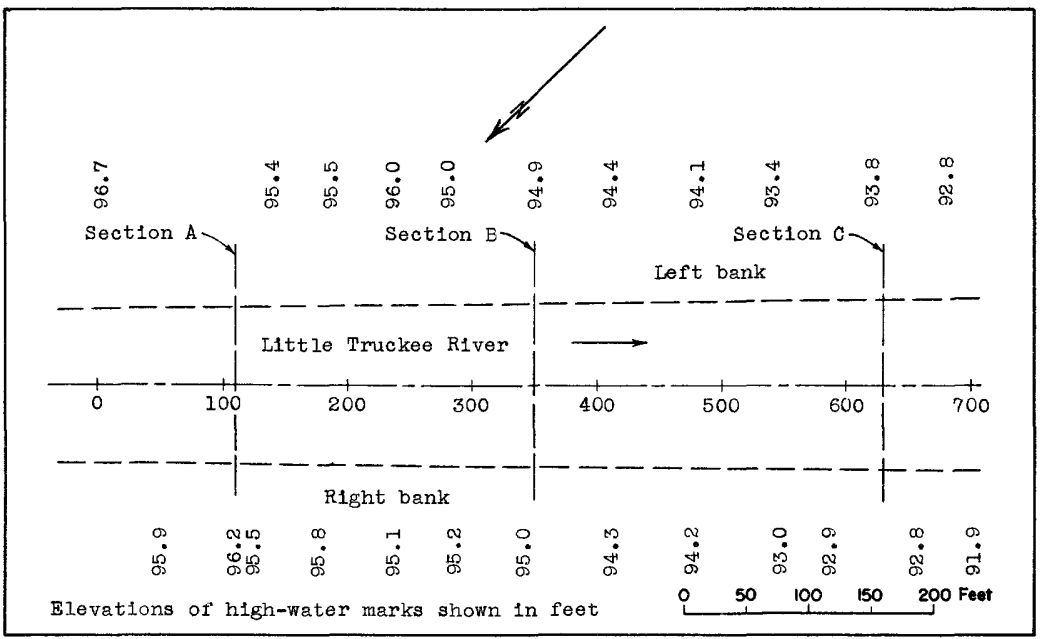

Sketch map

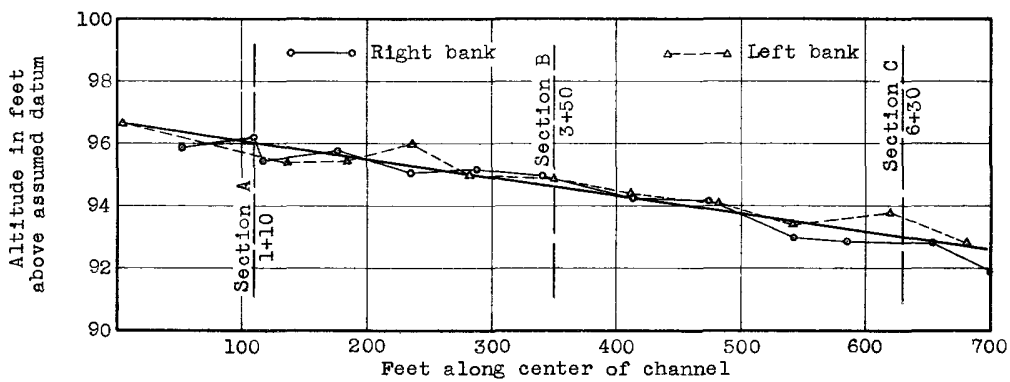

Proflle of high-water marks

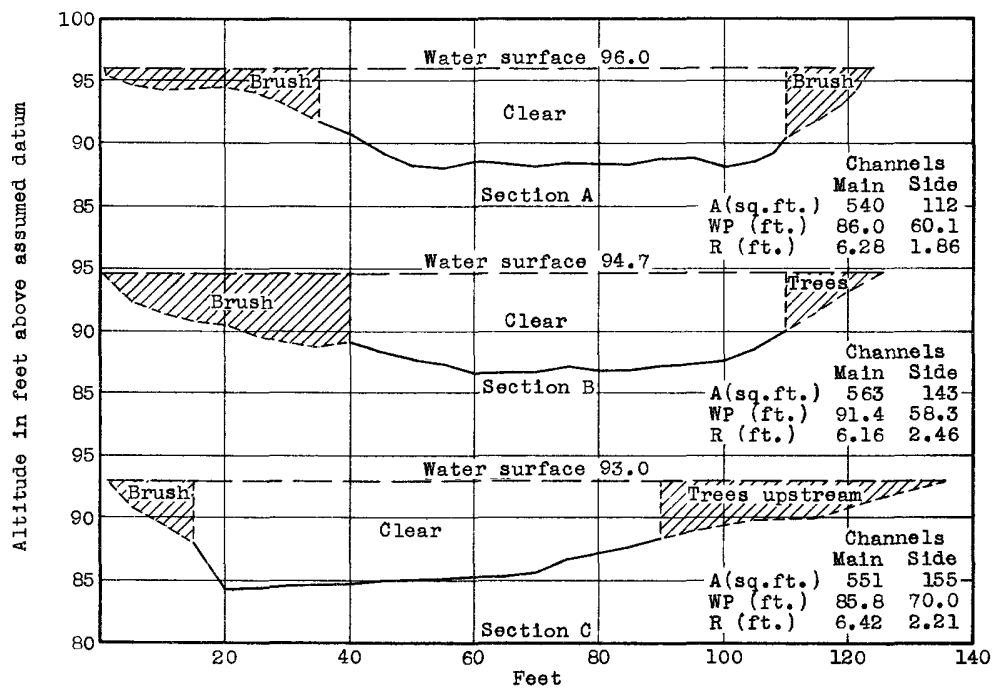

Sections 
One of the principal purposes of this report is to make available Information about the stages and discharges of streams during the flood of December 1937 in more detail than appears in the annual water-supply papers of the Geological Survey. Basic information is furnished for use in the study of the flood crests, the influence of crests from various tributaries, and the progress of flood peaks throughout a river system. This information is valuable for comparative studies of the characteristics of floods and for analysis that may lead to reliable forecasting of flood stages. The data are useful in planning flood protection and control works by reservoirs, levees, and channel improvements. The records should also be helpful in planning future bridge and highway construction as well as in the design and layout of hydraulic structures, other improvements, and urban development which may have a relation to stream channels or their flood plains.

Records published in this report are for streams on which floods occurred in December 1937, or that are situated adjacent to the margins of the storm-area and therefore serve to define the extent of the floods.

\section{Explanation of data}

The basic data systematically collected at river-measurement stations consist of stage, measurement of discharge, and general information useful in determining the daily flow. The records of stage are obtained by water-stage recorders, which give a continuous record of the fluctuations, or for a very few river-measurement stations, by direct readings on nonrecording gages. Peak stages during flood periods are obtained from flood marks at the station if they have not been previously observed or recorded. Measurements of discharge are generally made with a current meter according to methods outlined in standard text books on the measurement of river discharge. Typical river-measurement stations, equipped with water-stage recorder and measuring cable and car, are shown in plate 12, $A$, on page 12. At a few stations discharge is determined from venturi meters, calibrated gates, or output from hydroelectric plants.

In general the data presented for each river-measurement station in this report comprise a description of the station, a table of dally and monthly discharge throughout the 3-month period, November 1937 to January 1938, and a second table of stage and discharge at bi-hourly intervals from December 8 to 25, 1937. The presentation of the data has followed a uniform plan as far as practicable. 
The description of the station contains in the first paragraph information about the location of the gage and its datum in reference to mean sea level, when known. A second paragraph gives the size of the drainage area upstream from the station. The next paragraph, about gage-height record, describes the method of determining the stage during the flood. In a fourth paragraph, on stage-discharge relation, there is information about the range to which the rating curve is defined by current-meter measurements and the method used to extend the rating curve to the peak of the flood. This is followed by a paragraph on maximum stages which lists the discharge, time, date, and gage height of the peak flow during the December flood. Similar data are included for the largest flood that occurred auring the period of continuous record preceding December 1937, and also at some stations for floods antedating such period of record. The year indicating the beginning of the continuous record is the first year for which flood records are available. Therefore the initial year shown may be one year later than that indicated in the annual water-supply papers of the Geological Survey. For a few stations, where the December flood was followed by a flood peak in February or March 1938 which was higher than any previously recorded, the flood peak of 1938 has also been listed. The sixth and final paragraph, under the heading of "Remarks", furnishes data about storage or diversions upstream from the station, and other miscellaneous information.

The table following each description shows mean daily discharge in second-feet, mean monthly discharge in second-feet, and monthly run-off in acre-feet for the period November 1, 1937, to January 31, 1938. Th1s covers the flood period and sufficient time before and after it to show the relation of flood discharges to the prevalent discharges, and to give a general perspective of the December flood. For stations at which the records are materially affected by storage or diversions, the natural monthly mun-off in acre-feet has been computed and added to the table when the information necessary for the correction was avallable.

The table of gage height and discharge at indicated times was designed to present the details of the rise and recession of the flood. It begins on December 8 , one to three days before the start of the flood rise, and continues through December 25, when the flood had largely passed out of the river system into either the ocean or the lower broad reaches of the central Valley. This table is accompanied by footnotes of supplemental records of stage and discharge when needed to define accurately subsidiary peaks or valleys in the hydrograph that would 
otherwise not be disclosed in the bi-hourly listing. The table is designed to give sufficlent data so that complete stage or discharge graphs may be plotted. Some streams showed steady or slowly changing stages before and after the flood period and so it was not considered necessary to list in those records the b1-hourly data for the whole 18-day period. In reducing the number of items shown for each day, no data were omitted that would appreciably affect the accuracy when reproducing a graph of stage or discharge. Figure 30 gives two examples of stage and discharge plotted from typical computations of data; figure 31 shows graphs of mean dally discharge at selected river-measurement stations for the 3-month period; and alscharge graphs for various streams are shown in figures 32 to 41 .

The stages at indicated times were obtained from the water-stage recorders so far as such records were avallable. At a very few stations the records consist of a small number of gage readings each day, and at several others the water-stage recorders falled to operate or were submerged by high water. At the latter stations the peak stages were determined from flood marks. Where the avallable information was sufficient, stage graphs were completed by comparison with other recorais on the same stream or on nearby streams. Stages at indicated times were then taken from the constructed graphs. At a small number of stations the data were so meager that no attempt was made to complete the flood record.

The discharges at indicated times were obtained from the gage helghts by application of the rating table. At some river-measurement stations the flood caused a change in stage-discharge relation and two rating tables were used, one up to the peak and the other afterwards. It is assumed that generally the two rating curves and tables merge at the peak. For some stations, such as those with shifting sand channels, the stage-discharge relation changed continuously and a graduated correction was applied to the gage helghts before computing the discharges. For these stations it is explained in the paragraph on stage-discharge relation that the shifting control method was used. Where the normal stage-discharge relation was affected by backwater from tributarles or other cause, proper correction was made in the computation of discharge.

For six stations in Owens River Basin the bi-hourly data, as furm1shed by the city of Los Angeles, show mean gage helght and discharge for the two-hour period immediately preceding the hour l1sted, instead 

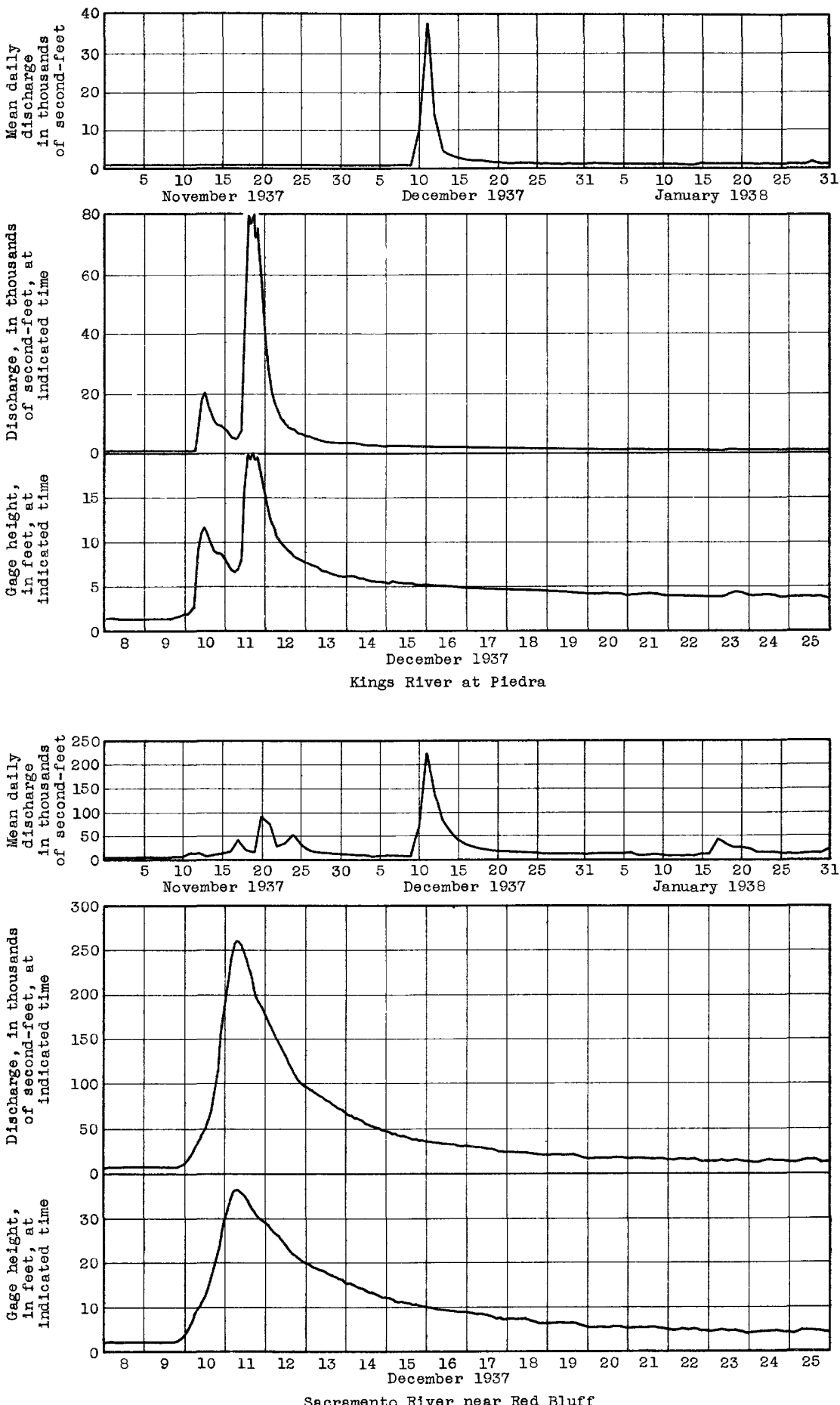

Figure 30.--Typical graphs of stage and discharge at river-measurement stations, plotted from records in this report. 


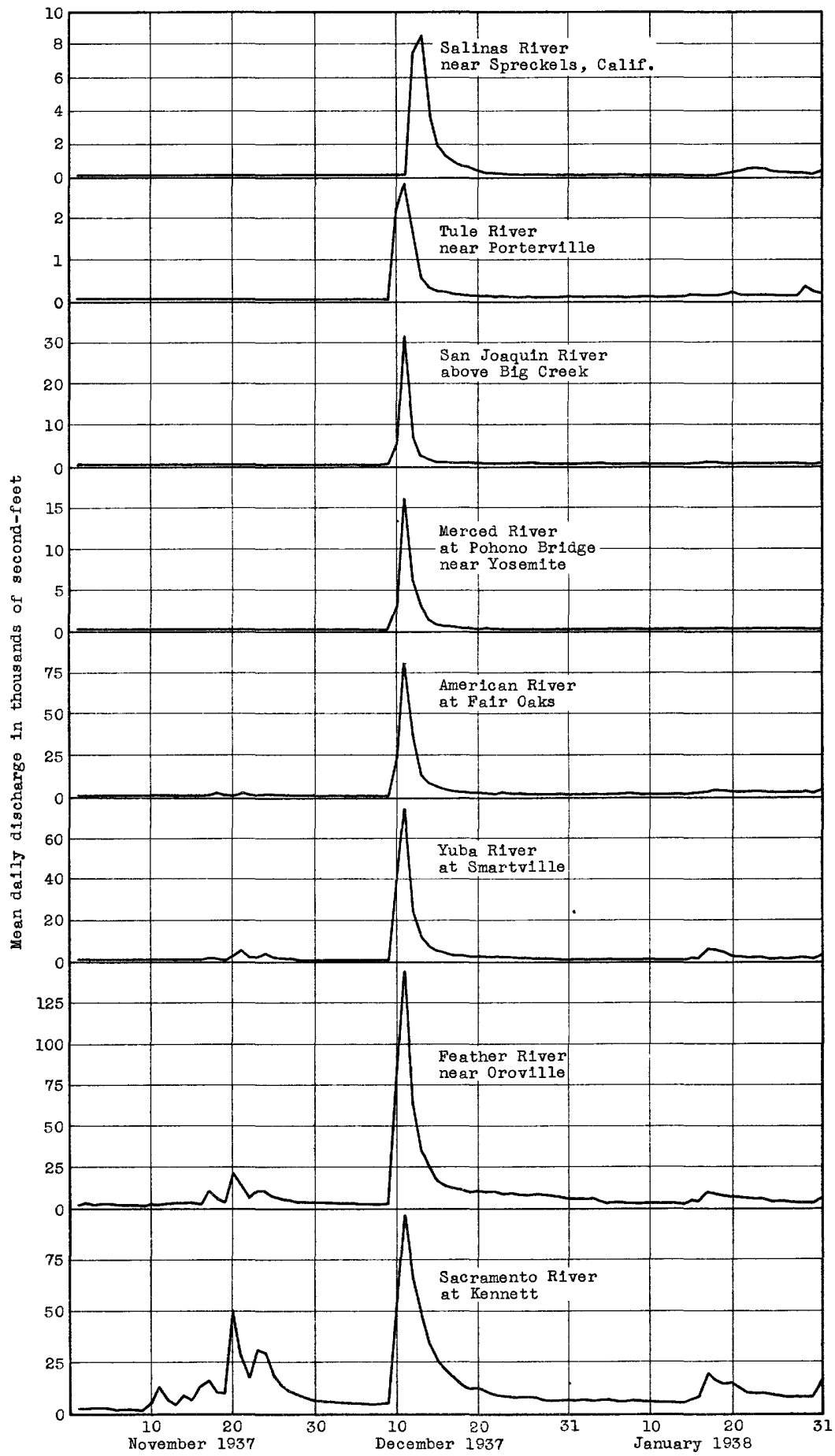

Figure 31.--Grapha of mean dally discharge at various river-measurement otations in northern California for the perfod November 1, 1937, to Jamary 31, 1938. 


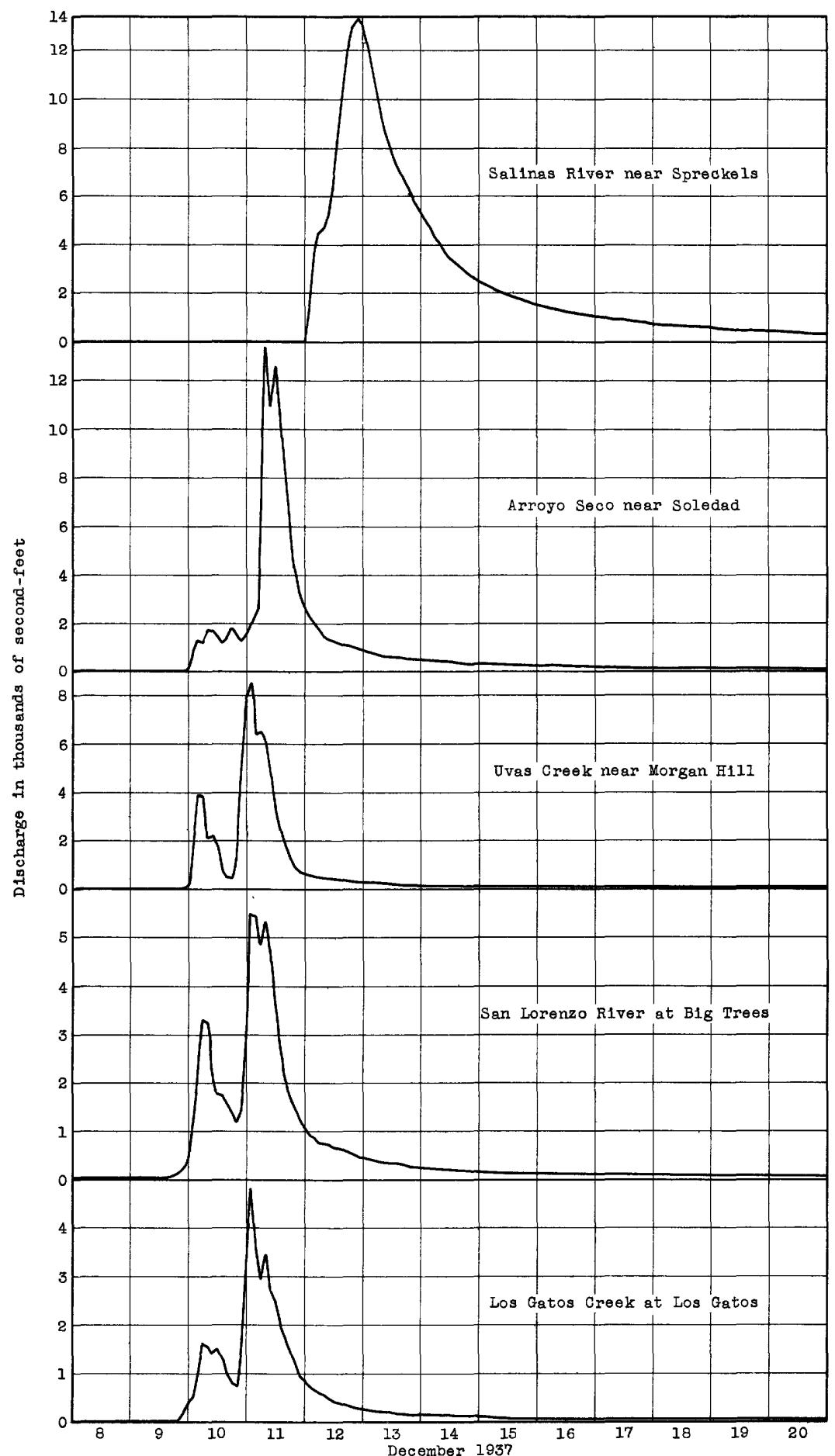

F1gure 32.--Graphs of discharge at varlous river-measurement stations in the Salinas River Basin and on nearby coastal and San Francisco Bay streams, December 8-20, 1937 . 


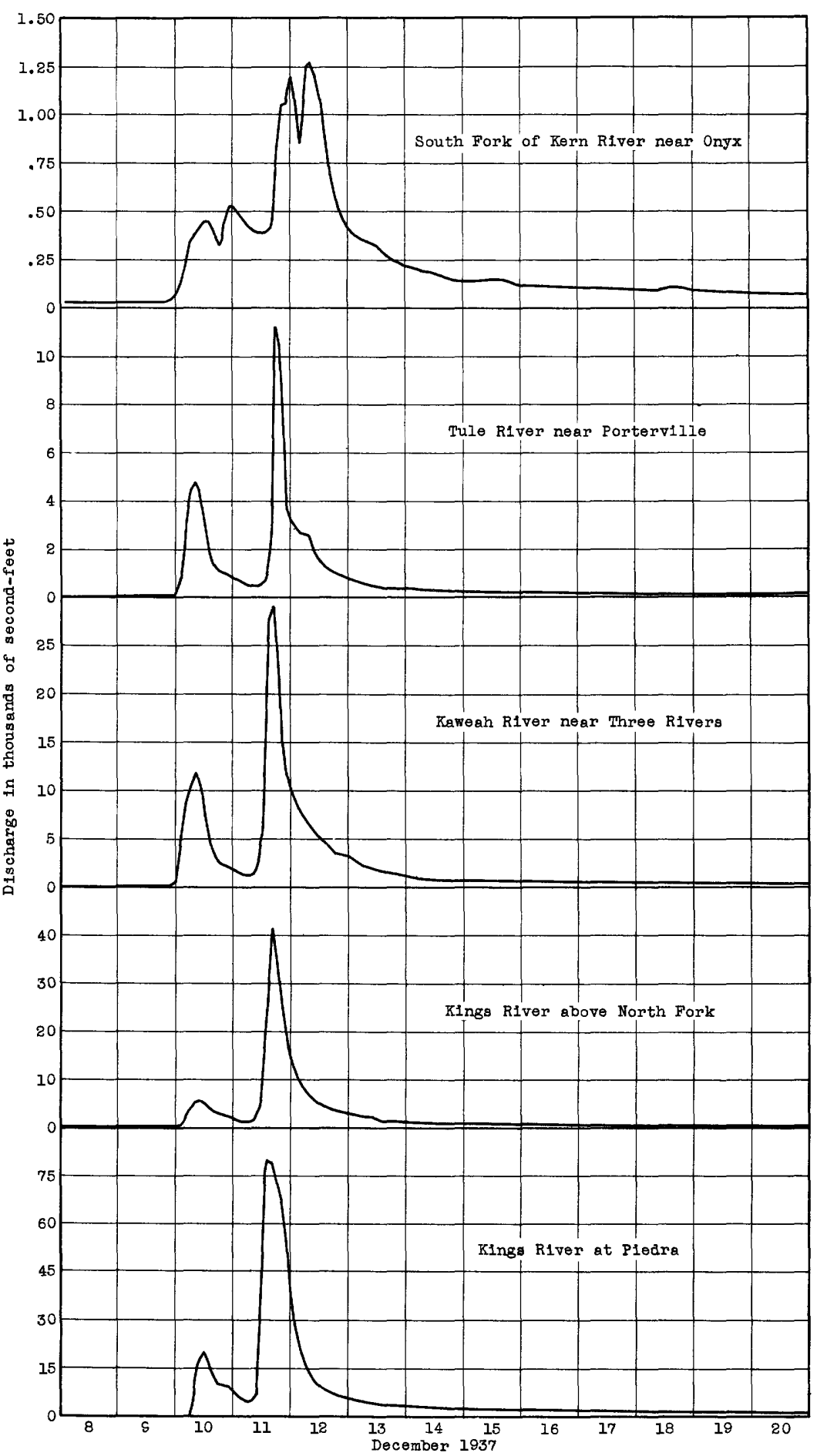

Figure 33.--Grapha of disoharge at various river-measurement atations in Buena Vista and Tulare Lake Basins, December 8-20, 1937. 


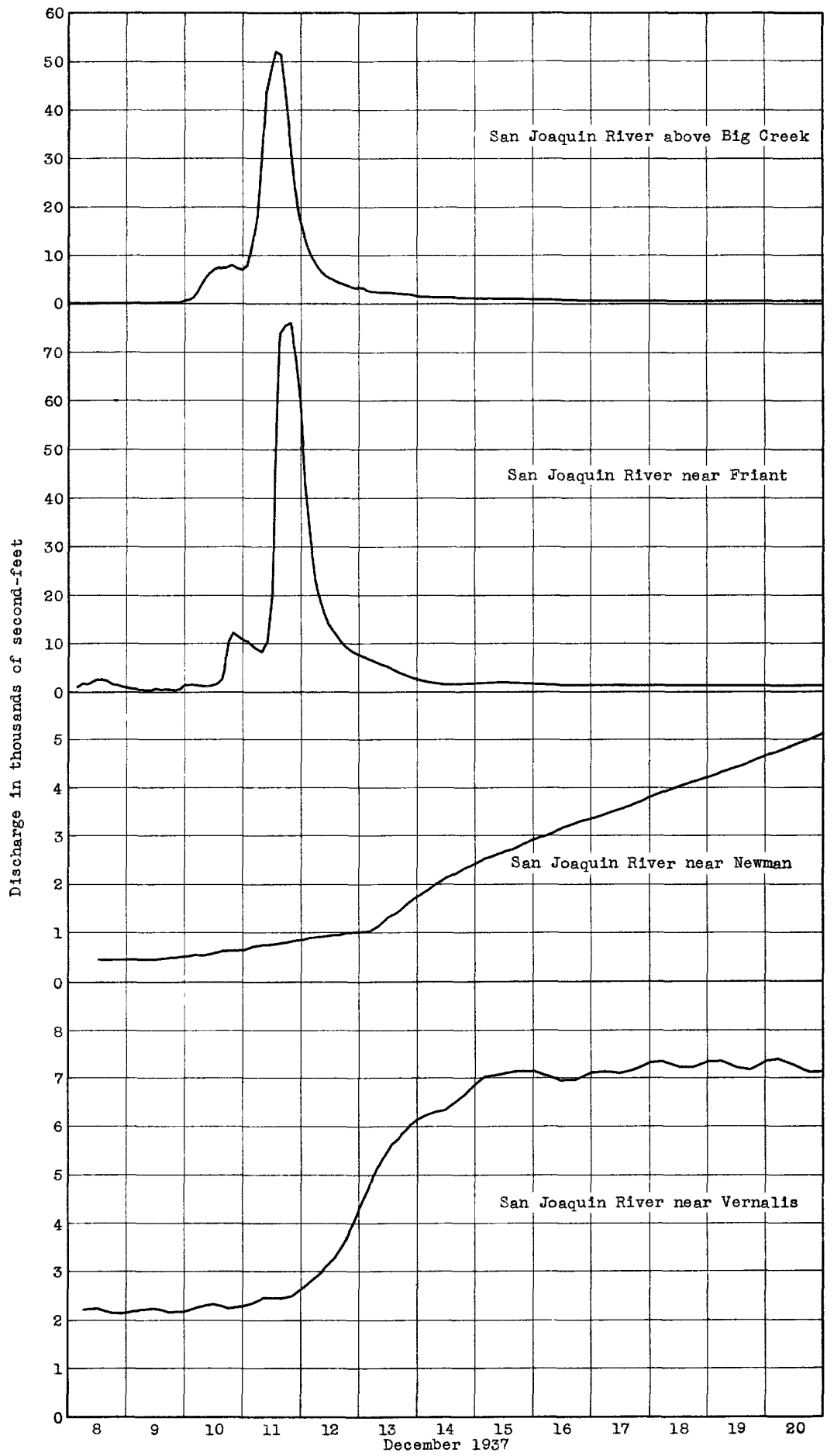

Figure 34.--Graphs of discharge at various river-measurement stations on the San Joaquin River, December 8-20, 1937. 


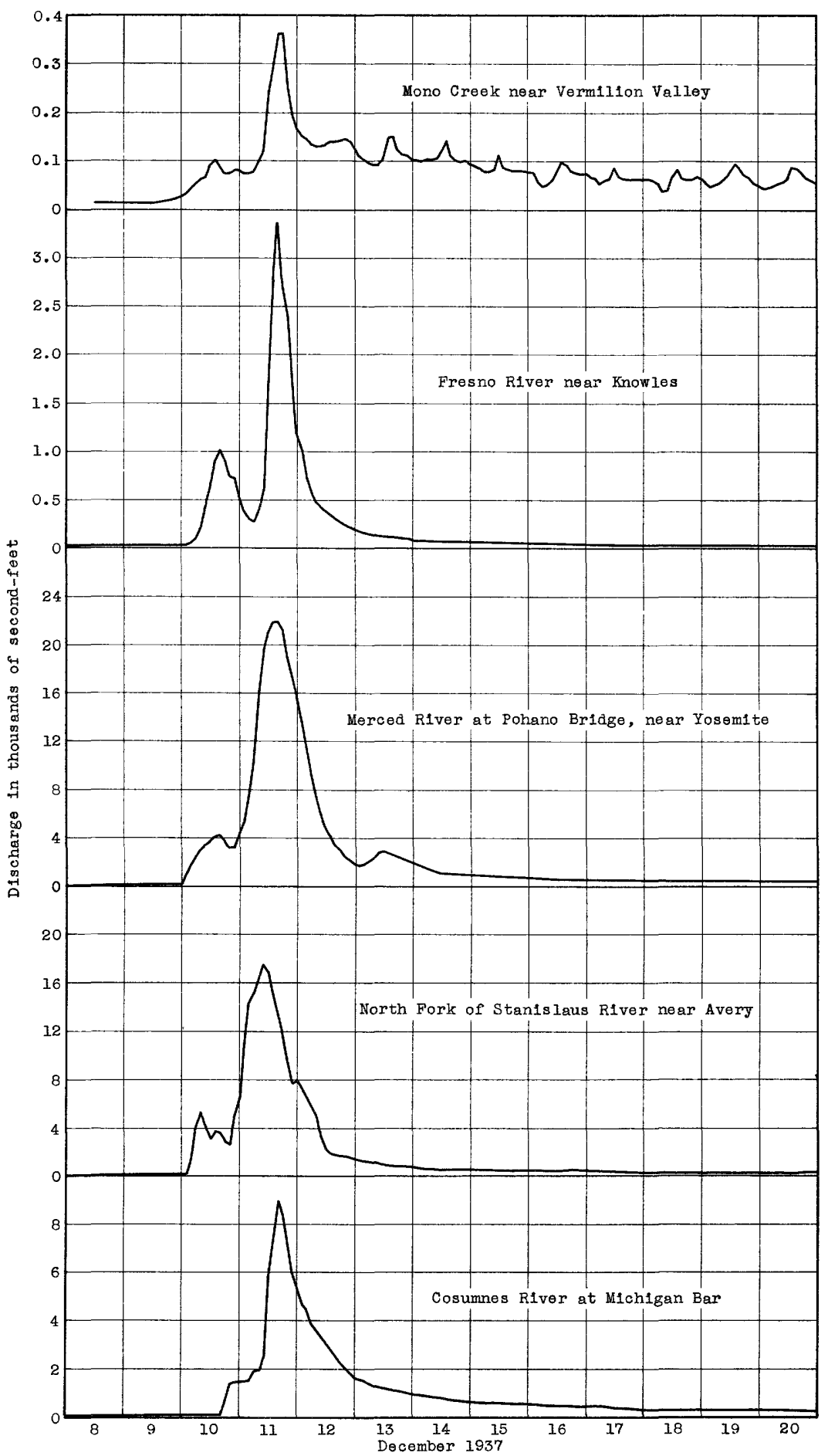

Figure 35.--Graphs of discharge at various river-measurement stations on tributaries to the San Joaquin River, December 8-20, 1937. 


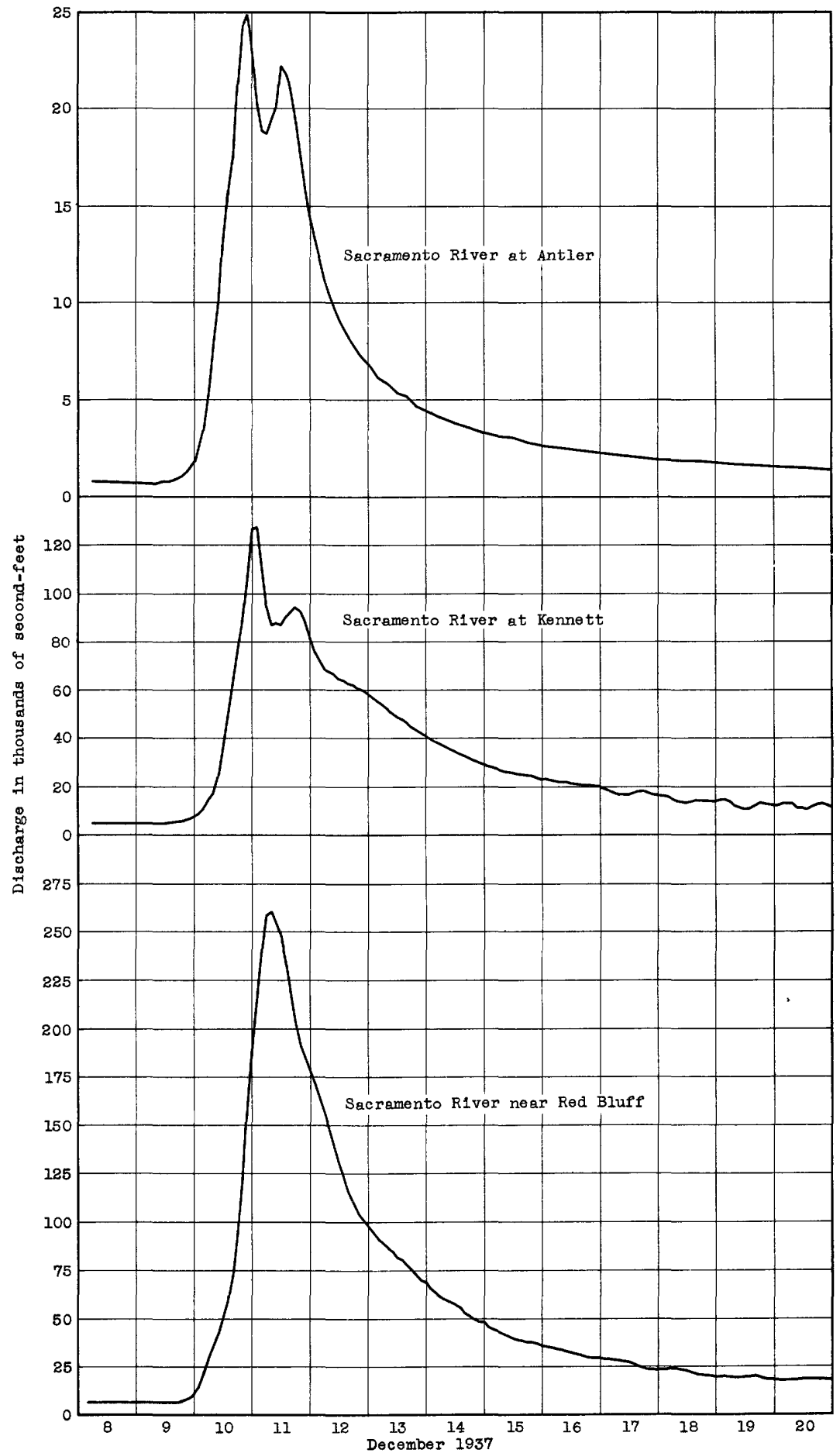

Figure 36.--Graphs of discharge at various river-measurement stations on the Sacramento River, December 8-20, 1937. 


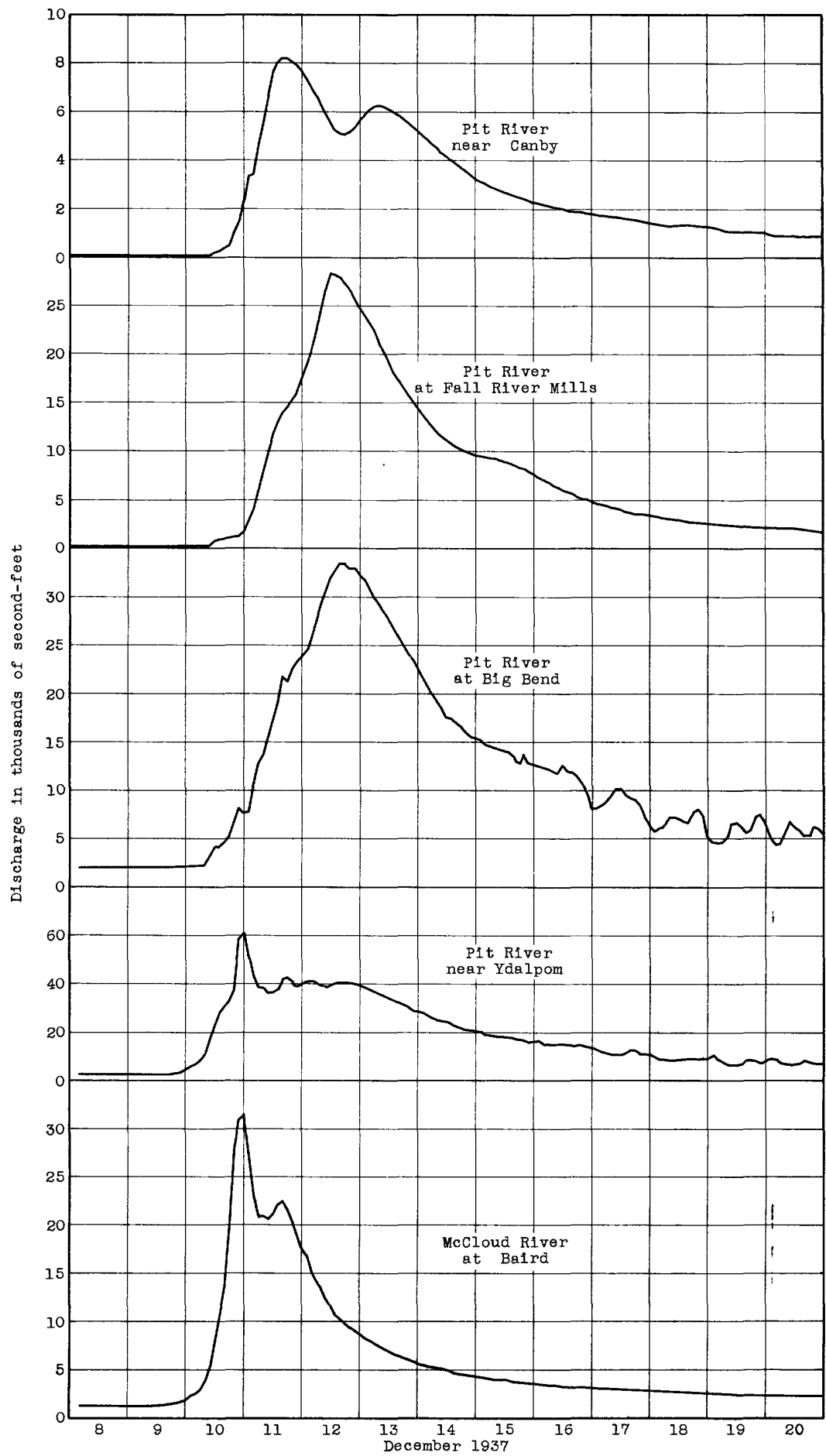

Figure 37.--Graphs of discharge at varlous river-measurement stations In the P1t R1ver Basin, December 8-20, 1937. 


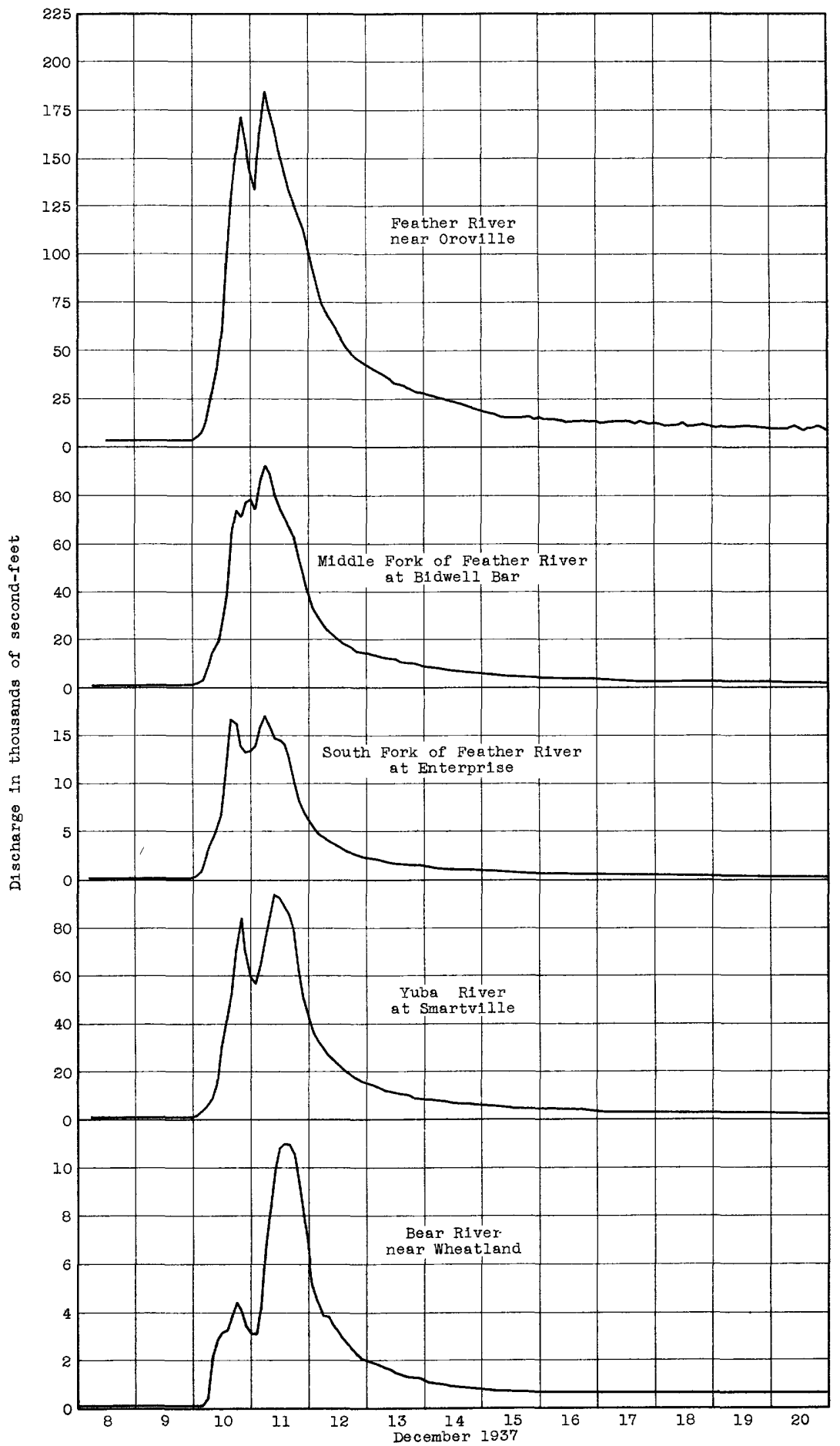

Figure 38.--Graphs of discharge at varlous river-measurement stations in the Feather River Basin, December 8-20, 1937. 


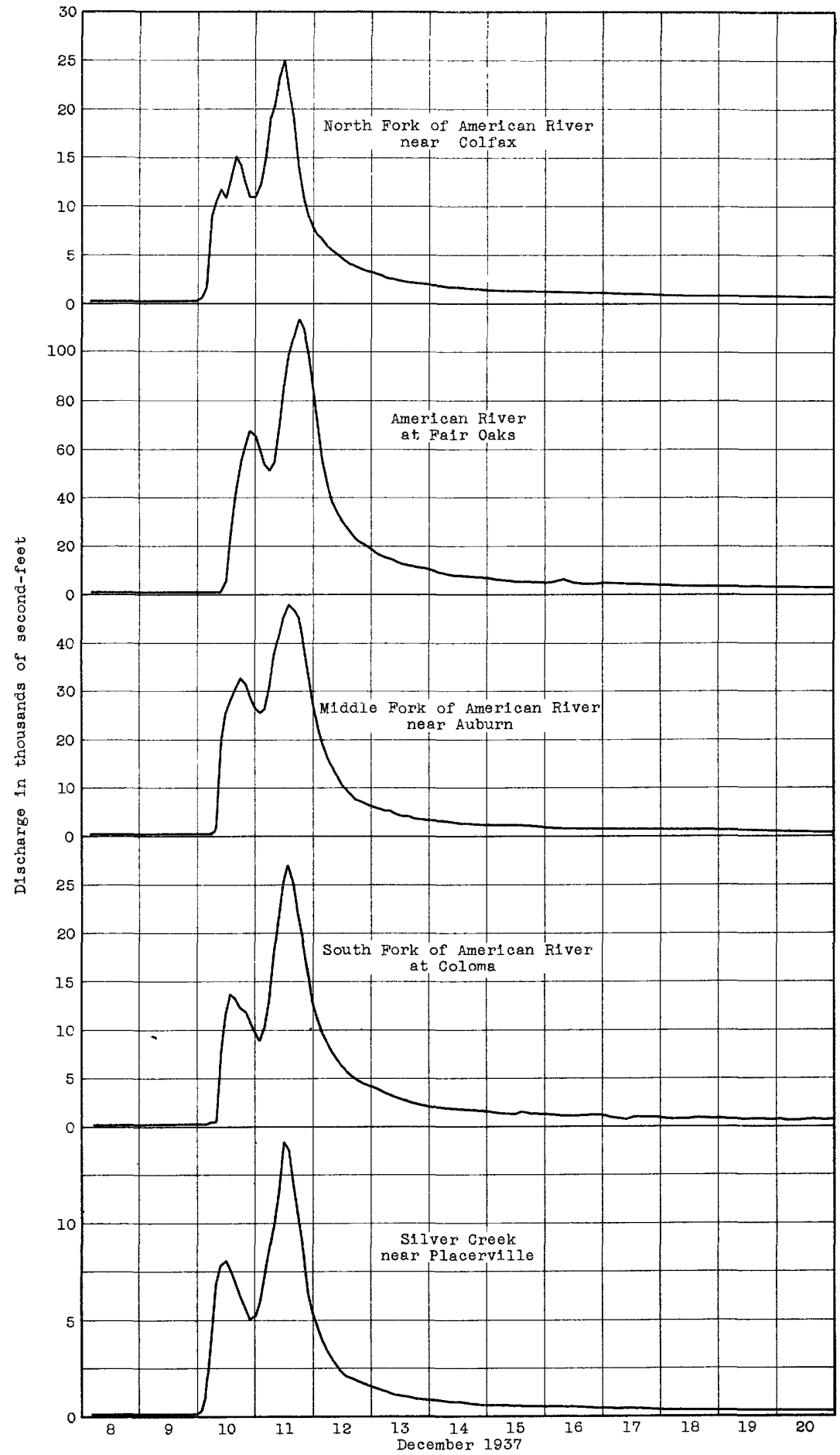

Figure 39.--Graphs of discharge at various river-measurement stations in the American River Basin, December 8-20, 1937. 


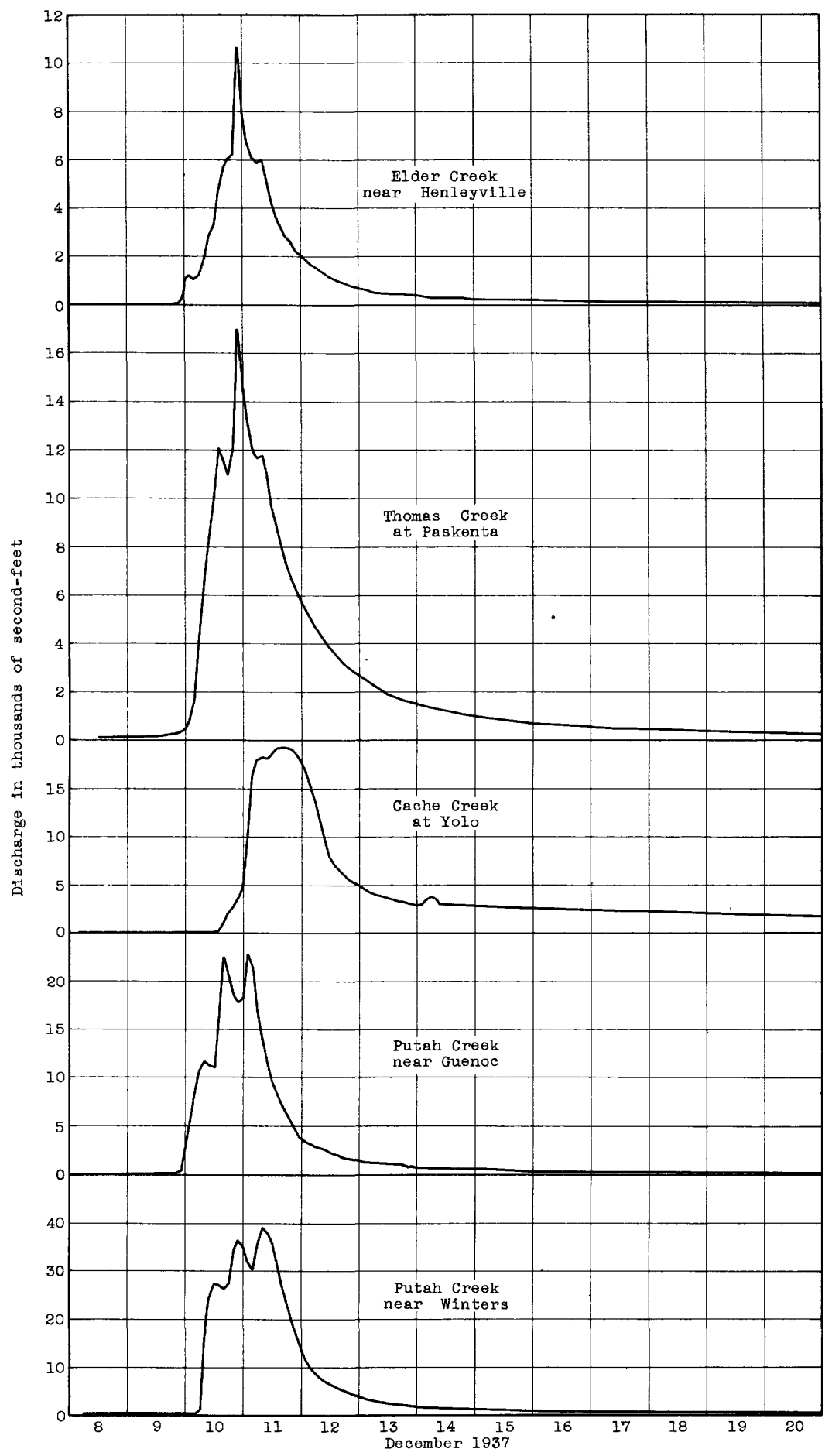

Figure 40.--Graphs of discharge at varlous river-measurement stations on tributaries to the Secramento River from the west, December 8-20, 1937. 


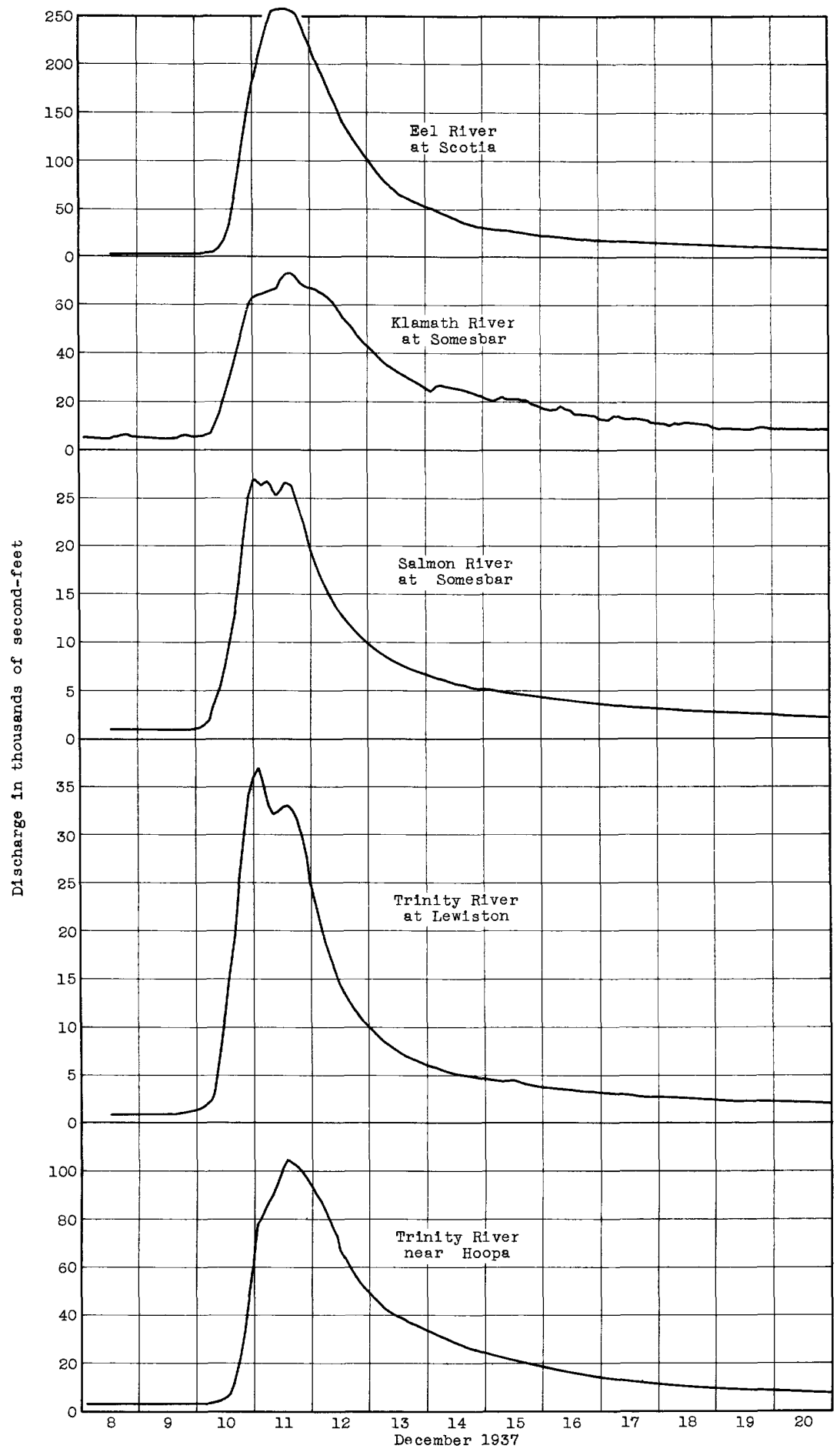

Figure 41.--Graphs of discharge at various river-measurement stations in the EeI and Klamath River Basins, December 8-20, 1937. 
of gage helght and discharge at the hour as for other records in the report.

The standardized forms for descriptions and tables have been modifled to meet the various types of records for storage reservoirs, and for special combinations of records for reservolrs, diversions, and river records.

Where a water-stage recorder record was avallable for reservolrs, the stage at midnight of any day was taken directiy from the original graph. But for many reservoirs a staff gage was read at a regular hour each day; for most of these a stage graph was constructed on the basis of the regular readings, peak stage, and any additional gage readings that may have been made during the flood period. From this constructed graph the dally midnight stage was obtained and used in computing contents for the day. As dally discharge records are based on the 24-hour perlod from midnight to midnight, reservoir records that are used for correction of river discharge records to ascertain natural flow should be based on contents at midnight.

The records are arranged in accordance with the regular plan used by the Geological Survey in its water-supply papers. The only exception is that, in the annual papers, records for the Great Basin in California are published in part 10 and those for the remainder of California in part 11 whereas in this special paper the Great Basin records are included, Immediately following those for the North Pacific basins.

The maximum discharges at river-measurement stations for the December flood, the highest flood in previous years, and other related information is summarized in table 4 (pp. 288-298). The momentary peak discharges for December 1937 as determined for a number of miscellaneous streams and locations have also been included in table 4.

One of the items included in table 4 is alscharge for the 24 consecutive hours of highest discharge. This item is listed under the heading of "maximum 24-hour average", and is to be distinguished from the maximum mean da1ly discharge, which is the largest mean discharge for a calendar day. The largest discharge for a calendar day may range from 50 percent to 100 percent of the maximum 24-hour discharge, and always includes the element of chance in the timing of the momentary peak. For any given basin the momentary peak may be influenced by such variable factors as soll molsture, temperature, frost, snow on the ground, vegetation, direction of storm movement, intensity and distribution of rainfall, and channel storage. The variable influence of many of these 
factors will be reduced or offset when maximum 24-hour discharge is used, and for some studies it therefore has definite advantages over the momentary peak discharge and maximum calendar day discharge. There are unexplored possibilities in the study of the maximum 24-hour discharge in comparison with the momentary peak and with the totel and average run-off for a storm. These relations are discussed in the section on "Run-off characteristics".

Table 4 also gives maximum 24-hour discharge per square mile. This term may possibly be more valuable for analysis of flood concentration than any other expression of discharge. It is especially useful in comparing the effects of a given storm upon adjacent basins.

Reference should be made to the water-supply papers of the Geological Survey for other records of flow of the streams discussed in this report. The records in this report are based on all information available at the time of compilation. Changes in river channels due to floods may have affected the stage-discharge relation for some rivermeasurement stations at medium and low discharges, without such changes being fully defined at the time these records were complled. Any revisions found necessary will be published in subsequent water-supply papers.

\section{Miscellaneous flood stages on the San Joaquin River}

Records of stage have been maintained by the calffornia state Division of Water Resources in cooperation with the United States Bureau of Reclamation, and by Miller \& Lux, Inc., at several locations on the San Joaquin River in addition to those for which discharge has been computed. The crest stages at these stations are summarized in table 10 in the section entitled "Flood crests".

The total flow of the San Joaquin River is in one channel and can be measured at the river-measurement stations near Friant and at Skaggs Bridge. Downstream from Skaggs Bridge the river, at flood stages, spreads over a wide area of overflow lands and sloughs, and it is not practicable to measure the total flow of the river again until the river-measurement station near Newman, below the mouth of the Merced River, is reached. Between Skaggs Brlage and Newman, records of stage only are avallable at several places. In order to show the relative stages at various places along the river, figure 42 has been prepared. It shows graphically the flattening effect of natural channel storage as the river spreads out downstream from Skaggs Bridge. 


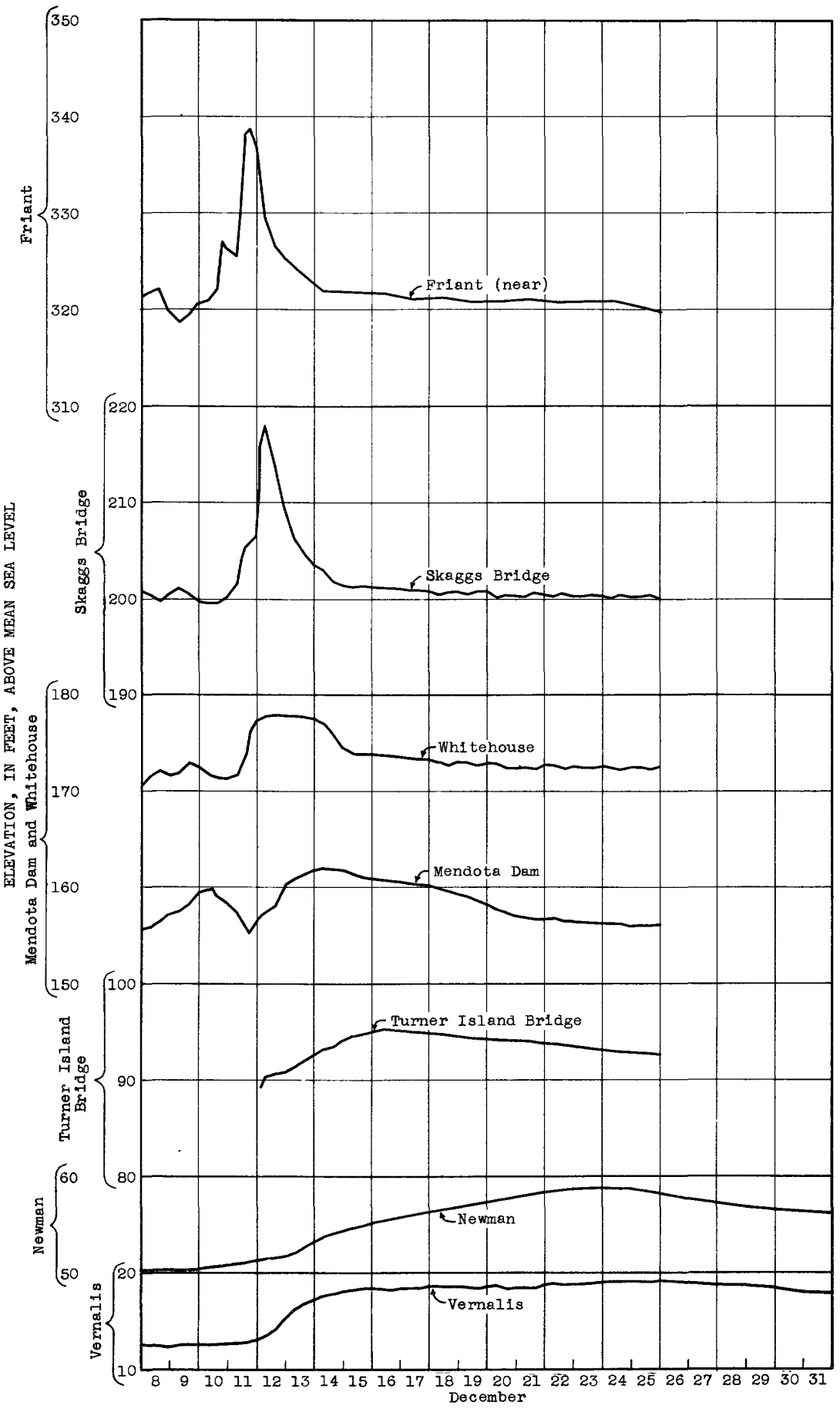


Salinas River near Santa Margarita, Calif.

Location.- Lat. $35^{\circ} 24^{\prime} 20^{\prime \prime}$, long. $120^{\circ} 34^{\prime} 05^{\prime \prime}$, in $\mathrm{N} \frac{1}{2}$ sec. 15, T. 29 S., R. 13 E., 250 feet below Calf Canyon highway briage, 250 feet above Morano Creek, and $2 \frac{1}{2}$ m1les northeast of Santa Margarita, San Luis obispo County. Alt1tude, about 960 feet above mean sea level.

Drainage area.- 150 square miles.

Gage-height record. - Water-stage recorder graph.

Stage-discharge relation.- Defined by current-meter measurements below 1,000 secondfeet; extended to peak stage on basis of shape of former rating curve defined to 3,000 second-feet. Shifting-control method used Nov. 1 to Dec. 11. Rating curve changed at peak stage.

Maxima.- December 1937: D1scharge, 3,550 second-feet 9:30 p.m. Dec. Il (gage height, 10.24 feet).

1932-November 1937: Discharge, 7,260 second-feet Feb. 6, 1937 (gage height, 14.35 feet), from rating curve extended above 3,000 second-feet on bas is of velocityarea study.

January-September 1938: D1scharge, about 11,000 second-feet 10 a.m. Peb. Il

(gage helght, 17.0 feet), from rating curve extended above 1,900 second-feet on basis of velocity-area study.

Remarks.- Flood mun-off not affected by artificial storage or diversions.

Yean dally discharge, in second-feet, November 1937 to January 1938

\begin{tabular}{|c|c|c|c|c|c|c|c|c|c|c|c|}
\hline Day & Nov. & Dec. & Jan. & Day & Nov. & Dec. & Jan. & Day & Nov. & Dec. & Jan. \\
\hline $\begin{array}{r}1 \\
2 \\
3 \\
4 \\
5 \\
6 \\
7 \\
8 \\
9 \\
10\end{array}$ & $\begin{array}{l}0 \\
.1 \\
.1 \\
.1 \\
.1 \\
.2 \\
.2 \\
.2 \\
.2 \\
.2\end{array}$ & $\begin{array}{l}0.8 \\
1.2 \\
1.2 \\
1.2 \\
1.6 \\
1.6 \\
1.6 \\
2.0 \\
2.4 \\
4.2\end{array}$ & $\begin{array}{l}7 \\
7.5 \\
6.5 \\
6 \\
5.5 \\
5 \\
5 \\
4.9 \\
4.7 \\
4.7\end{array}$ & $\begin{array}{l}11 \\
12 \\
13 \\
14 \\
15 \\
16 \\
17 \\
18 \\
19 \\
20\end{array}$ & $\begin{array}{r}0.5 \\
.8 \\
.3 \\
.5 \\
.5 \\
.5 \\
3.3 \\
2.4 \\
.8 \\
.5\end{array}$ & $\begin{array}{r}1,400 \\
553 \\
62 \\
34 \\
24 \\
19 \\
15 \\
13 \\
12 \\
11\end{array}$ & $\begin{array}{c}4.7 \\
4.4 \\
4.4 \\
4.4 \\
11 \\
9 \\
8 \\
8 \\
10 \\
9.5\end{array}$ & $\begin{array}{l}21 \\
22 \\
23 \\
24 \\
25 \\
26 \\
27 \\
28 \\
29 \\
30 \\
31\end{array}$ & $\begin{array}{r}0.5 \\
.5 \\
.5 \\
.8 \\
.5 \\
.5 \\
.5 \\
.8 \\
.8 \\
.8\end{array}$ & $\begin{array}{l}11 \\
10 \\
10 \\
9 \\
8.5 \\
9 \\
8.5 \\
8 \\
8 \\
7.5 \\
7\end{array}$ & $\begin{array}{c}8 \\
7 \\
6.5 \\
6.5 \\
6.5 \\
6.5 \\
6 \\
8 \\
10 \\
9 \\
12\end{array}$ \\
\hline $\begin{array}{l}\text { Mean } \\
\text { Run- }\end{array}$ & $\begin{array}{l}\text { nthl } \\
\text {, in }\end{array}$ & $\theta-1$ & $\cdots$ & & & & & & $\begin{array}{r}0.59 \\
35\end{array}$ & $\begin{array}{r}72.8 \\
4,480\end{array}$ & $\begin{array}{r}6.97 \\
429\end{array}$ \\
\hline
\end{tabular}

Gage helght, in feet, and discharge, in second-feet, at indicated time, 1937

\begin{tabular}{|c|c|c|c|c|c|c|c|c|c|c|c|c|}
\hline \multirow{2}{*}{$\begin{array}{l}\text { s. } \\
\text { ర్ }\end{array}$} & Feet & Sec.ft. & Feot & Sec.ft. & Feet & Sec.et. & Foet & Sec.ft. & Feet & Sec.et. & Foet & Sec.ft. \\
\hline & \multicolumn{2}{|c|}{ December 8} & \multicolumn{2}{|c|}{ December 9} & \multicolumn{2}{|c|}{ December 10} & \multicolumn{2}{|c|}{ December 11} & \multicolumn{2}{|c|}{ December 12} & \multicolumn{2}{|c|}{ December 13} \\
\hline $\begin{array}{r}2 \\
4 \\
6 \\
8 \\
10 \\
N \\
2 \\
4 \\
6 \\
8 \\
10 \\
\text { M }\end{array}$ & 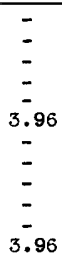 & $\begin{array}{c}- \\
\overline{-} \\
= \\
2.0 \\
\overline{-} \\
\overline{-} \\
- \\
2.0\end{array}$ & $\begin{array}{c}- \\
\overline{3.96} \\
\overline{-} \\
3.97 \\
\overline{-} \\
3.99 \\
\overline{3} \\
\overline{3.99}\end{array}$ & $\begin{array}{l}\bar{z} \\
\overline{2} .0 \\
\bar{z} \\
\overline{2} .4 \\
\bar{z} \\
\overline{3} .3 \\
\overline{3} \\
\overline{3} .3\end{array}$ & $\begin{array}{c}\overline{-} \\
4.02 \\
\overline{-} \\
4.02 \\
\overline{-} \\
4.02 \\
\overline{4} \\
4.00\end{array}$ & $\begin{array}{l}\overline{-} \\
4.6 \\
\overline{4} \\
4.6 \\
\overline{4} \\
4.6 \\
\overline{3.7}\end{array}$ & $\begin{array}{r}4.00 \\
4.00 \\
4.00 \\
4.20 \\
4.50 \\
5.35 \\
8.26 \\
9.35 \\
9.65 \\
9.90 \\
10.20 \\
8.97\end{array}$ & $\begin{array}{r}3.7 \\
3.7 \\
3.7 \\
23 \\
97 \\
407 \\
2,080 \\
2,870 \\
3,110 \\
3,310 \\
3,550 \\
2,480\end{array}$ & $\begin{array}{l}7.70 \\
6.95 \\
6.50 \\
5.97 \\
5.63 \\
5.34 \\
5.11 \\
4.94 \\
4.79 \\
4.67 \\
4.57 \\
4.47\end{array}$ & $\begin{array}{r}1,560 \\
1,070 \\
800 \\
516 \\
376 \\
285 \\
226 \\
188 \\
159 \\
138 \\
121 \\
106\end{array}$ & $\begin{array}{l}4.32 \\
\overline{4.18} \\
- \\
4.09 \\
- \\
4.00 \\
- \\
3.94 \\
- \\
3.89\end{array}$ & $\begin{array}{l}\overline{8} \\
- \\
69 \\
-59 \\
\overline{51} \\
\overline{46} \\
\overline{42}\end{array}$ \\
\hline & \multicolumn{2}{|c|}{ December 14} & \multicolumn{2}{|c|}{ December 15} & \multicolumn{2}{|c|}{ December 16} & \multicolumn{2}{|c|}{ Decomber 17} & \multicolumn{2}{|c|}{ December 18} & \multicolumn{2}{|c|}{ December 19} \\
\hline $\begin{array}{r}2 \\
4 \\
6 \\
8 \\
10 \\
\mathrm{~N} \\
2 \\
4 \\
6 \\
8 \\
10 \\
\text { M }\end{array}$ & $\begin{array}{c}- \\
\bar{z} \\
\overline{-} \\
\overline{-} \\
3.77 \\
\overline{-} \\
\overline{3.72} \\
\overline{-} \\
\overline{3.67}\end{array}$ & $\begin{array}{l}\overline{-} \\
\overline{3} 8 \\
- \\
\overline{3} 4 \\
\overline{-} \\
\overline{3} 0 \\
\overline{-} \\
\overline{27}\end{array}$ & $\begin{array}{c}- \\
\overline{3.63} \\
\vdots \\
3.60 \\
\overline{-} \\
3.58 \\
\overline{3} \\
\overline{3.56}\end{array}$ & $\begin{array}{l}\overline{-} \\
\overline{25} \\
- \\
\overline{23} \\
\overline{-} \\
\overline{22} \\
\overline{-} \\
\overline{21}\end{array}$ & $\begin{array}{c}- \\
\overline{3.54} \\
\overline{-} \\
\overline{3.52} \\
\overline{-} \\
3.49 \\
\overline{-} \\
\overline{3.48}\end{array}$ & $\begin{array}{l}\overline{-} \\
\overline{20} \\
\overline{-} \\
\overline{19} \\
\vdots \\
18 \\
\overline{1} \\
\overline{17}\end{array}$ & $\begin{array}{c}\overline{-} \\
\overline{3.45} \\
\overline{3} \\
3.44 \\
\overline{3} \\
\overline{3.43} \\
\overline{3.41}\end{array}$ & $\begin{array}{l}- \\
16 \\
\overline{-} \\
15 \\
\overline{-} \\
14 \\
\overline{14} \\
\overline{14}\end{array}$ & $\begin{array}{c}\overline{-} \\
\overline{3.40} \\
\overline{-} \\
3.40 \\
\overline{3} \\
3.39 \\
\overline{3} \\
\overline{3.38}\end{array}$ & $\begin{array}{l}\overline{-} \\
\overline{13} \\
\overline{-} \\
13 \\
\overline{1} \\
13 \\
\overline{1} \\
\overline{12}\end{array}$ & $\begin{array}{c}\overline{-} \\
= \\
= \\
3.37 \\
= \\
\overline{-} \\
\overline{3.36}\end{array}$ & $\begin{array}{l}\overline{-} \\
= \\
\overline{-} \\
12 \\
\bar{z} \\
\overline{-} \\
\overline{11}\end{array}$ \\
\hline & \multicolumn{2}{|c|}{ December 20} & \multicolumn{2}{|c|}{ December 21} & \multicolumn{2}{|c|}{ December 22} & \multicolumn{2}{|c|}{ December 23} & \multicolumn{2}{|c|}{ December 24} & \multicolumn{2}{|c|}{ December 25} \\
\hline $\begin{array}{r}2 \\
4 \\
6 \\
8 \\
10 \\
\mathbb{N} \\
2 \\
4 \\
6 \\
8 \\
10 \\
M\end{array}$ & $\begin{array}{c}\overline{-} \\
= \\
= \\
3.35 \\
= \\
= \\
= \\
3.34\end{array}$ & $\begin{array}{l}\overline{-} \\
\overline{-} \\
\overline{11} \\
\overline{-} \\
\overline{-} \\
\overline{11}\end{array}$ & $\begin{array}{c}= \\
= \\
= \\
3.34 \\
= \\
= \\
\overline{3.33}\end{array}$ & $\begin{array}{l}\bar{z} \\
\bar{z} \\
\overline{1} \\
\bar{z} \\
\bar{z} \\
\overline{1} \\
\overline{10}\end{array}$ & $\begin{array}{l}\bar{z} \\
\overline{-} \\
\bar{z} \\
3.32 \\
\bar{z} \\
\bar{z} \\
\overline{3.33}\end{array}$ & $\begin{array}{l}\overline{-} \\
\bar{z} \\
\overline{10} \\
\bar{z} \\
\bar{z} \\
\overline{10}\end{array}$ & $\begin{array}{l}\overline{ } \\
= \\
= \\
3.33 \\
= \\
= \\
\overline{3} \\
3.31\end{array}$ & $\begin{array}{l}\overline{-} \\
\overline{-} \\
\overline{10} \\
\overline{-} \\
\overline{-} \\
- \\
-9.5\end{array}$ & 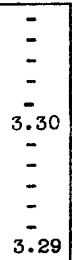 & $\begin{array}{l}= \\
= \\
= \\
= \\
= \\
= \\
-\end{array}$ & $\begin{array}{c}= \\
= \\
= \\
3.29 \\
= \\
= \\
3.29\end{array}$ & $\begin{array}{c}\bar{z} \\
\overline{-} \\
\overline{-} \\
\bar{z} \\
\bar{z} \\
\overline{-} \\
8.5\end{array}$ \\
\hline
\end{tabular}

Supplemental records.- Dec. $11,9: 30$ p.m., $10.24 \mathrm{ft} ., 3,550$ sec.-ft. 
Salinas.River near Spreckels, Calif.

Location.- Lat. $36^{\circ} 37^{\prime} 50^{\prime \prime}$, 1ong. $121^{\circ} 40^{\prime} 40^{n}$, In EI Toro grant, at bridge on SalinasMonterey highway, half a mile above Toro Creek, 2 miles west of Spreckels, and 4 miles south of Salinas, Monterey County. Altitude, about 50 feet above mean sea level.

Drainage area.- 4,180 square miles.

Gage-helght record. - Water-stage recorder graph.

Stage-discharge relation.- Defined by current-meter measurements for entire range of stage. Subject to large shifts at hlgh stages. Rating curve changed at peak stage.

Mexima.- December 1937: Discharge, 13,400 second-feet 10 p.m. Dec. 12 (gage helght, 16.77 foet).

1930-November 1937: Discharge, about 42,100 second-feet Dec. 29, 1931 (gage height, 20.40 feet), from rating curve extended above 26,000 second-feet on basis of slope-area determination of flood flow.

January-September 1938: Discharge, about 75,000 second-feet $6: 30$ a.m. Feb. 12 (gage helght, 25.0 feet), from rating curve extended above 25,800 second-feet with ald of area-velocity study, verifled by slope-area determination of flood flow.

1911-38: Maximum stage known, 26.6 feet, Mar. 7, 1911, from floodmark (d1scharge not determined).

Remarks.- Flood run-off not affected by artificial storage or diversions.

Mean daily discharge, In second-feet, November 1937 to January 1938

\begin{tabular}{|c|c|c|c|c|c|c|c|c|c|c|c|}
\hline Day & Nov. & Dec. & Jan. & Day & Nov. & Dec. & Jan. & Day & Nov. & Dec. & Jan. \\
\hline $\begin{array}{r}1 \\
2 \\
3 \\
4 \\
5 \\
6 \\
7 \\
8 \\
9 \\
10\end{array}$ & $\begin{array}{l}2.7 \\
2.5 \\
2.5 \\
2.7 \\
3.0 \\
2.8 \\
3.0 \\
3.2 \\
3.3 \\
3.5\end{array}$ & $\begin{array}{l}3.5 \\
3.5 \\
3.5 \\
3.5 \\
3.3 \\
3.3 \\
3.5 \\
3.6 \\
3.8 \\
5.5\end{array}$ & $\begin{array}{l}66 \\
57 \\
52 \\
44 \\
39 \\
37 \\
33 \\
31 \\
28 \\
27\end{array}$ & $\begin{array}{l}11 \\
12 \\
13 \\
14 \\
15 \\
16 \\
17 \\
18 \\
19 \\
20\end{array}$ & $\begin{array}{l}3.5 \\
3.5 \\
3.5 \\
3.8 \\
3.8 \\
3.8 \\
4.3 \\
4.1 \\
3.8 \\
3.6\end{array}$ & $\begin{array}{r}6 \\
7,520 \\
8,500 \\
3,650 \\
1,960 \\
1,290 \\
925 \\
670 \\
508 \\
392\end{array}$ & $\begin{array}{r}24 \\
23 \\
22 \\
21 \\
21 \\
20 \\
29 \\
167 \\
246 \\
309\end{array}$ & $\begin{array}{l}21 \\
22 \\
23 \\
24 \\
25 \\
26 \\
27 \\
28 \\
29 \\
30 \\
31\end{array}$ & $\begin{array}{l}3.6 \\
3.5 \\
3.5 \\
3.5 \\
3.5 \\
3.5 \\
3.3 \\
3.3 \\
3.3 \\
3.3\end{array}$ & $\begin{array}{r}305 \\
252 \\
230 \\
185 \\
158 \\
136 \\
120 \\
104 \\
92 \\
79 \\
72\end{array}$ & $\begin{array}{l}412 \\
535 \\
602 \\
490 \\
400 \\
340 \\
301 \\
272 \\
266 \\
252 \\
340\end{array}$ \\
\hline & & & & & & & & $\cdots$ & $\begin{array}{r}3.37 \\
201 \\
\end{array}$ & $\begin{array}{r}877 \\
53,930 \\
\end{array}$ & $\begin{array}{r}178 \\
10,920 \\
\end{array}$ \\
\hline
\end{tabular}

Gage height, in feet, and discharge, in second-feet, at indicated time, 1937

\begin{tabular}{|c|c|c|c|c|c|c|c|c|c|c|c|c|}
\hline$y$ & Feet & Sec.ft. & Feet & Sec.ft. & Feet & Sec.ft. & Feet & Sec.ft. & Feet & Sec.ft. & Feet & Soc.ft \\
\hline & Dece & mber 8 & Dece & mber 9 & Decen & ber 10 & Decen & ber II & Decer & ner 12 & Decen & mber 13 \\
\hline $\begin{array}{r}2 \\
4 \\
6 \\
8 \\
10 \\
N \\
2 \\
4 \\
6 \\
8 \\
10 \\
1\end{array}$ & $\begin{array}{c}\bar{z} \\
\bar{z} \\
\overline{3.69} \\
\bar{z} \\
\bar{z} \\
\overline{3.69}\end{array}$ & $\begin{array}{l}\overline{-} \\
= \\
\overline{3} .6 \\
= \\
= \\
\overline{3} .6\end{array}$ & $\begin{array}{l}3.69 \\
-6 \\
3.67 \\
- \\
3.68 \\
- \\
3.72 \\
- \\
3.73 \\
\overline{3.74}\end{array}$ & $\begin{array}{l}\overline{3} .6 \\
\overline{3} .3 \\
\overline{3} .5 \\
\overline{4} .3 \\
\overline{4} .6 \\
\overline{4} .9\end{array}$ & $\begin{array}{l}3.77 \\
-7 \\
3.76 \\
3.76 \\
3.75 \\
- \\
3.74 \\
- \\
3.73\end{array}$ & $\begin{array}{l}\overline{5} .5 \\
\overline{5} .5 \\
\overline{5} .5 \\
\overline{5} \\
\overline{4} .9 \\
\overline{4.6}\end{array}$ & $\begin{array}{l}3.76 \\
- \\
3.80 \\
--80 \\
3.8 \\
3.78 \\
-77 \\
3.77 \\
3.76\end{array}$ & $\begin{array}{l}\overline{5.5} \\
\overline{6} .5 \\
\overline{6} .5 \\
\overline{6} \\
\overline{5.5} \\
\overline{5.5}\end{array}$ & $\begin{array}{r}7.45 \\
10.20 \\
11.02 \\
11.23 \\
11.60 \\
12.59 \\
13.85 \\
15.11 \\
15.98 \\
16.55 \\
16.77 \\
16.62\end{array}$ & $\begin{array}{r}1,570 \\
3,650 \\
4,520 \\
4,780 \\
5,220 \\
6,530 \\
8,380 \\
10,500 \\
12,000 \\
13,000 \\
13,400 \\
13,100\end{array}$ & $\begin{array}{l}16.15 \\
15.62 \\
15.02 \\
14.41 \\
13.90 \\
13.52 \\
13.17 \\
12.88 \\
12.59 \\
12.32 \\
12.04 \\
11.75\end{array}$ & $\begin{array}{r}12,300 \\
11,400 \\
10,300 \\
9,300 \\
8,450 \\
7,880 \\
7,360 \\
6,930 \\
6,530 \\
6,150 \\
5,760 \\
5,400\end{array}$ \\
\hline & Decem & ber 14 & Decer & ber I5 & Decer & ber 16 & Decer & ber 17 & Decen & ber 18 & Decem & ber 19 \\
\hline $\begin{array}{r}2 \\
4 \\
6 \\
8 \\
10 \\
N \\
2 \\
4 \\
6 \\
8 \\
10 \\
M\end{array}$ & $\begin{array}{r}11.44 \\
11.14 \\
10.85 \\
10.58 \\
10.31 \\
10.06 \\
9.89 \\
9.69 \\
9.50 \\
9.32 \\
9.13 \\
8.96\end{array}$ & $\begin{array}{l}5,030 \\
4,670 \\
4,340 \\
4,040 \\
3,760 \\
3,510 \\
3,350 \\
3,170 \\
3,000 \\
2,860 \\
2,700 \\
2,570\end{array}$ & $\begin{array}{l}\overline{-} \\
8.63 \\
8.32 \\
\overline{8.06} \\
7.84 \\
\overline{7.63} \\
\overline{7.46}\end{array}$ & $\begin{array}{l}2, \overline{3} 20 \\
2, \overline{100} \\
1, \overline{9} \\
1, \overline{8} 00 \\
1, \overline{6} 80 \\
1, \overline{5} 70\end{array}$ & $\begin{array}{l}7.24 \\
- \\
7.08 \\
- \\
6.92 \\
- \\
6.80 \\
- \\
6.67 \\
- \\
6.54\end{array}$ & $\begin{array}{l}1, \overline{450} \\
1, \overline{3} 60 \\
1, \overline{2} 80 \\
\overline{\overline{2}} 10 \\
1, \overline{1} 140 \\
1, \overline{070}\end{array}$ & $\begin{array}{l}5.44 \\
- \\
6.32 \\
- \\
6.22 \\
-.12 \\
-.01 \\
\overline{6.95}\end{array}$ & $\begin{array}{l}1, \overline{0} \\
\overline{960} \\
\overline{9} \\
\overline{9} 10 \\
\overline{860} \\
\overline{810} \\
\overline{782}\end{array}$ & $\begin{array}{l}5.86 \\
- \\
5.79 \\
- \\
5.71 \\
- \\
5.65 \\
- \\
5.58 \\
5.52 \\
\end{array}$ & $\begin{array}{l}-\overline{742} \\
-710 \\
-774 \\
-\overline{648} \\
- \\
616 \\
589\end{array}$ & $\begin{array}{c}- \\
5.45 \\
5.39 \\
- \\
5.33 \\
5.29 \\
5.24 \\
5.18\end{array}$ & $\begin{array}{l}\overline{5} \\
\overline{5} \\
\overline{530} \\
\overline{5} 04 \\
\overline{486} \\
\overline{464} \\
\overline{438}\end{array}$ \\
\hline & Decem & ber 20 & Dece & aber 21 & Decer & ber 22 & Decen & ber 23 & Decen & ber 24 & Decem & aber 25 \\
\hline $\begin{array}{r}2 \\
4 \\
6 \\
8 \\
10 \\
N \\
2 \\
4 \\
6 \\
8 \\
10 \\
M\end{array}$ & $\begin{array}{l}5.14 \\
5.10 \\
5.06 \\
5.02 \\
- \\
4.98 \\
4.96\end{array}$ & $\begin{array}{l}\overline{4} \\
\overline{4} 104 \\
\overline{3} 88 \\
\overline{3} 72 \\
\overline{3} \\
\overline{3} 48\end{array}$ & $\begin{array}{l}= \\
= \\
= \\
4.85 \\
= \\
= \\
= \\
4.79\end{array}$ & $\begin{array}{l}= \\
= \\
= \\
305 \\
= \\
= \\
= \\
283\end{array}$ & $\begin{array}{l}= \\
= \\
= \\
4.70 \\
= \\
= \\
\bar{z} .66\end{array}$ & $\begin{array}{l}= \\
\bar{z} \\
\overline{2} \\
252 \\
= \\
=\end{array}$ & $\begin{array}{l}\bar{z} \\
\bar{z} \\
\overline{4} .63 \\
\bar{z} \\
\bar{z} \\
\overline{4} 57\end{array}$ & $\begin{array}{l}\bar{z} \\
\bar{z} \\
\overline{2} 30 \\
\bar{z} \\
\overline{-}\end{array}$ & $\begin{array}{l}\overline{-} \\
\bar{z} \\
\overline{4} \\
\overline{4}\end{array}$ & $\begin{array}{l}\overline{-} \\
\overline{-} \\
\overline{1} \\
\overline{-} \\
\overline{-} \\
\overline{173}\end{array}$ & $\begin{array}{l}= \\
= \\
\overline{4.40} \\
= \\
= \\
\overline{4}\end{array}$ & $\begin{array}{l}= \\
= \\
= \\
158 \\
= \\
= \\
\overline{1}\end{array}$ \\
\hline
\end{tabular}


Location. - Lat. $35^{\circ} 51^{\prime} 55^{n}$, long. $120^{\circ} 59^{\prime} 30^{n}$, in Pleyto grant, at highway bridge at old town site of Pleyto, Monterey County, 1.1 miles below Copperhead Creek and 15 miles west of Bradley. Altitude, about 720 feet above mean sea level.

Drainage area.- 288 square miles.

Gage-he1ght record. - Water-s tage recorder graph.

Stage-dlscharge relation.- Defined by current-meter measurements.

(axima.- December 1937: Discharge, 6,100 seoond-feet 4:30 p.m. Dec. 11 (gage helght, 4.30 feet)

1930-November 1937: Discharge, 7,460 second-feet Dec. 28, 1931 (gage height,

4.55 feet), from rating curve extended above 7,300 second-feet.

January-September 1938: Discharge, 10,700 second-feet 7 a.m. Feb. 11 (gage

helght, 5.10 feet), from rating curve extended above 7,300 second-feet.

Remarks. - Flood man-off not affected by artificial storage or diversion.

Mean da1ly discharge, in second-feet, November 1937 to Januery 1938

\begin{tabular}{|c|c|c|c|c|c|c|c||c|c|c|c|}
\hline Day & Nov. & Dec. & Jan. & Day & Nov. & Dec. & Jan. & Dey & Nov. & Dec. & Jan. \\
\hline 1 & 0 & 0 & 58 & 11 & 0 & 3,140 & 34 & 21 & 0 & 130 & 136 \\
2 & 0 & 0 & 54 & 12 & 0 & 1,660 & 33 & 22 & 0 & 128 & 112 \\
3 & 0 & 0 & 50 & 13 & 0 & 639 & 30 & 23 & 0 & 128 & 99 \\
4 & 0 & 0 & 47 & 14 & 0 & 429 & 30 & 24 & 0 & 125 & 89 \\
5 & 0 & 0 & 43 & 15 & 0 & 326 & 36 & 25 & 0 & 114 & 81 \\
6 & 0 & 0 & 43 & 16 & 0 & 243 & 40 & 26 & 0 & 109 & 72 \\
7 & 0 & 0 & 43 & 17 & 0 & 204 & 45 & 27 & 0 & 96 & 66 \\
8 & 0 & 0 & 40 & 18 & 0 & 194 & 117 & 28 & 0 & 85 & 87 \\
9 & 0 & 0 & 38 & 19 & 0 & 187 & 117 & 29 & 0 & 78 & 96 \\
10 & 0 & 299 & 36 & 20 & 0 & 147 & 156 & 30 & 0 & 72 & 114 \\
\end{tabular}

Gage height, in feet, and discherge, in second-feet, at indicated time, 1937

\begin{tabular}{|c|c|c|c|c|c|c|c|c|c|c|c|c|}
\hline \multirow{2}{*}{ 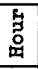 } & Feet & Sec.ft. & Feet & sec.ft. & Feet & Sec.ft. & Feet & Sec.ft. & Feet & sec.ft. & Feet & Sec.ft. \\
\hline & \multicolumn{2}{|c|}{ December 8} & \multicolumn{2}{|c|}{ December 9} & \multicolumn{2}{|c|}{ December 10} & \multicolumn{2}{|c|}{ December 11} & \multicolumn{2}{|c|}{ December 12} & \multicolumn{2}{|c|}{ December 13} \\
\hline \begin{tabular}{r|}
2 \\
4 \\
6 \\
8 \\
8 \\
10 \\
$\mathbb{N}$ \\
2 \\
4 \\
6 \\
8 \\
10 \\
W
\end{tabular} & & & & & 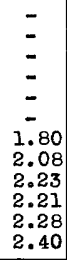 & $\begin{array}{r}0 \\
0 \\
0 \\
0 \\
0 \\
0 \\
440 \\
612 \\
718 \\
702 \\
755 \\
850\end{array}$ & $\begin{array}{l}2.40 \\
2.32 \\
2.49 \\
2.88 \\
2.93 \\
3.19 \\
4.15 \\
4.23 \\
4.21 \\
4.18 \\
4.18 \\
3.87\end{array}$ & $\begin{array}{r}850 \\
786 \\
931 \\
1,380 \\
1,460 \\
1,930 \\
5,350 \\
5,750 \\
5,650 \\
5,500 \\
5,500 \\
4,080\end{array}$ & $\begin{array}{l}3.58 \\
3.41 \\
3.26 \\
3.12 \\
2.98 \\
2.88 \\
2.75 \\
2.67 \\
2.58 \\
2.51 \\
2.43 \\
2.37\end{array}$ & $\begin{array}{r}2,990 \\
2,480 \\
2,100 \\
1,790 \\
1,540 \\
1,380 \\
1,210 \\
1,120 \\
1,020 \\
950 \\
877 \\
826\end{array}$ & $\begin{array}{l}2.32 \\
2.28 \\
2.22 \\
2.19 \\
2.15 \\
2.11 \\
2.07 \\
2.04 \\
2.01 \\
1.98 \\
1.95 \\
1.91\end{array}$ & $\begin{array}{l}786 \\
755 \\
710 \\
688 \\
660 \\
632 \\
606 \\
586 \\
566 \\
548 \\
530 \\
506\end{array}$ \\
\hline & \multicolumn{2}{|c|}{ December 14} & \multicolumn{2}{|c|}{ December 15} & \multicolumn{2}{|c|}{ December 16} & \multicolumn{2}{|c|}{ December 17} & \multicolumn{2}{|c|}{ December 18} & \multicolumn{2}{|c|}{ December 18} \\
\hline $\begin{array}{r}2 \\
4 \\
6 \\
8 \\
10 \\
N \\
2 \\
4 \\
6 \\
8 \\
10 \\
\text { M }\end{array}$ & $\begin{array}{l}1 . \overline{86} \\
1 . \overline{81} \\
1 . \overline{77} \\
1 . \overline{73} \\
1 . \overline{70} \\
1 . \overline{67}\end{array}$ & $\begin{array}{c}4 \overline{76} \\
446 \\
4 \overline{24} \\
4 \overline{0} \\
- \\
3 \overline{85} \\
3 \overline{70}\end{array}$ & $\begin{array}{l}1 . \overline{63} \\
1 . \overline{61} \\
-\overline{57} \\
1 . \overline{53} \\
1.51 \\
1 . \overline{47}\end{array}$ & $\begin{array}{l}3 \overline{50} \\
\overline{340} \\
3 \overline{2} \\
3 \overline{0} \\
\overline{2} \\
2 \overline{9} \\
2 \overline{7}\end{array}$ & $\begin{array}{l}\overline{1.44} \\
\overline{1.40} \\
\overline{1.36} \\
\overline{1.33} \\
\overline{1.32} \\
\overline{1.31}\end{array}$ & $\begin{array}{l}2 \overline{66} \\
\overline{2} \overline{0} \\
2 \overline{3} 6 \\
\overline{2} \overline{6} \\
\overline{2} \overline{2} \\
\overline{2} \overline{18}\end{array}$ & $\begin{array}{l}1 . \overline{3} 0 \\
-\overline{27} \\
\overline{-} \\
1 . \overline{27} \\
1 . \overline{26} \\
1 . \overline{26} \\
1 . \overline{26}\end{array}$ & $\begin{array}{l}\overline{2} 15 \\
\overline{204} \\
\overline{204} \\
\overline{201} \\
\overline{201} \\
\overline{201}\end{array}$ & $\begin{array}{c}\overline{-} \\
1 . \overline{26} \\
\overline{-} \\
1 . \overline{2} 4 \\
= \\
\bar{E} \\
\overline{2} \\
1 . \overline{2} 2\end{array}$ & $\begin{array}{c}\overline{-} \\
201 \\
\overline{-} \\
184 \\
\overline{-} \\
\overline{190} \\
\overline{187}\end{array}$ & $\begin{array}{c}\overline{-} \\
1 . \overline{22} \\
\overline{-} \\
1 . \overline{23} \\
\overline{-} \\
1 . \overline{2} 2 \\
\overline{-} \\
1 . \overline{10}\end{array}$ & $\begin{array}{c}\overline{-} \\
187 \\
\overline{-} \\
190 \\
\overline{-} \\
187 \\
\overline{-} \\
1 \overline{77}\end{array}$ \\
\hline & \multicolumn{2}{|c|}{ December 20} & \multicolumn{2}{|c|}{ December 21} & \multicolumn{2}{|c|}{ December 22} & \multicolumn{2}{|c|}{ December 23} & \multicolumn{2}{|c|}{ December 24} & \multicolumn{2}{|c|}{ December 25} \\
\hline $\begin{array}{r}2 \\
4 \\
6 \\
8 \\
10 \\
\mathbb{N} \\
2 \\
4 \\
6 \\
8 \\
10 \\
\mathbb{M}\end{array}$ & $\begin{array}{l}1 . \overline{17} \\
1 . \overline{13} \\
1 . \overline{0} \\
1 . \overline{03} \\
1 . \overline{04} \\
1 . \overline{0}\end{array}$ & $\begin{array}{c}\overline{171} \\
\overline{159} \\
\overline{142} \\
\overline{130} \\
\overline{133} \\
\overline{133}\end{array}$ & $\begin{array}{c}\overline{-} \\
1 . \overline{04} \\
\overline{-} \\
1.03 \\
= \\
1 . \overline{0} \\
- \\
1.02\end{array}$ & $\begin{array}{c}\overline{-} \\
133 \\
\overline{1} \\
\overline{130} \\
\overline{-} \\
133 \\
\overline{-} \\
128\end{array}$ & $\begin{array}{c} \pm \\
1.02 \\
\vdots \\
1.02 \\
\vdots \\
1.01 \\
= \\
1.02\end{array}$ & $\begin{array}{c}\overline{-} \\
128 \\
\overline{1} \\
128 \\
\vdots \\
125 \\
\overline{128}\end{array}$ & $\begin{array}{c}\overline{-} \\
1 . \overline{02} \\
\overline{-} \\
1.03 \\
\overline{-} \\
1 . \overline{03} \\
\overline{-} \\
1.02\end{array}$ & $\begin{array}{l}\bar{z} \\
\overline{128} \\
\overline{130} \\
\overline{1} \\
\overline{130} \\
\overline{-} \\
\overline{128}\end{array}$ & $\begin{array}{c}= \\
1.01 \\
- \\
1.01 \\
= \\
1.00 \\
= \\
.99\end{array}$ & $\begin{array}{c}\overline{-} \\
125 \\
- \\
125 \\
- \\
122 \\
- \\
119\end{array}$ & $\begin{array}{c}\overline{-} \\
0 . \overline{98} \\
\overline{-} \\
. \overline{8} \\
\overline{-} \\
. \overline{9} \\
\overline{-} \\
. \overline{86}\end{array}$ & $\begin{array}{c}- \\
117 \\
- \\
114 \\
\vdots \\
114 \\
- \\
112\end{array}$ \\
\hline
\end{tabular}

Supplemental records.- Dec. $10,12: 30$ p.m., no flow 3 l p.m., 1.50 ft., 290 sec.-ft. Dec. 11,4230 p.m., 4.30 ft., 6,100 sec.-ft. 
Location. - Lat. $36^{\circ} 16^{\prime} 05^{\prime \prime}$, long. $121^{\circ} 19^{\prime} 55^{\prime \prime}$, in NF/ sec. 21 , T. 19 S., R. 6 E. , half a mlle downstream from Vaquero Creok and 11 miles south of Soledad, Monterey County. Altitude, about 370 feet above mean sea level.

Dralnage area.- 238 square miles.

Gage-helght record. - Water-stage recorder graph.

Stage-discharge relation.- Defined by current-meter measurements below 7,000 second-

feet; extended to peak stage by $A \sqrt{d}$ method, verlfied by area-relocity study. Shifting-control method used Nov. 1 to Jan. 5. Rating curve changed at peak stage.

Maxima.- December 1937: Discharge, about 13,400 second-feet 8 a.m. Dec. Il (gage helght, 15.1 feet).

190i-November 1937: Discharge observed, about 22,000 second-feet Feb. 21, 1917 , and Nov. 25, 1926 (gage he1ght, 16.5 feet, from nonrecording gage), from rating curve extended above 7,500 second-feet.

January-September 1938: Discharge, about 16,000 second-fe日t Feb. Il (gage height, 16.5 feet), from rating curve extended above 7,000 second-feet.

Remarks. - Flood run-off not affected by artificial storage or diversion.

Mean dally discharge, in second-feet, November 1937 to January 1938

\begin{tabular}{|c|c|r|r||r|r|r|r|r|r|r|r|}
\hline Day & Nov. & Dec. & Jan. & Day & Nov. & Dec. & Jan. & Day & Nov. & Dec. & Jan. \\
\hline 1 & 3.3 & 12 & 67 & 11 & 6 & 6,880 & 57 & 21 & 12 & 117 & 170 \\
2 & 3.3 & 12 & 70 & 12 & 10 & 1,470 & 56 & 22 & 12 & 108 & 144 \\
3 & 3.6 & 12 & 77 & 13 & 12 & 669 & 55 & 23 & 12 & 105 & 128 \\
4 & 4.3 & 12 & 70 & 14 & 10 & 426 & 55 & 24 & 12 & 99 & 114 \\
5 & 4.3 & 13 & 67 & 15 & 11 & 299 & 72 & 25 & 12 & 91 & 105 \\
6 & 4.6 & 13 & 65 & 16 & 12 & 233 & 75 & 26 & 12 & 86 & 97 \\
7 & 5 & 13 & 63 & 17 & 11 & 190 & 137 & 27 & 12 & 81 & 91 \\
8 & 5 & 13 & 62 & 18 & 15 & 166 & 142 & 28 & 12 & 79 & 97 \\
9 & 5.5 & 17 & 60 & 19 & 16 & 144 & 162 & 29 & 12 & 76 & 220 \\
10 & 5.5 & 1,380 & 59 & 20 & 13 & 132 & 238 & 30 & 12 & 74 & 181 \\
\end{tabular}

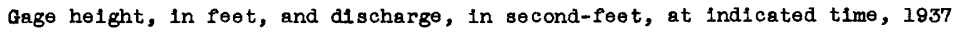

\begin{tabular}{|c|c|c|c|c|c|c|c|c|c|c|c|c|}
\hline \multirow{2}{*}{$\begin{array}{l}5 \\
\text { 号 } \\
\text { 足 }\end{array}$} & Feet & Sec.ft. & Feet & Sec.ft. & Feet & Sec.ft. & Feot & Sec.ft. & Foet & Sec.ft. & Feet & Sec.ft. \\
\hline & \multicolumn{2}{|c|}{ December 8} & \multicolumn{2}{|c|}{ December 9} & \multicolumn{2}{|c|}{ December 10} & \multicolumn{2}{|c|}{ December 11} & \multicolumn{2}{|c|}{ December 12} & \multicolumn{2}{|c|}{ December 13} \\
\hline $\begin{array}{r}2 \\
4 \\
6 \\
8 \\
10 \\
1 \\
2 \\
4 \\
6 \\
8 \\
10 \\
M \\
\end{array}$ & $\begin{array}{c} \\
- \\
- \\
- \\
2.25 \\
\overline{-} \\
= \\
= \\
2.25\end{array}$ & $\begin{array}{l}= \\
\bar{z} \\
\overline{13} \\
\bar{z} \\
= \\
\overline{1} \\
\overline{13}\end{array}$ & $\begin{array}{c}- \\
2.25 \\
- \\
2.26 \\
- \\
2.26 \\
- \\
2.31 \\
2.37 \\
-\overline{2.50}\end{array}$ & $\begin{array}{l}\overline{13} \\
\overline{14} \\
\overline{14} \\
\overline{18} \\
\overline{23} \\
\overline{33}\end{array}$ & $\begin{array}{l}5.13 \\
5.91 \\
5.84 \\
6.58 \\
6.52 \\
6.19 \\
5.85 \\
6.10 \\
6.61 \\
6.31 \\
5.85 \\
6.33\end{array}$ & $\begin{array}{r}865 \\
1,300 \\
1,250 \\
1,780 \\
1,740 \\
1,490 \\
1,260 \\
1,430 \\
1,810 \\
1,580 \\
1,320 \\
1,590\end{array}$ & $\begin{array}{r}6.90 \\
7.48 \\
11.00 \\
15.10 \\
13.78 \\
14.63 \\
13.34 \\
11.93 \\
10.38 \\
9.15 \\
8.20 \\
7.66\end{array}$ & $\begin{array}{r}2,040 \\
2,550 \\
6,850 \\
13,400 \\
11,000 \\
12,600 \\
10,400 \\
8,240 \\
5,980 \\
4,380 \\
3,300 \\
2,760 \\
\end{array}$ & $\begin{array}{l}7.21 \\
6.85 \\
6.50 \\
6.16 \\
5.95 \\
5.82 \\
5.70 \\
5.60 \\
5.50 \\
5.38 \\
5.25 \\
5.15 \\
\end{array}$ & $\begin{array}{r}2,360 \\
2,040 \\
1,760 \\
1,510 \\
1,370 \\
1,290 \\
1,220 \\
1,160 \\
1,100 \\
1,030 \\
958 \\
905 \\
\end{array}$ & $\begin{array}{l}- \\
4.95 \\
4.76 \\
- \\
4.62 \\
- \\
4.50 \\
- \\
4.38 \\
- \\
4.26\end{array}$ & $\begin{array}{c}805 \\
\overline{716} \\
\overline{6} \\
656 \\
\overline{608} \\
\overline{562} \\
- \\
518\end{array}$ \\
\hline & \multicolumn{2}{|c|}{ December 14} & \multicolumn{2}{|c|}{ December 15} & \multicolumn{2}{|c|}{ December 16} & \multicolumn{2}{|c|}{ December 17} & \multicolumn{2}{|c|}{ December 18} & \multicolumn{2}{|c|}{ December 19} \\
\hline $\begin{array}{r}2 \\
4 \\
6 \\
8 \\
10 \\
N \\
2 \\
4 \\
6 \\
8 \\
10 \\
M\end{array}$ & $\begin{array}{l}4.16 \\
--07 \\
4.0 \\
4.00 \\
3.92 \\
3.83 \\
-.75\end{array}$ & $\begin{array}{l}4 \overline{82} \\
4 \overline{50} \\
\overline{426} \\
\overline{399} \\
\overline{3} \\
\overline{3} \\
3 \overline{4}\end{array}$ & $\begin{array}{c}- \\
\overline{3.67} \\
- \\
- \\
3.61 \\
- \\
- \\
3.54 \\
- \\
\overline{-} \\
3.47\end{array}$ & $\begin{array}{c}\overline{-} \\
3 \overline{17} \\
\overline{-} \\
2 \overline{89} \\
\overline{-} \\
\overline{278} \\
\overline{-} \\
258\end{array}$ & $\begin{array}{c}\bar{z} \\
3.41 \\
\bar{z} \\
3.38 \\
\bar{z} \\
3.34 \\
\bar{z} \\
3.29\end{array}$ & $\begin{array}{c}\overline{-} \\
2 \overline{11} \\
\overline{-} \\
233 \\
\overline{-} \\
2 \overline{2} \\
\overline{2} \\
\overline{210}\end{array}$ & $\begin{array}{c}\overline{-} \\
\overline{3.23} \\
\overline{-} \\
\overline{3.21} \\
\overline{-} \\
\overline{3.18} \\
\bar{z} \\
\overline{3.13}\end{array}$ & $\begin{array}{c}\overline{-} \\
\overline{195} \\
\overline{-} \\
\overline{190} \\
\overline{-} \\
\overline{184} \\
\overline{-} \\
\overline{173}\end{array}$ & 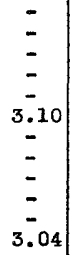 & $\begin{array}{c}\overline{-} \\
\overline{-} \\
\overline{166} \\
\overline{-} \\
\overline{-} \\
\overline{154}\end{array}$ & $\begin{array}{c}= \\
= \\
z \\
= \\
= \\
= \\
2.98\end{array}$ & $\begin{array}{c}\overline{-} \\
\overline{-} \\
\overline{142} \\
\overline{-} \\
\overline{-} \\
\overline{137}\end{array}$ \\
\hline & \multicolumn{2}{|c|}{ December 20} & \multicolumn{2}{|c|}{ December 21} & \multicolumn{2}{|c|}{ December 22} & \multicolumn{2}{|c|}{ December 23} & \multicolumn{2}{|c|}{ December 24} & \multicolumn{2}{|c|}{ December 25} \\
\hline $\begin{array}{r}2 \\
4 \\
6 \\
8 \\
10 \\
N \\
2 \\
4 \\
6 \\
8 \\
10 \\
M\end{array}$ & 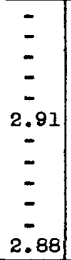 & $\begin{array}{c}\overline{-} \\
\overline{-} \\
130 \\
= \\
\bar{z} \\
\overline{124}\end{array}$ & 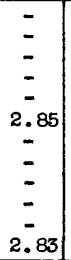 & $\begin{array}{c}\bar{z} \\
= \\
117 \\
= \\
= \\
\overline{114}\end{array}$ & $\begin{array}{c}\bar{z} \\
\bar{z} \\
\overline{2} \\
2.80 \\
\bar{z} \\
\bar{z} \\
2.78\end{array}$ & $\begin{array}{l}= \\
= \\
= \\
108 \\
= \\
= \\
105\end{array}$ & $\begin{array}{c}= \\
= \\
= \\
2.79 \\
= \\
= \\
2.77\end{array}$ & $\begin{array}{c}= \\
= \\
= \\
107 \\
= \\
= \\
104\end{array}$ & 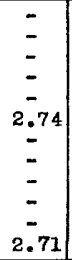 & $\begin{array}{l}\bar{z} \\
= \\
\overline{9} \\
= \\
= \\
= \\
\overline{9}\end{array}$ & $\begin{array}{c}= \\
= \\
= \\
2.68 \\
= \\
= \\
= \\
2.68\end{array}$ & $\begin{array}{l}= \\
= \\
= \\
= \\
= \\
= \\
90\end{array}$ \\
\hline
\end{tabular}


Uvas Creek near Morgan H111, Cal1f.

Location. - Lat. $37^{\circ} 04^{\prime} 00^{n}$, long. $121^{\circ} 41^{\prime} 30^{\prime \prime}$, in Las Uvas grant, 500 feet above Uvas Dam, 0.6 mile below Eastman Canyon, and 4.8 miles southwest of Morgan Hill, Santa Clara County. Altitude, about 390 feet above mean sea level.

Drainage area.- 30.2 square miles.

Gage-he1ght record. - Water-stage recorder graph except for period 11 p.m. Dec. 10 to 3 p.m. Dec. 14, when stage graph was based on peak stage obtalned from floodmark in well, partial recorder graph, two staff gage readings Dec. 11, and shape of stage graphs for nearby streams.

Stage-discharge relation.- Defined by current-meter measurements below 2,750 secondfeet; extended to peak stage with ald of area-velocity study. Rating curve changed at peak stage.

Maxima.- December 1937: Discharge, 8,630 second-feet 1 a.m. Dec. 11 (gage height,

13.7 feet, from floodmark in weil).

1930-November 1937: Discharge, 4,340 second-feet Dec. 27, 1931 (gage height, 10.82 feet), from rating curve extended above 2,100 second-feet.

Remarks.- Flood run-off not affected by artificial storage or diversion.

Mean da1ly discharge, in second-feet, November 1937 to January 1938

\begin{tabular}{|c|c|c|c|c|c|c|c|c|c|c|c|}
\hline Day & Nov. & Dec. & Jan. & Day & Nov. & Dec. & Jan. & Day & Nov. & Dec. & Jan. \\
\hline $\begin{array}{r}1 \\
2 \\
3 \\
4 \\
5 \\
6 \\
7 \\
8 \\
9 \\
10\end{array}$ & $\begin{array}{r}0.5 \\
.5 \\
.5 \\
.5 \\
.5 \\
.5 \\
.7 \\
.6 \\
.6 \\
.7\end{array}$ & $\begin{array}{r}1.2 \\
1.2 \\
1.2 \\
1.2 \\
1.2 \\
1.2 \\
1.2 \\
1.4 \\
12 \\
2,390\end{array}$ & $\begin{array}{l}18 \\
20 \\
18 \\
17 \\
17 \\
16 \\
15 \\
15 \\
15 \\
14\end{array}$ & $\begin{array}{l}11 \\
12 \\
13 \\
14 \\
15 \\
16 \\
17 \\
18 \\
19 \\
20\end{array}$ & $\begin{array}{l}2.0 \\
2.0 \\
1.1 \\
1.9 \\
2.2 \\
1.4 \\
4.1 \\
2.4 \\
1.5 \\
1.2\end{array}$ & $\begin{array}{r}3,950 \\
438 \\
194 \\
121 \\
93 \\
74 \\
61 \\
52 \\
46 \\
40\end{array}$ & $\begin{array}{l}14 \\
14 \\
14 \\
14 \\
14 \\
14 \\
28 \\
21 \\
47 \\
37\end{array}$ & $\begin{array}{l}21 \\
22 \\
23 \\
24 \\
25 \\
26 \\
27 \\
28 \\
29 \\
30 \\
31\end{array}$ & $\begin{array}{l}4.9 \\
2.6 \\
1.9 \\
1.7 \\
1.7 \\
1.5 \\
1.4 \\
1.2 \\
1.2 \\
1.2\end{array}$ & $\begin{array}{l}37 \\
33 \\
31 \\
29 \\
27 \\
25 \\
23 \\
22 \\
21 \\
20 \\
19\end{array}$ & $\begin{array}{r}27 \\
24 \\
21 \\
19 \\
18 \\
17 \\
17 \\
62 \\
66 \\
44 \\
523\end{array}$ \\
\hline $\begin{array}{l}\text { Mean } \\
\text { Run- }\end{array}$ & $\begin{array}{l}\text { nthl } \\
\text {, in }\end{array}$ & $\mathrm{re}$ & in & & & & & & $\begin{array}{r}1.49 \\
89\end{array}$ & $\begin{array}{r}251 \\
15,410 \\
\end{array}$ & $\begin{array}{r}39.4 \\
2,420 \\
\end{array}$ \\
\hline
\end{tabular}

Gage height, in feet, and discharge, in second-feet, at indicatea time, 1937

\begin{tabular}{|c|c|c|c|c|c|c|c|c|c|c|c|c|}
\hline \multirow{2}{*}{ 苟 } & Feet & Sec.ft. & Feet & Sec.ft. & Feet & Sec.ft. & Feet & Sec.ft. & Feet & Sec.ft. & Feet & Sec.ft. \\
\hline & \multicolumn{2}{|c|}{ December 8} & \multicolumn{2}{|c|}{ December 9} & \multicolumn{2}{|c|}{ December 10} & \multicolumn{2}{|c|}{ December 11} & \multicolumn{2}{|c|}{ December 12} & \multicolumn{2}{|c|}{ December 13} \\
\hline \multirow[t]{2}{*}{$\begin{array}{r}2 \\
4 \\
6 \\
8 \\
10 \\
\mathrm{~N} \\
2 \\
4 \\
6 \\
8 \\
10 \\
\mathrm{M}\end{array}$} & $\begin{array}{l}= \\
= \\
= \\
= \\
= \\
= \\
= \\
= \\
2.31\end{array}$ & $\begin{array}{l}- \\
= \\
= \\
= \\
1.2 \\
= \\
= \\
= \\
1.5\end{array}$ & $\begin{array}{l}2.31 \\
2.31 \\
2.31 \\
2.31 \\
2.32 \\
2.33 \\
2.35 \\
2.40 \\
2.45 \\
2.55 \\
2.86 \\
3.98\end{array}$ & $\begin{array}{r}1.5 \\
1.5 \\
1.5 \\
1.5 \\
1.7 \\
1.9 \\
2.2 \\
3.3 \\
4.6 \\
8 \\
26 \\
232\end{array}$ & $\begin{array}{r}7.23 \\
9.78 \\
9.74 \\
7.75 \\
7.83 \\
7.07 \\
5.50 \\
4.84 \\
4.74 \\
6.47 \\
11.00 \\
13.19\end{array}$ & $\begin{array}{r}1,840 \\
3,930 \\
3,890 \\
2,160 \\
2,220 \\
1,740 \\
845 \\
541 \\
499 \\
1,380 \\
5,290 \\
7,970\end{array}$ & $\begin{array}{r}13.62 \\
11.90 \\
12.00 \\
11.65 \\
10.00 \\
9.35 \\
8.22 \\
7.45 \\
6.69 \\
5.95 \\
5.50 \\
5.25\end{array}$ & $\begin{array}{r}8,530 \\
6,370 \\
6,490 \\
6,070 \\
4,160 \\
3,500 \\
2,510 \\
1,920 \\
1,380 \\
965 \\
760 \\
661\end{array}$ & $\begin{array}{l}- \\
4.98 \\
- \\
4.78 \\
- \\
4.60 \\
\overline{4.45} \\
- \\
4.30 \\
\overline{4.17}\end{array}$ & $\begin{array}{c}\overline{559} \\
- \\
4 \overline{87} \\
\overline{2} \\
4 \overline{2} \\
\overline{373} \\
\overline{324} \\
\overline{2} \overline{83}\end{array}$ & $\begin{array}{l}- \\
4.00 \\
- \\
3.90 \\
3.82 \\
\overline{3.75} \\
\overline{3.67} \\
\overline{3.60}\end{array}$ & $\begin{array}{c}\overline{2 \overline{34}} \\
\overline{2} \\
2 \overline{8} \\
\overline{189} \\
\overline{17 \overline{3}} \\
\overline{156} \\
\overline{142}\end{array}$ \\
\hline & \multicolumn{2}{|c|}{ December 14} & \multicolumn{2}{|c|}{ December 15} & \multicolumn{2}{|c|}{ December 16} & \multicolumn{2}{|c|}{ December 17} & \multicolumn{2}{|c|}{ December 18} & \multicolumn{2}{|c|}{ December 19} \\
\hline \multirow[t]{2}{*}{$\begin{array}{r}2 \\
4 \\
6 \\
8 \\
10 \\
\mathrm{~N} \\
2 \\
4 \\
6 \\
8 \\
10 \\
\mathrm{M}\end{array}$} & $\begin{array}{l}\overline{-} \\
3.52 \\
= \\
\overline{3.48} \\
= \\
\overline{3.46} \\
= \\
\overline{3.43}\end{array}$ & $\begin{array}{c}\overline{-} \\
\overline{127} \\
\overline{-} \\
\overline{119} \\
\overline{-} \\
\overline{116} \\
\overline{-} \\
\overline{110}\end{array}$ & $\begin{array}{l}= \\
\overline{3.36} \\
= \\
\overline{3.34} \\
= \\
\overline{3.30} \\
= \\
\overline{3.26}\end{array}$ & $\begin{array}{l}\overline{-} \\
\overline{98} \\
- \\
\overline{95} \\
\overline{-} \\
\overline{8} \\
- \\
\overline{82}\end{array}$ & $\begin{array}{l}\overline{-} \\
\overline{3.23} \\
\overline{-} \\
\overline{3.21} \\
\overline{-} \\
\overline{3.18} \\
\overline{-} \\
\overline{3.16}\end{array}$ & $\begin{array}{l}\overline{-} \\
\overline{77} \\
\overline{-} \\
\overline{74} \\
\overline{-} \\
\overline{6} \\
\overline{6} \\
\overline{6} \\
\overline{66}\end{array}$ & $\begin{array}{l}- \\
z \\
3.14 \\
- \\
3.12 \\
- \\
3.10 \\
- \\
3.09\end{array}$ & $\begin{array}{l}\overline{-} \\
\overline{64} \\
\overline{-} \\
\overline{61} \\
\overline{-} \\
\overline{5} \\
\overline{-} \\
\overline{57}\end{array}$ & $\begin{array}{l}\bar{z} \\
\overline{3.07} \\
\overline{-} \\
\overline{3.05} \\
\overline{-} \\
\overline{3.04} \\
\overline{-} \\
\overline{3.03}\end{array}$ & $\begin{array}{l}\overline{-} \\
\overline{54} \\
- \\
\overline{52} \\
- \\
\overline{51} \\
- \\
\overline{50}\end{array}$ & $\begin{array}{l}- \\
\overline{3.01} \\
= \\
\overline{3.00} \\
\overline{-} \\
\overline{2.98} \\
\overline{-} \\
2.97\end{array}$ & $\begin{array}{l}\overline{-} \\
\overline{47} \\
\overline{-} \\
\overline{46} \\
\overline{-} \\
\overline{4} \\
\overline{-} \\
\overline{43}\end{array}$ \\
\hline & \multicolumn{2}{|c|}{ December 20} & \multicolumn{2}{|c|}{ December 21} & \multicolumn{2}{|c|}{ December 22} & \multicolumn{2}{|c|}{ December 23} & \multicolumn{2}{|c|}{ December 24} & \multicolumn{2}{|c|}{ December 25} \\
\hline $\begin{array}{r}2 \\
4 \\
6 \\
8 \\
10 \\
\mathrm{~N} \\
2 \\
4 \\
6 \\
8 \\
10 \\
\mathrm{M}\end{array}$ & 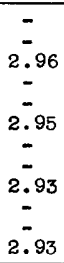 & $\begin{array}{l}- \\
\overline{42} \\
- \\
\overline{4} \\
- \\
\overline{3} \\
\overline{3} \\
\overline{3}\end{array}$ & $\begin{array}{c}- \\
\bar{z} \\
2.93 \\
\overline{-} \\
2.92 \\
\overline{-} \\
\bar{z} .91 \\
\overline{-} \\
\bar{z} .90\end{array}$ & $\begin{array}{l}- \\
\overline{38} \\
- \\
- \\
37 \\
- \\
\overline{36} \\
- \\
\overline{35}\end{array}$ & $\begin{array}{c}- \\
= \\
= \\
= \\
2.88 \\
= \\
= \\
= \\
\overline{2}\end{array}$ & $\begin{array}{l}\overline{-} \\
\overline{-} \\
\overline{-} \\
\overline{3} 3 \\
\overline{-} \\
\overline{-} \\
\overline{-} \\
\overline{3} 3\end{array}$ & $\begin{array}{c}- \\
- \\
= \\
= \\
2.86 \\
- \\
- \\
- \\
2.84\end{array}$ & $\begin{array}{l}- \\
- \\
- \\
\overline{3} 1 \\
- \\
= \\
\overline{-} \\
\overline{30}\end{array}$ & $\begin{array}{l}- \\
- \\
\overline{-} \\
2.83 \\
= \\
= \\
\overline{-} \\
2.82\end{array}$ & $\begin{array}{l}- \\
- \\
- \\
\overline{29} \\
- \\
- \\
- \\
- \\
28\end{array}$ & $\begin{array}{c}= \\
\bar{z} \\
\overline{-} \\
2.81 \\
= \\
= \\
= \\
2.80\end{array}$ & $\begin{array}{l}- \\
- \\
- \\
- \\
\overline{27} \\
- \\
- \\
- \\
- \\
\overline{26}\end{array}$ \\
\hline
\end{tabular}

Supplemental records.- Dec. 9, Il p.m., 3.32 ft., 86 sec.-ft. Dec. 10, $3: 30$ a.m., $10.30 \mathrm{ft} ., 4,490 \mathrm{sec},-\mathrm{ft}$; 5 g.m., $9.23 \mathrm{ft} ., 3,380$ sec.-ft.; 9 a.m., $6.90 \mathrm{ft} ., 1,640$ sec.-ft.; $10: 30$ a.m., $8.50 \mathrm{ft} ., 2,730$ sec.-ft,; $5: 30$ p.m., $4.60 \mathrm{ft} ., 442 \mathrm{sec.}-\mathrm{ft}$. Dec.

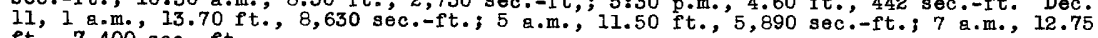


San Lorenzo R1ver at Big Trees, Calif.

Location. - Lat. $37^{\circ} 01^{\prime} 40^{n}$, long. $122^{\circ} 03^{\prime} 30^{n}$, in Canada Del Rincon grant, Santa Cruz county, half a mile south of Big Trees and 4 miles north of Santa Cruz. Altitude, about 150 foet above mean sea level.

Dra inage area.- 110 square miles.

Gage-helght record.- Water-stage recorder graph.

Stage-discharge relation. - Defined by current-meter measurements below 2,600 secondfeet; extended to peak stage. Rating curve changed Dec. 10.

Maximg.- December 1937: Discharge, 5,590 second-feet 3 a.m. Dec. 11 (gage height, 11.74 feet).

1936-November 1937: Discharge, 8,700 second-feet Feb. 14, 1937 (gage height, 14. I foet, from floodmarks), from rating curve extended above 2,600 second-feet.

January-September 1938: Discharge, 12,000 second-feet 3 p.m. Jan. 31 (gage helght, 16.8 feet from drift marks outslde of well; 16.3 feet inside of well,

affected by drawdown), from rating curve extended above 2,800 second-feet by averagIng discharges obtalned from extensions by area-velocity and $A \sqrt{d}$ methods.

Remarks.- Flood mun-off not affected by artiflclal storage; very slightly affected by many small diversions for domestic use above station.

Mean dajly discharge, in second-feet, November 1937 to January 1938

\begin{tabular}{|c|c|c|c|c|c|c|c|c|c|c|c|}
\hline Day & Nov. & Dec. & Jan. & Day & Nov. & Dec. & Jan. & Day & Nov. & Dec. & Jan. \\
\hline $\begin{array}{r}1 \\
2 \\
3 \\
4 \\
5 \\
6 \\
7 \\
8 \\
9 \\
10\end{array}$ & $\begin{array}{l}19 \\
18 \\
17 \\
17 \\
17 \\
17 \\
16 \\
17 \\
18 \\
19\end{array}$ & $\begin{array}{r}24 \\
23 \\
23 \\
23 \\
23 \\
23 \\
23 \\
23 \\
81 \\
1,880\end{array}$ & $\begin{array}{l}52 \\
72 \\
61 \\
55 \\
53 \\
52 \\
51 \\
49 \\
48 \\
47\end{array}$ & $\begin{array}{l}11 \\
12 \\
13 \\
14 \\
15 \\
16 \\
17 \\
18 \\
19 \\
20\end{array}$ & $\begin{array}{l}59 \\
38 \\
25 \\
45 \\
32 \\
26 \\
57 \\
39 \\
29 \\
32\end{array}$ & $\begin{array}{r}3,380 \\
688 \\
352 \\
213 \\
152 \\
124 \\
107 \\
94 \\
85 \\
80\end{array}$ & $\begin{array}{r}46 \\
46 \\
45 \\
45 \\
49 \\
51 \\
189 \\
99 \\
197 \\
164\end{array}$ & $\begin{array}{l}21 \\
22 \\
23 \\
24 \\
25 \\
26 \\
27 \\
28 \\
29 \\
30 \\
31\end{array}$ & $\begin{array}{l}47 \\
36 \\
33 \\
34 \\
30 \\
28 \\
26 \\
25 \\
24 \\
24\end{array}$ & $\begin{array}{l}74 \\
72 \\
71 \\
66 \\
64 \\
62 \\
59 \\
57 \\
56 \\
55 \\
54 \\
\end{array}$ & $\begin{array}{r}113 \\
96 \\
87 \\
79 \\
74 \\
71 \\
69 \\
104 \\
140 \\
116 \\
4,850\end{array}$ \\
\hline $\begin{array}{l}\text { Mear } \\
\text { Run }\end{array}$ & , 1 & old & & & & & & & $\begin{array}{r}28 \\
1,71\end{array}$ & $\begin{array}{r}262 \\
16,090\end{array}$ & $\begin{array}{r}235 \\
14,420\end{array}$ \\
\hline
\end{tabular}

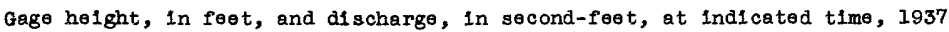

\begin{tabular}{|c|c|c|c|c|c|c|c|c|c|c|c|c|}
\hline \multirow{2}{*}{$\begin{array}{l}\text { 孚 } \\
\text { 号 }\end{array}$} & Feet & Sec.ft. & $F \theta \theta t$ & Sec.ft. & Feet & Sec.ft. & Feet & Sec.ft. & Feet & Sec.ft. & Feot & Sec.ft. \\
\hline & \multicolumn{2}{|c|}{ December 8} & \multicolumn{2}{|c|}{ December 9} & \multicolumn{2}{|c|}{ December 10} & \multicolumn{2}{|c|}{ December 11} & \multicolumn{2}{|c|}{ December 12} & \multicolumn{2}{|c|}{ December 13} \\
\hline \multirow[t]{2}{*}{$\begin{array}{r}2 \\
4 \\
6 \\
8 \\
10 \\
\mathrm{~N} \\
2 \\
4 \\
6 \\
8 \\
10 \\
\mathrm{H}\end{array}$} & $\begin{array}{l}1.13 \\
\overline{1.13} \\
= \\
\overline{1.13} \\
= \\
\overline{1.14} \\
= \\
\overline{1.14}\end{array}$ & $\begin{array}{l}22 \\
- \\
22 \\
- \\
- \\
22 \\
= \\
\overline{23} \\
- \\
\overline{23}\end{array}$ & $\begin{array}{l}1.14 \\
1.13 \\
1.13 \\
1.14 \\
1.21 \\
1.35 \\
1.57 \\
1.76 \\
2.06 \\
2.59 \\
3.46 \\
4.14\end{array}$ & $\begin{array}{r}23 \\
22 \\
22 \\
23 \\
26 \\
32 \\
45 \\
57 \\
81 \\
140 \\
289 \\
440\end{array}$ & $\begin{array}{l}5.88 \\
8.03 \\
9.43 \\
9.38 \\
7.83 \\
7.24 \\
7.14 \\
6.78 \\
6.35 \\
6.00 \\
6.56 \\
9.00\end{array}$ & $\begin{array}{l}1,150 \\
2,260 \\
3,290 \\
3,240 \\
2,140 \\
1,790 \\
1,740 \\
1,560 \\
1,360 \\
1,200 \\
1,460 \\
2,940\end{array}$ & $\begin{array}{r}11.63 \\
11.60 \\
11.06 \\
11.45 \\
10.92 \\
9.71 \\
8.66 \\
7.79 \\
7.00 \\
6.49 \\
6.04 \\
5.63\end{array}$ & $\begin{array}{l}5,510 \\
5,480 \\
4,890 \\
5,320 \\
4,730 \\
3,540 \\
2,680 \\
2,110 \\
1,670 \\
1,430 \\
1,220 \\
1,050\end{array}$ & $\begin{array}{l}5.28 \\
5.09 \\
4.83 \\
4.79 \\
4.72 \\
4.60 \\
4.52 \\
4.39 \\
4.24 \\
4.08 \\
3.95 \\
3.84\end{array}$ & $\begin{array}{l}921 \\
853 \\
764 \\
751 \\
727 \\
688 \\
662 \\
621 \\
574 \\
526 \\
490 \\
459\end{array}$ & $\begin{array}{l}3.75 \\
3.67 \\
3.60 \\
3.52 \\
3.45 \\
3.39 \\
3.34 \\
3.28 \\
3.23 \\
3.17 \\
3.13 \\
3.09\end{array}$ & $\begin{array}{l}435 \\
414 \\
396 \\
375 \\
357 \\
341 \\
328 \\
313 \\
297 \\
279 \\
267 \\
255\end{array}$ \\
\hline & \multicolumn{2}{|c|}{ December 14} & \multicolumn{2}{|c|}{ December 15} & \multicolumn{2}{|c|}{ December 16} & \multicolumn{2}{|c|}{ December 17} & \multicolumn{2}{|c|}{ December 18} & \multicolumn{2}{|c|}{ De cember 19} \\
\hline \multirow[t]{2}{*}{$\begin{array}{r}2 \\
4 \\
6 \\
8 \\
10 \\
\text { N } \\
2 \\
4 \\
6 \\
8 \\
10 \\
4\end{array}$} & $\begin{array}{l}3.05 \\
3.02 \\
2.99 \\
2.95 \\
2.92 \\
2.89 \\
2.87 \\
2.85 \\
2.83 \\
2.93 \\
2.78 \\
2.73\end{array}$ & $\begin{array}{l}245 \\
237 \\
230 \\
220 \\
213 \\
206 \\
201 \\
197 \\
193 \\
215 \\
182 \\
172\end{array}$ & $\begin{array}{l}-\overline{2.69} \\
- \\
2.65 \\
- \\
2.61 \\
- \\
2.58 \\
- \\
2.54 \\
- \\
2.51\end{array}$ & $\begin{array}{c}- \\
164 \\
- \\
158 \\
- \\
152 \\
\overline{147} \\
- \\
141 \\
136\end{array}$ & $\begin{array}{l}\overline{2.48} \\
\overline{2.45} \\
\overline{2.43} \\
\overline{2.40} \\
\overline{2.38} \\
\overline{2.36}\end{array}$ & $\begin{array}{c}\overline{132} \\
\overline{2} 8 \\
\overline{124} \\
\overline{120} \\
\overline{117} \\
\overline{114}\end{array}$ & $\begin{array}{l}\overline{-} \\
2.33 \\
- \\
2.32 \\
- \\
2.31 \\
- \\
2.28 \\
\overline{2.26} \\
\overline{2.24}\end{array}$ & $\begin{array}{c}\overline{110} \\
\overline{109} \\
\overline{107} \\
\overline{104} \\
\overline{102} \\
\overline{99}\end{array}$ & $\begin{array}{l}- \\
= \\
\overline{-} \\
2.19 \\
= \\
= \\
= \\
\bar{z} .14\end{array}$ & $\begin{array}{l}- \\
= \\
\overline{-} \\
= \\
- \\
\overline{-} \\
\overline{89}\end{array}$ & $\begin{array}{c}\overline{-} \\
= \\
\overline{2} \\
= \\
= \\
= \\
= \\
2.07\end{array}$ & $\begin{array}{l}- \\
\overline{-} \\
- \\
- \\
\overline{-} \\
= \\
- \\
- \\
82\end{array}$ \\
\hline & \multicolumn{2}{|c|}{ December 20} & \multicolumn{2}{|c|}{ December 21} & \multicolumn{2}{|c|}{ December 22} & \multicolumn{2}{|c|}{ December 23} & \multicolumn{2}{|c|}{ Decomber 24} & \multicolumn{2}{|c|}{ December 25} \\
\hline $\begin{array}{r}2 \\
4 \\
6 \\
8 \\
10 \\
\mathbb{N} \\
2 \\
4 \\
6 \\
8 \\
10 \\
4\end{array}$ & $\begin{array}{l}= \\
= \\
= \\
2.04 \\
= \\
= \\
= \\
2.00\end{array}$ & $\begin{array}{l}\overline{-} \\
\overline{-} \\
\overline{80} \\
\bar{z} \\
\bar{z} \\
\overline{7} 6\end{array}$ & $\begin{array}{l}= \\
= \\
= \\
1.98 \\
= \\
= \\
= \\
\overline{1.9} 96\end{array}$ & $\begin{array}{l}- \\
= \\
= \\
74 \\
= \\
= \\
= \\
73\end{array}$ & $\begin{array}{l}\bar{z} \\
= \\
= \\
\overline{1.95} \\
= \\
= \\
= \\
= \\
\overline{1.95}\end{array}$ & $\begin{array}{l}- \\
= \\
= \\
\overline{72} \\
= \\
= \\
= \\
\overline{72}\end{array}$ & $\begin{array}{l}\overline{-} \\
\overline{1.95} \\
= \\
\overline{1.995} \\
= \\
\overline{1.93} \\
\overline{-} \\
\overline{1.90}\end{array}$ & $\begin{array}{l}\overline{-} \\
\overline{72} \\
- \\
\overline{72} \\
= \\
\overline{70} \\
- \\
\overline{68}\end{array}$ & $\begin{array}{l}\overline{-} \\
\overline{1.89} \\
= \\
\overline{1.88} \\
\overline{-} \\
\overline{1.87} \\
\overline{-} \\
\overline{1.86}\end{array}$ & $\begin{array}{l}- \\
67 \\
= \\
\overline{66} \\
= \\
66 \\
\overline{-} \\
65\end{array}$ & $\begin{array}{l}\overline{-} \\
1.86 \\
\overline{-} \\
1.85 \\
= \\
1.85 \\
\overline{1 .} \\
\overline{1 .} 84\end{array}$ & $\begin{array}{l}- \\
\overline{65} \\
\overline{-} \\
64 \\
\overline{6} \\
\overline{64} \\
\overline{63}\end{array}$ \\
\hline
\end{tabular}

Supplemental records.- Dec. 10, 7 a.m., $9.79 \mathrm{ft.}, 3,610$ sec.-ft.; 11 a.m., 7.31 ft., 1,830 sec oft. Dec. 11, 3 a.m., il.74 ft., 5,590 sec.-ft. Dec. 14,7 p.m., 2.99 ft., 230 sec. $-f t$. 
San Francisquito Creek at Stanford Jniversity, Calif.

Location. - Lat. $37^{\circ} 25^{\prime} 20^{\prime \prime}$, long. $122^{\circ} 11^{\prime} 25^{\prime \prime}$, in Rinconada del Arroyo de San Francisquito grant, at golf course, three-quarters of a mile below junction with Los Trancos Creek, and 1.2 miles west of Stanford University post office, Santa Clara County. Altitude, about 120 feet above mean sea level.

Drainage area. - 37.7 square miles.

Gage-helght record.- Water-stage recorder graph.

Stage-discharge relation.- Defined by current-meter measurements for rango of stage of high water in December.

Maxima.- December 1937: Discharge, 940 second-feet 11 a.m. Dec. 11 (gage height, 5.00 feet).

1931-November 1937: Discharge, 2,620 second-feet Feb. 4, 1937 (gage he1ght, 9.15 feet), from rating curve extended above 1,800 second-feet on bas is of areavelocity study.

Remarks.- Flood run-off materially affected by artificial atorage in Searaville Lake (capacity, 952 acre-feet). Ios Trancos and Lagunita canals divert above station.

Monthly summaries adjusted for storage and diversion. Most of basic data furnished by Stanford University.

Mean dally discharge, in second-feet, November 1937 to January 1938

\begin{tabular}{|c|c|c|c|c|c|c|c|c|c|c|c|}
\hline Day & Nov. & Dec. & Jan. & Day & Nov. & Dec. & Jan. & Day & Nov. & Dec. & Jan. \\
\hline $\begin{array}{r}1 \\
2 \\
3 \\
4 \\
5 \\
6 \\
7 \\
8 \\
9 \\
10\end{array}$ & $\begin{array}{l}0 \\
0 \\
0 \\
0 \\
0 \\
0 \\
0 \\
0 \\
0 \\
0\end{array}$ & $\begin{array}{r}0.6 \\
.6 \\
.6 \\
.6 \\
.6 \\
.6 \\
.6 \\
.6 \\
147^{.7}\end{array}$ & $\begin{array}{r}0.3 \\
.3 \\
.3 \\
.3 \\
.3 \\
.3 \\
.4 \\
.4 \\
.3 \\
.3\end{array}$ & $\begin{array}{l}11 \\
12 \\
13 \\
14 \\
15 \\
16 \\
17 \\
18 \\
19 \\
20\end{array}$ & $\begin{array}{r}0.1 \\
.1 \\
.1 \\
.2 \\
.2 \\
.2 \\
.3 \\
.3 \\
.2 \\
.4\end{array}$ & $\begin{array}{r}588 \\
136 \\
19 \\
2.7 \\
.7 \\
.3 \\
.3 \\
.3 \\
.2 \\
.2\end{array}$ & $\begin{array}{r}0.3 \\
.3 \\
.3 \\
.3 \\
.4 \\
.4 \\
3.8 \\
107 \\
34\end{array}$ & $\begin{array}{l}21 \\
22 \\
23 \\
24 \\
25 \\
26 \\
27 \\
28 \\
29 \\
30 \\
31\end{array}$ & $\begin{array}{l}0.3 \\
.3 \\
.6 \\
.6 \\
.6 \\
.6 \\
.6 \\
.6 \\
.6 \\
.6\end{array}$ & $\begin{array}{r}0.2 \\
.2 \\
.3 \\
.3 \\
.2 \\
.2 \\
.2 \\
.2 \\
.3 \\
.3 \\
.3\end{array}$ & $\begin{array}{r}4.3 \\
.3 \\
.3 \\
.2 \\
.2 \\
.2 \\
.2 \\
6.5 \\
31 \\
13 \\
544\end{array}$ \\
\hline $\begin{array}{l}\text { Mean } \\
\text { Hean } \\
\text { Run- }\end{array}$ & $\begin{array}{l}\text { month } \\
\text { month } \\
\text { ff, } 1\end{array}$ & $\begin{array}{l}\text { Ischa } \\
\text { Ischar } \\
\text { re-fee }\end{array}$ & $\begin{array}{l}\text { in } \\
\text { in } \\
a d j u\end{array}$ & ond & $\begin{array}{l}\theta e t \\
\theta e t\end{array}$ & rved & & & $\begin{array}{r}0.25 \\
0.69 \\
41 \\
\end{array}$ & $\begin{array}{r}29.1 \\
42.6 \\
2,620 \\
\end{array}$ & $\begin{array}{r}24.2 \\
34.2 \\
2,100 \\
\end{array}$ \\
\hline
\end{tabular}

Gage height, in feet, and discharge, in second-feet, at indicated time, 1937

\begin{tabular}{|c|c|c|c|c|c|c|c|c|c|c|c|c|}
\hline \multirow{2}{*}{$\begin{array}{l}4 \\
\text { 量 }\end{array}$} & Feet & Sec.ft. & Feet & Sec.ft. & Feet & Sec.ft. & Feet & Sec.ft. & Feet & Sec.ft. & Feet & Sec.ft. \\
\hline & \multicolumn{2}{|c|}{ December 8} & \multicolumn{2}{|c|}{ December 9} & \multicolumn{2}{|c|}{ December 10} & \multicolumn{2}{|c|}{ December 11} & \multicolumn{2}{|c|}{ December 12} & \multicolumn{2}{|c|}{ December 13} \\
\hline $\begin{array}{r}2 \\
4 \\
6 \\
8 \\
10 \\
N \\
2 \\
4 \\
6 \\
8 \\
10 \\
M\end{array}$ & $\begin{array}{l}- \\
0.26 \\
- \\
.26 \\
.26 \\
-26 \\
-26 \\
.26\end{array}$ & $\begin{array}{c}-0.6 \\
-6 \\
-6 \\
.6 \\
.6 \\
.6 \\
-6\end{array}$ & $\begin{array}{l}0.26 \\
.26 \\
.27 \\
.27 \\
.27 \\
.27 \\
.27 \\
.27 \\
.28 \\
.31 \\
.35 \\
.35\end{array}$ & $\begin{array}{r}0.6 \\
.6 \\
.6 \\
.6 \\
.6 \\
.6 \\
.6 \\
.6 \\
.7 \\
.9 \\
1.3 \\
1.3\end{array}$ & $\begin{array}{r}0.39 \\
.32 \\
.27 \\
2.39 \\
2.42 \\
3.38 \\
2.74 \\
2.24 \\
1.92 \\
1.93 \\
2.30 \\
3.16\end{array}$ & $\begin{array}{r}1.7 \\
1.0 \\
179^{.6} \\
185 \\
406 \\
247 \\
153 \\
107 \\
108 \\
163 \\
348\end{array}$ & $\begin{array}{l}4.12 \\
3.91 \\
4.59 \\
4.73 \\
4.50 \\
4.83 \\
4.00 \\
3.57 \\
3.50 \\
3.45 \\
3.13 \\
2.73\end{array}$ & $\begin{array}{l}628 \\
561 \\
786 \\
837 \\
754 \\
875 \\
590 \\
460 \\
440 \\
426 \\
340 \\
245\end{array}$ & $\begin{array}{l}2.58 \\
2.47 \\
2.34 \\
2.49 \\
2.43 \\
2.28 \\
2.16 \\
2.02 \\
1.35 \\
1.24 \\
1.18 \\
1.14\end{array}$ & $\begin{array}{r}215 \\
194 \\
170 \\
197 \\
186 \\
160 \\
141 \\
120 \\
47 \\
38 \\
34 \\
31\end{array}$ & $\begin{array}{r}1.12 \\
1.11 \\
1.10 \\
1.09 \\
1.08 \\
.97 \\
.96 \\
.82 \\
.63 \\
.59 \\
.57 \\
.54\end{array}$ & $\begin{array}{l}29 \\
29 \\
28 \\
27 \\
27 \\
21 \\
20 \\
14 \\
6.5 \\
5.5 \\
4.9 \\
4.2\end{array}$ \\
\hline & \multicolumn{2}{|c|}{ December 14} & \multicolumn{2}{|c|}{ December 15} & \multicolumn{2}{|c|}{ December 16} & \multicolumn{2}{|c|}{ December 17} & \multicolumn{2}{|c|}{ December 18} & \multicolumn{2}{|c|}{ December 19} \\
\hline \multirow[t]{2}{*}{$\begin{array}{r}2 \\
4 \\
6 \\
8 \\
10 \\
\mathrm{~N} \\
2 \\
4 \\
6 \\
8 \\
10 \\
\mathrm{M}\end{array}$} & $\begin{array}{r}0.52 \\
.50 \\
.49 \\
.48 \\
.47 \\
.46 \\
.45 \\
.47 \\
.47 \\
.44 \\
.39 \\
.36\end{array}$ & $\begin{array}{l}3.8 \\
3.3 \\
3.2 \\
3.0 \\
2.8 \\
2.7 \\
2.6 \\
2.8 \\
2.8 \\
2.4 \\
1.7 \\
1.4\end{array}$ & $\begin{array}{l}- \\
0.33 \\
- \\
.30 \\
- \\
.27 \\
- \\
-25 \\
.23 \\
- \\
.22\end{array}$ & $\begin{array}{c}1.1 \\
-1 \\
.8 \\
.6 \\
-6 \\
-6 \\
.4 \\
.4\end{array}$ & $\begin{array}{l}- \\
- \\
0.21 \\
= \\
-20 \\
= \\
=20 \\
= \\
.20\end{array}$ & $\begin{array}{c}- \\
\overline{0.4} \\
- \\
- \\
.3 \\
- \\
- \\
.3 \\
- \\
.3\end{array}$ & $\begin{array}{l}- \\
0.19 \\
- \\
-19 \\
- \\
-19 \\
- \\
.19\end{array}$ & $\begin{array}{c}- \\
- \\
0.3 \\
- \\
- \\
.3 \\
- \\
-3 \\
- \\
- \\
.3\end{array}$ & $\begin{array}{l}- \\
0.19 \\
- \\
-19 \\
- \\
- \\
-19 \\
- \\
.18\end{array}$ & $\begin{array}{c}- \\
- \\
0.3 \\
- \\
- \\
-3 \\
\overline{-} \\
-3 \\
- \\
.2\end{array}$ & $\begin{array}{l}\overline{-} \\
\overline{-} \\
\overline{-} \\
0.18 \\
\overline{-} \\
= \\
\overline{-} \\
.18\end{array}$ & $\begin{array}{c}- \\
- \\
- \\
- \\
0.2 \\
- \\
- \\
- \\
\overline{.2}\end{array}$ \\
\hline & \multicolumn{2}{|c|}{ December 20} & \multicolumn{2}{|c|}{ December 21} & \multicolumn{2}{|c|}{ December 22} & \multicolumn{2}{|c|}{ December 23} & \multicolumn{2}{|c|}{ December 24} & \multicolumn{2}{|c|}{ December 25} \\
\hline $\begin{array}{r}2 \\
4 \\
6 \\
8 \\
10 \\
1 \\
2 \\
4 \\
6 \\
8 \\
10 \\
1\end{array}$ & $\begin{array}{l}\overline{-} \\
\overline{-} \\
= \\
0.18 \\
= \\
= \\
= \\
=18\end{array}$ & $\begin{array}{l}- \\
- \\
- \\
- \\
0.2 \\
- \\
- \\
- \\
- \\
.2\end{array}$ & $\begin{array}{l}\overline{-} \\
= \\
= \\
\overline{0} \\
= \\
= \\
= \\
= \\
.18\end{array}$ & $\begin{array}{c}\bar{z} \\
\overline{-} \\
\bar{z} \\
0.2 \\
- \\
- \\
- \\
- \\
- \\
.2\end{array}$ & $\begin{array}{l}\overline{-} \\
0.18 \\
- \\
-18 \\
= \\
.19 \\
- \\
.20\end{array}$ & $\begin{array}{c}- \\
- \\
0.2 \\
- \\
- \\
-2 \\
- \\
.3 \\
- \\
.3\end{array}$ & $\begin{array}{l}- \\
- \\
0.21 \\
- \\
- \\
-21 \\
- \\
.20 \\
- \\
-19\end{array}$ & $\begin{array}{l}- \\
- \\
0.4 \\
- \\
-4 \\
- \\
- \\
.3 \\
- \\
.3\end{array}$ & $\begin{array}{l}- \\
- \\
0.19 \\
- \\
.19 \\
- \\
- \\
.19 \\
- \\
.18\end{array}$ & $\begin{array}{c}- \\
- \\
0.3 \\
- \\
- \\
.3 \\
- \\
-3 \\
- \\
-2\end{array}$ & $\begin{array}{l}\bar{z} \\
0.18 \\
- \\
.18 \\
= \\
=18 \\
= \\
.18\end{array}$ & $\begin{array}{c}- \\
\overline{0.2} \\
- \\
- \\
-2 \\
\overline{-} \\
.2 \\
- \\
.2\end{array}$ \\
\hline
\end{tabular}

Supplemental records.- Dec. $10,6: 30$ a.m., 0.27 ft., 0.6 sec.-ft.; 7 a.m., 2.41 ft., 183 aec.-ft.; 9 a.m., 2.28 ft., 160 sec.-ft.; $7: 30$ p.m., 1.81 ft., 93 sec.-ft. Dec. 11 , 11 a.m., 5.00 ft., 940 sec. $-f$ t. 
San Francisquito Creek at Palo Alto, Cal1f.

Location.- Lat. $37^{\circ} 27^{\prime} 10^{n}$, long. $122^{\circ} 08^{\prime} 20^{\prime \prime}$, In Rancho de las Pulgas grant, 175 feet above Newell Avenue bridge in Palo Alto, Santa Clara County, and about $2 \mathrm{mlles}$ above mouth. Alt1tude, gbout 5 feet above mean sea level.

Drainage area.- 38.6 square miles.

Gage-helght record. - Water-stage recorder graph.

stage-discharge relation. - Defined by current-meter measurements for range of stage of high water in December.

Maxime.- December 1937: D1scharge, 840 second-feet 1:30 p.m. Dec. 11 (gage he1ght, 8.90 feet).

1931-November 1937: D1scharge, 2,550 second-feet Feb. 4, 1937 (gage helght, 16.05 feet), from rating curve extended above 1,900 second-feet.

Remarks. - Flood run-off materially affected by artific1al storage in Searsville Lake

(capac1ty, 952 acre-feet). Los Trancos and Lagunita canals divert above station.

Monthly sumaries ajusted for storage and diversions. Most of basic data furnished by Stanford University.

Mean da1ly discharge, in second-feet, November 1937 to January 1938

\begin{tabular}{|c|c|c|c|c|c|c|c|c|c|c|c|}
\hline Day & Nov. & Dec. & Jan. & Day & Nov. & Dec. & Jan. & Day & Nov. & Dec. & Jan. \\
\hline $\begin{array}{r}1 \\
2 \\
3 \\
4 \\
5 \\
6 \\
7 \\
8 \\
9 \\
10\end{array}$ & $\begin{array}{l}0 \\
0 \\
0 \\
0 \\
0 \\
0 \\
0 \\
0 \\
0 \\
0\end{array}$ & $\begin{array}{r}0 \\
0 \\
0 \\
0 \\
0 \\
0 \\
0 \\
0 \\
10 \\
116\end{array}$ & $\begin{array}{l}0 \\
0 \\
0 \\
0 \\
0 \\
0 \\
0 \\
0 \\
0 \\
0\end{array}$ & $\begin{array}{l}11 \\
12 \\
13 \\
14 \\
15 \\
16 \\
17 \\
18 \\
19 \\
20\end{array}$ & $\begin{array}{l}0 \\
0 \\
0 \\
0 \\
0 \\
0 \\
0 \\
0 \\
0 \\
0\end{array}$ & $\begin{array}{c}544 \\
156 \\
21 \\
1.9 \\
0.2 \\
0 \\
0 \\
0 \\
0 \\
0\end{array}$ & $\begin{array}{r}0 \\
0 \\
0 \\
0 \\
0 \\
0 \\
0 \\
0 \\
99 \\
40\end{array}$ & $\begin{array}{l}21 \\
22 \\
23 \\
24 \\
25 \\
26 \\
27 \\
28 \\
29 \\
30 \\
31\end{array}$ & $\begin{array}{l}0 \\
0 \\
0 \\
0 \\
0 \\
0 \\
0 \\
0 \\
0 \\
0\end{array}$ & $\begin{array}{l}0 \\
0 \\
0 \\
0 \\
0 \\
0 \\
0 \\
0 \\
0 \\
0\end{array}$ & $\begin{array}{c}5 \\
0^{-1} \\
0 \\
0 \\
0 \\
0 \\
2^{.3} \\
13 \\
510\end{array}$ \\
\hline $\begin{array}{l}\text { Mean } \\
\text { Mean } \\
\text { Run- }\end{array}$ & $\begin{array}{l}\text { onthl } \\
\text { onthl } \\
f, \text { in }\end{array}$ & $\begin{array}{l}\text { Isch } \\
13 \mathrm{ch} \theta \\
r \theta-f e\end{array}$ & $\begin{array}{l}\ln \\
\ln \\
\mathrm{adj} u\end{array}$ & $\begin{array}{l}\text { ond } \\
\text { ond } \\
\text { d). }\end{array}$ & $\begin{array}{l}\text { eet } \\
\text { eet }\end{array}$ & $\begin{array}{l}\text { erved } \\
\text { usted }\end{array}$ & & & $\begin{array}{r}0 \\
0.44 \\
26 \\
\end{array}$ & $\begin{array}{r}27.1 \\
40.5 \\
2,490 \\
\end{array}$ & $\begin{array}{r}22.4 \\
32.4 \\
1,990 \\
\end{array}$ \\
\hline
\end{tabular}

Gage helght, in feet, and dscharge, in second-feet, at inalcated time, 1937

\begin{tabular}{|c|c|c|c|c|c|c|c|c|c|c|c|c|}
\hline \multirow{2}{*}{ 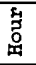 } & Feet & sec.ft. & Feet & sec.ft. & Feet & Sec.ft. & Feet & Sec.ft. & Feet & Sec.ft. & Feet & Sec.ft. \\
\hline & \multicolumn{2}{|c|}{ December 8} & \multicolumn{2}{|c|}{ December 9} & \multicolumn{2}{|c|}{ December 10} & \multicolumn{2}{|c|}{ December 11} & \multicolumn{2}{|c|}{ December 12} & \multicolumn{2}{|c|}{ December 13} \\
\hline \multirow[t]{2}{*}{$\begin{array}{r}2 \\
4 \\
6 \\
8 \\
10 \\
N \\
2 \\
4 \\
6 \\
8 \\
10 \\
M\end{array}$} & & & & & $\begin{array}{c}- \\
- \\
- \\
0.46 \\
3.96 \\
4.20 \\
5.94 \\
4.60 \\
3.75 \\
3.20 \\
3.20 \\
3.88\end{array}$ & $\begin{array}{c}0 \\
0 \\
0 \\
1.7 \\
174 \\
198 \\
389 \\
238 \\
154 \\
108 \\
108 \\
166\end{array}$ & $\begin{array}{l}5.47 \\
7.05 \\
7.13 \\
8.13 \\
8.52 \\
8.30 \\
8.65 \\
7.16 \\
6.41 \\
6.32 \\
6.12 \\
5.43\end{array}$ & $\begin{array}{l}334 \\
535 \\
547 \\
707 \\
772 \\
734 \\
795 \\
552 \\
445 \\
434 \\
410 \\
329\end{array}$ & $\begin{array}{l}4.68 \\
4.38 \\
4.18 \\
3.97 \\
4.20 \\
4.05 \\
3.78 \\
3.53 \\
3.27 \\
2.28 \\
2.08 \\
1.97\end{array}$ & $\begin{array}{l}247 \\
216 \\
196 \\
175 \\
198 \\
183 \\
157 \\
135 \\
114 \\
50 \\
40 \\
35\end{array}$ & $\begin{array}{r}1.86 \\
1.80 \\
1.76 \\
1.75 \\
1.74 \\
1.71 \\
1.62 \\
1.48 \\
1.45 \\
1.22 \\
.97 \\
.82\end{array}$ & $\begin{array}{l}30 \\
28 \\
26 \\
26 \\
26 \\
24 \\
21 \\
17 \\
16 \\
11 \\
6.5 \\
4.7\end{array}$ \\
\hline & \multicolumn{2}{|c|}{ December 14} & \multicolumn{2}{|c|}{ December 15} & \multicolumn{2}{|c|}{ December 16} & \multicolumn{2}{|c|}{ December 17} & \multicolumn{2}{|c|}{ December 18} & \multicolumn{2}{|c|}{ December 19} \\
\hline $\begin{array}{r}2 \\
4 \\
6 \\
8 \\
10 \\
11 \\
2 \\
4 \\
6 \\
8 \\
10 \\
M\end{array}$ & $\begin{array}{r}0.75 \\
.69 \\
.64 \\
.57 \\
.51 \\
.45 \\
.41 \\
.38 \\
.33 \\
.28 \\
.23 \\
.19\end{array}$ & $\begin{array}{r}3.8 \\
3.3 \\
2.9 \\
2.4 \\
2.0 \\
1.6 \\
1.4 \\
1.2 \\
1.0 \\
.7 \\
.5 \\
.4\end{array}$ & $\begin{array}{l}0.27 \\
.24 \\
.19 \\
.15 \\
= \\
= \\
= \\
= \\
= \\
=\end{array}$ & $\begin{array}{l}0.7 \\
.6 \\
.4 \\
.2 \\
0 \\
0 \\
0 \\
0 \\
0 \\
0 \\
0 \\
0\end{array}$ & & & & & & & & \\
\hline
\end{tabular}

Supplemental records.- Dec. 10, $9: 30$ a.m., 0.22 ft., 0.5 sec.-ft.; 9 p.m., 3.07 ft., 98 sec.-ft. Dec. 11, $11: 30$ a.m., 7.90 ft., 670 sec.-ft.; 1:30 p.m., 8.90 ft., 840 sec. $-f t$. 
Ios Trancos Creek at Stanford UnIversity, Cal1f.

Location.- Lat. $37^{\circ} 24^{\prime} 35^{\prime \prime}$, Iong. $122^{\circ} 12^{\prime} 35^{\prime \prime}$, In El Corte de Madera grant, about 8cC feet above mouth and $1.6 \mathrm{mlies}$ southwest of Stanford University post of 1 ice, Santa Clara County. Altitude, about 160 feet above mean sea level.

Drainage area.- 7.5 square miles.

Gage-helght record. - Water-stage recorder graph.

Stage-discharge relation. - Defined by current-meter measurements below 310 secondfeet.

Maxima.- December 1937: Discharge, 120 second-feet 8:30 a.m. Dec. I1 (gage he1ght, 1.94 feet).

1931-November 1937: D1scharge, 399 second-feet Mar. 21, 1937 (gage he1ght, 3.13 feet), from rating curve extended above 310 second-feet.

Remarks. - Flood mun-off not affected by artiflclal storage. Los Trancos canal diverts above station. Monthly summaries adjusted for diversion. Most of besic dete furnished by Stanford University.

Mean dally dlscharge, in second-feet, November 1937 to January 1938

\begin{tabular}{|c|c|c|c|c|c|c|c|c|c|c|c|}
\hline Day & Nov. & Doc. & Jan. & Day & Nov. & Dec. & Jan. & Day & Nov. & Dec. & Jan. \\
\hline $\begin{array}{r}1 \\
2 \\
3 \\
4 \\
5 \\
6 \\
7 \\
8 \\
9 \\
10\end{array}$ & $\begin{array}{l}0 \\
0 \\
0 \\
0 \\
0 \\
0 \\
0 \\
0 \\
0 \\
0\end{array}$ & $\begin{array}{l}0 \\
0 \\
0 \\
0 \\
0 \\
0 \\
0 \\
0 \\
0 \\
2.2\end{array}$ & $\begin{array}{l}0 \\
0 \\
0 \\
0 \\
0 \\
0 \\
0 \\
0 \\
0 \\
0\end{array}$ & $\begin{array}{l}11 \\
12 \\
13 \\
14 \\
15 \\
16 \\
17 \\
18 \\
19 \\
20\end{array}$ & $\begin{array}{l}0 \\
0 \\
0 \\
0 \\
0 \\
0 \\
0 \\
0 \\
0 \\
0\end{array}$ & $\begin{array}{r}37 \\
3.8 \\
.7 \\
.3 \\
.1 \\
0.1 \\
0 \\
0 \\
0 \\
0\end{array}$ & $\begin{array}{l}0 \\
0 \\
0 \\
0 \\
0 \\
0 \\
\\
.1 \\
.1 \\
.1 \\
5 \\
.6\end{array}$ & $\begin{array}{l}21 \\
22 \\
23 \\
24 \\
25 \\
26 \\
27 \\
28 \\
29 \\
30 \\
31\end{array}$ & $\begin{array}{l}0 \\
0 \\
0 \\
0 \\
0 \\
0 \\
0 \\
0 \\
0 \\
0\end{array}$ & $\begin{array}{l}0 \\
0 \\
0 \\
0 \\
0 \\
0 \\
0 \\
0 \\
0 \\
0 \\
0\end{array}$ & $\begin{array}{r}0.3 \\
.2 \\
.2 \\
.1 \\
.1 \\
.1 \\
.17 \\
.7 \\
1.6 \\
109^{.4}\end{array}$ \\
\hline \multicolumn{9}{|c|}{ 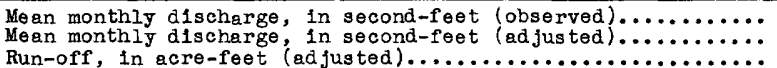 } & $\begin{array}{r}0 \\
0.11 \\
6.3\end{array}$ & $\begin{array}{r}1.43 \\
4.18 \\
257\end{array}$ & $\begin{array}{r}3.83 \\
6.59 \\
405\end{array}$ \\
\hline
\end{tabular}

Run-off, in ere-fee

Gage helght, in feet, and discherge, in second-feet, at indiceted time, 1937

\begin{tabular}{|c|c|c|c|c|c|c|c|c|c|c|c|c|}
\hline \multirow{2}{*}{$\begin{array}{l} \\
5 \\
0 \\
0\end{array}$} & Feet & Sec.ft. & Feet & Sec.ft. & Feet & Sec.ft. & Feet & Sec.ft. & Feet & Sec.ft. & Feet & Sec.ft. \\
\hline & \multicolumn{2}{|c|}{ December 8} & \multicolumn{2}{|c|}{ December 9} & \multicolumn{2}{|c|}{ December 10} & \multicolumn{2}{|c|}{ December 11} & \multicolumn{2}{|c|}{ December 12} & \multicolumn{2}{|c|}{ December 13} \\
\hline $\begin{array}{r}2 \\
4 \\
6 \\
8 \\
10 \\
\mathrm{~N} \\
2 \\
4 \\
6 \\
8 \\
10 \\
M\end{array}$ & & & & & $\begin{array}{r}0.19 \\
.33 \\
.30 \\
.23 \\
.19 \\
.16 \\
.15 \\
.14 \\
.13 \\
.15 \\
.20 \\
1.42\end{array}$ & $\begin{array}{l}0 \\
1.4 \\
1.1 \\
. .7 \\
0 \\
0 \\
0 \\
0 \\
0 \\
0 \\
{ }_{44}^{.5}\end{array}$ & $\begin{array}{r}1.58 \\
1.50 \\
1.27 \\
1.90 \\
1.48 \\
1.24 \\
.90 \\
.65 \\
1.00 \\
.99 \\
.65 \\
.50\end{array}$ & $\begin{array}{c}60 \\
51 \\
59 \\
112 \\
49 \\
30 \\
12 \\
5.5 \\
16 \\
16 \\
5.5 \\
3.2\end{array}$ & $\begin{array}{r}0.46 \\
.44 \\
.48 \\
.86 \\
.79 \\
.63 \\
.53 \\
.47 \\
.43 \\
.39 \\
.36 \\
.33\end{array}$ & $\begin{array}{c}2.7 \\
2.5 \\
3.0 \\
10 \\
8 \\
5 \\
3.6 \\
2.8 \\
2.4 \\
1.9 \\
1.6 \\
1.4\end{array}$ & $\begin{array}{l}- \\
0.27 \\
- \\
.24 \\
- \\
.22 \\
- \\
.20 \\
.18 \\
.17\end{array}$ & $\begin{array}{c}0.9 \\
-7 \\
\vdots 6 \\
\vdots \\
\vdots \\
0 \\
0 \\
0\end{array}$ \\
\hline
\end{tabular}

Supplemental records.- Dec. 10, 11 p.m., 0.7 ft., 6.5 sec.-ft. Dec. $11,8: 30$ a.m., $1.94 \mathrm{ft.}, 120 \mathrm{sec} . \mathrm{ft}$. Dec. 12,9 a.m., $0.97 \mathrm{ft} ., 15$ sec.-ft. 
Stevens Creok near Cupertino, Calif.

Location. - Lat. $37^{\circ} 18^{\prime} 20^{\prime \prime}$, long. $122^{\circ} 04^{\prime} 25^{\prime \prime}$, in SWr sec. 22, T. 7 S., R. 2 W., at county hlghway bridge, a quarter of a mlle below Stevens Creek Dam and about 4 miles west of Cupertino, Santa Clara County. Altitude, about 385 feet above mean sea level.

Dralnage area.- 18.1 square miles.

Gage-height record. - Water-stage recorder graph.

Stage-discharge relation. - Defined by current-meter measurements.

Maxima.- December 1937: Discharge (regulated), 55 second-feet 12:30 a.m. Dec. 11 (gage helght, 2.17 feet).

1930-November 1937: Discharge (unregulated), 709 second-feet Dec. 27, 1931 (gage height, 4.57 feet), from rating curve extended above 670 second-feet.

Remarks.- Flood run-off completely regulated by artificial storage in Stevens Creek

Reservolr (capacity, about 4,000 acre-feet). Monthly sumarles adjusted for storage.

Mean daily discharge, in second-feet, November 1937 to January 1938

\begin{tabular}{|r|c|c|c||c|c|c|c||c|c|c|c|}
\hline Day & Nov. & Dec. & Jan. & Day & Nov. & Dec. & Jan. & Day & Nov. & Dec. & Jan. \\
\hline 1 & 0.5 & 1.4 & 4.9 & 11 & 0.7 & 24 & 4.4 & 21 & 2.2 & 14 & 14 \\
2 & .5 & 1.6 & 7 & 12 & 1.4 & 22 & 4.1 & 22 & 2.2 & 12 & 12 \\
3 & .5 & 1.7 & 9.5 & 13 & 1.8 & 18 & 4.1 & 23 & 2.2 & 9.5 & 9.5 \\
4 & .5 & 1.7 & 7 & 14 & 1.8 & 21 & 4.1 & 24 & 2.2 & 8.5 & 9 \\
5 & .5 & 1.7 & 5.5 & 15 & 1.8 & 21 & 4.1 & 25 & 2.2 & 8.5 & 8.5 \\
6 & .5 & 1.7 & 4.6 & 16 & 1.8 & 22 & 4.6 & 26 & 2.0 & 8.5 & 7.5 \\
7 & .5 & 1.1 & 4.4 & 17 & 2.0 & 20 & 6 & 27 & 2.0 & 8.5 & 7 \\
8 & .5 & .4 & 4.4 & 18 & 2.2 & 25 & 8 & 28 & 2.0 & 8.5 & 9.5 \\
9 & .5 & 1.1 & 4.6 & 19 & 2.2 & 23 & 11 & 29 & 2.0 & 7 & 20 \\
10 & .5 & 17 & 4.6 & 20 & 2.2 & 24 & 14 & 30 & 1.7 & 4.6 & 26 \\
\end{tabular}


Guadalupe Creok at Guadalupe, Calif.

Location.- Lat. $37^{\circ} 13^{\prime} 0^{\prime \prime}$, long. $121^{\circ} 54^{\prime} 35^{\prime \prime}$, in Sw sec. 19, T. 8 S., R. I E., half a mile northwest of Guadalupe, Santa Clara County, and 3.4 miles upstream from junction with Alamitos Creek. Altitude, about 325 feet above mean sea level.

Drainage area.- 12.6 square miles.

Gage-helght record. - Water-stage recorder graph.

Stage-discharge relation.- Defined by current-meter measurements below 550 secondfeet; extended to peak stage. Shifting-control method used for period Nov. 1 to Dec. 9.

Max1ma.- December 1937: Discharge, 826 second-feet 1 a.m. Dec. 11 (gage helght, 3.41 feet).

1930-November 1937: Dlscharge (unregulated), 1,160 second-feet Dec. 28,1931 (gage helght, 4.05 feet, inside of well; about 4.5 feet, outside of weil, determined from drawdown relation observed at lower stages), from rating curve extended above 850 second-feet.

Remarks.- Flood run-off affected by artificlal storage in Guadalupe Reservoir (capac$1 t_{y}, 3,500$ acre feet); unaffected by diversions. Monthly summarles adjusted for storage.

\begin{tabular}{|c|c|c|c|c|c|c|c|c|c|c|c|}
\hline Day & Nov. & Dec. & $\operatorname{Jan}$. & Day & Nov. & Dec. & Jan. & Day & Nov. & Dec. & Jan. \\
\hline $\begin{array}{r}1 \\
2 \\
3 \\
4 \\
5 \\
6 \\
7 \\
8 \\
9 \\
10\end{array}$ & $\begin{array}{r}0.6 \\
.5 \\
.5 \\
.4 \\
.5 \\
.5 \\
.5 \\
.5 \\
.5 \\
.5\end{array}$ & $\begin{array}{r}0.6 \\
.6 \\
.6 \\
.6 \\
.7 \\
.6 \\
.6 \\
.6 \\
1.7 \\
117\end{array}$ & $\begin{array}{l}4.5 \\
5 \\
5 \\
5.5 \\
5.5 \\
5.5 \\
5.5 \\
5.5 \\
5.5 \\
5\end{array}$ & $\begin{array}{l}11 \\
12 \\
13 \\
14 \\
15 \\
18 \\
17 \\
18 \\
19 \\
20\end{array}$ & $\begin{array}{r}3.7 \\
1.3 \\
.9 \\
1.2 \\
1.0 \\
.8 \\
.8 \\
1.7 \\
1.0 \\
.9\end{array}$ & $\begin{array}{c}248 \\
49 \\
22 \\
15 \\
11 \\
8 \\
6.5 \\
5.5 \\
4.8 \\
5\end{array}$ & $\begin{array}{c}5 \\
5.5 \\
5.5 \\
5.5 \\
5.5 \\
5.5 \\
5.5 \\
5.5 \\
11 \\
7.5\end{array}$ & $\begin{array}{l}21 \\
22 \\
23 \\
24 \\
25 \\
26 \\
27 \\
28 \\
29 \\
30 \\
31\end{array}$ & $\begin{array}{r}1.7 \\
1.3 \\
1.1 \\
1.1 \\
.9 \\
.8 \\
.7 \\
.8 \\
.7 \\
.7\end{array}$ & $\begin{array}{l}5.5 \\
5.5 \\
5.5 \\
5.5 \\
5 \\
5 \\
4.8 \\
4.8 \\
4.5 \\
4.5 \\
4.5\end{array}$ & $\begin{array}{l}6.5 \\
6 \\
6 \\
6.5 \\
6.5 \\
6 \\
8 \\
13 \\
15 \\
11 \\
137\end{array}$ \\
\hline $\begin{array}{l}\text { Mean } \\
\text { Mean } \\
\text { Run- }\end{array}$ & $\begin{array}{l}\text { nonth] } \\
\text { nonth] } \\
\text { of, in }\end{array}$ & $\begin{array}{l}\text { Hischar } \\
\text { dischar } \\
\text { ere-fee }\end{array}$ & $\begin{array}{l}\text {, In } \\
\text { ind } \\
\text { adju }\end{array}$ & $\begin{array}{l}\text { ond } \\
\text { ond } \\
\text { d). }\end{array}$ & $\begin{array}{l}\text { eet } \\
\text { eet }\end{array}$ & $\begin{array}{l}\text { erved } \\
\text { usted }\end{array}$ & & & $\begin{array}{r}0.94 \\
.94 \\
56 \\
\end{array}$ & $\begin{array}{r}17.9 \\
52.4 \\
3,220 \\
\end{array}$ & $\begin{array}{r}10.8 \\
13.6 \\
838 \\
\end{array}$ \\
\hline
\end{tabular}

Gage helght, in feet, and discharge, in second-feet, at indicated time, 1937

\begin{tabular}{|c|c|c|c|c|c|c|c|c|c|c|c|c|}
\hline \multirow{2}{*}{$\begin{array}{l}\text { H } \\
\text { 号 }\end{array}$} & Feet & Sec.ft. & Feet & Sec.ft. & Feet & Sec.ft. & Feet & Sec.ft. & Feet & Sec.ft. & Feet & Sec.ft. \\
\hline & \multicolumn{2}{|c|}{ December 8} & \multicolumn{2}{|c|}{ December 9} & \multicolumn{2}{|c|}{ December 10} & \multicolumn{2}{|c|}{ December 11} & \multicolumn{2}{|c|}{ December 12} & \multicolumn{2}{|c|}{ December 13} \\
\hline \multirow[t]{2}{*}{$\begin{array}{r}2 \\
4 \\
6 \\
8 \\
10 \\
N \\
2 \\
4 \\
6 \\
8 \\
10 \\
M\end{array}$} & $\begin{array}{l}- \\
- \\
- \\
\overline{-} \\
0.50 \\
\overline{-} \\
\overline{-} \\
- \\
.50\end{array}$ & $\begin{array}{c}- \\
- \\
- \\
- \\
- \\
0.6 \\
- \\
- \\
- \\
- \\
.6\end{array}$ & $\begin{array}{r}0.50 \\
.50 \\
.50 \\
.50 \\
.51 \\
.52 \\
.54 \\
.55 \\
.57 \\
.63 \\
.84 \\
.88\end{array}$ & $\begin{array}{r}0.6 \\
.6 \\
.6 \\
.6 \\
.7 \\
.7 \\
.9 \\
1.0 \\
1.2 \\
2.0 \\
7.5 \\
9\end{array}$ & $\begin{array}{l}1.10 \\
1.30 \\
1.41 \\
1.36 \\
1.64 \\
1.72 \\
1.53 \\
1.43 \\
1.37 \\
1.89 \\
2.75 \\
3.16\end{array}$ & \begin{tabular}{|r|}
26 \\
45 \\
58 \\
52 \\
92 \\
106 \\
74 \\
81 \\
53 \\
142 \\
485 \\
683
\end{tabular} & $\begin{array}{l}2.83 \\
2.36 \\
2.47 \\
2.38 \\
2.38 \\
2.25 \\
2.05 \\
1.93 \\
1.82 \\
1.73 \\
1.54 \\
1.55\end{array}$ & $\begin{array}{r}505 \\
294 \\
338 \\
302 \\
294 \\
252 \\
185 \\
152 \\
126 \\
108 \\
92 \\
78\end{array}$ & $\begin{array}{l}1.50 \\
1.45 \\
1.40 \\
1.44 \\
1.36 \\
1.31 \\
1.28 \\
1.25 \\
1.22 \\
1.20 \\
1.17 \\
1.15\end{array}$ & $\begin{array}{l}70 \\
64 \\
57 \\
62 \\
52 \\
46 \\
43 \\
40 \\
37 \\
35 \\
32 \\
30\end{array}$ & $\begin{array}{c}- \\
1.10 \\
- \\
1.07 \\
- \\
1.05 \\
- \\
1.02 \\
\overline{1.00} \\
.08\end{array}$ & $\begin{array}{l}\overline{26} \\
\overline{24} \\
\overline{22} \\
\overline{20} \\
\overline{19} \\
\overline{18}\end{array}$ \\
\hline & \multicolumn{2}{|c|}{ December 14} & \multicolumn{2}{|c|}{ December 15} & \multicolumn{2}{|c|}{ December 16} & \multicolumn{2}{|c|}{ December 17} & \multicolumn{2}{|c|}{ December 18} & \multicolumn{2}{|c|}{ December 19} \\
\hline \multirow[t]{2}{*}{$\begin{array}{r}2 \\
4 \\
6 \\
8 \\
10 \\
\mathrm{~N} \\
2 \\
4 \\
6 \\
8 \\
10 \\
\mathrm{M} \\
\end{array}$} & $\begin{array}{l}- \\
\overline{0.95} \\
- \\
- \\
.93 \\
- \\
.90 \\
- \\
.88\end{array}$ & $\begin{array}{l}- \\
\overline{16} \\
- \\
\overline{15} \\
\overline{-} \\
\overline{14} \\
- \\
\overline{13}\end{array}$ & $\begin{array}{l}- \\
- \\
0.86 \\
- \\
.84 \\
- \\
-82 \\
- \\
-\end{array}$ & $\begin{array}{c}\overline{-} \\
\overline{12} \\
\overline{-} \\
\overline{11} \\
\overline{-} \\
\overline{9} .5 \\
\overline{8} \\
\overline{8} .5\end{array}$ & $\begin{array}{l}- \\
- \\
- \\
- \\
0.78 \\
- \\
- \\
- \\
- \\
.75\end{array}$ & $\begin{array}{c}\overline{-} \\
- \\
- \\
8^{-} \\
- \\
- \\
- \\
- \\
6.5\end{array}$ & $\begin{array}{l}- \\
- \\
- \\
0.74 \\
- \\
- \\
- \\
-73\end{array}$ & $\begin{array}{c}- \\
- \\
- \\
\overline{-} \\
= \\
- \\
- \\
- \\
6\end{array}$ & $\begin{array}{l}- \\
- \\
- \\
- \\
0.71 \\
- \\
\overline{-} \\
- \\
.70\end{array}$ & $\begin{array}{l}- \\
- \\
- \\
5.5 \\
- \\
- \\
- \\
5\end{array}$ & $\begin{array}{l}- \\
- \\
- \\
- \\
0.69 \\
- \\
- \\
- \\
- \\
.68\end{array}$ & $\begin{array}{c}- \\
- \\
- \\
- \\
\overline{4} .8 \\
- \\
- \\
- \\
- \\
4.5\end{array}$ \\
\hline & \multicolumn{2}{|c|}{ December 20} & \multicolumn{2}{|c|}{ December 21} & \multicolumn{2}{|c|}{ December 22} & \multicolumn{2}{|c|}{ December 23} & \multicolumn{2}{|c|}{ December 24} & \multicolumn{2}{|c|}{ December 25} \\
\hline $\begin{array}{r}2 \\
4 \\
6 \\
8 \\
10 \\
\mathrm{~N} \\
2 \\
4 \\
6 \\
8 \\
10 \\
\mathrm{M}\end{array}$ & $\begin{array}{l}- \\
0.68 \\
- \\
.67 \\
-67 \\
\vdots \\
.72 \\
.72 \\
.72\end{array}$ & $\begin{array}{c}4.5 \\
- \\
4.2 \\
-\overline{4} \\
\overline{-} \\
5.5 \\
- \\
5.5 \\
\overline{5.5}\end{array}$ & $\begin{array}{l}- \\
- \\
- \\
- \\
0.71 \\
- \\
- \\
- \\
-71\end{array}$ & $\begin{array}{c}\overline{-} \\
\overline{-} \\
- \\
5.5 \\
\overline{-} \\
- \\
- \\
5.5\end{array}$ & $\begin{array}{l}\overline{-} \\
\overline{-} \\
\overline{-} \\
0.71 \\
\overline{-} \\
\overline{-} \\
\overline{-} \\
.72\end{array}$ & $\begin{array}{c}\overline{-} \\
\overline{-} \\
- \\
5.5 \\
- \\
- \\
\overline{-} \\
- \\
5.5\end{array}$ & $\begin{array}{l}- \\
- \\
- \\
- \\
0.72 \\
- \\
- \\
- \\
- \\
.71\end{array}$ & $\begin{array}{c}\bar{z} \\
\bar{z} \\
\overline{5} \\
\overline{5} \\
\overline{-} \\
\overline{-} \\
\overline{-} \\
5.5\end{array}$ & $\begin{array}{l}- \\
- \\
\overline{-} \\
- \\
0.71 \\
- \\
= \\
= \\
- \\
.70\end{array}$ & $\begin{array}{l}- \\
- \\
- \\
5.5 \\
- \\
= \\
- \\
5\end{array}$ & $\begin{array}{c}- \\
- \\
- \\
- \\
- \\
0.70 \\
= \\
- \\
= \\
-70\end{array}$ & $\begin{array}{l}- \\
- \\
- \\
- \\
\overline{5} \\
- \\
- \\
- \\
- \\
\overline{5}\end{array}$ \\
\hline
\end{tabular}

Supplemental records.- Dec. 10, 5 a.m., $1.50 \mathrm{ft.,} 70 \mathrm{sec.-ft.;} 11$ a.m., 1.76 ft., 114 sec.-ft.; 7 p.m., 1.45 ft., 64 sec.-ft.; 9 p.m.; 2.18 ft., 228 sec.-ft.; 11 p.m., $2.70 \mathrm{ft.}, 440$ sec.-ft. Dec. il, 1 a.m., 3.41 ft., 826 sec. $f t$. 
Location. - Lat. $37^{\circ} 20^{\prime}$, long. $121^{\circ} 54^{\prime}, 100$ feet downstream from junction with Ios Gatos Creek, in c1ty of San Jose, Santa Clara County. Altitude, about 80 feet above mean sea level.

Drainage area. - 131 square miles.

Gage-helght record.- Water-stage recorder graph.

tage-discharge relation. - Defined by current-meter measurements below 3,500 secondfeet; extended to peak stage. Rating curve changed at peak stage.

Maxima.- December 1937: Discharge, 6,660 second-feet 4 a.m. Dec. Il (gage helght, 9.80 feet).

1930-November 1937: Discharge (unregulated), 6,700 second-feet Dec. 27,1931 (gage height, 11.12 feet), from rating curve extended above 3,200 second-feet on basis of area-velocity study.

Remarks:- Flood mun-off affected by artificial storage in 4 reservoirs on Ios Gatos, Alamitos, and Guadalupe Creeks (total capac1ty, about 15,600 acre-feet). Monthly summarles adjusted for storage.

Mean da11y discharge, in second-feet, November 1937 to January 1938

\begin{tabular}{|c|c|c|c|c|c|c|c|c|c|c|c|}
\hline Day & Nov. & Dec. & Jan. & Day & Nov. & Dec. & Jan. & Day & Nov. & Dec. & Jan. \\
\hline $\begin{array}{r}1 \\
2 \\
3 \\
4 \\
5 \\
6 \\
7 \\
8 \\
9 \\
10\end{array}$ & $\begin{array}{l}0 \\
0 \\
0 \\
0 \\
0 \\
0 \\
0 \\
0 \\
0 \\
0\end{array}$ & $\begin{array}{r}0 \\
0 \\
0 \\
0 \\
0 \\
0 \\
0 \\
0 \\
0 \\
385\end{array}$ & $\begin{array}{l}0 \\
0 \\
0 \\
0 \\
0 \\
0 \\
0 \\
0 \\
0 \\
0\end{array}$ & $\begin{array}{l}11 \\
12 \\
13 \\
14 \\
15 \\
16 \\
17 \\
18 \\
19 \\
20\end{array}$ & $\begin{array}{l}0 \\
0 \\
0 \\
0 \\
0 \\
0 \\
0 \\
0 \\
0 \\
0\end{array}$ & $\begin{array}{c}3,940 \\
887 \\
218 \\
62 \\
6 \\
0 \\
0 \\
0 \\
0 \\
0\end{array}$ & $\begin{array}{l}0 \\
0 \\
0 \\
0 \\
0 \\
0 \\
0 \\
0 \\
0 \\
0\end{array}$ & $\begin{array}{l}21 \\
22 \\
23 \\
24 \\
25 \\
26 \\
27 \\
28 \\
29 \\
30 \\
31\end{array}$ & $\begin{array}{l}0 \\
0 \\
0 \\
0 \\
0 \\
0 \\
0 \\
0 \\
0 \\
0\end{array}$ & $\begin{array}{l}0 \\
0 \\
0 \\
0 \\
0 \\
0 \\
0 \\
0 \\
0 \\
0 \\
0\end{array}$ & $\begin{array}{r}0 \\
0 \\
0 \\
0 \\
0 \\
0 \\
0 \\
0 \\
0 \\
0 \\
1,460\end{array}$ \\
\hline \multicolumn{9}{|c|}{$\begin{array}{l}\text { Mean } \\
\text { Mean } \\
\text { Run-o }\end{array}$} & $\begin{array}{l}0 \\
0 \\
0\end{array}$ & $\begin{array}{r}177 \\
264 \\
16,240 \\
\end{array}$ & $\begin{array}{r}47.1 \\
56.2 \\
3,460 \\
\end{array}$ \\
\hline
\end{tabular}

Gage helght, in feet, and discharge, in second-feet, at indicated time, 1937

\begin{tabular}{|c|c|c|c|c|c|c|c|c|c|c|c|c|}
\hline \multirow{2}{*}{ 宩 } & Feet & Sec.ft. & Feet & Sec.ft. & Feet & sec.ft. & Feet & sec.ft. & Feet & Sec.ft. & Feet & Sec.ft. \\
\hline & \multicolumn{2}{|c|}{ December 8} & \multicolumn{2}{|c|}{ December 9} & \multicolumn{2}{|c|}{ De cember 10} & \multicolumn{2}{|c|}{ December 11} & \multicolumn{2}{|c|}{ December 12} & \multicolumn{2}{|c|}{ December 13} \\
\hline \multirow[t]{2}{*}{$\begin{array}{r}2 \\
4 \\
6 \\
8 \\
10 \\
N \\
2 \\
4 \\
6 \\
8 \\
10 \\
M\end{array}$} & & & & & $\begin{array}{l}- \\
- \\
- \\
3.36 \\
2.87 \\
2.56 \\
2.59 \\
3.31 \\
3.20 \\
2.85 \\
2.94 \\
3.55\end{array}$ & $\begin{array}{r}0 \\
0 \\
0 \\
772 \\
430 \\
257 \\
270 \\
737 \\
660 \\
417 \\
478 \\
905\end{array}$ & $\begin{array}{l}5.83 \\
9.80 \\
8.35 \\
7.47 \\
8.15 \\
8.30 \\
7.76 \\
6.95 \\
6.18 \\
5.63 \\
5.10 \\
4.64\end{array}$ & $\begin{array}{l}2,690 \\
6,660 \\
5,280 \\
4,450 \\
5,090 \\
5,240 \\
4,720 \\
3,960 \\
3,260 \\
2,7770 \\
2,290 \\
1,890\end{array}$ & $\begin{array}{l}4.25 \\
3.96 \\
3.74 \\
3.57 \\
3.40 \\
3.36 \\
3.20 \\
3.07 \\
2.97 \\
2.90 \\
2.83 \\
2.75\end{array}$ & $\begin{array}{r}1,560 \\
1,320 \\
1,140 \\
1,010 \\
870 \\
838 \\
710 \\
612 \\
539 \\
490 \\
441 \\
388\end{array}$ & $\begin{array}{l}2.68 \\
2.62 \\
2.56 \\
2.50 \\
2.44 \\
2.34 \\
2.32 \\
2.29 \\
2.24 \\
2.23 \\
2.19 \\
2.14\end{array}$ & $\begin{array}{l}344 \\
309 \\
280 \\
252 \\
227 \\
187 \\
180 \\
169 \\
152 \\
148 \\
135 \\
120\end{array}$ \\
\hline & \multicolumn{2}{|c|}{ December 14} & \multicolumn{2}{|c|}{ December 15} & \multicolumn{2}{|c|}{ December 16} & \multicolumn{2}{|c|}{ December 17} & \multicolumn{2}{|c|}{ December 18} & \multicolumn{2}{|c|}{ December 19} \\
\hline $\begin{array}{r}2 \\
4 \\
6 \\
8 \\
10 \\
N \\
2 \\
4 \\
6 \\
8 \\
10 \\
M\end{array}$ & $\begin{array}{l}2.08 \\
2.03 \\
1.98 \\
1.97 \\
1.94 \\
1.87 \\
1.82 \\
1.76 \\
1.73 \\
1.69 \\
1.64 \\
1.52\end{array}$ & $\begin{array}{r}103 \\
90 \\
79 \\
77 \\
71 \\
58 \\
51 \\
44 \\
40 \\
36 \\
32 \\
24\end{array}$ & $\begin{array}{r}1.41 \\
1.18 \\
1.05 \\
.97 \\
.89 \\
.82 \\
.92 \\
.72 \\
.63 \\
.60 \\
.58 \\
.56\end{array}$ & $\begin{array}{r}19 \\
11 \\
7.5 \\
5.5 \\
4.0 \\
2.8 \\
4.6 \\
1.6 \\
.8 \\
.6 \\
.5 \\
.4\end{array}$ & $\begin{array}{l}0.54 \\
.53 \\
.51 \\
.49 \\
.46 \\
- \\
= \\
= \\
= \\
-\end{array}$ & $\begin{array}{l}0.4 \\
.3 \\
.2 \\
.2 \\
0 \\
0 \\
0 \\
0 \\
0 \\
0 \\
0 \\
0\end{array}$ & & & & & & \\
\hline
\end{tabular}

Supplemental records.- Dec. 10, 6:30 a.m., no flow; 7 a.m., 3.00 ft., 520 sec.-ft.: 9 a.m., 3.92 ft., 1,170 sec.-ft.; 11 p.m., 3.01 ft,. 527 sec.-ft. Dec. 11 , 3 a.m., 6.80 ft., 3,550 sec.-ft.: 7 a.m., 7.15 ft., 4,140 sec.-ft. 
Alamitos Creek near Edenvale, Cal1f.

Location.- Lat. $37^{\circ} 14^{\prime} 20^{\prime \prime}$, long. $121^{\circ} 52^{\prime} 15^{\prime \prime}$, in SW $\frac{1}{4}$ sec. 16, T. 8 S., R. I E., 0.4 mile above junction with Guadalupe Creok and 4 miles southwest of gdenvale, Santa Clara County. Altitude, about 200 feet above mean sea level.

Dralnage area.- 35.0 square miles.

Gage-helght record. - Water-stage recorder graph.

Stage-discharge relation.- Defined by current-meter measurements below 1,750 secondfeet; extended to peak stage.

Maxima.- December 1937: Discharge, 2,280 second-feet 1:30 a.m. Dec. 11 (gage height, 6.35 feet).

1930-November 1937: Discharge (unregulated), 2,670 second-feet Dec. 27, 1931 (gage helght, 6.60 feet).

Remarks. - Flood mun-off affected by artificlal storage in Almaden and Calero Reservolrs (capscities, 2,000 and 9,500 acre-feet, respectively); not appreclably affected by diversion. Monthly summaries adjusted for storage.

Mean dally discharge, in second-feet, November 1937 to January 1938

\begin{tabular}{|c|c|c|c|c|c|c|c|c|c|c|c|}
\hline Day & Nov. & Dec. & Jan. & Day & Nov. & Dec. & Jan. & Day & Nov. & Dec. & Jan. \\
\hline $\begin{array}{r}1 \\
2 \\
3 \\
4 \\
5 \\
6 \\
7 \\
8 \\
9 \\
10\end{array}$ & $\begin{array}{l}0 \\
0 \\
0 \\
0 \\
0 \\
0 \\
0 \\
0 \\
0 \\
0\end{array}$ & $\begin{array}{r}0 \\
0 \\
0 \\
0 \\
0 \\
0 \\
0 \\
0 \\
0 \\
28\end{array}$ & $\begin{array}{c}24 \\
15 \\
14 \\
12 \\
10 \\
4.8 \\
15 \\
9 \\
6.5 \\
8.5\end{array}$ & $\begin{array}{l}11 \\
12 \\
13 \\
14 \\
15 \\
16 \\
17 \\
18 \\
19 \\
20\end{array}$ & $\begin{array}{l}0 \\
0 \\
0 \\
0 \\
0 \\
0 \\
0 \\
0 \\
0 \\
0\end{array}$ & $\begin{array}{r}1,340 \\
307 \\
100 \\
51 \\
27 \\
29 \\
32 \\
39 \\
34 \\
36\end{array}$ & $\begin{array}{l}7.5 \\
7 \\
7 \\
7 \\
7 \\
7 \\
7.5 \\
7.5 \\
17 \\
21\end{array}$ & $\begin{array}{l}21 \\
22 \\
23 \\
24 \\
25 \\
26 \\
27 \\
28 \\
29 \\
30 \\
31\end{array}$ & $\begin{array}{l}0 \\
0 \\
0 \\
0 \\
0 \\
0 \\
0 \\
0 \\
0 \\
0\end{array}$ & $\begin{array}{l}39 \\
36 \\
31 \\
35 \\
34 \\
33 \\
38 \\
37 \\
32 \\
22 \\
31\end{array}$ & $\begin{array}{r}15 \\
12 \\
11 \\
10 \\
11 \\
10 \\
11 \\
16 \\
32 \\
15 \\
358\end{array}$ \\
\hline \multicolumn{9}{|c|}{ 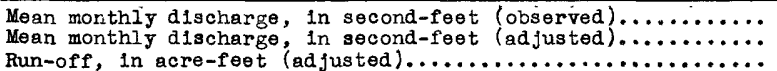 } & $\begin{array}{l}0 \\
0 \\
0\end{array}$ & $\begin{array}{r}77 . \overline{1} \\
129 \\
7,940 \\
\end{array}$ & $\begin{array}{r}23 \cdot 1 \\
29.3 \\
1,800 \\
\end{array}$ \\
\hline
\end{tabular}

Gage height, in feet, and discharge, in second-feet, at indicated time, 1937

\begin{tabular}{|c|c|c|c|c|c|c|c|c|c|c|c|c|}
\hline \multirow{2}{*}{$\begin{array}{l}\tilde{H} \\
0 \\
0\end{array}$} & Feet & sec.ft. & Feet & sec.ft. & Feet & sec.ft. & Feet & sec.ft. & Feet & Sec.ft. & Feet & Sec.ft. \\
\hline & \multicolumn{2}{|c|}{ December 8} & \multicolumn{2}{|c|}{ December 9} & \multicolumn{2}{|c|}{ December 10} & \multicolumn{2}{|c|}{ December 11} & \multicolumn{2}{|c|}{ December 12} & \multicolumn{2}{|c|}{ December 13} \\
\hline \multirow[t]{2}{*}{$\begin{array}{r}2 \\
4 \\
6 \\
8 \\
10 \\
\mathbf{N} \\
2 \\
4 \\
6 \\
8 \\
10 \\
\mathbf{M}\end{array}$} & & & & & $\begin{array}{l}- \\
- \\
- \\
- \\
= \\
= \\
= \\
- \\
5.42 \\
5.13\end{array}$ & $\begin{array}{r}0 \\
0 \\
0 \\
0 \\
0 \\
0 \\
0 \\
0 \\
0 \\
0 \\
93 \\
824\end{array}$ & $\begin{array}{l}6.27 \\
5.63 \\
5.01 \\
5.58 \\
6.30 \\
6.23 \\
5.91 \\
5.61 \\
5.38 \\
5.15 \\
4.93 \\
4.75\end{array}$ & $\begin{array}{r}2,160 \\
1,310 \\
737 \\
1,250 \\
2,200 \\
2,100 \\
1,650 \\
1,280 \\
1,040 \\
840 \\
684 \\
570\end{array}$ & $\begin{array}{l}4.60 \\
4.47 \\
4.33 \\
4.26 \\
4.25 \\
4.21 \\
4.12 \\
4.02 \\
3.96 \\
3.87 \\
3.74 \\
3.64\end{array}$ & $\begin{array}{l}485 \\
420 \\
355 \\
326 \\
322 \\
306 \\
273 \\
240 \\
222 \\
196 \\
160 \\
136\end{array}$ & $\begin{array}{l}3.56 \\
3.51 \\
3.46 \\
3.48 \\
3.50 \\
3.50 \\
3.49 \\
3.47 \\
3.45 \\
3.39 \\
3.32 \\
3.27\end{array}$ & $\begin{array}{l}119 \\
109 \\
100 \\
103 \\
107 \\
107 \\
105 \\
102 \\
98 \\
87 \\
76 \\
69\end{array}$ \\
\hline & \multicolumn{2}{|c|}{ December 14} & \multicolumn{2}{|c|}{ December 15} & \multicolumn{2}{|c|}{ December 16} & \multicolumn{2}{|c|}{ December it } & \multicolumn{2}{|c|}{ December 18} & \multicolumn{2}{|c|}{ December 19} \\
\hline \multirow[t]{2}{*}{$\begin{array}{r}2 \\
4 \\
6 \\
8 \\
10 \\
\mathrm{~N} \\
2 \\
4 \\
6 \\
8 \\
10 \\
\mathrm{M}\end{array}$} & $\begin{array}{l}3.24 \\
3.23 \\
3.22 \\
3.22 \\
3.21 \\
3.21 \\
3.20 \\
3.20 \\
3.04 \\
2.95 \\
2.91 \\
2.87\end{array}$ & $\begin{array}{l}65 \\
63 \\
62 \\
62 \\
60 \\
60 \\
59 \\
59 \\
39 \\
30 \\
26 \\
22\end{array}$ & $\begin{array}{l}2.85 \\
2.83 \\
2.82 \\
2.80 \\
2.79 \\
2.96 \\
3.03 \\
3.06 \\
3.07 \\
3.00 \\
2.94 \\
2.89\end{array}$ & $\begin{array}{l}21 \\
19 \\
18 \\
16 \\
16 \\
31 \\
38 \\
42 \\
43 \\
35 \\
29 \\
24\end{array}$ & $\begin{array}{l}2.87 \\
2.85 \\
2.85 \\
2.84 \\
2.83 \\
2.83 \\
3.01 \\
3.03 \\
3.04 \\
3.05 \\
3.05 \\
3.05\end{array}$ & $\begin{array}{l}22 \\
21 \\
21 \\
20 \\
19 \\
19 \\
36 \\
38 \\
39 \\
40 \\
40 \\
40\end{array}$ & $\begin{array}{l}3.05 \\
3.06 \\
3.06 \\
2.91 \\
2.83 \\
2.80 \\
2.77 \\
2.97 \\
3.02 \\
3.03 \\
3.04 \\
3.05\end{array}$ & $\begin{array}{l}40 \\
42 \\
42 \\
26 \\
19 \\
16 \\
15 \\
32 \\
37 \\
38 \\
39 \\
40\end{array}$ & $\begin{array}{c}3.05 \\
3.06 \\
3.06 \\
\overline{3.02} \\
3.00 \\
3.00\end{array}$ & $\begin{array}{l}\overline{40} \\
\overline{42} \\
\overline{42} \\
\overline{37} \\
\overline{35} \\
\overline{35}\end{array}$ & $\begin{array}{c}- \\
\overline{2.99} \\
- \\
\overline{2.99} \\
\overline{-} \\
2.99 \\
- \\
\overline{2.99}\end{array}$ & $\begin{array}{l}- \\
\overline{34} \\
- \\
\overline{34} \\
= \\
\overline{34} \\
\overline{-} \\
\overline{34}\end{array}$ \\
\hline & \multicolumn{2}{|c|}{ December 20} & \multicolumn{2}{|c|}{ December 21} & \multicolumn{2}{|c|}{ De cember 22} & \multicolumn{2}{|c|}{ December 23} & \multicolumn{2}{|c|}{ December 24} & \multicolumn{2}{|c|}{ December 25} \\
\hline $\begin{array}{r}2 \\
4 \\
6 \\
8 \\
10 \\
N \\
2 \\
4 \\
6 \\
8 \\
10 \\
M\end{array}$ & $\begin{array}{c}\overline{-} \\
2.99 \\
\overline{-} \\
2.99 \\
\overline{3} \\
\overline{3.04} \\
\overline{3.04}\end{array}$ & $\begin{array}{l}\overline{-} \\
\overline{34} \\
\overline{-} \\
\overline{34} \\
\overline{-} \\
\overline{39} \\
\overline{-} \\
\overline{39}\end{array}$ & $\begin{array}{c}\overline{-} \\
\overline{3.04} \\
\overline{-} \\
3.05 \\
\overline{-} \\
3.04 \\
\bar{z} \\
\overline{3.03}\end{array}$ & $\begin{array}{l}- \\
\overline{39} \\
- \\
\overline{40} \\
\overline{-} \\
\overline{39} \\
\overline{-} \\
\overline{38}\end{array}$ & $\begin{array}{c}\overline{-} \\
3.03 \\
\overline{-} \\
3.03 \\
\overline{-} \\
2.99 \\
\overline{-} \\
2.97\end{array}$ & $\begin{array}{l}\overline{-} \\
\overline{38} \\
\overline{-} \\
\overline{38} \\
\overline{-} \\
\overline{34} \\
\overline{-} \\
\overline{32}\end{array}$ & $\begin{array}{l}2.97 \\
2.97 \\
3.96 \\
2.96 \\
2.96 \\
2.96 \\
2.86 \\
2.96 \\
2.99 \\
3.00 \\
3.00 \\
3.00\end{array}$ & $\begin{array}{l}32 \\
32 \\
31 \\
31 \\
31 \\
31 \\
22 \\
31 \\
34 \\
35 \\
35 \\
35\end{array}$ & $\begin{array}{c}\overline{-} \\
3.00 \\
- \\
3.00 \\
- \\
3.00 \\
\overline{3.00}\end{array}$ & $\begin{array}{l}- \\
\overline{35} \\
\overline{-} \\
\overline{35} \\
\overline{-} \\
\overline{35} \\
\overline{-} \\
\overline{35}\end{array}$ & $\begin{array}{c}\overline{-} \\
\overline{2.99} \\
- \\
\overline{2.99} \\
\overline{-} \\
\overline{2.98} \\
- \\
\overline{2.97}\end{array}$ & $\begin{array}{l}- \\
\overline{34} \\
- \\
\overline{3} \\
\bar{z} \\
\overline{33} \\
\overline{-} \\
\overline{32}\end{array}$ \\
\hline
\end{tabular}

Supplemental records.- Dec. $10,9: 30$ p.m., no flow 11 p.m., 4.17 ft., 291 sec.-ft. Dec. $11,1: 30$ a.m., 6.35 ft., 2,280 sec.-ft. 
Los Gatos Creek at Los Gatos, Calif.

Location. - Lat. $37^{\circ} 13^{\prime} 15^{\prime \prime}$, long. $121^{\circ} 59^{\prime} 00^{\prime \prime}$, in SW $\frac{1}{4}$ sec. 21, T. 8 S., R. 1 W., about 700 feet upstream from highway brldge at Los Gatos, Santa Clara County. Altitude, about 360 feet above mean sea level.

Drainage area.- 40.0 square miles.

Gage-helght record. - Water-stage recorder graph.

Stage-discharge relation.- Deflned by current-meter measurements below 2,600 secondfeet; extended to peak stage with ald of area-velocity study. Shifting-control method used for period Nov. 1 to Dec. 8.

Maxima.- December 1937: Discharge, 4,800 second-feet 2 a.m. Dec. 11 (gage height, 12.20 feet).

1930-November 1937: Discharge, 5,500 second-feet Feb. 13, 1937 (gage he1ght, 12.90 feet), from rating curve extended above 2,600 second-feet $w 1$ th ald of areavelocity study.

Remarks.- Flood run-off slightly affected by artificial storage in four small reservolrs and by small diversions above station.

Mean daily discharge, in second-feet, November 1937 to January 1938

\begin{tabular}{|c|c|c|c|c|c|c|c|c|c|c|c|}
\hline Day & Nov. & Dec. & Jan. & Day & Nove & Dec. & Jan. & Day & Noy. & Dec. & Jan. \\
\hline $\begin{array}{r}1 \\
2 \\
3 \\
4 \\
5 \\
6 \\
7 \\
8 \\
9 \\
10\end{array}$ & $\begin{array}{r}0.6 \\
.6 \\
.3 \\
.3 \\
.4 \\
3.4 \\
3.1 \\
.4 \\
.4 \\
.4\end{array}$ & $\begin{array}{r}0.8 \\
.7 \\
.6 \\
.6 \\
.6 \\
1.0 \\
.6 \\
.6 \\
29 \\
1,250\end{array}$ & $\begin{array}{l}17 \\
31 \\
23 \\
16 \\
15 \\
14 \\
14 \\
14 \\
13 \\
11\end{array}$ & $\begin{array}{l}11 \\
12 \\
13 \\
14 \\
15 \\
16 \\
17 \\
18 \\
19 \\
20\end{array}$ & $\begin{array}{c}24 \\
10 \\
6.5 \\
11 \\
8 \\
1.7 \\
22 \\
8.5 \\
1.7 \\
4.8\end{array}$ & $\begin{array}{r}2,460 \\
480 \\
200 \\
131 \\
88 \\
65 \\
55 \\
48 \\
43 \\
38\end{array}$ & $\begin{array}{l}11 \\
12 \\
11 \\
11 \\
13 \\
14 \\
39 \\
26 \\
81 \\
47\end{array}$ & $\begin{array}{l}21 \\
22 \\
23 \\
24 \\
25 \\
26 \\
27 \\
28 \\
29 \\
30 \\
31\end{array}$ & $\begin{array}{r}19 \\
7 \\
3.9 \\
7.5 \\
1.8 \\
1.2 \\
1.0 \\
.8 \\
1.4 \\
.8\end{array}$ & $\begin{array}{l}35 \\
33 \\
31 \\
28 \\
28 \\
27 \\
23 \\
22 \\
20 \\
18 \\
18\end{array}$ & $\begin{array}{r}33 \\
27 \\
24 \\
18 \\
16 \\
16 \\
16 \\
75 \\
90 \\
56 \\
1,590\end{array}$ \\
\hline $\begin{array}{l}\text { Mean } \\
\text { Run- }\end{array}$ & , in & I1 schar & 11 & & & & & & $\begin{array}{r}5.08 \\
302\end{array}$ & $\begin{array}{r}167 \\
10,270\end{array}$ & $\begin{array}{r}77.2 \\
4,750\end{array}$ \\
\hline
\end{tabular}

Gage helght, in feet, and discharge, in second-feet, at thdicated time, 1937

\begin{tabular}{|c|c|c|c|c|c|c|c|c|c|c|c|c|}
\hline \multirow{2}{*}{ 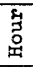 } & Feet & Sec.ft. & Feet & Sec,ft. & Feet & Sec,ft. & Feet & sec.ft. & Feet & Sec.ft. & Feet & Sec.ft. \\
\hline & \multicolumn{2}{|c|}{ December 8} & \multicolumn{2}{|c|}{ December 9} & \multicolumn{2}{|c|}{ December 10} & \multicolumn{2}{|c|}{ December 11} & \multicolumn{2}{|c|}{ December 12} & \multicolumn{2}{|c|}{ December 13} \\
\hline \multirow[t]{2}{*}{$\begin{array}{r}2 \\
4 \\
6 \\
8 \\
10 \\
\mathrm{~N} \\
2 \\
4 \\
6 \\
8 \\
10 \\
\mathrm{M}\end{array}$} & $\begin{array}{l}\overline{-} \\
\overline{-} \\
\overline{1.23} \\
\overline{-} \\
\overline{-} \\
\overline{-} \\
1.23\end{array}$ & $\begin{array}{l}- \\
- \\
- \\
- \\
0.6 \\
- \\
= \\
- \\
-6\end{array}$ & $\begin{array}{l}1.23 \\
1.23 \\
1.23 \\
1.23 \\
1.25 \\
1.27 \\
1.34 \\
1.37 \\
1.93 \\
2.31 \\
3.80 \\
3.95\end{array}$ & $\begin{array}{r}0.6 \\
.6 \\
.6 \\
.6 \\
.8 \\
.9 \\
1.5 \\
1.8 \\
12 \\
25 \\
214 \\
251\end{array}$ & $\begin{array}{r}4.95 \\
6.43 \\
7.82 \\
7.70 \\
7.34 \\
7.55 \\
6.95 \\
6.23 \\
5.78 \\
5.70 \\
8.05 \\
10.99\end{array}$ & $\begin{array}{r}528 \\
1,050 \\
1,630 \\
1,580 \\
1,420 \\
1,510 \\
1,260 \\
977 \\
811 \\
782 \\
1,740 \\
3,690\end{array}$ & $\begin{array}{r}12.20 \\
10.78 \\
10.00 \\
10.66 \\
9.66 \\
9.28 \\
8.50 \\
7.95 \\
7.53 \\
6.85 \\
6.22 \\
5.86\end{array}$ & $\begin{array}{r}4,800 \\
3,520 \\
2,940 \\
3,430 \\
2,700 \\
2,460 \\
1,990 \\
1,700 \\
1,500 \\
1,220 \\
974 \\
840\end{array}$ & $\begin{array}{l}5.56 \\
5.40 \\
5.18 \\
5.10 \\
4.83 \\
4.64 \\
4.52 \\
4.38 \\
4.30 \\
4.20 \\
4.11 \\
4.03\end{array}$ & $\begin{array}{l}732 \\
678 \\
603 \\
576 \\
490 \\
430 \\
396 \\
357 \\
336 \\
312 \\
290 \\
273\end{array}$ & $\begin{array}{l}3.95 \\
3.88 \\
3.82 \\
3.77 \\
3.72 \\
3.67 \\
3.62 \\
3.58 \\
3.53 \\
3.50 \\
3.48 \\
3.46\end{array}$ & $\begin{array}{l}255 \\
240 \\
226 \\
216 \\
206 \\
196 \\
186 \\
178 \\
169 \\
163 \\
159 \\
156\end{array}$ \\
\hline & \multicolumn{2}{|c|}{ De cember 14} & \multicolumn{2}{|c|}{ December 15} & \multicolumn{2}{|c|}{ December 16} & \multicolumn{2}{|c|}{ December 17} & \multicolumn{2}{|c|}{ December 18} & \multicolumn{2}{|c|}{ December 19} \\
\hline \multirow[t]{2}{*}{$\begin{array}{r}2 \\
4 \\
6 \\
8 \\
10 \\
\mathrm{~N} \\
2 \\
4 \\
6 \\
8 \\
10 \\
M\end{array}$} & $\begin{array}{c}\overline{3.42} \\
\overline{3.36} \\
\overline{3.31} \\
\overline{3.25} \\
\overline{3.22} \\
\overline{3.18}\end{array}$ & $\begin{array}{c}\overline{149} \\
\overline{138} \\
\overline{2} \\
129 \\
\overline{118} \\
\overline{113} \\
\overline{10}\end{array}$ & $\begin{array}{l}3.17 \\
3.16 \\
3.13 \\
3.12 \\
3.10 \\
3.04 \\
3.02 \\
3.01 \\
2.96 \\
2.95 \\
2.93 \\
2.92\end{array}$ & $\begin{array}{r}106 \\
104 \\
100 \\
98 \\
95 \\
87 \\
85 \\
83 \\
77 \\
76 \\
74 \\
72\end{array}$ & $\begin{array}{l}2.90 \\
2.88 \\
2.87 \\
2.86 \\
2.84 \\
2.83 \\
2.82 \\
2.81 \\
2.86 \\
2.85 \\
2.83 \\
2.82\end{array}$ & $\begin{array}{l}70 \\
68 \\
67 \\
66 \\
64 \\
63 \\
62 \\
61 \\
66 \\
65 \\
63 \\
62\end{array}$ & $\begin{array}{l}2.81 \\
2.80 \\
2.79 \\
2.78 \\
2.73 \\
2.72 \\
2.72 \\
2.71 \\
2.70 \\
2.70 \\
2.69 \\
2.69\end{array}$ & $\begin{array}{l}61 \\
60 \\
59 \\
58 \\
54 \\
53 \\
53 \\
52 \\
51 \\
51 \\
50 \\
50\end{array}$ & $\begin{array}{c}2.68 \\
2.67 \\
2.67 \\
2.66 \\
2.63 \\
- \\
2.62 \\
\overline{2} .61\end{array}$ & $\begin{array}{l}\overline{50} \\
\overline{49} \\
\overline{48} \\
\overline{4} \\
\overline{4} \\
\overline{45} \\
\overline{45}\end{array}$ & $\begin{array}{c}- \\
2.60 \\
- \\
2.58 \\
- \\
2.57 \\
- \\
2.56 \\
- \\
2.53 \\
\overline{2.52}\end{array}$ & $\begin{array}{l}\overline{44} \\
\overline{43} \\
\overline{42} \\
\overline{42} \\
\overline{40} \\
\overline{39}\end{array}$ \\
\hline & \multicolumn{2}{|c|}{ December 20} & \multicolumn{2}{|c|}{ December 21} & \multicolumn{2}{|c|}{ December 22} & \multicolumn{2}{|c|}{ December 23} & \multicolumn{2}{|c|}{ December 24} & \multicolumn{2}{|c|}{ December 25} \\
\hline $\begin{array}{r}2 \\
4 \\
6 \\
8 \\
10 \\
N \\
2 \\
4 \\
6 \\
8 \\
10 \\
M\end{array}$ & $\begin{array}{c}- \\
- \\
= \\
\overline{2} \\
=50 \\
= \\
= \\
= \\
2.47\end{array}$ & $\begin{array}{l}= \\
= \\
\overline{-} \\
38 \\
= \\
\bar{z} \\
\overline{3}\end{array}$ & $\begin{array}{l}\bar{z} \\
\bar{z} \\
\bar{z} \\
\overline{2} 45 \\
\overline{-} \\
\bar{z} \\
\overline{2.43}\end{array}$ & $\begin{array}{l}= \\
= \\
= \\
= \\
= \\
= \\
= \\
= \\
34\end{array}$ & $\begin{array}{c}= \\
= \\
= \\
2.41 \\
= \\
= \\
= \\
2.42\end{array}$ & $\begin{array}{l}= \\
= \\
\bar{z} \\
\overline{33} \\
\overline{-} \\
\overline{-} \\
\overline{3}\end{array}$ & $\begin{array}{c}\bar{z} \\
\bar{z} \\
\overline{2.38} \\
\overline{-} \\
\bar{z} \\
\overline{2.35}\end{array}$ & $\begin{array}{l}= \\
= \\
= \\
= \\
= \\
= \\
= \\
= \\
30\end{array}$ & $\begin{array}{c}\overline{-} \\
\overline{-} \\
\overline{2.33} \\
\overline{-} \\
\overline{-} \\
\overline{2.32}\end{array}$ & $\begin{array}{l}\overline{-} \\
\overline{-} \\
\overline{28} \\
\overline{-} \\
\overline{-} \\
\overline{28}\end{array}$ & $\begin{array}{c}\overline{-} \\
\bar{z} \\
\overline{2} \\
\bar{z} \\
\overline{-} \\
\overline{-} \\
\overline{2.30}\end{array}$ & $\begin{array}{l}- \\
\bar{z} \\
\overline{2} \\
28 \\
\overline{-} \\
\bar{z} \\
\overline{27}\end{array}$ \\
\hline
\end{tabular}

Supplemental records.- Dec. 9,9 p.m., 2.70 ft., 48 sec.-ft. 
Campbell Creek at Saratoga, Cal1f.

Location.- Lat. $37^{\circ} 15^{\prime} 15^{\prime \prime}$, long. $122^{\circ} 02^{\prime} 25^{\prime \prime}$, In Quito grant, half a mile southwest of Saratoga post office, Santa Clara County. Alt1tude, about 500 feet above mean sea level.

Drainage area.- 8.8 square miles.

Gage-helght record. - Water-stage recorder graph.

Stage-discharge relation. - Deflned by current-meter measurements for range of stage of high water in December. Shifting-control method used for period Dec. 12 to Jan. 4. Maxima.- December 1937: Discharge, 534 second-feet 1 a.m. Dec. 11 (gage he1ght, 3.57 feet; no drawdown of water level in well).

1933-November 1937: Discharge, 910 second-feet Feb. 13, 1937 (gage height, 3.8

feet, outside of well, from drawdown relation determined at lower stages; 3.4 feet, inside of well, affected by drawdown), from rating curve extended above 430 secondfeet.

January-September 1938: Discharge, 61l second-feet 8 a.m. Feb. 2 (gage helght, 3.71 feet; no drawdown of water level in well).

Remarks - Flood mun-off not materialiy affected by artiflclal storage or diversion.

Mean dally discharge, in second-feet, November 1937 to January 1938

\begin{tabular}{|c|c|c|c|c|c|c|c|c|c|c|c|}
\hline Day & Nov. & Dec. & Jan. & Day & Nov. & Dec. & Jan. & Day & Nov. & Dec. & Jan. \\
\hline $\begin{array}{r}1 \\
2 \\
3 \\
4 \\
5 \\
6 \\
7 \\
8 \\
9 \\
10\end{array}$ & $\begin{array}{r}0.8 \\
.8 \\
.8 \\
.5 \\
.4 \\
.5 \\
.7 \\
.8 \\
.6 \\
.5\end{array}$ & $\begin{array}{r}1.2 \\
1.2 \\
1.3 \\
1.1 \\
.9 \\
1.2 \\
1.2 \\
1.2 \\
5 \\
156\end{array}$ & $\begin{array}{l}3.7 \\
4.2 \\
3.7 \\
3.6 \\
3.6 \\
3.2 \\
3.2 \\
3.2 \\
3.2 \\
3.1\end{array}$ & $\begin{array}{l}11 \\
12 \\
13 \\
14 \\
15 \\
16 \\
17 \\
18 \\
19 \\
20\end{array}$ & $\begin{array}{l}3.9 \\
1.6 \\
1.1 \\
2.8 \\
1.5 \\
.9 \\
3.8 \\
1.9 \\
1.0 \\
1.8\end{array}$ & $\begin{array}{c}275 \\
77 \\
30 \\
17 \\
13 \\
11 \\
9.5 \\
9 \\
8 \\
7.5\end{array}$ & $\begin{array}{r}3.0 \\
2.7 \\
3.0 \\
3.0 \\
3.3 \\
3.5 \\
9.5 \\
7.5 \\
17 \\
12\end{array}$ & $\begin{array}{l}21 \\
22 \\
23 \\
24 \\
25 \\
26 \\
27 \\
28 \\
29 \\
30 \\
31\end{array}$ & $\begin{array}{l}2.6 \\
1.8 \\
1.8 \\
1.8 \\
1.6 \\
1.3 \\
1.0 \\
1.1 \\
1.3 \\
1.3\end{array}$ & $\begin{array}{l}7 \\
7 \\
6.5 \\
6 \\
5.5 \\
5.5 \\
5 \\
4.8 \\
4.5 \\
4.2 \\
4.0\end{array}$ & $\begin{array}{l}9 \\
8 \\
7.5 \\
7 \\
7 \\
7 \\
6.5 \\
11 \\
15 \\
12 \\
224\end{array}$ \\
\hline $\begin{array}{l}\text { Mean } \\
\text { Run- }\end{array}$ & nthl & & & & & & & & $\begin{array}{r}1.41 \\
84\end{array}$ & $\begin{array}{r}22.2 \\
1,360\end{array}$ & $\begin{array}{r}13.2 \\
820\end{array}$ \\
\hline
\end{tabular}

Gage height, In feet, and discharge, in second-feet, at indicated time, 1937

\begin{tabular}{|c|c|c|c|c|c|c|c|c|c|c|c|c|}
\hline \multirow{2}{*}{ 岁 } & Feet & Sec.ft. & Feet & sec.ft. & Feet & Sec.ft. & Feet & Sec.ft. & Feet & Sec.ft. & Feet & Sec.ft. \\
\hline & \multicolumn{2}{|c|}{ December 8} & \multicolumn{2}{|c|}{ December 9} & \multicolumn{2}{|c|}{ December 10} & \multicolumn{2}{|c|}{ December 11} & \multicolumn{2}{|c|}{ December 12} & \multicolumn{2}{|c|}{ December 13} \\
\hline \multirow[t]{2}{*}{$\begin{array}{r}2 \\
4 \\
6 \\
8 \\
10 \\
\mathrm{~N} \\
2 \\
4 \\
6 \\
8 \\
10 \\
M \\
\end{array}$} & $\begin{array}{l}0.81 \\
= \\
= \\
= \\
=81 \\
= \\
= \\
= \\
.82\end{array}$ & $\begin{array}{c}1.2 \\
- \\
- \\
- \\
1.2 \\
- \\
- \\
- \\
- \\
1.3\end{array}$ & $\begin{array}{r}0.82 \\
.82 \\
.82 \\
.82 \\
.82 \\
.84 \\
.86 \\
.87 \\
.92 \\
1.00 \\
1.45 \\
1.92\end{array}$ & \begin{tabular}{|l}
1.3 \\
1.3 \\
1.3 \\
1.3 \\
1.3 \\
1.5 \\
1.6 \\
1.7 \\
2.2 \\
3.2 \\
12 \\
41 \\
\end{tabular} & $\begin{array}{l}2.35 \\
2.83 \\
2.85 \\
2.62 \\
2.58 \\
2.52 \\
2.46 \\
2.36 \\
2.30 \\
2.40 \\
2.95 \\
3.45\end{array}$ & \begin{tabular}{|c|}
100 \\
213 \\
219 \\
155 \\
145 \\
132 \\
119 \\
101 \\
91 \\
108 \\
252 \\
470
\end{tabular} & $\begin{array}{l}3.44 \\
3.35 \\
3.25 \\
3.42 \\
3.02 \\
2.92 \\
2.74 \\
2.65 \\
2.65 \\
2.57 \\
2.50 \\
2.40\end{array}$ & $\begin{array}{l}465 \\
420 \\
372 \\
455 \\
278 \\
242 \\
186 \\
162 \\
162 \\
143 \\
127 \\
108\end{array}$ & $\begin{array}{l}2.36 \\
2.35 \\
2.28 \\
2.29 \\
2.26 \\
2.18 \\
2.13 \\
2.11 \\
2.06 \\
2.02 \\
1.97 \\
1.94\end{array}$ & $\begin{array}{r}106 \\
105 \\
93 \\
94 \\
89 \\
77 \\
69 \\
67 \\
60 \\
55 \\
49 \\
46\end{array}$ & $\begin{array}{l}1.88 \\
1.82 \\
1.80 \\
1.78 \\
1.76 \\
1.72 \\
1.69 \\
1.66 \\
1.66 \\
1.66 \\
1.65 \\
1.64\end{array}$ & \begin{tabular}{|l}
43 \\
37 \\
36 \\
34 \\
33 \\
30 \\
28 \\
25 \\
25 \\
25 \\
25 \\
24
\end{tabular} \\
\hline & \multicolumn{2}{|c|}{ December 14} & \multicolumn{2}{|c|}{ December 15} & \multicolumn{2}{|c|}{ December 16} & \multicolumn{2}{|c|}{ December 17} & \multicolumn{2}{|c|}{ December 18} & \multicolumn{2}{|c|}{ December 19} \\
\hline \multirow[t]{2}{*}{$\begin{array}{r}2 \\
4 \\
6 \\
8 \\
10 \\
N \\
2 \\
4 \\
6 \\
8 \\
10 \\
M\end{array}$} & $\begin{array}{c}- \\
1.62 \\
- \\
1.59 \\
- \\
1.57 \\
- \\
1.57 \\
\overline{1.56} \\
\overline{1.53}\end{array}$ & $\begin{array}{l}\overline{19} \\
\overline{18} \\
\overline{18} \\
\overline{17} \\
\overline{17} \\
\overline{16} \\
\overline{15}\end{array}$ & $\begin{array}{l}\overline{-} \\
\overline{1.51} \\
- \\
\overline{1 .} \\
\overline{-} \\
\overline{1.49} \\
\overline{-} \\
\overline{1.47}\end{array}$ & $\begin{array}{r}- \\
\overline{14} \\
\overline{-} \\
1 \overline{3} \\
\overline{-} \\
13 \\
\overline{-} \\
\overline{12}\end{array}$ & $\begin{array}{l}= \\
\overline{-} \\
= \\
1.44 \\
= \\
= \\
= \\
\overline{1.42}\end{array}$ & $\begin{array}{l}\overline{-} \\
\overline{-} \\
- \\
\overline{11} \\
\overline{-} \\
\overline{-} \\
\overline{-} \\
\overline{10}\end{array}$ & $\begin{array}{l}= \\
= \\
= \\
1.41 \\
= \\
= \\
= \\
1.39\end{array}$ & $\begin{array}{c}\overline{-} \\
\overline{-} \\
\overline{10} \\
\overline{-} \\
\overline{-} \\
\overline{-} \\
\overline{9} .5\end{array}$ & $\begin{array}{c}= \\
- \\
- \\
1.38 \\
- \\
= \\
- \\
- \\
1.37\end{array}$ & $\begin{array}{l}\overline{-} \\
\bar{z} \\
\overline{9} \\
\bar{z} \\
\overline{-} \\
\overline{-} \\
\overline{8.5}\end{array}$ & $\begin{array}{l}= \\
= \\
\bar{z} \\
1.36 \\
= \\
= \\
= \\
1.35\end{array}$ & $\begin{array}{l}- \\
- \\
- \\
- \\
8 \\
- \\
- \\
- \\
= \\
-\end{array}$ \\
\hline & \multicolumn{2}{|c|}{ December 20} & \multicolumn{2}{|c|}{ December 21} & \multicolumn{2}{|c|}{ December 22} & \multicolumn{2}{|c|}{ December 23} & \multicolumn{2}{|c|}{ December 24} & \multicolumn{2}{|c|}{ December 25} \\
\hline $\begin{array}{r}2 \\
4 \\
6 \\
8 \\
10 \\
N \\
2 \\
4 \\
6 \\
8 \\
10 \\
M\end{array}$ & $\begin{array}{l}\bar{z} \\
= \\
= \\
1.34 \\
= \\
= \\
= \\
\overline{1.33}\end{array}$ & $\begin{array}{c}\overline{-} \\
\overline{-} \\
- \\
7.5 \\
\overline{-} \\
\overline{-} \\
\overline{7.5}\end{array}$ & $\begin{array}{l}\overline{-} \\
= \\
= \\
1.33 \\
\overline{-} \\
= \\
\overline{1.33}\end{array}$ & $\begin{array}{l}\overline{-} \\
- \\
- \\
\overline{7} \\
= \\
- \\
- \\
\overline{7}\end{array}$ & $\begin{array}{l}= \\
= \\
= \\
= \\
= \\
= \\
= \\
= \\
1.34\end{array}$ & $\begin{array}{l}- \\
- \\
- \\
- \\
7 \\
- \\
- \\
- \\
- \\
\overline{7}\end{array}$ & $\begin{array}{l}= \\
= \\
= \\
= \\
1.32 \\
= \\
= \\
= \\
\overline{1}\end{array}$ & $\begin{array}{c}= \\
= \\
= \\
= \\
6.5 \\
= \\
\overline{-} \\
\overline{6.5}\end{array}$ & $\begin{array}{c}- \\
- \\
- \\
- \\
1.31 \\
- \\
- \\
- \\
\overline{1.31}\end{array}$ & $\begin{array}{l}- \\
- \\
- \\
- \\
6 \\
- \\
- \\
- \\
- \\
6\end{array}$ & $\begin{array}{l}= \\
= \\
= \\
= \\
= \\
= \\
1.29\end{array}$ & $\begin{array}{c}- \\
- \\
- \\
- \\
5.5 \\
- \\
- \\
- \\
- \\
5.5\end{array}$ \\
\hline
\end{tabular}

Supplemental records.- Dec. 9, 11 p.m., 1.93 ft., 42 sec.-ft. Dec. 10, $12: 30$ a.m. 1.89 ft., 38 gec.-ft. Dec. 11, I a.m., 3.57 ft., 534 sec, $-f t . ; 5$ a.m., 3.07 ft., 298 sec.-ft.; 7 a.m., 3.47 ft., 480 sec.-ft. 
Location. - Lat. $3^{\circ} 10^{\prime} 00^{\prime \prime}$, long. $121^{\circ} 37^{\prime} 40^{\prime \prime}$, in northwest comer of San Jose grant, a quarter of a mile above highway bridge at mouth of canyon, a quarter of a mile below Las Animas Creok, and 2.8 miles northeast of Madrone, Santa Clare County. Altitude, about 420 feot above mean sea level.

Drainage area.- 193 square miles.

Gage-height record.- Water-stage recorder graph. Record unreliable in periods Jan. $4-6,20$, when record was determined from partial recorder graph.

Stage-discharge relation.- Defined by current-meter megsurements.

Maxima.- December 1937: Discharge, 2,750 second-fe日t 4 a.m. Dec, 11 (gage height, 9.19 foet).

1902-12; 1917 -November 1937: D1scharge, about 25,000 second-feet (unregulated) Mar. 7, 1911, furmished by Duryea, Heehl \& Gilman.

Remarks. - Flood run-off affected by artificial storage in Coyote Reservolr (capacity, 30,000 acre-feet). Monthly summaries adjusted for storage.

Mean daily discharge, in second-feet, November 1937 to January 1938

\begin{tabular}{|c|c|c|c||c|c|c|c||c|c|c|c|}
\hline Day & Nov. & Dec. & Jan. & Day & Nov. & Dec. & Jan. & Day & Nov. & Dec. & Jan. \\
\hline 1 & 55 & 1.2 & 6.5 & 11 & 51 & 1,230 & 7.5 & 21 & 1.9 & 10 & 31 \\
2 & 55 & 1.3 & 7 & 12 & 50 & 129 & 19 & 22 & 1.7 & 11 & 30 \\
3 & 52 & 1.2 & 6.5 & 13 & 50 & 39 & 19 & 23 & 1.7 & 10 & 30 \\
4 & 52 & 1.1 & 6 & 14 & 51 & 17 & 21 & 24 & 1.6 & 9.5 & 29 \\
5 & 52 & 1.1 & 5.5 & 15 & 50 & 9.5 & 27 & 25 & 1.4 & 9 & 23 \\
6 & 51 & 1.1 & 5.5 & 16 & 46 & 7 & 28 & 26 & 1.4 & 9.5 & 32 \\
7 & 51 & 1.1 & 5.5 & 17 & 6.5 & 6 & 29 & 27 & 1.4 & 9.5 & 32 \\
8 & 51 & 1.1 & 5.5 & 18 & 3.2 & 5.5 & 27 & 28 & 1.3 & 9 & 52 \\
9 & 51 & 6 & 5 & 19 & 2.5 & 5 & 31 & 29 & 1.3 & 9.5 & 81 \\
10 & 50 & 70 & 5 & 20 & 2.1 & 5 & 34 & 30 & 1.2 & 9 & 69 \\
\multicolumn{7}{|l|}{} \\
\hline
\end{tabular}

Gage helght, in feet, and discharge, in second-feet, at indicated time, 1937

\begin{tabular}{|c|c|c|c|c|c|c|c|c|c|c|c|c|}
\hline \multirow{2}{*}{ 苟 } & Feet & Sec.ft. & Feet & Sec.ft. & Feet & Sec.ft. & Feet & Sec.ft. & Feet & Sec.ft. & Feet & Sec.ft. \\
\hline & \multicolumn{2}{|c|}{ December 8} & \multicolumn{2}{|c|}{ December 9} & \multicolumn{2}{|c|}{ December 10} & \multicolumn{2}{|c|}{ December 11} & \multicolumn{2}{|c|}{ December 12} & \multicolumn{2}{|c|}{ December 13} \\
\hline $\begin{array}{r}2 \\
4 \\
6 \\
8 \\
10 \\
\mathbb{N} \\
2 \\
4 \\
6 \\
8 \\
10 \\
M\end{array}$ & $\begin{array}{c}= \\
= \\
\overline{-} \\
2.02 \\
\bar{z} \\
\overline{-} \\
2.02\end{array}$ & $\begin{array}{c}= \\
\overline{-} \\
\bar{z} \\
\overline{-} \\
\overline{-} \\
1.1\end{array}$ & $\begin{array}{l}2.02 \\
2.40 \\
2.41 \\
2.42 \\
2.43 \\
2.44 \\
2.45 \\
2.45 \\
2.47 \\
2.52 \\
2.65 \\
2.70\end{array}$ & $\begin{array}{l}1.1 \\
5.5 \\
5.5 \\
6 \\
6 \\
6 \\
6 \\
6 \\
6.5 \\
7.5 \\
10 \\
11\end{array}$ & $\begin{array}{l}2.75 \\
3.01 \\
3.09 \\
3.02 \\
3.13 \\
3.47 \\
3.46 \\
3.27 \\
3.42 \\
4.72 \\
5.02 \\
6.04\end{array}$ & $\begin{array}{r}12 \\
20 \\
23 \\
20 \\
24 \\
40 \\
39 \\
30 \\
37 \\
158 \\
212 \\
526\end{array}$ & $\begin{array}{l}8.01 \\
9.19 \\
7.96 \\
8.55 \\
8.80 \\
7.72 \\
6.78 \\
6.18 \\
5.77 \\
5.55 \\
5.53 \\
5.27\end{array}$ & $\begin{array}{r}1,670 \\
2,750 \\
1,630 \\
2,120 \\
2,350 \\
1,450 \\
880 \\
587 \\
415 \\
339 \\
333 \\
267\end{array}$ & $\begin{array}{l}5.03 \\
4.82 \\
4.67 \\
4.53 \\
4.54 \\
4.53 \\
4.49 \\
4.36 \\
4.23 \\
4.11 \\
4.01 \\
3.93\end{array}$ & $\begin{array}{r}214 \\
174 \\
148 \\
129 \\
130 \\
129 \\
124 \\
107 \\
92 \\
80 \\
71 \\
64\end{array}$ & $\begin{array}{l}- \\
3.77 \\
- \\
3.62 \\
- \\
3.50 \\
- \\
3.38 \\
- \\
3.26 \\
3.16\end{array}$ & $\begin{array}{l}\overline{53} \\
\overline{43} \\
\overline{37} \\
\overline{31} \\
\overline{2} 6 \\
\overline{23}\end{array}$ \\
\hline & \multicolumn{2}{|c|}{ December 14} & \multicolumn{2}{|c|}{ December 15} & \multicolumn{2}{|c|}{ December 16} & \multicolumn{2}{|c|}{ December 17} & \multicolumn{2}{|c|}{ December 18} & \multicolumn{2}{|c|}{ December 19} \\
\hline \begin{tabular}{r|r|}
2 \\
4 \\
6 \\
8 \\
10 \\
1 \\
$N$ \\
2 \\
4 \\
6 \\
8 \\
10 \\
M
\end{tabular} & $\begin{array}{l}- \\
3.09 \\
- \\
3.01 \\
- \\
2.97 \\
- \\
2.90 \\
- \\
2.83 \\
- \\
2.79\end{array}$ & $\begin{array}{l}\overline{21} \\
\overline{18} \\
\overline{17} \\
\overline{15} \\
\overline{13} \\
\overline{12}\end{array}$ & $\begin{array}{c}\overline{-} \\
2.73 \\
\overline{-} \\
2.69 \\
\overline{-} \\
2.64 \\
\overline{-} \\
2.59\end{array}$ & $\begin{array}{l}- \\
11 \\
= \\
10 \\
= \\
-9 \\
-8\end{array}$ & $\begin{array}{c}- \\
\overline{2.57} \\
\overline{-} \\
\overline{2.56} \\
\overline{-} \\
2.53 \\
\overline{-} \\
2.51\end{array}$ & $\begin{array}{c}- \\
\overline{-} \\
7.5 \\
- \\
7 \\
\overline{-} \\
6.5 \\
\overline{-} \\
6.5\end{array}$ & $\begin{array}{c}- \\
= \\
= \\
= \\
2.50 \\
= \\
= \\
= \\
2.47\end{array}$ & $\begin{array}{l}\overline{-} \\
\overline{-} \\
\overline{6} \\
\overline{-} \\
\overline{-} \\
\overline{5} .5\end{array}$ & $\begin{array}{c}= \\
= \\
= \\
2.46 \\
\overline{-} \\
= \\
2.45\end{array}$ & $\begin{array}{c}- \\
\bar{z} \\
- \\
5.5 \\
- \\
- \\
- \\
- \\
5.5\end{array}$ & $\begin{array}{c}= \\
= \\
= \\
2.44 \\
= \\
= \\
= \\
2.43\end{array}$ & $\begin{array}{l}= \\
= \\
5 \\
5 \\
= \\
= \\
5\end{array}$ \\
\hline & \multicolumn{2}{|c|}{ December 20} & \multicolumn{2}{|c|}{ December 21} & \multicolumn{2}{|c|}{ December 22} & \multicolumn{2}{|c|}{ December 23} & \multicolumn{2}{|c|}{ December 24} & \multicolumn{2}{|c|}{ December 25} \\
\hline \begin{tabular}{r|}
2 \\
4 \\
6 \\
8 \\
10 \\
$\mathbb{N}$ \\
2 \\
4 \\
6 \\
8 \\
10 \\
$\mathrm{~N}$
\end{tabular} & $\begin{array}{c}= \\
= \\
= \\
2.43 \\
= \\
= \\
= \\
2.43\end{array}$ & $\begin{array}{l}\overline{-} \\
= \\
\overline{5} \\
\overline{-} \\
\bar{z} \\
\overline{5}\end{array}$ & $\begin{array}{l}2.42 \\
2.63 \\
2.75 \\
2.76 \\
2.76 \\
2.76 \\
2.75 \\
2.75 \\
2.75 \\
2.75 \\
2.75 \\
2.75\end{array}$ & $\begin{array}{l}4.8 \\
8.5 \\
11 \\
12 \\
12 \\
12 \\
11 \\
11 \\
11 \\
11 \\
11 \\
11\end{array}$ & $\begin{array}{c}= \\
= \\
= \\
2.74 \\
= \\
= \\
= \\
2.73\end{array}$ & $\begin{array}{l}\overline{-} \\
\overline{-} \\
\overline{11} \\
\bar{z} \\
\bar{z} \\
\overline{11}\end{array}$ & $\begin{array}{c}= \\
= \\
= \\
2.70 \\
= \\
= \\
= \\
2.67\end{array}$ & $\begin{array}{l}\overline{-} \\
\overline{-} \\
10 \\
\overline{-} \\
= \\
\overline{9} \\
\overline{9} .5\end{array}$ & $\begin{array}{c}= \\
= \\
= \\
2.67 \\
= \\
= \\
2.66\end{array}$ & $\begin{array}{c}\bar{z} \\
= \\
= \\
9.5 \\
= \\
= \\
= \\
9\end{array}$ & $\begin{array}{c}\bar{z} \\
= \\
= \\
2.66 \\
= \\
= \\
= \\
2.66\end{array}$ & $\begin{array}{l}= \\
= \\
\overline{9} \\
= \\
z \\
= \\
\overline{9}\end{array}$ \\
\hline
\end{tabular}

Supplemental records.- Dec. 10, 7 p.m., 3.99 ft., 72 sec.-ft.; 9 p.m., 4.78 ft., 169 sec.-ft.; 11 p.m., 5.47 ft., 316 gec.-ft. 
Coyote Creek near Edenvale, Calif.

Location. - Lat. $37^{\circ} 16^{\prime} 15^{\prime \prime}$, long. $121^{\circ} 47^{\prime} 55^{\prime \prime}$, at east boundary of Santa Teresa grant, at "The Narrow", $1 \frac{1}{2}$ miles northeast of Edenvale, Santa Clara County, and 7 miles south of San Jose. Altitude, about 190 feet above mean sea level.

Drainage area.- 229 square miles.

Gage-halght record. - Water-stage recorder graph.

stage-discharge relation.- Defined by current-meter measurements below 1,200 secondfeet; extended to peak stage parallel to rating curve for 1937 , which is defined by current-meter measurements to 3,500 second-feet.

Max1ma:- December 1937: D1scharge, 3,060 second-fe日t 8 a.m. Dec. 11 (gage he1ght, 6.00 fөet).

1917-November 1937: D1scharge (unregulated), 10,000 second-feet Feb. 10, 1922 (gage helght, 12.8 feet, from floodmarks), from rating curve extended above 4,900 second-feet parallel to curve for 1917 which was defined by current-meter measurements to 8,400 second-feet.

Remarks. - Flood run-off materially affected by artificial storage in Coyote Reservolr (capacity, 30,000 acre-feet).

Mean dally discharge, in second-feet, November 1937 to January 1938

\begin{tabular}{|c|c|c|c||c|c|c|c||c|c|c|c|}
\hline Day & Nov. & Dec. & Jan. & Day & Nov. & Dec. & Jan. & Day & Nov. & Dec. & Jan. \\
\hline 1 & 9.5 & 0 & 0 & 12 & 7.5 & 1,370 & 0 & 21 & 0 & 0 & 0 \\
2 & 9 & 0 & 0 & 12 & 5 & 365 & 0 & 22 & 0 & 0 & 0 \\
3 & 8 & 0 & 0 & 13 & 4.9 & 150 & 0 & 23 & 0 & 0 & 0 \\
4 & 5 & 0 & 0 & 14 & 8 & 75 & 0 & 24 & 0 & 0 & 0 \\
5 & 3.6 & 0 & 0 & 15 & 8 & 32 & 0 & 25 & 0 & 0 & 0 \\
6 & 4.6 & 0 & 0 & 16 & 8 & 12 & 0 & 26 & 0 & 0 & 0 \\
7 & 6 & 0 & 0 & 17 & 3.5 & 2.3 & .8 & 27 & 0 & 0 & 0 \\
8 & 6 & 0 & 0 & 18 & 0 & 0 & 7 & 28 & 0 & 0 & 0 \\
9 & 6 & 0 & 0 & 19 & 0 & 0 & 9 & 29 & 0 & 0 & 3.0 \\
10 & 4.9 & 0 & 0 & 20 & 0 & 0 & .6 & 30 & 0 & 0 & 30 \\
\end{tabular}

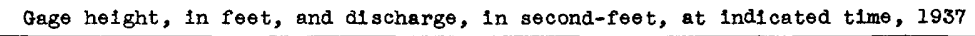

\begin{tabular}{|c|c|c|c|c|c|c|c|c|c|c|c|c|}
\hline \multirow{2}{*}{$\begin{array}{l}0 \\
5 \\
0\end{array}$} & Feet & Sec.ft. & Feet & Sec.ft. & Feet & Sec.ft. & Feet & Sec.ft. & Feet & sec.ft. & Fe日t & sec.ft. \\
\hline & \multicolumn{2}{|c|}{ December 8} & \multicolumn{2}{|c|}{ December 9} & \multicolumn{2}{|c|}{ December 10} & \multicolumn{2}{|c|}{ December 11} & \multicolumn{2}{|c|}{ December 12} & \multicolumn{2}{|c|}{ December 13} \\
\hline \begin{tabular}{r|}
2 \\
4 \\
6 \\
8 \\
10 \\
$\mathbf{N}$ \\
2 \\
4 \\
6 \\
8 \\
10 \\
$\mathbf{y}$
\end{tabular} & & & & & & & $\begin{array}{l}- \\
2.66 \\
4.20 \\
6.00 \\
5.75 \\
5.72 \\
5.67 \\
5.15 \\
4.69 \\
4.39 \\
4.17 \\
4.00\end{array}$ & $\begin{array}{r}0 \\
14 \\
705 \\
3,060 \\
2,650 \\
2,600 \\
2,520 \\
1,780 \\
1,200 \\
880 \\
681 \\
550\end{array}$ & $\begin{array}{l}3.91 \\
3.85 \\
3.77 \\
3.70 \\
3.65 \\
3.65 \\
3.64 \\
3.62 \\
3.60 \\
3.61 \\
3.55 \\
3.48\end{array}$ & \begin{tabular}{|l|}
492 \\
455 \\
407 \\
365 \\
335 \\
335 \\
329 \\
317 \\
305 \\
311 \\
278 \\
240
\end{tabular} & $\begin{array}{l}3 . \\
3.37 \\
\overline{3.30} \\
- \\
3.26 \\
- \\
3.22 \\
- \\
3.20 \\
\overline{3.16}\end{array}$ & $\begin{array}{c}\overline{188} \\
\overline{158} \\
\overline{143} \\
\overline{128} \\
\overline{120} \\
\overline{106}\end{array}$ \\
\hline & \multicolumn{2}{|c|}{ December 14} & \multicolumn{2}{|c|}{ December 15} & \multicolumn{2}{|c|}{ December 16} & \multicolumn{2}{|c|}{ December 17} & \multicolumn{2}{|c|}{ December 18} & \multicolumn{2}{|c|}{ December 19} \\
\hline $\begin{array}{r}2 \\
4 \\
6 \\
8 \\
10 \\
N \\
2 \\
4 \\
6 \\
8 \\
10 \\
1\end{array}$ & $\begin{array}{l}3.13 \\
- \\
3.09 \\
5.05 \\
- \\
3.02 \\
- \\
2.99 \\
2.95\end{array}$ & $\begin{array}{l}\overline{86} \\
\overline{83} \\
\overline{7} 2 \\
\overline{64} \\
\overline{57} \\
\overline{50}\end{array}$ & $\begin{array}{c}- \\
2.91 \\
- \\
2.88 \\
- \\
2.84 \\
- \\
2.81 \\
- \\
2.78 \\
- \\
2.75\end{array}$ & $\begin{array}{l}\overline{42} \\
\overline{3} 7 \\
\overline{3} 2 \\
\overline{27} \\
\overline{24} \\
\overline{2} \\
\overline{2}\end{array}$ & $\begin{array}{l}\tilde{2.71} \\
2.67 \\
\tilde{2.64} \\
\dot{2.60} \\
\dot{2.55} \\
\dot{2.51}\end{array}$ & $\begin{array}{c}1 \overline{8} \\
1 \overline{5} \\
1 \overline{3} \\
\overline{10} \\
\overline{8} \\
\overline{6} .5\end{array}$ & $\begin{array}{l}- \\
2.45 \\
2.40 \\
\dot{2.33} \\
- \\
2.26 \\
\dot{2.21} \\
\overline{2.19}\end{array}$ & $\begin{array}{c}- \\
4.6 \\
- \\
3.0 \\
- \\
1.6 \\
-7 \\
- \\
.3 \\
.2\end{array}$ & & & & \\
\hline
\end{tabular}

Supplemental records.- Dec. 11, 3:30 a.m., no flow. 
Alameda Creek near Niles, Calif.

Locat1on. - Lat. $37^{\circ} 35^{\prime} 15^{\prime \prime}$, long. $121^{\circ} 57^{\prime} 35^{\prime \prime}$, in Arroyo de la Alameda grant, an elghth of a mile above highway bridge and $1 \frac{1}{4}$ miles northeast of Niles, Alameda County. Altitude, about 100 feet above mean ser level.

Dralnage area.- 633 square miles.

Gage-helght record. - Water-stage recorder graph.

Stage-discharge relation. - Defined by current-meter measurements for entire range of stage. Shifting-control method used for period Nov, 20 to Dec. 9.

Maxima:- December 1937: Discharge, 5,180 second-feet 9 p.m. Dec. Il (gage height, 8.85 feet).

1917-November 1937: Discharge, 13,900 second-feet Feb. 10, 1922 (gage height, 12.44 feet, former site and datum, 800 feet upstream), from rating curve extended above 7,600 second-feet.

Remarks: - Flood run-off affected by artificial storage in Calaveras Reservolr (capacity, 100,000 acre-feet) and by diversions for San Francisco water supply and other diversions above station. Table on following page gives storage in Calaveras Reservolr, diversions, and ad justed dally discharge for Alameda Cresk. Most of basic data furnished by city of San Francisco.

Mean dally discharge, in second-feet, November 1937 to January 1938

\begin{tabular}{|c|c|c|c|c|c|c|c|c|c|c|c|}
\hline Day & Nov. & Dec. & Jan. & Day & Nov. & Dec. & Jan. & Dag & Nov. & Dec. & Jan. \\
\hline 1 & 13 & 1.6 & 148 & 11 & 11 & 2,750 & 151 & 21 & 8.5 & 148 & 133 \\
2 & 13 & 1.8 & 148 & 12 & 13 & 2,040 & 151 & 22 & 6 & 148 & 112 \\
3 & 13 & 2.1 & 148 & 13 & 15 & 688 & 151 & 23 & 6 & 148 & 108 \\
4 & 13 & 2.4 & 148 & 14 & 17 & 265 & 136 & 24 & 6 & 148 & 105 \\
5 & 13 & 2.4 & 148 & 15 & 16 & 95 & 105 & 25 & 4.3 & 145 & 108 \\
6 & 13 & 2.4 & 148 & 16 & 17 & 172 & 101 & 26 & 2.5 & 145 & 112 \\
7 & 13 & 2.5 & 148 & 17 & 19 & 172 & 115 & 27 & 2.1 & 148 & 112 \\
8 & 13 & 2.8 & 151 & 18 & 18 & 160 & 110 & 28 & 1.8 & 148 & 142 \\
9 & 13 & 17 & 151 & 19 & 17 & 154 & 115 & 29 & 1.6 & 148 & 172 \\
10 & 11 & 77 & 151 & 20 & 9 & 151 & 136 & 30 & 1.6 & 148 & 160 \\
&
\end{tabular}

Gage height, in fest, and discharge, in second-feet, at indicated time, 1937

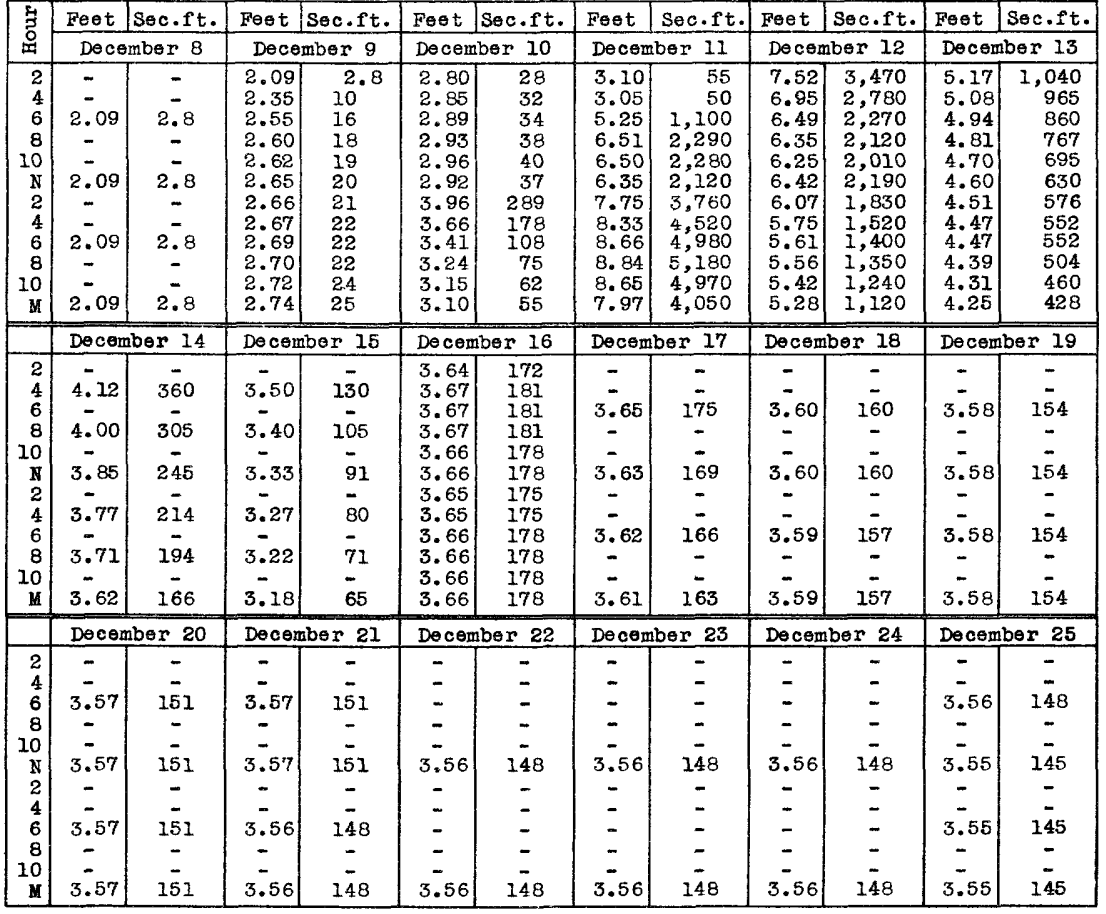

Supplemental recorás.- Dec. 11, 9 p.m., 8.85 ft., 5,180 sec.-ft. 
Alameda Creek near Niles, Calif.--Continued

Q a in or loss in storage, diversions, and adusted daliy discharge, December 1937 to January 1938

\begin{tabular}{|c|c|c|c|c|c|c|c|c|}
\hline \multicolumn{5}{|c|}{ December } & \multicolumn{4}{|c|}{ January } \\
\hline \multirow[b]{2}{*}{ Day } & \multicolumn{2}{|c|}{ Calaveres Reservoir } & \multirow[b]{2}{*}{$\begin{array}{l}\text { Diver- } \\
\text { sions } \\
\text { (acre- } \\
\text { feet) }\end{array}$} & \multirow[b]{2}{*}{$\begin{array}{l}\text { Ad justed } \\
\text { discharge } \\
(\text { sec.-ft.) }\end{array}$} & \multicolumn{2}{|c|}{ Caleveras Reservoir } & \multirow[b]{2}{*}{$\begin{array}{l}\text { Diver- } \\
\text { s lons } \\
\text { (ecre- } \\
\text { feet) }\end{array}$} & \multirow[b]{2}{*}{$\begin{array}{c}\text { Ad justed } \\
\text { discharge } \\
\text { (sec.-ft.) }\end{array}$} \\
\hline & $\begin{array}{c}\text { Contents } \\
(\operatorname{acre}-\mathrm{fe \theta})\end{array}$ & $\begin{array}{l}\text { Gein or } \\
\text { loss } \\
\text { (acre- } \\
\text { feet) }\end{array}$ & & & $\begin{array}{l}\text { Contents } \\
(\operatorname{acre}-\text { feet })\end{array}$ & $\begin{array}{l}\text { Gain or } \\
\text { loss } \\
\text { (acre- } \\
\text { feet) }\end{array}$ & & \\
\hline $\begin{array}{l}1 \\
2 \\
3 \\
4 \\
5\end{array}$ & $\begin{array}{l}52,817 \\
52,622 \\
52,427 \\
52,232 \\
52,037\end{array}$ & $\begin{array}{l}-195 \\
-195 \\
-195 \\
-195 \\
-195\end{array}$ & $\begin{array}{l}225 \\
226 \\
224 \\
223 \\
226\end{array}$ & $\begin{array}{l}17 \\
17 \\
17 \\
16 \\
18\end{array}$ & $\begin{array}{l}59,869 \\
59,589 \\
59,311 \\
59,058 \\
58,782\end{array}$ & $\begin{array}{l}-280 \\
-280 \\
-278 \\
-253 \\
-276\end{array}$ & $\begin{array}{l}44 \\
44 \\
44 \\
44 \\
44\end{array}$ & $\begin{array}{l}29 \\
29 \\
30 \\
43 \\
31\end{array}$ \\
\hline $\begin{array}{r}6 \\
7 \\
8 \\
9 \\
10\end{array}$ & $\begin{array}{l}51,843 \\
51,649 \\
51,455 \\
51,670 \\
56,884\end{array}$ & $\begin{array}{r}-194 \\
-194 \\
-194 \\
+215 \\
+5,214\end{array}$ & $\begin{array}{l}224 \\
223 \\
236 \\
243 \\
240\end{array}$ & $\begin{array}{r}18 \\
17 \\
24 \\
248 \\
2,830\end{array}$ & $\begin{array}{l}58,482 \\
58,161 \\
57,910 \\
57,635 \\
57,360\end{array}$ & $\begin{array}{l}-300 \\
-321 \\
-251 \\
-275 \\
-275\end{array}$ & $\begin{array}{l}44 \\
44 \\
44 \\
44 \\
44\end{array}$ & $\begin{array}{r}19 \\
8 \\
47 \\
35 \\
35\end{array}$ \\
\hline $\begin{array}{l}11 \\
12 \\
13 \\
14 \\
15\end{array}$ & $\begin{array}{l}62,667 \\
63,960 \\
64,250 \\
64,467 \\
64,443\end{array}$ & $\begin{array}{r}+5,783 \\
+1,293 \\
+290 \\
+217 \\
-24\end{array}$ & $\begin{array}{l}69 \\
33 \\
6.9 \\
33 \\
28\end{array}$ & $\begin{array}{r}5,700 \\
2,710 \\
838 \\
391 \\
97\end{array}$ & $\begin{array}{l}57,065 \\
56,771 \\
56,454 \\
56,341 \\
56,205\end{array}$ & $\begin{array}{l}-295 \\
-294 \\
-317 \\
-113 \\
-136\end{array}$ & $\begin{array}{r}44 \\
44 \\
-16 \\
-89 \\
42\end{array}$ & $\begin{array}{r}24 \\
25 \\
-17 \\
34 \\
58\end{array}$ \\
\hline $\begin{array}{l}16 \\
17 \\
18 \\
19 \\
20\end{array}$ & $\begin{array}{l}64,201 \\
63,936 \\
63,672 \\
63,457 \\
63,193\end{array}$ & $\begin{array}{l}-242 \\
-265 \\
-264 \\
-215 \\
-264\end{array}$ & $\begin{array}{l}42 \\
43 \\
43 \\
43 \\
43\end{array}$ & $\begin{array}{l}71 \\
60 \\
49 \\
67 \\
40\end{array}$ & $\begin{array}{l}56,115 \\
56,003 \\
55,891 \\
56,048 \\
55,981\end{array}$ & $\begin{array}{r}-90 \\
-112 \\
-112 \\
+157 \\
-67\end{array}$ & $\begin{array}{l}43 \\
42 \\
43 \\
44 \\
44\end{array}$ & $\begin{array}{r}77 \\
80 \\
75 \\
216 \\
124\end{array}$ \\
\hline $\begin{array}{l}21 \\
22 \\
23 \\
24 \\
25\end{array}$ & $\begin{array}{l}62,953 \\
62,667 \\
62,288 \\
62,074 \\
61,861\end{array}$ & $\begin{array}{l}-240 \\
-286 \\
-379 \\
-214 \\
-213\end{array}$ & $\begin{array}{l}39 \\
42 \\
43 \\
43 \\
44\end{array}$ & $\begin{array}{r}47 \\
25 \\
-21 \\
62 \\
60\end{array}$ & $\begin{array}{l}55,914 \\
55,780 \\
55,623 \\
55,466 \\
55,310\end{array}$ & $\begin{array}{l}-67 \\
-134 \\
-157 \\
-157 \\
-156\end{array}$ & $\begin{array}{l}45 \\
44 \\
44 \\
44 \\
44\end{array}$ & $\begin{array}{r}122 \\
67 \\
51 \\
48 \\
52\end{array}$ \\
\hline $\begin{array}{l}26 \\
27 \\
28 \\
29 \\
30 \\
31\end{array}$ & $\begin{array}{l}61,578 \\
61,296 \\
60,991 \\
60,710 \\
60,429 \\
60,149\end{array}$ & $\begin{array}{l}-283 \\
-282 \\
-305 \\
-281 \\
-281 \\
-280\end{array}$ & $\begin{array}{l}44 \\
45 \\
45 \\
44 \\
44 \\
44 \\
\end{array}$ & $\begin{array}{l}25 \\
29 \\
17 \\
29 \\
29 \\
29\end{array}$ & $\begin{array}{l}55,108 \\
54,958 \\
55,220 \\
55,578 \\
55,735 \\
59,729\end{array}$ & $\begin{array}{r}-202 \\
-155 \\
+267 \\
+358 \\
+157 \\
+3,994 \\
\end{array}$ & \begin{tabular}{|l|l}
44 \\
44 \\
44 \\
43 \\
44 \\
25 \\
\end{tabular} & $\begin{array}{r}32 \\
56 \\
299 \\
374 \\
261 \\
2,660 \\
\end{array}$ \\
\hline \multirow{2}{*}{\multicolumn{7}{|c|}{ 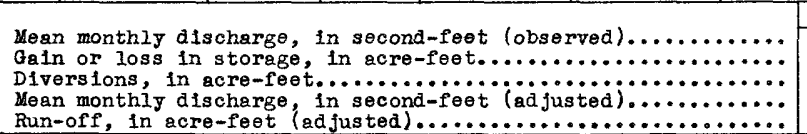 }} & December & January \\
\hline & & & & & & & $\begin{array}{r}270 \\
+7,140 \\
+3,150 \\
438 \\
26,930 \\
\end{array}$ & $\begin{array}{r}150 \\
-420 \\
+1,150 \\
162 \\
9,960 \\
\end{array}$ \\
\hline
\end{tabular}


Kern River near Kornville, Callf.

Location. - Lat. $35^{\circ} 56^{\prime}$, long. $118^{\circ} 29^{\prime}$, In NEt sec. 14, T. 23 S., R. 32 F., 3 miles above Salmon Creok and $15 \mathrm{mlles}$ north of Kernville, Kern County. Altitude, about 3,550 feet above mean sea level.

Draingge area. - 845 square miles.

Gage-he1ght record. - water-stage recorder graph.

Stage-discharge relation.- Definer by current-meter measurements below 6,200 secondfeet; extended to peak stage on basis of computation of peak flow of flood of Feb. 6 , 1937, over diversion dam 1 mile above gage; verifled by area-velocity etudy at gage. Shifting-control method used for perlods Nov. 1 to Dec. 10, Dec. 23 to Jan. 31.

Maxima.- Decomber 1937: D1scharge, 6,800 second-feet 8 p.m. Dec. 11 (gage height, 11.58 feot).

1912-November 1937: D1scharge (unregulated), 9,690 second-feet Jan. 17, 1916 (gage helght, 8.8 peot, former datum), from rating curve extended above 4 , 100 second-foet.

Remarks.- Flood run-off not affected by artificial storage. Kern River No. 3 canal diverts above station. Monthly summarles adjusted for diversion. Most of bas1c data furnished by Southerm California Edison Co., Ltd.

Mean daily discharge, in second-feet, Hovember 1937 to January 1938

\begin{tabular}{|c|c|c|c|c|c|c|c|c|c|c|c|}
\hline Day & Nov. & Dec. & Jan. & Day & Nov. & Dec. & Jan. & Day & Nor. & Dec. & Jan. \\
\hline $\begin{array}{r}1 \\
2 \\
3 \\
4 \\
5 \\
6 \\
7 \\
8 \\
9 \\
10\end{array}$ & $\begin{array}{l}6 \\
9.5 \\
6 \\
1.5 \\
1.4 \\
1.4 \\
1.4 \\
1.3 \\
1.2 \\
1.3\end{array}$ & $\begin{array}{r}1.4 \\
1.5 \\
1.3 \\
1.2 \\
1.2 \\
1.2 \\
1.1 \\
1.2 \\
15 \\
2,110\end{array}$ & $\begin{array}{l}0.6 \\
.6 \\
.6 \\
.7 \\
.8 \\
.8 \\
.8 \\
.8 \\
.7\end{array}$ & $\begin{array}{l}11 \\
12 \\
13 \\
14 \\
15 \\
16 \\
17 \\
18 \\
19 \\
20\end{array}$ & $\begin{array}{l}1.4 \\
1.4 \\
1.5 \\
1.5 \\
1.5 \\
1.5 \\
1.5 \\
1.5 \\
1.5 \\
1.3\end{array}$ & $\begin{array}{r}2,120 \\
1,900 \\
718 \\
460 \\
339 \\
269 \\
214 \\
170 \\
135 \\
109\end{array}$ & $\begin{array}{r}0.6 \\
.6 \\
.6 \\
12.6 \\
9.5 \\
1.7 \\
1.5 \\
1.5 \\
1.5\end{array}$ & $\begin{array}{l}21 \\
22 \\
23 \\
24 \\
25 \\
26 \\
27 \\
28 \\
29 \\
30 \\
31\end{array}$ & $\begin{array}{l}1.3 \\
1.3 \\
1.3 \\
1.4 \\
1.4 \\
1.4 \\
1.4 \\
1.3 \\
1.3 \\
1.3\end{array}$ & $\begin{array}{r}92 \\
79 \\
45 \\
2.0 \\
1.2 \\
1.1 \\
1.0 \\
.9 \\
.8 \\
.6 \\
.6\end{array}$ & $\begin{array}{l}1.4 \\
1.5 \\
1.4 \\
1.5 \\
1.5 \\
1.4 \\
1.4 \\
1.4 \\
1.5 \\
1.5 \\
1.6\end{array}$ \\
\hline $\begin{array}{l}\text { Mear } \\
\text { Mear } \\
\text { Run }\end{array}$ & & $r_{\theta}=f_{\theta}$ & & & & & & & $\begin{array}{r}1.97 \\
240 \\
14,310\end{array}$ & $\begin{array}{r}284 \\
610 \\
37,500\end{array}$ & $\begin{array}{r}1.72 \\
345 \\
21,190\end{array}$ \\
\hline
\end{tabular}

Gage helght, in feot, and discharge, in second-feot, at indicated time, 1937

\begin{tabular}{|c|c|c|c|c|c|c|c|c|c|c|c|c|}
\hline \multirow{2}{*}{$\begin{array}{l}5 \\
5 \\
\text { 要 }\end{array}$} & Feot & Sec.ft. & Foet & Sec.ft. & Feet & Sec.ft. & Feet & Sec.ft. & Feet & Sec.ft. & Feet & Sec.ft. \\
\hline & \multicolumn{2}{|c|}{ December 8} & \multicolumn{2}{|c|}{ December 9} & \multicolumn{2}{|c|}{ December 10} & \multicolumn{2}{|c|}{ December 11} & \multicolumn{2}{|c|}{ December 12} & \multicolumn{2}{|c|}{ December 13} \\
\hline \multirow[t]{2}{*}{\begin{tabular}{r|}
2 \\
4 \\
6 \\
8 \\
10 \\
$N$ \\
2 \\
4 \\
6 \\
8 \\
10 \\
$M$ \\
\end{tabular}} & $\begin{array}{l}\bar{z} \\
\bar{z} \\
\overline{2} \\
2.66 \\
\bar{z} \\
\bar{z} \\
\overline{2} .66\end{array}$ & $\begin{array}{c}\overline{-} \\
= \\
\overline{-} \\
1.2 \\
\bar{z} \\
\bar{z} \\
1.2\end{array}$ & $\begin{array}{l}2.66 \\
2.66 \\
2.66 \\
2.66 \\
2.66 \\
2.66 \\
2.67 \\
2.68 \\
2.72 \\
2.80 \\
2.91 \\
6.20\end{array}$ & $\begin{array}{l}1.2 \\
1.2 \\
1.2 \\
1.2 \\
1.2 \\
1.2 \\
1.2 \\
1.3 \\
1.8 \\
3.1 \\
5.7 \\
650\end{array}$ & $\begin{array}{l}9.43 \\
9.45 \\
9.87 \\
9.78 \\
9.28 \\
8.78 \\
8.16 \\
7.55 \\
7.08 \\
6.73 \\
6.47 \\
6.27\end{array}$ & $\begin{array}{r}3,220 \\
3,240 \\
3,840 \\
3,710 \\
3,030 \\
2,460 \\
1,870 \\
1,400 \\
1,110 \\
905 \\
775 \\
682\end{array}$ & $\begin{array}{r}6.07 \\
5.87 \\
5.72 \\
5.66 \\
5.63 \\
5.69 \\
6.18 \\
8.57 \\
10.58 \\
11.58 \\
10.86 \\
9.95\end{array}$ & $\begin{array}{r}598 \\
518 \\
460 \\
438 \\
428 \\
449 \\
642 \\
2,250 \\
4,970 \\
6,800 \\
5,450 \\
3,960\end{array}$ & $\begin{array}{l}9.48 \\
9.15 \\
8.85 \\
8.55 \\
8.18 \\
7.88 \\
7.62 \\
7.44 \\
7.30 \\
7.17 \\
7.05 \\
6.93\end{array}$ & $\begin{array}{l}3,280 \\
2,870 \\
2,540 \\
2,230 \\
1,880 \\
1,640 \\
1,450 \\
1,330 \\
1,240 \\
1,160 \\
1,090 \\
1,020\end{array}$ & $\begin{array}{l}6.81 \\
6.71 \\
6.61 \\
6.52 \\
6.43 \\
6.33 \\
6.24 \\
6.16 \\
6.10 \\
6.05 \\
6.01 \\
5.97\end{array}$ & $\begin{array}{l}946 \\
895 \\
845 \\
800 \\
755 \\
708 \\
668 \\
634 \\
610 \\
590 \\
574 \\
558\end{array}$ \\
\hline & \multicolumn{2}{|c|}{ December 14} & \multicolumn{2}{|c|}{ December 15} & \multicolumn{2}{|c|}{ December 16} & \multicolumn{2}{|c|}{ December 17} & \multicolumn{2}{|c|}{ December 18} & \multicolumn{2}{|c|}{ December 19} \\
\hline $\begin{array}{r}2 \\
4 \\
6 \\
8 \\
8 \\
10 \\
\mathbb{N} \\
2 \\
4 \\
6 \\
8 \\
10 \\
\mathrm{~N}\end{array}$ & $\begin{array}{c}- \\
5.90 \\
- \\
5.82 \\
- \\
5.71 \\
- \\
5.60 \\
- \\
5.53 \\
- \\
5.49\end{array}$ & $\begin{array}{l}- \\
5 \overline{30} \\
\overline{498} \\
\overline{-} \\
\overline{5} 6 \\
4 \overline{18} \\
\overline{3} \overline{6} \\
- \\
3 \overline{83}\end{array}$ & $\begin{array}{c}-\overline{-} \\
5.45 \\
- \\
5.41 \\
- \\
5.35 \\
- \\
5.28 \\
- \\
5.23 \\
- \\
5.19\end{array}$ & $\begin{array}{c}- \\
371 \\
- \\
359 \\
- \\
342 \\
- \\
322 \\
\overline{308} \\
- \\
297\end{array}$ & $\begin{array}{c}\overline{-} \\
\overline{5.15} \\
\overline{-} \\
5.08 \\
\overline{5} \\
5.01 \\
\overline{-} \\
4.94\end{array}$ & $\begin{array}{c}\overline{-} \\
2 \overline{87} \\
- \\
2 \overline{69} \\
\overline{-} \\
251 \\
\overline{-} \\
2 \overline{3} 3\end{array}$ & $\begin{array}{c}- \\
- \\
4.92 \\
\overline{-} \\
4.88 \\
\overline{4} \\
\overline{-} 80 \\
\overline{4.73}\end{array}$ & $\begin{array}{c}\overline{-} \\
2 \overline{2} \\
- \\
\overline{2} \\
\overline{18} \\
\overline{200} \\
\overline{185}\end{array}$ & $\begin{array}{c}- \\
- \\
4.71 \\
- \\
\overline{4} \\
4.67 \\
\overline{-} \\
4.60 \\
\overline{-} \\
4.55\end{array}$ & $\begin{array}{c}- \\
\overline{181} \\
\overline{-} \\
\overline{7} 3 \\
\overline{-} \\
160 \\
\overline{-} \\
152\end{array}$ & $\begin{array}{c}- \\
- \\
4.51 \\
- \\
- \\
4.46 \\
- \\
4.38 \\
\overline{-} \\
4.32\end{array}$ & $\begin{array}{c}\overline{-} \\
145 \\
\overline{-} \\
137 \\
\overline{-} \\
124 \\
\overline{1} \\
\overline{116}\end{array}$ \\
\hline & \multicolumn{2}{|c|}{ December 20} & \multicolumn{2}{|c|}{ December 21} & \multicolumn{2}{|c|}{ Decomber 22} & \multicolumn{2}{|c|}{ December 23} & \multicolumn{2}{|c|}{ December 24} & \multicolumn{2}{|c|}{ December 25} \\
\hline $\begin{array}{r}2 \\
4 \\
6 \\
8 \\
10 \\
\mathbb{N} \\
2 \\
4 \\
6 \\
8 \\
10 \\
\mathbb{M}\end{array}$ & $\begin{array}{c}\bar{z} \\
4.31 \\
\overline{4} \\
4.32 \\
\overline{4} \\
\overline{4.20} \\
\overline{4} \\
4.16\end{array}$ & $\begin{array}{c}\overline{-} \\
114 \\
\overline{-} \\
116 \\
\overline{-} \\
100 \\
\overline{85}\end{array}$ & $\begin{array}{c}\bar{z} \\
4.17 \\
\vdots \\
4.18 \\
\vdots \\
4.08 \\
\overline{4} \\
4.05\end{array}$ & $\begin{array}{l}\overline{-} \\
\overline{96} \\
\bar{z} \\
\overline{9} \\
\overline{8} \\
\bar{z} \\
\overline{83}\end{array}$ & $\begin{array}{l}4.05 \\
- \\
4.08 \\
- \\
4.07 \\
- \\
4.00 \\
- \\
3.90 \\
- \\
3.88\end{array}$ & $\begin{array}{l}\overline{83} \\
\overline{86} \\
\overline{85} \\
\overline{78} \\
- \\
68 \\
\overline{66}\end{array}$ & $\begin{array}{l}3.91 \\
3.95 \\
3.97 \\
4.04 \\
4.05 \\
3.71 \\
3.44 \\
3.25 \\
3.12 \\
3.01 \\
2.94 \\
2.89\end{array}$ & $\begin{array}{c}69 \\
73 \\
75 \\
82 \\
83 \\
49 \\
28 \\
17 \\
10 \\
7 \\
5 \\
3.9\end{array}$ & $\begin{array}{c}\bar{z} \\
2.80 \\
\bar{z} \\
2.75 \\
\bar{z} \\
2.74 \\
\overline{-} \\
2.72\end{array}$ & $\begin{array}{c}\overline{-} \\
2.3 \\
= \\
1.7 \\
\overline{-} \\
1.6 \\
\overline{-} \\
1.4\end{array}$ & $\begin{array}{c}\bar{z} \\
\bar{z} \\
\bar{z} \\
2.70 \\
\bar{z} \\
\bar{z} \\
\overline{2.69}\end{array}$ & $\begin{array}{l}= \\
= \\
1.2 \\
= \\
= \\
1.2\end{array}$ \\
\hline
\end{tabular}

Supplemental records.- Dec. 9, 11 p.m., 3.65 ft., 47 sec.-ft. 
Kern River above Kern Canyon power house, Calif.

Location. - Lat. $35^{\circ} 27^{\prime}$, long. $118^{\circ} 47^{\prime}$, In sec. 31, T. $28 \mathrm{~S}$, R. 30 E., about threequarters of a mile above Kern Canyon power house, Kern County. Altitude, about 770 feet above mean sea level.

Drainage area.- 2,310 square miles.

Gage-height record.- Water-stage recorder graph.

Stage-discharge relation. - Defined by current-meter measurements below 4,200 secondfeet; extended to peak stage of February 1937 on basis of computation of flow over Kem River No. 1 Intake dam, 11 miles above gage, plus flow through Kern River No. 1 power house, and by comparison of peak discharge and total runoff of flood with records for other stations in Kern River Basin.

Max Ima.- December 1937: Discharge, 7,900 second-feet 5:30 a.m. Dec. 12 (gage height, 16.65 feet).

1929-November 1937: Discharge, 19,200 second-feet Feb. 7, 1937 (gage he1ght, 22.4 feet, from floodmarks).

Remarks. - Flood run-off not affected by artificlal storage but by diversion above the station for Kern Canyon power house. Monthly summaries adjusted for diversion. Most of basic data furnished by San Joaquin Light \& Power Co.

Mean daily discharge, in second-feet, November 1937 to January 1938

\begin{tabular}{|c|c|c|c|c|c|c|c|c|c|c|c|}
\hline Day & Nov. & Dec. & Jan. & Day & Nov. & Dec. & Jan. & Day & Nov. & Dec. & Jan. \\
\hline $\begin{array}{r}1 \\
2 \\
3 \\
4 \\
5 \\
6 \\
7 \\
8 \\
9 \\
10\end{array}$ & $\begin{array}{l}4.8 \\
4.4 \\
3.9 \\
3.5 \\
3.3 \\
3.2 \\
3.2 \\
3.2 \\
3.2 \\
3.1\end{array}$ & $\begin{array}{r}2.6 \\
2.6 \\
2.6 \\
2.7 \\
2.6 \\
2.6 \\
2.6 \\
2.6 \\
2.6 \\
1,450\end{array}$ & $\begin{array}{l}5 \\
5 \\
5 \\
5 \\
5 \\
5 \\
5 \\
5 \\
5\end{array}$ & $\begin{array}{l}11 \\
12 \\
13 \\
14 \\
15 \\
16 \\
17 \\
18 \\
19 \\
20\end{array}$ & $\begin{array}{l}3.2 \\
3.2 \\
3.0 \\
2.9 \\
3.0 \\
2.9 \\
2.8 \\
2.8 \\
2.8 \\
2.8\end{array}$ & $\begin{array}{r}1,060 \\
4,300 \\
1,780 \\
844 \\
545 \\
333 \\
246 \\
181 \\
138 \\
84\end{array}$ & $\begin{array}{l}5 \\
5 \\
5 \\
5 \\
5.5 \\
5 \\
5 \\
23 \\
9 \\
5.5\end{array}$ & $\begin{array}{l}21 \\
22 \\
23 \\
24 \\
25 \\
26 \\
27 \\
28 \\
29 \\
30 \\
31\end{array}$ & $\begin{array}{l}2.7 \\
2.6 \\
2.6 \\
2.6 \\
2.6 \\
2.6 \\
2.6 \\
2.6 \\
2.6 \\
2.6\end{array}$ & $\begin{array}{l}49 \\
50 \\
9.5 \\
34 \\
8.5 \\
8.5 \\
7 \\
7 \\
6 \\
5.5 \\
5.5\end{array}$ & $\begin{array}{l}5 \\
4.9 \\
5 \\
5 \\
4.8 \\
5 \\
5 \\
5 \\
5 \\
5 \\
5\end{array}$ \\
\hline $\begin{array}{l}\text { Mean } \\
\text { Mean } \\
\text { Run- }\end{array}$ & $\begin{array}{l}\text { onth] } \\
\text { onth } \\
f, \text { in }\end{array}$ & $\begin{array}{l}\text { dischar } \\
\text { dischar } \\
\text { cre-fee }\end{array}$ & $\begin{array}{l}\text { in } \\
\text { in } \\
\text { adju }\end{array}$ & d) & $\begin{array}{l}e \theta t \\
e \theta t\end{array}$ & us ted & & & $\begin{array}{r}3.04 \\
272 \\
16,200 \\
\end{array}$ & $\begin{array}{r}360 \\
824 \\
50,660 \\
\end{array}$ & $\begin{array}{r}5.73 \\
474 \\
29,130 \\
\end{array}$ \\
\hline
\end{tabular}

Gage helght, in feet, and discharge, in second-feet, at indicated time, 1937

\begin{tabular}{|c|c|c|c|c|c|c|c|c|c|c|c|c|}
\hline \multirow{2}{*}{$\begin{array}{l}\text { 岁 } \\
\text { o } \\
\text { 至 }\end{array}$} & Feet & Sec.ft. & Feet & Sec.ft. & Feet & sec.ft. & Feet & Sec.ft. & Feet & Sec.ft. & Feet & Sec.ft \\
\hline & \multicolumn{2}{|c|}{ December 8} & \multicolumn{2}{|c|}{ December 9} & \multicolumn{2}{|c|}{ December 10} & \multicolumn{2}{|c|}{ December 11} & \multicolumn{2}{|c|}{ December 12} & \multicolumn{2}{|c|}{ December 13} \\
\hline \multirow[t]{2}{*}{$\begin{array}{r}2 \\
4 \\
6 \\
8 \\
10 \\
N \\
2 \\
4 \\
6 \\
8 \\
10 \\
M\end{array}$} & $\begin{array}{l}\bar{z} \\
= \\
= \\
= \\
3.10 \\
= \\
= \\
= \\
= \\
3.10\end{array}$ & $\begin{array}{c}- \\
- \\
\overline{-} \\
- \\
2.6 \\
z \\
\bar{z} \\
\overline{-} \\
\overline{2.6}\end{array}$ & $\begin{array}{l}- \\
3.10 \\
- \\
3.10 \\
- \\
3.10 \\
- \\
3.10 \\
3.10 \\
3.12\end{array}$ & $\begin{array}{c}2.6 \\
- \\
2.6 \\
2.6 \\
- \\
2.6 \\
2.6 \\
2.8\end{array}$ & $\begin{array}{r}3.13 \\
3.14 \\
3.15 \\
3.20 \\
3.37 \\
5.60 \\
11.50 \\
12.98 \\
13.48 \\
13.12 \\
12.49 \\
11.82\end{array}$ & $\begin{array}{r}2.8 \\
2.9 \\
3.0 \\
3.4 \\
4.8 \\
102 \\
2,210 \\
3,340 \\
3,810 \\
3,470 \\
2,930 \\
2,430\end{array}$ & \begin{tabular}{|r|}
11.15 \\
10.42 \\
9.80 \\
9.42 \\
9.12 \\
8.87 \\
8.68 \\
8.55 \\
8.45 \\
8.32 \\
8.25 \\
8.25
\end{tabular} & $\begin{array}{r}1,990 \\
1,580 \\
1,270 \\
1,100 \\
972 \\
872 \\
798 \\
749 \\
711 \\
663 \\
638 \\
638\end{array}$ & \begin{tabular}{|r|}
9.30 \\
16.40 \\
16.50 \\
15.68 \\
14.80 \\
14.30 \\
13.77 \\
13.12 \\
12.80 \\
12.48 \\
12.14 \\
11.90
\end{tabular} & $\begin{array}{l}1,050 \\
7,580 \\
7,740 \\
6,510 \\
5,320 \\
4,720 \\
4,110 \\
3,470 \\
3,180 \\
2,920 \\
2,660 \\
2,490\end{array}$ & $\begin{array}{r}11.66 \\
11.46 \\
11.35 \\
11.30 \\
11.16 \\
11.00 \\
10.70 \\
10.43 \\
10.16 \\
9.90 \\
9.70 \\
9.54\end{array}$ & $\begin{array}{l}2,320 \\
2,180 \\
2,110 \\
2,080 \\
2,000 \\
1,900 \\
1,720 \\
1,580 \\
1,450 \\
1,320 \\
1,220 \\
1,150\end{array}$ \\
\hline & \multicolumn{2}{|c|}{ December 14} & \multicolumn{2}{|c|}{ December 15} & \multicolumn{2}{|c|}{ December 16} & \multicolumn{2}{|c|}{ December 17} & \multicolumn{2}{|c|}{ December 18} & \multicolumn{2}{|c|}{ December 19} \\
\hline \multirow[t]{2}{*}{$\begin{array}{r}2 \\
4 \\
6 \\
8 \\
10 \\
N \\
2 \\
4 \\
6 \\
8 \\
10 \\
M\end{array}$} & $\begin{array}{l}9.40 \\
9.24 \\
9.10 \\
8.99 \\
8.85 \\
8.78 \\
8.70 \\
8.57 \\
8.50 \\
8.42 \\
8.35 \\
8.26\end{array}$ & $\begin{array}{r}1,090 \\
1,020 \\
964 \\
920 \\
864 \\
836 \\
806 \\
757 \\
730 \\
700 \\
674 \\
642\end{array}$ & $\begin{array}{l}8.18 \\
8.07 \\
7.96 \\
9.36 \\
7.74 \\
7.64 \\
7.69 \\
7.62 \\
7.57 \\
7.53 \\
7.47 \\
7.45\end{array}$ & $\begin{array}{r}613 \\
576 \\
542 \\
1,070 \\
477 \\
450 \\
463 \\
445 \\
432 \\
422 \\
407 \\
502\end{array}$ & $\begin{array}{l}7.40 \\
7.34 \\
7.28 \\
7.22 \\
7.18 \\
7.14 \\
7.10 \\
7.07 \\
7.03 \\
6.99 \\
6.96 \\
6.95\end{array}$ & $\begin{array}{l}390 \\
376 \\
362 \\
348 \\
340 \\
331 \\
322 \\
316 \\
308 \\
300 \\
294 \\
292\end{array}$ & $\begin{array}{l}6.92 \\
6.87 \\
7.02 \\
6.78 \\
6.71 \\
6.66 \\
6.62 \\
6.59 \\
6.55 \\
6.52 \\
6.49 \\
6.46\end{array}$ & $\begin{array}{l}286 \\
277 \\
306 \\
260 \\
248 \\
239 \\
232 \\
226 \\
220 \\
215 \\
211 \\
206\end{array}$ & $\begin{array}{l}6.42 \\
6.40 \\
6.39 \\
6.34 \\
6.30 \\
6.27 \\
6.22 \\
6.20 \\
6.17 \\
6.11 \\
6.08 \\
6.21\end{array}$ & $\begin{array}{l}201 \\
198 \\
197 \\
190 \\
184 \\
180 \\
173 \\
170 \\
166 \\
158 \\
155 \\
171\end{array}$ & $\begin{array}{l}6.19 \\
6.18 \\
6.16 \\
6.14 \\
5.82 \\
5.88 \\
5.83 \\
5.80 \\
5.73 \\
5.71 \\
5.70 \\
5.68\end{array}$ & $\begin{array}{l}169 \\
167 \\
165 \\
162 \\
124 \\
131 \\
125 \\
122 \\
115 \\
113 \\
112 \\
110\end{array}$ \\
\hline & \multicolumn{2}{|c|}{ December 20} & \multicolumn{2}{|c|}{ December 21} & \multicolumn{2}{|c|}{ December 22} & \multicolumn{2}{|c|}{ December 23} & \multicolumn{2}{|c|}{ December 24} & \multicolumn{2}{|c|}{ December 25} \\
\hline $\begin{array}{r}2 \\
4 \\
6 \\
8 \\
10 \\
N \\
2 \\
4 \\
6 \\
8 \\
10 \\
M\end{array}$ & $\begin{array}{l}5.64 \\
5.62 \\
5.56 \\
5.52 \\
5.48 \\
5.43 \\
5.35 \\
5.32 \\
5.28 \\
5.20 \\
5.17 \\
5.16\end{array}$ & $\begin{array}{r}106 \\
104 \\
98 \\
94 \\
90 \\
86 \\
79 \\
77 \\
73 \\
67 \\
65 \\
64\end{array}$ & $\begin{array}{l}5.20 \\
5.20 \\
5.10 \\
5.03 \\
4.99 \\
4.96 \\
4.91 \\
4.84 \\
4.76 \\
4.71 \\
4.62 \\
4.55\end{array}$ & $\begin{array}{l}67 \\
67 \\
60 \\
55 \\
52 \\
51 \\
48 \\
43 \\
39 \\
36 \\
32 \\
29\end{array}$ & $\begin{array}{l}4.52 \\
4.49 \\
4.49 \\
4.48 \\
4.47 \\
4.45 \\
6.90 \\
5.20 \\
4.34 \\
4.16 \\
4.04 \\
3.90\end{array}$ & $\begin{array}{r}28 \\
27 \\
27 \\
26 \\
26 \\
26 \\
282 \\
67 \\
22 \\
17 \\
14 \\
11\end{array}$ & $\begin{array}{l}3.84 \\
3.80 \\
3.77 \\
3.75 \\
3.74 \\
3.73 \\
3.81 \\
3.90 \\
3.82 \\
3.78 \\
3.76 \\
3.74\end{array}$ & $\begin{array}{l}10 \\
9.5 \\
9 \\
9 \\
8.5 \\
8.5 \\
9.5 \\
11 \\
10 \\
9 \\
9 \\
8.5\end{array}$ & $\begin{array}{l}3.71 \\
3.69 \\
4.76 \\
5.10 \\
5.21 \\
5.11 \\
4.92 \\
4.72 \\
4.56 \\
4.40 \\
4.20 \\
4.01\end{array}$ & $\begin{array}{l}8.5 \\
8 \\
39 \\
60 \\
68 \\
61 \\
48 \\
37 \\
29 \\
24 \\
18 \\
13\end{array}$ & $\begin{array}{l}3.84 \\
3.73 \\
3.71 \\
3.70 \\
3.67 \\
3.66 \\
3.66 \\
3.66 \\
3.66 \\
3.66 \\
3.73 \\
3.96\end{array}$ & $\begin{array}{c}10 \\
8.5 \\
8.5 \\
8 \\
8 \\
7.5 \\
7.5 \\
7.5 \\
7.5 \\
7.5 \\
8.5 \\
12\end{array}$ \\
\hline
\end{tabular}

Supplemental records.- Dec. $12,5: 30$ a.m., 16.65 ft., 7,900 sec.-ft. Dec. 15, 7 a.m., $9.40 \mathrm{ft.}, 1,090 \mathrm{sec} . \mathrm{ft.} ; 9$ a.m., $9.32 \mathrm{ft.}, 1,060 \mathrm{sec} . \mathrm{ft}$. Dec. $22,1: 30$ p.m., $6.88 \mathrm{ft.}$, 278 sec.-ft.; 3 p.m., $6.90 \mathrm{ft.,} 282$ sec.-ft. 
Kern River near Bakersfield, Callf.

Location. - Lat. $35^{\circ} 25^{\prime} 54^{\prime \prime}$, long. $118^{\circ} 56^{\prime} 43^{\prime \prime}$, In SW $\frac{1}{4}$ sec. 2 , T. 29 S., R. 28 E., at mouth of lower canyon, 5 miles northeast of Bakersfleld, Kern County. Altitude, about 470 feet above mean sea level.

Drainage area. - 2,420 square miles (revised).

Gage-he1ght record. - Water-stage recorder graph.

Maxima.-December i937: Discharge, 6,859 second-feet 11:30 a.m. Dec. 12.

1893-November 1937: Discharge, 20,000 second-feet Feb. 7, 1937 (gage helght, 9.12 feot).

Remarks.- Flood mun-off not materially affected by artificial storage or diversion. compiote record, except run-off in acre-feet and monthly summaries, furnished by Kern County Land Co.

Mean daily discharge, In second-feet, November 1937 to January 1938

\begin{tabular}{|r|r|r|r||r|r|r|r||r|r|r|r|}
\hline Day & Nov. & Dec. & Jan. & Day & Nov. & Dec. & Jan. & Day & Nov. & Dec. & Jan. \\
\hline 1 & 245 & 272 & 553 & 11 & 264 & 2,175 & 471 & 21 & 297 & 724 & 539 \\
2 & 262 & 268 & 552 & 12 & 268 & 4,227 & 471 & 22 & 298 & 707 & 501 \\
3 & 253 & 269 & 568 & 13 & 270 & 2,711 & 469 & 23 & 294 & 701 & 507 \\
4 & 257 & 270 & 569 & 14 & 273 & 1,353 & 469 & 24 & 290 & 705 & 503 \\
5 & 260 & 270 & 540 & 15 & 281 & 1,158 & 471 & 25 & 289 & 656 & 484 \\
6 & 255 & 271 & 520 & 16 & 282 & 1,049 & 478 & 26 & 288 & 609 & 467 \\
7 & 260 & 277 & 509 & 17 & 280 & 940 & 488 & 27 & 288 & 596 & 469 \\
8 & 267 & 286 & 495 & 18 & 284 & 859 & 536 & 28 & 284 & 589 & 470 \\
9 & 259 & 296 & 490 & 19 & 300 & 794 & 598 & 29 & 279 & 566 & 491 \\
10 & 259 & 926 & 477 & 20 & 296 & 753 & 558 & 30 & 275 & 552 & 536 \\
\end{tabular}

Supplemental records.- Dec. 12, 11:30 a.m., 6,859 sec.-ft. 
South Fork of Kerm River near Onyx, Calif.

Location. - Lat. $35^{\circ} 44^{\prime}$, long. $118^{\circ} 10^{\prime}$, in SW $\frac{1}{4}$ sec. 24 , T. 25 S., R. 35 E., threequarters of a mile north of Kernvilie-Walker Pass road, $1.4 \mathrm{miles}$ above Canebrake Creek, and 5 miles northeast of Onyx, Kern County. Altituade, about 2,900 feet above mean sea level.

Drainage area.- 531 square miles.

Gage-he1ght record. - Water-stage recorder graph except for period 9 p.m. Jan. 30 to midnight Jan. 3I, when it was based on partial recorder graph, shape of stage graph for South Fork at Isabella, and range of stage indicated on the recorder graph. Stage-discharge relation. - Defined by current-meter measurements below 1,900 secondfeet. Rating curve changed at peak stage.

Maxima.- December 1937: Discharge, 1,260 second-feet 8 a.m. Dec. 12 (gage height, 4.81 feet).

1911-14, 1919-November 1937: D1scharge, 3,130 second-feet Feb. 6, 1937 (gage height, 6.50 feet), from rating curve extended above 1,900 second-feet.

January-September 1938: Discharge, 3,450 second-feet $6 \mathrm{p} . \mathrm{m}$. Mar. 2 (gage helght, 6.69 feet), from rating curve extended above 1,900 second-feet with ald of areavelocity study.

Remarks.- Flood run-off not affected by artificlal storage or diversion.

Mean daily discharge, in second-feet, November 1937 to January 1938

\begin{tabular}{|c|c|c|c||c|c|c|c||c|c|c|c|}
\hline Day & Nov. & Dec. & Jan. & Day & Nov. & Dec. & Jar. & Day & Nov. & Dec. & Jan. \\
\hline 1 & 27 & 27 & 59 & 11 & 29 & 597 & 47 & 21 & 34 & 66 & 38 \\
2 & 27 & 29 & 60 & 12 & 30 & 864 & 47 & 22 & 33 & 66 & 49 \\
3 & 27 & 33 & 61 & 13 & 29 & 304 & 42 & 23 & 32 & 69 & 52 \\
4 & 27 & 31 & 54 & 14 & 30 & 180 & 48 & 24 & 32 & 47 & 45 \\
5 & 27 & 29 & 52 & 15 & 32 & 145 & 52 & 25 & 32 & 40 & 43 \\
6 & 27 & 29 & 45 & 16 & 30 & 122 & 47 & 26 & 32 & 49 & 44 \\
7 & 29 & 27 & 43 & 17 & 31 & 105 & 45 & 27 & 32 & 56 & 44 \\
8 & 29 & 27 & 43 & 18 & 35 & 96 & 52 & 28 & 31 & 47 & 45 \\
9 & 28 & 32 & 41 & 19 & 33 & 86 & 45 & 29 & 29 & 44 & 48 \\
10 & 29 & 356 & 46 & 20 & 32 & 74 & 41 & 30 & 28 & 48 & 40 \\
&
\end{tabular}

Gage helght, in feet, and discharge, in second-feet, at indicated time, 1937

\begin{tabular}{|c|c|c|c|c|c|c|c|c|c|c|c|c|}
\hline \multirow{2}{*}{\begin{tabular}{l}
$\xi$ \\
\multicolumn{5}{|c}{} \\
㞻
\end{tabular}} & Feet & Sec.ft. & Feet & Sec.ft. & Feet & Bec.ft. & Feet & Sec.ft. & Feet & Sec.ft. & Feet & Sec.ft. \\
\hline & \multicolumn{2}{|c|}{ December 8} & \multicolumn{2}{|c|}{ December 9} & \multicolumn{2}{|c|}{ December 10} & \multicolumn{2}{|c|}{ December Il } & \multicolumn{2}{|c|}{ December 12} & \multicolumn{2}{|c|}{ December 13} \\
\hline \begin{tabular}{r|}
2 \\
4 \\
6 \\
8 \\
10 \\
$\mathrm{~N}$ \\
2 \\
4 \\
6 \\
8 \\
10 \\
$\mathrm{H}$
\end{tabular} & $\begin{array}{l}1.49 \\
1.48 \\
1.49 \\
1.53 \\
1.50 \\
1.47 \\
1.46 \\
1.41 \\
1.36 \\
1.35 \\
1.35 \\
1.39\end{array}$ & $\begin{array}{l}30 \\
30 \\
30 \\
33 \\
31 \\
29 \\
29 \\
26 \\
23 \\
23 \\
23 \\
25 \\
\end{array}$ & $\begin{array}{l}1.46 \\
1.46 \\
1.49 \\
1.52 \\
1.51 \\
1.48 \\
1.47 \\
1.47 \\
1.51 \\
1.56 \\
1.66 \\
1.86\end{array}$ & $\begin{array}{l}29 \\
29 \\
30 \\
32 \\
32 \\
30 \\
29 \\
29 \\
32 \\
35 \\
42 \\
59 \\
\end{array}$ & $\begin{array}{l}2.28 \\
2.72 \\
3.06 \\
3.18 \\
3.25 \\
3.37 \\
3.33 \\
3.18 \\
2.98 \\
3.37 \\
3.52 \\
3.52\end{array}$ & $\begin{array}{l}124 \\
234 \\
341 \\
383 \\
410 \\
458 \\
442 \\
383 \\
314 \\
458 \\
525 \\
525\end{array}$ & $\begin{array}{l}3.46 \\
3.38 \\
3.30 \\
3.23 \\
3.19 \\
3.17 \\
3.19 \\
3.36 \\
4.11 \\
4.49 \\
4.48 \\
4.70\end{array}$ & $\begin{array}{r}497 \\
462 \\
430 \\
402 \\
386 \\
380 \\
386 \\
454 \\
836 \\
1,050 \\
1,050 \\
1,190\end{array}$ & $\begin{array}{l}4.39 \\
4.14 \\
4.58 \\
4.81 \\
4.72 \\
4.51 \\
4.17 \\
3.88 \\
3.67 \\
3.48 \\
3.36 \\
3.26\end{array}$ & $\begin{array}{r}994 \\
852 \\
1,110 \\
1,260 \\
1,200 \\
1,070 \\
868 \\
709 \\
600 \\
506 \\
454 \\
415\end{array}$ & $\begin{array}{l}3.20 \\
3.15 \\
3.10 \\
3.05 \\
3.01 \\
2.96 \\
2.90 \\
2.82 \\
2.76 \\
2.71 \\
2.67 \\
2.63\end{array}$ & $\begin{array}{l}393 \\
376 \\
358 \\
341 \\
327 \\
311 \\
291 \\
267 \\
250 \\
236 \\
225 \\
214 \\
\end{array}$ \\
\hline $\begin{array}{r}10 \\
\mathbf{M} \\
\end{array}$ & \multicolumn{2}{|c|}{ December 14} & \multicolumn{2}{|c|}{ December 15} & \multicolumn{2}{|c|}{ December 16} & \multicolumn{2}{|c|}{ December 17} & \multicolumn{2}{|c|}{ December 18} & \multicolumn{2}{|c|}{ December 19} \\
\hline $\begin{array}{r}2 \\
4 \\
6 \\
8 \\
10 \\
N \\
2 \\
4 \\
6 \\
8 \\
10 \\
M\end{array}$ & $\begin{array}{l}2.59 \\
2.57 \\
2.55 \\
2.53 \\
2.52 \\
2.51 \\
2.50 \\
2.47 \\
2.45 \\
2.43 \\
2.39 \\
2.36\end{array}$ & $\begin{array}{l}203 \\
198 \\
193 \\
188 \\
185 \\
183 \\
180 \\
173 \\
168 \\
163 \\
154 \\
147\end{array}$ & $\begin{array}{l}2.34 \\
2.33 \\
2.35 \\
2.36 \\
2.34 \\
2.35 \\
2.37 \\
2.36 \\
2.33 \\
2.31 \\
2.28 \\
2.26\end{array}$ & $\begin{array}{l}143 \\
141 \\
145 \\
147 \\
143 \\
145 \\
149 \\
147 \\
141 \\
136 \\
130 \\
126\end{array}$ & $\begin{array}{l}2.24 \\
2.23 \\
2.23 \\
2.23 \\
2.23 \\
2.22 \\
2.24 \\
2.26 \\
2.26 \\
2.23 \\
2.21 \\
2.18\end{array}$ & $\begin{array}{l}122 \\
120 \\
120 \\
120 \\
120 \\
118 \\
122 \\
126 \\
126 \\
120 \\
116 \\
110\end{array}$ & $\begin{array}{l}2.16 \\
2.15 \\
2.15 \\
2.15 \\
2.16 \\
2.14 \\
2.15 \\
2.17 \\
2.17 \\
2.16 \\
2.13 \\
2.11\end{array}$ & $\begin{array}{l}107 \\
105 \\
105 \\
105 \\
107 \\
103 \\
105 \\
109 \\
109 \\
107 \\
101 \\
98\end{array}$ & $\begin{array}{l}2.09 \\
2.07 \\
2.07 \\
2.08 \\
2.09 \\
2.07 \\
2.09 \\
2.13 \\
2.13 \\
2.12 \\
2.09 \\
2.07\end{array}$ & $\begin{array}{r}94 \\
92 \\
92 \\
93 \\
94 \\
92 \\
94 \\
101 \\
101 \\
100 \\
94 \\
92\end{array}$ & $\begin{array}{l}2.04 \\
2.03 \\
2.02 \\
2.03 \\
2.03 \\
2.03 \\
2.01 \\
1.99 \\
2.03 \\
2.03 \\
2.02 \\
2.01\end{array}$ & $\begin{array}{l}87 \\
86 \\
84 \\
86 \\
86 \\
86 \\
82 \\
80 \\
86 \\
86 \\
84 \\
82 \\
\end{array}$ \\
\hline & \multicolumn{2}{|c|}{ December 20} & \multicolumn{2}{|c|}{ December 21} & \multicolumn{2}{|c|}{ December 22} & \multicolumn{2}{|c|}{ December 23} & \multicolumn{2}{|c|}{ December 24} & \multicolumn{2}{|c|}{ December 25} \\
\hline $\begin{array}{r}2 \\
4 \\
6 \\
8 \\
10 \\
N \\
2 \\
4 \\
6 \\
8 \\
10 \\
M\end{array}$ & $\begin{array}{l}1.99 \\
1.98 \\
1.97 \\
1.97 \\
1.97 \\
1.97 \\
1.95 \\
1.89 \\
1.89 \\
1.90 \\
1.91 \\
1.96\end{array}$ & $\begin{array}{l}80 \\
78 \\
77 \\
77 \\
77 \\
77 \\
74 \\
67 \\
67 \\
68 \\
69 \\
76\end{array}$ & $\begin{array}{l}1.98 \\
1.93 \\
1.91 \\
1.91 \\
1.89 \\
1.88 \\
1.89 \\
1.84 \\
1.82 \\
1.82 \\
1.81 \\
1.82\end{array}$ & $\begin{array}{l}78 \\
72 \\
69 \\
69 \\
67 \\
66 \\
67 \\
62 \\
60 \\
60 \\
59 \\
60\end{array}$ & $\begin{array}{l}1.88 \\
1.87 \\
1.84 \\
1.83 \\
1.87 \\
1.94 \\
1.90 \\
1.86 \\
1.83 \\
1.89 \\
1.89 \\
1.93\end{array}$ & $\begin{array}{l}66 \\
65 \\
62 \\
61 \\
65 \\
73 \\
68 \\
64 \\
61 \\
67 \\
67 \\
72\end{array}$ & $\begin{array}{l}1.98 \\
1.97 \\
1.93 \\
1.92 \\
1.90 \\
1.88 \\
1.88 \\
1.88 \\
1.86 \\
1.84 \\
1.85 \\
1.88\end{array}$ & $\begin{array}{l}78 \\
77 \\
72 \\
71 \\
68 \\
66 \\
66 \\
66 \\
64 \\
62 \\
63 \\
66\end{array}$ & $\begin{array}{l}1.87 \\
1.84 \\
1.79 \\
1.76 \\
1.72 \\
1.67 \\
1.62 \\
1.57 \\
1.54 \\
1.51 \\
1.52 \\
1.62\end{array}$ & $\begin{array}{l}65 \\
62 \\
57 \\
54 \\
51 \\
47 \\
43 \\
39 \\
37 \\
35 \\
35 \\
43\end{array}$ & $\begin{array}{l}1.65 \\
1.82 \\
1.79 \\
1.72 \\
1.65 \\
1.58 \\
1.52 \\
1.47 \\
1.43 \\
1.40 \\
1.41 \\
1.71\end{array}$ & \begin{tabular}{|l|}
45 \\
60 \\
57 \\
51 \\
45 \\
40 \\
35 \\
32 \\
30 \\
28 \\
29 \\
50
\end{tabular} \\
\hline
\end{tabular}


Location. - Lat. $35^{\circ} 40^{\prime}$, long. $118^{\circ} 28^{\prime}$, in NWt sec. 20, T. 26 S., R. 33 E., a quarter of a mile above function with Kern River, at Isabella, Kern County. Altitude, about 2,480 feet above mean sea level.

Drainge area. - 985 square miles.

Gage-helght reccrd. - Water-stage reecrder graph.

Stage-discharge relation. - Defined by current-meter measurements for range cf stage of high water in December. Shifting-centrol method used for period Nov. 1 to Jan. 31.

Maxima.- December 1937: Discharge, a bcut 1,140 second-feet 2 a.m. Dec. 13 (gage height, 4.52 feet).

1929-November 1937: Discharge, about 4,100 second-feet Feb. 7, 1937 (gage height, 6. 92 feet), from rating curve extended abcve 1,600 second-feet; verified by area-

velocity study. Peak gage height is adfusted fcr estimated effect of back-water fron Kern River.

Remarks.- Flood run-off not affected by artificial storage or diversion but by channel storage, largely in overflow areas between Onyx and Isabella.

Mean dally alscharge, in second-feet, November 1937 to January 1938

\begin{tabular}{|c|c|c|c|c|c|c|c|c|c|c|c|}
\hline Dey & Nov. & Dec. & Jan. & Dey & Ncv. & Dec. & Jan. & Day & Nov. & Dec. & Jan. \\
\hline 1 & 12 & 16 & 80 & 11 & 13 & 249 & 78 & 21 & 11 & 105 & 79 \\
2 & 12 & 15 & 82 & 12 & 13 & 720 & 78 & 22 & 11 & 100 & 77 \\
3 & 12 & 15 & 83 & 13 & 13 & 725 & 78 & 23 & 12 & 98 & 80 \\
4 & 13 & 15 & 83 & 14 & 13 & 303 & 79 & 24 & 16 & 96 & 79 \\
5 & 13 & 16 & 83 & 15 & 13 & 204 & 82 & 25 & 16 & 88 & 76 \\
6 & 13 & 16 & 80 & 16 & 10 & 168 & 83 & 26 & 16 & 85 & 73 \\
7 & 13 & 16 & 77 & 17 & 9 & 145 & 81 & 27 & 15 & 84 & 72 \\
8 & 13 & 16 & 77 & 18 & 9 & 132 & 84 & 28 & 15 & 84 & 72 \\
9 & 13 & 17 & 74 & 19 & 11 & 122 & 84 & 29 & 16 & 81 & 74 \\
10 & 12 & 32 & 76 & 20 & 13 & 114 & 84 & 30 & 16 & 80 & 72 \\
\end{tabular}

Gage helght, in feet, and discharge, in second-feet, at indicated time, 1937

\begin{tabular}{|c|c|c|c|c|c|c|c|c|c|c|c|c|}
\hline \multirow{2}{*}{$\begin{array}{l}5 \\
\text { 吕 } \\
\end{array}$} & Feot & Sec.ft. & Feet & Sec.ft. & Feet & Sec.ft. & Feet & Sec.ft. & Feot & Sec.ft. & Feet & Sec.ft. \\
\hline & \multicolumn{2}{|c|}{ December 8} & \multicolumn{2}{|c|}{ December 9} & \multicolumn{2}{|c|}{ December 10} & \multicolumn{2}{|c|}{ December 11} & \multicolumn{2}{|c|}{ December 12} & \multicolumn{2}{|c|}{ December 13} \\
\hline $\begin{array}{r}2 \\
4 \\
6 \\
8 \\
10 \\
N \\
2 \\
4 \\
6 \\
8 \\
10 \\
M\end{array}$ & $\begin{array}{l}1.32 \\
1.32 \\
1.32 \\
1.33 \\
1.32 \\
1.32 \\
1.32 \\
1.32 \\
1.32 \\
1.32 \\
1.32 \\
1.33\end{array}$ & $\begin{array}{l}16 \\
16 \\
16 \\
16 \\
16 \\
16 \\
16 \\
16 \\
16 \\
16 \\
16 \\
16\end{array}$ & $\begin{array}{l}1.33 \\
1.33 \\
1.34 \\
1.33 \\
1.33 \\
1.33 \\
1.35 \\
1.36 \\
1.36 \\
1.36 \\
1.37 \\
1.38\end{array}$ & $\begin{array}{l}16 \\
16 \\
16 \\
16 \\
16 \\
16 \\
17 \\
17 \\
17 \\
17 \\
17 \\
17\end{array}$ & $\begin{array}{l}1.42 \\
1.55 \\
1.59 \\
1.61 \\
1.61 \\
1.60 \\
1.57 \\
1.52 \\
1.48 \\
1.49 \\
2.00 \\
2.29\end{array}$ & $\begin{array}{r}19 \\
25 \\
27 \\
28 \\
28 \\
28 \\
26 \\
24 \\
22 \\
22 \\
67 \\
120\end{array}$ & $\begin{array}{l}2.42 \\
2.52 \\
2.56 \\
2.57 \\
2.67 \\
2.77 \\
2.88 \\
2.99 \\
3.07 \\
3.13 \\
3.20 \\
3.22\end{array}$ & $\begin{array}{l}159 \\
177 \\
185 \\
187 \\
208 \\
232 \\
262 \\
294 \\
319 \\
340 \\
364 \\
372\end{array}$ & $\begin{array}{l}3.27 \\
3.32 \\
3.38 \\
3.53 \\
3.72 \\
3.95 \\
4.14 \\
4.24 \\
4.27 \\
4.33 \\
4.45 \\
4.50\end{array}$ & \begin{tabular}{|r|}
391 \\
410 \\
436 \\
505 \\
601 \\
730 \\
848 \\
922 \\
946 \\
994 \\
1,100 \\
1,140
\end{tabular} & $\begin{array}{l}4.52 \\
4.43 \\
4.28 \\
4.12 \\
3.96 \\
3.81 \\
3.69 \\
3.60 \\
3.53 \\
3.46 \\
3.40 \\
3.34\end{array}$ & \begin{tabular}{|r|}
, 140 \\
1,080 \\
954 \\
834 \\
736 \\
650 \\
585 \\
540 \\
505 \\
472 \\
444 \\
419
\end{tabular} \\
\hline & \multicolumn{2}{|c|}{ December 14} & \multicolumn{2}{|c|}{ December 15} & \multicolumn{2}{|c|}{ December 16} & \multicolumn{2}{|c|}{ December 17} & \multicolumn{2}{|c|}{ December 18} & \multicolumn{2}{|c|}{ December 19} \\
\hline \multirow[t]{2}{*}{$\begin{array}{r}2 \\
4 \\
6 \\
8 \\
10 \\
\mathrm{~N} \\
2 \\
4 \\
6 \\
8 \\
10 \\
\mathrm{M} \\
\end{array}$} & $\begin{array}{l}3.27 \\
3.20 \\
3.15 \\
3.10 \\
3.05 \\
3.00 \\
2.96 \\
2.92 \\
2.88 \\
2.85 \\
2.81 \\
2.78\end{array}$ & \begin{tabular}{|l|}
391 \\
364 \\
346 \\
329 \\
313 \\
297 \\
285 \\
273 \\
262 \\
254 \\
243 \\
235 \\
\end{tabular} & $\begin{array}{l}2.75 \\
2.73 \\
2.70 \\
2.68 \\
2.66 \\
2.65 \\
2.62 \\
2.59 \\
2.58 \\
2.57 \\
2.56 \\
2.55\end{array}$ & $\begin{array}{l}228 \\
222 \\
215 \\
211 \\
206 \\
204 \\
197 \\
191 \\
189 \\
187 \\
185 \\
183\end{array}$ & $\begin{array}{l}-\overline{2.52} \\
- \\
2.50 \\
- \\
2.47 \\
- \\
2.44 \\
- \\
2.41 \\
- \\
2.39\end{array}$ & $\begin{array}{c}\overline{177} \\
\overline{173} \\
\overline{6} 8 \\
\overline{16} \\
\overline{6} \\
15 \overline{7} \\
\overline{153}\end{array}$ & $\begin{array}{c}z \\
z \\
z \\
2.35 \\
z \\
= \\
= \\
2.30\end{array}$ & $\begin{array}{c}\overline{-} \\
\overline{-} \\
\overline{145} \\
\bar{z} \\
\bar{z} \\
\overline{136}\end{array}$ & $\begin{array}{c}= \\
= \\
= \\
2.27 \\
= \\
= \\
2.22\end{array}$ & $\begin{array}{c}= \\
= \\
\bar{z} \\
132 \\
= \\
= \\
\overline{124}\end{array}$ & $\begin{array}{c}= \\
= \\
= \\
2.20 \\
= \\
= \\
= \\
2.17\end{array}$ & $\begin{array}{c}= \\
= \\
= \\
122 \\
\overline{-} \\
= \\
\overline{-} \\
118\end{array}$ \\
\hline & \multicolumn{2}{|c|}{ December 20} & \multicolumn{2}{|c|}{ December 21} & \multicolumn{2}{|c|}{ December 22} & \multicolumn{2}{|c|}{ December 23} & \multicolumn{2}{|c|}{ December 24} & \multicolumn{2}{|c|}{ December 25} \\
\hline $\begin{array}{r}2 \\
4 \\
6 \\
8 \\
10 \\
N \\
2 \\
4 \\
6 \\
8 \\
10 \\
\mathbf{M}\end{array}$ & 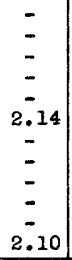 & $\begin{array}{c}\overline{-} \\
\overline{-} \\
\overline{114} \\
= \\
\overline{-} \\
\overline{109}\end{array}$ & $\begin{array}{c}\bar{z} \\
\bar{z} \\
\bar{z} \\
2.07 \\
\bar{z} \\
\bar{z} \\
\bar{z} .04\end{array}$ & $\begin{array}{c}\overline{-} \\
\overline{-} \\
\overline{-} \\
105 \\
\overline{-} \\
\overline{-} \\
\overline{-} \\
102\end{array}$ & $\begin{array}{c}= \\
= \\
\bar{z} \\
2.03 \\
= \\
= \\
= \\
2.02\end{array}$ & $\begin{array}{c}\bar{z} \\
\bar{z} \\
\overline{100} \\
= \\
\bar{z} \\
\overline{9} \\
\overline{9}\end{array}$ & $\begin{array}{c}= \\
z \\
z \\
2.01 \\
z \\
z \\
z \\
2.01\end{array}$ & $\begin{array}{l}\bar{z} \\
\bar{z} \\
\overline{9} 8 \\
\bar{z} \\
\bar{z} \\
\overline{9} 8\end{array}$ & $\begin{array}{c}= \\
= \\
= \\
1.99 \\
= \\
= \\
1.96\end{array}$ & $\begin{array}{l}\bar{z} \\
\bar{z} \\
\overline{9} \\
\bar{z} \\
\bar{z} \\
\overline{9} \\
\overline{9}\end{array}$ & $\begin{array}{c}= \\
= \\
\overline{1.93} \\
= \\
= \\
\overline{1.90}\end{array}$ & $\begin{array}{l}= \\
= \\
= \\
88 \\
= \\
= \\
= \\
85\end{array}$ \\
\hline
\end{tabular}


Tulare Lake in Kings County, Calif.

Iocation. - Staff gage, lat. $36^{\circ} 05^{\prime}$, long. $119^{\circ} 44^{\prime}$, at Sil corner sec. 31, T. 21 S., R. $21 \mathrm{~K} ., 12 \mathrm{miles}$ southeast of Stratford, Kings County, Calif.

Records available.- Yarch 1906 to September 1920 (incomplete) at various sites. Ho record 1921-23, Lake pract1cally dry 1924-36.

Bxtremes.- 1906-December 1937. Yaximum stage probably occurred June 21, 1907 (gage helght, 14.0 feet, former site and datum). Lake empty or practically dry part of 1906 , 1914, 1916, 1919, 1920-22, 1924-36.

Remarks,- Gage he1ghts interpolated for periods Dec. 2-7, 9, 12, 19, 25. Tulare Iake receives water from Kings, Keweah, and Tule Rivers during high-water periods and occasionaliy from Kern River, Deer Creek, and smaller intermittent streams. Iake boundaries have been greatiy altered in recent jears by levees and reclamation work. About Feb. 10, 1937, water reached lake for first time since April 1923 . After reaching a stage of 192.28 feet on June 16 (contents, about 420,000 acre-feet) the lake receded unt11 Dec. 14, when it began to receive water due to the December 1 lood. Iater in 1938 a much higher stage was reached. See 1938 anmual water supply paper for the complete 1937 and 1938 record. Data furnished by Tulare Lake Reclamation District 110.749 .

Da1ly gage height, in feet, December 1937

\begin{tabular}{|c|c|c|c|c|c|c|c|c|c|c|c|}
\hline Day & $\begin{array}{c}\text { Gage } \\
\text { helght }\end{array}$ & Day & $\begin{array}{c}\text { Gage } \\
\text { helght }\end{array}$ & Day & $\begin{array}{c}\text { Gage } \\
\text { helght }\end{array}$ & Day & $\begin{array}{c}\text { Gage } \\
\text { helght }\end{array}$ & Day & $\begin{array}{c}\text { Gage } \\
\text { height }\end{array}$ & Day & $\begin{array}{c}\text { Gage } \\
\text { height }\end{array}$ \\
\hline $\begin{array}{l}1 \\
2 \\
3 \\
4 \\
5\end{array}$ & $\begin{array}{l}186.0 \\
186.0 \\
186.0 \\
186.0 \\
186.0\end{array}$ & $\begin{array}{r}6 \\
7 \\
8 \\
9 \\
10\end{array}$ & $\begin{array}{l}186.0 \\
186.0 \\
185.9 \\
186.0 \\
186.0\end{array}$ & $\begin{array}{l}11 \\
12 \\
13 \\
14 \\
15\end{array}$ & $\begin{array}{l}186.0 \\
186.0 \\
186.0 \\
186.2 \\
186.4\end{array}$ & $\begin{array}{l}16 \\
17 \\
18 \\
19 \\
20\end{array}$ & $\begin{array}{l}186.6 \\
186.7 \\
186.7 \\
186.8 \\
186.8\end{array}$ & $\begin{array}{l}21 \\
22 \\
23 \\
24 \\
25\end{array}$ & $\begin{array}{l}186.9 \\
186.9 \\
186.9 \\
186.9 \\
186.9\end{array}$ & $\begin{array}{l}26 \\
27 \\
28 \\
29 \\
30 \\
31\end{array}$ & $\begin{array}{l}186.9 \\
186.9 \\
186.9 \\
186.9 \\
186.9 \\
186.9\end{array}$ \\
\hline
\end{tabular}

$1000020-00-0$ 
Location.- Lat. $36^{\circ} 05^{\prime}$, long. $118^{\circ} 55^{\prime}$, in NW/ sec. 25, T. 21 S., R. 28 E., at h1ghway bridge 1 mile above South Fork and 6 miles east of Fortervilie, Thlare County. Altitude, about 580 feet above mean sea level.

Drainage area.- 266 square miles.

Gage-helght record. - Water-a tage recorder graph.

Stage-discharge relation.- Defined by current-meter measurements below 3,300 secondfeet; extended to peak stage with aid of area-velocity study and slope-area de-

termination of flood flow. Rating curve changed at peak atage.

Maxima.- December 1937: Discharge, 11,300 second-feet 6 p.m. Dec. 11 (gage height, 10.3 feet, observed outside of well, and 9.5 feet, inside of well, affected by drawdown).

1901-November 1937: Discharge, 12,500 second-feet (revised) Feb. 13, 1936 (gage height, 10.55 feet, inside of well; 11.4 feet, outside of well, determined from observations of drawciown at lower stages), from rating curve extended above 3,700 second-feet on bastis of slope-area determination of flood flow and area-velocity study. Remarks.- Flood mun-of not affected by artificial storage or diversion.

Mean dally discharge, in second-feet, November 1937 to January 1938

\begin{tabular}{|c|c|c|c|c|c|c|c|c|c|c|c|}
\hline Day & Nov. & Dec. & Jen. & Day & Nov. & Dec. & Jan. & Day & Nov. & Dec. & Jan. \\
\hline 1 & 15 & 27 & 98 & 11 & 23 & 2,880 & 84 & 21 & 27 & 130 & 156 \\
\hline 2 & 14 & 27 & 100 & 12 & 28 & 1,800 & 82 & 22 & 28 & 123 & 148 \\
\hline 3 & 14 & 27 & 106 & 13 & 30 & 545 & 81 & 23 & 27 & 147 & 141 \\
\hline 4 & 15 & 21 & 98 & 14 & 28 & 334 & 79 & 24 & 28 & 134 & 134 \\
\hline 5 & 15 & 21 & 96 & 15 & 27 & 254 & 167 & 25 & 30 & 120 & 125 \\
\hline 6 & 17 & 20 & 91 & 16 & 27 & 214 & 134 & 26 & 31 & 114 & 123 \\
\hline 7 & 21 & 19 & 90 & 17 & 27 & 188 & 150 & 27 & 30 & 111 & 120 \\
\hline 8 & 22 & 20 & 88 & 18 & 36 & 166 & 165 & 28 & 28 & 105 & 118 \\
\hline 9 & 21 & & 85 & 19 & 34 & 152 & 184 & 29 & 28 & 102 & 387 \\
\hline 10 & 21 & 2,200 & 85 & 20 & 29 & 141 & 210 & $\begin{array}{l}30 \\
31\end{array}$ & 27 & $\begin{array}{l}102 \\
100\end{array}$ & $\begin{array}{l}228 \\
182\end{array}$ \\
\hline \multicolumn{9}{|c|}{ 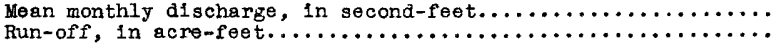 } & $\begin{array}{r}24.9 \\
1,480\end{array}$ & $\begin{array}{r}335 \\
20,570\end{array}$ & $\begin{array}{r}133 \\
8,200\end{array}$ \\
\hline
\end{tabular}

Gage helght, in feet, and discharge, in second-feet, at indicated time, 1937

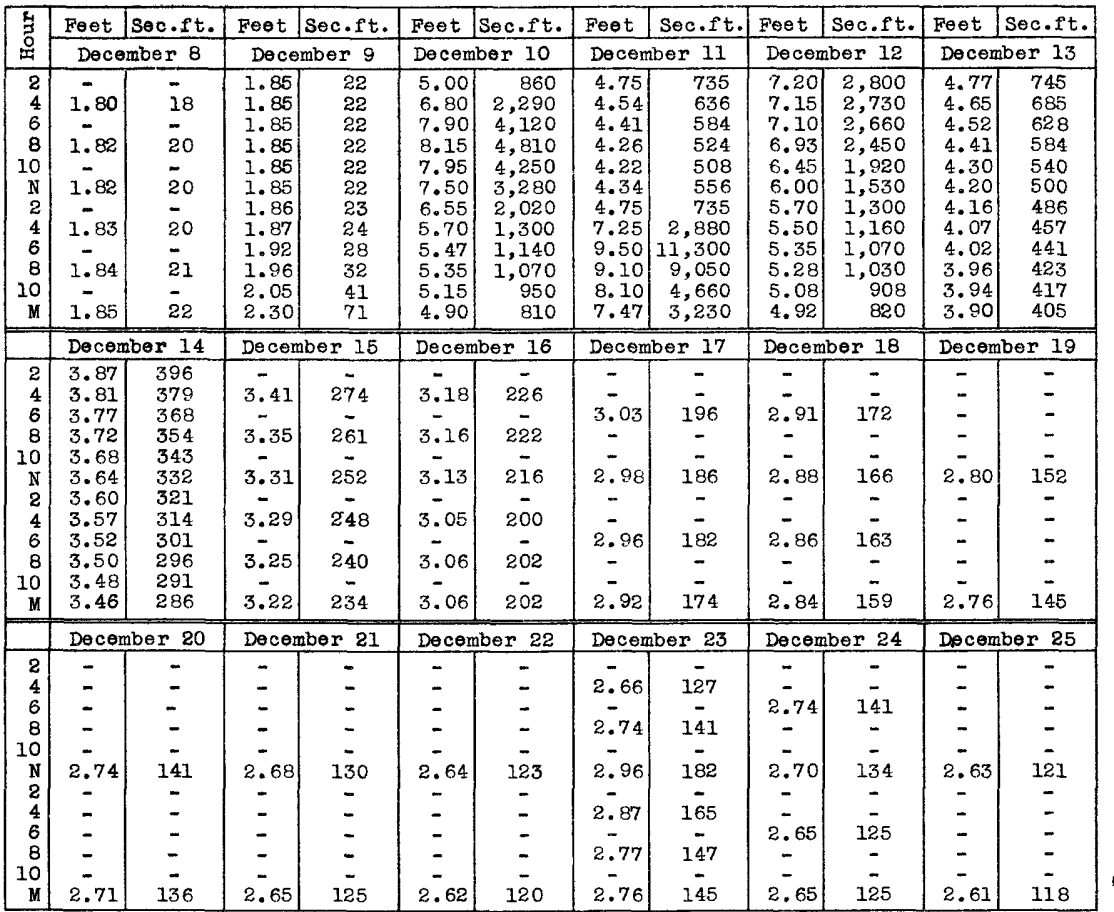

Supplemental recoras.- Dec. 10, I a.m., 2.53 ft., 105 sec.-ft. Dec. 11, 3. p.m., 5.45 ft., 1,130 sec.-ft.; 5 p.m., 9,00 ft., 8,500 sec.-ft. 
Location. - Lat. $36^{\circ} 03^{\prime}$, long. $118^{\circ} 51^{\prime}$, in NW/1 sec. 4, T. 22 S., R. 29 E., 3 miles southeast of Success, Tulare County, and 5 miles above mouth. Altitude, about 750 feet above mean sea level. Drainage area.- 106 square miles.

Gage-helght record. - Water-stage recorder graph.

stage-discharge relation.- Defined by current-meter measurements below 950 secondfeet.

Maxima.- Deoember 1937: Discharge, 1,060 second-feet 7 p.m. Deo. Il (gage height, 4.80 feet).

1930-November 1937: Discharge, 3,370 second-feet Feb.6, 1937 (gage height, 6.36 feet, inside of well; 7.1 feet, outside of well, from floodmarks f, from rating curve extended above 1,100 second-feet on bas is of area-velocity study; verified on basis of contracted-opening determination of discharge of 2,960 secondfeot Maroh 1938.

Remarks.- Flood run-off not affectèd by artificial storage or diversion.

Mean da1ly discharge, in second-feet, November 1937 to January 1938

\begin{tabular}{|c|c|c|c||c|c|c|c||c|c|c|c|}
\hline Day & Nov. & Dec. & Jan. & Day & Nov. & Dec. & Jan. & Day & Nov. & Dec. & Jan. \\
\hline 1 & 2.8 & 7.5 & 21 & 11 & 5 & 276 & 16 & 21 & 7 & 25 & 39 \\
2 & 2.8 & 7.5 & 22 & 12 & 8 & 267 & 16 & 22 & 6.5 & 24 & 37 \\
3 & 2.3 & 7.5 & 23 & 13 & 6.5 & 99 & 16 & 23 & 6.5 & 32 & 34 \\
4 & 2.0 & 7.5 & 21 & 14 & 6.5 & 62 & 16 & 24 & 6.5 & 27 & 31 \\
5 & 1.9 & 7.5 & 20 & 15 & 6.5 & 47 & 33 & 25 & 7.5 & 24 & 29 \\
6 & 2.0 & 7.5 & 19 & 16 & 6.5 & 39 & 28 & 26 & 8 & 24 & 27 \\
7 & 2.8 & 7.5 & 19 & 17 & 7 & 35 & 38 & 27 & 8 & 24 & 27 \\
8 & 3.9 & 7.5 & 18 & 18 & 12 & 31 & 41 & 28 & 7.5 & 23 & 27 \\
9 & 5.5 & 8 & 17 & 19 & 8 & 28 & 49 & 29 & 7.5 & 22 & 74 \\
10 & 5 & 300 & 16 & 20 & 7.5 & 26 & 55 & 30 & 7.5 & 22 & 57 \\
\end{tabular}

Gage helght, in feet, and discharge, in second-feet, at indicated time, 1937

\begin{tabular}{|c|c|c|c|c|c|c|c|c|c|c|c|c|}
\hline & Feet & Sec.ft. & Feet & sec.ft. & Feet & Sec.ft. & Fe日t & Sec.ft. & Feet & Sec.ft. & Feet & Sec.ft. \\
\hline & Dece & mber 8 & Dece & mber 9 & Decem & oer 10 & Decem & ber 11 & Decen & aber 12 & Decen & ber 13 \\
\hline & $\begin{array}{c}\bar{z} \\
\bar{z} \\
\overline{1.38} \\
\bar{z} \\
\bar{z} \\
\overline{1.38}\end{array}$ & $\begin{array}{c}= \\
= \\
\overline{7} \\
\overline{-} \\
= \\
\overline{7} \\
7.5\end{array}$ & $\begin{array}{l}- \\
1.38 \\
\overline{1.38} \\
- \\
1.38 \\
- \\
1.39 \\
- \\
1.41 \\
- \\
1.53\end{array}$ & $\begin{array}{l}\overline{7.5} \\
\overline{7} .5 \\
\overline{7} .5 \\
\overline{8} \\
\overline{9} \\
\overline{16}\end{array}$ & $\begin{array}{l}2.75 \\
3.75 \\
3.95 \\
3.80 \\
3.58 \\
3.18 \\
2.84 \\
2.60 \\
2.45 \\
2.32 \\
2.23 \\
2.15\end{array}$ & $\begin{array}{r}210 \\
550 \\
632 \\
570 \\
482 \\
338 \\
235 \\
170 \\
138 \\
113 \\
97 \\
84\end{array}$ & $\begin{array}{l}2.09 \\
2.05 \\
2.01 \\
1.98 \\
1.96 \\
2.02 \\
2.12 \\
2.48 \\
4.65 \\
4.54 \\
3.86 \\
3.51\end{array}$ & $\begin{array}{r}76 \\
70 \\
64 \\
61 \\
58 \\
66 \\
80 \\
144 \\
972 \\
912 \\
594 \\
456\end{array}$ & $\begin{array}{l}3.41 \\
3.35 \\
3.32 \\
3.27 \\
3.02 \\
2.87 \\
2.74 \\
2.64 \\
2.63 \\
2.57 \\
2.55 \\
2.47\end{array}$ & $\begin{array}{l}418 \\
396 \\
385 \\
368 \\
288 \\
244 \\
207 \\
180 \\
178 \\
163 \\
159 \\
142\end{array}$ & $\begin{array}{c}- \\
2.37 \\
- \\
2.29 \\
- \\
2.23 \\
- \\
2.17 \\
- \\
2.12 \\
- \\
2.08\end{array}$ & $\begin{array}{c}\overline{122} \\
\overline{107} \\
\overline{97} \\
\overline{88} \\
\overline{80} \\
\overline{74}\end{array}$ \\
\hline & Decen & ber 14 & Decen & ber 15 & Decem & ber 16 & Decem & ber 17 & Decem & ber 18 & Decem & ber 19 \\
\hline & $\begin{array}{c}\overline{-} \\
2.03 \\
\vdots \\
\overline{1.99} \\
\overline{-} \\
1.95 \\
\overline{-} \\
1.91\end{array}$ & $\begin{array}{l}- \\
- \\
67 \\
- \\
62 \\
- \\
\overline{5} \\
- \\
52\end{array}$ & $\begin{array}{c}- \\
\overline{1.88} \\
\overline{-} \\
1.86 \\
\overline{-} \\
1.84 \\
\overline{-} \\
1.82\end{array}$ & $\begin{array}{l}- \\
49 \\
- \\
- \\
47 \\
- \\
44 \\
- \\
42\end{array}$ & $\begin{array}{c}- \\
- \\
- \\
\bar{z} \\
1.79 \\
\bar{z} \\
\bar{z} \\
\bar{E} \\
1.77\end{array}$ & $\begin{array}{l}= \\
= \\
- \\
\overline{39} \\
= \\
= \\
\overline{3} \\
\overline{3}\end{array}$ & $\begin{array}{c}\bar{z} \\
= \\
\overline{-} \\
1.75 \\
\bar{z} \\
\overline{1} \\
\overline{1.73}\end{array}$ & $\begin{array}{l}- \\
\overline{-} \\
\overline{-} \\
\overline{3} 5 \\
\overline{-} \\
\overline{-} \\
\overline{3} 3\end{array}$ & $\begin{array}{c}\overline{-} \\
\overline{-} \\
\overline{-} \\
1.71 \\
\bar{z} \\
\overline{-} \\
\overline{-} \\
1.70\end{array}$ & $\begin{array}{l}\overline{-} \\
\overline{-} \\
\overline{3} 1 \\
\bar{z} \\
\overline{-} \\
\overline{3} 0\end{array}$ & $\begin{array}{c}\bar{z} \\
\bar{z} \\
\overline{5} \\
1.68 \\
\bar{z} \\
\overline{-} \\
1.67\end{array}$ & $\begin{array}{l}\overline{-} \\
\overline{-} \\
\overline{2} \\
28 \\
\bar{z} \\
\bar{z} \\
\overline{2}\end{array}$ \\
\hline & Decen & er 20 & Decer & ber 21 & Decen & er 22 & Decen & ber 23 & Decen & ber 24 & Decem & ber 25 \\
\hline & $\begin{array}{l}\bar{z} \\
\bar{z} \\
\overline{1} \\
\overline{5} 66 \\
\bar{z} \\
\overline{1} \\
1.65\end{array}$ & $\begin{array}{l}\overline{-} \\
\overline{-} \\
\overline{2} 6 \\
= \\
\overline{-} \\
\overline{-} \\
26\end{array}$ & $\begin{array}{l}= \\
= \\
= \\
1.64 \\
= \\
\bar{z} \\
1.64\end{array}$ & $\begin{array}{l}= \\
= \\
= \\
25 \\
= \\
= \\
= \\
25\end{array}$ & 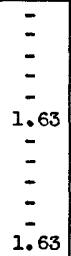 & $\begin{array}{l}= \\
= \\
= \\
24 \\
= \\
= \\
= \\
24\end{array}$ & $\begin{array}{c}1.64 \\
1.68 \\
- \\
1.80 \\
- \\
1.81 \\
- \\
1.71 \\
1.71\end{array}$ & $\begin{array}{l}\overline{25} \\
\overline{28} \\
- \\
40 \\
\overline{41} \\
\overline{31} \\
\overline{31}\end{array}$ & $\begin{array}{c}- \\
1.69 \\
- \\
1.67 \\
- \\
\overline{1.65} \\
- \\
- \\
1.63\end{array}$ & $\begin{array}{l}= \\
\overline{29} \\
= \\
27 \\
= \\
\overline{26} \\
\overline{-} \\
24\end{array}$ & $\begin{array}{c}\bar{z} \\
\vdots \\
\overline{-} \\
1.63 \\
\bar{z} \\
\bar{z} \\
\overline{1.63}\end{array}$ & $\begin{array}{l}\overline{-} \\
\overline{-} \\
\overline{24} \\
\overline{-} \\
\overline{-}\end{array}$ \\
\hline
\end{tabular}

Supplemental recorảs.- Dec. 11, 7 p.m., 4.80 ft., 1,060 sec.-ft. 


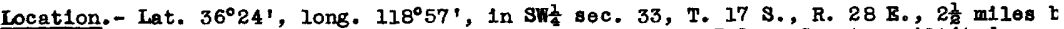
low South Fork and 3 miles southwest of Three Rivers, Tulare County. Altitude, about 620 feet above mean sea level.

Drainage area.- 520 square miles.

tgge-helght record.- Water-stage reoorder graph except for perlod 2 p.m. Dec. 11 to 4 p.m. Dec. 17, when the record was unreliable. Peak stage determined from observed level on outside of gage house; verifled by drift-marks on banks.

Stage-discharge relation.- Defined by current-meter measurements below 5,200 secondleet; extended to peak stage with ald of area-velocity study; verifled by $A \sqrt{d}$ method. Rating curve changed at park stage.

Haxima.- December 1937: Discharge, about 33,300 second-feet 3 p.m. Dec. 11 (gage helght, about 16.0 feet).

1903-Hovember 1937: D1scharge, 18,900 second-feet Feb. 6, 1937 (gage he1ght, 12.65 feet), from rating curve extended above 5,200 second-feet with ald of areavelocity 8 tudy.

Remarks.- Flood mun-off not affected by artificlal storage or diversion. D1scharge for perlod of unreliable gage-helght record determined from discharge graph based on peak stage, gage readings Dec. 13 and 14 , and general shape of recorder graph.

Mean dally alscharge, in second-feet, November 1937 to Januery 1938

\begin{tabular}{|c|c|c|c|c|c|c|c|c|c|c|c|}
\hline Day & Nov. & Dec. & Jan. & Day & Nov. & Dec. & Jan. & Day & Nov. & Dec. & Jan. \\
\hline $\begin{array}{r}1 \\
2 \\
3 \\
4 \\
5 \\
6 \\
7 \\
8 \\
9 \\
10\end{array}$ & $\begin{array}{l}66 \\
66 \\
65 \\
59 \\
65 \\
65 \\
66 \\
68 \\
69 \\
69\end{array}$ & $\begin{array}{r}69 \\
71 \\
72 \\
72 \\
71 \\
71 \\
71 \\
71 \\
84 \\
5,870\end{array}$ & $\begin{array}{l}317 \\
354 \\
372 \\
334 \\
313 \\
294 \\
282 \\
276 \\
264 \\
258\end{array}$ & $\begin{array}{l}11 \\
12 \\
13 \\
14 \\
15 \\
16 \\
17 \\
18 \\
19 \\
20\end{array}$ & $\begin{array}{l}71 \\
89 \\
80 \\
76 \\
77 \\
76 \\
86 \\
96 \\
82 \\
79\end{array}$ & $\begin{array}{r}10,800 \\
5,600 \\
1,900 \\
1,000 \\
800 \\
670 \\
578 \\
537 \\
485 \\
440\end{array}$ & $\begin{array}{l}258 \\
252 \\
247 \\
247 \\
410 \\
347 \\
432 \\
460 \\
436 \\
413\end{array}$ & $\begin{array}{l}21 \\
22 \\
23 \\
24 \\
25 \\
26 \\
27 \\
28 \\
29 \\
30 \\
31\end{array}$ & $\begin{array}{l}77 \\
76 \\
74 \\
74 \\
76 \\
74 \\
74 \\
72 \\
71 \\
68\end{array}$ & $\begin{array}{l}409 \\
379 \\
485 \\
405 \\
372 \\
361 \\
347 \\
337 \\
323 \\
320 \\
317\end{array}$ & $\begin{array}{l}372 \\
368 \\
354 \\
344 \\
334 \\
340 \\
334 \\
344 \\
497 \\
432 \\
413\end{array}$ \\
\hline 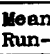 & & & & & & & & & $\begin{array}{r}73.5 \\
4,380\end{array}$ & $\begin{array}{r}1,077 \\
66,220\end{array}$ & $\begin{array}{r}341 \\
21,221 \\
\end{array}$ \\
\hline
\end{tabular}

Gage helght, In feet, and alscharge, in second-feet, at indicated time, 1937

\begin{tabular}{|c|c|c|c|c|c|c|c|c|c|c|c|c|}
\hline \multirow{2}{*}{$\begin{array}{l}\mathbf{4} \\
\mathbf{0} \\
\mathbf{0}\end{array}$} & Peet & sec.ft. & Peet & Sec.ft. & Peet & sec.ft. & Peet & sec.ft. & Peet & Sec.It. & Peet & Sec.ft \\
\hline & \multicolumn{2}{|c|}{ December 8} & \multicolumn{2}{|c|}{ December 9} & \multicolumn{2}{|c|}{ December 10} & \multicolumn{2}{|c|}{ December 11} & \multicolumn{2}{|c|}{ December 12} & \multicolumn{2}{|c|}{ December 13} \\
\hline $\begin{array}{r}2 \\
4 \\
6 \\
8 \\
10 \\
1 \\
2 \\
4 \\
6 \\
8 \\
10 \\
1\end{array}$ & $\begin{array}{l}- \\
= \\
= \\
= \\
= \\
= \\
= \\
= \\
.73\end{array}$ & $\begin{array}{l}\overline{-} \\
= \\
\overline{71} \\
\overline{7} \\
\overline{-} \\
\overline{-} \\
\overline{71}\end{array}$ & $\begin{array}{r}0.73 \\
.73 \\
.73 \\
.73 \\
.73 \\
.73 \\
.73 \\
.74 \\
.78 \\
.85 \\
1.05 \\
1.50\end{array}$ & $\begin{array}{r}71 \\
71 \\
71 \\
71 \\
71 \\
71 \\
71 \\
72 \\
79 \\
91 \\
134 \\
262\end{array}$ & $\begin{array}{l}6.50 \\
8.60 \\
9.42 \\
9.88 \\
9.50 \\
8.10 \\
6.55 \\
5.62 \\
5.05 \\
4.85 \\
4.55 \\
4.20\end{array}$ & $\begin{array}{r}4,640 \\
8,600 \\
10,600 \\
11,900 \\
10,800 \\
7,550 \\
4,720 \\
3,370 \\
2,660 \\
2,450 \\
2,150 \\
1,830\end{array}$ & $\begin{array}{r}3.90 \\
3.70 \\
3.52 \\
3.70 \\
5.50 \\
7.60 \\
14.60 \\
- \\
- \\
- \\
- \\
-\end{array}$ & $\begin{array}{r}1,590 \\
1,430 \\
1,300 \\
1,430 \\
3,210 \\
6,570 \\
27,900 \\
29,400 \\
21,900 \\
15,500 \\
11,900 \\
9,760\end{array}$ & $\begin{array}{l}- \\
\overline{-} \\
\overline{-} \\
\overline{-} \\
\overline{-} \\
= \\
-\end{array}$ & $\begin{array}{c}- \\
\overline{150} \\
7, \overline{-} \\
\overline{-} \\
5,300 \\
\overline{-} \\
3, \overline{6} 80 \\
- \\
2, \overline{840}\end{array}$ & $\begin{array}{l}- \\
\overline{-} \\
\overline{-} \\
\overline{-} \\
\overline{-} \\
\overline{-} \\
\overline{-} \\
-\end{array}$ & $\begin{array}{c}\overline{-} \\
2, \overline{28} \\
- \\
1, \overline{80} \\
- \\
\overline{-} \\
1, \overline{5} 0 \\
\overline{-} \\
1, \overline{271}\end{array}$ \\
\hline & \multicolumn{2}{|c|}{ December 14} & \multicolumn{2}{|c|}{ December 15} & \multicolumn{2}{|c|}{ December 16} & \multicolumn{2}{|c|}{ December 17} & \multicolumn{2}{|c|}{ December 18} & \multicolumn{2}{|c|}{ December 19} \\
\hline \multirow[t]{2}{*}{$\begin{array}{r}2 \\
4 \\
6 \\
8 \\
10 \\
1 \\
2 \\
4 \\
6 \\
8 \\
10 \\
4\end{array}$} & $\begin{array}{l}\overline{-} \\
\overline{-} \\
\bar{z} \\
\bar{z} \\
\overline{-} \\
=\end{array}$ & $\begin{array}{l}\overline{-} \\
1, \overline{110} \\
\overline{-} \\
\overline{9} \\
\overline{-} \\
\overline{9} \\
\overline{9} \\
\overline{8} \\
\overline{860}\end{array}$ & $\begin{array}{l}= \\
= \\
= \\
= \\
= \\
= \\
=\end{array}$ & $\begin{array}{c}- \\
- \\
= \\
780 \\
= \\
= \\
- \\
7 \overline{15}\end{array}$ & $\begin{array}{l}= \\
= \\
= \\
= \\
= \\
= \\
= \\
=\end{array}$ & $\begin{array}{c}- \\
- \\
- \\
- \\
660 \\
\overline{-} \\
\overline{-} \\
- \\
\overline{614}\end{array}$ & $\begin{array}{l}\overline{-} \\
2.10 \\
\overline{-} \\
2.05 \\
\overline{-} \\
2.01 \\
\overline{-} \\
2.05\end{array}$ & $\begin{array}{c}- \\
- \\
600 \\
- \\
578 \\
- \\
5 \overline{60} \\
- \\
5 \overline{78}\end{array}$ & $\begin{array}{c}\overline{-} \\
2.02 \\
\overline{-} \\
1.84 \\
\overline{-} \\
1.80 \\
\overline{-} \\
1.92\end{array}$ & $\begin{array}{c}\overline{-} \\
5 \overline{64} \\
\overline{5} \\
\overline{528} \\
\overline{-} \\
\overline{510} \\
\overline{-} \\
\overline{519}\end{array}$ & $\begin{array}{l}- \\
\overline{1.88} \\
- \\
\overline{1.82} \\
\overline{-} \\
1.77 \\
\overline{-} \\
1.84\end{array}$ & $\begin{array}{c}- \\
\overline{502} \\
\overline{-} \\
\overline{476} \\
- \\
\overline{456} \\
- \\
\overline{485}\end{array}$ \\
\hline & \multicolumn{2}{|c|}{ Decomber 20} & \multicolumn{2}{|c|}{ December 21} & \multicolumn{2}{|c|}{ December 22} & \multicolumn{2}{|c|}{ December 23} & \multicolumn{2}{|c|}{ December 24} & \multicolumn{2}{|c|}{ December $2 E$} \\
\hline $\begin{array}{r}2 \\
4 \\
6 \\
8 \\
10 \\
14 \\
2 \\
4 \\
6 \\
8 \\
10 \\
1\end{array}$ & $\begin{array}{l}- \\
1.78 \\
= \\
1.73 \\
= \\
1.66 \\
- \\
1.74\end{array}$ & $\begin{array}{c}\overline{-} \\
460 \\
\overline{-} \\
440 \\
\overline{-} \\
\overline{413} \\
\overline{-} \\
\overline{444}\end{array}$ & $\begin{array}{l}- \\
\overline{1.70} \\
= \\
\overline{1.66} \\
= \\
\overline{1.58} \\
\overline{-} \\
\overline{1.65}\end{array}$ & $\begin{array}{c}- \\
\overline{228} \\
- \\
413 \\
\overline{-} \\
3 \overline{83} \\
- \\
\overline{409}\end{array}$ & $\begin{array}{l}- \\
\overline{1.62} \\
- \\
\overline{1.57} \\
- \\
\overline{1.52} \\
- \\
\overline{1.59}\end{array}$ & $\begin{array}{c}\overline{-} \\
3 \overline{98} \\
\overline{-} \\
\overline{379} \\
\overline{-} \\
\overline{361} \\
\overline{-} \\
\overline{386}\end{array}$ & $\begin{array}{l}1.65 \\
1.73 \\
1.83 \\
2.10 \\
2.20 \\
2.08 \\
1.91 \\
1.79 \\
1.72 \\
1.70 \\
1.72 \\
1.79\end{array}$ & $\begin{array}{l}409 \\
440 \\
481 \\
600 \\
645 \\
591 \\
514 \\
464 \\
436 \\
428 \\
436 \\
464\end{array}$ & $\begin{array}{l}-\overline{1.80} \\
- \\
1.72 \\
- \\
1.61 \\
- \\
1.53 \\
- \\
1.52 \\
\overline{1.59}\end{array}$ & $\begin{array}{c}\overline{468} \\
\overline{436} \\
\overline{394} \\
\overline{365} \\
\overline{361} \\
\overline{386}\end{array}$ & $\begin{array}{c}-\overline{1.67} \\
- \\
1.58 \\
- \\
1.52 \\
- \\
1.48 \\
- \\
1.47 \\
-\overline{1.55}\end{array}$ & $\begin{array}{c}\overline{417} \\
\overline{-} \\
383 \\
\overline{361} \\
\overline{347} \\
\overline{344} \\
\overline{372}\end{array}$ \\
\hline
\end{tabular}

Supplemental rocords.- Dec. 11,1 p.m., $11.30 \mathrm{ft},, 16,200$ sec.-ft.; 3 p.m., 16.00 ft., 33,300 sec. $-\mathrm{ft}$. 
Kings River above North Fork, Calif.

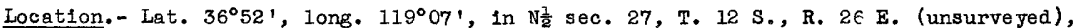
1 mile above North Fork of Kings River and $10 \mathrm{mlles}$ southeast of Trimer, Fresno county. Alt1tude, about 1,020 feet above mean 8 ea level.

Drainage area.- 956 square miles.

Gage-helght record.- Water-stage recorder graph.

Stage-discharge relation. - Defined by current-meter measurements below 11,000 secondfeet; extended to peak stage with ald of area-velocity study; verified by logarithmic extension. Rating curve changed at peak stage.

Max 1ma.- December 1937: D1scharge, 42,000 second-feet 4 p.m. Dec. 11 (gage he1ght, 12.02 feet).

1927-28; 1931-November 1937: D1scharge, 13,400 second-feet Feb. 6, 1937 (gage helght, 7.86 feet), from rating curve extended above 10,000 second-feet.

Remarks. - Flood run-off very slightly affected by artificial storage. No diversions.

Part of basic data furnished by Kings River Water Association and San Joaquin Light \& Power Corporation.

Mean daily discharge, in second-feet, November 1937 to January 1938

\begin{tabular}{|c|c|c|c||c|c|c|c|c|c|c|c}
\hline Day & Nov. & Dec. & Jan. & Day & Nov. & Dec. & Jan. & Day & Nov. & Dec. & Jan. \\
\hline 1 & 149 & 147 & 390 & 11 & 153 & 14,600 & 300 & 21 & 172 & 560 & 400 \\
2 & 149 & 149 & 415 & 12 & 200 & 5,990 & 296 & 22 & 167 & 525 & 410 \\
3 & 147 & 151 & 430 & 13 & 231 & 2,120 & 292 & 23 & 161 & 555 & 381 \\
4 & 145 & 143 & 400 & 14 & 207 & 1,310 & 292 & 24 & 161 & 485 & 372 \\
5 & 143 & 141 & 376 & 15 & 187 & 1,020 & 430 & 25 & 163 & 470 & 368 \\
6 & 141 & 141 & 354 & 16 & 169 & 871 & 390 & 26 & 161 & 455 & 368 \\
7 & 145 & 141 & 354 & 17 & 176 & 780 & 465 & 27 & 159 & 440 & 363 \\
8 & 145 & 138 & 340 & 18 & 183 & 698 & 460 & 28 & 155 & 420 & 395 \\
9 & 145 & 153 & 322 & 19 & 169 & 638 & 445 & 29 & 149 & 415 & 460 \\
10 & 147 & 3,340 & 322 & 20 & 172 & 590 & 415 & 30 & 149 & 415 & 410 \\
\end{tabular}

Gage helght, in feet, and discharge, in second-feet, at indicated time, 1937

\begin{tabular}{|c|c|c|c|c|c|c|c|c|c|c|c|c|}
\hline \multirow{2}{*}{ 先 } & Peet & Sec.ft. & Feet & Sec.ft. & Feet & Sec.ft. & Feet & Sec.ft. & Feet & Sec.ft. & Feet & Sec.ft. \\
\hline & \multicolumn{2}{|c|}{ December 8} & \multicolumn{2}{|c|}{ December 9} & \multicolumn{2}{|c|}{ December 10} & \multicolumn{2}{|c|}{ December 11} & \multicolumn{2}{|c|}{ December 12} & \multicolumn{2}{|c|}{ December 13} \\
\hline \multirow[t]{2}{*}{$\begin{array}{r}2 \\
4 \\
6 \\
8 \\
10 \\
\mathbb{N} \\
2 \\
4 \\
6 \\
8 \\
10 \\
M\end{array}$} & $\begin{array}{r}0.87 \\
.86 \\
.86 \\
.85 \\
.85 \\
.85 \\
.85 \\
.85 \\
.86 \\
.86 \\
.86 \\
.86\end{array}$ & $\begin{array}{l}140 \\
138 \\
138 \\
136 \\
136 \\
136 \\
136 \\
136 \\
138 \\
138 \\
138 \\
138\end{array}$ & $\begin{array}{r}0.86 \\
.85 \\
.85 \\
.86 \\
.85 \\
.85 \\
.86 \\
.87 \\
.95 \\
1.09 \\
1.21 \\
1.49\end{array}$ & $\begin{array}{l}138 \\
136 \\
136 \\
138 \\
136 \\
136 \\
138 \\
140 \\
155 \\
185 \\
215 \\
295\end{array}$ & $\begin{array}{l}2.12 \\
4.29 \\
5.24 \\
5.72 \\
5.88 \\
5.62 \\
5.20 \\
4.84 \\
4.68 \\
4.53 \\
4.25 \\
4.02\end{array}$ & $\begin{array}{r}539 \\
2,450 \\
4,070 \\
5,310 \\
5,850 \\
5,000 \\
3,980 \\
3,290 \\
3,030 \\
2,800 \\
2,390 \\
2,090\end{array}$ & $\begin{array}{r}3.82 \\
3.62 \\
3.53 \\
3.64 \\
5.07 \\
7.00 \\
9.95 \\
12.02 \\
11.05 \\
9.75 \\
8.80 \\
7.69\end{array}$ & $\begin{array}{r}1,850 \\
1,630 \\
1,540 \\
1,650 \\
3,720 \\
9,920 \\
25,600 \\
42,000 \\
34,200 \\
24,900 \\
19,200 \\
13,600\end{array}$ & & $\begin{array}{r}10,600 \\
8,750 \\
7,440 \\
6,490 \\
5,730 \\
5,000 \\
4,590 \\
4,230 \\
3,890 \\
3,770 \\
3,580 \\
3,320\end{array}$ & & $\begin{array}{l}2,980 \\
2,740 \\
2,500 \\
2,320 \\
2,120 \\
2,000 \\
1,870 \\
1,770 \\
1,690 \\
1,670 \\
1,660 \\
1,660\end{array}$ \\
\hline & \multicolumn{2}{|c|}{ December 14} & \multicolumn{2}{|c|}{ December 15} & \multicolumn{2}{|c|}{ December 16} & \multicolumn{2}{|c|}{ December 17} & \multicolumn{2}{|c|}{ December 18} & \multicolumn{2}{|c|}{ December 19} \\
\hline \multirow[t]{2}{*}{$\begin{array}{r}2 \\
4 \\
6 \\
8 \\
10 \\
\mathrm{~N} \\
2 \\
4 \\
6 \\
8 \\
10 \\
\mathrm{M}\end{array}$} & $\begin{array}{l}3.86 \\
3.80 \\
3.75 \\
3.67 \\
3.62 \\
3.59 \\
3.55 \\
3.52 \\
3.49 \\
3.48 \\
3.47 \\
3.47\end{array}$ & $\begin{array}{l}1,580 \\
1,500 \\
1,440 \\
1,350 \\
1,300 \\
1,270 \\
1,230 \\
1,200 \\
1,170 \\
1,160 \\
1,150 \\
1,150\end{array}$ & $\begin{array}{l}3.46 \\
3.43 \\
3.39 \\
3.37 \\
3.33 \\
3.31 \\
3.29 \\
3.27 \\
3.25 \\
3.24 \\
3.24 \\
3.23\end{array}$ & $\begin{array}{r}1,140 \\
1,120 \\
1,080 \\
1,060 \\
1,030 \\
1,010 \\
992 \\
976 \\
960 \\
952 \\
952 \\
944\end{array}$ & $\begin{array}{l}3.23 \\
3.20 \\
3.19 \\
3.16 \\
3.14 \\
3.11 \\
3.08 \\
3.05 \\
3.04 \\
3.04 \\
3.05 \\
3.06\end{array}$ & $\begin{array}{l}944 \\
920 \\
913 \\
892 \\
878 \\
857 \\
836 \\
815 \\
808 \\
808 \\
815 \\
822\end{array}$ & $\begin{array}{l}3.06 \\
3.05 \\
3.04 \\
3.02 \\
3.01 \\
2.99 \\
2.98 \\
2.95 \\
2.94 \\
2.93 \\
2.92 \\
2.93\end{array}$ & $\begin{array}{l}822 \\
815 \\
808 \\
794 \\
787 \\
773 \\
766 \\
745 \\
738 \\
731 \\
724 \\
731\end{array}$ & $\begin{array}{c}- \\
2.94 \\
- \\
2.91 \\
- \\
2.89 \\
- \\
2.86 \\
\overline{2 .-82} \\
\overline{2.81}\end{array}$ & $\begin{array}{c}7 \overline{38} \\
\overline{7} \\
7 \overline{7} \\
\overline{704} \\
\overline{-} \\
6 \overline{86} \\
\overline{6} \\
\overline{62} \\
6 \overline{6} 6\end{array}$ & $\begin{array}{l}-\overline{2 .} \\
- \\
2.83 \\
- \\
2.79 \\
- \\
2.74 \\
- \\
2.70 \\
- \\
2.74\end{array}$ & $\begin{array}{c}\overline{668} \\
\overline{68} \\
\overline{68} \\
6 \overline{44} \\
\overline{614} \\
\overline{590} \\
\overline{614}\end{array}$ \\
\hline & \multicolumn{2}{|c|}{ December 20} & \multicolumn{2}{|c|}{ December 21} & \multicolumn{2}{|c|}{ December 22} & \multicolumn{2}{|c|}{ December 23} & \multicolumn{2}{|c|}{ December 24} & \multicolumn{2}{|c|}{ December 25} \\
\hline $\begin{array}{r}2 \\
4 \\
6 \\
8 \\
10 \\
\mathrm{~N} \\
2 \\
4 \\
6 \\
8 \\
10 \\
M\end{array}$ & $\begin{array}{c}- \\
2.78 \\
- \\
2.77 \\
- \\
2.70 \\
- \\
2.63 \\
- \\
2.61 \\
- \\
2.66\end{array}$ & $\begin{array}{l}\overline{638} \\
\overline{632} \\
\overline{590} \\
\overline{555} \\
\overline{545} \\
\overline{570}\end{array}$ & $\begin{array}{c}- \\
2.70 \\
- \\
2.68 \\
- \\
2.63 \\
- \\
2.59 \\
- \\
2.58 \\
- \\
2.59\end{array}$ & $\begin{array}{c}\overline{590} \\
- \\
5 \overline{80} \\
\overline{5} \\
5 \overline{5} \\
\overline{5} \\
\overline{3} 5 \\
\overline{530} \\
\overline{53}\end{array}$ & $\begin{array}{c}2.61 \\
- \\
2.60 \\
- \\
2.58 \\
- \\
2.52 \\
-\overline{2.50} \\
- \\
2.55\end{array}$ & $\begin{array}{c}\overline{545} \\
\overline{40} \\
540 \\
\overline{530} \\
\overline{500} \\
\overline{4} \\
\overline{50} \\
\overline{5}\end{array}$ & $\begin{array}{l}2.60 \\
2.67 \\
2.72 \\
2.78 \\
2.75 \\
2.68 \\
2.62 \\
2.58 \\
2.56 \\
2.56 \\
2.56 \\
2.57\end{array}$ & $\begin{array}{l}540 \\
575 \\
608 \\
638 \\
620 \\
580 \\
550 \\
530 \\
520 \\
520 \\
520 \\
525\end{array}$ & $\begin{array}{l}2.56 \\
2.56 \\
2.55 \\
2.55 \\
2.53 \\
2.50 \\
2.47 \\
2.43 \\
2.40 \\
2.39 \\
2.41 \\
2.46\end{array}$ & $\begin{array}{l}520 \\
520 \\
515 \\
515 \\
505 \\
490 \\
475 \\
455 \\
440 \\
435 \\
445 \\
470\end{array}$ & $\begin{array}{l}2.50 \\
2.52 \\
2.53 \\
2.51 \\
2.48 \\
2.45 \\
2.43 \\
2.40 \\
2.38 \\
2.38 \\
2.39 \\
2.43\end{array}$ & $\begin{array}{l}490 \\
500 \\
505 \\
495 \\
480 \\
465 \\
455 \\
440 \\
430 \\
430 \\
435 \\
455\end{array}$ \\
\hline
\end{tabular}


Kings River at Pledra, Calif.

Location.- Lat. $36^{\circ} 49^{\prime} 02^{n}$, long. $119^{\circ} 23^{\prime} 08^{\prime \prime}$, in NW/ sec. 8, T. 13 S., R. 24 E., half a mile below highway bridge at Piedra, Fresno County, and 12 mlles northeast of Sanger. Altitude, about 500 feet above mean sea level.

Dralnage area.- 1,694 square miles.

Gage-height record. - Water-stage recorder graph.

Stage-discharge relation. - Defined by current-meter measurements below 26,000 secondfeet; extended to peak stage with ald of area-veloc1ty study. Rating curve changed at peak stage.

Maxima.- December 1937: D1scharge, 80,000 second-feet 4:30 p.m. Dec. 11 (gage height, 19.94 feet).

1895-November 1937: D1scharge, about 59,700 second-feet Jan. 25, 1914 (gage helght, 21,8 feet, from floodmarks, former s1te and datum 1,000 feet upstream), from rating curve extended above 15,000 second-feet.

Remarks. - Flood mun-off not affected by artificlal storage or diversion. Part of basic data furnlshed by Kings River Water Association.

Mean dally discharge, in second-feet, November 1937 to January 1938

\begin{tabular}{|c|c|c|r|r|r|r|r|r|r|r|r|}
\hline Day & Nov. & Dec. & Jan. & Day & Nov. & Dec. & Jan. & Day & Nov. & Dec. & Jan. \\
\hline 1 & 183 & 196 & 784 & 11 & 192 & 37,800 & 665 & 21 & 220 & 1,080 & 916 \\
2 & 187 & 192 & 832 & 12 & 213 & 12,900 & 645 & 22 & 220 & 964 & 910 \\
3 & 187 & 196 & 1,040 & 13 & 274 & 4,120 & 635 & 23 & 215 & 1,040 & 880 \\
4 & 183 & 194 & 922 & 14 & 286 & 2,680 & 635 & 24 & 215 & 1,000 & 820 \\
5 & 180 & 190 & 838 & 15 & 253 & 2,160 & 1,170 & 25 & 220 & 922 & 790 \\
6 & 176 & 187 & 790 & 16 & 259 & 1,840 & 1,080 & 26 & 218 & 880 & 790 \\
7 & 178 & 185 & 748 & 17 & 225 & 1,600 & 1,000 & 27 & 215 & 862 & 790 \\
8 & 185 & 185 & 725 & 18 & 235 & 1,460 & 1,140 & 28 & 208 & 826 & 927 \\
9 & 185 & 194 & 695 & 19 & 238 & 1,300 & 1,110 & 29 & 203 & 802 & 1,510 \\
10 & 185 & 9,190 & 675 & 20 & 223 & 1,180 & 1,110 & 30 & 199 & 790 & 1,080 \\
\end{tabular}

Gage helght, in feet, and alscharge, in second-feet, at indicated time, 1937

\begin{tabular}{|c|c|c|c|c|c|c|c|c|c|c|c|c|}
\hline \multirow{2}{*}{$\begin{array}{l}\dot{y} \\
\text { 号 } \\
\text { 足 }\end{array}$} & Feet & Sec.ft. & Feet & Sec.ft. & Feet & Sec.ft. & Feet & Sec.ft. & Feet & Sec.ft. & Feet & Sec.ft. \\
\hline & \multicolumn{2}{|c|}{ December 8} & \multicolumn{2}{|c|}{ December 9} & \multicolumn{2}{|c|}{ December 10} & \multicolumn{2}{|c|}{ December 11} & \multicolumn{2}{|c|}{ December 12} & \multicolumn{2}{|c|}{ December 13} \\
\hline \multirow[t]{2}{*}{$\begin{array}{r}8 \\
4 \\
6 \\
8 \\
10 \\
\mathrm{~N} \\
2 \\
4 \\
6 \\
8 \\
10 \\
\mathrm{M}\end{array}$} & $\begin{array}{l}1.43 \\
1.42 \\
1.42 \\
1.43 \\
1.44 \\
1.44 \\
1.44 \\
1.43 \\
1.43 \\
1.42 \\
1.41 \\
1.41\end{array}$ & $\begin{array}{l}185 \\
183 \\
183 \\
185 \\
187 \\
187 \\
187 \\
185 \\
185 \\
183 \\
180 \\
180\end{array}$ & $\begin{array}{l}1.41 \\
1.40 \\
1.40 \\
1.41 \\
1.42 \\
1.43 \\
1.43 \\
1.44 \\
1.50 \\
1.54 \\
1.63 \\
1.77\end{array}$ & $\begin{array}{l}180 \\
178 \\
178 \\
180 \\
183 \\
185 \\
185 \\
187 \\
201 \\
211 \\
232 \\
271\end{array}$ & $\begin{array}{r}1.95 \\
2.28 \\
2.80 \\
8.87 \\
10.92 \\
11.57 \\
10.67 \\
9.82 \\
8.96 \\
8.76 \\
8.71 \\
8.12 \\
\end{array}$ & $\begin{array}{r}328 \\
447 \\
675 \\
9,730 \\
17,300 \\
20,400 \\
16,200 \\
12,900 \\
10,000 \\
9,420 \\
9,280 \\
7,700\end{array}$ & $\begin{array}{r}7.45 \\
6.94 \\
6.65 \\
6.95 \\
8.00 \\
16.00 \\
19.87 \\
19.80 \\
19.20 \\
18.75 \\
17.20 \\
15.00\end{array}$ & $\begin{array}{r}6,140 \\
5,130 \\
4,620 \\
5,140 \\
7,400 \\
46,800 \\
79,700 \\
79,000 \\
72,500 \\
68,100 \\
54,200 \\
37,500\end{array}$ & $\begin{array}{r}13.50 \\
12.14 \\
11.37 \\
10.45 \\
9.80 \\
9.35 \\
8.97 \\
8.59 \\
8.28 \\
8.03 \\
7.88 \\
7.78\end{array}$ & $\begin{array}{r}27,800 \\
20,700 \\
17,100 \\
13,400 \\
11,200 \\
9,820 \\
8,760 \\
7,780 \\
7,030 \\
6,470 \\
6,140 \\
5,930\end{array}$ & & $\begin{array}{l}5,540 \\
5,230 \\
4,840 \\
4,470 \\
4,170 \\
3,910 \\
3,710 \\
3,560 \\
3,380 \\
3,270 \\
3,200 \\
3,180\end{array}$ \\
\hline & \multicolumn{2}{|c|}{ December 14} & \multicolumn{2}{|c|}{ December 15} & \multicolumn{2}{|c|}{ December 16} & \multicolumn{2}{|c|}{ December 17} & \multicolumn{2}{|c|}{ December 18} & \multicolumn{2}{|c|}{ Decembor 19} \\
\hline \multirow[t]{2}{*}{$\begin{array}{r}2 \\
4 \\
6 \\
8 \\
10 \\
\mathrm{~N} \\
2 \\
4 \\
6 \\
8 \\
10 \\
M\end{array}$} & $\begin{array}{l}6.20 \\
6.18 \\
6.10 \\
6.00 \\
5.88 \\
5.78 \\
5.70 \\
5.62 \\
5.57 \\
5.53 \\
5.48 \\
5.46\end{array}$ & $\begin{array}{l}3,210 \\
3,180 \\
3,070 \\
2,940 \\
2,780 \\
2,660 \\
2,560 \\
2,460 \\
2,400 \\
2,360 \\
2,300 \\
2,280\end{array}$ & $\begin{array}{l}5.48 \\
5.52 \\
5.52 \\
5.48 \\
5.43 \\
5.37 \\
5.32 \\
5.28 \\
5.25 \\
5.22 \\
5.20 \\
5.17\end{array}$ & $\begin{array}{l}2,300 \\
2,340 \\
2,340 \\
2,300 \\
2,240 \\
2,180 \\
2,126 \\
2,080 \\
2,040 \\
2,010 \\
1,990 \\
1,960\end{array}$ & $\begin{array}{l}5.16 \\
5.16 \\
5.15 \\
5.14 \\
5.11 \\
5.09 \\
5.06 \\
5.02 \\
4.97 \\
4.93 \\
4.90 \\
4.88\end{array}$ & $\begin{array}{l}1,950 \\
1,950 \\
1,940 \\
1,930 \\
1,900 \\
1,880 \\
1,950 \\
1,810 \\
1,760 \\
1,720 \\
1,690 \\
1,670\end{array}$ & $\begin{array}{l}4.87 \\
4.87 \\
4.88 \\
4.89 \\
4.87 \\
4.85 \\
4.82 \\
4.80 \\
4.77 \\
4.74 \\
4.72 \\
4.70\end{array}$ & $\begin{array}{l}1,660 \\
1,660 \\
1,670 \\
1,680 \\
1,660 \\
1,640 \\
1,620 \\
1,600 \\
1,570 \\
1,550 \\
1,530 \\
1,510\end{array}$ & $\begin{array}{l}4.68 \\
4.67 \\
4.67 \\
4.67 \\
4.68 \\
4.67 \\
4.65 \\
4.63 \\
4.61 \\
4.59 \\
4.56 \\
4.53\end{array}$ & $\begin{array}{l}1,490 \\
1,480 \\
1,480 \\
1,480 \\
1,490 \\
1,480 \\
1,460 \\
1,450 \\
1,430 \\
1,410 \\
1,390 \\
1,360\end{array}$ & $\begin{array}{l}4.49 \\
4.47 \\
4.47 \\
4.47 \\
4.48 \\
4.49 \\
4.48 \\
4.45 \\
4.43 \\
4.41 \\
4.36 \\
4.30\end{array}$ & $\begin{array}{l}1,330 \\
1,320 \\
1,320 \\
1,320 \\
1,320 \\
1,330 \\
1,320 \\
1,300 \\
1,280 \\
1,270 \\
1,230 \\
1,180\end{array}$ \\
\hline & \multicolumn{2}{|c|}{ December 20} & \multicolumn{2}{|c|}{ December 21} & \multicolumn{2}{|c|}{ December 22} & \multicolumn{2}{|c|}{ December 23} & \multicolumn{2}{|c|}{ December 24} & \multicolumn{2}{|c|}{ December 25} \\
\hline $\begin{array}{r}2 \\
4 \\
6 \\
8 \\
10 \\
\mathrm{~N} \\
2 \\
4 \\
6 \\
8 \\
10 \\
\mathrm{M}\end{array}$ & $\begin{array}{l}4.26 \\
4.25 \\
4.28 \\
4.32 \\
4.34 \\
4.35 \\
4.34 \\
4.31 \\
4.27 \\
4.24 \\
4.20 \\
4.17\end{array}$ & $\begin{array}{l}1,150 \\
1,140 \\
1,170 \\
1,200 \\
1,210 \\
1,220 \\
1,210 \\
1,190 \\
1,160 \\
1,140 \\
1,110 \\
1,090\end{array}$ & $\begin{array}{l}4.15 \\
4.12 \\
4.14 \\
4.18 \\
4.21 \\
4.22 \\
4.21 \\
4.20 \\
4.17 \\
4.15 \\
4.14 \\
4.11\end{array}$ & $\begin{array}{l}1,080 \\
1,050 \\
1,070 \\
1,100 \\
1,120 \\
1,120 \\
1,120 \\
1,110 \\
1,090 \\
1,080 \\
1,070 \\
1,050\end{array}$ & $\begin{array}{l}4.09 \\
4.06 \\
3.99 \\
3.95 \\
3.96 \\
3.98 \\
3.99 \\
3.98 \\
3.97 \\
3.96 \\
3.94 \\
3.92\end{array}$ & $\begin{array}{r}1,030 \\
1,010 \\
964 \\
940 \\
946 \\
958 \\
964 \\
958 \\
952 \\
946 \\
934 \\
922\end{array}$ & $\begin{array}{l}3.88 \\
3.83 \\
3.82 \\
3.90 \\
4.14 \\
4.25 \\
4.34 \\
4.39 \\
4.34 \\
4.25 \\
4.18 \\
4.12\end{array}$ & $\begin{array}{r}898 \\
868 \\
862 \\
910 \\
1,070 \\
1,140 \\
1,210 \\
1,250 \\
1,210 \\
1,140 \\
1,100 \\
1,050\end{array}$ & $\begin{array}{l}4.08 \\
4.07 \\
4.09 \\
4.12 \\
4.13 \\
4.12 \\
4.10 \\
4.07 \\
4.03 \\
3.97 \\
3.93 \\
3.91\end{array}$ & $\begin{array}{r}1,030 \\
1,020 \\
1,030 \\
1,050 \\
1,060 \\
1,050 \\
1,040 \\
1,020 \\
991 \\
952 \\
928 \\
916\end{array}$ & $\begin{array}{l}3.87 \\
3.85 \\
3.87 \\
3.93 \\
3.98 \\
3.99 \\
3.98 \\
3.96 \\
3.92 \\
3.88 \\
3.94 \\
3.80\end{array}$ & $\begin{array}{l}892 \\
880 \\
892 \\
928 \\
958 \\
964 \\
958 \\
946 \\
922 \\
898 \\
874 \\
850\end{array}$ \\
\hline
\end{tabular}

Supplemental records.- Dec. 11, 3:15 p.m., $19.57 \mathrm{ft.}, 76,700$ sec.-ft.; 4:30 p.m., 19.94 ft., 80,000 sec.-ft.; $6: 20$ p.m., 19.49 ft., 75,500 sec.-ft. 
Fresno by-pass, Fresno County, Calif.

Kings River, during flood perfods, flows into Thlare Lake but also contributes some water to the San Joaquin River by way of Fresno Slough and Fresno by-pass which joins the San Joaquin River near Mendota. Data furnished by C. L. Kaupke, water master, Kings River Fater Association. (See No. 3lla on figure 6.)

Dafly discharge, in second-feet, December 1937

\begin{tabular}{|c|c|c|c|c|c|c|c|c|c|c|c|}
\hline Day & Discharge & Day & Discharge & Day & Discharge & Day & Discharge & Day & Discharge & Day & Discharge \\
\hline $\begin{array}{l}1 \\
2 \\
3 \\
4 \\
5\end{array}$ & $\begin{array}{l}0 \\
0 \\
0 \\
0 \\
0\end{array}$ & $\begin{array}{r}6 \\
7 \\
8 \\
9 \\
10\end{array}$ & $\begin{array}{l}0 \\
0 \\
0 \\
0 \\
0\end{array}$ & $\begin{array}{l}11 \\
12 \\
13 \\
14 \\
15\end{array}$ & $\begin{array}{r}0 \\
0 \\
920 \\
1,850 \\
3,070\end{array}$ & $\begin{array}{l}16 \\
17 \\
18 \\
19 \\
20\end{array}$ & $\begin{array}{l}2,805 \\
2,025 \\
1,650 \\
1,550 \\
1,330\end{array}$ & \begin{tabular}{|l|}
21 \\
22 \\
23 \\
24 \\
25
\end{tabular} & $\begin{array}{r}1,100 \\
915 \\
830 \\
790 \\
760\end{array}$ & $\begin{array}{l}26 \\
27 \\
28 \\
29 \\
30 \\
31\end{array}$ & $\begin{array}{l}755 \\
680 \\
635 \\
610 \\
600 \\
595\end{array}$ \\
\hline & & & & & & & & & & & $\begin{array}{r}757 \\
46,550\end{array}$ \\
\hline
\end{tabular}


North Fork of Kings River near Cliff Camp, Calif.

Location.- Lat. $37^{\circ} 00^{\prime}$, long. $118^{\circ} 59^{\prime}$, in Nw $\frac{1}{4}$ sec. 12, T. 11 S., R. 27 E., at Cliff Camp Bridge, 1 mile northeast of Cilff Camp, Fresno County, and 2.3 miles below Woodchuck Creek. Altitude, about 6,150 feet above mean sea level.

Drainage area.- 174 square miles.

Gage-helght record. - Water-stage recorder graph except for period 11 a.m. Dec. 11 to 11 a.m. Jan. 26, when there was no record. Stage graph for Dec. 11 and Jan. 26 determined from partial recorder graph, floodmarks, and stage graphs for Kings River above North Fork and at Piedra. Peak stage obtained from floodmarks.

Stage-discharge relation. - Defined by current-meter measurements below 2,800 secondfeet; extended to peak stage with aid of area-velocity study; verified by logarithmic extension.

Maxima.- December 1937: Discharge, 14,000 second-feet about noon Dec. 11 (gage height, 18.0 feet).

1921-November 1937: Discharge, 6,030 second-feet June 4, 1922 (gage he1ght, 10.6 feet, former site and datum), from rating curve extended above 4,200 second-feet.

Remarks. - Flood run-off not affécted by artificial storage or diversion. Mean discharge for period Dec. 12-31 estimated as 300 second-feet; for period Jan. 1-25 estimated as 85 second-feet. Most of basic data furnished by San Joaquin Light \& Power Corporation.

Mean daily discharge, in second-feet, November 1937 to January 1938

\begin{tabular}{|c|c|c|c|c|c|c|c|c|c|c|c|}
\hline Day & Nov. & Dec. & Jan. & Day & Nov. & Dec. & Jan. & Day & Nov. & Dec. & Jan. \\
\hline $\begin{array}{r}1 \\
2 \\
3 \\
4 \\
5 \\
6 \\
7 \\
8 \\
9 \\
10\end{array}$ & $\begin{array}{l}8 \\
7.5 \\
7 \\
7 \\
6.5 \\
7 \\
8 \\
7.5 \\
7.5 \\
8.5\end{array}$ & $\begin{array}{l}8.5 \\
9.5 \\
9 \\
8 \\
7.5 \\
8 \\
7.5 \\
7.5 \\
39 \\
1,210\end{array}$ & $\begin{array}{l}- \\
- \\
- \\
- \\
- \\
- \\
- \\
-\end{array}$ & $\begin{array}{l}11 \\
12 \\
13 \\
14 \\
15 \\
16 \\
17 \\
18 \\
19 \\
20\end{array}$ & $\begin{array}{l}9.5 \\
10 \\
9.5 \\
12 \\
11 \\
10 \\
15 \\
11 \\
10 \\
13\end{array}$ & $\begin{array}{c}6,620 \\
= \\
- \\
- \\
- \\
= \\
- \\
- \\
-\end{array}$ & $\begin{array}{l}= \\
= \\
= \\
= \\
= \\
=\end{array}$ & $\begin{array}{l}21 \\
22 \\
23 \\
24 \\
25 \\
26 \\
27 \\
28 \\
29 \\
30 \\
31\end{array}$ & $\begin{array}{l}13 \\
11 \\
11 \\
13 \\
11 \\
11 \\
10 \\
9.5 \\
9 \\
8.5\end{array}$ & $\begin{array}{l}= \\
= \\
= \\
= \\
= \\
= \\
=\end{array}$ & $\begin{array}{c}\overline{-} \\
- \\
- \\
\overline{104} \\
98 \\
95 \\
97 \\
97 \\
95\end{array}$ \\
\hline $\begin{array}{l}\text { Mean } \\
\text { Run- }\end{array}$ & $\begin{array}{l}\text { onth } \\
\text {, i. }\end{array}$ & dischar & in & & & & & & $\begin{array}{r}9.75 \\
580\end{array}$ & $\begin{array}{r}450 \\
27,640\end{array}$ & $\begin{array}{r}87.5 \\
5,380\end{array}$ \\
\hline
\end{tabular}

Gage height, in feet, and discharge, in second-feet, at indicated time, 1937

\begin{tabular}{|c|c|c|c|c|c|c|c|c|c|c|c|c|}
\hline \multirow{2}{*}{\begin{tabular}{|l|} 
\\
马ु \\
品 \\
\end{tabular}} & Feet & Sec.ft. & Feet & Sec.ft. & Feet & Sec.ft. & Feet & Sec.ft. & Feet & Sec.ft. & Feet & Sec.ft. \\
\hline & \multicolumn{2}{|c|}{ December 8} & \multicolumn{2}{|c|}{ December 9} & \multicolumn{2}{|c|}{ December 10} & \multicolumn{2}{|c|}{ December 11} & \multicolumn{2}{|c|}{ December 12} & \multicolumn{2}{|c|}{ December 13} \\
\hline \multirow[t]{2}{*}{$\begin{array}{r}2 \\
4 \\
6 \\
8 \\
10 \\
N \\
2 \\
4 \\
6 \\
8 \\
10 \\
M \\
\end{array}$} & $\begin{array}{l}2.64 \\
2.73 \\
2.74 \\
2.75 \\
2.75 \\
2.68 \\
2.59 \\
2.51 \\
2.58 \\
2.69 \\
2.67 \\
2.63\end{array}$ & $\begin{array}{l}7 \\
9 \\
9 \\
9.5 \\
9.5 \\
8 \\
6.5 \\
5 \\
6 \\
8 \\
7.5 \\
7\end{array}$ & $\begin{array}{l}2.65 \\
2.74 \\
2.78 \\
2.79 \\
2.80 \\
2.81 \\
2.81 \\
2.81 \\
2.90 \\
3.14 \\
4.20 \\
5.45\end{array}$ & $\begin{array}{c}7.5 \\
9 \\
10 \\
10 \\
11 \\
11 \\
11 \\
11 \\
14 \\
24 \\
150 \\
440\end{array}$ & $\begin{array}{l}6.46 \\
7.08 \\
8.25 \\
8.75 \\
7.98 \\
7.15 \\
7.49 \\
8.25 \\
7.50 \\
6.83 \\
6.42 \\
6.64\end{array}$ & $\begin{array}{r}804 \\
1,060 \\
1,620 \\
1,920 \\
1,470 \\
1,090 \\
1,240 \\
1,620 \\
1,240 \\
952 \\
788 \\
876\end{array}$ & $\begin{array}{r}7.50 \\
8.60 \\
12.53 \\
14.95 \\
16.69 \\
18.00 \\
17.30 \\
14.50 \\
12.65 \\
11.65 \\
11.00 \\
10.50\end{array}$ & $\begin{array}{r}1,240 \\
1,830 \\
5,450 \\
8,820 \\
11,700 \\
14,000 \\
12,700 \\
8,140 \\
5,600 \\
4,420 \\
3,720 \\
3,240\end{array}$ & & & & \\
\hline & \multicolumn{2}{|c|}{ December 14} & \multicolumn{2}{|c|}{ De cember 15} & \multicolumn{2}{|c|}{ De cember 16} & \multicolumn{2}{|c|}{ December 17} & \multicolumn{2}{|c|}{ De cember 18} & \multicolumn{2}{|c|}{ December 19} \\
\hline \multirow[t]{2}{*}{\begin{tabular}{r|}
2 \\
4 \\
6 \\
8 \\
10 \\
$\mathrm{~N}$ \\
2 \\
4 \\
6 \\
8 \\
10 \\
$\mathrm{M}$ \\
\end{tabular}} & & & & & & & & & & & & \\
\hline & \multicolumn{2}{|c|}{ December 20} & \multicolumn{2}{|c|}{ December 21} & \multicolumn{2}{|c|}{ December 22} & \multicolumn{2}{|c|}{ December 23} & \multicolumn{2}{|c|}{ December 24} & \multicolumn{2}{|c|}{ December 25} \\
\hline $\begin{array}{r}2 \\
4 \\
6 \\
8 \\
10 \\
\mathrm{~N} \\
2 \\
4 \\
6 \\
8 \\
10 \\
1\end{array}$ & & & & & & & & & & & & \\
\hline
\end{tabular}

Supplementary reccrds.- Dec. 9,9 p.m., $3.26 \mathrm{ft.}, 33$ sec.-ft. 
North Fork of KIngs River below Rancheria Greek, Calif.

Location.- Lat. $36^{\circ} 56^{\prime}$, long. $119^{\circ} 00^{\prime}$, in SE⿺ sec. 34, T. 11 S., R. 27 E., 1 mile above Balch Diversion Dam and 1 mile below Rancheria Creek, Fresno County. Altitude, about 3,400 feet above mean sea level.

Drainage area.- 225 square miles.

Gage-helght record. - Water-stage recoraer graph prior to Nov. 30 except for periods Nov. $7-8,10-15$, and parts of Nov. $6,9,16,18,19,21$, 22, when gtage graph was based on partial recorder graph, occasional gage readings, and shape of stage graph for North Fork of Kings River near Cliff Camp. No record for perlod Dec. 1 to Jan. 31.

Stage-discharge relation. - Defined by current-meter messurements below 4,000 secondfeet; extended to peak stage on basis of computation of flow over Balch Forebay Dam plus discharge through sluice gates minus estimated inflow; verified by computation of flow over Balch Afterbay Dam plus discharge through sluice gates minus estimated inflow between gage and dam.

Maxima.- December 1937: Discharge, 21,000 second-feet Dec. 11 (gage height, about 23 feet, from floodmarks).

1927-November 1937: Discharge, 6,510 second-feet May 14, 1937 (gage height, 13.10 feet), from rating curve extended above 3,800 second-feet.

Remarks. - Flood run-off not affected by artificial storage or diversion. Mean discharge for period Dec. 12-31 estimated as 450 second-feet; for January, 140 second-feet. Most of basic data furnished by San Joaquin Light \& Power Corporation.

Mean da1ly discharge, in second-feet, November 2937 to January 1938

\begin{tabular}{|c|c|c|c|c|c|c|c|c|c|c|c|}
\hline Day & Nov. & Dec. & Jan. & Day & Nov. & Dec. & Jan. & Day & Nov. & Dec. & Jan. \\
\hline $\begin{array}{r}1 \\
2 \\
3 \\
4 \\
5 \\
6 \\
7 \\
8 \\
9 \\
10\end{array}$ & $\begin{array}{l}16 \\
16 \\
16 \\
16 \\
15 \\
16 \\
16 \\
16 \\
16 \\
17\end{array}$ & $\begin{array}{r}16 \\
15 \\
18 \\
16 \\
15 \\
14 \\
14 \\
14 \\
100 \\
1,500\end{array}$ & $\begin{array}{l}- \\
\overline{-} \\
= \\
- \\
- \\
- \\
-\end{array}$ & $\begin{array}{l}11 \\
12 \\
13 \\
14 \\
15 \\
16 \\
17 \\
18 \\
19 \\
20\end{array}$ & $\begin{array}{l}19 \\
20 \\
20 \\
22 \\
21 \\
20 \\
22 \\
26 \\
20 \\
22\end{array}$ & $\begin{array}{c}9,000 \\
= \\
= \\
= \\
= \\
= \\
= \\
=\end{array}$ & $\begin{array}{l}- \\
- \\
- \\
- \\
= \\
- \\
=\end{array}$ & $\begin{array}{l}21 \\
22 \\
2 z \\
24 \\
25 \\
26 \\
27 \\
28 \\
29 \\
30 \\
31\end{array}$ & $\begin{array}{l}23 \\
21 \\
21 \\
21 \\
23 \\
20 \\
20 \\
20 \\
18 \\
17\end{array}$ & $\begin{array}{l}\overline{-} \\
\overline{-} \\
\overline{-} \\
\overline{-} \\
\overline{-} \\
\overline{-}\end{array}$ & $\begin{array}{l}\overline{-} \\
\overline{-} \\
\overline{-} \\
\overline{-} \\
\bar{m} \\
\overline{-}\end{array}$ \\
\hline $\begin{array}{l}\text { Mear } \\
\text { Run }\end{array}$ & $\begin{array}{l}\text { onth } \\
\text { i, ir }\end{array}$ & re-fe & , 11 & & & & & & $\begin{array}{r}19.2 \\
1,140 \\
\end{array}$ & $\begin{array}{r}636 \\
39,120 \\
\end{array}$ & $\begin{array}{r}140 \\
8,610 \\
\end{array}$ \\
\hline
\end{tabular}


Los Gatos Creek near Coalinga, Calif.

Location. - Lat. $36^{\circ} 13^{\prime}$, long. $120^{\circ} 27^{\prime}$, in SWl sec. 4, T. 20 S., R. 14 E., at mouth of canyon, 3 miles below Dlaz Creek, and $7 \frac{1}{2}$ mlles northwest of Coalinga, Fresno County. Altitude, about 1,000 feet above mean sea level. Drainage area.- 105 square miles.

Gage-he1ght record. - Water-stage recorder graph. Affected by variable drawdown of water level in well at high stages.

Stage-discharge relation. - Defined by current-meter measurements below 300 second-feet; extended to peak stage on basis of slope-area determination of flood flow. Shiftingcontrol method used for periods Nov. I to Dec. 10, Jan. 16-31. Rating curve changed at peak stage.

Maxima.-December 1937: Discharge, about 1,530 second-feet 9:30 a.m. Dec. 11 (gage helght, 5.1 feet, from floodmarks on bank; 4.58 feet, inside of well, affected by drawdown).

1931-November 1937: Discharge, about 1,050 second-feet Dec. 23, 1931 (gage height, 4.66 feet, Inside of well, present datum), from rating curve extended above 15 second-feet on basis of slope-area determination of flood flow.

January-September 1938: Discharge, about 4,520 second-feet Feb. II (gage height, 8.0 feet, from floodmarks on banks; 6.23 feet, inside of well, due to drawdown), from rating curve extended above 300 second-feet on basis of area-velocity study. Remarks. - Flood run-off not affected by artificlal storage or diversion.

Mean dally alscharge, in second-feet, November 1937 to January 1938

\begin{tabular}{|c|c|c|c||c|c|c|c||c|c|c|c|}
\hline Day & Nov. & Dec. & Jan. & Day & Nov. & Dec. & Jan. & Day & Nov. & Dec. & Jan. \\
\hline 1 & 0.2 & 0.3 & 0.5 & 11 & 0.2 & 349 & 0.5 & 21 & 0.3 & 0.5 & 31 \\
2 & .2 & .3 & .5 & 12 & .2 & 49 & .5 & 22 & .3 & .5 & 28 \\
3 & .2 & .3 & .6 & 13 & .2 & 31 & .5 & 23 & .3 & .6 & 24 \\
4 & .2 & .3 & .5 & 14 & .2 & 14 & .5 & 24 & .3 & .5 & 23 \\
5 & .2 & .3 & .5 & 15 & .2 & 7.5 & 22 & 25 & .3 & .5 & 21 \\
6 & .2 & .3 & .5 & 16 & .2 & 3.4 & 2.9 & 26 & .3 & .5 & 20 \\
7 & .2 & .3 & .5 & 17 & .3 & 1.6 & 33 & 27 & .3 & .5 & 20 \\
8 & .2 & .3 & .5 & 18 & .3 & 1.0 & 31 & 28 & .3 & .5 & 35 \\
9 & .2 & .6 & .5 & 19 & .3 & .6 & 37 & 29 & .3 & .5 & 53 \\
10 & .2 & .5 & .5 & 20 & .3 & .5 & 45 & 30 & .3 & .5 & 40 \\
&
\end{tabular}

Gage height, in feet, and discharge, In second-feet, at indicated time, 1937

\begin{tabular}{|c|c|c|c|c|c|c|c|c|c|c|c|c|}
\hline \multirow{2}{*}{ 总 } & Feet & Sec.ft. & Feet & Sec.ft. & Feet & Sec.ft. & Feet & Sec.et. & Feet & Sec.ft. & Foet & Sec.ft. \\
\hline & \multicolumn{2}{|c|}{ December 8} & \multicolumn{2}{|c|}{ December 9} & \multicolumn{2}{|c|}{ December 10} & \multicolumn{2}{|c|}{ December 11} & \multicolumn{2}{|c|}{ December 12} & \multicolumn{2}{|c|}{ December 13} \\
\hline 2 & - & - & - & - & - & - & 0.54 & 0.3 & 1.69 & 97 & & \\
\hline 4 & - & - & 0.57 & 0.3 & & - & .55 & .5 & 1.58 & 74 & & \\
\hline 6 & - & - & - & - & 0.56 & 0.6 & .75 & 4.9 & 1.51 & 60 & & \\
\hline 8 & - & - & .57 & .3 & - & - & 1.35 & 56 & 1.47 & 53 & & \\
\hline 10 & - & - & - & - & - & - & 4.50 & 1,460 & 1.43 & 45 & & \\
\hline $\mathrm{N}$ & 0.57 & 0.3 & .58 & .5 & .55 & .5 & 3.57 & 862 & 1.41 & 42 & & \\
\hline 2 & - & - & & & - & - & 3.67 & 912 & 1.39 & 38 & & \\
\hline 4 & - & - & .64 & 1.5 & - & - & 2.90 & 480 & 1.36 & 34 & & \\
\hline 6 & - & - & - & - & .53 & .3 & 2.35 & 265 & 2.33 & 30 & & \\
\hline 8 & - & - & .61 & 1.0 & - & - & 2.10 & 195 & 1.31 & 26 & & \\
\hline 10 & - & - & - & - & - & - & 1.93 & 152 & 1.30 & 25 & & \\
\hline M & .57 & .3 & .57 & .3 & .54 & .3 & 1.79 & 119 & 1.29 & 24 & & \\
\hline
\end{tabular}

Supplemental records.- Dec. 11, 9 a.m., 2.75 ft., 412 sec.-ft.; 9:30 a.m., 4.58 ft., 1,530 sec.-ft.; 3 p.m., $3.10 \mathrm{ft.,} 580$ sec. $-\mathrm{ft}$. 
San Jogquin River above Big Creek, Calif.

Location. - Lat. $37^{\circ} 15^{\circ} 00^{n}$, long. $119^{\circ} 19^{\prime} 10^{n}$, in Nwet sec. Il, T. 8 S., R. 24 E., 3 miles above mouth of Big Creek, Fresno County. Altitude, about 2,500 feet above mean sea level.

Drainage area.- 1,042 square miles.

Gage-height record. - Water-stage recorder graph.

Stage-discharge relation.- Defined by current-meter measurements below 16,000 secondfeet; extended to peak stage with aid of area-velocity study; verified by comparisor of peak flow and total run-off of flood with record for San Joaquin River near Friant.

Maxima,- December 1937: Discharge, 52,500 second-feet 3 p.m. Dec. 11 (gage height, 24.05 feet).

1922-November 1937: D1scharge, 18,000 second-feet June 5, 1922 (gage helght, 17.34 feet).

Remarks.- Flood run-off slightly affected by artificial storage. Most of basic data furmished by Southern Californis Edison Co., Ltd.

Mean daliy discharge, in second-feet, November 1937 to January 1938

\begin{tabular}{|c|c|c|c|c|c|c|c|c|c|c|c|}
\hline Dey & Nov. & Dec. & Jan. & Day & Nov. & Dec. & Jan. & Day & Nov. & Dec. & Jan. \\
\hline 1 & 106 & 130 & 427 & 11 & 119 & 31,700 & 365 & 21 & 159 & 655 & 534 \\
\hline 2 & 106 & 126 & 530 & 12 & 140 & 6,890 & 358 & 22 & 161 & 602 & 581 \\
\hline 3 & 104 & 130 & 555 & 13 & 117 & 2,440 & 348 & 23 & 144 & 610 & 543 \\
\hline 4 & 102 & 125 & 506 & 14 & 126 & 1,590 & 348 & 24 & 146 & 539 & 498 \\
\hline 5 & 101 & 121 & 474 & 15 & 142 & 1,280 & 678 & 25 & 150 & 502 & 506 \\
\hline 6 & 99 & 119 & 438 & 16 & 128 & 1,090 & 589 & 26 & 144 & 498 & 514 \\
\hline 7 & 102 & 119 & 427 & 17 & 177 & 985 & 745 & 27 & 144 & 482 & 526 \\
\hline 8 & 106 & 117 & 408 & 18 & 212 & 885 & 722 & 28 & 136 & 454 & 539 \\
\hline$\overline{9}$ & 104 & 158 & 379 & 19 & 157 & 790 & 655 & 29 & 134 & 442 & 589 \\
\hline 10 & 106 & 5,500 & 372 & 20 & 157 & 700 & 581 & 30 & 132 & 442 & 560 \\
\hline & & & & & & & & 31 & & 438 & 572 \\
\hline \multicolumn{9}{|c|}{ 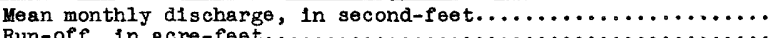 } & $7, \begin{array}{r}132 \\
760\end{array}$ & $\begin{array}{r}1,957 \\
120,300\end{array}$ & $\begin{array}{r}512 \\
31,470\end{array}$ \\
\hline
\end{tabular}

Gage helght, In feet, and discharge, in second-feet, at indicated time, 1937

\begin{tabular}{|c|c|c|c|c|c|c|c|c|c|c|c|c|}
\hline \multirow{2}{*}{ 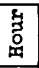 } & Feet & Sec.ft. & Feet & Sec.ft. & Feet & Sec.ft. & Feet & Sec.ft. & Feet & Sec.ft. & Feet & Sec.ft. \\
\hline & \multicolumn{2}{|c|}{ December 8} & \multicolumn{2}{|c|}{ December 9} & \multicolumn{2}{|c|}{ December 10} & \multicolumn{2}{|c|}{ December 11} & \multicolumn{2}{|c|}{ December 12} & \multicolumn{2}{|c|}{ December 13} \\
\hline \multirow[t]{2}{*}{$\begin{array}{r}2 \\
4 \\
6 \\
8 \\
10 \\
\mathrm{~N} \\
2 \\
4 \\
6 \\
8 \\
10 \\
\mathrm{M}\end{array}$} & $\begin{array}{l}6.93 \\
6.95 \\
6.96 \\
6.96 \\
6.95 \\
6.94 \\
6.93 \\
6.92 \\
6.91 \\
6.90 \\
6.90 \\
6.89\end{array}$ & $\begin{array}{l}117 \\
121 \\
123 \\
123 \\
121 \\
119 \\
117 \\
116 \\
114 \\
112 \\
112 \\
110\end{array}$ & $\begin{array}{l}6.92 \\
6.95 \\
6.96 \\
6.97 \\
6.96 \\
6.95 \\
6.95 \\
6.94 \\
7.01 \\
7.26 \\
7.68 \\
8.35\end{array}$ & $\begin{array}{l}116 \\
121 \\
123 \\
125 \\
123 \\
121 \\
121 \\
119 \\
132 \\
186 \\
300 \\
547\end{array}$ & $\begin{array}{r}9.07 \\
9.99 \\
11.92 \\
12.93 \\
13.68 \\
14.18 \\
14.43 \\
14.40 \\
14.46 \\
14.58 \\
14.32 \\
14.15\end{array}$ & $\begin{array}{r}878 \\
1,440 \\
3,070 \\
4,480 \\
6,010 \\
7,220 \\
7,870 \\
7,790 \\
7,950 \\
8,270 \\
7,580 \\
7,140\end{array}$ & $\begin{array}{l}14.44 \\
15.75 \\
17.50 \\
20.00 \\
22.65 \\
23.30 \\
23.95 \\
23.90 \\
22.90 \\
21.13 \\
19.22 \\
17.78\end{array}$ & $\begin{array}{r}7,890 \\
11,800 \\
18,200 \\
29,600 \\
44,100 \\
48,000 \\
52,200 \\
51,800 \\
44,800 \\
34,000 \\
24,100 \\
17,800\end{array}$ & $\begin{array}{l}16.62 \\
15.78 \\
15.11 \\
14.56 \\
14.12 \\
13.76 \\
13.44 \\
13.17 \\
12.93 \\
12.74 \\
12.59 \\
12.41\end{array}$ & $\begin{array}{r}13,400 \\
10,700 \\
8,750 \\
7,340 \\
6,340 \\
5,620 \\
5,020 \\
4,540 \\
4,160 \\
3,890 \\
3,680 \\
3,440\end{array}$ & $\begin{array}{l}12.21 \\
12.01 \\
11.83 \\
11.65 \\
11.49 \\
11.36 \\
11.23 \\
11.12 \\
11.00 \\
10.95 \\
10.93 \\
10.88\end{array}$ & $\begin{array}{l}3,210 \\
2,990 \\
2,810 \\
2,630 \\
2,480 \\
2,360 \\
2,250 \\
2,160 \\
2,060 \\
2,020 \\
2,000 \\
1,960\end{array}$ \\
\hline & \multicolumn{2}{|c|}{ De cember 14} & \multicolumn{2}{|c|}{ December 15} & \multicolumn{2}{|c|}{ December 16} & \multicolumn{2}{|c|}{ December 17} & \multicolumn{2}{|c|}{ December 18} & \multicolumn{2}{|c|}{ December 19} \\
\hline \multirow[t]{2}{*}{$\begin{array}{r}2 \\
4 \\
6 \\
8 \\
10 \\
N \\
2 \\
4 \\
6 \\
8 \\
10 \\
M\end{array}$} & $\begin{array}{l}10.78 \\
10.67 \\
10.55 \\
10.45 \\
10.37 \\
10.30 \\
10.25 \\
10.20 \\
10.15 \\
10.10 \\
10.10 \\
10.11\end{array}$ & $\begin{array}{l}1,890 \\
1,810 \\
1,720 \\
1,660 \\
1,610 \\
1,560 \\
1,530 \\
1,500 \\
1,460 \\
1,440 \\
1,440 \\
1,440\end{array}$ & $\begin{array}{r}10.10 \\
10.06 \\
10.01 \\
9.95 \\
9.90 \\
9.86 \\
9.82 \\
9.77 \\
9.74 \\
9.72 \\
9.70 \\
9.70\end{array}$ & $\begin{array}{l}1,440 \\
1,410 \\
1,380 \\
1,340 \\
1,320 \\
1,290 \\
1,270 \\
1,240 \\
1,220 \\
1,210 \\
1,200 \\
1,200\end{array}$ & $\begin{array}{l}9.68 \\
9.65 \\
9.62 \\
9.59 \\
9.55 \\
9.49 \\
9.43 \\
9.40 \\
9.36 \\
9.34 \\
9.34 \\
9.36\end{array}$ & $\begin{array}{l}1,190 \\
1,170 \\
1,160 \\
1,140 \\
1,120 \\
1,080 \\
1,050 \\
1,040 \\
1,020 \\
1,000 \\
1,000 \\
1,020\end{array}$ & $\begin{array}{l}9.40 \\
9.39 \\
9.37 \\
9.34 \\
9.31 \\
9.28 \\
9.25 \\
9.23 \\
9.21 \\
9.18 \\
9.17 \\
9.17\end{array}$ & $\begin{array}{r}1,040 \\
1,030 \\
1,020 \\
1,000 \\
990 \\
975 \\
960 \\
950 \\
940 \\
925 \\
920 \\
920\end{array}$ & $\begin{array}{l}9.19 \\
9.18 \\
9.17 \\
9.16 \\
9.14 \\
9.12 \\
9.09 \\
9.06 \\
9.01 \\
8.98 \\
8.99 \\
8.97\end{array}$ & $\begin{array}{l}930 \\
925 \\
920 \\
915 \\
905 \\
895 \\
880 \\
865 \\
840 \\
826 \\
830 \\
822\end{array}$ & $\begin{array}{l}9.03 \\
9.07 \\
9.05 \\
9.00 \\
8.95 \\
8.92 \\
8.86 \\
8.82 \\
8.76 \\
8.73 \\
8.72 \\
8.72\end{array}$ & \begin{tabular}{|l|}
850 \\
870 \\
860 \\
835 \\
812 \\
799 \\
772 \\
754 \\
727 \\
714 \\
709 \\
709 \\
\end{tabular} \\
\hline & \multicolumn{2}{|c|}{ December 20} & \multicolumn{2}{|c|}{ December 21} & \multicolumn{2}{|c|}{ December 22} & \multicolumn{2}{|c|}{ December 23} & \multicolumn{2}{|c|}{ December 24} & \multicolumn{2}{|c|}{ December 25} \\
\hline $\begin{array}{r}2 \\
4 \\
6 \\
8 \\
10 \\
\mathrm{~N} \\
2 \\
4 \\
6 \\
8 \\
10 \\
M\end{array}$ & $\begin{array}{l}8.79 \\
8.91 \\
8.90 \\
8.85 \\
8.78 \\
8.71 \\
8.65 \\
8.59 \\
8.54 \\
8.51 \\
8.49 \\
8.51\end{array}$ & $\begin{array}{l}740 \\
794 \\
790 \\
768 \\
736 \\
704 \\
678 \\
650 \\
628 \\
614 \\
606 \\
614\end{array}$ & $\begin{array}{l}8.55 \\
8.68 \\
8.77 \\
8.73 \\
8.67 \\
8.62 \\
8.58 \\
8.54 \\
8.51 \\
8.48 \\
8.48 \\
8.49\end{array}$ & $\begin{array}{l}632 \\
691 \\
732 \\
714 \\
686 \\
664 \\
646 \\
628 \\
612 \\
602 \\
602 \\
606\end{array}$ & $\begin{array}{l}8.52 \\
8.57 \\
8.62 \\
8.61 \\
8.57 \\
8.52 \\
8.47 \\
8.42 \\
8.37 \\
8.34 \\
8.33 \\
8.37\end{array}$ & $\begin{array}{l}619 \\
642 \\
664 \\
660 \\
642 \\
619 \\
597 \\
576 \\
555 \\
543 \\
539 \\
555\end{array}$ & $\begin{array}{l}8.46 \\
8.62 \\
8.72 \\
8.71 \\
8.67 \\
8.63 \\
8.54 \\
8.46 \\
8.40 \\
8.32 \\
8.27 \\
8.26\end{array}$ & $\begin{array}{l}593 \\
664 \\
709 \\
704 \\
686 \\
668 \\
628 \\
593 \\
568 \\
534 \\
514 \\
510\end{array}$ & $\begin{array}{l}8.30 \\
8.37 \\
8.44 \\
8.47 \\
8.46 \\
8.40 \\
8.35 \\
8.28 \\
8.24 \\
8.23 \\
8.22 \\
8.21\end{array}$ & $\begin{array}{l}526 \\
555 \\
585 \\
597 \\
593 \\
568 \\
547 \\
518 \\
502 \\
498 \\
494 \\
490\end{array}$ & $\begin{array}{l}8.22 \\
8.27 \\
8.33 \\
8.36 \\
8.32 \\
8.27 \\
8.21 \\
8.17 \\
8.15 \\
8.17 \\
8.18 \\
8.20\end{array}$ & \begin{tabular}{|l|}
494 \\
514 \\
539 \\
551 \\
534 \\
514 \\
490 \\
474 \\
466 \\
474 \\
478 \\
486
\end{tabular} \\
\hline
\end{tabular}

Supplementary records.- Dec. 11, 3 p.m., 24. 05 ft., 52,500 sec.-ft. 
San Joaquin River below Kerckhoff power house, Calif.

Location. - Lat. $37^{\circ} 05^{\prime}$, long. $119^{\circ} 34^{\prime}$, in SWl sec. 3, T. 10 S., R. 22 E., threequarters of a mile below Kerckhoff power house, Fresno County, and 2 miles above B1g Sandy Creek. Altitude, about 605 feet above mean sea level.

Dralnage area.- 1,480 square miles.

Gage-helght record.- Water-stage recorder graph prior to noon Dec. 11. Gage house destroyed by flood. Peak stage determined from floodmarks.

Stage-discharge relation. - Defined by current-meter measurements below 14,000 secondfeet; extended to peak stage with ald of area-velocity study; verified by peak discharge computed for flow over Kerckhoff Dam, 7 miles upstream, plus computed discharge through slufce gates at Kerckhoff power house.

Maxima.- December 1937: Discharge, 75,000 second-feet about $5 \mathrm{p} . \mathrm{m}$. Dec. 11 (gage height, 46.5 feet).

1936-November 1937: Discharge, 32,000 second-feet Feb. 6, 1937 (gage helght, 33.6 feet).

Remerks.- Flood mun-off affected by artificial storage in Florence, Huntington, and Shaver Lakes, and in Crane Valley Reservoir. Discharge for period from noon to midnight Dec. 11 based on comparison with records at Friant and Kerckhoff Dam. Discharge not determined for period Dec. 12 to Jan. 31.

Mean daily discharge, in second-feet, November 1937 to January 1938

\begin{tabular}{|c|c|c|c||c|c|c|c||c|c|c|c|}
\hline Day & Nov. & Dec. & Jan. & Day & Nov. & Dec. & Jan. & Day & Nov. & Dec. & Jan. \\
\hline 1 & 886 & 713 & - & 11 & 986 & 41,800 & - & 21 & 759 & - & - \\
2 & 1,060 & 665 & - & 12 & 1,060 & - & - & 22 & 962 & - & - \\
3 & 1,120 & 721 & - & 13 & 873 & - & - & 23 & 1,120 & - & - \\
4 & 1,100 & 620 & - & 14 & 691 & - & - & 24 & 1,090 & \pm & - \\
5 & 1,130 & 306 & - & 15 & 952 & - & - & 25 & 603 & - & - \\
6 & 1,080 & 907 & - & 16 & 689 & - & - & 26 & 618 & - & - \\
7 & 648 & 1,270 & - & 17 & 903 & - & - & 27 & 515 & - & $=$ \\
8 & 668 & 1,600 & - & 18 & 1,180 & - & - & 28 & 493 & - & - \\
9 & 1,110 & 760 & - & 19 & 1,090 & - & - & 29 & 597 & - & - \\
10 & 1,110 & 5,240 & - & 20 & 1,010 & - & - & 30 & 646 & - & - \\
\hline
\end{tabular}

Gage height, in feet, and discharge, in second-feet, at indicated time, 1937

\begin{tabular}{|c|c|c|c|c|c|c|c|c|c|c|c|c|}
\hline \multirow{2}{*}{ 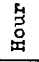 } & Feet & Sec.ft. & Feet & Sec.ft. & Feet & Sec.ft. & Feet & Sec.ft. & Feet & Sec.ft. & Feet & Sec.ft. \\
\hline & \multicolumn{2}{|c|}{ December 8} & \multicolumn{2}{|c|}{ December 9} & \multicolumn{2}{|c|}{ December 10} & \multicolumn{2}{|c|}{ December 11} & \multicolumn{2}{|c|}{ December 12} & \multicolumn{2}{|c|}{ December 13} \\
\hline 2 & 12.80 & 2,060 & 7.20 & 258 & 11.23 & 1,320 & 20.06 & 7,970 & & & & \\
\hline 4 & 13.50 & 2,460 & 10.00 & 890 & 10.80 & 1,160 & 19.75 & 7,620 & & & & \\
\hline 6 & 13.50 & 2,460 & 9.57 & 766 & 10.40 & 1,020 & 21.16 & 9,230 & & & & \\
\hline 8 & 13.88 & 2,690 & 8.62 & 530 & 10.00 & 890 & 25.20 & 15,000 & & & & \\
\hline 10 & 13.76 & 2,620 & 8.02 & 404 & 12.00 & 1,650 & 34.90 & 35,400 & & & & \\
\hline $\mathbf{N}$ & 12.79 & 2,050 & 7.60 & 324 & 12.00 & 1,650 & 44.50 & 67,000 & & & & \\
\hline 2 & 11.89 & 1,600 & 7.54 & 313 & 21.65 & 9,820 & - & 69,000 & & & & \\
\hline 4 & 10.42 & 1,030 & 9.00 & 620 & 23.05 & 11,800 & - & 74,000 & & & & \\
\hline 6 & 9.10 & 644 & 11.13 & 1,280 & 22.09 & 10,400 & - & 74,000 & & & & \\
\hline 8 & 7.94 & 388 & 11.07 & 1,260 & 21.50 & 9,640 & - & 68,000 & & & & \\
\hline 10 & 7.36 & 284 & 11.60 & 1,470 & 21.41 & 9,530 & - & 54,000 & & & & \\
\hline $\mathrm{M}$ & 7.33 & 279 & 11.72 & 1,520 & 20.85 & 8,860 & - & 39,000 & & & & \\
\hline
\end{tabular}

Supplemental records.- Dec. 11, about 5 p.m., 46.5 ft., 75,000 sec.-ft. 
San Joaquin River near Friant, Calif.

Location.- Lat. $3^{\circ} 00^{\prime} 32^{\prime \prime}$, long. $119^{\circ} 41^{\prime} 44^{\prime \prime}$, In NEt sec. 5, T. 11 S., R. 21 E., I mile above Cottonwood Creek' and 1 i miles northeast of Friant, Fresno County. Zero of gage is 315.03 feet above mean sea level.

Dralnage area. - 1,632 square miles.

Gage-helght record. - Water-stage recorder graph except for period Dec. 13 to Jan. 31 , when 1t was based on recorder graphs for stations on river below Friant and on Cottonwood Creek.

Stage-discharge relation. - Defined by current-meter measurementa below 25,000 secondfeet; extended to peak stage on basis of a drift-velocity measurement of 73,500 second-feet made 2 miles downstregm at station below Friant (negligible inflow); verified by area-velocity study. Rating curve changed at peak stage.

Maxima. - December 1937: Discharge, 77,200 second-feet 7 p.m. Dec. 11 (gage height, 23.8 feet).

1907-November 1937: Discharge, about 60,000 second-feet (revised) Jan. 25, 1914 (gage height, 21.72 feet), from rating curve extended above 13,000 second-feet on basis of rating curve for 1938.

Remarks. - Flood run-off affected by artificlal storage in Florence, Huntington, and Shaver Lakes, and in Crane Velley Reservoir. Discharge for period Dec. 13 to Jan. 31 computed from record of discharge for San Joaquin River below Friant, adjusted for flow of Cottonwood Creek. Part of basic data furnished by State of California, Division of Water Resources.

Mean daily discharge, in second-feet, November 1937 to January 1938

\begin{tabular}{|c|c|c|c|c|c|c|c|c|c|c|c|}
\hline Day & Nov. & Dec. & Jan. & Day & Nov. & Dec. & Jan. & Dey & Nov. & Dec. & Jan. \\
\hline $\begin{array}{r}1 \\
2 \\
3 \\
4 \\
5 \\
6 \\
7 \\
8 \\
9 \\
10\end{array}$ & $\begin{array}{r}890 \\
1,010 \\
1,070 \\
1,120 \\
1,070 \\
1,100 \\
794 \\
776 \\
1,060 \\
1,120\end{array}$ & $\begin{array}{r}726 \\
677 \\
698 \\
680 \\
452 \\
527 \\
1,360 \\
1,820 \\
524 \\
4,430\end{array}$ & $\begin{array}{r}988 \\
957 \\
1,400 \\
1,380 \\
1,270 \\
1,330 \\
1,220 \\
1,120 \\
1,040 \\
1,270\end{array}$ & $\begin{array}{l}11 \\
12 \\
13 \\
14 \\
15 \\
16 \\
17 \\
18 \\
19 \\
20\end{array}$ & $\begin{array}{r}1,030 \\
1,010 \\
1,000 \\
654 \\
877 \\
804 \\
673 \\
1,130 \\
1,120 \\
1,020\end{array}$ & $\begin{array}{r}37,900 \\
19,300 \\
5,100 \\
1,970 \\
2,070 \\
1,870 \\
1,530 \\
1,580 \\
1,370 \\
1,370\end{array}$ & & $\begin{array}{l}21 \\
22 \\
23 \\
24 \\
25 \\
26 \\
27 \\
28 \\
29 \\
30 \\
31\end{array}$ & $\begin{array}{r}830 \\
874 \\
1,120 \\
1,060 \\
778 \\
488 \\
640 \\
498 \\
526 \\
622\end{array}$ & $\begin{array}{r}1,460 \\
1,340 \\
1,340 \\
1,380 \\
896 \\
978 \\
1,310 \\
1,140 \\
1,310 \\
1,120 \\
1,170\end{array}$ & $\begin{array}{l}1,610 \\
1,570 \\
1,390 \\
1,260 \\
1,430 \\
1,430 \\
1,430 \\
1,460 \\
1,870 \\
1,560 \\
1,620\end{array}$ \\
\hline \multicolumn{12}{|c|}{ 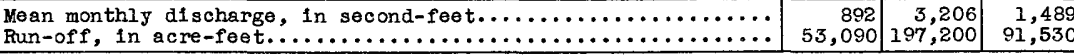 } \\
\hline
\end{tabular}

Gage height, in feet, and discharge, In second-feet, at indicated time, 1937

\begin{tabular}{|c|c|c|c|c|c|c|c|c|c|c|c|c|}
\hline \multirow{2}{*}{$\begin{array}{l}\text { gै } \\
\text { 号 }\end{array}$} & Feet & Sec.ft. & Feet & Sec.ft. & Feet & sec.ft. & Feet & sec.ft. & Feet & Sec.ft. & Feet & Sec.ft. \\
\hline & \multicolumn{2}{|c|}{ December 8} & \multicolumn{2}{|c|}{ December 9} & \multicolumn{2}{|c|}{ December 10} & \multicolumn{2}{|c|}{ December 11} & \multicolumn{2}{|c|}{ December 12} & \multicolumn{2}{|c|}{ December 13} \\
\hline \multirow[t]{2}{*}{$\begin{array}{r}2 \\
4 \\
6 \\
8 \\
10 \\
\mathrm{~N} \\
2 \\
4 \\
6 \\
8 \\
10 \\
\mathrm{M}\end{array}$} & $\begin{array}{l}5.30 \\
6.30 \\
6.42 \\
6.73 \\
7.06 \\
7.10 \\
7.33 \\
7.09 \\
6.57 \\
6.10 \\
5.42 \\
4.83\end{array}$ & $\begin{array}{r}1,050 \\
1,700 \\
1,800 \\
2,070 \\
2,380 \\
2,420 \\
2,650 \\
2,410 \\
1,920 \\
1,550 \\
1,120 \\
805\end{array}$ & $\begin{array}{l}4.36 \\
4.03 \\
3.78 \\
3.59 \\
3.53 \\
4.75 \\
4.55 \\
4.27 \\
4.06 \\
3.88 \\
3.80 \\
5.48\end{array}$ & $\begin{array}{r}594 \\
465 \\
375 \\
313 \\
295 \\
768 \\
678 \\
558 \\
476 \\
411 \\
382 \\
1,150\end{array}$ & $\begin{array}{r}5.69 \\
6.00 \\
6.08 \\
5.86 \\
5.78 \\
6.06 \\
6.62 \\
7.05 \\
11.43 \\
12.00 \\
11.75 \\
11.44\end{array}$ & $\begin{array}{r}1,270 \\
1,480 \\
1,540 \\
1,380 \\
1,330 \\
1,520 \\
1,970 \\
2,370 \\
10,700 \\
12,200 \\
11,500 \\
10,700\end{array}$ & $\begin{array}{l}11.33 \\
11.00 \\
10.72 \\
10.56 \\
11.35 \\
14.55 \\
20.88 \\
23.40 \\
23.62 \\
23.70 \\
23.10 \\
21.90\end{array}$ & $\begin{array}{r}10,400 \\
9,540 \\
8,810 \\
8,400 \\
10,400 \\
20,200 \\
55,000 \\
74,000 \\
75,600 \\
76,400 \\
71,200 \\
61,600\end{array}$ & $\begin{array}{l}19.26 \\
17.30 \\
15.60 \\
14.43 \\
13.43 \\
12.68 \\
12.10 \\
11.58 \\
11.18 \\
10.83 \\
10.54 \\
10.42\end{array}$ & $\begin{array}{r}43,000 \\
31,600 \\
23,800 \\
19,400 \\
16,000 \\
13,800 \\
12,100 \\
10,800 \\
9,720 \\
8,880 \\
8,190 \\
7,910\end{array}$ & & \\
\hline & \multicolumn{2}{|c|}{ December 14} & \multicolumn{2}{|c|}{ December 15} & \multicolumn{2}{|c|}{ December 16} & \multicolumn{2}{|c|}{ December 17} & \multicolumn{2}{|c|}{ December 18} & \multicolumn{2}{|c|}{ December 19} \\
\hline \multirow[t]{2}{*}{\begin{tabular}{r|}
2 \\
4 \\
6 \\
8 \\
10 \\
$N$ \\
2 \\
4 \\
6 \\
8 \\
10 \\
$M$ \\
\end{tabular}} & & & & & & & & & & & & \\
\hline & \multicolumn{2}{|c|}{ December 20} & \multicolumn{2}{|c|}{ December 21} & \multicolumn{2}{|c|}{ December 22} & \multicolumn{2}{|c|}{ December 23} & \multicolumn{2}{|c|}{ December 24} & \multicolumn{2}{|c|}{ December 25} \\
\hline $\begin{array}{r}2 \\
4 \\
6 \\
8 \\
10 \\
\mathrm{~N} \\
2 \\
4 \\
6 \\
8 \\
10 \\
\mathrm{M}\end{array}$ & & & & & & & & & & & & \\
\hline
\end{tabular}

Supplemental records.- Dec. 11, 7 p.m., 23.8 ft., 77,200 sec.-ft. 
San Joaquin River below Skaggs Bridge, Calif.

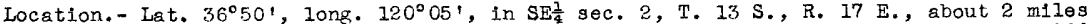
below Skaggs Bridge' and 7 miles west of Herndon, Fresno County. Alt1tude, about 200 feet above mean sea level.

Drainage area.- 1,760 square miles.

Gage-helght record. - Water-stage recorder graph.

Stage-discharge relation. - Defined by current-meter measurements to 26,000 second-feet; extended above. Rating curve changed at peak stage.

Maxima.- December 1937: Discharge, 55,000 second-feet 7 a.m. Dec. 12 (gage height, 20.90 feet).

Remarks.- Records furnished by State engineer.

Mean daily discharge, in second-feet, November 1937 to January 1938

\begin{tabular}{|c|c|c|c|c|c|c|c|c|c|c|c|}
\hline Day & Nov. & Dec. & Jan. & Day & Nov. & Dec. & Jan. & Day & Nov. & Dec. & Jan. \\
\hline $\begin{array}{r}1 \\
2 \\
3 \\
4 \\
5 \\
6 \\
7 \\
8 \\
9 \\
10\end{array}$ & $\begin{array}{r}921 \\
930 \\
1,050 \\
1,160 \\
1,150 \\
1,160 \\
1,150 \\
813 \\
930 \\
1,130\end{array}$ & $\begin{array}{r}653 \\
759 \\
714 \\
732 \\
705 \\
487 \\
593 \\
1,360 \\
1,780 \\
876\end{array}$ & $\begin{array}{l}1,300 \\
1,030 \\
1,150 \\
1,490 \\
1,460 \\
1,370 \\
1,430 \\
1,310 \\
1,180 \\
1,140\end{array}$ & $\begin{array}{l}11 \\
12 \\
13 \\
14 \\
15 \\
16 \\
17 \\
18 \\
19 \\
20\end{array}$ & $\begin{array}{r}1,190 \\
1,110 \\
1,150 \\
1,030 \\
786 \\
993 \\
831 \\
867 \\
1,240 \\
1,210\end{array}$ & $\begin{array}{r}5,920 \\
36,000 \\
9,450 \\
3,830 \\
2,520 \\
2,340 \\
2,130 \\
1,800 \\
1,800 \\
1,500\end{array}$ & $\begin{array}{l}1,300 \\
1,250 \\
1,240 \\
1,240 \\
1,660 \\
3,420 \\
2,160 \\
1,900 \\
2,080 \\
2,110\end{array}$ & $\begin{array}{l}21 \\
22 \\
23 \\
24 \\
25 \\
26 \\
27 \\
28 \\
29 \\
30 \\
31\end{array}$ & $\begin{array}{r}1,160 \\
948 \\
1,010 \\
1,240 \\
1,220 \\
858 \\
613 \\
653 \\
553 \\
580\end{array}$ & $\begin{array}{l}1,620 \\
1,560 \\
1,500 \\
1,460 \\
1,420 \\
1,020 \\
1,160 \\
1,370 \\
1,190 \\
1,370 \\
1,210\end{array}$ & $\begin{array}{l}1,840 \\
1,730 \\
1,600 \\
1,490 \\
1,390 \\
1,610 \\
1,550 \\
1,500 \\
1,800 \\
2,200 \\
1,820\end{array}$ \\
\hline $\begin{array}{l}\text { Mean } \\
\text { Run- }\end{array}$ & in & Cra & In $\mathrm{se}$ & ? & et & & & $\cdots$ & $\begin{array}{r}988 \\
58,780\end{array}$ & $\begin{array}{r}2,930 \\
180,200\end{array}$ & $\begin{array}{r}1,605 \\
98,720\end{array}$ \\
\hline
\end{tabular}

\begin{tabular}{|c|c|c|c|c|c|c|c|c|c|c|c|c|}
\hline \multirow{2}{*}{ 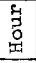 } & Feet & Sec.ft. & Feet & Sec.ft. & Feet & Sec.ft. & Feet & Sec.ft. & Feet & Sec.ft. & Feet & Sec.ft. \\
\hline & \multicolumn{2}{|c|}{ December 8} & \multicolumn{2}{|c|}{ December 9} & \multicolumn{2}{|c|}{ December 10} & \multicolumn{2}{|c|}{ December 11} & \multicolumn{2}{|c|}{ December 12} & \multicolumn{2}{|c|}{ December 13} \\
\hline \multirow[t]{2}{*}{$\begin{array}{r}2 \\
4 \\
6 \\
8 \\
10 \\
\mathrm{~N} \\
2 \\
4 \\
6 \\
8 \\
10 \\
\mathrm{M} \\
\end{array}$} & $\begin{array}{l}3.38 \\
3.43 \\
3.44 \\
3.41 \\
3.29 \\
3.12 \\
2.91 \\
2.75 \\
2.70 \\
2.82 \\
3.08 \\
3.38\end{array}$ & $\begin{array}{r}1,590 \\
1,640 \\
1,650 \\
1,620 \\
1,500 \\
1,340 \\
1,160 \\
1,010 \\
966 \\
1,070 \\
1,310 \\
1,590 \\
\end{array}$ & $\begin{array}{l}3.65 \\
3.87 \\
4.02 \\
4.05 \\
4.00 \\
3.84 \\
3.65 \\
3.45 \\
3.25 \\
3.06 \\
2.90 \\
2.75\end{array}$ & $\begin{array}{l}1,850 \\
2,080 \\
2,230 \\
2,260 \\
2,210 \\
2,050 \\
1,850 \\
1,660 \\
1,460 \\
1,290 \\
1,150 \\
1,010\end{array}$ & $\begin{array}{l}2.61 \\
2.52 \\
2.50 \\
2.52 \\
2.55 \\
2.52 \\
2.46 \\
2.42 \\
2.50 \\
2.72 \\
2.97 \\
3.13\end{array}$ & $\begin{array}{r}885 \\
804 \\
786 \\
804 \\
831 \\
804 \\
750 \\
714 \\
786 \\
984 \\
1,210 \\
1,350 \\
\end{array}$ & $\begin{array}{r}3.22 \\
3.30 \\
3.57 \\
4.50 \\
6.00 \\
7.07 \\
7.98 \\
8.45 \\
8.67 \\
8.74 \\
8.90 \\
10.30\end{array}$ & $\begin{array}{r}1,440 \\
1,510 \\
1,770 \\
2,750 \\
4,680 \\
6,390 \\
8,000 \\
8,890 \\
9,320 \\
9,470 \\
9,790 \\
12,900\end{array}$ & $\begin{array}{l}13.80 \\
19.10 \\
20.80 \\
20.87 \\
20.20 \\
19.05 \\
18.00 \\
16.50 \\
15.00 \\
14.00 \\
13.00 \\
12.10\end{array}$ & $\begin{array}{l}22,800 \\
45,500 \\
54,000 \\
55,000 \\
52,000 \\
45,000 \\
39,500 \\
32,700 \\
27,000 \\
23,500 \\
20,300 \\
17,400\end{array}$ & $\begin{array}{r}11.25 \\
10.45 \\
9.78 \\
9.10 \\
8.60 \\
8.24 \\
7.90 \\
7.62 \\
7.28 \\
6.98 \\
6.71 \\
6.57\end{array}$ & $\begin{array}{r}15,100 \\
13,200 \\
11,700 \\
10,200 \\
9,180 \\
8,490 \\
7,850 \\
7,350 \\
6,740 \\
6,230 \\
5,790 \\
5,560 \\
\end{array}$ \\
\hline & \multicolumn{2}{|c|}{ December 14} & \multicolumn{2}{|c|}{ December 15} & \multicolumn{2}{|c|}{ December 16} & \multicolumn{2}{|c|}{ December 17} & \multicolumn{2}{|c|}{ December 18} & \multicolumn{2}{|c|}{ December 19} \\
\hline \multirow[t]{2}{*}{$\begin{array}{r}2 \\
4 \\
6 \\
8 \\
10 \\
N \\
2 \\
4 \\
6 \\
8 \\
10 \\
M \\
\end{array}$} & $\begin{array}{l}6.47 \\
6.33 \\
6.12 \\
5.80 \\
5.50 \\
5.23 \\
4.97 \\
4.75 \\
4.55 \\
4.42 \\
4.36 \\
4.32\end{array}$ & $\begin{array}{l}5,400 \\
5,180 \\
4,860 \\
4,400 \\
3,980 \\
3,620 \\
3,300 \\
3,040 \\
2,800 \\
2,660 \\
2,590 \\
2,550\end{array}$ & $\begin{array}{l}4.29 \\
4.25 \\
4.22 \\
4.21 \\
4.23 \\
4.30 \\
4.35 \\
4.34 \\
4.34 \\
4.32 \\
4.29 \\
4.25\end{array}$ & $\begin{array}{l}2,520 \\
2,470 \\
2,440 \\
2,430 \\
2,450 \\
2,530 \\
2,580 \\
2,570 \\
2,570 \\
2,550 \\
2,520 \\
2,470\end{array}$ & $\begin{array}{l}4.20 \\
4.18 \\
4.16 \\
4.15 \\
4.15 \\
4.13 \\
4.11 \\
4.10 \\
4.09 \\
4.08 \\
4.05 \\
4.02\end{array}$ & $\begin{array}{l}2,420 \\
2,400 \\
2,380 \\
2,370 \\
2,370 \\
2,340 \\
2,320 \\
2,310 \\
2,300 \\
2,290 \\
2,260 \\
2,230\end{array}$ & $\begin{array}{l}4.00 \\
3.98 \\
3.96 \\
3.95 \\
3.94 \\
3.92 \\
3.91 \\
3.91 \\
3.89 \\
3.87 \\
3.82 \\
3.74\end{array}$ & $\begin{array}{l}2,210 \\
2,190 \\
2,170 \\
2,160 \\
2,150 \\
2,130 \\
2,120 \\
2,120 \\
2,100 \\
2,080 \\
2,020 \\
1,940\end{array}$ & $\begin{array}{l}3.60 \\
3.48 \\
3.40 \\
3.40 \\
3.48 \\
3.57 \\
3.63 \\
3.70 \\
3.74 \\
3.75 \\
3.75 \\
3.72\end{array}$ & $\begin{array}{l}1,800 \\
1,680 \\
1,610 \\
1,610 \\
1,680 \\
1,770 \\
1,830 \\
1,900 \\
1,940 \\
1,950 \\
1,950 \\
1,920\end{array}$ & $\begin{array}{l}3.62 \\
3.52 \\
3.43 \\
3.40 \\
3.43 \\
3.53 \\
3.63 \\
3.70 \\
3.73 \\
3.74 \\
3.72 \\
3.66\end{array}$ & $\begin{array}{l}1,820 \\
1,720 \\
1,640 \\
1,610 \\
1,640 \\
1,730 \\
1,830 \\
1,900 \\
1,930 \\
1,940 \\
1,920 \\
1,860\end{array}$ \\
\hline & \multicolumn{2}{|c|}{ December 20} & \multicolumn{2}{|c|}{ December 21} & \multicolumn{2}{|c|}{ December 22} & \multicolumn{2}{|c|}{ December 23} & \multicolumn{2}{|c|}{ December 24} & \multicolumn{2}{|c|}{ December 25} \\
\hline $\begin{array}{r}2 \\
4 \\
6 \\
8 \\
10 \\
\mathrm{~N} \\
2 \\
4 \\
6 \\
8 \\
10 \\
\mathbf{M}\end{array}$ & $\begin{array}{l}3.57 \\
3.43 \\
3.27 \\
3.15 \\
3.08 \\
3.09 \\
3.18 \\
3.26 \\
3.32 \\
3.35 \\
3.35 \\
3.32\end{array}$ & $\begin{array}{l}1,770 \\
1,640 \\
1,480 \\
1,370 \\
1,310 \\
1,320 \\
1,400 \\
1,480 \\
1,540 \\
1,560 \\
1,560 \\
1,530\end{array}$ & $\begin{array}{l}3.27 \\
3.23 \\
3.20 \\
3.21 \\
3.28 \\
3.47 \\
3.57 \\
3.62 \\
3.63 \\
3.59 \\
3.53 \\
3.45\end{array}$ & $\begin{array}{l}1,480 \\
1,450 \\
1,420 \\
1,430 \\
1,490 \\
1,670 \\
1,770 \\
1,820 \\
1,830 \\
1,790 \\
1,730 \\
1,660\end{array}$ & $\begin{array}{l}3.37 \\
3.27 \\
3.20 \\
3.18 \\
3.29 \\
3.38 \\
3.45 \\
3.49 \\
3.49 \\
3.43 \\
3.35 \\
3.27\end{array}$ & $\begin{array}{l}1,580 \\
1,480 \\
1,420 \\
1,400 \\
1,500 \\
1,590 \\
1,660 \\
1,690 \\
1,690 \\
1,640 \\
1,560 \\
1,480\end{array}$ & $\begin{array}{l}3.22 \\
3.18 \\
3.17 \\
3.17 \\
3.20 \\
3.28 \\
3.35 \\
3.42 \\
3.45 \\
3.44 \\
3.37 \\
3.29\end{array}$ & $\begin{array}{l}1,440 \\
1,400 \\
1,390 \\
1,390 \\
1,420 \\
1,490 \\
1,560 \\
1,630 \\
1,660 \\
1,650 \\
1,580 \\
1,500\end{array}$ & $\begin{array}{l}3.21 \\
3.15 \\
3.10 \\
3.08 \\
3.14 \\
3.22 \\
3.31 \\
3.37 \\
3.42 \\
3.42 \\
3.34 \\
3.25\end{array}$ & $\begin{array}{l}1,430 \\
1,370 \\
1,330 \\
1,310 \\
1,360 \\
1,440 \\
1,520 \\
1,580 \\
1,630 \\
1,630 \\
1,550 \\
1,460\end{array}$ & $\begin{array}{l}3.19 \\
3.14 \\
3.12 \\
3.12 \\
3.17 \\
3.25 \\
3.31 \\
3.33 \\
3.27 \\
3.17 \\
3.08 \\
3.00\end{array}$ & $\begin{array}{l}1,420 \\
1,370 \\
1,350 \\
1,350 \\
1,400 \\
1,480 \\
1,530 \\
1,550 \\
1,490 \\
1,400 \\
1,320 \\
1,240\end{array}$ \\
\hline
\end{tabular}

Supplemental records.- I c. 12,7 a.m., $20.90 \mathrm{ft} ., 55,000$ sec.-ft. 
San Joaquin River near Newman, Calif.

Location. - Lat. $37^{\circ} 21^{1} 02^{n}$, long. $120^{\circ} 58^{\prime} 34^{n}$, in Sw/ sec. 3, T. 7 S., R. 9 E. , at highWhy bridge on Hills Ferry road, 300 feet below mouth of Merced River and $3 \frac{1}{2}$ miles northeast of Newman, Stanislaus County. Zero of gage is 51.0 feet (datum of Corps of Engineers, U. S. Army).

Drainage area.- 9,990 square miles.

Gage-helght record. - Water-stage recorder graph.

Stage-discharge relation. - Defined by current-meter measurements for entire range of stage.

Maxima.- December 1937: Discharge, 6,050 second-feet morning Dec. 24 (gage height, 11. 41 feet).

1912-November 1937: Discharge observed (unregulated), 20,700 second-feet (main channel only) Jan. 27, 1914 (gage helght, 18.0 feet), from rating curve extended above 12,400 second-feet.

January-September 1938: Discharge 33,000 second-feet 12:30 a.m. Mar. 7 (gage helght, 18.50 feet), from rating curve extended above 32,000 second-feet.

Remarks. - Flood run-off very materlally affected by storage in Lake McClure and other storage reservolrs and by natural channel storage.

Mean da1ly discharge, in second-feet, November 1937 to January 1938

\begin{tabular}{|c|c|c|c|c|c|c|c|c|c|c|c|}
\hline Day & Nov. & Dec. & Jan. & Dey & Nov. & Dec. & Jan. & Day & Nov. & Dec. & Jan. \\
\hline $\begin{array}{r}1 \\
2 \\
3 \\
4 \\
5 \\
6 \\
7 \\
8 \\
9 \\
10\end{array}$ & $\begin{array}{l}314 \\
304 \\
294 \\
289 \\
282 \\
277 \\
277 \\
279 \\
286 \\
289\end{array}$ & $\begin{array}{l}466 \\
466 \\
483 \\
483 \\
434 \\
434 \\
450 \\
466 \\
483 \\
606\end{array}$ & $\begin{array}{l}3,720 \\
3,640 \\
3,640 \\
3,560 \\
3,400 \\
3,330 \\
3,260 \\
3,330 \\
3,120 \\
3,190\end{array}$ & $\begin{array}{l}11 \\
12 \\
13 \\
14 \\
15 \\
16 \\
17 \\
18 \\
19 \\
20\end{array}$ & $\begin{array}{l}296 \\
299 \\
294 \\
284 \\
279 \\
274 \\
282 \\
294 \\
327 \\
419\end{array}$ & $\begin{array}{r}780 \\
960 \\
1,320 \\
2,100 \\
2,700 \\
3,190 \\
3,560 \\
4,040 \\
4,390 \\
4,840\end{array}$ & $\begin{array}{l}3,330 \\
3,330 \\
3,120 \\
3,050 \\
3,050 \\
3,560 \\
3,880 \\
4,120 \\
4,480 \\
4,840\end{array}$ & $\begin{array}{l}21 \\
22 \\
23 \\
24 \\
25 \\
26 \\
27 \\
28 \\
29 \\
30 \\
31\end{array}$ & $\begin{array}{l}450 \\
434 \\
466 \\
500 \\
517 \\
517 \\
483 \\
434 \\
434 \\
434\end{array}$ & $\begin{array}{l}5,380 \\
5,750 \\
5,950 \\
6,050 \\
5,850 \\
5,290 \\
4,750 \\
4,390 \\
4,120 \\
3,880 \\
3,720\end{array}$ & $\begin{array}{l}5,020 \\
4,930 \\
4,840 \\
4,660 \\
4,480 \\
4,210 \\
3,960 \\
3,800 \\
3,640 \\
3,720 \\
3,640\end{array}$ \\
\hline \multicolumn{9}{|c|}{ 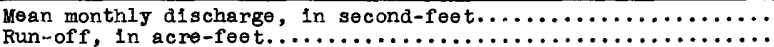 } & $\begin{array}{r}354 \\
21,040\end{array}$ & $\begin{array}{r}2,832 \\
174,100\end{array}$ & $\begin{array}{r}3,802 \\
233,800\end{array}$ \\
\hline
\end{tabular}

Gage helght, in feet, and dscharge, in second-feet, at indicated time, 1937

\begin{tabular}{|c|c|c|c|c|c|c|c|c|c|c|c|c|}
\hline \multirow{2}{*}{$\begin{array}{l}5 \\
\text { 总 } \\
\end{array}$} & Feet & Sec.ft. & Feet & Sec.ft. & Feet & Sec.ft. & Feet & Sec.ft. & Feet & Sec.ft. & Feet & Sec.ft. \\
\hline & \multicolumn{2}{|c|}{ December 8} & \multicolumn{2}{|c|}{ December 9} & \multicolumn{2}{|c|}{ December 10} & \multicolumn{2}{|c|}{ De cember 11} & \multicolumn{2}{|c|}{ December 12} & \multicolumn{2}{|c|}{ December 13} \\
\hline 2 & - & - & - & - & - & - & - & - & - & - & - & - \\
\hline 4 & - & - & - & - & 3.06 & 556 & 3.51 & 724 & 3.95 & 900 & 4.41 & 1,090 \\
\hline 6 & - & - & 2.83 & 476 & & - & - & - & & & & - \\
\hline 8 & - & - & - & - & 3.14 & 584 & 3.61 & 764 & 4.02 & 928 & 4.55 & 1,160 \\
\hline 10 & 2.79 & $\overline{463}$ & -8 & $\overline{483}$ & -720 & $\overline{60}$ & - & $\overline{788}$ & 4.09 & $\bar{g}_{56}$ & 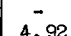 & $\overline{320}$ \\
\hline $\begin{array}{l}\mathrm{N} \\
2\end{array}$ & 2.79 & $\begin{array}{c}463 \\
-\end{array}$ & 2.85 & 483 & 3.20 & 606 & $\begin{array}{l}3.67 \\
-\end{array}$ & 788 & $\begin{array}{l}4.09 \\
-\end{array}$ & 956 & $\begin{array}{l}4.92 \\
-\end{array}$ & 1,320 \\
\hline 4 & - & - & - & - & 3.26 & 629 & 3.74 & 816 & 4.15 & 980 & 5.18 & $1, \overline{450}$ \\
\hline 6 & - & - & 2.92 & 507 & - & - & - & - & - & - & - & - \\
\hline 8 & - & - & - & - & 3.32 & 652 & 3.81 & 844 & 4.20 & 1,000 & 5.47 & 1,600 \\
\hline \multirow{3}{*}{$\begin{array}{r}10 \\
\text { M }\end{array}$} & 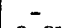 & & - & - & & - & & - & & & & \\
\hline & 2.81 & 469 & 2.99 & 531 & 3.40 & 682 & 3.89 & 876 & 4.27 & 1,030 & 5.77 & 1,740 \\
\hline & \multicolumn{2}{|c|}{ December 14} & \multicolumn{2}{|c|}{ December 15} & \multicolumn{2}{|c|}{ December 16} & \multicolumn{2}{|c|}{ December 17} & \multicolumn{2}{|c|}{ December 18} & \multicolumn{2}{|c|}{ December 19} \\
\hline 2 & - & - & - & - & - & - & - & - & - & - & - & - \\
\hline 4 & 6.03 & 1,880 & 7.12 & 2,530 & 7.84 & 3,010 & - & - & - & - & - & - \\
\hline 6 & - & - & - & - & - & - & 8.51 & 3,490 & 9.04 & 3,910 & 9.51 & 4,310 \\
\hline 8 & 6.27 & 2,020 & 7.25 & 2,610 & 7.95 & 3,080 & - & - & - & - & - & - \\
\hline 10 & & - ico & - & - & 0 & $=5$ & $\therefore$ & $=$ & - & - & - & - \\
\hline $\begin{array}{l}N \\
2\end{array}$ & 6.50 & 160 & 7.40 & 2,700 & 8.08 & 3,180 & $\begin{array}{l}8.62 \\
-\end{array}$ & 3,580 & 9.18 & 4,020 & 9.65 & $\begin{array}{c}4,440 \\
-\end{array}$ \\
\hline 4 & 6.66 & 2,260 & 7.52 & 2,780 & 8.19 & 3,250 & - & - & - & - & - & - \\
\hline 6 & & - & - & - & - & - & 8.76 & 3,690 & 8.30 & 4,120 & 8.77 & 4,540 \\
\hline $\mathbf{s}$ & 6.81 & 2,350 & 7.64 & 2,870 & 8.29 & 3,320 & - & & & - & - & \\
\hline \multirow{3}{*}{$\begin{array}{r}10 \\
\mathrm{M}\end{array}$} & & - & - & ${ }^{-7}$ & - & $=\overline{-}$ & & & - & Ean & - & - \\
\hline & 6.98 & 2,450 & 7.74 & 2,940 & 8.37 & 3,380 & 8.91 & 3,810 & 8.41 & 4,220 & 9.90 & 4,660 \\
\hline & \multicolumn{2}{|c|}{ December 20} & \multicolumn{2}{|c|}{ December 21} & \multicolumn{2}{|c|}{ December 22} & \multicolumn{2}{|c|}{ December 23} & \multicolumn{2}{|c|}{ December 24} & \multicolumn{2}{|c|}{ December 25} \\
\hline 2 & - & - & - & - & - & - & - & - & - & - & - & - \\
\hline 4 & - & $-\infty$ & - & 5 & & -1 & & $=-7$ & & & & \\
\hline $\begin{array}{l}6 \\
8\end{array}$ & 10.02 & $\begin{array}{c}4,770 \\
-\end{array}$ & 10.57 & 5,260 & 11.04 & 5,690 & 11.28 & 5,930 & 11.41 & 6,050 & 11.29 & $\begin{array}{c}5,940 \\
-\end{array}$ \\
\hline 10 & $\sim$ & - & - & - & - & - & - & - & - & - & - & - \\
\hline $\mathbf{N}$ & 10.14 & 4,880 & 10.71 & 5,390 & 11.12 & 5,770 & 11.31 & 5,960 & 11.40 & 6,050 & 11.16 & 5,810 \\
\hline $\begin{array}{l}2 \\
4\end{array}$ & $\overline{-}$ & - & - & - & & & - & - & $=$ & - & $=$ & $=$ \\
\hline 6 & 10.28 & 5,000 & 10.82 & 5,490 & 11.20 & 5,850 & 11.33 & 5,980 & 11.37 & $6, \overline{020}$ & 11.01 & 5,660 \\
\hline $\begin{array}{r}8 \\
10\end{array}$ & - & $=$ & $=$ & $\overline{-}$ & $\overline{-}$ & $\overline{-}$ & $=$ & - & $=$ & $=$ & $=$ & - \\
\hline M & 10.43 & 5,140 & 10.95 & 5,600 & 11.26 & 5,910 & 11.38 & 6,030 & 11.34 & 5,990 & 10.91 & 5,570 \\
\hline
\end{tabular}


San Joaquin River near Vernalis, Calif.

Location. - Lat. $37^{\circ} 40^{\prime} 34^{\prime \prime}$, long. $121^{\circ} 15^{\prime} 51^{\prime \prime}$, in El Pescadero grant, at Durham Ferry highway bridge, 3 miles below Stanis laus River and $3 \frac{1}{2}$ miles northeast of Vernalis, San Joaquin County. Alt1tude, about 10 feet above mean sea level. Drainage area.- 14,010 square miles.

Gage-helght record. - Water-stage recorder graph.

Stage-discharge relation.- Defined by current-meter measurements. Shifting control method used during November.

Maxima.- December 1937: Discharge, 7,960 second-feet 2 to 4 a.m. Dec. 26 (gage helght, 14.36 feet).

1922-November 1937: Discharge, 28,700 second-feet Feb. 25, 1936 (gage he1ght, 25.47 feet), from rating curve for 1937.

January-September 1938: Discharge, 51,200 second-feet 1 a.m. Mar. I6 (gage helght, 26.64 feet). Peak discharge includes measured flow through levee break on right bank of Stanislaus River, 500 feet upstream from junction with San Joaquin River and about 3 miles upstream from gaging station.

Remarks. - Flood run-off very materially affected by artificial storage in Hetch Hetchy, Don Pedro, and Melones Reservoirs and Lake McClure. Many irrigation diversions above station.

Mean daily discharge, in second-feet, November 1937 to January 1938

\begin{tabular}{|c|c|c|c|c|c|c|c|c|c|c|c|}
\hline Day & Nov. & Dec. & Jan. & Day & Nov. & Dec. & Jan. & Day & Nov. & Dec. & Jan. \\
\hline $\begin{array}{r}1 \\
2 \\
3 \\
4 \\
5 \\
6 \\
7 \\
8 \\
9 \\
10\end{array}$ & $\begin{array}{l}1,720 \\
1,720 \\
1,860 \\
1,900 \\
1,900 \\
1,900 \\
1,930 \\
1,930 \\
1,860 \\
1,930\end{array}$ & $\begin{array}{l}2,140 \\
2,210 \\
2,210 \\
2,210 \\
2,210 \\
2,280 \\
2,280 \\
2,210 \\
2,210 \\
2,280\end{array}$ & $\begin{array}{l}6,460 \\
6,170 \\
5,720 \\
5,540 \\
5,810 \\
5,810 \\
5,630 \\
5,630 \\
5,540 \\
5,270\end{array}$ & $\begin{array}{l}11 \\
12 \\
13 \\
14 \\
15 \\
16 \\
17 \\
18 \\
19 \\
20\end{array}$ & $\begin{array}{l}1,930 \\
1,930 \\
1,930 \\
1,960 \\
1,930 \\
1,960 \\
1,930 \\
1,960 \\
1,960 \\
2,000\end{array}$ & $\begin{array}{l}7,420 \\
3,260 \\
5,360 \\
6,460 \\
7,060 \\
7,060 \\
7,160 \\
7,260 \\
7,260 \\
7,260\end{array}$ & $\begin{array}{l}5,090 \\
5,270 \\
5,270 \\
5,270 \\
5,180 \\
5,360 \\
5,540 \\
5,720 \\
6,080 \\
6,660\end{array}$ & $\begin{array}{l}21 \\
22 \\
23 \\
24 \\
25 \\
26 \\
27 \\
28 \\
29 \\
30 \\
31\end{array}$ & $\begin{array}{l}2,070 \\
2,140 \\
2,070 \\
2,140 \\
2,210 \\
2,210 \\
2,140 \\
2,140 \\
2,140 \\
2,070\end{array}$ & $\begin{array}{l}7,160 \\
7,460 \\
7,660 \\
7,860 \\
7,860 \\
7,860 \\
7,660 \\
7,360 \\
7,260 \\
6,960 \\
6,660\end{array}$ & $\begin{array}{l}7,160 \\
7,460 \\
7,360 \\
7,160 \\
6,960 \\
7,360 \\
7,360 \\
7,260 \\
7,060 \\
6,860 \\
7,160\end{array}$ \\
\hline \multicolumn{9}{|c|}{ 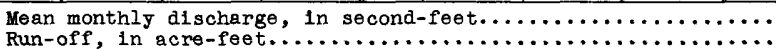 } & $\begin{array}{r}1,979 \\
117,800\end{array}$ & $\begin{array}{r}5,308 \\
326,400\end{array}$ & $\begin{array}{r}6,199 \\
381,200\end{array}$ \\
\hline
\end{tabular}

Gage helght, in feet, and discharge, in second-feet, at indicated time, 1937

\begin{tabular}{|c|c|c|c|c|c|c|c|c|c|c|c|c|}
\hline \multirow{2}{*}{ 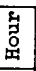 } & Feet & Sec.ft. & Feet & Sec.ft. & Feet & Sec.ft. & Feet & Sec.ft. & Feet & Sec.ft. & Feet & Sec.ft. \\
\hline & \multicolumn{2}{|c|}{ December 8} & \multicolumn{2}{|c|}{ December 9} & \multicolumn{2}{|c|}{ December 10} & \multicolumn{2}{|c|}{ December 11} & \multicolumn{2}{|c|}{ December 12} & \multicolumn{2}{|c|}{ December 13} \\
\hline \begin{tabular}{r|}
2 \\
4 \\
6 \\
8 \\
10 \\
$\mathrm{~N}$ \\
2 \\
4 \\
6 \\
8 \\
10 \\
$\mathrm{M}$
\end{tabular} & $\begin{array}{c}- \\
\overline{7.80} \\
- \\
- \\
7.80 \\
- \\
\overline{7.71} \\
\overline{-} \\
7.71\end{array}$ & $\begin{array}{c}\overline{-} \\
2, \overline{2} 10 \\
\overline{-} \\
2, \overline{2} 10 \\
\overline{-} \\
2, \overline{150} \\
\overline{-} \\
2, \overline{150}\end{array}$ & $\begin{array}{c}\overline{-} \\
\overline{7.80} \\
\overline{-} \\
\overline{7.83} \\
\overline{-} \\
\overline{7.76} \\
\overline{-} \\
\overline{7.77}\end{array}$ & $\begin{array}{c}\overline{-} \\
2, \overline{2} 10 \\
\overline{-} \\
2, \overline{2} 30 \\
\overline{-} \\
2, \overline{1} 80 \\
\overline{-} \\
2, \overline{1} 90\end{array}$ & $\begin{array}{c}\overline{-} \\
7.92 \\
\overline{-} \\
7.95 \\
\overline{-} \\
7.89 \\
\overline{-} \\
7.94\end{array}$ & $\begin{array}{c}\overline{-} \\
2, \overline{2} 90 \\
\overline{-} \\
2, \overline{3} 20 \\
\overline{-} \\
2, \overline{2} 70 \\
\overline{-} \\
2, \overline{3} 10\end{array}$ & $\begin{array}{l}8 \overline{0} 05 \\
\overline{-} \\
-14 \\
8.15 \\
\overline{8.14} \\
\overline{8.23} \\
\overline{8.43}\end{array}$ & $\begin{array}{c}2, \overline{3} 80 \\
\overline{2}, \overline{450} \\
\overline{4} \\
2, \overline{4} 60 \\
2, \overline{450} \\
2, \overline{5} 10 \\
\overline{-} \\
2, \overline{6} 50\end{array}$ & $\begin{array}{r}8.55 \\
8.65 \\
8.75 \\
8.85 \\
9.00 \\
9.14 \\
9.27 \\
9.45 \\
9.68 \\
9.95 \\
10.23 \\
10.50\end{array}$ & $\begin{array}{l}2,740 \\
2,820 \\
2,900 \\
2,980 \\
3,100 \\
3,210 \\
3,320 \\
3,460 \\
3,640 \\
3,860 \\
4,080 \\
4,300\end{array}$ & $\begin{array}{l}10.76 \\
11.06 \\
11.30 \\
11.51 \\
11.70 \\
11.85 \\
11.99 \\
12.10 \\
12.23 \\
12.33 \\
12.44 \\
12.53 \\
\end{array}$ & $\begin{array}{l}4,510 \\
4,780 \\
5,000 \\
5,190 \\
5,360 \\
5,500 \\
5,620 \\
5,720 \\
5,840 \\
5,930 \\
6,030 \\
6,110\end{array}$ \\
\hline & \multicolumn{2}{|c|}{ December 14} & \multicolumn{2}{|c|}{ December 15} & \multicolumn{2}{|c|}{ December 16} & \multicolumn{2}{|c|}{ December 17} & \multicolumn{2}{|c|}{ December 18} & \multicolumn{2}{|c|}{ December 19} \\
\hline $\begin{array}{r}2 \\
4 \\
6 \\
8 \\
10 \\
\mathrm{~N} \\
2 \\
4 \\
6 \\
8 \\
10 \\
\mathrm{M}\end{array}$ & $\begin{array}{c}- \\
12.67 \\
- \\
12.75 \\
- \\
12.83 \\
12.96 \\
- \\
13.12 \\
- \\
13.31\end{array}$ & $\begin{array}{l}6, \overline{2} \\
\overline{-} \\
6, \overline{3} 10 \\
6, \overline{3} 90 \\
6, \overline{5} 20 \\
6, \overline{6} 80 \\
6, \overline{870}\end{array}$ & $\begin{array}{c}13.45 \\
- \\
13.52 \\
- \\
13.55 \\
- \\
13.57 \\
- \\
13.60 \\
- \\
13.60\end{array}$ & $\begin{array}{l}7, \overline{0} 10 \\
7, \overline{0} \\
\overline{-} \\
710 \\
7, \overline{1} 30 \\
7, \overline{1} 60 \\
7, \overline{1}\end{array}$ & $\begin{array}{c}\overline{-} \\
\overline{-} \\
13.51 \\
- \\
\overline{-} \\
13.40\end{array}$ & $\begin{array}{c}\overline{-} \\
7, \overline{0} 70 \\
\overline{-} \\
6, \overline{9} 60 \\
\overline{-} \\
6, \overline{9} 70 \\
\overline{-} \\
7, \overline{100}\end{array}$ & $\begin{array}{c}- \\
- \\
13.60 \\
- \\
- \\
13.56 \\
- \\
- \\
13.64 \\
\overline{-} \\
13.80\end{array}$ & $\begin{array}{c}\overline{-} \\
7, \overline{1} 60 \\
\overline{-} \\
7, \overline{1} 20 \\
\overline{-} \\
7, \overline{2} 00 \\
\overline{-} \\
7, \overline{3} 60\end{array}$ & $\begin{array}{c}- \\
\overline{-} \\
13.81 \\
\overline{-} \\
\overline{-} \\
13.68 \\
\overline{-} \\
13.67 \\
\overline{-} \\
13.79\end{array}$ & $\begin{array}{c}\overline{-} \\
7, \overline{3} 70 \\
\overline{-} \\
7, \overline{2} 40 \\
\overline{-} \\
7, \overline{2} 30 \\
\overline{-} \\
7, \overline{3} 50\end{array}$ & $\begin{array}{c}- \\
\overline{-} \\
13.79 \\
- \\
- \\
13.65 \\
- \\
- \\
13.63 \\
- \\
\overline{-} \\
13.77\end{array}$ & $\begin{array}{c}\overline{-} \\
7, \overline{350} \\
\overline{-} \\
7, \overline{2} 10 \\
\overline{-} \\
7, \overline{190} \\
\overline{-} \\
7, \overline{3330}\end{array}$ \\
\hline & \multicolumn{2}{|c|}{ December 20} & \multicolumn{2}{|c|}{ December 21} & \multicolumn{2}{|c|}{ December 22} & \multicolumn{2}{|c|}{ December 23} & \multicolumn{2}{|c|}{ December 24} & \multicolumn{2}{|c|}{ December 25} \\
\hline $\begin{array}{r}2 \\
4 \\
6 \\
8 \\
10 \\
\mathrm{~N} \\
2 \\
4 \\
6 \\
8 \\
10 \\
\mathrm{M}\end{array}$ & $\begin{array}{c}- \\
\overline{1} \\
13.83 \\
\overline{-} \\
13.71 \\
\overline{-} \\
13.58 \\
\overline{-} \\
13.55\end{array}$ & $\begin{array}{c}\overline{-} \\
7, \overline{3} 90 \\
- \\
\overline{\overline{2}} \mathbf{2 7 0} \\
\overline{-} \\
7, \overline{1} 40 \\
\overline{-} \\
7, \overline{1} 10\end{array}$ & $\begin{array}{c}- \\
\overline{-} \\
13.55 \\
- \\
\overline{-} \\
13.55 \\
- \\
13.67 \\
\overline{-} \\
13.86\end{array}$ & $\begin{array}{c}\overline{-} \\
7, \overline{110} \\
\overline{-} \\
7, \overline{110} \\
\overline{-} \\
7, \overline{2} 30 \\
\overline{-} \\
7, \overline{420}\end{array}$ & $\begin{array}{c}\overline{-} \\
13.97 \\
- \\
\overline{-} \\
13.91\end{array}$ & $\begin{array}{c}\overline{-} \\
7, \overline{530} \\
\overline{-} \\
7,470 \\
\overline{-} \\
7, \overline{4} 80 \\
\overline{-} \\
7, \overline{6} 00\end{array}$ & $\begin{array}{c}- \\
- \\
14.15 \\
- \\
- \\
14.11\end{array}$ & $\begin{array}{c}\overline{-} \\
7, \overline{7} 10 \\
\overline{-} \\
7, \overline{670} \\
-\end{array}$ & $\begin{array}{c}\overline{-} \\
\overline{-} \\
14.34 \\
\overline{-} \\
14.30 \\
\overline{-} \\
14.27 \\
\overline{-} \\
14.28\end{array}$ & $\begin{array}{c}\overline{-} \\
\overline{\overline{9}} \\
\overline{-} \\
\overline{\bar{s}} \\
7, \overline{8} 60 \\
\overline{-} \\
\overline{\overline{8}} \overline{830} \\
\overline{\bar{c}} \\
\overline{\overline{8}} \mathbf{8 4 0}\end{array}$ & $\begin{array}{c}\overline{-} \\
\overline{14.34} \\
\overline{-} \\
14.34 \\
\overline{-} \\
14.33 \\
\overline{-} \\
14.36\end{array}$ & $\begin{array}{c}\overline{-} \\
7, \overline{9} 00 \\
\bar{z} \\
7, \overline{900} \\
\overline{-} \\
7, \overline{8} 90 \\
\overline{-} \\
7, \overline{9} 20\end{array}$ \\
\hline
\end{tabular}

$1003020-30-10$ 
Location. - Lat. $37^{\circ} 77^{\prime}$, long. $118^{\circ} 58^{\prime}$, In SE sec, 36, T. 7 S., R. 27 E., in gatehouse of Ward Tunnel, upstream from dam on South Fork of San Joaquin River, 16 miles northeast of Big Creek, Fresno County. Zero of gage is at mean sea level.

Drainage area.- 171 square miles.

Gage-helght recom water-stage recorder graph.

Remarks. Flood run-off completely controlied in lake. Elevation of top of spillway gates is $7,327.5$ feet above mean sea level (capacity, 64,406 acre-feet). See record for South Fork of San Joaquin River at Florence Lake. Records of gage height and contents at midnight furnished by Southern California Edison Co., Ltd. Contents show amount available for release.

Elevation and contents, November 1937 to January 1938

\begin{tabular}{|c|c|c|c|c|c|c|}
\hline \multirow[b]{2}{*}{ Day } & \multicolumn{2}{|c|}{ November } & \multicolumn{2}{|c|}{ December } & \multicolumn{2}{|c|}{ January } \\
\hline & $\begin{array}{l}\text { Elevation } \\
\text { (feet) }\end{array}$ & $\begin{array}{l}\text { Contents } \\
(\text { acre-feet) }\end{array}$ & $\begin{array}{l}\text { Elevation } \\
\text { (feet) }\end{array}$ & $\begin{array}{l}\text { Contents } \\
(\text { acre-feet) }\end{array}$ & $\begin{array}{l}\text { Elevation } \\
\text { (feet) }\end{array}$ & $\begin{array}{l}\text { Contents } \\
(\text { acre-feet })\end{array}$ \\
\hline $\begin{array}{l}1 \\
2 \\
3 \\
4 \\
5\end{array}$ & $\begin{array}{l}7,315.21 \\
7,315.23 \\
7,315.24 \\
7,315.25 \\
7,315.27\end{array}$ & $\begin{array}{l}52,915 \\
52,934 \\
52,943 \\
52,952 \\
52,970\end{array}$ & $\begin{array}{l}7,249.38 \\
7,241.12 \\
7,232.98 \\
7,227.77 \\
7,225.26\end{array}$ & $\begin{array}{r}6,386 \\
3,332 \\
1,387 \\
591 \\
306\end{array}$ & $\begin{array}{l}7,224.28 \\
7,224.28 \\
7,224.24 \\
7,224.24 \\
7,224.21\end{array}$ & $\begin{array}{l}162 \\
162 \\
159 \\
159 \\
157\end{array}$ \\
\hline $\begin{array}{r}6 \\
7 \\
8 \\
9 \\
10\end{array}$ & $\begin{array}{l}7,313.19 \\
7,312.52 \\
7,311.34 \\
7,310.09 \\
7,308.84\end{array}$ & $\begin{array}{l}51,101 \\
50,504 \\
49,460 \\
48,363 \\
47,276\end{array}$ & $\begin{array}{l}7,224.18 \\
7,223.77 \\
7,223.61 \\
7,224.30 \\
7,226.88\end{array}$ & $\begin{array}{l}214 \\
184 \\
116 \\
163 \\
415\end{array}$ & $\begin{array}{l}7,224.16 \\
7,224.13 \\
7,224.09 \\
7,224.09 \\
7,224.06\end{array}$ & $\begin{array}{l}154 \\
151 \\
149 \\
149 \\
147\end{array}$ \\
\hline $\begin{array}{l}11 \\
12 \\
13 \\
14 \\
15\end{array}$ & $\begin{array}{l}7,307.27 \\
7,305.67 \\
7,305 \cdot 10 \\
7,304.56 \\
7,303.98\end{array}$ & $\begin{array}{l}45,924 \\
44,562 \\
44,080 \\
43,625 \\
43,138\end{array}$ & $\begin{array}{l}7,236.91 \\
7,232.80 \\
7,229.74 \\
7,228.30 \\
7,226.95\end{array}$ & $\begin{array}{r}2,192 \\
1,355 \\
850 \\
658 \\
489\end{array}$ & $\begin{array}{l}7,224.03 \\
7,224.02 \\
7,224.01 \\
7,224.03 \\
7,224.02\end{array}$ & $\begin{array}{l}144 \\
144 \\
143 \\
144 \\
144\end{array}$ \\
\hline $\begin{array}{l}16 \\
17 \\
18 \\
19 \\
20\end{array}$ & $\begin{array}{l}7,303.43 \\
7,302.56 \\
7,300.27 \\
7,296.65 \\
7,292.67\end{array}$ & $\begin{array}{l}42,679 \\
41,956 \\
40,071 \\
37,153 \\
34,023\end{array}$ & $\begin{array}{l}7,226.26 \\
7,225.98 \\
7,225.82 \\
7,225.68 \\
7,225.59\end{array}$ & $\begin{array}{l}410 \\
313 \\
297 \\
284 \\
275\end{array}$ & $\begin{array}{l}7,224.20 \\
7,224.28 \\
7,224.33 \\
7,224.28 \\
7,224.23\end{array}$ & $\begin{array}{l}156 \\
162 \\
166 \\
162 \\
158\end{array}$ \\
\hline $\begin{array}{l}21 \\
22 \\
23 \\
24 \\
25\end{array}$ & $\begin{array}{l}7,288.34 \\
7,283.82 \\
7,279.21 \\
7,276.09 \\
7,275.19\end{array}$ & $\begin{array}{l}30,707 \\
27,347 \\
24,028 \\
21,846 \\
21,228\end{array}$ & $\begin{array}{l}7,225.28 \\
7,225.02 \\
7,224.84 \\
7,224.80 \\
7,224.78\end{array}$ & $\begin{array}{l}245 \\
219 \\
205 \\
202 \\
200\end{array}$ & $\begin{array}{l}7,224.30 \\
7,224.26 \\
7,224.27 \\
7,224.20 \\
7,224.18\end{array}$ & $\begin{array}{l}163 \\
161 \\
157 \\
156 \\
155\end{array}$ \\
\hline $\begin{array}{l}26 \\
27 \\
28 \\
29 \\
30\end{array}$ & $\begin{array}{l}7,274.57 \\
7,271.82 \\
7,266.79 \\
7,261.69 \\
7,256.09\end{array}$ & $\begin{array}{r}20,804 \\
18,954 \\
15,697 \\
12,589 \\
9,501\end{array}$ & $\begin{array}{l}7,224.74 \\
7,224.72 \\
7,224.71 \\
7,224.52 \\
7,224.38 \\
7,224.28\end{array}$ & $\begin{array}{l}197 \\
196 \\
195 \\
180 \\
169 \\
162\end{array}$ & $\begin{array}{l}7,224.18 \\
7,224.18 \\
7,224.13 \\
7,224.26 \\
7,224.34 \\
7,224.30\end{array}$ & $\begin{array}{l}155 \\
155 \\
151 \\
161 \\
166 \\
163\end{array}$ \\
\hline
\end{tabular}


South Fork of San Joaquin River near Florence Lake, Calif.

Location. - Lat. $37^{\circ} 16^{\prime} 20^{\prime \prime}$, long. $118^{\circ} 57^{\prime} 50^{\prime \prime}$, in $\mathrm{SE} \frac{1}{4}$ sec. 36, T. 7 S., R. 27 E., just below splilway of Florence Lake Dam, Fresno County, and $6 \mathrm{miles}$ above mouth of Bear

Creek. Altitude, about 7,200 feet above mean sea level.

Drainage area.- 171 square miles.

Gage-height record. - Water-stage recorder graph.

Stage-discharge relation. - Defined by current-meter measurements.

Maxíma. - December 1937: Flood run-off regulated in Florence Lake.

1921-November 1937: Discharge (unregulated), 3,460 second-feet June 4, 1922 (gage helght, 13.75 feet).

Remarks.- Flood mun-off regulated in Florence Lake. See record for Florence Lake. Record of adjusted mean daliy discharge furnished by Southern California Edison Co., Ltd., has been adjusted for storage in Florence Lake and release into Ward tunnel. Most of basic data furnished by Southera California Edison Co., Ltd.

Observed mean dally discharge, in second-feet, November 1937 to January 1938

\begin{tabular}{|r|r|r|r||r|r|r|r||r|r|r|r|}
\hline Day & Nov. & Dec. & Jan. & Day & Nov. & Dec. & Jan. & Day & Nov. & Dec. & Jan. \\
\hline 1 & 0.9 & 0.1 & 0.9 & 11 & 0.2 & 1.9 & 0.7 & 21 & 0.1 & 1.5 & 0.7 \\
2 & .9 & .1 & .9 & 12 & .1 & .4 & .7 & 22 & .1 & 1.3 & .5 \\
3 & .9 & .1 & .9 & 13 & .1 & .2 & .7 & 23 & .1 & 1.3 & .4 \\
4 & .9 & .1 & .7 & 14 & .2 & .1 & .7 & 24 & .1 & 1.3 & .4 \\
5 & .9 & .1 & .7 & 15 & .1 & .1 & .9 & 25 & .1 & 1.1 & .4 \\
6 & .7 & .1 & .7 & 16 & .2 & .1 & .9 & 26 & .1 & .9 & .4 \\
7 & .7 & .1 & .7 & 17 & .3 & 15 & .9 & 27 & .1 & .9 & .4 \\
8 & .5 & 14 & .7 & 18 & .2 & 2.3 & .9 & 28 & .1 & .9 & .4 \\
9 & .2 & 2.6 & .7 & 19 & .2 & 1.9 & .9 & 29 & .1 & .9 & .4 \\
10 & .2 & 2.6 & .7 & 20 & .2 & 1.7 & .7 & 30 & .1 & .9 & .4 \\
\hline
\end{tabular}

Adjusted mean daily discharge, December 8-25, 1937

\begin{tabular}{|c|c|c|c|c|c|}
\hline Day & Second-feet & Day & Second-fe日t & Day & Second-fe日t \\
\hline $\begin{array}{r}8 \\
9 \\
10 \\
11 \\
12 \\
13\end{array}$ & $\begin{array}{r}14 \\
60 \\
302 \\
1,450 \\
369 \\
243\end{array}$ & $\begin{array}{l}14 \\
15 \\
16 \\
17 \\
18 \\
19\end{array}$ & $\begin{array}{r}195 \\
179 \\
142 \\
108 \\
110 \\
98\end{array}$ & $\begin{array}{l}20 \\
21 \\
22 \\
23 \\
24 \\
25\end{array}$ & $\begin{array}{l}91 \\
83 \\
78 \\
75 \\
65 \\
63\end{array}$ \\
\hline
\end{tabular}


Bear Creek near Vermilion Valley, Calif.

Location. - Lat. $37^{\circ} 20^{\circ}$, long. $118^{\circ} 58^{\prime}$, in SW $\frac{1}{4}$ sec. 12, T. 7 S., R. 27 E., 2 mjles above mouth of Vermilion Valley, Fresno County. Altitude, about 7,400 feet above mean sea level.

Drainage area. - 53.5 square miles.

Gage-helght record. - Water-stage recorder graph.

Stage-discharge relation.- Affected by 1ce for periods Nov. 9-10, Nov. 12 to Dec. 8 , Dec. 24 to Jan. 31. Defined by current-meter measurements for range of stage of hi.gh water in December.

Maxima.- December 1937: Discharge, 634 second-feet 1 p.m. Dec. Il (gage height, 5.47 fert).

1921-November 1937: Discharge, 1,600 second-feet (revised) July 21, 1936 (gage helght, 6.90 feet), from rating curve extended above 950 second-feet.

Remarks.- Flood mun-off not affected by artificial storage or diversion. Discharge for periods of $1 \mathrm{ce}$ effect computed on basis of weather records, 3 discharge measurements, and records for Mono Creek and Ward tunnel. Most of basic data furnished by Southern California Edison Co., Ltd.

Mean daily discharge, in second-feet, November 1937 to January 1938

\begin{tabular}{|c|c|c|c|c|c|c|c|c|c|c|c|}
\hline Dey & Nov. & Dec。 & Jan. & Day & Nov. & Dec. & Jan. & Day & Nov. & Dec. & Jan. \\
\hline $\begin{array}{r}1 \\
2 \\
3 \\
4 \\
5 \\
6 \\
7 \\
8 \\
9 \\
10\end{array}$ & $\begin{array}{l}6 \\
6 \\
5.5 \\
5 \\
4.9 \\
5 \\
4.9 \\
4.3 \\
4.5 \\
4.5\end{array}$ & $\begin{array}{r}6 \\
6 \\
6 \\
6 \\
6 \\
6 \\
6 \\
5 \\
7 \\
61\end{array}$ & $\begin{array}{l}18 \\
17 \\
17 \\
16 \\
16 \\
16 \\
15 \\
15 \\
15 \\
14\end{array}$ & $\begin{array}{l}11 \\
12 \\
13 \\
14 \\
15 \\
16 \\
17 \\
18 \\
19 \\
20\end{array}$ & $\begin{array}{l}4.3 \\
4.5 \\
4.5 \\
5 \\
5 \\
5 \\
5 \\
5 \\
6 \\
6\end{array}$ & $\begin{array}{r}242 \\
79 \\
69 \\
67 \\
52 \\
42 \\
37 \\
33 \\
33 \\
31\end{array}$ & $\begin{array}{l}14 \\
14 \\
14 \\
14 \\
14 \\
15 \\
15 \\
15 \\
16 \\
16\end{array}$ & $\begin{array}{l}21 \\
22 \\
23 \\
24 \\
25 \\
26 \\
27 \\
28 \\
29 \\
30 \\
31\end{array}$ & $\begin{array}{l}6 \\
6 \\
6 \\
6 \\
6 \\
6 \\
6 \\
6 \\
6 \\
6\end{array}$ & $\begin{array}{l}28 \\
28 \\
23 \\
22 \\
22 \\
21 \\
20 \\
20 \\
19 \\
18 \\
18\end{array}$ & $\begin{array}{l}16 \\
16 \\
17 \\
17 \\
17 \\
18 \\
18 \\
18 \\
20 \\
20 \\
20\end{array}$ \\
\hline $\begin{array}{l}\text { Mean } \\
\text { Run- }\end{array}$ &, $1 n$ & 4 & 4. & & & & & & $\begin{array}{r}5.36 \\
319\end{array}$ & $\begin{array}{r}33.5 \\
2,060\end{array}$ & $\begin{array}{r}16.2 \\
998\end{array}$ \\
\hline
\end{tabular}

Gage height, in feet, and discharge, in second-feet, at indicated time, I937

\begin{tabular}{|c|c|c|c|c|c|c|c|c|c|c|c|c|}
\hline \multirow{2}{*}{$\begin{array}{l} \\
\\
3 \\
\text { 㞻 } \\
\end{array}$} & Feet & Sec.ft. & Feet & Sec.ft. & Feet & Sec.ft. & Feet & Sec.ft. & Feet & Sec.ft. & Feet & Sec.ft. \\
\hline & \multicolumn{2}{|c|}{ December 8} & \multicolumn{2}{|c|}{ December 9} & \multicolumn{2}{|c|}{ December 10} & \multicolumn{2}{|c|}{ December 11} & \multicolumn{2}{|c|}{ December 12} & \multicolumn{2}{|c|}{ December 13} \\
\hline \multirow[t]{2}{*}{$\begin{array}{r}2 \\
4 \\
6 \\
8 \\
10 \\
N \\
2 \\
4 \\
6 \\
8 \\
10 \\
M\end{array}$} & & & $\begin{array}{l}3.05 \\
3.04 \\
3.03 \\
3.06 \\
3.12 \\
3.11 \\
3.09 \\
3.09 \\
3.12 \\
3.15 \\
3.22 \\
3.30\end{array}$ & $\begin{array}{l}5.5 \\
5 \\
4.9 \\
6 \\
8 \\
7.5 \\
6.5 \\
6.5 \\
8 \\
9 \\
12 \\
17\end{array}$ & $\begin{array}{l}3.43 \\
3.63 \\
3.81 \\
4.07 \\
3.88 \\
3.79 \\
3.78 \\
3.75 \\
3.72 \\
3.68 \\
3.63 \\
3.60\end{array}$ & $\begin{array}{r}27 \\
48 \\
72 \\
113 \\
82 \\
69 \\
67 \\
64 \\
60 \\
54 \\
48 \\
44\end{array}$ & $\begin{array}{l}3.60 \\
3.67 \\
3.80 \\
4.63 \\
5.10 \\
5.33 \\
5.40 \\
4.88 \\
4.54 \\
4.30 \\
4.15 \\
4.06\end{array}$ & $\begin{array}{r}44 \\
53 \\
70 \\
242 \\
440 \\
556 \\
595 \\
338 \\
215 \\
156 \\
127 \\
111\end{array}$ & $\begin{array}{l}4.00 \\
3.93 \\
3.87 \\
3.83 \\
3.78 \\
3.77 \\
3.80 \\
3.88 \\
3.86 \\
3.84 \\
3.80 \\
3.76\end{array}$ & $\begin{array}{r}101 \\
90 \\
80 \\
74 \\
67 \\
66 \\
70 \\
82 \\
79 \\
76 \\
70 \\
65\end{array}$ & $\begin{array}{l}3.74 \\
3.73 \\
3.73 \\
3.73 \\
3.73 \\
3.71 \\
3.89 \\
3.94 \\
3.90 \\
3.85 \\
3.82 \\
3.80\end{array}$ & $\begin{array}{l}62 \\
61 \\
61 \\
61 \\
61 \\
58 \\
84 \\
91 \\
85 \\
78 \\
73 \\
70\end{array}$ \\
\hline & \multicolumn{2}{|c|}{ December 14} & \multicolumn{2}{|c|}{ December 15} & \multicolumn{2}{|c|}{ December 16} & \multicolumn{2}{|c|}{ December 17} & \multicolumn{2}{|c|}{ December 18} & \multicolumn{2}{|c|}{ December 19} \\
\hline \multirow[t]{2}{*}{$\begin{array}{r}2 \\
4 \\
6 \\
8 \\
10 \\
N \\
2 \\
4 \\
6 \\
8 \\
10 \\
M\end{array}$} & $\begin{array}{l}3.80 \\
3.81 \\
3.81 \\
3.81 \\
3.81 \\
3.75 \\
3.73 \\
3.76 \\
3.77 \\
3.76 \\
3.74 \\
3.71\end{array}$ & $\begin{array}{l}70 \\
72 \\
72 \\
72 \\
72 \\
64 \\
61 \\
65 \\
66 \\
65 \\
62 \\
58\end{array}$ & $\begin{array}{l}3.70 \\
3.68 \\
3.67 \\
3.66 \\
3.65 \\
3.65 \\
3.66 \\
3.67 \\
3.68 \\
3.67 \\
3.64 \\
3.61\end{array}$ & $\begin{array}{l}57 \\
54 \\
53 \\
52 \\
50 \\
50 \\
52 \\
53 \\
54 \\
53 \\
49 \\
45\end{array}$ & $\begin{array}{l}3.58 \\
3.57 \\
3.57 \\
3.58 \\
3.59 \\
3.57 \\
3.57 \\
3.60 \\
3.61 \\
3.60 \\
3.58 \\
3.56\end{array}$ & $\begin{array}{l}42 \\
41 \\
41 \\
42 \\
43 \\
41 \\
41 \\
44 \\
45 \\
44 \\
42 \\
40\end{array}$ & $\begin{array}{l}3.55 \\
3.54 \\
3.54 \\
3.54 \\
3.55 \\
3.51 \\
3.52 \\
3.55 \\
3.56 \\
3.56 \\
3.55 \\
3.53\end{array}$ & $\begin{array}{l}38 \\
37 \\
37 \\
37 \\
38 \\
34 \\
35 \\
38 \\
40 \\
40 \\
38 \\
36\end{array}$ & $\begin{array}{l}3.52 \\
3.49 \\
3.48 \\
3.47 \\
3.48 \\
3.48 \\
3.52 \\
3.53 \\
3.53 \\
3.51 \\
3.47 \\
3.46\end{array}$ & $\begin{array}{l}35 \\
32 \\
31 \\
30 \\
31 \\
31 \\
35 \\
36 \\
36 \\
34 \\
30 \\
29\end{array}$ & $\begin{array}{l}3.45 \\
3.47 \\
3.50 \\
3.53 \\
3.56 \\
3.52 \\
3.51 \\
3.53 \\
3.50 \\
3.47 \\
3.46 \\
3.45\end{array}$ & $\begin{array}{l}28 \\
30 \\
33 \\
36 \\
40 \\
35 \\
34 \\
36 \\
33 \\
30 \\
29 \\
28\end{array}$ \\
\hline & \multicolumn{2}{|c|}{ December 20} & \multicolumn{2}{|c|}{ December 21} & \multicolumn{2}{|c|}{ December 22} & \multicolumn{2}{|c|}{ December 23} & \multicolumn{2}{|c|}{ December 24} & \multicolumn{2}{|c|}{ December 25} \\
\hline $\begin{array}{r}2 \\
4 \\
6 \\
8 \\
10 \\
\mathrm{~N} \\
2 \\
4 \\
6 \\
8 \\
10 \\
M\end{array}$ & $\begin{array}{l}3.45 \\
3.45 \\
3.47 \\
3.49 \\
3.53 \\
3.51 \\
3.50 \\
3.49 \\
3.47 \\
3.45 \\
3.43 \\
3.43\end{array}$ & $\begin{array}{l}28 \\
28 \\
30 \\
32 \\
36 \\
34 \\
33 \\
32 \\
30 \\
28 \\
27 \\
27\end{array}$ & $\begin{array}{l}3.43 \\
3.44 \\
3.45 \\
3.47 \\
3.49 \\
3.48 \\
3.45 \\
3.46 \\
3.44 \\
3.42 \\
3.40 \\
3.40\end{array}$ & $\begin{array}{l}27 \\
28 \\
28 \\
30 \\
32 \\
31 \\
28 \\
29 \\
28 \\
26 \\
24 \\
24\end{array}$ & $\begin{array}{l}3.39 \\
3.40 \\
3.43 \\
3.45 \\
3.47 \\
3.50 \\
3.45 \\
3.46 \\
3.46 \\
3.43 \\
3.40 \\
3.39\end{array}$ & $\begin{array}{l}23 \\
24 \\
27 \\
28 \\
30 \\
33 \\
28 \\
29 \\
29 \\
27 \\
24 \\
23\end{array}$ & $\begin{array}{l}3.29 \\
3.39 \\
3.37 \\
3.38 \\
3.38 \\
3.39 \\
3.40 \\
3.37 \\
3.38 \\
3.37 \\
3.37 \\
3.37\end{array}$ & $\begin{array}{l}23 \\
23 \\
22 \\
23 \\
23 \\
23 \\
24 \\
22 \\
23 \\
22 \\
22 \\
22\end{array}$ & & & & \\
\hline
\end{tabular}

Supplemental recoras.- Dec. Il, I p.m., $5.47 \mathrm{ft.,} 634 \mathrm{sec.-ft.}$ 
Mono Creek near Vermilion Valley, Calif.

Location.- Let. $37^{\circ} 22^{\prime}$, long. $118^{\circ} 59^{\prime}$, in swo sec. 35, T. 6 S., R. 27 E. (unsurveged), I mile below lower end of Vermilion Valley, Fresno County, and 6 miles belov mouth of North Fork. Altitude, about 7,400 feet above mean sea level.

Drainage area.- 92.0 square miles.

Gage-helght record. - Water-stage recorder graph.

Stage-discharge relation.- Affected by Ice for periods Nov. 9 to Dec. 9, Dec. 24 to Jan. 31. Defined by current-meter measurements for entire range of stage.

Maxima.- December 1937: Discharge, 389 second-feet 5 p.m. Dec. 11 (gage he1ght, 6.26 feet).

1921-November 1937: Discharge, 1,420 second-feet June 16, 1927 (gage he1ght, 8.09 feet), June 22,1932 (gage helght, 8.10 feet), from rating curve deflned to 1,400 second-feet.

January-September 1938: Discharge, 1,760 second-feet 10:30 p.m. June 2 (gage helght, 8.62 feet) from rating curve extended above 1,500 second-feet with ald of area-velocity study.

Remarks. - Flood mun-off not affected by artificlal storage or diversion. Discharge for periods of ice effect computed on basis of 2 discharge measurements and flow of Bear Creek and Ward Tunnel.

Mean dally discharge, in second-feet, November 1937 to January 1938

\begin{tabular}{|c|c|c|c|c|c|c|c|c|c|c|c|}
\hline Day & Nov. & Dec. & Jan. & Day & Nov. & Dec. & Jan. & Day & Nov. & Dec. & Jan. \\
\hline $\begin{array}{r}1 \\
2 \\
3 \\
4 \\
5 \\
6 \\
7 \\
8 \\
9 \\
10\end{array}$ & $\begin{array}{l}19 \\
19 \\
18 \\
17 \\
17 \\
18 \\
17 \\
16 \\
16 \\
16\end{array}$ & $\begin{array}{l}15 \\
15 \\
15 \\
15 \\
15 \\
15 \\
15 \\
15 \\
15 \\
71\end{array}$ & $\begin{array}{l}40 \\
40 \\
39 \\
38 \\
38 \\
37 \\
36 \\
36 \\
35 \\
34\end{array}$ & $\begin{array}{l}11 \\
12 \\
13 \\
14 \\
15 \\
16 \\
17 \\
18 \\
19 \\
20\end{array}$ & $\begin{array}{l}17 \\
17 \\
17 \\
17 \\
17 \\
17 \\
17 \\
17 \\
17 \\
17\end{array}$ & $\begin{array}{r}193 \\
143 \\
116 \\
109 \\
87 \\
72 \\
67 \\
60 \\
64 \\
62\end{array}$ & $\begin{array}{l}34 \\
33 \\
33 \\
33 \\
35 \\
36 \\
36 \\
36 \\
36 \\
36\end{array}$ & $\begin{array}{l}21 \\
22 \\
23 \\
24 \\
25 \\
26 \\
27 \\
28 \\
29 \\
30 \\
31\end{array}$ & $\begin{array}{l}16 \\
16 \\
16 \\
16 \\
16 \\
16 \\
16 \\
16 \\
16 \\
16\end{array}$ & $\begin{array}{l}57 \\
60 \\
50 \\
48 \\
47 \\
46 \\
45 \\
44 \\
43 \\
42 \\
41\end{array}$ & $\begin{array}{l}36 \\
36 \\
36 \\
36 \\
36 \\
36 \\
36 \\
38 \\
38 \\
38 \\
38\end{array}$ \\
\hline $\begin{array}{l}\text { Me an } \\
\text { Run- }\end{array}$ & , i & $10-1$ & 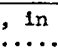 & & & & & & $\begin{array}{r}16.8 \\
998\end{array}$ & $\begin{array}{r}54.9 \\
3,380\end{array}$ & $\begin{array}{r}36.3 \\
2,230\end{array}$ \\
\hline
\end{tabular}

Gage helght, in feet, and discharge, in second-feet, at indicated time, 1937

\begin{tabular}{|c|c|c|c|c|c|c|c|c|c|c|c|c|}
\hline \multirow{2}{*}{$\begin{array}{l} \\
5 \\
0 \\
0 \\
0\end{array}$} & Feet & sec.ft. & Feet & Sec.ft. & Feet & sec.ft. & Feet & sec.ft. & Feet & Sec.ft. & Feet & Sec.ft. \\
\hline & \multicolumn{2}{|c|}{ December 8} & \multicolumn{2}{|c|}{ December 9} & \multicolumn{2}{|c|}{ December 10} & \multicolumn{2}{|c|}{ December 11} & \multicolumn{2}{|c|}{ December 12} & \multicolumn{2}{|c|}{ December 13} \\
\hline \multirow[t]{2}{*}{$\begin{array}{r}2 \\
4 \\
6 \\
8 \\
10 \\
N \\
2 \\
4 \\
6 \\
8 \\
10 \\
4 \\
\end{array}$} & & & & & $\begin{array}{l}4.92 \\
5.03 \\
5.12 \\
5.27 \\
5.20 \\
5.32 \\
5.37 \\
5.30 \\
5.24 \\
5.22 \\
5.27 \\
5.27\end{array}$ & \begin{tabular}{|r}
32 \\
45 \\
57 \\
65 \\
70 \\
93 \\
104 \\
89 \\
78 \\
74 \\
83 \\
83 \\
\end{tabular} & $\begin{array}{l}5.24 \\
5.23 \\
5.25 \\
5.33 \\
5.45 \\
5.88 \\
6.03 \\
6.20 \\
6.20 \\
5.92 \\
5.73 \\
5.63\end{array}$ & $\begin{array}{r}78 \\
76 \\
80 \\
96 \\
123 \\
243 \\
297 \\
365 \\
365 \\
256 \\
197 \\
169 \\
\end{array}$ & $\begin{array}{l}5.57 \\
5.55 \\
5.51 \\
5.49 \\
5.49 \\
5.51 \\
5.53 \\
5.53 \\
5.54 \\
5.55 \\
5.53 \\
5.50\end{array}$ & $\begin{array}{l}153 \\
148 \\
138 \\
133 \\
133 \\
138 \\
143 \\
143 \\
145 \\
148 \\
143 \\
135\end{array}$ & $\begin{array}{l}5.40 \\
5.36 \\
5.34 \\
5.33 \\
5.33 \\
5.39 \\
5.56 \\
5.58 \\
5.45 \\
5.42 \\
5.41 \\
5.37\end{array}$ & \begin{tabular}{|r|}
111 \\
102 \\
98 \\
96 \\
96 \\
109 \\
151 \\
156 \\
123 \\
116 \\
113 \\
104 \\
\end{tabular} \\
\hline & \multicolumn{2}{|c|}{ December 14} & \multicolumn{2}{|c|}{ December 15} & \multicolumn{2}{|c|}{ December 16} & \multicolumn{2}{|c|}{ December 17} & \multicolumn{2}{|c|}{ December 18} & \multicolumn{2}{|c|}{ December 19} \\
\hline \multirow[t]{2}{*}{$\begin{array}{r}2 \\
4 \\
6 \\
8 \\
10 \\
1 \\
2 \\
4 \\
6 \\
8 \\
10 \\
M \\
\end{array}$} & $\begin{array}{l}5.36 \\
5.35 \\
5.36 \\
5.37 \\
5.39 \\
5.45 \\
5.54 \\
5.41 \\
5.36 \\
5.35 \\
5.36 \\
5.34\end{array}$ & $\begin{array}{r}102 \\
100 \\
102 \\
104 \\
109 \\
123 \\
145 \\
113 \\
102 \\
100 \\
102 \\
98\end{array}$ & $\begin{array}{l}5.32 \\
5.30 \\
5.25 \\
5.25 \\
5.27 \\
5.41 \\
5.30 \\
5.28 \\
5.27 \\
5.27 \\
5.27 \\
5.26\end{array}$ & $\begin{array}{r}93 \\
89 \\
80 \\
80 \\
83 \\
113 \\
89 \\
85 \\
83 \\
83 \\
83 \\
81\end{array}$ & $\begin{array}{l}5.25 \\
5.15 \\
5.06 \\
5.08 \\
5.14 \\
5.24 \\
5.35 \\
5.32 \\
5.25 \\
5.23 \\
5.22 \\
5.21\end{array}$ & $\begin{array}{r}80 \\
62 \\
49 \\
51 \\
60 \\
78 \\
100 \\
93 \\
80 \\
76 \\
74 \\
72\end{array}$ & $\begin{array}{l}5.20 \\
5.19 \\
5.11 \\
5.15 \\
5.17 \\
5.30 \\
5.20 \\
5.17 \\
5.16 \\
5.16 \\
5.17 \\
5.17\end{array}$ & $\begin{array}{l}70 \\
68 \\
56 \\
62 \\
65 \\
89 \\
70 \\
65 \\
64 \\
64 \\
65 \\
65\end{array}$ & $\begin{array}{l}5.16 \\
5.15 \\
5.11 \\
4.98 \\
5.00 \\
5.16 \\
5.27 \\
5.18 \\
5.16 \\
5.16 \\
5.20 \\
5.16\end{array}$ & $\begin{array}{l}64 \\
62 \\
56 \\
39 \\
41 \\
64 \\
83 \\
67 \\
64 \\
64 \\
70 \\
64\end{array}$ & $\begin{array}{l}5.10 \\
5.06 \\
5.07 \\
5.12 \\
5.16 \\
5.21 \\
5.34 \\
5.29 \\
5.21 \\
5.16 \\
5.10 \\
5.07\end{array}$ & $\begin{array}{l}54 \\
49 \\
50 \\
57 \\
64 \\
72 \\
98 \\
87 \\
72 \\
64 \\
54 \\
50 \\
\end{array}$ \\
\hline & \multicolumn{2}{|c|}{ December 20} & \multicolumn{2}{|c|}{ December 21} & \multicolumn{2}{|c|}{ December 22} & \multicolumn{2}{|c|}{ December 23} & \multicolumn{2}{|c|}{ December 24} & \multicolumn{2}{|c|}{ December 25} \\
\hline $\begin{array}{r}2 \\
4 \\
6 \\
8 \\
10 \\
\mathrm{~N} \\
2 \\
4 \\
6 \\
8 \\
10 \\
4\end{array}$ & $\begin{array}{l}5.04 \\
5.03 \\
5.06 \\
5.10 \\
5.12 \\
5.16 \\
5.30 \\
5.30 \\
5.21 \\
5.18 \\
5.15 \\
5.11\end{array}$ & $\begin{array}{l}46 \\
45 \\
49 \\
54 \\
57 \\
64 \\
89 \\
89 \\
72 \\
67 \\
62 \\
56\end{array}$ & $\begin{array}{l}5.07 \\
5.06 \\
5.06 \\
5.06 \\
5.09 \\
5.14 \\
5.26 \\
5.26 \\
5.17 \\
5.11 \\
5.10 \\
5.03\end{array}$ & $\begin{array}{l}50 \\
49 \\
49 \\
49 \\
53 \\
60 \\
81 \\
81 \\
65 \\
56 \\
54 \\
45\end{array}$ & $\begin{array}{l}5.04 \\
5.06 \\
5.06 \\
5.08 \\
5.11 \\
5.13 \\
5.29 \\
5.28 \\
5.22 \\
5.17 \\
5.13 \\
5.12\end{array}$ & $\begin{array}{l}46 \\
49 \\
49 \\
51 \\
56 \\
59 \\
87 \\
85 \\
74 \\
65 \\
59 \\
57\end{array}$ & $\begin{array}{l}5.06 \\
5.03 \\
5.01 \\
4.99 \\
4.99 \\
5.02 \\
5.12 \\
5.11 \\
5.10 \\
5.10 \\
5.11 \\
5.11\end{array}$ & $\begin{array}{l}49 \\
45 \\
42 \\
40 \\
40 \\
44 \\
57 \\
56 \\
54 \\
54 \\
56 \\
56\end{array}$ & & & & \\
\hline
\end{tabular}

Supplemental records.- Dec. 11,5 p.m., $6.26 \mathrm{ft}, 389$ sec.-ft. 
Huntington Lake near Big Creek, Calif.

Location.- Irt. $37^{\circ} 14^{\prime}$, long. $119^{\circ} 13^{\prime}$, in SW sec. 14, T. 8 S., R. 25 E., at dam on Big Creek, 2 miles northeast of town of Big Creek, Fresno County. Zero of gage is at mean sea level.

Drainage area.- 79 square miles.

Gage-helght record. - Water-stage recorder graph.

Remarks. Flood min-uff completely controlled in lake. Elevation of crest of overflow spilivay is 6,950 feet above mean sea level (capacity, 88, 834 acre-feet). See record. for $\mathrm{Big}$ Creek below Huntington Lake. Record of contents and gage height at midnight furnished by Southern California Edison Co., Ltd. Contents show amount available for release.

Elevation and contents, November 1937 to January 1938

\begin{tabular}{|c|c|c|c|c|c|c|}
\hline \multirow[b]{2}{*}{ Day } & \multicolumn{2}{|c|}{ November } & \multicolumn{2}{|c|}{ Deceraber } & \multicolumn{2}{|c|}{ January } \\
\hline & $\begin{array}{c}\text { Elevation } \\
\text { (feet) }\end{array}$ & $\begin{array}{l}\text { Contents } \\
\text { (acre-feet) }\end{array}$ & $\begin{array}{c}\text { Elevation } \\
\text { (feet) }\end{array}$ & $\begin{array}{l}\text { Contents } \\
(\text { acre-feet })\end{array}$ & $\begin{array}{c}\text { Elevation } \\
\text { (feet) }\end{array}$ & $\begin{array}{l}\text { Contents } \\
\left(\operatorname{acre}-\mathrm{fee}^{\prime}\right)\end{array}$ \\
\hline $\begin{array}{l}1 \\
2 \\
3 \\
4 \\
5\end{array}$ & $\begin{array}{l}6,856.48 \\
6,852.84 \\
6,848.76 \\
6,843.75 \\
6,839.38\end{array}$ & $\begin{array}{l}5,960 \\
4,897 \\
3,844 \\
2,734 \\
1,915\end{array}$ & $\begin{array}{l}6,899.62 \\
6,901.88 \\
6,903.25 \\
6,903.58 \\
6,903.47\end{array}$ & $\begin{array}{l}30,2 \mathrm{C2} \\
32,186 \\
33,425 \\
33,727 \\
33,627\end{array}$ & $\begin{array}{l}6,906.33 \\
6,906.03 \\
6,905.44 \\
6,904.84 \\
6,904.21\end{array}$ & $\begin{array}{l}36,300 \\
36,014 \\
35,457 \\
34,893 \\
34,307\end{array}$ \\
\hline $\begin{array}{r}6 \\
7 \\
8 \\
9 \\
10\end{array}$ & $\begin{array}{l}6,844.90 \\
6,845.30 \\
6,844.94 \\
6,845.03 \\
6,845.03\end{array}$ & $\begin{array}{l}2,971 \\
3,057 \\
2,980 \\
2,998 \\
2,998\end{array}$ & $\begin{array}{l}6,902.84 \\
6,902.20 \\
6,901.59 \\
6,901.08 \\
6,903.06\end{array}$ & $\begin{array}{l}33,052 \\
32,474 \\
31,929 \\
31,475 \\
33,251\end{array}$ & $\begin{array}{l}6,903 \cdot 56 \\
6,902 \cdot 90 \\
6,902 \cdot 24 \\
6,901.73 \\
6,901.04\end{array}$ & $\begin{array}{l}33,709 \\
33,106 \\
32,510 \\
32,053 \\
31,440\end{array}$ \\
\hline $\begin{array}{l}11 \\
12 \\
13 \\
14 \\
15\end{array}$ & $\begin{array}{l}6,846.17 \\
6,848.91 \\
6,851.19 \\
6,853.65 \\
6,855.67\end{array}$ & $\begin{array}{l}3,246 \\
3,879 \\
4,454 \\
5,124 \\
5,714\end{array}$ & $\begin{array}{l}6,908.72 \\
6,911 \cdot 05 \\
6,912.62 \\
6,913.67 \\
6,914.58\end{array}$ & $\begin{array}{l}38,615 \\
40,941 \\
42,547 \\
43,636 \\
44,591\end{array}$ & $\begin{array}{l}6,900.36 \\
6,899.64 \\
6,898.90 \\
6,898.17 \\
6,897.62\end{array}$ & $\begin{array}{l}30,844 \\
30,219 \\
29,583 \\
28,965 \\
28,504\end{array}$ \\
\hline $\begin{array}{l}16 \\
17 \\
18 \\
19 \\
2 C\end{array}$ & $\begin{array}{l}6,857.27 \\
6,858.37 \\
6,86 C .35 \\
6,865.53 \\
6,870.43\end{array}$ & $\begin{array}{r}6,205 \\
6,556 \\
7,215 \\
9,102 \\
11,154\end{array}$ & $\begin{array}{l}6,914.57 \\
6,914.32 \\
6,914.67 \\
6,913.88 \\
6,913.46\end{array}$ & $\begin{array}{l}44,581 \\
44,317 \\
44, C 54 \\
43,855 \\
43,417\end{array}$ & $\begin{array}{l}6,897.16 \\
6,896.65 \\
6,896.15 \\
6,895.54 \\
6,894.88\end{array}$ & $\begin{array}{l}28,120 \\
27,700 \\
27,290 \\
26,797 \\
26,267\end{array}$ \\
\hline $\begin{array}{l}21 \\
22 \\
23 \\
24 \\
25\end{array}$ & $\begin{array}{l}6,875.36 \\
6,879.73 \\
6,883.54 \\
6,885.85 \\
6,886.26\end{array}$ & $\begin{array}{l}13,517 \\
15,884 \\
18,175 \\
19,667 \\
19,941\end{array}$ & $\begin{array}{l}6,912 \cdot 91 \\
6,912 \cdot 32 \\
6,911.78 \\
6,911.16 \\
6,910.77\end{array}$ & $\begin{array}{l}42,845 \\
42,238 \\
41,684 \\
41,053 \\
40,659\end{array}$ & $\begin{array}{l}6,894.22 \\
6,893.56 \\
6,893.05 \\
6,892.42 \\
6,891.69\end{array}$ & $\begin{array}{l}25,745 \\
25,229 \\
24,833 \\
24,352 \\
23,800\end{array}$ \\
\hline $\begin{array}{l}26 \\
27 \\
28 \\
29 \\
30\end{array}$ & $\begin{array}{l}6,885 \cdot 88 \\
6,887 \cdot 22 \\
6,891 \cdot 07 \\
6,894 \cdot 14 \\
6,896.96\end{array}$ & $\begin{array}{l}19,687 \\
20,590 \\
23,336 \\
25,682 \\
27,954\end{array}$ & $\begin{array}{l}6,910.41 \\
6,909.77 \\
6,909.03 \\
6,908.25 \\
6,907.56 \\
6,906.84\end{array}$ & $\begin{array}{l}40,296 \\
39,655 \\
38,920 \\
38,154 \\
37,483 \\
36,788\end{array}$ & $\begin{array}{l}6,890.97 \\
6,890.25 \\
6,889.60 \\
6,888.92 \\
6,888.36 \\
6,887.80\end{array}$ & $\begin{array}{l}23,262 \\
22,734 \\
22,262 \\
21,775 \\
21,380 \\
20,989\end{array}$ \\
\hline
\end{tabular}


B1g Creek below Huntington Lake, Calif.

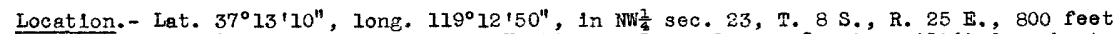
above Grouse Creek and 1 mile velow Funtington Lake, Fresno County. Altitude, about 6,600 feet above mean sea level.

Drainage area. - 80.0 square miles.

Gage-helght record. - Water-stage recorder graph.

stage-discharge relations. - Defined by current-meter measurements.

Maxima.-December 193\%: Discharge, 28 second-feet 2 p.m. Dec. 11 (gage helght, 3.67

feet) represents natural mun-off for small area betwoen dam No. 1 and gage; run-off for major part of dralnage regulated in Kuntington Lake.

1925-November 1937: Discharge, 2,040 second-feet June 23, 1925 (gage helght, 10.3 feet); siphon splllways operating at dam №. 1.

Remarks. - Flood run-of $f$ regulated in Funtington Lake. Seo record for Huntington Lake. Record of adjusted mean dally discharge fumished by Southern California Bdison Co., Ltd., has been adjusted for Ward tumel inflow, Huntington Lake storage, and release to Big Creek power house No. I. Most of basic data furnished by Southern Califormla Edison Co., Ltd.

Observed mean dally discharge, in second-feet, November 1937 to January 1938

\begin{tabular}{|c|c|c|c|c|c|c|c|c|c|c|c|}
\hline Day & Nov. & Dec. & Jan. & Day & Nov. & Dec. & Jan. & Day & Nov. & Dec. & Jan. \\
\hline $\begin{array}{r}1 \\
2 \\
3 \\
4 \\
5 \\
6 \\
7 \\
8 \\
9 \\
10\end{array}$ & $\begin{array}{r}0.3 \\
.3 \\
.3 \\
.3 \\
.3 \\
.3 \\
.3 \\
.2 \\
.2 \\
.3\end{array}$ & $\begin{array}{r}0.2 \\
.2 \\
.2 \\
.2 \\
.2 \\
.2 \\
.2 \\
.2 \\
.4 \\
6\end{array}$ & $\begin{array}{l}0.5 \\
.5 \\
.5 \\
.5 \\
.5 \\
.4 \\
.4 \\
.4 \\
.4 \\
.4\end{array}$ & $\begin{array}{l}11 \\
12 \\
13 \\
14 \\
15 \\
16 \\
17 \\
18 \\
19 \\
20\end{array}$ & $\begin{array}{r}0.3 \\
.3 \\
.3 \\
.3 \\
.3 \\
.3 \\
.4 \\
.3 \\
.3 \\
.3\end{array}$ & $\begin{array}{r}12 \\
3.7 \\
1.7 \\
1.3 \\
.9 \\
.8 \\
.8 \\
.7 \\
.6 \\
.6\end{array}$ & $\begin{array}{r}0.4 \\
.4 \\
.4 \\
.4 \\
.5 \\
.4 \\
.7 \\
.6 \\
.6 \\
.5\end{array}$ & $\begin{array}{l}21 \\
22 \\
23 \\
24 \\
25 \\
26 \\
27 \\
28 \\
29 \\
30 \\
31\end{array}$ & $\begin{array}{r}0.3 \\
.3 \\
.3 \\
.3 \\
.3 \\
.3 \\
.2 \\
.2 \\
.2 \\
.2\end{array}$ & $\begin{array}{l}0.6 \\
.6 \\
.6 \\
.5 \\
.5 \\
.5 \\
.5 \\
.5 \\
.5 \\
.5 \\
.5\end{array}$ & $\begin{array}{l}0.5 \\
.5 \\
.5 \\
.5 \\
.5 \\
.6 \\
.6 \\
.6 \\
.6 \\
.6 \\
.6\end{array}$ \\
\hline \multicolumn{9}{|c|}{ 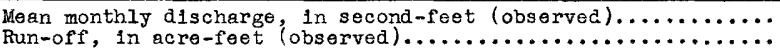 } & $\begin{array}{r}0.28 \\
17\end{array}$ & 1.19 & $\begin{array}{r}.50 \\
31\end{array}$ \\
\hline
\end{tabular}

Ad justed mean dally discharge, in second-feet, Dec. 8-25, 1937

\begin{tabular}{|r|c||c|c||c|c|}
\hline Day & Discharge & Day & Discharge & Day & D1scharge \\
\hline 8 & 15 & 14 & 145 & 20 & 71 \\
9 & 123 & 15 & 127 & 21 & 56 \\
10 & 639 & 16 & 1.04 & 22 & 66 \\
11 & 1,890 & 17 & 95 & 23 & 89 \\
12 & 316 & 18. & 79 & 24 & 51 \\
13 & 183 & 19 & 70 & 25 & 49 \\
\hline
\end{tabular}


Pltman Creek below Tamarack Creek, Cal1f.

Location.- Lat. $37^{\circ} 12^{\prime}$, long. $119^{\circ} 12^{\prime}$, in Wwt sec. 35, T. 8 S., R. 25 E., 500 feet below Tamarack Creek, 3 miles above mouth, and 3 miles southeast of Big Creek, Fresno county. Altitude, about 7,100 feet above mean sea level.

Drainage area.- 22.0 square miles.

Gage-height record. - Water-stage recorder graph.

Stage-discharge relation.- Affected by ice for period Dec. 13 to Jan. 31. Defined by current-meter measurements below 1,000 second-feet; extended to peak stage with ald of area-velocity study. Rating curve changed at peak stage.

Maxima.- December 1937: Discharge, 2,320 second-feet 11:30 a.m. Dec. I1 (gage height, 9.65 feet).

1927-November 1937: Discharge, 885 second-feet May 13, 1937 (gage he1ght, 6.44 feet).

Remarks.- Flood run-off not affected by artificlal storage or diversion. Discharge for period of ice effect determined on basis of one discharge measurement and record for Huntington-Shaver Conduit at outlet. Most of basic data furnished by Southern Galifornia Edison Co., Ltd.

Mean daily discharge, in second-feet, November 1937 to January 1938

\begin{tabular}{|c|c|c|c|c|c|c|c|c|c|c|c|}
\hline Day & Nov. & Dec. & Jan. & Day & Hov. & Dec. & Jan. & Day & Nov. & Dec. & Jan. \\
\hline $\begin{array}{r}1 \\
2 \\
3 \\
4 \\
5 \\
6 \\
7 \\
8 \\
9 \\
10\end{array}$ & $\begin{array}{r}0.3 \\
.3 \\
.3 \\
.3 \\
.3 \\
.3 \\
.3 \\
.3 \\
.3 \\
.3\end{array}$ & $\begin{array}{r}0.5 \\
.5 \\
.5 \\
.5 \\
.5 \\
.5 \\
.4 \\
.4 \\
8.5 \\
139\end{array}$ & $\begin{array}{l}17 \\
20 \\
19 \\
17 \\
17 \\
16 \\
16 \\
14 \\
14 \\
14\end{array}$ & $\begin{array}{l}11 \\
12 \\
13 \\
14 \\
15 \\
16 \\
17 \\
18 \\
19 \\
20\end{array}$ & $\begin{array}{r}0.4 \\
.4 \\
.4 \\
.4 \\
.5 \\
.5 \\
1.4 \\
.9 \\
.7 \\
.7\end{array}$ & $\begin{array}{r}941 \\
143 \\
69 \\
49 \\
43 \\
37 \\
35 \\
31 \\
27 \\
24\end{array}$ & $\begin{array}{l}14 \\
13 \\
13 \\
13 \\
13 \\
16 \\
16 \\
15 \\
14 \\
13\end{array}$ & $\begin{array}{l}21 \\
22 \\
23 \\
24 \\
25 \\
26 \\
27 \\
28 \\
29 \\
30 \\
31\end{array}$ & $\begin{array}{r}0.7 \\
.5 \\
.7 \\
.5 \\
.5 \\
.5 \\
.5 \\
.5 \\
.5 \\
.5\end{array}$ & $\begin{array}{l}23 \\
21 \\
16 \\
13 \\
17 \\
17 \\
17 \\
17 \\
16 \\
17 \\
17\end{array}$ & $\begin{array}{l}13 \\
15 \\
14 \\
13 \\
13 \\
14 \\
14 \\
14 \\
15 \\
14 \\
13\end{array}$ \\
\hline $\begin{array}{l}\text { Mean } \\
\text { Run- }\end{array}$ & $\begin{array}{l}\text { onthl } \\
\text { [, in }\end{array}$ & $\begin{array}{l}\text { is cha } \\
r \theta-f \theta\end{array}$ & 1 & & & & & & $\begin{array}{r}0.49 \\
29\end{array}$ & $\begin{array}{r}56.2 \\
3,450\end{array}$ & $\begin{array}{r}14.7 \\
904\end{array}$ \\
\hline
\end{tabular}

Gage height, In feet, and discharge, in second-feet, at indicated time, 1937

\begin{tabular}{|c|c|c|c|c|c|c|c|c|c|c|c|c|}
\hline \multirow{2}{*}{ 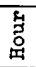 } & Feet & Sec.ft. & Feet & Sec.ft. & Feet & Sec.ft. & Feet & Sec.ft. & Feet & Sec.ft. & Feet & sec.ft. \\
\hline & \multicolumn{2}{|c|}{ December 8} & \multicolumn{2}{|c|}{ Décember 9} & \multicolumn{2}{|c|}{ December 10} & \multicolumn{2}{|c|}{ December 11} & \multicolumn{2}{|c|}{ December 12} & \multicolumn{2}{|c|}{ December 13} \\
\hline $\begin{array}{r}2 \\
4 \\
6 \\
8 \\
10 \\
\mathrm{~N} \\
2 \\
4 \\
6 \\
8 \\
10 \\
\mathrm{M}\end{array}$ & $\begin{array}{l}\overline{1.88} \\
\overline{1.89} \\
\overline{1.90} \\
\overline{1.89} \\
\overline{1.89} \\
-8 \\
1.89\end{array}$ & $\begin{array}{l}- \\
0.3 \\
- \\
-4 \\
- \\
.5 \\
- \\
-4 \\
-4 \\
-4 \\
.4\end{array}$ & $\begin{array}{l}1.89 \\
1.89 \\
1.90 \\
1.90 \\
1.90 \\
1.90 \\
1.90 \\
1.92 \\
1.98 \\
2.42 \\
2.99 \\
3.35\end{array}$ & $\begin{array}{r}0.4 \\
.4 \\
.5 \\
.5 \\
.5 \\
.5 \\
.5 \\
.9 \\
2.3 \\
18 \\
45 \\
70\end{array}$ & $\begin{array}{l}4.02 \\
4.25 \\
4.50 \\
4.83 \\
4.64 \\
4.26 \\
3.85 \\
3.65 \\
3.53 \\
3.52 \\
3.47 \\
3.54\end{array}$ & $\begin{array}{r}132 \\
162 \\
204 \\
278 \\
233 \\
164 \\
114 \\
94 \\
83 \\
83 \\
79 \\
84\end{array}$ & $\begin{array}{l}4.20 \\
4.94 \\
6.00 \\
7.75 \\
9.00 \\
9.44 \\
8.53 \\
6.86 \\
6.38 \\
5.40 \\
4.95 \\
4.67\end{array}$ & $\begin{array}{r}155 \\
305 \\
680 \\
1,470 \\
2,030 \\
2,260 \\
1,780 \\
984 \\
770 \\
412 \\
302 \\
249\end{array}$ & $\begin{array}{l}4.47 \\
4.32 \\
4.20 \\
4.10 \\
4.01 \\
3.94 \\
3.90 \\
3.82 \\
3.72 \\
3.61 \\
3.53 \\
3.47\end{array}$ & $\begin{array}{r}213 \\
189 \\
170 \\
155 \\
143 \\
135 \\
130 \\
120 \\
109 \\
99 \\
92 \\
87\end{array}$ & & \\
\hline
\end{tabular}

\begin{tabular}{|c|c|c|c|c|c|c|}
\hline & December 14 & December 15 & De cember 16 & December 17 & December 18 & December 19 \\
\hline 2 & & & & & & \\
\hline
\end{tabular}

4

8
10

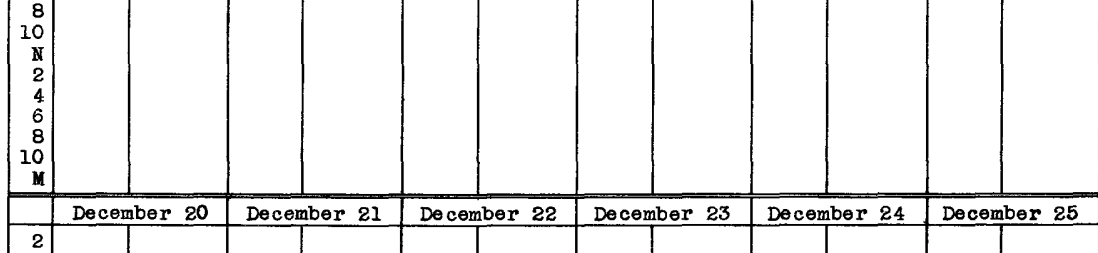

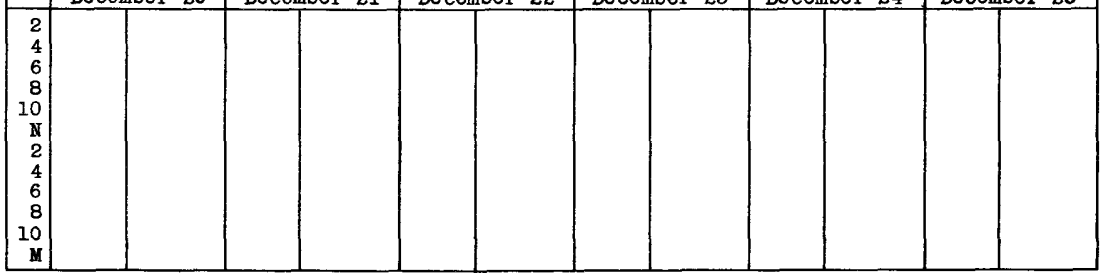

Supplemental records.- Dec. 11, 11:30 a.m., 9.65 ft., 2,320 sec.-ft. 
Shaver Lake near BIg Creek, Calif.

Location. - Lat. $37^{\circ} 09^{\prime}$, long. $119^{\circ} 18^{\prime}$, in SEl seo. 13, T. 9 S., R. 24 S., at dam on Stevenson Creek 6 miles southwest of BIg Creek, Fresno County. Zero of gage is at mean sea level.

Gage-helght reoord. - Water-stage recorder graph.

Remarks.- Flood run-off completely controlied in lake. Elevation of crest of sp1ll-

way is 5,370 feet above mean sea level (capacity, 135,283 aore-feet). Water is recelved from Huntington Lake and Pitman Creek through Huntington-Shaver Conduit and is released through power house $2 \mathrm{~A}$ on BIg Creek. Record of contents and gage height at midnight furnished by Southern California Edison Co., Ltd. Contents show amount available for release.

Elevation and contents, November 1937 to January 1938

\begin{tabular}{|c|c|c|c|c|c|c|}
\hline \multirow[b]{2}{*}{ Day } & \multicolumn{2}{|c|}{ November } & \multicolumn{2}{|c|}{ December } & \multicolumn{2}{|c|}{ January } \\
\hline & $\begin{array}{l}\text { Blevation } \\
\text { (feet) }\end{array}$ & $\begin{array}{l}\text { Contents } \\
(\text { acre-feet })\end{array}$ & $\begin{array}{l}\text { Elevation } \\
\text { (feet) }\end{array}$ & $\begin{array}{l}\text { Contents } \\
(\operatorname{acre}-f e \theta t)\end{array}$ & $\begin{array}{c}\text { Elevation } \\
\text { (feet) }\end{array}$ & $\begin{array}{l}\text { Contents } \\
(\text { acre-feet) }\end{array}$ \\
\hline $\begin{array}{l}1 \\
2 \\
3 \\
4 \\
5\end{array}$ & $\begin{array}{l}5,322.44 \\
5,321.90 \\
5,321.35 \\
5,320.78 \\
5,320.10\end{array}$ & $\begin{array}{l}50,098 \\
49,363 \\
48,618 \\
47,848 \\
46,932\end{array}$ & $\begin{array}{l}5,308.47 \\
5,308.40 \\
5,308.33 \\
5,308.34 \\
5,308.34\end{array}$ & $\begin{array}{l}32,733 \\
32,655 \\
32,577 \\
32,588 \\
32,588\end{array}$ & $\begin{array}{l}5,313.81 \\
5,314.02 \\
5,313.82 \\
5,313.54 \\
5,313.25\end{array}$ & $\begin{array}{l}38,949 \\
39,203 \\
38,961 \\
38,622 \\
38,272\end{array}$ \\
\hline $\begin{array}{r}6 \\
7 \\
8 \\
9 \\
10\end{array}$ & $\begin{array}{l}5,319.32 \\
5,318.96 \\
5,318.46 \\
5,317.93 \\
5,317.36\end{array}$ & $\begin{array}{l}45,904 \\
45,432 \\
44,784 \\
44,098 \\
43,368\end{array}$ & $\begin{array}{l}5,308.22 \\
5,308.11 \\
5,308.05 \\
5,308.20 \\
5,309.48\end{array}$ & $\begin{array}{l}32,454 \\
32,332 \\
32,265 \\
32,432 \\
33,867\end{array}$ & $\begin{array}{l}5,312.96 \\
5,312.64 \\
5,312.47 \\
5,312.40 \\
5,312.06\end{array}$ & $\begin{array}{l}37,922 \\
37,541 \\
37,338 \\
37,255 \\
36,849\end{array}$ \\
\hline $\begin{array}{l}11 \\
12 \\
13 \\
14 \\
15\end{array}$ & $\begin{array}{l}5,317.07 \\
5,316.51 \\
5,315.58 \\
5,314.68 \\
5,313.73\end{array}$ & $\begin{array}{l}42,997 \\
42,289 \\
41,123 \\
40,011 \\
38,852\end{array}$ & $\begin{array}{l}5,312.64 \\
5,313.09 \\
5,313.28 \\
5,313.47 \\
5,313.61\end{array}$ & $\begin{array}{l}37,541 \\
38,079 \\
38,308 \\
38,538 \\
38,707\end{array}$ & $\begin{array}{l}5,311.62 \\
5,311.22 \\
5,310.84 \\
5,310.59 \\
5,310.69\end{array}$ & $\begin{array}{l}36,333 \\
35,864 \\
35,422 \\
35,134 \\
35,249\end{array}$ \\
\hline $\begin{array}{l}16 \\
17 \\
18 \\
19 \\
20\end{array}$ & $\begin{array}{l}5,312.79 \\
5,311.98 \\
5,311.56 \\
5,311.07 \\
5,310.79\end{array}$ & $\begin{array}{l}37,720 \\
36,754 \\
36,262 \\
35,688 \\
35,364\end{array}$ & $\begin{array}{l}5,313.68 \\
5,313.73 \\
5,313.79 \\
5,313.86 \\
5,313.87\end{array}$ & $\begin{array}{l}38,792 \\
38,852 \\
38,925 \\
38,997 \\
39,021\end{array}$ & $\begin{array}{l}5,310.72 \\
5,310.52 \\
5,310.18 \\
5,309.93 \\
5,309.60\end{array}$ & $\begin{array}{l}35,284 \\
35,054 \\
34,662 \\
34,376 \\
34,003\end{array}$ \\
\hline $\begin{array}{l}21 \\
22 \\
23 \\
24 \\
25\end{array}$ & $\begin{array}{l}5,310.68 \\
5,310.12 \\
5,309.52 \\
5,309.00 \\
5,309.02\end{array}$ & $\begin{array}{l}35,238 \\
34,593 \\
33,912 \\
33,324 \\
33,346\end{array}$ & $\begin{array}{l}5,313.84 \\
5,313.87 \\
5,313.88 \\
5,313.89 \\
5,313.95\end{array}$ & $\begin{array}{l}38,985 \\
39,021 \\
39,033 \\
39,045 \\
39,118\end{array}$ & $\begin{array}{l}5,309.34 \\
5,309.25 \\
5,309.27 \\
5,308.94 \\
5,308.58\end{array}$ & $\begin{array}{l}33,708 \\
33,607 \\
33,629 \\
33,257 \\
32,856\end{array}$ \\
\hline $\begin{array}{l}26 \\
27 \\
28 \\
29 \\
30 \\
31\end{array}$ & $\begin{array}{l}5,308.91 \\
5,308.83 \\
5,308.84 \\
5,308.74 \\
5,308.61\end{array}$ & $\begin{array}{l}33,223 \\
33,134 \\
33,145 \\
33,034 \\
32,889\end{array}$ & $\begin{array}{l}5,313.98 \\
5,313.99 \\
5,313.96 \\
5,313.95 \\
5,313.85 \\
5,313.76\end{array}$ & $\begin{array}{l}39,154 \\
39,166 \\
39,130 \\
39,118 \\
38,997 \\
38,888\end{array}$ & $\begin{array}{l}5,308.33 \\
5,307.95 \\
5,307.70 \\
5,307.55 \\
5,307.55 \\
5,307.26\end{array}$ & $\begin{array}{l}32,577 \\
32,154 \\
31,880 \\
31,716 \\
31,716 \\
31,398\end{array}$ \\
\hline
\end{tabular}


North Fork of W1llow Creek at Crane Valley Reservoir, Calif.

Location.- Lat. $37^{\circ} 17^{\prime}$, long. $119^{\circ} 32^{\prime}$, in SW $\frac{3}{4}$ sec. 25, T. 7 S., R. 22 E., at outlet of Crane Valley Reservoir and $4.7 \mathrm{miles}$ north of North Fork, Madera County. Altitude, about 3,250 feet above mean sea level.

Drainage area. - 51.3 square miles.

Remarks.- Flood mun off completely regulated in Crane Valley Reservolr (capacity, about 45,000 acre-feet). In table, observed discharge is water released down creek channel, plus flow in No. 3 ditch, and evaporation. Adjusted discharge has been adjustec for change in storage in reservoir. All data furnished by San Joaquin Light \& Power Corporation.

Discharge, in second-feet, and gain or loss in storage, in acre-feet, November 1937 to January 1938

\begin{tabular}{|c|c|c|c|c|c|c|c|c|c|}
\hline \multirow[b]{2}{*}{ Day } & \multicolumn{3}{|c|}{ November } & \multicolumn{3}{|c|}{ December } & \multicolumn{3}{|c|}{ January } \\
\hline & $\begin{array}{r}\text { Observed } \\
\text { aischarge }\end{array}$ & $\begin{array}{l}\text { Gain or } \\
\text { loss in } \\
\text { storage }\end{array}$ & $\begin{array}{l}\text { Ad jus ted } \\
\text { discharge }\end{array}$ & $\begin{array}{l}\text { Observed } \\
\text { discharge }\end{array}$ & $\begin{array}{l}\text { Gain or } \\
\text { loss in } \\
\text { storage }\end{array}$ & $\begin{array}{l}\text { Ad jus ted } \\
\text { aischarge }\end{array}$ & $\begin{array}{l}\text { Observed } \\
\text { discharge }\end{array}$ & $\begin{array}{l}\text { Gain or } \\
\text { loss in } \\
\text { storage }\end{array}$ & $\begin{array}{l}\text { Adjusted } \\
\text { discharge }\end{array}$ \\
\hline $\begin{array}{l}1 \\
2 \\
3 \\
4 \\
5\end{array}$ & $\begin{array}{l}14 \\
14 \\
16 \\
19 \\
22\end{array}$ & $\begin{array}{r}-16 \\
0 \\
+8 \\
0 \\
-16\end{array}$ & $\begin{array}{r}6 \\
14 \\
20 \\
19 \\
14\end{array}$ & $\begin{array}{l}20 \\
21 \\
68 \\
20 \\
21\end{array}$ & $\begin{array}{l}-16 \\
-16 \\
-94 \\
-15 \\
-8\end{array}$ & $\begin{array}{l}12 \\
13 \\
21 \\
13 \\
17\end{array}$ & $\begin{array}{l}61 \\
97 \\
73 \\
39 \\
30\end{array}$ & $\begin{array}{l}-28 \\
+75 \\
+56 \\
+57 \\
+75\end{array}$ & $\begin{array}{r}47 \\
134 \\
102 \\
68 \\
68\end{array}$ \\
\hline $\begin{array}{r}6 \\
7 \\
8 \\
9 \\
10\end{array}$ & $\begin{array}{l}18 \\
20 \\
14 \\
22 \\
21\end{array}$ & $\begin{array}{l}-8 \\
-8 \\
0 \\
-8 \\
-8\end{array}$ & $\begin{array}{l}14 \\
16 \\
14 \\
18 \\
17\end{array}$ & $\begin{array}{r}20 \\
20 \\
90 \\
90 \\
0\end{array}$ & $\begin{array}{r}-15 \\
-15 \\
-162 \\
+77 \\
+1,688\end{array}$ & $\begin{array}{c}12 \\
13 \\
8,5 \\
129 \\
851\end{array}$ & $\begin{array}{l}34 \\
36 \\
65 \\
64 \\
54\end{array}$ & $\begin{array}{l}+57 \\
+28 \\
+10 \\
-38 \\
+38\end{array}$ & $\begin{array}{l}63 \\
50 \\
70 \\
45 \\
74\end{array}$ \\
\hline $\begin{array}{l}11 \\
12 \\
13 \\
14 \\
15\end{array}$ & $\begin{array}{l}36 \\
20 \\
21 \\
40 \\
20\end{array}$ & $\begin{array}{r}-16 \\
-8 \\
0 \\
-8 \\
-8\end{array}$ & $\begin{array}{l}28 \\
16 \\
21 \\
36 \\
16\end{array}$ & $\begin{array}{l}0 \\
0 \\
1.6 \\
2.4 \\
2.4\end{array}$ & $\begin{array}{r}+4,214 \\
+707 \\
+277 \\
+204 \\
+186\end{array}$ & $\begin{array}{r}2,120 \\
356 \\
141 \\
105 \\
96\end{array}$ & $\begin{array}{l}61 \\
56 \\
54 \\
70 \\
60\end{array}$ & $\begin{array}{r}-10 \\
-9 \\
-10 \\
+285 \\
+496\end{array}$ & $\begin{array}{r}56 \\
52 \\
4.9 \\
213 \\
311\end{array}$ \\
\hline $\begin{array}{l}16 \\
17 \\
18 \\
19 \\
20\end{array}$ & $\begin{array}{l}18 \\
47 \\
28 \\
38 \\
23\end{array}$ & $\begin{array}{r}0 \\
+8 \\
-8 \\
-24 \\
0\end{array}$ & $\begin{array}{l}18 \\
51 \\
24 \\
26 \\
23\end{array}$ & $\begin{array}{l}13 \\
3.2 \\
3.2 \\
3.2 \\
84\end{array}$ & $\begin{array}{r}+205 \\
+195 \\
+167 \\
+149 \\
-18\end{array}$ & $\begin{array}{r}117 \\
102 \\
87 \\
78 \\
75\end{array}$ & $\begin{array}{l}75 \\
54 \\
32 \\
49 \\
54\end{array}$ & $\begin{array}{l}+154 \\
+202 \\
+241 \\
+146 \\
+136\end{array}$ & $\begin{array}{l}152 \\
155 \\
153 \\
123 \\
122\end{array}$ \\
\hline $\begin{array}{l}21 \\
22 \\
23 \\
24 \\
25\end{array}$ & $\begin{array}{l}37 \\
36 \\
24 \\
23 \\
20\end{array}$ & $\begin{array}{r}-16 \\
-40 \\
-24 \\
-24 \\
-8\end{array}$ & $\begin{array}{l}29 \\
16 \\
12 \\
10 \\
16\end{array}$ & $\begin{array}{l}33 \\
30 \\
33 \\
30 \\
75\end{array}$ & $\begin{array}{r}+83 \\
+140 \\
+46 \\
+84 \\
-37\end{array}$ & $\begin{array}{r}75 \\
101 \\
56 \\
73 \\
56\end{array}$ & $\begin{array}{l}55 \\
53 \\
82 \\
54 \\
74\end{array}$ & $\begin{array}{l}+87 \\
+98 \\
+30 \\
+78 \\
+20\end{array}$ & $\begin{array}{r}99 \\
102 \\
97 \\
93 \\
84\end{array}$ \\
\hline $\begin{array}{l}26 \\
27 \\
28 \\
29 \\
30 \\
31\end{array}$ & $\begin{array}{l}20 \\
22 \\
22 \\
23 \\
22\end{array}$ & $\begin{array}{r}-8 \\
0 \\
-16 \\
-16 \\
-15\end{array}$ & $\begin{array}{l}16 \\
22 \\
14 \\
15 \\
14\end{array}$ & $\begin{array}{l}51 \\
36 \\
41 \\
51 \\
40 \\
31\end{array}$ & $\begin{array}{r}+28 \\
+65 \\
+76 \\
0 \\
-10 \\
+66\end{array}$ & $\begin{array}{l}65 \\
69 \\
79 \\
51 \\
35 \\
64\end{array}$ & $\begin{array}{l}74 \\
55 \\
56 \\
48 \\
68 \\
40\end{array}$ & $\begin{array}{r}-10 \\
+98 \\
+176 \\
+137 \\
+40 \\
+456\end{array}$ & $\begin{array}{r}69 \\
104 \\
145 \\
118 \\
88 \\
270\end{array}$ \\
\hline \multirow{2}{*}{\multicolumn{2}{|c|}{$\begin{array}{l}\text { Mean monthly } \\
\text { Gain or loss } \\
\text { Mean monthly } \\
\text { Run-off, in }\end{array}$}} & \multirow[b]{2}{*}{$\begin{array}{l}\text { discharg } \\
\text { in stora } \\
\text { discharg } \\
\text { gre-feet }\end{array}$} & \multirow[b]{2}{*}{$\begin{array}{l}\text { In sec } \\
\text {, in ac } \\
\text { in adjustec }\end{array}$} & \multirow{2}{*}{\multicolumn{2}{|c|}{$\begin{array}{l}\text { (observed) } \\
\text { (adjuste..... } \\
\ldots \ldots \ldots . . . .\end{array}$}} & \multirow[b]{2}{*}{$\begin{array}{c}\ldots \ldots \\
\ldots \ldots \\
\ldots \ldots \\
\ldots \ldots\end{array}$} & November & December & January \\
\hline & & & & & & & $\begin{array}{r}24.0 \\
-287 \\
19.2 \\
1,140\end{array}$ & $\begin{array}{r}30.2 \\
+8,250 \\
164 \\
10,110\end{array}$ & $\begin{array}{r}57.3 \\
+3,170 \\
109 \\
6,700\end{array}$ \\
\hline
\end{tabular}


B1g Sandy Creek near Auberry, Calif.

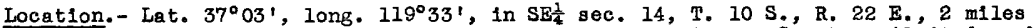
above mouth and about 5 miles southwest of Auberry, Fresno County. Altitude, about 1,300 feet above mean sea level.

Drainage area.- 34 square miles.

Gage-height record. - Water-atage recorder graph.

Stage-discharge relation. - Defined by current-meter megsurements.

Taxima.-December 1937: Discharge, 1,850 second-feet 6:30 p.m. Dec. 11 (gage he1ght, 5.4 feet).

Remarks. - Record furnished by State engineer.

Mean dally discharge, in second-feet, November 1937 to January 1938

\begin{tabular}{|c|c|r|r||r|r|r|r|r|r|r|r|}
\hline Day & Nov. & Dec. & Jan. & Day & Nov. & Dec. & Jan. & Day & Nov. & Dec. & Jan. \\
\hline 1 & 0.2 & 0.3 & 3 & 11 & 0.3 & 511 & 5 & 21 & 0.3 & 3.3 & 23 \\
2 & 0 & .3 & 14 & 12 & .3 & 139 & 6 & 22 & .3 & 3.0 & 19 \\
3 & 0 & .3 & 13 & 13 & .3 & 30 & 6 & 23 & .3 & 12 & 18 \\
4 & .2 & .3 & 7 & 14 & .3 & 16 & 11 & 24 & .3 & 6 & 15 \\
5 & .2 & .3 & 5 & 15 & .3 & 11 & 230 & 25 & .3 & 4.0 & 15 \\
6 & .2 & .3 & 5 & 16 & .3 & 8 & 42 & 26 & .3 & 4.0 & 14 \\
7 & .2 & .3 & 5 & 17 & .3 & 6 & 43 & 27 & .3 & 3.3 & 14 \\
8 & .3 & .3 & 4.0 & 18 & .3 & 6 & 27 & 28 & .3 & 2.8 & 20 \\
9 & .3 & .4 & 4.0 & 19 & .3 & 5 & 46 & 29 & .3 & 2.8 & 51 \\
10 & .3 & 61 & 4.0 & 20 & .3 & 4.0 & 52 & 30 & .3 & 2.8 & 28 \\
\multicolumn{7}{|l|}{} \\
\hline
\end{tabular}

Gage helght, in feet, and discharge, in second-feet, at indicated time, 1937

\begin{tabular}{|c|c|c|c|c|c|c|c|c|c|c|c|}
\hline \multirow{2}{*}{ 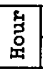 } & Feot Sec.ft. & Feet & Sec.ft. & Feet & sec.et. & Feet & sec.ft. & Feet & Sec.ft. & Feet & Sec.ft. \\
\hline & December 8 & \multicolumn{2}{|c|}{ December 9} & \multicolumn{2}{|c|}{ December 10} & \multicolumn{2}{|c|}{ December 11} & \multicolumn{2}{|c|}{ December 12} & \multicolumn{2}{|c|}{ December 13} \\
\hline \begin{tabular}{r|}
2 \\
4 \\
6 \\
8 \\
10 \\
$\mathbb{N}$ \\
2 \\
4 \\
6 \\
8 \\
10 \\
$M$
\end{tabular} & & $\begin{array}{l}1.08 \\
1.08 \\
1.08 \\
1.08 \\
1.08 \\
1.08 \\
1.08 \\
1.09 \\
1.12 \\
1.17 \\
1.26 \\
1.31\end{array}$ & $\begin{array}{l}0.3 \\
.3 \\
.3 \\
.3 \\
.3 \\
.3 \\
.3 \\
.3 \\
.3 \\
.5 \\
.7 \\
.8\end{array}$ & $\begin{array}{l}1.33 \\
1.38 \\
1.44 \\
1.49 \\
1.95 \\
2.48 \\
2.38 \\
2.25 \\
2.14 \\
2.05 \\
1.93 \\
1.84\end{array}$ & \begin{tabular}{|c|}
0.9 \\
1.4 \\
2.4 \\
3.6 \\
48 \\
187 \\
154 \\
117 \\
88 \\
65 \\
45 \\
34
\end{tabular} & $\begin{array}{l}1.77 \\
1.80 \\
1.85 \\
1.93 \\
2.12 \\
3.88 \\
4.10 \\
3.75 \\
5.00 \\
4.30 \\
3.50 \\
3.11\end{array}$ & $\begin{array}{r}27 \\
30 \\
35 \\
45 \\
83 \\
808 \\
903 \\
737 \\
1,540 \\
1,050 \\
614 \\
435\end{array}$ & $\begin{array}{l}2.77 \\
2.55 \\
2.41 \\
2.30 \\
2.25 \\
2.20 \\
2.22 \\
2.20 \\
2.13 \\
2.04 \\
2.00 \\
1.94\end{array}$ & \begin{tabular}{|r|}
289 \\
210 \\
163 \\
130 \\
117 \\
104 \\
109 \\
104 \\
86 \\
63 \\
57 \\
47
\end{tabular} & $\begin{array}{l}1.90 \\
1.87 \\
1.85 \\
1.83 \\
1.80 \\
1.78 \\
1.76 \\
1.76 \\
1.75 \\
1.74 \\
1.72 \\
1.71\end{array}$ & \begin{tabular}{|l|}
40 \\
37 \\
35 \\
33 \\
30 \\
28 \\
26 \\
26 \\
25 \\
24 \\
22 \\
21
\end{tabular} \\
\hline
\end{tabular}

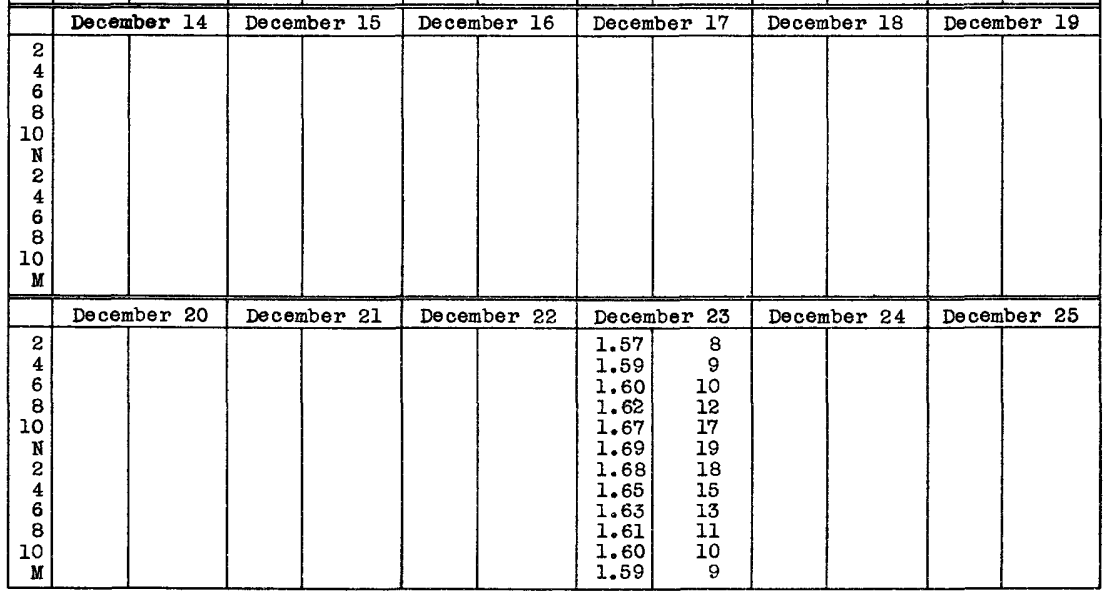


Fine Gold Creek near Friant, Calif.

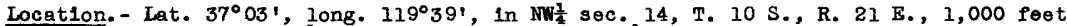
below Willow Creok, $1 \frac{1}{2}$ miles above mouth, and $5 \frac{1}{2}$ milos northoast of Friant, Fresno county. Altitude, about 680 feet above mean sea level.

Dralnage area.- 89.2 square miles.

Gage-helght record. - Water-stage recorder graph.

Stage-discharge relation.- Defined by current-meter measurements below 1,100 secondfeet; extended on basis of arift-velocity determination of 6,300 second-feet. Rating curve changed at peak stage.

Maxima.- December 1937: Discharge, 4,900 second-feet 6 p.m. Dec. 11 (gage height, 13.95 feet).

1936-November 1937: Discharge, 6,780 second-feet Feb. 6, 1937 (gage height, 16. 45 feet), from rating curve extended above 6,300 second-feet.

January-September 1938: Discharge, 10,300 second-feet about" 9 p.m. Mar. 12

(gage helght, 20.4 feet, from floodmarks), from rating curve extended above 6,300

second-feet on basis of area-velocity study.

Remarks.- Flood run-off not affected by artificlal storage or diversion.

Mean daily discharge, in second-feet, November 1937 to January 1938

\begin{tabular}{|c|c|c|c|c|c|c|c|c|c|c|c|}
\hline Day & Nov. & Dec. & Jan. & Day & Nov. & Dec. & Jan. & Day & Nov. & Dec. & Jan. \\
\hline $\begin{array}{r}1 \\
2 \\
3 \\
4 \\
5 \\
6 \\
7 \\
8 \\
9 \\
10\end{array}$ & $\begin{array}{l}2.1 \\
2.3 \\
2.3 \\
2.3 \\
2.1 \\
2.1 \\
2.3 \\
2.6 \\
2.7 \\
2.7\end{array}$ & $\begin{array}{r}3.7 \\
3.7 \\
3.7 \\
3.7 \\
3.9 \\
3.9 \\
4.7 \\
4.7 \\
5.5 \\
397\end{array}$ & $\begin{array}{l}12 \\
14 \\
21 \\
14 \\
13 \\
13 \\
12 \\
12 \\
12 \\
12\end{array}$ & $\begin{array}{l}11 \\
12 \\
13 \\
14 \\
15 \\
16 \\
17 \\
18 \\
19 \\
20\end{array}$ & $\begin{array}{l}3.2 \\
4.3 \\
3.7 \\
3.5 \\
3.5 \\
3.5 \\
4.1 \\
4.6 \\
3.9 \\
3.7\end{array}$ & $\begin{array}{r}1,610 \\
392 \\
91 \\
44 \\
30 \\
24 \\
20 \\
17 \\
16 \\
15\end{array}$ & $\begin{array}{r}11 \\
11 \\
11 \\
67 \\
1,030 \\
181 \\
173 \\
104 \\
100 \\
141\end{array}$ & $\begin{array}{l}21 \\
22 \\
23 \\
24 \\
25 \\
26 \\
27 \\
28 \\
29 \\
30 \\
31\end{array}$ & $\begin{array}{l}3.7 \\
3.7 \\
3.7 \\
3.7 \\
3.7 \\
3.7 \\
3.9 \\
3.9 \\
3.7 \\
3.7\end{array}$ & $\begin{array}{l}14 \\
14 \\
23 \\
17 \\
14 \\
14 \\
13 \\
12 \\
12 \\
12 \\
12\end{array}$ & $\begin{array}{r}81 \\
66 \\
55 \\
49 \\
44 \\
41 \\
39 \\
58 \\
205 \\
92 \\
100\end{array}$ \\
\hline $\begin{array}{l}\text { Mean } \\
\text { Run- }\end{array}$ & , in & $r e-$ & & & & & & & $\begin{array}{r}3.30 \\
196\end{array}$ & $\begin{array}{r}91.9 \\
5,650\end{array}$ & $\begin{array}{r}90.1 \\
5,540\end{array}$ \\
\hline
\end{tabular}

Gage helght, in feet, and discharge, in second-feet, at indicated time, 1937

\begin{tabular}{|c|c|c|c|c|c|c|c|c|c|c|c|c|}
\hline \multirow{2}{*}{$\begin{array}{l}\text { 岁 } \\
\text { 品 }\end{array}$} & Feet & Sec.ft. & Feet & Sec,ft. & Feet & Sec.ft. & Feet & Sec.ft. & $F \theta e t$ & Sec.ft. & Feet & Sec.ft. \\
\hline & \multicolumn{2}{|c|}{ December 8} & \multicolumn{2}{|c|}{ December 9} & \multicolumn{2}{|c|}{ December 10} & \multicolumn{2}{|c|}{ December 11} & \multicolumn{2}{|c|}{ December 12} & \multicolumn{2}{|c|}{ December 13} \\
\hline $\begin{array}{r}2 \\
4 \\
6 \\
8 \\
10 \\
1 \\
2 \\
4 \\
6 \\
8 \\
10 \\
M\end{array}$ & $\begin{array}{l}\overline{-} \\
\overline{1.10} \\
\overline{-} \\
\overline{1.12} \\
- \\
\overline{1.13} \\
\overline{-} \\
\overline{1.13}\end{array}$ & $\begin{array}{c}- \\
- \\
3.7 \\
- \\
- \\
4.1 \\
- \\
- \\
4.3 \\
- \\
4.3\end{array}$ & $\begin{array}{l}1.12 \\
1.12 \\
1.12 \\
1.13 \\
1.13 \\
1.13 \\
1.14 \\
1.15 \\
1.20 \\
1.29 \\
1.46 \\
1.59\end{array}$ & $\begin{array}{l}4.1 \\
4.1 \\
4.1 \\
4.3 \\
4.3 \\
4.3 \\
4.5 \\
4.6 \\
5.6 \\
7.5 \\
12 \\
15\end{array}$ & $\begin{array}{l}1.75 \\
2.02 \\
2.60 \\
3.35 \\
5.30 \\
6.98 \\
6.10 \\
5.26 \\
4.75 \\
4.19 \\
3.80 \\
3.35\end{array}$ & \begin{tabular}{|r}
21 \\
34 \\
86 \\
212 \\
618 \\
1,060 \\
818 \\
609 \\
497 \\
380 \\
302 \\
212
\end{tabular} & $\begin{array}{r}3.05 \\
2.86 \\
2.81 \\
3.01 \\
3.85 \\
11.08 \\
10.80 \\
10.60 \\
13.95 \\
11.50 \\
8.95 \\
7.25\end{array}$ & $\begin{array}{r}153 \\
122 \\
114 \\
146 \\
312 \\
2,900 \\
2,730 \\
2,610 \\
4,900 \\
3,160 \\
1,780 \\
1,140\end{array}$ & $\begin{array}{l}5.86 \\
5.13 \\
4.43 \\
4.05 \\
4.05 \\
3.94 \\
3.89 \\
3.80 \\
3.52 \\
3.35 \\
3.19 \\
3.06\end{array}$ & $\begin{array}{l}756 \\
581 \\
428 \\
352 \\
352 \\
330 \\
320 \\
302 \\
246 \\
212 \\
180 \\
155\end{array}$ & $\begin{array}{l}2.97 \\
2.89 \\
2.82 \\
2.74 \\
2.69 \\
2.62 \\
2.55 \\
2.50 \\
2.44 \\
2.39 \\
2.35 \\
2.30\end{array}$ & $\begin{array}{r}139 \\
126 \\
116 \\
105 \\
98 \\
89 \\
80 \\
74 \\
68 \\
63 \\
60 \\
56\end{array}$ \\
\hline & \multicolumn{2}{|c|}{ December 14} & \multicolumn{2}{|c|}{ December 15} & \multicolumn{2}{|c|}{ December 16} & \multicolumn{2}{|c|}{ December 17} & \multicolumn{2}{|c|}{ December 18} & \multicolumn{2}{|c|}{ December 19} \\
\hline \multirow[t]{2}{*}{$\begin{array}{r}2 \\
4 \\
6 \\
8 \\
10 \\
\mathbf{N} \\
2 \\
4 \\
6 \\
8 \\
10 \\
\mathbf{M}\end{array}$} & $\begin{array}{c}- \\
2.23 \\
- \\
2.17 \\
- \\
2.13 \\
- \\
2.09 \\
- \\
2.05 \\
- \\
2.00\end{array}$ & $\begin{array}{l}- \\
50 \\
\overline{46} \\
\overline{43} \\
\overline{40} \\
\overline{3} 8 \\
\overline{35}\end{array}$ & $\begin{array}{l}\overline{-} \\
\overline{1.95} \\
- \\
\overline{1.9} \\
\bar{z} \\
\overline{1.80} \\
\overline{1.87} \\
\overline{1.84}\end{array}$ & $\begin{array}{l}\overline{3} \\
\overline{32} \\
\overline{30} \\
\overline{-} \\
\overline{28} \\
\overline{-} \\
\overline{27}\end{array}$ & $\begin{array}{l}\overline{-} \\
1.80 \\
- \\
\overline{1.76} \\
\overline{-} \\
\overline{1.73} \\
\overline{-} \\
\overline{1.71}\end{array}$ & $\begin{array}{l}\overline{-} \\
25 \\
\overline{23} \\
\overline{23} \\
\overline{22} \\
\overline{21}\end{array}$ & $\begin{array}{l}\overline{-} \\
1.69 \\
- \\
\overline{1.67} \\
\overline{-} \\
\overline{1.65} \\
\overline{-} \\
\overline{1.64}\end{array}$ & $\begin{array}{l}\overline{-} \\
21 \\
\overline{2} \\
20 \\
\overline{1} \\
19 \\
\overline{19}\end{array}$ & $\begin{array}{l}\overline{-} \\
\overline{1.62} \\
- \\
\overline{1.61} \\
\overline{-} \\
\overline{1.60} \\
\overline{-} \\
\overline{1.59}\end{array}$ & $\begin{array}{l}- \\
18 \\
\overline{17} \\
= \\
\overline{17} \\
\overline{-} \\
17\end{array}$ & $\begin{array}{l}\overline{-} \\
1.58 \\
- \\
\overline{1.56} \\
\overline{-} \\
\overline{1.55} \\
- \\
\overline{1.54}\end{array}$ & $\begin{array}{l}- \\
16 \\
\overline{16} \\
\overline{16} \\
\overline{16} \\
\overline{-} \\
\overline{15}\end{array}$ \\
\hline & \multicolumn{2}{|c|}{ December 20} & \multicolumn{2}{|c|}{ December 21} & \multicolumn{2}{|c|}{ December 22} & \multicolumn{2}{|c|}{ December 23} & \multicolumn{2}{|c|}{ December 24} & \multicolumn{2}{|c|}{ December 25} \\
\hline $\begin{array}{r}2 \\
4 \\
6 \\
8 \\
10 \\
1 \\
2 \\
4 \\
6 \\
8 \\
10 \\
M\end{array}$ & $\begin{array}{l}\overline{-} \\
\overline{1.54} \\
- \\
\overline{1.53} \\
- \\
\overline{1.51} \\
- \\
\overline{1.50}\end{array}$ & $\begin{array}{l}- \\
\overline{15} \\
- \\
\overline{15} \\
\overline{-} \\
\overline{14} \\
\overline{-} \\
\overline{14}\end{array}$ & $\begin{array}{l}\overline{-} \\
\overline{-} \\
\overline{-} \\
\overline{1.50} \\
\overline{-} \\
\overline{-} \\
\overline{-} \\
\overline{1.49}\end{array}$ & $\begin{array}{l}- \\
- \\
- \\
\overline{1} \\
- \\
\overline{-} \\
\overline{-} \\
\overline{14}\end{array}$ & $\begin{array}{c}- \\
\overline{-} \\
\overline{-} \\
\overline{1.49} \\
\overline{-} \\
\overline{-} \\
\overline{1.49}\end{array}$ & $\begin{array}{l}- \\
- \\
- \\
- \\
14 \\
- \\
- \\
- \\
- \\
- \\
14\end{array}$ & $\begin{array}{c}- \\
1.60 \\
- \\
1.73 \\
- \\
1.80 \\
- \\
1.85 \\
- \\
1.84 \\
- \\
1.74\end{array}$ & $\begin{array}{l}\overline{17} \\
\overline{22} \\
\overline{25} \\
\overline{28} \\
\overline{27} \\
\overline{23}\end{array}$ & $\begin{array}{c}- \\
1.66 \\
- \\
1.61 \\
- \\
1.59 \\
- \\
1.56 \\
- \\
1.54 \\
- \\
1.53\end{array}$ & $\begin{array}{l}\overline{19} \\
\overline{17} \\
\overline{17} \\
\overline{16} \\
\overline{15} \\
\overline{15}\end{array}$ & $\begin{array}{c}- \\
\overline{1.52} \\
- \\
\overline{1.51} \\
- \\
\overline{1.50} \\
- \\
\overline{1.50}\end{array}$ & $\begin{array}{l}- \\
15 \\
\overline{-} \\
14 \\
- \\
\overline{14} \\
\overline{14}\end{array}$ \\
\hline
\end{tabular}


Location. - Lat. $37^{\circ} 00^{\prime}$, long. $119^{\circ} 43^{\prime}$, in SEt sec. 6, T. 11 S., R. 21 E., half a mile above mouth and about 1 mile northwest of Friant, Madera county. Altitude, about 360 feet above mean sea level.

Drainage area.- 38 square miles.

Gage-helght record. - Water-stage recorder graph.

Stage-discharge relation. - Defined by current-meter messurements.

Haxima:- December 1937: Discharge, 180 second-feet at 6 p.m. Dec. 11 (gage height, 2.50 (eet).

Remarks.- Record furnished by State engineer.

Yean dally discharge, in second-feet, Hovember 1937 to January 1938

\begin{tabular}{|c|c|c|c|c|c|c|c|c|c|c|c|}
\hline Day & Nov. & Dec. & Jan. & Day & Nov. & Dec. & Jan. & Day & Nov. & Dec. & Jan. \\
\hline 1 & 0 & 0 & 0.5 & 11 & 0 & 42 & 0.5 & 21 & 0 & 0.5 & 13 \\
2 & 0 & 0 & .9 & 12 & 0 & 8.5 & 0.5 & 22 & 0 & 0.5 & 12 \\
3 & 0 & 0 & .5 & 13 & 0 & 2.4 & 0.5 & 23 & 0 & 1.4 & 11 \\
4 & 0 & 0 & .5 & 14 & 0 & 1.1 & 3.0 & 24 & 0 & .9 & 10 \\
5 & 0 & 0 & .5 & 15 & 0 & .6 & 74 & 25 & 0 & .5 & 9 \\
6 & 0 & 0 & .5 & 16 & 0 & .5 & 22 & 26 & 0 & .5 & 9 \\
7 & 0 & 0 & .5 & 17 & 0 & .5 & 26 & 27 & 0 & .5 & 9 \\
8 & 0 & 0 & .5 & 18 & 0 & .5 & 17 & 28 & 0 & .5 & 18 \\
9 & 0 & 0 & .5 & 19 & 0 & .5 & 20 & 29 & 0 & .5 & 53 \\
10 & 0 & .5 & .5 & 20 & 0 & .5 & 20 & 30 & 0 & .5 & 23 \\
\end{tabular}

Gage height, In feot, and discharge, in second-feet, at indicated time, 1937

\begin{tabular}{|c|c|c|c|c|c|c|c|c|c|c|}
\hline \multirow{2}{*}{$\begin{array}{l}{ }^{2} \\
\text { 吕 }\end{array}$} & Feet Isec.ft. & Feet l sec.ft. & Feet & Sec.ft. & Feet & sec.ft & Poet & sec.ft. & Foot & sec.ft. \\
\hline & December 8 & December 9 & \multicolumn{2}{|c|}{ December 10} & \multicolumn{2}{|c|}{ December 11} & \multicolumn{2}{|c|}{ December 12} & \multicolumn{2}{|c|}{ December 13} \\
\hline \begin{tabular}{r|}
2 \\
4 \\
6 \\
8 \\
10 \\
11 \\
2 \\
4 \\
6 \\
8 \\
10 \\
1
\end{tabular} & & & $\begin{array}{l}= \\
= \\
= \\
= \\
= \\
0.76 \\
.76 \\
.75 \\
.75\end{array}$ & $\begin{array}{l}0 \\
0 \\
0 \\
0 \\
0 \\
0 \\
0 \\
0 \\
.8 \\
.8 \\
.6 \\
.6\end{array}$ & $\begin{array}{r}0.74 \\
.73 \\
.73 \\
.80 \\
.83 \\
.95 \\
1.00 \\
1.35 \\
2.50 \\
2.35 \\
1.86 \\
1.52\end{array}$ & $\begin{array}{r}0.5 \\
0.5 \\
0.5 \\
1.4 \\
2.0 \\
5 \\
7 \\
27 \\
180 \\
154 \\
83 \\
44\end{array}$ & $\begin{array}{l}1.32 \\
1.20 \\
1.13 \\
1.07 \\
1.03 \\
1.00 \\
.97 \\
.95 \\
.94 \\
.92 \\
.90 \\
.88\end{array}$ & $\begin{array}{l}25 \\
16 \\
12 \\
9.5 \\
8 \\
7 \\
6 \\
5 \\
4.9 \\
4.3 \\
3.7 \\
3.2\end{array}$ & & \\
\hline
\end{tabular}


Location. - Lat. $36^{\circ} 56^{\prime}$, long. $119^{\circ} 41^{\prime}$, in SWt sec. 28 , T. 11 S., R. 21 E., about 3.5 miles southeast of Friant, Fresno County, and 4 miles upstream from mouth. Altitude, about 360 feet above mean sea level.

Drainage area. - 58 square miles.

Gage-helght record. - Water-stage recorder graph.

Stage-discharge relation. - Defined by current-meter measurements.

Maxima- December 1937: Discharge, 198 second-fe日t 2 a.m. Dec. I2 (gage helght, 2.81 fert).

Remarks.- Record furnished by State engineer.

Kean dally dscharge, in second-feet, November 1937 to January 1938

\begin{tabular}{|c|c|c|c|c|c|c|c|c|c|c|c|}
\hline Dey & Nov. & Dec. & Jan. & Day & Nov. & Dec. & Jan. & Day & Nov. & Dec. & Jan. \\
\hline $\begin{array}{r}1 \\
2 \\
3 \\
4 \\
5 \\
6 \\
7 \\
8 \\
9 \\
10\end{array}$ & $\begin{array}{l}0 \\
0 \\
0 \\
0 \\
0 \\
0 \\
0 \\
0 \\
0 \\
0\end{array}$ & $\begin{array}{l}0 \\
0 \\
0 \\
0 \\
0 \\
0 \\
0 \\
0 \\
0 \\
1.8\end{array}$ & $\begin{array}{l}6 \\
9.5 \\
13 \\
8 \\
7.5 \\
7.5 \\
7.5 \\
7 \\
6 \\
6\end{array}$ & $\begin{array}{l}11 \\
12 \\
13 \\
14 \\
15 \\
16 \\
17 \\
18 \\
19 \\
20\end{array}$ & $\begin{array}{l}0 \\
0 \\
0 \\
0 \\
0 \\
0 \\
0 \\
0 \\
0 \\
0\end{array}$ & $\begin{array}{l}39 \\
85 \\
21 \\
11 \\
9 \\
8.5 \\
8 \\
8.5 \\
8 \\
7.5\end{array}$ & $\begin{array}{c}5.5 \\
5 \\
4.6 \\
19 \\
270 \\
53 \\
56 \\
32 \\
35 \\
39\end{array}$ & $\begin{array}{l}21 \\
22 \\
23 \\
24 \\
25 \\
26 \\
27 \\
28 \\
29 \\
30 \\
31\end{array}$ & $\begin{array}{l}0 \\
0 \\
0 \\
0 \\
0 \\
0 \\
0 \\
0 \\
0 \\
0\end{array}$ & $\begin{array}{l}7.5 \\
7 \\
9 \\
8.5 \\
7.5 \\
7 \\
6 \\
6 \\
6 \\
6 \\
6\end{array}$ & $\begin{array}{l}21 \\
17 \\
14 \\
13 \\
11 \\
11 \\
10 \\
25 \\
86 \\
31 \\
42\end{array}$ \\
\hline $\begin{array}{l}\text { Mean } \\
\text { Run- }\end{array}$ & nth] & . & 1 & & & & & & $\begin{array}{l}0 \\
0\end{array}$ & $\begin{array}{l}9.2 \\
563\end{array}$ & $\begin{array}{r}28.3 \\
1,740\end{array}$ \\
\hline
\end{tabular}

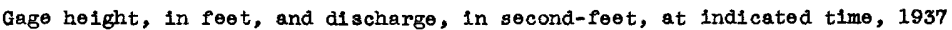

\begin{tabular}{|c|c|c|c|c|c|c|c|c|c|c|c|c|}
\hline \multirow{2}{*}{ 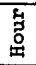 } & Feet & Sec.ft. & Feet & Sec. ft. & Feet & Sec.ft. & Feet & Sec.ft. & Feet & Sec.ft. & Feet & Sec.ft. \\
\hline & \multicolumn{2}{|c|}{ December 8} & \multicolumn{2}{|c|}{ December 9} & \multicolumn{2}{|c|}{ December 10} & \multicolumn{2}{|c|}{ December 11} & \multicolumn{2}{|c|}{ December 12} & \multicolumn{2}{|c|}{ December 13} \\
\hline $\begin{array}{r}2 \\
4 \\
6 \\
8 \\
10 \\
\mathrm{~N} \\
2 \\
4 \\
6 \\
8 \\
10 \\
M\end{array}$ & & & & & $\begin{array}{l}- \\
- \\
1.00 \\
1.10 \\
1.10 \\
1.10 \\
1.10 \\
1.08 \\
1.06 \\
1.05 \\
1.03 \\
1.03\end{array}$ & $\begin{array}{l}0 \\
0 \\
1.8 \\
2.5 \\
2.5 \\
2.5 \\
2.5 \\
2.4 \\
2.3 \\
2.2 \\
2.0 \\
2.0\end{array}$ & $\begin{array}{l}1.02 \\
1.02 \\
1.05 \\
1.12 \\
1.16 \\
1.20 \\
1.30 \\
1.65 \\
2.00 \\
2.50 \\
2.67 \\
2.77\end{array}$ & $\begin{array}{c}1.9 \\
1.9 \\
2.2 \\
2.7 \\
3.0 \\
3.4 \\
5.5 \\
18 \\
47 \\
122 \\
162 \\
187\end{array}$ & $\begin{array}{l}2.81 \\
2.58 \\
2.40 \\
2.28 \\
2.17 \\
2.10 \\
2.05 \\
2.05 \\
2.04 \\
2.04 \\
1.98 \\
1.92\end{array}$ & \begin{tabular}{|r|}
198 \\
140 \\
104 \\
85 \\
69 \\
59 \\
53 \\
53 \\
52 \\
52 \\
45 \\
38
\end{tabular} & & \\
\hline
\end{tabular}


Location. - Lat. $37^{\circ} 14^{\prime}$, long. $119^{\circ} 46^{\prime}$, in $\mathrm{NW}^{\mathrm{t}} \mathrm{s}$ sec. 15, T. 8 S., R. 20 E., at Fresno crossing, 0.1 mile below Bean Gulch and 6 miles northeast of Knowles, Madera County. Altitude, about 1,140 feet above mean sea level.

Dralnage area.- 132 square miles.

Gage-helght record. - Water-stage recorder graph.

Stage-discharge relation. - Defined by current-meter measuraments below 6,000 secondfeot.

Max1ma.- December 1937: D1scharge, 3,380 second-feet 4 p.m. Dec. 11 (gage helght, 5.57 feet).

1911-13, 1915-November 1937: D1scharge, 6,880 second-feet Feb. 6, 1937 (gage height, 8.16 feat).

January-September 1938: D1scharge, 7,630 second-feet 5 p.m. Mar. 12 (gage

helght, 8.67 feet), from rating curve extended above 6,000 second-feet.

Remarks. - Flood run-off not materially affected by artiflc1al storage or diversion.

Mean da1ly discharge, in second-feet, November 1937 to January 1938

\begin{tabular}{|r|c|c|c||c|c|c|c|c|c|c|c|}
\hline Day & Nov. & Dec. & Jan. & Day & Nov. & Dec. & Jan. & Day & Nov. & Dec. & Jan. \\
\hline 1 & 10 & 18 & 26 & 11 & 13 & 1,480 & 26 & 21 & 19 & 31 & 118 \\
2 & 14 & 18 & 30 & 12 & 19 & 488 & 26 & 22 & 19 & 31 & 101 \\
3 & 18 & 18 & 48 & 13 & 19 & 136 & 26 & 23 & 18 & 40 & 90 \\
4 & 13 & 17 & 36 & 14 & 19 & 81 & 95 & 24 & 18 & 34 & 81 \\
5 & 9.5 & 17 & 33 & 15 & 20 & 59 & 846 & 25 & 18 & 30 & 76 \\
6 & 9.5 & 18 & 31 & 16 & 19 & 50 & 246 & 26 & 18 & 29 & 70 \\
7 & 9.5 & 18 & 30 & 17 & 20 & 43 & 232 & 27 & 18 & 29 & 66 \\
8 & 10 & 17 & 29 & 18 & 34 & 38 & 190 & 28 & 17 & 29 & 94 \\
9 & 10 & 19 & 27 & 19 & 25 & 34 & 160 & 29 & 17 & 27 & 43 \\
10 & 11 & 517 & 26 & 20 & 20 & 33 & 164 & 30 & 17 & 27 & 122 \\
&
\end{tabular}

Gage helght, in feet, and discharge, in second-feet, at indicated time, I937

\begin{tabular}{|c|c|c|c|c|c|c|c|c|c|c|c|c|}
\hline \multirow{2}{*}{$\begin{array}{l} \\
\text { 岁 } \\
\text { 品 }\end{array}$} & Feet & Sec.ft. & Feot & ec.ft. & Feet I & Sec.ft. & Feet & sec.ft. & Feet & Sec.ft. & Feet & Sec.ft. \\
\hline & \multicolumn{2}{|c|}{ December 8} & \multicolumn{2}{|c|}{ December 9} & \multicolumn{2}{|c|}{ December 10} & \multicolumn{2}{|c|}{ December 11} & \multicolumn{2}{|c|}{ December 12} & \multicolumn{2}{|c|}{ December 13} \\
\hline \multirow[t]{2}{*}{$\begin{array}{r}2 \\
4 \\
6 \\
8 \\
10 \\
\mathrm{~N} \\
2 \\
4 \\
6 \\
8 \\
10 \\
\mathrm{M} \\
\end{array}$} & $\begin{array}{l}1.29 \\
1.29 \\
1.28 \\
1.27 \\
1.27 \\
1.26 \\
1.26 \\
1.27 \\
1.26 \\
1.27 \\
1.26 \\
1.27\end{array}$ & $\begin{array}{l}18 \\
18 \\
18 \\
17 \\
17 \\
16 \\
16 \\
17 \\
16 \\
17 \\
16 \\
17\end{array}$ & $\begin{array}{l}1.27 \\
1.27 \\
1.27 \\
1.27 \\
1.27 \\
1.28 \\
1.30 \\
1.33 \\
1.34 \\
1.35 \\
1.37 \\
1.42\end{array}$ & $\begin{array}{l}17 \\
17 \\
17 \\
17 \\
17 \\
18 \\
19 \\
23 \\
24 \\
25 \\
27 \\
34\end{array}$ & $\begin{array}{l}1.46 \\
1.60 \\
1.72 \\
2.01 \\
2.46 \\
2.81 \\
3.12 \\
3.25 \\
3.10 \\
2.90 \\
2.87 \\
2.60\end{array}$ & $\begin{array}{r}41 \\
70 \\
105 \\
223 \\
461 \\
687 \\
926 \\
1,030 \\
910 \\
750 \\
729 \\
545\end{array}$ & $\begin{array}{l}2.34 \\
2.20 \\
2.16 \\
2.40 \\
2.70 \\
4.00 \\
5.05 \\
5.57 \\
5.00 \\
4.70 \\
4.08 \\
3.45\end{array}$ & $\begin{array}{r}392 \\
315 \\
295 \\
425 \\
610 \\
1,720 \\
2,780 \\
3,380 \\
2,720 \\
2,420 \\
1,800 \\
1,200\end{array}$ & $\begin{array}{l}3.25 \\
2.89 \\
2.65 \\
2.49 \\
2.41 \\
2.35 \\
2.26 \\
2.20 \\
2.15 \\
2.07 \\
2.01 \\
1.98\end{array}$ & $\begin{array}{r}1,030 \\
743 \\
578 \\
479 \\
431 \\
398 \\
348 \\
315 \\
290 \\
251 \\
223 \\
209\end{array}$ & $\begin{array}{l}1.93 \\
1.90 \\
1.87 \\
1.84 \\
1.82 \\
1.80 \\
1.78 \\
1.76 \\
1.75 \\
1.73 \\
1.72 \\
1.70\end{array}$ & \begin{tabular}{|r|}
186 \\
172 \\
160 \\
148 \\
140 \\
132 \\
125 \\
118 \\
115 \\
108 \\
105 \\
98
\end{tabular} \\
\hline & \multicolumn{2}{|c|}{ Decermber 14} & \multicolumn{2}{|c|}{ December 15} & \multicolumn{2}{|c|}{ December 16} & \multicolumn{2}{|c|}{ December 17} & \multicolumn{2}{|c|}{ December 18} & \multicolumn{2}{|c|}{ December 19} \\
\hline \multirow[t]{2}{*}{$\begin{array}{r}2 \\
4 \\
6 \\
8 \\
10 \\
\mathrm{~N} \\
2 \\
4 \\
6 \\
8 \\
10 \\
\mathrm{M}\end{array}$} & $\begin{array}{l}1.69 \\
1.68 \\
1.67 \\
1.66 \\
1.65 \\
1.64 \\
1.63 \\
1.62 \\
1.61 \\
1.60 \\
1.60 \\
1.59\end{array}$ & $\begin{array}{l}95 \\
92 \\
90 \\
87 \\
84 \\
81 \\
78 \\
76 \\
73 \\
70 \\
70 \\
68\end{array}$ & \begin{tabular}{l|}
1.58 \\
1.57 \\
1.56 \\
1.56 \\
1.56 \\
1.55 \\
1.55 \\
1.54 \\
1.54 \\
1.54 \\
1.53 \\
1.52
\end{tabular} & $\begin{array}{l}66 \\
63 \\
61 \\
61 \\
61 \\
59 \\
59 \\
57 \\
57 \\
57 \\
55 \\
52\end{array}$ & $\begin{array}{l}1.52 \\
1.52 \\
1.52 \\
1.51 \\
1.51 \\
1.51 \\
1.50 \\
1.50 \\
1.50 \\
1.50 \\
1.50 \\
1.49\end{array}$ & $\begin{array}{l}52 \\
52 \\
52 \\
50 \\
50 \\
50 \\
48 \\
48 \\
48 \\
48 \\
48 \\
46\end{array}$ & $\begin{array}{c}\overline{1.49} \\
\overline{1.48} \\
\overline{1.47} \\
\overline{1.46} \\
\overline{1.46} \\
\overline{1.46}\end{array}$ & $\begin{array}{l}-\overline{46} \\
- \\
45 \\
- \\
43 \\
\overline{41} \\
\overline{41} \\
- \\
41\end{array}$ & $\begin{array}{c}\overline{1.45} \\
\overline{1.45} \\
\overline{1.44} \\
- \\
1.44 \\
\overline{1.43} \\
\overline{1.43}\end{array}$ & $\begin{array}{l}\overline{40} \\
\overline{40} \\
\overline{38} \\
\overline{38} \\
\overline{36} \\
\overline{36}\end{array}$ & $\begin{array}{c}- \\
1.43 \\
- \\
1.42 \\
- \\
1.42 \\
- \\
1.42 \\
\overline{1.42} \\
- \\
1.41\end{array}$ & $\begin{array}{l}\overline{36} \\
\overline{34} \\
\overline{34} \\
\overline{34} \\
\overline{34} \\
\overline{33}\end{array}$ \\
\hline & \multicolumn{2}{|c|}{ December 20} & \multicolumn{2}{|c|}{ December 21} & \multicolumn{2}{|c|}{ December 22} & \multicolumn{2}{|c|}{ December 23} & \multicolumn{2}{|c|}{ December 24} & \multicolumn{2}{|c|}{ December 25} \\
\hline $\begin{array}{r}2 \\
4 \\
6 \\
8 \\
10 \\
\mathrm{~N} \\
2 \\
4 \\
6 \\
8 \\
10 \\
\mathrm{M}\end{array}$ & $\begin{array}{c}- \\
1.41 \\
\tilde{1.41} \\
\overline{1.41} \\
- \\
1.41 \\
- \\
1.40 \\
- \\
1.40\end{array}$ & $\begin{array}{l}\overline{33} \\
\overline{33} \\
\overline{33} \\
\overline{33} \\
\overline{31} \\
\overline{31}\end{array}$ & $\begin{array}{c}\bar{z} \\
\bar{z} \\
\overline{1.40} \\
\bar{z} \\
\bar{z} \\
1.40\end{array}$ & $\begin{array}{l}= \\
= \\
\overline{31} \\
= \\
= \\
= \\
31\end{array}$ & $\begin{array}{c}= \\
= \\
= \\
1.40 \\
= \\
= \\
= \\
1.40\end{array}$ & $\begin{array}{l}= \\
= \\
= \\
31 \\
= \\
= \\
= \\
31\end{array}$ & $\begin{array}{c}- \\
1.42 \\
- \\
1.44 \\
- \\
1.45 \\
- \\
1.46 \\
- \\
1.48 \\
- \\
1.45\end{array}$ & $\begin{array}{l}\overline{34} \\
\overline{38} \\
\overline{40} \\
\overline{41} \\
\overline{45} \\
\overline{40}\end{array}$ & $\begin{array}{c}\overline{1.42} \\
\overline{1} \\
1.41 \\
\overline{1.41} \\
\overline{1.40}\end{array}$ & $\begin{array}{l}\overline{36} \\
\overline{34} \\
\overline{34} \\
\overline{33} \\
\overline{33} \\
\overline{31}\end{array}$ & $\begin{array}{c}- \\
1.40 \\
- \\
1.39 \\
- \\
1.40\end{array}$ & $\begin{array}{l}\overline{31} \\
\overline{30} \\
\overline{31} \\
\overline{30} \\
\overline{30} \\
\overline{29}\end{array}$ \\
\hline
\end{tabular}


Fresno River near Daulton, Calif.

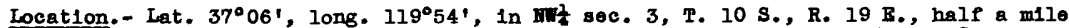
below mouth of Cottonwood Oreok and 5 miles southeast of Daulton, Madera County. Alt tude, about 390 foet above mean sea lovel.

Drainage area. - 258 square milos.

Gage-holght record. - Water-8tage recorder graph.

stage-discharge relation. - Defined by current-meter measurements. Shifting-control method used.

Kax1ma.- Decomber 1937: D1scharge, 3,660 second-foet 6 p.m. Dec. 11 (gage ho1ght, 5.80 feot).

Remarks. - Record furnishod bJ state ongineor.

Mean dally discharge, in second-feet, Hovember 1937 to January 1938

\begin{tabular}{|c|c|c|c|c|c|c|c|c|c|c|c|}
\hline Day & Hov. & Dec. & Jan. & Day & Nov. & Dec. & Jan. & Day & Hov. & Dec. & Jan. \\
\hline $\begin{array}{r}1 \\
2 \\
3 \\
4 \\
5 \\
6 \\
7 \\
8 \\
9 \\
10\end{array}$ & $\begin{array}{l}= \\
= \\
= \\
= \\
= \\
=\end{array}$ & $\begin{array}{r}30 \\
30 \\
30 \\
30 \\
31 \\
33 \\
30 \\
34 \\
33 \\
260\end{array}$ & $\begin{array}{l}31 \\
33 \\
49 \\
49 \\
39 \\
38 \\
38 \\
34 \\
36 \\
34\end{array}$ & $\begin{array}{l}11 \\
12 \\
13 \\
14 \\
15 \\
16 \\
17 \\
18 \\
19 \\
20\end{array}$ & $\begin{array}{l}= \\
= \\
= \\
= \\
= \\
= \\
=\end{array}$ & $\begin{array}{r}1,400 \\
993 \\
271 \\
143 \\
111 \\
84 \\
60 \\
54 \\
47 \\
44\end{array}$ & $\begin{array}{r}34 \\
33 \\
31 \\
36 \\
1,550 \\
486 \\
338 \\
325 \\
258 \\
348\end{array}$ & $\begin{array}{l}21 \\
22 \\
23 \\
24 \\
25 \\
26 \\
27 \\
28 \\
29 \\
30 \\
31\end{array}$ & $\begin{array}{l}= \\
= \\
= \\
= \\
= \\
=\end{array}$ & $\begin{array}{l}44 \\
44 \\
46 \\
50 \\
44 \\
36 \\
31 \\
31 \\
30 \\
28 \\
30\end{array}$ & $\begin{array}{l}215 \\
180 \\
161 \\
148 \\
132 \\
129 \\
129 \\
129 \\
457 \\
271 \\
259\end{array}$ \\
\hline $\begin{array}{l}\text { Mean } \\
\text { Run- }\end{array}$ & $2,1 n$ & & & & & & & & & $\begin{array}{r}134 \\
8,260\end{array}$ & $11, \frac{1}{9}$ \\
\hline
\end{tabular}

Oage height, in foet, and discharge, in second-foet, at indicated time, 1937

\begin{tabular}{|c|c|c|c|c|c|c|c|c|c|c|c|c|}
\hline \multirow{2}{*}{ 照 } & Feot & sec.ett. & Feet & Sec.ft. & Peet & sec.ft. & Feet & sec.ft. & Foet & Sec.et. & Feet & Sec.ft. \\
\hline & \multicolumn{2}{|c|}{ December 8} & \multicolumn{2}{|c|}{ December 9} & \multicolumn{2}{|c|}{ December 10} & \multicolumn{2}{|c|}{ December 11} & \multicolumn{2}{|c|}{ December 12} & \multicolumn{2}{|c|}{ December 13} \\
\hline $\begin{array}{r}2 \\
4 \\
6 \\
8 \\
10 \\
4 \\
2 \\
4 \\
6 \\
8 \\
10 \\
4\end{array}$ & & & & & $\begin{array}{l}1.17 \\
1.17 \\
1.19 \\
1.22 \\
1.28 \\
1.36 \\
1.55 \\
2.05 \\
2.80 \\
3.12 \\
3.34 \\
3.10\end{array}$ & $\begin{array}{r}25 \\
25 \\
28 \\
33 \\
42 \\
55 \\
103 \\
253 \\
579 \\
772 \\
900 \\
759\end{array}$ & $\begin{array}{l}3.02 \\
2.98 \\
2.60 \\
2.42 \\
2.30 \\
2.24 \\
2.37 \\
3.30 \\
5.80 \\
5.72 \\
5.36 \\
5.25\end{array}$ & $\begin{array}{r}728 \\
778 \\
525 \\
448 \\
405 \\
380 \\
462 \\
1,110 \\
3,660 \\
3,560 \\
3,100 \\
2,980\end{array}$ & $\begin{array}{l}4.75 \\
3.97 \\
3.50 \\
3.12 \\
2.80 \\
2.63 \\
2.50 \\
2.43 \\
2.40 \\
2.28 \\
2.15 \\
2.06\end{array}$ & $\begin{array}{r}2,380 \\
1,630 \\
1,240 \\
967 \\
759 \\
659 \\
589 \\
552 \\
536 \\
477 \\
414 \\
376\end{array}$ & $\begin{array}{l}2.00 \\
1.95 \\
1.92 \\
1.88 \\
1.85 \\
1.80 \\
1.70 \\
1.65 \\
1.62 \\
1.59 \\
1.57 \\
1.55\end{array}$ & \begin{tabular}{|l}
348 \\
328 \\
313 \\
299 \\
285 \\
267 \\
229 \\
211 \\
197 \\
183 \\
177 \\
169
\end{tabular} \\
\hline & \multicolumn{2}{|c|}{ December 14} & \multicolumn{2}{|c|}{ December 15} & \multicolumn{2}{|c|}{ December 16} & \multicolumn{2}{|c|}{ De cember 17} & \multicolumn{2}{|c|}{ December 18} & \multicolumn{2}{|c|}{ December 19} \\
\hline $\begin{array}{r}2 \\
4 \\
6 \\
8 \\
10 \\
1 \\
2 \\
4 \\
6 \\
8 \\
10 \\
4\end{array}$ & $\begin{array}{l}1.53 \\
1.48 \\
1.46 \\
1.44 \\
1.45 \\
1.43 \\
1.42 \\
1.44 \\
1.43 \\
1.41 \\
1.40 \\
1.40\end{array}$ & $\begin{array}{l}190 \\
167 \\
161 \\
153 \\
140 \\
145 \\
140 \\
143 \\
137 \\
129 \\
127 \\
121\end{array}$ & & & & & & & & & & \\
\hline
\end{tabular}


Location.- Lat. $37^{\circ} 13^{\prime}$, long. $120^{\circ} 00^{\prime}$, in SW $\frac{1}{4}$ sec. 22, T. 8 S., R. 18 E., $1.4 \mathrm{miles}$ above Raynor Creek and 5 miles west of Raymond, Madera County. Altitude, about 390 feet above mean sea level. Drainage area.- 238 square miles.

Gage-he1ght record. - Water-stage recorder graph.

Stage-discharge relation.- Defined by current-meter measurements below 4,600 secondfeet; extended to peak stage. Rating curve changed at peak stage.

Maxima.- December 1937: Discharge, 7,020 second-feet 4 p.m. Dec. 11. (gage he1ght, 10.74 feet).

1921-23, 1930-November 1937: Discharge, about 12,000 second-feet Feb. 6, 1937 (gage helght, 13.0 feet), from rating curve extended above 4,600 second-feet.

January-September 1938: Discharge, about 15,000 second-feet probably Mar. 2, 1938 (gage helght, 14.4 feet, from floodmarks), from rating curve extended above 4,600 second-feet.

Remarks.- Flood run-off not affected by artiflclal storage or diversion.

Mean dally discharge, in second-reet, November 1937 to January 1938

\begin{tabular}{|c|c|c|c|c|c|c|c||c|c|c|c|}
\hline Day & Nov. & Dec. & Jan. & Day & Nov. & Dec. & Jan. & Day & Nov. & Dec. & Jan. \\
\hline 1 & 3.1 & 8 & 24 & 11 & 4.7 & 2,340 & 24 & 21 & 10 & 32 & 252 \\
2 & 3.2 & 7 & 26 & 12 & 6 & 835 & 24 & 22 & 9.5 & 30 & 196 \\
3 & 3.7 & 7 & 56 & 13 & 8.5 & 279 & 24 & 23 & 9 & 35 & 164 \\
4 & 3.7 & 7 & 45 & 14 & 7.5 & 152 & 26 & 24 & 8.5 & 47 & 139 \\
5 & 3.6 & 7 & 33 & 15 & 6.5 & 94 & 2,840 & 25 & 8.5 & 34 & 122 \\
6 & 3.7 & 7 & 31 & 16 & 6.5 & 69 & 705 & 26 & 8.5 & 31 & 110 \\
7 & 3.7 & 7 & 30 & 17 & 8 & 53 & 457 & 27 & 8.5 & 28 & 104 \\
8 & 3.8 & 7 & 29 & 18 & 10 & 43 & 386 & 28 & 9 & 27 & 100 \\
9 & 4.0 & 11 & 27 & 19 & 15 & 38 & 278 & 29 & 9 & 26 & 175 \\
10 & 4.3 & 615 & 26 & 20 & 12 & 36 & 386 & 30 & 9 & 26 & 206 \\
\end{tabular}

Gage helght, In feet, and discharge, in second-feet, at indicated time, 1937

\begin{tabular}{|c|c|c|c|c|c|c|c|c|c|c|c|c|}
\hline \multirow{2}{*}{ 旨 } & Feet & Sec.ft. & Feet & Sec.ft. & Feet & Sec.ft. & Feet & Sec.ft. & Feet & sec.ft. & $F \theta \theta t$ & Sec.ft. \\
\hline & \multicolumn{2}{|c|}{ December 8} & \multicolumn{2}{|c|}{ December 9} & \multicolumn{2}{|c|}{ December 10} & \multicolumn{2}{|c|}{ December 11} & \multicolumn{2}{|c|}{ December 12} & \multicolumn{2}{|c|}{ December 13} \\
\hline \multirow[t]{2}{*}{$\begin{array}{r}2 \\
4 \\
6 \\
8 \\
10 \\
\mathrm{~N} \\
2 \\
4 \\
6 \\
8 \\
10 \\
\mathrm{M}\end{array}$} & $\begin{array}{l}1.37 \\
1.37 \\
1.37 \\
1.37 \\
1.37 \\
1.37 \\
1.37 \\
1.38 \\
1.38 \\
1.38 \\
1.39 \\
1.39\end{array}$ & $\begin{array}{l}7 \\
7 \\
7 \\
7 \\
7 \\
7 \\
7 \\
7 \\
7 \\
7 \\
7.5 \\
7.5\end{array}$ & $\begin{array}{l}1.40 \\
1.41 \\
1.42 \\
1.44 \\
1.46 \\
1.47 \\
1.48 \\
1.50 \\
1.60 \\
1.67 \\
1.72 \\
1.78\end{array}$ & \begin{tabular}{|l|}
7.5 \\
8 \\
8 \\
8.5 \\
9 \\
9 \\
9.5 \\
10 \\
12 \\
15 \\
16 \\
19
\end{tabular} & $\begin{array}{l}1.83 \\
1.88 \\
1.95 \\
1.99 \\
2.05 \\
4.30 \\
4.90 \\
7.11 \\
6.40 \\
5.87 \\
5.50 \\
5.25\end{array}$ & $\begin{array}{r}21 \\
24 \\
27 \\
29 \\
33 \\
440 \\
660 \\
2,050 \\
1,500 \\
1,150 \\
940 \\
816\end{array}$ & $\begin{array}{r}5.05 \\
4.85 \\
4.62 \\
4.50 \\
4.75 \\
5.00 \\
9.50 \\
10.74 \\
9.06 \\
9.02 \\
7.75 \\
7.15\end{array}$ & $\begin{array}{r}724 \\
640 \\
552 \\
508 \\
601 \\
702 \\
4,910 \\
7,020 \\
4,240 \\
4,190 \\
2,650 \\
2,080\end{array}$ & $\begin{array}{l}6.35 \\
5.97 \\
5.66 \\
5.29 \\
5.10 \\
4.97 \\
4.94 \\
4.90 \\
4.85 \\
4.81 \\
4.60 \\
4.34\end{array}$ & $\begin{array}{r}1,460 \\
1,190 \\
996 \\
795 \\
705 \\
646 \\
633 \\
615 \\
595 \\
579 \\
504 \\
425\end{array}$ & $\begin{array}{l}4.16 \\
4.06 \\
3.96 \\
3.86 \\
3.77 \\
3.70 \\
3.62 \\
3.52 \\
3.47 \\
3.41 \\
3.35 \\
3.30\end{array}$ & $\begin{array}{l}376 \\
350 \\
325 \\
303 \\
283 \\
268 \\
252 \\
232 \\
223 \\
212 \\
201 \\
192\end{array}$ \\
\hline & \multicolumn{2}{|c|}{ December 14} & \multicolumn{2}{|c|}{ December 15} & \multicolumn{2}{|c|}{ December 16} & \multicolumn{2}{|c|}{ December 17} & \multicolumn{2}{|c|}{ December 18} & \multicolumn{2}{|c|}{ December 19} \\
\hline \multirow[t]{2}{*}{\begin{tabular}{|r|}
2 \\
4 \\
6 \\
8 \\
10 \\
$\mathrm{~N}$ \\
2 \\
4 \\
6 \\
8 \\
10 \\
$\mathrm{M}$ \\
\end{tabular}} & $\begin{array}{c}\overline{3.21} \\
- \\
3.13 \\
\overline{3.05} \\
\overline{2.97} \\
\overline{2.90} \\
\overline{2.82}\end{array}$ & $\begin{array}{c}\overline{177} \\
\overline{164} \\
\overline{152} \\
\overline{3} \\
1 \overline{9} \\
\overline{128} \\
\overline{1} \overline{17}\end{array}$ & $\begin{array}{c}- \\
2.77 \\
- \\
2.71 \\
- \\
2.65 \\
- \\
2.59 \\
- \\
2.54 \\
\overline{2.50}\end{array}$ & $\begin{array}{c}\overline{110} \\
\overline{102} \\
\overline{9} \\
\overline{9} \\
\overline{87} \\
\overline{81} \\
\overline{77}\end{array}$ & $\begin{array}{c}- \\
2.46 \\
- \\
2.44 \\
- \\
2.42 \\
\overline{2.38} \\
\overline{2.36} \\
\overline{2.34}\end{array}$ & $\begin{array}{l}\overline{73} \\
\overline{7} 0 \\
\overline{68} \\
\overline{64} \\
\overline{62} \\
\overline{60}\end{array}$ & $\begin{array}{c}\overline{-} \\
\overline{2.30} \\
= \\
\overline{2.27} \\
\overline{-} \\
2.24 \\
\overline{-} \\
\overline{2.21}\end{array}$ & $\begin{array}{l}- \\
- \\
56 \\
- \\
- \\
53 \\
- \\
- \\
51 \\
- \\
\overline{4}\end{array}$ & $\begin{array}{c}\overline{-} \\
2.18 \\
- \\
\overline{2.15} \\
\overline{-} \\
2.12 \\
- \\
\overline{2.10}\end{array}$ & $\begin{array}{l}- \\
\overline{45} \\
- \\
\overline{4} \\
43 \\
- \\
\overline{41} \\
- \\
\overline{39}\end{array}$ & $\begin{array}{c}- \\
\overline{2} \\
2.09 \\
= \\
2.08 \\
\overline{-} \\
2.08 \\
- \\
\bar{z} .07\end{array}$ & $\begin{array}{l}\overline{-} \\
\overline{38} \\
- \\
- \\
38 \\
- \\
- \\
38 \\
- \\
\overline{37}\end{array}$ \\
\hline & \multicolumn{2}{|c|}{ December 20} & \multicolumn{2}{|c|}{ December 21} & \multicolumn{2}{|c|}{ December 22} & \multicolumn{2}{|c|}{ December 23} & \multicolumn{2}{|c|}{ December 24} & \multicolumn{2}{|c|}{ December 25} \\
\hline $\begin{array}{r}2 \\
4 \\
6 \\
8 \\
10 \\
N \\
2 \\
4 \\
6 \\
8 \\
10 \\
M\end{array}$ & $\begin{array}{c}\overline{-} \\
2.06 \\
- \\
\overline{2.05} \\
- \\
\overline{2.03} \\
- \\
\overline{2.02}\end{array}$ & $\begin{array}{l}- \\
\overline{36} \\
- \\
\overline{3} 6 \\
- \\
\overline{3} \\
- \\
\overline{33}\end{array}$ & $\begin{array}{c}\bar{z} \\
\overline{2.01} \\
\overline{-} \\
\overline{2.00} \\
\overline{-} \\
\overline{1.99} \\
\overline{-} \\
\overline{1.9}\end{array}$ & $\begin{array}{l}\overline{-} \\
\overline{33} \\
- \\
\overline{32} \\
- \\
\overline{31} \\
- \\
\overline{31}\end{array}$ & $\begin{array}{l}- \\
\overline{1.97} \\
\overline{-} \\
\overline{1.97} \\
\overline{-} \\
\overline{1.96} \\
\overline{-} \\
\overline{1.97}\end{array}$ & $\begin{array}{l}\overline{-} \\
\overline{30} \\
- \\
\overline{30} \\
\overline{-} \\
\overline{30} \\
\overline{-} \\
\overline{30}\end{array}$ & $\begin{array}{l}\overline{2.00} \\
\overline{2.01} \\
\overline{2} \\
\overline{2.02} \\
\overline{2.04} \\
\overline{2.06} \\
\overline{2.25}\end{array}$ & $\begin{array}{l}\overline{32} \\
\overline{33} \\
\overline{3} \\
33 \\
\overline{35} \\
\overline{3} \\
\overline{3} \\
\overline{52}\end{array}$ & $\begin{array}{c}- \\
2.26 \\
- \\
2.22 \\
- \\
2.20 \\
- \\
2.16 \\
- \\
2.13 \\
- \\
2.10\end{array}$ & $\begin{array}{l}\overline{52} \\
- \\
49 \\
\overline{47} \\
\overline{4} \\
\overline{4} \\
\overline{41} \\
\overline{39}\end{array}$ & $\begin{array}{c}- \\
2.06 \\
- \\
2.04 \\
- \\
2.02 \\
\overline{2.01} \\
\overline{-} \\
2.00 \\
\overline{2.00}\end{array}$ & $\begin{array}{l}\overline{36} \\
- \\
35 \\
- \\
33 \\
\overline{33} \\
\overline{32} \\
\overline{32}\end{array}$ \\
\hline
\end{tabular}

$1603020-39-11$ 
Bear Creek near Planada, Calıf.

Location. - Lat. $37^{\circ} 20^{\prime}$, long. $120^{\circ} 19^{\prime}$, in SWl sec. 10, T. 7 S., R. 15 E., fust below mouth of Burns Creek and 3 miles north of Plonada, Merced County. Altitude, about 235 feet above mean sea level.

Dralnage area. - 161 square miles.

Gage-he1ght record. - Water-stage recorder graph.

Stage-discharge relation.- Defined by current-meter measurements for range of stage occurring in December.

Maxima.- December 1937: Discharge, 6,220 second-feet 6 p.m. Dec. 11 (gage helght, 12.37 feet).

Remarks.- Flood mun-off not affected by artificlal storage or diversion. Basic data furnished by Merced Irrigation District.

Mean dally discharge, in second-feet, November 1937 to January 1938

\begin{tabular}{|c|c|c|c|c|c|c|c|c|c|c|c|}
\hline Dey & Nov. & Dec. & Jan. & Day & Nov. & Dec. & Jan. & Day & Nov. & Dec. & Jan. \\
\hline 1 & - & 0 & - & 11 & - & 1,320 & - & 21 & - & 10 & - \\
\hline 2 & - & 0 & - & 12 & - & 376 & - & 22 & - & 9 & - \\
\hline 3 & - & 0 & - & 13 & - & 106 & - & 23 & - & 10 & - \\
\hline 4 & - & 0 & - & 14 & - & 41 & - & 24 & - & 11 & - \\
\hline 5 & - & 0 & - & 15 & - & 24 & - & 25 & - & 14 & - \\
\hline 6 & - & 0 & - & 16 & - & 18 & - & 26 & - & 12 & - \\
\hline 7 & - & 0 & - & 17 & - & 15 & - & 27 & - & 10 & - \\
\hline 8 & - & 0 & - & 18 & - & 13 & - & 28 & - & 10 & - \\
\hline 9 & - & .1 & - & 19 & - & 21 & - & 29 & - & 9 & - \\
\hline 10 & - & .4 & - & 20 & - & 10 & - & 30 & - & 9 & - \\
\hline & & & & & & & & 31 & & 9 & - \\
\hline \multicolumn{9}{|c|}{ 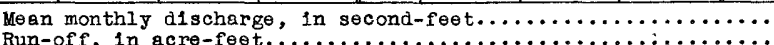 } & $\overline{-}$ & $\begin{array}{r}66.0 \\
4,060\end{array}$ & $\overline{-}$ \\
\hline
\end{tabular}

Gage height, in feet, and discharge, in second-feet, at indicated time, 1937

\begin{tabular}{|c|c|c|c|c|c|c|c|c|c|c|c|c|}
\hline \multirow{2}{*}{ 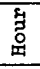 } & Feet & Sec.ft. & Feet & Sec.ft. & Foet & Sec.ft. & Feet & Sec.ft. & Feet & Sec.ft. & Feet & sec.ft. \\
\hline & \multicolumn{2}{|c|}{ December 8} & \multicolumn{2}{|c|}{ December 9} & \multicolumn{2}{|c|}{ December 10} & \multicolumn{2}{|c|}{ December 11} & \multicolumn{2}{|c|}{ December 12} & \multicolumn{2}{|c|}{ December 13} \\
\hline $\begin{array}{r}2 \\
4 \\
6 \\
8 \\
10 \\
N \\
2 \\
4 \\
6 \\
8 \\
10 \\
M\end{array}$ & & & $\begin{array}{l}= \\
= \\
= \\
= \\
= \\
0.47 \\
.48 \\
.49 \\
.49\end{array}$ & $\begin{array}{l}0 \\
0 \\
0 \\
0 \\
0 \\
0 \\
0 \\
0 \\
.2 \\
.3 \\
.4 \\
.4 \\
.4\end{array}$ & $\begin{array}{l}0.48 \\
- \\
.49 \\
-50 \\
- \\
.49 \\
.48 \\
.48\end{array}$ & $\begin{array}{c}- \\
0.3 \\
- \\
.4 \\
-5 \\
-5 \\
.4 \\
.3 \\
.3\end{array}$ & $\begin{array}{r}0.48 \\
.48 \\
.48 \\
.58 \\
.61 \\
.92 \\
5.90 \\
9.40 \\
12.37 \\
9.00 \\
6.50 \\
5.00\end{array}$ & $\begin{array}{r}0.3 \\
.3 \\
.3 \\
1.7 \\
2.3 \\
13 \\
1,230 \\
3,340 \\
6,220 \\
3,020 \\
1,500 \\
875\end{array}$ & $\begin{array}{l}4.15 \\
3.60 \\
3.15 \\
2.87 \\
2.72 \\
2.82 \\
2.97 \\
3.45 \\
4.00 \\
3.45 \\
3.10 \\
2.80\end{array}$ & $\begin{array}{l}595 \\
434 \\
316 \\
251 \\
218 \\
240 \\
273 \\
393 \\
550 \\
393 \\
304 \\
236\end{array}$ & $\begin{array}{l}2.58 \\
2.39 \\
2.25 \\
2.13 \\
2.03 \\
1.96 \\
1.89 \\
1.83 \\
1.77 \\
1.71 \\
1.67 \\
1.62\end{array}$ & \begin{tabular}{|r|}
188 \\
152 \\
130 \\
113 \\
100 \\
91 \\
83 \\
76 \\
70 \\
64 \\
60 \\
56 \\
\end{tabular} \\
\hline & \multicolumn{2}{|c|}{ December 14} & \multicolumn{2}{|c|}{ December 15} & \multicolumn{2}{|c|}{ December 16} & \multicolumn{2}{|c|}{ December 17} & \multicolumn{2}{|c|}{ December 18} & \multicolumn{2}{|c|}{ December 19} \\
\hline $\begin{array}{r}2 \\
4 \\
6 \\
8 \\
10 \\
N \\
2 \\
4 \\
6 \\
8 \\
10 \\
M\end{array}$ & $\begin{array}{c}\overline{-} \\
1.52 \\
\vdots \\
1.41 \\
\overline{-} \\
1.32 \\
\vdots \\
1.27\end{array}$ & $\begin{array}{l}\overline{-} \\
48 \\
\bar{y} \\
40 \\
\overline{3} \\
\overline{33} \\
\overline{30}\end{array}$ & $\begin{array}{c}\overline{ } \\
1.21 \\
\overline{-} \\
1.17 \\
\overline{-} \\
\overline{1.13} \\
\overline{1.10}\end{array}$ & $\begin{array}{l}- \\
\overline{27} \\
- \\
\overline{24} \\
- \\
\overline{22} \\
\overline{-} \\
\overline{21}\end{array}$ & $\begin{array}{c}- \\
\overline{1.08} \\
\overline{1} \\
1.04 \\
\overline{-} \\
1.01 \\
\overline{-} \\
1.0\end{array}$ & $\begin{array}{l}= \\
20 \\
= \\
18 \\
= \\
16 \\
= \\
16\end{array}$ & $\begin{array}{l}\overline{-} \\
0.98 \\
- \\
-97 \\
- \\
-96 \\
- \\
.95\end{array}$ & $\begin{array}{l}\overline{-} \\
15 \\
\overline{-} \\
15 \\
\overline{-} \\
\overline{14} \\
\overline{-} \\
14\end{array}$ & 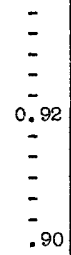 & $\begin{array}{l}\overline{-} \\
= \\
\overline{13} \\
\bar{z} \\
\overline{-} \\
\overline{12}\end{array}$ & $\begin{array}{l}= \\
= \\
= \\
0.88 \\
= \\
= \\
= \\
.87\end{array}$ & $\begin{array}{l}\overline{-} \\
= \\
- \\
11 \\
= \\
= \\
- \\
11\end{array}$ \\
\hline & \multicolumn{2}{|c|}{ December 20} & \multicolumn{2}{|c|}{ December 21} & \multicolumn{2}{|c|}{ December 22} & \multicolumn{2}{|c|}{ December 23} & \multicolumn{2}{|c|}{ December 24} & \multicolumn{2}{|c|}{ December 25} \\
\hline $\begin{array}{r}2 \\
4 \\
6 \\
8 \\
10 \\
N \\
2 \\
4 \\
6 \\
8 \\
10 \\
M\end{array}$ & $\begin{array}{l}= \\
\vdots \\
\vdots \\
0.86 \\
\vdots \\
\vdots \\
.84\end{array}$ & $\begin{array}{l}= \\
= \\
= \\
10 \\
= \\
= \\
= \\
10\end{array}$ & $\begin{array}{l}= \\
= \\
= \\
0.84 \\
= \\
= \\
= \\
.84\end{array}$ & $\begin{array}{l}= \\
= \\
\overline{10} \\
= \\
= \\
\overline{10}\end{array}$ & 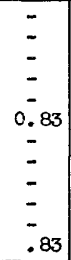 & $\begin{array}{l}\overline{-} \\
\overline{-} \\
\overline{9} \\
\bar{z} \\
\bar{z} \\
\overline{9}\end{array}$ & $\begin{array}{l}= \\
= \\
= \\
0.84 \\
= \\
= \\
= \\
.84\end{array}$ & $\begin{array}{l}= \\
= \\
\overline{10} \\
= \\
= \\
\overline{1} \\
\overline{10}\end{array}$ & $\begin{array}{l}- \\
0.86 \\
\vdots \\
- \\
\vdots 87 \\
- \\
\dot{9} \\
- \\
.94\end{array}$ & $\begin{array}{l}\overline{-} \\
\overline{10} \\
\overline{1} \\
\overline{11} \\
\overline{12} \\
\overline{12} \\
\overline{14}\end{array}$ & $\begin{array}{l}\overline{-} \\
= \\
\overline{-} \\
0.96 \\
= \\
= \\
= \\
.92\end{array}$ & $\begin{array}{l} \pm \\
= \\
\overline{-} \\
14 \\
\bar{z} \\
= \\
\overline{1} \\
\overline{13}\end{array}$ \\
\hline
\end{tabular}


Location. - Lat. $37^{\circ} 16^{\prime}$, long. $120^{\circ} 12^{\prime}$, in sec. 2, T. 8 S., R. 16 E., about 4 miles northeast of Le Grand, Merced county. Altitude, about 310 feet above mean sea level.

Drainage area. - 111 square miles.

Gage-helght record. - Water-stage recorder graph.

Stage-discharge relation.- Defined by current-meter measurements for range of stage occurring in Decenber.

Mexima.- December 1937: Discharge, 3,160 second-feet 2 p.m. Dec. 11 (gage helght, 5.17 feet).

Remarks.- Flood mu-off not affected by artificial storage or diversion. Basic data furnished by Merced Irrigation District.

Mean daily discharge, in second-feet, November 1937 to January 1938

\begin{tabular}{|c|c|c|c|c|c|c|c|c|c|c|c|}
\hline Day & Nov. & Dec. & Jan. & Day & Nov. & Dec. & Jan. & Day & Nov. & Dec. & Jan. \\
\hline 1 & - & 0 & - & 11 & - & 769 & - & 21 & - & 3.4 & - \\
\hline 2 & - & 0 & - & 12 & - & 285 & - & 22 & - & 3.4 & - \\
\hline 3 & - & 0 & - & 13 & - & 96 & - & 23 & - & 2.4 & - \\
\hline 4 & - & 0 & - & 14 & - & 30 & - & 24 & - & 2.8 & - \\
\hline 5 & - & 0 & - & 15 & - & 17 & - & 25 & - & 5.5 & - \\
\hline 6 & - & 0 & - & 16 & - & 13 & - & 26 & - & 5.5 & - \\
\hline 7 & - & 0 & - & 17 & - & 8 & - & 27 & - & 2.8 & - \\
\hline 8 & - & 0 & - & 18 & - & 6 & - & 28 & - & 2.6 & - \\
\hline 9 & - & 0 & - & 19 & - & 5.5 & - & 29 & - & 2.8 & - \\
\hline 10 & - & 49 & - & 20 & - & 4.2 & - & $\begin{array}{l}30 \\
31\end{array}$ & - & $\begin{array}{l}3.8 \\
3.4\end{array}$ & $\overline{-}$ \\
\hline \multicolumn{9}{|c|}{ 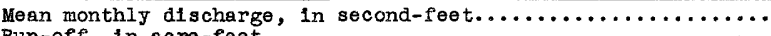 } & $\overline{-}$ & 42.6 & $\overline{-}$ \\
\hline
\end{tabular}

Gage helght, in feet, and discharge, in second-feet, at indicated time, 1937

\begin{tabular}{|c|c|c|c|c|c|c|c|c|c|c|c|c|}
\hline \multirow{2}{*}{$\begin{array}{l}\text { 苟 } \\
\text { 总 }\end{array}$} & Feet & Sec.ft. & Feet & Sec.ft. & Feet & sec.ft. & Feet & Sec.ft. & Feet & Sec.ft. & Feet & Sec.ft. \\
\hline & \multicolumn{2}{|c|}{ December 8} & \multicolumn{2}{|c|}{ December 9} & \multicolumn{2}{|c|}{ December 10} & \multicolumn{2}{|c|}{ December 11} & \multicolumn{2}{|c|}{ December 12} & \multicolumn{2}{|c|}{ December 13} \\
\hline $\begin{array}{r}2 \\
4 \\
6 \\
8 \\
10 \\
N \\
2 \\
4 \\
6 \\
8 \\
10 \\
M\end{array}$ & & & & & $\begin{array}{c}= \\
= \\
= \\
= \\
= \\
= \\
2.46 \\
2.36\end{array}$ & \begin{tabular}{c|}
0 \\
0 \\
0 \\
0 \\
0 \\
0 \\
0 \\
0 \\
0 \\
0 \\
351 \\
293
\end{tabular} & $\begin{array}{l}2.28 \\
2.20 \\
2.13 \\
2.10 \\
2.26 \\
2.40 \\
5.17 \\
4.24 \\
3.59 \\
3.23 \\
3.25 \\
3.06\end{array}$ & $\begin{array}{r}250 \\
210 \\
178 \\
165 \\
240 \\
315 \\
3,160 \\
1,930 \\
1,230 \\
904 \\
920 \\
768\end{array}$ & $\begin{array}{l}2.77 \\
2.55 \\
2.38 \\
2.27 \\
2.17 \\
2.11 \\
2.13 \\
2.12 \\
2.07 \\
2.31 \\
2.33 \\
2.23\end{array}$ & $\begin{array}{l}554 \\
408 \\
304 \\
245 \\
196 \\
170 \\
178 \\
174 \\
153 \\
266 \\
276 \\
225\end{array}$ & $\begin{array}{l}2.06 \\
- \\
1.93 \\
- \\
1.83 \\
- \\
1.77 \\
- \\
1.71 \\
- \\
1.67\end{array}$ & $\begin{array}{c}\overline{149} \\
\overline{103} \\
\overline{7} 6 \\
\overline{6} \\
\overline{5} \\
\overline{50} \\
\overline{4}\end{array}$ \\
\hline & \multicolumn{2}{|c|}{ Decomber 14} & \multicolumn{2}{|c|}{ December 15} & \multicolumn{2}{|c|}{ December 16} & \multicolumn{2}{|c|}{ December 17} & \multicolumn{2}{|c|}{ December 18} & \multicolumn{2}{|c|}{ December 19} \\
\hline $\begin{array}{r}2 \\
4 \\
6 \\
8 \\
10 \\
N \\
2 \\
4 \\
6 \\
8 \\
10 \\
\mathrm{M}\end{array}$ & $\begin{array}{l}-\overline{1.63} \\
- \\
1.60 \\
- \\
1.57 \\
- \\
1.55 \\
- \\
1.53 \\
\overline{1.50}\end{array}$ & $\begin{array}{l}\overline{37} \\
\overline{32} \\
\overline{2} 9 \\
\overline{2} 6 \\
\overline{2} 4 \\
\overline{21}\end{array}$ & $\begin{array}{l}- \\
1.49 \\
- \\
1.46 \\
\overline{1.45} \\
- \\
1.41 \\
\overline{1.45} \\
- \\
1.42\end{array}$ & $\begin{array}{l}\overline{20} \\
\overline{18} \\
\overline{17} \\
\overline{14} \\
\overline{17} \\
\overline{15}\end{array}$ & $\begin{array}{c}\overline{-} \\
\overline{1.42} \\
- \\
\overline{1.40} \\
\overline{-} \\
1.38 \\
\overline{-} \\
\overline{1.36}\end{array}$ & $\begin{array}{l}\overline{-} \\
\overline{15} \\
\overline{-} \\
\overline{13} \\
\overline{-} \\
\overline{12} \\
\overline{-} \\
\overline{11}\end{array}$ & $\begin{array}{c}- \\
- \\
- \\
\overline{1 .} \\
\overline{-} \\
= \\
- \\
\overline{1 .}\end{array}$ & $\begin{array}{l}= \\
\bar{z} \\
\overline{8} \\
\bar{z} \\
\overline{-} \\
\overline{7}\end{array}$ & $\begin{array}{c}= \\
= \\
= \\
1.28 \\
= \\
= \\
\overline{1} \\
1.27\end{array}$ & $\begin{array}{l}= \\
= \\
\bar{z} \\
= \\
= \\
= \\
\overline{6}\end{array}$ & $\begin{array}{c}\overline{-} \\
\overline{-} \\
\overline{1.26} \\
\overline{-} \\
\overline{-} \\
\overline{1.25}\end{array}$ & $\begin{array}{c}= \\
= \\
5 \\
5 \\
= \\
z \\
\overline{5}\end{array}$ \\
\hline & \multicolumn{2}{|c|}{ December 20} & \multicolumn{2}{|c|}{ December 21} & \multicolumn{2}{|c|}{ December 22} & \multicolumn{2}{|c|}{ December 23} & \multicolumn{2}{|c|}{ December 24} & \multicolumn{2}{|c|}{ December 25} \\
\hline $\begin{array}{r}2 \\
4 \\
6 \\
8 \\
10 \\
N \\
2 \\
4 \\
6 \\
8 \\
10 \\
M\end{array}$ & $\begin{array}{c}\overline{-} \\
\bar{z} \\
\overline{1} \\
1.23 \\
\bar{z} \\
\bar{z} \\
1.22\end{array}$ & $\begin{array}{c}= \\
= \\
= \\
4.2 \\
= \\
= \\
= \\
3.8\end{array}$ & $\begin{array}{l}= \\
- \\
= \\
1.21 \\
= \\
= \\
\overline{1} \\
1.21\end{array}$ & $\begin{array}{l}= \\
= \\
= \\
3.4 \\
= \\
= \\
= \\
3.4\end{array}$ & $\begin{array}{c}\bar{z} \\
\bar{z} \\
\bar{z} \\
1.20 \\
\bar{z} \\
\bar{z} \\
\overline{1.21}\end{array}$ & $\begin{array}{c}= \\
= \\
= \\
3.0 \\
= \\
= \\
= \\
3.4\end{array}$ & $\begin{array}{c}- \\
1.21 \\
- \\
1.21 \\
- \\
1.21 \\
- \\
1.19 \\
- \\
1.11 \\
- \\
1.02\end{array}$ & $\begin{array}{c}- \\
3.4 \\
- \\
3.4 \\
- \\
3.4 \\
- \\
2.8 \\
- \\
1.2 \\
- \\
.2\end{array}$ & $\begin{array}{c}- \\
1.23 \\
- \\
1.23 \\
- \\
1.23 \\
- \\
1.21 \\
- \\
1.07 \\
- \\
1.18\end{array}$ & $\begin{array}{c}- \\
4.2 \\
- \\
4.2 \\
- \\
4.2 \\
- \\
3.4 \\
-7 \\
-7 \\
2.6\end{array}$ & $\begin{array}{c}\overline{-} \\
\overline{1.22} \\
\overline{-} \\
\overline{1.30} \\
\overline{-} \\
\overline{1.29} \\
\overline{-} \\
1.28\end{array}$ & $\begin{array}{c}= \\
3.8 \\
= \\
7 \\
= \\
= \\
=\end{array}$ \\
\hline
\end{tabular}

Supplemental records,- Dec. 10, 9 p.m., 2.49 ft., 369 sec.-tt. Dec. 1l, 1 p.m., 2.48 ft., 363 sec.-ft. 
Merced River at Happy Isles Bridge, near Yosemite, Calif.

Location.- Lat. $37^{\circ} 43^{\prime} 54^{\prime \prime}$, long. $119^{\circ} 33^{\prime} 28^{\prime \prime}$, In Yosemite National Park, at Happy Isles Bridge, $0.4 \mathrm{mlle}$ below Illilouette Creek and 1 is mlies southeast of Yosemite Lodge, Mariposa County. Altitude, about 4,000 feet above mean sea level.

Drainage area.- 181 square miles.

Gage-helght record. - Water-stage recorder graph except for period midnight Nov. 16 to 3 p.m. Nov. 19, when there was no record. Stage graph for Nov. 19 based on partial recorder graph.

Stage-discharge relation. - Defined by current-meter measurements below 4,000 secondfeet; extended to peak atage on basis of area-velocity study; verified by contracted opening determinations of flood flow at Happy Isles Bridge and at Clark's Bridge, $\frac{1}{2}$ mile below gage. Rating curve changed at peak stage. Shifting-control method used for period Dec. 14 to Jan. 31 .

Maxima. - December 1937: Discharge, 10,600 second-feet 1:30 p.m. Dec. II (gage he1ght, 10.4 feet).

1915-November 1937: Discharge, 3,800 second-feet May 28, 1919 (gage height, 7.1C feet), from rating curve extended above 2,800 second-feet.

Remarks. - Flood run-off not affected by artiflclal storage or diversion. Discharge for period of missing gage-helght record determined from comparlson with recorda for Merced Rlver at Pohono Bridge and Tenaya Creek near Yosemite.

Mean da1ly discharge, in second-feet, November 1937 to Januery 1938

\begin{tabular}{|c|c|c|c|c|c|c|c|c|c|c|c|}
\hline Dey & Nor. & Dec. & Jan. & Day & NOV. & Dec. & Jan. & Dey & Nov. & Dec. & Jan. \\
\hline $\begin{array}{r}1 \\
2 \\
3 \\
4 \\
5 \\
6 \\
7 \\
8 \\
9 \\
10\end{array}$ & $\begin{array}{l}4.6 \\
4.6 \\
4.3 \\
4.1 \\
4.3 \\
4.6 \\
4.6 \\
4.9 \\
4.9 \\
4.9\end{array}$ & $\begin{array}{l}14 \\
14 \\
13 \\
12 \\
12 \\
11 \\
11 \\
11 \\
15 \\
960\end{array}$ & $\begin{array}{l}84 \\
92 \\
87 \\
80 \\
78 \\
71 \\
71 \\
69 \\
66 \\
66\end{array}$ & $\begin{array}{l}11 \\
12 \\
13 \\
14 \\
15 \\
16 \\
17 \\
18 \\
19 \\
20\end{array}$ & $\begin{array}{l}6.5 \\
7.5 \\
7 \\
8.5 \\
8.5 \\
8.5 \\
16 \\
20 \\
13 \\
17\end{array}$ & $\begin{array}{r}5,380 \\
1,700 \\
644 \\
432 \\
352 \\
288 \\
258 \\
225 \\
193 \\
168\end{array}$ & $\begin{array}{l}64 \\
66 \\
64 \\
68 \\
90 \\
87 \\
98 \\
96 \\
90 \\
81\end{array}$ & $\begin{array}{l}21 \\
22 \\
23 \\
24 \\
25 \\
26 \\
27 \\
28 \\
29 \\
30 \\
31\end{array}$ & $\begin{array}{l}28 \\
21 \\
20 \\
20 \\
18 \\
17 \\
16 \\
16 \\
15 \\
15\end{array}$ & $\begin{array}{r}149 \\
128 \\
118 \\
102 \\
104 \\
99 \\
96 \\
90 \\
90 \\
87 \\
84\end{array}$ & $\begin{array}{l}87 \\
92 \\
84 \\
79 \\
79 \\
83 \\
86 \\
86 \\
88 \\
80 \\
86\end{array}$ \\
\hline $\begin{array}{l}\text { Mean } \\
\text { Run- }\end{array}$ & $\begin{array}{l}\text { onthl } \\
\text { f, in }\end{array}$ & $\begin{array}{l}1 \mathrm{ch} \theta \\
\mathrm{re}-\mathrm{fe}\end{array}$ & in & & & & & & $\begin{array}{r}11.5 \\
683\end{array}$ & $\begin{array}{r}383 \\
23,520\end{array}$ & $\begin{array}{r}80.6 \\
4,950\end{array}$ \\
\hline
\end{tabular}

Gage height, in feet, and discharge, in second-feet, at indicated time, 1937

\begin{tabular}{|c|c|c|c|c|c|c|c|c|c|c|c|c|}
\hline \multirow{2}{*}{$\begin{array}{l}\mathbf{4} \\
3 \\
0 \\
0\end{array}$} & Feet & Sec.ft. & Fest & Sec.ft. & Feet & sec.ft. & Fest & Sec.ft. & Feet & Sec.ft. & Feet & Sec.ft. \\
\hline & \multicolumn{2}{|c|}{ December 8} & \multicolumn{2}{|c|}{ December 9} & \multicolumn{2}{|c|}{ December 10} & \multicolumn{2}{|c|}{ December 11} & \multicolumn{2}{|c|}{ December 12} & \multicolumn{2}{|c|}{ December 13} \\
\hline \multirow[t]{2}{*}{$\begin{array}{r}2 \\
4 \\
6 \\
8 \\
10 \\
N \\
2 \\
4 \\
6 \\
8 \\
10 \\
M \\
\end{array}$} & $\begin{array}{l}- \\
0.81 \\
.78 \\
.7 \\
.72 \\
.87 \\
.83 \\
.83\end{array}$ & $\begin{array}{l}-12 \\
\overline{10} \\
- \\
8 \\
\overline{14} \\
\overline{12} \\
\overline{12} \\
12\end{array}$ & $\begin{array}{r}0.83 \\
.83 \\
.83 \\
.83 \\
.82 \\
.82 \\
.82 \\
.83 \\
.87 \\
.95 \\
1.05 \\
1.31\end{array}$ & $\begin{array}{l}12 \\
12 \\
12 \\
12 \\
12 \\
12 \\
12 \\
12 \\
14 \\
19 \\
25 \\
45\end{array}$ & $\begin{array}{l}2.40 \\
3.03 \\
3.28 \\
4.10 \\
4.67 \\
4.74 \\
4.65 \\
4.60 \\
4.50 \\
4.27 \\
4.20 \\
4.45\end{array}$ & $\begin{array}{r}232 \\
442 \\
547 \\
980 \\
1,380 \\
1,430 \\
1,360 \\
1,320 \\
1,250 \\
1,090 \\
1,040 \\
1,220\end{array}$ & $\begin{array}{r}5.15 \\
5.70 \\
6.60 \\
6.92 \\
7.50 \\
8.90 \\
10.25 \\
10.10 \\
9.15 \\
8.55 \\
8.00 \\
7.50\end{array}$ & $\begin{array}{r}1,790 \\
2,350 \\
3,440 \\
3,860 \\
4,690 \\
7,140 \\
10,200 \\
9,780 \\
7,230 \\
5,810 \\
4,660 \\
3,740\end{array}$ & $\begin{array}{l}7.03 \\
6.58 \\
6.35 \\
6.03 \\
5.68 \\
5.45 \\
5.26 \\
5.13 \\
4.98 \\
4.88 \\
4.76 \\
4.63\end{array}$ & $\begin{array}{r}3,020 \\
2,460 \\
2,210 \\
1,900 \\
1,590 \\
1,410 \\
1,270 \\
1,180 \\
1,090 \\
1,020 \\
951 \\
876\end{array}$ & $\begin{array}{l}4.52 \\
4.40 \\
4.30 \\
4.20 \\
4.12 \\
4.06 \\
4.00 \\
3.98 \\
3.96 \\
3.94 \\
3.88 \\
3.81\end{array}$ & $\begin{array}{l}820 \\
760 \\
712 \\
666 \\
631 \\
605 \\
580 \\
572 \\
564 \\
556 \\
532 \\
506\end{array}$ \\
\hline & \multicolumn{2}{|c|}{ December 14} & \multicolumn{2}{|c|}{ December 15} & \multicolumn{2}{|c|}{ December 16} & \multicolumn{2}{|c|}{ December 17} & \multicolumn{2}{|c|}{ December 18} & \multicolumn{2}{|c|}{ December 19} \\
\hline $\begin{array}{r}2 \\
4 \\
6 \\
8 \\
10 \\
N \\
2 \\
4 \\
6 \\
8 \\
10 \\
M\end{array}$ & $\begin{array}{c}- \\
- \\
3.68 \\
- \\
z .58 \\
- \\
\overline{3.55} \\
\bar{z} \\
3.53\end{array}$ & $\begin{array}{c}- \\
\overline{-} \\
450 \\
\overline{-} \\
\overline{4} \\
\overline{-} \\
4 \overline{0} \\
\overline{3} \\
\overline{396}\end{array}$ & $\begin{array}{c}\bar{z} \\
\overline{3.46} \\
\overline{-} \\
3.40 \\
\overline{-} \\
3.38 \\
\overline{-} \\
\overline{3.35}\end{array}$ & $\begin{array}{c}\overline{-} \\
3 \overline{65} \\
\overline{-} \\
\overline{345} \\
\overline{-} \\
3 \overline{39} \\
\overline{-} \\
\overline{329}\end{array}$ & $\begin{array}{c}- \\
\overline{3.27} \\
- \\
- \\
3.22 \\
- \\
\overline{3.20} \\
- \\
\overline{3.22}\end{array}$ & $\begin{array}{c}- \\
\overline{2} \\
- \\
\overline{-} \\
2 \overline{8} \\
- \\
\overline{27} \\
\overline{-} \\
\overline{2}\end{array}$ & $\begin{array}{c}- \\
- \\
3.19 \\
- \\
- \\
3.15 \\
- \\
\overline{3.13} \\
- \\
- \\
3.12\end{array}$ & $\begin{array}{c}- \\
\overline{267} \\
\overline{-} \\
\overline{256} \\
\overline{-} \\
2 \overline{50} \\
\overline{-} \\
\overline{247}\end{array}$ & $\begin{array}{c}- \\
\overline{3.10} \\
- \\
\overline{3.05} \\
\overline{-} \\
3.02 \\
- \\
\overline{3.04}\end{array}$ & $\begin{array}{c}- \\
\overline{236} \\
- \\
\overline{222} \\
\overline{-} \\
2 \overline{14} \\
\overline{-} \\
\overline{220}\end{array}$ & $\begin{array}{c}- \\
\overline{2} \\
\bar{z} \\
\overline{2} \\
2.93 \\
\overline{-} \\
2.93 \\
- \\
\overline{2.94}\end{array}$ & $\begin{array}{c}\overline{-} \\
\overline{201} \\
\overline{-} \\
\overline{186} \\
\overline{-} \\
\overline{186} \\
- \\
\overline{188}\end{array}$ \\
\hline M & \multicolumn{2}{|c|}{ December 20} & \multicolumn{2}{|c|}{ December 21} & \multicolumn{2}{|c|}{ December 22} & \multicolumn{2}{|c|}{ December 23} & \multicolumn{2}{|c|}{ December 24} & \multicolumn{2}{|c|}{ December 25} \\
\hline $\begin{array}{r}2 \\
4 \\
6 \\
8 \\
10 \\
N \\
2 \\
4 \\
6 \\
8 \\
10 \\
M\end{array}$ & $\begin{array}{c}\overline{-} \\
2.87 \\
\overline{-} \\
2.83 \\
- \\
\overline{2.85} \\
\overline{-} \\
2.87\end{array}$ & $\begin{array}{c}= \\
\overline{168} \\
\overline{-} \\
158 \\
- \\
\overline{163} \\
\overline{-} \\
1 \overline{68}\end{array}$ & $\begin{array}{c}- \\
\overline{2.82} \\
= \\
2.81 \\
= \\
\overline{2.80} \\
= \\
2.79\end{array}$ & $\begin{array}{c}\overline{-} \\
\overline{15} 1 \\
\overline{-} \\
\overline{149} \\
\overline{-} \\
\overline{147} \\
\overline{-} \\
\overline{145}\end{array}$ & $\begin{array}{c}- \\
- \\
2.60 \\
\overline{-} \\
2.56 \\
\overline{-} \\
2.61 \\
\overline{-} \\
2.64\end{array}$ & $\begin{array}{c}- \\
\overline{130} \\
\overline{-} \\
\overline{122} \\
\overline{-} \\
\overline{132} \\
\overline{-} \\
\overline{138}\end{array}$ & $\begin{array}{c}- \\
\overline{-} \\
2.58 \\
- \\
2 . \overline{47} \\
\overline{-} \\
2.51 \\
- \\
\bar{z} \\
2.52\end{array}$ & $\begin{array}{c}\overline{-} \\
126 \\
\overline{106} \\
\overline{-} \\
\overline{113} \\
\overline{-} \\
114\end{array}$ & $\begin{array}{c}- \\
- \\
2.38 \\
- \\
= \\
2.38 \\
- \\
= \\
2.53 \\
- \\
- \\
2.48\end{array}$ & $\begin{array}{c}- \\
\overline{92} \\
- \\
- \\
92 \\
- \\
116 \\
- \\
\overline{108}\end{array}$ & $\begin{array}{c}\overline{-} \\
2.41 \\
\overline{-} \\
2.42 \\
\overline{-} \\
2.50 \\
\overline{-} \\
2.50\end{array}$ & $\begin{array}{c}\overline{9} \\
\overline{9} \\
\overline{-} \\
\overline{9} \\
- \\
\overline{111} \\
- \\
\overline{111}\end{array}$ \\
\hline
\end{tabular}

Supplemental records.- Dec. 1l, I:30 p.m., 10.4 ft., 10,600 sec.-ft. 
Merced River at Pohono Bridge, near Yosemite, Calif.

Location. - Lat. $37^{\circ} 43^{\prime} 01^{\prime \prime}$, long. $119^{\circ} 39^{\prime} 55^{\prime \prime}, 0.4$ mile above Artist Creek and 5 miles below Yosemite Lodge, in Yosemite Nat1onal Park, Mariposa County. Altitude, about 3,870 feet above mean sea level.

Drainage area.- 321 square miles.

Gage-helght record. - Water-stage recorder graph except for period 10 a.m. Dec. 11 to 2:30 p.m. Dec. 22 , when there was no record. Stage graph for pertods Dec. 11-12, 22 based on partial graph, peak stage obtained from floodmarks, and shape of stage graph of Merced River at Happy Is les Bridge.

Stage-discharge relation. - Defined by current-meter measurements below 6,800 secondfeet; extended to peak stage on basis of computation of flow over dam about 1 nile below gage; verified by contracted opening determination of flood flow at Pohono Bridge. Rating curve changed at peak stage.

Maxima.- December 1937: Discharge, 22,000 second-feet about $3 \mathrm{p} . \mathrm{m}$. Dec. 11 (gage height, 19.10 feet)

1916-November 1937: Discharge, 6,370 second-feet June 5, 1922 (gage helght, 10.0 feet), from rating curve extended above 5,600 second-feet.

Remarks. - Flood mun-off not affected by artificlal storage or diversion. Discharge for period of missing gage-helght record, Dec. 13-21, determined frum record of Merced River at Happy Is les Bridge.

Mean da1ly discharge, in second-feet, November 1937 to January 1938

\begin{tabular}{|c|c|c|c|c|c|c|c|c|c|c|c|}
\hline Day & Nov. & Dec. & Jan. & Day & Nov. & Dec. & Jan. & Day & Nov. & Dec. & Jan. \\
\hline $\begin{array}{r}1 \\
2 \\
3 \\
4 \\
5 \\
6 \\
7 \\
8 \\
9 \\
10\end{array}$ & $\begin{array}{l}21 \\
21 \\
21 \\
21 \\
21 \\
21 \\
21 \\
21 \\
22 \\
22\end{array}$ & $\begin{array}{r}29 \\
28 \\
27 \\
27 \\
26 \\
25 \\
25 \\
25 \\
43 \\
3,030\end{array}$ & $\begin{array}{l}209 \\
229 \\
215 \\
207 \\
199 \\
185 \\
180 \\
178 \\
169 \\
166\end{array}$ & $\begin{array}{l}11 \\
12 \\
13 \\
14 \\
15 \\
16 \\
17 \\
18 \\
19 \\
20\end{array}$ & $\begin{array}{l}25 \\
25 \\
25 \\
26 \\
25 \\
25 \\
36 \\
39 \\
32 \\
30\end{array}$ & $\begin{array}{r}16,000 \\
6,420 \\
3,000 \\
1,200 \\
900 \\
700 \\
600 \\
500 \\
450 \\
400\end{array}$ & $\begin{array}{l}164 \\
161 \\
158 \\
171 \\
249 \\
223 \\
254 \\
243 \\
227 \\
205\end{array}$ & $\begin{array}{l}21 \\
22 \\
23 \\
24 \\
25 \\
26 \\
27 \\
28 \\
29 \\
30 \\
31\end{array}$ & $\begin{array}{l}46 \\
40 \\
36 \\
36 \\
34 \\
32 \\
31 \\
30 \\
30 \\
29\end{array}$ & $\begin{array}{l}350 \\
300 \\
271 \\
238 \\
236 \\
229 \\
221 \\
215 \\
211 \\
213 \\
207\end{array}$ & $\begin{array}{l}211 \\
227 \\
207 \\
197 \\
199 \\
205 \\
211 \\
215 \\
211 \\
195 \\
205\end{array}$ \\
\hline $\begin{array}{l}\text { Mean } \\
\text { Run- }\end{array}$ &, 1 & 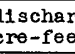 & & & & & & & $\begin{array}{r}28 . \\
1,670\end{array}$ & $\begin{array}{r}1,166 \\
71,690\end{array}$ & $\begin{array}{r}202 \\
12,450 \\
\end{array}$ \\
\hline
\end{tabular}

Gage helght, in feet, and discharge, in second-feet, at Indicated time, 1937

\begin{tabular}{|c|c|c|c|c|c|c|c|c|c|c|c|c|}
\hline \multirow{2}{*}{ 岁 } & Feet & Sec.ft. & Feet & Sec.ft. & Feet & sec.ft. & Feet & Sec.ft. & Feet & Sec.ft. & Feet & sec.ft. \\
\hline & \multicolumn{2}{|c|}{ December 8} & \multicolumn{2}{|c|}{ December 9} & \multicolumn{2}{|c|}{ December 10} & \multicolumn{2}{|c|}{ December 11} & \multicolumn{2}{|c|}{ December 12} & \multicolumn{2}{|c|}{ December 13} \\
\hline \begin{tabular}{r|}
2 \\
4 \\
6 \\
8 \\
10 \\
$\mathrm{~N}$ \\
2 \\
4 \\
6 \\
8 \\
10 \\
$\mathbf{M}$
\end{tabular} & & & $\begin{array}{l}1.09 \\
1.09 \\
1.08 \\
1.08 \\
1.09 \\
1.10 \\
1.13 \\
1.17 \\
1.24 \\
1.43 \\
1.80 \\
2.50\end{array}$ & $\begin{array}{r}25 \\
25 \\
25 \\
25 \\
25 \\
26 \\
28 \\
31 \\
36 \\
53 \\
93 \\
214\end{array}$ & $\begin{array}{l}4.30 \\
5.83 \\
6.86 \\
7.47 \\
7.89 \\
8.09 \\
8.38 \\
8.54 \\
8.19 \\
7.65 \\
7.66 \\
8.35\end{array}$ & \begin{tabular}{|r}
830 \\
1,730 \\
2,520 \\
3,090 \\
3,530 \\
3,760 \\
4,110 \\
4,310 \\
3,880 \\
3,270 \\
3,280 \\
4,070
\end{tabular} & $\begin{array}{r}9.35 \\
10.43 \\
11.77 \\
13.99 \\
16.25 \\
18.02 \\
19.06 \\
19.07 \\
18.40 \\
15.80 \\
14.71 \\
13.76\end{array}$ & \begin{tabular}{|r|}
5,470 \\
7,320 \\
10,200 \\
15,800 \\
19,400 \\
21,100 \\
22,000 \\
22,000 \\
21,400 \\
18,900 \\
17,500 \\
16,000
\end{tabular} & $\begin{array}{r}12.68 \\
11.83 \\
11.05 \\
10.28 \\
9.46 \\
8.68 \\
8.05 \\
7.55 \\
7.03 \\
6.57 \\
6.20 \\
5.87\end{array}$ & $\begin{array}{r}13,600 \\
11,400 \\
9,480 \\
7,800 \\
6,230 \\
5,000 \\
4,160 \\
3,540 \\
2,970 \\
2,520 \\
2,200 \\
1,940\end{array}$ & & \\
\hline
\end{tabular}

Supplemental records.- Dec. 11, about 3 p.m., 19.10 ft., 22,000 sec.-ft. 
Locat1on.- Lat. $37^{\circ} 39^{\prime}$, long. $120^{\circ} 11^{\prime}$, in sec. 26 , T. 3 S., R. 16 E., 0.2 mile below Whites Gulch, a quarter of a mile below Kittridge, Marlposa County, and 3 miles above Horseshoe Bend. Alt1tude, about 750 feet above mean sea level.

Dralnage area.- 935 square miles.

Gage-helght record. - Water-stage recorder graph for period 4 p.m. Dec. 16 to Jan. 31. Stage graph for Dec. 16 based on partial recorder graph. Occasional staff gage readings were made Nov. I to Dec. 14. Peak stage was determined from floodmarks.

Stage-discharge relation.- Defined by current-meter measurements below 10,000 secondfeet; extended to perk stage on basis of computations of change in storage in Lake Mcclure, adjusted for inflow between gage and lake. Rating curve changed at peak stage.

Max1ma.- December 1937: D1scharge, 59,000 second-feet about 3 p.m. Dec. 11. (gage helght, 31.0 feat).

1922-November 1937: D1scharge, 33,200 second-feet Feb. 6, 1937 (gage helght, 22.6 feet, from floodmarks), from rating curve extended above 7,500 second-feet on basis of computations of change in storage in Lake Mcclure.

Remarks. - Flood run-off not affected by artificlal storage or diversion. Discharge for perlod Nov. I to Dec. 15 determined from discharge graph based on occas lonal staff gage readings, floodmarks, and records for Lake Mcolure, Merced R1ver at Pohono Bridge, and Chowchilla River at Buchanan dam site. Most of basic data furnished by Merced Irrigation District.

Mean daily discharge, in second-feet, November 1937 to January 1938

\begin{tabular}{|c|c|c|c|c|c|c|c|c|c|c|c|}
\hline Day & Nov. & Dec. & Jan. & Day & Nov. & Dec. & Jan. & Day & Nov. & Dec. & Jan. \\
\hline 1 & 66 & 98 & 482 & 11 & 75 & 32,100 & 397 & 21 & 125 & 798 & 798 \\
2 & 66 & 94 & 544 & 12 & 85 & 12,800 & 391 & 22 & 115 & 775 & 752 \\
3 & 66 & 92 & 685 & 13 & 98 & 4,070 & 391 & 23 & 110 & 798 & 708 \\
4 & 67 & 92 & 580 & 14 & 105 & 2,300 & 391 & 24 & 108 & 685 & 600 \\
5 & 67 & 90 & 520 & 15 & 110 & 1,710 & 7,650 & 25 & 106 & 620 & 552 \\
6 & 68 & 90 & 499 & 16 & 105 & 1,420 & 2,020 & 26 & 105 & 600 & 540 \\
7 & 68 & 89 & 457 & 17 & 101 & 1,230 & 1,660 & 27 & 104 & 580 & 540 \\
8 & 69 & 89 & 443 & 18 & 130 & 1,080 & 1,320 & 28 & 104 & 548 & 532 \\
9 & 69 & 89 & 422 & 19 & 150 & 975 & 1,060 & 29 & 102 & 502 & 640 \\
10 & 70 & 4,430 & 409 & 20 & 135 & 970 & 975 & 30 & 100 & 492 & 580 \\
&
\end{tabular}

Gage helght, in feet, and discharge, in second-feet, at indicated time, 1937

\begin{tabular}{|c|c|c|c|c|c|c|c|c|c|c|c|c|}
\hline \multirow{2}{*}{ 量 } & Feet & Sec.ft. & Feot & Soc.ft. & Foet & Sec.ft. & Feet & Sec.ft. & Fest & Sec.ft. & Feet & Sec.ft. \\
\hline & \multicolumn{2}{|c|}{ December 8} & \multicolumn{2}{|c|}{ December 9} & \multicolumn{2}{|c|}{ December 10} & \multicolumn{2}{|c|}{ December 11} & \multicolumn{2}{|c|}{ Decomber 12} & \multicolumn{2}{|c|}{ December 13} \\
\hline $\begin{array}{r}2 \\
4 \\
6 \\
8 \\
10 \\
\mathrm{~N} \\
2 \\
4 \\
6 \\
8 \\
10 \\
\mathrm{M}\end{array}$ & & & & & $\begin{array}{l}= \\
= \\
= \\
= \\
= \\
= \\
=\end{array}$ & \begin{tabular}{|r|}
160 \\
235 \\
305 \\
375 \\
450 \\
1,600 \\
2,750 \\
10,200 \\
10,800 \\
11,500 \\
10,300 \\
9,050
\end{tabular} & $\begin{array}{l}= \\
= \\
= \\
= \\
= \\
= \\
=\end{array}$ & $\begin{array}{r}8,600 \\
8,650 \\
9,600 \\
12,000 \\
27,500 \\
45,400 \\
58,500 \\
57,500 \\
55,700 \\
46,200 \\
36,800 \\
29,200\end{array}$ & $\begin{array}{l}= \\
= \\
= \\
= \\
= \\
= \\
=\end{array}$ & $\begin{array}{c}\overline{-} \\
15,800 \\
\overline{-} \\
10,500 \\
\overline{-} \\
7,580 \\
\overline{-} \\
5,860\end{array}$ & & \\
\hline
\end{tabular}

Supplementary records.- Dec. 11, about 3 p.m., 31.0 ft., 59,000 sec.-ft. 
Lake McClure at Exchequer, Cal1f.

Location. - Lat. $37^{\circ} 35^{\prime}$, long. $120^{\circ} 16^{\prime}$, in Sw $\frac{1}{4}$ sec. 13, T. 4 S., R. 15 E., at Exchequer Dam on Merced Rlver' 5 mlies northeast of Merced Falls. Zero of gage is at mean sea lovel.

Drainage area.- 1,020 square miles.

Gage-helght record. - Gage read to tenths daily at midnight.

Remarks.-Flood run-off completely controlled in reservolr. Crest of sp111way is 693.0 feet above mean sea level (capacity, 245,600 acre-feet). See record for Merced River

at Exchequer. Baslc data furnished by Merced Irrigation Distrlct.

Elevation and contents, November 1937 to Jamary 1938

\begin{tabular}{|c|c|c|c|c|c|c|}
\hline \multirow[b]{2}{*}{ Day } & \multicolumn{2}{|c|}{ November } & \multicolumn{2}{|c|}{ December } & \multicolumn{2}{|c|}{ January } \\
\hline & $\begin{array}{c}\text { Dlevation } \\
\text { (feet) }\end{array}$ & $\begin{array}{c}\text { Contents } \\
\text { (acre-feet) }\end{array}$ & $\begin{array}{c}\text { Elevation } \\
\text { (feet) }\end{array}$ & $\begin{array}{c}\text { Contents } \\
\text { (acre-feet) }\end{array}$ & $\begin{array}{c}\text { Elevation } \\
\text { (feet) }\end{array}$ & $\begin{array}{c}\text { Contents } \\
\text { (acre-feet) }\end{array}$ \\
\hline $\begin{array}{l}1 \\
2 \\
3 \\
4 \\
5\end{array}$ & $\begin{array}{l}571.1 \\
571.2 \\
571.3 \\
571.3 \\
571.4\end{array}$ & $\begin{array}{l}48,290 \\
48,380 \\
48,470 \\
48,470 \\
48,560\end{array}$ & $\begin{array}{l}575.0 \\
575.1 \\
575.2 \\
575.3 \\
575.5\end{array}$ & $\begin{array}{l}52,000 \\
52,100 \\
52,200 \\
52,300 \\
52,500\end{array}$ & $\begin{array}{l}657.0 \\
656.3 \\
655.8 \\
655.2 \\
654.4\end{array}$ & $\begin{array}{l}167,800 \\
166,470 \\
165,520 \\
164,380 \\
162,920\end{array}$ \\
\hline $\begin{array}{r}6 \\
7 \\
8 \\
9 \\
10\end{array}$ & $\begin{array}{l}571.4 \\
571.5 \\
571.5 \\
571.6 \\
571.6\end{array}$ & $\begin{array}{l}48,560 \\
48,650 \\
48,650 \\
48,740 \\
48,740\end{array}$ & $\begin{array}{l}575.6 \\
575.7 \\
575.8 \\
576.0 \\
584.7\end{array}$ & $\begin{array}{l}52,600 \\
52,700 \\
52,800 \\
53,000 \\
62,070\end{array}$ & $\begin{array}{l}653.7 \\
652.9 \\
652.1 \\
651.3 \\
650.4\end{array}$ & $\begin{array}{l}161,660 \\
160,220 \\
158,780 \\
157,340 \\
155,720\end{array}$ \\
\hline $\begin{array}{l}11 \\
12 \\
13 \\
14 \\
15\end{array}$ & $\begin{array}{l}571.8 \\
571.9 \\
572.0 \\
572.1 \\
572.3\end{array}$ & $\begin{array}{l}48,920 \\
49,010 \\
49,100 \\
49,190 \\
49,370\end{array}$ & $\begin{array}{l}634.8 \\
650.0 \\
654.1 \\
656.4 \\
658.1\end{array}$ & $\begin{array}{l}129,380 \\
155,000 \\
162,380 \\
166,660 \\
169,890\end{array}$ & $\begin{array}{l}649.6 \\
648.8 \\
647.9 \\
647.1 \\
656.1\end{array}$ & $\begin{array}{l}154,280 \\
152,840 \\
151,230 \\
149,870 \\
166,090\end{array}$ \\
\hline $\begin{array}{l}16 \\
17 \\
18 \\
19 \\
20\end{array}$ & $\begin{array}{l}572.4 \\
572.6 \\
572.9 \\
573.1 \\
573.3\end{array}$ & $\begin{array}{l}49,460 \\
49,640 \\
49,910 \\
50,100 \\
50,300\end{array}$ & $\begin{array}{l}659.5 \\
660.7 \\
661.7 \\
662.6 \\
663.4\end{array}$ & $\begin{array}{l}172,550 \\
174,900 \\
176,900 \\
178,700 \\
180,300\end{array}$ & $\begin{array}{l}657.4 \\
658.0 \\
658.5 \\
658.5 \\
658.4\end{array}$ & $\begin{array}{l}168,560 \\
169,700 \\
170,650 \\
170,650 \\
170,460\end{array}$ \\
\hline $\begin{array}{l}21 \\
22 \\
23 \\
24 \\
25\end{array}$ & $\begin{array}{l}573.5 \\
573.6 \\
573.8 \\
574.0 \\
574.2\end{array}$ & $\begin{array}{l}50,500 \\
50,600 \\
50,800 \\
51,000 \\
51,200\end{array}$ & $\begin{array}{l}664.0 \\
663.6 \\
663.1 \\
662.6 \\
662.0\end{array}$ & $\begin{array}{l}181,500 \\
180,700 \\
179,700 \\
178,700 \\
177,500\end{array}$ & $\begin{array}{l}658.1 \\
657.8 \\
657.4 \\
656.9 \\
656.3\end{array}$ & $\begin{array}{l}169,890 \\
169,320 \\
168,560 \\
167,610 \\
166,470\end{array}$ \\
\hline $\begin{array}{l}26 \\
27 \\
28 \\
29 \\
30 \\
31 \\
\end{array}$ & $\begin{array}{l}574.3 \\
574.5 \\
574.6 \\
574.7 \\
574.9\end{array}$ & $\begin{array}{l}51,300 \\
51,500 \\
51,600 \\
51,700 \\
51,900\end{array}$ & $\begin{array}{l}661.3 \\
660.6 \\
660.0 \\
659.2 \\
658.5 \\
657.7\end{array}$ & $\begin{array}{l}176,100 \\
174,700 \\
173,500 \\
171,980 \\
170,650 \\
169,130\end{array}$ & $\begin{array}{l}655.8 \\
655.2 \\
654.7 \\
654.3 \\
655.0 \\
657.0\end{array}$ & $\begin{array}{l}165,520 \\
164,380 \\
163,460 \\
162,740 \\
164,000 \\
167,800\end{array}$ \\
\hline
\end{tabular}


Merced River at Exchequer, Cal1f.

Location.- Lat. $37^{\circ} 35^{\prime}$, long. $120^{\circ} 17^{\prime}$, about on I1ne between secs. 14 and $23, \mathrm{~T} .4 \mathrm{~S}$. , R. 15 E., at Exchequer, Mariposa County, half a mile below Lake McClure, $0.7 \mathrm{mile}$ below Cotton Creek, and 5 miles northeast of Merced Falls. Altitude, about 400 feet above mean sea level.

Drainage area.- 1,035 square miles.

Gage-helght record. - Water-stage recorder graph.

Stage-discharge relation.- Defined by current-meter measurements below 12,200 secondfeet.

Maxima,- December 1937: D1scharge (regulated), 1,520 second-feet at intervals during period Dec. 22-25 (gage helght, 3.74 feet).

1916-November 1937: Discharge observed (unregulated), about 22,000 second-feet Jan. 17, 1916 (gage height, 20.0 feet, from nonrecording gage, former site and datum), from rating curve extended above 8,600 second-feet.

Remarks.- Flood run-off completely controlled in Lake Mcclure. Monthly summarles adjusted $f$ changes in storage. See record for Lake McGlure at Exchequer. Most of basic data furmished by Merced Irrigation District.

Mean daily discharge, In second-feet, November 1937 to January 1938

\begin{tabular}{|c|c|c|c|c|c|c|c|c|c|c|c|}
\hline Day & Nov. & Dec. & Jan. & Day & Nov. & Dec. & Jan. & Day & Nov. & Dec. & Jan, \\
\hline $\begin{array}{r}1 \\
2 \\
3 \\
4 \\
5 \\
6 \\
7 \\
8 \\
9 \\
10\end{array}$ & $\begin{array}{l}38 \\
38 \\
38 \\
39 \\
37 \\
36 \\
36 \\
36 \\
36 \\
36\end{array}$ & $\begin{array}{l}35 \\
35 \\
35 \\
35 \\
35 \\
35 \\
35 \\
35 \\
35 \\
36\end{array}$ & $\begin{array}{l}1,190 \\
1,190 \\
1,180 \\
1,180 \\
1,180 \\
1,190 \\
1,190 \\
1,180 \\
1,180 \\
1,170\end{array}$ & $\begin{array}{l}11 \\
12 \\
13 \\
14 \\
15 \\
16 \\
17 \\
18 \\
19 \\
20\end{array}$ & $\begin{array}{l}36 \\
36 \\
36 \\
36 \\
36 \\
36 \\
36 \\
36 \\
36 \\
36\end{array}$ & $\begin{array}{l}29 \\
31 \\
30 \\
29 \\
28 \\
17 \\
14 \\
26 \\
27 \\
27\end{array}$ & $\begin{array}{l}1,170 \\
1,160 \\
1,160 \\
1,160 \\
1,200 \\
1,190 \\
1,190 \\
1,190 \\
1,190 \\
1,190\end{array}$ & $\begin{array}{l}21 \\
22 \\
23 \\
24 \\
25 \\
26 \\
27 \\
28 \\
29 \\
30 \\
31\end{array}$ & $\begin{array}{l}36 \\
35 \\
35 \\
35 \\
35 \\
35 \\
35 \\
35 \\
35 \\
35\end{array}$ & $\begin{array}{r}49 \\
1,170 \\
1,220 \\
1,210 \\
1,220 \\
1,210 \\
1,210 \\
1,200 \\
1,200 \\
1,200 \\
1,200\end{array}$ & $\begin{array}{r}1,190 \\
1,190 \\
1,190 \\
1,200 \\
1,200 \\
1,190 \\
1,190 \\
1,190 \\
1,190 \\
53 \\
26\end{array}$ \\
\hline \multicolumn{9}{|c|}{ 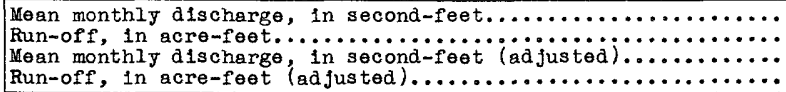 } & $\begin{array}{r}36.0 \\
2,140 \\
96.6 \\
5,750\end{array}$ & $\begin{array}{r}410 \\
25,190 \\
2,316 \\
142,400 \\
\end{array}$ & $\begin{array}{r}1,111 \\
68,310 \\
1,089 \\
66,980\end{array}$ \\
\hline
\end{tabular}


Merced River near Livingston, Calif.

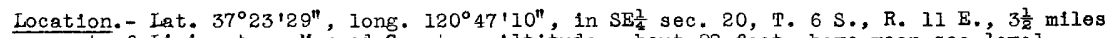
west of Livingston, Merced County. Altitude, about 82 feet above mean sea level.

Drainage area.- 1,245 square miles.

Gage-helght record. - Water-stage recorder graph except for period noon Dec. 21 to $10: 30$ a.m. Dec. 24, when there was no record. Stage graph for Dec. 21 based on partial recorder graph.

Stage-discharge relation.- Defined by current-meter measurements for range of stage of high water in December.

Maxima.- December 1937: Discharge, 1,470 second-feet 6 p.m. Dec. 31 (gage height, 5.78 feet).

1922-24, 1926-November 1937: Discharge, 10,900 second-feet (revised) Feb. 24, 1936 (gage helght, 19.24 feet), from rating curve for 1938 extended above 8,500 second-feet.

January-September 1933: Discharge, 11,100 second-feet II p.m. Feb. 12 (gage helght, 19.44 feet) from rating curve extended above 8,500 second-feet.

Remarks.- Flood mun-off very materialiy affected by artificial storage in Lake McClure (capacity, about 250,000 acre-feet). Discharge for period of missing gage-height record determined from range of stage shown on recorder graph, partial recorder graph Dec. 24, and record for Merced River at Exchequer. Most of basic data furmished by Merced Irrigation District.

Mean daily discharge, in second-feet, November 1937 to January 1938

\begin{tabular}{|c|c|c|c|c|c|c|c|c|c|c|c|}
\hline Day & Nov. & Dec. & Jan. & Day & Nov. & Dec. & Jan. & Day & Nov. & Dec. & Jan. \\
\hline $\begin{array}{r}1 \\
2 \\
3 \\
4 \\
5 \\
6 \\
7 \\
8 \\
9 \\
10\end{array}$ & $\begin{array}{l}114 \\
117 \\
117 \\
112 \\
112 \\
111 \\
111 \\
111 \\
112 \\
112\end{array}$ & $\begin{array}{l}164 \\
137 \\
127 \\
125 \\
124 \\
122 \\
120 \\
119 \\
119 \\
134\end{array}$ & $\begin{array}{l}1,260 \\
1,260 \\
1,260 \\
1,260 \\
1,260 \\
1,260 \\
1,260 \\
1,260 \\
1,260 \\
1,260\end{array}$ & $\begin{array}{l}11 \\
12 \\
13 \\
14 \\
15 \\
16 \\
17 \\
18 \\
19 \\
20\end{array}$ & $\begin{array}{l}114 \\
114 \\
112 \\
112 \\
116 \\
116 \\
119 \\
124 \\
122 \\
122\end{array}$ & $\begin{array}{l}153 \\
232 \\
364 \\
245 \\
195 \\
173 \\
209 \\
241 \\
195 \\
175\end{array}$ & $\begin{array}{l}1,260 \\
1,260 \\
1,260 \\
1,260 \\
1,440 \\
2,130 \\
1,500 \\
1,470 \\
1,400 \\
1,470\end{array}$ & $\begin{array}{l}21 \\
22 \\
23 \\
24 \\
25 \\
26 \\
27 \\
28 \\
29 \\
30 \\
31\end{array}$ & $\begin{array}{l}120 \\
119 \\
120 \\
119 \\
119 \\
122 \\
119 \\
117 \\
119 \\
144\end{array}$ & $\begin{array}{r}161 \\
150 \\
650 \\
1,000 \\
1,160 \\
1,190 \\
1,190 \\
1,220 \\
1,220 \\
1,220 \\
1,260\end{array}$ & $\begin{array}{r}1,500 \\
1,400 \\
1,360 \\
1,330 \\
1,330 \\
1,330 \\
1,330 \\
1,330 \\
1,400 \\
1,540 \\
762\end{array}$ \\
\hline an & & & & & & & & & $\begin{array}{r}117 \\
6,980\end{array}$ & $\begin{array}{r}448 \\
27,560 \\
\end{array}$ & $\begin{array}{r}1,344 \\
82,640\end{array}$ \\
\hline
\end{tabular}


Location. - Lat. $37^{\circ} 44^{\prime} 33^{\prime \prime}$, Iong. $119^{\circ} 33^{\prime} 25^{\prime \prime}$, at bridge in Yosemite Nat1onal Park, 0.7 mile above junction with Merced River and 1.9 miles east of Yosemite Irodge, Mariposa County. Altitude, about 4,000 feet above mean sea level.

Drainage area.- 47 square miles.

Gage-helght record. Water-stage recorder graph except for perlod 3:30 to 4:30 p.m. Dec. 11, when stage graph was based on floodmarks in the well.

Stage-discharge relation.- Defined by current-meter measurements below 1,400 secondfeet; extended to peak stage on basis of area-velocity study; verifled by extension of a rating curve for a temporary station upstream. Shifting-control method used for period Nov. I to Dec. 9. Rating curve changed at peak stage.

Maxima.- December 1937: Discharge, 5,550 second-feet 4 p.m. Dec. 11 (gage helght, 10.0 feet).

1904-9, 1912-November 1937: Discharge, 1,730 second-feet May 28, 1919 (gage

helght, 7.05 feet), from rating curve extended above 450 second-feet.

Remarks. - Flood run-off not affected by artificlal storage or diversion.

Mean dally discharge, in second-feet, November 1937 to January 1938

\begin{tabular}{|c|c|c|c||c|c|c|c||c|c|c|c|}
\hline Day & Nov. & Dec. & Jan. & Day & Nov. & Dec. & Jan. & Day & Nov. & Dec. & Jan. \\
\hline 1 & 1.2 & 1.1 & 37 & 11 & 1.2 & 3,430 & 29 & 21 & 1.1 & 65 & 42 \\
2 & 1.2 & 1.1 & 40 & 12 & 1.1 & 1,240 & 28 & 22 & 1.1 & 60 & 43 \\
3 & 1.2 & 1.1 & 38 & 13 & 1.0 & 416 & 28 & 23 & 1.1 & 56 & 40 \\
4 & 1.2 & 1.1 & 37 & 14 & 1.1 & 243 & 28 & 24 & 1.2 & 53 & 37 \\
5 & 1.2 & 1.1 & 35 & 15 & 1.1 & 177 & 40 & 25 & 1.2 & 49 & 37 \\
6 & 1.1 & 1.2 & 34 & 16 & 1.1 & 136 & 41 & 26 & 1.2 & 48 & 38 \\
7 & 1.2 & 1.2 & 3.3 & 17 & 1.1 & 117 & 48 & 27 & 1.1 & 43 & 40 \\
8 & 1.2 & 1.2 & 32 & 18 & 1.1 & 98 & 48 & 28 & 1.1 & 41 & 39 \\
9 & 1.2 & 1.4 & 30 & 19 & 1.0 & 83 & 46 & 29 & 1.1 & 40 & 38 \\
10 & 1.1 & 692 & 30 & 20 & 1.0 & 69 & 42 & 30 & 1.1 & 40 & 37 \\
\end{tabular}

Gage height, in feet, and discharge, in second-feet, at indicated time, 1937

\begin{tabular}{|c|c|c|c|c|c|c|c|c|c|c|c|c|}
\hline \multirow{2}{*}{$\begin{array}{l}\text { 今̊ } \\
0 \\
\text { 出 }\end{array}$} & Feet & sec.ft. & Feet & ec.ft. & Feet & Sec.ft. & Feet & Sec.ft. & Feet & Sec.ft. & Feet & Sec.ft. \\
\hline & \multicolumn{2}{|c|}{ December 8} & \multicolumn{2}{|c|}{ December 9} & \multicolumn{2}{|c|}{ December 10} & \multicolumn{2}{|c|}{ December 11} & \multicolumn{2}{|c|}{ December 12} & \multicolumn{2}{|c|}{ December 13} \\
\hline 2 & - & - & - & - & 2.13 & & 4.76 & 871 & 6.65 & 2,280 & - & - \\
\hline 4 & - & - & 0.81 & 1.2 & 3.21 & 287 & 5.38 & 1,250 & 6.34 & 1,910 & 4,35 & 509 \\
\hline 6 & - & - & - & - & 3.73 & 451 & 6.35 & 2,100 & & 1,610 & - & - \\
\hline 8 & - & - & .81 & 1.2 & 4.24 & 646 & 6.92 & 2,760 & 5.77 & 1,360 & 4.18 & 440 \\
\hline 10 & - & & & - & 5.00 & 995 & 7.17 & 3,080 & 5.53 & 1,160 & - & - \\
\hline N & 0.81 & 1.2 & .82 & 1.2 & 5.32 & 1,200 & 9.49 & 5,300 & 5.30 & 995 & 4.05 & 389 \\
\hline 2 & - & - & - & - & 4.98 & 984 & 9.52 & 5,320 & 5.13 & 888 & - & - \\
\hline 4 & - & - & . 85 & 1.5 & 4.90 & 940 & 10.00 & 5,550 & 5.00 & 815 & 3.99 & 367 \\
\hline 6 & - & - & & - & 4.83 & 905 & 9.19 & 5,130 & 4.95 & 788 & - & - \\
\hline 8 & - & - & .88 & 1.9 & 4.61 & 801 & 8.39 & 4,540 & 4.82 & 720 & 3.91 & 339 \\
\hline 10 & - & - & - & - & 4.40 & 710 & 7.50 & 3,530 & 4.69 & 657 & - & - \\
\hline \multirow[t]{2}{*}{ M } & .81 & 1.2 & .96 & 2.9 & 4.43 & 723 & 7.03 & 2,820 & 4.56 & 598 & 3.77 & 295 \\
\hline & \multicolumn{2}{|c|}{ December 14} & \multicolumn{2}{|c|}{ December 15} & \multicolumn{2}{|c|}{ December 16} & \multicolumn{2}{|c|}{ December 17} & \multicolumn{2}{|c|}{ December 18} & \multicolumn{2}{|c|}{ December 19} \\
\hline 2 & - & - & - & - & - & - & - & - & - & - & - & - \\
\hline 4 & 3.68 & 268 & - & - & - & - & - & - & - & - & - & - \\
\hline 6 & - & - & 3.38 & 188 & 3.15 & 140 & 3.05 & 121 & 2.95 & 104 & 2.83 & 86 \\
\hline 8 & 3.61 & 249 & - & - & - & - & - & - & - & - & - & - \\
\hline 10 & - & - & - & - & - & $\approx$ & $\overrightarrow{0}$ & - & - & - & & $=$ \\
\hline $\mathbf{N}$ & 3.54 & 229 & 3.31 & 172 & 3.12 & 134 & 3.00 & 112 & 2.88 & 93 & 2.78 & 79 \\
\hline 2 & $=-$ & - & - & - & - & - & - & - & - & - & - & - \\
\hline 4 & 3.52 & 224 & - & - & - & - & - & - & - & - & - & - \\
\hline 6 & - & - & 3.28 & 166 & 3.10 & 130 & 2.99 & 110 & 2.88 & 93 & 2.80 & 82 \\
\hline 8 & 3.53 & 226 & - & - & - & - & - & - & - & - & - & - \\
\hline \multirow{3}{*}{$\begin{array}{r}10 \\
M \\
\end{array}$} & - & - & - & - & - & - & $\sim$ & - & - & - & - & - \\
\hline & 3.48 & 213 & 3.24 & 158 & 3.10 & 130 & 2.99 & 110 & 2.88 & 93 & 2.79 & 81 \\
\hline & \multicolumn{2}{|c|}{ December 20} & \multicolumn{2}{|c|}{ December 21} & \multicolumn{2}{|c|}{ December 22} & \multicolumn{2}{|c|}{ December 23} & \multicolumn{2}{|c|}{ December 24} & \multicolumn{2}{|c|}{ December 25} \\
\hline 2 & - & - & - & - & - & - & - & - & - & - & - & - \\
\hline 4 & & - & - & - & 2.65 & 64 & 2.63 & 61 & - & $=$ & - & - \\
\hline 6 & 2.72 & 72 & 2.65 & 64 & - & - & - & - & 2.56 & 54 & 2.51 & 49 \\
\hline 8 & - & - & - & - & 2.61 & 59 & 2.54 & 52 & - & - & - & - \\
\hline 10 & - & - & - & - & & - & & - & - & - & & - \\
\hline $\mathrm{N}$ & 2.67 & 66 & 2.65 & 64 & 2.57 & 55 & 2.50 & 48 & 2.50 & 48 & 2.49 & 47 \\
\hline 2 & - & - & - & - & - & - & - & - & - & - & - & - \\
\hline 4 & - & - & - & - & 2.62 & 60 & 2.55 & 53 & - & - & - & - \\
\hline 6 & 2.70 & 69 & 2.67 & 66 & - & - & - & - & 2.57 & 55 & 2.54 & 52 \\
\hline 8 & - & - & & - & 2.62 & 65 & 2.64 & 62 & 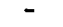 & - & & $\sim$ \\
\hline 10 & $0^{-}$ & - & - & - & - & - & - & - & - & - & - & $=$ \\
\hline M & 2.67 & 66 & 2.67 & 66 & 2.65 & 64 & 2.62 & 60 & 2.55 & 53 & 2.53 & 51 \\
\hline
\end{tabular}


Orestimba Creek near Newman, Calif.

Location. - Lat. $37^{\circ} 19^{\prime} 09^{\prime \prime}$, long. $121^{\circ} 07^{\prime} 14^{\prime \prime}$, in NW/ sec. 20, T. 7 S., R. 8 E., 3 miles below oso Creek, at highway bridge 5 miles west of Newman, Stanislaus County. Altitude, about 190 feet above mean sea level.

Drainage area.- 129 square miles.

Gage-helght record. - Water-stage recorder graph except for perlods 5 a.m. Dec. 21 to $1: 30$ p.m. Dec. 22,4 a.m. Dec. 24 to $4: 30$ p.m. Jan. 24, when there was no record. Stage-discharge relation.- Defined by current-meter measurements below 1,200 secondfeet; extended to peak stage on basis of slope-area computations for 1932 peak discharges; verified with ald of area-velocity study. Shifting-control method for period Dec. 11-17.

Maxima.- December 1937: D1scharge, 2,040 second-feet 1 p.m. Dec. 11 (gage helght, 4.22 fe日t).

1932-November 1937: D1scharge, 3,440 second-feet Feb. 8, 1932 (gege helght 5.15 feet), from rating curve extended above 390 second-feet on basis of slopearea computation of flood flow.

Remarks. - Flood mun-off not affected by artificlal storage or diversion. Discharge for perlods of missing gage-height record based on range in stage indicated on recorder graph and on study of rainfall records.

Mean dafly dscharge, in second-feet, November 1937 to January 1938

\begin{tabular}{|c|c|c|c|c|c|c|c|c|c|c|c|}
\hline Day & Nov. & Dec. & Jan. & Day & Nov, & Dec. & Jan. & Day & Nov. & Dec. & Jan. \\
\hline $\begin{array}{r}1 \\
2 \\
3 \\
4 \\
5 \\
6 \\
7 \\
8 \\
9 \\
10\end{array}$ & $\begin{array}{l}0 \\
0 \\
0 \\
0 \\
0 \\
0 \\
0 \\
0 \\
0 \\
0\end{array}$ & $\begin{array}{l}0 \\
0 \\
0 \\
0 \\
0 \\
0 \\
0 \\
0 \\
0 \\
0\end{array}$ & $\begin{array}{l}0 \\
0 \\
0 \\
0 \\
0 \\
0 \\
0 \\
0 \\
0 \\
0\end{array}$ & $\begin{array}{l}11 \\
12 \\
13 \\
14 \\
15 \\
16 \\
17 \\
18 \\
19 \\
20\end{array}$ & $\begin{array}{l}0 \\
0 \\
0 \\
0 \\
0 \\
0 \\
0 \\
0 \\
0 \\
0\end{array}$ & \begin{tabular}{|c|}
, 070 \\
197 \\
51 \\
19 \\
7.5 \\
2.5 \\
. .7 \\
0 \\
0 \\
0
\end{tabular} & $\begin{array}{l}0 \\
0 \\
0 \\
0 \\
1 \\
1 \\
2 \\
2 \\
4 \\
3\end{array}$ & $\begin{array}{l}21 \\
22 \\
23 \\
24 \\
25 \\
26 \\
27 \\
28 \\
29 \\
30 \\
31\end{array}$ & $\begin{array}{l}0 \\
0 \\
0 \\
0 \\
0 \\
0 \\
0 \\
0 \\
0 \\
0\end{array}$ & $\begin{array}{l}0 \\
0 \\
0 \\
0 \\
0 \\
0 \\
0 \\
0 \\
0 \\
0 \\
0\end{array}$ & $\begin{array}{l}2 \\
2 \\
1 \\
.4 \\
.1 \\
0 \\
0 \\
.3 \\
2.5 \\
5.5 \\
54\end{array}$ \\
\hline \multicolumn{9}{|c|}{ 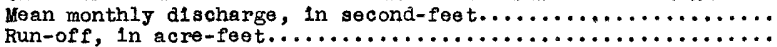 } & $\begin{array}{l}0 \\
0\end{array}$ & $\begin{array}{r}43.5 \\
2,670\end{array}$ & $\begin{array}{r}2.61 \\
160\end{array}$ \\
\hline
\end{tabular}

Gage helght, in feet, and discharge, in second-feet, at indicated time, 1937

\begin{tabular}{|c|c|c|c|c|c|c|c|c|c|c|c|c|}
\hline \multirow{2}{*}{ 㟧 } & Feet & Sec.ft. & Feet & Sec.ft. & Feet & Sec.ft. & Feet & Sec.ft. & Feet & Sec.ft. & Feet & sec.ft. \\
\hline & \multicolumn{2}{|c|}{ December 8} & \multicolumn{2}{|c|}{ December 9} & \multicolumn{2}{|c|}{ December 10} & \multicolumn{2}{|c|}{ December 11} & \multicolumn{2}{|c|}{ December 12} & \multicolumn{2}{|c|}{ December 13} \\
\hline \multirow[t]{2}{*}{$\begin{array}{r}2 \\
4 \\
6 \\
B \\
10 \\
N \\
2 \\
4 \\
6 \\
8 \\
10 \\
M\end{array}$} & & & & & & & $\begin{array}{c}- \\
3 . \\
3.90 \\
4.00 \\
3.83 \\
4.20 \\
4.15 \\
3.82 \\
3.43 \\
3.10 \\
2.83 \\
2.63\end{array}$ & $\begin{array}{r}0 \\
0 \\
1,660 \\
1,780 \\
1,580 \\
2,040 \\
1,980 \\
1,560 \\
1,130 \\
810 \\
601 \\
473\end{array}$ & $\begin{array}{l}2.46 \\
2.33 \\
2.19 \\
2.10 \\
2.03 \\
1.95 \\
1.89 \\
1.88 \\
1.88 \\
1.84 \\
1.79 \\
1.73\end{array}$ & $\begin{array}{c}373 \\
305 \\
241 \\
205 \\
180 \\
154 \\
135 \\
132 \\
132 \\
121 \\
106 \\
92\end{array}$ & $\begin{array}{c}-\overline{1.63} \\
- \\
1.54 \\
\overline{1.45} \\
- \\
1.39 \\
- \\
1.32 \\
- \\
1.28\end{array}$ & $\begin{array}{l}\overline{73} \\
\overline{59} \\
\overline{46} \\
\overline{40} \\
\overline{34} \\
\overline{30}\end{array}$ \\
\hline & \multicolumn{2}{|c|}{ December 14} & \multicolumn{2}{|c|}{ December 15} & \multicolumn{2}{|c|}{ December 16} & \multicolumn{2}{|c|}{ December 17} & \multicolumn{2}{|c|}{ December 18} & \multicolumn{2}{|c|}{ De cember 19} \\
\hline \multirow[t]{2}{*}{$\begin{array}{r}2 \\
4 \\
6 \\
8 \\
10 \\
N \\
2 \\
4 \\
6 \\
8 \\
10 \\
M\end{array}$} & $\begin{array}{c}-\overline{1.23} \\
- \\
1.19 \\
-\overline{1.15} \\
- \\
1.11 \\
- \\
1.07 \\
- \\
1.04\end{array}$ & $\begin{array}{l}\overline{26} \\
\overline{2} \\
\overline{2} \\
\overline{19} \\
\overline{1} \\
\overline{16} \\
\overline{13} \\
\overline{11}\end{array}$ & $\begin{array}{l}- \\
1.01 \\
- \\
.99 \\
.96 \\
.93 \\
-90 \\
.88\end{array}$ & $\begin{array}{c}9.5 \\
9.0 \\
7.5 \\
6^{-} \\
5^{-} \\
4.5\end{array}$ & $\begin{array}{c}- \\
0.86 \\
-83 \\
-8 \\
.80 \\
.77 \\
-.75 \\
-72\end{array}$ & $\begin{array}{c}3 . \overline{0} \\
\overline{3.0} \\
-\overline{2} \\
-\overline{5} \\
2.0 \\
\overline{1.7} \\
1.3\end{array}$ & $\begin{array}{l}- \\
0.70 \\
-68 \\
-66 \\
.65 \\
.61 \\
.55 \\
.42\end{array}$ & $\begin{array}{c}1.1 \\
-1.0 \\
-7 \\
-5 \\
-5 \\
-2 \\
0\end{array}$ & & & & \\
\hline & \multicolumn{2}{|c|}{ December 20} & \multicolumn{2}{|c|}{ December 21} & \multicolumn{2}{|c|}{ December 22} & \multicolumn{2}{|c|}{ December 23} & \multicolumn{2}{|c|}{ December 24} & \multicolumn{2}{|c|}{ December 25} \\
\hline $\begin{array}{r}2 \\
4 \\
6 \\
8 \\
10 \\
\mathrm{~N} \\
2 \\
4 \\
6 \\
8 \\
10 \\
M\end{array}$ & & & & & & & & & & & & \\
\hline
\end{tabular}

Supplemental recorôs.- Dec. 11, 5:15 a.14., no flow; 5:30 a.m., 3.70 ft., 1,420 sec.-ft.; 1 p.m., 4.22 ft., 2,040 sec.-ft. 
Hetch Hetchy Reservoir at Hetch Hetchy, Calif.

Locstion.- Lat. $37^{\circ} 57^{\prime}$, long. $119^{\circ} 47^{\prime}$, in sec. 16, T. I N., R. 20 E., at O'Shaughnessy

Dam on Tholumne River, Tuolumne County. Zero of gage is at about mean sea level. Drainage area.- 460 square miles.

Gage-height record.- Gage read to tenths dally at 7 a.m.

Remarks.- Flood run-off completely controlled in reservoir. Elevation of spiliway

crest is $3,796.0$ feet above mean sea level (capacity, 340,830 acre-feet). Some water relessed during flood period. See record for Tuolume River near Hetch Hetchy.

Basic data furnished by city of San Francisco.

Elevation and contents, November 1937 to January 1938

\begin{tabular}{|c|c|c|c|c|c|c|}
\hline \multirow[b]{2}{*}{ Day } & \multicolumn{2}{|c|}{ November } & \multicolumn{2}{|c|}{ December } & \multicolumn{2}{|c|}{ January } \\
\hline & $\begin{array}{c}\text { Elevation } \\
\text { (feet) }\end{array}$ & $\begin{array}{c}\text { Contents } \\
(\mathrm{acre}-\mathrm{feet})\end{array}$ & $\begin{array}{c}\text { Elevation } \\
(\text { feet })\end{array}$ & $\begin{array}{l}\text { Contents } \\
(\operatorname{scr} \theta-f e \theta t)\end{array}$ & $\begin{array}{c}\text { Elevation } \\
(\text { feet })\end{array}$ & $\begin{array}{l}\text { Contents } \\
\text { (acre-feet) }\end{array}$ \\
\hline $\begin{array}{l}1 \\
2 \\
3 \\
4 \\
5\end{array}$ & $\begin{array}{l}3,651.3 \\
3,650.4 \\
3,649.5 \\
3,648.5 \\
3,647.5\end{array}$ & $\begin{array}{l}109,720 \\
108,670 \\
107,640 \\
106,520 \\
105,400\end{array}$ & $\begin{array}{l}3,622.1 \\
3,621.1 \\
3,620.1 \\
3,619.1 \\
3,618.1\end{array}$ & $\begin{array}{l}78,600 \\
77,600 \\
76,600 \\
75,640 \\
74,680\end{array}$ & $\begin{array}{l}3,670.2 \\
3,669.6 \\
3,669.0 \\
3,668.5 \\
3,668.0\end{array}$ & $\begin{array}{l}132,970 \\
132,190 \\
131,420 \\
130,780 \\
130,140\end{array}$ \\
\hline $\begin{array}{r}6 \\
7 \\
8 \\
9 \\
10\end{array}$ & $\begin{array}{l}3,646.5 \\
3,645.4 \\
3,644.4 \\
3,643.3 \\
3,642.2\end{array}$ & $\begin{array}{r}104,280 \\
103,050 \\
101,930 \\
100,700 \\
99,460\end{array}$ & $\begin{array}{l}3,617.1 \\
3,616.1 \\
3,615 \cdot 1 \\
3,614.1 \\
3,615.2\end{array}$ & $\begin{array}{l}73,720 \\
72,760 \\
71,800 \\
70,840 \\
71,890\end{array}$ & $\begin{array}{l}3,667.4 \\
3,666.8 \\
3,666.2 \\
3,665.5 \\
3,664.8\end{array}$ & $\begin{array}{l}129,370 \\
128,600 \\
127,840 \\
126,940 \\
126,040\end{array}$ \\
\hline $\begin{array}{l}11 \\
12 \\
13 \\
14 \\
15\end{array}$ & $\begin{array}{l}3,641.1 \\
3,640.0 \\
3,638.8 \\
3,637.7 \\
3,636.7\end{array}$ & $\begin{array}{l}98,230 \\
97,000 \\
95,740 \\
94,580 \\
93,540\end{array}$ & $\begin{array}{l}3,623.0 \\
3,668.3 \\
3,673.0 \\
3,674.9 \\
3,676.0\end{array}$ & $\begin{array}{r}79,500 \\
130,520 \\
136,750 \\
139,320 \\
140,800\end{array}$ & $\begin{array}{l}3,663.9 \\
3,662.9 \\
3,661.9 \\
3,661.0 \\
3.662 .1\end{array}$ & $\begin{array}{l}124,890 \\
123,610 \\
122,330 \\
121,180 \\
122,590\end{array}$ \\
\hline $\begin{array}{l}16 \\
17 \\
18 \\
19 \\
20\end{array}$ & $\begin{array}{l}3,635.7 \\
3,634.7 \\
3,633.8 \\
3,632.8 \\
3,631.8\end{array}$ & $\begin{array}{l}92,480 \\
91,440 \\
90,490 \\
89,440 \\
88,390\end{array}$ & $\begin{array}{l}3,676.5 \\
3,676.8 \\
3,676.9 \\
3,676.8 \\
3,676.7\end{array}$ & $\begin{array}{l}141,480 \\
141,880 \\
142,020 \\
141,880 \\
141,740\end{array}$ & $\begin{array}{l}3,661.1 \\
3,660.1 \\
3,659.9 \\
3,659.6 \\
3,659.1\end{array}$ & $\begin{array}{l}121,310 \\
120,030 \\
119,780 \\
119,430 \\
118,850\end{array}$ \\
\hline $\begin{array}{l}21 \\
22 \\
23 \\
24 \\
25\end{array}$ & $\begin{array}{l}3,630.9 \\
3,630.2 \\
3,629.5 \\
3,628.7 \\
3,627.7\end{array}$ & $\begin{array}{l}87,440 \\
86,710 \\
86,000 \\
85,200 \\
84,200\end{array}$ & $\begin{array}{l}3,676.4 \\
3,676.0 \\
3,675.6 \\
3,675.2 \\
3,674.7\end{array}$ & $\begin{array}{l}141,340 \\
140,800 \\
140,260 \\
139,720 \\
139,040\end{array}$ & $\begin{array}{l}3,658.5 \\
3,658.0 \\
3,657.4 \\
3,656.7 \\
3,656.0\end{array}$ & $\begin{array}{l}118,140 \\
117,560 \\
116,860 \\
116,040 \\
115,220\end{array}$ \\
\hline $\begin{array}{l}26 \\
27 \\
28 \\
29 \\
30 \\
31 \\
\end{array}$ & $\begin{array}{l}3,626.8 \\
3,625.9 \\
3,625.0 \\
3,624.1 \\
3,623.1\end{array}$ & $\begin{array}{l}83,300 \\
82,400 \\
81,500 \\
80,600 \\
79,600\end{array}$ & $\begin{array}{l}3,674.0 \\
3,673.3 \\
3,672.6 \\
3,672.0 \\
3,671.4 \\
3,670.8\end{array}$ & $\begin{array}{l}138,100 \\
137,160 \\
136,210 \\
135,400 \\
134,590 \\
133,780\end{array}$ & $\begin{array}{l}3,655.3 \\
3,654.6 \\
3,653.9 \\
3,653.2 \\
3,652.5 \\
3,651.9\end{array}$ & $\begin{array}{l}114,400 \\
113,580 \\
112,760 \\
111,940 \\
111,120 \\
110,420\end{array}$ \\
\hline
\end{tabular}


Location.- Lat. $37^{\circ} 56^{\prime}$, long. $119^{\circ} 48^{\prime}$, in SE妾 sec. 17, T. I N., R. 20 E., 1n Yosemite National Park, three-quarters of a mile below 0 'Shaughnessy Dam and Hetch Hetchy

Reservolr, Tuolumne County. Altitude, about 3,450 feet above mean sea level.

Drainage area. - 462 square miles.

Gage-helght record. - Water-stage recorder graph.

Stage-discharge relation. - Defined by current-meter measurements.

Maxima.- December 1937: Discharge (regulated), 715 second-feet 4 p.m. Dec. 24 to 5

p.m. Dec. 27 (gage height, 5.95 feet). Adjusted maximum discharge, about 50,000 second-feet morning Dec. 11, based on record of changes in storage.

1915-November 1937: Discharge, 12,000 second-feet (reservo1r full and spilling) June 16, 1829 (gage height, 13.58 feet), from rating curve extended above 7,300 second-feet.

Remarks. - Flood run-off completely regulated in Hetch Hetchy Reservolr (capac1ty, 340,830 acre-feet). Daily gain or loss in storage computed from contents at midnight determined from graph based on readings at 7 a.m. See record for Hetch Hetchy Reservoir at Hetch Hetchy. Part of baslc data furnished by city of San Francisco.

Discharge, in second-feet, and gain or loss in storage, in acre-feet, November 1937 to January 1938

\begin{tabular}{|c|c|c|c|c|c|c|c|c|c|}
\hline \multirow[b]{2}{*}{ Day } & \multicolumn{3}{|c|}{ November } & \multicolumn{3}{|c|}{ December } & \multicolumn{3}{|c|}{ January } \\
\hline & $\begin{array}{l}\text { Observed } \\
\text { discharge }\end{array}$ & $\begin{array}{l}\text { Gain or } \\
\text { loss in } \\
\text { storage }\end{array}$ & $\begin{array}{l}\text { Ad justed } \\
\text { d1scharge }\end{array}$ & $\begin{array}{l}\text { Observed } \\
\text { discharge }\end{array}$ & $\begin{array}{l}\text { Gain or } \\
\text { loss in } \\
\text { storage }\end{array}$ & $\begin{array}{l}\text { Ad justed } \\
\text { d 1scharge }\end{array}$ & $\begin{array}{l}\text { Observed } \\
\text { discharge }\end{array}$ & $\begin{array}{l}\text { Gain or } \\
\text { loss in } \\
\text { storage }\end{array}$ & $\begin{array}{l}\text { Ad jus ted } \\
\text { discharge }\end{array}$ \\
\hline $\begin{array}{l}1 \\
2 \\
3 \\
4 \\
5\end{array}$ & $\begin{array}{l}552 \\
552 \\
578 \\
628 \\
615\end{array}$ & $\begin{array}{l}-1,050 \\
-1,040 \\
-1,090 \\
-1,120 \\
-1,120\end{array}$ & $\begin{array}{l}23 \\
28 \\
28 \\
63 \\
50\end{array}$ & $\begin{array}{l}565 \\
590 \\
602 \\
590 \\
565\end{array}$ & $\begin{array}{r}-1,000 \\
-1,000 \\
-970 \\
-960 \\
-960\end{array}$ & $\begin{array}{r}61 \\
86 \\
113 \\
106 \\
81\end{array}$ & $\begin{array}{l}685 \\
685 \\
628 \\
628 \\
670\end{array}$ & $\begin{array}{l}-790 \\
-780 \\
-670 \\
-640 \\
-740\end{array}$ & $\begin{array}{l}287 \\
292 \\
290 \\
305 \\
297\end{array}$ \\
\hline $\begin{array}{r}6 \\
7 \\
8 \\
9 \\
10\end{array}$ & $\begin{array}{l}628 \\
655 \\
640 \\
655 \\
670\end{array}$ & $\begin{array}{l}-1,200 \\
-1,150 \\
-1,200 \\
-1,240 \\
-1,230\end{array}$ & $\begin{array}{l}23 \\
75 \\
35 \\
30 \\
50\end{array}$ & $\begin{array}{l}565 \\
552 \\
552 \\
578 \\
540\end{array}$ & $\begin{array}{r}-960 \\
-960 \\
-960 \\
+180 \\
+3,700\end{array}$ & $\begin{array}{r}81 \\
68 \\
68 \\
669 \\
2,400\end{array}$ & $\begin{array}{l}700 \\
730 \\
745 \\
730 \\
700\end{array}$ & $\begin{array}{r}-770 \\
-760 \\
-860 \\
-900 \\
-1,070\end{array}$ & $\begin{array}{l}312 \\
347 \\
311 \\
276 \\
161\end{array}$ \\
\hline $\begin{array}{l}11 \\
12 \\
13 \\
14 \\
15\end{array}$ & $\begin{array}{l}685 \\
685 \\
670 \\
615 \\
578\end{array}$ & $\begin{array}{l}-1,230 \\
-1,250 \\
-1,190 \\
-1,080 \\
-1,050\end{array}$ & $\begin{array}{l}65 \\
55 \\
70 \\
70 \\
47\end{array}$ & $\begin{array}{l}590 \\
602 \\
615 \\
640 \\
655\end{array}$ & $\begin{array}{r}+50,700 \\
+9,700 \\
+3,500 \\
+1,500 \\
+880\end{array}$ & $\begin{array}{r}26,200 \\
5,490 \\
2,380 \\
1,400 \\
1,100\end{array}$ & $\begin{array}{l}700 \\
700 \\
700 \\
730 \\
760\end{array}$ & $\begin{array}{r}-1,250 \\
-1,280 \\
-1,180 \\
+80 \\
0\end{array}$ & $\begin{array}{r}70 \\
55 \\
105 \\
770 \\
760\end{array}$ \\
\hline $\begin{array}{l}16 \\
17 \\
18 \\
19 \\
20\end{array}$ & $\begin{array}{l}590 \\
602 \\
615 \\
615 \\
602\end{array}$ & $\begin{array}{r}-1,050 \\
-970 \\
-1,020 \\
-1,050 \\
-980\end{array}$ & $\begin{array}{r}61 \\
113 \\
101 \\
86 \\
108\end{array}$ & $\begin{array}{l}685 \\
700 \\
700 \\
700 \\
685\end{array}$ & $\begin{array}{r}+480 \\
+220 \\
-60 \\
-140 \\
-320\end{array}$ & $\begin{array}{l}927 \\
811 \\
670 \\
629 \\
524\end{array}$ & $\begin{array}{l}745 \\
745 \\
628 \\
640 \\
745\end{array}$ & $\begin{array}{r}-1,200 \\
-550 \\
-320 \\
-510 \\
-670\end{array}$ & $\begin{array}{l}140 \\
468 \\
467 \\
383 \\
407\end{array}$ \\
\hline $\begin{array}{l}21 \\
22 \\
23 \\
24 \\
25\end{array}$ & $\begin{array}{l}540 \\
520 \\
552 \\
565 \\
565\end{array}$ & $\begin{array}{l}-800 \\
-710 \\
-780 \\
-940 \\
-930\end{array}$ & $\begin{array}{r}137 \\
162 \\
159 \\
91 \\
96\end{array}$ & $\begin{array}{l}670 \\
670 \\
670 \\
700 \\
715\end{array}$ & $\begin{array}{l}-500 \\
-540 \\
-540 \\
-640 \\
-870\end{array}$ & $\begin{array}{l}418 \\
398 \\
398 \\
377 \\
276\end{array}$ & $\begin{array}{l}745 \\
745 \\
745 \\
745 \\
745\end{array}$ & $\begin{array}{l}-620 \\
-670 \\
-780 \\
-820 \\
-820\end{array}$ & $\begin{array}{l}432 \\
407 \\
352 \\
332 \\
332\end{array}$ \\
\hline $\begin{array}{l}26 \\
27 \\
28 \\
29 \\
30 \\
31\end{array}$ & $\begin{array}{l}565 \\
565 \\
540 \\
530 \\
565\end{array}$ & $\begin{array}{r}-900 \\
-900 \\
-900 \\
-970 \\
-1,000\end{array}$ & $\begin{array}{r}111 \\
111 \\
86 \\
41 \\
61\end{array}$ & $\begin{array}{l}715 \\
715 \\
700 \\
685 \\
685 \\
685\end{array}$ & $\begin{array}{l}-940 \\
-940 \\
-850 \\
-810 \\
-810 \\
-810\end{array}$ & $\begin{array}{l}241 \\
241 \\
271 \\
277 \\
277 \\
277\end{array}$ & $\begin{array}{l}730 \\
730 \\
730 \\
730 \\
730 \\
745\end{array}$ & $\begin{array}{l}-820 \\
-820 \\
-820 \\
-820 \\
-740 \\
-610\end{array}$ & $\begin{array}{l}317 \\
317 \\
317 \\
317 \\
357 \\
437\end{array}$ \\
\hline \multicolumn{7}{|c|}{ 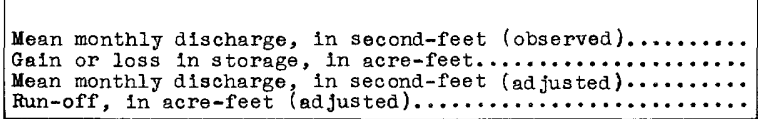 } & \begin{tabular}{|r|} 
Novernber \\
598 \\
$-31,140$ \\
74.5 \\
4,440
\end{tabular} & $\begin{array}{r}\text { December } \\
+541 \\
+54,320 \\
1,525 \\
93,750\end{array}$ & $\begin{array}{r}\text { January } \\
713 \\
-23,200 \\
336 \\
20,660\end{array}$ \\
\hline
\end{tabular}


Location. - Lat. $37^{\circ} 42^{\prime} 48^{\prime \prime}$, long. $120^{\circ} 24^{\prime} 14^{\prime \prime}$, in SW sec. 35, T. 2 S., R. 14 E. at Don Pedro Dam on Tuolumne River, 1 mile below Rogers Creek and $5.5 \mathrm{miles}$ above La Grange, Stanislaus County. Zero af gage is at mean sea level.

Drainage area.- 1,540 square miles.

Gage-height record.- Gage read to tenths dally at 8 a.m.

Remarks.-Flood run-off completely centrolled in reservolr. Elevation of crest of spiliway is 596.55 feet abcve mean sea leve1 (capacity, 262,2c0 acre-feet). Elevation of top of splliway gates is 605.55 feet above mean sea level (capacity, 290,400 acre-feet). See recora for Tuolumne RIver abave La Grange Dam. Basic data furnished by Turlock and Modesto Irrigation Districts.

Elevation and cantents, November 1937 to January 1938

\begin{tabular}{|c|c|c|c|c|c|c|}
\hline \multirow[b]{2}{*}{ Day } & \multicolumn{2}{|c|}{ November } & \multicolumn{2}{|c|}{ December } & \multicolumn{2}{|c|}{ January } \\
\hline & $\begin{array}{c}\text { Elevation } \\
\text { (feet) }\end{array}$ & $\begin{array}{l}\text { Contents } \\
(\text { acre-feet })\end{array}$ & $\begin{array}{c}\text { Elevation } \\
\text { (feet) }\end{array}$ & $\begin{array}{l}\text { Contents } \\
(\text { acre-feet) }\end{array}$ & $\begin{array}{l}\text { Elevation } \\
(\text { feet) }\end{array}$ & $\begin{array}{l}\text { Contenta } \\
(\text { acre-feet })\end{array}$ \\
\hline $\begin{array}{l}1 \\
2 \\
3 \\
4 \\
5\end{array}$ & $\begin{array}{l}513.7 \\
513.3 \\
513.2 \\
513.1 \\
513.0\end{array}$ & $\begin{array}{l}69,200 \\
68,600 \\
68,500 \\
68,400 \\
68,200\end{array}$ & $\begin{array}{l}512.4 \\
512.4 \\
512.7 \\
512.8 \\
512.7\end{array}$ & $\begin{array}{l}67,400 \\
67,400 \\
67,800 \\
68,000 \\
67,800\end{array}$ & $\begin{array}{l}583.1 \\
583.2 \\
583.8 \\
584.4 \\
585.0\end{array}$ & $\begin{array}{l}222,200 \\
222,500 \\
224,300 \\
226,000 \\
227,700\end{array}$ \\
\hline $\begin{array}{r}6 \\
7 \\
8 \\
9 \\
10\end{array}$ & $\begin{array}{l}512.9 \\
512.8 \\
512.4 \\
512.3 \\
512.2\end{array}$ & $\begin{array}{l}68,100 \\
68,000 \\
67,400 \\
67,300 \\
67,100\end{array}$ & $\begin{array}{l}511.8 \\
511.7 \\
511.8 \\
511.8 \\
511.9\end{array}$ & $\begin{array}{l}66,600 \\
66,400 \\
66,600 \\
66,600 \\
66,700\end{array}$ & $\begin{array}{l}585.5 \\
585.8 \\
586.1 \\
586.5 \\
586.7\end{array}$ & $\begin{array}{l}229,200 \\
230,100 \\
231,000 \\
232,100 \\
232,800\end{array}$ \\
\hline $\begin{array}{l}11 \\
12 \\
13 \\
14 \\
15\end{array}$ & $\begin{array}{l}512.1 \\
512.0 \\
512.0 \\
512.1 \\
511.5\end{array}$ & $\begin{array}{l}67,000 \\
66,900 \\
66,900 \\
67,000 \\
66,200\end{array}$ & $\begin{array}{l}534.9 \\
574.6 \\
580.4 \\
582.4 \\
583.4\end{array}$ & $\begin{array}{l}103,200 \\
198,200 \\
214,500 \\
220,200 \\
223,100\end{array}$ & $\begin{array}{l}587.0 \\
587.3 \\
587.7 \\
587.9 \\
589.8\end{array}$ & $\begin{array}{l}233,600 \\
234,500 \\
235,600 \\
236,200 \\
241,900\end{array}$ \\
\hline $\begin{array}{l}16 \\
17 \\
18 \\
19 \\
20\end{array}$ & $\begin{array}{l}511.7 \\
511.9 \\
511.9 \\
512.2 \\
512.3\end{array}$ & $\begin{array}{l}66,400 \\
66,700 \\
66,700 \\
67,100 \\
67,300\end{array}$ & $\begin{array}{l}584.1 \\
584.7 \\
584.8 \\
584.9 \\
584.7\end{array}$ & $\begin{array}{l}225,100 \\
226,900 \\
227,200 \\
227,500 \\
226,900\end{array}$ & $\begin{array}{l}594.0 \\
595.7 \\
596.8 \\
597.4 \\
597.5\end{array}$ & $\begin{array}{l}254,500 \\
259,600 \\
263,000 \\
264,800 \\
265,100\end{array}$ \\
\hline $\begin{array}{l}21 \\
22 \\
23 \\
24 \\
25\end{array}$ & $\begin{array}{l}512.3 \\
512.1 \\
512.3 \\
512.3 \\
512.3\end{array}$ & $\begin{array}{l}67,300 \\
67,000 \\
67,300 \\
67,300 \\
67,300\end{array}$ & $\begin{array}{l}584.7 \\
584.6 \\
584.5 \\
584.4 \\
584.3\end{array}$ & $\begin{array}{l}226,900 \\
226,600 \\
226,300 \\
226,000 \\
225,700\end{array}$ & $\begin{array}{l}597.3 \\
597.2 \\
597.2 \\
597.0 \\
597.1\end{array}$ & $\begin{array}{l}264,500 \\
264,200 \\
264,200 \\
263,600 \\
263,900\end{array}$ \\
\hline $\begin{array}{l}26 \\
27 \\
28 \\
29 \\
30 \\
31\end{array}$ & $\begin{array}{l}512.3 \\
512.5 \\
512.8 \\
512.6 \\
512.6\end{array}$ & $\begin{array}{l}67,300 \\
67,500 \\
68,000 \\
67,700 \\
67,700\end{array}$ & $\begin{array}{l}584.0 \\
583.8 \\
583.7 \\
583.5 \\
583.3 \\
583.1\end{array}$ & $\begin{array}{l}224,800 \\
224,300 \\
224,000 \\
223,400 \\
222,800 \\
222,200\end{array}$ & $\begin{array}{l}597.1 \\
597.2 \\
597.1 \\
597.3 \\
597.3 \\
597.2\end{array}$ & $\begin{array}{l}263,900 \\
264,200 \\
263,900 \\
264,500 \\
264,500 \\
264,200\end{array}$ \\
\hline
\end{tabular}


Tuolume River above La Grange Dam, near La Grange, Calif.

Location.- Lat. $37^{\circ} 42^{\prime} 35^{\prime \prime}$, long. $120^{\circ} 24^{\prime} 45^{\prime \prime}$, in NE⿺ sec. 3, T. 3 S., R. 14 E., half a

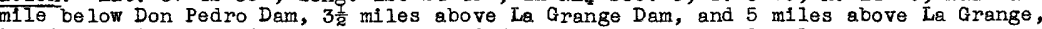
Stanislaus County. Altitude, about 330 feet above mean sea level.

Drainage area. - 1,540 square miles.

Gage-helght record. - Water-stage recorder graph.

Stage-discharge relation. - Defined by current-meter measurements.

Maxima. December 1937: Flood mun-off completely controlled In Don Pedro Reservolr.

1915-November 1937: D1scharge (regulated), 38,100 second-feet Mar. 25, 1928 (gage helght, 29.6 feet), from rating curve extended above 17,000 second-feet.

1895-1915: Discharge (unregulated), about 60,300 second-feet Jan. 31,1911 (gage helght, 16.45 feet, from stage graph constmicted from frequent gage readings, former site and datum at La Grange Dam), from rating curve extended above 18,000 secondfeet.

Remarks.- Flood mun-off completely controlled in Don Pedro Reservo1r (capacity, 262,200 acre-feet at elevation of crest of splilway). See record for Don Pedro Reservolr near La Grange. Daily and monthiy discharges adjusted for changes in storage in Don Pedro Reservoir but not for storage in Hetch Hetchy Reservo1r, Lake Eleanor, or for diversions. Contents at midnight in Don Pedro Reservoir determined from graph based on daliy readings at $8 \mathrm{a.m}$. Mean monthly diversion through San Francisco Aqueduct: November, 12 second-feet; December, 3 second-feet; January, 3 second-feet.

Discharge, in second-feet, and gain or loss in storage, in acre-feet, November 1937 to January 1938

\begin{tabular}{|c|c|c|c|c|c|c|c|c|c|}
\hline \multirow[b]{2}{*}{ Day } & \multicolumn{3}{|c|}{ November } & \multicolumn{3}{|c|}{ December } & \multicolumn{3}{|c|}{ January } \\
\hline & $\begin{array}{l}\text { Observed } \\
\text { discharge }\end{array}$ & $\begin{array}{l}\text { Gain or } \\
\text { loss in } \\
\text { storage }\end{array}$ & $\begin{array}{l}\text { Ad justed } \\
\text { discharge }\end{array}$ & $\begin{array}{l}\text { Observed } \\
\text { discharge }\end{array}$ & $\begin{array}{l}\text { Gain or } \\
\text { loss in } \\
\text { storage }\end{array}$ & $\begin{array}{r}\text { Ad jus ted } \\
\text { discharge }\end{array}$ & $\begin{array}{r}\text { Observed } \\
\text { discharge }\end{array}$ & $\begin{array}{l}\text { Gain or } \\
\text { loss in } \\
\text { storage }\end{array}$ & $\begin{array}{l}\text { Ad justed } \\
\text { discharge }\end{array}$ \\
\hline $\begin{array}{l}1 \\
2 \\
3 \\
4 \\
5\end{array}$ & $\begin{array}{l}915 \\
913 \\
923 \\
919 \\
933\end{array}$ & $\begin{array}{l}-630 \\
-270 \\
-100 \\
-160 \\
-140\end{array}$ & $\begin{array}{l}597 \\
777 \\
873 \\
838 \\
862\end{array}$ & $\begin{array}{r}867 \\
825 \\
846 \\
866 \\
1,030\end{array}$ & $\begin{array}{r}-100 \\
+270 \\
+260 \\
-60 \\
-870\end{array}$ & $\begin{array}{l}817 \\
961 \\
977 \\
836 \\
591\end{array}$ & $\begin{array}{l}839 \\
798 \\
885 \\
871 \\
852\end{array}$ & $\begin{array}{r}+200 \\
+1,300 \\
+1,730 \\
+1,700 \\
+1,570\end{array}$ & $\begin{array}{r}940 \\
1,450 \\
1,760 \\
1,730 \\
1,640\end{array}$ \\
\hline $\begin{array}{r}6 \\
7 \\
8 \\
9 \\
10\end{array}$ & $\begin{array}{l}938 \\
827 \\
948 \\
954 \\
920\end{array}$ & $\begin{array}{l}-100 \\
-430 \\
-270 \\
-160 \\
-140\end{array}$ & $\begin{array}{l}888 \\
610 \\
812 \\
873 \\
849\end{array}$ & $\begin{array}{l}882 \\
898 \\
894 \\
910 \\
841\end{array}$ & $\begin{array}{r}-530 \\
+60 \\
+70 \\
+70 \\
+16,830\end{array}$ & $\begin{array}{r}615 \\
928 \\
929 \\
945 \\
9,330\end{array}$ & $\begin{array}{l}865 \\
866 \\
854 \\
794 \\
876\end{array}$ & $\begin{array}{r}+1,100 \\
+900 \\
+1,030 \\
+840 \\
+760\end{array}$ & $\begin{array}{l}1,420 \\
1,320 \\
1,370 \\
1,220 \\
1,260\end{array}$ \\
\hline $\begin{array}{l}11 \\
12 \\
13 \\
14 \\
15\end{array}$ & $\begin{array}{l}828 \\
909 \\
908 \\
758 \\
850\end{array}$ & $\begin{array}{r}-100 \\
-30 \\
+70 \\
-500 \\
-140\end{array}$ & $\begin{array}{l}778 \\
894 \\
943 \\
506 \\
779\end{array}$ & $\begin{array}{l}1,110 \\
1,650 \\
1,630 \\
1,630 \\
1,620\end{array}$ & $\begin{array}{r}+99,000 \\
+28,400 \\
+8,100 \\
+3,400 \\
+2,200\end{array}$ & $\begin{array}{r}51,000 \\
16,000 \\
5,710 \\
3,340 \\
2,730\end{array}$ & $\begin{array}{l}872 \\
859 \\
872 \\
868 \\
832\end{array}$ & $\begin{array}{r}+870 \\
+1,030 \\
+770 \\
+3,300 \\
+11,300\end{array}$ & $\begin{array}{l}1,310 \\
1,380 \\
1,260 \\
2,530 \\
6,530\end{array}$ \\
\hline $\begin{array}{l}16 \\
17 \\
18 \\
19 \\
20\end{array}$ & $\begin{array}{l}883 \\
855 \\
869 \\
880 \\
881\end{array}$ & $\begin{array}{r}+270 \\
+100 \\
+270 \\
+260 \\
+70\end{array}$ & $\begin{array}{r}1,020 \\
905 \\
1,010 \\
1,010 \\
916\end{array}$ & $\begin{array}{l}1,690 \\
1,680 \\
1,640 \\
1,590 \\
1,660\end{array}$ & $\begin{array}{r}+1,700 \\
+800 \\
+300 \\
-300 \\
-200\end{array}$ & $\begin{array}{l}2,550 \\
2,080 \\
1,790 \\
1,440 \\
1,560\end{array}$ & $\begin{array}{r}812 \\
845 \\
1,270 \\
2,200 \\
2,320\end{array}$ & $\begin{array}{r}+7,500 \\
+4,000 \\
+2,100 \\
+800 \\
-300\end{array}$ & $\begin{array}{l}4,590 \\
2,860 \\
2,330 \\
2,600 \\
2,170\end{array}$ \\
\hline $\begin{array}{l}21 \\
22 \\
23 \\
24 \\
25\end{array}$ & $\begin{array}{l}740 \\
872 \\
895 \\
880 \\
744\end{array}$ & $\begin{array}{r}-200 \\
+100 \\
+100 \\
0 \\
0\end{array}$ & $\begin{array}{l}639 \\
922 \\
945 \\
880 \\
744\end{array}$ & $\begin{array}{l}1,660 \\
1,650 \\
1,650 \\
1,660 \\
1,560\end{array}$ & $\begin{array}{l}-200 \\
-300 \\
-300 \\
-300 \\
-700\end{array}$ & $\begin{array}{l}1,560 \\
1,500 \\
1,500 \\
1,510 \\
1,210\end{array}$ & $\begin{array}{l}2,160 \\
2,040 \\
1,760 \\
1,600 \\
1,760\end{array}$ & $\begin{array}{r}-400 \\
-100 \\
-400 \\
0 \\
+100\end{array}$ & $\begin{array}{l}1,960 \\
1,990 \\
1,560 \\
1,600 \\
1,810\end{array}$ \\
\hline $\begin{array}{l}26 \\
27 \\
28 \\
29 \\
30 \\
31 \\
\end{array}$ & $\begin{array}{l}817 \\
838 \\
750 \\
855 \\
884\end{array}$ & $\begin{array}{r}+130 \\
+400 \\
-30 \\
-100 \\
-200\end{array}$ & $\begin{array}{r}883 \\
1,040 \\
735 \\
805 \\
783\end{array}$ & $\begin{array}{l}1,560 \\
1,650 \\
1,660 \\
1,650 \\
1,660 \\
1,660 \\
\end{array}$ & $\begin{array}{l}-630 \\
-370 \\
-500 \\
-600 \\
-600 \\
-200\end{array}$ & $\begin{array}{l}1,240 \\
1,460 \\
1,410 \\
1,350 \\
1,360 \\
1,560\end{array}$ & $\begin{array}{l}1,800 \\
1,840 \\
1,760 \\
2,040 \\
1,800 \\
2,200\end{array}$ & $\begin{array}{r}+200 \\
-100 \\
+300 \\
+200 \\
-200 \\
+3,030 \\
\end{array}$ & $\begin{array}{l}1,900 \\
1,790 \\
1,910 \\
2,140 \\
1,700 \\
3,730\end{array}$ \\
\hline \multirow{2}{*}{\multicolumn{7}{|c|}{ 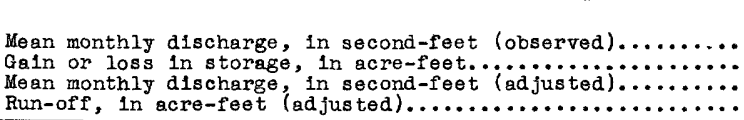 }} & November & December & January \\
\hline & & & & & & & $\begin{array}{r}870 \\
-1,930 \\
837 \\
49,810\end{array}$ & $\begin{array}{r}1,380 \\
+154,700 \\
3,897 \\
239,600\end{array}$ & $\begin{array}{r}1,323 \\
+45,130 \\
2,057 \\
126,500\end{array}$ \\
\hline
\end{tabular}


Falls Creek near Hetch Hetchy, Calif.

Location.- Lat. $37^{\circ} 58^{\prime}$, long. $119^{\circ} 46^{\prime}$, in NEt sec. 3, T. I N., R. 20 E., in Yosemite National Park, a quarter of a mfle above Wampana Falls, 1 mile above mouth, and 2 miles northeast of Hetch Hetchy, Tuolumne County. Altitude, about 5,600 feet above mean sea level.

Drainage area. - 45.2 square miles.

Gage-he1ght record. - Water-stage recorder graph.

Stage-discharge relation.- Defined by current-meter measurements below 1,250 secondfeet; extended to peak stage with ald of area-velocity study. Rating curve changed at peak stage.

Maxima.- December 1937: Discharge, 6,300 second-feet 3 p.m. Dec. Il (gage height, 8.90 feet).

1915-November 1937: Discharge, 1,740 second-feet Mar. 25, 1928 (gage height, 6.45 feet), from rating curve extended above 1,100 second-feet on bas is of 1938 area-velocity study.

Remarks.- Flood run-off not affected by artificlal storage or diversion.

Mean da1ly discharge, in second-feet, November 1937 to January 1938

\begin{tabular}{|c|c|c|c|c|c|c|c|c|c|c|c|}
\hline Day & Nov. & Dec. & Jan. & Day & Nov. & Dec. & $\operatorname{Jan}$. & Day & Nov. & Dec. & Jan. \\
\hline $\begin{array}{r}1 \\
2 \\
3 \\
4 \\
5 \\
6 \\
7 \\
8 \\
9 \\
10\end{array}$ & $\begin{array}{r}0.2 \\
.1 \\
.1 \\
.1 \\
.1 \\
.1 \\
.1 \\
.1 \\
.1 \\
.1\end{array}$ & \begin{tabular}{|c|}
11 \\
10 \\
9 \\
9 \\
8.5 \\
9 \\
9 \\
9.5 \\
41 \\
1,300
\end{tabular} & $\begin{array}{l}38 \\
50 \\
54 \\
50 \\
44 \\
39 \\
35 \\
32 \\
30 \\
28\end{array}$ & $\begin{array}{l}11 \\
12 \\
13 \\
14 \\
15 \\
16 \\
17 \\
18 \\
19 \\
20\end{array}$ & $\begin{array}{r}0.1 \\
.2 \\
.5 \\
1.7 \\
3.2 \\
1.8 \\
30 \\
15 \\
11 \\
25\end{array}$ & $\begin{array}{r}3,970 \\
1,960 \\
566 \\
275 \\
191 \\
148 \\
121 \\
104 \\
91 \\
78\end{array}$ & $\begin{array}{r}27 \\
26 \\
25 \\
30 \\
114 \\
81 \\
102 \\
86 \\
78 \\
77\end{array}$ & $\begin{array}{l}21 \\
22 \\
23 \\
24 \\
25 \\
26 \\
27 \\
28 \\
29 \\
30 \\
31\end{array}$ & $\begin{array}{l}31 \\
22 \\
17 \\
21 \\
18 \\
15 \\
14 \\
13 \\
12 \\
11\end{array}$ & $\begin{array}{l}78 \\
68 \\
68 \\
68 \\
68 \\
57 \\
52 \\
44 \\
41 \\
40 \\
38\end{array}$ & $\begin{array}{l}69 \\
74 \\
66 \\
60 \\
57 \\
64 \\
68 \\
62 \\
62 \\
59 \\
56\end{array}$ \\
\hline \multicolumn{9}{|c|}{ 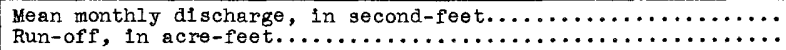 } & $\begin{array}{r}8.79 \\
523\end{array}$ & $\begin{array}{r}308 \\
18,930\end{array}$ & $\begin{array}{r}56.2 \\
3,460\end{array}$ \\
\hline
\end{tabular}

Gage height, in feet, and discharge, in second-feet, at indicated time, 1937

\begin{tabular}{|c|c|c|c|c|c|c|c|c|c|c|c|c|}
\hline \multirow{2}{*}{ 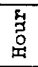 } & Feet & Sec.ft. & Feet & Sec.ft. & Feet & Sec.ft. & Feet & Sec.ft. & Feet & Sec.ft. & Feet & Sec.ft. \\
\hline & \multicolumn{2}{|c|}{ December 8} & \multicolumn{2}{|c|}{ December 9} & \multicolumn{2}{|c|}{ December 10} & \multicolumn{2}{|c|}{ December 11} & \multicolumn{2}{|c|}{ December 12} & \multicolumn{2}{|c|}{ December 13} \\
\hline \multirow[t]{2}{*}{$\begin{array}{r}2 \\
4 \\
6 \\
8 \\
10 \\
\mathrm{~N} \\
2 \\
4 \\
6 \\
8 \\
10 \\
\mathrm{M} \\
\end{array}$} & $\begin{array}{l}1.60 \\
1.60 \\
1.60 \\
1.60 \\
1.60 \\
1.60 \\
1.61 \\
1.61 \\
1.60 \\
1.60 \\
1.61 \\
1.61\end{array}$ & $\begin{array}{c}9.5 \\
9.5 \\
9.5 \\
9.5 \\
9.5 \\
9.5 \\
10 \\
10 \\
9.5 \\
9.5 \\
10 \\
10\end{array}$ & $\begin{array}{l}1.61 \\
1.61 \\
1.61 \\
1.62 \\
1.62 \\
1.62 \\
1.63 \\
1.68 \\
1.72 \\
2.06 \\
2.88 \\
3.68\end{array}$ & $\begin{array}{r}10 \\
10 \\
10 \\
10 \\
10 \\
10 \\
11 \\
12 \\
14 \\
34 \\
162 \\
388\end{array}$ & $\begin{array}{l}4.46 \\
5.15 \\
5.60 \\
5.84 \\
5.82 \\
5.90 \\
6.04 \\
6.06 \\
6.04 \\
6.04 \\
6.10 \\
6.33\end{array}$ & $\begin{array}{r}672 \\
992 \\
1,240 \\
1,370 \\
1,360 \\
1,410 \\
1,500 \\
1,510 \\
1,500 \\
1,500 \\
1,540 \\
1,700\end{array}$ & $\begin{array}{l}6.60 \\
6.88 \\
7.12 \\
7.36 \\
7.62 \\
8.50 \\
8.80 \\
8.85 \\
8.70 \\
8.55 \\
8.30 \\
8.15\end{array}$ & $\begin{array}{l}1,930 \\
2,200 \\
2,460 \\
2,760 \\
3,130 \\
5,000 \\
5,960 \\
6,130 \\
5,620 \\
5,140 \\
4,420 \\
4,070\end{array}$ & $\begin{array}{c}- \\
7.55 \\
- \\
7.01 \\
- \\
6.50 \\
- \\
6.13 \\
- \\
5.80 \\
5.48\end{array}$ & $\begin{array}{c}2, \overline{930} \\
\overline{-} \\
2,190 \\
\overline{6} \\
1,670 \\
\overline{-} \\
1,360 \\
\overline{-} \\
1,10 \\
\overline{8} \\
\overline{892}\end{array}$ & $\begin{array}{c}- \\
5.23 \\
- \\
5.02 \\
- \\
4.82 \\
- \\
4.69 \\
- \\
4.59 \\
- \\
4.47\end{array}$ & $\begin{array}{c}\overline{738} \\
- \\
6 \overline{25} \\
- \\
5 \overline{25} \\
\overline{466} \\
\overline{426} \\
\overline{380}\end{array}$ \\
\hline & \multicolumn{2}{|c|}{ December 14} & \multicolumn{2}{|c|}{ December 15} & \multicolumn{2}{|c|}{ December 16} & \multicolumn{2}{|c|}{ December 17} & \multicolumn{2}{|c|}{ December 18} & \multicolumn{2}{|c|}{ December 19} \\
\hline $\begin{array}{r}2 \\
4 \\
6 \\
8 \\
10 \\
\mathrm{~N} \\
2 \\
4 \\
6 \\
8 \\
10 \\
\mathrm{M}\end{array}$ & $\begin{array}{l}4.41 \\
4.34 \\
4.24 \\
4.15 \\
4.10 \\
4.08 \\
4.04 \\
4.01 \\
4.00 \\
4.00 \\
3.98 \\
3.96\end{array}$ & $\begin{array}{l}358 \\
334 \\
302 \\
275 \\
260 \\
255 \\
245 \\
238 \\
235 \\
235 \\
230 \\
225\end{array}$ & $\begin{array}{c}- \\
3.91 \\
- \\
3.85 \\
- \\
3.80 \\
- \\
3.77 \\
- \\
3.74 \\
- \\
3.72\end{array}$ & $\begin{array}{c}2 \overline{12} \\
\overline{198} \\
\overline{186} \\
\overline{1} \\
1 \overline{7} 9 \\
\overline{173} \\
\overline{16}\end{array}$ & $\begin{array}{c}3.69 \\
- \\
3.63 \\
- \\
3.59 \\
- \\
3.55 \\
- \\
3.53 \\
- \\
3.54\end{array}$ & $\begin{array}{c}1 \overline{162} \\
\overline{150} \\
\overline{1} \\
142 \\
\overline{-} \\
134 \\
\overline{13} 1 \\
\overline{13} 3\end{array}$ & $\begin{array}{c}- \\
3.54 \\
- \\
3.52 \\
- \\
3.48 \\
- \\
3.45 \\
- \\
3.44 \\
- \\
3.43\end{array}$ & $\begin{array}{c}\overline{133} \\
\overline{129} \\
\overline{12} 1 \\
\overline{1} \\
\overline{116} \\
\overline{114} \\
\overline{1} \\
\overline{12}\end{array}$ & $\begin{array}{c}\overline{3.42} \\
\overline{-} \\
3.41 \\
- \\
3.38 \\
- \\
3.35 \\
\overline{3.32} \\
\overline{3.34}\end{array}$ & $\begin{array}{c}\overline{111} \\
\overline{109} \\
\overline{104} \\
\overline{9} \\
\overline{9} \\
\overline{9} \\
\overline{9} \\
\overline{9}\end{array}$ & $\begin{array}{c}\overline{3} .35 \\
- \\
3.32 \\
- \\
3.28 \\
- \\
3.26 \\
- \\
3.26 \\
- \\
3.30\end{array}$ & \begin{tabular}{|l}
$\overline{99}$ \\
$\overline{9}$ \\
$\overline{9}$ \\
$\overline{8}$ \\
$\overline{88}$ \\
$\overline{85}$ \\
$\overline{8}$ \\
$\overline{85}$ \\
$\overline{91}$
\end{tabular} \\
\hline & \multicolumn{2}{|c|}{ December 20} & \multicolumn{2}{|c|}{ December 21} & \multicolumn{2}{|c|}{ December 22} & \multicolumn{2}{|c|}{ December 23} & \multicolumn{2}{|c|}{ December 24} & \multicolumn{2}{|c|}{ December 25} \\
\hline $\begin{array}{r}2 \\
4 \\
6 \\
8 \\
10 \\
\mathrm{~N} \\
2 \\
4 \\
6 \\
8 \\
10 \\
\mathrm{M}\end{array}$ & $\begin{array}{c}- \\
3.30 \\
- \\
3.26 \\
- \\
3.18 \\
- \\
3.14 \\
\overline{3.17} \\
- \\
3.23\end{array}$ & $\begin{array}{l}\overline{91} \\
\overline{85} \\
\overline{72} \\
\overline{6} \\
\overline{66} \\
\overline{70} \\
\overline{80}\end{array}$ & $\begin{array}{c}- \\
3.26 \\
- \\
3.24 \\
- \\
3.22 \\
- \\
3.19 \\
- \\
3.17 \\
- \\
3.18\end{array}$ & $\begin{array}{l}\overline{85} \\
\overline{81} \\
\overline{7} \\
\overline{78} \\
\overline{74} \\
\overline{70} \\
\overline{72}\end{array}$ & $\begin{array}{c}- \\
3.20 \\
- \\
3.18 \\
- \\
3.15 \\
- \\
3.12 \\
- \\
3.10 \\
- \\
3.11\end{array}$ & $\begin{array}{l}\overline{75} \\
\overline{72} \\
\overline{6} \\
\overline{6} \\
\overline{6} \\
\overline{6} \\
\overline{60} \\
\overline{62}\end{array}$ & $\begin{array}{c}- \\
3.18 \\
- \\
3.17 \\
- \\
3.15 \\
- \\
3.13 \\
- \\
3.12 \\
- \\
3.11\end{array}$ & $\begin{array}{l}\overline{72} \\
\overline{70} \\
\overline{68} \\
\overline{-} \\
64 \\
\overline{63} \\
\overline{62}\end{array}$ & $\begin{array}{l}3.12 \\
3.13 \\
3.14 \\
3.20 \\
3.26 \\
3.23 \\
3.13 \\
3.12 \\
3.12 \\
3.12 \\
3.11 \\
3.11\end{array}$ & \begin{tabular}{|c|}
63 \\
64 \\
66 \\
75 \\
85 \\
80 \\
64 \\
63 \\
63 \\
63 \\
62 \\
62
\end{tabular} & $\begin{array}{l}3.16 \\
3.23 \\
3.27 \\
3.29 \\
3.28 \\
3.15 \\
3.08 \\
3.07 \\
3.07 \\
3.07 \\
3.06 \\
3.06\end{array}$ & $\begin{array}{l}69 \\
80 \\
86 \\
89 \\
88 \\
68 \\
57 \\
56 \\
56 \\
56 \\
54 \\
54\end{array}$ \\
\hline
\end{tabular}

Supplemental records.- Dec. 11,3 p.m., 8.90 ft., 6,300 sec.-ft. 
Cherry Creek near Hetch Hetchy, Calif.

Location.- Lat. $38^{\circ} 00^{\prime}$, long. $119^{\circ} 54^{\prime}$, in SWt sec. 28, T. 2 N., R. 19 E., 3 miles northwest of Lake Eleanor Dam, 4 miles above Eleanor Creek, and 7i miles northwest of Hetch Hetchy, Tuolumne County. Altitude, about 4,800 feet above mean sea level.

Drainage area. - 111 square miles.

Gage-helght record. - Water-stage recorâer graph except for period 11 a.m. Dec. 10 to 4 p.m. Dec. 18, when there was no record. Peak stage determined from floodmarks inside of cabin.

Stage-discharge relation. - Defined by current-meter measurements below 3,900 secondfeet; extended to peak stage with aid of area-velocity study. Rating curve changed at peak stage.

Max1ma.- December 1937: Discharge, 18,100 second-feet about 2 p.m. Dec. Il (gage helght, 25.1 feet, from floodmarks).

1910-November 1937: Discharge, about 7,750 second-feet June 16, 1929 (gage helght, 13.57 feet), from rating curve extended above 3,600 second-feet.

Remarks.- Flood mun-off not affected by artificial storage or diversion. Discharge for period of missing gage-helght record based on floodmarks and record for Eleanor Creek near Hetch Hөtchy.

Mean dally dscharge, in second-feet, November 1937 to January 1938

\begin{tabular}{|c|c|c|c|c|c|c|c|c|c|c|c|}
\hline Day & Nov. & Dec. & Jan. & Day & Nov. & Dec. & Jan. & Day & Nov. & Dec. & Jan. \\
\hline $\begin{array}{r}1 \\
2 \\
3 \\
4 \\
5 \\
6 \\
7 \\
8 \\
9 \\
10\end{array}$ & $\begin{array}{l}5.5 \\
5.5 \\
5.5 \\
5.5 \\
5.5 \\
5 \\
5 \\
5.5 \\
5.5 \\
5.5\end{array}$ & $\begin{array}{r}53 \\
48 \\
41 \\
43 \\
43 \\
46 \\
49 \\
44 \\
266 \\
7,800\end{array}$ & $\begin{array}{r}100 \\
180 \\
180 \\
160 \\
134 \\
115 \\
104 \\
96 \\
86 \\
84\end{array}$ & $\begin{array}{l}11 \\
12 \\
13 \\
14 \\
15 \\
16 \\
17 \\
18 \\
19 \\
20\end{array}$ & $\begin{array}{r}9 \\
20 \\
21 \\
31 \\
34 \\
27 \\
273 \\
76 \\
77 \\
248\end{array}$ & $\begin{array}{r}11,600 \\
4,000 \\
1,600 \\
800 \\
600 \\
500 \\
400 \\
300 \\
224 \\
180\end{array}$ & $\begin{array}{r}84 \\
84 \\
79 \\
220 \\
530 \\
292 \\
352 \\
274 \\
227 \\
205\end{array}$ & $\begin{array}{l}21 \\
22 \\
23 \\
24 \\
25 \\
26 \\
27 \\
28 \\
29 \\
30 \\
31\end{array}$ & $\begin{array}{r}144 \\
82 \\
74 \\
119 \\
74 \\
68 \\
66 \\
61 \\
55 \\
53\end{array}$ & $\begin{array}{r}169 \\
147 \\
157 \\
166 \\
141 \\
122 \\
113 \\
106 \\
100 \\
102 \\
96\end{array}$ & $\begin{array}{l}211 \\
234 \\
195 \\
174 \\
189 \\
214 \\
214 \\
180 \\
177 \\
157 \\
147\end{array}$ \\
\hline $\begin{array}{l}\text { Mear } \\
\text { Run- }\end{array}$ & $\operatorname{tn}$ & $e-1$ & & & & & & & $\begin{array}{r}55.5 \\
3,300\end{array}$ & $\begin{array}{r}970 \\
59,620\end{array}$ & $\begin{array}{r}183 \\
11,260\end{array}$ \\
\hline
\end{tabular}

Gage height, in feөt, and discharge, in second-feet, at indicated time, 1937

\begin{tabular}{|c|c|c|c|c|c|c|c|c|c|c|c|c|}
\hline \multirow{2}{*}{$\begin{array}{l}5 \\
\text { ? } \\
0\end{array}$} & Feet & Sec.ft. & Feet & Sec.ft. & Feet & Sec.fit. & Peet & Sec.ft. & Feet & Sec.ft. & Feet & Sec.ft. \\
\hline & \multicolumn{2}{|c|}{ December 8} & \multicolumn{2}{|c|}{ December 9} & \multicolumn{2}{|c|}{ December 10} & \multicolumn{2}{|c|}{ December 11} & \multicolumn{2}{|c|}{ December 12} & \multicolumn{2}{|c|}{ December 13} \\
\hline \multirow[t]{2}{*}{$\begin{array}{r}2 \\
4 \\
6 \\
8 \\
10 \\
N \\
2 \\
4 \\
6 \\
8 \\
10 \\
M\end{array}$} & $\begin{array}{l}1.79 \\
1.82 \\
1.81 \\
1.80 \\
1.77 \\
1.75 \\
1.71 \\
1.67 \\
1.64 \\
1.62 \\
1.66 \\
1.71\end{array}$ & \begin{tabular}{|l}
51 \\
55 \\
53 \\
52 \\
49 \\
46 \\
42 \\
38 \\
35 \\
33 \\
37 \\
42
\end{tabular} & $\begin{array}{l}1.75 \\
1.75 \\
1.73 \\
1.70 \\
1.67 \\
1.66 \\
1.65 \\
1.67 \\
1.77 \\
2.96 \\
4.92 \\
7.30\end{array}$ & \begin{tabular}{|r|}
46 \\
46 \\
44 \\
41 \\
38 \\
37 \\
36 \\
38 \\
49 \\
384 \\
1,240 \\
2,720 \\
\end{tabular} & $\begin{array}{c}9.83 \\
11.75 \\
13.95 \\
15.49 \\
15.86 \\
- \\
- \\
- \\
- \\
- \\
- \\
-\end{array}$ & $\begin{array}{r}4,520 \\
6,060 \\
7,820 \\
9,140 \\
9,460 \\
10,000 \\
9,000 \\
8,000 \\
8,800 \\
7,000 \\
8,000 \\
9,200\end{array}$ & $\begin{array}{c}- \\
- \\
- \\
- \\
25.1 \\
- \\
- \\
- \\
-\end{array}$ & $\begin{array}{r}10,400 \\
11,600 \\
13,000 \\
14,200 \\
15,400 \\
16,600 \\
18,100 \\
13,600 \\
7,500 \\
6,400 \\
5,600 \\
5,500\end{array}$ & $\begin{array}{l}- \\
- \\
- \\
- \\
= \\
- \\
= \\
= \\
-\end{array}$ & $\begin{array}{l}5,200 \\
4,950 \\
4,650 \\
4,500 \\
4,250 \\
4,000 \\
3,800 \\
3,600 \\
3,350 \\
3,150 \\
2,850 \\
2,600\end{array}$ & $\begin{array}{l}- \\
- \\
- \\
- \\
\overline{-} \\
- \\
- \\
- \\
-\end{array}$ & $\begin{array}{l}2,400 \\
2,200 \\
2,000 \\
1,750 \\
1,500 \\
1,350 \\
1,300 \\
1,250 \\
1,200 \\
1,150 \\
1,100 \\
1,050\end{array}$ \\
\hline & \multicolumn{2}{|c|}{ December 14} & \multicolumn{2}{|c|}{ December 15} & \multicolumn{2}{|c|}{ December 16} & \multicolumn{2}{|c|}{ December 17} & \multicolumn{2}{|c|}{ December 18} & \multicolumn{2}{|c|}{ December 19} \\
\hline \multirow[t]{2}{*}{$\begin{array}{r}2 \\
4 \\
6 \\
8 \\
10 \\
\mathrm{~N} \\
2 \\
4 \\
6 \\
8 \\
10 \\
M\end{array}$} & $\begin{array}{l}- \\
= \\
= \\
= \\
= \\
= \\
= \\
= \\
=\end{array}$ & \begin{tabular}{|r}
, 000 \\
950 \\
900 \\
850 \\
800 \\
750 \\
730 \\
715 \\
700 \\
680 \\
665 \\
650
\end{tabular} & $\begin{array}{l}- \\
\overline{-} \\
- \\
\overline{-} \\
- \\
\overline{-} \\
\overline{-} \\
\overline{-} \\
-\end{array}$ & $\begin{array}{l}- \\
\overline{-} \\
- \\
- \\
=600 \\
- \\
- \\
- \\
- \\
-\end{array}$ & $\begin{array}{l}- \\
- \\
= \\
= \\
= \\
= \\
= \\
=\end{array}$ & $\begin{array}{l}= \\
= \\
= \\
\overline{-} \\
* 500 \\
- \\
- \\
- \\
- \\
-\end{array}$ & $\begin{array}{l}- \\
- \\
- \\
- \\
- \\
- \\
- \\
- \\
- \\
-\end{array}$ & $\begin{array}{l}= \\
= \\
- \\
= \\
= \\
- \\
- \\
- \\
- \\
-\end{array}$ & $\begin{array}{c}- \\
- \\
- \\
- \\
- \\
- \\
2.57 \\
2.57 \\
2.65 \\
2.68 \\
2.67\end{array}$ & $\begin{array}{l}370 \\
360 \\
350 \\
340 \\
330 \\
280 \\
250 \\
240 \\
240 \\
268 \\
278 \\
274\end{array}$ & $\begin{array}{l}2.63 \\
2.60 \\
2.56 \\
2.53 \\
2.50 \\
2.46 \\
2.43 \\
2.42 \\
2.44 \\
2.51 \\
2.55 \\
2.54\end{array}$ & $\begin{array}{l}260 \\
250 \\
237 \\
227 \\
217 \\
205 \\
195 \\
192 \\
198 \\
220 \\
234 \\
230\end{array}$ \\
\hline & \multicolumn{2}{|c|}{ December 20} & \multicolumn{2}{|c|}{ December 21} & \multicolumn{2}{|c|}{ December 22} & \multicolumn{2}{|c|}{ December 23} & \multicolumn{2}{|c|}{ December 24} & \multicolumn{2}{|c|}{ December 25} \\
\hline $\begin{array}{r}2 \\
4 \\
6 \\
8 \\
10 \\
1 \\
2 \\
4 \\
6 \\
8 \\
10 \\
\text { M }\end{array}$ & $\begin{array}{l}2.52 \\
2.47 \\
2.41 \\
2.35 \\
2.32 \\
2.28 \\
2.26 \\
2.26 \\
2.32 \\
2.38 \\
2.45 \\
2.46\end{array}$ & $\begin{array}{l}224 \\
208 \\
189 \\
172 \\
163 \\
152 \\
147 \\
147 \\
163 \\
180 \\
202 \\
205\end{array}$ & $\begin{array}{l}2.46 \\
2.45 \\
2.41 \\
2.35 \\
2.31 \\
2.27 \\
2.25 \\
2.24 \\
2.27 \\
2.32 \\
2.36 \\
2.37\end{array}$ & $\begin{array}{l}205 \\
202 \\
189 \\
172 \\
160 \\
149 \\
144 \\
141 \\
149 \\
163 \\
174 \\
177\end{array}$ & $\begin{array}{l}2.35 \\
2.32 \\
2.30 \\
2.27 \\
2.24 \\
2.21 \\
2.18 \\
2.15 \\
2.16 \\
2.22 \\
2.28 \\
2.37\end{array}$ & $\begin{array}{l}172 \\
163 \\
157 \\
149 \\
141 \\
134 \\
126 \\
120 \\
122 \\
136 \\
152 \\
177\end{array}$ & $\begin{array}{l}2.36 \\
2.32 \\
2.29 \\
2.26 \\
2.21 \\
2.17 \\
2.17 \\
2.20 \\
2.31 \\
2.42 \\
2.43 \\
2.43\end{array}$ & $\begin{array}{l}174 \\
163 \\
154 \\
147 \\
134 \\
124 \\
124 \\
131 \\
160 \\
192 \\
195 \\
195\end{array}$ & $\begin{array}{l}2.40 \\
2.33 \\
2.30 \\
2.30 \\
2.27 \\
2.37 \\
2.28 \\
2.32 \\
2.36 \\
2.37 \\
2.36 \\
2.34\end{array}$ & $\begin{array}{l}186 \\
166 \\
157 \\
157 \\
149 \\
160 \\
152 \\
163 \\
174 \\
177 \\
174 \\
169\end{array}$ & $\begin{array}{l}2.30 \\
2.25 \\
2.22 \\
2.22 \\
2.21 \\
2.23 \\
2.19 \\
2.19 \\
2.22 \\
2.25 \\
2.25 \\
2.25\end{array}$ & $\begin{array}{l}157 \\
144 \\
136 \\
136 \\
134 \\
139 \\
129 \\
129 \\
136 \\
144 \\
144 \\
144\end{array}$ \\
\hline
\end{tabular}

Supplemental records.- Dec. 9, 7 p.m., 2.17 ft., 117 sec.-ft.; 9 p.m., 4.02 ft.,

819 sec.-ft.; 11 p.m., 5.98 ft., 1,840 sec.-ft.

* Mean for the day. 
Lake Eleanor near Hetch Hetchy, Calif.

Location. - Lat. $37^{\circ} 58^{\prime}$, long. $119^{\circ} 53^{\prime}$, in NW/ sec. 3, T. 1 N., R. 19 E., at dam on Eleanor Creek, $1.7 \mathrm{mlles}$ above Miguel Creek and $5 \frac{1}{2}$ miles northwest of Hetchy Hetchy, Tholumne County. Zero of gage is at about mean sea level.

Dralnage area. - 79 square miles.

Gage-height record. - Water-stage recorder graph prior to $1 \mathrm{p.m.} \mathrm{Dec.} \mathrm{11;} \mathrm{elevations} \mathrm{at}$ mldnight used to determine contents. Staff gage read to tenths daily at 7 a.m. for period Dec. 12 to Jan. 31; elevations at midnight determined from graph based on readings.

Remarks.- Flood mun-off controlled partially in reservoir. Elevation of crest of spillway is 4,655 feet above mean sea level (capacity, 23,160 acre-feet). Reservoir began to spill at 7 a.m. Dec. 11. Maximum elevation, 4,663.4 feet 2 p.m. Dec. 11

contents, 31,010 acre-feet); water flowing over full length of dam. See record for Eleanor Creek near Hetchy Hetchy. Basic data furnished by city of San Francisco.

Elevation and contents, November 1937 to January 1938

\begin{tabular}{|c|c|c|c|c|c|c|}
\hline \multirow[b]{2}{*}{ Day } & \multicolumn{2}{|c|}{ November } & \multicolumn{2}{|c|}{ December } & \multicolumn{2}{|c|}{ January } \\
\hline & $\begin{array}{l}\text { Elevation } \\
\text { (feet) }\end{array}$ & $\begin{array}{l}\text { Contents } \\
\text { (acre-feet) }\end{array}$ & $\begin{array}{c}\text { Elevation } \\
\text { (feet) }\end{array}$ & $\begin{array}{l}\text { Contents } \\
\text { (acre-feet) }\end{array}$ & $\begin{array}{l}\text { Elevation } \\
\text { (feet) }\end{array}$ & $\begin{array}{c}\text { Contents } \\
\text { (acre-feet) }\end{array}$ \\
\hline $\begin{array}{l}1 \\
2 \\
3 \\
4 \\
5\end{array}$ & $\begin{array}{l}4,631.4 \\
4,631.0 \\
4,630.6 \\
4,630.4 \\
4,630.2\end{array}$ & $\begin{array}{l}4,900 \\
4,680 \\
4,450 \\
4,340 \\
4,230\end{array}$ & $\begin{array}{l}4,631.0 \\
4,631.0 \\
4,630.9 \\
4,630.8 \\
4,630.6\end{array}$ & $\begin{array}{l}4,680 \\
4,680 \\
4,620 \\
4,560 \\
4,450\end{array}$ & $\begin{array}{l}4,655.2 \\
4,655.0 \\
4,654.9 \\
4,654.8 \\
4,654.7\end{array}$ & $\begin{array}{l}23,340 \\
23,160 \\
23,070 \\
22,980 \\
22,890\end{array}$ \\
\hline $\begin{array}{r}6 \\
7 \\
8 \\
9 \\
10\end{array}$ & $\begin{array}{l}4,630.0 \\
4,629.7 \\
4,629.5 \\
4,629.4 \\
4,629.3\end{array}$ & $\begin{array}{l}4,110 \\
3,970 \\
3,870 \\
3,820 \\
3,770\end{array}$ & $\begin{array}{l}4,630.3 \\
4,630.1 \\
4,629.8 \\
4,630.2 \\
4,647.8\end{array}$ & $\begin{array}{r}4,280 \\
4,170 \\
4,020 \\
4,230 \\
16,760\end{array}$ & $\begin{array}{l}4,654.6 \\
4,654.4 \\
4,654.2 \\
4,654.0 \\
4,653.8\end{array}$ & $\begin{array}{l}22,800 \\
22,620 \\
22,440 \\
22,260 \\
22,080\end{array}$ \\
\hline $\begin{array}{l}11 \\
12 \\
13 \\
14 \\
15\end{array}$ & $\begin{array}{l}4,629.3 \\
4,629.2 \\
4,629.2 \\
4,629.1 \\
4,629.1\end{array}$ & $\begin{array}{l}3,770 \\
3,730 \\
3,730 \\
3,680 \\
3,680\end{array}$ & $\begin{array}{l}4,661.3 \\
4,659.5 \\
4,658.7 \\
4,658.3 \\
4,658.0\end{array}$ & $\begin{array}{l}29,020 \\
27,340 \\
26,600 \\
26,230 \\
25,950\end{array}$ & $\begin{array}{l}4,653 \cdot 6 \\
4,653 \cdot 3 \\
4,653 \cdot 2 \\
4,653 \cdot 2 \\
4,653.7\end{array}$ & $\begin{array}{l}21,900 \\
21,620 \\
21,540 \\
21,540 \\
21,990\end{array}$ \\
\hline $\begin{array}{l}16 \\
17 \\
18 \\
19 \\
20\end{array}$ & $\begin{array}{l}4,629.1 \\
4,629.8 \\
4,630.0 \\
4,630.1 \\
4,630.4\end{array}$ & $\begin{array}{l}3,680 \\
4,020 \\
4,110 \\
4,170 \\
4,340\end{array}$ & $\begin{array}{l}4,657.8 \\
4,657.8 \\
4,657.7 \\
4,657.6 \\
4,657.5\end{array}$ & $\begin{array}{l}25,760 \\
25,760 \\
25,670 \\
25,580 \\
25,480\end{array}$ & $\begin{array}{l}4,654.3 \\
4,654.8 \\
4,655.2 \\
4,655.6 \\
4,656.0\end{array}$ & $\begin{array}{l}22,530 \\
22,980 \\
23,340 \\
23,720 \\
24,090\end{array}$ \\
\hline $\begin{array}{l}21 \\
22 \\
23 \\
24 \\
25\end{array}$ & $\begin{array}{l}4,630 \cdot 8 \\
4,631 \cdot 0 \\
4,631 \cdot 0 \\
4,631 \cdot 3 \\
4,631 \cdot 5\end{array}$ & $\begin{array}{l}4,560 \\
4,680 \\
4,680 \\
4,850 \\
4,960\end{array}$ & $\begin{array}{l}4,657 \cdot 5 \\
4,657 \cdot 5 \\
4,657 \cdot 6 \\
4,657 \cdot 6 \\
4,657 \cdot 5\end{array}$ & $\begin{array}{l}25,480 \\
25,480 \\
25,580 \\
25,580 \\
25,480\end{array}$ & $\begin{array}{l}4,656.2 \\
4,656.5 \\
4,656.8 \\
4,657.0 \\
4,657.2\end{array}$ & $\begin{array}{l}24,280 \\
24,550 \\
24,830 \\
25,020 \\
25,200\end{array}$ \\
\hline $\begin{array}{l}26 \\
27 \\
28 \\
29 \\
30 \\
31\end{array}$ & $\begin{array}{l}4,631 \cdot 4 \\
4,631.2 \\
4,631.1 \\
4,631.0 \\
4,631.0\end{array}$ & $\begin{array}{l}4,900 \\
4,790 \\
4,730 \\
4,680 \\
4,680\end{array}$ & $\begin{array}{l}4,657.4 \\
4,657.3 \\
4,657.0 \\
4,656.4 \\
4,655.8 \\
4,655.4\end{array}$ & $\begin{array}{l}25,390 \\
25,300 \\
25,020 \\
24,460 \\
23,900 \\
23,530\end{array}$ & $\begin{array}{l}4,657.3 \\
4,657.4 \\
4,657.6 \\
4,657.8 \\
4,657.8 \\
4,657.9\end{array}$ & $\begin{array}{l}25,300 \\
25,390 \\
25,580 \\
25,760 \\
25,760 \\
25,860\end{array}$ \\
\hline
\end{tabular}


Locat1on. - Lat. $37^{\circ} 58^{\prime}$, long. $119^{\circ} 52^{\prime}$, in swl sec. 3, T. I N., R. 19 E., In Yosem1te National Park, $0.6 \mathrm{~m} 1 \mathrm{le}$ below Lake Eleanor Dam, $1.1 \mathrm{miles}$ above Miguel Creek, and $5 \frac{1}{c}$ mlies northwest of Hetch Hetchy, Tuolumne County, Alt1tude, about 4,600 feet above mean sea level.

Dralnage area.- 80 square miles.

Gage-helght record.- Water-stage recorder graph.

Stage-discharge relation.- Defined by current-meter measurements below 1,500 secondfeet; extended to peak stage on basis of area-velocity study. Rating curve changec at peak stage.

Maxima.- December 1937: Discharge, 10,500 second-feet 3 p.m. Dec. 11 (gage he1ght, 13.95 feet). Incomplete storage record indicates a higher rate of lnflow to Lake Eleanor earlier in the day.

1910-November 1937: Discharge, 6,400 second-feet Mar. 25, 1928 (gage helght, 11.0 feet), from rating curve extended above 1,500 second-feet.

Remarks.- Flood mun-off affected by storage in Lake Eleanor (capacity, 23,160 acre-

feet). Lake began to sp111 at 7 a.m. Dec. 11. No diversions. See record for

Lake Eleanor near Hetch Hetchy. Monthly summarlos adjusted for storage.

Mean daily discharge, in second-feet, November 1937 to January 1938

\begin{tabular}{|c|c|c|c|c|c|c|c|c|c|c|c|}
\hline Day & Nov. & Dec. & Jan. & Day & Nov. & Dec. & Jan. & Day & Nov. & Dec. & Jan. \\
\hline $\begin{array}{r}1 \\
2 \\
3 \\
4 \\
5 \\
6 \\
7 \\
8 \\
9 \\
10\end{array}$ & $\begin{array}{r}137 \\
137 \\
115 \\
47 \\
49 \\
49 \\
49 \\
49 \\
35 \\
26\end{array}$ & $\begin{array}{l}40 \\
40 \\
40 \\
50 \\
84 \\
84 \\
82 \\
84 \\
85 \\
40\end{array}$ & $\begin{array}{l}190 \\
249 \\
152 \\
152 \\
154 \\
152 \\
152 \\
152 \\
152 \\
164\end{array}$ & $\begin{array}{l}11 \\
12 \\
13 \\
14 \\
15 \\
16 \\
17 \\
18 \\
19 \\
20\end{array}$ & $\begin{array}{l}26 \\
26 \\
26 \\
26 \\
9.5 \\
8.5 \\
7.5 \\
3.0 \\
24 \\
14\end{array}$ & $\begin{array}{r}4,450 \\
2,910 \\
1,140 \\
630 \\
452 \\
337 \\
256 \\
210 \\
156 \\
122\end{array}$ & $\begin{array}{r}171 \\
158 \\
27 \\
96 \\
65 \\
9 \\
11 \\
10 \\
10 \\
9.5\end{array}$ & $\begin{array}{l}21 \\
22 \\
23 \\
24 \\
25 \\
26 \\
27 \\
28 \\
29 \\
30 \\
31\end{array}$ & $\begin{array}{l}3.2 \\
16 \\
50 \\
30 \\
36 \\
71 \\
85 \\
85 \\
68 \\
41\end{array}$ & $\begin{array}{r}107 \\
88 \\
81 \\
96 \\
92 \\
95 \\
210 \\
152 \\
362 \\
358 \\
351\end{array}$ & $\begin{array}{l}10 \\
14 \\
30 \\
34 \\
39 \\
51 \\
65 \\
66 \\
58 \\
61 \\
66\end{array}$ \\
\hline $\begin{array}{l}\text { Mean } \\
\text { Mean } \\
\text { Run-c }\end{array}$ & $\begin{array}{l}\text { onthl } \\
\text { onthl } \\
f, \text { in }\end{array}$ & 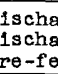 & $\begin{array}{l}\text { in } \\
\text { in } \\
\text { adj }\end{array}$ & $\begin{array}{l}\text { ond } \\
\text { ond } \\
\text { d). }\end{array}$ & $\begin{array}{l}e \theta t \\
\theta \theta t \\
\ldots .\end{array}$ & erved & & & $\begin{array}{r}45 . \cup \\
35.6 \\
2,120\end{array}$ & $\begin{array}{r}429 \\
735 \\
45,200\end{array}$ & $\begin{array}{r}88.0 \\
127 \\
7,830\end{array}$ \\
\hline
\end{tabular}

Gage height, in feet, and discharge, in second-feet, at indicated time, 1937

\begin{tabular}{|c|c|c|c|c|c|c|c|c|c|c|c|c|}
\hline \multirow{2}{*}{ 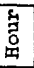 } & Feet & Sec.ft. & Feet & Sec.ft. & Feet & Sec.ft. & Feet & Sec.ft. & Feet & Sec.ft. & Feet & Sec.ft. \\
\hline & \multicolumn{2}{|c|}{ December 8} & \multicolumn{2}{|c|}{ December 9} & \multicolumn{2}{|c|}{ December 10} & \multicolumn{2}{|c|}{ December 11} & \multicolumn{2}{|c|}{ December 12} & \multicolumn{2}{|c|}{ December 13} \\
\hline \multirow[t]{2}{*}{$\begin{array}{r}2 \\
4 \\
6 \\
8 \\
10 \\
N \\
2 \\
4 \\
6 \\
8 \\
10 \\
1\end{array}$} & $\begin{array}{l}2.88 \\
2.88 \\
2.88 \\
2.89 \\
2.89 \\
2.89 \\
2.89 \\
2.89 \\
2.89 \\
2.89 \\
2.89 \\
2.89\end{array}$ & $\begin{array}{l}83 \\
83 \\
83 \\
84 \\
84 \\
84 \\
84 \\
84 \\
84 \\
84 \\
84 \\
84\end{array}$ & $\begin{array}{l}2.90 \\
2.90 \\
2.90 \\
2.90 \\
2.90 \\
2.90 \\
2.90 \\
2.90 \\
2.90 \\
2.91 \\
2.93 \\
2.96\end{array}$ & $\begin{array}{l}85 \\
85 \\
85 \\
85 \\
85 \\
85 \\
85 \\
85 \\
85 \\
86 \\
90 \\
94\end{array}$ & $\begin{array}{l}3.03 \\
3.14 \\
3.15 \\
2.08 \\
1.99 \\
1.96 \\
1.91 \\
1.83 \\
1.87 \\
1.91 \\
2.00 \\
2.12\end{array}$ & $\begin{array}{c}105 \\
125 \\
127 \\
14 \\
11 \\
9.5 \\
7.5 \\
5.5 \\
6.5 \\
7.5 \\
11 \\
16\end{array}$ & $\begin{array}{r}2.13 \\
2.18 \\
2.14 \\
2.26 \\
6.65 \\
10.60 \\
13.70 \\
13.65 \\
12.70 \\
11.55 \\
10.58 \\
9.65\end{array}$ & $\begin{array}{r}16 \\
19 \\
17 \\
24 \\
2,040 \\
6,220 \\
10,100 \\
10,000 \\
8,780 \\
7,380 \\
6,230 \\
5,200\end{array}$ & $\begin{array}{l}9.00 \\
8.45 \\
8.15 \\
7.95 \\
7.52 \\
7.36 \\
7.00 \\
6.69 \\
6.54 \\
6.43 \\
6.32 \\
6.20\end{array}$ & $\begin{array}{l}4,490 \\
3,880 \\
3,580 \\
3,380 \\
2,950 \\
2,790 \\
2,430 \\
2,150 \\
2,020 \\
1,920 \\
1,820 \\
1,710\end{array}$ & $\begin{array}{l}5.99 \\
5.90 \\
5.77 \\
5.65 \\
5.54 \\
5.43 \\
5.34 \\
5.22 \\
5.15 \\
5.05 \\
4.97 \\
4.88\end{array}$ & $\begin{array}{r}1,540 \\
1,470 \\
1,370 \\
1,280 \\
1,210 \\
1,130 \\
1,070 \\
1,000 \\
960 \\
900 \\
855 \\
810\end{array}$ \\
\hline & \multicolumn{2}{|c|}{ December 14} & \multicolumn{2}{|c|}{ December 15} & \multicolumn{2}{|c|}{ December 16} & \multicolumn{2}{|c|}{ December 17} & \multicolumn{2}{|c|}{ December 18} & \multicolumn{2}{|c|}{ December 19} \\
\hline \multirow[t]{2}{*}{\begin{tabular}{r|}
2 \\
4 \\
6 \\
8 \\
10 \\
$\mathrm{~N}$ \\
2 \\
4 \\
6 \\
8 \\
10 \\
$\mathbf{M}$
\end{tabular}} & $\begin{array}{l}4.78 \\
4.72 \\
4.65 \\
4.59 \\
4.53 \\
4.48 \\
4.42 \\
4.37 \\
4.32 \\
4.28 \\
4.24 \\
4.20\end{array}$ & $\begin{array}{l}760 \\
730 \\
698 \\
670 \\
644 \\
622 \\
598 \\
578 \\
558 \\
542 \\
526 \\
510 \\
\end{array}$ & $\begin{array}{l}4.16 \\
4.13 \\
4.10 \\
4.06 \\
4.13 \\
4.11 \\
4.06 \\
4.02 \\
3.99 \\
3.96 \\
3.93 \\
3.90\end{array}$ & $\begin{array}{l}494 \\
482 \\
470 \\
456 \\
482 \\
474 \\
456 \\
442 \\
432 \\
421 \\
410 \\
400\end{array}$ & $\begin{array}{l}3.87 \\
3.84 \\
3.81 \\
3.78 \\
3.76 \\
3.72 \\
3.68 \\
3.65 \\
3.62 \\
3.60 \\
3.58 \\
3.57\end{array}$ & $\begin{array}{l}390 \\
379 \\
368 \\
358 \\
351 \\
337 \\
323 \\
312 \\
302 \\
295 \\
288 \\
285\end{array}$ & $\begin{array}{l}3.55 \\
3.53 \\
3.51 \\
3.49 \\
3.47 \\
3.46 \\
3.45 \\
3.43 \\
3.48 \\
3.46 \\
3.44 \\
3.42\end{array}$ & $\begin{array}{l}278 \\
272 \\
265 \\
259 \\
253 \\
250 \\
247 \\
241 \\
256 \\
250 \\
244 \\
238\end{array}$ & $\begin{array}{l}3.41 \\
3.39 \\
3.37 \\
3.34 \\
3.32 \\
3.32 \\
3.31 \\
3.30 \\
3.22 \\
3.21 \\
3.20 \\
3.19\end{array}$ & $\begin{array}{l}235 \\
229 \\
224 \\
215 \\
210 \\
210 \\
207 \\
204 \\
183 \\
181 \\
178 \\
176\end{array}$ & $\begin{array}{l}3.18 \\
3.17 \\
3.16 \\
3.15 \\
3.14 \\
3.12 \\
3.06 \\
3.06 \\
3.05 \\
3.01 \\
3.01 \\
3.01 \\
\end{array}$ & $\begin{array}{l}173 \\
171 \\
168 \\
166 \\
164 \\
159 \\
146 \\
146 \\
144 \\
135 \\
135 \\
135\end{array}$ \\
\hline & \multicolumn{2}{|c|}{ December 20} & \multicolumn{2}{|c|}{ December 21} & \multicolumn{2}{|c|}{ December 22} & \multicolumn{2}{|c|}{ December 23} & \multicolumn{2}{|c|}{ December 24} & \multicolumn{2}{|c|}{ December 25} \\
\hline $\begin{array}{r}2 \\
4 \\
6 \\
8 \\
10 \\
1 \\
2 \\
4 \\
6 \\
8 \\
10 \\
M\end{array}$ & $\begin{array}{l}3.00 \\
2.99 \\
2.98 \\
2.98 \\
2.97 \\
2.91 \\
2.90 \\
2.90 \\
2.89 \\
2.89 \\
2.88 \\
2.88\end{array}$ & $\begin{array}{l}133 \\
131 \\
129 \\
129 \\
128 \\
117 \\
115 \\
115 \\
113 \\
113 \\
112 \\
112\end{array}$ & $\begin{array}{l}2.88 \\
2.87 \\
2.87 \\
2.86 \\
2.86 \\
2.85 \\
2.84 \\
2.83 \\
2.82 \\
2.82 \\
2.81 \\
2.81\end{array}$ & $\begin{array}{l}112 \\
110 \\
110 \\
109 \\
109 \\
107 \\
105 \\
104 \\
102 \\
102 \\
101 \\
101\end{array}$ & $\begin{array}{l}2.80 \\
2.80 \\
2.79 \\
2.79 \\
2.78 \\
2.78 \\
2.77 \\
2.61 \\
2.62 \\
2.62 \\
2.61 \\
2.64\end{array}$ & $\begin{array}{l}99 \\
99 \\
98 \\
98 \\
96 \\
96 \\
95 \\
74 \\
75 \\
75 \\
74 \\
78\end{array}$ & $\begin{array}{l}2.66 \\
2.66 \\
2.67 \\
2.67 \\
2.67 \\
2.67 \\
2.67 \\
2.67 \\
2.67 \\
2.67 \\
2.67 \\
2.67\end{array}$ & $\begin{array}{l}80 \\
80 \\
81 \\
81 \\
81 \\
81 \\
81 \\
81 \\
81 \\
81 \\
81 \\
81\end{array}$ & $\begin{array}{l}2.67 \\
2.67 \\
2.67 \\
2.67 \\
2.66 \\
2.66 \\
2.90 \\
2.93 \\
2.93 \\
2.92 \\
2.92 \\
2.91\end{array}$ & $\begin{array}{r}81 \\
81 \\
81 \\
81 \\
80 \\
80 \\
115 \\
120 \\
120 \\
119 \\
119 \\
117\end{array}$ & $\begin{array}{l}2.89 \\
2.88 \\
2.86 \\
2.85 \\
2.84 \\
2.82 \\
2.81 \\
2.71 \\
2.55 \\
2.55 \\
2.56 \\
2.56\end{array}$ & $\begin{array}{r}113 \\
112 \\
109 \\
107 \\
105 \\
102 \\
101 \\
86 \\
68 \\
68 \\
69 \\
69\end{array}$ \\
\hline
\end{tabular}

Supplemental records.-Dec. 11, 3 p.in., $13.95 \mathrm{ft}, 10.500$ sec. $\mathrm{ft}$. 
Location-- Lat. $37^{\circ} 49^{\prime}$, long. $120^{\circ} 00^{\prime}$, in $\mathrm{SE} \frac{1}{4} \mathrm{sec} .29, \mathrm{~T} .1 \mathrm{~S} ., \mathrm{R} .18$ E., 75 feet below highway bridge on Big Oak Flat road, half a mile southwest of Oakland Recreation

Camp, Tholumne County, and $0.6 \mathrm{mile}$ above junction with Middle Tholumne River.

Altitude, about 2,800 feet above mean sea level.

Drainage area.- 87.6 square miles.

Gage-he1ght record. - Water-stage recorder graph.

Stage-discharge relation.- Defined by current-meter measurements below 1,000 second-

feet; extended to peak stage on basis of area-velocity study. Rating curve changed at peak stage.

Maxims.- December 1937: D1scharge, 6,950 second-feet 4 p.m. Dec. Il lgage height, 10.0 feet).

1923-November 1937: D1scherge, 2,850 second-feet (revised) Apr. 8, 1935 (gage

helght, 7.07 feet), from rating curve extended above 1,000 second-feet on basis of

1938 area-velocity study.

Remarks.- Flood run-off not affected by artificlal storage or diversion.

Mean dally discharge, in second-feet, November 1937 to January 1938

\begin{tabular}{|c|c|c|c|c|c|c|c|c|c|c|c|}
\hline Day & Nov. & Dec. & Jan. & Day & Nov. & Dec. & Jan. & Day & Nov. & Dec. & Jan. \\
\hline $\begin{array}{r}1 \\
2 \\
3 \\
4 \\
5 \\
6 \\
7 \\
8 \\
9 \\
10\end{array}$ & $\begin{array}{l}12 \\
12 \\
12 \\
12 \\
12 \\
12 \\
13 \\
13 \\
13 \\
13\end{array}$ & $\begin{array}{r}14 \\
14 \\
14 \\
14 \\
14 \\
14 \\
14 \\
14 \\
17 \\
500\end{array}$ & $\begin{array}{l}50 \\
76 \\
72 \\
60 \\
56 \\
52 \\
50 \\
47 \\
46 \\
45\end{array}$ & $\begin{array}{l}11 \\
12 \\
13 \\
14 \\
15 \\
16 \\
17 \\
18 \\
19 \\
20\end{array}$ & $\begin{array}{l}18 \\
18 \\
14 \\
16 \\
16 \\
15 \\
32 \\
24 \\
18 \\
16\end{array}$ & $\begin{array}{r}3,130 \\
542 \\
218 \\
148 \\
117 \\
99 \\
87 \\
79 \\
71 \\
65\end{array}$ & $\begin{array}{r}44 \\
44 \\
43 \\
77 \\
767 \\
222 \\
242 \\
184 \\
151 \\
120\end{array}$ & $\begin{array}{l}21 \\
22 \\
23 \\
24 \\
25 \\
26 \\
27 \\
28 \\
29 \\
30 \\
31\end{array}$ & $\begin{array}{l}18 \\
17 \\
16 \\
19 \\
17 \\
16 \\
16 \\
15 \\
15 \\
15\end{array}$ & $\begin{array}{l}62 \\
61 \\
64 \\
53 \\
52 \\
52 \\
52 \\
52 \\
51 \\
51 \\
50\end{array}$ & $\begin{array}{r}101 \\
96 \\
86 \\
79 \\
77 \\
74 \\
72 \\
73 \\
77 \\
68 \\
95\end{array}$ \\
\hline $\begin{array}{l}\text { Mean } \\
\text { Run- }\end{array}$ & $\begin{array}{l}\text { onth] } \\
\text {, in }\end{array}$ & $\begin{array}{l}\text { 1sch } \\
\text { re-fe }\end{array}$ & in & & & & & & $\begin{array}{r}15.8 \\
942\end{array}$ & $\begin{array}{r}187 \\
11,470\end{array}$ & $\begin{array}{r}108 \\
6,640\end{array}$ \\
\hline
\end{tabular}

Gage height, in feet, and discharge, in second-feet, at indicated time, 1937

\begin{tabular}{|c|c|c|c|c|c|c|c|c|c|c|c|c|}
\hline \multirow{2}{*}{$\begin{array}{l}4 \\
0 \\
0 \\
0\end{array}$} & Feet & sec.ft. & Feet & Sec.ft. & $F \theta \theta t$ & sec.ft. & Feet & sec.ft. & Feet & Sec.ft. & Feet & Sec.ft. \\
\hline & \multicolumn{2}{|c|}{ December 8} & \multicolumn{2}{|c|}{ December 9} & \multicolumn{2}{|c|}{ December 10} & \multicolumn{2}{|c|}{ December 11} & \multicolumn{2}{|c|}{ December 12} & \multicolumn{2}{|c|}{ December 13} \\
\hline \multirow[t]{2}{*}{$\begin{array}{r}2 \\
4 \\
6 \\
8 \\
10 \\
\mathrm{~N} \\
2 \\
4 \\
6 \\
8 \\
10 \\
M\end{array}$} & $\begin{array}{l}1.32 \\
1.32 \\
1.33 \\
1.32 \\
1.32 \\
1.35 \\
1.36 \\
1.35 \\
1.35 \\
1.34 \\
1.34 \\
1.31\end{array}$ & $\begin{array}{l}14 \\
14 \\
14 \\
14 \\
14 \\
14 \\
14 \\
14 \\
14 \\
14 \\
14 \\
13 \\
\end{array}$ & $\begin{array}{l}1.33 \\
1.35 \\
1.33 \\
1.32 \\
1.35 \\
1.36 \\
1.37 \\
1.40 \\
1.45 \\
1.57 \\
1.71 \\
1.92 \\
\end{array}$ & $\begin{array}{l}14 \\
14 \\
14 \\
14 \\
14 \\
14 \\
15 \\
16 \\
17 \\
20 \\
26 \\
37 \\
\end{array}$ & $\begin{array}{l}2.21 \\
2.86 \\
3.28 \\
3.70 \\
3.90 \\
4.13 \\
4.45 \\
4.77 \\
5.11 \\
4.67 \\
4.24 \\
4.08\end{array}$ & $\begin{array}{r}59 \\
140 \\
231 \\
360 \\
434 \\
529 \\
682 \\
867 \\
1,080 \\
807 \\
578 \\
508 \\
\end{array}$ & $\begin{array}{r}5.05 \\
5.68 \\
7.18 \\
8.02 \\
8.10 \\
8.85 \\
8.70 \\
10.00 \\
7.55 \\
6.29 \\
5.76 \\
5.48\end{array}$ & $\begin{array}{l}1,040 \\
1,480 \\
3,010 \\
4,080 \\
4,190 \\
5,240 \\
5,030 \\
6,950 \\
3,260 \\
1,830 \\
1,390 \\
1,200\end{array}$ & $\begin{array}{l}5.06 \\
4.75 \\
4.55 \\
4.43 \\
4.30 \\
4.18 \\
4.05 \\
3.94 \\
3.85 \\
3.78 \\
3.71 \\
3.64 \\
\end{array}$ & $\begin{array}{l}924 \\
750 \\
648 \\
590 \\
530 \\
478 \\
428 \\
390 \\
360 \\
338 \\
317 \\
297 \\
\end{array}$ & $\begin{array}{l}3.57 \\
3.50 \\
3.44 \\
3.37 \\
3.33 \\
3.28 \\
3.22 \\
3.18 \\
3.15 \\
3.12 \\
3.09 \\
3.07 \\
\end{array}$ & $\begin{array}{l}279 \\
262 \\
249 \\
233 \\
225 \\
214 \\
202 \\
194 \\
189 \\
184 \\
178 \\
175 \\
\end{array}$ \\
\hline & \multicolumn{2}{|c|}{ December 14} & \multicolumn{2}{|c|}{ December 15} & \multicolumn{2}{|c|}{ December 16} & \multicolumn{2}{|c|}{ December 17} & \multicolumn{2}{|c|}{ December 18} & \multicolumn{2}{|c|}{ December 19} \\
\hline $\begin{array}{r}2 \\
4 \\
6 \\
8 \\
10 \\
\mathrm{~N} \\
2 \\
4 \\
6 \\
8 \\
10 \\
\mathrm{M}\end{array}$ & $\begin{array}{l}3.00 \\
- \\
2.95 \\
\overline{2.88} \\
\overline{2.85} \\
2.81 \\
\overline{2.80}\end{array}$ & $\begin{array}{c}\overline{162} \\
\overline{154} \\
\overline{143} \\
\overline{138} \\
\overline{132} \\
\overline{130}\end{array}$ & $\begin{array}{l}\overline{-} \\
\overline{-} \\
\overline{-} \\
2.72 \\
= \\
= \\
\overline{-} \\
\overline{2.65}\end{array}$ & $\begin{array}{c}\overline{-} \\
\overline{-} \\
\overline{1} \\
\overline{1} \\
\overline{-} \\
\overline{-} \\
\overline{107}\end{array}$ & $\begin{array}{l}- \\
- \\
- \\
- \\
2.58 \\
= \\
= \\
= \\
- \\
2.53\end{array}$ & $\begin{array}{l}- \\
\overline{-} \\
\overline{98} \\
\overline{-} \\
\overline{-} \\
\overline{92}\end{array}$ & $\begin{array}{l}- \\
\bar{z} \\
\bar{z} \\
\bar{z} .49 \\
\overline{-} \\
\overline{-} \\
\overline{-} \\
\overline{2.45}\end{array}$ & $\begin{array}{l}= \\
= \\
- \\
- \\
87 \\
= \\
- \\
- \\
82\end{array}$ & $\begin{array}{l}\overline{-} \\
\overline{-} \\
\bar{z} \\
2.42 \\
\overline{-} \\
\overline{-} \\
\overline{-} \\
2.38\end{array}$ & $\begin{array}{l}- \\
- \\
- \\
- \\
\overline{79} \\
= \\
- \\
\bar{z} \\
= \\
\overline{75}\end{array}$ & $\begin{array}{l}\overline{-} \\
\overline{-} \\
\overline{-} \\
2.34 \\
\overline{-} \\
\overline{-} \\
\overline{-} \\
2.32\end{array}$ & $\begin{array}{l}- \\
= \\
= \\
71 \\
= \\
= \\
= \\
69\end{array}$ \\
\hline & \multicolumn{2}{|c|}{ December 20} & \multicolumn{2}{|c|}{ December 21} & \multicolumn{2}{|c|}{ December 22} & \multicolumn{2}{|c|}{ December 23} & \multicolumn{2}{|c|}{ December 24} & \multicolumn{2}{|c|}{ December 25} \\
\hline $\begin{array}{r}2 \\
4 \\
6 \\
8 \\
10 \\
\mathrm{~N} \\
2 \\
4 \\
6 \\
8 \\
10 \\
\mathrm{M}\end{array}$ & $\begin{array}{l}\bar{z} \\
- \\
\overline{-} \\
\overline{2.27} \\
\overline{-} \\
\overline{-} \\
\overline{-} \\
\overline{2.27}\end{array}$ & $\begin{array}{l}- \\
- \\
\overline{-} \\
64 \\
= \\
= \\
\overline{6} \\
64\end{array}$ & $\begin{array}{c}- \\
2.26 \\
- \\
2.25 \\
- \\
2.24 \\
- \\
2.23 \\
- \\
2.22 \\
- \\
2.23\end{array}$ & $\begin{array}{l}- \\
63 \\
\overline{62} \\
\overline{62} \\
\overline{61} \\
\overline{60} \\
\overline{61}\end{array}$ & $\begin{array}{l}2.23 \\
2.22 \\
2.22 \\
2.22 \\
2.21 \\
2.21 \\
2.21 \\
2.20 \\
2.20 \\
2.19 \\
2.36 \\
2.45\end{array}$ & $\begin{array}{l}61 \\
60 \\
60 \\
60 \\
59 \\
59 \\
59 \\
58 \\
58 \\
57 \\
73 \\
82\end{array}$ & $\begin{array}{l}2.47 \\
2.45 \\
2.40 \\
2.35 \\
2.30 \\
2.24 \\
2.21 \\
2.18 \\
2.16 \\
2.14 \\
2.16 \\
2.18\end{array}$ & $\begin{array}{l}85 \\
82 \\
77 \\
72 \\
67 \\
62 \\
59 \\
56 \\
55 \\
53 \\
55 \\
56 \\
\end{array}$ & $\begin{array}{c}-\overline{2.15} \\
- \\
2.10 \\
2.07 \\
2.20 \\
- \\
2.17 \\
- \\
2.18\end{array}$ & $\begin{array}{l}- \\
54 \\
- \\
50 \\
- \\
48 \\
\overline{58} \\
\overline{56} \\
\overline{56}\end{array}$ & $\begin{array}{c}- \\
2.13 \\
- \\
2.06 \\
- \\
2.05 \\
- \\
2.19 \\
- \\
2.20 \\
2.21\end{array}$ & $\begin{array}{l}- \\
52 \\
- \\
47 \\
\overline{46} \\
- \\
57 \\
\overline{58} \\
\overline{59}\end{array}$ \\
\hline
\end{tabular}

Supplemental records.- Dec. 11, 11 a.m., 8.05 ft., 4,120 sec.-ft.; 3 p.m., 8.75 ft., 5, 100 sec. $-\mathrm{ft}$. 
Middle Tholumne River near Buck Meadows, Callf.

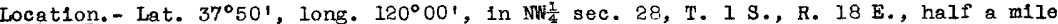
above junction with South Fork of Tuolume River and 4 miles east of Buck Meadows, Marlposa County. Altitude, about 2,800 foet above mean sea level.

Dralnage area. - 71.0 square miles.

Gage-helght record. - Water-stage recorder graph except for period 5 a.m. Dec. 10 to 4:30 p.m. Dec. 12, when there was no record. Stage graph for Dec. 12 based on partial recorder graph. Peak stage determined from floodmarks.

Stage-discharge relation. - Defined by current-meter measurements below 950 secondfeet; extended to peak stage with ald of area-velocity study. Rating curve changed at peak stage.

Max Ima. - December 1937: Discharge, 2,910 second-feet about 4 p.m. Dec. Il (gage holght, 10.4 feet).

1917-November 1937: Discharge, 1,330 second-feet May 28, 1919 (gage helght, 8.15 feet), from rating curve extended above 550 second-feet.

Remarks. - Flood mun-off not affected by artiflclal storage or diversion. D1scharge for period Dec, 10-1l determined from discharge graph based on record for South Fork of Tuolumne River near Oakland Recreation Camp.

Mean daily discharge, in second-feet, November 1937 to January 1938

\begin{tabular}{|c|c|c|c|c|c|c|c|c|c|c|c|}
\hline Dey & Nov. & Dec. & Jan. & Day & Nov. & Dec. & Jan. & Day & Nov. & Dec. & Jan. \\
\hline 1 & 2.2 & 4.2 & 45 & 11 & 5 & 1,500 & 31 & 21 & 7.5 & 49 & 47 \\
\hline 2 & 2.4 & 4.2 & 61 & 12 & 6 & 320 & 30 & 22 & 9 & 43 & 50 \\
\hline 3 & 2.5 & 4.3 & 50 & 13 & 4.3 & 164 & 29 & 23 & 7 & 46 & 42 \\
\hline 4 & 2.5 & 4.0 & 43 & 14 & 4.6 & 110 & 54 & 24 & 7 & 29 & 38 \\
\hline 5 & 2.5 & 4.0 & 39 & 15 & 5 & 90 & 379 & 25 & 7 & 37 & 41 \\
\hline 6 & 2.5 & 4.0 & 34 & 16 & 5 & 76 & 94 & 26 & 6 & 40 & 39 \\
\hline 7 & 2.6 & 4.0 & 36 & 17 & 7.5 & 67 & 96 & 27 & 5 & 42 & 39 \\
\hline 8 & 2.6 & 3.8 & 34 & 18 & 10 & 58 & 76 & 28 & 4.8 & $4 I$ & 38 \\
\hline 9 & 2.6 & 5 & 32 & 19 & 7 & 50 & 64 & 29 & 4.3 & 43 & 39 \\
\hline 10 & 2.6 & 250 & 32 & 20 & 6 & 46 & 48 & 30 & 4.2 & 47 & 31 \\
\hline & & & & & & & & 31 & & 45 & 69 \\
\hline \multicolumn{9}{|c|}{ 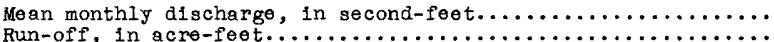 } & $\begin{array}{r}4.91 \\
292\end{array}$ & $\begin{array}{r}104 \\
6,410\end{array}$ & 37.4 \\
\hline
\end{tabular}

Gage helght, in feet, and discharge, in second-feet, at indicated time, 1937

\begin{tabular}{|c|c|c|c|c|c|c|c|c|c|c|c|c|}
\hline \multirow{2}{*}{ 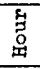 } & Feet & Sec.ft. & Feet & Sec.ft. & Feet & Sec.ft. & Feet & Sec.ft. & Feet & Sec.ft. & Feet & Sec.ft. \\
\hline & \multicolumn{2}{|c|}{ December 8} & \multicolumn{2}{|c|}{ December 9} & \multicolumn{2}{|c|}{ December 10} & \multicolumn{2}{|c|}{ December 11} & \multicolumn{2}{|c|}{ December 12} & \multicolumn{2}{|c|}{ December 13} \\
\hline $\begin{array}{r}2 \\
4 \\
6 \\
8 \\
10 \\
N \\
2 \\
4 \\
6 \\
8 \\
10 \\
\text { M }\end{array}$ & $\begin{array}{l}1.02 \\
1.07 \\
1.20 \\
1.26 \\
1.23 \\
1.20 \\
1.17 \\
1.16 \\
1.14 \\
1.11 \\
1.08 \\
1.05\end{array}$ & $\begin{array}{l}2.2 \\
2.8 \\
4.8 \\
6 \\
5.5 \\
4.8 \\
4.3 \\
4.2 \\
3.5 \\
3.4 \\
3.0 \\
2.6\end{array}$ & $\begin{array}{l}1.03 \\
1.13 \\
1.26 \\
1.24 \\
1.20 \\
1.19 \\
1.19 \\
1.19 \\
1.20 \\
1.29 \\
1.41 \\
1.51\end{array}$ & \begin{tabular}{|c|}
2.4 \\
3.7 \\
6 \\
5.5 \\
4.8 \\
4.6 \\
4.6 \\
4.6 \\
4.8 \\
6.5 \\
9 \\
12
\end{tabular} & $\begin{array}{l}1.56 \\
1.88 \\
= \\
= \\
= \\
= \\
= \\
=\end{array}$ & $\begin{array}{r}13 \\
26 \\
100 \\
170 \\
235 \\
310 \\
380 \\
470 \\
525 \\
410 \\
285 \\
150\end{array}$ & $\begin{array}{c}\bar{z} \\
\bar{z} \\
= \\
\bar{E} \\
10.4 \\
= \\
= \\
=\end{array}$ & $\begin{array}{r}510 \\
900 \\
1,220 \\
1,520 \\
1,600 \\
2,120 \\
2,100 \\
2,910 \\
2,000 \\
1,400 \\
1,100 \\
800\end{array}$ & 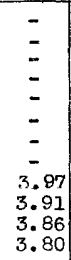 & $\begin{array}{l}510 \\
380 \\
300 \\
290 \\
280 \\
275 \\
270 \\
265 \\
264 \\
252 \\
242 \\
231\end{array}$ & $\begin{array}{l}- \\
3.64 \\
3.50 \\
- \\
3.40 \\
\overline{3.32} \\
\overline{3.27} \\
- \\
3.30\end{array}$ & $\begin{array}{c}\overline{-} \\
201 \\
1 \overline{7} 5 \\
\overline{157} \\
\overline{143} \\
\overline{135} \\
\overline{140}\end{array}$ \\
\hline & \multicolumn{2}{|c|}{ December 14} & \multicolumn{2}{|c|}{ December 15} & \multicolumn{2}{|c|}{ December 16} & \multicolumn{2}{|c|}{ December 17} & \multicolumn{2}{|c|}{ December 18} & \multicolumn{2}{|c|}{ December 19} \\
\hline $\begin{array}{r}2 \\
4 \\
6 \\
8 \\
10 \\
\mathrm{~N} \\
2 \\
4 \\
6 \\
8 \\
10 \\
\mathrm{M}\end{array}$ & $\begin{array}{l}3 . \\
- \\
- \\
3.15 \\
- \\
3.09 \\
\overline{3.06} \\
- \\
3.02 \\
- \\
3.01\end{array}$ & $\begin{array}{c}\overline{124} \\
\overline{116} \\
\overline{108} \\
\overline{104} \\
\overline{99} \\
\overline{97}\end{array}$ & $\begin{array}{l}- \\
3.00 \\
- \\
2.98 \\
\overline{2.95} \\
\overline{2.92} \\
\overline{2.91} \\
\overline{2.89}\end{array}$ & $\begin{array}{l}\overline{96} \\
\overline{94} \\
\overline{80} \\
\overline{86} \\
\overline{85} \\
\overline{83}\end{array}$ & $\begin{array}{c}- \\
\overline{2.87} \\
- \\
\overline{2.83} \\
\overline{-} \\
2.80 \\
\overline{-} \\
2.79\end{array}$ & $\begin{array}{l}\overline{-} \\
\overline{81} \\
\overline{-} \\
\overline{76} \\
\overline{-} \\
\overline{7} 3 \\
\overline{-} \\
\overline{7} 2\end{array}$ & $\begin{array}{c}- \\
\overline{2.77} \\
\overline{-} \\
\overline{2.74} \\
\overline{-} \\
2.71 \\
\overline{-} \\
\overline{2.70}\end{array}$ & $\begin{array}{l}\overline{-} \\
\overline{70} \\
- \\
\overline{67} \\
\overline{-} \\
\overline{6} 4 \\
- \\
\overline{63}\end{array}$ & $\begin{array}{c}\overline{-} \\
2.70 \\
\overline{-} \\
2.67 \\
\overline{-} \\
2.64 \\
\overline{-} \\
2.58\end{array}$ & $\begin{array}{l}- \\
\overline{63} \\
\overline{-} \\
60 \\
- \\
\overline{5} \\
- \\
\overline{52}\end{array}$ & $\begin{array}{l}2.66 \\
2.65 \\
2.62 \\
2.61 \\
2.60 \\
2.58 \\
2.56 \\
2.48 \\
2.45 \\
2.51 \\
2.51 \\
2.50\end{array}$ & $\begin{array}{l}59 \\
58 \\
56 \\
55 \\
54 \\
52 \\
50 \\
43 \\
41 \\
46 \\
46 \\
45\end{array}$ \\
\hline & \multicolumn{2}{|c|}{ December 20} & \multicolumn{2}{|c|}{ December 21} & \multicolumn{2}{|c|}{ December 22} & \multicolumn{2}{|c|}{ December 23} & \multicolumn{2}{|c|}{ December 24} & \multicolumn{2}{|c|}{ December 25} \\
\hline $\begin{array}{r}2 \\
4 \\
6 \\
8 \\
10 \\
\mathrm{~N} \\
2 \\
4 \\
6 \\
8 \\
10 \\
\mathrm{M}\end{array}$ & $\begin{array}{l}2.60 \\
2.65 \\
2.61 \\
2.55 \\
2.48 \\
2.41 \\
2.41 \\
2.40 \\
2.37 \\
2.43 \\
2.64 \\
2.59\end{array}$ & $\begin{array}{l}54 \\
58 \\
55 \\
50 \\
43 \\
38 \\
38 \\
37 \\
35 \\
39 \\
58 \\
\mathbf{5 3}\end{array}$ & $\begin{array}{l}2.65 \\
2.70 \\
2.63 \\
2.59 \\
2.51 \\
2.44 \\
2.41 \\
2.41 \\
2.40 \\
2.49 \\
2.65 \\
2.55\end{array}$ & \begin{tabular}{|l|}
58 \\
63 \\
57 \\
53 \\
46 \\
40 \\
38 \\
38 \\
37 \\
44 \\
58 \\
50
\end{tabular} & $\begin{array}{l}2.53 \\
2.62 \\
2.60 \\
2.49 \\
2.40 \\
2.37 \\
2.36 \\
2.35 \\
2.30 \\
2.31 \\
2.74 \\
2.80\end{array}$ & $\begin{array}{l}48 \\
56 \\
54 \\
44 \\
37 \\
35 \\
34 \\
34 \\
30 \\
31 \\
67 \\
73\end{array}$ & $\begin{array}{l}2.81 \\
2.80 \\
2.75 \\
2.65 \\
2.50 \\
2.40 \\
2.36 \\
2.37 \\
2.36 \\
2.33 \\
2.30 \\
2.25\end{array}$ & $\begin{array}{l}74 \\
73 \\
68 \\
58 \\
45 \\
37 \\
34 \\
35 \\
34 \\
32 \\
30 \\
27\end{array}$ & $\begin{array}{l}2.22 \\
2.18 \\
2.14 \\
2.13 \\
2.20 \\
2.26 \\
2.29 \\
2.41 \\
2.44 \\
2.41 \\
2.40 \\
2.40\end{array}$ & \begin{tabular}{|l|}
25 \\
23 \\
21 \\
20 \\
24 \\
28 \\
29 \\
38 \\
40 \\
38 \\
37 \\
37
\end{tabular} & $\begin{array}{l}2.40 \\
2.38 \\
2.36 \\
2.36 \\
2.39 \\
2.32 \\
2.35 \\
2.46 \\
2.46 \\
2.46 \\
2.45 \\
2.45\end{array}$ & $\begin{array}{l}37 \\
36 \\
34 \\
34 \\
36 \\
32 \\
34 \\
42 \\
42 \\
42 \\
41 \\
41\end{array}$ \\
\hline
\end{tabular}


Woads Creek near Jacksonville, Calif.

Location.- Lat. $37^{\circ} 51^{\prime}$, long. $120^{\circ} 24^{\prime}$, in swit sec. 12, T. I S., R. 14 E., 1술 miles above mouth and $1 \frac{1}{2}$ inles northwest of Jacksonvilie, Tuolumne County. Altitude, about 645 feet above mean sea level.

Drainage area.- 98.4 square miles.

Gage-height record.- Water-stage recorder graph except for perlod 7 a.m. Nov. 30 to 2.30 p.m. Dec. 8, when there was no record. Record for Nov. 30 and Dec. 8 based on partial recorder graph and study of weather records.

Stage-discharge relation.- Defined by current-meter measurements below 1,000 secondfeet; extended to peak stage with ald of area-velocity study. Shifting-control method used for perlod Nov. 8 to Dec. 10. Rating curve changed at peak stage.

Maxime.- December 1937: Discharge, 5,500 second-feet 11:30 a.m. Dec. II (gage he1ght, 7.65 feet).

1925-November 1937: Discharge, 10,600 second-feet Feb. 6, 1937 (gage helght,

9.12 feet), from rating curve extended above 1,000 second-feet.

January-September 1938: D1scharge, 13,500 second-feet 8 p.m. Feb. 9 (gage helght, 10.5 feet), from rating curve extended above 1,000 second-feet with aid of area-velocity study.

Femarks. - Flood mun-off not affected by artificial storage or diversion. Discharge for period of missing gage-helght record, Dec. 1-7, based on study of rainfall records and stream-flow records for nearby streams.

Mean dally discharge, in second-feet, November 1937 to January 1938

\begin{tabular}{|c|c|c|c|c|c|c|c|c|c|c|c|}
\hline Day & Nov. & Dec. & Jan. & Day & Nov. & Dec. & Jan. & Day & Nov. & Dec. & Jan. \\
\hline $\begin{array}{r}1 \\
2 \\
3 \\
4 \\
5 \\
6 \\
7 \\
8 \\
9 \\
10\end{array}$ & $\begin{array}{l}7 \\
6.5 \\
6 \\
6 \\
6 \\
6 \\
6 \\
6 \\
6 \\
6\end{array}$ & $\begin{array}{l}10 \\
10 \\
10 \\
10 \\
10 \\
10 \\
10 \\
9.5 \\
10 \\
72\end{array}$ & $\begin{array}{l}34 \\
45 \\
64 \\
59 \\
54 \\
51 \\
48 \\
44 \\
39 \\
35\end{array}$ & $\begin{array}{l}11 \\
12 \\
13 \\
14 \\
15 \\
16 \\
17 \\
18 \\
19 \\
20\end{array}$ & $\begin{array}{c}8 \\
8 \\
8 \\
8 \\
8.5 \\
11 \\
23 \\
14 \\
4.5 \\
6\end{array}$ & $\begin{array}{r}1,770 \\
610 \\
120 \\
70 \\
46 \\
34 \\
27 \\
22 \\
18 \\
13\end{array}$ & $\begin{array}{r}32 \\
29 \\
32 \\
40 \\
1,490 \\
176 \\
213 \\
155 \\
99 \\
144\end{array}$ & $\begin{array}{l}21 \\
22 \\
23 \\
24 \\
25 \\
26 \\
27 \\
28 \\
29 \\
30 \\
31\end{array}$ & $\begin{array}{l}9.5 \\
9.5 \\
10 \\
11 \\
11 \\
11 \\
11 \\
10 \\
10 \\
10\end{array}$ & $\begin{array}{l}12 \\
12 \\
44 \\
56 \\
80 \\
45 \\
35 \\
35 \\
34 \\
34 \\
34\end{array}$ & $\begin{array}{r}68 \\
45 \\
34 \\
29 \\
25 \\
21 \\
21 \\
22 \\
130 \\
68 \\
501\end{array}$ \\
\hline \multicolumn{9}{|c|}{ 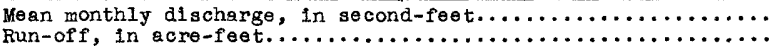 } & $\begin{array}{r}8.78 \\
523\end{array}$ & $\begin{array}{r}107 \\
6,570\end{array}$ & 7,630 \\
\hline
\end{tabular}

Gage helght, in feet, and discharge, in second-feet, at indicated time, 193'

\begin{tabular}{|c|c|c|c|c|c|c|c|c|c|c|c|c|}
\hline \multirow{2}{*}{$\begin{array}{l}5 \\
0 \\
0 \\
0\end{array}$} & Feet & Sec.ft. & Feet & Sec.ft. & Fert & sec.ft. & Feet & sec.ft. & Feet & Sec.ft. & Feet & sec.ft. \\
\hline & \multicolumn{2}{|c|}{ December 8} & \multicolumn{2}{|c|}{ December 9} & \multicolumn{2}{|c|}{ December 10} & \multicolumn{2}{|c|}{ December 11} & \multicolumn{2}{|c|}{ December 12} & \multicolumn{2}{|c|}{ December 13} \\
\hline \multirow[t]{2}{*}{$\begin{array}{r}2 \\
4 \\
6 \\
8 \\
10 \\
\mathrm{~N} \\
2 \\
4 \\
6 \\
8 \\
10 \\
M \\
\end{array}$} & $\begin{array}{l}- \\
- \\
= \\
\overline{1.67} \\
= \\
= \\
= \\
1.67\end{array}$ & $\begin{array}{c}- \\
- \\
- \\
- \\
9.5 \\
- \\
= \\
- \\
- \\
9.5\end{array}$ & $\begin{array}{l}1.67 \\
1.67 \\
1.67 \\
1.67 \\
1.67 \\
1.67 \\
1.67 \\
1.68 \\
1.69 \\
1.69 \\
1.70 \\
1.70\end{array}$ & $\begin{array}{l}9.5 \\
9.5 \\
9.5 \\
9.5 \\
9.5 \\
9.5 \\
9.5 \\
10 \\
11 \\
11 \\
12 \\
12 \\
\end{array}$ & $\begin{array}{l}1.70 \\
1.70 \\
1.75 \\
1.87 \\
2.35 \\
3.06 \\
2.80 \\
2.28 \\
2.05 \\
1.78 \\
1.76 \\
1.75\end{array}$ & $\begin{array}{r}12 \\
12 \\
16 \\
30 \\
109 \\
292 \\
215 \\
96 \\
57 \\
19 \\
17 \\
16\end{array}$ & $\begin{array}{l}1.75 \\
1.75 \\
3.35 \\
6.12 \\
7.34 \\
7.42 \\
6.09 \\
4.95 \\
4.12 \\
3.55 \\
3.45 \\
3.04\end{array}$ & $\begin{array}{r}16 \\
16 \\
404 \\
2,880 \\
4,980 \\
5,140 \\
3,070 \\
1,840 \\
1,190 \\
875 \\
825 \\
646\end{array}$ & $\begin{array}{l}2.81 \\
2.61 \\
2.34 \\
2.35 \\
3.10 \\
4.62 \\
3.75 \\
3.05 \\
2.60 \\
2.26 \\
2.06 \\
1.84\end{array}$ & $\begin{array}{r}554 \\
484 \\
392 \\
395 \\
670 \\
1,560 \\
975 \\
650 \\
480 \\
368 \\
308 \\
250 \\
\end{array}$ & $\begin{array}{l}1.65 \\
1.52 \\
1.42 \\
1.33 \\
1.25 \\
1.18 \\
1.12 \\
1.07 \\
1.06 \\
1.06 \\
1.06 \\
1.05\end{array}$ & $\begin{array}{r}202 \\
171 \\
148 \\
130 \\
114 \\
100 \\
90 \\
81 \\
80 \\
80 \\
80 \\
78 \\
\end{array}$ \\
\hline & \multicolumn{2}{|c|}{ December 14} & \multicolumn{2}{|c|}{ December 15} & \multicolumn{2}{|c|}{ December 16} & \multicolumn{2}{|c|}{ December 17} & \multicolumn{2}{|c|}{ December 18} & \multicolumn{2}{|c|}{ December 19} \\
\hline \multirow[t]{2}{*}{$\begin{array}{r}2 \\
4 \\
6 \\
8 \\
10 \\
\mathrm{~N} \\
2 \\
4 \\
6 \\
8 \\
10 \\
\mathrm{M} \\
\end{array}$} & $\begin{array}{l}\bar{z} \\
- \\
\overline{-} \\
1.01 \\
- \\
\overline{-} \\
- \\
.93\end{array}$ & $\begin{array}{l}\bar{z} \\
- \\
- \\
\overline{72} \\
- \\
- \\
- \\
\overline{59}\end{array}$ & $\begin{array}{l}- \\
0.88 \\
- \\
- \\
-85 \\
- \\
-81 \\
- \\
-80\end{array}$ & $\begin{array}{l}\bar{z} \\
\overline{51} \\
\overline{-} \\
\overline{46} \\
\overline{-} \\
\overline{40} \\
\overline{-} \\
\overline{39}\end{array}$ & $\begin{array}{l}- \\
- \\
- \\
- \\
0.76 \\
- \\
- \\
- \\
- \\
.73\end{array}$ & $\begin{array}{l}\overline{-} \\
\overline{-} \\
\bar{z} \\
\overline{3} \\
- \\
\overline{-} \\
\overline{-} \\
\overline{30}\end{array}$ & $\begin{array}{l}- \\
= \\
= \\
0.71 \\
= \\
= \\
= \\
.68\end{array}$ & $\begin{array}{l}= \\
\overline{-} \\
\overline{-} \\
27 \\
\overline{-} \\
\overline{-} \\
\overline{2} \\
2\end{array}$ & $\begin{array}{l}- \\
- \\
- \\
- \\
0.67 \\
- \\
- \\
- \\
- \\
.64\end{array}$ & $\begin{array}{l}\overline{-} \\
- \\
- \\
- \\
22 \\
- \\
- \\
- \\
- \\
19\end{array}$ & $\begin{array}{l}- \\
\overline{-} \\
\overline{-} \\
0.63 \\
\overline{-} \\
\overline{-} \\
\overline{-} \\
.61\end{array}$ & $\begin{array}{l}= \\
- \\
- \\
- \\
18 \\
- \\
- \\
- \\
- \\
15\end{array}$ \\
\hline & \multicolumn{2}{|c|}{ December 20} & \multicolumn{2}{|c|}{ December 21} & \multicolumn{2}{|c|}{ December 22} & \multicolumn{2}{|c|}{ December 23} & \multicolumn{2}{|c|}{ December 24} & \multicolumn{2}{|c|}{ December 25} \\
\hline $\begin{array}{r}2 \\
4 \\
6 \\
8 \\
10 \\
N \\
2 \\
4 \\
6 \\
8 \\
10 \\
M\end{array}$ & $\begin{array}{l}- \\
= \\
- \\
- \\
0.59 \\
- \\
= \\
- \\
-58\end{array}$ & $\begin{array}{l}- \\
- \\
- \\
\overline{13} \\
= \\
\overline{-} \\
\overline{12}\end{array}$ & $\begin{array}{l}- \\
- \\
- \\
- \\
0.58 \\
- \\
- \\
- \\
- \\
.57\end{array}$ & $\begin{array}{l}= \\
= \\
= \\
12 \\
= \\
= \\
\overline{12}\end{array}$ & $\begin{array}{r}0.57 \\
.57 \\
.57 \\
.57 \\
.57 \\
.57 \\
.57 \\
.57 \\
.57 \\
.57 \\
.57 \\
.63\end{array}$ & $\begin{array}{l}12 \\
12 \\
12 \\
12 \\
12 \\
12 \\
12 \\
12 \\
12 \\
12 \\
12 \\
18\end{array}$ & $\begin{array}{r}0.72 \\
.75 \\
.77 \\
.80 \\
.82 \\
.85 \\
.88 \\
.90 \\
.92 \\
.93 \\
.93 \\
.93\end{array}$ & $\begin{array}{l}29 \\
32 \\
35 \\
39 \\
42 \\
46 \\
51 \\
54 \\
57 \\
59 \\
59 \\
59 \\
\end{array}$ & $\begin{array}{r}0.93 \\
.92 \\
.91 \\
.90 \\
.89 \\
.87 \\
.87 \\
.85 \\
.84 \\
.83 \\
1.12 \\
1.14\end{array}$ & $\begin{array}{l}59 \\
57 \\
56 \\
54 \\
52 \\
50 \\
50 \\
46 \\
45 \\
44 \\
90 \\
93\end{array}$ & $\begin{array}{r}1.13 \\
1.12 \\
1.45 \\
1.28 \\
.98 \\
.97 \\
.97 \\
.96 \\
.95 \\
.94 \\
.92 \\
.91\end{array}$ & $\begin{array}{r}91 \\
90 \\
155 \\
120 \\
67 \\
65 \\
65 \\
64 \\
62 \\
60 \\
57 \\
56 \\
\end{array}$ \\
\hline
\end{tabular}

Supplemental records.- Dec. 11, 5 a.m., 1.93 ft., 18 sec.-ft.; 11:30 2.m., 7.65 ft., 5,500 sec.-ft.; 9 p.m., 3.62 ft., 910 sec.-ft. Dec. 12,11 2.m., 4.82 ft., 1,720 sec. $-\mathrm{ft}$. Dec. $24,9: 30$ p.m, $0.82 \mathrm{ft.}, 42$ sec. $-\mathrm{ft}$. 
Middle Fork of Stanislaus River at Sand Bar Flat, near Avery, Calif.

Location.- Lat. $38^{\circ} 11^{\prime}$, long. $120^{\circ} 09^{\prime}$, in sec. 19, T. 4 N., R. 17 E., about a mile upstream from diversion dam of Pacific Gas \& Electric Co. at Sand Bar Flat and 11 miles southeast of Avery, Calaveras County. Altitude, about 2,450 feet above mean sea level.

Drainage area.- 318 square miles at gaging station; 329 square miles at diversion dam. Gage-helght record. - Water-stage recorder graph except for perlod 8 a.m. Dec, 4 to Jan. 31, when there was no record. Peak stage obtained from floodmarks on banks.

Stage-discharge relation. - Defined by current-meter measurements below 5,400 secondfeet; extended to peak stage on basis of area-velocity study; verifled by computation of peak flow over Sand Bar Dam. Rating curve changed at peak stage.

Maxima.- December 1937: D1scharge, 26,500 second-feet about noon Dec. 11 (gage he1ght, 21.0 feet, from floodmarks).

1905-November 1937: Discharge observed, 9,760 second-feet Mar. 19, 1907.

Remarks. - Flood mun-off probably affected by artiflcial storage in Relief Reservolr and other smaller reservolrs for wilch no records are ava1lable. Discharge for period of missing gage-nelght record computed from discharge graph of flow at Sand Bar Dam

based on 4 staff-gage readings daliy; verified by comparison with shape of discharge graph for North Fork of Stanislaus River near Avery. Part of basic data furnlshed by Pacific Gas \& Electric Co.

Mean da11y discharge, in second-feet, November 1937 to January 1938

\begin{tabular}{|c|c|c|c|c|c|c|c|c|c|c|c|}
\hline Day & Nov, & Dec. & Jan. & Day & Nov. & Dec. & Jan. & Day & Nov. & Dec. & Jan. \\
\hline $\begin{array}{r}1 \\
2 \\
3 \\
4 \\
5 \\
6 \\
7 \\
8 \\
9 \\
10\end{array}$ & $\begin{array}{l}124 \\
123 \\
121 \\
119 \\
118 \\
116 \\
116 \\
115 \\
115 \\
116\end{array}$ & $\begin{array}{r}125 \\
124 \\
123 \\
120 \\
120 \\
120 \\
120 \\
120 \\
140 \\
4,900\end{array}$ & $\begin{array}{l}310 \\
340 \\
330 \\
310 \\
300 \\
280 \\
280 \\
270 \\
270 \\
260\end{array}$ & $\begin{array}{l}11 \\
12 \\
13 \\
14 \\
15 \\
16 \\
17 \\
18 \\
19 \\
20\end{array}$ & $\begin{array}{r}121 \\
120 \\
116 \\
130 \\
109 \\
75 \\
118 \\
127 \\
91 \\
115\end{array}$ & $\begin{array}{r}18,500 \\
4,500 \\
1,800 \\
1,350 \\
1,150 \\
1,000 \\
860 \\
660 \\
550 \\
490\end{array}$ & $\begin{array}{l}260 \\
270 \\
270 \\
270 \\
530 \\
390 \\
450 \\
440 \\
410 \\
370\end{array}$ & $\begin{array}{l}21 \\
22 \\
23 \\
24 \\
25 \\
26 \\
27 \\
28 \\
29 \\
30 \\
31\end{array}$ & $\begin{array}{l}204 \\
135 \\
115 \\
132 \\
146 \\
138 \\
132 \\
132 \\
128 \\
127\end{array}$ & $\begin{array}{l}470 \\
430 \\
410 \\
390 \\
370 \\
350 \\
350 \\
340 \\
330 \\
330 \\
320\end{array}$ & $\begin{array}{l}360 \\
390 \\
370 \\
350 \\
360 \\
360 \\
340 \\
320 \\
320 \\
330 \\
340\end{array}$ \\
\hline an & in & CHa &. & & & & & & $\begin{array}{r}123 \\
7,330\end{array}$ & $\begin{array}{r}1,321 \\
81,250\end{array}$ & $\begin{array}{r}337 \\
20,730\end{array}$ \\
\hline
\end{tabular}


Melones Reservolr at Melones Dam, Galif.

Location.- Lat. $37^{\circ} 57^{\prime} 15^{\prime \prime}$, long. $120^{\circ} 30^{\prime} 45^{\prime \prime}$, near center of sec. 11, T. I N., R. 13 E., at Melones Dam on Stanislaus River, Tuolumne County, 0.1 mile below Bear Creok. Zero of gage is at mean sea level.

Drainage area.- 897 square miles.

Gage-height record. - Gage read to tenths daily at 7 a.m.

Remarks.- Flood run-off largely controlled in reservolr (capacity, 91,680 acre-feet at elevation of crest of splilway, 723.0 feet; 112,610 acre-feet at elevation of top of spillway gates, 735.0 feet). Reservoir began to spill about noon Dec. 11 . See record for Stanislaus River below Melones power house. Basic data furnished by Pacific Gas E Electric Co.

Elevation and contents, November 1937 to January 1938

\begin{tabular}{|c|c|c|c|c|c|c|}
\hline \multirow{2}{*}{ Day } & \multicolumn{2}{|c|}{ November } & \multicolumn{2}{|c|}{ December } & \multicolumn{2}{|c|}{ Jamuary } \\
\hline & $\begin{array}{c}\text { Elevation } \\
\text { (feet) }\end{array}$ & $\begin{array}{l}\text { Contents } \\
(\text { acre-feet) }\end{array}$ & $\begin{array}{c}\text { Elevation } \\
\text { (feet) }\end{array}$ & $\begin{array}{l}\text { Contents } \\
(\text { acre-feet })\end{array}$ & $\begin{array}{c}\text { Elevation } \\
\text { (feet) }\end{array}$ & $\begin{array}{l}\text { Contents } \\
(\text { acre-feet) }\end{array}$ \\
\hline $\begin{array}{l}1 \\
2 \\
3 \\
4 \\
5\end{array}$ & $\begin{array}{l}631.1 \\
630.9 \\
630.8 \\
631.8 \\
631.7\end{array}$ & $\begin{array}{l}7,422 \\
7,358 \\
7,326 \\
7,646 \\
7,614\end{array}$ & $\begin{array}{l}638.1 \\
638.0 \\
637.8 \\
637.8 \\
637.7\end{array}$ & $\begin{array}{l}9,911 \\
9,870 \\
9,794 \\
9,794 \\
9,756\end{array}$ & $\begin{array}{l}723.5 \\
723.8 \\
724.2 \\
723.7 \\
723.3\end{array}$ & $\begin{array}{l}92,498 \\
92,985 \\
93,645 \\
92,823 \\
92,173\end{array}$ \\
\hline $\begin{array}{r}6 \\
7 \\
8 \\
9 \\
10\end{array}$ & $\begin{array}{l}631.6 \\
631.6 \\
631.6 \\
631.7 \\
631.7\end{array}$ & $\begin{array}{l}7,582 \\
7,582 \\
7,582 \\
7,614 \\
7,614\end{array}$ & $\begin{array}{l}638.4 \\
638.1 \\
639.1 \\
640.1 \\
640.3\end{array}$ & $\begin{array}{r}10,032 \\
9,911 \\
10,315 \\
10,722 \\
10,807\end{array}$ & $\begin{array}{l}722.8 \\
722.3 \\
722.0 \\
722.2 \\
722.5\end{array}$ & $\begin{array}{l}91,360 \\
90,548 \\
90,060 \\
90,385 \\
90,873\end{array}$ \\
\hline $\begin{array}{l}11 \\
12 \\
13 \\
14 \\
15\end{array}$ & $\begin{array}{l}631.7 \\
631.8 \\
632.3 \\
632.6 \\
632.5\end{array}$ & $\begin{array}{l}7,614 \\
7,646 \\
7,812 \\
7,914 \\
7,880\end{array}$ & $\begin{array}{l}672.7 \\
723.2 \\
725.0 \\
725.0 \\
725.5\end{array}$ & $\begin{array}{l}31,151 \\
92,010 \\
94,985 \\
94,985 \\
95,823\end{array}$ & $\begin{array}{l}722.0 \\
721.8 \\
721.5 \\
721.1 \\
720.8\end{array}$ & $\begin{array}{l}90,060 \\
39,747 \\
89,278 \\
88,652 \\
88,182\end{array}$ \\
\hline $\begin{array}{l}16 \\
17 \\
18 \\
19 \\
20\end{array}$ & $\begin{array}{l}632.5 \\
632.6 \\
632.8 \\
633.4 \\
633.6\end{array}$ & $\begin{array}{l}7,880 \\
7,914 \\
7,982 \\
8,186 \\
8,254\end{array}$ & $\begin{array}{l}725.5 \\
724.8 \\
724.7 \\
724.4 \\
724.3\end{array}$ & $\begin{array}{l}95,823 \\
94,650 \\
94,483 \\
93,980 \\
93,813\end{array}$ & $\begin{array}{l}722.5 \\
723.7 \\
724.0 \\
723.7 \\
723.9\end{array}$ & $\begin{array}{l}90,873 \\
92,823 \\
93,310 \\
92,823 \\
93,148\end{array}$ \\
\hline $\begin{array}{l}21 \\
22 \\
23 \\
24 \\
25\end{array}$ & $\begin{array}{l}634.1 \\
635.5 \\
635.7 \\
636.0 \\
636.0\end{array}$ & $\begin{array}{l}8,426 \\
8,930 \\
9,002 \\
9,110 \\
9,110\end{array}$ & $\begin{array}{l}724.0 \\
723.8 \\
723.7 \\
723.8 \\
724.0\end{array}$ & $\begin{array}{l}93,310 \\
92,985 \\
92,823 \\
92,985 \\
93,310\end{array}$ & $\begin{array}{l}723.9 \\
723.8 \\
724.0 \\
724.1 \\
723.6\end{array}$ & $\begin{array}{l}93,148 \\
92,985 \\
93,310 \\
93,478 \\
92,660\end{array}$ \\
\hline $\begin{array}{l}26 \\
27 \\
28 \\
29 \\
30 \\
31\end{array}$ & $\begin{array}{l}637.1 \\
637.2 \\
637.3 \\
638.1 \\
638.1\end{array}$ & $\begin{array}{l}9,528 \\
9,566 \\
9,604 \\
9,911 \\
9,911\end{array}$ & $\begin{array}{l}724.1 \\
724.2 \\
723.9 \\
723.5 \\
723.5 \\
723.5\end{array}$ & $\begin{array}{l}93,478 \\
93,645 \\
93,148 \\
92,498 \\
92,498 \\
92,498\end{array}$ & $\begin{array}{l}723.4 \\
723.4 \\
723.3 \\
723.6 \\
724.2 \\
724.2\end{array}$ & $\begin{array}{l}92,335 \\
92,335 \\
92,173 \\
92,660 \\
93,645 \\
93,645\end{array}$ \\
\hline
\end{tabular}


Stanislaus River below Melones power house, Calif.

Location.- Lat. $37^{\circ} 56^{\prime} 50^{\prime \prime}$, long. $120^{\circ} 31^{\prime} 45^{\prime \prime}$, near Ilne between secs. 10 and 15 , T. 1 N., R. 13 E., 300 feet below power house, half a mile above Bear Gulch, and 1 mile below Melones Dam, Tuolumne County. Alt1tude, about 500 feet above mean sea level. Drainage area.- 898 square miles.

Gage-helght record.- Water-stage recorder graph.

Stage-discharge relation.- Defined by current-meter measurements below 14,700 secondieet.

Maxima.- December 1937: Discharge, 7,460 second-feet 12:30 p.m. Dec. 12 (gage he1ght, 10.50 feet).

1931-November 1937: D1scharge, 19,300 second-feet (revised) Feb. 22, 1936 (gage helght, 16.1 feet), from rating curve for 1938 extended above 15,000 second-feet. Remarks.- Flood run-off largely controlled by Melones Reservolr (capac1ty, 91,680 acrefeet). Contents at midnlght determined from graph based on readings made at 7 a.m. Dally and monthly discharges not adjusted for storage in small reservolrs upstream from Melones Reservolr. See record for Melones Reservolr at Melones Dam. Most of basic data furnished by Pacific Gas \& Electric Co.

Discharge, in second-feet, and gain or loss in storage, in acre-feet, November 1937 to January 1938

\begin{tabular}{|c|c|c|c|c|c|c|c|c|c|}
\hline & \multicolumn{3}{|c|}{ November } & \multicolumn{3}{|c|}{ December } & \multicolumn{3}{|c|}{ January } \\
\hline Day & $\begin{array}{l}\text { Observed } \\
\text { discharge }\end{array}$ & $\begin{array}{l}\text { Gain or } \\
\text { loss in } \\
\text { storage }\end{array}$ & $\begin{array}{l}\text { Adjusted } \\
\text { discharge }\end{array}$ & $\begin{array}{l}\text { Observed } \\
\text { discharge }\end{array}$ & $\begin{array}{l}\text { Gain or } \\
\text { loss in } \\
\text { storage }\end{array}$ & $\begin{array}{l}\text { Ad justed } \\
\text { di scharge }\end{array}$ & $\begin{array}{l}\text { Observed } \\
\text { discharge }\end{array}$ & \begin{tabular}{l|} 
Gain or \\
loss in \\
storage
\end{tabular} & $\begin{array}{l}\text { Ad justed } \\
\text { discharge }\end{array}$ \\
\hline $\begin{array}{l}1 \\
2 \\
3 \\
4 \\
5\end{array}$ & $\begin{array}{r}149 \\
160 \\
54 \\
155 \\
156\end{array}$ & $\begin{array}{r}-64 \\
-42 \\
+218 \\
+70 \\
-32\end{array}$ & $\begin{array}{l}117 \\
139 \\
164 \\
190 \\
140\end{array}$ & $\begin{array}{r}222 \\
220 \\
216 \\
218 \\
15\end{array}$ & $\begin{array}{r}-29 \\
-66 \\
-22 \\
-27 \\
+185\end{array}$ & $\begin{array}{l}207 \\
187 \\
205 \\
204 \\
108\end{array}$ & $\begin{array}{r}356 \\
419 \\
1,360 \\
1,160 \\
1,020\end{array}$ & $\begin{array}{l}+345 \\
+610 \\
-390 \\
-700 \\
-766\end{array}$ & $\begin{array}{r}530 \\
727 \\
1,160 \\
807 \\
634\end{array}$ \\
\hline $\begin{array}{r}6 \\
7 \\
8 \\
9 \\
10\end{array}$ & $\begin{array}{l}155 \\
147 \\
148 \\
148 \\
150\end{array}$ & $\begin{array}{r}-9 \\
0 \\
+23 \\
+9 \\
0\end{array}$ & $\begin{array}{l}150 \\
147 \\
160 \\
152 \\
150\end{array}$ & $\begin{array}{c}221 \\
14 \\
2.3 \\
280 \\
346\end{array}$ & $\begin{array}{r}-6 \\
+251 \\
+406 \\
+179 \\
+10,218\end{array}$ & $\begin{array}{r}218 \\
141 \\
207 \\
370 \\
5,500\end{array}$ & $\begin{array}{r}1,020 \\
988 \\
660 \\
47 \\
1,020\end{array}$ & $\begin{array}{r}-812 \\
-583 \\
+88 \\
+441 \\
-434\end{array}$ & $\begin{array}{l}611 \\
694 \\
704 \\
269 \\
801\end{array}$ \\
\hline $\begin{array}{l}11 \\
12 \\
13 \\
14 \\
15\end{array}$ & $\begin{array}{l}144 \\
150 \\
164 \\
164 \\
166\end{array}$ & $\begin{array}{r}+23 \\
+127 \\
+120 \\
+6 \\
-10\end{array}$ & $\begin{array}{l}156 \\
214 \\
224 \\
167 \\
161\end{array}$ & $\begin{array}{l}2,560 \\
6,290 \\
4,610 \\
3,200 \\
2,910\end{array}$ & $\begin{array}{r}+65,700 \\
+7,417 \\
+868 \\
+594 \\
+244\end{array}$ & $\begin{array}{r}35,700 \\
10,000 \\
5,050 \\
3,500 \\
3,030\end{array}$ & $\begin{array}{r}641 \\
790 \\
805 \\
1,020 \\
685\end{array}$ & $\begin{array}{r}-459 \\
-423 \\
-580 \\
-516 \\
+1,769\end{array}$ & $\begin{array}{r}410 \\
577 \\
513 \\
760 \\
1,580\end{array}$ \\
\hline $\begin{array}{l}16 \\
17 \\
18 \\
19 \\
20\end{array}$ & $\begin{array}{l}162 \\
168 \\
183 \\
188 \\
184\end{array}$ & $\begin{array}{r}+24 \\
+58 \\
+164 \\
+108 \\
+142\end{array}$ & $\begin{array}{l}174 \\
197 \\
266 \\
242 \\
256\end{array}$ & $\begin{array}{r}2,920 \\
2,240 \\
1,850 \\
988 \\
1,570\end{array}$ & $\begin{array}{l}-831 \\
-460 \\
-405 \\
-265 \\
-405\end{array}$ & $\begin{array}{r}2,500 \\
2,010 \\
1,650 \\
854 \\
1,370\end{array}$ & $\begin{array}{r}75 \\
902 \\
1,530 \\
890 \\
1,030\end{array}$ & $\begin{array}{r}+2,166 \\
+914 \\
-203 \\
+88 \\
+95\end{array}$ & $\begin{array}{r}1,170 \\
1,360 \\
1,430 \\
934 \\
1,080\end{array}$ \\
\hline $\begin{array}{l}21 \\
22 \\
23 \\
24 \\
25\end{array}$ & $\begin{array}{r}14 \\
210 \\
215 \\
203 \\
14\end{array}$ & $\begin{array}{r}+407 \\
+198 \\
+97 \\
+32 \\
+296\end{array}$ & $\begin{array}{l}219 \\
310 \\
264 \\
219 \\
163\end{array}$ & $\begin{array}{r}1,060 \\
1,110 \\
805 \\
634 \\
634\end{array}$ & $\begin{array}{r}-377 \\
-210 \\
+68 \\
+277 \\
+214\end{array}$ & $\begin{array}{r}870 \\
1,000 \\
839 \\
774 \\
742\end{array}$ & $\begin{array}{r}902 \\
768 \\
775 \\
1,300 \\
970\end{array}$ & $\begin{array}{l}-115 \\
+182 \\
+214 \\
-530 \\
-469\end{array}$ & $\begin{array}{r}844 \\
860 \\
883 \\
1,030 \\
734\end{array}$ \\
\hline $\begin{array}{l}26 \\
27 \\
28 \\
29 \\
30 \\
31\end{array}$ & $\begin{array}{r}210 \\
212 \\
15 \\
208 \\
211\end{array}$ & $\begin{array}{r}+149 \\
+38 \\
+228 \\
+90 \\
0\end{array}$ & $\begin{array}{l}285 \\
231 \\
130 \\
253 \\
211\end{array}$ & $\begin{array}{r}648 \\
997 \\
1,020 \\
730 \\
620 \\
508\end{array}$ & $\begin{array}{r}+167 \\
-303 \\
-605 \\
-190 \\
0 \\
0\end{array}$ & $\begin{array}{l}732 \\
844 \\
715 \\
634 \\
620 \\
508\end{array}$ & $\begin{array}{r}845 \\
890 \\
632 \\
324 \\
805 \\
1,370\end{array}$ & $\begin{array}{r}-95 \\
-115 \\
+298 \\
+840 \\
+287 \\
+712\end{array}$ & $\begin{array}{r}797 \\
832 \\
782 \\
748 \\
950 \\
1,730\end{array}$ \\
\hline \multirow{2}{*}{\multicolumn{7}{|c|}{ 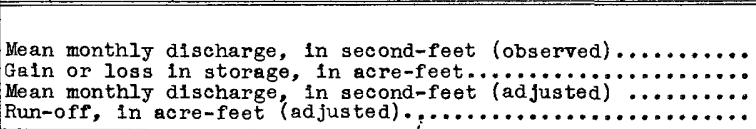 }} & November & December & January \\
\hline & & & & & & & $\begin{array}{r}154 \\
+2,470 \\
195 \\
11,610\end{array}$ & $\begin{array}{r}1,279 \\
+82,590 \\
2,622 \\
161,200\end{array}$ & $\begin{array}{r}839 \\
+1,860 \\
869 \\
53,440\end{array}$ \\
\hline
\end{tabular}


Location. - Iat. $38^{\circ} 14^{\prime}$, long. $120^{\circ} 17$ ', in sec. 35 , T. 5 N., R. 15 E., 700 feet above Intake of Utics Mining Co.'s canal, $3 \frac{1}{2}$ miles above Besver Creok, and 5 miles northeast of Avery, Calaveras County. Altitude, about 3,400 feot above mean sea level. Dralnage area.- 163 square miles.

Gage-height record.- Water-stage recorder graph except for perlod 7 a.m. Dec. 11 to 1:30 p.m. Dec. 12, when $\mathrm{stag} \theta$ graph was based on peak stage, 4 gage readings, partial recorder graph, and comparison with stage graphs for nearby stations.

Stage-discharge relation.- Defined by current-meter measurements below 3,400 secondfeet; extended to peak stage by $A \sqrt{d}$ method.

Maxima.- December 1937: Discharge, 17,700 second-feet-about 9 a.m. Dec. Il (gage helght, about 14.1 feet, from floodmark).

1914-22; 1928-November 1937: Discharge observed, 5,250 second-feet May 11, 1915 (gage height, 8.7 feet), from rating curve extended above 2,400 second-feet.

Remarks.- Flood run-off not materially affected by artfficial storage or diversion. Part of basic data furnished by Utica Mining 00 .

Mean daliy discharge, in second-feet, November 1937 to January 1938

\begin{tabular}{|c|c|c|c|c|c|c|c|c|c|c|c|}
\hline Day & Nov. & Dec. & Jan. & Day & Nov. & Dec. & Jan. & Day & Nov. & Dec. & Jan. \\
\hline $\begin{array}{r}1 \\
2 \\
3 \\
4 \\
5 \\
6 \\
7 \\
8 \\
9 \\
10\end{array}$ & $\begin{array}{l}40 \\
40 \\
40 \\
40 \\
39 \\
40 \\
41 \\
41 \\
41 \\
44\end{array}$ & $\begin{array}{r}60 \\
60 \\
58 \\
57 \\
56 \\
54 \\
53 \\
53 \\
57 \\
3,240\end{array}$ & $\begin{array}{l}182 \\
220 \\
232 \\
210 \\
194 \\
180 \\
171 \\
163 \\
154 \\
149\end{array}$ & $\begin{array}{l}11 \\
12 \\
13 \\
14 \\
15 \\
16 \\
17 \\
18 \\
19 \\
20\end{array}$ & $\begin{array}{r}57 \\
56 \\
52 \\
58 \\
53 \\
49 \\
103 \\
81 \\
59 \\
68\end{array}$ & $\begin{array}{r}12,900 \\
3,620 \\
1,060 \\
700 \\
558 \\
464 \\
400 \\
361 \\
318 \\
280\end{array}$ & $\begin{array}{l}148 \\
145 \\
142 \\
144 \\
290 \\
245 \\
285 \\
254 \\
232 \\
216\end{array}$ & $\begin{array}{l}21 \\
22 \\
23 \\
24 \\
25 \\
26 \\
27 \\
28 \\
29 \\
30 \\
31\end{array}$ & $\begin{array}{r}119 \\
70 \\
60 \\
72 \\
68 \\
61 \\
60 \\
58 \\
60 \\
60\end{array}$ & $\begin{array}{l}261 \\
245 \\
245 \\
230 \\
220 \\
210 \\
200 \\
193 \\
187 \\
183 \\
183\end{array}$ & $\begin{array}{l}198 \\
228 \\
224 \\
200 \\
200 \\
214 \\
228 \\
222 \\
218 \\
191 \\
204\end{array}$ \\
\hline $\begin{array}{l}\text { Mean } \\
\text { Run- }\end{array}$ & in & & & & & & & & $\begin{array}{r}57.7 \\
3,430\end{array}$ & $\begin{array}{r}863 \\
53,090 \\
\end{array}$ & $\begin{array}{r}203 \\
12,460 \\
\end{array}$ \\
\hline
\end{tabular}

Gage height, in feet, and discharge, in second-feet, at indicated time, 1937

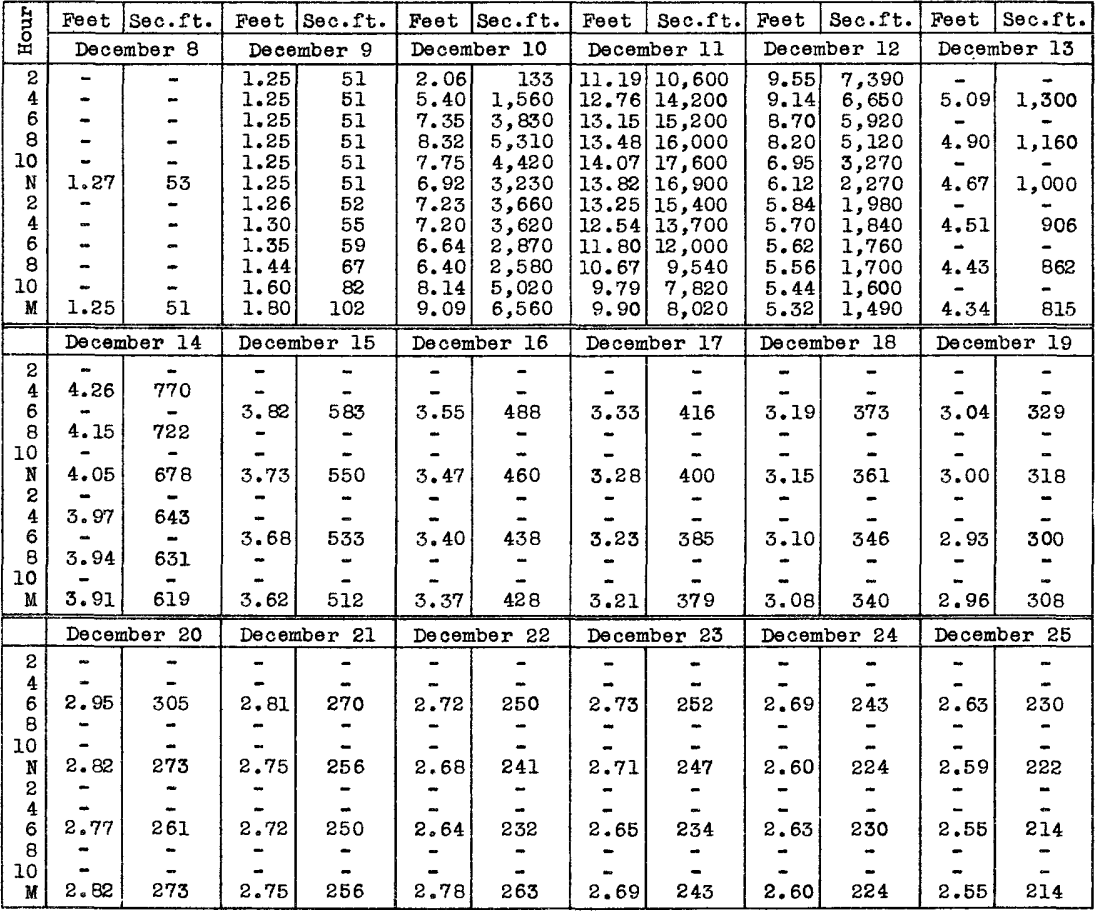

Sufrlemantal records.- Dec. 11,9 a.m., 14.10 ft., 17,700 sec.-ft. 


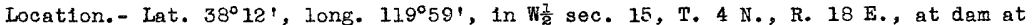
Straviberry Reservoir, I mile northwest of Pine Crest, Tuolumne County. Altitude, about 5,600 feet above mean sea level.

Drainage area.- 45.5 square miles.

Gage-height record. - One gage reading daıly at Strawberry Reservoir and at weir below reservolr.

Remarks.- Flood mun-off largely controlled in Strawberry Reservolr. Elevation of crest of spillway is $5,611.5$ feet above mean sea level (capacity, 16,550 acre-feet). Reservolr began to spili 5:30 a.m. Dec. 13. Gain or loss in storage computed from contents at midnight determined from graph based on daily readings at 10 a.m. Record of observed daily discharge and other basic data furnished by Pacific Gas Electric Co.

Contents, gain or loss in storage, and mean dally discharge, December 1937

\begin{tabular}{|c|c|c|c|c|}
\hline \multirow[b]{2}{*}{ Day } & \multicolumn{2}{|c|}{ Strawberry Reservotr } & \multicolumn{2}{|c|}{ River } \\
\hline & $\begin{array}{c}\text { Contents } \\
(a c r e-f e e t)\end{array}$ & $\begin{array}{l}\text { Gain or loss } \\
\text { in storage } \\
\text { (acre-feet) }\end{array}$ & $\begin{array}{l}\text {-0bserved } \\
\text { discharge } \\
\text { (second-feet) }\end{array}$ & $\begin{array}{c}\text { Ad fusted } \\
\text { discharge } \\
\text { (second-feet) }\end{array}$ \\
\hline $\begin{array}{l}1 \\
2 \\
3 \\
4 \\
5\end{array}$ & $\begin{array}{l}5,075 \\
5,045 \\
5,005 \\
4,970 \\
4,930\end{array}$ & $\begin{array}{l}-45 \\
-30 \\
-40 \\
-35 \\
-40\end{array}$ & $\begin{array}{l}28 \\
28 \\
28 \\
28 \\
28\end{array}$ & $\begin{array}{c}6 \\
13 \\
8.5 \\
11 \\
8.5\end{array}$ \\
\hline $\begin{array}{r}6 \\
7 \\
8 \\
9 \\
10\end{array}$ & $\begin{array}{r}4,895 \\
4,860 \\
4,825 \\
5,130 \\
10,050\end{array}$ & $\begin{array}{r}-35 \\
-35 \\
-35 \\
+305 \\
+4,920\end{array}$ & $\begin{array}{l}28 \\
28 \\
28 \\
28 \\
12\end{array}$ & $\begin{array}{r}11 \\
11 \\
11 \\
182 \\
2,490\end{array}$ \\
\hline $\begin{array}{l}11 \\
12 \\
13 \\
14 \\
15\end{array}$ & $\begin{array}{l}15,320 \\
16,600 \\
16,750 \\
16,710 \\
16,600\end{array}$ & $\begin{array}{r}+5,270 \\
+1,280 \\
+150 \\
-40 \\
-110\end{array}$ & $\begin{array}{r}0 \\
0 \\
92 \\
188 \\
151\end{array}$ & $\begin{array}{r}2,660 \\
645 \\
168 \\
167 \\
95\end{array}$ \\
\hline $\begin{array}{l}16 \\
17 \\
18 \\
19 \\
20\end{array}$ & $\begin{array}{l}16,500 \\
16,470 \\
16,460 \\
16,460 \\
16,420\end{array}$ & $\begin{array}{r}-100 \\
-30 \\
-10 \\
0 \\
-40\end{array}$ & $\begin{array}{c}127 \\
39 \\
28 \\
2.0 \\
33\end{array}$ & $\begin{array}{l}77 \\
24 \\
23 \\
2.0 \\
13\end{array}$ \\
\hline $\begin{array}{l}21 \\
22 \\
23 \\
24 \\
25\end{array}$ & $\begin{array}{l}16,300 \\
16,140 \\
15,990 \\
15,840 \\
15,680\end{array}$ & $\begin{array}{l}-120 \\
-160 \\
-150 \\
-150 \\
-160\end{array}$ & $\begin{array}{r}90 \\
107 \\
107 \\
107 \\
107\end{array}$ & $\begin{array}{l}30 \\
26 \\
31 \\
31 \\
26\end{array}$ \\
\hline $\begin{array}{l}26 \\
27 \\
28 \\
29 \\
30 \\
31\end{array}$ & $\begin{array}{l}15,520 \\
15,350 \\
15,180 \\
15,020 \\
14,850 \\
14,690\end{array}$ & $\begin{array}{l}-160 \\
-170 \\
-170 \\
-160 \\
-170 \\
-160\end{array}$ & $\begin{array}{l}107 \\
107 \\
107 \\
107 \\
107 \\
107\end{array}$ & $\begin{array}{l}26 \\
21 \\
21 \\
26 \\
21 \\
26\end{array}$ \\
\hline
\end{tabular}

Observed mean dally discharge, In second-feet, November 1937 to January 1938

\begin{tabular}{|r|c|c|c||r|r|r|r||r|r|r|r|}
\hline Day & Nov. & Dec. & Jan. & Day & Nov. & Dec. & Jan. & Day & Nov. & Dec. & Jan. \\
\hline 1 & 53 & 28 & 107 & 11 & 53 & 0 & 107 & 21 & 0 & 90 & 107 \\
2 & 53 & 28 & 107 & 12 & 53 & 0 & 107 & 22 & 0 & 107 & 107 \\
3 & 53 & 28 & 107 & 23 & 53 & 92 & 107 & 23 & 0 & 107 & 107 \\
4 & 53 & 28 & 107 & 14 & 53 & 188 & 107 & 24 & 28 & 107 & 107 \\
5 & 53 & 28 & 107 & 15 & 0 & 151 & 107 & 25 & 28 & 107 & 107 \\
6 & 53 & 28 & 107 & 16 & 0 & 127 & 107 & 26 & 28 & 107 & 107 \\
7 & 53 & 28 & 107 & 17 & 0 & 39 & 107 & 27 & 28 & 107 & 70 \\
8 & 53 & 28 & 107 & 18 & 0 & 28 & 107 & 28 & 28 & 107 & 50 \\
9 & 53 & 28 & 107 & 19 & 0 & 2.0 & 107 & 29 & 28 & 107 & 50 \\
10 & 53 & 12 & 107 & 20 & 0 & 33 & 107 & 30 & 28 & 107 & 50 \\
\end{tabular}


Location. - Lat. $38^{\circ} 05^{\prime}$, long. $120^{\circ} 11^{\prime}$, In sec. 25, T. 3 N., R. I6 E., about 600 feet beI0w Lyons Dam, Tholumne County, and $14 \mathrm{miles}$ northeast of Sonora. Altitude, about 4,100 feet above mean sea level.

Drainage area. - 67.2 square miles.

Gage-helght record.- Water-stage recorder graph from beginning of record, Nov. 8, 1937. Stage-discharge relation. - Defined by current-meter measurements below 1,400 secondfe日t.

Maxima.- December 1937: Discharge (regulated), 342 second-feet 5 p.m. Dec. 12 (gage heIght, 3.30 fe日t). Maximum discharge, adjusted for changers in storage in tyons Reservolr, about 2,800 second-fe日t morning Dec. 1 i.

Remarks; - Flood run-off affected by storage in Lyons Reservolr (capacity, 5,500 acrefeet), slightly by diversions into Philadelphia and Tuolume ditches, and to some extent by storage in Strawberry Reservoir. Dally and monthly discharges adjusted for storage and diversion as shown in table but not for storage in Strawberry Reservolr. Contents at midnight for Lyons Reservolr detemined from graph based on daily readings at $10 \mathrm{a} . \mathrm{m}$. Most of basic data furnished by Pacific Gas \& Electric Co.

Storage, diversion, and discharge, December 1937

\begin{tabular}{|c|c|c|c|c|c|c|}
\hline \multirow[b]{2}{*}{ Day } & \multicolumn{2}{|c|}{ Lyons Reservolr } & \multirow[b]{2}{*}{$\begin{array}{c}\text { Philadelphia } \\
\text { Canal } \\
(\text { sec.-ft.) }\end{array}$} & \multirow[b]{2}{*}{$\begin{array}{l}\text { Tuolumne } \\
\text { Cansl } \\
\text { (sec.-ft.) }\end{array}$} & \multicolumn{2}{|c|}{ River } \\
\hline & $\begin{array}{l}\text { Contents } \\
(\text { acre-feet) }\end{array}$ & $\begin{array}{l}\text { Gain or loss } \\
\text { in storage } \\
(\text { acr } \theta-f \theta \theta t)\end{array}$ & & & $\begin{array}{l}\text { Observed } \\
\text { discharge } \\
(\text { sec.-ft.) }\end{array}$ & $\begin{array}{c}\text { Adjusted } \\
\text { discharge } \\
\text { (sec.-ft.) }\end{array}$ \\
\hline $\begin{array}{l}1 \\
2 \\
3 \\
4 \\
5\end{array}$ & $\begin{array}{l}394 \\
395 \\
395 \\
395 \\
395\end{array}$ & $\begin{array}{r}0 \\
+1 \\
0 \\
0 \\
0\end{array}$ & $\begin{array}{l}27 \\
27 \\
26 \\
26 \\
26\end{array}$ & $\begin{array}{l}7 \\
7 \\
7 \\
7 \\
7\end{array}$ & $\begin{array}{l}0 \\
0 \\
0 \\
0 \\
0\end{array}$ & $\begin{array}{l}34 \\
34 \\
33 \\
33 \\
33\end{array}$ \\
\hline $\begin{array}{r}6 \\
7 \\
8 \\
9 \\
10\end{array}$ & $\begin{array}{r}393 \\
392 \\
392 \\
425 \\
1,280\end{array}$ & $\begin{array}{r}-2 \\
-1 \\
0 \\
+33 \\
+855\end{array}$ & $\begin{array}{l}26 \\
26 \\
26 \\
30 \\
40\end{array}$ & $\begin{array}{l}6.5 \\
7 \\
6.5 \\
7 \\
7\end{array}$ & $\begin{array}{l}0 \\
0 \\
0 \\
: 1 \\
1.6\end{array}$ & $\begin{array}{r}32 \\
32 \\
32 \\
54 \\
480\end{array}$ \\
\hline $\begin{array}{l}11 \\
12 \\
13 \\
14 \\
15\end{array}$ & $\begin{array}{l}4,350 \\
4,700 \\
4,675 \\
4,675 \\
4,669\end{array}$ & $\begin{array}{r}+3,070 \\
+350 \\
-25 \\
0 \\
-6\end{array}$ & $\begin{array}{l}46 \\
15 \\
18 \\
31 \\
37\end{array}$ & $\begin{array}{l}10 \\
9 \\
5 \\
4.8 \\
4.7\end{array}$ & $\begin{array}{l}2.2 \\
250 \\
214 \\
197 \\
186\end{array}$ & $\begin{array}{r}1,610 \\
450 \\
224 \\
233 \\
225\end{array}$ \\
\hline $\begin{array}{l}16 \\
17 \\
18 \\
19 \\
20\end{array}$ & $\begin{array}{l}4,636 \\
4,611 \\
4,619 \\
4,609 \\
4,590\end{array}$ & $\begin{array}{r}-33 \\
-25 \\
+8 \\
-10 \\
-19\end{array}$ & $\begin{array}{l}38 \\
38 \\
38 \\
37 \\
38\end{array}$ & $\begin{array}{l}4.8 \\
5 \\
4.8 \\
4.8 \\
9.5\end{array}$ & $\begin{array}{r}126 \\
102 \\
79 \\
62 \\
56\end{array}$ & $\begin{array}{r}152 \\
132 \\
126 \\
99 \\
94\end{array}$ \\
\hline $\begin{array}{l}21 \\
22 \\
23 \\
24 \\
25\end{array}$ & $\begin{array}{l}4,601 \\
4,628 \\
4,625 \\
4,616 \\
4,606\end{array}$ & $\begin{array}{r}+11 \\
+27 \\
-3 \\
-9 \\
-10\end{array}$ & $\begin{array}{l}37 \\
37 \\
41 \\
44 \\
44\end{array}$ & $\begin{array}{l}13 \\
16 \\
20 \\
23 \\
24\end{array}$ & $\begin{array}{l}59 \\
84 \\
90 \\
67 \\
65\end{array}$ & $\begin{array}{l}115 \\
151 \\
149 \\
129 \\
128\end{array}$ \\
\hline $\begin{array}{l}26 \\
27 \\
28 \\
29 \\
30 \\
31\end{array}$ & $\begin{array}{l}4,601 \\
4,601 \\
4,601 \\
4,601 \\
4,601 \\
4,601\end{array}$ & $\begin{array}{r}-5 \\
0 \\
0 \\
0 \\
0 \\
0\end{array}$ & $\begin{array}{l}43 \\
43 \\
43 \\
43 \\
44 \\
45\end{array}$ & $\begin{array}{l}24 \\
24 \\
24 \\
24 \\
24 \\
25\end{array}$ & $\begin{array}{l}64 \\
63 \\
64 \\
62 \\
62 \\
54\end{array}$ & $\begin{array}{l}128 \\
130 \\
131 \\
129 \\
130 \\
124\end{array}$ \\
\hline
\end{tabular}

Observed mean dally discharge, in second-fe日t, November 1937 to January 1938

\begin{tabular}{|c|c|c|c|c|c|c|c|c|c|c|c|}
\hline Day & Nov. & Dec. & Jan. & Day & Nov. & Dec. & Jan. & Day & Nov. & Dec. & Jan. \\
\hline $\begin{array}{r}1 \\
2 \\
3 \\
4 \\
5 \\
6 \\
7 \\
8 \\
9 \\
10\end{array}$ & $\begin{array}{l}0 \\
0 \\
0 \\
0 \\
0 \\
0 \\
0 \\
0 \\
0 \\
0\end{array}$ & $\begin{array}{l}0 \\
0 \\
0 \\
0 \\
0 \\
0 \\
0 \\
0 \\
.1 \\
1.6\end{array}$ & $\begin{array}{l}59 \\
73 \\
69 \\
62 \\
60 \\
55 \\
52 \\
52 \\
57 \\
58\end{array}$ & $\begin{array}{l}11 \\
12 \\
13 \\
14 \\
15 \\
16 \\
17 \\
18 \\
19 \\
20\end{array}$ & $\begin{array}{l}0 \\
0 \\
0 \\
0 \\
.1 \\
.1 \\
.6 \\
.2 \\
.2 \\
.2\end{array}$ & $\begin{array}{c}2.2 \\
250 \\
214 \\
197 \\
186 \\
126 \\
102 \\
79 \\
62 \\
56\end{array}$ & $\begin{array}{r}57 \\
55 \\
53 \\
63 \\
199 \\
109 \\
136 \\
121 \\
111 \\
96\end{array}$ & $\begin{array}{l}21 \\
22 \\
23 \\
24 \\
25 \\
26 \\
27 \\
28 \\
29 \\
30 \\
31\end{array}$ & $\begin{array}{r}0.2 \\
.2 \\
.2 \\
.2 \\
.2 \\
.2 \\
.2 \\
.2 \\
.2 \\
.1\end{array}$ & $\begin{array}{l}59 \\
84 \\
90 \\
67 \\
65 \\
64 \\
63 \\
64 \\
62 \\
62 \\
54\end{array}$ & $\begin{array}{l}90 \\
88 \\
83 \\
77 \\
77 \\
75 \\
68 \\
25 \\
22 \\
18 \\
22\end{array}$ \\
\hline $\begin{array}{l}\text { Mean } \\
\text { Gain } \\
\text { Mean } \\
\text { Mean } \\
\text { Run- }\end{array}$ & $\begin{array}{l}\text { month } \\
\text { or lo } \\
\text { month } \\
\text { month } \\
\text { ff, } 1\end{array}$ & $\begin{array}{l}\text { disch } \\
\text { In st } \\
\text { diver } \\
\text { disch } \\
\operatorname{cre-f}\end{array}$ & , in & (1) & & & & & $\begin{array}{r}0.14 \\
-235 \\
42.6 \\
39.0 \\
2,320\end{array}$ & $\begin{array}{r}64.8 \\
+4,207 \\
46.9 \\
180 \\
11,080\end{array}$ & $\begin{array}{r}72.3 \\
-30 \\
68.9 \\
141 \\
8,660\end{array}$ \\
\hline
\end{tabular}


Calaveras River at Jenny Lind, Galif.

Location. - Lat. $38^{\circ} 05^{\prime}$, long. $120^{\circ} 52^{\prime}$, in SWt sec. 22, T. 3 N., R. $10 \mathrm{E}$, at highway bridge on Milton road a quarter of a mile south of Jenny Lind, Calaveras County, and $6 \frac{1}{2}$ miles below Cosgrove creek. Altitude, about 220 feet above mean sea level. Drainage area.- 395 square miles.

Gage-helght record. - Water-stage recorder graph.

stage-discharge relation.- Defined by current-meter measurements below 3,400 seconafeet. Rating curve changed at peak stage.

Maxima.- December 1937: Discharge (regulated), 3,370 second-feet 4 to 6 p.m. Dec. Il (gage he1ght, 6.48 feet).

1907-November 1937: Discharge observed (unregulated), about 69,600 second-feet Jan. 31, 1911 (gage height, 14.0 feet), from rating curve extended above 32,500 second-feet.

Remarks. - Flood mun-off affected by detention in Hogan flood-control reservolr (capacity, 76,000 acre-feet); not affected by diversions. See following page for storage record and adjusted river discharge. Contents of reservolr at midnight determined from graph based on dally gage readings. Part of basic data furnished by city of stockton.

Mean dally discharge, in second-feet, November 1937 to January 1938

\begin{tabular}{|c|c|c|c||c|r|r|r||r|r|r|r|}
\hline Day & Nov. & Dec. & Jan. & Day & Nov. & Dec. & Jan. & Dey & Nov. & Dec. & Jan. \\
\hline 1 & 0 & 19 & 56 & 11 & 0 & 2,040 & 58 & 21 & 28 & 66 & 342 \\
2 & 0 & 18 & 57 & 12 & 0 & 3,100 & 56 & 22 & 26 & 62 & 245 \\
3 & 0 & 18 & 78 & 13 & 0 & 2,020 & 54 & 23 & 26 & 69 & 197 \\
4 & 0 & 17 & 95 & 14 & 0 & 544 & 54 & 24 & 25 & 105 & 160 \\
5 & 0 & 17 & 83 & 15 & 0 & 211 & 194 & 25 & 26 & 93 & 138 \\
6 & 0 & 17 & 76 & 16 & 0 & 138 & 444 & 26 & 24 & 78 & 124 \\
7 & 0 & 16 & 73 & 17 & 5 & 107 & 310 & 27 & 21 & 71 & 114 \\
8 & 0 & 16 & 69 & 18 & 18 & 89 & 328 & 28 & 20 & 66 & 127 \\
9 & 0 & 17 & 68 & 19 & 26 & 78 & 270 & 29 & 20 & 64 & 498 \\
10 & 0 & 28 & 62 & 20 & 27 & 71 & 395 & 30 & 20 & 62 & 575 \\
\end{tabular}

Gage helght, in feet, and discharge, in second-feet, at indicated time, 1937

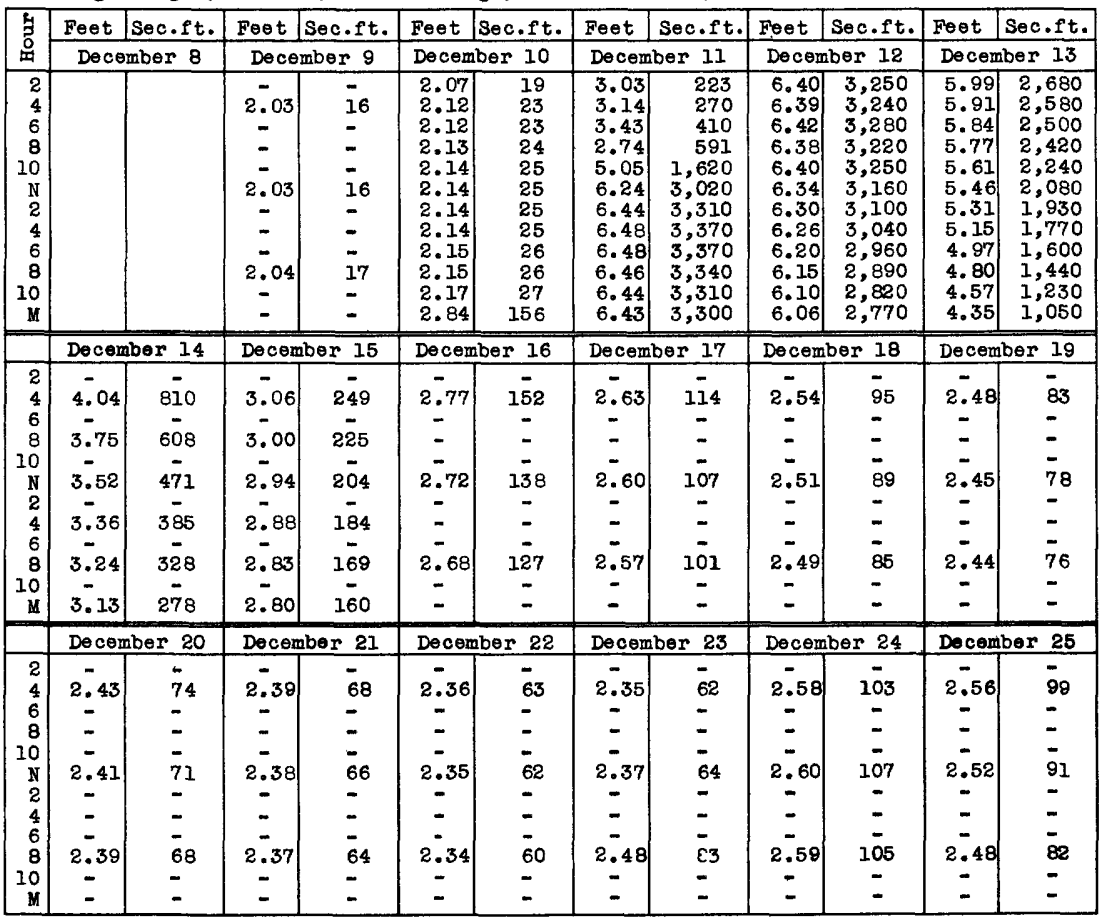


Calaveras River at Jenny Linả, Calif.--Continued

Gain or loss in storage and mean daily discharge, December 1937

\begin{tabular}{|c|c|c|c|c|c|}
\hline \multirow[b]{2}{*}{ Day } & \multicolumn{2}{|c|}{ Hogan Reservoir } & \multicolumn{3}{|c|}{ Calaveras River } \\
\hline & $\begin{array}{l}\text { Contents } \\
\text { (acre-feet) }\end{array}$ & Gain or loss in atorage & $\begin{array}{c}\text { Observed discharge } \\
\text { (second-feet) }\end{array}$ & $\begin{array}{l}\text { Ad justed } \\
\text { (secor }\end{array}$ & $\begin{array}{l}\text { discharge } \\
\text { d-feet) }\end{array}$ \\
\hline $\begin{array}{l}1 \\
2 \\
3 \\
4 \\
5\end{array}$ & $\begin{array}{l}902 \\
902 \\
902 \\
902 \\
902\end{array}$ & $\begin{array}{l}0 \\
0 \\
0 \\
0 \\
0\end{array}$ & $\begin{array}{l}19 \\
18 \\
18 \\
17 \\
17\end{array}$ & & $\begin{array}{l}19 \\
18 \\
18 \\
17 \\
17\end{array}$ \\
\hline $\begin{array}{r}6 \\
7 \\
8 \\
9 \\
10\end{array}$ & $\begin{array}{r}902 \\
902 \\
902 \\
902 \\
1,100\end{array}$ & $\begin{array}{r}0 \\
0 \\
0 \\
0 \\
+198\end{array}$ & $\begin{array}{l}17 \\
16 \\
16 \\
17 \\
28\end{array}$ & & $\begin{array}{r}17 \\
16 \\
16 \\
17 \\
128\end{array}$ \\
\hline $\begin{array}{l}11 \\
12 \\
13 \\
14 \\
15\end{array}$ & $\begin{array}{l}8,100 \\
4,330 \\
1,770 \\
1,205 \\
1,000\end{array}$ & $\begin{array}{r}+7,000 \\
-3,770 \\
-2,560 \\
-565 \\
-205\end{array}$ & $\begin{array}{r}2,040 \\
3,100 \\
2,020 \\
544 \\
211\end{array}$ & & $\begin{array}{l}570 \\
200 \\
730 \\
259 \\
108\end{array}$ \\
\hline $\begin{array}{l}16 \\
17 \\
18 \\
19 \\
20\end{array}$ & $\begin{array}{l}990 \\
990 \\
990 \\
990 \\
990\end{array}$ & $\begin{array}{r}-10 \\
0 \\
0 \\
0 \\
0\end{array}$ & $\begin{array}{r}138 \\
107 \\
89 \\
78 \\
71\end{array}$ & & $\begin{array}{r}133 \\
107 \\
89 \\
78 \\
71\end{array}$ \\
\hline $\begin{array}{l}21 \\
22 \\
23 \\
24 \\
25\end{array}$ & $\begin{array}{l}990 \\
990 \\
990 \\
990 \\
990\end{array}$ & $\begin{array}{l}0 \\
0 \\
0 \\
0 \\
0\end{array}$ & $\begin{array}{r}66 \\
62 \\
69 \\
105 \\
93\end{array}$ & & $\begin{array}{r}66 \\
62 \\
69 \\
105 \\
93\end{array}$ \\
\hline $\begin{array}{l}26 \\
27 \\
28 \\
29 \\
30 \\
31\end{array}$ & $\begin{array}{l}990 \\
990 \\
990 \\
990 \\
990 \\
948\end{array}$ & $\begin{array}{r}0 \\
0 \\
0 \\
0 \\
0 \\
-42\end{array}$ & $\begin{array}{l}78 \\
71 \\
66 \\
64 \\
62 \\
57\end{array}$ & & $\begin{array}{l}78 \\
71 \\
66 \\
64 \\
62 \\
36\end{array}$ \\
\hline \multicolumn{5}{|c|}{ 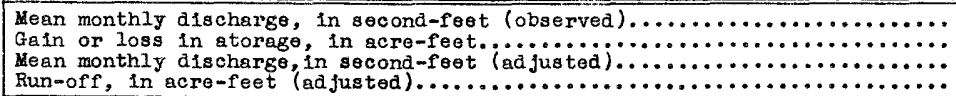 } & $\begin{array}{r}302 \\
+46 \\
303 \\
18,640\end{array}$ \\
\hline
\end{tabular}


Cosgrove Creek near Valley Springs, Calff.

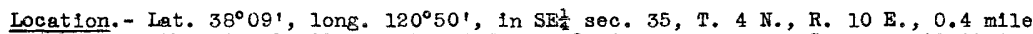
above mouth and 2.5 miles south of Valley Springs, Calaveras County. Alt1tude, about 580 feet above mean sea level.

Dra1nage area. - 20.6 square miles.

Gage-helght record.- Water-stage recorder graph.

Stage-d1scharge relation. - Defined by current-meter measurements below 800 secondfeet. Rating curve changed at peak stage.

Maxima:- December 1937: Discharge, 288 second-feet 8:15 a.m. Dec, 11 (gage helght, 4.05 feet).

1929-November 1937: Discharge, 2,600 second-feet (rev1sed) Feb, 22, 1936 (gage height, 7.80 feet), from rating curve extended above 800 second-feet with aid of area-velocity study.

Remarks. - Flood run-off not affected by artificial storage or diversion.

Mean dally discharge, in second-feet, November 1937 to January 1938

\begin{tabular}{|c|c|c|c|c|c|c|c|c|c|c|c|}
\hline Day & Nov. & Dec. & Jan. & Day & Nov. & Dec. & Jan. & Day & Nov. & Dec. & Jan. \\
\hline $\begin{array}{r}1 \\
2 \\
3 \\
4 \\
5 \\
6 \\
7 \\
8 \\
9 \\
10\end{array}$ & $\begin{array}{l}0 \\
0 \\
0 \\
0 \\
0 \\
0 \\
0 \\
0 \\
0 \\
0\end{array}$ & $\begin{array}{l}0 \\
0 \\
0 \\
0 \\
0 \\
0 \\
0 \\
0 \\
0 \\
.1\end{array}$ & $\begin{array}{r}0.3 \\
1.9 \\
4.1 \\
1.9 \\
1.2 \\
1.0 \\
.9 \\
.7 \\
.6 \\
.5\end{array}$ & $\begin{array}{l}11 \\
12 \\
13 \\
14 \\
15 \\
16 \\
17 \\
18 \\
19 \\
20\end{array}$ & $\begin{array}{l}0 \\
0 \\
0 \\
0 \\
0 \\
0 \\
0 \\
0 \\
0 \\
0\end{array}$ & $\begin{array}{r}70 \\
55 \\
9 \\
3.2 \\
1.5 \\
.9 \\
.6 \\
.5 \\
.4 \\
.3\end{array}$ & $\begin{array}{r}0.5 \\
.5 \\
.5 \\
47 \\
47 \\
12 \\
17 \\
11 \\
12 \\
19\end{array}$ & $\begin{array}{l}21 \\
22 \\
23 \\
24 \\
25 \\
26 \\
27 \\
28 \\
29 \\
30 \\
31\end{array}$ & $\begin{array}{l}0 \\
0 \\
0 \\
0 \\
0 \\
0 \\
0 \\
0 \\
0 \\
0\end{array}$ & $\begin{array}{r}0.3 \\
.3 \\
2.5 \\
1.7 \\
.8 \\
.5 \\
.5 \\
.4 \\
.3 \\
.3 \\
.3 \\
\end{array}$ & $\begin{array}{r}8 \\
5.5 \\
3.8 \\
2.9 \\
2.5 \\
2.3 \\
1.9 \\
17 \\
144 \\
22 \\
283 \\
\end{array}$ \\
\hline $\begin{array}{l}\text { Mean } \\
\text { Run- }\end{array}$ & $\begin{array}{l}\text { onthl } \\
f, \text { in }\end{array}$ & $13 \mathrm{cha}$ & in & and & $\theta \theta t$. & & & $\cdots$ & 0 & $\begin{array}{r}4.82 \\
296\end{array}$ & $\begin{array}{r}20.2 \\
1,240\end{array}$ \\
\hline
\end{tabular}

Gage helght, in feet, and discharge, in second-feet, at indicated time, 1937

\begin{tabular}{|c|c|c|c|c|c|c|c|c|c|c|c|c|}
\hline \multirow{2}{*}{$\begin{array}{l}5 \\
3 \\
0\end{array}$} & Feet & Sec.ft. & Feet & sec.ft. & Feot & sec.ft. & Feet & Sec.ft. & Feet & Sec.ft. & Feet & Sec.ft. \\
\hline & \multicolumn{2}{|c|}{ December 8} & \multicolumn{2}{|c|}{ December 9} & \multicolumn{2}{|c|}{ December 10} & \multicolumn{2}{|c|}{ December 11} & \multicolumn{2}{|c|}{ December 12} & \multicolumn{2}{|c|}{ December 13} \\
\hline $\begin{array}{r}2 \\
4 \\
6 \\
8 \\
10 \\
\mathrm{~N} \\
2 \\
4 \\
6 \\
8 \\
10 \\
M\end{array}$ & & & & & & & $\begin{array}{l}2.09 \\
2.14 \\
2.87 \\
3.96 \\
3.66 \\
3.30 \\
3.14 \\
3.08 \\
2.95 \\
2.83 \\
2.74 \\
2.66\end{array}$ & $\begin{array}{r}0.5 \\
1.0 \\
39 \\
260 \\
180 \\
103 \\
75 \\
66 \\
48 \\
34 \\
26 \\
21\end{array}$ & $\begin{array}{l}2.60 \\
2.58 \\
3.05 \\
3.74 \\
3.38 \\
3.12 \\
2.96 \\
2.85 \\
2.77 \\
2.70 \\
2.65 \\
2.59\end{array}$ & $\begin{array}{r}17 \\
16 \\
62 \\
200 \\
118 \\
72 \\
50 \\
36 \\
29 \\
23 \\
20 \\
16\end{array}$ & $\begin{array}{c}- \\
2.52 \\
- \\
2.47 \\
- \\
2.43 \\
- \\
2.39 \\
- \\
2.35 \\
- \\
2.33\end{array}$ & $\begin{array}{c}13 \\
\overline{11} \\
\overline{9} \\
\overline{7} \\
\overline{7} .5 \\
\overline{6} \\
\overline{5}\end{array}$ \\
\hline & \multicolumn{2}{|c|}{ December 14} & \multicolumn{2}{|c|}{ December 15} & \multicolumn{2}{|c|}{ December 16} & \multicolumn{2}{|c|}{ December 17} & \multicolumn{2}{|c|}{ December 18} & \multicolumn{2}{|c|}{ December 19} \\
\hline \multirow[t]{2}{*}{$\begin{array}{r}2 \\
4 \\
6 \\
8 \\
10 \\
\mathrm{~N} \\
2 \\
4 \\
6 \\
8 \\
10 \\
\mathrm{M} \\
\end{array}$} & $\begin{array}{c}\overline{2.30} \\
\overline{2.29} \\
\overline{2.27} \\
\overline{-} \\
\overline{2.25} \\
\overline{2.24} \\
\overline{2.22}\end{array}$ & $\begin{array}{c}4.1 \\
- \\
3.8 \\
3.2 \\
- \\
2.7 \\
2.5 \\
2.7\end{array}$ & $\begin{array}{c}- \\
- \\
2.20 \\
- \\
z .19 \\
- \\
- \\
2.18 \\
- \\
- \\
2.17\end{array}$ & $\begin{array}{c}- \\
\overline{1.7} \\
\overline{-} \\
1.5 \\
\overline{-} \\
1.4 \\
- \\
- \\
1.2\end{array}$ & $\begin{array}{c}- \\
\overline{2.16} \\
\overline{-} \\
2.14 \\
\overline{-} \\
2.13 \\
\overline{-} \\
2.12\end{array}$ & $\begin{array}{c}- \\
1.1 \\
- \\
.9 \\
- \\
- \\
-8 \\
- \\
.7\end{array}$ & $\begin{array}{c}\overline{-} \\
2.11 \\
\overline{-} \\
2.11 \\
\overline{-} \\
2.10 \\
\overline{-} \\
2.10\end{array}$ & $\begin{array}{l}- \\
0.6 \\
- \\
.6 \\
- \\
- \\
.5 \\
- \\
.5\end{array}$ & $\begin{array}{c}- \\
- \\
2.09 \\
- \\
- \\
2.09 \\
- \\
- \\
2.08 \\
- \\
2.08\end{array}$ & $\begin{array}{c}- \\
\overline{0.5} \\
\overline{-} \\
.5 \\
- \\
- \\
.4 \\
- \\
-4\end{array}$ & $\begin{array}{c}= \\
= \\
= \\
2.07 \\
= \\
= \\
= \\
2.06\end{array}$ & $\begin{array}{c}\overline{-} \\
- \\
\overline{-} \\
0.4 \\
\overline{-} \\
- \\
- \\
- \\
.3\end{array}$ \\
\hline & \multicolumn{2}{|c|}{ December 20} & \multicolumn{2}{|c|}{ December 21} & \multicolumn{2}{|c|}{ December 22} & \multicolumn{2}{|c|}{ December 23} & \multicolumn{2}{|c|}{ December 24} & \multicolumn{2}{|c|}{ December 25} \\
\hline $\begin{array}{r}2 \\
4 \\
6 \\
8 \\
10 \\
\mathrm{~N} \\
2 \\
4 \\
6 \\
8 \\
10 \\
M\end{array}$ & $\begin{array}{c}= \\
= \\
= \\
= \\
2.06 \\
= \\
= \\
= \\
2.05\end{array}$ & $\begin{array}{c}- \\
- \\
- \\
- \\
0.3 \\
- \\
- \\
- \\
- \\
.3\end{array}$ & $\begin{array}{c}- \\
- \\
- \\
- \\
2.05 \\
- \\
- \\
= \\
= \\
2.05\end{array}$ & $\begin{array}{l}- \\
- \\
- \\
- \\
0.3 \\
- \\
- \\
- \\
- \\
.3\end{array}$ & $\begin{array}{c}- \\
2.05 \\
- \\
2.05 \\
- \\
2.04 \\
\overline{2.04} \\
\overline{2.09} \\
\overline{2.10}\end{array}$ & $\begin{array}{c}0.3 \\
- \\
.3 \\
-3 \\
- \\
.3 \\
-.5 \\
-.5\end{array}$ & $\begin{array}{c}- \\
2.15 \\
- \\
2.22 \\
- \\
2.31 \\
- \\
2.30 \\
- \\
2.27 \\
- \\
2.25\end{array}$ & $\begin{array}{c}1.0 \\
- \\
2.1 \\
- \\
4.4 \\
\overline{4} .1 \\
--2 \\
3.7\end{array}$ & $\begin{array}{c}\overline{-} \\
2.22 \\
- \\
- \\
2.19 \\
- \\
\overline{2.17} \\
- \\
\overline{2.15}\end{array}$ & $\begin{array}{c}- \\
- \\
2.1 \\
- \\
- \\
1.5 \\
- \\
1.2 \\
- \\
1.0\end{array}$ & $\begin{array}{c}- \\
\overline{2.14} \\
\overline{-} \\
2.13 \\
- \\
\overline{2.12} \\
\overline{-} \\
\overline{2.11}\end{array}$ & $\begin{array}{c}- \\
- \\
0.9 \\
- \\
-8 \\
- \\
- \\
-7 \\
- \\
.6\end{array}$ \\
\hline
\end{tabular}

Supplemental recoras.- Dec. 11, $8: 15$ a.m., $4.05 \mathrm{ft.}, 288 \mathrm{sec.}-\mathrm{ft}$. 
Salt Springs Reservolr near West Point, Calif.

Location. - Lat. $38^{\circ} 30^{\prime}$, long. $120^{\circ} 12^{\prime}$, in SE sec. 33, T. 8 N., R. 16 E., at Salt Springs Dam on North Fork of Mokelume River 2 miles above Cold Credk and 18 miles northeast of West Point, Calaveras County. Zero ot gage is at mean sea level.

Drainage area.- 160 square miles.

Gage-height record.- Gage read to tenths daily at $3 \mathrm{p.m.} \mathrm{except} \mathrm{on} \mathrm{Dec.} \mathrm{1l,} \mathrm{when} \mathrm{it}$ was read at 1 p.m.

Remarks. - Flood run-off completely controlled in reservolr (capac1ty, 129,540 acrefeet at elevation of crest of splliway, 3,947 feet). Small amount of water released during flood period. See record for North Fork of Mokelumne River below Salt Springs Reservoir. Basic data furnished by Paciflc Gas \& Electric Co.

Elevation and contents, November 1937 to January 1938

\begin{tabular}{|c|c|c|c|c|c|c|}
\hline \multirow[b]{2}{*}{ Day } & \multicolumn{2}{|c|}{ November } & \multicolumn{2}{|c|}{ December } & \multicolumn{2}{|c|}{ January } \\
\hline & $\begin{array}{l}\text { Elevation } \\
\text { (feet) }\end{array}$ & $\begin{array}{l}\text { Contents } \\
\text { (acre-feet) }\end{array}$ & $\begin{array}{c}\text { Elevation } \\
\text { (feet) }\end{array}$ & $\begin{array}{l}\text { Contents } \\
(\text { acre-feet) }\end{array}$ & $\begin{array}{l}\text { Flevation } \\
\text { (feet) }\end{array}$ & $\begin{array}{l}\text { Contents } \\
\text { (acre-feet) }\end{array}$ \\
\hline $\begin{array}{l}1 \\
2 \\
3 \\
4 \\
5\end{array}$ & $\begin{array}{l}3,833.9 \\
3,832.2 \\
3,830.5 \\
3,828.9 \\
3,827.1\end{array}$ & $\begin{array}{l}43,347 \\
42,392 \\
41,448 \\
40,568 \\
39,590\end{array}$ & $\begin{array}{l}3,800.0 \\
3,798.6 \\
3,798.3 \\
3,797.6 \\
3,796.6\end{array}$ & $\begin{array}{l}26,119 \\
25,486 \\
25,351 \\
25,038 \\
24,592\end{array}$ & $\begin{array}{l}3,881.5 \\
3,880.7 \\
3,880.2 \\
3,879.1 \\
3,878.2\end{array}$ & $\begin{array}{l}74,672 \\
74,080 \\
73,710 \\
72,900 \\
72,241\end{array}$ \\
\hline $\begin{array}{r}6 \\
7 \\
8 \\
9 \\
10\end{array}$ & $\begin{array}{l}3,826.3 \\
3,825.6 \\
3,824.4 \\
3,823.0 \\
3,821.6\end{array}$ & $\begin{array}{l}39,158 \\
38,782 \\
38,141 \\
37,399 \\
36,663\end{array}$ & $\begin{array}{l}3,795.5 \\
3,794.5 \\
3,793.5 \\
3,792.5 \\
3,808.2\end{array}$ & $\begin{array}{l}24,106 \\
23,668 \\
23,233 \\
22,802 \\
29,948\end{array}$ & $\begin{array}{l}3,877.4 \\
3,876.4 \\
3,875.4 \\
3,874.4 \\
3,873.4\end{array}$ & $\begin{array}{l}71,657 \\
70,929 \\
70,204 \\
69,482 \\
68,763\end{array}$ \\
\hline $\begin{array}{l}11 \\
12 \\
13 \\
14 \\
15\end{array}$ & $\begin{array}{l}3,820.8 \\
3,819.6 \\
3,819.0 \\
3,818.4 \\
3,817.1\end{array}$ & $\begin{array}{l}36,245 \\
35,623 \\
35,313 \\
35,005 \\
34,340\end{array}$ & $\begin{array}{l}3,865.0 \\
3,883.8 \\
3,887.3 \\
3,888.5 \\
3,889.6\end{array}$ & $\begin{array}{l}62,849 \\
76,384 \\
79,020 \\
79,933 \\
80,772\end{array}$ & $\begin{array}{l}3,872.3 \\
3,871.2 \\
3,870.1 \\
3,869.5 \\
3,869.8\end{array}$ & $\begin{array}{l}67,976 \\
67,193 \\
66,413 \\
65,990 \\
66,201\end{array}$ \\
\hline $\begin{array}{l}16 \\
17 \\
18 \\
19 \\
20\end{array}$ & $\begin{array}{l}3,816.0 \\
3,814.9 \\
3,814.0 \\
3,813.3 \\
3,812.0\end{array}$ & $\begin{array}{l}33,783 \\
33,230 \\
32,780 \\
32,433 \\
31,791\end{array}$ & $\begin{array}{l}3,890.0 \\
3,890.2 \\
3,890.2 \\
3,890.2 \\
3,889.7\end{array}$ & $\begin{array}{l}81,078 \\
81,232 \\
81,232 \\
81,232 \\
80,849\end{array}$ & $\begin{array}{l}3,870.0 \\
3,870.1 \\
3,870.0 \\
3,869.8 \\
3,869.4\end{array}$ & $\begin{array}{l}66,342 \\
66,413 \\
66,342 \\
66,201 \\
65,919\end{array}$ \\
\hline $\begin{array}{l}21 \\
22 \\
23 \\
24 \\
25\end{array}$ & $\begin{array}{l}3,811.7 \\
3,810.6 \\
3,809.2 \\
3,807.5 \\
3,806.8\end{array}$ & $\begin{array}{l}31,644 \\
31,107 \\
30,429 \\
29,614 \\
29,280\end{array}$ & $\begin{array}{l}3,889.2 \\
3,888.6 \\
3,888.1 \\
3,887.4 \\
3,886.9\end{array}$ & $\begin{array}{l}89,466 \\
80,009 \\
79,628 \\
79,096 \\
78,717\end{array}$ & $\begin{array}{l}3,869.2 \\
3,869.1 \\
3,869.1 \\
3,868.9 \\
3,868.5\end{array}$ & $\begin{array}{l}65,778 \\
65,708 \\
65,708 \\
65,567 \\
65,286\end{array}$ \\
\hline $\begin{array}{l}26 \\
27 \\
28 \\
29 \\
30 \\
31\end{array}$ & $\begin{array}{l}3,806.0 \\
3,804.6 \\
3,803.6 \\
3,802.3 \\
3,801.2\end{array}$ & $\begin{array}{l}28,901 \\
28,243 \\
27,776 \\
27,173 \\
26,667\end{array}$ & $\begin{array}{l}3,886.3 \\
3,885.6 \\
3,884.7 \\
3,883.9 \\
3,883.0 \\
3,882.3\end{array}$ & $\begin{array}{l}78,264 \\
77,735 \\
77,059 \\
76,459 \\
75,787 \\
75,266\end{array}$ & $\begin{array}{l}3,868.0 \\
3,867.4 \\
3,867.0 \\
3,866.9 \\
3,867.0 \\
3,866.5\end{array}$ & $\begin{array}{l}64,935 \\
64,516 \\
64,237 \\
64,167 \\
64,237 \\
63,889\end{array}$ \\
\hline
\end{tabular}


North Fork of Mokelumme River below Salt Springs Dam, Callf.

Location.- Let. $38^{\circ} 29^{\prime}$, long. $120^{\circ} 13^{\prime}$, in Sitt sec. 33, T. 8 H., R. 16 E., $0.3 \mathrm{mile} \mathrm{be-}$ Iow Salt Springs Dam and 1.7 miles upstream from Cold Creek, Calaveras County. Altitude, about 3,600 feet above mean sea level.

Drainage area.- 160 square miles.

Gage-height record.- Vater-stage recorder graph.

Stage-discharge relation.- Defined by current-meter measurements below 3,300 secondfeet.

Maxima.- December 1937: Discharge regulated to maximum of 516 second-feet at times Dec. 23 and 24 (gage height, 2.85 feet). Maximum discharge adjusted for changes in storage, about 21,000 second-feet early morning Dec. 11 .

1926-37: Discharge (unregulated), 8,740 second-feet Mar. 25, 1928 (gage helght, 13.62 feet).

Remarks.- Flood mun-off completely regulated in Salt Springs Reservoir (capacity,

129,540 acre-feet). Daily discharge for December and all monthly summaries adjusted for storage and diversion as shown but not for possible storage in small reservolrs upstream. Gain or loss in storage computed from contents at midnight determined

from graph based on daily readings at 3 p.m. See record for Salt Springs Reservoir near West Point. Most of basic data furnished by Pacific Gas \& Blectric Co.

Storage, diversion, and discharge, December 1937

\begin{tabular}{|c|c|c|c|c|}
\hline Day & $\begin{array}{l}\text { Observed } \\
\text { discharge } \\
\text { (second-feet) }\end{array}$ & $\begin{array}{l}\text { Gain or loss } \\
\text { in storage } \\
\text { (acre-feet) }\end{array}$ & $\begin{array}{l}\text { Tiger Creek } \\
\text { Conduit diversion } \\
\text { (second-feet) }\end{array}$ & $\begin{array}{l}\text { Ad jus ted } \\
\text { discharge } \\
\text { (second-feet) }\end{array}$ \\
\hline $\begin{array}{l}1 \\
2 \\
3 \\
4 \\
5\end{array}$ & $\begin{array}{l}2.5 \\
2.5 \\
2.6 \\
2.6 \\
2.5\end{array}$ & $\begin{array}{l}-630 \\
-440 \\
-140 \\
-380 \\
-480\end{array}$ & $\begin{array}{l}297 \\
288 \\
178 \\
176 \\
177\end{array}$ & \}$* 20$ \\
\hline $\begin{array}{r}6 \\
7 \\
8 \\
9 \\
10\end{array}$ & $\begin{array}{l}2.5 \\
2.5 \\
2.3 \\
2.6 \\
8.5\end{array}$ & $\begin{array}{r}-450 \\
-460 \\
-430 \\
+230 \\
+21,200\end{array}$ & $\begin{array}{r}266 \\
245 \\
250 \\
247 \\
36\end{array}$ & $\begin{array}{r}35 \\
366 \\
10,700\end{array}$ \\
\hline $\begin{array}{l}11 \\
12 \\
13 \\
14 \\
15\end{array}$ & $\begin{array}{r}26 \\
15 \\
316 \\
360 \\
346\end{array}$ & $\begin{array}{r}+27,000 \\
+6,400 \\
+1,510 \\
+880 \\
+640\end{array}$ & $\begin{array}{l}3.8 \\
130 \\
183 \\
174 \\
178\end{array}$ & $\begin{array}{r}13,600 \\
3,370 \\
1,260 \\
978 \\
847\end{array}$ \\
\hline $\begin{array}{l}16 \\
17 \\
18 \\
19 \\
20\end{array}$ & $\begin{array}{l}401 \\
372 \\
425 \\
425 \\
230\end{array}$ & $\begin{array}{r}+230 \\
+70 \\
0 \\
-80 \\
-450\end{array}$ & $\begin{array}{c}90 \\
114 \\
5.5 \\
5 \\
259\end{array}$ & $\begin{array}{l}607 \\
521 \\
430 \\
390 \\
262\end{array}$ \\
\hline $\begin{array}{l}21 \\
22 \\
23 \\
24 \\
25\end{array}$ & $\begin{array}{l}220 \\
205 \\
318 \\
455 \\
410\end{array}$ & $\begin{array}{l}-410 \\
-430 \\
-410 \\
-520 \\
-380\end{array}$ & $\begin{array}{r}269 \\
281 \\
164 \\
40 \\
17\end{array}$ & $\begin{array}{l}282 \\
269 \\
275 \\
233 \\
235\end{array}$ \\
\hline $\begin{array}{l}26 \\
27 \\
28 \\
29 \\
30 \\
31\end{array}$ & $\begin{array}{l}410 \\
291 \\
313 \\
318 \\
267 \\
242\end{array}$ & $\begin{array}{l}-490 \\
-560 \\
-680 \\
-610 \\
-640 \\
-520\end{array}$ & $\begin{array}{r}17 \\
194 \\
195 \\
187 \\
249 \\
207\end{array}$ & $\begin{array}{l}180 \\
203 \\
165 \\
197 \\
193 \\
187\end{array}$ \\
\hline
\end{tabular}

Observed mean daily discharge, in second-feet, November 1937 to January 1938

\begin{tabular}{|c|c|c|c|c|c|c|c|c|c|c|c|}
\hline Day & Hov. & Dec. & Jan. & Day & Hov. & Dec. & Jan. & Day & Hov. & Dec. & Jan. \\
\hline $\begin{array}{r}1 \\
2 \\
3 \\
4 \\
5 \\
6 \\
7 \\
8 \\
9 \\
10\end{array}$ & $\begin{array}{l}4.1 \\
4.1 \\
4.0 \\
4.0 \\
3.8 \\
3.8 \\
3.6 \\
3.6 \\
3.6 \\
3.6\end{array}$ & $\begin{array}{l}2.5 \\
2.5 \\
2.6 \\
2.6 \\
2.5 \\
2.5 \\
2.5 \\
2.5 \\
2.6 \\
8.5\end{array}$ & $\begin{array}{r}374 \\
386 \\
124 \\
42 \\
32 \\
46 \\
126 \\
120 \\
120 \\
62\end{array}$ & $\begin{array}{l}11 \\
12 \\
13 \\
14 \\
15 \\
16 \\
17 \\
18 \\
19 \\
20\end{array}$ & $\begin{array}{l}3.6 \\
3.4 \\
3.2 \\
3.2 \\
3.1 \\
3.1 \\
3.4 \\
2.9 \\
2.7 \\
2.9\end{array}$ & $\begin{array}{r}26 \\
15 \\
316 \\
360 \\
346 \\
401 \\
372 \\
425 \\
425 \\
230\end{array}$ & $\begin{array}{l}33 \\
31 \\
11 \\
3.4 \\
6 \\
5 \\
5 \\
4.5 \\
4.3 \\
4.1\end{array}$ & $\begin{array}{l}21 \\
22 \\
23 \\
24 \\
25 \\
26 \\
27 \\
28 \\
29 \\
30 \\
31\end{array}$ & $\begin{array}{l}2.7 \\
2.7 \\
2.7 \\
2.7 \\
2.7 \\
2.7 \\
2.7 \\
2.6 \\
2.5 \\
2.5\end{array}$ & $\begin{array}{l}220 \\
205 \\
318 \\
455 \\
410 \\
410 \\
291 \\
313 \\
318 \\
267 \\
242\end{array}$ & $\begin{array}{c}4.0 \\
4.0 \\
4.1 \\
3.6 \\
17 \\
71 \\
105 \\
88 \\
102 \\
30 \\
27\end{array}$ \\
\hline $\begin{array}{l}\text { Mean } \\
\text { Gain } \\
\text { Mean } \\
\text { Mean } \\
\text { Run c }\end{array}$ & $\begin{array}{l}\text { month } \\
\text { or los } \\
\text { month } \\
\text { month. } \\
\text { if, ir }\end{array}$ & $\begin{array}{l}\text { in st } \\
\text { diver } \\
\text { disch } \\
\text { cre-f }\end{array}$ & $\begin{array}{l}\text { Tig } \\
\text { in } \\
\text { d }\end{array}$ & $\theta d$ & & in & & & $\begin{array}{r}3.21 \\
-17,290 \\
325 \\
37.3 \\
2,221\end{array}$ & $\begin{array}{r}206 \\
+48,570 \\
1,165 \\
1,162 \\
71,420\end{array}$ & $\begin{array}{r}64.4 \\
-11,190 \\
289 \\
172 \\
10,550\end{array}$ \\
\hline
\end{tabular}

* Mean for the period.

$1000020-39-13$ 
Mokelumne Rlver near Mokelumne Hill, Cal1f.

Location.- Lat. $38^{\circ} 18^{\prime} 40^{\prime \prime}$, long. $120^{\circ} 43^{\prime} 10^{\prime \prime}$, in sec. 1, T. 5 N., R. 11 E., at highway bridge 1.2 miles northwest of Mokelumne Hill, Calaveras County, and 8 miles below

junction of North and South Forks. Altitude, about 650 feet above mean sea level. Drainage area. - 538 square miles.

Gage-he1ght record. - Water-stage recorder graph.

Stage-discharge reiation.- Defined by current-meter measurements below 17,000 secondfeet. Shifing-control method used for period Nov. 1 to Dec. 10. Rating curve changed at peak stage.

Maxima.- December 1937: Discharge, 17,700 second-feet 11:20 a.m. Dec. 11 (gage hel ght, 15.25 feet).

1927-November 1937: Discharge, 23,300 second-feet Mar. 25, 1928 (gage height, 16.10 feet), from rating curve extended above 10,200 second-feet on bas is of areavelocity study.

Remarks. - Flood run-off affected by artificial storage in Salt Springs and other reservolis, and to a sifght extent by diversions.

Mean daily discharge, in second-feet, November 1937 to January 1938

\begin{tabular}{|c|c|c|c|c|c|c|c|c|c|c|c|}
\hline Day & Nov. & Dec. & Jan. & Day & Nov. & Dec. & Jan. & Day & Nov. & Dec. & Jan. \\
\hline $\begin{array}{r}1 \\
2 \\
3 \\
4 \\
5 \\
6 \\
7 \\
8 \\
9 \\
10\end{array}$ & $\begin{array}{l}278 \\
398 \\
507 \\
498 \\
462 \\
337 \\
154 \\
290 \\
370 \\
390\end{array}$ & $\begin{array}{r}367 \\
327 \\
305 \\
246 \\
130 \\
213 \\
270 \\
315 \\
297 \\
2,170\end{array}$ & $\begin{array}{l}597 \\
557 \\
760 \\
760 \\
732 \\
678 \\
634 \\
624 \\
547 \\
645\end{array}$ & $\begin{array}{l}11 \\
12 \\
13 \\
14 \\
15 \\
16 \\
17 \\
18 \\
19 \\
20\end{array}$ & $\begin{array}{l}386 \\
334 \\
203 \\
181 \\
297 \\
444 \\
531 \\
507 \\
394 \\
406\end{array}$ & $\begin{array}{r}11,200 \\
2,770 \\
1,400 \\
1,130 \\
1,060 \\
1,030 \\
842 \\
815 \\
705 \\
732\end{array}$ & $\begin{array}{l}639 \\
645 \\
645 \\
517 \\
639 \\
430 \\
617 \\
613 \\
645 \\
624\end{array}$ & $\begin{array}{l}21 \\
22 \\
23 \\
24 \\
25 \\
26 \\
27 \\
28 \\
29 \\
30 \\
31\end{array}$ & $\begin{array}{l}326 \\
398 \\
540 \\
570 \\
402 \\
272 \\
398 \\
326 \\
355 \\
392\end{array}$ & $\begin{array}{l}732 \\
760 \\
788 \\
732 \\
672 \\
613 \\
639 \\
694 \\
683 \\
661 \\
694 \\
\end{array}$ & $\begin{array}{l}557 \\
537 \\
405 \\
492 \\
470 \\
547 \\
645 \\
678 \\
678 \\
547 \\
787 \\
\end{array}$ \\
\hline $\begin{array}{l}\text { ean } \\
\text { un- }\end{array}$ & 11 & & 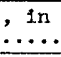 & & & & & & $\begin{array}{r}378 \\
22,500 \\
\end{array}$ & $\begin{array}{r}1,097 \\
67,420\end{array}$ & $\begin{array}{r}609 \\
37,470 \\
\end{array}$ \\
\hline
\end{tabular}

Gage height, in feet, and discharge, in second-feet, at indicated time, 1937

\begin{tabular}{|c|c|c|c|c|c|c|c|c|c|c|c|c|}
\hline \multirow{2}{*}{ 岇 } & Feet & Sec.ft. & Feet & Sec.ft. & Feet & sec.ft. & Feet & sec.ft. & Feet & Sec.ft. & Feet & sec.ft. \\
\hline & \multicolumn{2}{|c|}{ December 8} & \multicolumn{2}{|c|}{ December 9} & \multicolumn{2}{|c|}{ December 10} & \multicolumn{2}{|c|}{ December 11} & \multicolumn{2}{|c|}{ December 12} & \multicolumn{2}{|c|}{ December 13} \\
\hline \multirow[t]{2}{*}{$\begin{array}{r}2 \\
4 \\
6 \\
8 \\
10 \\
\mathbf{N} \\
2 \\
4 \\
6 \\
8 \\
10 \\
\mathrm{M} \\
\end{array}$} & & & $\begin{array}{l}\bar{z} \\
= \\
\bar{z} \\
\bar{z} \\
\bar{z} \\
\bar{z} \\
\overline{2}\end{array}$ & $\begin{array}{c}\overline{-} \\
\overline{-} \\
\overline{-} \\
\bar{z} \\
\overline{-} \\
\overline{-} \\
\overline{220}\end{array}$ & $\begin{array}{l}2.30 \\
2.44 \\
2.59 \\
3.15 \\
3.45 \\
7.46 \\
7.98 \\
7.30 \\
5.80 \\
5.30 \\
5.70 \\
5.82\end{array}$ & $\begin{array}{r}234 \\
278 \\
330 \\
570 \\
731 \\
4,720 \\
5,450 \\
4,500 \\
2,600 \\
2,070 \\
2,490 \\
2,620\end{array}$ & $\begin{array}{r}5.78 \\
6.08 \\
10.51 \\
13.97 \\
14.45 \\
14.80 \\
14.54 \\
13.97 \\
12.75 \\
11.46 \\
9.73 \\
8.11\end{array}$ & $\begin{array}{r}2,580 \\
2,920 \\
9,400 \\
15,400 \\
16,300 \\
17,000 \\
16,500 \\
15,500 \\
13,400 \\
11,300 \\
8,600 \\
6,160\end{array}$ & $\begin{array}{l}7.49 \\
6.74 \\
6.20 \\
5.73 \\
5.58 \\
5.44 \\
4.86 \\
4.40 \\
4.60 \\
4.46 \\
4.44 \\
4.20\end{array}$ & $\begin{array}{l}5,250 \\
4,200 \\
3,480 \\
2,890 \\
2,710 \\
2,550 \\
1,950 \\
1,520 \\
1,700 \\
1,570 \\
1,560 \\
1,360\end{array}$ & & \\
\hline & \multicolumn{2}{|c|}{ Decomber 14} & \multicolumn{2}{|c|}{ December 15} & \multicolumn{2}{|c|}{ De cember 16} & \multicolumn{2}{|c|}{ December 17} & \multicolumn{2}{|c|}{ December 18} & \multicolumn{2}{|c|}{ December 19} \\
\hline \multirow[t]{2}{*}{\begin{tabular}{r|}
2 \\
4 \\
6 \\
8 \\
10 \\
$\mathrm{~N}$ \\
2 \\
4 \\
6 \\
8 \\
10 \\
$\mathrm{M}$
\end{tabular}} & & & & & & & & & & & & \\
\hline & \multicolumn{2}{|c|}{ December 20} & \multicolumn{2}{|c|}{ December 21} & \multicolumn{2}{|c|}{ December 22} & \multicolumn{2}{|c|}{ December 23} & \multicolumn{2}{|c|}{ December 24} & \multicolumn{2}{|c|}{ December 25} \\
\hline $\begin{array}{r}2 \\
4 \\
6 \\
8 \\
10 \\
\mathrm{~N} \\
2 \\
4 \\
6 \\
8 \\
10 \\
M\end{array}$ & & & & & & & & & & & & \\
\hline
\end{tabular}

Supplemental records.- Dec. 10, 11 a.m., $7.10 \mathrm{ft.,} 4,220 \mathrm{sec.-ft.;} \mathrm{1} \mathrm{p.m.,} 7.53 \mathrm{ft.}$ 4,820 sec.-ft.; 7 p.m., $5.10 \mathrm{ft.}, 1,890 \mathrm{sec.-ft.;} 11$ p.m., 6.02 ft., 2,840 sec.-ft. Dec. 11,5 a.m., $8.00 \mathrm{ft}, 5,480$ sec.-ft.; 7 a.m., $15.20 \mathrm{ft}, 14,100$ sec. $-\mathrm{ft}$ : 11.20 a.m., 15.25 ft., 17,700 sec.-ft. Dec. 12, 1 p.m., 5.35 ft., 2, 450 sec.-ft.; 3 p.m.

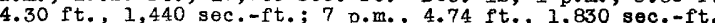


Mokelume River at Lancha Plana, Galif.

cation.- Lat. $38^{\circ} 13^{\prime} 25^{\prime \prime}$, long. $120^{\circ} 53^{\prime} 20^{\prime \prime}$, in swo sec. 4, T. 4 N., R. $10 \mathrm{E}$., I mile east of Lancha Plana, Calaveras County, 3 miles downstream from Pardee Dam, and 5 miles above Camanche Creek. Zero of gage is 158.95 feet above mean sea level, from bench mark of East Bay Munic1pal Utility District.

alnage area.- 584 square miles.

ige-height record. - Water-stage recorder graph at both gaging stations and at Pardee Dam.

jage-discharge relation. - Defined by current-meter measurements for entire range of stage. Shifting-control method used for period Dec. 1-29. Diversion measured by Venturi meter.

Ixima.- December 1937: Discharge (regulated), 2,150 second-feet 7:30 a.m. Dec. 14 (gage helght, 5.54 feet).

1926-November 1937: Discharge (unregulated), 27,300 second-feet Mar. 25, 1928 (gage height, 19.65 feet), from rating curve extended above 15,500 second-feet on basis of area-velocity study.

marks. - Observed discharge is that passing river gaging station. Diversion is flow Into East Bay Munic1pal Utility District Aqueduct at Pardee Dam. Adjusted discharge is obtained by combining observed discharge, change in storage at Pardee Reservoir computed from readings at midnight, and diversion. Salt Springs and several smaller reservolrs, four hydroelectric plants, and diversions above station.

Storage, diversion, and discharge, December 1937

\begin{tabular}{|c|c|c|c|c|c|c|}
\hline \multirow[b]{2}{*}{ Day } & \multicolumn{3}{|c|}{ Pardee Reservoir } & \multirow{2}{*}{$\begin{array}{l}\text { Aqueduct } \\
\text { diversion } \\
\text { (sec.-ft.) }\end{array}$} & \multicolumn{2}{|c|}{ D1scharge } \\
\hline & $\begin{array}{c}\text { Elevation } \\
\text { (feet) }\end{array}$ & $\begin{array}{l}\text { Contents } \\
(\text { acre-feet) }\end{array}$ & $\begin{array}{l}\text { Gain or loss } \\
\text { in storage } \\
\text { (acre-feet) }\end{array}$ & & $\begin{array}{l}\text { Observed } \\
(\text { sec.-ft. })\end{array}$ & $\begin{array}{l}\text { Adjusted } \\
\text { (sec.-ft.) }\end{array}$ \\
\hline $\begin{array}{l}1 \\
2 \\
3 \\
4 \\
5\end{array}$ & $\begin{array}{l}546.35 \\
546.01 \\
545.65 \\
545.25 \\
544.78\end{array}$ & $\begin{array}{l}165,640 \\
164,991 \\
164,310 \\
163,552 \\
162,666\end{array}$ & $\begin{array}{l}-572 \\
-649 \\
-681 \\
-758 \\
-886\end{array}$ & $\begin{array}{l}62 \\
62 \\
62 \\
62 \\
62\end{array}$ & $\begin{array}{l}578 \\
569 \\
569 \\
560 \\
457\end{array}$ & $\begin{array}{r}352 \\
304 \\
288 \\
240 \\
72\end{array}$ \\
\hline $\begin{array}{r}6 \\
7 \\
8 \\
9 \\
10\end{array}$ & $\begin{array}{l}544.31 \\
543.98 \\
543.63 \\
543.31 \\
545.05\end{array}$ & $\begin{array}{l}161,783 \\
161,164 \\
160,512 \\
159,916 \\
163,174\end{array}$ & $\begin{array}{r}-883 \\
-619 \\
-652 \\
-596 \\
+3,258\end{array}$ & $\begin{array}{l}62 \\
62 \\
62 \\
62 \\
61\end{array}$ & $\begin{array}{l}574 \\
565 \\
547 \\
556 \\
574\end{array}$ & $\begin{array}{r}191 \\
315 \\
280 \\
318 \\
2,280\end{array}$ \\
\hline $\begin{array}{l}11 \\
12 \\
13 \\
14 \\
15\end{array}$ & $\begin{array}{l}556.47 \\
557.24 \\
556.53 \\
555.54 \\
554.44\end{array}$ & $\begin{array}{l}185,746 \\
187,346 \\
185,870 \\
183,826 \\
181,574\end{array}$ & $\begin{array}{r}+22,572 \\
+1,600 \\
-1,476 \\
-2,044 \\
-2,252\end{array}$ & $\begin{array}{l}63 \\
64 \\
64 \\
64 \\
64\end{array}$ & $\begin{array}{r}705 \\
2,000 \\
2,110 \\
2,110 \\
2,110\end{array}$ & $\begin{array}{r}12,100 \\
2,870 \\
1,430 \\
1,140 \\
1,040\end{array}$ \\
\hline $\begin{array}{l}16 \\
17 \\
18 \\
19 \\
20\end{array}$ & $\begin{array}{l}554.27 \\
554.41 \\
554.50 \\
554.48 \\
554.48\end{array}$ & $\begin{array}{l}181,227 \\
181,513 \\
181,696 \\
181,656 \\
181,656\end{array}$ & $\begin{array}{r}-347 \\
+286 \\
+183 \\
-40 \\
0\end{array}$ & $\begin{array}{l}64 \\
64 \\
63 \\
64 \\
63\end{array}$ & $\begin{array}{r}1,210 \\
641 \\
661 \\
656 \\
646\end{array}$ & $\begin{array}{r}1,100 \\
849 \\
816 \\
700 \\
709\end{array}$ \\
\hline $\begin{array}{l}21 \\
22 \\
23 \\
24 \\
25\end{array}$ & $\begin{array}{l}554.48 \\
554.57 \\
554.65 \\
554.65 \\
554.60\end{array}$ & $\begin{array}{l}181,656 \\
181,839 \\
182,002 \\
182,002 \\
181,900\end{array}$ & $\begin{array}{r}0 \\
+183 \\
+163 \\
0 \\
-102\end{array}$ & $\begin{array}{l}63 \\
63 \\
64 \\
63 \\
63\end{array}$ & $\begin{array}{l}636 \\
631 \\
631 \\
641 \\
636\end{array}$ & $\begin{array}{l}699 \\
786 \\
777 \\
704 \\
648\end{array}$ \\
\hline $\begin{array}{l}26 \\
27 \\
28 \\
29 \\
30 \\
31\end{array}$ & $\begin{array}{l}554.50 \\
554.43 \\
554.39 \\
554.37 \\
554.33 \\
554.32\end{array}$ & $\begin{array}{l}181,696 \\
181,554 \\
181,472 \\
181,431 \\
181,350 \\
181,329\end{array}$ & $\begin{array}{r}-204 \\
-142 \\
-82 \\
-41 \\
-81 \\
-21\end{array}$ & $\begin{array}{l}64 \\
64 \\
64 \\
64 \\
63 \\
63\end{array}$ & $\begin{array}{l}641 \\
641 \\
646 \\
641 \\
641 \\
641\end{array}$ & $\begin{array}{l}602 \\
633 \\
669 \\
684 \\
663 \\
693\end{array}$ \\
\hline
\end{tabular}

Observed mean da11y discharge, in second-feet, November 1937 to January 1938

\begin{tabular}{r|r|c|c||c|c|c|c||r|r|r|r|}
\hline Jay & Nov. & Dec. & Jan. & Day & Nov. & Dec. & Jan. & Day & Nov. & Dec. & Jan. \\
\hline 1 & 583 & 578 & 641 & 11 & 487 & 705 & 641 & 21 & 464 & 636 & 631 \\
2 & 565 & 569 & 646 & 12 & 574 & 2,000 & 641 & 22 & 592 & 631 & 646 \\
3 & 560 & 569 & 641 & 13 & 583 & 2,110 & 641 & 23 & 602 & 631 & 641 \\
4 & 560 & 560 & 646 & 14 & 468 & 2,110 & 641 & 24 & 569 & 641 & 646 \\
5 & 565 & 457 & 646 & 15 & 578 & 2,110 & 651 & 25 & 569 & 636 & 646 \\
6 & 543 & 574 & 641 & 16 & 592 & 1,210 & 641 & 26 & 556 & 641 & 646 \\
7 & 464 & 565 & 641 & 17 & 597 & 641 & 646 & 27 & 560 & 641 & 646 \\
8 & 574 & 547 & 641 & 18 & 592 & 661 & 641 & 28 & 464 & 646 & 651 \\
9 & 574 & 556 & 641 & 19 & 588 & 656 & 646 & 29 & 551 & 641 & 661 \\
10 & 592 & 574 & 641 & 20 & 565 & 646 & 646 & 30 & 574 & 641 & 646 \\
&
\end{tabular}


Mokelume River near Clements, Calif.

Location. - Lat. $38^{\circ} 12^{\prime} 25^{n}$, long. $121^{\circ} 05120^{n}$, in $1 w \frac{1}{6}$ sec. 15, T. 4 N., R. 8 F., 700 fer above highway bridge, i mile north of Clements, San Josquin County, and 3 miles be Iow Murphy Creek. Aititude, about 80 feet above mean sea level.

Drainage area. - 630 square miles.

Gage-he1ght record. - Water-stage recorder graph.

Stage-discharge relation.- Defined by current-meter measurements.

Taxima.- December 1937: Discharge, 2,240 second-feet 2 p.m. Dec. 12 (gage height, 6.82 feet).

1904-November 1937: Discharge (not meterially regulated), 25,600 second-feet Mar. 25, 1928 (gage height, 22.45 feet, at station below bridge), from rating curve extended above 4,600 second-feet; verifled by comparison of peak discharge and total run-off of flood with record for Mokelume River at Iancha Plana.

Remerks.- Flood run-off largely controlled by artificlal storage in Pardee, Salt Springs, and other reservolrs, and affected by diversion into Bast Bay Municipal otility District Aqueduct.

Mean daliy discharge, in second-feet, November 1937 to January 1938

\begin{tabular}{|c|c|c|c|c|c|c|c|c|c|c|c}
\hline Day & Nov. & Dec. & Jan. & Day & Nov. & Dec. & Jan. & Day & Nov. & Dec. & Jan. \\
\hline 1 & 555 & 572 & 642 & 11 & 500 & 820 & 642 & 21 & 492 & 637 & 637 \\
2 & 551 & 589 & 659 & 12 & 567 & 1,920 & 637 & 22 & 538 & 642 & 642 \\
3 & 545 & 576 & 650 & 13 & 576 & 2,180 & 637 & 23 & 602 & 646 & 637 \\
4 & 545 & 580 & 646 & 14 & 504 & 2,220 & 637 & 24 & 602 & 646 & 642 \\
5 & 555 & 480 & 642 & 15 & 530 & 2,200 & 715 & 25 & 551 & 642 & 646 \\
6 & 559 & 538 & 642 & 16 & 593 & 1,570 & 655 & 26 & 567 & 637 & 646 \\
7 & 472 & 567 & 642 & 17 & 602 & 650 & 682 & 27 & 555 & 642 & 646 \\
8 & 525 & 572 & 642 & 18 & 593 & 642 & 664 & 28 & 484 & 646 & 677 \\
9 & 563 & 572 & 642 & 19 & 593 & 642 & 664 & 29 & 525 & 637 & 715 \\
10 & 589 & 606 & 642 & 20 & 576 & 642 & 616 & 30 & 567 & 637 & 664 \\
\end{tabular}

Gage height, in feet, and dscharge, in second-feet, at indicated time, 1937

\begin{tabular}{|c|c|c|c|c|c|c|c|c|c|c|c|c|}
\hline \multirow{2}{*}{$\begin{array}{l}5 \\
0 \\
0\end{array}$} & Feet & Sec.ft. & Feet & Sec.ft. & Poet & sec.et. & Foet & sec.ft. & Feet & Sec.ft. & Foet & Sec.ft \\
\hline & \multicolumn{2}{|c|}{ December 8} & \multicolumn{2}{|c|}{ December 9} & \multicolumn{2}{|c|}{ Decomber 10} & \multicolumn{2}{|c|}{ December 11} & \multicolumn{2}{|c|}{ December 12} & \multicolumn{2}{|c|}{ December 13} \\
\hline \multirow[t]{2}{*}{\begin{tabular}{r|}
2 \\
4 \\
6 \\
8 \\
10 \\
1 \\
2 \\
4 \\
6 \\
8 \\
10 \\
1
\end{tabular}} & $\begin{array}{l}3.99 \\
3.72 \\
3.54 \\
3.52 \\
3.51 \\
3.50 \\
3.63 \\
3.95 \\
3.99 \\
4.00 \\
4.01 \\
4.02\end{array}$ & $\begin{array}{l}664 \\
546 \\
472 \\
464 \\
460 \\
456 \\
509 \\
646 \\
664 \\
668 \\
673 \\
677 \\
\end{array}$ & $\begin{array}{l}3.80 \\
3.57 \\
3.52 \\
3.51 \\
3.51 \\
3.50 \\
3.72 \\
4.00 \\
4.05 \\
4.06 \\
4.05 \\
4.07\end{array}$ & $\begin{array}{l}580 \\
484 \\
464 \\
460 \\
460 \\
456 \\
546 \\
668 \\
692 \\
696 \\
692 \\
701\end{array}$ & $\begin{array}{l}4.04 \\
3.76 \\
3.66 \\
3.65 \\
3.64 \\
3.60 \\
3.75 \\
4.00 \\
4.04 \\
4.05 \\
4.07 \\
4.10\end{array}$ & $\begin{array}{l}687 \\
563 \\
521 \\
517 \\
513 \\
496 \\
559 \\
668 \\
687 \\
692 \\
701 \\
715\end{array}$ & $\begin{array}{l}4.15 \\
4.10 \\
4.19 \\
4.67 \\
4.58 \\
4.38 \\
4.34 \\
4.24 \\
4.17 \\
4.12 \\
4.35 \\
4.89\end{array}$ & \begin{tabular}{|r|}
738 \\
715 \\
757 \\
998 \\
950 \\
850 \\
830 \\
781 \\
748 \\
724 \\
835 \\
1,120 \\
\end{tabular} & $\begin{array}{l}5.05 \\
5.35 \\
5.78 \\
6.00 \\
6.42 \\
6.78 \\
6.82 \\
6.80 \\
6.78 \\
6.77 \\
6.77 \\
6.76\end{array}$ & $\begin{array}{l}1,210 \\
1,370 \\
1,610 \\
1,740 \\
1,990 \\
2,220 \\
2,240 \\
2,230 \\
2,220 \\
2,210 \\
2,210 \\
2,200\end{array}$ & $\begin{array}{l}6.75 \\
6.75 \\
6.75 \\
6.75 \\
6.75 \\
6.72 \\
6.64 \\
6.69 \\
6.70 \\
6.70 \\
6.71 \\
6.73\end{array}$ & $\begin{array}{l}2,200 \\
2,200 \\
2,200 \\
2,200 \\
2,200 \\
2,180 \\
2,130 \\
2,160 \\
2,160 \\
2,160 \\
2,170 \\
2,180\end{array}$ \\
\hline & \multicolumn{2}{|c|}{ December 14} & \multicolumn{2}{|c|}{ December 15} & \multicolumn{2}{|c|}{ December 16} & \multicolumn{2}{|c|}{ December 17} & \multicolumn{2}{|c|}{ December 18} & \multicolumn{2}{|c|}{ December 19} \\
\hline \multirow[t]{2}{*}{\begin{tabular}{r|}
2 \\
4 \\
6 \\
8 \\
10 \\
1 \\
2 \\
4 \\
6 \\
8 \\
10 \\
4 \\
\end{tabular}} & $\begin{array}{l}6.78 \\
6.78 \\
6.78 \\
6.78 \\
6.79 \\
6.79 \\
6.75 \\
6.73 \\
6.75 \\
6.77 \\
6.78 \\
6.76\end{array}$ & $\begin{array}{l}2,220 \\
2,220 \\
2,220 \\
2,220 \\
2,220 \\
2,220 \\
2,200 \\
2,180 \\
2,200 \\
2,210 \\
2,210 \\
2,200\end{array}$ & $\begin{array}{l}6.77 \\
6.78 \\
6.78 \\
6.78 \\
6.78 \\
6.78 \\
6.75 \\
6.73 \\
6.73 \\
6.73 \\
6.73 \\
6.72\end{array}$ & $\begin{array}{l}2,210 \\
2,220 \\
2,220 \\
2,220 \\
2,220 \\
2,220 \\
2,200 \\
2,180 \\
2,180 \\
2,180 \\
2,180 \\
2,180\end{array}$ & $\begin{array}{l}6.76 \\
6.77 \\
6.78 \\
6.78 \\
6.78 \\
6.76 \\
5.48 \\
4.30 \\
4.09 \\
4.04 \\
4.01 \\
3.99\end{array}$ & $\begin{array}{r}2,200 \\
2,210 \\
2,220 \\
2,220 \\
2,220 \\
2,200 \\
1,440 \\
810 \\
710 \\
687 \\
673 \\
664\end{array}$ & & 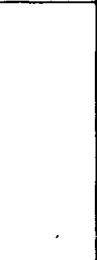 & & & & \\
\hline & \multicolumn{2}{|c|}{ December 20} & \multicolumn{2}{|c|}{ December 21} & \multicolumn{2}{|c|}{ December 22} & \multicolumn{2}{|c|}{ December 23} & \multicolumn{2}{|c|}{ December 24} & \multicolumn{2}{|c|}{ December 25} \\
\hline $\begin{array}{r}2 \\
4 \\
6 \\
8 \\
10 \\
N \\
2 \\
4 \\
6 \\
8 \\
10 \\
1\end{array}$ & & & & & & & & & & & & \\
\hline
\end{tabular}


Mokelume Rlver at Woodbridge, Callf.

Location. - Lat. $38^{\circ} 09^{\prime} 30^{n}$, long. $121^{\circ} 18^{\prime} 10^{n}$, In $\mathrm{NB}_{4}^{3} \mathrm{sec}_{3} 34$, T. 4 N., R. $6 \mathrm{E}$, threeefghths of a mile downstream from dam of Woodbridge Irrigation District at Wocdbrldge, San Joaquin County. Alt1tude, about 30 feot above mean sea level. Dralnage area. - 644 square miles.

Gage-helght record. - Water-stage recorder graph except for perlod 5 p.m. Dec. 31 to $10: 30 \mathrm{a.m}$. Jan. 3, when stage graph was based on range of stage indicated on recorder graph and comparison ith graph of Mokelume River near Clements.

Stage-discharge relation. - Defined by current-meter measurements below 2,000 secondfeet. Shifting-control method used for period Nov. 1 to Jan. 2 .

Maxima.- December 1937: Discharge, 2,010 second-feet 6 p.m. Dec. 16 (gage height, 14. 39 feet).

1924-November 1937: Maximum gage he1ght, 26.58 feot Mar. 26, 1928, former s1te and datum; about 30.6 feet, present datum (a1scharge not determíned).

Remarks.- Flood mun-off almost completely controlled by artificial storage in several reservolrs, Hany diverslons.

Nean dally discharge, in second-feet, November 1937 to January 1938

\begin{tabular}{|c|c|c|c||c|c|c|c|c|c|c|c|}
\hline Day & Nov. & Dec. & Jan. & Day & Nov. & Dec. & Jan. & Day & Nev. & Dec. & Jan. \\
\hline 1 & 401 & 591 & 666 & 11 & 493 & 691 & 660 & 21 & 593 & 700 & 641 \\
2 & 491 & 590 & 673 & 12 & 439 & 1,040 & 658 & 22 & 480 & 683 & 654 \\
3 & 485 & 584 & 675 & 13 & 906 & 1,700 & 658 & 23 & 601 & 683 & 660 \\
4 & 471 & 595 & 669 & 14 & 626 & 1,840 & 656 & 24 & 612 & 679 & 656 \\
5 & 471 & 578 & 666 & 15 & 507 & 1,930 & 684 & 25 & 588 & 675 & 656 \\
6 & 458 & 487 & 666 & 16 & 595 & 1,970 & 690 & 26 & 595 & 671 & 656 \\
7 & 448 & 572 & 664 & 17 & 633 & 1,160 & 679 & 27 & 563 & 664 & 654 \\
8 & 368 & 586 & 664 & 18 & 628 & 795 & 681 & 28 & 563 & 669 & 660 \\
9 & 428 & 584 & 662 & 19 & 622 & 743 & 675 & 29 & 485 & 671 & 698 \\
10 & 458 & 614 & 660 & 20 & 608 & 721 & 671 & 30 & 561 & 664 & 688 \\
\multicolumn{7}{|c|}{} \\
\hline
\end{tabular}

Gage holght, in feot, and discharge, in second-feet, at indicated time, 1937

\begin{tabular}{|c|c|c|c|c|c|c|c|c|c|c|c|c|}
\hline \multirow{2}{*}{ 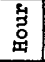 } & Foet & sec.ft. & Feot & Sec.ft. & Feot & Sec.ft. & Feot & Sec.ft. & Feot & Sec.ft. & Foet & Sec.ft. \\
\hline & \multicolumn{2}{|c|}{ December 8} & \multicolumn{2}{|c|}{ December 9} & \multicolumn{2}{|c|}{ December 10} & \multicolumn{2}{|c|}{ December 11} & \multicolumn{2}{|c|}{ December 12} & \multicolumn{2}{|c|}{ December 13} \\
\hline \begin{tabular}{r|}
2 \\
4 \\
6 \\
8 \\
10 \\
$\mathrm{~N}$ \\
2 \\
4 \\
6 \\
8 \\
10 \\
$\mathrm{M}$ \\
\end{tabular} & $\begin{array}{l}8.83 \\
8.98 \\
9.11 \\
9.20 \\
9.24 \\
9.24 \\
9.15 \\
9.01 \\
8.86 \\
8.76 \\
8.68 \\
8.69\end{array}$ & $\begin{array}{l}557 \\
586 \\
610 \\
628 \\
635 \\
635 \\
618 \\
591 \\
563 \\
545 \\
530 \\
532 \\
\end{array}$ & $\begin{array}{l}8.82 \\
8.98 \\
9.12 \\
9.22 \\
9.25 \\
9.22 \\
9.10 \\
8.94 \\
8.81 \\
8.71 \\
8.68 \\
8.73\end{array}$ & $\begin{array}{l}556 \\
586 \\
612 \\
631 \\
637 \\
631 \\
608 \\
578 \\
554 \\
536 \\
530 \\
539 \\
\end{array}$ & $\begin{array}{l}8.87 \\
9.09 \\
9.26 \\
9.36 \\
9.40 \\
9.38 \\
9.32 \\
9.20 \\
9.06 \\
8.93 \\
8.87 \\
8.88\end{array}$ & $\begin{array}{l}565 \\
607 \\
639 \\
658 \\
666 \\
662 \\
650 \\
628 \\
601 \\
576 \\
565 \\
567 \\
\end{array}$ & $\begin{array}{r}8.99 \\
9.19 \\
9.33 \\
9.45 \\
9.51 \\
9.55 \\
9.58 \\
9.67 \\
9.81 \\
9.97 \\
10.02 \\
10.01 \\
\end{array}$ & $\begin{array}{l}582 \\
620 \\
646 \\
669 \\
681 \\
688 \\
694 \\
711 \\
741 \\
7777 \\
788 \\
786\end{array}$ & $\begin{array}{r}9.95 \\
9.93 \\
9.87 \\
9.94 \\
10.22 \\
10.73 \\
11.18 \\
11.66 \\
12.11 \\
12.48 \\
12.79 \\
13.01 \\
\end{array}$ & \begin{tabular}{|r|}
761 \\
756 \\
743 \\
758 \\
824 \\
952 \\
1,070 \\
1,200 \\
1,320 \\
1,430 \\
1,520 \\
1,580 \\
\end{tabular} & $\begin{array}{l}13.19 \\
13.28 \\
13.35 \\
13.40 \\
13.43 \\
13.47 \\
13.50 \\
13.52 \\
13.55 \\
13.58 \\
13.62 \\
13.66\end{array}$ & $\begin{array}{l}1,620 \\
1,650 \\
1,670 \\
1,690 \\
1,700 \\
1,710 \\
1,720 \\
1,720 \\
1,730 \\
1,740 \\
1,750 \\
1,770\end{array}$ \\
\hline & \multicolumn{2}{|c|}{ December 14} & \multicolumn{2}{|c|}{ December 15} & \multicolumn{2}{|c|}{ December 16} & \multicolumn{2}{|c|}{ December 17} & \multicolumn{2}{|c|}{ December 18} & \multicolumn{2}{|c|}{ December 19} \\
\hline \multirow[t]{2}{*}{$\begin{array}{r}2 \\
4 \\
6 \\
8 \\
10 \\
\mathbf{1} \\
2 \\
4 \\
6 \\
8 \\
10 \\
\mathrm{M} \\
\end{array}$} & & & $\begin{array}{l}= \\
= \\
= \\
= \\
= \\
= \\
14.25\end{array}$ & $\begin{array}{l}= \\
= \\
= \\
= \\
= \\
= \\
1,950\end{array}$ & $\begin{array}{l}14.26 \\
14.27 \\
14.28 \\
14.29 \\
14.31 \\
14.33 \\
14.35 \\
14.37 \\
14.39 \\
14.37 \\
14.25 \\
13.90\end{array}$ & $\begin{array}{l}1,970 \\
1,970 \\
1,970 \\
1,980 \\
1,980 \\
1,990 \\
2,000 \\
2,000 \\
2,010 \\
2,000 \\
1,960 \\
1,850\end{array}$ & $\begin{array}{l}13.40 \\
12.76 \\
12.21 \\
11.72 \\
11.37 \\
11.12 \\
10.94 \\
10.79 \\
10.67 \\
10.58 \\
10.51 \\
10.46\end{array}$ & $\begin{array}{r}1,690 \\
1,500 \\
1,340 \\
1,210 \\
1,110 \\
1,040 \\
996 \\
957 \\
926 \\
903 \\
885 \\
872\end{array}$ & $\begin{array}{l}10.37 \\
10.32 \\
10.27 \\
10.22 \\
10.18 \\
10.15 \\
10.13 \\
10.10 \\
10.07 \\
10.05 \\
10.02 \\
10.00\end{array}$ & \begin{tabular}{|l}
840 \\
828 \\
816 \\
804 \\
795 \\
788 \\
784 \\
777 \\
770 \\
765 \\
758 \\
754 \\
\end{tabular} & & \\
\hline & \multicolumn{2}{|c|}{ December 20} & \multicolumn{2}{|c|}{ December 21} & \multicolumn{2}{|c|}{ December 22} & \multicolumn{2}{|c|}{ December 23} & \multicolumn{2}{|c|}{ December 24} & \multicolumn{2}{|c|}{ December 25} \\
\hline $\begin{array}{r}2 \\
4 \\
6 \\
8 \\
10 \\
\mathbf{W} \\
2 \\
4 \\
6 \\
8 \\
8 \\
10 \\
\mathbf{M}\end{array}$ & & & & & & & & & & & & \\
\hline
\end{tabular}


Cold Creek near Mokelumne Peak, Calif.

Location. - Lat. $38^{\circ} 31^{\prime}$, long. $120^{\circ} 13^{\prime}$, in sec. 28 , T. $8 \mathrm{~N} .$, R. $16 \mathrm{~F} .$, , 1 1 miles north of Salt Springs Dam and $6 \mathrm{mlles}$ southwest of Mokelume Peak, Amador County. Alt1tude, about 6,000 feet above mean sea level.

Drainage area. - 23 square miles.

Gage-helght record. - Water-stage recorder graph.

Stage-discharge relation.- Affected by 1ce for periods Dec. 1-9, 22-31, Jan. 4-7, 2031. Defined by current-meter measurements below 900 second-feet; extended to peak stage on basis of area-velocity study.

Maxima.- December 1937: Discharge, 4,100 second-feet $10 \mathrm{a.m.} \mathrm{Dec.} 11$ (gage helght, 8.98 feet).

1927-November 1937: Discharge, 3,000 second-feet (revised) Mar. 25, 1928 (gage holght, 7.79 feet).

Remarks.- Flood run-off not affected by artificlal storage or diversion. Discharge for perlods of ice effect computed on bas is of weather records and flow of nearby streams. Part of basic data furnished by Pacific Gas \& Electric Co.

Mean da1ly discharge, in second-feet, November 1937 to January 1938

\begin{tabular}{|c|c|c|c|c|c|c|c|c|c|c|c|}
\hline Day & Nov. & Dec. & Jan. & Day & Nov. & Dec. & Jan. & Day & Nov. & Dec. & Jan. \\
\hline $\begin{array}{r}1 \\
2 \\
3 \\
4 \\
5 \\
6 \\
7 \\
8 \\
9 \\
10\end{array}$ & $\begin{array}{l}0.2 \\
.2 \\
.2 \\
.2 \\
.2 \\
.2 \\
.2 \\
.2 \\
.3 \\
.3\end{array}$ & $\begin{array}{r}3.5 \\
3.5 \\
3.5 \\
3 \\
3 \\
3 \\
3 \\
3 \\
3 \\
1,610\end{array}$ & $\begin{array}{l}18 \\
21 \\
19 \\
17 \\
16 \\
15 \\
15 \\
15 \\
14 \\
14\end{array}$ & $\begin{array}{l}11 \\
12 \\
13 \\
14 \\
15 \\
16 \\
17 \\
18 \\
19 \\
20\end{array}$ & $\begin{array}{r}0.2 \\
.3 \\
.3 \\
.3 \\
.4 \\
.4 \\
2.6 \\
.8 \\
31.8\end{array}$ & $\begin{array}{r}2,440 \\
254 \\
110 \\
73 \\
62 \\
49 \\
43 \\
38 \\
30 \\
23\end{array}$ & $\begin{array}{l}14 \\
14 \\
14 \\
14 \\
21 \\
35 \\
29 \\
28 \\
30 \\
28\end{array}$ & $\begin{array}{l}21 \\
22 \\
23 \\
24 \\
25 \\
26 \\
27 \\
28 \\
29 \\
30 \\
31\end{array}$ & $\begin{array}{l}19 \\
9.5 \\
6.5 \\
7 \\
7 \\
6 \\
6 \\
5.5 \\
5.5 \\
4.9\end{array}$ & $\begin{array}{l}22 \\
20 \\
20 \\
20 \\
20 \\
19 \\
19 \\
19 \\
19 \\
18 \\
18\end{array}$ & $\begin{array}{l}26 \\
24 \\
22 \\
20 \\
18 \\
16 \\
14 \\
12 \\
12 \\
12 \\
12\end{array}$ \\
\hline & & & & & & & & & $\begin{array}{r}3.87 \\
230\end{array}$ & $\begin{array}{r}160 \\
9,870\end{array}$ & $\begin{array}{r}18.7 \\
1,150\end{array}$ \\
\hline
\end{tabular}

Gage height, in feet, and discharge, in second-feet, at indicated time, 1937

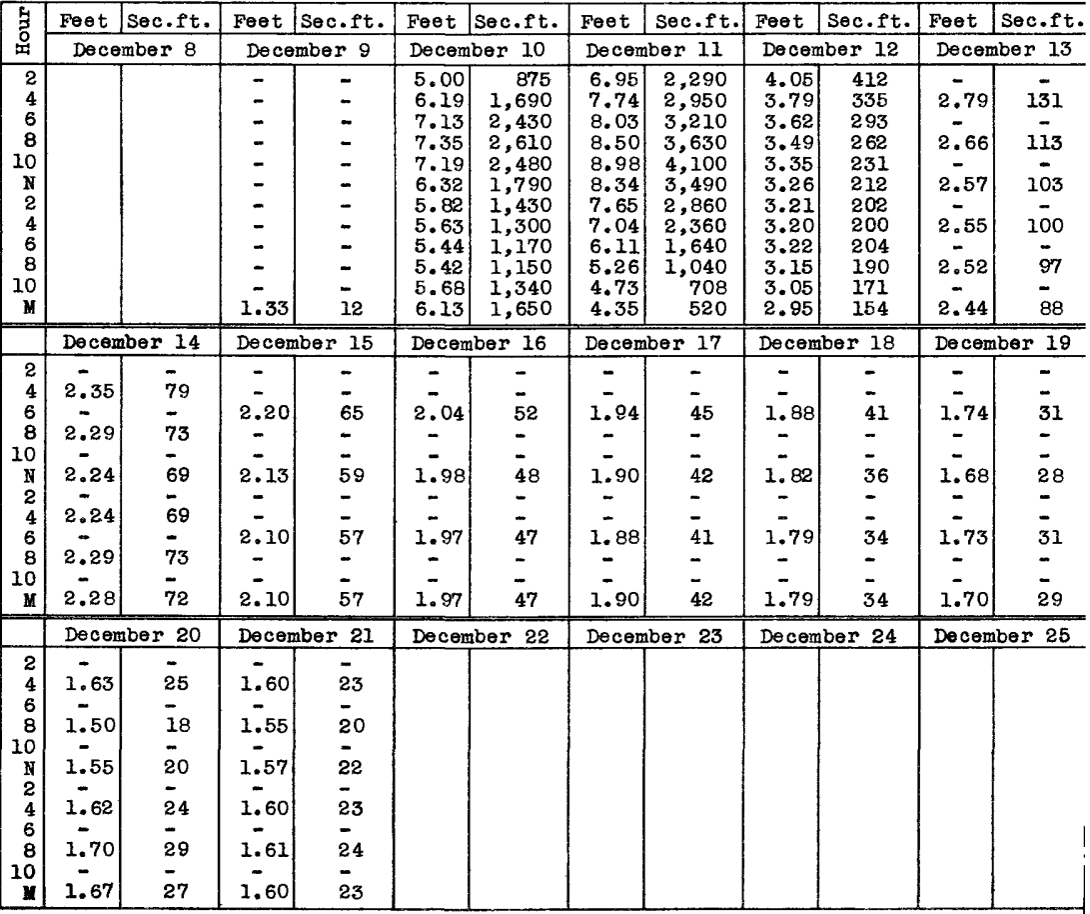

Supplemental records,- Dec. 10, I a.m., 4.15 ft., 445 sec.-ft.; 7 a.m., 7.47 ft., 2,710 sec.-ft.; 9 a.m., 7.45 ft., 2,690 sec.-ft. 
Location.- Lat. $38^{\circ} 32^{\prime}$, long. $120^{\circ} 15^{\prime}$, in sec. 18, T. 8 N., R. 16 E., at Pardoo Camp, Amador County, 2 miles below Bear River Reservolr. Altitude, about 5,650 feet above mean sea level.

Drainage area.- 33.0 square miles.

Gage-he1ght record.- Water-stage recorder graph except for periods 8:30 p.m. Dec. 1 to 11:30 a.m. Dec. 8, 5 a.m. to $1 \mathrm{p.m}$. Dec. 11, when there was no record. Record unrellable for period noon Dec. 12 to $3 \mathrm{p} . \mathrm{m}$. Dec. 13. Stage graph for periods of missing record based on partial recorder graph, range of stage indicated on recorder graph, and floodmark in well.

Stage-discharge relation.- Defined by current-meter measurements below 1,400 secondfeet; extended to peak stage on basis of area-velocity study. Rating curve changed at peak stage.

Maxima.- December 1937: Discharge, 5,850 second-feet about 9 a.m. Dec. 11 (gage helght, 12.0 feet, from floodmarks

1927-November 1937: Discharge, 4,090 second-feet (rev1sed) Mar. 25, 1928 (gage height, 9.75 feet), from rating curve for 1938 .

Remarks.- Flood run-off affected by artificial storage in Bear River Reservolr (capac1ty, about 6,600 acre-feet). Monthly summaries adjusted for storage. Reservolr began to spili about $10 \mathrm{p.m}$. Dec. 10. Discharge interpolated for period Dec. 2-7. Part of basic data furnished by Pacific Gas \& Electric 00 .

Yean dally discharge, in second-feet, November 1937 to January 1938

\begin{tabular}{|r|c|c|c||c|c|c|c|c|c|c|c|}
\hline Day & Nov. & Dec. & Jan. & Day & Nov. & Doc. & Jan. & Day & Nov. & Dec. & Jan. \\
\hline 1 & 0.7 & 8.5 & 36 & 11 & 1.2 & 3,910 & 21 & 21 & 49 & 50 & 41 \\
2 & .6 & 8 & 49 & 12 & 1.3 & 429 & 21 & 22 & 40 & 46 & 53 \\
3 & .6 & 8 & 48 & 13 & 1.4 & 168 & 21 & 23 & 30 & 46 & 50 \\
4 & .6 & 7.5 & 40 & 14 & 4.2 & 163 & 22 & 24 & 22 & 44 & 44 \\
5 & .6 & 7 & 35 & 15 & 6 & 137 & 53 & 25 & 17 & 42 & 44 \\
6 & .6 & 7 & 30 & 16 & 19 & 108 & 46 & 26 & 15 & 40 & 48 \\
7 & .7 & 6.5 & 27 & 17 & 42 & 94 & 62 & 27 & 12 & 38 & 90 \\
8 & .8 & 6.5 & 26 & 18 & 26 & 82 & 52 & 28 & 10 & 36 & 124 \\
8 & .8 & 12 & 23 & 19 & 16 & 65 & 49 & 29 & 9.5 & 33 & 123 \\
10 & .8 & 385 & 21 & 20 & 56 & 52 & 43 & 30 & 8.5 & 32 & 121 \\
& \multicolumn{7}{|l|}{} \\
\hline
\end{tabular}

Gage height, in feet, and discharge, in second-feet, at indicated time, 1937

\begin{tabular}{|c|c|c|c|c|c|c|c|c|c|c|c|c|}
\hline \multirow{2}{*}{ 宫 } & Feot & Sec.ft. & Fert & Sec.ft. & Feet & Sec.ft. & Feet & Sec.ft. & Feet & Sec.ft. & Feet & Sec.ft. \\
\hline & \multicolumn{2}{|c|}{ December 8} & \multicolumn{2}{|c|}{ December 9} & \multicolumn{2}{|c|}{ December 10} & \multicolumn{2}{|c|}{ December 11} & \multicolumn{2}{|c|}{ December 12} & \multicolumn{2}{|c|}{ December 13} \\
\hline $\begin{array}{r}2 \\
4 \\
6 \\
8 \\
10 \\
7 \\
2 \\
4 \\
6 \\
8 \\
10 \\
4\end{array}$ & $\begin{array}{l}- \\
- \\
- \\
- \\
0.84 \\
- \\
.85 \\
- \\
.84\end{array}$ & $\begin{array}{c}- \\
- \\
6.5 \\
- \\
6.5 \\
- \\
6.5 \\
- \\
6.5\end{array}$ & $\begin{array}{r}0.84 \\
.84 \\
.83 \\
.83 \\
.83 \\
.84 \\
.84 \\
.85 \\
.87 \\
.93 \\
1.11 \\
2.78 \\
\end{array}$ & $\begin{array}{r}6.5 \\
6.5 \\
6.5 \\
6.5 \\
6.5 \\
6.5 \\
6.5 \\
6.5 \\
7 \\
8 \\
12 \\
181 \\
\end{array}$ & $\begin{array}{l}3.40 \\
3.73 \\
4.11 \\
3.75 \\
3.24 \\
3.48 \\
3.25 \\
3.10 \\
3.06 \\
3.27 \\
3.38 \\
7.50\end{array}$ & $\begin{array}{r}304 \\
386 \\
497 \\
391 \\
269 \\
323 \\
271 \\
240 \\
232 \\
275 \\
300 \\
2,390 \\
\end{array}$ & $\begin{array}{r}9.32 \\
10.53 \\
11.02 \\
11.90 \\
11.95 \\
11.34 \\
10.50 \\
9.47 \\
7.96 \\
6.49 \\
5.56 \\
5.00 \\
\end{array}$ & $\begin{array}{r}3,710 \\
4,670 \\
5,070 \\
5,770 \\
5,810 \\
5,320 \\
4,650 \\
3,880 \\
2,820 \\
1,800 \\
1,250 \\
925\end{array}$ & $\begin{array}{l}4.66 \\
4.35 \\
4.09 \\
3.92 \\
3.75 \\
3.61 \\
3.47 \\
3.35 \\
3.22 \\
3.11 \\
3.00 \\
2.90 \\
\end{array}$ & \begin{tabular}{|l|}
752 \\
621 \\
529 \\
474 \\
424 \\
387 \\
351 \\
322 \\
292 \\
268 \\
244 \\
224 \\
\end{tabular} & $\begin{array}{l}2.79 \\
2.71 \\
2.63 \\
2.53 \\
2.45 \\
2.38 \\
2.33 \\
2.38 \\
2.66 \\
2.76 \\
2.76 \\
2.73 \\
\end{array}$ & \begin{tabular}{|l|}
202 \\
188 \\
173 \\
155 \\
142 \\
131 \\
123 \\
131 \\
179 \\
197 \\
197 \\
191 \\
\end{tabular} \\
\hline & \multicolumn{2}{|c|}{ December 14} & \multicolumn{2}{|c|}{ December 15} & \multicolumn{2}{|c|}{ December 16} & \multicolumn{2}{|c|}{ December 17} & \multicolumn{2}{|c|}{ December 18} & \multicolumn{2}{|c|}{ December 19} \\
\hline $\begin{array}{r}2 \\
4 \\
6 \\
8 \\
10 \\
N \\
2 \\
4 \\
6 \\
8 \\
10 \\
M\end{array}$ & $\begin{array}{c}- \\
2.64 \\
- \\
2.56 \\
- \\
2.50 \\
- \\
2.51 \\
- \\
2.59 \\
- \\
2.60\end{array}$ & $\begin{array}{l}\overline{175} \\
\overline{161} \\
\overline{150} \\
\overline{152} \\
\overline{156} \\
\overline{168}\end{array}$ & $\begin{array}{c}- \\
2.53 \\
- \\
2.46 \\
- \\
2.39 \\
- \\
2.36 \\
- \\
2.36 \\
- \\
2.37\end{array}$ & $\begin{array}{c}\overline{155} \\
\overline{144} \\
\overline{132} \\
\overline{128} \\
\overline{128} \\
\overline{129}\end{array}$ & $\begin{array}{c}\overline{-} \\
\overline{2.27} \\
\overline{-} \\
2.19 \\
\overline{-} \\
2.18 \\
\overline{-} \\
2.20\end{array}$ & $\begin{array}{c}\overline{-} \\
114 \\
- \\
\overline{103} \\
\overline{-} \\
102 \\
\overline{-} \\
\overline{104}\end{array}$ & $\begin{array}{c}- \\
- \\
2.15 \\
- \\
- \\
2.10 \\
\vdots \\
\vdots \\
2.07 \\
\overline{-} \\
2.12\end{array}$ & $\begin{array}{l}\overline{-} \\
\overline{98} \\
- \\
\overline{9} \\
\overline{-} \\
\overline{8} \\
\overline{-} \\
\overline{9} 4\end{array}$ & $\begin{array}{c}- \\
\overline{2.09} \\
\overline{-} \\
2.00 \\
\overline{-} \\
1.94 \\
\overline{-} \\
1.99\end{array}$ & $\begin{array}{l}\overline{-} \\
\overline{91} \\
\overline{-} \\
\overline{80} \\
\overline{7} \\
\overline{73} \\
\overline{7} \\
\overline{79}\end{array}$ & $\begin{array}{c}- \\
1.90 \\
- \\
1.77 \\
- \\
1.75 \\
- \\
1.84 \\
-\overline{2.03} \\
- \\
1.78\end{array}$ & $\begin{array}{l}69 \\
\overline{56} \\
- \\
54 \\
\overline{63} \\
\overline{84} \\
\overline{57} \\
\end{array}$ \\
\hline & \multicolumn{2}{|c|}{ Decémber 20} & \multicolumn{2}{|c|}{ December 21} & \multicolumn{2}{|c|}{ December 22} & \multicolumn{2}{|c|}{ December 23} & \multicolumn{2}{|c|}{ December 24} & \multicolumn{2}{|c|}{ December 25} \\
\hline $\begin{array}{r}2 \\
4 \\
6 \\
8 \\
10 \\
\text { N } \\
2 \\
4 \\
6 \\
8 \\
10 \\
\text { M }\end{array}$ & $\begin{array}{c}- \\
1.75 \\
- \\
1.69 \\
- \\
1.65 \\
- \\
1.76 \\
- \\
1.72 \\
- \\
1.77\end{array}$ & $\begin{array}{l}\overline{54} \\
\overline{49} \\
\overline{46} \\
\overline{55} \\
\overline{52} \\
\overline{56}\end{array}$ & $\begin{array}{c}-\overline{1.77} \\
- \\
1.72 \\
- \\
1.67 \\
- \\
1.64 \\
- \\
1.69 \\
- \\
1.72\end{array}$ & $\begin{array}{l}\overline{56} \\
- \\
52 \\
\overline{4} \\
\overline{4} \\
\overline{4} \\
\overline{4} 9 \\
- \\
52\end{array}$ & $\begin{array}{c}- \\
1.71 \\
- \\
1.67 \\
- \\
1.61 \\
- \\
1.59 \\
- \\
1.66 \\
- \\
1.78\end{array}$ & $\begin{array}{l}\overline{51} \\
\overline{4} 8 \\
\overline{43} \\
\overline{41} \\
\overline{4} 7 \\
\overline{57}\end{array}$ & $\begin{array}{c}- \\
1.80 \\
- \\
1.69 \\
- \\
1.61 \\
- \\
1.56 \\
- \\
1.58 \\
- \\
1.62\end{array}$ & $\begin{array}{l}\overline{59} \\
\overline{49} \\
\overline{43} \\
\overline{39} \\
\overline{40} \\
\overline{44}\end{array}$ & $\begin{array}{c}\overline{-} \\
\overline{1.62} \\
- \\
- \\
1.61 \\
\overline{-} \\
\overline{1.65} \\
\overline{-} \\
1.65\end{array}$ & $\begin{array}{l}- \\
\overline{44} \\
- \\
- \\
43 \\
- \\
\overline{46} \\
- \\
46\end{array}$ & & \\
\hline
\end{tabular}

Supplemental records, - Dec. 10, 11 p.m., $5.70 \mathrm{ft.}, 1,230 \mathrm{sec} . \mathrm{ft}$. Dec. 11, about 9 a.m., 12.0 ft., 5,850 sec.-ft. 
Location. - Lat. $38^{\circ} 23^{\prime} 15^{\prime \prime}$, long. $120^{\circ} 31^{\prime} 40^{\prime \prime}$, in sec. 10 T. 6 N., R. 13 F., 200 feet

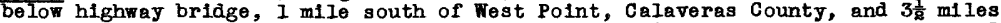
above junction with South Fork. Altitude, about 2,500 feet above mean sea level. Drainage area. - 67.2 square miles.

Gage-he1ght record. - Water-stage recorder graph except for period 4 a.m. Dec. 19 to $3: 45 \mathrm{p} . \mathrm{m}$. Jan. 3, when there was no record and stage graph was based on record for South Fork of Mokelume River near West Point.

Stage-discharge relation.- Defined by current-meter measurements below 1,000 secondfeet; extended to peak s tage by paralleling former curve which was extended on basis of slope-area computation of flood flow.

Maxima.- December 1937: Discharge, 1,460 second-feet 9 a.m. Dec. 11 (gage helght, 5.97 feet).

1911-November 1937: Discharge observed, 2,550 second-feet Jan. 23, 1914 (gage height, 10.0 feet, former site and datum), from rating curve extended above 490 second-feet.

Remarks.- Flood run-off not affected by artificlal storage. Several small diversions above station.

Mean daily discherge, in second-feet, November 1937 to January 1938

\begin{tabular}{|c|c|c|c|c|c|c|c|c|c|c|c|}
\hline Day & Nov. & Dec. & Jan. & Day & Nov. & Dec. & Jan. & Day & Nov. & Dec. & Jan. \\
\hline 1 & 7 & 10 & 22 & 11 & 13 & 837 & 22 & 21 & 17 & 30 & 45 \\
2 & 7 & 10 & 30 & 12 & 13 & 294 & 22 & 22 & 13 & 31 & 42 \\
3 & 7 & 9.5 & 31 & 13 & 10 & 122 & 21 & 23 & 13 & 36 & 39 \\
4 & 7 & 9.5 & 26 & 14 & 12 & 81 & 21 & 24 & 19 & 29 & 36 \\
5 & 7 & 9.5 & 25 & 15 & 13 & 63 & 73 & 25 & 14 & 26 & 34 \\
6 & 7 & 9.5 & 24 & 16 & 11 & 50 & 49 & 26 & 12 & 24 & 33 \\
7 & 8.5 & 9 & 23 & 17 & 31 & 42 & 59 & 27 & 12 & 23 & 32 \\
8 & 7.5 & 9 & 23 & 18 & 20 & 38 & 56 & 28 & 11 & 23 & 36 \\
9 & 7.5 & 11 & 22 & 19 & 14 & 35 & 57 & 29 & 11 & 22 & 48 \\
10 & 7.5 & 123 & 22 & 20 & 13 & 32 & 51 & 30 & 10 & 22 & 42 \\
\multicolumn{7}{|l|}{} \\
\hline
\end{tabular}

Gage height, in feet, and discharge, in second-feet, at indicated time, 1937

\begin{tabular}{|c|c|c|c|c|c|c|c|c|c|c|c|c|}
\hline \multirow{2}{*}{$\begin{array}{l}5 \\
5 \\
0 \\
0\end{array}$} & Feet & Sec.ft. & Feet & ec.ft. & Feet & Sec.ft. & Feot & Sec.ft. & Foet & Sec.ft. & Feet & Sec.ft. \\
\hline & \multicolumn{2}{|c|}{ December 8} & \multicolumn{2}{|c|}{ December 9} & \multicolumn{2}{|c|}{ December 10} & \multicolumn{2}{|c|}{ December 11} & \multicolumn{2}{|c|}{ December 12} & \multicolumn{2}{|c|}{ December 13} \\
\hline $\begin{array}{r}2 \\
4 \\
6 \\
8 \\
10 \\
\mathbb{N} \\
2 \\
4 \\
6 \\
8 \\
10 \\
4\end{array}$ & & & $\begin{array}{l}1.03 \\
1.03 \\
1.03 \\
1.03 \\
1.03 \\
1.03 \\
1.03 \\
1.03 \\
1.04 \\
1.07 \\
1.1 .6 \\
1.26 \\
\end{array}$ & $\begin{array}{c}9 \\
9 \\
9 \\
9 \\
9 \\
9 \\
9 \\
9 \\
9.5 \\
11 \\
16 \\
22 \\
\end{array}$ & $\begin{array}{l}1.35 \\
1.60 \\
2.08 \\
2.27 \\
2.41 \\
2.35 \\
2.28 \\
2.20 \\
2.12 \\
2.14 \\
2.19 \\
2.31\end{array}$ & $\begin{array}{r}28 \\
5 I \\
120 \\
154 \\
182 \\
170 \\
156 \\
141 \\
127 \\
130 \\
139 \\
162\end{array}$ & $\begin{array}{l}2.80 \\
3.49 \\
4.47 \\
5.80 \\
5.66 \\
5.42 \\
5.55 \\
5.18 \\
4.80 \\
4.32 \\
3.95 \\
3.65\end{array}$ & $\begin{array}{r}268 \\
443 \\
733 \\
1,350 \\
1,280 \\
1,160 \\
1,220 \\
1,040 \\
862 \\
683 \\
571 \\
487 \\
\end{array}$ & $\begin{array}{l}3.43 \\
3.26 \\
3.26 \\
3.23 \\
3.04 \\
2.84 \\
2.70 \\
2.59 \\
2.51 \\
2.44 \\
2.38 \\
2.32\end{array}$ & $\begin{array}{l}427 \\
382 \\
382 \\
374 \\
326 \\
278 \\
245 \\
220 \\
203 \\
188 \\
176 \\
164 \\
\end{array}$ & $\begin{array}{c}\overline{2.83} \\
\overline{2.14} \\
\tilde{2.08} \\
\overline{2.02} \\
\overline{1.97} \\
\overline{1.93}\end{array}$ & $\begin{array}{c}\overline{147} \\
\overline{130} \\
\overline{120} \\
\overline{109} \\
\overline{101} \\
\overline{95}\end{array}$ \\
\hline & \multicolumn{2}{|c|}{ December 14} & \multicolumn{2}{|c|}{ December 15} & \multicolumn{2}{|c|}{ December 16} & \multicolumn{2}{|c|}{ December 17} & \multicolumn{2}{|c|}{ December 18} & \multicolumn{2}{|c|}{ December 19} \\
\hline \multirow[t]{2}{*}{\begin{tabular}{r|}
2 \\
4 \\
6 \\
8 \\
10 \\
1 \\
2 \\
4 \\
6 \\
8 \\
10 \\
$M$ \\
\end{tabular}} & $\begin{array}{c}- \\
- \\
1.87 \\
- \\
- \\
1.83 \\
- \\
- \\
1.79 \\
- \\
1.75\end{array}$ & $\begin{array}{l}\overline{-} \\
\overline{85} \\
\overline{-} \\
\overline{80} \\
\overline{-} \\
\overline{74} \\
\overline{69}\end{array}$ & $\begin{array}{c}- \\
\overline{1.72} \\
\overline{-} \\
1.70 \\
\overline{-} \\
1.66 \\
\overline{-} \\
1.65\end{array}$ & $\begin{array}{l}\overline{-} \\
65 \\
- \\
- \\
63 \\
- \\
58 \\
- \\
\overline{5}\end{array}$ & $\begin{array}{c} \pm \\
1.62 \\
- \\
\overline{1.61} \\
\vdots \\
\overline{1.56} \\
\overline{-} \\
1.54\end{array}$ & $\begin{array}{l}\overline{-} \\
\overline{53} \\
- \\
\overline{5} 2 \\
\overline{-} \\
\overline{4} 7 \\
\overline{4} \\
\overline{4} 5\end{array}$ & & & & & & \\
\hline & \multicolumn{2}{|c|}{ December 20} & \multicolumn{2}{|c|}{ December 21} & \multicolumn{2}{|c|}{ December 22} & \multicolumn{2}{|c|}{ December 23} & \multicolumn{2}{|c|}{ December 24} & \multicolumn{2}{|c|}{ December 25} \\
\hline $\begin{array}{r}2 \\
4 \\
6 \\
8 \\
10 \\
\mathbb{N} \\
8 \\
4 \\
6 \\
8 \\
10 \\
M\end{array}$ & & & & & & & & & & & & \\
\hline
\end{tabular}

Supplemental records.- Dec. 11. 9 a.m., 5.97 ft., 1,460 sec.-ft.; 10850 a.m., 5.75 ft., 1,320 sec.-ft.; $12: 20$ p.m., $5.34 \mathrm{ft.}, i, 120$ sec.-ft. 
South Fork of Mokelume River near West Polnt, Calif.

Location. - Lat. $38^{\circ} 22^{\prime}$, long. $120^{\circ} 33^{\prime}$, in Swe sec. 16, T. 6 N., R. 13 E., 600 feet below Sawyer Bridge, 2 miles above junction with ulddle Fork, and $2 \frac{1}{2}$ miles southwest of West Point, Calaveras County. Altitude, about 2,000 feet above mean sea level. Drainage area.- 73.8 square miles.

Gage-helght record. - Water-stage recorder graph.

stage-discharge relation. - Defined by current-meter measurements for range of stage of December high water. Shifting control method used for perlod Dec. 10 to Jan. 31 . Maxima.- December 1937: Discherge, 1,810 second-feet 8 a.m. Dec. 11 (gage helght, $7 . \overline{8} 4$ feet).

1933-November 1937: Discharge, 3,600 second-feet Feb. 22, 1936 (gage height, 8.90 feet), from rating curve extended above 710 second-feet.

Remarks. - Flood run-off not affected by artiflclal storage or diversion.

Mean dally discherge, in second-feet, November 1937 to January 1938

\begin{tabular}{|c|c|c|c|c|c|c|c|c|c|c|c|}
\hline Day & Nov. & Dec. & Jan. & Day & Nov. & Dec. & Jan. & Day & Nov. & Dec. & Jan. \\
\hline $\begin{array}{r}1 \\
2 \\
3 \\
4 \\
5 \\
6 \\
7 \\
8 \\
9 \\
10\end{array}$ & $\begin{array}{l}8.5 \\
9 \\
9 \\
9 \\
8.5 \\
8.5 \\
9 \\
9 \\
9 \\
9\end{array}$ & $\begin{array}{l}12 \\
12 \\
12 \\
12 \\
12 \\
12 \\
12 \\
12 \\
13 \\
160\end{array}$ & $\begin{array}{l}28 \\
36 \\
41 \\
35 \\
34 \\
31 \\
30 \\
29 \\
27 \\
27\end{array}$ & $\begin{array}{l}11 \\
12 \\
13 \\
14 \\
15 \\
16 \\
17 \\
18 \\
19 \\
20\end{array}$ & $\begin{array}{l}19 \\
18 \\
14 \\
16 \\
17 \\
14 \\
35 \\
26 \\
17 \\
17\end{array}$ & $\begin{array}{r}1,010 \\
304 \\
128 \\
87 \\
70 \\
58 \\
51 \\
47 \\
41 \\
38\end{array}$ & $\begin{array}{r}27 \\
26 \\
26 \\
26 \\
110 \\
66 \\
80 \\
75 \\
78 \\
73\end{array}$ & $\begin{array}{l}21 \\
22 \\
23 \\
24 \\
25 \\
26 \\
27 \\
28 \\
29 \\
30 \\
31\end{array}$ & $\begin{array}{l}20 \\
16 \\
15 \\
18 \\
17 \\
15 \\
14 \\
14 \\
13 \\
13\end{array}$ & $\begin{array}{l}36 \\
35 \\
46 \\
35 \\
34 \\
32 \\
32 \\
30 \\
29 \\
29 \\
29\end{array}$ & $\begin{array}{r}61 \\
57 \\
53 \\
49 \\
47 \\
45 \\
43 \\
47 \\
74 \\
61 \\
170\end{array}$ \\
\hline $\begin{array}{l}\text { Yean } \\
\text { Run- }\end{array}$ & , in & re- & & & & & & & $\begin{array}{r}14.6 \\
866\end{array}$ & $\begin{array}{r}79.9 \\
4,900\end{array}$ & $\begin{array}{r}52.0 \\
3,200\end{array}$ \\
\hline
\end{tabular}

Gage helght, in feet, and discharge, in second-feet, at indicated time, 1937

\begin{tabular}{|c|c|c|c|c|c|c|c|c|c|c|c|c|}
\hline \multirow{2}{*}{ 急 } & Feet & sec.ft. & Feet & sec.ft. & Feet & Sec.ft. & Feet & Sec.ft. & Feet & Sec.ft. & Feet & Sec.ft. \\
\hline & \multicolumn{2}{|c|}{ December 8} & \multicolumn{2}{|c|}{ December 9} & \multicolumn{2}{|c|}{ December 10} & \multicolumn{2}{|c|}{ December 11} & \multicolumn{2}{|c|}{ December 12} & \multicolumn{2}{|c|}{ December 13} \\
\hline \multirow[t]{2}{*}{$\begin{array}{r}2 \\
4 \\
6 \\
8 \\
10 \\
N \\
2 \\
4 \\
6 \\
8 \\
10 \\
M\end{array}$} & & & $\begin{array}{c}.31 \\
-31 \\
3.31 \\
- \\
3.31 \\
- \\
3.31 \\
3.32 \\
3.35 \\
3.45 \\
3.60\end{array}$ & $\begin{array}{l}- \\
12 \\
- \\
12 \\
- \\
12 \\
- \\
12 \\
12 \\
14 \\
19 \\
28\end{array}$ & $\begin{array}{l}3.74 \\
4.07 \\
4.66 \\
5.01 \\
4.98 \\
4.91 \\
4.88 \\
4.80 \\
4.75 \\
4.85 \\
4.85 \\
5.01\end{array}$ & \begin{tabular}{|r}
37 \\
68 \\
144 \\
238 \\
228 \\
205 \\
196 \\
174 \\
162 \\
188 \\
188 \\
238
\end{tabular} & $\begin{array}{l}5.57 \\
6.08 \\
7.24 \\
7.84 \\
7.46 \\
7.20 \\
7.38 \\
6.88 \\
6.48 \\
6.18 \\
5.89 \\
5.67\end{array}$ & $\begin{array}{r}440 \\
689 \\
1,370 \\
1,810 \\
1,520 \\
1,350 \\
1,470 \\
1,140 \\
904 \\
740 \\
592 \\
486\end{array}$ & $\begin{array}{l}5.52 \\
5.41 \\
5.36 \\
5.37 \\
5.31 \\
5.21 \\
5.12 \\
5.04 \\
4.99 \\
4.94 \\
4.89 \\
4.84\end{array}$ & \begin{tabular}{|l|}
427 \\
380 \\
359 \\
363 \\
339 \\
301 \\
269 \\
241 \\
224 \\
208 \\
194 \\
179
\end{tabular} & $\begin{array}{c}- \\
\overline{4} \\
4.69 \\
- \\
\overline{4.57} \\
\overline{-} \\
4.47 \\
- \\
\overline{4} .38\end{array}$ & $\begin{array}{c}\overline{-} \\
\overline{146} \\
\overline{-} \\
\overline{125} \\
\overline{-} \\
\overline{111} \\
\overline{-} \\
1 \overline{0}\end{array}$ \\
\hline & \multicolumn{2}{|c|}{ December 14} & \multicolumn{2}{|c|}{ December 15} & \multicolumn{2}{|c|}{ December 16} & \multicolumn{2}{|c|}{ December 17} & \multicolumn{2}{|c|}{ December 18} & \multicolumn{2}{|c|}{ December 19} \\
\hline \multirow[t]{2}{*}{$\begin{array}{r}2 \\
4 \\
6 \\
8 \\
10 \\
1 \\
2 \\
4 \\
6 \\
8 \\
10 \\
1 \\
\end{array}$} & & & & & & & & & & & & \\
\hline & \multicolumn{2}{|c|}{ December 20} & \multicolumn{2}{|c|}{ December 21} & \multicolumn{2}{|c|}{ De cember 22} & \multicolumn{2}{|c|}{ December 23} & \multicolumn{2}{|c|}{ December 24} & \multicolumn{2}{|c|}{ December 25} \\
\hline $\begin{array}{r}2 \\
4 \\
6 \\
8 \\
10 \\
\mathrm{~N} \\
2 \\
4 \\
6 \\
8 \\
10 \\
\mathbf{H}\end{array}$ & & & & & $\begin{array}{c}3.73 \\
- \\
3.73 \\
- \\
3.73 \\
- \\
3.73 \\
- \\
3.72 \\
3.73 \\
3.81 \\
3.98\end{array}$ & \begin{tabular}{|l}
34 \\
$\overline{34}$ \\
$\overline{34}$ \\
- \\
34 \\
$\overline{34}$ \\
34 \\
41 \\
56
\end{tabular} & $\begin{array}{l}4.03 \\
4.01 \\
3.95 \\
3.92 \\
3.90 \\
3.86 \\
3.84 \\
3.83 \\
3.82 \\
3.80 \\
3.78 \\
3.78\end{array}$ & $\begin{array}{l}61 \\
59 \\
53 \\
50 \\
48 \\
45 \\
43 \\
42 \\
41 \\
40 \\
38 \\
38\end{array}$ & & & - & \\
\hline
\end{tabular}

Supplemental records.- Dec. 11, 12840 p.m., $7.08 \mathrm{ft} ., 1,270$ sec.-ft. 
Sutter Creek near Sutter Creek, Calif.

Locstion. - Lat. $38^{\circ} 23^{\prime} 30^{n}$, long. $120^{\circ} 46^{\prime} 50^{n}$, in sec. 9, T. 6 N., R. $11 \mathrm{E} ., 1.3 \mathrm{~m} 11 \mathrm{es}$ east of Sutter Creek, Amader County. Altitude, sbout 1,150 feet sbove mesn sea level.

Dralnage ares. - 50.6 square miles.

Gage-height record. - One gage resding daily. Record unrelisble and not used for period Dec. $13-25$.

Stage-discharge relation. - Defined by current-meter messurements below 1,800 secondreet.

Maxima.- December 1937: Discharge, 575 second-feet probably Dec. II (gage helght, 7.0 feet, from floodrark).

1922-November 1937: Discharge, 3,900 seconö-feet Feb. 22, 1936 (gage helght, 12.0 feet, from floodmark), from rating curve extended above 1,400 second-feet.

Remarks. - Flood mun-off not affected by artificial storage or diversion. Discharge for period of unreliable gage-helght record determined by comparison with records for nearby stations.

Mean dafly discharge, In second-feet, November 1937 to January 1938

\begin{tabular}{|r|c|c|c||c|c|c|c||c|c|c|r|}
\hline Day & Nov. & Dec. & Jan. & Day & Nov. & Dec. & Jan. & Day & Nov. & Dec. & Jan. \\
\hline 1 & 3.1 & 5.5 & 8 & 11 & 5.5 & 316 & 6.5 & 21 & 5 & 10 & 25 \\
2 & 2.6 & 5 & 9 & 12 & 5.5 & 192 & 6.5 & 22 & 5.5 & 16 & 23 \\
3 & 2.6 & 5 & 9 & 13 & 4.4 & 23 & 6.5 & 23 & 6 & 15 & 23 \\
4 & 2.6 & 4.7 & 8.5 & 14 & 4.1 & 22 & 6.5 & 24 & 9 & 15 & 22 \\
5 & 2.6 & 4.4 & 8.5 & 15 & 3.8 & 19 & 55 & 25 & 7.5 & 13 & 17 \\
6 & 2.4 & 4.4 & 8 & 16 & 5 & 16 & 20 & 26 & 6 & 12 & 15 \\
7 & 2.4 & 4.7 & 8 & 17 & 9 & 14 & 48 & 27 & 5.5 & 10 & 11 \\
8 & 2.4 & 4.7 & 7.5 & 18 & 10 & 12 & 25 & 28 & 5.5 & 9 & 11 \\
9 & 2.4 & 5.5 & 7.5 & 19 & 6 & 11 & 27 & 29 & 5.5 & 8.5 & 61 \\
10 & 2.4 & 88 & 7 & 20 & 5 & 11 & 25 & 30 & 5.5 & 7.5 & 59 \\
\end{tabular}


Location. - Lat. $38^{\circ} 36^{\prime}$, long. $120^{\circ} 51^{\prime}$, in NEs sec. 35, T. 9 N., R. 10 E., 1 milo north of Nashvilie, 2.7 miles above mouth, and 6 miles south of E1 Dorado, El Dorado County. Altitude, about 910 feet above mean sea level. Drainage area.- 202 square miles.

Gage-helght record. - Water-stage recorder graph.

stage-discharge relation.- Defined by current-meter measurements below 3,900 secondfeet. Rating curve chenged at peak stage.

Maxima.- December 1937: Discharge, 3,880 second-feet 3 p.m. Dec. 11 (gage height, 6.70 feet).

1911-November 1937: Discharge, about 7,600 second-feet Mar. 25, 1928 (gage

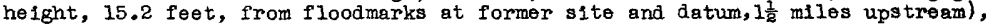

from rating curve extended above 1,000 second-feet. Remarks.- Flood mun-off not affected by artificial storage or diversion.

Mean daily discharge, in second-feet, November 1937 to January 1938

\begin{tabular}{|c|c|c|c|c|c|c|c|c|c|c|c|}
\hline Day & Nov. & Dec. & Jan. & Day & Nov. & Dec. & Jan. & Day & Nov. & Dec. & Jan. \\
\hline 1 & 12 & 27 & 74 & 11 & 18 & 2,160 & 64 & 21 & 51 & 110 & 148 \\
2 & 12 & 26 & 80 & 12 & 37 & 1,320 & 62 & 22 & 51 & 102 & 132 \\
3 & 12 & 25 & 86 & 13 & 33 & 558 & 60 & 23 & 45 & 145 & 132 \\
4 & 12 & 25 & 82 & 14 & 28 & 361 & 59 & 24 & 64 & 107 & 122 \\
5 & 13 & 24 & 76 & 15 & 33 & 268 & 161 & 25 & 64 & 100 & 117 \\
6 & 13 & 23 & 74 & 16 & 30 & 220 & 145 & 26 & 45 & 91 & 110 \\
7 & 13 & 23 & 70 & 17 & 45 & 182 & 158 & 27 & 38 & 86 & 107 \\
8 & 12 & 23 & 68 & 18 & 84 & 158 & 228 & 28 & 31 & 82 & 120 \\
9 & 13 & 23 & 66 & 19 & 50 & 132 & 189 & 29 & 28 & 80 & 193 \\
10 & 13 & 328 & 64 & 20 & 41 & 120 & 182 & 30 & 28 & 76 & 151 \\
\end{tabular}

Gage helght, in feet, and ds scharge, in second-feet, at indicated time, 1937

\begin{tabular}{|c|c|c|c|c|c|c|c|c|c|c|c|c|}
\hline \multirow{2}{*}{$\begin{array}{r}4 \\
3 \\
0 \\
4\end{array}$} & Feet & Sec.f't. & Fee't & sec.ft. & Feet & sec.ft. & Feet & Sec.ft. & Feet & Sec.ft. & Feet & Sec.ft. \\
\hline & \multicolumn{2}{|c|}{ December 8} & \multicolumn{2}{|c|}{ December 9} & \multicolumn{2}{|c|}{ December 10} & \multicolumn{2}{|c|}{ December 11} & \multicolumn{2}{|c|}{ December 12} & \multicolumn{2}{|c|}{ December 13} \\
\hline \multirow[t]{2}{*}{$\begin{array}{r}2 \\
4 \\
6 \\
8 \\
10 \\
\mathrm{~N} \\
2 \\
4 \\
6 \\
8 \\
10 \\
\mathrm{M}\end{array}$} & $\begin{array}{c}-\overline{1.30} \\
- \\
1.30 \\
- \\
1.29 \\
- \\
1.30 \\
\overline{1.30} \\
\overline{1.30}\end{array}$ & $\begin{array}{l}\overline{23} \\
\overline{23} \\
\overline{2} \\
\overline{2} \\
\overline{23} \\
\overline{23} \\
\overline{23}\end{array}$ & $\begin{array}{c}- \\
1.29 \\
- \\
1.29 \\
- \\
1.30 \\
- \\
1.31 \\
- \\
1.32 \\
- \\
1.36\end{array}$ & $\begin{array}{l}\overline{22} \\
\overline{22} \\
\overline{23} \\
\overline{2} \\
\overline{24} \\
\overline{25} \\
\overline{29}\end{array}$ & $\begin{array}{l}1.39 \\
1.45 \\
1.53 \\
1.62 \\
1.77 \\
1.93 \\
2.86 \\
3.10 \\
3.12 \\
3.09 \\
3.00 \\
3.00\end{array}$ & \begin{tabular}{|r}
32 \\
40 \\
51 \\
68 \\
100 \\
141 \\
545 \\
675 \\
687 \\
670 \\
620 \\
620
\end{tabular} & $\begin{array}{l}3.04 \\
3.03 \\
3.27 \\
3.67 \\
5.00 \\
5.96 \\
6.64 \\
6.59 \\
6.23 \\
5.73 \\
5.48 \\
5.19\end{array}$ & $\begin{array}{r}642 \\
636 \\
777 \\
1,040 \\
2,100 \\
3,070 \\
3,810 \\
3,760 \\
3,360 \\
2,840 \\
2,590 \\
2,320\end{array}$ & $\begin{array}{l}4.97 \\
4.70 \\
4.45 \\
4.25 \\
4.12 \\
3.94 \\
3.75 \\
3.57 \\
3.43 \\
3.32 \\
3.23 \\
3.18\end{array}$ & $\begin{array}{r}2,120 \\
1,880 \\
1,680 \\
1,520 \\
1,420 \\
1,270 \\
1,140 \\
1,010 \\
911 \\
838 \\
780 \\
748\end{array}$ & $\begin{array}{l}3.13 \\
3.07 \\
3.00 \\
2.95 \\
2.88 \\
2.85 \\
2.80 \\
2.75 \\
2.72 \\
2.68 \\
2.65 \\
2.62\end{array}$ & $\begin{array}{l}718 \\
682 \\
640 \\
610 \\
569 \\
552 \\
525 \\
498 \\
481 \\
460 \\
445 \\
430\end{array}$ \\
\hline & \multicolumn{2}{|c|}{ December 14} & \multicolumn{2}{|c|}{ December 15} & \multicolumn{2}{|c|}{ December 16} & \multicolumn{2}{|c|}{ December 17} & \multicolumn{2}{|c|}{ December 18} & \multicolumn{2}{|c|}{ December 19} \\
\hline \multirow[t]{2}{*}{$\begin{array}{r}2 \\
4 \\
6 \\
8 \\
10 \\
\mathrm{~N} \\
2 \\
4 \\
6 \\
8 \\
10 \\
\mathrm{M}\end{array}$} & $\begin{array}{l}\overline{2.56} \\
= \\
2.52 \\
\overline{2.47} \\
= \\
2.43 \\
- \\
2.39 \\
\overline{2.35}\end{array}$ & $\begin{array}{l}\overline{400} \\
\overline{380} \\
\overline{356} \\
\overline{3} \\
\overline{3} 8 \\
\overline{300} \\
3 \overline{0}\end{array}$ & $\begin{array}{l}\overline{-} \\
\overline{2.31} \\
- \\
\overline{2.27} \\
\overline{-} \\
\overline{2.24} \\
\overline{-} \\
\overline{2.18}\end{array}$ & $\begin{array}{c}\overline{-} \\
2 \overline{84} \\
\overline{-} \\
2 \overline{68} \\
\overline{-} \\
2 \overline{56} \\
\overline{-} \\
2 \overline{3}\end{array}$ & $\begin{array}{c}\overline{-} \\
2.17 \\
- \\
\overline{2.14} \\
\overline{-} \\
2.12 \\
\overline{-} \\
2.10\end{array}$ & $\begin{array}{c}\overline{-} \\
2 \overline{28} \\
\overline{-} \\
\overline{216} \\
\overline{-} \\
\overline{208} \\
\overline{-} \\
2 \overline{00}\end{array}$ & $\begin{array}{c}\overline{-} \\
\overline{2.07} \\
- \\
\overline{-} \\
2.05 \\
- \\
\overline{2.03} \\
\overline{-} \\
\overline{2.01}\end{array}$ & $\begin{array}{c}- \\
\overline{189} \\
\overline{-} \\
\overline{182} \\
\overline{-} \\
\overline{175} \\
\overline{-} \\
\overline{168}\end{array}$ & $\begin{array}{c}- \\
\overline{1.99} \\
- \\
\overline{1.99} \\
- \\
\overline{1.96} \\
\overline{-} \\
\overline{1.94}\end{array}$ & $\begin{array}{c}\overline{-} \\
161 \\
\overline{-} \\
154 \\
\overline{-} \\
\overline{151} \\
\overline{-} \\
\overline{145}\end{array}$ & $\begin{array}{l}\overline{-} \\
\overline{1.92} \\
\overline{-} \\
\overline{1.80} \\
- \\
\overline{1.89} \\
\overline{1.88}\end{array}$ & $\begin{array}{c}\overline{-} \\
\overline{138} \\
\overline{-} \\
\overline{132} \\
\overline{-} \\
\overline{130} \\
\overline{127}\end{array}$ \\
\hline & \multicolumn{2}{|c|}{ December 20} & \multicolumn{2}{|c|}{ December 21} & \multicolumn{2}{|c|}{ December 22} & \multicolumn{2}{|c|}{ December 23} & \multicolumn{2}{|c|}{ December 24} & \multicolumn{2}{|c|}{ December 25} \\
\hline $\begin{array}{r}2 \\
4 \\
6 \\
8 \\
10 \\
\mathrm{~N} \\
2 \\
4 \\
6 \\
8 \\
10 \\
\mathbf{M}\end{array}$ & $\begin{array}{c}\overline{-} \\
\overline{1.87} \\
- \\
\overline{1.85} \\
- \\
\overline{1 .} 84 \\
\overline{-} \\
\overline{1.83}\end{array}$ & $\begin{array}{c}\overline{124} \\
\overline{-} \\
\overline{120} \\
\overline{-} \\
\overline{117} \\
\overline{-} \\
\overline{114}\end{array}$ & $\begin{array}{l}\overline{-} \\
1.82 \\
- \\
\overline{1 .} \\
- \\
\overline{1 .} \\
\overline{1 .} 80 \\
\overline{1.79}\end{array}$ & $\begin{array}{c}\overline{1} \\
1 \overline{1} \\
\overline{-} \\
110 \\
\overline{-} \\
107 \\
\overline{105}\end{array}$ & $\begin{array}{c}- \\
1.77 \\
- \\
1.78 \\
= \\
1.84\end{array}$ & $\begin{array}{c}\overline{102} \\
\overline{-} \\
\overline{100} \\
\overline{-} \\
\overline{102} \\
\overline{-} \\
\overline{117}\end{array}$ & $\begin{array}{c}- \\
1.92 \\
- \\
2.04 \\
- \\
1.98 \\
\overline{1.92} \\
\overline{1.88} \\
\overline{1.84}\end{array}$ & $\begin{array}{c}-\overline{138} \\
- \\
1 \overline{7} 8 \\
- \\
1 \overline{58} \\
\overline{138} \\
\overline{127} \\
\overline{117}\end{array}$ & $\begin{array}{c}- \\
1.80 \\
- \\
- \\
1.80 \\
- \\
\overline{1.79} \\
- \\
\overline{1.77}\end{array}$ & $\begin{array}{c}\overline{107} \\
- \\
107 \\
\overline{105} \\
\overline{100}\end{array}$ & $\begin{array}{c}- \\
1.78 \\
\overline{-} \\
1.78 \\
- \\
1.77 \\
\overline{1.73}\end{array}$ & $\begin{array}{c}\overline{102} \\
\overline{102} \\
\overline{102} \\
\overline{100} \\
\overline{-} \\
\overline{91}\end{array}$ \\
\hline
\end{tabular}

Supplemental records.- Dec. 11,3 p.m., $6.70 \mathrm{ft} ., 3,880$ sec.-ft. 
Cosumes River at Michlgan Bar, Calif.

Location. - Lat. $38^{\circ} 30^{\prime} 00^{\prime \prime}$, long. $121^{\circ} 02^{\prime} 45^{\prime \prime}$, in SE $\frac{1}{4}$ sec. 36 , T. 8 N., R. 8 E., at highway bridge at Michigan Bar, Sacramento County, 5i miles southwest of Latrobe. North and Middle Forks unite 12 miles above station. Altitude, about 190 feet above mean sea level.

Drainage area. - 537 square miles.

Gage-helght record. - Water-stage recorder graph.

Stage-discharge relation.- Defined by current-meter measurements below 9,000 secondfeet. Rating curve changed at peak stage.

Maxima.- December 1937: Discharge, 9,000 second-feet 4 p.m. Dec. Il (gage heigit, 7.58 feet).

1907-November 1937: Discharge observed, 23,800 second-feet Feb. 6, 1925 (gage helght, 11.2 feet, from nonrecording gage), from rating curve extended above

10,000 second-feet.

Remarks. - Flood mun-off not affected by artificial storage or diversion.

Mean daily discharge, in second-feet, November 1937 to January 1938

\begin{tabular}{|c|c|c|c||c|c|c|c|c|c|c|c|}
\hline Day & Nov. & Dec. & Jan. & Day & Nov. & Dec. & Jan. & Day & Nov. & Dec. & Jan. \\
\hline 1 & 13 & 48 & 156 & 11 & 19 & 4,680 & 133 & 21 & 80 & 243 & 360 \\
2 & 14 & 45 & 177 & 12 & 37 & 3,030 & 128 & 22 & 97 & 226 & 315 \\
3 & 15 & 45 & 204 & 13 & 63 & 1,260 & 126 & 23 & 82 & 296 & 301 \\
4 & 15 & 45 & 183 & 14 & 50 & 808 & 123 & 24 & 89 & 251 & 287 \\
5 & 14 & 45 & 168 & 15 & 45 & 599 & 517 & 25 & 116 & 218 & 260 \\
6 & 14 & 44 & 159 & 16 & 54 & 480 & 402 & 26 & 89 & 197 & 247 \\
7 & 15 & 43 & 151 & 17 & 54 & 396 & 396 & 27 & 72 & 183 & 243 \\
8 & 15 & 43 & 148 & 18 & 143 & 345 & 487 & 28 & 63 & 180 & 264 \\
9 & 17 & 44 & 143 & 19 & 108 & 305 & 480 & 29 & 53 & 168 & 522 \\
10 & 16 & 410 & 138 & 20 & 77 & 273 & 494 & 30 & 49 & 159 & 396 \\
\end{tabular}

Gage height, in feet, and discharge, in second-feet, at indicated time, 1937

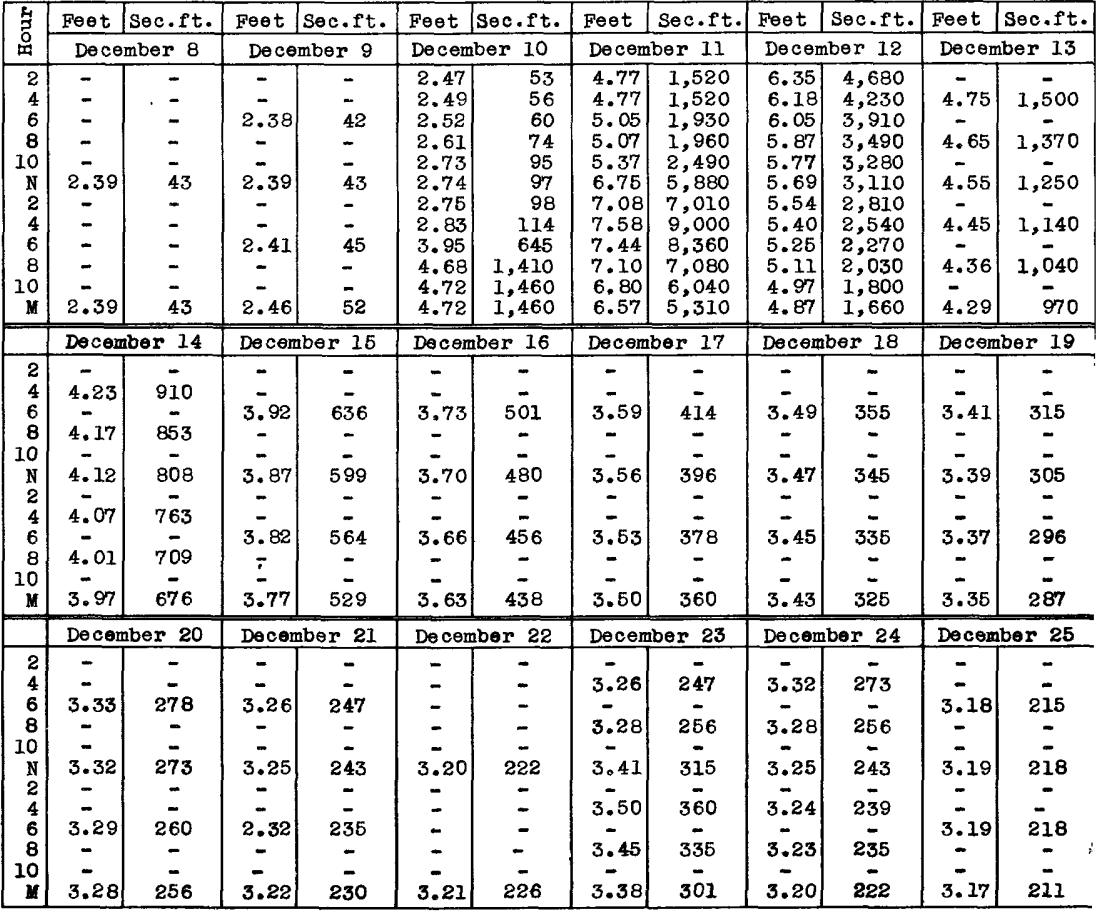


Location. - Lat. $40^{\circ} 53^{\prime}$, long. $122^{\circ} 23^{\prime}$, in SEt sec. 13, T. 35 N., R. 5 W., a quarter of a mile below highway bridge at Antler, Shasta County. Gregory Creek enters 1,000 feet above gage and P1t River 14 miles below. Zero of gage 1s 934.4 feet above mean sea level.

Drainage area.- 461 square miles.

Gage-he1ght record. - Water-stage recorder graph.

tage-discharge relation.- Defined by current-meter megsurements below 6,300 secondfeet; extended to peak stage on basis of area-velocity study; verified by comparison of peak discharge and total run-off of flood with records for other stations in Sacramento River Basin.

Maxima.- December 1937: D1scharge, 24,900 second-feet 10 p.m. Dec. 10 (gage he1ght, 14.55 feet).

1910-11, 1919-November 1937: D1scharge, 34,000 second-feet Mar. 26, 1928 (gage height, 19.4 feet, from floodmarks at former site and datum, a quarter of a mile upstream), from rating curve extended above 11,600 second-feet on bas 1s of areaveloc1ty study.

Remarks.- Flood run-off not affected by artificlal storage or diversion.

Mean delly discharge, in second-feet, November 1937 to January 1938

\begin{tabular}{|c|c|c|c|c|c|c|c|c|c|c|c|}
\hline Day & Nov. & ec. & Jan. & Day & Nov. & Dec. & Jan, & Day & Nov. & Dec. & in. \\
\hline $\begin{array}{r}1 \\
2 \\
3 \\
4 \\
5 \\
6 \\
7 \\
8 \\
9 \\
10\end{array}$ & $\begin{array}{r}218 \\
215 \\
209 \\
209 \\
209 \\
209 \\
209 \\
209 \\
212 \\
2,780\end{array}$ & $\begin{array}{r}1,210 \\
1,090 \\
1,020 \\
950 \\
880 \\
841 \\
802 \\
770 \\
915 \\
13,100\end{array}$ & $\begin{array}{r}1,060 \\
1,170 \\
1,170 \\
1,130 \\
1,060 \\
1,020 \\
985 \\
950 \\
880 \\
867\end{array}$ & $\begin{array}{l}11 \\
12 \\
13 \\
14 \\
15 \\
16 \\
17 \\
18 \\
19 \\
20\end{array}$ & $\begin{array}{r}6,590 \\
1,850 \\
1,380 \\
2,160 \\
1,700 \\
4,820 \\
4,660 \\
2,460 \\
3,530 \\
13,000\end{array}$ & $\begin{array}{r}19,700 \\
9,660 \\
5,520 \\
3,860 \\
3,050 \\
2,460 \\
2,110 \\
1,900 \\
1,700 \\
1,510\end{array}$ & $\begin{array}{r}848 \\
828 \\
808 \\
848 \\
1,210 \\
1,720 \\
4,100 \\
2,980 \\
2,640 \\
2,340\end{array}$ & $\begin{array}{l}21 \\
22 \\
23 \\
24 \\
25 \\
26 \\
27 \\
28 \\
29 \\
30 \\
31\end{array}$ & & & \\
\hline \multicolumn{12}{|c|}{\begin{tabular}{|c|r|r|r}
$\ldots \ldots \ldots \ldots \ldots \ldots \ldots \ldots \ldots$ & 2,809 & 2,777 & 1,560 \\
$\cdots \ldots \ldots \ldots \ldots \ldots \ldots \ldots$ & 167,100 & 170,800 & 95,910 \\
\end{tabular}} \\
\hline
\end{tabular}

Gage helght, in feet, and discharge, in second-feet, at indicated time, 1937

\begin{tabular}{|c|c|c|c|c|c|c|c|c|c|c|c|c|}
\hline \multirow{2}{*}{ 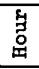 } & $\theta \theta \theta t$ & Sec.ft. & Feet & Sec.ft. & Feet & Sec.ft. & Feet & Sec.ft. & Feet & Sec.ft. & Feet & Sec,ft. \\
\hline & \multicolumn{2}{|c|}{ December 8} & \multicolumn{2}{|c|}{ December 9} & \multicolumn{2}{|c|}{ December 10} & \multicolumn{2}{|c|}{ December 11} & \multicolumn{2}{|c|}{ December 12} & \multicolumn{2}{|c|}{ December 13} \\
\hline $\begin{array}{r}2 \\
4 \\
6 \\
8 \\
10 \\
\text { N } \\
2 \\
4 \\
6 \\
8 \\
10 \\
\text { W }\end{array}$ & $\begin{array}{c}\bar{z} \\
2.84 \\
- \\
2.82 \\
\vdots \\
2.81 \\
\overline{2} \\
2.80\end{array}$ & $\begin{array}{c}- \\
\overline{776} \\
\overline{-} \\
7 \overline{6} \\
= \\
\overline{756} \\
= \\
7 \overline{50}\end{array}$ & $\begin{array}{l}2.80 \\
2.80 \\
2.79 \\
2.78 \\
2.80 \\
2.83 \\
2.92 \\
3.04 \\
3.23 \\
3.46 \\
3.80 \\
4.18\end{array}$ & $\begin{array}{r}750 \\
750 \\
744 \\
738 \\
750 \\
770 \\
828 \\
908 \\
1,040 \\
1,220 \\
1,510 \\
1,880\end{array}$ & \begin{tabular}{|r|}
4.74 \\
5.52 \\
6.65 \\
7.87 \\
9.00 \\
10.26 \\
11.35 \\
12.07 \\
13.36 \\
14.40 \\
14.55 \\
14.00
\end{tabular} & $\begin{array}{r}2,510 \\
3,570 \\
5,430 \\
7,740 \\
10,100 \\
13,000 \\
15,800 \\
17,700 \\
21,300 \\
24,300 \\
24,900 \\
23,100\end{array}$ & \begin{tabular}{|l|}
13.00 \\
12.55 \\
12.47 \\
12.73 \\
13.23 \\
13.73 \\
13.58 \\
13.33 \\
12.77 \\
12.12 \\
11.41 \\
10.86
\end{tabular} & $\begin{array}{l}20,300 \\
19,000 \\
18,800 \\
19,500 \\
20,900 \\
22,300 \\
21,900 \\
21,200 \\
19,700 \\
17,800 \\
16,000 \\
14,500\end{array}$ & $\begin{array}{r}10.36 \\
9.90 \\
9.53 \\
9.18 \\
8.86 \\
8.59 \\
8.36 \\
8.13 \\
7.92 \\
7.73 \\
7.57 \\
7.41 \\
\end{array}$ & $\begin{array}{r}13,300 \\
12,200 \\
11,300 \\
10,500 \\
9,790 \\
9,200 \\
8,720 \\
8,260 \\
7,840 \\
7,460 \\
7,140 \\
6,820\end{array}$ & $\begin{array}{l}7.07 \\
- \\
6.88 \\
6.63 \\
- \\
6.42 \\
- \\
6.25 \\
- \\
6.10\end{array}$ & $\begin{array}{c}6, \overline{190} \\
\overline{8}, \overline{840} \\
\overline{5} \\
5, \overline{3} 90 \\
5, \overline{2} 20 \\
\overline{\overline{7}} \overline{740} \\
4, \overline{5} 00\end{array}$ \\
\hline & \multicolumn{2}{|c|}{ December 14} & \multicolumn{2}{|c|}{ December 15} & \multicolumn{2}{|c|}{ December 16} & \multicolumn{2}{|c|}{ December 17} & \multicolumn{2}{|c|}{ December 18} & \multicolumn{2}{|c|}{ December 19} \\
\hline $\begin{array}{r}2 \\
4 \\
6 \\
8 \\
10 \\
\mathbb{N} \\
2 \\
4 \\
6 \\
8 \\
10 \\
\text { M }\end{array}$ & $\begin{array}{c}- \\
- \\
5.89 \\
- \\
5.70 \\
\overline{5} \\
5.53 \\
\overline{5.38}\end{array}$ & $\begin{array}{c}\overline{-} \\
4, \overline{160} \\
\overline{-} \\
3, \overline{8} 60 \\
\overline{-} \\
3, \overline{5} 90 \\
\overline{-} \\
3, \overline{370}\end{array}$ & $\begin{array}{c}- \\
\overline{5.26} \\
\overline{-} \\
5.14 \\
\overline{-} \\
5.00 \\
\overline{4} \\
4.90\end{array}$ & $\begin{array}{c}\overline{-} \\
\overline{-}, \overline{200} \\
\overline{-} \\
3, \overline{0} 40 \\
\overline{-} \\
2, \overline{8} 40 \\
\overline{-} \\
2, \overline{7} 00\end{array}$ & $\begin{array}{c}- \\
\overline{-} \\
4.80 \\
\overline{-} \\
\overline{4.73} \\
\overline{-} \\
4.64 \\
\overline{-} \\
\overline{4} .53\end{array}$ & $\begin{array}{c}\overline{-} \\
2, \overline{5} 80 \\
- \\
\overline{-} \\
2, \overline{5} 00 \\
\overline{-} \\
2, \overline{3} 90 \\
\overline{-} \\
2, \overline{2} 80\end{array}$ & $\begin{array}{c}\overline{-} \\
\overline{4.48} \\
\overline{-} \\
\overline{4.42} \\
\overline{-} \\
\overline{4.35} \\
\overline{-} \\
\overline{4.28}\end{array}$ & $2, \overline{200}$ & $\begin{array}{c}\overline{-} \\
\overline{4.23} \\
\overline{-} \\
\overline{4.18} \\
\overline{-} \\
\overline{4.12} \\
\overline{-} \\
\overline{4.07}\end{array}$ & $\begin{array}{c}\overline{-} \\
1, \overline{9} 30 \\
\overline{-} \\
\overline{8} 80 \\
\overline{-} \\
\overline{8} \\
1, \overline{8} 20 \\
\overline{-} \\
1, \overline{7} 70\end{array}$ & $\begin{array}{c}\overline{-} \\
3.98 \\
\overline{-} \\
3.93 \\
\overline{-} \\
3.88\end{array}$ & $\begin{array}{c}\overline{-} \\
\overline{-} \\
1,720 \\
\overline{-} \\
1, \overline{6} 80 \\
\overline{-} \\
1, \overline{6} \\
\overline{-} \\
\overline{-}\end{array}$ \\
\hline & \multicolumn{2}{|c|}{ December 20} & \multicolumn{2}{|c|}{ December 21} & \multicolumn{2}{|c|}{ December 22} & \multicolumn{2}{|c|}{ December 23} & \multicolumn{2}{|c|}{ December 24} & \multicolumn{2}{|c|}{ December 25} \\
\hline $\begin{array}{r}2 \\
4 \\
6 \\
8 \\
10 \\
\mathbb{N} \\
2 \\
4 \\
6 \\
8 \\
10 \\
\mathbb{M}\end{array}$ & $\begin{array}{c}\overline{-} \\
3.85 \\
\vdots \\
3.81 \\
\vdots \\
\overline{3.76} \\
\overline{3} \\
3.74\end{array}$ & $\begin{array}{c}\overline{-} \\
1, \overline{5} 60 \\
\overline{-} \\
1, \overline{520} \\
\overline{-} \\
1, \overline{470} \\
\overline{-} \\
1, \overline{4} 60\end{array}$ & $\begin{array}{c}\overline{-} \\
3.71 \\
\overline{-} \\
3.68 \\
- \\
\overline{3.65} \\
- \\
\overline{3.63}\end{array}$ & $\begin{array}{c}\overline{-} \\
1, \overline{430} \\
\overline{-} \\
1, \overline{4} 00 \\
\overline{-} \\
1, \overline{3} 80 \\
\overline{-} \\
1, \overline{3} 60\end{array}$ & $\begin{array}{c}- \\
\overline{3.60} \\
\overline{-} \\
\overline{3.58} \\
\overline{-} \\
\overline{3.59} \\
\overline{-} \\
3.56\end{array}$ & $\begin{array}{c}\overline{-} \\
1, \overline{3} 30 \\
\overline{-} \\
1, \overline{3} 10 \\
\overline{-} \\
1, \overline{3} 20 \\
\overline{-} \\
1, \overline{3} 00\end{array}$ & $\begin{array}{c}\overline{-} \\
3.53 \\
\overline{-} \\
3.49 \\
\overline{-} \\
3.46 \\
\overline{3.44}\end{array}$ & $\begin{array}{c}\overline{-} \\
1, \overline{2} 70 \\
\overline{-} \\
1, \overline{2} 40 \\
\overline{-} \\
1, \overline{2} 20 \\
\overline{-} \\
1, \overline{2} 00\end{array}$ & $\begin{array}{c}\bar{z} \\
3.48 \\
\overline{-} \\
3.55 \\
\overline{-} \\
3.50 \\
\overline{3.42}\end{array}$ & $\begin{array}{c}\overline{-} \\
1, \overline{2} 30 \\
\overline{-} \\
1, \overline{2} 90 \\
\overline{-} \\
1, \overline{2} 50 \\
\overline{-} \\
1, \overline{1} 90\end{array}$ & $\begin{array}{c}- \\
\overline{3.39} \\
\overline{-} \\
3.35 \\
\overline{-} \\
3.33 \\
\overline{-} \\
3.32\end{array}$ & $\begin{array}{c}\overline{-} \\
1, \overline{1} 60 \\
\overline{-} \\
1, \overline{13} 0 \\
\overline{-} \\
1, \overline{110} \\
\overline{-} \\
1, \overline{1110}\end{array}$ \\
\hline
\end{tabular}


Location. - Lat. $40^{\circ} 44^{\prime}$, long. $122^{\circ} 24^{\prime}$, in Swi sec. 2 , T. 33 N., R. 5 k., at highway bridge at Kennett, Shasta county. Zero of gage is 618.26 feet above mean sea lovel. Gage set to read 2.OC feet more than U. S. Weather Bureau gage at same location. Drainase area.- 6,600 square miles (not including Goose Lake Basin). Gage-helght record. - Water-stage recorder graph.

Stage-discharge relation. - Defined by current-meter measurements below 66,000 seccndfeet; extended to peak stage on basis of area-velceity study and $A \sqrt{d}$ method; verifled by comparison of peak discharge and total run-off of flood with records for other stations in Sacramento River Basin.

Maximg.- December 1937: Discharge, 132,000 second-feet 1 a.m. Dec. 11 (gage height, 30.6 feet)

1925-November 1937: Discharge, 94,900 second-feet Mar. 26, 1928 (gage height,

25.1 feet), from rating curve extended above 66,000 second-feet.

Remarks. - Flood mun-off not materially affected by artificlal storage or diversion.

Mean daily discharge, in second-feet, November 1937 to January 1938

\begin{tabular}{|c|c|c|c|c|c|c|c|c|c|c|c|}
\hline Dey & Nov. & Dec. & Jan. & Dey & Nov. & Dec. & Jan. & Day & Nov. & Dec. & Jan. \\
\hline $\begin{array}{r}1 \\
2 \\
3 \\
4 \\
5 \\
6 \\
7 \\
8 \\
9 \\
10\end{array}$ & $\begin{array}{l}2,910 \\
3,020 \\
3,020 \\
3,130 \\
3,130 \\
2,650 \\
2,500 \\
2,650 \\
2,860 \\
6,210\end{array}$ & $\begin{array}{r}7,050 \\
6,460 \\
6,280 \\
5,750 \\
5,590 \\
5,270 \\
5,120 \\
5,120 \\
5,430 \\
47,000\end{array}$ & $\begin{array}{l}7,460 \\
7,250 \\
7,050 \\
7,670 \\
7,460 \\
7,050 \\
6,850 \\
6,850 \\
6,850 \\
5,750\end{array}$ & $\begin{array}{l}11 \\
12 \\
13 \\
14 \\
15 \\
16 \\
17 \\
18 \\
19 \\
20\end{array}$ & $\begin{array}{r}13,900 \\
7,050 \\
5,270 \\
9,920 \\
7,890 \\
13,900 \\
17,000 \\
11,100 \\
10,600 \\
51,200\end{array}$ & $\begin{array}{l}97,200 \\
66,400 \\
49,800 \\
35,100 \\
26,500 \\
22,000 \\
18,200 \\
14,700 \\
13,100 \\
12,400\end{array}$ & $\begin{array}{r}5,920 \\
5,920 \\
5,920 \\
5,750 \\
7,050 \\
8,770 \\
20,100 \\
16,100 \\
15,300 \\
15,300\end{array}$ & $\begin{array}{l}21 \\
22 \\
23 \\
24 \\
25 \\
26 \\
27 \\
28 \\
29 \\
30 \\
31\end{array}$ & $\begin{array}{r}28,200 \\
17,600 \\
31,800 \\
29,900 \\
18,500 \\
14,200 \\
11,600 \\
9,680 \\
8,330 \\
7,460\end{array}$ & $\begin{array}{r}11,100 \\
9,920 \\
9,440 \\
9,210 \\
8,550 \\
8,110 \\
8,330 \\
7,890 \\
7,250 \\
7,250 \\
7,890\end{array}$ & $\begin{array}{r}12,600 \\
11,400 \\
10,900 \\
10,600 \\
9,680 \\
8,990 \\
8,330 \\
8,770 \\
8,990 \\
8,550 \\
16,300\end{array}$ \\
\hline Run & & & & & & & & & $\begin{array}{r}11,910 \\
708.5\end{array}$ & $\begin{array}{r}17,720 \\
1,090\end{array}$ & $\begin{array}{l}9,403 \\
578.1\end{array}$ \\
\hline
\end{tabular}

Gage height, in feet, and discharge, in second-feet, at indicated time, 1937

\begin{tabular}{|c|c|c|c|c|c|c|c|c|c|c|c|c|}
\hline \multirow{2}{*}{ 告 } & $F e \theta t$ & Sec.ft. & Feet & Sec.ft. & Feet & Sec.ft. & Feet & Sec.ft. & Feet & Sec.ft. & Feet & sec.ft. \\
\hline & \multicolumn{2}{|c|}{ December 8} & \multicolumn{2}{|c|}{ December 9} & \multicolumn{2}{|c|}{ December 10} & \multicolumn{2}{|c|}{ December 11} & \multicolumn{2}{|c|}{ December 12} & \multicolumn{2}{|c|}{ December 13} \\
\hline \multirow[t]{2}{*}{$\begin{array}{r}2 \\
4 \\
6 \\
8 \\
10 \\
N \\
2 \\
4 \\
6 \\
8 \\
10 \\
M\end{array}$} & $\begin{array}{c}\overline{-} \\
\overline{2.70} \\
- \\
\overline{2.66} \\
\overline{-} \\
\overline{2.63} \\
\overline{-} \\
\overline{2.64}\end{array}$ & $\begin{array}{c}-\overline{120} \\
5, \overline{-} \\
5, \overline{0} 60 \\
\overline{-} \\
5, \overline{0} 20 \\
\overline{-} \\
5, \overline{0} 30\end{array}$ & $\begin{array}{l}2.60 \\
2.60 \\
2.62 \\
2.61 \\
2.62 \\
2.63 \\
2.72 \\
2.90 \\
3.07 \\
3.30 \\
3.63 \\
4.22\end{array}$ & $\begin{array}{l}4,970 \\
4,970 \\
5,000 \\
4,980 \\
5,000 \\
5,020 \\
5,150 \\
5,430 \\
5,700 \\
6,100 \\
6,710 \\
7,930\end{array}$ & $\begin{array}{r}5.00 \\
5.88 \\
6.90 \\
8.00 \\
10.45 \\
13.40 \\
16.10 \\
18.70 \\
21.50 \\
23.50 \\
26.20 \\
29.70\end{array}$ & $\begin{array}{r}9,680 \\
11,800 \\
14,500 \\
17,600 \\
25,600 \\
37,200 \\
49,300 \\
62,200 \\
77,400 \\
88,800 \\
105,000 \\
127,000\end{array}$ & $\begin{array}{l}30.00 \\
27.20 \\
24.70 \\
23.30 \\
23.40 \\
23.30 \\
23.75 \\
24.20 \\
24.60 \\
24.35 \\
23.60 \\
22.30\end{array}$ & $\begin{array}{r}128,000 \\
111,000 \\
95,800 \\
87,600 \\
88,200 \\
87,600 \\
90,200 \\
92,900 \\
95,200 \\
93,800 \\
89,400 \\
81,900\end{array}$ & $\begin{array}{l}21.30 \\
20.55 \\
20.00 \\
19.80 \\
19.60 \\
19.35 \\
19.10 \\
18.90 \\
18.70 \\
18.50 \\
18.30 \\
18.05\end{array}$ & $\begin{array}{l}76,300 \\
72,100 \\
69,100 \\
68,000 \\
67,000 \\
65,700 \\
64,300 \\
63,300 \\
62,200 \\
61,200 \\
60,200 \\
58,900\end{array}$ & $\begin{array}{l}17.80 \\
17.50 \\
17.15 \\
16.80 \\
16.50 \\
16.20 \\
15.90 \\
14.60 \\
15.30 \\
15.00 \\
14.70 \\
14.40\end{array}$ & $\begin{array}{l}57,600 \\
56,100 \\
54,400 \\
52,600 \\
51,200 \\
49,800 \\
48,300 \\
47,000 \\
45,600 \\
44,200 \\
42,800 \\
41,500\end{array}$ \\
\hline & \multicolumn{2}{|c|}{ December 14} & \multicolumn{2}{|c|}{ December 15} & \multicolumn{2}{|c|}{ December 16} & \multicolumn{2}{|c|}{ December 17} & \multicolumn{2}{|c|}{ December 18} & \multicolumn{2}{|c|}{ December 19} \\
\hline \multirow[t]{2}{*}{$\begin{array}{r}2 \\
4 \\
6 \\
8 \\
10 \\
N \\
2 \\
4 \\
6 \\
8 \\
10 \\
M\end{array}$} & $\begin{array}{c}13.85 \\
- \\
13.30 \\
- \\
12.80 \\
- \\
12.40 \\
12.00 \\
- \\
11.55\end{array}$ & $\begin{array}{c}39,100 \\
36,800 \\
- \\
34,700 \\
33,000 \\
31,400 \\
29,700\end{array}$ & $\begin{array}{c}11.20 \\
- \\
10.95 \\
- \\
10.65 \\
- \\
10.45 \\
- \\
10.27 \\
- \\
9.80\end{array}$ & $\begin{array}{c}28,400 \\
27,400 \\
26,300 \\
25,600 \\
- \\
25,000 \\
23,300\end{array}$ & $\begin{array}{l}9.93 \\
9.70 \\
9.60 \\
9.51 \\
9.45 \\
9.38 \\
9.29 \\
9.18 \\
9.25 \\
9.10 \\
9.08 \\
8.92\end{array}$ & $\begin{array}{l}23,800 \\
23,000 \\
22,600 \\
22,300 \\
22,100 \\
21,900 \\
21,600 \\
21,300 \\
21,500 \\
21,000 \\
21,000 \\
20,400\end{array}$ & $\begin{array}{l}8.75 \\
8.39 \\
8.10 \\
7.81 \\
7.82 \\
7.90 \\
8.05 \\
8.25 \\
8.32 \\
8.11 \\
7.97 \\
7.85\end{array}$ & $\begin{array}{l}19,900 \\
18,800 \\
17,900 \\
17,000 \\
17,100 \\
17,300 \\
17,800 \\
18,400 \\
18,600 \\
17,900 \\
17,500 \\
17,200\end{array}$ & $\begin{array}{l}7.71 \\
7.57 \\
7.13 \\
6.82 \\
6.70 \\
6.75 \\
6.80 \\
7.03 \\
7.00 \\
6.94 \\
6.87 \\
6.80\end{array}$ & $\begin{array}{l}16,700 \\
16,300 \\
15,100 \\
14,200 \\
13,900 \\
14,000 \\
14,200 \\
14,800 \\
14,700 \\
14,600 \\
14,400 \\
14,200\end{array}$ & $\begin{array}{l}7.17 \\
7.10 \\
6.73 \\
6.10 \\
5.94 \\
5.86 \\
5.86 \\
6.10 \\
6.47 \\
6.36 \\
6.27 \\
6.08\end{array}$ & $\begin{array}{l}15,200 \\
15,000 \\
14,000 \\
12,400 \\
11,900 \\
11,700 \\
11,700 \\
12,400 \\
13,300 \\
13,000 \\
12,800 \\
12,300\end{array}$ \\
\hline & \multicolumn{2}{|c|}{ December 20} & \multicolumn{2}{|c|}{ December 21} & \multicolumn{2}{|c|}{ December 22} & \multicolumn{2}{|c|}{ December 23} & \multicolumn{2}{|c|}{ December 24} & \multicolumn{2}{|c|}{ December 25} \\
\hline $\begin{array}{r}2 \\
4 \\
6 \\
8 \\
10 \\
N \\
2 \\
4 \\
6 \\
8 \\
10 \\
M\end{array}$ & $\begin{array}{l}6.55 \\
6.60 \\
6.55 \\
6.10 \\
5.70 \\
5.49 \\
5.59 \\
6.00 \\
6.29 \\
6.06 \\
5.95 \\
5.72\end{array}$ & $\begin{array}{l}13,500 \\
13,700 \\
13,500 \\
12,400 \\
11,400 \\
10,900 \\
11,100 \\
12,100 \\
12,900 \\
12,300 \\
12,000 \\
11,400\end{array}$ & $\begin{array}{l}5.90 \\
6.04 \\
5.96 \\
5.65 \\
5.40 \\
5.30 \\
5.06 \\
5.06 \\
5.81 \\
5.59 \\
5.48 \\
5.20\end{array}$ & $\begin{array}{r}11,800 \\
12,200 \\
12,000 \\
11,200 \\
10,600 \\
10,400 \\
9,820 \\
9,820 \\
11,600 \\
11,100 \\
10,800 \\
10,200\end{array}$ & $\begin{array}{l}5.49 \\
5.42 \\
5.10 \\
4.87 \\
4.62 \\
4.70 \\
4.75 \\
5.02 \\
5.47 \\
5.31 \\
5.23\end{array}$ & $\begin{array}{r}10,900 \\
10,700 \\
9,920 \\
9,370 \\
8,810 \\
8,990 \\
9,100 \\
9,730 \\
10,800 \\
10,400 \\
10,200 \\
9,990\end{array}$ & $\begin{array}{l}5.41 \\
5.45 \\
5.10 \\
4.77 \\
4.49 \\
4.38 \\
4.40 \\
4.48 \\
4.92 \\
5.03 \\
4.99 \\
4.95\end{array}$ & $\begin{array}{r}10,700 \\
10,800 \\
9,920 \\
9,140 \\
8,530 \\
8,290 \\
8,330 \\
8,510 \\
9,490 \\
9,750 \\
9,660 \\
9,560\end{array}$ & $\begin{array}{l}4.94 \\
5.25 \\
5.05 \\
4.86 \\
4.51 \\
4.20 \\
4.12 \\
4.25 \\
5.00 \\
5.20 \\
5.18 \\
5.05\end{array}$ & $\begin{array}{r}9,540 \\
10,300 \\
9,800 \\
9,350 \\
8,570 \\
7,890 \\
7,710 \\
8,000 \\
9,680 \\
10,200 \\
10,100 \\
9,800\end{array}$ & $\begin{array}{l}5.25 \\
5.20 \\
4.90 \\
4.63 \\
4.20 \\
3.92 \\
3.87 \\
4.02 \\
4.19 \\
4.25 \\
4.30\end{array}$ & $\begin{array}{r}10,300 \\
10,200 \\
9,440 \\
8,840 \\
7,890 \\
7,290 \\
7,190 \\
7,500 \\
7,870 \\
8,000 \\
8,110 \\
8,110\end{array}$ \\
\hline
\end{tabular}

Supplemental records.- Dec. 11,1 a.m., 30.6 ft., 132,000 sec.-ft.; 9 a.m., 23.1

ft., 86,500 sec. $-f t$. 
Location. - Lat. $40^{\circ} 13^{\prime} 55^{\prime \prime}$, long. $122^{\circ} 10^{\prime} 50^{\prime \prime}$, in SE sec. 34, T. 28 N., R. 3 w., at lower end of Iron Canyon, half a mile below Sevenmile Creek and 4 miles northeast of Red Bluff, Tehama County. Alt1tude, about 250 feet above mean sea level.

Dra1nage area.- 9,300 square milos (not including Goose Lake Basin).

Gage-helght record. - Water-stage recorder graph.

Stage-discharge relation.- Defined by current-meter measurements below 125,000 secondfeet; extended to peak stage on bas is of area-velocity study at gage section; veriFled by slope-area determination of flood flow and logarithmic extension to peak stage.

Maxima.- December 1937: Discharge, 262,000 seoond-feet 7:30 a.m. Dec. 11 (gage heIght, 36.50 feet).

1895-November 1937: Discharge observed, 261,000 second-feet (rev1sed) Feb. 3 ,

1909 (gage helght, 35.2 feet, from nonrecording gage), from rating curve extended above 110,000 second-feet on basis of shape of rating curve for 1937-38.

Remarks. - Flood run-off not materially affected by artificlal storage or diversion.

Mean dally discharge, in second-feet, November 1937 to January 1938

\begin{tabular}{|c|c|c|c|c|c|c|c|c|c|c|c|}
\hline Day & Nov. & Dec. & Jan. & Day & Nov. & Dec. & Jan. & Day & Nov. & Dec. & Jan. \\
\hline $\begin{array}{r}1 \\
2 \\
3 \\
4 \\
5 \\
6 \\
7 \\
8 \\
9 \\
10\end{array}$ & $\begin{array}{l}3,610 \\
3,700 \\
3,700 \\
3,700 \\
3,790 \\
3,700 \\
3,350 \\
3,180 \\
3,520 \\
3,880\end{array}$ & $\begin{array}{r}10,000 \\
9,430 \\
8,870 \\
8,320 \\
7,780 \\
7,510 \\
7,240 \\
6,980 \\
7,240 \\
66,600\end{array}$ & $\begin{array}{r}10,900 \\
10,900 \\
11,200 \\
11,200 \\
10,900 \\
10,600 \\
10,300 \\
10,000 \\
10,000 \\
9,150\end{array}$ & $\begin{array}{l}11 \\
12 \\
13 \\
14 \\
15 \\
16 \\
17 \\
18 \\
19 \\
20\end{array}$ & $\begin{array}{r}14,300 \\
13,400 \\
7,780 \\
10,500 \\
13,400 \\
18,100 \\
42,800 \\
20,100 \\
16,000 \\
91,100\end{array}$ & $\begin{array}{r}225,000 \\
134,000 \\
82,400 \\
56,800 \\
41,300 \\
32,900 \\
27,400 \\
22,800 \\
19,800 \\
17,700\end{array}$ & $\begin{array}{r}8,590 \\
8,870 \\
8,870 \\
8,590 \\
11,200 \\
11,800 \\
43,100 \\
32,900 \\
27,400 \\
28,300\end{array}$ & $\begin{array}{l}21 \\
22 \\
23 \\
24 \\
25 \\
26 \\
27 \\
28 \\
29 \\
30 \\
31\end{array}$ & $\begin{array}{l}76,200 \\
30,100 \\
37,800 \\
51,200 \\
31,000 \\
22,000 \\
17,700 \\
14,300 \\
12,400 \\
10,900\end{array}$ & $\begin{array}{l}16,700 \\
15,000 \\
14,300 \\
13,700 \\
14,300 \\
12,400 \\
12,100 \\
12,100 \\
11,200 \\
10,600 \\
11,200\end{array}$ & $\begin{array}{l}21,600 \\
18,400 \\
17,300 \\
16,000 \\
15,300 \\
14,000 \\
13,100 \\
13,400 \\
15,600 \\
13,700 \\
19,800\end{array}$ \\
\hline $\begin{array}{l}\text { Yea } \\
\text { Run }\end{array}$ & 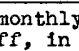 & & & & & & & & $\begin{array}{r}19,570 \\
1.165\end{array}$ & $\begin{array}{r}30,440 \\
1,872\end{array}$ & $\begin{array}{r}15,260 \\
938.1\end{array}$ \\
\hline
\end{tabular}

Gage helght, in feet, and discharge, in second-feet, at indicated time, 1937

\begin{tabular}{|c|c|c|c|c|c|c|c|c|c|c|c|c|}
\hline \multirow{2}{*}{ 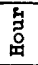 } & Feet & Sec.ft. & Feet & Sec.ft. & Feet & Sec.ft. & Feet & Sec.ft. & Feet & Sec.ft. & Feet & sec.ft. \\
\hline & \multicolumn{2}{|c|}{ December 8} & \multicolumn{2}{|c|}{ December 9} & \multicolumn{2}{|c|}{ December 10} & \multicolumn{2}{|c|}{ December 11} & \multicolumn{2}{|c|}{ December 12} & \multicolumn{2}{|c|}{ December 13} \\
\hline \multirow[t]{2}{*}{$\begin{array}{r}2 \\
4 \\
6 \\
8 \\
10 \\
1 \\
2 \\
4 \\
6 \\
8 \\
10 \\
M \\
\end{array}$} & $\begin{array}{c}\overline{2} \\
\overline{-} \\
= \\
2.21 \\
= \\
= \\
2.16 \\
=\end{array}$ & $\begin{array}{c}6, \overline{980} \\
- \\
- \\
6, \overline{9} \\
= \\
= \\
6, \overline{9} \\
= \\
=\end{array}$ & $\begin{array}{l}2.17 \\
2.16 \\
2.15 \\
2.15 \\
2.15 \\
2.16 \\
2.16 \\
2.17 \\
2.24 \\
2.47 \\
3.00 \\
3.65\end{array}$ & $\begin{array}{r}6,980 \\
6,980 \\
6,980 \\
6,980 \\
6,980 \\
6,980 \\
6,980 \\
6,980 \\
6,980 \\
7,780 \\
9,150 \\
10,900\end{array}$ & $\begin{array}{r}5.00 \\
6.80 \\
8.70 \\
10.00 \\
11.40 \\
12.85 \\
14.50 \\
16.85 \\
19.7 \\
22.7 \\
27.0 \\
30.0\end{array}$ & \begin{tabular}{|r|}
15,300 \\
21,600 \\
29,600 \\
35,000 \\
42,800 \\
50,100 \\
59,800 \\
74,300 \\
94,700 \\
119,000 \\
158,000 \\
188,000
\end{tabular} & \begin{tabular}{|l|}
32.6 \\
34.76 \\
36.2 \\
36.45 \\
35.9 \\
35.25 \\
34.15 \\
32.8 \\
31.4 \\
30.45 \\
29.95 \\
29.25
\end{tabular} & $\begin{array}{l}217,000 \\
242,000 \\
258,000 \\
261,000 \\
255,000 \\
246,000 \\
234,000 \\
219,000 \\
203,000 \\
192,000 \\
188,000 \\
180,000\end{array}$ & $\begin{array}{l}28.4 \\
27.6 \\
26.8 \\
26.05 \\
25.15 \\
24.14 \\
23.35 \\
22.45 \\
21.75 \\
21.0 \\
20.6 \\
20.1\end{array}$ & $\begin{array}{r}172,000 \\
164,000 \\
156,000 \\
148,000 \\
141,000 \\
132,000 \\
125,000 \\
116,000 \\
111,000 \\
104,000 \\
101,000 \\
97,700\end{array}$ & $\begin{array}{l}19.7 \\
19.3 \\
19.0 \\
18.7 \\
18.35 \\
18.0 \\
17.7 \\
17.3 \\
16.95 \\
16.6 \\
16.25 \\
15.90\end{array}$ & $\begin{array}{l}94,700 \\
91,700 \\
89,500 \\
87,400 \\
85,200 \\
82,400 \\
80,400 \\
77,600 \\
75,600 \\
73,000 \\
70,300 \\
68,400\end{array}$ \\
\hline & \multicolumn{2}{|c|}{ December 14} & \multicolumn{2}{|c|}{ December 15} & \multicolumn{2}{|c|}{ December 16} & \multicolumn{2}{|c|}{ December 17} & \multicolumn{2}{|c|}{ December 18} & \multicolumn{2}{|c|}{ December 19} \\
\hline \multirow[t]{2}{*}{\begin{tabular}{r|}
2 \\
4 \\
6 \\
8 \\
10 \\
$\mathrm{~N}$ \\
2 \\
4 \\
6 \\
8 \\
10 \\
$\mathrm{M}$
\end{tabular}} & \begin{tabular}{|l|}
15.55 \\
15.22 \\
14.91 \\
14.58 \\
14.26 \\
13.90 \\
13.62 \\
13.36 \\
13.06 \\
12.82 \\
12.58 \\
12.32
\end{tabular} & $\begin{array}{l}66,500 \\
64,000 \\
62,200 \\
60,400 \\
58,600 \\
56,200 \\
54,600 \\
53,400 \\
51,800 \\
50,100 \\
49,000 \\
47,400\end{array}$ & \begin{tabular}{|l|}
12.10 \\
11.85 \\
11.64 \\
11.44 \\
11.26 \\
11.02 \\
10.85 \\
10.70 \\
10.55 \\
10.40 \\
10.26 \\
10.12
\end{tabular} & $\begin{array}{l}46,300 \\
44,800 \\
43,800 \\
42,800 \\
42,300 \\
40,800 \\
39,800 \\
39,300 \\
38,800 \\
37,800 \\
37,300 \\
36,300\end{array}$ & $\begin{array}{l}9.98 \\
9.86 \\
9.73 \\
9.59 \\
9.45 \\
9.36 \\
9.26 \\
9.16 \\
9.03 \\
8.98 \\
8.90 \\
8.80\end{array}$ & $\begin{array}{l}35,800 \\
35,300 \\
34,400 \\
33,900 \\
32,900 \\
32,900 \\
32,400 \\
32,000 \\
31,000 \\
30,100 \\
30,500 \\
30,100\end{array}$ & $\begin{array}{l}8.73 \\
8.66 \\
8.60 \\
8.54 \\
8.43 \\
8.28 \\
8.07 \\
7.84 \\
7.64 \\
7.50 \\
7.48\end{array}$ & $\begin{array}{l}29,600 \\
29,600 \\
29,200 \\
28,700 \\
28,300 \\
27,800 \\
26,900 \\
25,700 \\
24,800 \\
24,400 \\
24,400 \\
24,400\end{array}$ & $\begin{array}{c}7.60 \\
- \\
7.45 \\
- \\
7.22 \\
- \\
6.89 \\
-\overline{4} 49 \\
-\overline{6.41}\end{array}$ & $\begin{array}{c}24,800 \\
24,000 \\
- \\
23,200 \\
2 \overline{,}, 000 \\
20,500 \\
20,100\end{array}$ & $\begin{array}{c}- \\
6.48 \\
6.44 \\
- \\
6.36 \\
= \\
6.48 \\
- \\
6.00 \\
5.67\end{array}$ & $\begin{array}{c}20,500 \\
20,100 \\
20,100 \\
- \\
20,500 \\
18,700 \\
- \\
17,700\end{array}$ \\
\hline & \multicolumn{2}{|c|}{ December 20} & \multicolumn{2}{|c|}{ December 21} & \multicolumn{2}{|c|}{ December 22} & \multicolumn{2}{|c|}{ December 23} & \multicolumn{2}{|c|}{ December 24} & \multicolumn{2}{|c|}{ December 25} \\
\hline $\begin{array}{r}2 \\
4 \\
6 \\
8 \\
10 \\
N \\
2 \\
4 \\
6 \\
8 \\
10 \\
M\end{array}$ & $\begin{array}{c}- \\
5.68 \\
\overline{5.84} \\
\overline{5.72} \\
\overline{5.92} \\
\overline{5.69} \\
\overline{5.30}\end{array}$ & $\begin{array}{c}17,700 \\
- \\
18,000 \\
- \\
17,700 \\
18,400 \\
- \\
17,700 \\
16,300\end{array}$ & $\begin{array}{c}-\overline{433} \\
\overline{5} .54 \\
\overline{5} \\
\overline{-} \\
5.41 \\
\overline{-} \\
\overline{-} \\
4.98\end{array}$ & $\begin{array}{c}16,700 \\
17,000 \\
16,700 \\
16,700 \\
16,300 \\
- \\
15,300\end{array}$ & $\begin{array}{c}- \\
4.91 \\
- \\
5.10 \\
- \\
4.91 \\
- \\
4.97 \\
\overline{4.75} \\
\overline{4.52}\end{array}$ & $\begin{array}{c}15,000 \\
15,600 \\
15,000 \\
- \\
15,300 \\
14,700\end{array}$ & $\begin{array}{c}-\overline{4.66} \\
\overline{4.92} \\
- \\
4.84 \\
- \\
4.90 \\
\overline{4.61} \\
\overline{4.28}\end{array}$ & $\begin{array}{c}14,300 \\
- \\
15,000 \\
14,700\end{array}$ & $\begin{array}{c}- \\
4.22 \\
- \\
4.48 \\
-\overline{4} \\
-56 \\
4.60\end{array}$ & $\begin{array}{c}12,700 \\
13,700 \\
14,000 \\
- \\
14,000 \\
14,000\end{array}$ & $\begin{array}{c}- \\
4.34 \\
4.94 \\
- \\
4.97 \\
- \\
4.89 \\
- \\
4.64 \\
-\end{array}$ & $\begin{array}{c}13,100 \\
- \\
15,000 \\
15,300\end{array}$ \\
\hline
\end{tabular}

Supplemental records.- Dec. 11, 7:30 a.m., 36.50 ft., 262,000 sec.-ft. 


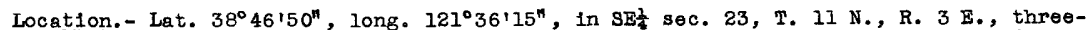
quarters of a mile southeast of Verona, Sutter County, and $i$ mile downstream from mouth of Feather River. Gage 1s set to datum of Corps of Engineers, U. S. Army.

Drainage area.- 21,400 square miles (not including Goose Lake Basin).

Gage-helght record. - Water-stage recorder graph.

Stage-discharge relation. - Defined by current-meter measurements below 57,000 secondfeet; extended to peak stage. Backwater corrections used for period Dec. $2-J a n .31$.

Maxima.- December 1937: Dlscharge, 68,400 second-feet 3 a.m. Dec. 14 (gage helght, 38.23 feet).

1929-November 1937: Discharge observed, 61,800 second-feet Feb. 25, 1936 (gage helght, 36.62 feet), from rating curve extended above 56,000 second-feet.

Remarks. - Flood run-off not materially affected by artificial storage. At discharges above 50,000 second-feet unmeasured flow beglns over Fremont we1r ( 1 mile upstream) 1nto Yolo by-pass. Elevation of crest of Fremont weir is 33.5 feet, datum of Corps of Engineers, U. S. Army.

Mean dally discharge, in second-feet, November 1937 to January 1938

\begin{tabular}{|c|c|c|c|c|c|c|c|c|c|c|c|}
\hline Day & Nov. & Dec. & Jan. & Day & Nov. & Dec. & Jan. & Day & Nov. & Dec. & Jan. \\
\hline 1 & 6,260 & 40,300 & 27,200 & 11 & 6,540 & 41,600 & 18,800 & 21 & 34,200 & 54,100 & 46,300 \\
2 & 6,260 & 34,400 & 25,300 & 12 & 6,840 & 61,600 & 18,300 & 22 & 40,500 & 52,500 & 47,600 \\
3 & 6,260 & 29,600 & 24,300 & 13 & 10,500 & 66,700 & 17,700 & 23 & 44,400 & 50,700 & 47,600 \\
4 & 6,540 & 26,200 & 23,800 & 14 & 14,400 & 68,100 & 17,200 & 24 & 49,100 & 48,100 & 46,000 \\
5 & 6,400 & 22,700 & 23,400 & 15 & 13,100 & 65,600 & 17,000 & 25 & 54,100 & 45,000 & 42,900 \\
6 & 6,540 & 19,200 & 22,500 & 16 & 13,100 & 62,500 & 18,800 & 26 & 54,400 & 41,600 & 39,500 \\
7 & 6,680 & 17,200 & 21,800 & 17 & 15,500 & 60,200 & 22,500 & 27 & 53,500 & 38,500 & 36,100 \\
8 & 6,540 & 16,100 & 21,000 & 18 & 22,500 & 58,300 & 30,800 & 28 & 52,500 & 35,400 & 33,400 \\
9 & 6,260 & 15,200 & 20,100 & 19 & 29,600 & 56,900 & 38,500 & 29 & 49,900 & 32,700 & 31,300 \\
10 & 6,260 & 16,300 & 19,200 & 20 & 31,000 & 55,200 & 43,400 & 30 & 45,700 & 30,800 & 30,100 \\
\end{tabular}

Gage helght, in feet, and discharge, in second-feet, at indicated t1me, 1937

\begin{tabular}{|c|c|c|c|c|c|c|c|c|c|c|c|c|}
\hline \multirow{2}{*}{$\begin{array}{l}5 \\
0 \\
0 \\
\end{array}$} & $9 \theta t$ & Sec.ft. & Peot & Sec.ft. & Feot & Sec.ft. & eet & Sec.ft. & $\theta \theta t$ & Sec.ft. & $\theta \theta t$ & Sec.te. \\
\hline & \multicolumn{2}{|c|}{ December 8} & \multicolumn{2}{|c|}{ December 9} & \multicolumn{2}{|c|}{ December 10} & \multicolumn{2}{|c|}{ December 11} & \multicolumn{2}{|c|}{ December 12} & \multicolumn{2}{|c|}{ December 13} \\
\hline $\begin{array}{r}2 \\
4 \\
6 \\
8 \\
10 \\
N \\
2 \\
4 \\
6 \\
8\end{array}$ & $\begin{array}{l}7.84 \\
- \\
7.74 \\
-.65 \\
7.65 \\
7.55 \\
- \\
7.46 \\
7.43\end{array}$ & $\begin{array}{c}16,200 \\
16,000 \\
15,800 \\
15,700\end{array}$ & $\begin{array}{c}17.41 \\
\overline{-} \\
17.32 \\
17.22 \\
\overline{-} \\
17.18 \\
\overline{-} \\
17.14 \\
\overline{17.20}\end{array}$ & 15,200 & & & & & & & $\begin{array}{c}36.85 \\
- \\
37.35 \\
37.74 \\
37.96 \\
38.15 \\
- \\
38.22\end{array}$ & $\begin{array}{l}64,60 \\
66,00 \\
67,10 \\
67,70 \\
68,20 \\
- \\
68,40\end{array}$ \\
\hline & \multicolumn{2}{|c|}{ Docember 14} & \multicolumn{2}{|c|}{ December 15} & \multicolumn{2}{|c|}{ December 16} & \multicolumn{2}{|c|}{ December 17} & \multicolumn{2}{|c|}{ December 18} & \multicolumn{2}{|c|}{ December 19} \\
\hline $\begin{array}{l}2 \\
4 \\
6 \\
8\end{array}$ & $\begin{array}{l}- \\
8.22 \\
- \\
8.20 \\
- \\
8.14\end{array}$ & $\begin{array}{l}68,400 \\
- \\
68,400 \\
68,200 \\
- \\
67,900 \\
=-500 \\
67,- \\
67,100\end{array}$ & $\begin{array}{c}-\overline{-} \\
37.58 \\
- \\
37.41\end{array}$ & $\begin{array}{c}65,000 \\
5 \\
64,500 \\
63,900\end{array}$ & $\begin{array}{l}5.94 \\
-.79 \\
5.79 \\
5.65\end{array}$ & $\begin{array}{l}62,000 \\
61,000 \\
61,200\end{array}$ & 35.07 & $\begin{array}{c}\bar{z} \\
59,600 \\
\overline{-} \\
59,100\end{array}$ & $\begin{array}{c}- \\
34.75 \\
- \\
- \\
34.59\end{array}$ & $\begin{array}{c}58,700 \\
- \\
- \\
58,300 \\
- \\
\bar{z}, 900 \\
\overline{-} \\
57,500\end{array}$ & $\begin{array}{l}- \\
4.20\end{array}$ & $\begin{array}{c}- \\
57,20\end{array}$ \\
\hline & \multicolumn{2}{|c|}{ December 20} & \multicolumn{2}{|c|}{ December 21} & \multicolumn{2}{|c|}{ December 22} & \multicolumn{2}{|c|}{ December 23} & \multicolumn{2}{|c|}{ December 24} & \multicolumn{2}{|c|}{ December 25} \\
\hline $\begin{array}{r}10 \\
\mathbf{N}\end{array}$ & $\begin{array}{c}\overline{-} \\
\overline{33.59} \\
\overline{-} \\
\overline{3} .47 \\
\overline{-} \\
\overline{3} .36\end{array}$ & $\begin{array}{c}54,800 \\
\overline{-} \\
54,500\end{array}$ & $33^{-} 12$ & $\begin{array}{c}53,700 \\
\overline{-} \\
53,400\end{array}$ & $3 \bar{i}^{-} 67$ & $\begin{array}{c}\overline{-} \\
52,900 \\
\overline{-} \\
52,600 \\
\overline{-} \\
52,200 \\
\overline{-} \\
51,700\end{array}$ & $\begin{array}{c}- \\
\overline{-} \\
32.05 \\
- \\
31.86\end{array}$ & $\begin{array}{c}\overline{-} \\
51,300 \\
\overline{-} \\
50,800 \\
\overline{-} \\
50,300 \\
\overline{-} \\
49,700\end{array}$ & $\begin{array}{c}31.16 \\
\overline{-} \\
30.87 \\
\pm \\
30.56 \\
\overline{-} \\
30.27\end{array}$ & $\begin{array}{c}\overline{-} \\
48,800 \\
\overline{-} \\
48,000 \\
\vdots \\
47,200 \\
\overline{-} \\
46,400\end{array}$ & $2 \overline{29.67}$ & 44,900 \\
\hline
\end{tabular}

Supplemental records.- Dec, 14, 3 a.m. $38.23 \mathrm{ft}, 68,400$ sec.-ft. 
Location. - Record for Sacramento River at Sacramento obtalned from U. S. Weather Bureau water-stage recorder at I Street bridge. Record for Yolo by-pass obtained from waterstage recorder of California State Department of Public Works at Lisbon sub-station 10 miles southwest of Sacramento.

Remarks. - During extreme high water gates are opened in Sacramento weir (on right bank of river 5 miles northwest of Sacramento and 4 miles upstream from American River) to permit spill into Yolo by-pass. Discharge of Yolo by-pass at Lisbon includes flow over Sacramento weIr as weil as that of Cache and Putah Creeks and other streams entering Sacramento River from the west. Combined flow of Sacramento River at Sacramento and Yolo by-pass at Lisbon gives practically total run-off from Sacramento

Valley to and including putah Creek. Complete records furnished by State engineer.

Discharge, in second-feet, December 1937

\begin{tabular}{|c|c|c|c|}
\hline Day & Sacramento R1ver & Yolo by-pass & Total \\
\hline $\begin{array}{l}1 \\
2 \\
3 \\
4 \\
5\end{array}$ & $\begin{array}{l}42,000 \\
36,500 \\
29,500 \\
26,000 \\
24,000\end{array}$ & $=$ & $\begin{array}{l}- \\
\bar{z} \\
=\end{array}$ \\
\hline $\begin{array}{r}6 \\
7 \\
8 \\
9 \\
10\end{array}$ & $\begin{array}{c}\overline{-} \\
25,000\end{array}$ & $\begin{array}{l}\overline{-} \\
\overline{-}\end{array}$ & $\overline{-}$ \\
\hline $\begin{array}{l}11 \\
12 \\
13 \\
14 \\
15\end{array}$ & $\begin{array}{r}\text { a } 70,000 \\
\text { b } 73,000 \\
66,200 \\
63,600 \\
62,500\end{array}$ & 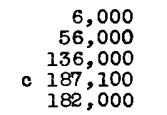 & $\begin{array}{r}76,000 \\
129,000 \\
202,000 \\
251,000 \\
244,000\end{array}$ \\
\hline $\begin{array}{l}16 \\
17 \\
18 \\
19 \\
20\end{array}$ & $\begin{array}{l}60,500 \\
60,000 \\
59,500 \\
58,900 \\
58,000\end{array}$ & $\begin{array}{r}142,000 \\
115,000 \\
81,700 \\
66,000 \\
42,000\end{array}$ & $\begin{array}{l}202,000 \\
175,000 \\
141,000 \\
125,000 \\
100,000\end{array}$ \\
\hline $\begin{array}{l}21 \\
22 \\
23 \\
24 \\
25\end{array}$ & $\begin{array}{l}56,500 \\
54,000 \\
53,000 \\
50,800 \\
49,200\end{array}$ & $\begin{array}{l}32,000 \\
22,000 \\
16,000 \\
13,000 \\
11,500\end{array}$ & $\begin{array}{l}88,500 \\
76,000 \\
69,000 \\
63,800 \\
60,700\end{array}$ \\
\hline $\begin{array}{l}26 \\
27 \\
28 \\
29 \\
30 \\
31\end{array}$ & $\begin{array}{l}46,000 \\
41,000 \\
38,000 \\
35,000 \\
32,500 \\
29,000\end{array}$ & $\begin{array}{r}10,000 \\
9,000 \\
7,000 \\
6,500 \\
6,000 \\
5,500\end{array}$ & $\begin{array}{l}56,000 \\
50,000 \\
45,000 \\
41,500 \\
38,500 \\
34,500\end{array}$ \\
\hline
\end{tabular}

a 48 gates of Sacramentc weir opened about 5 p.m. Dec. 11.

b Peak stage, 27.7 feet 2 a.m. Dec. 11 (discharge, 79,000 second-feet).

c Peak stage, 20.95 feet $8 \mathrm{p} . \mathrm{m}$. Dec. 14 (discharge, 194,000 second-feet).

Miscellaneous discharge measurements made by Corps of Engineers, U. S. Army, during flcod of December 1937 at varlous points on Sacramento River and adjecent channels

\begin{tabular}{|c|c|c|c|}
\hline Place of measurement & Date & $\begin{array}{c}\text { Elevation* } \\
\text { (feet) }\end{array}$ & $\begin{array}{c}\text { Discharge } \\
\text { (second-feet) }\end{array}$ \\
\hline $\begin{array}{l}\text { Colusa weir } \\
\text { Do. } \\
\text { Do. } \\
\text { Sutter by-pass at Long Bridge } \\
\text { Sacramento River at Tisdale weir } \\
\text { Sutter by-pass at Sutter causeway } \\
\text { Do. } \\
\text { Do. } \\
\text { Do. } \\
\text { Do. } \\
\text { Sacramento River at Knights Landing } \\
\text { Do. } \\
\text { Do. } \\
\text { Do. } \\
\text { Knights Landing Ridge cut at highway bridge } \\
\text { Do. } \\
\text { Do. } \\
\text { Do. }\end{array}$ & $\begin{array}{l}12 \\
12 \\
13 \\
13 \\
14 \\
12 \\
12-13 \\
13 \\
13 \\
13 \\
12 \\
13 \\
13 \\
14 \\
15 \\
15-16 \\
16 \\
18\end{array}$ & $\begin{array}{l}66.08 \\
66.35 \\
67.26 \\
54.05 \\
51.20 \\
39.95 \\
42.45 \\
45.05 \\
46.75 \\
47.25 \\
38.23 \\
39.02 \\
39.69 \\
40.16 \\
33.49 \\
34.70 \\
35.56 \\
36.38\end{array}$ & $\begin{array}{r}56,900 \\
59,200 \\
30,800 \\
147,000 \\
16,100 \\
13,000 \\
61,100 \\
106,000 \\
142,000 \\
148,000 \\
20,700 \\
20,300 \\
21,400 \\
23,100 \\
2,780 \\
6,560 \\
11,200 \\
12,700\end{array}$ \\
\hline
\end{tabular}

*Datum of Corps of Engineers, U. S. Army. 
Plt Rfver near Canby, Calif.

Location.- Lat. $41^{\circ} 24^{\prime}$, long. $120^{\circ} 55^{\prime}$, in SWr sec. 10, T. 41 N., R. 9 E., at lower end of Warm Spring Valley, about 4 mlles southwest of Canby, Modoc County. Alt1tude, about 4,300 leet above mean sea level.

Drainage area.- 1,430 square miles (revised), not including Goose Lake Basin.

Gage-helght record.- Water-stage recorder graph.

Stage-discharge relation.- Defined by current-meter measurements below 3,600 secondfeet extended to peak stage on bas is of area-velocity study.

Maxime,- December 1937: Discharge, 8,210 second-feet 5 p.m. Dec. 11 (gage he1ght, 12.65 feet).

1904-5, 1929-November 1937: Discharge observed, 17,000 second-feet (rev1sed)

Mar. 8, 1904 (gage he1ght, 14.0 feet, nonrecording gage, former datum), from rating curve extended above 6,000 second-feet.

Remarks.- Flood mun-off silghtly affected by artificlal storage.

Mean deliy discherge, in second-feet, November 1937 to January 1938

\begin{tabular}{|c|c|c|c|c|c|c|c|c|c|c|c|}
\hline Dey & Nov. & Dec. & Jan. & Dey & Nov. & Dec. & Jan. & Day & Nov. & Dec. & Jan. \\
\hline $\begin{array}{r}1 \\
2 \\
3 \\
4 \\
5 \\
6 \\
7 \\
8 \\
9 \\
10\end{array}$ & $\begin{array}{l}26 \\
24 \\
23 \\
22 \\
24 \\
38 \\
31 \\
33 \\
29 \\
26\end{array}$ & $\begin{array}{r}90 \\
90 \\
73 \\
67 \\
63 \\
58 \\
56 \\
52 \\
62 \\
473\end{array}$ & $\begin{array}{l}241 \\
246 \\
241 \\
232 \\
223 \\
205 \\
184 \\
162 \\
144 \\
125\end{array}$ & $\begin{array}{l}11 \\
12 \\
13 \\
14 \\
15 \\
16 \\
17 \\
18 \\
19 \\
20\end{array}$ & $\begin{array}{r}31 \\
33 \\
33 \\
36 \\
50 \\
40 \\
60 \\
60 \\
83 \\
107\end{array}$ & $\begin{array}{r}6,570 \\
5,950 \\
5,950 \\
4,170 \\
2,800 \\
2,060 \\
1,680 \\
1,400 \\
1,140 \\
932\end{array}$ & $\begin{array}{l}125 \\
122 \\
125 \\
129 \\
140 \\
144 \\
158 \\
184 \\
179 \\
171\end{array}$ & $\begin{array}{l}21 \\
22 \\
23 \\
24 \\
25 \\
26 \\
27 \\
28 \\
29 \\
30 \\
31\end{array}$ & $\begin{array}{r}144 \\
158 \\
260 \\
246 \\
192 \\
171 \\
155 \\
132 \\
116 \\
98\end{array}$ & $\begin{array}{l}788 \\
668 \\
521 \\
416 \\
335 \\
295 \\
260 \\
246 \\
241 \\
241 \\
241\end{array}$ & $\begin{array}{l}166 \\
223 \\
255 \\
305 \\
290 \\
250 \\
232 \\
205 \\
192 \\
184 \\
179\end{array}$ \\
\hline & & & & & & & & $\cdots$ & $\begin{array}{r}82.7 \\
4,920 \\
\end{array}$ & $\begin{array}{r}1,225 \\
75,330 \\
\end{array}$ & $\begin{array}{r}192 \\
11,820 \\
\end{array}$ \\
\hline
\end{tabular}

Gage height, in feet, and discharge, in second-feet, at indicated time, 1937

\begin{tabular}{|c|c|c|c|c|c|c|c|c|c|c|c|c|}
\hline \multirow{2}{*}{ 胞 } & peot & Sec.ft. & Feet & Sec.ft. & Feet & Sec.ft. & Feet & Sec.ft. & Feet & Sec.ft. & Feet & sec.ft. \\
\hline & \multicolumn{2}{|c|}{ December 8} & \multicolumn{2}{|c|}{ December 9} & \multicolumn{2}{|c|}{ December 10} & \multicolumn{2}{|c|}{ December 11} & \multicolumn{2}{|c|}{ December 12} & \multicolumn{2}{|c|}{ December 13} \\
\hline \multirow[t]{2}{*}{\begin{tabular}{r|}
2 \\
4 \\
6 \\
8 \\
10 \\
$\mathrm{~N}$ \\
2 \\
4 \\
6 \\
8 \\
10 \\
$\mathrm{M}$
\end{tabular}} & $\begin{array}{c}\overline{-} \\
2.52 \\
= \\
\overline{2.51} \\
= \\
2.50 \\
\overline{-} \\
2.51\end{array}$ & $\begin{array}{l}\overline{5} \\
54 \\
\overline{5} \\
52 \\
\overline{50} \\
\overline{5} \\
52\end{array}$ & $\begin{array}{c}\overline{-} \\
2.50 \\
\overline{-} \\
2.50 \\
\overline{-} \\
\overline{2.50} \\
\overline{-} \\
2.51\end{array}$ & $\begin{array}{l}\overline{-} \\
50 \\
5 \\
50 \\
= \\
\overline{5} 0 \\
- \\
52\end{array}$ & $\begin{array}{l}2.51 \\
2.52 \\
2.53 \\
2.55 \\
2.57 \\
3.10 \\
3.25 \\
3.52 \\
3.74 \\
4.62 \\
5.25 \\
6.45\end{array}$ & $\begin{array}{r}52 \\
54 \\
56 \\
60 \\
65 \\
250 \\
325 \\
466 \\
587 \\
1,120 \\
1,540 \\
2,380\end{array}$ & $\begin{array}{r}7.73 \\
8.49 \\
9.14 \\
10.00 \\
11.23 \\
12.12 \\
12.45 \\
12.63 \\
12.61 \\
12.48 \\
12.36 \\
12.17\end{array}$ & $\begin{array}{l}3,390 \\
4,070 \\
4,690 \\
5,550 \\
6,780 \\
7,680 \\
8,040 \\
8,210 \\
8,210 \\
8,080 \\
7,950 \\
7,740\end{array}$ & $\begin{array}{r}11.84 \\
11.50 \\
11.15 \\
10.75 \\
10.42 \\
10.09 \\
9.78 \\
9.59 \\
9.66 \\
9.66 \\
9.84 \\
10.11\end{array}$ & $\begin{array}{l}7,390 \\
7,050 \\
6,700 \\
6,300 \\
5,970 \\
5,640 \\
5,330 \\
5,140 \\
5,110 \\
5,210 \\
5,390 \\
5,660\end{array}$ & $\begin{array}{r}10.37 \\
10.57 \\
10.69 \\
10.70 \\
10.67 \\
10.60 \\
10.49 \\
10.35 \\
10.20 \\
10.04 \\
9.88 \\
9.69\end{array}$ & \begin{tabular}{|l|}
5,920 \\
6,120 \\
6,240 \\
6,250 \\
6,220 \\
6,150 \\
6,040 \\
5,900 \\
5,750 \\
5,590 \\
5,430 \\
5,240
\end{tabular} \\
\hline & \multicolumn{2}{|c|}{ December 14} & \multicolumn{2}{|c|}{ December 15} & \multicolumn{2}{|c|}{ December 16} & \multicolumn{2}{|c|}{ December 17} & \multicolumn{2}{|c|}{ December 18} & \multicolumn{2}{|c|}{ December 19} \\
\hline \multirow[t]{2}{*}{$\begin{array}{r}2 \\
4 \\
6 \\
8 \\
10 \\
4 \\
2 \\
4 \\
6 \\
8 \\
10 \\
M \\
\end{array}$} & $\begin{array}{l}9.51 \\
9.32 \\
9.16 \\
8.98 \\
8.79 \\
8.63 \\
8.45 \\
8.36 \\
8.12 \\
7.97 \\
7.88 \\
7.64\end{array}$ & $\begin{array}{l}5,060 \\
4,870 \\
4,710 \\
4,530 \\
4,340 \\
4,200 \\
4,040 \\
3,900 \\
3,740 \\
3,600 \\
3,470 \\
3,310\end{array}$ & $\begin{array}{c}6.98 \\
- \\
6.78 \\
- \\
6.57 \\
- \\
6.39\end{array}$ & $\begin{array}{c}3, \overline{100} \\
\overline{-} \\
2,830 \\
\overline{-} \\
2, \overline{7} 80 \\
2, \overline{620} \\
2, \overline{4} 60 \\
2, \overline{330}\end{array}$ & $\begin{array}{c}- \\
6.24 \\
- \\
6.09 \\
- \\
5.97 \\
- \\
5.87 \\
- \\
5.79 \\
5.69\end{array}$ & $\begin{array}{l}2, \overline{2} 30 \\
2, \overline{120} \\
2, \overline{0} \\
\overline{9} \\
1, \overline{9} 70 \\
1, \overline{910} \\
1, \overline{840}\end{array}$ & $\begin{array}{c}- \\
5.62 \\
- \\
5.58 \\
- \\
5.49 \\
- \\
5.37 \\
- \\
5.26 \\
\overline{5.17}\end{array}$ & $\begin{array}{c}1, \overline{7} 90 \\
1, \overline{7} 70 \\
- \\
1, \overline{7} 00 \\
1, \overline{6} \\
\overline{5} \overline{5} 40 \\
\overline{4} \mathbf{4} 80\end{array}$ & $\begin{array}{c}- \\
5.05 \\
- \\
4.98 \\
- \\
5.01 \\
5.04 \\
- \\
4.99 \\
- \\
4.89\end{array}$ & $\begin{array}{l}1, \overline{400} \\
1, \overline{3} 60 \\
1, \overline{3} 80 \\
1, \overline{4} 00 \\
1, \overline{3} 60 \\
\overline{-} \\
1,300\end{array}$ & $\begin{array}{c}-79 \\
\overline{4} \\
4.71 \\
- \\
4.63 \\
- \\
4.57 \\
\overline{4.52} \\
- \\
4.46\end{array}$ & $\begin{array}{l}1, \overline{2} 30 \\
1, \overline{180} \\
\overline{1} \overline{130} \\
1, \overline{0} 00 \\
1, \overline{0} \\
1, \overline{0} 0\end{array}$ \\
\hline & \multicolumn{2}{|c|}{ December 20} & \multicolumn{2}{|c|}{ Decembar 21} & \multicolumn{2}{|c|}{ December 22} & \multicolumn{2}{|c|}{ December 23} & \multicolumn{2}{|c|}{ December 24} & \multicolumn{2}{|c|}{ Decembar 25} \\
\hline $\begin{array}{r}2 \\
4 \\
6 \\
8 \\
10 \\
\mathbb{N} \\
2 \\
4 \\
6 \\
8 \\
10 \\
y\end{array}$ & $\begin{array}{r}4.29 \\
4.25 \\
4.20\end{array}$ & $\begin{array}{l}\overline{986} \\
\overline{950} \\
\overline{914}\end{array}$ & $\overline{4.12}$ & $\overline{812}$ & $\begin{array}{c}\bar{z} \\
3.88 \\
\overline{3} \\
3.83\end{array}$ & $\begin{array}{c}\overline{3} 8 \\
\overline{598}\end{array}$ & $\begin{array}{c}\overline{5} \\
\overline{3.64}\end{array}$ & $\begin{array}{c}\overline{-} \\
5 \overline{3} 2 \\
\overline{5} \\
\overline{5} 10\end{array}$ & $\begin{array}{c}3.45 \\
- \\
- \\
3.40\end{array}$ & $\begin{array}{c}4 \overline{28} \\
\overline{-} \\
\overline{400} \\
\overline{3} \\
\overline{355}\end{array}$ & $\begin{array}{c}\overline{-} \\
\overline{3.29} \\
\bar{z} \\
\overline{3.28} \\
\overline{-} \\
\overline{3.23} \\
\bar{z} \\
\overline{3.20}\end{array}$ & $\begin{array}{c}\overline{-} \\
345 \\
\overline{-} \\
340 \\
\overline{-} \\
316\end{array}$ \\
\hline
\end{tabular}

Supplemental records.- Dec. 11, 5 p.m., 12.65 ft., 8,210 sec.-ft. 
Location.- Lat. $41^{\circ} 00^{\prime}$, long. $121^{\circ} 26^{\prime}$, in NEt sec. 6, T. $36 \mathrm{~N}$, R. 5 E., 0.8 mile below Fali River and town of Fall River Mills, Shasta County. Altitude, about 3,235 feet above mean sea level.

Drainage area.- 4,150 square miles (not 1ncluding Goose Lake Basin).

Gage-helght record.- Water-stage recorder graph except for perlod $10 \mathrm{a.m}$. Dec. 10 to 9 a.m. Dec. 13, when there was no record. Peak stage determined from floodmarks.

Stage-discharge relation. - Defined by current-meter measurements below 8,800 secondfeet; extended to peak stage by $A \sqrt{a}$ method; verifled by area-velocity study.

Mexima.- December 1937: D1scharge, 28,600 second feet about noon Dec. 12 (gage helght, 11.8 feet, Inside gage; 12.1 feet, outside gage, from floodmarks).

1921-November 1937: D1scharge, 13,000 second-feet (revised) Mar. 28, 1928 (gage helght, 7.89 feet), from rating curve for 1938 .

Remarks.- Flood run-off slightly offected by artificial storage and diversion. Discharge for period of missing gage-he1ght record, Dec. 10-12, determined from discharge hydrograph based on record for Pit River below Pit No. 4 dam. Discharge for period Dec. 11-12 includes about 800 second-foet from Fall River, which is usually diverted around station through P1t No. 1 power house. Most of basic data furnished by Pacific Gas \& Electric Co.

Mean dally discharge, in second-feet, November 1937 to January 1938

\begin{tabular}{|c|c|c|c||c|r|r|r||r|r|r|r|}
\hline Day & Hov. & Dec. & Jan. & Day & Nov. & Dec. & Jan. & Day & Nov. & Dec. & \multicolumn{1}{|c|}{ Jan. } \\
\hline 1 & 63 & 322 & 618 & 11 & 95 & 10,500 & 402 & 21 & 740 & 1,730 & 778 \\
2 & 62 & 290 & 660 & 12 & 100 & 24,500 & 380 & 22 & 653 & 1,520 & 882 \\
3 & 62 & 266 & 748 & 13 & 96 & 19,700 & 365 & 23 & 1,380 & 1,330 & 1,250 \\
4 & 60 & 243 & 667 & 14 & 95 & 11,300 & 360 & 24 & 1,420 & 1,120 & 1,090 \\
5 & 62 & 229 & 618 & 15 & 100 & 8,900 & 365 & 25 & 1,190 & 850 & 890 \\
6 & 63 & 209 & 554 & 16 & 146 & 6,200 & 434 & 26 & 930 & 818 & 802 \\
7 & 67 & 191 & 518 & 17 & 440 & 4,100 & 606 & 27 & 695 & 740 & 732 \\
8 & 84 & 179 & 476 & 18 & 250 & 3,040 & 906 & 28 & 536 & 653 & 674 \\
9 & 71 & 179 & 446 & 19 & 243 & 2,480 & 1,080 & 29 & 440 & 599 & 640 \\
10 & 77 & 750 & 424 & 20 & 680 & 2,050 & 842 & 30 & 360 & 573 & 600 \\
\end{tabular}

Gage helght, in feet, and discharge, in second-feet, at indicated time, 1937

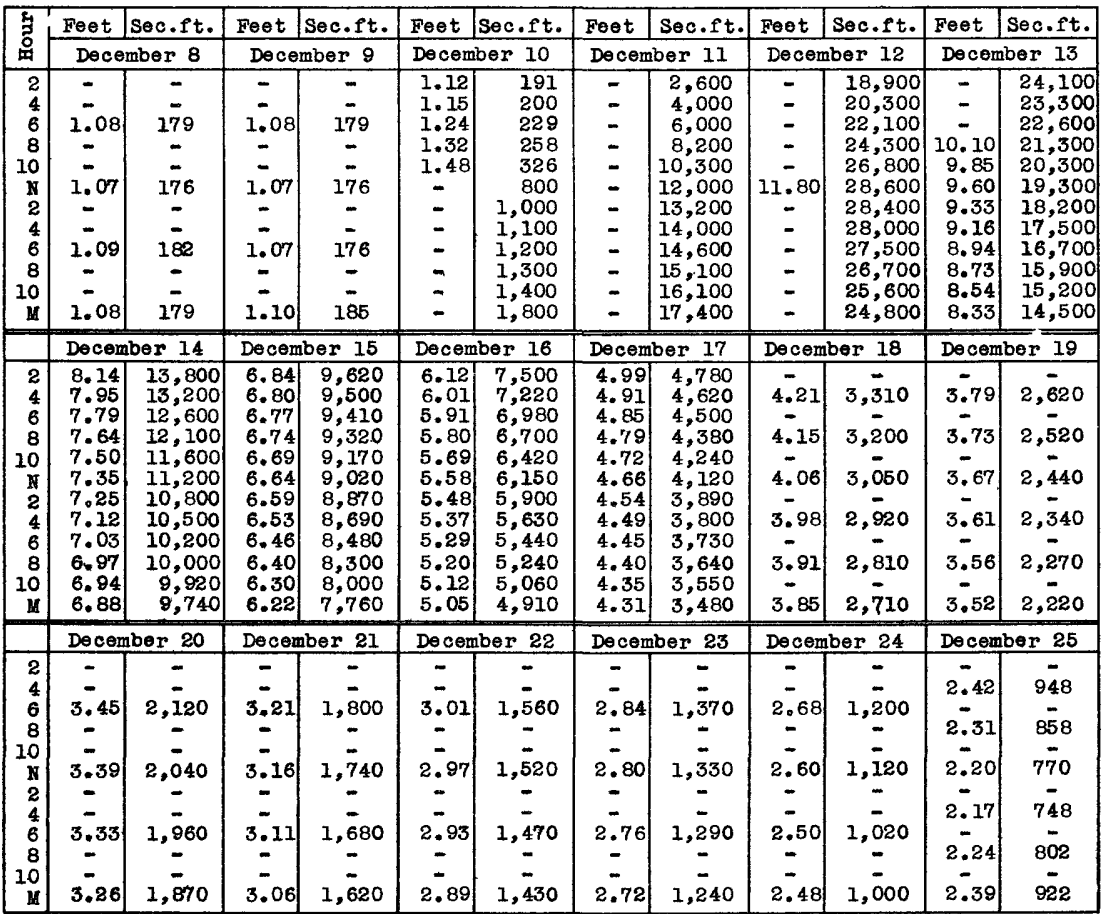


Pit River below Pit No. 4 dam, Calif.

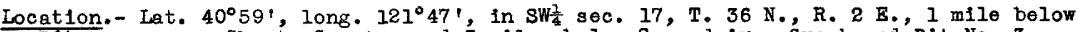
Pft No. 4 dam, Shasta County, and 3 miles below Screwdriver Creok and Pit No. 3 power house. Altitude, about 2,345 feet above mean sea level.

Drainage area.- 4,860 square miles (not including Goose Lake Basin).

Gage-helght record. - Water-stage recorder graph.

Stage-discharge relation. - Defined by current-meter measurements below 7,300 secondfeet; extended to peak stage on basis of area-velocity study; verifled by computation of flow over Pit No, 3 dam 8 miles above, plus flow through the diversion tunnel from Pit No. 3 dam, plus estimated inflow between the dam and the gage, and by comparison of peak discharge and total run-off of flood with fecords for other stations on Pit River. Rating curve otranged at peak stage.

Maxima. - December 1937: Discharge, 30,200 second -feet 6 p.m. Dec. 12 (gage height, 17.90 feet).

1927-November 1937: Discharge, 18,400 second-feet (revised) Apr. 8, 1935 (gage helght, 14.7 feet), from rating curve extended above 7,300 second-feet on basis of area-velocity study for 1938.

Remarks. - Flood mun-off slightly affected by artificlal storage and diversion. Part of basic data furnished by Pacific Gas blectric Co.

Mean daily discharge, in second-feet, November 1937 to January 1938

\begin{tabular}{|c|c|c|c||c|c|c|c||c|c|c|c|}
\hline Day & Nov. & Dec. & Jan. & Day & Nov. & Dec. & Jan. & Day & Nov. & Dec. & Jan. \\
\hline 1 & 1,900 & 2,300 & 2,920 & 11 & 2,120 & 12,000 & 2,480 & 21 & 3,590 & 4,210 & 3,000 \\
2 & 1,900 & 2,240 & 2,550 & 12 & 2,060 & 26,200 & 2,480 & 22 & 2,770 & 3,930 & 3,000 \\
3 & 1,950 & 2,120 & 3,000 & 13 & 1,840 & 25,800 & 2,410 & 23 & 2,910 & 3,660 & 3,400 \\
4 & 2,000 & 2,000 & 3,080 & 14 & 1,780 & 16,500 & 2,340 & 24 & 3,750 & 3,490 & 3,580 \\
5 & 1,840 & 1,950 & 3,000 & 15 & 1,840 & 12,400 & 2,410 & 25 & 3,750 & 2,780 & 3,240 \\
6 & 1,430 & 1,950 & 3,000 & 16 & 1,950 & 10,300 & 2,550 & 26 & 3,670 & 3,080 & 2,850 \\
7 & 1,380 & 1,950 & 3,000 & 17 & 2,500 & 8,100 & 3,000 & 27 & 3,130 & 3,580 & 2,780 \\
8 & 1,630 & 1,950 & 3,160 & 18 & 2,500 & 6,160 & 3,400 & 28 & 2,630 & 3,000 & 2,920 \\
9 & 1,730 & 1,950 & 2,480 & 19 & 2,120 & 5,350 & 3,580 & 29 & 2,240 & 2,340 & 3,000 \\
10 & 1,730 & 2,680 & 2,150 & 20 & 2,500 & 4,970 & 3,490 & 30 & 2,240 & 3,080 & 2,620 \\
\end{tabular}

Gage height, in feet, and discharge, in second-feet, at indicated time, 1937

\begin{tabular}{|c|c|c|c|c|c|c|c|c|c|c|c|c|}
\hline \multirow{2}{*}{$\begin{array}{l}5 \\
\text { 总 }\end{array}$} & Feet & Sec.ft. & Feot & Sec.ft. & Feot & Sec.ft. & Feet & Sec.ft. & Feet & Sec.ft. & Feet & Sec.ft. \\
\hline & \multicolumn{2}{|c|}{ December 8} & \multicolumn{2}{|c|}{ December 9} & \multicolumn{2}{|c|}{ December 10} & \multicolumn{2}{|c|}{ December 11} & \multicolumn{2}{|c|}{ December 12} & \multicolumn{2}{|c|}{ December 13} \\
\hline $\begin{array}{r}2 \\
4 \\
6 \\
8 \\
10 \\
1 \\
2 \\
4 \\
6 \\
8 \\
10\end{array}$ & $\begin{array}{l}\overline{7.17} \\
\overline{7.22} \\
\overline{7.24} \\
\overline{7.18} \\
\overline{7.22} \\
\overline{7.22}\end{array}$ & $\begin{array}{l}1, \overline{9} 20 \\
1, \overline{9} 70 \\
1, \overline{9} 90 \\
1, \overline{9} \\
1, \overline{9} 0 \\
1, \overline{9}\end{array}$ & $\begin{array}{c}\overline{7.18} \\
- \\
7.22 \\
\overline{7.23} \\
\overline{7.23} \\
\overline{7.23} \\
\overline{7.17}\end{array}$ & $\begin{array}{l}1, \overline{9} 30 \\
\overline{\overline{9}} \\
1, \overline{9} \\
1, \overline{9} 80 \\
1, \overline{9} 80 \\
1, \overline{9}\end{array}$ & $\begin{array}{l}7.17 \\
7.18 \\
7.18 \\
7.19 \\
7.73 \\
7.75 \\
7.77 \\
7.78 \\
8.26 \\
8.50 \\
8.58 \\
8.61\end{array}$ & $\begin{array}{l}1,920 \\
1,930 \\
1,930 \\
1,940 \\
2,600 \\
2,630 \\
2,660 \\
2,670 \\
3,370 \\
3,750 \\
3,880 \\
3,930\end{array}$ & $\begin{array}{r}8.63 \\
8.60 \\
11.90 \\
10.95 \\
11.55 \\
12.55 \\
13.12 \\
14.50 \\
14.25 \\
14.60 \\
14.85 \\
15.10\end{array}$ & $\begin{array}{r}3,960 \\
3,910 \\
10,400 \\
8,180 \\
9,520 \\
12,000 \\
13,600 \\
17,700 \\
17,000 \\
18,000 \\
18,900 \\
19,800\end{array}$ & & & & \\
\hline & \multicolumn{2}{|c|}{ December 14} & \multicolumn{2}{|c|}{ December 15} & \multicolumn{2}{|c|}{ December 16} & \multicolumn{2}{|c|}{ December 17} & \multicolumn{2}{|c|}{ December 18} & \multicolumn{2}{|c|}{ December 19} \\
\hline \multirow[t]{2}{*}{\begin{tabular}{r|}
2 \\
4 \\
6 \\
8 \\
10 \\
$\mathrm{~N}$ \\
2 \\
4 \\
6 \\
8 \\
10 \\
$\mathrm{M}$
\end{tabular}} & \begin{tabular}{|l|}
15.15 \\
14.86 \\
14.65 \\
14.45 \\
14.28 \\
14.10 \\
13.92 \\
13.81 \\
13.60 \\
13.45 \\
13.34 \\
13.24
\end{tabular} & $\begin{array}{l}19,900 \\
18,900 \\
18,200 \\
17,600 \\
17,000 \\
16,500 \\
16,000 \\
15,600 \\
15,000 \\
14,600 \\
14,200 \\
13,900\end{array}$ & $\begin{array}{l}13.15 \\
13.03 \\
12.96 \\
12.88 \\
12.82 \\
12.76 \\
12.70 \\
12.40 \\
12.30 \\
12.57 \\
12.29 \\
12.21\end{array}$ & $\begin{array}{l}13,600 \\
13,300 \\
13,100 \\
12,900 \\
12,700 \\
12,500 \\
12,400 \\
11,600 \\
11,300 \\
12,000 \\
11,300 \\
11,100\end{array}$ & \begin{tabular}{l|}
12.21 \\
12.19 \\
12.14 \\
12.07 \\
12.00 \\
12.21 \\
12.10 \\
12.00 \\
11.83 \\
11.38 \\
11.10 \\
10.62
\end{tabular} & $\begin{array}{r}11,100 \\
11,100 \\
10,900 \\
10,700 \\
10,600 \\
11,100 \\
10,800 \\
10,600 \\
10,100 \\
9,010 \\
8,340 \\
7,260\end{array}$ & $\begin{array}{r}10.62 \\
10.72 \\
10.91 \\
11.25 \\
11.50 \\
11.40 \\
11.20 \\
11.01 \\
10.91 \\
10.81 \\
10.45 \\
9.95\end{array}$ & \begin{tabular}{|l|}
7,260 \\
7,480 \\
7,900 \\
8,700 \\
9,300 \\
9,060 \\
8,580 \\
8,120 \\
7,900 \\
7,680 \\
6,900 \\
5,850
\end{tabular} & $\begin{array}{r}9.71 \\
9.78 \\
9.89 \\
10.20 \\
10.29 \\
10.20 \\
10.15 \\
10.10 \\
10.35 \\
10.63 \\
10.45 \\
9.59\end{array}$ & & $\begin{array}{r}9.19 \\
9.12 \\
9.08 \\
9.32 \\
9.78 \\
9.99 \\
9.86 \\
9.56 \\
10.05 \\
10.19 \\
10.35 \\
9.67\end{array}$ & \\
\hline & \multicolumn{2}{|c|}{ December 20} & \multicolumn{2}{|c|}{ December 21} & \multicolumn{2}{|c|}{ December 22} & \multicolumn{2}{|c|}{ December 23} & \multicolumn{2}{|c|}{ December 24} & \multicolumn{2}{|c|}{ December 25} \\
\hline $\begin{array}{r}2 \\
4 \\
6 \\
8 \\
10 \\
1 \\
2 \\
4 \\
6 \\
8 \\
10\end{array}$ & $\begin{array}{r}9.21 \\
8.94 \\
9.14 \\
9.57 \\
10.10 \\
9.80 \\
9.70 \\
9.42 \\
9.67 \\
9.85 \\
9.75 \\
9.37\end{array}$ & $\begin{array}{l}4,420 \\
3,910 \\
4,290 \\
5,100 \\
6,160 \\
5,550 \\
5,350 \\
4,820 \\
5,290 \\
5,650 \\
5,450 \\
4,720\end{array}$ & $\begin{array}{l}9.04 \\
8.84 \\
8.65 \\
9.19 \\
9.65 \\
9.36 \\
9.12 \\
8.98 \\
9.19 \\
9.33 \\
8.92 \\
8.55\end{array}$ & $\begin{array}{l}4,100 \\
3,730 \\
3,400 \\
4,380 \\
5,260 \\
4,700 \\
4,250 \\
3,980 \\
4,380 \\
4,650 \\
3,880 \\
3,240\end{array}$ & $\begin{array}{l}8.35 \\
8.45 \\
8.50 \\
8.98 \\
9.34 \\
9.17 \\
9.08 \\
8.99 \\
9.36 \\
9.40 \\
9.00 \\
8.52\end{array}$ & \begin{tabular}{|l|}
2,920 \\
3,080 \\
3,160 \\
3,980 \\
4,670 \\
4,340 \\
4,170 \\
4,000 \\
4,700 \\
4,780 \\
4,020 \\
3,190
\end{tabular} & $\begin{array}{l}8.26 \\
8.22 \\
8.30 \\
8.60 \\
8.98 \\
9.05 \\
9.02 \\
8.95 \\
9.19 \\
9.30 \\
8.94 \\
8.55\end{array}$ & \begin{tabular}{|l|}
2,790 \\
2,730 \\
2,850 \\
3,320 \\
3,980 \\
4,120 \\
4,060 \\
3,930 \\
4,380 \\
4,590 \\
3,910 \\
3,240
\end{tabular} & $\begin{array}{l}8.02 \\
7.85 \\
7.86 \\
8.50 \\
8.93 \\
9.05 \\
9.05 \\
9.00 \\
8.95 \\
9.35 \\
9.17 \\
8.82\end{array}$ & & $\begin{array}{l}8.08 \\
8.22 \\
8.29 \\
8.33 \\
8.35 \\
8.53 \\
8.60 \\
8.52\end{array}$ & $\begin{array}{l}2,120 \\
2,280 \\
2,520 \\
2,730 \\
2,840 \\
2,900 \\
2,920 \\
3,210 \\
3,320 \\
3,190\end{array}$ \\
\hline
\end{tabular}


Pit River at Big Bend, Calif.

Location.- Lat. $41^{\circ} \mathrm{O} 1^{\prime}$, long. $121^{\circ} 55^{\prime}$, In sec. 31, T. 37 N., R. 1 E., at B1g Bend, Shasta County. Nelson Creek enters half a mlle above and Kosk Creek 1 mile below station. Altitude, about 1,700 feet above mean sea level.

Drainage area.- 4,920 square miles (not including Goose Lake Basin).

Gage-helght record. - Water-stage recorder graph.

Stage-discharge relation. - Defined by current-meter measurements below 10,800 secondfeet; extended to peak stage on basis of area-velocity study; verifled by compar1son of peak discharge and total run-off of flood with records for other stations on P1t River.

Max1ma.- December 1937: D1scharge, 34,200 second-feet 5 p.m. Dec. 12 (gage he1ght, 16.26 feet).

1910-November 1937: D1scharge, 20,400 second-feet (revised) Apr. 8, 1935 (gage

he1ght, 13.96 feet), from rating curve for 1938 .

Remarks.- Flood mun-off slightly affected by artificial storage and diversion.

Mean da1ly discharge, in second-feet, November 1937 to January 1938

\begin{tabular}{|c|c|c|c|c|c|c|c|c|c|c|c|}
\hline Day & Nov. & Dec. & Jan. & Day & Nov. & Dec. & Jan. & Day & Nov. & Dec. & Jan. \\
\hline $\begin{array}{r}1 \\
2 \\
3 \\
4 \\
5 \\
6 \\
7 \\
8 \\
9 \\
10\end{array}$ & $\begin{array}{l}1,830 \\
1,830 \\
1,950 \\
1,950 \\
1,830 \\
1,450 \\
1,390 \\
1,660 \\
1,770 \\
1,830\end{array}$ & $\begin{array}{l}2,510 \\
2,440 \\
2,290 \\
2,220 \\
2,080 \\
2,080 \\
2,080 \\
2,080 \\
2,150 \\
4,290\end{array}$ & $\begin{array}{l}3,170 \\
2,750 \\
3,350 \\
3,350 \\
3,260 \\
3,170 \\
3,260 \\
3,350 \\
2,830 \\
2,360\end{array}$ & $\begin{array}{l}11 \\
12 \\
13 \\
14 \\
15 \\
16 \\
17 \\
18 \\
19 \\
20\end{array}$ & $\begin{array}{l}2,290 \\
2,220 \\
1,950 \\
1,950 \\
1,950 \\
2,220 \\
2,830 \\
2,830 \\
2,440 \\
4,840\end{array}$ & $\begin{array}{r}17,000 \\
30,300 \\
27,900 \\
18,400 \\
14,100 \\
11,800 \\
8,770 \\
6,970 \\
5,880 \\
5,630\end{array}$ & $\begin{array}{l}2,670 \\
2,750 \\
2,590 \\
2,590 \\
2,670 \\
2,830 \\
3,350 \\
3,820 \\
4,010 \\
3,910\end{array}$ & $\begin{array}{l}21 \\
22 \\
23 \\
24 \\
25 \\
26 \\
27 \\
28 \\
29 \\
30 \\
31\end{array}$ & $\begin{array}{l}6,280 \\
4,520 \\
4,310 \\
5,390 \\
4,840 \\
4,520 \\
3,720 \\
3,080 \\
2,510 \\
2,440\end{array}$ & $\begin{array}{l}4,730 \\
4,210 \\
3,910 \\
3,820 \\
3,000 \\
3,440 \\
3,910 \\
3,260 \\
2,590 \\
3,350 \\
3,350\end{array}$ & $\begin{array}{l}3,440 \\
3,350 \\
3,720 \\
4,010 \\
3,620 \\
3,170 \\
3,080 \\
3,350 \\
3,350 \\
2,920 \\
2,920\end{array}$ \\
\hline $\begin{array}{l}\text { Mea } \\
\text { Run }\end{array}$ & & & & & & & & & $\begin{array}{r}2,821 \\
167,800\end{array}$ & $\begin{array}{r}6,792 \\
417,600\end{array}$ & $\begin{array}{r}3,193 \\
196,300\end{array}$ \\
\hline
\end{tabular}

Gage height, in feet, and discharge, in second-feet, at indicated time, 1937

\begin{tabular}{|c|c|c|c|c|c|c|c|c|c|c|c|c|}
\hline \multirow{2}{*}{ 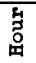 } & Feet & Sec.ft. & Feet & Sec.ft. & Feet & Sec.ft. & Feet & sec.ft. & Feet & Sec.ft. & Feet & Sec.It. \\
\hline & \multicolumn{2}{|c|}{ December 8} & \multicolumn{2}{|c|}{ December 9} & \multicolumn{2}{|c|}{ December 10} & \multicolumn{2}{|c|}{ December 11} & \multicolumn{2}{|c|}{ December 12} & \multicolumn{2}{|c|}{ December 13} \\
\hline \multirow[t]{2}{*}{$\begin{array}{r}2 \\
4 \\
6 \\
8 \\
10 \\
1 \\
2 \\
4 \\
6 \\
8 \\
10 \\
\text { M }\end{array}$} & $\begin{array}{l}\overline{8.09} \\
\overline{8.10} \\
\overline{8.15} \\
\overline{8.12} \\
\overline{8.12} \\
\overline{8.13}\end{array}$ & $\begin{array}{c}2, \overline{0} 70 \\
\overline{-} \\
2,080 \\
\overline{-} \\
2, \overline{150} \\
\overline{-} \\
2, \overline{110} \\
\overline{1} \\
2, \overline{110} \\
2, \overline{120}\end{array}$ & $\begin{array}{c}\overline{8.09} \\
\overline{8.10} \\
\overline{8.16} \\
\overline{8.17} \\
\overline{8.20} \\
\overline{8.22}\end{array}$ & $\begin{array}{l}2, \overline{070} \\
2, \overline{0} \\
2, \overline{160} \\
2, \overline{180} \\
2, \overline{2} \\
2, \overline{250}\end{array}$ & $\begin{array}{r}8.22 \\
8.28 \\
8.38 \\
8.38 \\
8.76 \\
9.41 \\
9.36 \\
9.59 \\
9.92 \\
10.40 \\
10.91 \\
10.80\end{array}$ & $\begin{array}{l}2,250 \\
2,330 \\
2,480 \\
2,480 \\
3,100 \\
4,330 \\
4,230 \\
4,710 \\
5,440 \\
6,690 \\
8,180 \\
7,850\end{array}$ & $\begin{array}{l}10.81 \\
11.64 \\
12.30 \\
12.53 \\
12.98 \\
13.40 \\
13.75 \\
14.25 \\
14.20 \\
14.42 \\
14.57 \\
14.65\end{array}$ & $\begin{array}{r}7,880 \\
10,500 \\
12,900 \\
13,800 \\
15,600 \\
17,500 \\
19,200 \\
21,800 \\
21,500 \\
22,700 \\
23,500 \\
24,000\end{array}$ & $\begin{array}{l}14.75 \\
14.99 \\
15.23 \\
15.53 \\
15.77 \\
15.97 \\
16.10 \\
16.20 \\
16.20 \\
16.13 \\
16.12 \\
16.05\end{array}$ & $\begin{array}{l}24,600 \\
26,000 \\
27,500 \\
29,300 \\
30,700 \\
32,000 \\
32,800 \\
33,500 \\
33,500 \\
33,000 \\
33,000 \\
32,500\end{array}$ & $\begin{array}{l}15.97 \\
15.83 \\
15.65 \\
15.55 \\
15.41 \\
15.26 \\
15.12 \\
14.96 \\
14.85 \\
14.71 \\
14.60 \\
14.43\end{array}$ & $\begin{array}{l}32,000 \\
21,100 \\
30,000 \\
29,400 \\
28,600 \\
22,700 \\
26,800 \\
25,900 \\
25,200 \\
24,400 \\
23,700 \\
22,800\end{array}$ \\
\hline & \multicolumn{2}{|c|}{ December 14} & \multicolumn{2}{|c|}{ December 15} & \multicolumn{2}{|c|}{ December 16} & \multicolumn{2}{|c|}{ December 17} & \multicolumn{2}{|c|}{ December 18} & \multicolumn{2}{|c|}{ December 19} \\
\hline \multirow[t]{2}{*}{$\begin{array}{r}2 \\
4 \\
6 \\
8 \\
10 \\
\mathbf{N} \\
2 \\
4 \\
6 \\
8 \\
10 \\
\text { M }\end{array}$} & $\begin{array}{l}14.26 \\
14.09 \\
13.91 \\
13.78 \\
13.63 \\
13.45 \\
13.39 \\
13.29 \\
13.19 \\
13.08 \\
13.01 \\
12.95\end{array}$ & $\begin{array}{l}21,800 \\
20,900 \\
20,000 \\
19,300 \\
18,600 \\
17,700 \\
17,500 \\
17,000 \\
16,600 \\
16,100 \\
15,700 \\
15,500\end{array}$ & $\begin{array}{l}12.89 \\
12.80 \\
12.75 \\
12.70 \\
12.66 \\
12.61 \\
12.58 \\
12.44 \\
12.27 \\
12.54 \\
12.27 \\
12.23\end{array}$ & $\begin{array}{l}15,300 \\
14,900 \\
14,700 \\
14,500 \\
14,300 \\
14,100 \\
14,000 \\
13,500 \\
12,800 \\
13,900 \\
12,800 \\
12,700\end{array}$ & $\begin{array}{l}12.20 \\
12.17 \\
13.13 \\
12.08 \\
12.03 \\
12.21 \\
12.08 \\
12.04 \\
11.91 \\
11.73 \\
11.41 \\
10.90\end{array}$ & $\begin{array}{r}12,600 \\
12,400 \\
12,300 \\
12,100 \\
11,900 \\
12,600 \\
12,100 \\
12,000 \\
11,500 \\
10,900 \\
9,760 \\
8,150\end{array}$ & $\begin{array}{l}10.93 \\
11.03 \\
11.14 \\
11.40 \\
11.57 \\
11.57 \\
11.37 \\
11.30 \\
11.20 \\
11.03 \\
10.58 \\
10.20\end{array}$ & $\begin{array}{r}8,240 \\
8,550 \\
8,900 \\
9,730 \\
10,300 \\
10,300 \\
9,630 \\
9,410 \\
9,090 \\
8,550 \\
7,200 \\
6,140\end{array}$ & $\begin{array}{r}10.14 \\
10.24 \\
10.31 \\
10.62 \\
10.60 \\
10.55 \\
10.50 \\
10.46 \\
10.80 \\
10.86 \\
10.66 \\
9.88\end{array}$ & $\begin{array}{l}5,980 \\
6,250 \\
6,440 \\
7,320 \\
7,260 \\
7,120 \\
6,970 \\
6,860 \\
7,850 \\
8,030 \\
7,430 \\
5,340\end{array}$ & $\begin{array}{r}9.61 \\
9.55 \\
9.58 \\
9.90 \\
10.33 \\
10.42 \\
10.18 \\
10.01 \\
10.15 \\
10.57 \\
10.67 \\
10.27\end{array}$ & $\begin{array}{l}4,750 \\
4,620 \\
4,690 \\
5,390 \\
6,490 \\
6,750 \\
6,090 \\
5,660 \\
6,010 \\
7,170 \\
7,460 \\
6,330\end{array}$ \\
\hline & \multicolumn{2}{|c|}{ December 20} & \multicolumn{2}{|c|}{ December 21} & \multicolumn{2}{|c|}{ December 22} & \multicolumn{2}{|c|}{ December 23} & \multicolumn{2}{|c|}{ December 24} & \multicolumn{2}{|c|}{ December 25} \\
\hline $\begin{array}{r}2 \\
4 \\
6 \\
8 \\
10 \\
N \\
2 \\
4 \\
6 \\
8 \\
10 \\
M\end{array}$ & $\begin{array}{r}9.78 \\
9.47 \\
9.51 \\
9.95 \\
10.45 \\
10.24 \\
10.12 \\
9.88 \\
9.88 \\
10.26 \\
10.18 \\
9.89\end{array}$ & $\begin{array}{l}5,120 \\
4,460 \\
4,540 \\
5,510 \\
6,830 \\
6,250 \\
5,930 \\
5,340 \\
5,340 \\
6,300 \\
6,090 \\
5,370\end{array}$ & \begin{tabular}{r|}
9.50 \\
9.48 \\
9.11 \\
9.17 \\
10.13 \\
9.84 \\
9.73 \\
9.40 \\
9.53 \\
9.92 \\
9.50 \\
9.12
\end{tabular} & $\begin{array}{l}4,520 \\
4,480 \\
3,740 \\
3,850 \\
5,960 \\
5,250 \\
5,010 \\
4,310 \\
4,580 \\
5,440 \\
4,520 \\
3,760\end{array}$ & $\begin{array}{l}8.77 \\
8.92 \\
8.95 \\
9.07 \\
9.81 \\
9.69 \\
9.56 \\
9.48 \\
9.55 \\
9.97 \\
9.54 \\
9.12\end{array}$ & $\begin{array}{l}3,120 \\
3,390 \\
3,440 \\
3,660 \\
5,180 \\
4,920 \\
4,650 \\
4,480 \\
4,620 \\
5,560 \\
4,600 \\
3,760\end{array}$ & $\begin{array}{l}8.66 \\
8.60 \\
8.70 \\
8.83 \\
9.41 \\
9.54 \\
9.49 \\
9.45 \\
9.40 \\
9.86 \\
9.55 \\
9.29\end{array}$ & $\begin{array}{l}2,930 \\
2,830 \\
3,000 \\
3,220 \\
4,330 \\
4,600 \\
4,500 \\
4,420 \\
4,310 \\
5,300 \\
4,620 \\
4,090\end{array}$ & $\begin{array}{l}8.60 \\
8.19 \\
8.21 \\
8.48 \\
9.46 \\
9.57 \\
9.52 \\
9.48 \\
9.42 \\
9.84 \\
9.48 \\
9.14\end{array}$ & $\begin{array}{l}2,830 \\
2,210 \\
2,230 \\
2,640 \\
4,440 \\
4,670 \\
4,560 \\
4,480 \\
4,350 \\
5,250 \\
4,480 \\
3,800\end{array}$ & $\begin{array}{l}8.51 \\
8.15 \\
8.17 \\
8.47 \\
8.66 \\
8.75 \\
8.80 \\
8.83 \\
8.85 \\
9.10 \\
9.11 \\
8.97\end{array}$ & $\begin{array}{l}2,690 \\
2,150 \\
2,180 \\
2,620 \\
2,930 \\
3,080 \\
3,170 \\
3,220 \\
3,260 \\
3,720 \\
3,740 \\
3,480\end{array}$ \\
\hline
\end{tabular}

Supplemental records.- Dec. 12,5 p.m., 16.26 ft., 34,200 sec.-ft. 
P1t River near Ydalpom, Calif.

Iocation. - Lat. $40^{\circ} 46^{\prime}$, Iong. $122^{\circ} 14^{\prime}$, in Nwt sec. 32, T. 34 N., R. 3 W., at S1lverthorne Ferry, $1 \frac{1}{2} \mathrm{mlies}$ southwest of Ydalpom, Shasta County. Squaw Creek enters half a mile above and McCloud River 4 mlles below station. Altitude, about 735 feet above mean sea level.

Drainage area.- 5,350 square miles (not including Goose Lake Basin).

Gage-helght record. - Water atage recorder graph.

Stage-discharge relation.- Defined by current-meter measurements below 21,000 secondfeet; extended to peak stage on basis of area-velocity study and A $\sqrt{\alpha}$ method; verified by comparison of peak discharge and total mun-off of flood with record of Sacramento River near Kennet..

Maxima.- December 1937: Discharge, 65,000 second-feet 11 p.m. Dec. 10 (gage helght, 24.20 feet).

1910-November 1937: Discharge, about 47,000 second-feet Dec. 31, 1913 (gage helght, about 20.7 feet, from floodmarks, present datum), from rating curve extended above 27,200 second-feet

Remerks.- Flood run-off slightly affected by artificial storage and diversion.

Mean daily discharge, in second-feet, November 1937 to January 1938

\begin{tabular}{|c|c|c|c|c|c|c|c|c|c|c|c|}
\hline Day & Nov. & Dec. & Jan. & Day & Nov. & Dec. & Jan. & Day & Nov. & Dec. & Jan. \\
\hline $\begin{array}{r}1 \\
2 \\
3 \\
4 \\
5 \\
6 \\
7 \\
8 \\
9 \\
10\end{array}$ & $\begin{array}{l}2,000 \\
2,000 \\
2,060 \\
2,160 \\
2,110 \\
1,690 \\
1,540 \\
1,740 \\
1,890 \\
2,220\end{array}$ & $\begin{array}{r}3,600 \\
3,380 \\
3,240 \\
3,100 \\
2,900 \\
2,840 \\
2,840 \\
2,780 \\
3,100 \\
24,900\end{array}$ & $\begin{array}{l}4,610 \\
4,130 \\
4,210 \\
4,610 \\
4,450 \\
4,290 \\
4,290 \\
4,370 \\
4,210 \\
3,240\end{array}$ & $\begin{array}{l}11 \\
12 \\
13 \\
14 \\
15 \\
16 \\
17 \\
18 \\
19 \\
20\end{array}$ & $\begin{array}{r}3,520 \\
3,100 \\
2,520 \\
3,970 \\
3,670 \\
5,220 \\
6,170 \\
4,610 \\
4,610 \\
21,300\end{array}$ & $\begin{array}{r}41,900 \\
40,400 \\
34,300 \\
24,200 \\
18,600 \\
15,400 \\
11,900 \\
9,340 \\
8,060 \\
7,660\end{array}$ & $\begin{array}{l}3,600 \\
3,670 \\
3,520 \\
3,450 \\
4,050 \\
4,610 \\
9,560 \\
7,660 \\
7,860 \\
7,860\end{array}$ & $\begin{array}{l}21 \\
22 \\
23 \\
24 \\
25 \\
26 \\
27 \\
28 \\
29 \\
30 \\
31\end{array}$ & $\begin{array}{r}11,900 \\
7,090 \\
10,600 \\
12,400 \\
8,060 \\
6,710 \\
5,630 \\
4,610 \\
3,900 \\
3,600\end{array}$ & $\begin{array}{l}6,710 \\
5,990 \\
5,630 \\
5,630 \\
4,950 \\
4,780 \\
5,120 \\
4,610 \\
4,210 \\
4,450 \\
4,780\end{array}$ & $\begin{array}{l}6,530 \\
5,990 \\
5,990 \\
5,990 \\
5,460 \\
4,950 \\
4,780 \\
5,120 \\
5,120 \\
4,780 \\
5,990\end{array}$ \\
\hline $\begin{array}{l}\text { Mea } \\
\text { Run }\end{array}$ & . & & & & & & & & $\begin{array}{r}5,087 \\
302,700\end{array}$ & $\begin{array}{r}10,360 \\
637,300\end{array}$ & $\begin{array}{r}5,127 \\
315,300\end{array}$ \\
\hline
\end{tabular}

Gage height, in feet, and discharge, in second-feet, at indicated time, 1937

\begin{tabular}{|c|c|c|c|c|c|c|c|c|c|c|c|c|}
\hline \multirow{2}{*}{$\begin{array}{l}4 \\
3 \\
0 \\
\text { 出 }\end{array}$} & Feet & Sec.ft. & Feet & Sec.ft. & Feet & sec.ft. & Feet & sec.ft. & Feet & Sec.ft. & Feet & Sec.ft. \\
\hline & \multicolumn{2}{|c|}{ December 8} & \multicolumn{2}{|c|}{ December 9} & \multicolumn{2}{|c|}{ December 10} & \multicolumn{2}{|c|}{ December 11} & \multicolumn{2}{|c|}{ December 12} & \multicolumn{2}{|c|}{ December 13} \\
\hline \multirow[t]{2}{*}{$\begin{array}{r}2 \\
4 \\
6 \\
8 \\
10 \\
\mathrm{~N} \\
2 \\
4 \\
6 \\
8 \\
10 \\
\mathrm{M}\end{array}$} & $\begin{array}{c}- \\
5.37 \\
- \\
5.37 \\
- \\
5.33 \\
- \\
5.37 \\
- \\
5.37 \\
- \\
5.32\end{array}$ & $\begin{array}{c}2, \overline{800} \\
2, \overline{800} \\
2, \overline{750} \\
\overline{-} \\
2, \overline{800} \\
\bar{z}, \overline{800} \\
2, \overline{740}\end{array}$ & $\begin{array}{l}5.35 \\
5.35 \\
5.36 \\
5.35 \\
5.31 \\
5.34 \\
5.40 \\
5.52 \\
5.70 \\
5.89 \\
6.32 \\
6.91\end{array}$ & $\begin{array}{l}2,780 \\
2,780 \\
2,790 \\
2,780 \\
2,720 \\
2,760 \\
2,840 \\
3,000 \\
3,240 \\
3,510 \\
4,160 \\
5,140\end{array}$ & \begin{tabular}{|r|}
7.50 \\
8.05 \\
8.67 \\
9.78 \\
12.20 \\
14.20 \\
15.72 \\
16.38 \\
17.00 \\
17.87 \\
22.85 \\
23.50
\end{tabular} & $\begin{array}{r}6,170 \\
7,180 \\
8,400 \\
10,900 \\
17,400 \\
23,500 \\
28,700 \\
31,100 \\
33,500 \\
37,000 \\
58,800 \\
61,800 \\
\end{array}$ & \begin{tabular}{|l|}
21.25 \\
19.47 \\
18.27 \\
18.31 \\
17.81 \\
17.78 \\
18.17 \\
19.18 \\
19.36 \\
18.96 \\
18.54 \\
18.66
\end{tabular} & $\begin{array}{l}51,500 \\
43,700 \\
38,600 \\
38,800 \\
36,700 \\
36,600 \\
38,200 \\
42,500 \\
43,200 \\
41,500 \\
39,800 \\
40,300\end{array}$ & \begin{tabular}{|l|}
18.88 \\
18.98 \\
18.78 \\
18.58 \\
18.51 \\
18.60 \\
18.73 \\
18.77 \\
18.78 \\
18.73 \\
18.64 \\
18.48
\end{tabular} & $\begin{array}{l}41,200 \\
41,600 \\
40,800 \\
39,900 \\
39,600 \\
40,600 \\
40,600 \\
40,700 \\
40,800 \\
40,600 \\
40,200 \\
39,500\end{array}$ & $\begin{array}{l}18.30 \\
18.11 \\
17.92 \\
17.71 \\
17.50 \\
17.26 \\
17.01 \\
16.79 \\
16.54 \\
16.29 \\
16.04 \\
15.79\end{array}$ & $\begin{array}{l}38,800 \\
38,000 \\
37,200 \\
36,300 \\
35,500 \\
34,500 \\
33,500 \\
32,700 \\
31,700 \\
30,800 \\
29,800 \\
28,900\end{array}$ \\
\hline & \multicolumn{2}{|c|}{ December 14} & \multicolumn{2}{|c|}{ December 15} & \multicolumn{2}{|c|}{ December 16} & \multicolumn{2}{|c|}{ December 17} & \multicolumn{2}{|c|}{ December 18} & \multicolumn{2}{|c|}{ December 19} \\
\hline \multirow[t]{2}{*}{$\begin{array}{r}2 \\
4 \\
6 \\
8 \\
10 \\
\mathrm{~N} \\
2 \\
4 \\
6 \\
8 \\
10 \\
\mathrm{M}\end{array}$} & $\begin{array}{l}15.55 \\
15.29 \\
15.08 \\
14.84 \\
14.58 \\
14.37 \\
14.16 \\
13.96 \\
13.75 \\
13.57 \\
13.36 \\
13.23\end{array}$ & $\begin{array}{l}28,100 \\
27,200 \\
26,500 \\
25,700 \\
24,800 \\
24,100 \\
23,400 \\
22,800 \\
22,100 \\
21,500 \\
20,900 \\
20,500\end{array}$ & $\begin{array}{l}13.13 \\
12.99 \\
12.87 \\
12.73 \\
12.63 \\
12.53 \\
12.43 \\
12.34 \\
12.27 \\
12.17 \\
11.80 \\
11.92\end{array}$ & $\begin{array}{l}20,200 \\
19,800 \\
19,400 \\
19,000 \\
18,700 \\
18,400 \\
18,100 \\
17,800 \\
17,600 \\
17,300 \\
16,200 \\
16,600\end{array}$ & \begin{tabular}{|l|}
11.88 \\
11.65 \\
11.59 \\
11.55 \\
11.50 \\
11.43 \\
11.33 \\
11.28 \\
11.35 \\
11.33 \\
11.17 \\
11.00
\end{tabular} & $\begin{array}{l}16,500 \\
15,800 \\
15,700 \\
15,500 \\
15,400 \\
15,200 \\
14,900 \\
14,800 \\
15,000 \\
14,900 \\
14,500 \\
14,000\end{array}$ & $\begin{array}{r}10.57 \\
10.22 \\
9.77 \\
9.75 \\
9.85 \\
10.04 \\
10.40 \\
10.56 \\
10.38 \\
10.19 \\
10.04 \\
9.89\end{array}$ & $\begin{array}{l}12,900 \\
12,000 \\
10,900 \\
10,900 \\
11,100 \\
11,600 \\
12,400 \\
12,900 \\
12,400 \\
11,900 \\
11,600 \\
11,900\end{array}$ & $\begin{array}{l}9.75 \\
9.25 \\
8.82 \\
8.65 \\
8.74 \\
8.82 \\
9.17 \\
9.15 \\
9.08 \\
9.01 \\
8.95 \\
9.25\end{array}$ & $\begin{array}{r}10,900 \\
9,670 \\
8,720 \\
8,360 \\
8,550 \\
8,720 \\
9,490 \\
9,450 \\
9,300 \\
9,140 \\
9,010 \\
9,670\end{array}$ & $\begin{array}{l}9.43 \\
9.20 \\
8.37 \\
7.92 \\
7.93 \\
7.80 \\
8.02 \\
8.58 \\
8.68 \\
8.52 \\
8.23 \\
8.68\end{array}$ & $\begin{array}{r}10,100 \\
9,560 \\
7,800 \\
6,940 \\
6,960 \\
6,710 \\
7,130 \\
8,220 \\
8,420 \\
8,100 \\
7,530 \\
8,420\end{array}$ \\
\hline & \multicolumn{2}{|c|}{ December 20} & \multicolumn{2}{|c|}{ December 21} & \multicolumn{2}{|c|}{ December 22} & \multicolumn{2}{|c|}{ December 23} & \multicolumn{2}{|c|}{ December 24} & \multicolumn{2}{|c|}{ December 25} \\
\hline $\begin{array}{r}2 \\
4 \\
6 \\
8 \\
10 \\
N \\
2 \\
4 \\
6 \\
8 \\
10 \\
M\end{array}$ & $\begin{array}{l}8.90 \\
9.00 \\
8.38 \\
7.82 \\
7.61 \\
7.70 \\
8.20 \\
8.72 \\
8.40 \\
8.27 \\
7.98 \\
8.18\end{array}$ & $\begin{array}{l}8,900 \\
9,120 \\
7,820 \\
6,940 \\
6,370 \\
6,530 \\
7,470 \\
8,500 \\
7,860 \\
7,600 \\
7,050 \\
7,430\end{array}$ & $\begin{array}{l}8.40 \\
8.30 \\
7.95 \\
7.59 \\
7.50 \\
7.18 \\
7.29 \\
8.22 \\
7.90 \\
7.76 \\
7.44 \\
7.65\end{array}$ & $\begin{array}{l}7,860 \\
7,660 \\
7,000 \\
6,330 \\
6,170 \\
5,600 \\
5,790 \\
7,510 \\
6,900 \\
6,640 \\
6,060 \\
6,440\end{array}$ & $\begin{array}{l}7.90 \\
7.47 \\
7.11 \\
6.80 \\
6.88 \\
6.93 \\
7.12 \\
7.88 \\
7.70 \\
7.58 \\
7.47 \\
7.67\end{array}$ & $\begin{array}{l}6,900 \\
6,120 \\
5,480 \\
4,950 \\
5,090 \\
5,170 \\
5,490 \\
6,860 \\
6,530 \\
6,310 \\
6,120 \\
6,480\end{array}$ & $\begin{array}{l}7.93 \\
7.49 \\
7.06 \\
6.68 \\
6.55 \\
6.61 \\
6.74 \\
7.33 \\
7.46 \\
7.42 \\
7.35 \\
7.34\end{array}$ & $\begin{array}{l}6,960 \\
6,150 \\
5,390 \\
4,750 \\
4,530 \\
4,630 \\
4,850 \\
5,860 \\
6,100 \\
6,030 \\
5,900 \\
5,880\end{array}$ & $\begin{array}{l}7.76 \\
7.45 \\
7.14 \\
6.60 \\
6.25 \\
6.22 \\
6.46 \\
7.48 \\
7.62 \\
7.58 \\
7.51 \\
7.55\end{array}$ & $\begin{array}{l}6,640 \\
6,080 \\
5,530 \\
4,610 \\
4,050 \\
4,000 \\
4,390 \\
6,130 \\
6,390 \\
6,310 \\
6,190 \\
6,260\end{array}$ & $\begin{array}{l}7.80 \\
7.41 \\
7.06 \\
6.51 \\
6.16 \\
6.11 \\
6.33 \\
6.55 \\
6.64 \\
6.69 \\
6.71 \\
6.73\end{array}$ & $\begin{array}{l}6,710 \\
6,010 \\
5,390 \\
4,470 \\
3,910 \\
3,840 \\
4,180 \\
4,530 \\
4,680 \\
4,760 \\
4,800 \\
4,830\end{array}$ \\
\hline
\end{tabular}

Supplemental records.- Dec. 10, 11 p.m., 24.20 ft., 65,000 sec.-ft. 
Location. - Lat. $41^{\circ} 14^{\prime}$, long. $120^{\circ} 25^{\prime}$, in $\mathrm{NE} \frac{1}{4}$ sec. 11, T. $39 \mathrm{~N} ., \mathrm{R} .13 \mathrm{E} ., 1.3 \mathrm{mile}$ below West Valiey Crék and 3.5 miles east of Likely, Modoc County. Altitude, about 4,580 feet above mean sea level.

Drainage area. - 248 square miles (revised).

Gage-height record. - Water-stage recorder graph.

Stage-discharge reiation.- Affected by ice for periods Jan. 6-10, 24-26. Defined by current-meter measurements below 600 second-feet; extended to peak atage. Shiftingcontrol method used for period Dec. 12-29.

Maxima.- December 1937: Discharge, 746 second-feet 3 a.m. Dec. 11 (gage helght, 4.86 feet).

1928-November 1937: D1scharge, 1,060 second-feet Apr. 27, 1932 (gage height, 5.55 feet), from rating curve extended above 550 second-feet.

Remarks.- Flood run-off affected by artificial storage in West VaIley Reservoir on West Valley Creek, which stored 7,200 acre-feet during storm period Dec. 10-15. Dis-

charge for periods of ice effect computed on basis of weather records and record for Pit River near Oanby.

Mean daily discharge, in second-feet, November 1937 to January 1938

\begin{tabular}{|c|c|c|c|c|c|c|c|c|c|c|c|}
\hline Day & Nov. & Dec. & Jan. & Day & Nov. & Dec. & Jan. & Day & Nov. & Dec. & Jan. \\
\hline $\begin{array}{r}1 \\
2 \\
3 \\
4 \\
5 \\
6 \\
7 \\
8 \\
9 \\
10\end{array}$ & $\begin{array}{l}14 \\
14 \\
14 \\
14 \\
13 \\
14 \\
14 \\
14 \\
12 \\
12\end{array}$ & $\begin{array}{r}13 \\
11 \\
11 \\
13 \\
16 \\
19 \\
22 \\
21 \\
16 \\
121\end{array}$ & $\begin{array}{l}40 \\
45 \\
43 \\
39 \\
36 \\
32 \\
31 \\
31 \\
31 \\
31\end{array}$ & $\begin{array}{l}11 \\
12 \\
13 \\
14 \\
15 \\
16 \\
17 \\
18 \\
19 \\
20\end{array}$ & $\begin{array}{l}16 \\
13 \\
13 \\
12 \\
11 \\
24 \\
40 \\
23 \\
15 \\
19\end{array}$ & $\begin{array}{r}629 \\
428 \\
214 \\
151 \\
132 \\
95 \\
85 \\
74 \\
61 \\
55\end{array}$ & $\begin{array}{l}31 \\
30 \\
30 \\
31 \\
34 \\
33 \\
37 \\
38 \\
33 \\
31\end{array}$ & $\begin{array}{l}21 \\
22 \\
23 \\
24 \\
25 \\
26 \\
27 \\
28 \\
29 \\
30 \\
31\end{array}$ & $\begin{array}{l}25 \\
14 \\
19 \\
20 \\
12 \\
8 \\
6.5 \\
8 \\
12 \\
14\end{array}$ & $\begin{array}{l}53 \\
46 \\
47 \\
46 \\
40 \\
44 \\
40 \\
38 \\
37 \\
40 \\
39\end{array}$ & $\begin{array}{l}33 \\
40 \\
38 \\
38 \\
36 \\
36 \\
34 \\
33 \\
33 \\
31 \\
33\end{array}$ \\
\hline $\begin{array}{l}\text { Mean } \\
\text { Run- }\end{array}$ & in & & & & & & & & $\begin{array}{r}15.3 \\
911\end{array}$ & $\begin{array}{r}85.7 \\
5,270\end{array}$ & $\begin{array}{r}34.6 \\
2,130\end{array}$ \\
\hline
\end{tabular}

Gage height, in feet, and discharge, in second-feet, at indicated time, 1937

\begin{tabular}{|c|c|c|c|c|c|c|c|c|c|c|c|c|}
\hline \multirow{2}{*}{$\begin{array}{l}5 \\
5 \\
5 \\
0 \\
4\end{array}$} & Feet & Sec.ft. & Feet & Sec.ft. & Feet & Sec.ft. & $F \theta \theta t$ & Sec.ft. & Feet & Sec.ft. & Feet & sec.ft. \\
\hline & \multicolumn{2}{|c|}{ December 8} & \multicolumn{2}{|c|}{ December 9} & \multicolumn{2}{|c|}{ December 10} & \multicolumn{2}{|c|}{ December 11} & \multicolumn{2}{|c|}{ December 12} & \multicolumn{2}{|c|}{ December 13} \\
\hline \multirow[t]{2}{*}{$\begin{array}{r}2 \\
4 \\
6 \\
8 \\
10 \\
\mathbf{N} \\
2 \\
4 \\
6 \\
8 \\
10 \\
\mathrm{M} \\
\end{array}$} & $\begin{array}{l}1.90 \\
1.94 \\
1.98 \\
1.95 \\
1.87 \\
1.92 \\
1.86 \\
1.90 \\
1.86 \\
1.82 \\
1.81 \\
1.83\end{array}$ & $\begin{array}{l}21 \\
23 \\
26 \\
24 \\
20 \\
22 \\
19 \\
21 \\
19 \\
17 \\
16 \\
18\end{array}$ & $\begin{array}{l}1.82 \\
1.81 \\
1.80 \\
1.80 \\
1.80 \\
1.80 \\
1.80 \\
1.81 \\
1.81 \\
1.82 \\
1.82 \\
1.83\end{array}$ & $\begin{array}{l}17 \\
16 \\
16 \\
16 \\
16 \\
16 \\
16 \\
16 \\
16 \\
17 \\
17 \\
18\end{array}$ & $\begin{array}{l}1.84 \\
1.85 \\
1.88 \\
1.88 \\
1.91 \\
2.02 \\
2.12 \\
2.82 \\
2.98 \\
3.50 \\
3.90 \\
4.52\end{array}$ & $\begin{array}{r}18 \\
18 \\
20 \\
20 \\
22 \\
29 \\
37 \\
123 \\
153 \\
284 \\
406 \\
618\end{array}$ & $\begin{array}{l}4.84 \\
4.76 \\
4.63 \\
4.38 \\
4.29 \\
4.41 \\
4.62 \\
4.53 \\
4.51 \\
4.41 \\
4.37 \\
4.33\end{array}$ & $\begin{array}{l}742 \\
710 \\
659 \\
567 \\
535 \\
578 \\
656 \\
621 \\
614 \\
578 \\
563 \\
549\end{array}$ & $\begin{array}{l}4.29 \\
4.24 \\
4.19 \\
4.15 \\
4.08 \\
4.01 \\
3.94 \\
3.88 \\
3.81 \\
3.75 \\
3.67 \\
3.59\end{array}$ & $\begin{array}{l}524 \\
507 \\
490 \\
478 \\
454 \\
432 \\
409 \\
390 \\
368 \\
350 \\
326 \\
302\end{array}$ & $\begin{array}{l}3.51 \\
3.43 \\
3.37 \\
3.31 \\
3.26 \\
3.21 \\
3.16 \\
3.15 \\
3.14 \\
3.15 \\
3.16 \\
3.15\end{array}$ & $\begin{array}{l}278 \\
256 \\
240 \\
225 \\
212 \\
199 \\
187 \\
185 \\
188 \\
185 \\
187 \\
185\end{array}$ \\
\hline & \multicolumn{2}{|c|}{ December 14} & \multicolumn{2}{|c|}{ December 15} & \multicolumn{2}{|c|}{ December 16} & \multicolumn{2}{|c|}{ December 17} & \multicolumn{2}{|c|}{ December 18} & \multicolumn{2}{|c|}{ Docember 19} \\
\hline \multirow[t]{2}{*}{\begin{tabular}{r|}
2 \\
4 \\
6 \\
8 \\
10 \\
$\mathrm{~N}$ \\
2 \\
4 \\
6 \\
8 \\
10 \\
$\mathrm{M}$
\end{tabular}} & $\begin{array}{l}3.09 \\
\overline{3.02} \\
- \\
2.96 \\
\overline{2.95} \\
\overline{2.94} \\
2.93\end{array}$ & $\begin{array}{c}\overline{171} \\
- \\
155 \\
\overline{143} \\
\overline{141} \\
\overline{139} \\
\overline{137}\end{array}$ & $\begin{array}{l}2.90 \\
- \\
2.91 \\
-\overline{2.92} \\
\overline{2.89} \\
\overline{2.84} \\
\overline{2.79}\end{array}$ & $\begin{array}{c}\overline{132} \\
\overline{13} 4 \\
\overline{13} \\
\overline{135} \\
\overline{130} \\
\overline{12} \\
\overline{1} \mathbf{2} \\
\overline{114}\end{array}$ & $\begin{array}{c}- \\
2.74 \\
- \\
2.67 \\
\overline{2.61} \\
2.62 \\
\overline{2.66} \\
2.67 \\
2.67\end{array}$ & $\begin{array}{c}\overline{106} \\
\overline{95} \\
\overline{86} \\
\overline{88} \\
\overline{90} \\
\overline{95}\end{array}$ & $\begin{array}{c}- \\
2.63 \\
- \\
2.59 \\
2.56 \\
- \\
2.59 \\
- \\
2.62 \\
2.61\end{array}$ & $\begin{array}{l}\overline{89} \\
\overline{84} \\
\overline{80} \\
\overline{84} \\
\overline{88} \\
\overline{8} \\
\overline{86}\end{array}$ & $\begin{array}{c}- \\
2.57 \\
- \\
2.53 \\
- \\
2.48 \\
- \\
2.45 \\
- \\
2.45 \\
-\overline{2.51}\end{array}$ & $\begin{array}{l}\overline{81} \\
\overline{76} \\
\overline{70} \\
\overline{66} \\
\overline{66} \\
\overline{74}\end{array}$ & $\begin{array}{l}2.47 \\
- \\
2.40 \\
- \\
2.36 \\
2.34 \\
- \\
2.36 \\
- \\
2.41\end{array}$ & $\begin{array}{l}\overline{69} \\
\overline{61} \\
\overline{5} \\
\overline{57} \\
\overline{55} \\
\overline{57} \\
\overline{62}\end{array}$ \\
\hline & \multicolumn{2}{|c|}{ December 20} & \multicolumn{2}{|c|}{ December 21} & \multicolumn{2}{|c|}{ December 22} & \multicolumn{2}{|c|}{ December 23} & \multicolumn{2}{|c|}{ December 24} & \multicolumn{2}{|c|}{ December 25} \\
\hline $\begin{array}{r}2 \\
4 \\
6 \\
8 \\
10 \\
\mathrm{~N} \\
2 \\
4 \\
6 \\
8 \\
10 \\
\mathrm{M}\end{array}$ & $\begin{array}{l}2.41 \\
2.39 \\
2.38 \\
2.37 \\
2.33 \\
2.28 \\
2.35 \\
2.28 \\
2.28 \\
2.30 \\
2.34 \\
2.36\end{array}$ & $\begin{array}{l}62 \\
60 \\
59 \\
58 \\
54 \\
49 \\
56 \\
49 \\
49 \\
51 \\
55 \\
57\end{array}$ & $\begin{array}{l}2.36 \\
2.34 \\
2.32 \\
2.30 \\
2.29 \\
2.32 \\
2.33 \\
2.27 \\
2.27 \\
2.29 \\
2.31 \\
2.31\end{array}$ & \begin{tabular}{|l|}
57 \\
55 \\
53 \\
51 \\
50 \\
53 \\
54 \\
48 \\
48 \\
50 \\
52 \\
52
\end{tabular} & $\begin{array}{l}2.31 \\
2.27 \\
2.24 \\
2.25 \\
2.22 \\
2.21 \\
2.21 \\
2.23 \\
2.24 \\
2.25 \\
2.27 \\
2.27\end{array}$ & $\begin{array}{l}52 \\
48 \\
45 \\
46 \\
43 \\
42 \\
42 \\
44 \\
45 \\
46 \\
48 \\
48\end{array}$ & $\begin{array}{l}2.25 \\
2.25 \\
2.26 \\
2.27 \\
2.27 \\
2.266 \\
2.24 \\
2.24 \\
2.23 \\
2.29 \\
2.23 \\
2.23\end{array}$ & $\begin{array}{l}46 \\
46 \\
47 \\
48 \\
48 \\
47 \\
45 \\
45 \\
44 \\
50 \\
44 \\
44\end{array}$ & $\begin{array}{l}2.22 \\
2.25 \\
2.28 \\
2.31 \\
2.31 \\
2.23 \\
2.26 \\
2.22 \\
2.20 \\
2.19 \\
2.17 \\
2.17\end{array}$ & $\begin{array}{l}43 \\
46 \\
49 \\
52 \\
52 \\
44 \\
47 \\
43 \\
41 \\
40 \\
39 \\
39\end{array}$ & $\begin{array}{l}2.17 \\
2.17 \\
2.21 \\
2.25 \\
2.24 \\
2.18 \\
2.17 \\
2.17 \\
2.18 \\
2.19 \\
2.19 \\
2.19\end{array}$ & $\begin{array}{l}39 \\
39 \\
42 \\
46 \\
45 \\
40 \\
39 \\
39 \\
40 \\
40 \\
40 \\
40\end{array}$ \\
\hline
\end{tabular}

Supplemental records.- Dec. 11, 3 a.m., $4.86 \mathrm{ft} ., 746$ sec.-ft. Dec. 25, 10.30 a.m., 2.17 ft., 39 sec.-ft. 
Hat Creok near Hat Creok, Calif.

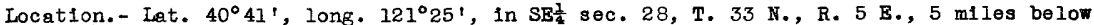
BIg Springs and 11 miles southeast of Hat Creok, Shasta County. Altitude, about 4,500 feet above mean sea level.

Drainage area. - 155 square miles.

Gage-helght record. - Water-stage recorder graph except for perlod 6 a.m. Jan. 6 to Jan. 31, when there was no record.

Stage-discharge relation. - Defined by current-meter measurements below 160 second-feet; extended to peak stage on bas is of slope-area computation of flood flow. Rating curve changed at peak stage.

Maxima.- December 1937: Discharge, about 2,500 second-feet 2 a.m. Dec. Il (gage heIght, 7.75 feet)

1926-November 1937: Discharge, 450 second-feet June 16, 1937 (gage he1ght, 4.12 feet).

Remarks. - Flood run-off not appreclably affected by artificial storage or diversion. Discharge for perlod of missing gage-height record determined from discharge graph based on range of stage shown on recorder graph and record for South Fork of P1t River near Likely.

Mean dally discharge, in second-feet, November 1937 to January 1938

\begin{tabular}{|c|c|c|c||c|c|c|c||c|c|c|c|}
\hline Day & Nov. & Doc. & Jan. & Day & Nov. & Doc. & Jan. & Day & Nov. & Dec. & Jan. \\
\hline 1 & 85 & 104 & 118 & 11 & 91 & 1,340 & 112 & 21 & 186 & 120 & 113 \\
2 & 85 & 103 & 120 & 12 & 86 & 331 & 112 & 22 & 135 & 120 & 116 \\
3 & 85 & 101 & 118 & 13 & 88 & 206 & 112 & 23 & 188 & 118 & 115 \\
4 & 85 & 101 & 118 & 14 & 88 & 176 & 112 & 24 & 135 & 117 & 115 \\
5 & 86 & 101 & 117 & 15 & 86 & 163 & 114 & 25 & 121 & 117 & 114 \\
6 & 88 & 101 & 115 & 16 & 94 & 151 & 114 & 26 & 115 & 120 & 114 \\
7 & 86 & 100 & 114 & 17 & 100 & 145 & 116 & 27 & 110 & 118 & 113 \\
8 & 85 & 100 & 113 & 18 & 91 & 135 & 116 & 28 & 107 & 116 & 113 \\
9 & 84 & 102 & 112 & 19 & 101 & 130 & 115 & 29 & 105 & 116 & 112 \\
10 & 86 & 964 & 112 & 20 & 394 & 123 & 114 & 30 & 104 & 118 & 112 \\
&
\end{tabular}

Gage height, in feet, and discharge, in second-feet, at indicated time, 1937

\begin{tabular}{|c|c|c|c|c|c|c|c|c|c|c|c|c|}
\hline \multirow{2}{*}{$\begin{array}{l}5 \\
\text { 苟 } \\
\text { 品 }\end{array}$} & Feet & Sec.ft. & Feot & Sec.ft. & Feet & Sec.ft. & Feet & Sec.ft. & Feet & Sec.ft. & Feet & Sec.ft. \\
\hline & \multicolumn{2}{|c|}{ December 8} & \multicolumn{2}{|c|}{ December 9} & \multicolumn{2}{|c|}{ December 10} & \multicolumn{2}{|c|}{ December 11} & \multicolumn{2}{|c|}{ December 12} & \multicolumn{2}{|c|}{ December 13} \\
\hline $\begin{array}{r}2 \\
4 \\
6 \\
8 \\
10 \\
\mathbb{N} \\
2 \\
4 \\
6 \\
8 \\
10 \\
M\end{array}$ & $\begin{array}{c}\overline{-} \\
2.46 \\
\overline{2} \\
2.44 \\
\overline{2.51} \\
\bar{z} \\
2.48\end{array}$ & $\begin{array}{c}\overline{-} \\
\overline{99} \\
\overline{-} \\
\overline{96} \\
\overline{104} \\
\overline{-} \\
101\end{array}$ & $\begin{array}{l}- \\
2.48 \\
\ddot{2.47} \\
\dot{2.47} \\
\dot{2.48} \\
\ddot{2.50} \\
\dot{2.56}\end{array}$ & $\begin{array}{c}\overline{101} \\
\overline{100} \\
\overline{100} \\
\overline{101} \\
\overline{103} \\
\overline{110}\end{array}$ & $\begin{array}{l}2.61 \\
2.86 \\
3.30 \\
3.85 \\
4.27 \\
4.62 \\
5.81 \\
6.50 \\
7.15 \\
7.36 \\
7.20 \\
7.48\end{array}$ & $\begin{array}{r}115 \\
147 \\
220 \\
340 \\
453 \\
567 \\
1,100 \\
1,520 \\
1,980 \\
2,150 \\
2,020 \\
2,240 \\
\end{array}$ & $\begin{array}{l}7.75 \\
7.00 \\
6.52 \\
6.05 \\
6.10 \\
5.87 \\
5.77 \\
5.46 \\
5.00 \\
4.43 \\
4.12 \\
3.98 \\
\end{array}$ & $\begin{array}{r}2,500 \\
2,000 \\
1,710 \\
1,450 \\
1,480 \\
1,350 \\
1,300 \\
1,140 \\
918 \\
675 \\
561 \\
514 \\
\end{array}$ & $\begin{array}{l}3.83 \\
3.66 \\
3.53 \\
3.41 \\
3.33 \\
3.27 \\
3.22 \\
3.18 \\
3.13 \\
3.08 \\
3.02 \\
2.97\end{array}$ & \begin{tabular}{|l|}
467 \\
417 \\
380 \\
347 \\
326 \\
310 \\
297 \\
287 \\
275 \\
263 \\
250 \\
238 \\
\end{tabular} & $\begin{array}{c}- \\
2.90 \\
- \\
2.85 \\
- \\
2.80 \\
\overline{2.79} \\
- \\
2.75 \\
- \\
2.72\end{array}$ & $\begin{array}{c}2 \overline{233} \\
2 \overline{2} \\
\overline{202} \\
2 \overline{0} \\
\overline{-} \\
192 \\
\overline{187}\end{array}$ \\
\hline & \multicolumn{2}{|c|}{ December 14} & \multicolumn{2}{|c|}{ December 15} & \multicolumn{2}{|c|}{ December 16} & \multicolumn{2}{|c|}{ December 17} & \multicolumn{2}{|c|}{ December 18} & \multicolumn{2}{|c|}{ December 19} \\
\hline $\begin{array}{r}2 \\
4 \\
6 \\
8 \\
10 \\
\mathbb{N} \\
2 \\
4 \\
6 \\
8\end{array}$ & $\begin{array}{l}- \\
2.69 \\
- \\
2.66 \\
- \\
2.65 \\
- \\
2.64 \\
- \\
2.63 \\
- \\
2.62\end{array}$ & $\begin{array}{c}\overline{181} \\
\overline{176} \\
\overline{17} 4 \\
\overline{172} \\
\overline{170} \\
\overline{169}\end{array}$ & $\begin{array}{c}\overline{-} \\
2.60 \\
\overline{-} \\
2.60 \\
\overline{-} \\
2.58 \\
\overline{-} \\
2.56\end{array}$ & $\begin{array}{c}\overline{-} \\
165 \\
\overline{-} \\
165 \\
\overline{-} \\
162 \\
\overline{1} \\
\overline{158}\end{array}$ & $\begin{array}{c}- \\
- \\
2.54 \\
- \\
- \\
2.52 \\
\overline{-} \\
2.51 \\
- \\
- \\
2.50\end{array}$ & $\begin{array}{c}\overline{-} \\
155 \\
- \\
\overline{151} \\
\overline{-} \\
150 \\
\overline{-} \\
148\end{array}$ & $\begin{array}{c}\overline{-} \\
2.49 \\
\overline{-} \\
2.48 \\
\overline{-} \\
2.47 \\
\overline{-} \\
2.46\end{array}$ & $\begin{array}{c}\overline{-} \\
146 \\
- \\
\overline{145} \\
\overline{-} \\
143 \\
\overline{-} \\
142\end{array}$ & $\begin{array}{c}- \\
2.44 \\
\vdots \\
2.42 \\
- \\
5.42 \\
\overline{2} \\
\overline{2.41}\end{array}$ & $\begin{array}{c}\overline{ } \\
\overline{338} \\
\overline{-} \\
1 \overline{3} 5 \\
\overline{-} \\
\overline{3} 5 \\
\overline{-} \\
134\end{array}$ & $\begin{array}{c}\overline{ } \\
2.40 \\
\overline{-} \\
2.39 \\
\overline{-} \\
2.37 \\
\overline{-} \\
2.37\end{array}$ & $\begin{array}{c}\overline{-} \\
132 \\
\overline{-} \\
130 \\
\overline{-} \\
128 \\
\overline{128} \\
\overline{12}\end{array}$ \\
\hline & \multicolumn{2}{|c|}{ December 20} & \multicolumn{2}{|c|}{ December 21} & \multicolumn{2}{|c|}{ December 22} & \multicolumn{2}{|c|}{ December 23} & \multicolumn{2}{|c|}{ December 24} & \multicolumn{2}{|c|}{ December 25} \\
\hline $\begin{array}{l}2 \\
4 \\
6\end{array}$ & $\begin{array}{c}\overline{-} \\
2.35 \\
\overline{-} \\
2.34 \\
\overline{-} \\
\overline{2.34} \\
\overline{-} \\
\overline{2.32}\end{array}$ & $\begin{array}{c}\overline{-} \\
1 \overline{24} \\
\overline{1} \\
1 \overline{23} \\
\overline{1} \\
\overline{123} \\
\overline{120} \\
\overline{120}\end{array}$ & $\begin{array}{c}- \\
\overline{2.32} \\
\overline{-} \\
2.32 \\
\overline{-} \\
2.34 \\
\overline{-} \\
2.32\end{array}$ & $\begin{array}{c}\overline{-} \\
120 \\
\overline{120}\end{array}$ & $\begin{array}{c}\bar{z} \\
\bar{z} \\
\bar{z} \\
2.32 \\
\bar{z} \\
\bar{z} \\
\overline{2} \\
2.32\end{array}$ & $\begin{array}{c}\overline{-} \\
\bar{z} \\
\overline{120} \\
\bar{z} \\
\bar{z} \\
\overline{1} \\
\overline{120}\end{array}$ & $\begin{array}{c}- \\
- \\
2.30 \\
\overline{-} \\
2.31 \\
\overline{-} \\
2.32 \\
\overline{-} \\
2.31\end{array}$ & $\begin{array}{c}\overline{-} \\
\overline{117} \\
\overline{-} \\
\overline{118} \\
\overline{-} \\
\overline{120} \\
\overline{-} \\
\overline{118}\end{array}$ & 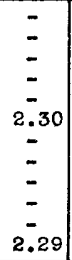 & $\begin{array}{c}= \\
= \\
\overline{-} \\
117 \\
= \\
= \\
\overline{-} \\
116\end{array}$ & $\begin{array}{c}\overline{-} \\
2.28 \\
\overline{-} \\
2.27 \\
\bar{z} \\
\overline{2.32} \\
\overline{-} \\
2.30\end{array}$ & $\begin{array}{c}\overline{-} \\
\overline{114} \\
\overline{-} \\
\overline{113} \\
\overline{-} \\
1 \overline{2} 0 \\
\overline{-} \\
\overline{117}\end{array}$ \\
\hline
\end{tabular}


McCloud River near McCloud, Calif.

Location.- Lat. $41^{\circ} 11^{\prime}$, long. $122^{\circ} 04^{\prime}$, in $\mathrm{NE}_{\frac{1}{4}}$ sec. 34 , T. $39 \mathrm{~N} .$, R. $2 \mathrm{w}$. , half a mile below Angel Creek and 6 miles southeast of McCloud, Siskiyou County. Altitude, about 2,750 feet above mean sea level.

Drainage area.- 388 square miles.

Gage-helght record. - Water-stage recorder graph except for period 10 p.m. Dec. 1 to 2 p.m. Dec. 22, when there was no record. Peak s tage obtained from floodmark in well.

Stage-discharge relation.- Defined by current-meter measurements below 2,400 secondfeet; extended to peak s tage by averaging discharges obtained from extensions by area-velocity study and Ave method. Rating curve changed at peak stage.

Haxima.- December 1937: Discharge, 4,600 second-feet probably Dec. 10 (gage height, 5.4 (eet).

1931-November 1937: Discharge, 2,760 second-feet (revised) Feb. 22, 1936 (gage helght, 3.62 feet), from rating curve extended above 1,200 second-feet on bas is of area-velocity and $A \sqrt{a}$ studies in 1938.

Remarks.- Flood run-off not affected by artificial storage or diversion. Discharge durIng period of missing gage-helght record determined from discharge hydrograph based on record of MeCloud River at Baird.

Mean daily discharge, in second-feet, November 1937 to January 1938

\begin{tabular}{|c|c|c|c|c|c|c|c|c|c|c|c|}
\hline Day & Nov. & Dec. & Jan. & Day & Nov, & Dec. & Jan. & Day & Nov. & Dec. & Jan. \\
\hline $\begin{array}{r}1 \\
2 \\
3 \\
4 \\
5 \\
6 \\
7 \\
8 \\
9 \\
10\end{array}$ & $\begin{array}{l}587 \\
587 \\
587 \\
587 \\
587 \\
587 \\
587 \\
581 \\
581 \\
639\end{array}$ & $\begin{array}{r}738 \\
730 \\
720 \\
700 \\
690 \\
680 \\
670 \\
660 \\
680 \\
2,500\end{array}$ & $\begin{array}{l}721 \\
721 \\
714 \\
708 \\
702 \\
689 \\
689 \\
683 \\
677 \\
671\end{array}$ & $\begin{array}{l}11 \\
12 \\
13 \\
14 \\
15 \\
16 \\
17 \\
18 \\
19 \\
20\end{array}$ & $\begin{array}{r}706 \\
651 \\
639 \\
682 \\
694 \\
757 \\
795 \\
757 \\
744 \\
1,200\end{array}$ & $\begin{array}{r}3,500 \\
2,500 \\
1,700 \\
1,400 \\
1,200 \\
1,100 \\
1,030 \\
970 \\
920 \\
880\end{array}$ & $\begin{array}{l}671 \\
665 \\
665 \\
671 \\
689 \\
695 \\
695 \\
695 \\
695 \\
683\end{array}$ & $\begin{array}{l}21 \\
22 \\
23 \\
24 \\
25 \\
26 \\
27 \\
28 \\
29 \\
30 \\
31\end{array}$ & $\begin{array}{r}1,200 \\
968 \\
1,320 \\
1,360 \\
1,080 \\
954 \\
880 \\
821 \\
789 \\
763\end{array}$ & $\begin{array}{l}850 \\
825 \\
806 \\
799 \\
773 \\
766 \\
754 \\
740 \\
728 \\
728 \\
728\end{array}$ & $\begin{array}{l}677 \\
677 \\
677 \\
671 \\
671 \\
665 \\
665 \\
671 \\
671 \\
671 \\
683\end{array}$ \\
\hline $\begin{array}{l}\text { Noa } \\
\text { Fun }\end{array}$ & , in & & & & & & & & $\begin{array}{r}789 \\
46,950\end{array}$ & $\begin{array}{r}1,047 \\
64,390\end{array}$ & $\begin{array}{r}684 \\
42,050\end{array}$ \\
\hline
\end{tabular}


Location. - Lat. $40^{\circ} 47^{\prime}$, long. $122^{\circ} 18^{\prime}$, in SEz sec. 22 , T. 34 N., R. 4 W., half a mile below Bafrd post office, Shasta County, and $1 \frac{1}{2}$ miles above junction with P1t RIver. Altitude, about 700 feet above mean sea level.

Dralnage area.- 668 square miles.

Gage-helght record. - Water-s tage recorder graph.

Stage-discharge relation. - Defined by current-meter measurements below 9,200 secondfeet; extended to peak stage on basis of areg-velocity study and comparison with extension of rating for former station 1 mile upstream; verified by comparison of peak discharge and total run-off of flood with records at other stations in upper Sacramento River Basin.

Maxima.- December 1937: Discharge, 32,200 second-feet 11 p.m. Dec. 10 (gage he1ght, 23.35 feet, poss1bly affected by backwater from P1t River).

1910-November 1937: Discherge observed, 27,600 second-feet Feb. 25, 1917 (gage

helght, 14.3 feet, from nonrecording gage at former site and datum, 1 mile upstream). Remarks.- Flood run-off not affected by artificial storage or diversion.

Mean da1ly discharge, in second-feet, November 1937 to January 1938

\begin{tabular}{|r|c|r|c|c|c|c|c|c|c|c|c|}
\hline Day & Hov. & Dec. & Jan. & Day & Nov. & Dec. & Jan. & Day & Hov. & Dec. & Jan. \\
\hline 1 & 750 & 1,840 & 1,630 & 11 & 2,450 & 22,100 & 1,420 & 21 & 6,450 & 2,210 & 2,790 \\
2 & 750 & 1,740 & 1,700 & 12 & 1,570 & 12,200 & 1,400 & 22 & 4,080 & 2,130 & 2,530 \\
3 & 750 & 1,630 & 1,660 & 13 & 1,340 & 7,010 & 1,400 & 23 & 8,960 & 2,050 & 2,290 \\
4 & 750 & 1,540 & 1,630 & 14 & 2,610 & 5,020 & 1,400 & 24 & 8,750 & 1,980 & 2,130 \\
5 & 750 & 1,480 & 1,600 & 15 & 2,050 & 4,080 & 1,630 & 25 & 5,020 & 1,910 & 2,050 \\
6 & 750 & 1,420 & 1,570 & 16 & 3,350 & 3,450 & 2,050 & 26 & 3,550 & 1,840 & 1,980 \\
7 & 750 & 1,400 & 1,540 & 17 & 3,970 & 3,060 & 3,970 & 27 & 2,880 & 1,770 & 1,910 \\
8 & 750 & 1,370 & 1,510 & 18 & 2,610 & 2,790 & 3,450 & 28 & 2,450 & 1,740 & 1,910 \\
9 & 750 & 1,420 & 1,480 & 19 & 2,640 & 2,530 & 3,350 & 29 & 2,210 & 1,700 & 1,910 \\
10 & 1,420 & 12,200 & 1,450 & 20 & 11,100 & 2,370 & 3,150 & 30 & 1,980 & 1,700 & 1,840 \\
& & & & & & & & 31 & & 1,660 & 3,610 \\
\hline
\end{tabular}

Gage helght, in feet, and discharge, in second-feet, at indlcated time, 1937

\begin{tabular}{|c|c|c|c|c|c|c|c|c|c|c|c|c|}
\hline \multirow{2}{*}{ 总 } & eet & Sec.ft. & Feet & sec.ft. & Feet & Sec.ft. & Feet & sec.ft. & Feet & Sec.ft. & Feet & Sec.ft. \\
\hline & \multicolumn{2}{|c|}{ December 8} & \multicolumn{2}{|c|}{ December 9} & \multicolumn{2}{|c|}{ December 10} & \multicolumn{2}{|c|}{ December 11} & \multicolumn{2}{|c|}{ December 12} & \multicolumn{2}{|c|}{ December 13} \\
\hline $\begin{array}{r}2 \\
4 \\
6 \\
8 \\
10 \\
10 \\
2 \\
4 \\
6 \\
8 \\
10\end{array}$ & $\begin{array}{l}2 . \\
2.86 \\
- \\
2.85 \\
- \\
2.84 \\
- \\
2.82 \\
- \\
2.81 \\
- \\
2.80\end{array}$ & $\begin{array}{l}1, \overline{3} 70 \\
\overline{3} 70 \\
1, \overline{3} 60 \\
1, \overline{3} 50 \\
1, \overline{3} 50 \\
\overline{-} \\
1,340\end{array}$ & $\begin{array}{l}2.80 \\
2.80 \\
2.79 \\
2.78 \\
2.79 \\
2.82 \\
2.88 \\
2.98 \\
3.11 \\
3.22 \\
3.40 \\
3.72\end{array}$ & $\begin{array}{l}1,340 \\
1,340 \\
1,330 \\
1,330 \\
1,330 \\
1,350 \\
1,380 \\
1,440 \\
1,520 \\
1,580 \\
1,700 \\
1,920\end{array}$ & $\begin{array}{r}4.22 \\
4.64 \\
5.21 \\
5.90 \\
7.40 \\
9.10 \\
11.15 \\
12.75 \\
16.35 \\
21.00 \\
22.75 \\
23.00\end{array}$ & \begin{tabular}{|r|}
2,310 \\
2,650 \\
3,160 \\
3,860 \\
5,670 \\
8,000 \\
11,100 \\
13,600 \\
19,600 \\
27,900 \\
31,000 \\
31,500
\end{tabular} & $\begin{array}{l}20.80 \\
18.30 \\
17.13 \\
17.15 \\
17.02 \\
17.26 \\
17.85 \\
18.08 \\
17.64 \\
16.86 \\
15.90 \\
15.20\end{array}$ & $\begin{array}{l}27,500 \\
23,000 \\
20,900 \\
21,000 \\
20,700 \\
21,200 \\
22,200 \\
22,600 \\
21,900 \\
20,500 \\
18,800 \\
17,600\end{array}$ & \begin{tabular}{|r|}
14.66 \\
13.78 \\
13.11 \\
12.56 \\
12.03 \\
11.46 \\
11.00 \\
10.60 \\
10.30 \\
10.06 \\
9.80 \\
9.53
\end{tabular} & $\begin{array}{r}16,700 \\
15,200 \\
14,200 \\
13,300 \\
12,400 \\
11,500 \\
10,800 \\
10,200 \\
9,800 \\
9,440 \\
9,050 \\
8,640\end{array}$ & $\begin{array}{l}9.35 \\
9.17 \\
8.95 \\
8.75 \\
8.55 \\
8.36 \\
8.18 \\
8.02 \\
7.86 \\
7.70 \\
7.57 \\
7.45\end{array}$ & $\begin{array}{l}8,380 \\
8,100 \\
7,780 \\
7,500 \\
7,220 \\
6,950 \\
6,700 \\
6,480 \\
6,270 \\
6,060 \\
5,890 \\
5,740\end{array}$ \\
\hline & \multicolumn{2}{|c|}{ December 14} & \multicolumn{2}{|c|}{ December 15} & \multicolumn{2}{|c|}{ December 16} & \multicolumn{2}{|c|}{ December 17} & \multicolumn{2}{|c|}{ December 18} & \multicolumn{2}{|c|}{ December 19} \\
\hline \multirow[t]{2}{*}{$\begin{array}{r}2 \\
4 \\
6 \\
8 \\
10 \\
N \\
2 \\
4 \\
6 \\
8 \\
10 \\
M\end{array}$} & $\begin{array}{l}7.33 \\
7.21 \\
7.12 \\
7.04 \\
6.95 \\
6.89 \\
6.76 \\
6.67 \\
6.63 \\
6.52 \\
6.49 \\
6.41\end{array}$ & $\begin{array}{l}5,580 \\
5,420 \\
5,310 \\
5,200 \\
5,080 \\
5,010 \\
4,850 \\
4,740 \\
4,700 \\
4,560 \\
4,530 \\
4,430\end{array}$ & $\begin{array}{l}- \\
6.29 \\
- \\
6.17 \\
-.06 \\
6 .-95 \\
5.95 \\
5.86 \\
- \\
5.75\end{array}$ & $\begin{array}{l}4, \overline{2} 90 \\
4, \overline{1} 60 \\
4, \overline{0} 40 \\
3, \overline{920} \\
3, \overline{8} 20 \\
3, \overline{7} 00\end{array}$ & $\begin{array}{c}5.66 \\
- \\
5.59 \\
- \\
5.51 \\
- \\
5.43 \\
- \\
5.36 \\
- \\
5.29\end{array}$ & $\begin{array}{l}3, \overline{610} \\
\overline{3}, \overline{5} 40 \\
\overline{4}, \overline{6} \\
\overline{3}, \overline{3} 80 \\
\overline{3}, \overline{3} 10 \\
\overline{3}, \overline{240}\end{array}$ & $\begin{array}{l}5 . \\
5.21 \\
5.15 \\
- \\
5.09 \\
-.04 \\
5.04 \\
4.99 \\
- \\
4.92\end{array}$ & $\begin{array}{l}3, \overline{160} \\
3, \overline{100} \\
3, \overline{0} \\
\overline{3}, \overline{0} 10 \\
\overline{-}, \overline{9} 60 \\
\overline{-}, \overline{900}\end{array}$ & $\begin{array}{c}\overline{-} \\
\overline{4.83} \\
\overline{-} \\
4.75 \\
\overline{-} \\
4.68 \\
\overline{-} \\
4.62\end{array}$ & $\begin{array}{c}\overline{-} \\
2,820 \\
\overline{-} \\
2, \overline{7} 40 \\
\overline{-} \\
2, \overline{6} 80 \\
- \\
\overline{-} \\
2, \overline{630}\end{array}$ & $\begin{array}{c}\bar{E} \\
\overline{4.55} \\
\bar{z} \\
4.48 \\
\bar{z} \\
\overline{4.43} \\
\bar{z} \\
4.37\end{array}$ & $\begin{array}{c}\overline{-} \\
2, \overline{5} 70 \\
\overline{-} \\
2, \overline{5} 10 \\
\overline{-} \\
2,470 \\
\overline{-} \\
2,430\end{array}$ \\
\hline & \multicolumn{2}{|c|}{ December 20} & \multicolumn{2}{|c|}{ December 21} & \multicolumn{2}{|c|}{ December 22} & \multicolumn{2}{|c|}{ December 23} & \multicolumn{2}{|c|}{ December 24} & \multicolumn{2}{|c|}{ December 25} \\
\hline $\begin{array}{r}2 \\
4 \\
6 \\
8 \\
10 \\
\mathrm{~N}\end{array}$ & $\begin{array}{c}\overline{-} \\
4.32 \\
= \\
4.27 \\
= \\
4.22 \\
= \\
4.17\end{array}$ & $\begin{array}{c}\overline{-} \\
2, \overline{3} 90 \\
\overline{-} \\
2, \overline{3} 50 \\
\overline{-} \\
2, \overline{3} 10 \\
\bar{z} \\
2, \overline{2} 70\end{array}$ & $\begin{array}{c}\bar{z} \\
4.13 \\
= \\
4.09 \\
= \\
4.04 \\
= \\
4.02\end{array}$ & $\begin{array}{c}\overline{-} \\
2, \overline{2} 30 \\
\overline{-} \\
2, \overline{2} 00 \\
\overline{-} \\
2, \overline{1} 60 \\
\overline{-} \\
2, \overline{1} 50\end{array}$ & $\begin{array}{c}\overline{-} \\
4.00 \\
\overline{-} \\
3.97 \\
\overline{-} \\
3.96 \\
\overline{3.94}\end{array}$ & $\begin{array}{c}\overline{-} \\
2, \overline{130} \\
- \\
2, \overline{110} \\
-\end{array}$ & $\begin{array}{l}= \\
3.90 \\
= \\
3.86 \\
= \\
3.82\end{array}$ & $\begin{array}{c}\overline{-} \\
2,050 \\
- \\
2, \overline{0}\end{array}$ & $\begin{array}{l}- \\
3.77 \\
- \\
3.86 \\
\tilde{3.91} \\
\tilde{3.91} \\
- \\
3.80 \\
- \\
3.76\end{array}$ & $\begin{array}{l}1, \overline{9} 60 \\
2, \overline{0} \\
2, \overline{0} 00 \\
2, \overline{0} \\
\overline{0}, \overline{9} 0 \\
1, \overline{9} \\
\overline{9}\end{array}$ & $\begin{array}{c} \\
\overline{3.70} \\
- \\
\overline{3.67} \\
\bar{z} \\
3.64 \\
- \\
\overline{3.62} .\end{array}$ & $\begin{array}{c}\overline{-} \\
1, \overline{9} 10 \\
- \\
1, \overline{8} 90 \\
-\end{array}$ \\
\hline
\end{tabular}

Supplemental records.- Dec. 10, 11 p.m., 23.35 ft., 32,200 sec.-ft. 


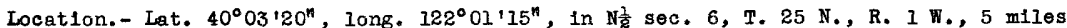
abcre mouth and 5 mlles northeast of Los Molinos, Tehama County. Altitude, about 420 feet above mean sea level.

Drainage area.- 134 square miles (revised).

Ggge-helght record. - Water-stage recorder graph except for periods midnight Dec. 10 to 4 p.m. Dec. 21, 7 a.m. Dec. 29 to 1l:30 a.m. Jan. 2l. Stage graph for periods Dec. 11-17, 21, 29, and Jan. 21 based on floodmarks, partial recorder graph, and a few outslde staff-gage readings. Peak stage obtalneá from floodmarks on banks.

Stage-discharge relation.- Defined by current-meter measurements below 3,900 secondfeet; extended to peak stage on bas is of slope-area computation of flood flow; verifled by area-velocity study. Rating curve changed at peak stage.

Maxima.- December 1937: Discharge, 23,000 second-feet about 2 a.m. Dec. Il (gage holght, 23.4 foet from floodmarks).

1929-November 1937: Discharge, 6,000 second-feet Dec. 15, 1929 (gage-helght, 10.05 feet), from rating curve extended above 3,900 second-feet.

Remarks. - Flood flow not affected by artificial storage or diversion. Dlacharge for perlods of missing gage-helght record, Dec. 18-20 and Dec. 30 to Jan. 20, determined from range of stage indicated on recorder graph, partial recorder graph, a few outside staff-gage readings, weather recorás, and comparison with records for nearby streams.

Mean daily discharge, in second-feet, November 1937 to January 1938

\begin{tabular}{|c|r|r|r|r|r|r|r|r|r|r|r|}
\hline Day & Nov. & Dec. & Jan. & Day & Nov. & Dec. & Jan. & Day & Nov. & Dec. & Jan. \\
\hline 1 & 90 & 225 & 250 & 11 & 420 & 12,300 & 220 & 21 & 1,190 & 324 & 305 \\
2 & 89 & 208 & 280 & 12 & 222 & 4,050 & 210 & 22 & 593 & 314 & 305 \\
3 & 86 & 196 & 300 & 13 & 148 & 1,920 & 210 & 23 & 1,320 & 314 & 308 \\
4 & 85 & 185 & 290 & 14 & 233 & 1,020 & 200 & 24 & 1,260 & 292 & 279 \\
5 & 85 & 172 & 290 & 15 & 231 & 655 & 400 & 25 & 662 & 286 & 264 \\
6 & 89 & 167 & 270 & 16 & 928 & 530 & 500 & 26 & 468 & 270 & 255 \\
7 & 104 & 165 & 260 & 17 & 1,130 & 470 & 900 & 27 & 364 & 258 & 246 \\
8 & 91 & 162 & 250 & 18 & 400 & 460 & 600 & 28 & 308 & 246 & 246 \\
9 & 91 & 21.0 & 240 & 19 & 440 & 410 & 500 & 29 & 269 & 246 & 243 \\
10 & 103 & 5,660 & 220 & 20 & 2,640 & 370 & 400 & 30 & 244 & 250 & 236 \\
\end{tabular}

Gage height, in feet, and discharge, in second-feet, at indicated time, 1937

\begin{tabular}{|c|c|c|c|c|c|c|c|c|c|c|c|c|}
\hline \multirow{2}{*}{ 点 } & Feot & sec.ft. & Feot & Sec.ft. & Feet & Sec.ft. & Feet & Sec.ft. & Feet & Sec.ft. & Feet & Sec.ft. \\
\hline & \multicolumn{2}{|c|}{ December 8} & \multicolumn{2}{|c|}{ December 9} & \multicolumn{2}{|c|}{ December 10} & \multicolumn{2}{|c|}{ December II } & \multicolumn{2}{|c|}{ December 12} & \multicolumn{2}{|c|}{ Docember 13} \\
\hline $\begin{array}{r}2 \\
4 \\
6 \\
8 \\
10 \\
N \\
2 \\
4 \\
6 \\
8 \\
10 \\
4\end{array}$ & $\begin{array}{l}= \\
= \\
= \\
1.52 \\
= \\
= \\
1.50\end{array}$ & $\begin{array}{c}= \\
= \\
= \\
162 \\
= \\
= \\
158\end{array}$ & $\begin{array}{l}1.50 \\
1.50 \\
1.50 \\
1.49 \\
1.49 \\
1.49 \\
1.50 \\
1.56 \\
1.65 \\
1.97 \\
2.85 \\
3.75\end{array}$ & $\begin{array}{l}158 \\
158 \\
158 \\
156 \\
156 \\
156 \\
158 \\
169 \\
185 \\
244 \\
440 \\
732\end{array}$ & $\begin{array}{r}3.93 \\
4.00 \\
4.09 \\
4.90 \\
5.95 \\
8.10 \\
11.85 \\
11.85 \\
13.50 \\
14.00 \\
17.10 \\
20.00\end{array}$ & $\begin{array}{r}802 \\
830 \\
866 \\
1,210 \\
1,740 \\
3,450 \\
7,510 \\
7,510 \\
9,510 \\
10,200 \\
14,200 \\
18,200 \\
\end{array}$ & $\begin{array}{l}23.4 \\
22.0 \\
19.0 \\
16.4 \\
15.2 \\
14.0 \\
12.8 \\
12.2 \\
11.7 \\
11.1 \\
10.7 \\
10.2\end{array}$ & $\begin{array}{r}23,000 \\
21,000 \\
16,900 \\
13,500 \\
12,000 \\
10,400 \\
8,960 \\
8,240 \\
7,650 \\
6,990 \\
6,550 \\
6,000\end{array}$ & $\begin{array}{c}= \\
9.0 \\
= \\
8.2 \\
= \\
7.4 \\
= \\
6.8\end{array}$ & $\begin{array}{c}\overline{-} \\
4, \overline{750} \\
\overline{-} \\
3, \overline{9} 50 \\
\overline{-} \\
3, \overline{190} \\
\overline{-} \\
2, \overline{650}\end{array}$ & $\begin{array}{c}- \\
\overline{-} \\
= \\
\overline{5.8} \\
\vdots \\
5.4 \\
= \\
5.0\end{array}$ & $\begin{array}{c}\overline{-} \\
2, \overline{240} \\
- \\
\overline{8} \\
1, \overline{-} \\
\overline{-} \\
1, \overline{5} 70 \\
- \\
1, \overline{330}\end{array}$ \\
\hline & \multicolumn{2}{|c|}{ December 14} & \multicolumn{2}{|c|}{ December 15} & \multicolumn{2}{|c|}{ December 16} & \multicolumn{2}{|c|}{ December 17} & \multicolumn{2}{|c|}{ December 18} & \multicolumn{2}{|c|}{ December 19} \\
\hline $\begin{array}{r}2 \\
4 \\
6 \\
8 \\
10 \\
\mathrm{~N} \\
2 \\
4 \\
6 \\
8 \\
10 \\
\mathrm{M}\end{array}$ & $\begin{array}{c}= \\
4.7 \\
= \\
4.4 \\
= \\
4.1 \\
= \\
3.9\end{array}$ & $\begin{array}{c}\bar{z} \\
1, \overline{170} \\
\bar{z} \\
1,020 \\
\bar{z} \\
\overline{8} 80 \\
\overline{7} \\
\overline{7} 90\end{array}$ & $\begin{array}{c}- \\
\overline{3.7} \\
= \\
\overline{3.6} \\
= \\
3.5 \\
= \\
3.4\end{array}$ & $\begin{array}{c}\overline{-} \\
700 \\
\overline{0} \\
6 \overline{5} \\
\overline{-} \\
610 \\
\overline{5} \\
5 \overline{7} 0\end{array}$ & $\begin{array}{l}= \\
= \\
= \\
= \\
= \\
= \\
=\end{array}$ & $\begin{array}{c}= \\
= \\
= \\
530 \\
= \\
= \\
= \\
=\end{array}$ & $\begin{array}{l}= \\
= \\
= \\
3.15 \\
= \\
= \\
=\end{array}$ & $\begin{array}{c}= \\
= \\
= \\
470 \\
= \\
= \\
=\end{array}$ & $\begin{array}{l}\bar{z} \\
\bar{z} \\
\bar{z} \\
\bar{z} \\
\bar{z}\end{array}$ & $\begin{array}{l}= \\
= \\
= \\
z 460 \\
z \\
z \\
=\end{array}$ & $\begin{array}{l}\bar{z} \\
\bar{z} \\
\bar{z} \\
\bar{z} \\
\bar{z} \\
\bar{z}\end{array}$ & $\begin{array}{l}= \\
= \\
= \\
= \\
= \\
= \\
= \\
= \\
=\end{array}$ \\
\hline & \multicolumn{2}{|c|}{ December 20} & \multicolumn{2}{|c|}{ December 21} & \multicolumn{2}{|c|}{ December 22} & \multicolumn{2}{|c|}{ December 23} & \multicolumn{2}{|c|}{ December 24} & \multicolumn{2}{|c|}{ December 25} \\
\hline $\begin{array}{r}2 \\
4 \\
6 \\
8 \\
10 \\
N \\
2 \\
4 \\
6 \\
8 \\
10 \\
M\end{array}$ & $\begin{array}{l}= \\
= \\
= \\
= \\
= \\
= \\
=\end{array}$ & $\begin{array}{l}\bar{z} \\
\bar{z} \\
\overline{3} 70 \\
= \\
= \\
= \\
=\end{array}$ & $\begin{array}{l}= \\
= \\
= \\
= \\
= \\
=\end{array}$ & $\begin{array}{l}= \\
= \\
= \\
=324 \\
= \\
= \\
=\end{array}$ & $\begin{array}{c}\overline{-} \\
2.74 \\
\vdots \\
2.73 \\
\vdots \\
2.72 \\
\vdots \\
2.78\end{array}$ & $\begin{array}{c}\overline{-} \\
3 \overline{21} \\
- \\
3 \overline{18} \\
\overline{3} \\
3 \overline{14} \\
\overline{334} \\
\overline{3}\end{array}$ & $\begin{array}{c}- \\
2.74 \\
\overline{-} \\
2.71 \\
\overline{-} \\
2.67 \\
\overline{2.66}\end{array}$ & $\begin{array}{c}\overline{-} \\
3 \overline{2} \\
\vdots \\
3 \bar{i} \\
\vdots \\
2 \overline{9} \\
\overline{2} \\
\overline{2} \overline{9}\end{array}$ & $\begin{array}{l}= \\
= \\
= \\
2.65 \\
= \\
= \\
= \\
2.65\end{array}$ & $\begin{array}{c}\overline{-} \\
\overline{-} \\
- \\
292 \\
\bar{z} \\
\bar{z} \\
\overline{-} \\
292\end{array}$ & $\begin{array}{c}= \\
= \\
= \\
2.63 \\
= \\
= \\
= \\
2.60\end{array}$ & $\begin{array}{c}= \\
= \\
- \\
286 \\
= \\
= \\
\overline{2} \\
276\end{array}$ \\
\hline
\end{tabular}

Supplemental records.- Dec. 10,3 p.m., $12.30 \mathrm{ft.}, 8,050$ sec.-ft.

- Mean for the day. 
Elder Creok near Henleyville, Calif.

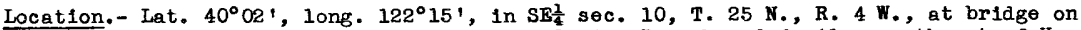
Paskenta-Red Bluff road, $1.2 \mathrm{mlles}$ above Spring Branch and 6 miles northeast of Henlejville, Tehama county. Altitude, about 310 feet above mean sea level.

Dralnage area.- 147 square miles.

Gagerhelght record. - Water-stage recorder graph.

Stage-discharge relation.- Defined by current-meter measurements below 4, 900 secondfert; extended to peak atage on basis of areanvelocity study and $A \sqrt{d}$ method.

Maxima.- December 1937: Discharge, 10,700 second-feet 10 p.m. Dec. 10 (gege helght, 9.7 feet, from floodmarks on right bank; 10.4 feet, from gage in well at bridge pier in midstream).

1930-November 1937: Discharge, about 6,300 second-feet Jan. 1, 1934 (gage height, 7.26 feet, in we11; outside gage height very nearly the same), from rating curve extended above 1,000 second-feet on basis of slope-area determination of flood flow.

Remarks.- Flood mun-off not affected by artificlal storage or diversion.

Mean da1ly discharge, in second-feet, November 1937 to January 1938

\begin{tabular}{|c|c|c|c|c|c|c|c|c|c|c|c|}
\hline Day & Nov. & Dec. & Jan. & Day & Nov. & Dec. & Jan. & Day & Nov. & Dec. & Jan. \\
\hline $\begin{array}{r}1 \\
2 \\
3 \\
4 \\
5 \\
6 \\
7 \\
8 \\
9 \\
10\end{array}$ & $\begin{array}{l}0 \\
0 \\
0 \\
0 \\
0 \\
0 \\
0 \\
0 \\
0 \\
0\end{array}$ & $\begin{array}{r}48 \\
44 \\
41 \\
38 \\
35 \\
34 \\
32 \\
31 \\
71 \\
4,080\end{array}$ & $\begin{array}{l}70 \\
95 \\
95 \\
82 \\
77 \\
74 \\
70 \\
67 \\
62 \\
60\end{array}$ & $\begin{array}{l}11 \\
12 \\
13 \\
14 \\
15 \\
16 \\
17 \\
18 \\
19 \\
20\end{array}$ & $\begin{array}{r}54 \\
32 \\
14 \\
42 \\
31 \\
356 \\
584 \\
109 \\
971 \\
4,270\end{array}$ & $\begin{array}{r}4,530 \\
1,300 \\
545 \\
337 \\
253 \\
200 \\
170 \\
146 \\
129 \\
115\end{array}$ & $\begin{array}{r}60 \\
58 \\
58 \\
58 \\
90 \\
172 \\
1,180 \\
253 \\
205 \\
158\end{array}$ & $\begin{array}{l}21 \\
22 \\
23 \\
24 \\
25 \\
26 \\
27 \\
28 \\
29 \\
30 \\
31\end{array}$ & $\begin{array}{r}575 \\
240 \\
220 \\
162 \\
126 \\
101 \\
82 \\
70 \\
62 \\
54\end{array}$ & $\begin{array}{r}109 \\
104 \\
98 \\
95 \\
90 \\
84 \\
82 \\
77 \\
74 \\
72 \\
72 \\
\end{array}$ & $\begin{array}{r}132 \\
129 \\
126 \\
115 \\
107 \\
101 \\
95 \\
98 \\
107 \\
93 \\
1,100\end{array}$ \\
\hline $\begin{array}{l}\theta \text { an } \\
\text { un- }\end{array}$ & , 1 & 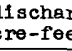 & & & & & & & $\begin{array}{r}272 \\
16,180 \\
\end{array}$ & 26,050 & $\begin{array}{r}169 \\
10,410 \\
\end{array}$ \\
\hline
\end{tabular}

Gage height, in feet, and discharge, in second-feet, at indicated time, 1937

\begin{tabular}{|c|c|c|c|c|c|c|c|c|c|c|c|c|}
\hline \multirow{2}{*}{ 孚 } & Feet & sec.ft. & Fert & Sec.ft. & Feet & Sec.ft. & Feet & Sec.ft. & Feet & Sec.ft. & Feet & Sec.ft. \\
\hline & \multicolumn{2}{|c|}{ December 8} & \multicolumn{2}{|c|}{ December 9} & \multicolumn{2}{|c|}{ December 10} & \multicolumn{2}{|c|}{ December 11} & \multicolumn{2}{|c|}{ December 12} & \multicolumn{2}{|c|}{ December 13} \\
\hline \multirow[t]{2}{*}{$\begin{array}{r}2 \\
4 \\
6 \\
8 \\
10 \\
\mathrm{~N} \\
2 \\
4 \\
6 \\
8 \\
10 \\
M\end{array}$} & $\begin{array}{l}\overline{-} \\
\overline{-} \\
\overline{2} \\
\overline{-} \\
\overline{-} \\
\overline{-} \\
\overline{2.52}\end{array}$ & $\begin{array}{l}- \\
\overline{-} \\
\overline{-} \\
\overline{3} \\
\overline{-} \\
\overline{-} \\
- \\
\overline{-} \\
\overline{31}\end{array}$ & $\begin{array}{l}2.52 \\
2.52 \\
2.52 \\
2.52 \\
2.52 \\
2.53 \\
2.56 \\
2.59 \\
2.62 \\
2.68 \\
3.10 \\
3.72\end{array}$ & \begin{tabular}{|r|}
31 \\
31 \\
31 \\
31 \\
31 \\
32 \\
36 \\
41 \\
46 \\
58 \\
190 \\
718
\end{tabular} & $\begin{array}{r}4.06 \\
3.97 \\
4.03 \\
4.35 \\
4.78 \\
5.00 \\
5.70 \\
6.30 \\
6.60 \\
6.75 \\
10.40 \\
8.00\end{array}$ & $\begin{array}{r}1,320 \\
1,130 \\
1,250 \\
1,950 \\
2,920 \\
3,380 \\
4,710 \\
5,680 \\
6,130 \\
6,340 \\
10,700 \\
8,010\end{array}$ & $\begin{array}{l}7.10 \\
6.60 \\
6.45 \\
6.55 \\
6.00 \\
5.48 \\
5.15 \\
4.95 \\
4.78 \\
4.65 \\
4.50 \\
4.43\end{array}$ & $\begin{array}{l}6,830 \\
6,130 \\
5,900 \\
6,060 \\
5,200 \\
4,310 \\
3,680 \\
3,280 \\
2,920 \\
2,630 \\
2,290 \\
2,130\end{array}$ & $\begin{array}{c}\overline{-} \\
4.26 \\
\overline{4.15} \\
\overline{4.03} \\
\overline{3.92} \\
\overline{3.83} \\
\overline{3.73}\end{array}$ & $\begin{array}{c}\overline{1,750} \\
\overline{-} \\
1, \overline{5} 10 \\
\overline{-} \\
1, \overline{250} \\
\overline{-} \\
1, \overline{040} \\
\overline{8} \\
\overline{8} \\
\overline{732}\end{array}$ & $\begin{array}{c}- \\
3.67 \\
- \\
3.61 \\
- \\
3.55 \\
- \\
3.51 \\
- \\
3.47 \\
- \\
3.43\end{array}$ & $\begin{array}{c}\overline{6} \\
6 \overline{56} \\
\overline{586} \\
\overline{5} \\
5 \overline{5} \\
\overline{4} \overline{5} \\
\overline{4} \\
\overline{48} \\
\overline{412}\end{array}$ \\
\hline & \multicolumn{2}{|c|}{ December 14} & \multicolumn{2}{|c|}{ December 15} & \multicolumn{2}{|c|}{ December 16} & \multicolumn{2}{|c|}{ December 17} & \multicolumn{2}{|c|}{ December 18} & \multicolumn{2}{|c|}{ December 19} \\
\hline $\begin{array}{r}2 \\
4 \\
6 \\
8 \\
10 \\
\mathbf{N} \\
2 \\
4 \\
6 \\
8 \\
10 \\
\mathbf{M}\end{array}$ & $\begin{array}{l}\overline{-} \\
\overline{3.37} \\
\overline{-} \\
3.33 \\
\overline{-} \\
\overline{3.30} \\
\overline{-} \\
\overline{3.27}\end{array}$ & $\begin{array}{c}- \\
\overline{361} \\
- \\
- \\
3 \overline{2} \\
- \\
\overline{0} \\
- \\
\overline{0} \\
2 \overline{86}\end{array}$ & $\begin{array}{c}- \\
\overline{3.24} \\
- \\
\overline{3.22} \\
\overline{-} \\
3.18 \\
- \\
\overline{3.17}\end{array}$ & $\begin{array}{c}\overline{-} \\
2 \overline{66} \\
\overline{-} \\
2 \overline{53} \\
- \\
\overline{-} \\
2 \overline{30} \\
- \\
\overline{2} \overline{2}\end{array}$ & $\begin{array}{l}\overline{-} \\
3.14 \\
\overline{-} \\
3.12 \\
= \\
\overline{3.10} \\
= \\
3.08\end{array}$ & $\begin{array}{c}\overline{-} \\
\overline{210} \\
\overline{-} \\
\overline{200} \\
\overline{-} \\
\overline{190} \\
- \\
\overline{182}\end{array}$ & $\begin{array}{l}- \\
= \\
- \\
- \\
3.05 \\
- \\
- \\
- \\
- \\
3.02\end{array}$ & $\begin{array}{c}- \\
\overline{-} \\
- \\
\overline{170} \\
- \\
- \\
- \\
- \\
\overline{158}\end{array}$ & $\begin{array}{c}- \\
- \\
- \\
z \\
2.99 \\
- \\
= \\
- \\
- \\
2.96\end{array}$ & $\begin{array}{c}\overline{-} \\
\overline{-} \\
\overline{-} \\
146 \\
\overline{-} \\
- \\
- \\
\overline{1} \\
\overline{136}\end{array}$ & & \\
\hline
\end{tabular}

Supplemental records.- Dec. 9, 9 p.m., 2.80 ft., 87 sec.-ft.; 11 p.m., 3.35 ft., 345 sec. $-\mathrm{ft}$. 
Thomas Creek at Paskenta, Cal1f.

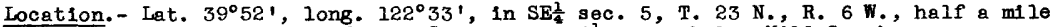
upstream from Paskenta, Tehama County, and $4 \frac{1}{2}$ miles below Mill Creek.

Dralnage area.- 188 square miles.

Gage-helght record. - Water-stage recorder graph except for per1od 8 p.m. Dec. 10 to 1 p.m. Dec. 14, when there was no record. Peak atage determined from floodmarks In well and on left bank. Stage graph Dec. 14 based on partial recorder graph.

Stage-discharge relation. - Defined by current-meter measurements below 6,900 secondfeet; extended to peak stage on basis of area-velocity study. Rating curve changed at peak a tage.

Maxima.- December 1937: Discharge, 16,500 second-feet about 10 p.m. Dec. 10 (gage helght, 16.8 feet).

1921-November 1937: Discharge observed, about 16,600 second-feet Mar. 26, 1928 (gage height, 10.5 feet, from nonrecording gage, former site and datum, half a mile downstream), from rating curve extended above 6,000 second-feet on bas is of areavelocity study.

Remarks.- Flood mun-off not affected by artificial storage or diversion. Discharge for period of missing gage-height record, Dec. 11-13, determined from discharge graph based on records of Elder Creek near Henleyville and Stony Creek above Stony Gorge Reservolr.

Mean dally discharge, in second-feet, November 1937 to January 1938

\begin{tabular}{|c|c|c|c|c|c|c|c|c|c|c|c|}
\hline Day & Nov. & Dec. & Jan. & Dey & Nov. & Dec. & Jan. & Day & Nov. & Dec. & Jan. \\
\hline $\begin{array}{r}1 \\
2 \\
3 \\
4 \\
5 \\
6 \\
7 \\
8 \\
9 \\
10\end{array}$ & $\begin{array}{l}6.5 \\
7 \\
7 \\
7 \\
6.5 \\
6.5 \\
6 \\
6 \\
6 \\
9.5\end{array}$ & $\begin{array}{r}270 \\
248 \\
228 \\
212 \\
198 \\
188 \\
178 \\
174 \\
215 \\
8,520\end{array}$ & $\begin{array}{l}190 \\
240 \\
248 \\
224 \\
212 \\
200 \\
190 \\
178 \\
164 \\
156\end{array}$ & $\begin{array}{l}11 \\
12 \\
13 \\
14 \\
15 \\
16 \\
17 \\
18 \\
19 \\
20\end{array}$ & $\begin{array}{r}156 \\
113 \\
66 \\
204 \\
172 \\
990 \\
1,740 \\
511 \\
3,040 \\
5,990\end{array}$ & $\begin{array}{r}9,700 \\
4,000 \\
2,000 \\
1,260 \\
880 \\
680 \\
530 \\
438 \\
362 \\
310\end{array}$ & $\begin{array}{l}148 \\
140 \\
137 \\
137 \\
209 \\
215 \\
642 \\
530 \\
425 \\
350\end{array}$ & $\begin{array}{l}21 \\
22 \\
23 \\
24 \\
25 \\
26 \\
27 \\
28 \\
29 \\
30 \\
31\end{array}$ & $\begin{array}{r}1,700 \\
940 \\
1,180 \\
856 \\
674 \\
562 \\
462 \\
382 \\
332 \\
296\end{array}$ & $\begin{array}{l}276 \\
256 \\
238 \\
230 \\
209 \\
197 \\
190 \\
176 \\
164 \\
203 \\
210\end{array}$ & $\begin{array}{l}330 \\
515 \\
560 \\
450 \\
400 \\
375 \\
375 \\
388 \\
362 \\
340 \\
488\end{array}$ \\
\hline \multicolumn{12}{|c|}{ 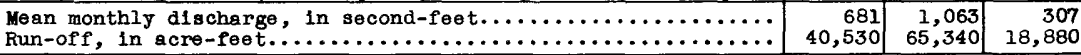 } \\
\hline
\end{tabular}

Gage height, in feet, and discharge, in second-feet, at indicated time, 1937

\begin{tabular}{|c|c|c|c|c|c|c|c|c|c|c|c|c|}
\hline \multirow{2}{*}{ 岁 } & Feet & sec.ft. & Feet & Sec.ft. & Feet & sec.ft. & Feet & sec.ft. & Foet & Sec.ft. & Feet & Sec.ft. \\
\hline & \multicolumn{2}{|c|}{ Docember 8} & \multicolumn{2}{|c|}{ December 9} & \multicolumn{2}{|c|}{ December 10} & \multicolumn{2}{|c|}{ December 11} & \multicolumn{2}{|c|}{ December 12} & \multicolumn{2}{|c|}{ December 13} \\
\hline \multirow[t]{2}{*}{$\begin{array}{r}2 \\
4 \\
6 \\
8 \\
10 \\
N \\
2 \\
4 \\
6 \\
8 \\
10 \\
\mathbf{H}\end{array}$} & $\begin{array}{l}\bar{z} \\
\bar{z} \\
\overline{-} \\
2.02 \\
\overline{-} \\
\overline{-} \\
\overline{2.01}\end{array}$ & $\begin{array}{l}\overline{-} \\
\bar{z} \\
\overline{172} \\
\overline{-} \\
\overline{-} \\
\overline{1} \\
\overline{170}\end{array}$ & $\begin{array}{l}2.01 \\
2.00 \\
2.00 \\
2.00 \\
2.01 \\
2.07 \\
2.16 \\
2.24 \\
2.35 \\
2.52 \\
2.79 \\
2.99\end{array}$ & $\begin{array}{l}170 \\
168 \\
168 \\
168 \\
170 \\
182 \\
200 \\
217 \\
241 \\
279 \\
345 \\
399\end{array}$ & $\begin{array}{r}4.30 \\
5.55 \\
8.35 \\
10.90 \\
12.60 \\
13.75 \\
15.00 \\
14.85 \\
14.08 \\
- \\
16.8 \\
-\end{array}$ & $\begin{array}{r}910 \\
1,740 \\
4,160 \\
6,660 \\
8,510 \\
9,980 \\
12,100 \\
11,800 \\
10,500 \\
12,000 \\
16,500 \\
15,200\end{array}$ & $\begin{array}{l}\overline{-} \\
\overline{-} \\
\overline{-} \\
\overline{-} \\
\overline{-} \\
\overline{-}\end{array}$ & $\begin{array}{r}13,100 \\
12,000 \\
11,700 \\
11,800 \\
11,000 \\
9,700 \\
8,800 \\
8,000 \\
7,300 \\
6,800 \\
6,300 \\
5,800\end{array}$ & $\begin{array}{l}- \\
z \\
z \\
z \\
z \\
z \\
z \\
-\end{array}$ & $\begin{array}{c}\overline{-} \\
4, \overline{7} 00 \\
- \\
\overline{-} \\
3, \overline{9} 00 \\
\overline{-} \\
3, \overline{200} \\
- \\
\overline{-}, \overline{7} 00\end{array}$ & $\begin{array}{l}\overline{-} \\
\overline{-} \\
\bar{z} \\
\bar{z} \\
\overline{-} \\
\overline{-} \\
\overline{-}\end{array}$ & $\begin{array}{c}\overline{-} \\
2, \overline{300} \\
\overline{-} \\
\overline{9} \\
1, \overline{9} 00 \\
\overline{-} \\
1, \overline{7} 00 \\
- \\
\overline{5} \\
1, \overline{500}\end{array}$ \\
\hline & \multicolumn{2}{|c|}{ December 14} & \multicolumn{2}{|c|}{ December 15} & \multicolumn{2}{|c|}{ December 16} & \multicolumn{2}{|c|}{ December 17} & \multicolumn{2}{|c|}{ December 18} & \multicolumn{2}{|c|}{ December 19} \\
\hline \multirow[t]{2}{*}{$\begin{array}{r}2 \\
4 \\
6 \\
8 \\
10 \\
1 \\
2 \\
4 \\
6 \\
8 \\
10 \\
M\end{array}$} & $\begin{array}{c}\overline{-} \\
7.75 \\
- \\
\overline{7.55} \\
\overline{-} \\
7.35 \\
= \\
\overline{7.18}\end{array}$ & $\begin{array}{c}\overline{-} \\
1, \overline{4} 00 \\
- \\
\overline{2} 60 \\
\overline{-} \\
1, \overline{130} \\
- \\
\overline{1}, 030\end{array}$ & $\begin{array}{l}- \\
\overline{-} .05 \\
- \\
\overline{6} \\
\overline{-} \\
\overline{-} \\
6.75 \\
\overline{-} \\
\overline{6.66}\end{array}$ & $\begin{array}{c}- \\
\overline{9} \\
95 \\
- \\
\overline{890} \\
\overline{-} \\
\overline{808} \\
- \\
\overline{7}\end{array}$ & $\begin{array}{c}\overline{-} \\
6.53 \\
\overline{-} \\
\overline{6.45} \\
\overline{-} \\
6.34 \\
\overline{-} \\
6.21\end{array}$ & $\begin{array}{c}- \\
\overline{712} \\
- \\
\overline{-} \\
6 \overline{80} \\
- \\
\overline{-} \\
6 \overline{3} \\
\overline{-} \\
\overline{594}\end{array}$ & $\begin{array}{c}- \\
- \\
6.05 \\
- \\
- \\
5.98 \\
- \\
\overline{5.88} \\
- \\
\overline{5.78}\end{array}$ & $\begin{array}{c}\overline{-} \\
\overline{545} \\
\overline{-} \\
\overline{524} \\
\overline{-} \\
4 \overline{95} \\
\overline{-} \\
\overline{470}\end{array}$ & $\begin{array}{c}- \\
- \\
5.71 \\
- \\
- \\
5.63 \\
- \\
\overline{5.55} \\
- \\
\overline{5.47}\end{array}$ & $\begin{array}{c}- \\
\overline{452} \\
\overline{-} \\
\overline{432} \\
\overline{-} \\
4 \overline{12} \\
\overline{-} \\
3 \overline{9}\end{array}$ & $\begin{array}{c}\bar{z} \\
\overline{5.40} \\
\overline{-} \\
\overline{5.33} \\
\overline{-} \\
\overline{5.27} \\
\overline{-} \\
\overline{5.21}\end{array}$ & $\begin{array}{c}- \\
\overline{375} \\
- \\
- \\
3 \overline{58} \\
\overline{-} \\
\overline{344} \\
\overline{-} \\
\overline{332}\end{array}$ \\
\hline & \multicolumn{2}{|c|}{ December 20} & \multicolumn{2}{|c|}{ December 21} & \multicolumn{2}{|c|}{ December 22} & \multicolumn{2}{|c|}{ December 23} & \multicolumn{2}{|c|}{ December 24} & \multicolumn{2}{|c|}{ December 25} \\
\hline $\begin{array}{r}2 \\
4 \\
6 \\
8 \\
10 \\
N \\
2 \\
4 \\
6 \\
8 \\
10 \\
M\end{array}$ & $\begin{array}{l}\bar{z} \\
\overline{5.15} \\
\bar{z} \\
5.08 \\
- \\
\overline{5.04} \\
- \\
\overline{4.99}\end{array}$ & $\begin{array}{c}\overline{-} \\
\overline{320} \\
\overline{3} \\
\overline{306} \\
\overline{-} \\
\overline{2} \overline{8} \\
\overline{-} \\
\overline{288}\end{array}$ & $\begin{array}{l}\overline{-} \\
4.96 \\
\overline{-} \\
\overline{4.93} \\
\overline{-} \\
\overline{4.90} \\
\overline{-} \\
\overline{4.87}\end{array}$ & $\begin{array}{c}- \\
\overline{2} \\
\overline{-} \\
\overline{2} \\
276 \\
- \\
\overline{270} \\
- \\
\overline{264}\end{array}$ & $\begin{array}{l}\overline{-} \\
\overline{4.83} \\
- \\
\overline{4} \\
\overline{-} 82 \\
\overline{-} \\
4.81 \\
- \\
\overline{4} \\
\overline{4} 83\end{array}$ & $\begin{array}{c}- \\
\overline{256} \\
- \\
\overline{2} \\
254 \\
- \\
- \\
252 \\
- \\
- \\
256\end{array}$ & $\begin{array}{c}- \\
- \\
4.78 \\
- \\
4.72 \\
- \\
\overline{4} \\
\overline{-} \\
- \\
4.68\end{array}$ & $\begin{array}{c}\overline{-} \\
2 \overline{46} \\
- \\
\overline{234} \\
- \\
\overline{2} \\
\overline{-} \\
\overline{2} \\
2 \overline{7}\end{array}$ & $\begin{array}{l}\overline{-} \\
4.65 \\
\bar{z} \\
4.70 \\
\overline{-} \\
\overline{4} \\
\overline{-75} \\
\overline{4.67}\end{array}$ & $\begin{array}{c}\overline{-} \\
\overline{222} \\
\overline{-} \\
2 \overline{30} \\
\overline{-} \\
\overline{240} \\
\overline{-} \\
\overline{226}\end{array}$ & $\begin{array}{l}- \\
\overline{4.62} \\
- \\
\overline{4.54} \\
\overline{-} \\
\overline{4.50} \\
\overline{-} \\
\overline{4.52}\end{array}$ & $\begin{array}{c}\overline{-} \\
2 \overline{18} \\
\overline{-} \\
\overline{206} \\
\overline{-} \\
\overline{200} \\
\overline{-} \\
\overline{203}\end{array}$ \\
\hline
\end{tabular}


Deer Greek near Vina, Calif.

Eocation.- Lat. $40^{\circ} \mathrm{O} 1^{\prime}$, long. $121^{\circ} 56^{\prime}$, in $\mathrm{NE}-\mathrm{sec} .23, \mathrm{~T} .25 \mathrm{~N} ., \mathrm{R}, 1 \mathrm{~W}, 0.8 \mathrm{mile}$ above concrete diverzion dam and 9 miles northeast of Vina, Tehame County. Altitude, about 480 feet above mean sea level.

Drainage area.- 200 square miles.

Gage-height record.- Water-stage recorder graph prior to $10 \mathrm{p} . \mathrm{m}$. Dec. 10, when station was destroyed. Peak stage determined from floodmarks on banks.

Stage-discharge relation.- Defined by current-meter measurements below 7,000 secondfeet; extended to peak stage on basis of area-velocity study.

Maxims.- December 1937: Discharge, 23,800 second-feet about midnight Dec. 10 (gage height, 16.6 feet, from floodmarks).

1911-15, 1920-November 1937: Discharge, 12,200 second-feet Mar. 26, I928 (gage

height, 15.0 feet, from floodmarks, former site and datum,0.8 mile downstream).

Remarks.- Flood run-off not affected by artificial storage or diversion.

Mean daily discharge, in second-feet, November 1937 to January 1938

\begin{tabular}{|c|c|c|c|c|c|c|c|c|c|c|c|}
\hline Day & Nov. & Dec. & Jan. & Day & Nov. & Dec. & Jan. & Day & Nov. & Dec. & Jan. \\
\hline $\begin{array}{r}1 \\
2 \\
3 \\
4 \\
5 \\
6 \\
7 \\
8 \\
9 \\
10\end{array}$ & $\begin{array}{l}86 \\
82 \\
80 \\
80 \\
80 \\
83 \\
89 \\
89 \\
86 \\
95\end{array}$ & $\begin{array}{r}202 \\
186 \\
177 \\
168 \\
157 \\
149 \\
144 \\
140 \\
186 \\
5,520\end{array}$ & $\begin{array}{l}\overline{-} \\
\overline{-} \\
\overline{-} \\
\overline{-} \\
\overline{-} \\
\overline{-} \\
\overline{-}\end{array}$ & $\begin{array}{l}11 \\
12 \\
13 \\
14 \\
15 \\
16 \\
17 \\
18 \\
19 \\
20\end{array}$ & $\begin{array}{r}282 \\
212 \\
138 \\
153 \\
212 \\
504 \\
1,060 \\
394 \\
363 \\
2,550\end{array}$ & $\begin{array}{l}= \\
= \\
= \\
= \\
= \\
=\end{array}$ & $\begin{array}{l}\overline{-} \\
\overline{-} \\
\overline{-} \\
\overline{-} \\
- \\
\overline{-} \\
-\end{array}$ & $\begin{array}{l}21 \\
22 \\
23 \\
24 \\
25 \\
26 \\
27 \\
28 \\
29 \\
30 \\
31\end{array}$ & $\begin{array}{r}1,100 \\
518 \\
1,190 \\
1,100 \\
630 \\
452 \\
353 \\
295 \\
252 \\
222\end{array}$ & $\begin{array}{l}= \\
\bar{z} \\
= \\
\bar{z} \\
= \\
= \\
=\end{array}$ & $\begin{array}{l}= \\
= \\
= \\
= \\
= \\
=\end{array}$ \\
\hline \multicolumn{9}{|c|}{ 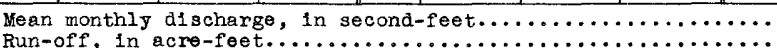 } & $\begin{array}{r}428 \\
25,450\end{array}$ & - & - \\
\hline
\end{tabular}

Gage height, in feet, and discharge, in second-feet, at indicated time, 1937

\begin{tabular}{|c|c|c|c|c|c|c|c|c|c|c|c|c|}
\hline \multirow{2}{*}{$\begin{array}{l}91 \\
5 \\
0 \\
0\end{array}$} & Feet & sec.ft. & Feet & Sec.ft. & Feet & Sec.ft. & Feet & Sec.ft. & Feet & Sec.ft. & Feet & Sec.ft. \\
\hline & \multicolumn{2}{|c|}{ December 8} & \multicolumn{2}{|c|}{ December 9} & \multicolumn{2}{|c|}{ December 10} & \multicolumn{2}{|c|}{ December 11} & \multicolumn{2}{|c|}{ December 12} & \multicolumn{2}{|c|}{ December 13} \\
\hline $\begin{array}{r}2 \\
4 \\
6 \\
8 \\
10 \\
N \\
2 \\
4 \\
6 \\
8 \\
10 \\
M\end{array}$ & $\begin{array}{r}0.93 \\
.93 \\
.92 \\
.92 \\
.92 \\
.92 \\
.93 \\
.94 \\
.94 \\
.93 \\
.92 \\
.92\end{array}$ & \begin{tabular}{|l|}
140 \\
140 \\
138 \\
138 \\
138 \\
138 \\
140 \\
142 \\
142 \\
140 \\
138 \\
138
\end{tabular} & $\begin{array}{r}0.91 \\
.90 \\
.90 \\
.90 \\
.91 \\
.92 \\
.94 \\
.98 \\
1.08 \\
1.26 \\
1.84 \\
2.16\end{array}$ & $\begin{array}{l}136 \\
134 \\
134 \\
134 \\
136 \\
138 \\
142 \\
151 \\
173 \\
215 \\
394 \\
514\end{array}$ & $\begin{array}{r}2.24 \\
2.25 \\
2.33 \\
2.61 \\
3.28 \\
5.50 \\
9.45 \\
9.05 \\
10.95 \\
11.15 \\
14.25 \\
16.60\end{array}$ & $\begin{array}{r}547 \\
551 \\
585 \\
715 \\
1,060 \\
2,600 \\
6,860 \\
6,320 \\
9,020 \\
9,360 \\
15,900 \\
23,800\end{array}$ & & & & & & \\
\hline
\end{tabular}


Chico Creek near Chico, Calif.

Location. - Lat. $39^{\circ} 46^{\prime}$, long. $121^{\circ} 46^{\prime}$, in Arroyo Chico grant, 1 mile above golf clubhouse in Municipal Park and 6 miles northeast of Chico, Butte County. Altitude, about 400 feet above mean sea level.

Drainage area.- 68.3 square miles.

Gage-helght record.- Water-stage recorder graph except for period midnight Dec. 10 to noon Dec. 13, when there was no record. Peak stage determined from floodmarks on bank.

Stage-discharge relation.- Defined by current-meter measurements below 4,200 secondfeet; extended to peak stage on basis of extension of stage-discharge relation at cable section; verified by area-velocity study and logarithmic extension. Rating curve changed at peak stage.

Maxima.- December 1937: Discharge, 8,260 second-feet midnight Dec. 10 (gage height, 16.6 feet).

1930-November 1937: Discharge, 4,940 second-feet Feb. 21, 1936 (gage helght, 12.70 feet), from rating curve extended above 4,250 second-feet.

Remarks. - Flood mun off not affected by artiflcial storage or diversion. Discharge for perfod of missing gage-helght record determined from discharge graph based on records of Butte Creek.

Mean dafly discharge, in second-feet, November 1937 to January 1938

\begin{tabular}{|c|c|c|c|c|c|c|c|c|c|c|c|}
\hline Day & Nov. & Dec. & Jan. & Dey & Nov. & Dec. & Jan. & Day & Nov. & Dec. & Jan. \\
\hline 1 & 27 & 75 & 83 & 11 & 98 & 5,530 & 62 & 21 & 625 & 129 & 259 \\
\hline 2 & 25 & 67 & 90 & 12 & 84 & 1,850 & 61 & 22 & 237 & 123 & 233 \\
\hline 3 & 24 & 61 & 88 & 13 & 49 & 904 & 60 & 23 & 406 & 123 & 216 \\
\hline 4 & 24 & 57 & 83 & 14 & 64 & 564 & 59 & 24 & 595 & 113 & 190 \\
\hline 5 & 24 & 53 & 80 & 15 & 99 & 395 & 136 & 25 & 308 & 110 & 167 \\
\hline 6 & 24 & 53 & 75 & 16 & 153 & 302 & 134 & 26 & 198 & 103 & 152 \\
\hline 7 & 27 & 44 & 73 & 17 & 457 & 238 & 656 & 27 & 148 & 96 & 143 \\
\hline 8 & 27 & 43 & 70 & 18 & 146 & 198 & 428 & 28 & 116 & 92 & 156 \\
\hline 9 & 25 & 68 & 67 & 19 & 107 & 167 & 382 & 29 & 99 & 88 & 148 \\
\hline 10 & 27 & 3,290 & 64 & 20 & 1,340 & 147 & 314 & 30 & 85 & 86 & 133 \\
\hline \multirow{2}{*}{\multicolumn{9}{|c|}{ 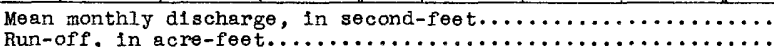 }} & & & \\
\hline & & & & & & & & & 11,240 & $\begin{array}{r}492 \\
30,250\end{array}$ & $\begin{array}{r}179 \\
10,990\end{array}$ \\
\hline
\end{tabular}

Gage helght, in feet, and discharge, in second-feet, at indicated time, 1937

\begin{tabular}{|c|c|c|c|c|c|c|c|c|c|c|c|c|}
\hline \multirow{2}{*}{$\begin{array}{l}4 \\
3 \\
0 \\
\end{array}$} & Feet & Sec.ft. & Feet & Sec.ft. & Fe日t & sec.ft. & Feet & Sec.ft. & $F \in \theta t$ & Sec.ft. & Feet & Sec.ft. \\
\hline & \multicolumn{2}{|c|}{ December 8} & \multicolumn{2}{|c|}{ Deceniber 9} & \multicolumn{2}{|c|}{ December 10} & \multicolumn{2}{|c|}{ December 11} & \multicolumn{2}{|c|}{ December 12} & \multicolumn{2}{|c|}{ December 13} \\
\hline $\begin{array}{r}2 \\
4 \\
6 \\
8 \\
10 \\
\mathrm{~N} \\
2 \\
4 \\
6 \\
8 \\
10 \\
M\end{array}$ & $\begin{array}{l}- \\
\overline{1.87} \\
= \\
\overline{1.87} \\
\overline{-} \\
\overline{1.87} \\
- \\
\overline{1 .}\end{array}$ & $\begin{array}{l}- \\
\overline{43} \\
- \\
\overline{43} \\
- \\
\overline{43} \\
\overline{-} \\
\overline{42}\end{array}$ & $\begin{array}{l}1.86 \\
1.86 \\
1.86 \\
1.86 \\
1.86 \\
1.88 \\
1.89 \\
1.95 \\
2.12 \\
2.32 \\
2.81 \\
3.07\end{array}$ & $\begin{array}{r}42 \\
42 \\
42 \\
42 \\
42 \\
44 \\
45 \\
52 \\
70 \\
96 \\
174 \\
224\end{array}$ & $\begin{array}{r}3.30 \\
3.65 \\
4.38 \\
5.55 \\
6.95 \\
9.70 \\
12.60 \\
12.50 \\
13.10 \\
14.15 \\
15.90 \\
16.60\end{array}$ & $\begin{array}{r}276 \\
365 \\
574 \\
952 \\
1,510 \\
2,960 \\
4,870 \\
4,800 \\
5,260 \\
6,100 \\
7,630 \\
8,260\end{array}$ & $\begin{array}{l}- \\
\overline{-} \\
\overline{-} \\
\overline{-} \\
\overline{-} \\
\overline{-} \\
\overline{-}\end{array}$ & $\begin{array}{l}8,000 \\
7,500 \\
6,900 \\
6,300 \\
5,800 \\
5,300 \\
4,950 \\
4,550 \\
4,150 \\
3,750 \\
3,450 \\
3,100\end{array}$ & $\begin{array}{l}= \\
- \\
= \\
= \\
= \\
= \\
= \\
-\end{array}$ & $\begin{array}{l}2,800 \\
2,500 \\
2,200 \\
2,000 \\
1,820 \\
1,700 \\
1,600 \\
1,500 \\
1,400 \\
1,320 \\
1,260 \\
1,200\end{array}$ & $\begin{array}{c}- \\
- \\
- \\
- \\
- \\
5.38 \\
5.27 \\
5.17 \\
5.06 \\
4.96 \\
4.87 \\
4.78\end{array}$ & $\begin{array}{r}1,140 \\
1,080 \\
1,020 \\
980 \\
930 \\
883 \\
844 \\
810 \\
772 \\
739 \\
710 \\
682\end{array}$ \\
\hline & \multicolumn{2}{|c|}{ December 14} & \multicolumn{2}{|c|}{ December 15} & \multicolumn{2}{|c|}{ December 16} & \multicolumn{2}{|c|}{ December 17} & \multicolumn{2}{|c|}{ December 18} & \multicolumn{2}{|c|}{ December 19} \\
\hline $\begin{array}{r}2 \\
4 \\
6 \\
8 \\
10 \\
N \\
2 \\
4 \\
6 \\
8 \\
10 \\
M\end{array}$ & $\begin{array}{l}4.71 \\
4.63 \\
4.56 \\
4.49 \\
4.43 \\
4.37 \\
4.31 \\
4.25 \\
4.20 \\
4.15 \\
4.10 \\
4.05\end{array}$ & $\begin{array}{l}659 \\
634 \\
612 \\
591 \\
573 \\
555 \\
537 \\
519 \\
504 \\
490 \\
476 \\
462\end{array}$ & $\begin{array}{c}- \\
3.97 \\
- \\
3.88 \\
- \\
3.81 \\
\overline{3.74} \\
\overline{3.67} \\
\overline{3.60}\end{array}$ & $\begin{array}{c}\overline{4} \\
\overline{4} 0 \\
4 \overline{14} \\
\overline{395} \\
\overline{3} \\
3 \overline{6} \\
\overline{358} \\
\overline{340}\end{array}$ & $\begin{array}{l}\bar{z} \\
3.54 \\
\overline{3.49} \\
- \\
3.45 \\
\overline{3.39} \\
\overline{3.35} \\
\overline{3.30}\end{array}$ & $\begin{array}{c}3 \overline{24} \\
\overline{312} \\
\overline{302} \\
\overline{2} \\
\overline{88} \\
\overline{278} \\
\overline{2} \overline{66}\end{array}$ & $\begin{array}{l}- \\
3.24 \\
- \\
- \\
3.19 \\
- \\
\overline{3.14} \\
- \\
- \\
3.08\end{array}$ & $\begin{array}{c}- \\
\overline{252} \\
- \\
\overline{240} \\
\overline{-} \\
\overline{2} \overline{9} \\
= \\
\overline{216}\end{array}$ & $\begin{array}{c}- \\
3.02 \\
- \\
- \\
2.99 \\
- \\
- \\
2.95 \\
- \\
z .91\end{array}$ & $\begin{array}{c}\overline{-} \\
\overline{204} \\
\overline{-} \\
\overline{198} \\
\overline{-} \\
\overline{190} \\
- \\
\overline{182}\end{array}$ & $\begin{array}{c}\overline{-} \\
\overline{2.87} \\
- \\
- \\
2.84 \\
- \\
\overline{2 .} \\
- \\
- \\
2.77\end{array}$ & $\begin{array}{c}\overline{-} \\
\overline{174} \\
- \\
\overline{6} \\
169 \\
- \\
\overline{161} \\
- \\
\overline{156}\end{array}$ \\
\hline & \multicolumn{2}{|c|}{ December 20} & \multicolumn{2}{|c|}{ December 21} & \multicolumn{2}{|c|}{ December 22} & \multicolumn{2}{|c|}{ December 23} & \multicolumn{2}{|c|}{ December 24} & \multicolumn{2}{|c|}{ December 25} \\
\hline $\begin{array}{r}2 \\
4 \\
6 \\
8 \\
10 \\
\mathrm{~N} \\
2 \\
4 \\
6 \\
8 \\
10 \\
\mathrm{M}\end{array}$ & $\begin{array}{c}- \\
\overline{2.74} \\
\overline{-} \\
\overline{2.72} \\
\overline{-} \\
\overline{2.69} \\
\overline{-} \\
\overline{2.67}\end{array}$ & $\begin{array}{c}- \\
\overline{150} \\
- \\
\overline{4} \\
147 \\
\overline{-} \\
\overline{141} \\
\overline{-} \\
\overline{13} 8\end{array}$ & $\begin{array}{c} \pm \\
2.64 \\
- \\
- \\
2.62 \\
- \\
- \\
2.61 \\
- \\
- \\
2.59\end{array}$ & $\begin{array}{c}\overline{-} \\
\overline{133} \\
\overline{-} \\
\overline{129} \\
\overline{-} \\
\overline{128} \\
\overline{-} \\
\overline{124}\end{array}$ & $\begin{array}{c}- \\
\overline{2.58} \\
\overline{-} \\
\overline{2.57} \\
\overline{-} \\
\overline{2.57} \\
- \\
\overline{2.60}\end{array}$ & $\begin{array}{c}\overline{-} \\
\overline{123} \\
\overline{-} \\
\overline{121} \\
\overline{-} \\
\overline{121} \\
\overline{-} \\
\overline{126}\end{array}$ & $\begin{array}{c}- \\
2.65 \\
- \\
2.60 \\
- \\
2.57 \\
- \\
2.55 \\
- \\
2.54 \\
- \\
2.53\end{array}$ & $\begin{array}{c}\overline{134} \\
\overline{126} \\
\overline{1 \overline{1}} \\
\overline{118} \\
\overline{11} 6 \\
\overline{1} \overline{15}\end{array}$ & $\begin{array}{c}- \\
2.52 \\
- \\
2.50 \\
\overline{2.50} \\
\overline{2.52} \\
-\overline{2.55} \\
- \\
2.53\end{array}$ & $\begin{array}{c}\overline{113} \\
\overline{110} \\
\overline{10} \\
\overline{113} \\
\overline{118} \\
\overline{115}\end{array}$ & $\begin{array}{c}\overline{-} \\
\overline{2.53} \\
\overline{-} \\
\overline{2.50} \\
\overline{-} \\
2.47 \\
- \\
\overline{2.46}\end{array}$ & $\begin{array}{c}\overline{-} \\
\overline{115} \\
\overline{-} \\
\overline{110} \\
\overline{-} \\
\overline{106} \\
- \\
\overline{104}\end{array}$ \\
\hline
\end{tabular}


Location.- Lat. $39^{\circ} 30^{\prime} 05^{\prime \prime}$, long. $122^{\circ} 31^{\prime} 00^{n}$, In sec. 15, T. 19 N., R. 6 W., 700 feet downstream from road briage and $6 \mathrm{mlles}$ south of Stony Gorge Dam, Glenn County. Drainage area.- 266 square miles.

Gage-helght record. - Water-stage recorder graph except for perlod Nov. 20-21, when 1t was based on records at diversion dam about $10 \mathrm{miles}$ upstream, and at Stony Gorge Reservo1r.

Stage-discharge relation.- Defined by current-meter measurements below 2,000 secondfeet; extended to peak stage on basis of study of computed flow into and out of Stony Gorge Reservolr; verifled by area-velocity study. Rating curve changed at peak stage.

Maxima.- December 1937: D1scharge, 20,800 second-feet 11:30 p.m. Dec. 10 (gage helght, 13.1 feet).

1933-November 1937: D1scharge, 7,160 second-feet Feb. 21, 1936 (gage he1ght, 8. 6 feet), from rating curve extended above 2,200 second-feet.

Remariks. - Flood run-off slightly offected by storage in East Park Reservolr. Monthly sumarles adjusted for storage. Part of basic data furnished by Bureau of Reclamation.

Mean da11y discharge, in second-feet, November 1937 to January 1938

\begin{tabular}{|c|c|r|r|r|r|r|r|r|r|r|r|}
\hline Day & Hov. & Dec. & Jan. & Day & Nov. & Dec. & Jan. & Day & Nov. & Dec. & Jan. \\
\hline 1 & 18 & 154 & 278 & 11 & 151 & 12,100 & 247 & 21 & 1,060 & 860 & 535 \\
2 & 18 & 141 & 414 & 12 & 116 & 5,610 & 241 & 22 & 578 & 830 & 530 \\
3 & 19 & 136 & 368 & 13 & 64 & 2,990 & 235 & 23 & 644 & 800 & 490 \\
4 & 19 & 124 & 320 & 14 & 98 & 1,920 & 238 & 24 & 590 & 772 & 445 \\
5 & 20 & 116 & 292 & 15 & 144 & 1,370 & 268 & 25 & 419 & 745 & 414 \\
6 & 20 & 109 & 285 & 16 & 484 & 1,180 & 388 & 26 & 322 & 734 & 396 \\
7 & 20 & 105 & 274 & 17 & 1,210 & 1,080 & 1,770 & 27 & 260 & 728 & 368 \\
8 & 20 & 101 & 260 & 18 & 391 & 980 & 830 & 28 & 220 & 706 & 364 \\
9 & 21 & 242 & 250 & 19 & 641 & 950 & 772 & 29 & 188 & 690 & 348 \\
10 & 24 & 6,830 & 250 & 20 & 2,950 & 890 & 615 & 30 & 168 & 454 & 328 \\
\end{tabular}

Gage height, in feet, and discharge, in second-feet, at indicated time, 1937

\begin{tabular}{|c|c|c|c|c|c|c|c|c|c|c|c|c|}
\hline \multirow{2}{*}{$\begin{array}{l}\text { \& } \\
\text { 号 }\end{array}$} & eet & sec.ft. & eet & Sec.ft. & Feet & sec.ft. & Feot & Sec.ft. & Feet & Sec.ft. & Feot & Sec.ft. \\
\hline & \multicolumn{2}{|c|}{ December 8} & \multicolumn{2}{|c|}{ December 9} & \multicolumn{2}{|c|}{ December 10} & \multicolumn{2}{|c|}{ December 11} & \multicolumn{2}{|c|}{ December 12} & \multicolumn{2}{|c|}{ December 13} \\
\hline $\begin{array}{r}2 \\
4 \\
6 \\
8 \\
10 \\
11 \\
2 \\
4 \\
6 \\
8 \\
10 \\
1\end{array}$ & $\begin{array}{c}\bar{z} \\
2.34 \\
\bar{z} \\
2.33 \\
\bar{z} \\
2.32 \\
\overline{-} \\
2.31\end{array}$ & $\begin{array}{c}\overline{-} \\
\overline{103} \\
- \\
\overline{101} \\
\overline{-} \\
\overline{9} 8 \\
\overline{9} \\
\overline{9} 6\end{array}$ & $\begin{array}{l}2.31 \\
2.31 \\
2.31 \\
2.32 \\
2.32 \\
2.36 \\
2.40 \\
2.46 \\
2.60 \\
3.05 \\
4.10 \\
4.55\end{array}$ & $\begin{array}{r}96 \\
96 \\
96 \\
98 \\
98 \\
107 \\
116 \\
131 \\
168 \\
318 \\
930 \\
1,340\end{array}$ & $\begin{array}{r}4.75 \\
5.40 \\
5.75 \\
6.15 \\
6.45 \\
7.25 \\
8.65 \\
9.15 \\
9.97 \\
10.20 \\
11.45 \\
13.00\end{array}$ & $\begin{array}{r}1,560 \\
2,340 \\
2,810 \\
3,380 \\
3,820 \\
5,040 \\
7,500 \\
8,530 \\
10,400 \\
11,000 \\
14,700 \\
20,400\end{array}$ & $\begin{array}{r}12.15 \\
11.35 \\
11.00 \\
10.75 \\
10.55 \\
10.50 \\
10.50 \\
10.35 \\
9.95 \\
9.55 \\
9.25 \\
9.00\end{array}$ & $\begin{array}{r}17,200 \\
14,400 \\
13,200 \\
12,500 \\
11,900 \\
11,800 \\
11,800 \\
11,400 \\
10,300 \\
9,240 \\
8,520 \\
7,940\end{array}$ & $\begin{array}{l}8.80 \\
8.61 \\
8.42 \\
8.22 \\
8.05 \\
7.88 \\
7.72 \\
7.53 \\
7.35 \\
7.20 \\
7.08 \\
6.96\end{array}$ & $\begin{array}{l}7,490 \\
7,070 \\
6,670 \\
6,250 \\
5,910 \\
5,570 \\
5,260 \\
4,900 \\
4,570 \\
4,300 \\
4,100 \\
3,900\end{array}$ & $\begin{array}{c}- \\
6.74 \\
- \\
6.53 \\
- \\
6.32 \\
- \\
6.15 \\
- \\
5.98 \\
- \\
5.82\end{array}$ & $\begin{array}{l}3, \overline{550} \\
3, \overline{240} \\
2, \overline{950} \\
2, \overline{7} 20 \\
2, \overline{4} 90 \\
2, \overline{2} 90\end{array}$ \\
\hline & \multicolumn{2}{|c|}{ December 14} & \multicolumn{2}{|c|}{ Decomber 15} & \multicolumn{2}{|c|}{ December 16} & \multicolumn{2}{|c|}{ December 17} & \multicolumn{2}{|c|}{ December 18} & \multicolumn{2}{|c|}{ Decomber 19} \\
\hline $\begin{array}{r}2 \\
4 \\
6 \\
8 \\
10 \\
1 \\
2 \\
4 \\
6 \\
8 \\
10 \\
\text { 1 }\end{array}$ & $\begin{array}{c}5.68 \\
5.57 \\
5.57 \\
5.46 \\
\overline{5.34} \\
5.25 \\
5.16\end{array}$ & $\begin{array}{l}2, \overline{130} \\
2, \overline{0} \\
1, \overline{8} 80 \\
1, \overline{7} \\
1, \overline{6} \\
1, \overline{5} 60\end{array}$ & $\begin{array}{c}5.07 \\
5.00 \\
- \\
4.93 \\
- \\
4.86 \\
-7.78 \\
-7.72\end{array}$ & $\begin{array}{l}1, \overline{470} \\
1, \overline{4} 10 \\
\overline{-} \\
1, \overline{3} 50 \\
1, \overline{3} 00 \\
1, \overline{2} 40 \\
1, \overline{1} 90\end{array}$ & $\begin{array}{c}- \\
4.64 \\
- \\
4.58 \\
- \\
4.54 \\
- \\
4.86 \\
- \\
4.82 \\
-7.74\end{array}$ & $\begin{array}{l}1, \overline{140} \\
1, \overline{100} \\
1, \overline{0} 70 \\
1, \overline{3} 00 \\
1, \overline{2} 70 \\
1, \overline{2} 10\end{array}$ & $\begin{array}{l}- \\
4.64 \\
- \\
4.60 \\
- \\
4.55 \\
- \\
4.53 \\
- \\
4.50 \\
- \\
4.48\end{array}$ & 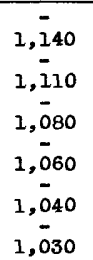 & $\begin{array}{c} \\
\overline{4} \\
\overline{-} \\
\overline{4.46} \\
\overline{-} \\
\overline{4.41} \\
\overline{-} \\
4.39\end{array}$ & $\begin{array}{c}\overline{-} \\
1, \overline{020} \\
\overline{-} \\
\overline{9} 92 \\
\overline{9} \\
\overline{9} 86 \\
\overline{974}\end{array}$ & $\begin{array}{c}\bar{z} \\
\overline{4.34} \\
\overline{-} \\
\overline{4} 33 \\
\overline{-} \\
4.31 \\
\overline{-} \\
\overline{4.30}\end{array}$ & $\begin{array}{c}\overline{-} \\
944 \\
\overline{-} \\
938 \\
\overline{-} \\
926 \\
\overline{920}\end{array}$ \\
\hline & \multicolumn{2}{|c|}{ December 20} & \multicolumn{2}{|c|}{ December 21} & \multicolumn{2}{|c|}{ December 22} & \multicolumn{2}{|c|}{ December 23} & \multicolumn{2}{|c|}{ December 24} & \multicolumn{2}{|c|}{ December 25} \\
\hline $\begin{array}{r}2 \\
4 \\
6 \\
8 \\
10 \\
1 \\
2 \\
4 \\
6 \\
8 \\
8 \\
10 \\
1\end{array}$ & 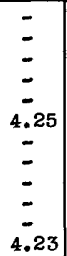 & $\begin{array}{c}\bar{z} \\
\bar{z} \\
890 \\
\bar{z} \\
\bar{z} \\
878\end{array}$ & $\begin{array}{c}\bar{z} \\
\bar{z} \\
\bar{z} \\
4.21 \\
\bar{z} \\
\bar{z} \\
4.19\end{array}$ & $\begin{array}{c}\bar{z} \\
\bar{z} \\
866 \\
\bar{z} \\
\bar{z} \\
854\end{array}$ & $\begin{array}{c}\bar{z} \\
z \\
= \\
4.16 \\
\bar{z} \\
\bar{z} \\
\overline{4.14}\end{array}$ & $\begin{array}{c}\bar{z} \\
\bar{z} \\
\overline{836} \\
\bar{z} \\
\bar{z} \\
\overline{824}\end{array}$ & $\begin{array}{c}z \\
= \\
z \\
4.11 \\
z \\
z \\
\overline{4} \\
4.08\end{array}$ & $\begin{array}{c}\bar{z} \\
\overline{-} \\
\overline{8} \\
\overline{-} \\
\bar{z} \\
\overline{-} \\
\overline{789}\end{array}$ & $\begin{array}{c}\bar{z} \\
\bar{z} \\
\overline{-} \\
4.06 \\
\bar{z} \\
\bar{z} \\
\overline{4} \\
4.04\end{array}$ & $\begin{array}{c}\overline{-} \\
\bar{z} \\
\overline{-} \\
7 \overline{7} 8 \\
\bar{z} \\
\overline{-} \\
\overline{767}\end{array}$ & $\begin{array}{c}\bar{z} \\
\bar{z} \\
\overline{4} \\
\overline{5} .02 \\
\bar{z} \\
\overline{-} \\
4.00\end{array}$ & $\begin{array}{c}\bar{z} \\
\overline{-} \\
\overline{756} \\
\bar{z} \\
\bar{z} \\
\overline{745}\end{array}$ \\
\hline
\end{tabular}

Supplemental records.- Doc. 10, 11230 p.m., 13.1 ft., 20,800 sec.-ft. 
Stony Gorge Reservolr near Elk Creek, Callf.

Location.- Lat. $39^{\circ} 35^{\prime}$, Iong. $122^{\circ} 32^{\prime}$, in $\mathrm{NE} \frac{1}{4} \mathrm{sec}, 16$, T. $20 \mathrm{~N} ., \mathrm{R}$. 6 W., at Stony Gorge Dam on Stony Creek, 1 mile south of Elk Creok, Glenn County. Zero of' gage is at mean sea level.

Drainege area.- 301 square miles.

Gage-helght record.- Gage read to tenths dally at 7 a.m.

Remarks.-Flood run-off partiy regulated in reservolr. Elevation of crest of sp111way Is 841 feet above mean sea level (capacity, 50,200 acre-feet). Reservolr began to spill about $4 \mathrm{a} \cdot \mathrm{m}$. Dec. 11. Maximum discharge over spil1way, about 16,800 secondfeet 5:30 a.m. Dec. 11. Basic data furnished by Bureau of Reclamation.

Elevation and contents, November 1937 to January 1938

\begin{tabular}{|c|c|c|c|c|c|c|}
\hline \multirow{2}{*}{ Day } & \multicolumn{2}{|c|}{ November } & \multicolumn{2}{|c|}{ December } & \multicolumn{2}{|c|}{ January } \\
\hline & $\begin{array}{c}\text { Elevation } \\
\text { (feet) }\end{array}$ & $\begin{array}{c}\text { Contents } \\
(\operatorname{acre-fe\theta t})\end{array}$ & $\begin{array}{c}\text { Elevation } \\
\text { (feet) }\end{array}$ & $\begin{array}{l}\text { Contents } \\
(\mathrm{acre}-\mathrm{fe \theta t})\end{array}$ & $\begin{array}{c}\text { Elevation } \\
\text { (feet) }\end{array}$ & $\begin{array}{l}\text { Contents } \\
(\operatorname{acre}-f e \theta t)\end{array}$ \\
\hline $\begin{array}{l}1 \\
2 \\
3 \\
4 \\
5\end{array}$ & $\begin{array}{l}784.0 \\
784.1 \\
784.1 \\
784.1 \\
784.2\end{array}$ & $\begin{array}{l}5,220 \\
5,250 \\
5,250 \\
5,250 \\
5,290\end{array}$ & $\begin{array}{l}821.2 \\
821.4 \\
821.7 \\
822.0 \\
822.3\end{array}$ & $\begin{array}{l}28,180 \\
28,360 \\
28,630 \\
28,900 \\
29,200\end{array}$ & $\begin{array}{l}834.8 \\
834.8 \\
834.9 \\
834.8 \\
834.8\end{array}$ & $\begin{array}{l}42,460 \\
42,460 \\
42,580 \\
42,460 \\
42,460\end{array}$ \\
\hline $\begin{array}{r}6 \\
7 \\
8 \\
9 \\
10\end{array}$ & $\begin{array}{l}784.2 \\
784.2 \\
784.2 \\
784.0 \\
783.8\end{array}$ & $\begin{array}{l}5,290 \\
5,290 \\
5,290 \\
5,220 \\
5,160\end{array}$ & $\begin{array}{l}822.4 \\
822.6 \\
822.9 \\
823.0 \\
825.0\end{array}$ & $\begin{array}{l}29,300 \\
29,500 \\
29,800 \\
29,900 \\
31,900\end{array}$ & $\begin{array}{l}834.7 \\
834.7 \\
834.6 \\
834.6 \\
834.6\end{array}$ & $\begin{array}{l}42,340 \\
42,340 \\
42,220 \\
42,220 \\
42,220\end{array}$ \\
\hline $\begin{array}{l}11 \\
12 \\
13 \\
14 \\
15\end{array}$ & $\begin{array}{l}783.9 \\
785.1 \\
785.6 \\
786.0 \\
786.2\end{array}$ & $\begin{array}{l}5,190 \\
5,590 \\
5,760 \\
5,900 \\
5,970\end{array}$ & $\begin{array}{l}841.2 \\
838.7 \\
838.3 \\
838.3 \\
837.8\end{array}$ & $\begin{array}{l}50,460 \\
47,210 \\
46,690 \\
46,690 \\
46,060\end{array}$ & $\begin{array}{l}834.6 \\
834.6 \\
834.6 \\
834.6 \\
834.6\end{array}$ & $\begin{array}{l}42,220 \\
42,220 \\
42,220 \\
42,220 \\
42,220\end{array}$ \\
\hline $\begin{array}{l}16 \\
17 \\
18 \\
19 \\
20\end{array}$ & $\begin{array}{l}787.6 \\
792.6 \\
795.8 \\
797.1 \\
802.8\end{array}$ & $\begin{array}{r}6,490 \\
8,650 \\
10,220 \\
10,870 \\
13,840\end{array}$ & $\begin{array}{l}838.5 \\
837.6 \\
836.5 \\
836.0 \\
835.8\end{array}$ & $\begin{array}{l}46,950 \\
45,820 \\
44,500 \\
43,900 \\
43,660\end{array}$ & $\begin{array}{l}834.6 \\
836.2 \\
836.3 \\
835.8 \\
835.6\end{array}$ & $\begin{array}{l}42,220 \\
44,140 \\
44,260 \\
43,660 \\
43,420\end{array}$ \\
\hline $\begin{array}{l}21 \\
22 \\
23 \\
24 \\
25\end{array}$ & $\begin{array}{l}811.0 \\
813.3 \\
814.7 \\
816.4 \\
817.6\end{array}$ & $\begin{array}{l}19,600 \\
21,440 \\
22,560 \\
23,990 \\
25,010\end{array}$ & $\begin{array}{l}835.7 \\
835.6 \\
835.6 \\
835.6 \\
835.5\end{array}$ & $\begin{array}{l}43,540 \\
43,420 \\
43,420 \\
43,420 \\
43,300\end{array}$ & $\begin{array}{l}835.4 \\
835.2 \\
835.2 \\
835.1 \\
835.0\end{array}$ & $\begin{array}{l}43,180 \\
42,940 \\
42,940 \\
42,820 \\
42,700\end{array}$ \\
\hline $\begin{array}{l}26 \\
27 \\
28 \\
29 \\
30 \\
31\end{array}$ & $\begin{array}{l}818.6 \\
819.2 \\
819.8 \\
820.4 \\
820.8\end{array}$ & $\begin{array}{l}25,860 \\
26,380 \\
26,920 \\
27,460 \\
27,820\end{array}$ & $\begin{array}{l}835.5 \\
835.5 \\
835.5 \\
835.4 \\
835.4 \\
835.0\end{array}$ & $\begin{array}{l}43,300 \\
43,300 \\
43,300 \\
43,180 \\
43,180 \\
42,700\end{array}$ & $\begin{array}{l}835.0 \\
834.9 \\
834.9 \\
834.8 \\
834.8 \\
835.2\end{array}$ & $\begin{array}{l}42,700 \\
42,580 \\
42,580 \\
42,460 \\
42,460 \\
42,940\end{array}$ \\
\hline
\end{tabular}

$1603020-39-15$ 
Butte Creok near Chico, Calif.

Location. - Lat. $39^{\circ} 44^{\prime}$, long. $121^{\circ} 42^{\prime}$, in sec. 25 , T. $22 \mathrm{~N}$, , R. 2 E., half a mile below junction with Littie Butte Creek and $7 \frac{1}{2}$ miles east of Chlco, Butte County. Altitude, about 350 feet above mean sea level.

Dralnage area. - 148 square miles.

Gage-helght record. - Water-stage recorder graph.

Stage-discharge relation. - Defíned by current-meter measurements below 8,200 secondfeet; extended to peak stage on basis of area-velocity $\mathrm{study}$; verified by logarithmic extensions at cable and gage sections. Rating curve changed at peak stage. Maxima.- December 1937: Discharge, 17,000 second-feet 1:30 a.m. Dec. 11 (gage height,
18.9 feet).

1930-November 1937: Discharge, 8,660 second-feet Feb. 21, 1936 (gage helght, 13.13 fe日t), from rating curve extended above 8,200 second-fe日t.

Remarks. - Flood run-off not materially affected by artificlal storage or diversion, but affected by Inflow from West Branch Feather River Basin $\nabla$ ia De Sable and Centerville power plants. Monthly summaries adjusted for inflow.

Mean daily discharge, in second-feet, November 1937 to January 1938

\begin{tabular}{|c|c|c|c|c|c|c|c|c|c|c|c|}
\hline Day & Nov. & Dec. & Jan. & Day & Nov. & Dec. & Jan. & Day & Nov. & Dec. & Jan. \\
\hline 1 & 121 & 287 & 375 & 11 & 318 & 11,200 & 305 & 21 & 1,260 & 656 & 556 \\
\hline 2 & 116 & 267 & 400 & 12 & 264 & 3,930 & 305 & 22 & 540 & 534 & 534 \\
\hline 3 & 110 & 233 & 408 & 13 & 197 & 2,260 & 317 & 23 & 1,060 & 520 & 508 \\
\hline 4 & 110 & 262 & 389 & 14 & 234 & 1,550 & 302 & 24 & 1,160 & 488 & 460 \\
\hline 5 & 112 & 246 & 364 & 15 & 278 & 1,240 & 488 & 25 & 646 & 468 & 460 \\
\hline 6 & 112 & 227 & 354 & 16 & 326 & 1,030 & 432 & 26 & 496 & 436 & 400 \\
\hline 7 & 117 & 246 & 332 & 17 & 788 & 911 & 1,150 & 27 & 414 & 412 & 420 \\
\hline 8 & 114 & 235 & 332 & 18 & 352 & 758 & 830 & 28 & 335 & 420 & 428 \\
\hline 9 & 110 & 273 & 338 & 19 & 305 & 660 & 675 & 29 & 329 & 382 & 404 \\
\hline 10 & 117 & 6,210 & 294 & 20 & 2,830 & 601 & 630 & $\begin{array}{l}30 \\
31\end{array}$ & 319 & $\begin{array}{l}375 \\
389\end{array}$ & $\begin{array}{l}382 \\
758\end{array}$ \\
\hline \multirow{3}{*}{\multicolumn{9}{|c|}{$\begin{array}{l}\text { Mean monthly discharge, in second-feet (observed) } \ldots \ldots \ldots \ldots \ldots \\
\text { Mean monthly discharge, in second-feet (adjusted) } \ldots \ldots \ldots \ldots\end{array}$}} & 453 & 1,216 & \\
\hline & & & & & & & & & 397 & 1,143 & 387 \\
\hline & & & & & & & & & 23,650 & 70,300 & 23,800 \\
\hline
\end{tabular}

Gage helght, in feet, and discharge, in second-feet, at indicated time, 1937

\begin{tabular}{|c|c|c|c|c|c|c|c|c|c|c|c|c|}
\hline \multirow{2}{*}{ 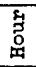 } & Feet & Sec.ft. & Feet & Sec.ft. & Feet & Sec.ft. & Feet & Sec.ft. & Feet & Sec.ft. & Feet & Sec.ft. \\
\hline & \multicolumn{2}{|c|}{ December 8} & \multicolumn{2}{|c|}{ December 9} & \multicolumn{2}{|c|}{ Deceraber 10} & \multicolumn{2}{|c|}{ December 11} & \multicolumn{2}{|c|}{ December 12} & \multicolumn{2}{|c|}{ December 13} \\
\hline 2 & - & - & - & - & 4.55 & 870 & 18.55 & 16,600 & 9.00 & 5,700 & 6.04 & $\longdiv { 2 , 6 7 0 }$ \\
\hline 4 & 3.05 & 243 & 3.04 & 240 & 5.02 & 1,170 & & 15,200 & 8.50 & & & 2,620 \\
\hline 6 & - & - & - & - & 5.67 & 1,640 & & 13,400 & & & & 2,490 \\
\hline 8 & 2.96 & 220 & 2.92 & 209 & 6.34 & 2,200 & 15.00 & 12,300 & 7. & 4,050 & 67 & 2,360 \\
\hline 10 & - & - & - & - & 7.15 & 2,900 & & 11,400 & & & & 2,260 \\
\hline $\mathbf{N}$ & 3.02 & 235 & 3.06 & 246 & 10.00 & 5,500 & 13.80 & 11,000 & 7.00 & 3,650 & & 2,220 \\
\hline 2 & - & - & - & - & 12.50 & 8,200 & 13.20 & 10,300 & 6.72 & & & 2,130 \\
\hline 4 & 3.05 & 243 & 3.13 & 264 & 12.95 & 8,800 & 12.30 & 9,330 & 6.48 & 3,150 & & 2,040 \\
\hline 6 & - & - & - & - & 13.55 & 9,600 & 11.40 & 8,340 & 6.48 & & & 2,000 \\
\hline \multirow{4}{*}{$\begin{array}{r}10 \\
M\end{array}$} & 3.05 & 243 & 3.32 & 322 & 14.72 & & 10.85 & 7,6 & & & & 1,910 \\
\hline & - & - & & - & 16.60 & & 10.52 & 7,350 & & & & 1,830 \\
\hline & 3.05 & 243 & 4.10 & 622 & 18.50 & 400 & 9.65 & 6,420 & 6.14 & 2,760 & 5.01 & 1,790 \\
\hline & \multicolumn{2}{|c|}{ December 14} & \multicolumn{2}{|c|}{ December 15} & \multicolumn{2}{|c|}{ December 16} & \multicolumn{2}{|c|}{ December 17} & \multicolumn{2}{|c|}{ December 18} & \multicolumn{2}{|c|}{ December 19} \\
\hline 2 & - & $T_{10}$ & - & - & - & - & - & - & - & - & - & - \\
\hline 4 & 4.90 & 1,710 & 4.38 & 1,310 & 4.11 & 1,100 & 3.87 & 939 & 3.63 & 788 & 3.42 & 670 \\
\hline 6 & - & - & - & - & - & - & - & - & - & - & - & - \\
\hline 8 & 4.78 & 1,630 & - & - & - & - & - & - & - & - & - & - \\
\hline 10 & & - & & - & - & - & - & - & - & - & - & - \\
\hline N & 4.68 & 1,550 & 4.32 & 1,240 & 4.01 & 1,030 & 3.82 & 904 & 3.60 & 770 & 3.37 & 645 \\
\hline 2 & - & - & & - & - & - & - & - & - & - & - & - \\
\hline 4 & 4.59 & 1,470 & - & - & - & - & - & - & - & - & - & - \\
\hline 6 & - & $\overline{7}=0$ & -0 & in & $=03$ & $\bar{a}$ & $=-70$ & $\bar{g}$ & & & $7=00$ & $\bar{c}$ \\
\hline 8 & 4.57 & 1,430 & 4.24 & 1,200 & 3.93 & 995 & 3.79 & 884 & 3.54 & 734 & 3.40 & 660 \\
\hline \multirow{3}{*}{ M } & 547 & $\overline{350}$ & $\bar{z}$ & $\overline{-}$ & $\overline{-}$ & $=$ & - & $=$ & - & $\overline{-}$ & $\overline{-}$ & $\overline{-}$ \\
\hline & \multirow{2}{*}{\multicolumn{2}{|c|}{ December 20}} & \multirow{2}{*}{\multicolumn{2}{|c|}{ December 21}} & \multirow{2}{*}{\multicolumn{2}{|c|}{ December 22}} & \multirow{2}{*}{\multicolumn{2}{|c|}{ December 23}} & \multirow{2}{*}{\multicolumn{2}{|c|}{ December 24}} & \multirow{2}{*}{\multicolumn{2}{|c|}{ December 25}} \\
\hline & & & & & & & & & & & & \\
\hline 2 & - & - & - & - & - & - & - & - & - & - & - & - \\
\hline 4 & 3.28 & 601 & 3.17 & 552 & 3.11 & 524 & 3.09 & 516 & 2.98 & 472 & 2.95 & 460 \\
\hline 6 & - & - & - & - & - & - & 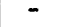 & - & - & - & - & - \\
\hline 8 & - & - & - & - & & - & & - & - & - & - & - \\
\hline 10 & $\therefore=2$ & - & $=-$ & - & - & - & - & - & - & 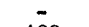 & - & - \\
\hline N & 3.31 & 615 & 3.19 & 560 & 3.11 & 524 & 3.12 & 529 & 3.02 & 488 & 2.98 & 472 \\
\hline 2 & & - & & & & - & & - & & - & & - \\
\hline 4 & $\overline{-}$ & - & - & $\overline{-}$ & - & $\overline{-}$ & - & - & - & - & - & - \\
\hline 8 & 3.28 & 601 & 3.19 & $5 \overline{60}$ & 3.19 & $5 \overline{60}$ & 3.10 & $5 \overline{20}$ & 3.11 & $5 \overline{24}$ & 2.98 & 472 \\
\hline 10 & - & - & vet & - & - & - & - & - & - & - & - & - \\
\hline $\mathrm{m}$ & - & - & - & & & - & - & - & - & - & - & - \\
\hline
\end{tabular}

Supplemental records. - Dec. 11, 1:30 a.m., 18.9 ft., 17,000 sec.-ft. 
Lake Almanor near Prattville, Calif.

Location. - Lat. $40^{\circ} 10^{\prime} 30^{\prime \prime}$, long. $121^{\circ} 05^{\prime} 25^{\prime \prime}$, in NWt sec. 28, T. 27 N., R. 8 E., at outlet tower at dam on North Fork of Feather River, 5 miles southeast of Prattvilie, Plumas County. Zero of gage is at mean sea level.

Drainage area. - 506 square mlles.

Gage-helght record. - Gage read to hundredths da1ly at 7 a.m. Elevation and contents at midnight shown in table obtained by interpolation.

Remarks.- Flood run-off completely controlled in lake (capacity, 1,532,800 acre-fe日t at elevation 4,515 feet). See record for North Fork of Feather River near Prattvilie. Basic data furnished by Paciflc Gas \& Electric Co.

Elevation and contents, November 1937 to Januery 1938

\begin{tabular}{|c|c|c|c|c|c|c|}
\hline \multirow[b]{2}{*}{ Day } & \multicolumn{2}{|c|}{ November } & \multicolumn{2}{|c|}{ December } & \multicolumn{2}{|c|}{ January } \\
\hline & $\begin{array}{l}\text { Elevation } \\
(f e \theta t)\end{array}$ & $\begin{array}{l}\text { Contents } \\
(\text { acre-feet) }\end{array}$ & $\begin{array}{c}\text { Elevation } \\
\text { (feet) }\end{array}$ & $\begin{array}{l}\text { Contents } \\
\text { (acre-feet) }\end{array}$ & $\begin{array}{l}\text { Elevation } \\
\text { (feet) }\end{array}$ & $\begin{array}{l}\text { Contents } \\
(\operatorname{acr} \theta-f e \theta t)\end{array}$ \\
\hline $\begin{array}{l}1 \\
2 \\
3 \\
4 \\
5\end{array}$ & $\begin{array}{l}4,459.82 \\
4,459.71 \\
4,459.59 \\
4,459.46 \\
4,459.34\end{array}$ & $\begin{array}{l}372,863 \\
370,971 \\
368,911 \\
366,686 \\
364,637\end{array}$ & $\begin{array}{l}4,459.31 \\
4,459.28 \\
4,459.24 \\
4,459.20 \\
4,459.16\end{array}$ & $\begin{array}{l}364.126 \\
363,615 \\
362,935 \\
362,254 \\
361,575\end{array}$ & $\begin{array}{l}4,460.37 \\
4,460.36 \\
4,460.41 \\
4,460.47 \\
4,460.52\end{array}$ & $\begin{array}{l}382,388 \\
382,214 \\
383,085 \\
384,131 \\
385,003\end{array}$ \\
\hline $\begin{array}{r}6 \\
7 \\
8 \\
9 \\
10\end{array}$ & $\begin{array}{l}4,459.22 \\
4,459.10 \\
4,458.97 \\
4,458.82 \\
4,458.73\end{array}$ & $\begin{array}{l}362,594 \\
360,556 \\
358,354 \\
355,820 \\
354,304\end{array}$ & $\begin{array}{l}4,459.11 \\
4,459.04 \\
4,458.96 \\
4,459.03 \\
4,459.83\end{array}$ & $\begin{array}{l}360,726 \\
359,539 \\
358,185 \\
359,370 \\
373,035\end{array}$ & $\begin{array}{l}4,460.53 \\
4,460.53 \\
4,460.55 \\
4,460.52 \\
4,460.38\end{array}$ & $\begin{array}{l}385,178 \\
385,178 \\
385,527 \\
385,003 \\
382,562\end{array}$ \\
\hline $\begin{array}{l}11 \\
12 \\
13 \\
14 \\
15\end{array}$ & $\begin{array}{l}4,458.77 \\
4,458.75 \\
4,458.71 \\
4,458.69 \\
4,458.63\end{array}$ & $\begin{array}{l}354,978 \\
354,641 \\
353,967 \\
353,631 \\
352,622\end{array}$ & $\begin{array}{l}4,461.43 \\
4,462.29 \\
4,462.60 \\
4,462.76 \\
4,462.89\end{array}$ & $\begin{array}{l}401,028 \\
416,406 \\
422,001 \\
424,900 \\
427,261\end{array}$ & $\begin{array}{l}4,460.26 \\
4,460.15 \\
4,460.08 \\
4,460.06 \\
4,460.12\end{array}$ & $\begin{array}{l}380,475 \\
378,566 \\
377,353 \\
377,007 \\
378,046\end{array}$ \\
\hline $\begin{array}{l}16 \\
17 \\
18 \\
19 \\
20\end{array}$ & $\begin{array}{l}4,458.73 \\
4,458.78 \\
4,458.78 \\
4,458.85 \\
4,459.11\end{array}$ & $\begin{array}{l}354,304 \\
355,146 \\
355,146 \\
356,326 \\
360,726\end{array}$ & $\begin{array}{l}4,462.93 \\
4,462.79 \\
4,462.61 \\
4,462.43 \\
4,462.25\end{array}$ & $\begin{array}{l}427,988 \\
425,444 \\
422,182 \\
418,929 \\
415,686\end{array}$ & $\begin{array}{l}4,460.14 \\
4,460.18 \\
4,460.20 \\
4,460.27 \\
4,460.34\end{array}$ & $\begin{array}{l}378,393 \\
379,086 \\
379,433 \\
380,649 \\
381,866\end{array}$ \\
\hline $\begin{array}{l}21 \\
22 \\
23 \\
24 \\
25\end{array}$ & $\begin{array}{l}4,459.23 \\
4,459.28 \\
4,459.42 \\
4,459.49 \\
4,459.50\end{array}$ & $\begin{array}{l}362,764 \\
363,615 \\
366,002 \\
367,199 \\
367,370\end{array}$ & $\begin{array}{l}4,462.04 \\
4,461.86 \\
4,461.67 \\
4,461.49 \\
4,461.29\end{array}$ & $\begin{array}{l}411,913 \\
408,690 \\
405,298 \\
402,094 \\
398,546\end{array}$ & $\begin{array}{l}4,460.43 \\
4,460.54 \\
4,460.62 \\
4,460.68 \\
4,460.74\end{array}$ & $\begin{array}{l}383,433 \\
385,353 \\
386,751 \\
387,801 \\
388,853\end{array}$ \\
\hline $\begin{array}{l}26 \\
27 \\
28 \\
29 \\
30 \\
31\end{array}$ & $\begin{array}{l}4,459.49 \\
4,459.45 \\
4,459.41 \\
4,459.36 \\
4,459.34\end{array}$ & $\begin{array}{l}367,199 \\
366,515 \\
365,832 \\
364,979 \\
364,637\end{array}$ & $\begin{array}{l}4,461.12 \\
4,460.98 \\
4,460.71 \\
4,460.55 \\
4,460.38 \\
4,460.35\end{array}$ & $\begin{array}{l}395,539 \\
393,070 \\
388,327 \\
385,527 \\
382,562 \\
382,040\end{array}$ & $\begin{array}{l}4,460.80 \\
4,460.87 \\
4,460.98 \\
4,461.07 \\
4,461.18 \\
4,461.40\end{array}$ & $\begin{array}{l}389,905 \\
391,135 \\
393,070 \\
394,657 \\
396,599 \\
400,496\end{array}$ \\
\hline
\end{tabular}


Location. - Lat. $40^{\circ} 10^{\prime}$, Iong. $121^{\circ} 06^{\prime}$, in SW sec. 28, T. 27 N., R. 8 E., half a mile below Aimanor Dam, 5 miles southeast of Prattvilie, Plumas County, and about 9 miles upstream from mouth of Butt Creok. Altitude, about 4,380 feet above mean sea level.

Drsinage area.- 507 square miles.

Gage-helght record. - Water-s tage recorder graph.

Stage-discharge relation. - Defined by current-meter measurements.

Maxima, - December 1937: Discharge (regulated), 2,620 second-feet 6 a.m. to 4 p.m. Dec. 23 (gage helght, 7.20 feet).

1905-Novemer 1937: Discharge (unregulated), about 10,000 second-feet Mar. 19, 1907 (gage height, 16.2 feet, former site and datum), from rating curve extended above 3,700 second-feet.

Remarks. - Flood run-off completely controlled in Lake Almanor. See record for Lake

Alman age in and diversion from Lake Almanor but not for $\mathbf{s}$ torage in Mountain Meadows Reservoir. Most of basic data furnished by Pacific Gas slectric Co.

Discharge, gain or loss in storage, and diversion, December 1937

\begin{tabular}{|c|c|c|c|c|}
\hline Day & $\begin{array}{c}\text { Observed } \\
\text { discharge } \\
\text { (second-feet) }\end{array}$ & $\begin{array}{l}\text { Gain or loss } \\
\text { In storage } \\
\text { (acre-fe日t) }\end{array}$ & $\begin{array}{l}\text { Tunnel No. } 1 \\
\text { diversion } \\
\text { (second-feet) }\end{array}$ & 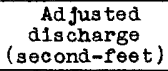 \\
\hline $\begin{array}{l}1 \\
2 \\
3 \\
4 \\
5\end{array}$ & $\begin{array}{l}2.5 \\
21 \\
52 \\
25 \\
72\end{array}$ & $\begin{array}{l}-511 \\
-511 \\
-680 \\
-681 \\
-679\end{array}$ & $\begin{array}{r}1,020 \\
1,000 \\
990 \\
992 \\
992\end{array}$ & $\begin{array}{l}764 \\
763 \\
699 \\
674 \\
722\end{array}$ \\
\hline $\begin{array}{r}6 \\
7 \\
8 \\
9 \\
10\end{array}$ & $\begin{array}{r}121 \\
80 \\
343 \\
155 \\
30\end{array}$ & $\begin{array}{r}-849 \\
-1,187 \\
-1,354 \\
+1,185 \\
+13,665\end{array}$ & $\begin{array}{r}993 \\
993 \\
993 \\
999 \\
1,120\end{array}$ & $\begin{array}{r}686 \\
475 \\
653 \\
1,750 \\
8,040\end{array}$ \\
\hline $\begin{array}{l}11 \\
12 \\
13 \\
14 \\
15\end{array}$ & $\begin{array}{r}31 \\
190 \\
1,560 \\
1,930 \\
1,960\end{array}$ & $\begin{array}{r}+27,993 \\
+15,378 \\
+5,595 \\
+2,899 \\
+2,361\end{array}$ & $\begin{array}{r}850 \\
305 \\
43 \\
55 \\
38\end{array}$ & $\begin{array}{r}15,000 \\
8,250 \\
4,420 \\
3,450 \\
3,190\end{array}$ \\
\hline $\begin{array}{l}16 \\
17 \\
18 \\
19 \\
20\end{array}$ & $\begin{array}{l}2,240 \\
2,280 \\
2,280 \\
2,350 \\
2,520\end{array}$ & $\begin{array}{r}+7 i 7 \\
-2,544 \\
-3,262 \\
-3,253 \\
-3,243\end{array}$ & $\begin{array}{r}310 \\
1,110 \\
1,100 \\
1,100 \\
1,120\end{array}$ & $\begin{array}{l}2,920 \\
2,110 \\
1,740 \\
1,810 \\
2,000\end{array}$ \\
\hline $\begin{array}{l}21 \\
22 \\
23 \\
24 \\
25\end{array}$ & $\begin{array}{l}2,520 \\
2,490 \\
2,560 \\
2,520 \\
2,520\end{array}$ & $\begin{array}{l}-3,773 \\
-3,223 \\
-3,392 \\
-3,204 \\
-3,548\end{array}$ & $\begin{array}{l}1,120 \\
1,110 \\
1,120 \\
1,120 \\
1,120\end{array}$ & $\begin{array}{l}1,740 \\
1,980 \\
1,970 \\
2,020 \\
1,850\end{array}$ \\
\hline $\begin{array}{l}26 \\
27 \\
28 \\
29 \\
30 \\
31\end{array}$ & $\begin{array}{l}2,520 \\
2,490 \\
2,490 \\
2,490 \\
2,070 \\
1,040\end{array}$ & $\begin{array}{r}-3,007 \\
-2,469 \\
-4,743 \\
-2,800 \\
-2,965 \\
-522\end{array}$ & $\begin{array}{r}1,130 \\
1,140 \\
930 \\
30 \\
21 \\
23\end{array}$ & $\begin{array}{r}2,130 \\
2,380 \\
1,030 \\
1,110 \\
596 \\
800\end{array}$ \\
\hline
\end{tabular}

Observed mean dally discharge, in second-feet, November 1937 to Jamary 1938

\begin{tabular}{|c|c|c|c|c|c|c|c|c|c|c|c|}
\hline Day & Nov. & Dec. & Jan. & Day & Nov, & Dec. & Jan. & Day & Nov, & Dec. & Jan. \\
\hline $\begin{array}{r}1 \\
2 \\
3 \\
4 \\
5 \\
6 \\
7 \\
8 \\
9 \\
10\end{array}$ & $\begin{array}{l}543 \\
543 \\
543 \\
538 \\
538 \\
538 \\
534 \\
534 \\
534 \\
450\end{array}$ & $\begin{array}{c}2.5 \\
21 \\
52 \\
25 \\
72 \\
121 \\
80 \\
343 \\
155 \\
30\end{array}$ & $\begin{array}{l}552 \\
552 \\
552 \\
552 \\
552 \\
552 \\
552 \\
552 \\
552 \\
552\end{array}$ & $\begin{array}{l}11 \\
12 \\
13 \\
14 \\
15 \\
16 \\
17 \\
18 \\
19 \\
20\end{array}$ & $\begin{array}{c}31 \\
31 \\
31 \\
31 \\
31 \\
30 \\
13 \\
2.5 \\
2.5 \\
4.4\end{array}$ & $\begin{array}{r}31 \\
190 \\
1,560 \\
1,930 \\
1,960 \\
2,240 \\
2,280 \\
2,280 \\
2,350 \\
2,520\end{array}$ & $\begin{array}{r}552 \\
552 \\
234 \\
43 \\
43 \\
43 \\
43 \\
43 \\
43 \\
43\end{array}$ & \begin{tabular}{|l}
21 \\
22 \\
23 \\
24 \\
25 \\
26 \\
27 \\
28 \\
29 \\
30 \\
31
\end{tabular} & $\begin{array}{l}2.5 \\
2.5 \\
3.0 \\
2.8 \\
2.5 \\
2.5 \\
2.5 \\
2.5 \\
2.5 \\
2.5\end{array}$ & $\begin{array}{l}2,520 \\
2,490 \\
2,560 \\
2,520 \\
2,520 \\
2,520 \\
2,490 \\
2,490 \\
2,490 \\
2,070 \\
1,040\end{array}$ & $\begin{array}{l}43 \\
44 \\
44 \\
44 \\
44 \\
44 \\
44 \\
44 \\
44 \\
44 \\
44\end{array}$ \\
\hline \multicolumn{9}{|c|}{ 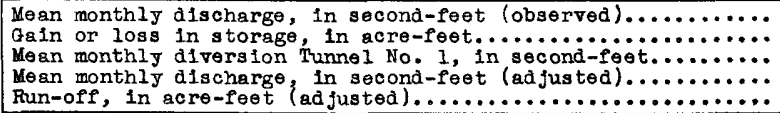 } & $\begin{array}{r}-18,120 \\
1,016 \\
1,030 \\
61,320 \\
\end{array}$ & $\begin{array}{r}1,418 \\
+17,400 \\
806 \\
2,507 \\
154,200\end{array}$ & $\begin{array}{r}247 \\
+18,460 \\
387 \\
93 \\
57,410\end{array}$ \\
\hline
\end{tabular}


Feather River near Oroville, Calif.

Location. - Lat. $39^{\circ} 32^{\prime}$, long. $121^{\circ} 29^{\prime}$, in NE⿺ sec. 2, T. 19 N., R. 4 E., 2 miles below function of North and Middle Forks and 3 miles northesst of Oroville, Butte County. Zero of gage is 182.02 feet above mean sea level (general adjustment of 1929).

Drainage area.- 3,611 square miles.

Gage-helght record. - Water-stage recorder graph except for period 3 p.m. Dec. 10 to 3 p.m. Doc. 15, when stage graph was based on floodmarks, occaslonal staff gage readings, and graphs at other stations on Feather RIver.

Stage-discharge relation.- Defined by current-meter measurements below 62,000 secondfeet; extended to perk stage on basis of area-velocity study and $A \sqrt{d}$ method; verifled by slope-area computations of flood flow. Rating curvo changed at peak stage.

Naxima.- December 1937: Discharge, 185,000 second-feet about 6 a.m. Dec. Il (gage helght, 73.6 feet).

1902-November 1937: D1scherge, about 230,000 second-feet (rov1sed) Mar. 19, 1907 (gage height, 28.2 foet, former site and datum at Oroville).

Remarks.- Flood run-off affected by storage in Lake Almanor and Bucks, Butt Valley, and other storage reservolrs.

Mean dally discharge, In second-feet, November 1937 to January 1938

\begin{tabular}{|c|c|c|c|c|c|c|c|c|c|c|c|}
\hline Day & Nov. & Dec. & Jan. & Day & Nov. & Dec. & Jan. & Day & Nov. & Dec. & Jan. \\
\hline $\begin{array}{r}1 \\
2 \\
3 \\
4 \\
5 \\
6 \\
7 \\
8 \\
9 \\
10\end{array}$ & $\begin{array}{l}2,190 \\
2,490 \\
2,440 \\
2,440 \\
2,440 \\
2,340 \\
2,190 \\
2,290 \\
2,390 \\
2,440\end{array}$ & $\begin{array}{r}3,930 \\
3,690 \\
3,510 \\
3,330 \\
3,150 \\
3,210 \\
3,210 \\
3,150 \\
3,570 \\
77,800\end{array}$ & $\begin{array}{l}5,180 \\
5,500 \\
5,640 \\
4,980 \\
4,790 \\
4,600 \\
4,460 \\
4,280 \\
3,860 \\
3,920\end{array}$ & $\begin{array}{l}11 \\
12 \\
13 \\
14 \\
15 \\
16 \\
17 \\
18 \\
19 \\
20\end{array}$ & $\begin{array}{r}2,860 \\
2,980 \\
2,390 \\
2,700 \\
3,620 \\
3,030 \\
10,300 \\
5,570 \\
4,400 \\
20,600\end{array}$ & $\begin{array}{r}145,000 \\
63,400 \\
35,200 \\
24,400 \\
17,100 \\
14,800 \\
13,300 \\
12,100 \\
11,000 \\
10,200\end{array}$ & $\begin{array}{r}3,800 \\
3,680 \\
3,680 \\
3,200 \\
5,050 \\
4,860 \\
10,200 \\
9,340 \\
8,080 \\
7,200\end{array}$ & $\begin{array}{l}21 \\
22 \\
23 \\
24 \\
25 \\
26 \\
27 \\
28 \\
29 \\
30 \\
31\end{array}$ & $\begin{array}{r}14,700 \\
7,010 \\
11,100 \\
11,400 \\
7,290 \\
5,610 \\
5,070 \\
4,050 \\
3,930 \\
4,110\end{array}$ & $\begin{array}{l}9,970 \\
9,700 \\
9,160 \\
8,720 \\
8,400 \\
8,080 \\
7,840 \\
7,680 \\
7,440 \\
7,280 \\
6,190\end{array}$ & $\begin{array}{l}6,190 \\
5,770 \\
5,640 \\
5,310 \\
4,860 \\
4,660 \\
4,530 \\
4,720 \\
4,460 \\
4,100 \\
5,950\end{array}$ \\
\hline \multicolumn{12}{|c|}{ 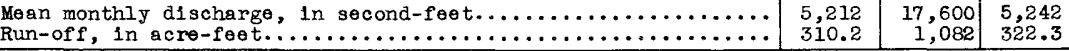 } \\
\hline
\end{tabular}

Gage helght, In feet, and discharge, in second-feet, at indicated time, 1937

\begin{tabular}{|c|c|c|c|c|c|c|c|c|c|c|c|c|}
\hline \multirow{2}{*}{$\begin{array}{l}5 \\
\text { 至 }\end{array}$} & Feet & Sec.ft. & eet & Sec.ft. & Feet & Sec.ft. & Feet & Sec.ft. & Feet & Sec.ft. & Feet & Sec.ft. \\
\hline & \multicolumn{2}{|c|}{ December 8} & \multicolumn{2}{|c|}{ December 9} & \multicolumn{2}{|c|}{ December 10} & \multicolumn{2}{|c|}{ December 11} & \multicolumn{2}{|c|}{ December 12} & \multicolumn{2}{|c|}{ December 13} \\
\hline \multirow[t]{2}{*}{$\begin{array}{r}2 \\
4 \\
6 \\
8 \\
10 \\
N \\
2 \\
4 \\
6 \\
8 \\
10 \\
M \\
\end{array}$} & $\begin{array}{l}9.61 \\
9.16 \\
8.66 \\
8.36 \\
8.36 \\
9.98 \\
9.98 \\
9.98 \\
9.98 \\
9.96 \\
9.96 \\
9.95\end{array}$ & $\begin{array}{l}3,220 \\
2,960 \\
2,690 \\
2,520 \\
2,520 \\
3,440 \\
3,440 \\
3,440 \\
3,440 \\
3,430 \\
3,430 \\
3,420\end{array}$ & $\begin{array}{r}10.00 \\
10.00 \\
10.00 \\
10.00 \\
9.60 \\
10.00 \\
10.00 \\
10.05 \\
10.25 \\
10.40 \\
10.80 \\
12.35\end{array}$ & $\begin{array}{l}3,450 \\
3,450 \\
3,450 \\
3,450 \\
3,210 \\
3,450 \\
3,450 \\
3,480 \\
3,600 \\
3,690 \\
3,930 \\
4,860\end{array}$ & $\begin{array}{l}15.00 \\
17.45 \\
25.60 \\
33.40 \\
40.40 \\
47.45 \\
57.00 \\
64.00 \\
68.00 \\
71.50 \\
69.50 \\
66.60\end{array}$ & \begin{tabular}{|r|}
6,520 \\
8,360 \\
16,300 \\
27,400 \\
41,500 \\
60,200 \\
95,000 \\
128,000 \\
151,000 \\
172,000 \\
160,000 \\
143,000 \\
\end{tabular} & $\begin{array}{l}65.00 \\
70.20 \\
73.60 \\
72.00 \\
70.30 \\
68.50 \\
67.00 \\
65.00 \\
63.80 \\
62.30 \\
61.00 \\
59.00\end{array}$ & $\begin{array}{l}134,000 \\
164,000 \\
185,000 \\
175,000 \\
165,000 \\
154,000 \\
145,000 \\
134,000 \\
128,000 \\
120,000 \\
114,000 \\
104,000\end{array}$ & \begin{tabular}{|l|}
56.50 \\
54.10 \\
51.90 \\
50.40 \\
49.00 \\
47.50 \\
46.30 \\
44.80 \\
43.50 \\
42.60 \\
41.90 \\
41.20
\end{tabular} & $\begin{array}{l}93,000 \\
83,400 \\
74,800 \\
69,600 \\
65,000 \\
60,300 \\
56,700 \\
52,400 \\
48,900 \\
46,600 \\
45,000 \\
43,300\end{array}$ & $\begin{array}{l}40.70 \\
40.10 \\
39.30 \\
38.70 \\
38.00 \\
37.30 \\
36.60 \\
36.20 \\
35.50 \\
35.15 \\
34.70 \\
34.40\end{array}$ & $\begin{array}{l}42,100 \\
40,800 \\
39,100 \\
37,700 \\
36,200 \\
34,700 \\
33,300 \\
32,500 \\
31,200 \\
30,500 \\
29,700 \\
29,100\end{array}$ \\
\hline & \multicolumn{2}{|c|}{ December 14} & \multicolumn{2}{|c|}{ December 15} & \multicolumn{2}{|c|}{ December 16} & \multicolumn{2}{|c|}{ December 17} & \multicolumn{2}{|c|}{ December 18} & \multicolumn{2}{|c|}{ December 19} \\
\hline \multirow[t]{2}{*}{$\begin{array}{r}2 \\
4 \\
6 \\
8 \\
10 \\
1 \\
2 \\
4 \\
6 \\
8 \\
10 \\
M\end{array}$} & $\begin{array}{l}- \\
- \\
- \\
= \\
- \\
= \\
- \\
-\end{array}$ & $\begin{array}{c}27,100 \\
- \\
25,700 \\
- \\
24,400 \\
- \\
22,700 \\
- \\
21,100 \\
- \\
19,900\end{array}$ & $\begin{array}{c}\overline{-} \\
- \\
- \\
- \\
- \\
- \\
25.75 \\
25.80 \\
26.10 \\
25.00 \\
25.30\end{array}$ & $\begin{array}{l}19,000 \\
18,300 \\
17,800 \\
17,200 \\
16,700 \\
16,200 \\
16,300 \\
16,500 \\
16,600 \\
16,900 \\
15,600 \\
16,000\end{array}$ & $\begin{array}{l}25.08 \\
24.75 \\
24.65 \\
24.30 \\
24.40 \\
23.58 \\
23.85 \\
23.88 \\
23.98 \\
23.75 \\
23.72 \\
23.70\end{array}$ & \begin{tabular}{|l|}
15,700 \\
15,300 \\
15,200 \\
14,800 \\
14,900 \\
14,100 \\
14,400 \\
14,400 \\
14,500 \\
14,200 \\
14,200 \\
14,200
\end{tabular} & $\begin{array}{l}22.30 \\
23.15 \\
23.18 \\
23.05 \\
23.75 \\
22.45 \\
22.90 \\
22.20 \\
22.95 \\
22.92 \\
22.10 \\
22.42\end{array}$ & $\begin{array}{l}12,800 \\
13,600 \\
13,700 \\
13,600 \\
14,200 \\
13,000 \\
13,400 \\
12,700 \\
13,400 \\
13,400 \\
12,600 \\
12,900\end{array}$ & $\begin{array}{l}22.00 \\
21.32 \\
21.65 \\
21.75 \\
21.95 \\
22.15 \\
20.90 \\
21.15 \\
21.35 \\
22.00 \\
21.20 \\
20.45\end{array}$ & $\begin{array}{l}12,500 \\
11,800 \\
12,200 \\
12,200 \\
12,400 \\
12,600 \\
11,400 \\
11,600 \\
11,800 \\
12,500 \\
11,700 \\
11,000\end{array}$ & $\begin{array}{l}20.60 \\
20.70 \\
20.75 \\
20.70 \\
20.65 \\
20.60 \\
20.55 \\
20.40 \\
21.25 \\
20.40 \\
20.05 \\
19.65\end{array}$ & $\begin{array}{l}11,100 \\
11,200 \\
11,300 \\
11,200 \\
11,200 \\
11,100 \\
11,100 \\
11,000 \\
11,800 \\
11,000 \\
10,600 \\
10,300\end{array}$ \\
\hline & \multicolumn{2}{|c|}{ December 20} & \multicolumn{2}{|c|}{ December 21} & \multicolumn{2}{|c|}{ December 22} & \multicolumn{2}{|c|}{ December 23} & \multicolumn{2}{|c|}{ December 24} & \multicolumn{2}{|c|}{ December 25} \\
\hline $\begin{array}{r}2 \\
4 \\
6 \\
8 \\
10 \\
\mathrm{~N} \\
2 \\
4 \\
6 \\
8 \\
10 \\
\mathrm{M}\end{array}$ & $\begin{array}{l}19.40 \\
19.45 \\
19.70 \\
19.80 \\
20.40 \\
19.55 \\
19.00 \\
19.80 \\
19.50 \\
20.75 \\
19.40 \\
18.15\end{array}$ & $\begin{array}{r}10,100 \\
10,100 \\
10,300 \\
10,400 \\
11,000 \\
10,200 \\
9,700 \\
10,400 \\
10,200 \\
11,300 \\
10,100 \\
8,940\end{array}$ & $\begin{array}{l}19.27 \\
19.27 \\
19.15 \\
19.20 \\
19.80 \\
19.80 \\
19.68 \\
19.55 \\
19.40 \\
19.25 \\
19.15 \\
19.00\end{array}$ & $\begin{array}{r}9,940 \\
9,940 \\
9,840 \\
9,880 \\
10,400 \\
10,400 \\
10,300 \\
10,200 \\
10,100 \\
9,920 \\
9,840 \\
9,700\end{array}$ & \begin{tabular}{|l|}
19.05 \\
19.10 \\
19.15 \\
19.20 \\
19.25 \\
19.65 \\
18.65 \\
18.90 \\
18.65 \\
18.95 \\
20.05 \\
18.40
\end{tabular} & \begin{tabular}{|r|}
9,740 \\
9,790 \\
9,840 \\
9,880 \\
9,920 \\
10,300 \\
9,380 \\
9,610 \\
9,380 \\
9,660 \\
10,600 \\
9,160
\end{tabular} & $\begin{array}{l}18.30 \\
18.75 \\
18.42 \\
18.42 \\
18.42 \\
19.75 \\
18.30 \\
17.85 \\
18.00 \\
18.80 \\
18.10 \\
18.00\end{array}$ & \begin{tabular}{|r|}
9,070 \\
9,480 \\
9,180 \\
9,180 \\
9,180 \\
10,400 \\
9,070 \\
8,860 \\
8,800 \\
9,520 \\
8,890 \\
8,800
\end{tabular} & $\begin{array}{l}17.80 \\
17.87 \\
17.82 \\
17.82 \\
18.02 \\
18.90 \\
17.85 \\
18.30 \\
17.00 \\
17.75 \\
17.45 \\
17.90\end{array}$ & $\begin{array}{l}8,640 \\
8,700 \\
8,660 \\
8,660 \\
8,820 \\
9,610 \\
8,680 \\
9,070 \\
8,000 \\
8,600 \\
8,360 \\
8,720\end{array}$ & $\begin{array}{l}18.50 \\
17.20 \\
17.60 \\
17.60 \\
17.75 \\
17.40 \\
17.30 \\
17.30 \\
17.10 \\
17.40 \\
17.25 \\
17.20\end{array}$ & $\begin{array}{l}9,250 \\
8,160 \\
8,480 \\
8,480 \\
8,440 \\
8,320 \\
8,240 \\
8,240 \\
8,080 \\
8,320 \\
8,200 \\
8,160\end{array}$ \\
\hline
\end{tabular}

Supplemental records.- Dec. 16, $9: 30$ a.m., 24.75 ft., 15,300 sec.-ft. Dec. 18, 3 a.m., $22.15 \mathrm{ft}, 12,600$ sec.-ft; 7 p.m., $22.60 \mathrm{ft.}, 13,100$ sec.-ft; 9 p.m., $20.90 \mathrm{ft}$, 11,400 sec.-ft. Dec. 23, 1 a.m., 17.85 ft., 8,680 sec.-ft. Dec. 24, 7 p.m., 16.45 ft., 7,560 sec.-ft. Dec. 25,1 a.m., 18.55 ft., 9,300 sec.-ft. 
Indian Creek near Crescent Mills, Galif.

Location. - Lat. $40^{\circ} 05^{\prime}$, long. $120^{\circ} 56^{\prime}$, in SW $\frac{1}{4}$ sec. 25, T. 26 N., R. 9 E., 0.8 mile above mouth of Dixle Creek and about $1 \frac{1}{2}$ mlles below Crescent Milis, Plumes County. Altitude, about 3,500 feet above mean sea level.

Drainage area. - 746 square miles.

Gage-height record.- Water-stage recorder graph.

Stage-discharge relation. - Defined by current-meter measurements below 5,500 secondfeet; extended to peak stage on bas $1 \mathrm{~s}$ of area-velocity study. Rating curve changed at peak stage.

Haxima.- December 1937: Discharge, 11,500 second-feet 3 a.m. Dec. 12 (gage height, 15.00 feet).

1906-9, i911-18, 1930-November 1937: Discharge, about 11,700 second-feet Mar. 19, 1907 (gage helght, 20.2 feet, from floodmark, former site and datum, 500 feet upstream), from rating curve extended above 3,200 second-feet.

Remarks.- Flood run-off not affected by artificlal storage or irrigation diversions in Indian and Genesee Valleys.

Mean deily discharge, in second-feet, November 1937 to January 1938

\begin{tabular}{|c|c|c|c||c|c|c|c||c|c|c|c|}
\hline Day & Nov. & Dec. & Jan. & Day & Nov. & Dec. & Jan. & Day & Nov. & Dec. & Jan. \\
\hline 1 & 33 & 195 & 330 & 11 & 64 & 6,970 & 243 & 21 & 980 & 600 & 502 \\
2 & 33 & 180 & 344 & 12 & 82 & 10,600 & 241 & 22 & 860 & 520 & 468 \\
3 & 33 & 169 & 379 & 13 & 66 & 6,450 & 245 & 23 & 752 & 502 & 468 \\
4 & 33 & 160 & 367 & 14 & 76 & 3,170 & 245 & 24 & 860 & 434 & 415 \\
5 & 34 & 148 & 338 & 15 & 81 & 2,060 & 379 & 25 & 729 & 418 & 397 \\
6 & 34 & 140 & 304 & 16 & 114 & 1,560 & 418 & 26 & 530 & 391 & 388 \\
7 & 36 & 134 & 276 & 17 & 357 & 1,240 & 520 & 27 & 382 & 367 & 376 \\
8 & 36 & 131 & 259 & 18 & 354 & 1,030 & 720 & 28 & 300 & 350 & 373 \\
9 & 35 & 139 & 256 & 19 & 258 & 855 & 670 & 29 & 254 & 327 & 367 \\
10 & 34 & 789 & 252 & 20 & 454 & 695 & 580 & 30 & 215 & 322 & 350 \\
\end{tabular}

Gage height, in feet, and discharge, in second-feet, at indicated time, 1937

\begin{tabular}{|c|c|c|c|c|c|c|c|c|c|c|c|c|}
\hline \multirow{2}{*}{$\begin{array}{l}5 \\
5 \\
\end{array}$} & Feet & Sec.fti. & Feet & Sec.ft & Feet & Sec.ft. & Feet & Sec.fit. & Feet & Sec.ft. & Feet & Sec.ft. \\
\hline & \multicolumn{2}{|c|}{ December 8} & \multicolumn{2}{|c|}{ December 9} & \multicolumn{2}{|c|}{ December 10} & \multicolumn{2}{|c|}{ December 11} & \multicolumn{2}{|c|}{ December 12} & \multicolumn{2}{|c|}{ December 13} \\
\hline $\begin{array}{r}2 \\
4 \\
6 \\
8 \\
10 \\
\mathrm{~N} \\
2 \\
4 \\
6 \\
8 \\
10 \\
M\end{array}$ & $\begin{array}{c}\overline{-} \\
2.82 \\
\overline{-} \\
2.81 \\
\overline{-} \\
2.81 \\
\overline{-} \\
2.80\end{array}$ & $\begin{array}{c}\overline{-} \\
132 \\
\bar{z} \\
\overline{131} \\
\bar{z} \\
\overline{13} 1 \\
\overline{-} \\
1 \overline{2} 9\end{array}$ & $\begin{array}{l}2.80 \\
- \\
2.80 \\
- \\
2.80 \\
- \\
2.82 \\
- \\
2.97 \\
- \\
3.31\end{array}$ & $\begin{array}{c}\overline{129} \\
\overline{129} \\
\overline{129} \\
\overline{132} \\
\overline{157} \\
\overline{2} \overline{1}\end{array}$ & $\begin{array}{l}3.53 \\
3.69 \\
3.85 \\
4.02 \\
4.25 \\
4.51 \\
4.96 \\
5.38 \\
5.74 \\
6.02 \\
6.29 \\
6.57\end{array}$ & $\begin{array}{r}267 \\
302 \\
341 \\
388 \\
465 \\
575 \\
808 \\
1,060 \\
1,270 \\
1,440 \\
1,600 \\
1,770\end{array}$ & $\begin{array}{r}7.12 \\
7.97 \\
9.00 \\
10.37 \\
11.33 \\
12.24 \\
13.11 \\
13.73 \\
14.22 \\
14.64 \\
14.87 \\
14.96\end{array}$ & $\begin{array}{r}2,130 \\
2,720 \\
3,580 \\
4,960 \\
6,130 \\
7,340 \\
8,560 \\
9,500 \\
10,300 \\
10,900 \\
11,300 \\
11,400\end{array}$ & \begin{tabular}{|l|}
14.98 \\
14.98 \\
14.93 \\
14.81 \\
14.68 \\
14.51 \\
14.31 \\
14.07 \\
13.81 \\
13.52 \\
13.25 \\
12.95
\end{tabular} & $\begin{array}{r}11,500 \\
11,500 \\
11,400 \\
11,300 \\
11,100 \\
10,900 \\
10,600 \\
10,300 \\
9,950 \\
9,580 \\
9,220 \\
8,840\end{array}$ & $\begin{array}{r}12.63 \\
12.30 \\
11.95 \\
11.62 \\
11.29 \\
10.96 \\
10.63 \\
10.30 \\
9.97 \\
9.65 \\
9.35 \\
9.09\end{array}$ & $\begin{array}{l}8,420 \\
8,010 \\
7,590 \\
7,190 \\
6,800 \\
6,400 \\
6,010 \\
5,610 \\
5,240 \\
4,880 \\
4,560 \\
4,270\end{array}$ \\
\hline & \multicolumn{2}{|c|}{ December 14} & \multicolumn{2}{|c|}{ December 15} & \multicolumn{2}{|c|}{ December 16} & \multicolumn{2}{|c|}{ December 17} & \multicolumn{2}{|c|}{ December 18} & \multicolumn{2}{|c|}{ December 19} \\
\hline $\begin{array}{r}2 \\
4 \\
6 \\
8 \\
10 \\
\mathbb{N} \\
2 \\
4 \\
6 \\
8 \\
10 \\
M\end{array}$ & $\begin{array}{l}8.82 \\
8.60 \\
8.40 \\
8.23 \\
8.08 \\
7.93 \\
7.79 \\
7.68 \\
7.57 \\
7.46 \\
7.34 \\
7.24\end{array}$ & $\begin{array}{l}3,990 \\
3,770 \\
3,570 \\
3,400 \\
3,250 \\
3,100 \\
2,970 \\
2,870 \\
2,770 \\
2,670 \\
2,570 \\
2,480\end{array}$ & $\begin{array}{l}- \\
7.03 \\
- \\
6.85 \\
- \\
6.71 \\
- \\
6.60 \\
- \\
6.49 \\
- \\
6.39\end{array}$ & $\begin{array}{l}2, \overline{290} \\
2, \overline{140} \\
2, \overline{0} \\
1, \overline{9} 40 \\
\overline{-} \\
1, \overline{8} 50 \\
1, \overline{7} 70\end{array}$ & $\begin{array}{c}6.29 \\
- \\
6.19 \\
- \\
6.11 \\
- \\
6.03 \\
- \\
5.96 \\
- \\
5.88\end{array}$ & $\begin{array}{l}1, \overline{6} \\
\overline{6} \\
1,620 \\
1, \overline{5} 70 \\
1, \overline{5} 10 \\
\overline{-} \\
1,460 \\
1, \overline{4} 10\end{array}$ & $\begin{array}{c}- \\
5.79 \\
5.72 \\
5 \\
5.65 \\
5.56 \\
- \\
5.50 \\
5.44\end{array}$ & $\begin{array}{l}1, \overline{3} 40 \\
1, \overline{2} 90 \\
1, \overline{2} 40 \\
1, \overline{1} 90 \\
1, \overline{1} 150 \\
\overline{1}, \overline{110}\end{array}$ & $\begin{array}{c}- \\
5.36 \\
\overline{-} \\
5.28 \\
\overline{-} \\
5.21 \\
\overline{-} \\
5.14\end{array}$ & $\begin{array}{c}- \\
\bar{z}, 070 \\
- \\
\bar{z}, 020 \\
\overline{-} \\
\overline{9} 76 \\
\overline{-} \\
\overline{9} 34\end{array}$ & $\begin{array}{c}- \\
5.06 \\
\overline{-} \\
4.99 \\
\overline{-} \\
4.92 \\
\overline{-} \\
4.84\end{array}$ & $\begin{array}{c}- \\
888 \\
- \\
850 \\
\overline{-} \\
8 \overline{11} \\
\overline{-} \\
767\end{array}$ \\
\hline & \multicolumn{2}{|c|}{ December 20} & \multicolumn{2}{|c|}{ December 21} & \multicolumn{2}{|c|}{ December 22} & \multicolumn{2}{|c|}{ December 23} & \multicolumn{2}{|c|}{ December 24} & \multicolumn{2}{|c|}{ December 25} \\
\hline 2 & - & - & - & - & - & - & - & - & - & - & - & - \\
\hline $\begin{array}{l}4 \\
6\end{array}$ & 4.77 & $\overline{730}$ & 4.52 & $6 \overline{00}$ & $\overline{4.32}$ & $5 \overline{28}$ & $\overline{4.27}$ & $5 \overline{10}$ & 4.10 & $4 \overline{50}$ & 4.00 & $4 \overline{18}$ \\
\hline 8 & & $\overline{-}$ & & & & - & & - & - & - & - & - \\
\hline $\begin{array}{r}10 \\
\mathbb{N}\end{array}$ & 4.72 & $\overline{705}$ & 4.48 & $5 \overline{9} 2$ & 4.28 & $5 \overline{13}$ & 4.26 & $5 \overline{06}$ & 4.07 & $4 \overline{40}$ & 4.00 & $4 \overline{18}$ \\
\hline 2 & & 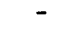 & & & & & & . & & & 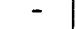 & - \\
\hline 6 & 4.66 & 675 & 4.45 & $5 \overline{80}$ & 4.28 & $5 \overline{13}$ & 4.22 & 492 & 4.02 & $\overline{424}$ & 4.01 & $4 \overline{21}$ \\
\hline & & - & & & & & & & & & & - \\
\hline$M$ & $\overline{4.59}$ & $6 \overline{40}$ & 4.38 & $5 \overline{52}$ & 4.30 & $5 \overline{20}$ & $\overline{4.15}$ & $4 \overline{68}$ & 4.00 & $4 \overline{18}$ & 3.96 & $4 \overline{06}$ \\
\hline
\end{tabular}

Supplemental records.- Dec. 12, 3 a.m., 15.00 ft., 11,500 sec.-ft. 
Spanish Creek at Keddie, Calif.

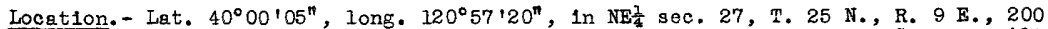
feet above Blackhawk Creek and $0.9 \mathrm{mlle}$ southeast of Kedd1e, Plumas County. Alt1tude, about 3,250 feet above mean sea level.

Drainage area.- 184 square miles.

Gage-he1ght record.- Water-stage recorder graph except for period Nov. 1 to 3:30 p.m. Nov. 17, when It was based on occaslonal gage readings, range of stage indicated on recorder graph, and stage-graph for Indian Creek near Crescent M11ls.

Stage-discharge relation.- Defined by current-meter measurements below 4,500 secondfeet; extended to peak stage by $A \sqrt{d}$ method; verified by area-velocity study. Rating curve changed at peak stage.

ilax1ma.- December 1937: D1scharge, 11,500 second-feet II a.m. Dec. 11 (gage he1ght, 12.43 feet).

1911-November 1937: Discharge, about 11,000 second-feet Mar. 26, 1928 (gage height, 15.5 feet, from floodmarks, former site and datum, $1.2 \mathrm{mlles}$ downstream), from rating curve extended above 900 second-feet.

Remarks.- Flood mun-off not appreclabiy affected by artificial storage or diversions.

Mean dally discharge, in second-feet, November 1937 to January 1938

\begin{tabular}{|c|c|c|c|c|c|c|c|c|c|c|c|}
\hline Day & Nov. & Dec. & Jan. & Day & Nov. & Dec. & Jan. & Dey & Nov. & Dec. & Jan. \\
\hline $\begin{array}{r}1 \\
2 \\
3 \\
4 \\
5 \\
6 \\
7 \\
8 \\
9 \\
10\end{array}$ & $\begin{array}{l}40 \\
40 \\
40 \\
40 \\
40 \\
42 \\
42 \\
40 \\
40 \\
40\end{array}$ & $\begin{array}{r}140 \\
129 \\
121 \\
117 \\
111 \\
106 \\
102 \\
99 \\
108 \\
4,600\end{array}$ & $\begin{array}{l}176 \\
205 \\
208 \\
137 \\
176 \\
168 \\
158 \\
153 \\
149 \\
146\end{array}$ & $\begin{array}{l}11 \\
12 \\
13 \\
14 \\
15 \\
16 \\
17 \\
18 \\
19 \\
20\end{array}$ & $\begin{array}{r}80 \\
88 \\
80 \\
75 \\
80 \\
140 \\
545 \\
237 \\
173 \\
1,190\end{array}$ & $\begin{array}{r}9,610 \\
3,370 \\
1,460 \\
865 \\
649 \\
505 \\
420 \\
361 \\
321 \\
281\end{array}$ & $\begin{array}{l}146 \\
144 \\
142 \\
142 \\
374 \\
305 \\
813 \\
757 \\
532 \\
401\end{array}$ & $\begin{array}{l}21 \\
22 \\
23 \\
24 \\
25 \\
26 \\
27 \\
28 \\
29 \\
30 \\
31\end{array}$ & $\begin{array}{l}845 \\
330 \\
609 \\
736 \\
414 \\
291 \\
234 \\
193 \\
168 \\
151\end{array}$ & $\begin{array}{l}255 \\
255 \\
266 \\
238 \\
228 \\
208 \\
193 \\
190 \\
181 \\
181 \\
181\end{array}$ & $\begin{array}{l}337 \\
341 \\
341 \\
289 \\
266 \\
248 \\
241 \\
245 \\
234 \\
214 \\
440\end{array}$ \\
\hline \multicolumn{9}{|c|}{ 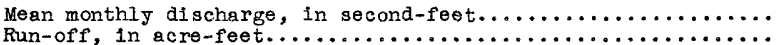 } & 14,010 & $\begin{array}{r}834 \\
51,270\end{array}$ & $\begin{array}{r}280 \\
17,210\end{array}$ \\
\hline
\end{tabular}

Gage helght, In feet, and discharge, in second-feet, at indicated t1me, 1937

\begin{tabular}{|c|c|c|c|c|c|c|c|c|c|c|c|c|}
\hline \multirow{2}{*}{$\begin{array}{l}4 \\
3 \\
0 \\
0\end{array}$} & Feet & sec.ft. & Feet & sec.ft. & Feet & Sec.ft. & Feet & sec.ft. & Feet & Sec.ft. & Feet & Sec.ft. \\
\hline & \multicolumn{2}{|c|}{ December 8} & \multicolumn{2}{|c|}{ December 9} & \multicolumn{2}{|c|}{ December 10} & \multicolumn{2}{|c|}{ December 11} & \multicolumn{2}{|c|}{ December 12} & \multicolumn{2}{|c|}{ December 13} \\
\hline $\begin{array}{r}2 \\
4 \\
6 \\
8 \\
10 \\
\text { N } \\
2 \\
4 \\
6 \\
8 \\
10 \\
M\end{array}$ & $\begin{array}{c}- \\
\overline{-} \\
\overline{-} \\
2.22 \\
\overline{-} \\
\overline{-} \\
\overline{2.24}\end{array}$ & $\begin{array}{c}\overline{-} \\
\overline{-} \\
\overline{-} \\
\overline{9} \\
\overline{-} \\
\overline{-} \\
\overline{-} \\
\overline{101}\end{array}$ & $\begin{array}{l}2.24 \\
2.24 \\
2.23 \\
2.23 \\
2.22 \\
2.22 \\
2.23 \\
2.24 \\
2.26 \\
2.34 \\
2.47 \\
2.70\end{array}$ & $\begin{array}{r}101 \\
101 \\
99 \\
99 \\
97 \\
97 \\
99 \\
101 \\
104 \\
119 \\
146 \\
208\end{array}$ & $\begin{array}{r}3.02 \\
3.44 \\
3.87 \\
4.40 \\
4.85 \\
5.45 \\
7.20 \\
9.14 \\
11.67 \\
12.19 \\
11.87 \\
11.52\end{array}$ & \begin{tabular}{|r|}
322 \\
512 \\
776 \\
1,160 \\
1,540 \\
2,120 \\
4,140 \\
6,700 \\
10,400 \\
11,200 \\
10,700 \\
10,200 \\
\end{tabular} & $\begin{array}{r}11.42 \\
11.39 \\
11.64 \\
12.12 \\
12.36 \\
12.37 \\
11.97 \\
11.41 \\
10.57 \\
9.75 \\
8.87 \\
8.29\end{array}$ & $\begin{array}{r}10,000 \\
9,980 \\
10,400 \\
11,100 \\
11,400 \\
11,500 \\
10,900 \\
10,000 \\
8,760 \\
7,590 \\
6,360 \\
5,600\end{array}$ & $\begin{array}{l}7.84 \\
7.44 \\
7.05 \\
6.76 \\
6.50 \\
6.31 \\
6.13 \\
5.95 \\
5.78 \\
5.55 \\
5.46 \\
5.32\end{array}$ & $\begin{array}{l}5,010 \\
4,490 \\
4,020 \\
3,670 \\
3,370 \\
3,160 \\
2,960 \\
2,760 \\
2,580 \\
2,340 \\
2,250 \\
2,110\end{array}$ & $\begin{array}{l}5.18 \\
5.04 \\
4.89 \\
4.77 \\
4.64 \\
4.55 \\
4.49 \\
4.43 \\
4.38 \\
4.33 \\
4.27 \\
4.20\end{array}$ & $\begin{array}{l}1,970 \\
1,830 \\
1,680 \\
1,570 \\
1,460 \\
1,380 \\
1,320 \\
1,270 \\
1,220 \\
1,180 \\
1,120 \\
1,060\end{array}$ \\
\hline & \multicolumn{2}{|c|}{ December 14} & \multicolumn{2}{|c|}{ December 15} & \multicolumn{2}{|c|}{ December 16} & \multicolumn{2}{|c|}{ December 17} & \multicolumn{2}{|c|}{ December 18} & \multicolumn{2}{|c|}{ December 19} \\
\hline $\begin{array}{r}2 \\
4 \\
6 \\
8 \\
10 \\
N \\
2 \\
4 \\
6 \\
8 \\
10 \\
M\end{array}$ & $\begin{array}{l}4.14 \\
4.11 \\
4.07 \\
4.03 \\
3.99 \\
3.95 \\
3.92 \\
3.90 \\
3.86 \\
3.83 \\
3.79 \\
3.76\end{array}$ & \begin{tabular}{|r|}
1,010 \\
984 \\
951 \\
919 \\
888 \\
858 \\
835 \\
820 \\
792 \\
771 \\
744 \\
724
\end{tabular} & $\begin{array}{c}- \\
3.71 \\
- \\
3.67 \\
- \\
3.64 \\
- \\
3.59 \\
- \\
3.54 \\
\tilde{3.49}\end{array}$ & $\begin{array}{c}\overline{6} \\
6 \overline{2} \\
\overline{6} \\
\overline{67} \\
\overline{649} \\
\overline{-} \\
6 \overline{19} \\
\overline{5} \\
\overline{89} \\
\overline{5} \overline{60}\end{array}$ & $\begin{array}{c}- \\
- \\
3.42 \\
- \\
- \\
3.38 \\
- \\
\overline{3.34} \\
- \\
- \\
3.29\end{array}$ & $\begin{array}{c}- \\
\overline{-} \\
521 \\
- \\
- \\
5 \overline{0} 0 \\
- \\
- \\
4 \overline{80} \\
- \\
\overline{455}\end{array}$ & $\begin{array}{c}- \\
- \\
3.25 \\
- \\
- \\
3.21 \\
- \\
- \\
3.17 \\
- \\
- \\
3.15\end{array}$ & $\begin{array}{c}\overline{-} \\
\overline{3} 5 \\
- \\
\overline{4} \\
\overline{-} \\
\overline{3} \\
\overline{-} \\
\overline{3} \overline{88}\end{array}$ & $\begin{array}{c}- \\
\overline{3.12} \\
- \\
\overline{3.09} \\
\overline{-} \\
3.06 \\
\overline{-} \\
3.04\end{array}$ & $\begin{array}{c}\overline{-} \\
3 \overline{7} \\
\overline{-} \\
\overline{361} \\
\overline{-} \\
349 \\
- \\
\overline{341}\end{array}$ & $\begin{array}{c}- \\
- \\
3.00 \\
- \\
\overline{2.97} \\
- \\
\overline{2.96} \\
- \\
\overline{2.94}\end{array}$ & $\begin{array}{c}\overline{-} \\
325 \\
- \\
\overline{313} \\
- \\
\overline{309} \\
- \\
\overline{301}\end{array}$ \\
\hline & \multicolumn{2}{|c|}{ December 20} & \multicolumn{2}{|c|}{ December 21} & \multicolumn{2}{|c|}{ December 22} & \multicolumn{2}{|c|}{ December 23} & \multicolumn{2}{|c|}{ December 24} & \multicolumn{2}{|c|}{ December 25} \\
\hline $\begin{array}{r}2 \\
4 \\
6 \\
8 \\
10 \\
N \\
2 \\
4 \\
6 \\
8 \\
10 \\
M\end{array}$ & $\begin{array}{c}- \\
\overline{2} \\
2.91 \\
\bar{z} \\
2.89 \\
- \\
2.88 \\
- \\
\overline{2.86}\end{array}$ & $\begin{array}{c}- \\
2 \overline{89} \\
\overline{-} \\
2 \overline{81} \\
\overline{-} \\
2 \overline{7} 8 \\
- \\
2 \overline{7} 0\end{array}$ & $\begin{array}{c}- \\
= \\
= \\
= \\
2.81 \\
= \\
= \\
= \\
2.82\end{array}$ & $\begin{array}{c}\overline{-} \\
\overline{-} \\
\overline{-} \\
252 \\
- \\
- \\
- \\
- \\
255\end{array}$ & $\begin{array}{c}- \\
2.81 \\
- \\
2.79 \\
- \\
2.77 \\
- \\
2.81 \\
- \\
2.91 \\
- \\
2.95\end{array}$ & $\begin{array}{c}\overline{25 \overline{2}} \\
- \\
2 \overline{45} \\
\overline{238} \\
- \\
2 \overline{5} \\
- \\
2 \overline{89} \\
\overline{305}\end{array}$ & $\begin{array}{c}- \\
- \\
2.87 \\
- \\
- \\
2.83 \\
- \\
- \\
2.83 \\
- \\
- \\
2.81\end{array}$ & $\begin{array}{c}- \\
274 \\
- \\
259 \\
- \\
259 \\
- \\
252\end{array}$ & $\begin{array}{c}- \\
- \\
- \\
- \\
2.76 \\
- \\
- \\
- \\
- \\
2.75\end{array}$ & $\begin{array}{c}\overline{-} \\
\overline{-} \\
\overline{-} \\
\overline{23} 4 \\
- \\
\overline{-} \\
\overline{-} \\
\overline{2} \overline{3}\end{array}$ & $\begin{array}{c}- \\
- \\
- \\
- \\
2.73 \\
- \\
- \\
- \\
- \\
2.72\end{array}$ & $\begin{array}{c}\overline{-} \\
\overline{-} \\
\overline{-} \\
2 \overline{2} 4 \\
- \\
\overline{-} \\
\overline{2} \\
\overline{2} \overline{2}\end{array}$ \\
\hline
\end{tabular}

Supplemental records.- Dec. 11, 11 a.m., $12.43 \mathrm{ft}, 11,500$ sec.-ft. 
Bucks Creek storage reservoir near Bucks ranch, Calif.

Location. - Lst. $39^{\circ} 54^{\prime}$, long. $121^{\circ} 12^{\prime}$, in $W^{2} \frac{2}{4}$ sec. 33 , T. 24 N., R. $7 \mathrm{E}$, at dam on Bucks Creek 2 miles northwest of former Bucks ranch and 15 miles west of Quincy, Plumas County. Zero of gage is at mean sea level.

Drainage area.- 28 square miles.

Gage-height record. - Water-stage recorder graph. Elevations at midnight used to determine contents.

Remarks.- Flood run-off completely controlled in reservolr (capacity, 101,650 acre-feet at elevation of crest of spillway, 5, 154.85 feet). See record for Bucks Creek, at Bucks Creek storage reservoir. Basic data furnished by Pacific Gas Electric Co.

Elevation and contents, November 1937 to January 1938

\begin{tabular}{|c|c|c|c|c|c|c|}
\hline \multirow[b]{2}{*}{ Day } & \multicolumn{2}{|c|}{ November } & \multicolumn{2}{|c|}{ December } & \multicolumn{2}{|c|}{ January } \\
\hline & $\begin{array}{l}\text { Elevation } \\
\text { (feet) }\end{array}$ & $\begin{array}{l}\text { Contents } \\
(\text { acre-feet })\end{array}$ & $\begin{array}{l}\text { Elevation } \\
\text { (feet) }\end{array}$ & $\begin{array}{l}\text { Contents } \\
(\text { acre-feet })\end{array}$ & $\begin{array}{c}\text { Elevation } \\
\text { (feet) }\end{array}$ & $\begin{array}{l}\text { Contents } \\
\text { (acre-feet) }\end{array}$ \\
\hline $\begin{array}{l}1 \\
2 \\
3 \\
4 \\
5\end{array}$ & $\begin{array}{l}5,138.00 \\
5,137.75 \\
5,137.45 \\
5,137.15 \\
5,136.95\end{array}$ & $\begin{array}{l}72,621 \\
72,216 \\
71,730 \\
71,244 \\
70,920\end{array}$ & $\begin{array}{l}5,138.9 \\
5,138.85 \\
5,138.95 \\
5,139.0 \\
5,139.1\end{array}$ & $\begin{array}{l}74,089 \\
74,008 \\
74,170 \\
74,252 \\
74,416\end{array}$ & $\begin{array}{l}5,147.55 \\
5,147.4 \\
5,147.25 \\
5,147.1 \\
5,146.95\end{array}$ & $\begin{array}{l}88,665 \\
88,406 \\
88,145 \\
87,885 \\
87,626\end{array}$ \\
\hline $\begin{array}{r}6 \\
7 \\
8 \\
9 \\
10\end{array}$ & $\begin{array}{l}5,136.65 \\
5,136.35 \\
5,136.0 \\
5,135.65 \\
5,135.5\end{array}$ & $\begin{array}{l}70,437 \\
69,955 \\
69,392 \\
68,833 \\
68,594\end{array}$ & $\begin{array}{l}5,139.0 \\
5,139.0 \\
5,138.9 \\
5,138.8 \\
5,140.6\end{array}$ & $\begin{array}{l}74,252 \\
74,252 \\
74,089 \\
73,926 \\
76,886\end{array}$ & $\begin{array}{l}5,146.85 \\
5,146.7 \\
5,146.45 \\
5,146.15 \\
5,145.75\end{array}$ & $\begin{array}{l}87,454 \\
87,195 \\
86,764 \\
86,248 \\
85,561\end{array}$ \\
\hline $\begin{array}{l}11 \\
12 \\
13 \\
14 \\
15\end{array}$ & $\begin{array}{l}5,135 \cdot 4 \\
5,135 \cdot 15 \\
5,135 \cdot 0 \\
5,135.2 \\
5,135 \cdot 3\end{array}$ & $\begin{array}{l}68,434 \\
68,035 \\
67,795 \\
68,114 \\
68,274\end{array}$ & $\begin{array}{l}5,145.4 \\
5,147 \cdot 45 \\
5,148 \cdot 75 \\
5,149 \cdot 45 \\
5,149.5\end{array}$ & $\begin{array}{l}84,962 \\
88,492 \\
90,755 \\
91,983 \\
92,071\end{array}$ & $\begin{array}{l}5,145 \cdot 35 \\
5,145.05 \\
5,144.95 \\
5,145.15 \\
5,145.3\end{array}$ & $\begin{array}{l}84,876 \\
84,362 \\
84,192 \\
84,533 \\
84,791\end{array}$ \\
\hline $\begin{array}{l}16 \\
17 \\
18 \\
19 \\
20\end{array}$ & $\begin{array}{l}5,135 \cdot 4 \\
5,135.55 \\
5,135.7 \\
5,136.15 \\
5,137.0\end{array}$ & $\begin{array}{l}68,434 \\
68,674 \\
68,913 \\
69,633 \\
71,001\end{array}$ & $\begin{array}{l}5,149.45 \\
5,149.35 \\
5,149.15 \\
5,149.05 \\
5,149.0\end{array}$ & $\begin{array}{l}91,983 \\
91,807 \\
91,450 \\
91,280 \\
91,192\end{array}$ & $\begin{array}{l}5,145.55 \\
5,145.85 \\
5,145.9 \\
5,146.15 \\
5,146.35\end{array}$ & $\begin{array}{l}85,218 \\
85,733 \\
85,818 \\
86,247 \\
86,592\end{array}$ \\
\hline $\begin{array}{l}21 \\
22 \\
23 \\
24 \\
25\end{array}$ & $\begin{array}{l}5,137.3 \\
5,137.6 \\
5,137.9 \\
5,138.2 \\
5,138.4\end{array}$ & $\begin{array}{l}71,487 \\
71,973 \\
72,459 \\
72,947 \\
73,273\end{array}$ & $\begin{array}{l}5,148.8 \\
5,148.6 \\
5,148.55 \\
5,148.45 \\
5,148.35\end{array}$ & $\begin{array}{l}90,843 \\
90,494 \\
90,406 \\
90,231 \\
90,057\end{array}$ & $\begin{array}{l}5,146.45 \\
5,146.55 \\
5,146.7 \\
5,146.8 \\
5,146.75\end{array}$ & $\begin{array}{l}86,764 \\
86,937 \\
87,195 \\
87,367 \\
87,281\end{array}$ \\
\hline $\begin{array}{l}26 \\
27 \\
28 \\
29 \\
30 \\
31\end{array}$ & $\begin{array}{l}5,138.6 \\
5,138.7 \\
5,138.7 \\
5,138.7 \\
5,138.7\end{array}$ & $\begin{array}{l}73,600 \\
73,763 \\
73,763 \\
73,763 \\
73,763\end{array}$ & $\begin{array}{l}5,148.35 \\
5,148.3 \\
5,148.1 \\
5,147.95 \\
5,147.85 \\
5,147.75\end{array}$ & $\begin{array}{l}90,057 \\
89,970 \\
89,621 \\
89,360 \\
89,186 \\
89,008\end{array}$ & $\begin{array}{l}5,146.6 \\
5,146.6 \\
5,146.75 \\
5,146.8 \\
5,146.85 \\
5,146.95\end{array}$ & $\begin{array}{l}87,023 \\
87,023 \\
87,281 \\
87,367 \\
87,454 \\
87,626\end{array}$ \\
\hline
\end{tabular}


Bucks Creek at Bucks Creek storage reservolr, Cal1f.

Location.- Lat. $39^{\circ} 54^{\prime}$, long. $121^{\circ} 12^{\prime}$, in Nite sec. 33 , T. 24 N., R. 7 F., at dam on Bucks Creek 2 miles northwest of former Bucks Ranch and 15 miles west of quincy, Plumas County. Altitude, about 5,000 feet above mean sea level.

Drainage area.- 28 square miles.

Maxima.- December 1937: Discharge regulated to maximum of 238 second-feet. Maximum discharge adjusted for changes in storage, about 5,500 second-feet 3 to 6 .m. Dec. 11 .

Remarks.- Flood run-off completely regulated in Bucks Creek storage reservolr (capacity, 101,650 acre-feet). Dally records of storage and release (observed discharge) furnished by Paciflc Gas Electrlc Co. Dally and monthly discharges adjusted for changes in storage. See record for Bucks Creek storage reservolr.

Discharge and gain or loss in storage, December 1937

\begin{tabular}{|c|c|c|c|c|c|c|c|c|c|}
\hline Day & $\begin{array}{l}\text { Observed } \\
\text { discharge } \\
\text { (sec.-ft.) }\end{array}$ & $\begin{array}{c}\text { Gain or loss } \\
\text { In } s \text { torage } \\
(\text { acre-feet) }\end{array}$ & $\begin{array}{l}\text { Ad justed } \\
\text { discharge } \\
(\text { sec.-ft. })\end{array}$ & Day & $\begin{array}{l}\text { Observed } \\
\text { discharge } \\
(\text { sec.-ft.) }\end{array}$ & $\begin{array}{l}\text { Gain or } \\
\text { In stor } \\
\text { (acre-f }\end{array}$ & $\begin{array}{l}\text { loss } \\
\text { cage } \\
\text { (e日t) }\end{array}$ & & $\begin{array}{l}\text { djusted } \\
\text { Ischarge } \\
\theta \text { c.-ft。) }\end{array}$ \\
\hline $\begin{array}{l}1 \\
2 \\
3 \\
4 \\
5\end{array}$ & $\begin{array}{l}0 \\
0 \\
0 \\
0 \\
0\end{array}$ & $\begin{array}{r}+326 \\
-81 \\
+162 \\
+82 \\
+164\end{array}$ & $* 41$ & $\begin{array}{l}16 \\
17 \\
18 \\
19 \\
20\end{array}$ & $\begin{array}{l}238 \\
238 \\
238 \\
238 \\
238\end{array}$ & $\begin{array}{r}-88 \\
-176 \\
-357 \\
-170 \\
-88\end{array}$ & & & $\begin{array}{r}194 \\
149 \\
58 \\
152 \\
194\end{array}$ \\
\hline $\begin{array}{r}6 \\
7 \\
8 \\
9 \\
10\end{array}$ & $\begin{array}{r}0 \\
0 \\
166 \\
238 \\
76\end{array}$ & $\begin{array}{r}-164 \\
0 \\
-163 \\
-163 \\
+2,960\end{array}$ & $\begin{array}{r}156 \\
1,570\end{array}$ & $\begin{array}{l}21 \\
22 \\
23 \\
24 \\
26\end{array}$ & $\begin{array}{l}238 \\
238 \\
238 \\
238 \\
238\end{array}$ & $\begin{array}{r}-349 \\
-349 \\
-88 \\
-175 \\
-174\end{array}$ & & & $\begin{array}{r}62 \\
62 \\
194 \\
150 \\
150\end{array}$ \\
\hline $\begin{array}{l}11 \\
12 \\
13 \\
14 \\
15\end{array}$ & $\begin{array}{r}0 \\
0 \\
0 \\
0 \\
154\end{array}$ & $\begin{array}{r}+8,076 \\
+3,530 \\
+2,263 \\
+1,228 \\
+88\end{array}$ & $\begin{array}{r}4,070 \\
1,780 \\
1,140 \\
619 \\
198\end{array}$ & $\begin{array}{l}26 \\
27 \\
28 \\
29 \\
30 \\
31\end{array}$ & $\begin{array}{l}238 \\
238 \\
238 \\
238 \\
238 \\
238\end{array}$ & $\begin{array}{r}0 \\
-87 \\
-349 \\
-261 \\
-174 \\
-178\end{array}$ & & & $\begin{array}{r}238 \\
194 \\
62 \\
106 \\
150 \\
148\end{array}$ \\
\hline \multirow[b]{2}{*}{$\begin{array}{l}\text { Mean } \\
\text { Gain } \\
\text { Mean } \\
\text { Run= }\end{array}$} & \multirow{2}{*}{\multicolumn{2}{|c|}{$\begin{array}{l}\text { monthly discharge, } \\
\text { or loss in storage, } \\
\text { monthly discharge, } \\
\text { of , in acre-feet }\end{array}$}} & \multirow{2}{*}{\multicolumn{2}{|c|}{ 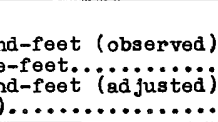 }} & & November & \multicolumn{2}{|c|}{ December } & Jamuary \\
\hline & & & & & & $\begin{array}{r}114 \\
+408 \\
121 \\
7,200\end{array}$ & \multicolumn{2}{|c|}{$\begin{array}{r}143 \\
+15,240 \\
391 \\
24,060\end{array}$} & $\begin{array}{r}106 \\
-1,380 \\
83.1 \\
5,110\end{array}$ \\
\hline
\end{tabular}

*Hean for the period. 
Grizzly Creek near Storrle, Callf.

Location.- Lat. $39^{\circ} 52^{\prime}$, long. $121^{\circ} 14^{\prime}$, in swt sec. 5, T. 23 N., R. 7 E., about 2,000 feet above outlet of tunnel from Bucks Creek and 6 mlles southeast of Storrie, Plumas County. Alt1tude, about 4,900 feet above mean sea level.

Drainage area.- 6.2 square miles.

Gage-helght recorr. - Water-stage recorder graph except for period 8 a.m. Jan. 2 to 9 a.m. Jan. 5, when there was no record. Stage graph for Jan. 2 and 5 based on partial recorder graph.

Stage-discharge relation.- Defined by current-meter measurements below 150 second-feet; extended to peak stage on bas1s of area-velocity study; verified by extension of rating curve for discontinued station below Bucks Creek Tunnel, which is well defined to 600 second-feet. Rating curve changed at peak stage.

Maxima.- December 1937: Discharge, 1,570 second-feet 11 a.m. Dec. 10 (gage he1ght, 7.20 feet).

1929-1932, 1934-November 1937: D1scharge, about 1,000 second-feet Dec. 12, 1929 (gage helght, 4.85 feet, from floodmerk 1n well), and Feb. 2l, 1936 (gage helght, 4.86 feet , from rating curve extended above 150 second-feet.

Remarks. - Flood mu-off not affected by artificlal storage or diversion. Discharge for perlod of missing gage-height record, Jan. 3-4, interpolated. Part of basic data furnished by Pacific Gas Blectric Co.

Wean dally discharge, in second-feet, November 1937 to January 1938

\begin{tabular}{|c|c|c|c|c|c|c|c|c|c|c|c|}
\hline Day & Nov. & Dec. & Jan. & Day & Nov. & Dec. & Jan. & Day & Nov. & Dec. & Jan. \\
\hline 1 & 1.8 & 17 & 7.5 & 11 & 12 & 569 & 7.5 & 21 & 81 & 14 & 19 \\
2 & 1.6 & 15 & 14 & 12 & 8 & 167 & 8 & 22 & 48 & 12 & 24 \\
3 & 1.5 & 14 & 12 & 13 & 5 & 84 & 8.5 & 23 & 140 & 13 & 25 \\
4 & 1.4 & 14 & 11 & 14 & 31 & 58 & 10 & 24 & 68 & 15 & 21 \\
5 & 1.3 & 13 & 10 & 15 & 20 & 45 & 46 & 25 & 43 & 12 & 20 \\
6 & 1.4 & 13 & 9.5 & 16 & 90 & 37 & 22 & 26 & 33 & 12 & 20 \\
7 & 1.6 & 12 & 9 & 17 & 126 & 30 & 41 & 27 & 26 & 9.5 & 20 \\
8 & 1.5 & 12 & 8 & 18 & 38 & 24 & 34 & 28 & 22 & 9 & 20 \\
9 & 1.5 & 106 & 8 & 19 & 106 & 16 & 25 & 29 & 20 & 8.5 & 19 \\
10 & 1.7 & 1,090 & 8 & 20 & 275 & 14 & 21 & 30 & 18 & 8.5 & 19 \\
\end{tabular}

Gage height, in feet, and discharge, in second-feet, at indicated time, 1937

\begin{tabular}{|c|c|c|c|c|c|c|c|c|c|c|c|c|}
\hline \multirow{2}{*}{$\begin{array}{l} \\
\\
\end{array}$} & Feet & Sec.ft. & Feet & Sec.ft. & Feet & sec.ft. & Feet & Sec.ft. & Feet & Sec.ft. & Feet & sec.ft. \\
\hline & \multicolumn{2}{|c|}{ December 8} & \multicolumn{2}{|c|}{ December 9} & \multicolumn{2}{|c|}{ December 10} & \multicolumn{2}{|c|}{ December 11} & \multicolumn{2}{|c|}{ December 12} & \multicolumn{2}{|c|}{ December 13} \\
\hline \begin{tabular}{r|}
2 \\
4 \\
6 \\
8 \\
10 \\
$\mathbb{N}$ \\
2 \\
4 \\
6 \\
8 \\
10 \\
$\mathbf{M}$
\end{tabular} & $\begin{array}{c}= \\
= \\
- \\
- \\
1.57 \\
= \\
= \\
= \\
1.57\end{array}$ & $\begin{array}{l}= \\
= \\
i 2 \\
= \\
= \\
i\end{array}$ & $\begin{array}{l}1.57 \\
1.57 \\
1.57 \\
1.57 \\
1.58 \\
1.68 \\
1.97 \\
2.48 \\
2.96 \\
3.43 \\
3.55 \\
4.70\end{array}$ & $\begin{array}{r}12 \\
12 \\
12 \\
12 \\
12 \\
18 \\
40 \\
95 \\
175 \\
273 \\
300 \\
606 \\
\end{array}$ & $\begin{array}{l}5.91 \\
6.48 \\
6.52 \\
6.13 \\
6.80 \\
6.23 \\
6.10 \\
5.37 \\
6.10 \\
5.70 \\
6.03 \\
5.90\end{array}$ & $\begin{array}{r}1,020 \\
1,250 \\
1,270 \\
1,110 \\
1,390 \\
1,150 \\
1,100 \\
824 \\
1,100 \\
940 \\
1,070 \\
1,020\end{array}$ & $\begin{array}{l}5.68 \\
5.20 \\
5.36 \\
5.48 \\
5.28 \\
4.12 \\
3.93 \\
3.66 \\
3.61 \\
3.60 \\
3.53 \\
3.38\end{array}$ & $\begin{array}{l}933 \\
766 \\
821 \\
863 \\
793 \\
443 \\
394 \\
328 \\
316 \\
314 \\
299 \\
266 \\
\end{array}$ & $\begin{array}{l}3.25 \\
3.16 \\
3.08 \\
3.00 \\
2.91 \\
2.85 \\
2.78 \\
2.71 \\
2.65 \\
2.60 \\
2.56 \\
2.51\end{array}$ & \begin{tabular}{|l|}
240 \\
222 \\
206 \\
190 \\
174 \\
163 \\
151 \\
140 \\
130 \\
122 \\
116 \\
109 \\
\end{tabular} & $\begin{array}{c}- \\
2.43 \\
- \\
2.37 \\
- \\
2.32 \\
- \\
2.26 \\
- \\
2.22 \\
- \\
2.18\end{array}$ & $\begin{array}{l}\overline{98} \\
\overline{90} \\
\overline{84} \\
\overline{77} \\
\overline{72} \\
\overline{68} \\
\end{array}$ \\
\hline & \multicolumn{2}{|c|}{ December 14} & \multicolumn{2}{|c|}{ December 15} & \multicolumn{2}{|c|}{ December 16} & \multicolumn{2}{|c|}{ December 17} & \multicolumn{2}{|c|}{ December 18} & \multicolumn{2}{|c|}{ December 19} \\
\hline $\begin{array}{r}2 \\
4 \\
6 \\
8 \\
80 \\
\mathbb{N} \\
2 \\
4 \\
6 \\
8 \\
10 \\
\mathbf{M}\end{array}$ & $\begin{array}{l}2.15 \\
2.12 \\
- \\
2.09 \\
2.06 \\
- \\
2.04 \\
2.02\end{array}$ & $\begin{array}{l}\overline{64} \\
\overline{60} \\
\overline{5} \\
\overline{54} \\
\overline{5} 2 \\
\overline{50}\end{array}$ & $\begin{array}{c}\overline{-} \\
2.00 \\
= \\
1.97 \\
\overline{-} \\
1.94 \\
= \\
1.93\end{array}$ & $\begin{array}{l}\overline{-} \\
48 \\
= \\
45 \\
\overline{-} \\
42 \\
= \\
41\end{array}$ & $\begin{array}{c}\bar{z} \\
\overline{1.90} \\
\overline{1} \\
1.88 \\
\overline{1} \\
1.86 \\
\overline{1 .} \\
1.84\end{array}$ & $\begin{array}{l}\overline{-} \\
\overline{38} \\
\bar{z} \\
\overline{36} \\
\bar{z} \\
\overline{3} 4 \\
\bar{z} \\
\overline{33}\end{array}$ & $\begin{array}{c}- \\
1.83 \\
\vdots \\
\overline{1.81} \\
\vdots \\
1.79 \\
- \\
\overline{1.77}\end{array}$ & $\begin{array}{l}\overline{-} \\
32 \\
\overline{-} \\
30 \\
\overline{-} \\
28 \\
\overline{-} \\
27\end{array}$ & $\begin{array}{c}- \\
1.76 \\
\overline{1} \\
1.74 \\
\overline{-} \\
1.73 \\
\overline{-} \\
-\end{array}$ & $\begin{array}{l}\overline{-} \\
26 \\
\overline{-} \\
24 \\
\overline{-} \\
23 \\
\overline{-} \\
-\end{array}$ & $\begin{array}{c}\bar{z} \\
\bar{z} \\
\overline{1.62} \\
\bar{z} \\
\bar{z} \\
\overline{1.59}\end{array}$ & $\begin{array}{l}\overline{-} \\
\overline{-} \\
\overline{16} \\
\overline{-} \\
\overline{-} \\
\overline{14}\end{array}$ \\
\hline & \multicolumn{2}{|c|}{ December 20} & \multicolumn{2}{|c|}{ December 21} & \multicolumn{2}{|c|}{ December 22} & \multicolumn{2}{|c|}{ December 23} & \multicolumn{2}{|c|}{ December 24} & \multicolumn{2}{|c|}{ December 25} \\
\hline $\begin{array}{r}2 \\
4 \\
6 \\
8 \\
10 \\
N \\
2 \\
4 \\
6 \\
8 \\
10 \\
M\end{array}$ & $\begin{array}{c}- \\
\overline{-} \\
- \\
\overline{1.59} \\
\overline{-} \\
\overline{-} \\
\overline{1} \\
1.57\end{array}$ & $\begin{array}{l}\bar{z} \\
\overline{1} \\
= \\
= \\
\overline{14}\end{array}$ & $\begin{array}{c}= \\
= \\
= \\
1.58 \\
= \\
= \\
= \\
1.56\end{array}$ & $\begin{array}{l}= \\
= \\
\overline{14} \\
= \\
\bar{z} \\
\bar{z} \\
13\end{array}$ & $\begin{array}{c}= \\
= \\
= \\
\overline{1.55} \\
= \\
= \\
\overline{-} \\
1.56\end{array}$ & $\begin{array}{l}= \\
= \\
= \\
12 \\
= \\
= \\
= \\
13\end{array}$ & $\begin{array}{c}\overline{-} \\
= \\
= \\
1.56 \\
= \\
= \\
\overline{1.55}\end{array}$ & $\begin{array}{l}= \\
= \\
= \\
13 \\
= \\
= \\
= \\
12\end{array}$ & $\begin{array}{c}- \\
\overline{1.53} \\
- \\
\overline{1.60} \\
\overline{-} \\
\overline{1.65} \\
\overline{-} \\
\overline{1.66}\end{array}$ & $\begin{array}{l}\overline{-} \\
12 \\
- \\
\overline{15} \\
\overline{-} \\
18 \\
\overline{1} \\
\overline{19}\end{array}$ & $\begin{array}{c}- \\
1.60 \\
- \\
1.55 \\
- \\
1.55 \\
- \\
3.55 \\
- \\
1.55 \\
- \\
1.54\end{array}$ & $\begin{array}{l}\overline{15} \\
\overline{12} \\
\overline{12} \\
\overline{12} \\
\overline{12} \\
\overline{12}\end{array}$ \\
\hline
\end{tabular}

Supplemental records.. Dec. 10, 11 a.m., 7.20 ft., 1,570 sec.-ft. 
West Branch of Feather R1ver near Yankee H111, Cal1f.

Location. - Lat. $39^{\circ} 42^{\prime}$, long. $121^{\circ} 34^{\prime}$, in SWt sec. 5, T. 21 N., R. 4 B., at highway bridge $1.4 \mathrm{mlles}$ below Concow Creek and 2 mlles west of Yankee H111, But te County. Altitude, about 1,1 co feet above mean sea level.

Draingge area. - 145 square miles.

Gage-helght record. - Water-stage recorder graph except for perlods 8 p.m. Dec. 10 to 9:30 a.m. Dec. 14, 6 p.m. Dec. 21 to about 2 p.m. Jan. 2, when there was no record. Gage read at 4 p.m. Dec. 12 and 7 a.m. Dec. 14. Peak stage obtalned from floodmark. Stage graph for Dec. 14 based on staff gage reading and partial recorder record.

Stage-discharge relation.- Deffned by current-meter measurements below 14,300 secondfeet; extended to peak stage; verifled by area-velocity study and comparison of peak discharge and total run-off of flood with records on Butte, Chico and Concor Creaks. Rating curve chenged at poak stage.

Maxima.- December 1937: Discharge, 21,400 second-feet about 2 a.m. Dec. 11 (gage helght, 30.3 feet).

1930-November 1937: D1scharge, 14,400 second-feet Feb. 21, 1936 (gage helght, 23.6 feet), from rating curve defined to 14,300 second-feet.

Remarks. - Flood run-off probably not materlally affected by artificlal storage or diversion. Discharge for perlods of missing gage-helght record determined from discharge graph based on records for Butte and Concow Creeks.

Mean dally discharge, in second-feet, November 1937 to January 1938

\begin{tabular}{|c|c|r|r|r|r|r|r|r|r|r|r|}
\hline Day & Nov. & Dec. & Jan. & Day & Nov. & Dec. & Jan. & Day & Nov. & Dec. & Jan. \\
\hline 1 & 11 & 230 & 250 & 11 & 192 & 14,500 & 165 & 21 & 1,380 & 522 & 538 \\
2 & 8.5 & 203 & 270 & 12 & 160 & 4,460 & 156 & 22 & 550 & 490 & 490 \\
3 & 7.5 & 186 & 290 & 13 & 52 & 2,120 & 146 & 23 & 1,790 & 470 & 474 \\
4 & 7 & 170 & 254 & 14 & 111 & 1,450 & 146 & 24 & 1,260 & 430 & 388 \\
5 & 7 & 154 & 234 & 15 & 288 & 1,090 & 461 & 25 & 696 & 400 & 340 \\
6 & 7 & 144 & 224 & 16 & 368 & 930 & 403 & 26 & 536 & 360 & 309 \\
7 & 8 & 143 & 210 & 17 & 1,310 & 815 & 1,250 & 27 & 412 & 325 & 293 \\
8 & 8 & 128 & 196 & 18 & 379 & 528 & 815 & 28 & 336 & 320 & 293 \\
9 & 7.5 & 157 & 178 & 19 & 385 & 640 & 510 & 29 & 288 & 280 & 282 \\
10 & 8 & 11,400 & 176 & 20 & 4,120 & 570 & 658 & 30 & 254 & 250 & 251 \\
\end{tabular}

Gage helght, in feet, and discharge, in second-feet, at indicated time, 1937

\begin{tabular}{|c|c|c|c|c|c|c|c|c|c|c|c|c|}
\hline \multirow{2}{*}{$\begin{array}{l}5 \\
0 \\
0\end{array}$} & Feet & Sec.ft. & Feet & sec.ft. & Feet & sec.ft. & Feet & Sec.ft. & Feet & Sec.ft. & Feat & sec.ft. \\
\hline & \multicolumn{2}{|c|}{ December 8} & \multicolumn{2}{|c|}{ December 9} & \multicolumn{2}{|c|}{ December 10} & \multicolumn{2}{|c|}{ December 11} & \multicolumn{2}{|c|}{ December 12} & \multicolumn{2}{|c|}{ December 13} \\
\hline \begin{tabular}{r|}
2 \\
4 \\
6 \\
8 \\
10 \\
$N$ \\
2 \\
4 \\
6 \\
8 \\
10 \\
$\mathbb{M}$
\end{tabular} & $\begin{array}{l}.38 \\
3.34 \\
3.32 \\
3.30 \\
3.30 \\
3.29 \\
3.28 \\
3.27 \\
3.26 \\
3.37 \\
3.39 \\
3.39\end{array}$ & $\begin{array}{l}136 \\
131 \\
128 \\
126 \\
126 \\
125 \\
124 \\
122 \\
121 \\
134 \\
137 \\
137\end{array}$ & $\begin{array}{l}3.38 \\
3.37 \\
3.36 \\
3.36 \\
3.35 \\
3.35 \\
3.35 \\
3.40 \\
3.60 \\
3.75 \\
4.25 \\
5.30\end{array}$ & $\begin{array}{l}136 \\
134 \\
133 \\
133 \\
132 \\
132 \\
132 \\
138 \\
164 \\
185 \\
262 \\
484\end{array}$ & $\begin{array}{r}8.00 \\
10.80 \\
13.30 \\
14.70 \\
17.35 \\
23.50 \\
26.40 \\
25.20 \\
25.00 \\
27.90 \\
29.0 \\
30.0\end{array}$ & $\begin{array}{r}1,420 \\
2,960 \\
4,840 \\
5,960 \\
8,320 \\
14,300 \\
17,200 \\
16,000 \\
15,800 \\
18,800 \\
20,000 \\
21,100\end{array}$ & $\begin{array}{c}30.3 \\
= \\
= \\
= \\
= \\
= \\
= \\
=\end{array}$ & $\begin{array}{r}21,400 \\
21,000 \\
19,000 \\
17,000 \\
15,200 \\
13,800 \\
12,600 \\
11,500 \\
10,400 \\
9,400 \\
8,400 \\
7,400\end{array}$ & $\begin{array}{c}\bar{z} \\
= \\
= \\
= \\
12.48 \\
= \\
= \\
=\end{array}$ & \begin{tabular}{|l}
6,600 \\
6,000 \\
5,400 \\
4,900 \\
4,520 \\
4,180 \\
3,840 \\
3,560 \\
3,380 \\
3,160 \\
2,940 \\
2,720
\end{tabular} & $\begin{array}{l}= \\
= \\
= \\
= \\
= \\
= \\
=\end{array}$ & $\begin{array}{l}2,560 \\
2,420 \\
2,320 \\
2,220 \\
2,160 \\
2,080 \\
2,000 \\
1,950 \\
1,900 \\
1,850 \\
1,800 \\
1,750\end{array}$ \\
\hline & \multicolumn{2}{|c|}{ December 14} & \multicolumn{2}{|c|}{ December 15} & \multicolumn{2}{|c|}{ December 16} & \multicolumn{2}{|c|}{ December 17} & \multicolumn{2}{|c|}{ December 18} & \multicolumn{2}{|c|}{ December 19} \\
\hline $\begin{array}{r}2 \\
4 \\
6 \\
8 \\
8 \\
10 \\
1 \\
2 \\
4 \\
6 \\
8 \\
10 \\
M\end{array}$ & $\begin{array}{c}9.30 \\
--15 \\
9.98 \\
8.98 \\
8.83 \\
-.62 \\
- \\
8.50\end{array}$ & $\begin{array}{l}1, \overline{6} 00 \\
1, \overline{5} 20 \\
1, \overline{4} 40 \\
1, \overline{3} 60 \\
1, \overline{2} 60 \\
1, \overline{2} 10\end{array}$ & $\begin{array}{c}8.41 \\
- \\
8.32 \\
- \\
8.25 \\
- \\
8.17 \\
--11 \\
\overline{8.02}\end{array}$ & $\begin{array}{l}1, \overline{170} \\
1, \overline{1} \\
1, \overline{1} 10 \\
1, \overline{0} \\
1, \overline{0} \\
1, \overline{0} \\
\overline{0}\end{array}$ & $\begin{array}{c}7.96 \\
\vdots \\
\overline{7.81} \\
\vdots \\
\overline{7.68} \\
-\end{array}$ & $\begin{array}{c}994 \\
\overline{-} \\
\overline{9} \\
\overline{-} \\
\overline{-} \\
882 \\
\overline{-}\end{array}$ & $\begin{array}{c}7.58 \\
\overline{-} \\
\overline{7.50} \\
\overline{-} \\
\overline{7.42} \\
\overline{-}\end{array}$ & $\begin{array}{c}843 \\
\overline{-} \\
\overline{815} \\
\overline{-} \\
\overline{-} \\
\overline{-} \\
\overline{-}\end{array}$ & $\begin{array}{l}7.33 \\
= \\
\overline{7.25} \\
= \\
\overline{7.17} \\
=\end{array}$ & $\begin{array}{c}5 \overline{5} 6 \\
\overline{-} \\
\overline{-} \\
\overline{-} \\
\overline{-} \\
\overline{700} \\
\overline{-}\end{array}$ & $\begin{array}{c}7.10 \\
\vdots \\
\overline{7.03} \\
\vdots \\
\overline{0} \\
=\end{array}$ & $\begin{array}{c}675 \\
\overline{-} \\
\overline{-} \\
\overline{-} \\
\overline{-} \\
5 \overline{9} \\
\overline{-}\end{array}$ \\
\hline & \multicolumn{2}{|c|}{ December 20} & \multicolumn{2}{|c|}{ December 21} & \multicolumn{2}{|c|}{ December 22} & \multicolumn{2}{|c|}{ December 23} & \multicolumn{2}{|c|}{ December 24} & \multicolumn{2}{|c|}{ December 25} \\
\hline $\begin{array}{r}2 \\
4 \\
6 \\
8 \\
10 \\
N \\
2 \\
4 \\
6 \\
8 \\
10 \\
M\end{array}$ & $\begin{array}{c}- \\
6.83 \\
\vdots \\
\vdots \\
6.78 \\
\vdots \\
- \\
\vdots .75 \\
-\end{array}$ & $\begin{array}{c}580 \\
= \\
5 \\
564 \\
\overline{-} \\
551 \\
=\end{array}$ & $\begin{array}{c}- \\
6.70 \\
= \\
\overline{6} \\
= \\
= \\
= \\
=\end{array}$ & $\begin{array}{c}5 \overline{38} \\
\overline{-} \\
5 \overline{28} \\
\overline{-} \\
5 \overline{00} \\
\overline{-}\end{array}$ & & & & & & & & \\
\hline
\end{tabular}

Supplemental records.- Dec. 9, 11 p.m., 4.55 ft., 316 sec.-ft. 
Concow Creek near Yankee H111, Cal1f.

Location.- Lat. $39^{\circ} 46^{\prime}$, long. $121^{\circ} 32^{\prime}$, in $\mathrm{NE}^{\frac{1}{4}}$ sec. 16, T. 22 N., R. 4 E., at diversion dam for Spring Valley Ditch, 300 feet below Lake Wilenor Dam and 4 miles north of Yan kee Hill post office, Butte County. Altitude, about 1,850 feet above mean sea level. Drainage area.- 14.7 square miles.

Gage-helght record. - Water-stage recorder graph except for period midnight Dec. 10 to 10 a.m. Dec. 11, when there was no record.

Stage-discharge relation.- Defined by current-meter measurementa below 500 second-feet; extended to peak stage on basis of rating for spiliway of Lake Wilenor Dam.

Naxima.- December 1937: Discharge, 770 second-feet 10 a.m. Dec. I1 (gage helght, 2.44 feet).

1927-November 1937: Discharge, 1,840 second-feet Mar. 26, 1928 (gage he1ght, 5.9 feet), from rating curve extended above 300 second-feet on basis of computation of peak discharge over Lake Wilenor Dam.

Remarks. - Flood mun-off affected by storage in Lake Wilenor. Elevation of crest or spillway is $1,967.0$ feet above mean ser level (capacity, 7,300 acre-feet). Lake started to spill about 2 a.m. Dec. 11. Discharge for period of missing gage-helght record obtained from discharge graph based on changes in storage in Lake wilenor and comparison with records for nearby streams. Discharge adjusted for storage and diversion. Elevation at midnight and corresponding contents in Lake Wilenor determined from graph based on dally readings at about $10 \mathrm{a} . \mathrm{m}$. Part of basic data furnished by Table Mountain and Thermalito Irrigation Districts.

Storage, diversion, and discharge, December 1937

\begin{tabular}{|c|c|c|c|c|c|c|}
\hline \multirow[b]{2}{*}{ Day } & \multicolumn{3}{|c|}{ Leke wilenor } & \multirow{2}{*}{$\begin{array}{c}\text { Spring } \\
\text { Valley Ditch } \\
\text { diversion } \\
\text { (sec.-ft.) }\end{array}$} & \multicolumn{2}{|c|}{ Discharge } \\
\hline & $\begin{array}{l}\text { Elevation } \\
\text { (feet) }\end{array}$ & $\begin{array}{l}\text { Contents } \\
(\operatorname{acr} \theta-f \theta \theta t)\end{array}$ & $\begin{array}{r}\text { Gain or loss } \\
\text { (acre-feet) }\end{array}$ & & $\begin{array}{l}\text { Observed } \\
\text { (sec.-ft.) }\end{array}$ & $\begin{array}{l}\text { Adjusted } \\
(s e c .-f t .)\end{array}$ \\
\hline $\begin{array}{l}1 \\
2 \\
3 \\
4 \\
5\end{array}$ & $\begin{array}{l}1,952.7 \\
1,952.8 \\
1,952.9 \\
1,953.0 \\
1,953.1\end{array}$ & $\begin{array}{l}3,840 \\
3,860 \\
3,880 \\
3,900 \\
3,920\end{array}$ & $\begin{array}{l}+20 \\
+20 \\
+20 \\
+20 \\
+20\end{array}$ & $\begin{array}{r}0.2 \\
.2 \\
.2 \\
.2 \\
.2\end{array}$ & $\begin{array}{l}0 \\
0 \\
0 \\
0 \\
0\end{array}$ & $* 7.5$ \\
\hline $\begin{array}{r}6 \\
7 \\
8 \\
9 \\
10\end{array}$ & $\begin{array}{l}1,953.1 \\
1,953.2 \\
1,953.2 \\
1,954.0 \\
1,964.8\end{array}$ & $\begin{array}{l}3,920 \\
3,940 \\
3,940 \\
4,100 \\
6,650\end{array}$ & $\begin{array}{r}0 \\
+20 \\
0 \\
+160 \\
+2,550\end{array}$ & $\begin{array}{r}.2 \\
.2 \\
.2 \\
.4 \\
2.1\end{array}$ & $\begin{array}{l}0 \\
0 \\
0 \\
0 \\
0\end{array}$ & $\begin{array}{r}81 \\
1,290\end{array}$ \\
\hline $\begin{array}{l}11 \\
12 \\
13 \\
14 \\
15\end{array}$ & $\begin{array}{l}1,968.0 \\
1,967.5 \\
1,967.3 \\
1,967.2 \\
1,967.2\end{array}$ & $\begin{array}{l}7,600 \\
7,450 \\
7,390 \\
7,360 \\
7,360\end{array}$ & $\begin{array}{r}+950 \\
-150 \\
-60 \\
-30 \\
0\end{array}$ & $\begin{array}{r}2.0 \\
.5 \\
.4 \\
.4 \\
.4\end{array}$ & $\begin{array}{r}491 \\
223 \\
102 \\
62 \\
45\end{array}$ & $\begin{array}{r}972 \\
148 \\
72 \\
47 \\
45\end{array}$ \\
\hline $\begin{array}{l}16 \\
17 \\
18 \\
19 \\
20\end{array}$ & $\begin{array}{l}1,967.2 \\
1,967 \cdot 1 \\
1,967.1 \\
1,967.1 \\
1,967.0\end{array}$ & $\begin{array}{l}7,360 \\
7,330 \\
7,330 \\
7,330 \\
7,300\end{array}$ & $\begin{array}{r}0 \\
-30 \\
0 \\
0 \\
-30\end{array}$ & $\begin{array}{r}.4 \\
.4 \\
.4 \\
.4 \\
.4\end{array}$ & $\begin{array}{l}35 \\
29 \\
25 \\
19 \\
19\end{array}$ & $\begin{array}{l}35 \\
14 \\
25 \\
19 \\
43\end{array}$ \\
\hline $\begin{array}{l}21 \\
22 \\
23 \\
24 \\
25\end{array}$ & $\begin{array}{l}1,967.0 \\
1,967.0 \\
1,967.1 \\
1,967.1 \\
1,967.1\end{array}$ & $\begin{array}{l}7,300 \\
7,300 \\
7,330 \\
7,330 \\
7,330\end{array}$ & $\begin{array}{r}0 \\
0 \\
+30 \\
0 \\
0\end{array}$ & $\begin{array}{l}.4 \\
.4 \\
.4 \\
.4 \\
.4\end{array}$ & $\begin{array}{l}14 \\
15 \\
17 \\
19 \\
19\end{array}$ & $\begin{array}{l}14 \\
15 \\
32 \\
19 \\
19\end{array}$ \\
\hline $\begin{array}{l}26 \\
27 \\
28 \\
29 \\
30 \\
31\end{array}$ & $\begin{array}{l}1,967.1 \\
1,967.0 \\
1,967.0 \\
1,967.0 \\
1,967.0 \\
1,967.0\end{array}$ & $\begin{array}{l}7,330 \\
7,300 \\
7,300 \\
7,300 \\
7,300 \\
7,300\end{array}$ & $\begin{array}{r}0 \\
-30 \\
0 \\
0 \\
0 \\
0\end{array}$ & $\begin{array}{l}.4 \\
.4 \\
.4 \\
.4 \\
.4 \\
.4\end{array}$ & $\begin{array}{l}17 \\
16 \\
17 \\
16 \\
16 \\
15\end{array}$ & $\begin{array}{l}17 \\
1.3 \\
17 \\
16 \\
16 \\
15\end{array}$ \\
\hline
\end{tabular}

Observed mean da1ly discharge, in second-feet, November 1937 to January 1938

\begin{tabular}{|c|c|c|c|c|c|c|c|c|c|c|c|}
\hline Day & Nov. & Dec. & Jan. & Day & Nov. & Dec. & Jan. & Day & Nov. & Dec. & Jan. \\
\hline $\begin{array}{r}1 \\
2 \\
3 \\
4 \\
5 \\
6 \\
7 \\
8 \\
9 \\
10\end{array}$ & $\begin{array}{l}0 \\
0 \\
0 \\
0 \\
0 \\
0 \\
0 \\
0 \\
0 \\
0\end{array}$ & $\begin{array}{l}0 \\
0 \\
0 \\
0 \\
0 \\
0 \\
0 \\
0 \\
0 \\
0\end{array}$ & $\begin{array}{l}14 \\
16 \\
16 \\
15 \\
14 \\
15 \\
14 \\
4.7 \\
0.2\end{array}$ & $\begin{array}{l}11 \\
12 \\
13 \\
14 \\
15 \\
16 \\
17 \\
18 \\
19 \\
20\end{array}$ & $\begin{array}{l}0 \\
0 \\
0 \\
0 \\
0 \\
0 \\
0 \\
0 \\
0 \\
0\end{array}$ & $\begin{array}{r}491 \\
223 \\
102 \\
62 \\
45 \\
35 \\
29 \\
25 \\
19 \\
19\end{array}$ & $\begin{array}{r}0 \\
0 \\
0 \\
0 \\
8 \\
24 \\
209 \\
87 \\
77 \\
70\end{array}$ & $\begin{array}{l}21 \\
22 \\
23 \\
24 \\
25 \\
26 \\
27 \\
28 \\
29 \\
30\end{array}$ & $\begin{array}{l}0 \\
0 \\
0 \\
0 \\
0 \\
0 \\
0 \\
0 \\
0 \\
0\end{array}$ & $\begin{array}{l}14 \\
15 \\
17 \\
19 \\
19 \\
17 \\
16 \\
16 \\
17 \\
16 \\
16 \\
15\end{array}$ & $\begin{array}{l}51 \\
43 \\
35 \\
29 \\
24 \\
17 \\
15 \\
14 \\
14 \\
13 \\
81\end{array}$ \\
\hline $\begin{array}{l}\text { Mean } \\
\text { Gain } \\
\text { Mean } \\
\text { Mean } \\
\text { Run-0 }\end{array}$ & $\begin{array}{l}\text { monthly } \\
\text { or loss } \\
\text { monthly } \\
\text { monthly } \\
\text { ff, in }\end{array}$ & $\begin{array}{l}\text { discha } \\
\text { in sto } \\
\text { d1vers } \\
\text { discha } \\
\text { cre-fe }\end{array}$ & $\begin{array}{l}\text { in } \\
\text { in } \mathrm{s} \\
\text { in } \\
\text { ad jus }\end{array}$ & $\begin{array}{l}\text { ag } \\
\text { ond }\end{array}$ & ley & $h, 1$ & . & $\begin{array}{l}\ldots \\
\cdots \\
\ddot{e} \\
\ldots\end{array}$ & $\begin{array}{r}0 \\
+1,840 \\
10.4 \\
41.3 \\
2,460\end{array}$ & $\begin{array}{r}39.7 \\
+3,480 \\
.46 \\
96.8 \\
5,950\end{array}$ & $\begin{array}{r}29.7 \\
+210 \\
8.67 \\
41.6 \\
2,560\end{array}$ \\
\hline
\end{tabular}

* Mean for the period. 
Middle Fork of Feather River near C110, Cal1f.

Location.- Lat. $39^{\circ} 45^{\prime}$, long, $120^{\circ} 36^{\prime}$, in El sec. 23, T. 22 N., R. $12 \mathrm{E} ., 0.3 \mathrm{~m} 1 \mathrm{le}$ above Frazler Creek and li miles northwest of clio, Plumas County. Aititude, about 4,350 feet above mean sea level.

Drainage area. - 699 square miles.

Gage-he1ght record.- Water-stage recorder graph for period Nov. 1-27. No record Nov. 28 to Jan. 31. Peak stage determined from floodmark.

Stage-discharge relation. - Defined by current-meter measurements below 2,600 secondfeet; extended to peak stage on basis of area-velocity study.

Maxima:- December 1937: D1scharge, 5,320 second-feet probably Dec. Il (gage helght, 10. 4 feet).

1925-November 1937: Discharge, 11,000 second-feet Mar. 26, 1928 (gage helght, 12.0 feet), from rating curve extended above 4,750 second-feet.

Remarks.- Flood mun-off not affected by artiflclal storage or diversion. The followIng mean discharges for periods of missing gage-height record were determined from floodmark and discharge graph based on records for Spanish Creek at Koddie and Indlan Creek near Crescent Mills: Dec. 1-9, 80 sec.-ft.; Dec. 10-15, 1,700 sec.-ft.; Dec. 16-31, 170 sec.-ft.

Mean da11y discharge, in second-feet, November 1937 to January 1938

\begin{tabular}{|c|c|c|c|c|c|c|c|c|c|c|c|}
\hline Day & Nov. & Dec. & Jan. & Day & Nov. & Dec. & Jan. & Day & Nov. & Dec. & Jan. \\
\hline $\begin{array}{r}1 \\
2 \\
3 \\
4 \\
5 \\
6 \\
7 \\
8 \\
9 \\
10\end{array}$ & $\begin{array}{l}23 \\
23 \\
23 \\
23 \\
23 \\
24 \\
24 \\
23 \\
23 \\
23\end{array}$ & $\begin{array}{l}- \\
- \\
- \\
- \\
- \\
- \\
- \\
-\end{array}$ & $\begin{array}{l}- \\
- \\
- \\
- \\
- \\
- \\
-\end{array}$ & $\begin{array}{l}11 \\
12 \\
13 \\
14 \\
15 \\
16 \\
17 \\
18 \\
19 \\
20\end{array}$ & $\begin{array}{r}38 \\
41 \\
31 \\
51 \\
38 \\
43 \\
211 \\
86 \\
68 \\
291\end{array}$ & $\begin{array}{l}- \\
\overline{-} \\
\overline{-} \\
\overline{-} \\
- \\
- \\
-\end{array}$ & $\begin{array}{l}- \\
- \\
- \\
- \\
- \\
- \\
- \\
-\end{array}$ & $\begin{array}{l}21 \\
22 \\
23 \\
24 \\
25 \\
26 \\
27 \\
28 \\
29 \\
30 \\
31\end{array}$ & $\begin{array}{l}351 \\
158 \\
153 \\
199 \\
136 \\
114 \\
107 \\
105 \\
102 \\
100\end{array}$ & $\begin{array}{l}\overline{-} \\
\overline{-} \\
\overline{-} \\
\overline{-} \\
\overline{-} \\
- \\
-\end{array}$ & $\begin{array}{l}- \\
\overline{-} \\
\overline{-} \\
\overline{-} \\
- \\
\overline{-} \\
-\end{array}$ \\
\hline \multicolumn{9}{|c|}{ 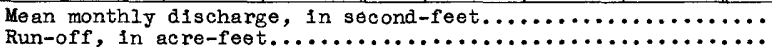 } & $\begin{array}{r}88,5 \\
5,270\end{array}$ & $\begin{array}{r}440 \\
27,050\end{array}$ & $\begin{array}{r}150 \\
9,220\end{array}$ \\
\hline
\end{tabular}

Supplemental records.- Dec. 11, $10.4 \mathrm{ft} ., 5,320$ sec.-ft. 
Middle Fork of Feather River at Bidwell Bar, Calif.

Location.- Lat. $39^{\circ} 33^{\prime}$, long. $121^{\circ} 26^{\prime}$, in Nwe sec. 32, T. 20 N., R. 5 E., at highway bridge at Bldwell Bar, 2 miles above junction with North Fork and 7 miles northeast of Oroville, Butte County. Altitude, about 290 feet above mean sea level.

Drainage area.- 1,353 square miles.

Gage-he1ght record. - Water-stage recorder graph except for pertods 3 a.m. Dec. 11 to 1 p.m. Dec. 12,4 p.m. Dec. 24 to $7: 30$ a.m. Jan. 11, when 1 t was based on peak stage, range of stage 1ndicated on recorder graph, and stage graphs for nearby stations. Peak stage obtalned from floodmarks.

Stage-discharge relation.- Defined by current-meter measurements below 20,000 secondfeet; extended to peak stage; verifled by area-velocity study and AVa method. Ratlng curve changed at peak stage.

Maxima.- December 1937: Discharge, 93,000 second-feet about 6 a.m. Dec. 11 (gage helght, 24.0 feet, from floodmarks).

1911-November 1937: D1scharge, about 90,000 second-feet Mar. 26, 1928 (gage

helght, 22.8 fe日t, from floodmarks), from rating curve extended above 10,500 secondfeet on basis of slope-area computation of flood flow.

Remarks. - Flood mun-off not materially affected by artificlal storage or diversion.

Mean dally discharge, in second-feet, November 1937 to January 1938

\begin{tabular}{|c|c|c|c|c|c|c|c|c|c|c|c|}
\hline Day & Nov. & Dec. & Jan. & Day & Nov. & Dec. & Jan. & Day & Hov. & Dec. & Jan. \\
\hline $\begin{array}{r}9 \\
1 \\
2 \\
3 \\
4 \\
5 \\
6 \\
7 \\
8 \\
9 \\
10\end{array}$ & $\begin{array}{l}233 \\
247 \\
249 \\
247 \\
244 \\
244 \\
252 \\
249 \\
247 \\
244\end{array}$ & \begin{tabular}{r|}
975 \\
895 \\
846 \\
798 \\
774 \\
726 \\
703 \\
680 \\
717 \\
36,700
\end{tabular} & $\begin{array}{l}1,540 \\
1,570 \\
1,600 \\
1,500 \\
1,460 \\
1,430 \\
1,400 \\
1,370 \\
1,370 \\
1,340\end{array}$ & $\begin{array}{l}11 \\
12 \\
13 \\
14 \\
15 \\
16 \\
17 \\
18 \\
19 \\
20\end{array}$ & $\begin{array}{r}462 \\
634 \\
450 \\
625 \\
948 \\
822 \\
3,680 \\
1,810 \\
1,210 \\
6,610\end{array}$ & $\begin{array}{r}72,000 \\
22,500 \\
12,200 \\
7,920 \\
5,620 \\
4,520 \\
3,690 \\
3,250 \\
2,840 \\
2,500\end{array}$ & $\begin{array}{l}1,340 \\
1,280 \\
1,280 \\
1,250 \\
2,020 \\
1,900 \\
4,160 \\
3,580 \\
3,040 \\
2,740\end{array}$ & $\begin{array}{l}21 \\
22 \\
23 \\
24 \\
25 \\
26 \\
27 \\
28 \\
29 \\
30 \\
31\end{array}$ & $\begin{array}{l}4,890 \\
2,290 \\
3,440 \\
3,610 \\
2,340 \\
1,760 \\
1,440 \\
1,270 \\
1,150 \\
1,060\end{array}$ & $\begin{array}{l}2,280 \\
2,190 \\
2,140 \\
2,020 \\
1,900 \\
1,860 \\
1,820 \\
1,740 \\
1,710 \\
1,640 \\
1,570\end{array}$ & $\begin{array}{l}2,460 \\
2,320 \\
2,320 \\
2,100 \\
1,980 \\
1,860 \\
1,820 \\
1,980 \\
1,860 \\
1,740 \\
2,550\end{array}$ \\
\hline \multicolumn{9}{|c|}{ 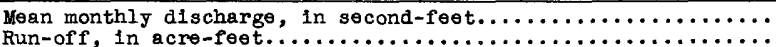 } & $\begin{array}{r}1,432 \\
85,200\end{array}$ & $\begin{array}{r}6,507 \\
400,100\end{array}$ & $\begin{array}{r}1,941 \\
119,300\end{array}$ \\
\hline
\end{tabular}

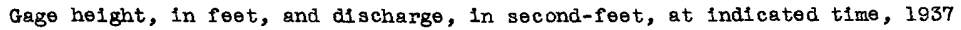

\begin{tabular}{|c|c|c|c|c|c|c|c|c|c|c|c|c|}
\hline \multirow{2}{*}{$\begin{array}{l}5 \\
0 \\
0 \\
\end{array}$} & Feet & Sec.ft. & Feet & sec.ft. & Feet & Sec.ft. & Feet & Sec.ft. & Feet & Sec.ft. & Feet & Sec.ft. \\
\hline & \multicolumn{2}{|c|}{ December 8} & \multicolumn{2}{|c|}{ December 9} & \multicolumn{2}{|c|}{ December 10} & \multicolumn{2}{|c|}{ December 11} & \multicolumn{2}{|c|}{ December 12} & \multicolumn{2}{|c|}{ December 13} \\
\hline $\begin{array}{r}10 \\
\text { N } \\
2 \\
4 \\
6 \\
8 \\
10\end{array}$ & $\begin{array}{c}\overline{-} \\
3.41 \\
\overline{3} \\
\overline{3.40} \\
\overline{-} \\
3.39 \\
\overline{-} \\
3.38\end{array}$ & $\begin{array}{c}\overline{-} \\
685 \\
\overline{-} \\
680 \\
\overline{-} \\
675 \\
\overline{-} \\
671\end{array}$ & $\begin{array}{l}3.38 \\
3.37 \\
3.36 \\
3.36 \\
3.36 \\
3.36 \\
3.37 \\
3.42 \\
3.50 \\
3.60 \\
3.82 \\
4.45\end{array}$ & $\begin{array}{r}671 \\
666 \\
662 \\
662 \\
662 \\
662 \\
666 \\
689 \\
726 \\
774 \\
880 \\
1,240\end{array}$ & $\begin{array}{r}9.90 \\
12.05 \\
13.05 \\
14.42 \\
16.65 \\
20.60 \\
21.65 \\
11.38 \\
22.07 \\
2.25\end{array}$ & $\begin{array}{r}2,140 \\
3,510 \\
8,960 \\
15,000 \\
18,800 \\
25,200 \\
38,200 \\
65,800 \\
74,200 \\
72,000 \\
77,600 \\
79,000\end{array}$ & $\begin{array}{c}21.70 \\
24.0 \\
= \\
= \\
= \\
=\end{array}$ & & $\begin{array}{c}= \\
= \\
= \\
- \\
13.97 \\
13.64 \\
13.37 \\
13.11 \\
12.92 \\
12.83\end{array}$ & & & $\begin{array}{r}14,100 \\
13,600 \\
13,100 \\
12,600 \\
12,200 \\
11,700 \\
11,300 \\
10,800 \\
10,400 \\
10,000 \\
9,630\end{array}$ \\
\hline & \multicolumn{2}{|c|}{ December 14} & \multicolumn{2}{|c|}{ December 15} & \multicolumn{2}{|c|}{ December 16} & \multicolumn{2}{|c|}{ December 17} & \multicolumn{2}{|c|}{ December 18} & \multicolumn{2}{|c|}{ Docember 19} \\
\hline \multirow[t]{2}{*}{\begin{tabular}{r|}
2 \\
4 \\
6 \\
8 \\
10 \\
$\mathrm{~N}$ \\
2 \\
4 \\
6 \\
8 \\
10 \\
$M$
\end{tabular}} & $\begin{array}{c}- \\
10.92 \\
- \\
10.63 \\
10.38 \\
10.14 \\
--90 \\
-- \\
9.68\end{array}$ & $\begin{array}{l}9, \overline{000} \\
8, \overline{3} 80 \\
7, \overline{8} 80 \\
7, \overline{4} 00 \\
6, \overline{9} 60 \\
6, \overline{5} 60\end{array}$ & $\begin{array}{c}- \\
9.48 \\
- \\
9.30 \\
- \\
9.15 \\
- \\
8.97 \\
- \\
8.82 \\
- \\
8.66\end{array}$ & $\begin{array}{l}6, \overline{230} \\
5, \overline{9} 40 \\
5, \overline{700} \\
5, \overline{4} 40 \\
5, \overline{2} 30 \\
5, \overline{0}\end{array}$ & $\begin{array}{l}- \\
8.51 \\
- \\
8.37 \\
- \\
8.26 \\
- \\
8.14 \\
- \\
8.03 \\
- \\
7.92\end{array}$ & $\begin{array}{l}4, \overline{7} 90 \\
\overline{-} \\
400 \\
4, \overline{470} \\
4, \overline{3300} \\
4, \overline{200} \\
4, \overline{0}\end{array}$ & $\begin{array}{c}7.82 \\
- \\
7.73 \\
- \\
7.64 \\
- \\
7.56 \\
- \\
7.49 \\
- \\
7.42\end{array}$ & $\begin{array}{l}3,840 \\
\overline{3} \\
3,730 \\
\overline{-650} \\
3,- \\
3,570 \\
-\end{array}$ & $\begin{array}{c}- \\
7.34 \\
- \\
7.28 \\
7.17 \\
- \\
7.08 \\
7.01 \\
6.94\end{array}$ & $\begin{array}{l}3, \overline{400} \\
3, \overline{3} 40 \\
3, \overline{2} \\
3, \overline{120} \\
3, \overline{0}\end{array}$ & $\begin{array}{c}- \\
6.88 \\
- \\
6.82 \\
- \\
6.78 \\
6.71 \\
6.64 \\
6.59\end{array}$ & $\begin{array}{l}2, \overline{9} 20 \\
2, \overline{8} 60 \\
2, \overline{820} \\
2, \overline{7} 50 \\
2, \overline{6} 80 \\
2, \overline{630} \\
\end{array}$ \\
\hline & \multicolumn{2}{|c|}{ December 20} & \multicolumn{2}{|c|}{ December 21} & \multicolumn{2}{|c|}{ December 22} & \multicolumn{2}{|c|}{ December 23} & \multicolumn{2}{|c|}{ December 24} & \multicolumn{2}{|c|}{ December 25 } \\
\hline $\begin{array}{l}2 \\
4\end{array}$ & $\begin{array}{c}\bar{z} \\
6.54 \\
\overline{6} \\
\overline{6.47} \\
\overline{-} \\
6.37 \\
\overline{-} \\
6.30\end{array}$ & $\begin{array}{c}\overline{-} \\
2, \overline{5} 90 \\
\overline{-} \\
2, \overline{5} 20 \\
\overline{-} \\
2, \overline{4} 30 \\
\overline{-} \\
2, \overline{3} 70\end{array}$ & $\begin{array}{c}\bar{z} \\
6.24 \\
\overline{6} \\
6.21 \\
\overline{6} \\
6.10 \\
\overline{-} \\
6.05\end{array}$ & $\begin{array}{c}\overline{-} \\
2, \overline{320} \\
\overline{-} \\
2, \overline{2} 90\end{array}$ & $\begin{array}{c}- \\
\overline{6.04} \\
- \\
6.02\end{array}$ & $\begin{array}{c}\overline{-} \\
2, \overline{1} 40 \\
\overline{-} \\
2, \overline{1} 20\end{array}$ & $\begin{array}{l}- \\
6.18 \\
6.08 \\
6.01\end{array}$ & $\begin{array}{l}2, \overline{2} 60 \\
2, \overline{170} \\
2, \overline{1} 10\end{array}$ & $\begin{array}{c}5 \\
5.84 \\
- \\
5.84 \\
5.96 \\
5.96 \\
= \\
= \\
=\end{array}$ & $\begin{array}{l}1, \overline{970} \\
1, \overline{970} \\
2, \overline{0} \\
\overline{0} \\
2, \overline{0} 0 \\
2, \overline{0} \\
\overline{-} \\
1, \overline{9} 0\end{array}$ & $\begin{array}{l}= \\
= \\
= \\
= \\
= \\
= \\
=\end{array}$ & $\begin{array}{c}\overline{-} \\
1, \overline{930} \\
\overline{-} \\
1, \overline{9} 20 \\
\overline{-} \\
1, \overline{9} 10 \\
\overline{-} \\
1, \overline{9} 00\end{array}$ \\
\hline
\end{tabular}

Supplemental records.- Dec. 10, 11 p.m., $22.4 \mathrm{ft.}, 80,200$ sec.-ft. 
South Fork of Feather River at Enterprise, Calif.

Location.- Lat. $39^{\circ} 32^{\prime}$, long. $121^{\circ} 21^{\prime}$, In Sw sec. 6, T. 19 N., R. 6 E., 0.8 mile above Mccabe Creek and 1 mile above highway bridge at Enterprise, Butte County. Alt1tude, about 550 feet above mean sea level.

Drainage area. - 134 square miles.

Gage-helght record. - Water-stage recorder graph.

Stage-discharge relation.- Defined by current-meter measurements below 4,500 secondfeet; extended to peak stage; verifled by area-veloc1ty study and Avd method. RatIng curve changed at peak stage.

Maxima.- December 1937: Discharge, 17,300 second-feet 5 p.m. Dec. 10 (gage helght, 20.4 feet).

1911-November 1937: D1scharge (regulated), about 15,200 second-feet Mar. 26, 1928 (gage height, 16.0 feet, from floodmarks at former site and datum, half a mile downstream), from rating curve extended above 2,000 second-feet on basis of computed flow over Palermo Canal diversion dam about $I$ mile above station.

Remarks. - Flood mun-off affected by artificlal storage in Lost Creek Reservolr (capacity, about 5,700 acre-feet) and by diverslons into Forbestown ditch and Palermo canal. Monthly summaries adjusted for storage and diversion.

Mean dally discharge, in second-feet, November 1937 to January 1938

\begin{tabular}{|c|c|c|c|c|c|c|c|c|c|c|c|}
\hline Day & Nov. & Deo. & Jan. & Day & Nov. & Dec. & Jan. & Day & Nov. & Dec. & Jan. \\
\hline $\begin{array}{r}1 \\
2 \\
3 \\
4 \\
5 \\
6 \\
7 \\
8 \\
9 \\
10\end{array}$ & $\begin{array}{l}11 \\
29 \\
28 \\
28 \\
28 \\
28 \\
30 \\
29 \\
28 \\
28\end{array}$ & $\begin{array}{r}147 \\
137 \\
130 \\
124 \\
117 \\
110 \\
99 \\
93 \\
114 \\
8,360\end{array}$ & $\begin{array}{l}276 \\
306 \\
316 \\
286 \\
276 \\
267 \\
258 \\
240 \\
232 \\
229\end{array}$ & $\begin{array}{l}11 \\
12 \\
13 \\
14 \\
15 \\
16 \\
17 \\
18 \\
19 \\
20\end{array}$ & $\begin{array}{r}70 \\
72 \\
57 \\
104 \\
138 \\
118 \\
768 \\
283 \\
184 \\
1,310\end{array}$ & $\begin{array}{r}12,900 \\
3,760 \\
1,900 \\
1,300 \\
940 \\
740 \\
610 \\
545 \\
470 \\
430\end{array}$ & $\begin{array}{l}223 \\
220 \\
217 \\
213 \\
380 \\
347 \\
890 \\
628 \\
530 \\
470\end{array}$ & $\begin{array}{l}21 \\
22 \\
23 \\
24 \\
25 \\
26 \\
27 \\
28 \\
29 \\
30 \\
31 \\
\end{array}$ & $\begin{array}{l}760 \\
372 \\
614 \\
622 \\
424 \\
314 \\
260 \\
217 \\
191 \\
167\end{array}$ & $\begin{array}{l}392 \\
392 \\
392 \\
369 \\
347 \\
326 \\
306 \\
306 \\
306 \\
286 \\
286\end{array}$ & $\begin{array}{l}418 \\
405 \\
405 \\
369 \\
358 \\
336 \\
336 \\
358 \\
347 \\
326 \\
628\end{array}$ \\
\hline $\begin{array}{l}\text { Mean } \\
\text { Mean } \\
\text { Run- }\end{array}$ & $\begin{array}{l}\text { onth } \\
\text { onth. } \\
f, 1\end{array}$ & $\begin{array}{l}\text { Ischa } \\
\text { Ischa } \\
\text { re-fe }\end{array}$ & $\begin{array}{l}\text { In } \\
\text { in }\end{array}$ & n & $\begin{array}{l}\text { eet } \\
\text { eet }\end{array}$ & erved) & & & $\begin{array}{r}244 \\
343 \\
20,430 \\
\end{array}$ & $\begin{array}{r}1,185 \\
1,200 \\
73,800 \\
\end{array}$ & $\begin{array}{r}358 \\
368 \\
22,610 \\
\end{array}$ \\
\hline
\end{tabular}

Gage helght, in feet, and discharge, in second-feet, at indicated time, 1937

\begin{tabular}{|c|c|c|c|c|c|c|c|c|c|c|c|c|}
\hline \multirow{2}{*}{$\begin{array}{l}\text { 多 } \\
\text { 品 }\end{array}$} & Feet & Sec.ft. & Feet & Sec.ft. & Feet & Sec.ft. & Feet & Sec.ft. & Feet & Sec. It. & Feet & Sec.ft. \\
\hline & \multicolumn{2}{|c|}{ December 8} & \multicolumn{2}{|c|}{ December 9} & \multicolumn{2}{|c|}{ December 10} & \multicolumn{2}{|c|}{ December 11} & \multicolumn{2}{|c|}{ December 12} & \multicolumn{2}{|c|}{ December 13} \\
\hline \multirow[t]{2}{*}{$\begin{array}{r}2 \\
4 \\
6 \\
8 \\
10 \\
\mathrm{~N} \\
2 \\
4 \\
6 \\
8 \\
10 \\
\mathbf{M}\end{array}$} & $\begin{array}{l}- \\
- \\
3.25 \\
- \\
\overline{3.24} \\
- \\
\overline{3.23} \\
- \\
\overline{3.22}\end{array}$ & $\begin{array}{l}\overline{-} \\
\overline{94} \\
\overline{-} \\
\overline{93} \\
\overline{-} \\
\overline{92} \\
\overline{-} \\
\overline{91}\end{array}$ & $\begin{array}{l}3.22 \\
3.22 \\
3.23 \\
3.24 \\
3.25 \\
3.26 \\
3.27 \\
3.34 \\
3.48 \\
3.60 \\
3.90 \\
4.50\end{array}$ & $\begin{array}{r}91 \\
91 \\
92 \\
93 \\
94 \\
95 \\
96 \\
103 \\
120 \\
134 \\
177 \\
292\end{array}$ & $\begin{array}{r}5.50 \\
6.95 \\
10.00 \\
11.30 \\
12.10 \\
13.50 \\
17.40 \\
20.10 \\
19.90 \\
18.50 \\
18.10 \\
18.20\end{array}$ & $\begin{array}{r}558 \\
1,110 \\
3,000 \\
4,180 \\
5,060 \\
6,790 \\
12,300 \\
16,800 \\
16,400 \\
14,000 \\
13,300 \\
13,500\end{array}$ & \begin{tabular}{|l|}
18.50 \\
19.70 \\
20.30 \\
19.60 \\
19.00 \\
18.90 \\
18.60 \\
17.70 \\
16.30 \\
14.90 \\
14.20 \\
13.60
\end{tabular} & $\begin{array}{r}14,000 \\
16,000 \\
17,100 \\
15,900 \\
14,800 \\
14,700 \\
14,200 \\
12,600 \\
10,300 \\
8,150 \\
7,130 \\
6,290\end{array}$ & $\begin{array}{l}13.00 \\
12.50 \\
12.20 \\
11.85 \\
11.60 \\
11.30 \\
11.05 \\
10.80 \\
10.60 \\
10.45 \\
10.30 \\
10.10\end{array}$ & $\begin{array}{l}5,500 \\
4,880 \\
4,520 \\
4,140 \\
3,860 \\
3,560 \\
3,310 \\
3,080 \\
2,900 \\
2,760 \\
2,640 \\
2,480\end{array}$ & $\begin{array}{l}9.95 \\
9.80 \\
9.65 \\
9.50 \\
9.40 \\
9.30 \\
9.20 \\
9.10 \\
9.00 \\
8.90 \\
8.85 \\
8.80\end{array}$ & $\begin{array}{l}2,360 \\
2,240 \\
2,120 \\
2,000 \\
1,930 \\
1,860 \\
1,790 \\
1,720 \\
1,650 \\
1,580 \\
1,540 \\
1,510\end{array}$ \\
\hline & \multicolumn{2}{|c|}{ December 14} & \multicolumn{2}{|c|}{ December 15} & \multicolumn{2}{|c|}{ December 16} & \multicolumn{2}{|c|}{ December 17} & \multicolumn{2}{|c|}{ December 18} & \multicolumn{2}{|c|}{ December 19} \\
\hline $\begin{array}{r}2 \\
4 \\
6 \\
8 \\
10 \\
1 \\
2 \\
4 \\
6 \\
8 \\
10 \\
\mathbf{y}\end{array}$ & $\begin{array}{l}\overline{8.65} \\
\overline{8.85} \\
\overline{8.40} \\
\overline{8.30} \\
\overline{8.18} \\
\overline{8.05}\end{array}$ & $\begin{array}{c}1, \overline{420} \\
\overline{-} \\
1, \overline{3} 60 \\
\overline{1} \\
1, \overline{2} 70 \\
1, \overline{2} 10 \\
1, \overline{1} 40 \\
1, \overline{0} 60\end{array}$ & $\begin{array}{l}7.95 \\
= \\
= \\
7.77 \\
= \\
= \\
7.60 \\
= \\
=\end{array}$ & $\begin{array}{c}-\overline{0} \\
1,0 \\
- \\
- \\
925 \\
- \\
- \\
\overline{8} \\
- \\
-\end{array}$ & $\begin{array}{l}7.45 \\
= \\
= \\
7.32 \\
= \\
= \\
7.22 \\
= \\
=\end{array}$ & $\begin{array}{c}780 \\
- \\
\overline{-} \\
728 \\
- \\
- \\
\overline{688} \\
= \\
=\end{array}$ & $\begin{array}{l}\overline{7.10} \\
\overline{-} \\
\overline{-} \\
7.02 \\
- \\
- \\
\overline{6.92} \\
- \\
-\end{array}$ & $\begin{array}{l}- \\
645 \\
- \\
- \\
\overline{617} \\
- \\
- \\
5 \overline{82} \\
- \\
-\end{array}$ & $\begin{array}{l}- \\
6.85 \\
- \\
- \\
6.77 \\
- \\
- \\
6.70 \\
= \\
-\end{array}$ & $\begin{array}{c}- \\
560 \\
- \\
- \\
- \\
536 \\
- \\
- \\
\overline{515} \\
- \\
-\end{array}$ & $\begin{array}{l}- \\
6.63 \\
- \\
- \\
6.57 \\
- \\
- \\
6.50 \\
- \\
-\end{array}$ & $\begin{array}{c}\overline{-} 94 \\
- \\
\overline{4} \\
\overline{4} 6 \\
- \\
\overline{4} \\
= \\
-\end{array}$ \\
\hline $\mathbf{M}$ & \multicolumn{2}{|c|}{ December 20} & \multicolumn{2}{|c|}{ December 21} & \multicolumn{2}{|c|}{ December 22} & \multicolumn{2}{|c|}{ December 23} & \multicolumn{2}{|c|}{ December 24} & \multicolumn{2}{|c|}{ December 25} \\
\hline $\begin{array}{r}2 \\
4 \\
6 \\
8 \\
10 \\
\text { N } \\
2 \\
4 \\
6 \\
8 \\
10 \\
\mathbf{M}\end{array}$ & $\begin{array}{l}6.46 \\
= \\
= \\
6.40 \\
= \\
= \\
= \\
=\end{array}$ & $\begin{array}{c}\overline{4} \\
- \\
- \\
\overline{430} \\
- \\
- \\
\overline{-} \\
415 \\
- \\
-\end{array}$ & $\begin{array}{l}- \\
6.30 \\
= \\
= \\
6.27 \\
= \\
= \\
6.23 \\
= \\
=\end{array}$ & $\begin{array}{c}\overline{405} \\
- \\
- \\
\overline{398} \\
\overline{-} \\
\overline{-} \\
388 \\
- \\
-\end{array}$ & $\begin{array}{l}- \\
6.20 \\
- \\
- \\
6.17 \\
= \\
- \\
6.39 \\
= \\
-\end{array}$ & $\begin{array}{c}\overline{380} \\
\overline{-} \\
\overline{373} \\
\overline{-} \\
\overline{-} \\
428 \\
\overline{-} \\
-\end{array}$ & $\begin{array}{c}- \\
6.35 \\
- \\
- \\
6.20 \\
- \\
- \\
6.13 \\
- \\
-\end{array}$ & $\begin{array}{c}\overline{4} \\
\overline{-} \\
\overline{-} \\
380 \\
\overline{-} \\
\overline{-} \\
365 \\
- \\
-\end{array}$ & $\begin{array}{l}6.08 \\
= \\
= \\
6.18 \\
= \\
= \\
\overline{-} \\
=\end{array}$ & $\begin{array}{c}- \\
354 \\
- \\
- \\
\overline{3} \\
- \\
- \\
- \\
376 \\
- \\
-\end{array}$ & $\begin{array}{l}- \\
6.05 \\
- \\
\overline{-} \\
6.03 \\
- \\
- \\
6.02 \\
-\end{array}$ & $\begin{array}{c}347 \\
- \\
- \\
343 \\
- \\
- \\
340 \\
- \\
-\end{array}$ \\
\hline
\end{tabular}

Supplemental records.- Dec. 10, 5 p.m., 20.40 ft., 17,300 sec.-ft. 
Lost Creek near Clipper M111s, Calif.

Location.- Lat. $39^{\circ} 34^{\prime}$, long. $121^{\circ} 09^{\prime}$, in sec. 24, T. 20 N., R. 7 E., 1,000 feet below Lost Creek Dam and 2 miles north of Clipper Milis, Butte County. Altitude, about 3,050 feet above mean sea level.

Drainage area.- 30.1 square miles.

Gage-helght record. - Water-stage recorder graph except for per1od 10:30 a.m. Dec. 23 to $10: 30 \mathrm{~g} \cdot \mathrm{m}$. Jan. 20 , when there was no record. Stage graph for Dec. 23 and Jan. 20 based on partial recorder graph.

Stage-discharge relation. - Defined by current-meter measurements below 450 second-feet; extended to peak stage on bas is of computed flow over Lost Creek Dam. Rating curve changed at peak stage.

Maxima.- December 1937: Discharge, 3,380 second-feet 4 p.m. Dec. 10 (gage height, 6.80 fe日t).

1927-November 1937: Discharge, 2,900 second-feet Mar. 26, 1928 (gage height, 6.10 feet).

Remarks.- Discharge for period of missing gage-height record, Dec, 24 to Jan. 19 , de-

termined from staff-gage readings at and corresponding flow over Lost Creek Dam.

Flood run-off affected by artificlal storage in Iost Creek Reservoir (capacity,

about 5,700 aore-feet) and by diversion into Forbestown ditch. Reservo1r began

to spili about 6 a.m. Dec. 8. Monthly summaries adjusted for storage and diversion.

Mean dally dlscharge, in second-feet, November 1937 to January 1938

\begin{tabular}{|c|c|c|c|c|c|c|c|c|c|c|c|}
\hline Day & Nov. & Dec. & Jan. & Day & Nov. & Dec. & Jan. & Day & Nov. & Dec. & Jan. \\
\hline $\begin{array}{r}1 \\
2 \\
3 \\
4 \\
5 \\
6 \\
7 \\
8 \\
9 \\
10\end{array}$ & $\begin{array}{r}0.2 \\
.2 \\
.2 \\
.2 \\
.2 \\
.2 \\
.2 \\
.2 \\
.2 \\
.2\end{array}$ & $\begin{array}{r}0.2 \\
.2 \\
.2 \\
.2 \\
.2 \\
.2 \\
.2 \\
2.7 \\
40 \\
1,490\end{array}$ & $\begin{array}{r}90 \\
100 \\
100 \\
90 \\
95 \\
95 \\
90 \\
90 \\
85 \\
85\end{array}$ & $\begin{array}{l}11 \\
12 \\
13 \\
14 \\
15 \\
16 \\
17 \\
18 \\
19 \\
20\end{array}$ & $\begin{array}{r}0.4 \\
.2 \\
.2 \\
.4 \\
.2 \\
.7 \\
1.1 \\
.2 \\
.2 \\
2.5\end{array}$ & $\begin{array}{r}2,040 \\
738 \\
426 \\
310 \\
246 \\
202 \\
175 \\
155 \\
137 \\
124\end{array}$ & $\begin{array}{r}80 \\
80 \\
80 \\
80 \\
170 \\
110 \\
300 \\
210 \\
170 \\
110\end{array}$ & $\begin{array}{l}21 \\
22 \\
23 \\
24 \\
25 \\
26 \\
27 \\
28 \\
29 \\
30 \\
31\end{array}$ & $\begin{array}{r}0.4 \\
.2 \\
.6 \\
.5 \\
.3 \\
.2 \\
.2 \\
.2 \\
.2 \\
.2\end{array}$ & $\begin{array}{r}117 \\
120 \\
117 \\
110 \\
105 \\
100 \\
90 \\
90 \\
90 \\
85 \\
85\end{array}$ & $\begin{array}{r}100 \\
103 \\
100 \\
91 \\
84 \\
81 \\
84 \\
103 \\
96 \\
82 \\
144\end{array}$ \\
\hline \multicolumn{9}{|c|}{ 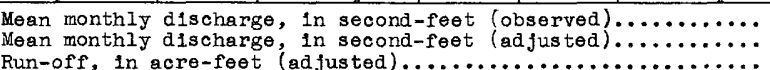 } & $\begin{array}{r}0.37 \\
83.5 \\
4,970\end{array}$ & $\begin{array}{r}232 \\
247 \\
15,210\end{array}$ & $\begin{array}{r}109 \\
119 \\
7,310\end{array}$ \\
\hline
\end{tabular}

Gage helght, in feet, and alscharge, in second-feet, at indicated time, I937

\begin{tabular}{|c|c|c|c|c|c|c|c|c|c|c|c|c|}
\hline \multirow{2}{*}{ 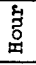 } & Fe日t & Sec.ft. & $F \theta \theta t$ & Sec.ft. & Feet & Sec.ft. & Feet & Sec.ft. & Feet & Sec.ft. & $F \ominus \theta t$ & Sec.ft. \\
\hline & \multicolumn{2}{|c|}{ December 8} & \multicolumn{2}{|c|}{ December 9} & \multicolumn{2}{|c|}{ December 10} & \multicolumn{2}{|c|}{ December 11} & \multicolumn{2}{|c|}{ December 12} & \multicolumn{2}{|c|}{ December 13} \\
\hline $\begin{array}{r}2 \\
4 \\
6 \\
8 \\
10 \\
\mathrm{~N} \\
2 \\
4 \\
6 \\
8 \\
10 \\
\mathrm{M}\end{array}$ & $\begin{array}{r}0.08 \\
.08 \\
.10 \\
.22 \\
.58 \\
1.06 \\
1.22 \\
1.30 \\
1.34 \\
1.37 \\
1.39 \\
1.40\end{array}$ & $\begin{array}{r}0.2 \\
.2 \\
.2 \\
.2 \\
.3 \\
1.3 \\
2.8 \\
4.2 \\
5.5 \\
6.5 \\
7.2 \\
7.5\end{array}$ & $\begin{array}{l}1.40 \\
1.42 \\
1.43 \\
1.43 \\
1.44 \\
1.47 \\
1.49 \\
1.60 \\
1.74 \\
1.95 \\
2.35 \\
2.80\end{array}$ & $\begin{array}{c}7.5 \\
9 \\
10 \\
10 \\
10 \\
13 \\
14 \\
24 \\
39 \\
68 \\
143 \\
252\end{array}$ & $\begin{array}{l}3.15 \\
3.70 \\
4.06 \\
4.33 \\
4.65 \\
5.00 \\
5.80 \\
6.80 \\
5.80 \\
5.40 \\
5.30 \\
5.40\end{array}$ & $\begin{array}{r}375 \\
610 \\
806 \\
971 \\
1,200 \\
1,470 \\
2,250 \\
3,380 \\
2,250 \\
1,840 \\
1,740 \\
1,840 \\
\end{array}$ & $\begin{array}{l}5.54 \\
6.08 \\
6.37 \\
6.14 \\
5.98 \\
5.98 \\
5.78 \\
5.55 \\
5.22 \\
4.90 \\
4.77 \\
4.62\end{array}$ & $\begin{array}{l}1,980 \\
2,560 \\
2,880 \\
2,620 \\
2,450 \\
2,350 \\
2,230 \\
1,990 \\
1,670 \\
1,390 \\
1,290 \\
1,170\end{array}$ & $\begin{array}{l}4.41 \\
4.29 \\
4.20 \\
4.10 \\
4.00 \\
3.94 \\
3.85 \\
3.77 \\
3.72 \\
3.66 \\
3.60 \\
3.57\end{array}$ & $\begin{array}{r}1,030 \\
943 \\
880 \\
815 \\
750 \\
713 \\
659 \\
614 \\
587 \\
556 \\
526 \\
512\end{array}$ & $\begin{array}{c}- \\
3.50 \\
- \\
3.42 \\
- \\
3.36 \\
- \\
3.30 \\
\overline{3.25} \\
\overline{3.21}\end{array}$ & $\begin{array}{c}\overline{478} \\
- \\
4 \overline{43} \\
\overline{4} \\
\overline{18} \\
3 \overline{94} \\
\overline{375} \\
\overline{360}\end{array}$ \\
\hline & \multicolumn{2}{|c|}{ December 14} & \multicolumn{2}{|c|}{ December 15} & \multicolumn{2}{|c|}{ December 16} & \multicolumn{2}{|c|}{ December 17} & \multicolumn{2}{|c|}{ Docember 18} & \multicolumn{2}{|c|}{ December 19} \\
\hline $\begin{array}{r}2 \\
4 \\
6 \\
8 \\
10 \\
N \\
2 \\
4 \\
6 \\
8 \\
10 \\
M\end{array}$ & $\begin{array}{c}- \\
3.16 \\
- \\
3.11 \\
- \\
3.07 \\
- \\
3.03 \\
- \\
2.99 \\
- \\
2.96\end{array}$ & $\begin{array}{c}\overline{342} \\
\overline{3} 4 \\
\overline{310} \\
\overline{2} \overline{96} \\
\overline{2} \\
\overline{83} \\
\overline{272}\end{array}$ & $\begin{array}{c}\overline{-} \\
2.92 \\
- \\
2.89 \\
\overline{-} \\
2.87 \\
\overline{2.84} \\
\overline{-} \\
2.82 \\
\overline{2.79}\end{array}$ & $\begin{array}{c}\overline{259} \\
- \\
2 \overline{49} \\
\overline{2} \overline{42} \\
\overline{233} \\
\overline{2} \overline{6} \\
\overline{2} \overline{7}\end{array}$ & $\begin{array}{c}- \\
2.77 \\
- \\
2.76 \\
- \\
2.72 \\
- \\
2.72 \\
- \\
2.70 \\
- \\
2.69\end{array}$ & $\begin{array}{c}\overline{211} \\
\overline{208} \\
\overline{196} \\
\overline{196} \\
\overline{190} \\
\overline{187}\end{array}$ & $\begin{array}{c}- \\
2.67 \\
- \\
2.66 \\
\overline{2.66} \\
\overline{-} \\
2.63 \\
- \\
2.62 \\
\overline{2.61}\end{array}$ & $\begin{array}{c}\overline{181} \\
\overline{7} \\
178 \\
\overline{172} \\
\overline{169} \\
\overline{166} \\
\overline{163}\end{array}$ & $\begin{array}{c}- \\
2.59 \\
- \\
2.58 \\
- \\
2.56 \\
\overline{2.55} \\
- \\
2.54 \\
- \\
2.52\end{array}$ & $\begin{array}{c}\overline{157} \\
\overline{155} \\
\overline{150} \\
\overline{147} \\
\overline{144} \\
\overline{139}\end{array}$ & $\begin{array}{c}- \\
2.52 \\
- \\
2.51 \\
- \\
2.51 \\
- \\
2.50 \\
- \\
2.49 \\
- \\
2.49\end{array}$ & $\begin{array}{c}- \\
139 \\
- \\
137 \\
- \\
137 \\
- \\
134 \\
\overline{132} \\
\overline{132}\end{array}$ \\
\hline $\begin{array}{r}10 \\
M\end{array}$ & \multicolumn{2}{|c|}{ December 20} & \multicolumn{2}{|c|}{ December 21} & \multicolumn{2}{|c|}{ December 22} & \multicolumn{2}{|c|}{ December 23} & \multicolumn{2}{|c|}{ December 24} & \multicolumn{2}{|c|}{ December 25} \\
\hline $\begin{array}{r}2 \\
4 \\
6 \\
8 \\
10 \\
\mathbf{N} \\
2 \\
4 \\
6 \\
8 \\
10 \\
\mathbf{M}\end{array}$ & $\begin{array}{l}3 . \\
\overline{-} \\
2.46 \\
- \\
2.46 \\
\overline{2.45} \\
- \\
2.45 \\
- \\
2.44\end{array}$ & $\begin{array}{c}\overline{127} \\
\overline{124} \\
\overline{124} \\
\overline{122} \\
\overline{122} \\
\overline{120}\end{array}$ & $\begin{array}{c}\overline{2.43} \\
\overline{2.43} \\
\overline{-} .42 \\
\overline{-} \\
\overline{-} 43 \\
2.42 \\
\overline{2.41}\end{array}$ & $\begin{array}{c}\overline{177} \\
\overline{117} \\
\overline{115} \\
\overline{117} \\
\overline{115} \\
\overline{112}\end{array}$ & $\begin{array}{c}2 . \\
2.41 \\
- \\
2.40 \\
- \\
2.40 \\
- \\
2.47 \\
-\overline{2.52} \\
- \\
2.50\end{array}$ & $\begin{array}{c}\overline{112} \\
\overline{110} \\
\overline{110} \\
\overline{127} \\
\overline{139} \\
\overline{13}\end{array}$ & & & & & & \\
\hline
\end{tabular}


Middle Fork of Yuba River at Milton, Calif.

Location. - Lat. $39^{\circ} 31^{\prime} 22^{\prime \prime}$, long. $120^{\circ} 35^{\prime} 01^{\prime \prime}$, in SW/ sec. 12, T. 19 N., R. 12 E., at diversion dam of Nevada Irrigation District at old town site of Milton, Sierra County, 8 miles above South Fork of Middle Fork of Yuba River. Altitude, about 5,700 feet above mean sea level.

Dralnage area. - 41 square miles.

Gage-helght record. - Water-stage recorder graph.

Stage-discharge relation.- Defined by current-meter measurements below 1,500 secondfeet; extended to peak stage on bas is of computed flow over diversion dem.

Maxima.- December 1937: D1scharge, 6,800 second-feet 10 a.m. Dec. 11 (gage hejght, 4.18 feet).

1925-November 1937: Discharge (regulated), 4,070 second-feet Mar. 25, 1928 (gage height, 9.45 feet, former site and datum, $0.2 \mathrm{mlle}$ downstream).

Remarks.- Flood man-off slightly affected by storage in diversion reservolr and diversion through Milton-Bowman tunnel. Monthly summaries adjusted for diversion. Most of basic data furnished by Nevada Irrigation District.

Mean daily discharge, in second-feet, November 1937 to January 1938

\begin{tabular}{|c|c|c|c|c|c|c|c|c|c|c|c|}
\hline Day & Nov. & Dec. & Jan. & Day & Nov. & Dec. & Jan. & Day & Nov. & Dec. & Jan. \\
\hline $\begin{array}{r}1 \\
2 \\
3 \\
4 \\
5 \\
6 \\
7 \\
8 \\
9 \\
10\end{array}$ & $\begin{array}{l}0 \\
0 \\
0 \\
0 \\
0 \\
0 \\
0 \\
0 \\
0 \\
0\end{array}$ & $\begin{array}{r}0 \\
0 \\
0 \\
0 \\
0 \\
0 \\
0 \\
0 \\
0 \\
2,240\end{array}$ & $\begin{array}{l}0 \\
0 \\
0 \\
0 \\
0 \\
0 \\
0 \\
0 \\
0 \\
0\end{array}$ & $\begin{array}{l}11 \\
12 \\
13 \\
14 \\
15 \\
16 \\
17 \\
18 \\
19 \\
20\end{array}$ & $\begin{array}{l}0 \\
0 \\
0 \\
0 \\
0 \\
0 \\
0 \\
0 \\
0 \\
0\end{array}$ & $\begin{array}{c}4,010 \\
450 \\
126 \\
19 \\
0 \\
0 \\
0 \\
0 \\
0\end{array}$ & $\begin{array}{l}0 \\
0 \\
0 \\
0 \\
0 \\
0 \\
0 \\
0 \\
0 \\
0\end{array}$ & $\begin{array}{l}21 \\
22 \\
23 \\
24 \\
25 \\
26 \\
27 \\
28 \\
29 \\
30 \\
31\end{array}$ & $\begin{array}{l}0 \\
0 \\
0 \\
0 \\
0 \\
0 \\
0 \\
0 \\
0 \\
0\end{array}$ & $\begin{array}{l}0 \\
0 \\
0 \\
0 \\
0 \\
0 \\
0 \\
0 \\
0 \\
0 \\
0\end{array}$ & $\begin{array}{l}0 \\
0 \\
0 \\
0 \\
0 \\
0 \\
0 \\
0 \\
0 \\
0 \\
0\end{array}$ \\
\hline $\begin{array}{l}\text { Mean } \\
\text { Mean } \\
\text { Run-c }\end{array}$ & $\begin{array}{l}\text { month } \\
\text { month } \\
f f, \text { in }\end{array}$ & $\begin{array}{l}\text { dischar } \\
\text { dischar } \\
\text { cre-fee }\end{array}$ & , in & cond & eet & $\begin{array}{l}\text { served } \\
\text { justed }\end{array}$ & . & $\ddot{*}$ & $\begin{array}{r}0 \\
20.2^{\overline{0}} \\
1, \overline{2} 00^{2}\end{array}$ & $\begin{array}{r}221 \\
313 \\
19,220\end{array}$ & $\begin{array}{r}0 \\
47.2 \\
2,900\end{array}$ \\
\hline
\end{tabular}

Gage height, in feet, and discharge, in second-feet, at indicated time, 1937

\begin{tabular}{|c|c|c|c|c|c|c|c|c|c|c|c|c|}
\hline \multirow{2}{*}{ 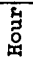 } & Feet & sec.ft. & Feet & Sec.ft. & Feet & Sec.ft. & Feet & Sec.ft. & Feet & Sec.ft. & Feet & Sec.ft. \\
\hline & \multicolumn{2}{|c|}{ December 8} & \multicolumn{2}{|c|}{ December 9} & \multicolumn{2}{|c|}{ December 10} & \multicolumn{2}{|c|}{ December 11} & \multicolumn{2}{|c|}{ December 12} & \multicolumn{2}{|c|}{ De cember 13} \\
\hline $\begin{array}{r}2 \\
4 \\
6 \\
8 \\
10 \\
N \\
2 \\
4 \\
6 \\
8 \\
10 \\
M\end{array}$ & & & & & $\begin{array}{r}0.00 \\
.06 \\
1.56 \\
2.10 \\
2.22 \\
2.20 \\
2.61 \\
2.86 \\
2.69 \\
2.64 \\
2.68 \\
2.58\end{array}$ & \begin{tabular}{|c|}
0 \\
2.4 \\
1,360 \\
2,210 \\
2,420 \\
2,380 \\
3,140 \\
3,650 \\
3,300 \\
3,200 \\
3,280 \\
3,080
\end{tabular} & $\begin{array}{l}2.67 \\
3.67 \\
3.75 \\
3.87 \\
4.18 \\
3.79 \\
3.40 \\
2.79 \\
2.10 \\
1.69 \\
1.47 \\
1.29\end{array}$ & $\begin{array}{r}3,260 \\
5,490 \\
5,680 \\
5,980 \\
6,800 \\
5,780 \\
4,840 \\
3,500 \\
2,210 \\
1,560 \\
1,230 \\
987\end{array}$ & $\begin{array}{r}.14 \\
1.01 \\
.90 \\
.81 \\
.75 \\
.75 \\
.72 \\
.69 \\
.66 \\
.62 \\
.57 \\
.53\end{array}$ & $\begin{array}{l}798 \\
651 \\
535 \\
450 \\
397 \\
397 \\
371 \\
346 \\
323 \\
292 \\
256 \\
228\end{array}$ & $\begin{array}{l}0.49 \\
.46 \\
.42 \\
.40 \\
.38 \\
.35 \\
.34 \\
.33 \\
.31 \\
.29 \\
.26 \\
.24\end{array}$ & $\begin{array}{r}201 \\
181 \\
156 \\
143 \\
132 \\
116 \\
110 \\
104 \\
94 \\
83 \\
68 \\
58\end{array}$ \\
\hline & \multicolumn{2}{|c|}{ December 14} & \multicolumn{2}{|c|}{ De cember 15} & \multicolumn{2}{|c|}{ December 16} & \multicolumn{2}{|c|}{ December 17} & \multicolumn{2}{|c|}{ De cember 18} & \multicolumn{2}{|c|}{ December 19} \\
\hline $\begin{array}{r}2 \\
4 \\
6 \\
8 \\
10 \\
\text { N } \\
2 \\
4 \\
6 \\
8 \\
10 \\
M\end{array}$ & $\begin{array}{r}0.22 \\
.20 \\
.18 \\
.16 \\
.13 \\
.12 \\
.11 \\
.09 \\
.07 \\
.04 \\
.02 \\
.00\end{array}$ & $\begin{array}{c}50 \\
42 \\
34 \\
26 \\
16 \\
13 \\
11 \\
7 \\
3.7 \\
1.0 \\
0.4\end{array}$ & & & & & & & & & & \\
\hline
\end{tabular}

Supplemental records.- Dec. 10, 5 a.m., 1.08 ft., 728 sec.-ft. Dec. 11, 5 a.m., . $3.84 \mathrm{ft.}, 5,900$ sec. $-\mathrm{ft}$.

$1800020-90-10$ 
Mlddle Fork of Yuba River near North San Juan, Calif.

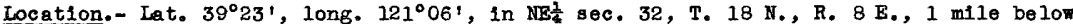
Oregon Creek and 1 mile north of North San Juan, Nevada County. Zero of gage is I,400.62 feet above mean sea level (general adjustment of 1929).

Draingge area. - 207 square miles.

Gage-helght record. - Water-stage recorder graph. Affected by drawdown of water level in well.

Stage-disoharge relation.- Defined by current-meter measurements below 23,000 secondfeet. Rating curve changed at peak stage.

Maxima.- December 1937: Discharge, 24,000 second-feet 7:30 a.m. Dec. 11 (gage height, 13.7 feet, from floodmarks on bank; 13.3 feet, in well, affected by drawdown).

1911-November 1937: Discharge, about 26,000 second-feet Mar. 25, 1928 (gage height, 15.3 feet, from floodmarks at former site and datum, 0.4 mile upstream), from rating curve extended above 1,200 second-feet on bas 1s of slope-area determination of flood flow.

Remarks. - Flood mun-off not materialiy affected by artiflcial storage. Mliton-Bowman tunnel diverts water above station. Monthly summaries adjusted for diversion.

Mean daily discherge, in second-feet, November 1937 to January 1938

\begin{tabular}{|c|c|r|r||c|r|r|r|r|r|r|r|}
\hline Day & Nov. & Dec. & Jan. & Day & Nov. & Dec. & Jan. & Day & Nov. & Dec. & Jan. \\
\hline 1 & 41 & 107 & 190 & 11 & 92 & 16,100 & 144 & 21 & 488 & 258 & 398 \\
2 & 40 & 100 & 209 & 12 & 97 & 3,840 & 141 & 22 & 220 & 258 & 385 \\
3 & 39 & 94 & 220 & 13 & 67 & 1,600 & 139 & 23 & 400 & 264 & 377 \\
4 & 39 & 89 & 201 & 14 & 150 & 953 & 136 & 24 & 522 & 246 & 333 \\
5 & 39 & 84 & 192 & 15 & 132 & 688 & 298 & 25 & 295 & 234 & 305 \\
6 & 39 & 81 & 181 & 16 & 149 & 541 & 261 & 26 & 212 & 218 & 288 \\
7 & 39 & 78 & 197 & 17 & 639 & 446 & 1,180 & 27 & 167 & 206 & 280 \\
8 & 39 & 75 & 166 & 18 & 244 & 377 & 748 & 28 & 144 & 206 & 291 \\
9 & 39 & 84 & 156 & 19 & 148 & 325 & 586 & 29 & 126 & 201 & 288 \\
10 & 39 & 7,300 & 151 & 20 & 429 & 284 & 476 & 30 & 115 & 196 & 267 \\
\end{tabular}

Gage height, in feet, and discharge, in second-feet, at indicated time, 1937

\begin{tabular}{|c|c|c|c|c|c|c|c|c|c|c|c|c|}
\hline \multirow{2}{*}{ 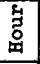 } & Feet & sec.ft. & Feet & Sec.ft. & Feet & Sec.ft. & Feet & Sec.ft. & Feet & sec.ft. & Feet & Sec.ft. \\
\hline & \multicolumn{2}{|c|}{ December 8} & \multicolumn{2}{|c|}{ December 9} & \multicolumn{2}{|c|}{ December 10} & \multicolumn{2}{|c|}{ December 11} & \multicolumn{2}{|c|}{ December 12} & \multicolumn{2}{|c|}{ December 13} \\
\hline \multirow[t]{2}{*}{\begin{tabular}{r|}
2 \\
4 \\
6 \\
8 \\
10 \\
$\mathbb{N}$ \\
2 \\
4 \\
6 \\
8 \\
10 \\
$M$ \\
\end{tabular}} & $\begin{array}{l}2.79 \\
2.79 \\
2.78 \\
2.78 \\
2.78 \\
2.78 \\
2.78 \\
2.78 \\
2.78 \\
2.78 \\
2.77 \\
2.77\end{array}$ & $\begin{array}{l}77 \\
77 \\
75 \\
75 \\
75 \\
75 \\
75 \\
75 \\
75 \\
75 \\
74 \\
74 \\
\end{array}$ & $\begin{array}{l}2.77 \\
2.77 \\
2.77 \\
2.76 \\
2.75 \\
2.76 \\
2.77 \\
2.81 \\
2.85 \\
2.93 \\
3.03 \\
3.30\end{array}$ & $\begin{array}{r}74 \\
74 \\
74 \\
72 \\
72 \\
72 \\
74 \\
80 \\
86 \\
99 \\
115 \\
172 \\
\end{array}$ & $\begin{array}{r}3.98 \\
5.55 \\
7.42 \\
8.17 \\
8.63 \\
9.12 \\
9.31 \\
9.88 \\
10.07 \\
9.80 \\
9.51 \\
9.47\end{array}$ & $\begin{array}{r}396 \\
1,500 \\
4,440 \\
6,260 \\
7,520 \\
8,960 \\
9,530 \\
11,400 \\
12,000 \\
11,100 \\
10,200 \\
10,000\end{array}$ & $\begin{array}{r}9.60 \\
10.28 \\
12.28 \\
13.20 \\
12.49 \\
12.30 \\
12.25 \\
11.25 \\
10.10 \\
9.23 \\
8.53 \\
8.01\end{array}$ & $\begin{array}{r}10,500 \\
12,700 \\
20,100 \\
24,000 \\
22,700 \\
21,900 \\
21,800 \\
18,000 \\
13,800 \\
10,800 \\
8,460 \\
6,930\end{array}$ & $\begin{array}{l}7.70 \\
7.44 \\
7.23 \\
7.07 \\
6.85 \\
6.66 \\
6.47 \\
6.34 \\
6.25 \\
6.16 \\
6.08 \\
5.97 \\
\end{array}$ & $\begin{array}{l}6,080 \\
5,400 \\
4,870 \\
4,490 \\
3,970 \\
3,650 \\
3,160 \\
2,910 \\
2,740 \\
2,680 \\
2,450 \\
2,270 \\
\end{array}$ & $\begin{array}{l}5.87 \\
5.77 \\
5.69 \\
5.61 \\
5.53 \\
5.45 \\
5.38 \\
5.30 \\
5.24 \\
5.19 \\
5.13 \\
5.08\end{array}$ & $\begin{array}{l}2,120 \\
1,970 \\
1,860 \\
1,760 \\
1,660 \\
1,560 \\
1,490 \\
1,400 \\
1,340 \\
1,290 \\
1,240 \\
1,190 \\
\end{array}$ \\
\hline & \multicolumn{2}{|c|}{ December 14} & \multicolumn{2}{|c|}{ December 15} & \multicolumn{2}{|c|}{ December 16} & \multicolumn{2}{|c|}{ December 17} & \multicolumn{2}{|c|}{ December 18} & \multicolumn{2}{|c|}{ December 19} \\
\hline $\begin{array}{r}2 \\
4 \\
6 \\
8 \\
10 \\
11 \\
2 \\
4 \\
6 \\
8 \\
8 \\
10 \\
M\end{array}$ & $\begin{array}{l}4.98 \\
-.87 \\
4.87 \\
4.78 \\
- \\
4.70 \\
- \\
4.61 \\
- \\
4.54\end{array}$ & $\begin{array}{c}1, \overline{100} \\
1, \overline{020} \\
\overline{9}_{46} \\
\overline{890} \\
\overline{8} 27 \\
\overline{7}\end{array}$ & $\begin{array}{l}-\overline{-} \\
4.48 \\
4.42 \\
-\overline{4.37} \\
- \\
4.32 \\
- \\
4.27 \\
\overline{4.23}\end{array}$ & $\begin{array}{l}7 \overline{4} \\
7 \overline{12} \\
6 \overline{8} \\
\overline{-} \\
652 \\
\overline{624} \\
\overline{602}\end{array}$ & 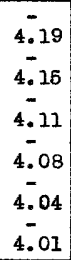 & $\begin{array}{c}5 \overline{80} \\
\overline{558} \\
\overline{-} \\
536 \\
5 \overline{20} \\
\overline{500} \\
\overline{485}\end{array}$ & $\begin{array}{l}3.98 \\
-.95 \\
3.95 \\
--93 \\
3.90 \\
3.87 \\
-.84\end{array}$ & $\begin{array}{l}4 \overline{70} \\
\overline{-} \\
4 \overline{5} \\
4 \overline{45} \\
\overline{3} 0 \\
\overline{116} \\
\overline{403}\end{array}$ & $\begin{array}{l}3.82 \\
3.80 \\
3.78 \\
3.76 \\
-7.72 \\
- \\
3.71\end{array}$ & $\begin{array}{l}3 \overline{94} \\
\overline{-} \\
\overline{8} 5 \\
377 \\
3 \overline{69} \\
- \\
353 \\
349\end{array}$ & $\begin{array}{l}3.68 \\
- \\
3.66 \\
- \\
3.65 \\
-- \\
3.62 \\
--61 \\
3.59\end{array}$ & $\begin{array}{l}3 \overline{37} \\
\overline{329} \\
\overline{3} \overline{-} \\
\overline{313} \\
\overline{309} \\
\overline{302}\end{array}$ \\
\hline & \multicolumn{2}{|c|}{ December 20} & \multicolumn{2}{|c|}{ December 21} & \multicolumn{2}{|c|}{ December 22} & \multicolumn{2}{|c|}{ December 23} & \multicolumn{2}{|c|}{ December 24} & \multicolumn{2}{|c|}{ December 25} \\
\hline $\begin{array}{r}2 \\
4 \\
6 \\
8 \\
8 \\
10 \\
\mathbb{N} \\
2 \\
4 \\
6 \\
8 \\
10 \\
M\end{array}$ & $\begin{array}{l}3.57 \\
3.56 \\
- \\
3.54 \\
3.52 \\
- \\
3.51 \\
- \\
3.50\end{array}$ & $\begin{array}{c}2 \overline{-} \\
2 \overline{91} \\
\overline{284} \\
2 \overline{77} \\
2 \overline{7} 4 \\
2 \overline{70}\end{array}$ & $\begin{array}{l}- \\
3.48 \\
- \\
3.47 \\
\overline{3.46} \\
-\overline{3.45} \\
- \\
3.44 \\
- \\
3.43\end{array}$ & $\begin{array}{l}2 \overline{64} \\
\overline{261} \\
2 \overline{58} \\
\overline{256} \\
\overline{252} \\
\overline{249}\end{array}$ & $\begin{array}{l}3.42 \\
3.42 \\
3.42 \\
3.41 \\
3.41 \\
3.40 \\
3.42 \\
3.45 \\
3.48 \\
3.51 \\
3.57 \\
3.61\end{array}$ & $\begin{array}{l}246 \\
246 \\
246 \\
243 \\
243 \\
240 \\
246 \\
255 \\
264 \\
274 \\
294 \\
309\end{array}$ & $\begin{array}{l}3.63 \\
3.59 \\
3.55 \\
3.51 \\
3.48 \\
3.46 \\
3.44 \\
3.42 \\
3.41 \\
3.40 \\
3.40 \\
3.40\end{array}$ & $\begin{array}{l}317 \\
302 \\
288 \\
274 \\
264 \\
258 \\
252 \\
246 \\
243 \\
240 \\
240 \\
240\end{array}$ & $\begin{array}{l}- \\
3.39 \\
- \\
3.38 \\
- \\
3.41 \\
-\overline{3.45} \\
3.45 \\
- \\
3.44\end{array}$ & $\begin{array}{l}2 \overline{37} \\
2 \overline{3} 4 \\
2 \overline{43} \\
-\overline{5} \\
25 \\
2 \overline{5} \\
\overline{252}\end{array}$ & $\begin{array}{l}3.40 \\
-- \\
3.37 \\
- \\
3.36 \\
-- \\
3.35 \\
3.35 \\
--35\end{array}$ & $\begin{array}{l}\overline{240} \\
\overline{232} \\
\overline{2} \overline{9} \\
\overline{226} \\
\overline{2} \overline{6} \\
\overline{226}\end{array}$ \\
\hline
\end{tabular}

Supplemental records.- Dec. 11, 7:30 a.m., $13.3 \mathrm{ft} ., 24,000$ sec.-ft. 
Location. - Lat. $39^{\circ} 13^{\prime}$, long. $121^{\circ} 18^{\prime}$, in sw/ sec. 22, T. 16 N., R. 6 E., at Narrows, 1 mile below Deer Creek and $1 \mathrm{mlle}$ north of Smartville, Yuba County. Zero of gage is 264.17 feet above mean sea level. Dralnage area.- 1,201 square miles.

Gage-height record. - Water-stage recorder graph.

Stage-discharge relation.- Defined by current-meter measurements below 30,000 secondfeet; extended to peak stage on basis of area-velocity study; verifled by $A \sqrt{a}$ method. Rating curve changed at peak stage.

Maxima.- December 1937: Discharge, 95,000 second-feet 9 a.m. Dec. Il (gage helght, 26.0 feet).

1903-November 1937: Discharge, about 120,000 second-feet Mar. 26, 1928 (gage helght, 31.2 feөt, present datum, from floodmarks), from rating curve extended above 6,500 second-feet on basis of slope-area computation of flood flow. Maximum gage helght, 29.2 feet Mar. 19, 1907, former datum; equal to 34.4 feet present datum. Remarks. - Flood mun-off affected somewhat by artiftclal storage and diverstons. Lake Spaulding (capacity, 70,500 acre-feet), Bowman Lake (capac1ty, 67,400 acre-feet), and Fordyce Lake (capacity, 42,000 acre-feet).

Mean deily discharge, in second-feet, November 1937 to January 1938

\begin{tabular}{|c|c|c|c|c|c|c|c|c|c|c|c|}
\hline Day & Nor. & Dec. & Jan. & Day & Nov. & Dec. & Jan. & Day & Nov. & Dec. & $\operatorname{Jan}$. \\
\hline $\begin{array}{r}1 \\
2 \\
3 \\
4 \\
5 \\
6 \\
7 \\
8 \\
9 \\
10\end{array}$ & $\begin{array}{l}318 \\
297 \\
297 \\
304 \\
304 \\
311 \\
270 \\
285 \\
304 \\
318\end{array}$ & $\begin{array}{r}842 \\
808 \\
819 \\
808 \\
753 \\
786 \\
786 \\
808 \\
878 \\
34,900\end{array}$ & $\begin{array}{r}1,290 \\
1,310 \\
1,470 \\
1,320 \\
1,220 \\
1,180 \\
1,080 \\
1,030 \\
980 \\
910\end{array}$ & $\begin{array}{l}11 \\
12 \\
13 \\
14 \\
15 \\
16 \\
17 \\
18 \\
19 \\
20\end{array}$ & $\begin{array}{r}530 \\
630 \\
518 \\
705 \\
855 \\
755 \\
2,480 \\
1,670 \\
1,320 \\
3,350\end{array}$ & $\begin{array}{r}74,200 \\
24,900 \\
11,900 \\
7,460 \\
5,720 \\
4,460 \\
3,730 \\
3,240 \\
2,860 \\
2,560\end{array}$ & $\begin{array}{r}862 \\
817 \\
781 \\
772 \\
1,860 \\
1,800 \\
6,200 \\
5,960 \\
4,170 \\
3,240\end{array}$ & $\begin{array}{l}21 \\
22 \\
23 \\
24 \\
25 \\
26 \\
27 \\
28 \\
29 \\
30 \\
31\end{array}$ & $\begin{array}{r}5,970 \\
2,520 \\
2,980 \\
4,210 \\
2,650 \\
1,890 \\
1,500 \\
1,240 \\
1,070 \\
938\end{array}$ & $\begin{array}{l}2,340 \\
2,270 \\
2,340 \\
2,130 \\
2,060 \\
1,930 \\
1,800 \\
1,740 \\
1,660 \\
1,580 \\
1,400\end{array}$ & $\begin{array}{l}2,560 \\
2,340 \\
2,270 \\
2,060 \\
1,860 \\
1,670 \\
1,670 \\
1,800 \\
1,930 \\
1,640 \\
3,240\end{array}$ \\
\hline & & & & & & & & & $\begin{array}{r}1,360 \\
80,900\end{array}$ & $\begin{array}{r}6,596 \\
405,600\end{array}$ & $\begin{array}{r}1,977 \\
121,600\end{array}$ \\
\hline
\end{tabular}

Gage height, In feet, and discharge, in second-feet, at indicated time, 1937

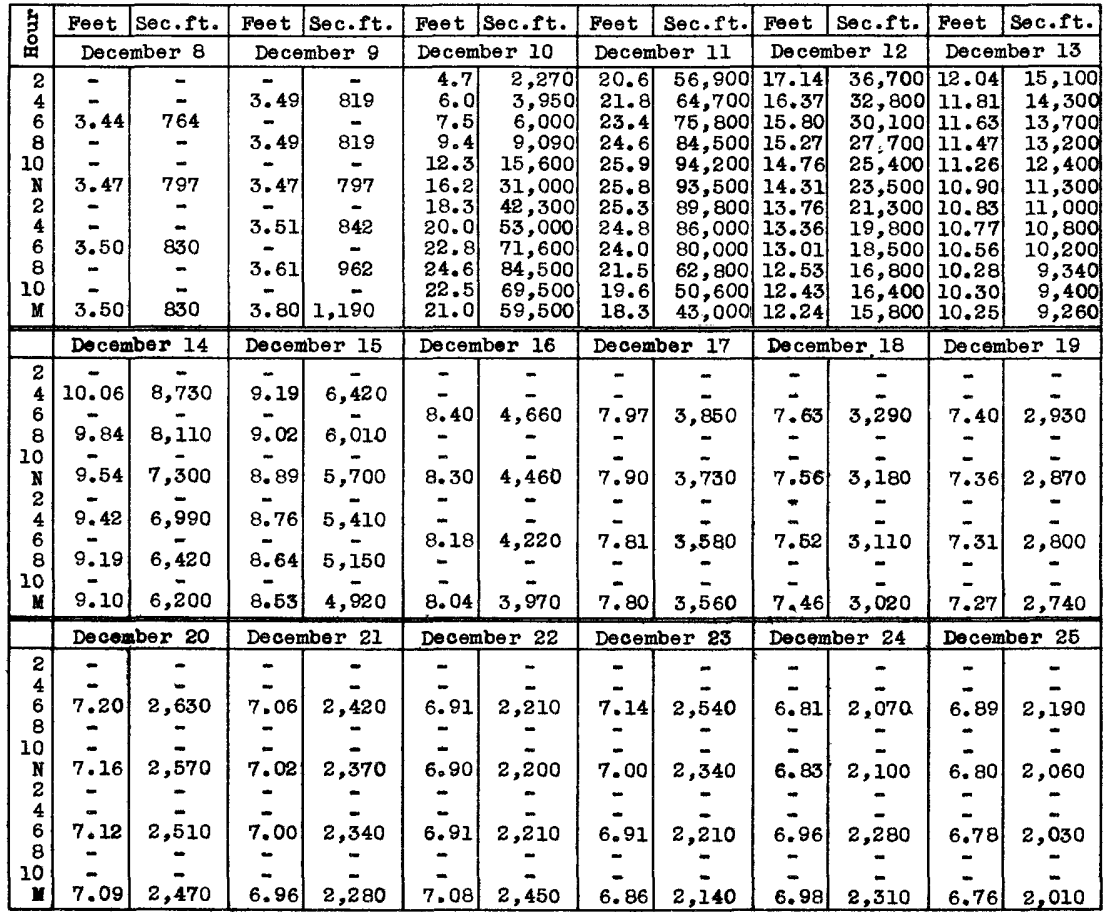

Supplemental records.- Dec. 11, 9 a.m., 26.0 ft., 95,000 sec.-ft. 
Oregon Creok near North San Juan, Callf.

Location. - Lat. $39^{\circ} 24^{\prime}$, long. $121^{\circ} 05^{\prime}$, in swl sec. 22 , T. $18 \mathrm{~N}$, , R. 8 F., 1 mile above mouth and 3 miles northeast of North San Juan, Nevada County. Altitude, about 1,500 feet above mean sea level.

Drainage area. - 35.1 square miles.

Gage-he1ght record. - Water-stage recorder graph except for period 6:30 a.m. Jan. 22 to Jan. 31, when there was no record.

Stage-discharge relation.- Defined by current-meter measurements below 2,100 secondfeot; extended to pork stage.

Mexima:- December 1937: Discharge, 2,750 second-feet 6 a.m. Dec. 11 (gage height, 9.25 foet).

1911-November 1937: Discharge observed, about 4,000 second-feet (revised) Mar.

25,1928 (gage helght, 9.5 feet, from nonrecording gage, former site and datum) from rating curve extended above 250 second-feet.

Remarks. - Plood mun-off not affected by artificlal storage or diversion. Discharge for perlod of missing gage-helght record determined from discharge graph based on record for Middle Fork of Yuba River near North San Juan.

Mean dally discharge, in second-feet, November 1937 to January 1938

\begin{tabular}{|c|c|c|c||c|c|c|c|c|c|c|c|}
\hline Day & Nov. & Dec. & Jan. & Day & Nov. & Dec. & Jan. & Day & Nov. & Dec. & Jan. \\
\hline 1 & 4.8 & 16 & 35 & 11 & 14 & 1,540 & 28 & 21 & 76 & 46 & 125 \\
2 & 4.5 & 14 & 42 & 12 & 15 & 560 & 27 & 22 & 34 & 47 & 115 \\
3 & 4.3 & 13 & 46 & 13 & 8.5 & 268 & 27 & 23 & 90 & 49 & 110 \\
4 & 4.3 & 12 & 42 & 14 & 25 & 179 & 26 & 24 & 110 & 46 & 105 \\
5 & 4.3 & 11 & 40 & 15 & 20 & 130 & 72 & 25 & 54 & 42 & 90 \\
6 & 4.1 & 10 & 37 & 16 & 27 & 102 & 65 & 26 & 37 & 39 & 82 \\
7 & 4.1 & 9.5 & 35 & 17 & 112 & 81 & 571 & 27 & 29 & 37 & 76 \\
8 & 3.8 & 9 & 33 & 18 & 36 & 68 & 289 & 28 & 24 & 36 & 76 \\
9 & 3.8 & 15 & 31 & 19 & 23 & 58 & 194 & 29 & 20 & 36 & 74 \\
10 & 3.8 & 832 & 30 & 20 & 107 & 52 & 149 & 30 & 18 & 34 & 72 \\
\end{tabular}

Gage helght, in feet, and discharge, in second-feet, at 1ndicated time, 1937

\begin{tabular}{|c|c|c|c|c|c|c|c|c|c|c|c|c|}
\hline \multirow{2}{*}{$\begin{array}{l}5 \\
5 \\
0 \\
0\end{array}$} & Feet & Sec.ft. & Feet & Sec.ft. & Feot & Sec.ft. & Foet & Sec.ft. & Feet & Sec.ft. & Feet & Sec.ft. \\
\hline & \multicolumn{2}{|c|}{ December 8} & \multicolumn{2}{|c|}{ December 9} & \multicolumn{2}{|c|}{ December 10} & \multicolumn{2}{|c|}{ De cember 11} & \multicolumn{2}{|c|}{ December 12} & \multicolumn{2}{|c|}{ December 13} \\
\hline $\begin{array}{r}2 \\
4 \\
6 \\
8 \\
10 \\
N \\
2 \\
4 \\
6 \\
8 \\
10 \\
11\end{array}$ & $\begin{array}{c}\overline{-} \\
\overline{1.82} \\
- \\
\overline{1.83} \\
\overline{-} \\
1.82 \\
\overline{-} \\
1.82\end{array}$ & $\begin{array}{c}\overline{9} \\
= \\
9.5 \\
= \\
= \\
=\end{array}$ & $\begin{array}{l}1.82 \\
1.82 \\
1.82 \\
1.82 \\
1.82 \\
1.82 \\
1.84 \\
1.88 \\
1.95 \\
2.09 \\
2.35 \\
3.10\end{array}$ & $\begin{array}{r}9 \\
9 \\
9 \\
9 \\
9 \\
9 \\
10 \\
11 \\
14 \\
19 \\
30 \\
74\end{array}$ & $\begin{array}{l}4.30 \\
6.30 \\
6.88 \\
6.88 \\
6.40 \\
6.41 \\
6.70 \\
6.41 \\
6.33 \\
6.20 \\
6.06 \\
6.04\end{array}$ & $\begin{array}{r}220 \\
860 \\
1,150 \\
1,150 \\
910 \\
915 \\
1,060 \\
915 \\
875 \\
815 \\
752 \\
743\end{array}$ & $\begin{array}{l}6.19 \\
7.95 \\
9.25 \\
8.24 \\
7.94 \\
8.30 \\
8.15 \\
7.64 \\
7.18 \\
6.75 \\
6.42 \\
6.20\end{array}$ & $\begin{array}{r}810 \\
1,820 \\
2,750 \\
2,020 \\
1,810 \\
2,060 \\
1,960 \\
1,600 \\
1,330 \\
1,080 \\
920 \\
815\end{array}$ & $\begin{array}{l}6.08 \\
6.01 \\
5.93 \\
5.82 \\
5.66 \\
5.56 \\
5.44 \\
5.34 \\
5.23 \\
5.12 \\
5.00 \\
4.89\end{array}$ & $\begin{array}{l}761 \\
730 \\
694 \\
648 \\
584 \\
541 \\
500 \\
467 \\
433 \\
402 \\
370 \\
344\end{array}$ & $\begin{array}{c}- \\
4.75 \\
- \\
4.62 \\
- \\
4.51 \\
- \\
4.41 \\
- \\
4.35 \\
- \\
4.26\end{array}$ & $\begin{array}{c}3 \overline{11} \\
\overline{282} \\
2 \overline{60} \\
\overline{240} \\
2 \overline{2} 9 \\
\overline{2} 14\end{array}$ \\
\hline & \multicolumn{2}{|c|}{ December 14} & \multicolumn{2}{|c|}{ December 15} & \multicolumn{2}{|c|}{ December 16} & \multicolumn{2}{|c|}{ December 17} & \multicolumn{2}{|c|}{ December 18} & \multicolumn{2}{|c|}{ December 19} \\
\hline $\begin{array}{r}2 \\
4 \\
6 \\
8 \\
8 \\
10 \\
\mathbb{N} \\
2 \\
4 \\
6 \\
8 \\
10 \\
\mathbf{M}\end{array}$ & $\begin{array}{c}- \\
4.18 \\
4.10 \\
- \\
4.02 \\
3.95 \\
-- \\
3.87 \\
- \\
3.81\end{array}$ & $\begin{array}{c}2 \overline{01} \\
\overline{189} \\
\overline{178} \\
\overline{168} \\
\overline{15} \\
\overline{149}\end{array}$ & $\begin{array}{c}3.75 \\
- \\
3.70 \\
- \\
3.65 \\
- \\
3.60 \\
- \\
3.55 \\
- \\
3.50\end{array}$ & $\begin{array}{l}\overline{142} \\
\overline{136} \\
\overline{130} \\
\overline{124} \\
\overline{118} \\
\overline{113}\end{array}$ & $\begin{array}{c}- \\
- \\
3.45 \\
- \\
3.39 \\
- \\
3.34 \\
\overline{-} \\
3.27\end{array}$ & $\begin{array}{c}\overline{-} \\
108 \\
- \\
\overline{101} \\
\overline{9} \\
\overline{9} \\
\overline{89} \\
\overline{89}\end{array}$ & $\begin{array}{c}- \\
\overline{3.23} \\
\overline{-} \\
3.19 \\
\overline{-} \\
3.15 \\
\overline{-} \\
3.11\end{array}$ & $\begin{array}{l}\overline{-} \\
86 \\
\overline{-} \\
82 \\
\overline{-} \\
78 \\
\overline{7} \\
\overline{75}\end{array}$ & $\begin{array}{c}- \\
\bar{z} .07 \\
- \\
\overline{3.03} \\
\overline{-} \\
2.99 \\
\overline{-} \\
2.95\end{array}$ & $\begin{array}{l}\overline{-} \\
72 \\
- \\
- \\
68 \\
- \\
\overline{65} \\
- \\
62\end{array}$ & $\begin{array}{c}- \\
2.92 \\
\overline{-} \\
\overline{2.89} \\
\overline{-} \\
\overline{2.86} \\
\overline{-} \\
2.83\end{array}$ & $\begin{array}{l}\overline{-} \\
- \\
- \\
58 \\
- \\
57 \\
\overline{5} \\
55\end{array}$ \\
\hline & \multicolumn{2}{|c|}{ December 20} & \multicolumn{2}{|c|}{ December 21} & \multicolumn{2}{|c|}{ December 22} & \multicolumn{2}{|c|}{ December 23} & \multicolumn{2}{|c|}{ December 24} & \multicolumn{2}{|c|}{ December 25} \\
\hline $\begin{array}{r}2 \\
4 \\
6 \\
8 \\
10 \\
N \\
2 \\
4 \\
6 \\
8 \\
10 \\
\mathbf{Y}\end{array}$ & $\begin{array}{c}\bar{z} \\
2.80 \\
\overline{-} \\
2.78 \\
\bar{z} \\
2.75 \\
\overline{-} \\
2.73\end{array}$ & $\begin{array}{l}- \\
\overline{53} \\
- \\
\overline{52} \\
\overline{-} \\
\overline{50} \\
\overline{-} \\
49\end{array}$ & $\begin{array}{c}- \\
- \\
2.70 \\
\overline{-} \\
\overline{2.69} \\
\bar{z} \\
2.67 \\
\overline{-} \\
2.65\end{array}$ & $\begin{array}{l}- \\
47 \\
- \\
- \\
46 \\
\vdots \\
46 \\
= \\
44\end{array}$ & $\begin{array}{c}- \\
2.64 \\
- \\
2.63 \\
- \\
2.63 \\
2.70 \\
\overline{2.80} \\
\overline{2.94}\end{array}$ & $\begin{array}{l}\overline{4} \\
- \\
44 \\
- \\
44 \\
- \\
47 \\
- \\
53 \\
- \\
62\end{array}$ & $\begin{array}{c}- \\
2.85 \\
- \\
2.75 \\
- \\
2.70 \\
- \\
2.66 \\
- \\
2.64 \\
- \\
2.63\end{array}$ & $\begin{array}{l}-56 \\
- \\
50 \\
- \\
47 \\
- \\
45 \\
- \\
44 \\
-44\end{array}$ & $\begin{array}{c}- \\
2.62 \\
- \\
2.61 \\
- \\
2.65 \\
- \\
2.72 \\
- \\
2.71 \\
- \\
2.66\end{array}$ & $\begin{array}{l}\overline{43} \\
- \\
42 \\
- \\
44 \\
\overline{48} \\
\overline{4} \\
\overline{4} \\
45\end{array}$ & $\begin{array}{c}- \\
- \\
2.62 \\
- \\
- \\
2.58 \\
- \\
\dot{2} .57 \\
\overline{-} \\
2.57\end{array}$ & $\begin{array}{l}\overline{-} \\
43 \\
= \\
41 \\
- \\
40 \\
- \\
40\end{array}$ \\
\hline
\end{tabular}

Supplemental records.. Dec. 11, 3 a.m., $6.64 \mathrm{ft.,} 1,030$ sec.-ft. 


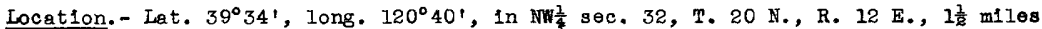
west of Slerra City, Slerra County, and $2 \frac{1}{2} \mathrm{mlles}$ below South Fork of North Fork of Yubs River. Altitude, about 4,100 feet above mean sea level.

Drainage area. - 91.3 square miles.

Gage-he1ght record. - Water-s tage recorder graph except for period 7:30 a.m. Dec. 26 to 3 p.m. Dec. 28, when 1t was based on range of stage indicated on recorder graph. Gage heights shown are gage helghts inside of well. At high stages gage inside of well usually reads lower than gage outslde of well because of effect of drawdown, but near peak stage water entered well through ventilators, causing outside and Inside gages to read about the same.

Stage-discharge relation.- Defined by current-meter measurements below 2,500 secondfeet; extended to peak stage by averaging discharges determined on basis of areavelocity study and $A \sqrt{a}$ method; verifled by logarithmic extension. Rating curve changed at peak stage.

Maxima.- December 1937: Discharge, 9,800 second-feet about 4 a.m. Dec. 11 (gage helght, about 10.0 fe日t).

1911-13, 1923-November 1937: D1scharge, 5,920 second-feet Mar. 25, 1928 (gage helght, 8.50 feet), from rating curve extended above 600 second-feet on basis of area-velocity study.

Remarks.- Flood man-off not meterially affected by artificlal storage or diversion.

Mean dally discharge, in second-feet, November 1937 to January 1938

\begin{tabular}{|c|c|r|c||c|c|c|c|c|c|c|c|}
\hline Day & Nov. & Dec. & Jan. & Day & Nov. & Dec. & Jan. & Day & Nov. & Dec. & Jan. \\
\hline 1 & 46 & 87 & 148 & 11 & 57 & 5,300 & 124 & 21 & 218 & 211 & 133 \\
2 & 45 & 85 & 153 & 12 & 50 & 1,300 & 122 & 22 & 136 & 200 & 138 \\
3 & 45 & 82 & 148 & 13 & 54 & 810 & 122 & 23 & 160 & 191 & 133 \\
4 & 44 & 79 & 142 & 14 & 70 & 565 & 122 & 24 & 148 & 188 & 127 \\
5 & 44 & 76 & 138 & 15 & 61 & 448 & 135 & 25 & 127 & 183 & 130 \\
6 & 45 & 74 & 132 & 16 & 97 & 374 & 128 & 26 & 114 & 166 & 128 \\
7 & 45 & 73 & 132 & 17 & 191 & 322 & 155 & 27 & 107 & 162 & 128 \\
8 & 45 & 73 & 128 & 18 & 105 & 286 & 148 & 28 & 100 & 157 & 130 \\
9 & 45 & 136 & 127 & 19 & 103 & 250 & 140 & 29 & 94 & 153 & 128 \\
10 & 45 & 4,310 & 125 & 20 & 304 & 227 & 135 & 30 & 90 & 151 & 125 \\
&
\end{tabular}

Gage helght, in feet, and discharge, in second-feet, at indicated time, 1937

\begin{tabular}{|c|c|c|c|c|c|c|c|c|c|c|c|c|}
\hline \multirow{2}{*}{$\begin{array}{l}5 \\
0 \\
0 \\
\end{array}$} & Feet & Sec.ft. & Feet & Sec.ft. & Feet & Sec.ft. & Feet & Sec.ft. & Fe日t & Sec.ft. & Feet & Sec.ft. \\
\hline & \multicolumn{2}{|c|}{ December 8} & \multicolumn{2}{|c|}{ December 9} & \multicolumn{2}{|c|}{ December 10} & \multicolumn{2}{|c|}{ December 11} & \multicolumn{2}{|c|}{ December 12} & \multicolumn{2}{|c|}{ December 13} \\
\hline $\begin{array}{r}2 \\
4 \\
6 \\
8 \\
10 \\
N \\
2 \\
4 \\
6 \\
8 \\
10 \\
y\end{array}$ & $\begin{array}{c}- \\
\overline{1.84} \\
- \\
\overline{1.84} \\
- \\
1.84 \\
- \\
1.84\end{array}$ & $\begin{array}{l}\overline{-} \\
\overline{73} \\
\bar{z} \\
\overline{7} 3 \\
\overline{-} \\
\overline{7} 3 \\
\bar{z} \\
\overline{7} 3\end{array}$ & $\begin{array}{l}1.83 \\
1.83 \\
1.83 \\
1.83 \\
1.83 \\
1.84 \\
1.87 \\
1.96 \\
2.15 \\
2.47 \\
2.83 \\
4.04\end{array}$ & $\begin{array}{r}72 \\
72 \\
72 \\
72 \\
72 \\
73 \\
76 \\
87 \\
110 \\
159 \\
254 \\
966\end{array}$ & $\begin{array}{l}4.60 \\
5.53 \\
5.83 \\
6.08 \\
6.30 \\
7.02 \\
7.30 \\
6.90 \\
6.85 \\
6.96 \\
6.95 \\
7.25\end{array}$ & $\begin{array}{l}1,560 \\
2,840 \\
3,320 \\
3,750 \\
4,130 \\
5,480 \\
6,050 \\
5,240 \\
5,140 \\
5,360 \\
5,340 \\
5,940\end{array}$ & $\begin{array}{r}7.96 \\
10.00 \\
8.16 \\
7.71 \\
7.16 \\
6.66 \\
5.50 \\
5.52 \\
5.25 \\
4.90 \\
4.66 \\
4.45\end{array}$ & $\begin{array}{l}7,470 \\
9,800 \\
8,120 \\
7,280 \\
6,290 \\
5,390 \\
3,500 \\
3,530 \\
3,130 \\
2,640 \\
2,310 \\
2,060\end{array}$ & $\begin{array}{l}4.20 \\
4.02 \\
3.90 \\
3.81 \\
3.76 \\
3.70 \\
3.69 \\
3.67 \\
3.61 \\
3.52 \\
3.47 \\
3.42\end{array}$ & \begin{tabular}{|l|}
1,760 \\
1,560 \\
1,440 \\
1,360 \\
1,310 \\
1,260 \\
1,250 \\
1,240 \\
1,190 \\
1,120 \\
1,080 \\
1,040
\end{tabular} & $\begin{array}{l}3.30 \\
- \\
3.18 \\
- \\
3.09 \\
- \\
3.02 \\
- \\
2.91 \\
- \\
2.83\end{array}$ & $\begin{array}{c}\overline{950} \\
\overline{866} \\
\overline{804} \\
\overline{6} \\
\overline{6} \\
\overline{696} \\
\overline{652}\end{array}$ \\
\hline & \multicolumn{2}{|c|}{ December 14} & \multicolumn{2}{|c|}{ December 15} & \multicolumn{2}{|c|}{ December 16} & \multicolumn{2}{|c|}{ December 17} & \multicolumn{2}{|c|}{ December 18} & \multicolumn{2}{|c|}{ December 19} \\
\hline $\begin{array}{r}2 \\
4 \\
6 \\
8 \\
10 \\
N \\
2 \\
4 \\
6 \\
8 \\
10 \\
\text { u }\end{array}$ & $\begin{array}{l}- \\
2.75 \\
\overline{2.70} \\
\overline{2.65} \\
\dot{-} \\
2.63 \\
- \\
2.57 \\
\overline{2.52}\end{array}$ & $\begin{array}{c}\overline{-} \\
608 \\
5 \overline{80} \\
\overline{5} \\
\overline{5} \\
5 \overline{45} \\
\overline{15} \\
\overline{150}\end{array}$ & $\begin{array}{c}- \\
\overline{2.47} \\
\overline{-} \\
2.42 \\
\overline{-} \\
2.39 \\
\overline{-} \\
2.33\end{array}$ & $\begin{array}{c}\overline{-} \\
466 \\
\overline{-} \\
444 \\
\overline{-} \\
430 \\
\overline{-} \\
404\end{array}$ & $\begin{array}{c}\overline{-} \\
2.29 \\
\vdots \\
2.25 \\
\overline{-} \\
2.23 \\
\overline{2.19}\end{array}$ & $\begin{array}{c}\overline{-} \\
386 \\
\overline{-} \\
3 \overline{7} 0 \\
\overline{-} \\
3 \overline{6} \\
\overline{-} \\
346\end{array}$ & $\begin{array}{c}- \\
\overline{2.15} \\
- \\
\overline{2.12} \\
\overline{-} \\
2.12 \\
\overline{-} \\
2.09\end{array}$ & $\begin{array}{c}\overline{-} \\
330 \\
\overline{-} \\
\overline{318} \\
\overline{-} \\
\overline{318} \\
\overline{-} \\
306\end{array}$ & $\begin{array}{c}- \\
2.05 \\
\overline{-} \\
2.02 \\
\overline{-} \\
2.02 \\
\overline{-} \\
1.98\end{array}$ & $\begin{array}{c}\overline{-} \\
2 \overline{9} \\
\overline{-} \\
2 \overline{82} \\
\overline{-} \\
2 \overline{8} \\
\overline{-} \\
2 \overline{68}\end{array}$ & $\begin{array}{c}- \\
\overline{1.95} \\
\overline{-} \\
1.93 \\
\overline{-} \\
1.93 \\
\overline{1.89} \\
1.89\end{array}$ & $\begin{array}{c}\overline{-} \\
258 \\
\overline{-} \\
250 \\
- \\
250 \\
- \\
237\end{array}$ \\
\hline & \multicolumn{2}{|c|}{ December 20} & \multicolumn{2}{|c|}{ December 21} & \multicolumn{2}{|c|}{ December 22} & \multicolumn{2}{|c|}{ December 23} & \multicolumn{2}{|c|}{ December 24} & \multicolumn{2}{|c|}{ December 25} \\
\hline 2 & - & - & - & - & - & - & - & - & -1 & - & -1 & 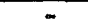 \\
\hline $\begin{array}{l}4 \\
6\end{array}$ & 1.85 & $2 \overline{24}$ & $\overline{1.80}$ & 208 & $\overline{1.77}$ & $2 \overline{00}$ & 1.74 & $\overline{191}$ & $\overline{1.74}$ & $\overline{191}$ & $\overline{1.71}$ & 183 \\
\hline 8 & 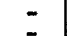 & $=$ & & $=$ & & $=$ & & $\overline{-}$ & 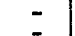 & $=$ & $=$ & $=$ \\
\hline 10 & $\overline{1.84}$ & $\overline{2}_{1}$ & 1.80 & $2 \overline{08}$ & $\overline{1.77}$ & $2 \overline{00}$ & $\overline{1.76}$ & 197 & $\overline{1.74}$ & $1 \overline{191}$ &.$\overline{7.71}$ & $1 \overline{83}$ \\
\hline 2 & 1800 & - & & - & & - & 10.64 & - & $10.1=$ & - & - & - \\
\hline 4 & - & $\bar{n}$ & - & - & - & in & - & - & $-m$ & $\vec{B}$ & - & $=$ \\
\hline 6 & 1.87 & 230 & 1.84 & 221 & 1.81 & 211 & 1.78 & 202 & 1.72 & 186 & 1.71 & 183 \\
\hline $\begin{array}{r}8 \\
10\end{array}$ & - & $\overline{-}$ & - & - & - & $\overline{-}$ & - & $\overline{-}$ & - & $\overline{-}$ & - & $\overline{-}$ \\
\hline$x$ & 1.83 & 218 & 1.81 & 211 & 1.70 & 180 & 1.74 & 191 & 1.72 & 186 & 1.68 & 175 \\
\hline
\end{tabular}


Lake Spaulding noar Emigrant Gap, Calif.

Location.- Lat. $39^{\circ} 20^{\prime}$, long. $120^{\circ} 38^{\prime}$, in sec. 20, T. 17 N., R. 12 E., at dam on South Fork of Yuba River $2 \frac{1}{2}$ miles northeast of Emigrant Gap, Placer County. Zero of gage is 4,621 foet above mean sea levol.

Drainage area.- 118 square miles.

Gage-height record. - Gage read to tenths daily at $5 \mathrm{p.m}$.

Remarks.- Flood run-off largely controlied in lake (capacity, 71,000 acre-feot at olovation of crest of splilway, 4,821 feet). Reservolr spliled for period 8 a.m. Dec. Il to 11 a.m. Dec. 15. See record for South Fork of Yuba River at lake Spaulding. Basic data furnished by Pacific Gas \& Electric Co.

Gage helght and contents, November 1937 to January 1938

\begin{tabular}{|c|c|c|c|c|c|c|}
\hline \multirow[b]{2}{*}{ Day } & \multicolumn{2}{|c|}{ November } & \multicolumn{2}{|c|}{ December } & \multicolumn{2}{|c|}{ January } \\
\hline & $\begin{array}{c}\text { Gage height } \\
(f \in e t)\end{array}$ & $\begin{array}{c}\text { Contents } \\
(\text { acre-feet })\end{array}$ & ${ }_{(f \theta e t)}^{\text {Gage } h \theta 1 g h t}$ & $\begin{array}{l}\text { Contents } \\
(\text { acre-feet })\end{array}$ & $\begin{array}{c}\text { Gage } h \theta 1 g h t \\
(f \theta \theta t)\end{array}$ & $\begin{array}{l}\text { Contents } \\
(\operatorname{acr} \theta-f \theta \theta t)\end{array}$ \\
\hline $\begin{array}{l}1 \\
2 \\
3 \\
4 \\
5\end{array}$ & $\begin{array}{l}166.4 \\
165.5 \\
164.6 \\
163.6 \\
162.6\end{array}$ & $\begin{array}{l}50,116 \\
49,603 \\
49,090 \\
48,528 \\
47,978\end{array}$ & $\begin{array}{l}157.8 \\
156.7 \\
155.8 \\
154.7 \\
153.6\end{array}$ & $\begin{array}{l}45,363 \\
44,780 \\
44,304 \\
43,721 \\
43,138\end{array}$ & $\begin{array}{l}177.8 \\
177.6 \\
177.6 \\
177.5 \\
177.3\end{array}$ & $\begin{array}{l}56,788 \\
56,667 \\
56,667 \\
56,607 \\
56,487\end{array}$ \\
\hline $\begin{array}{r}6 \\
7 \\
8 \\
9 \\
10\end{array}$ & $\begin{array}{l}161.7 \\
161.1 \\
160.1 \\
159.3 \\
158.1\end{array}$ & $\begin{array}{l}47,483 \\
47,153 \\
46,603 \\
46,163 \\
45,521\end{array}$ & $\begin{array}{l}152.8 \\
151.9 \\
150.6 \\
149.5 \\
175.0\end{array}$ & $\begin{array}{l}42,714 \\
32,237 \\
41,548 \\
40,965 \\
55,102\end{array}$ & $\begin{array}{l}177.0 \\
176.3 \\
176.0 \\
175.5 \\
175.0\end{array}$ & $\begin{array}{l}56,306 \\
55,885 \\
55,704 \\
55,403 \\
55,102\end{array}$ \\
\hline $\begin{array}{l}11 \\
12 \\
13 \\
14 \\
15\end{array}$ & $\begin{array}{l}157.4 \\
156.7 \\
156.1 \\
156.1 \\
156.1\end{array}$ & $\begin{array}{l}45,151 \\
44,780 \\
44,462 \\
44,462 \\
44,462\end{array}$ & $\begin{array}{l}205.2 \\
201.7 \\
201.2 \\
200.7 \\
199.7\end{array}$ & $\begin{array}{l}74,626 \\
72,197 \\
71,850 \\
71,503 \\
70,809\end{array}$ & $\begin{array}{l}174.5 \\
174.0 \\
173.3 \\
172.9 \\
173.5\end{array}$ & $\begin{array}{l}54,801 \\
54,500 \\
54,094 \\
53,861 \\
54,210\end{array}$ \\
\hline $\begin{array}{l}16 \\
17 \\
18 \\
19 \\
20\end{array}$ & $\begin{array}{l}156.0 \\
157.1 \\
157.0 \\
156.6 \\
157.4\end{array}$ & $\begin{array}{l}44,409 \\
44,992 \\
44,939 \\
44,727 \\
45,151\end{array}$ & $\begin{array}{l}199.0 \\
198.0 \\
196.8 \\
195.5 \\
194.0\end{array}$ & $\begin{array}{l}70,323 \\
69,678 \\
68,905 \\
68,067 \\
67,100\end{array}$ & $\begin{array}{l}173.7 \\
174.0 \\
174.0 \\
173.9 \\
173.8\end{array}$ & $\begin{array}{l}54,326 \\
54,500 \\
54,500 \\
54,442 \\
54,384\end{array}$ \\
\hline $\begin{array}{l}21 \\
22 \\
23 \\
24 \\
25\end{array}$ & $\begin{array}{l}158.0 \\
159.7 \\
160.1 \\
161.1 \\
161.9\end{array}$ & $\begin{array}{l}45,468 \\
46,383 \\
46,603 \\
47,153 \\
47,593\end{array}$ & $\begin{array}{l}192.9 \\
191.5 \\
190.0 \\
188.2 \\
187.0\end{array}$ & $\begin{array}{l}66,396 \\
65,500 \\
64,540 \\
63,372 \\
62,580\end{array}$ & $\begin{array}{l}173.4 \\
173.2 \\
173.6 \\
174.1 \\
173.8\end{array}$ & $\begin{array}{l}54,152 \\
54,036 \\
54,268 \\
54,560 \\
54,384\end{array}$ \\
\hline $\begin{array}{l}26 \\
27 \\
28 \\
29 \\
30 \\
31\end{array}$ & $\begin{array}{l}162.2 \\
161.4 \\
160.4 \\
159.3 \\
158.6\end{array}$ & $\begin{array}{l}47,758 \\
47,318 \\
46,768 \\
46,163 \\
45,876\end{array}$ & $\begin{array}{l}185.5 \\
183.7 \\
182.1 \\
180.2 \\
178.8 \\
178.0\end{array}$ & $\begin{array}{l}61,590 \\
60,415 \\
59,426 \\
58,252 \\
57,390 \\
56,908\end{array}$ & $\begin{array}{l}173.7 \\
173.2 \\
172.9 \\
172.8 \\
172.7 \\
172.6\end{array}$ & $\begin{array}{l}54,326 \\
54,036 \\
53,861 \\
53,803 \\
53,745 \\
53,687\end{array}$ \\
\hline
\end{tabular}


South Fork of Yuba River at Lake Spaulding, Cal1f.

Location.- Lat. $39^{\circ} 20^{\prime}$, long. $120^{\circ} 38^{\prime}$, in sec. 20, T. 17 N., R. 12 E., st Lake Spaulding Dam, Nevada County.

Drainage area.- 118 square miles.

Gage-helght record. - Water-stage recorder graph (lake and splllway record) for period 8 a.m. Dec. II to 11 s.m. Dec. 15. Staff gage on lake read dally at 5 p.m. Waterstage recorder graph for Bowman-Spaulding canal. Record of da1ly discharge furnished for splll and release.

Max1ma.- December 1937: Greatest outflow, 19,600 second-feet about 12:15 p.m. Dec. 11, computed from records of spill and release. Maximum inflow to reservoli probabiy occurred earlier, while $1 t$ was rising rapidly,

Remariss.- Computed river discharge has been adjusted for 1tems shown in table but not for storage in Lake Fordyce or other upstream reservoirs. Gain or loss in storage computed from contents at midnight determined from graph based on da 1 iy readings at 5 p.m. See record for Lake Spaulding near Emigrant Gap. Most of basic data fumished by Pacific Gas \& Blectric Co.

Storage, release, Inflow, and discharge, December 1-20, 1937

\begin{tabular}{|c|c|c|c|c|c|c|}
\hline \multirow[b]{2}{*}{ Day } & \multicolumn{4}{|c|}{ Lake Spaulding } & \multirow[b]{2}{*}{$\begin{array}{c}\text { Inflow from } \\
\text { Bowman-spaulding } \\
\text { canal } \\
\text { (sec.-ft.) }\end{array}$} & \multirow[b]{2}{*}{$\begin{array}{c}\text { Computed river } \\
\text { discharge } \\
\text { (sec.-ft.) }\end{array}$} \\
\hline & $\begin{array}{l}\text { Contents } \\
(\text { acre-feet })\end{array}$ & $\begin{array}{l}\text { Gain or loss } \\
\text { in storage } \\
(\text { acre-feet) }\end{array}$ & $\begin{array}{c}\text { sp11I } \\
(s \theta c .-f t .)\end{array}$ & $\begin{array}{c}\operatorname{Release} \\
(\mathrm{sec},-\mathrm{ft} .)\end{array}$ & & \\
\hline $\begin{array}{l}1 \\
2 \\
3 \\
4 \\
5\end{array}$ & $\begin{array}{l}45,193 \\
44,641 \\
44,134 \\
43,551 \\
43,014\end{array}$ & $\begin{array}{l}-470 \\
-552 \\
-507 \\
-583 \\
-537\end{array}$ & $\begin{array}{l}0 \\
0 \\
0 \\
0 \\
0\end{array}$ & $\begin{array}{l}550 \\
550 \\
549 \\
550 \\
535\end{array}$ & \begin{tabular}{|l|}
229 \\
229 \\
229 \\
229 \\
229
\end{tabular} & $* 49$ \\
\hline $\begin{array}{r}6 \\
7 \\
8 \\
9 \\
10\end{array}$ & $\begin{array}{l}42,575 \\
42,036 \\
41,378 \\
41,900 \\
59,500\end{array}$ & $\begin{array}{r}-439 \\
-539 \\
-658 \\
+522 \\
+17,600\end{array}$ & $\begin{array}{l}0 \\
0 \\
0 \\
0 \\
0\end{array}$ & $\begin{array}{l}551 \\
551 \\
550 \\
537 \\
359\end{array}$ & $\begin{array}{r}229 \\
229 \\
229 \\
206 \\
39\end{array}$ & $\begin{array}{l}594 \\
9,190\end{array}$ \\
\hline $\begin{array}{l}11 \\
12 \\
13 \\
14 \\
15\end{array}$ & $\begin{array}{l}73,200 \\
72,130 \\
71,800 \\
71,295 \\
70,667\end{array}$ & $\begin{array}{r}+13,700 \\
-1,070 \\
-330 \\
-505 \\
-628\end{array}$ & $\begin{array}{r}4,830 \\
1,580 \\
507 \\
255 \\
30\end{array}$ & $\begin{array}{l}626 \\
797 \\
696 \\
781 \\
894\end{array}$ & $\begin{array}{l}26^{.2} \\
106 \\
130 \\
135\end{array}$ & $\begin{array}{r}12,400 \\
1,810 \\
931 \\
651 \\
472\end{array}$ \\
\hline $\begin{array}{l}16 \\
17 \\
18 \\
19 \\
20\end{array}$ & $\begin{array}{l}70,135 \\
69,453 \\
68,661 \\
67,785 \\
66,895\end{array}$ & $\begin{array}{l}-532 \\
-682 \\
-792 \\
-876 \\
-890\end{array}$ & $\begin{array}{l}0 \\
0 \\
0 \\
0 \\
0\end{array}$ & $\begin{array}{l}902 \\
924 \\
944 \\
944 \\
944\end{array}$ & $\begin{array}{l}126 \\
106 \\
112 \\
111 \\
111\end{array}$ & $\begin{array}{l}508 \\
474 \\
433 \\
391 \\
384\end{array}$ \\
\hline
\end{tabular}

* Mean for the period. 
Bowman Lake near Granitev111e, Cal1f.

Location.- Lat. $39^{\circ} 27^{\prime}$, long. $120^{\circ} 39^{\prime}$, In Sw sec. 5, T. 18 N., R, 12 E., at Bowman Dam, on Canyon Creok, 4 miles east of Graniteville, Nevada County. Zero of gage 1s at mean sea level.

Dralnage area.- 30 square miles.

Gage-helght record.- Gage read to tenths da11y at 4:30 p.m. except on days for wh1ch no record is shown.

Remarks.- Flood run-off completely controlled in lake (capac1ty, 62 , 400 acre-feet at elevation of crest of splliway of concrete dam, 5555.75 feet). Elevation of top of rock-fill dam 1s 5,567 feet. Water is brought into the lake from Middle Fork of Yuba River through Milton-Bowman tunnel and is released through Bowman-Spaulding canal. See record for Canyon Creek below Bowman Lake. Baslc data furnished by Nevada Irrigation Distriet.

Elevation and contents, November 1937 to January 1938

\begin{tabular}{|c|c|c|c|c|c|c|}
\hline \multirow[b]{2}{*}{ Day } & \multicolumn{2}{|c|}{ November } & \multicolumn{2}{|c|}{ December } & \multicolumn{2}{|c|}{ January } \\
\hline & $\begin{array}{l}\text { Elevation } \\
\text { (feet) }\end{array}$ & $\begin{array}{l}\text { Contents } \\
(\operatorname{acre}-f e \theta t)\end{array}$ & $\begin{array}{l}\text { Elevation } \\
(\text { feet })\end{array}$ & $\begin{array}{l}\text { Contents } \\
\text { (acre-feet) }\end{array}$ & $\begin{array}{l}\text { Elevation } \\
\text { (feet) }\end{array}$ & $\begin{array}{l}\text { Contents } \\
(\operatorname{acre}-\mathrm{fe \theta})\end{array}$ \\
\hline $\begin{array}{l}1 \\
2 \\
3 \\
4 \\
5\end{array}$ & $\begin{array}{l}5,509.9 \\
5,509.1 \\
5,508.3 \\
5,507.4 \\
5,506.6\end{array}$ & $\begin{array}{l}29,940 \\
29,460 \\
28,980 \\
28,440 \\
27,960\end{array}$ & $\begin{array}{c}5,493.9 \\
5,493.3 \\
5,492.9 \\
= \\
-\end{array}$ & $\begin{array}{c}20,850 \\
20,550 \\
20,350 \\
- \\
-\end{array}$ & $\begin{array}{c}5,521.4 \\
\ldots \\
5,520.8 \\
5,520.6\end{array}$ & $\begin{array}{c}36,840 \\
- \\
36,480 \\
36,360\end{array}$ \\
\hline $\begin{array}{r}6 \\
7 \\
8 \\
9 \\
10\end{array}$ & $\begin{array}{l}5,505.8 \\
5,505.0 \\
5,504 \cdot 1 \\
5,503.2 \\
5,502.4\end{array}$ & $\begin{array}{l}27,480 \\
27,000 \\
26,460 \\
25,920 \\
25,440\end{array}$ & $\begin{array}{l}5,491.2 \\
5,490.5 \\
5,489.8 \\
5,489.1 \\
5,493.7\end{array}$ & $\begin{array}{l}19,500 \\
19,150 \\
18,800 \\
18,450 \\
20,750\end{array}$ & $\begin{array}{c}5,520.3 \\
- \\
- \\
5,518.9\end{array}$ & $\begin{array}{c}36,180 \\
- \\
- \\
35,340\end{array}$ \\
\hline $\begin{array}{l}11 \\
12 \\
13 \\
14 \\
15\end{array}$ & $\begin{array}{l}5,501.6 \\
5,500.8 \\
5,500.0 \\
5,499.2 \\
5,498.5\end{array}$ & $\begin{array}{l}24,960 \\
24,480 \\
24,000 \\
23,520 \\
23,150\end{array}$ & $\begin{array}{c}5,511.2 \\
5,516.0 \\
- \\
5,518.0 \\
5,518.9\end{array}$ & $\begin{array}{c}30,720 \\
33,600 \\
- \\
34,800 \\
35,340\end{array}$ & $\begin{array}{l}5,518.4 \\
5,518.0 \\
5,517.5 \\
5,517.0 \\
5,516.8\end{array}$ & $\begin{array}{l}35,040 \\
34,800 \\
34,500 \\
34,200 \\
34,080\end{array}$ \\
\hline $\begin{array}{l}16 \\
17 \\
18 \\
19 \\
20\end{array}$ & $\begin{array}{l}5,497.9 \\
5,498 \cdot 1 \\
5,497.9 \\
5,497.5 \\
5,497.4\end{array}$ & $\begin{array}{l}22,850 \\
22,950 \\
23,850 \\
22,650 \\
22,600\end{array}$ & $\begin{array}{c}5,519.8 \\
5,520.4 \\
- \\
5,521.1\end{array}$ & $\begin{array}{c}35,880 \\
36,240 \\
= \\
- \\
36,660\end{array}$ & $\begin{array}{c}5,516.4 \\
5,516.2 \\
5,515.9 \\
5,515.7 \\
-\end{array}$ & $\begin{array}{c}33,840 \\
33,720 \\
33,540 \\
33,420 \\
-\end{array}$ \\
\hline $\begin{array}{l}21 \\
22 \\
23 \\
24 \\
25\end{array}$ & $\begin{array}{l}5,497.5 \\
5,497.2 \\
5,497.1 \\
5,497.0 \\
5,496.7\end{array}$ & $\begin{array}{l}22,650 \\
22,500 \\
22,450 \\
22,400 \\
22,250\end{array}$ & $\begin{array}{l}5,521.6 \\
5,521.7 \\
5,521.8 \\
5,521.9\end{array}$ & $\begin{array}{c}- \\
36,960 \\
37,020 \\
37,080 \\
37,140\end{array}$ & $\begin{array}{c}5,414.8 \\
5,514.4 \\
- \\
5,513.6 \\
5,513.1\end{array}$ & $\begin{array}{c}32,880 \\
32,640 \\
- \\
32,160 \\
31,860\end{array}$ \\
\hline $\begin{array}{l}26 \\
27 \\
28 \\
29 \\
30 \\
31\end{array}$ & $\begin{array}{l}5,496.4 \\
5,495.9 \\
5,495.4 \\
5,495.0 \\
5,494.5\end{array}$ & $\begin{array}{l}22,100 \\
21,850 \\
21,600 \\
21,400 \\
21,150\end{array}$ & $\begin{array}{l}5,522.0 \\
5,522.0 \\
5,522.0 \\
5,521.9 \\
5,521.8 \\
5,521.6\end{array}$ & $\begin{array}{l}37,200 \\
37,200 \\
37,200 \\
37,140 \\
37,080 \\
36,960\end{array}$ & $\begin{array}{l}5,512.7 \\
5,512.3 \\
5,511.9 \\
5,511.5 \\
5,511.0 \\
5,510.5\end{array}$ & $\begin{array}{l}31,620 \\
31,380 \\
31,140 \\
30,900 \\
30,600 \\
30,300\end{array}$ \\
\hline
\end{tabular}


Location. - Lat. $39^{\circ} 26^{\prime}$, long. $120^{\circ} 40^{\prime}$, in SE⿺ sec. 7, T. 18 N., R. 12 E., 1 mile below Bowman Lake, Nevada County, and 3 miles upstream from mouth of Texas Creok. Alt1tude, about 5,100 feet above mean sea level.

Drainage area.- 31.7 square miles.

Gage-height record. - Water-stage recorder graph except for period Dec. 3 to 11 , when record was furnished by Nevada Irrigation District.

Stege-discherge relation. - Defined by current-meter measurements for range of stage occurring in December.

Maxima.- December 1937: Discharge (regulated), 88 second-fe日t 9:30 a.m. Dec. 11 (gage helght, 2.20 fe日t). Maximum discharge computed from increase in storgge, about 5,200 second-fe日t early morning Dec. 11.

1927-November 1937: Discharge (reservoir splling), 1,460 second-feet June 6 ,

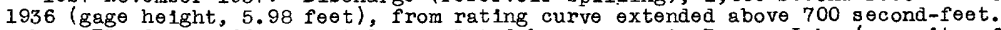

Remarks. - Flood min-off completely regulated by storage in Bowman Lake (capac1ty, 62,400 acre-feet). Daily discharge for December and all monthly discharges adjusted for storgge, inflow, and diversion ss shown, but not for possible storsge in small

reservoirs upstream. Gain or loss in storage computed from contents at midnight determined from graph based on dally readings at $4: 30 \mathrm{p} . \mathrm{m}$. Se record for Bowman Lake near Granitevilie. Most of basic data furnished by Nevada Irrigation District.

Discharge, gain or loss in storege, inflow, and diversions, December 1937

\begin{tabular}{|c|c|c|c|c|c|}
\hline Dey & $\begin{array}{c}\text { Observed } \\
\text { discharge } \\
\text { (second-fe日t) }\end{array}$ & $\begin{array}{l}\text { Gain or loss } \\
\text { in storage } \\
(a \operatorname{cr} \theta-f \theta \theta)\end{array}$ & $\begin{array}{l}\text { Milton-Bowman } \\
\text { Tunnel Inflow } \\
\text { (second-fe日t) }\end{array}$ & $\begin{array}{l}\text { Bowman-Spaulding } \\
\text { Canal diversion } \\
\text { (second-feet) }\end{array}$ & $\begin{array}{c}\text { Ad justed } \\
\text { discharge } \\
\text { (second-feet) }\end{array}$ \\
\hline $\begin{array}{l}1 \\
2 \\
3 \\
4 \\
5\end{array}$ & $\begin{array}{r}0.8 \\
.8 \\
.8 \\
.8 \\
.8\end{array}$ & $\begin{array}{l}-290 \\
-280 \\
-200 \\
-280 \\
-300\end{array}$ & $\begin{array}{l}17 \\
16 \\
15 \\
15 \\
14\end{array}$ & $\begin{array}{l}229 \\
229 \\
229 \\
229 \\
229\end{array}$ & $\begin{array}{r}67 \\
73 \\
114 \\
74 \\
65\end{array}$ \\
\hline $\begin{array}{r}6 \\
7 \\
8 \\
9 \\
10\end{array}$ & $\begin{array}{r}.8 \\
.8 \\
40^{.8}\end{array}$ & $\begin{array}{r}-310 \\
-370 \\
-350 \\
-70 \\
+5,600\end{array}$ & $\begin{array}{r}13 \\
12 \\
13 \\
14 \\
120\end{array}$ & $\begin{array}{r}229 \\
229 \\
229 \\
206 \\
39\end{array}$ & $\begin{array}{r}61 \\
31 \\
41 \\
162 \\
2,780\end{array}$ \\
\hline $\begin{array}{l}11 \\
12 \\
13 \\
14 \\
15\end{array}$ & $\begin{array}{r}65 \\
32 \\
.4 \\
.2 \\
1.4\end{array}$ & $\begin{array}{r}+8,000 \\
+1,600 \\
+600 \\
+570 \\
+550\end{array}$ & $\begin{array}{l}200 \\
276 \\
232 \\
227 \\
211\end{array}$ & $\begin{array}{l}26^{+2} \\
106 \\
130 \\
135\end{array}$ & $\begin{array}{r}3,900 \\
589 \\
176 \\
190 \\
202\end{array}$ \\
\hline $\begin{array}{l}16 \\
17 \\
18 \\
19 \\
20\end{array}$ & $\begin{array}{r}1.4 \\
1.3 \\
1.2 \\
1.0 \\
.9\end{array}$ & $\begin{array}{l}+520 \\
+230 \\
+140 \\
+140 \\
+170\end{array}$ & $\begin{array}{r}200 \\
121 \\
88 \\
103 \\
100\end{array}$ & $\begin{array}{l}126 \\
106 \\
112 \\
111 \\
111\end{array}$ & $\begin{array}{r}189 \\
102 \\
96 \\
80 \\
98\end{array}$ \\
\hline $\begin{array}{l}21 \\
22 \\
23 \\
24 \\
25\end{array}$ & $\begin{array}{l}.9 \\
.8 \\
.9 \\
.9 \\
.9\end{array}$ & $\begin{array}{r}+160 \\
+100 \\
+60 \\
+60 \\
+60\end{array}$ & $\begin{array}{l}96 \\
91 \\
81 \\
79 \\
77\end{array}$ & $\begin{array}{l}142 \\
155 \\
154 \\
152 \\
152\end{array}$ & $\begin{array}{l}128 \\
115 \\
104 \\
104 \\
106\end{array}$ \\
\hline $\begin{array}{l}26 \\
27 \\
28 \\
29 \\
30 \\
31\end{array}$ & $\begin{array}{r}.9 \\
.9 \\
.9 \\
1.0 \\
1.0 \\
1.0\end{array}$ & $\begin{array}{r}+40 \\
0 \\
-20 \\
-60 \\
-70 \\
-130\end{array}$ & $\begin{array}{l}74 \\
76 \\
72 \\
67 \\
62 \\
61\end{array}$ & $\begin{array}{l}152 \\
159 \\
174 \\
195 \\
204 \\
207\end{array}$ & $\begin{array}{r}99 \\
84 \\
93 \\
99 \\
108 \\
81\end{array}$ \\
\hline
\end{tabular}

Observed mean daily discharge, in second-feet, November 1937 to Januery 1938

\begin{tabular}{|c|c|c|c|c|c|c|c|c|c|c|c|}
\hline Dey & Nov. & Dec. & Jan. & Day & Nov. & Dec. & Jan. & Day & Nov. & Dec. & Jan. \\
\hline $\begin{array}{r}1 \\
2 \\
3 \\
4 \\
5 \\
6 \\
7 \\
8 \\
9 \\
10\end{array}$ & $\begin{array}{r}0.5 \\
.5 \\
.5 \\
.4 \\
.4 \\
.4 \\
.4 \\
.4 \\
.5 \\
.5\end{array}$ & $\begin{array}{r}0.8 \\
.8 \\
.8 \\
.8 \\
.8 \\
.8 \\
.8 \\
.8 \\
5 \\
40\end{array}$ & $\begin{array}{r}1.0 \\
1.9 \\
1.6 \\
1.2 \\
1.0 \\
1.0 \\
.9 \\
.9 \\
.9 \\
.9\end{array}$ & $\begin{array}{l}11 \\
12 \\
13 \\
14 \\
15 \\
16 \\
17 \\
18 \\
19 \\
20\end{array}$ & $\begin{array}{c}1.4 \\
1.2 \\
.8 \\
4.3 \\
2.5 \\
12 \\
19 \\
2.9 \\
3.1 \\
11\end{array}$ & $\begin{array}{r}65 \\
32 \\
.4 \\
.2 \\
1.4 \\
1.4 \\
1.3 \\
1.2 \\
1.0 \\
.9\end{array}$ & $\begin{array}{r}0.9 \\
.8 \\
.8 \\
.8 \\
1.6 \\
1.2 \\
3.1 \\
2.0 \\
1.6 \\
1.4\end{array}$ & $\begin{array}{l}21 \\
22 \\
23 \\
24 \\
25 \\
26 \\
27 \\
28 \\
29 \\
30\end{array}$ & $\begin{array}{l}3.5 \\
2.0 \\
4.1 \\
3.5 \\
2.5 \\
2.0 \\
1.8 \\
1.4 \\
1.3 \\
1.0\end{array}$ & $\begin{array}{r}0.9 \\
.8 \\
.9 \\
.9 \\
.9 \\
.9 \\
.9 \\
1.0 \\
1.0 \\
1.0\end{array}$ & $\begin{array}{l}1.6 \\
2.4 \\
2.4 \\
1.8 \\
1.6 \\
1.8 \\
1.8 \\
1.8 \\
1.8 \\
1.8 \\
2.0\end{array}$ \\
\hline \multicolumn{9}{|c|}{ 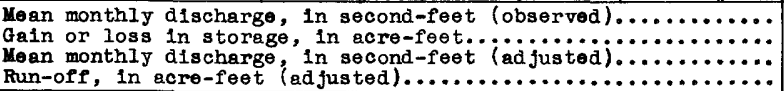 } & $\begin{array}{r}2,86 \\
-9,220 \\
46.7 \\
2,780\end{array}$ & $\begin{array}{r}5.36 \\
+15,870 \\
329 \\
20,250\end{array}$ & $\begin{array}{r}1.49 \\
-6,720 \\
62.6 \\
3,850\end{array}$ \\
\hline
\end{tabular}


Deer Greek near Smartv1110, Cal1f.

Locat1on. - Lat. $39^{\circ} 13^{\prime} 20^{\prime \prime}$, long. $121^{\circ} 16^{\prime} 00^{\prime \prime}$, In sec. 23, T. 16 N., R. 6 E., 1 m11e above mouth and 2 miles northeast of Smartv11le, Yuba County. 'Altitude, about 500 feet above mean sea level.

Drainage area.- 83.5 square miles.

Gage-helght record. - One gage reading da1ly. A stage graph was drawn for per1od Dec. 8 to 14 based on gage readings, floodmark, and comparison with stage graphs at nearby stations.

Stage-d1scharge relation.- Deflned by current-meter measurements below 3,500 secondfeet; extended to peak stage by $A \sqrt{d}$ method; verified by area-velocity study. Rating curve changed at peak stage.

Max1ma.- December 1937: Discharge, 10,800 second-feet about 9 a.m. Dec. 11 (gage helght, 13.2 feet, from floodmark).

1935-November 1937: Discharge, 7,520 second-feet Feb. 4, 1937 (gage helght, 11.5 feet), from rating curve extended above 3,500 second-feet on bas 1 s of area-veloc1ty study and $A \sqrt{\alpha}$ method.

Remarks.- Flood mn-off probably not materialiy affected by diversion or artiflcial storage in Deer Creek Reservolr.

Mean da1ly discharge, in second-feet, November 1937 to January 1938

\begin{tabular}{|c|c|c|c|c|c|c|c|c|c|c|c|}
\hline Day & Nov. & Dec. & Jan. & Day & Nov. & Dec. & Jan. & Day & Nov, & Dec. & Jan. \\
\hline $\begin{array}{r}1 \\
2 \\
3 \\
4 \\
5 \\
6 \\
7 \\
8 \\
9 \\
10\end{array}$ & $\begin{array}{l}33 \\
45 \\
31 \\
55 \\
65 \\
65 \\
76 \\
76 \\
82 \\
82\end{array}$ & $\begin{array}{r}36 \\
65 \\
15 \\
45 \\
40 \\
40 \\
36 \\
35 \\
88 \\
2,420\end{array}$ & $\begin{array}{l}70 \\
72 \\
68 \\
66 \\
63 \\
59 \\
53 \\
57 \\
57 \\
55\end{array}$ & $\begin{array}{l}11 \\
12 \\
13 \\
14 \\
15 \\
16 \\
17 \\
18 \\
19 \\
20\end{array}$ & $\begin{array}{r}88 \\
88 \\
88 \\
76 \\
76 \\
76 \\
500 \\
67 \\
41 \\
460\end{array}$ & $\begin{array}{r}6,820 \\
1,930 \\
455 \\
170 \\
138 \\
138 \\
101 \\
88 \\
82 \\
66\end{array}$ & $\begin{array}{r}55 \\
53 \\
53 \\
51 \\
272 \\
154 \\
1,100 \\
420 \\
285 \\
248\end{array}$ & $\begin{array}{l}21 \\
22 \\
23 \\
24 \\
25 \\
26 \\
27 \\
28 \\
29 \\
30 \\
31\end{array}$ & $\begin{array}{r}715 \\
1,290 \\
500 \\
198 \\
162 \\
115 \\
36 \\
28 \\
19 \\
14\end{array}$ & $\begin{array}{r}70 \\
94 \\
101 \\
68 \\
72 \\
82 \\
75 \\
70 \\
72 \\
68 \\
77\end{array}$ & $\begin{array}{r}138 \\
130 \\
122 \\
115 \\
108 \\
88 \\
94 \\
138 \\
130 \\
130 \\
990\end{array}$ \\
\hline \multicolumn{9}{|c|}{ 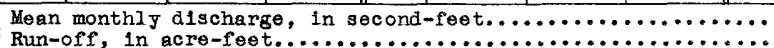 } & 10,410 & 26,690 & 10,900 \\
\hline
\end{tabular}


Location. - Lat. $39^{\circ} 00^{\prime}$, long. $121^{\circ} 25^{\prime}$, in sec. 3, T. 13 N., R. 5 E., I mile southeast of Whertland, Yuba County, $6 \frac{1}{2}$ miles below Rock Creek, and 12 miles above mouth. Altitude, about 85 feet above mean sea level.

Drainage area.- 295 square mlies.

Gage-he1ght record. - Water-stage recorder graph.

Stage-discharge relation. - Defined by current-meter messurements. Rating curve changed at poak stage.

Maxima.- December 1937: Discharge, 11,000 second-feet 2:30 p.m. Dec. 11 (gage height, 11.32 feet).

1928-November 1937: Discharge, 21,600 second-feet Apr. 8, 1935 (gage height,

15.15 feet), from rating curve extended above 16,100 second-feet.

1904-28: Discharge, about 29,600 second-feet Jan. 14, 1909 (gage height, 18.9 feet, from nonrecording gage, former site and datum, 8 miles upstream; drainage area, 263 square miles), from rating curve extended ebove 1,900 second-feet.

Remarks.- Flood run-off silghtly offected by artificlel storage and many diversions into and out of drainage basin. Camp Far West Reservolr (capacity, 5,000 acre-feet) and Combie Reservolr (cepac1ty, 9,000 acre-feet).

Mean dally discharge, in second-feet, November 1937 to January 1938

\begin{tabular}{|c|c|c|c|c|c|c|c|c|c|c|c|}
\hline Day & Nov. & Dec. & Jan. & Day & Nov. & Dec. & Jan. & Day. & Nov. & Dec. & Jan. \\
\hline 1 & 33 & 168 & 518 & 11 & 56 & 8,180 & 248 & 21 & 542 & 601 & 619 \\
2 & 36 & 176 & 513 & 12 & 81 & 3,390 & 212 & 22 & 464 & 595 & 571 \\
3 & 36 & 176 & 491 & 13 & 60 & 1,570 & 191 & 23 & 908 & 613 & 589 \\
4 & 34 & 180 & 452 & 14 & 88 & 962 & 194 & 24 & 870 & 589 & 530 \\
5 & 36 & 180 & 385 & 15 & 88 & 746 & 573 & 25 & 613 & 601 & 502 \\
6 & 36 & 153 & 252 & 16 & 74 & 674 & 442 & 26 & 516 & 589 & 486 \\
7 & 38 & 143 & 272 & 17 & 426 & 649 & 827 & 27 & 398 & 571 & 469 \\
8 & 36 & 102 & 345 & 18 & 234 & 631 & 799 & 28 & 234 & 571 & 464 \\
9 & 38 & 100 & 268 & 19 & 284 & 625 & 714 & 29 & 197 & 559 & 486 \\
10 & 39 & 2,460 & 244 & 20 & 446 & 613 & 720 & 30 & 184 & 547 & 447 \\
\end{tabular}

Gage helght, in feet, and discharge, in second-feet, at indicated time, 1937

\begin{tabular}{|c|c|c|c|c|c|c|c|c|c|c|c|c|}
\hline \multirow{2}{*}{$\begin{array}{l}5 \\
\text { : }\end{array}$} & Feet & Sec.ft. & Feet & Sec.ft. & Feot & Sec.ft. & Feot & sec.ft. & Feet & sec.ft. & $F \theta \theta t$ & Sec.ft. \\
\hline & \multicolumn{2}{|c|}{ December 8} & \multicolumn{2}{|c|}{ December 9} & \multicolumn{2}{|c|}{ December 10} & \multicolumn{2}{|c|}{ December 11} & \multicolumn{2}{|c|}{ December 12} & \multicolumn{2}{|c|}{ December 13} \\
\hline $\begin{array}{r}2 \\
4 \\
6 \\
8 \\
10 \\
\mathrm{~N} \\
2 \\
4 \\
6 \\
8 \\
10 \\
\mathrm{M}\end{array}$ & $\begin{array}{c}- \\
\overline{1.05} \\
- \\
\overline{1.05} \\
- \\
\overline{1.05} \\
\overline{-} \\
1.04\end{array}$ & $\begin{array}{c}\overline{-} \\
102 \\
- \\
\overline{102} \\
\overline{102} \\
\overline{100}\end{array}$ & $\begin{array}{c}- \\
1.02 \\
1.02 \\
- \\
1.01 \\
- \\
1.02 \\
- \\
1.05 \\
1.19\end{array}$ & $\begin{array}{c}\overline{94} \\
\overline{94} \\
\overline{9} 1 \\
\overline{94} \\
\overline{0} \overline{2} \\
\overline{146}\end{array}$ & $\begin{array}{l}1.25 \\
1.32 \\
1.70 \\
4.05 \\
4.85 \\
5.26 \\
5.34 \\
5.88 \\
6.42 \\
6.13 \\
5.50 \\
5.22\end{array}$ & $\begin{array}{r}168 \\
197 \\
410 \\
2,080 \\
2,790 \\
3,200 \\
3,280 \\
3,850 \\
4,440 \\
4,220 \\
3,440 \\
3,160\end{array}$ & $\begin{array}{r}5.22 \\
6.12 \\
8.36 \\
9.47 \\
10.65 \\
11.14 \\
11.30 \\
11.28 \\
11.03 \\
10.42 \\
9.26 \\
7.99\end{array}$ & $\begin{array}{r}3,160 \\
4,110 \\
6,680 \\
8,160 \\
9,940 \\
10,800 \\
11,000 \\
11,000 \\
10,600 \\
9,570 \\
7,860 \\
6,240\end{array}$ & $\begin{array}{l}7.00 \\
6.39 \\
5.97 \\
5.94 \\
5.58 \\
5.32 \\
5.00 \\
4.73 \\
4.53 \\
4.25 \\
4.05 \\
4.02\end{array}$ & $\begin{array}{l}5,080 \\
4,410 \\
3,950 \\
3,910 \\
3,520 \\
3,260 \\
2,940 \\
2,680 \\
2,500 \\
2,240 \\
2,060 \\
2,040\end{array}$ & $\begin{array}{l}3.93 \\
3.84 \\
3.76 \\
3.66 \\
3.56 \\
3.45 \\
3.33 \\
3.24 \\
3.20 \\
3.16 \\
3.09 \\
3.03\end{array}$ & $\begin{array}{l}1,960 \\
1,880 \\
1,800 \\
1,710 \\
1,620 \\
1,520 \\
1,420 \\
1,350 \\
1,320 \\
1,290 \\
1,230 \\
1,180\end{array}$ \\
\hline & \multicolumn{2}{|c|}{ December 14} & \multicolumn{2}{|c|}{ December 15} & \multicolumn{2}{|c|}{ December 16} & \multicolumn{2}{|c|}{ December 17} & \multicolumn{2}{|c|}{ December 18} & \multicolumn{2}{|c|}{ December 19} \\
\hline $\begin{array}{r}2 \\
4 \\
5 \\
8 \\
10 \\
N \\
2 \\
4 \\
6 \\
8 \\
10 \\
34\end{array}$ & $\begin{array}{c}- \\
2.90 \\
- \\
2.81 \\
- \\
2.73 \\
- \\
2.66 \\
- \\
2.61 \\
- \\
2.55\end{array}$ & $\begin{array}{l}1, \overline{080} \\
1, \overline{0} 10 \\
\overline{9} \\
\overline{8} \\
\overline{8} \\
\overline{8} 62 \\
\overline{820}\end{array}$ & $\begin{array}{l}- \\
2.50 \\
-5 \\
2.47 \\
- \\
2.43 \\
- \\
2.41 \\
- \\
2.39 \\
- \\
2.37\end{array}$ & $\begin{array}{c}7 \overline{85} \\
7 \overline{66} \\
740 \\
7 \overline{26} \\
\overline{714} \\
7 \overline{00}\end{array}$ & $\begin{array}{c}- \\
2.35 \\
\overline{-} \\
2.32 \\
\overline{-} \\
2.31 \\
\overline{-} \\
2.31\end{array}$ & $\begin{array}{c}\overline{-} \\
688 \\
\overline{-} \\
668 \\
\overline{-} \\
662 \\
\overline{-} \\
662\end{array}$ & $\begin{array}{c} \\
\overline{2} \\
-30 \\
\bar{z} \\
2.29 \\
\bar{z} \\
\overline{2.28} \\
\overline{-} \\
2.28\end{array}$ & $\begin{array}{c}- \\
\overline{-} \\
655 \\
\overline{-} \\
649 \\
\overline{-} \\
643 \\
\overline{-} \\
643\end{array}$ & $\begin{array}{c}- \\
\overline{2.27} \\
\overline{-} \\
2.26 \\
\overline{-} \\
2.25 \\
\overline{-} \\
2.26\end{array}$ & $\begin{array}{c}- \\
\overline{-} \\
637 \\
\overline{-} \\
631 \\
\overline{-} \\
\overline{-} \\
\overline{-} \\
631\end{array}$ & $\begin{array}{c}- \\
\overline{2.26} \\
\overline{-} \\
2.25 \\
\overline{-} \\
2.24 \\
\bar{z} \\
2.24\end{array}$ & $\begin{array}{c}\overline{-} \\
631 \\
\overline{-} \\
625 \\
\overline{-} \\
6 \overline{9} \\
\overline{-} \\
619\end{array}$ \\
\hline & \multicolumn{2}{|c|}{ December 20} & \multicolumn{2}{|c|}{ December 21} & \multicolumn{2}{|c|}{ December 22} & \multicolumn{2}{|c|}{ December 23} & \multicolumn{2}{|c|}{ Docember 24} & \multicolumn{2}{|c|}{ December 25} \\
\hline $\begin{array}{r}2 \\
4 \\
6 \\
8 \\
10 \\
\mathrm{~N} \\
2 \\
4 \\
6 \\
8 \\
10 \\
\mathrm{M}\end{array}$ & $\begin{array}{c}- \\
\overline{2.23} \\
- \\
\overline{2.22} \\
\overline{-} \\
2.22 \\
\overline{-} \\
2.22\end{array}$ & $\begin{array}{c}- \\
613 \\
- \\
- \\
607 \\
- \\
607 \\
- \\
607\end{array}$ & 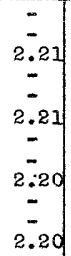 & $\begin{array}{c}\overline{-} \\
6 \overline{01} \\
\overline{-} \\
601 \\
\overline{-} \\
5 \overline{95} \\
\overline{-} \\
5 \overline{95}\end{array}$ & $\begin{array}{c}\overline{ } \\
\overline{2.20} \\
\bar{z} \\
2.20 \\
\bar{z} \\
2.20 \\
\overline{-} \\
2.20\end{array}$ & $\begin{array}{c}\overline{-} \\
5 \overline{95} \\
\overline{-} \\
5 \overline{95} \\
\overline{-} \\
5 \overline{9} \\
\overline{5} \\
\overline{595}\end{array}$ & $\begin{array}{c} \pm \\
2.25 \\
\bar{z} \\
2.25 \\
\overline{-} \\
2.22 \\
\bar{z} \\
2.21\end{array}$ & $\begin{array}{c}\overline{-} \\
625 \\
\overline{-} \\
825 \\
\overline{-} \\
607 \\
\overline{-} \\
601\end{array}$ & $\begin{array}{c} \pm \\
2.20 \\
\bar{z} \\
2.19 \\
\pm \\
2.19 \\
\overline{2} \\
\overline{2.19}\end{array}$ & $\begin{array}{c}\overline{-} \\
5 \overline{5} \\
\overline{-} \\
589 \\
\overline{-} \\
5 \overline{8} \\
\overline{-} \\
5 \overline{89}\end{array}$ & $\begin{array}{c}- \\
- \\
2.21 \\
\overline{-} \\
2.22 \\
\overline{-} \\
2.21 \\
\overline{-} \\
2.20\end{array}$ & $\begin{array}{c}\overline{-} \\
601 \\
\overline{-} \\
607 \\
\overline{-} \\
601 \\
\overline{5} \\
5 \overline{5}\end{array}$ \\
\hline
\end{tabular}

Supplementel records.- Dec. 11, $2: 30$ p.m., 11.32 ft., 11,000 sec.-ft. 
Location. - Lat. $39^{\circ} 02^{\prime}$, long. $120^{\circ} 54^{\prime}$, in Nw sec. 30, T. 14 N., R. 10 E., 50 feet downstream from bridge on Colfax-Forest Hill road, 200 feet below mouth of Shirttail Canyon Creek, and 5 miles southeast of Colfax, Placer County. Zero of gage is 897.29 feet above mean sea level (general adjustment of 1929 ).

Drainage area.- 308 square miles.

Gage-height record.- Water-stage recorder graph.

Stage-discharge relation.- Defined by current-meter measurements below 20,300 secondfeet; extended to peak stage by $A \sqrt{d}$ method; verified by area-velocity study and by comparison of peak discharge and total run-off of flood with records for other stations in American River Basin. Rating curve changed at peak stage.

Maxima.- December 1937: Discharge, 26,700 second-feet 11:30 a.m. Dec. 11 (gage height, 18.2 feet, inside gage; 19.4 feet, outside gage, determined from drawdown relation curvel.

1911-November 1937: Discharge, about 37,000 second-feet (revised) Mar. 25, 1928 (gage height, 25.2 feet, from floodmarks, present datum), from rating curve extended above 2,650 second-feet on bas is of slope-area determination of flood flow.

Romarks.- Flood mun-off slightly affected by artificial storage and diversion.

Mean dally discharge, in second-feet, November $193^{7}$ to January 1938

\begin{tabular}{|c|c|c|c|c|c|c|c|c|c|c|c|}
\hline Day & Nov. & Dec. & Jan. & Day & Nov. & Dec. & Jan. & Day & Nov. & Dec. & Jan. \\
\hline $\begin{array}{r}1 \\
2 \\
3 \\
4 \\
5 \\
6 \\
7 \\
8 \\
9 \\
10\end{array}$ & $\begin{array}{l}57 \\
57 \\
55 \\
54 \\
54 \\
54 \\
54 \\
54 \\
52 \\
51\end{array}$ & $\begin{array}{r}198 \\
186 \\
177 \\
163 \\
155 \\
155 \\
149 \\
146 \\
157 \\
9,710\end{array}$ & $\begin{array}{l}415 \\
450 \\
470 \\
425 \\
390 \\
364 \\
346 \\
332 \\
310 \\
296\end{array}$ & $\begin{array}{l}11 \\
12 \\
13 \\
14 \\
15 \\
16 \\
17 \\
18 \\
19 \\
20\end{array}$ & $\begin{array}{r}100 \\
133 \\
85 \\
160 \\
157 \\
128 \\
907 \\
468 \\
248 \\
437\end{array}$ & $\begin{array}{r}16,500 \\
4,980 \\
2,550 \\
1,740 \\
1,340 \\
1,160 \\
1,020 \\
895 \\
799 \\
715\end{array}$ & $\begin{array}{r}287 \\
274 \\
269 \\
260 \\
506 \\
470 \\
960 \\
1,060 \\
895 \\
799\end{array}$ & $\begin{array}{l}21 \\
22 \\
23 \\
24 \\
25 \\
26 \\
27 \\
28 \\
29 \\
30 \\
31\end{array}$ & $\begin{array}{l}751 \\
357 \\
369 \\
710 \\
441 \\
341 \\
290 \\
255 \\
234 \\
214\end{array}$ & $\begin{array}{l}649 \\
627 \\
676 \\
616 \\
594 \\
495 \\
512 \\
490 \\
440 \\
425 \\
425\end{array}$ & $\begin{array}{l}715 \\
721 \\
704 \\
616 \\
578 \\
566 \\
561 \\
566 \\
583 \\
522 \\
853\end{array}$ \\
\hline \multicolumn{9}{|c|}{ 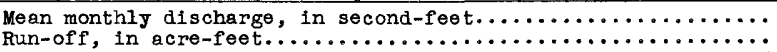 } & 14,530 & $\begin{array}{r}1,576 \\
96,880\end{array}$ & 32,850 \\
\hline
\end{tabular}

Gage height, in feet, and discharge, in second-feet, at indicated time, 1937

\begin{tabular}{|c|c|c|c|c|c|c|c|c|c|c|c|c|}
\hline \multirow{2}{*}{ 峁 } & Feet & Sec.ft. & Feet & Sec.ft. & Feet & Sec.ft. & Foet & Sec.ft. & Feet & Sec.ft. & Feet & Sec.ft. \\
\hline & \multicolumn{2}{|c|}{ December 8} & \multicolumn{2}{|c|}{ December 9} & \multicolumn{2}{|c|}{ December 10} & \multicolumn{2}{|c|}{ December 11} & \multicolumn{2}{|c|}{ December 12} & \multicolumn{2}{|c|}{ December 13} \\
\hline \multirow[t]{2}{*}{$\begin{array}{r}2 \\
4 \\
6 \\
8 \\
10 \\
\mathrm{~N} \\
2 \\
4 \\
6 \\
8 \\
10 \\
\mathrm{M}\end{array}$} & $\begin{array}{c}-\overline{1.96} \\
- \\
1.95 \\
- \\
1.95 \\
- \\
1.95 \\
- \\
1.94 \\
- \\
1.94\end{array}$ & $\begin{array}{c}\overline{149} \\
\overline{146} \\
\overline{146} \\
\overline{146} \\
\overline{144} \\
\overline{144}\end{array}$ & $\begin{array}{l}1.94 \\
1.94 \\
1.94 \\
1.93 \\
1.93 \\
1.93 \\
1.93 \\
1.94 \\
1.98 \\
2.03 \\
2.15 \\
2.46\end{array}$ & $\begin{array}{l}144 \\
144 \\
144 \\
141 \\
141 \\
141 \\
141 \\
144 \\
155 \\
169 \\
204 \\
311\end{array}$ & $\begin{array}{r}3.07 \\
4.65 \\
10.12 \\
11.00 \\
11.53 \\
11.09 \\
12.20 \\
13.26 \\
12.87 \\
11.83 \\
11.17 \\
11.18\end{array}$ & $\begin{array}{r}575 \\
1,540 \\
9,100 \\
10,700 \\
11,700 \\
10,800 \\
13,000 \\
15,200 \\
14,300 \\
12,300 \\
11,000 \\
11,000\end{array}$ & $\begin{array}{r}11.89 \\
13.23 \\
15.07 \\
15.58 \\
16.80 \\
17.48 \\
16.07 \\
14.56 \\
12.79 \\
11.13 \\
10.10 \\
9.35\end{array}$ & $\begin{array}{r}12,400 \\
15,100 \\
19,200 \\
20,400 \\
23,300 \\
25,000 \\
21,600 \\
18,000 \\
14,200 \\
10,900 \\
9,060 \\
7,820\end{array}$ & $\begin{array}{l}8.90 \\
8.53 \\
8.19 \\
7.88 \\
7.58 \\
7.29 \\
7.06 \\
6.82 \\
6.67 \\
6.56 \\
6.40 \\
6.24\end{array}$ & $\begin{array}{l}7,100 \\
6,510 \\
5,980 \\
5,520 \\
5,090 \\
4,690 \\
4,380 \\
4,070 \\
3,870 \\
3,730 \\
3,540 \\
3,350\end{array}$ & $\begin{array}{l}6.10 \\
5.95 \\
5.81 \\
5.67 \\
5.56 \\
5.44 \\
5.32 \\
5.23 \\
5.15 \\
5.06 \\
5.00 \\
4.97\end{array}$ & $\begin{array}{l}3,190 \\
3,020 \\
2,870 \\
2,720 \\
2,610 \\
2,490 \\
2,370 \\
2,280 \\
2,200 \\
2,110 \\
2,060 \\
2,030\end{array}$ \\
\hline & \multicolumn{2}{|c|}{ December 14} & \multicolumn{2}{|c|}{ December 15} & \multicolumn{2}{|c|}{ December 16} & \multicolumn{2}{|c|}{ December 17} & \multicolumn{2}{|c|}{ December 18} & \multicolumn{2}{|c|}{ December 19} \\
\hline \multirow[t]{2}{*}{$\begin{array}{r}2 \\
4 \\
6 \\
8 \\
10 \\
\mathrm{~N} \\
2 \\
4 \\
6 \\
8 \\
10 \\
\mathrm{M}\end{array}$} & $\begin{array}{l}4.90 \\
4.85 \\
4.78 \\
4.72 \\
4.67 \\
4.62 \\
4.58 \\
4.53 \\
4.48 \\
4.43 \\
4.38 \\
4.35\end{array}$ & $\begin{array}{l}1,970 \\
1,920 \\
1,860 \\
1,810 \\
1,760 \\
1,720 \\
1,680 \\
1,640 \\
1,600 \\
1,560 \\
1,520 \\
1,500\end{array}$ & $\begin{array}{c}- \\
4.30 \\
\overline{4.22} \\
\overline{4.16} \\
\overline{-} \\
4.10 \\
\overline{-} 03 \\
\overline{3.97}\end{array}$ & $\begin{array}{c}1, \overline{4} 60 \\
\overline{4} \\
1, \overline{4} 00 \\
\overline{-} \\
1, \overline{3} 50 \\
\overline{1} \\
1, \overline{3} 00 \\
1, \overline{2} 50 \\
1, \overline{2} 10\end{array}$ & $\begin{array}{c}- \\
3.94 \\
- \\
3.96 \\
- \\
3.91 \\
- \\
3.87 \\
\overline{3} .82 \\
-\overline{3.78}\end{array}$ & $\begin{array}{c}\overline{1}, \overline{190} \\
\overline{2} \\
1, \overline{2} 00 \\
\overline{1} \\
1, \overline{1} 70 \\
\overline{1}, \overline{140} \\
1, \overline{100} \\
1, \overline{0} \\
\text { o80 }\end{array}$ & $\begin{array}{c}- \\
3.75 \\
- \\
3.71 \\
- \\
3.68 \\
- \\
3.66 \\
- \\
3.62 \\
- \\
3.58\end{array}$ & $\begin{array}{c}1, \overline{060} \\
\overline{0} \\
1, \overline{030} \\
\overline{0} \\
1,010 \\
\overline{9} \\
\overline{9} \\
\overline{973} \\
\overline{9} \\
\overline{947}\end{array}$ & $\begin{array}{c}- \\
3.56 \\
- \\
3.54 \\
- \\
3.52 \\
- \\
3.50 \\
- \\
3.46 \\
- \\
3.41\end{array}$ & $\begin{array}{c}\overline{936} \\
- \\
9 \overline{21} \\
\overline{908} \\
\overline{895} \\
\overline{871} \\
\overline{841}\end{array}$ & $\begin{array}{c}- \\
3.38 \\
- \\
3.35 \\
- \\
3.34 \\
- \\
3.32 \\
- \\
3.29 \\
- \\
3.26\end{array}$ & $\begin{array}{c}8 \overline{23} \\
\overline{805} \\
\overline{799} \\
\overline{787} \\
\overline{769} \\
\overline{751}\end{array}$ \\
\hline & \multicolumn{2}{|c|}{ December 20} & \multicolumn{2}{|c|}{ December 21} & \multicolumn{2}{|c|}{ December 22} & \multicolumn{2}{|c|}{ December 23} & \multicolumn{2}{|c|}{ December 24} & \multicolumn{2}{|c|}{ December 25} \\
\hline $\begin{array}{r}2 \\
4 \\
6 \\
8 \\
10 \\
N \\
2 \\
4 \\
6 \\
8 \\
10 \\
\mathrm{M}\end{array}$ & $\begin{array}{l}- \\
3.24 \\
- \\
3.23 \\
= \\
3.21 \\
- \\
3.16 \\
- \\
3.14 \\
\overline{3.11}\end{array}$ & $\begin{array}{c}\overline{739} \\
\overline{733} \\
\overline{721} \\
\overline{-} \\
6 \overline{3} \\
- \\
6 \overline{82} \\
- \\
6 \overline{6} 6\end{array}$ & $\begin{array}{l}- \\
3.10 \\
\overline{3.09} \\
\overline{3.09} \\
\overline{3.06} \\
\overline{-} \\
3.05 \\
\overline{3.04}\end{array}$ & $\begin{array}{c}\overline{660} \\
- \\
6 \overline{54} \\
- \\
6 \overline{54} \\
\overline{-} \\
6 \overline{8} \\
- \\
632 \\
\overline{627}\end{array}$ & $\begin{array}{l}3.04 \\
3.03 \\
3.02 \\
3.02 \\
3.01 \\
3.01 \\
3.00 \\
3.00 \\
3.00 \\
3.07 \\
3.15 \\
3.25\end{array}$ & $\begin{array}{l}627 \\
622 \\
616 \\
616 \\
610 \\
610 \\
606 \\
605 \\
605 \\
644 \\
688 \\
745\end{array}$ & $\begin{array}{l}3.32 \\
3.32 \\
3.29 \\
3.21 \\
3.14 \\
3.08 \\
3.05 \\
3.04 \\
3.03 \\
3.02 \\
3.02 \\
3.02\end{array}$ & $\begin{array}{l}787 \\
787 \\
769 \\
721 \\
682 \\
649 \\
632 \\
627 \\
622 \\
616 \\
616 \\
616\end{array}$ & $\begin{array}{l}3.02 \\
3.02 \\
3.02 \\
3.01 \\
3.00 \\
2.99 \\
2.99 \\
3.00 \\
3.03 \\
3.04 \\
3.04 \\
3.03\end{array}$ & $\begin{array}{l}616 \\
616 \\
616 \\
610 \\
605 \\
600 \\
600 \\
605 \\
622 \\
627 \\
627 \\
622\end{array}$ & $\begin{array}{l}3.01 \\
2.99 \\
2.99 \\
2.97 \\
2.97 \\
2.96 \\
2.95 \\
2.95 \\
2.94 \\
2.94 \\
2.94 \\
2.94\end{array}$ & \begin{tabular}{|l}
610 \\
600 \\
600 \\
588 \\
588 \\
583 \\
578 \\
578 \\
572 \\
572 \\
572 \\
572
\end{tabular} \\
\hline
\end{tabular}

Supplemental records.- Dec. 11, $11: 30$ a.m., 18.20 ft., 26,700 sec.-ft. 
Iocat1on.- Lat. $38^{\circ} 38^{\prime} 15^{\prime \prime}$, long. $121^{\circ} 15^{\prime} 55^{\prime \prime}$, just above highway bridge at Fa1r 0aka, Sacramento County, and 10 miles below South Fork. Altitude, about 72 fe日t above mean sea level.

Drainage area.- 1,921 square m1les.

Gage-helght record. - Water-stage recorder graph.

Stage-discharge relation. - Defined by current-meter measurements below 102,000 secondfeet; extended to peak stage; verlfled by area-velocity study and by comparison of peak discharge and total mun-off of flood with records for other stations in American Rlver Basin. Shifting-control method used for perlod Dec. $12-20$.

Kaxima.- December 1937: Discharge, 114,000 second-feet 6 p.m. Dec. il (gage helght, 29.06 foet).

1904-November 1937: Discharge, 140,000 second-fe日t (revised) Mar. 19, 1907, and Mar. 25, 1928 (gage he1ght, 3i.4 feet, present datum), from rating curve extended above 75,000 second-feet.

Remarks. - Flood man-off not materlally affected by artiflclal storage or divera1on.

Mean dally discharge, in second-feet, November 1937 to January 1938

\begin{tabular}{|c|c|c|c|c|c|c|c|c|c|c|c|}
\hline Day & Nov. & Dec. & Jan. & Day & Nov. & Dec. & Jan. & Day & Nov. & Dec. & Jan. \\
\hline $\begin{array}{r}1 \\
2 \\
3 \\
4 \\
5 \\
6 \\
7 \\
8 \\
9 \\
10\end{array}$ & $\begin{array}{l}585 \\
604 \\
560 \\
585 \\
585 \\
595 \\
595 \\
590 \\
600 \\
604\end{array}$ & $\begin{array}{r}1,040 \\
970 \\
970 \\
925 \\
902 \\
880 \\
880 \\
880 \\
858 \\
24,300\end{array}$ & $\begin{array}{l}1,870 \\
1,940 \\
2,010 \\
2,010 \\
1,800 \\
1,800 \\
1,600 \\
1,570 \\
1,630 \\
1,470\end{array}$ & $\begin{array}{l}11 \\
12 \\
13 \\
14 \\
15 \\
16 \\
17 \\
18 \\
19 \\
20\end{array}$ & $\begin{array}{r}658 \\
835 \\
880 \\
858 \\
995 \\
970 \\
1,430 \\
2,810 \\
1,630 \\
1,890\end{array}$ & $\begin{array}{r}81,100 \\
37,000 \\
13,600 \\
8,240 \\
5,820 \\
4,920 \\
4,300 \\
3,760 \\
3,410 \\
3,000\end{array}$ & $\begin{array}{l}1,470 \\
1,470 \\
1,440 \\
1,380 \\
2,010 \\
2,540 \\
3,100 \\
4,920 \\
3,890 \\
3,760\end{array}$ & $\begin{array}{l}21 \\
22 \\
23 \\
24 \\
25 \\
26 \\
27 \\
28 \\
29 \\
30 \\
31\end{array}$ & $\begin{array}{l}2,730 \\
2,150 \\
1,600 \\
2,220 \\
2,080 \\
1,500 \\
1,290 \\
1,200 \\
1,100 \\
1,070\end{array}$ & $\begin{array}{l}2,720 \\
2,540 \\
2,900 \\
2,540 \\
2,460 \\
2,300 \\
2,010 \\
2,010 \\
1,940 \\
1,870 \\
1,800\end{array}$ & $\begin{array}{l}3,000 \\
2,720 \\
2,810 \\
2,630 \\
2,380 \\
2,300 \\
2,220 \\
2,300 \\
2,810 \\
2,630 \\
3,200\end{array}$ \\
\hline $\begin{array}{l}\text { Yean } \\
\text { Run- }\end{array}$ & 1 & & & & & & & & $\begin{array}{r}1,173 \\
69,820\end{array}$ & $\begin{array}{r}7,189 \\
442,000\end{array}$ & $\begin{array}{r}2,345 \\
144,200\end{array}$ \\
\hline
\end{tabular}

Gage helght, In feet, and discharge, in second-feet, at indicated t1me, 1937

\begin{tabular}{|c|c|c|c|c|c|c|c|c|c|c|c|c|}
\hline \multirow{2}{*}{$\begin{array}{l}\text { है } \\
\text { 㞤 }\end{array}$} & Feet & Sec.ft. & Feet & Sec.ft. & Feet & Sec.ft. & Feet & Sec oft. & Feet & Sec.ft. & Feot & Sec.ft. \\
\hline & \multicolumn{2}{|c|}{ December 8} & \multicolumn{2}{|c|}{ December 9} & \multicolumn{2}{|c|}{ December 10} & \multicolumn{2}{|c|}{ December 11} & \multicolumn{2}{|c|}{ December 12} & \multicolumn{2}{|c|}{ December 13} \\
\hline \multirow[t]{2}{*}{$\begin{array}{r}2 \\
4 \\
6 \\
8 \\
10 \\
\mathrm{~N} \\
2 \\
4 \\
6 \\
8 \\
10 \\
4\end{array}$} & $\begin{array}{l}\overline{2.82} \\
\overline{2.69} \\
\overline{2.83} \\
\overline{2.88} \\
\overline{2.60} \\
\overline{2.85}\end{array}$ & $\begin{array}{l}\overline{889} \\
\overline{830} \\
\overline{894} \\
\overline{916} \\
\overline{790} \\
\overline{902}\end{array}$ & $\begin{array}{c}- \\
2.78 \\
2.79 \\
- \\
2.81 \\
\overline{2.71} \\
2.76 \\
- \\
2.93\end{array}$ & $\begin{array}{c}\overline{871} \\
\overline{-} \\
876 \\
\overline{884} \\
\overline{840} \\
\overline{862} \\
\overline{838}\end{array}$ & $\begin{array}{r}3.03 \\
3.18 \\
3.26 \\
3.50 \\
3.69 \\
7.43 \\
13.87 \\
17.59 \\
20.00 \\
21.30 \\
22.23 \\
21.92\end{array}$ & $\begin{array}{r}985 \\
1,060 \\
1,100 \\
1,230 \\
1,340 \\
4,970 \\
24,300 \\
41,100 \\
54,200 \\
61,800 \\
67,500 \\
65,500\end{array}$ & $\begin{array}{l}20.96 \\
19.94 \\
19.47 \\
20.00 \\
22.21 \\
25.02 \\
27.00 \\
28.24 \\
29.06 \\
28.54 \\
27.28 \\
25.05\end{array}$ & $\begin{array}{r}59,800 \\
53,900 \\
51,200 \\
54,200 \\
67,400 \\
85,600 \\
99,000 \\
108,000 \\
114,000 \\
110,000 \\
101,000 \\
85,800\end{array}$ & $\begin{array}{l}22.60 \\
20.10 \\
18.33 \\
17.08 \\
16.19 \\
15.40 \\
14.75 \\
14.15 \\
13.57 \\
13.17 \\
12.77 \\
12.44\end{array}$ & $\begin{array}{l}69,900 \\
54,800 \\
45,000 \\
38,500 \\
34,300 \\
30,800 \\
28,000 \\
25,400 \\
23,100 \\
21,600 \\
20,100 \\
18,900\end{array}$ & $\begin{array}{r}12.12 \\
11.85 \\
11.62 \\
11.38 \\
11.16 \\
10.96 \\
10.73 \\
10.60 \\
10.44 \\
10.27 \\
10.10 \\
9.95\end{array}$ & $\begin{array}{l}17,400 \\
16,400 \\
15,700 \\
14,900 \\
14,200 \\
13,500 \\
12,900 \\
12,400 \\
11,900 \\
11,400 \\
10,900 \\
10,500\end{array}$ \\
\hline & \multicolumn{2}{|c|}{ December 14} & \multicolumn{2}{|c|}{ December 15} & \multicolumn{2}{|c|}{ December 16} & \multicolumn{2}{|c|}{ December 17} & \multicolumn{2}{|c|}{ December 18} & \multicolumn{2}{|c|}{ December 19} \\
\hline \multirow[t]{2}{*}{$\begin{array}{r}2 \\
4 \\
6 \\
8 \\
10 \\
1 \\
2 \\
4 \\
6 \\
8 \\
10 \\
4 \\
\end{array}$} & $\begin{array}{l}\overline{9.66} \\
- \\
9.45 \\
-\overline{9.25} \\
\overline{9.16} \\
\overline{8.99} \\
\overline{8.79}\end{array}$ & $\begin{array}{l}9, \overline{160} \\
8, \overline{6} 10 \\
8, \overline{120} \\
\overline{7}, \overline{900} \\
7, \overline{500} \\
7, \overline{040}\end{array}$ & $\begin{array}{c}8.64 \\
8.49 \\
8.35 \\
- \\
8.32 \\
- \\
8.22 \\
8.13\end{array}$ & $\begin{array}{c}6, \overline{300} \\
\overline{0} \\
6,000 \\
\overline{5}, \overline{720} \\
\overline{6} \\
5,60 \\
5, \overline{480} \\
\overline{5,310}\end{array}$ & $\begin{array}{c}-.98 \\
7.86 \\
7.82 \\
7.72 \\
- \\
7.67 \\
- \\
7.58 \\
7.55\end{array}$ & $\begin{array}{c}5, \overline{400} \\
\overline{-} \\
6,190 \\
4, \overline{9} \\
\overline{-} \\
4, \overline{870} \\
4, \overline{730} \\
4, \overline{680}\end{array}$ & $\begin{array}{c}7.42 \\
7.29 \\
7.11 \\
7.06 \\
6.99 \\
7.04\end{array}$ & $\begin{array}{c}, \overline{630} \\
\overline{-} \\
4, \overline{430} \\
\overline{170} \\
4, \overline{170} \\
4, \overline{100} \\
4, \overline{0} \\
4, \overline{0} \\
40\end{array}$ & $\begin{array}{c}-7.90 \\
6.78 \\
-6.66 \\
\overline{6.64} \\
6.60 \\
6.66\end{array}$ & $\begin{array}{c}4, \overline{020} \\
\overline{3} \\
3, \overline{860} \\
\overline{3,710} \\
\overline{3,690} \\
\overline{3,640} \\
\overline{3,710}\end{array}$ & $\begin{array}{l}- \\
6.55 \\
- \\
6.42 \\
- \\
6.29 \\
- \\
6.23 \\
- \\
6.18 \\
6.20\end{array}$ & $\begin{array}{c}3, \overline{640} \\
3, \overline{490} \\
\overline{3, \overline{3}} \\
\overline{3} \\
3, \overline{280} \\
\overline{3, \overline{2}} \\
\overline{3,250}\end{array}$ \\
\hline & \multicolumn{2}{|c|}{ December 20} & \multicolumn{2}{|c|}{ December 21} & \multicolumn{2}{|c|}{ December 22} & \multicolumn{2}{|c|}{ December 23} & \multicolumn{2}{|c|}{ December 24} & \multicolumn{2}{|c|}{ December 25} \\
\hline $\begin{array}{r}2 \\
4 \\
6 \\
8 \\
10 \\
1 \\
2 \\
4 \\
6 \\
8 \\
10 \\
\mathbf{1}\end{array}$ & $\begin{array}{l}6.10 \\
\overline{5} \\
5.93 \\
= \\
5.89 \\
= \\
5.84 \\
\overline{-} \\
\overline{5} \\
5.80\end{array}$ & $\begin{array}{l}3, \overline{200} \\
3, \overline{030} \\
2, \overline{9} \\
2, \overline{9} \\
2, \overline{-} \\
2, \overline{890} \\
2, \overline{900}\end{array}$ & $\begin{array}{c}5.76 \\
- \\
5.56 \\
- \\
5.50 \\
- \\
5.44 \\
\overline{5.45} \\
5.51\end{array}$ & $\begin{array}{l}2, \overline{860} \\
2, \overline{680} \\
\overline{6}, \overline{630} \\
2, \overline{580} \\
2, \overline{580} \\
2, \overline{640}\end{array}$ & $\begin{array}{c}5.47 \\
- \\
5.33 \\
- \\
5.34 \\
- \\
5.31 \\
-\overline{5.30} \\
5.36\end{array}$ & $\begin{array}{c}2, \overline{600} \\
2, \overline{480} \\
2, \overline{490} \\
2, \overline{-} \\
2, \overline{470} \\
2, \overline{460} \\
2, \overline{5} 10\end{array}$ & $\begin{array}{c}-\overline{5.58} \\
\overline{5.75} \\
- \\
6.11 \\
- \\
6.02 \\
- \\
5.30 \\
5.69\end{array}$ & $\begin{array}{c}2, \overline{700} \\
\overline{8} \\
2, \overline{860} \\
\overline{-} \\
3, \overline{2} 10 \\
\overline{3}, \overline{120} \\
2, \overline{900} \\
2, \overline{800}\end{array}$ & $\begin{array}{c}- \\
5.55 \\
- \\
5.36 \\
- \\
5.35 \\
- \\
5.24 \\
- \\
5.21 \\
- \\
5.23\end{array}$ & $\begin{array}{c}2, \overline{6} 80 \\
2, \overline{5} 10 \\
\overline{-} \\
2, \overline{5} 00 \\
\overline{-} \\
2, \overline{4} 10 \\
2, \overline{3} 90 \\
2, \overline{400}\end{array}$ & $\begin{array}{c}- \\
5.39 \\
- \\
5.33 \\
- \\
5.46 \\
- \\
5.41 \\
- \\
5.22 \\
- \\
5.16\end{array}$ & $\begin{array}{c}\overline{-}, \overline{530} \\
-\overline{430} \\
2, \overline{5} \\
2, \overline{5} 90 \\
\overline{-} \\
2, \overline{5} 50 \\
\overline{2,400} \\
2, \overline{350}\end{array}$ \\
\hline
\end{tabular}


Middlo Fork of American River near Auburn, Calif.

Location.- Lat. $38^{\circ} 55^{\prime}$, long. $121^{\circ} 00^{\prime}$, in Nw sec. 5, T. 12 N., R. 9 E., at Mountain Quarry Co.'s plant 1.7 miles above Junction with North Fork of American River and $3 \frac{1}{2}$ miles northeast of Auburn, Placer County. Altitude, about 580 feet above mean sea level.

Drainsge area.- 619 square miles.

Gage-helght record.- Water-stage recorder graph.

Stage-discharge reiation.- Defined by current-meter measurements below 28,800 secondfeet; extended to peak stage on basis of area-velocity study and by $A \sqrt{d}$ method; verifled by comparison of peak discharge and total run-off of flood with records

for other stationg in American River Basin. Rating curve changed at peak stage.

Maxima.- December 1937: Discharge, 47,900 second-feet 2 p.m. Dec. 11 (gage he1ght, 27.3 feet).

1911-November 1937: Discharge, 62,000 second-feet (revised) Mar. 25, 1928 (gage helght, 35.6 feot, former site and datum, from floodmarks), from rating curve extended above 4,000 second-feet on basis of slope-area determination of flood flow. Remarks. - Flood mun-off not materialiy affected by artificlal storage or diversion.

Mean dally alscharge, in second-feet, November 1937 to January 1938

\begin{tabular}{|c|c|c|c|c|c|c|c|c|c|c|c|}
\hline Day & Nov. & Dec. & Jen. & Day & Nov. & Dec. & Jan. & Day & Nov. & Dec. & Jan. \\
\hline $\begin{array}{r}1 \\
2 \\
3 \\
4 \\
5 \\
6 \\
7 \\
8 \\
9 \\
10\end{array}$ & $\begin{array}{l}82 \\
82 \\
79 \\
79 \\
78 \\
76 \\
78 \\
79 \\
79 \\
80\end{array}$ & $\begin{array}{r}238 \\
224 \\
213 \\
204 \\
195 \\
188 \\
185 \\
185 \\
190 \\
18,100\end{array}$ & $\begin{array}{l}581 \\
640 \\
700 \\
640 \\
581 \\
539 \\
502 \\
481 \\
452 \\
418\end{array}$ & $\begin{array}{l}11 \\
12 \\
13 \\
14 \\
15 \\
16 \\
17 \\
18 \\
19 \\
20\end{array}$ & $\begin{array}{l}112 \\
169 \\
149 \\
172 \\
219 \\
195 \\
743 \\
840 \\
388 \\
360\end{array}$ & $\begin{array}{r}37,700 \\
12,700 \\
4,710 \\
2,920 \\
2,250 \\
1,800 \\
1,540 \\
1,340 \\
1,110 \\
975\end{array}$ & $\begin{array}{r}404 \\
394 \\
384 \\
384 \\
660 \\
700 \\
1,200 \\
1,590 \\
1,290 \\
1,160\end{array}$ & $\begin{array}{l}21 \\
22 \\
23 \\
24 \\
25 \\
26 \\
27 \\
28 \\
29 \\
30 \\
31\end{array}$ & $\begin{array}{r}1,510 \\
650 \\
462 \\
800 \\
580 \\
416 \\
347 \\
308 \\
273 \\
254\end{array}$ & $\begin{array}{l}846 \\
804 \\
909 \\
783 \\
783 \\
720 \\
680 \\
660 \\
620 \\
581 \\
581\end{array}$ & $\begin{array}{r}975 \\
952 \\
1,060 \\
930 \\
846 \\
804 \\
804 \\
846 \\
975 \\
888 \\
1,290\end{array}$ \\
\hline \multicolumn{9}{|c|}{ 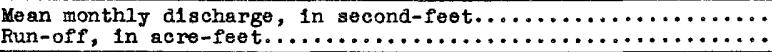 } & 19,320 & $\begin{array}{r}3,062 \\
188,300\end{array}$ & 47,740 \\
\hline
\end{tabular}

Gage height, in feet, and alscharge, in second-feet, at Indicated t1mo, 1937

\begin{tabular}{|c|c|c|c|c|c|c|c|c|c|c|c|c|}
\hline \multirow{2}{*}{$\begin{array}{l}3 \\
3 \\
3 \\
\end{array}$} & Feet & Sec.ft. & Feet & Sec.ft. & Feet & Sec.ft. & Feet & sec.ft. & Feet & Sec.ft. & Feet & sec.ft. \\
\hline & \multicolumn{2}{|c|}{ December 8} & \multicolumn{2}{|c|}{ December 9} & \multicolumn{2}{|c|}{ December 10} & \multicolumn{2}{|c|}{ December 11} & \multicolumn{2}{|c|}{ December 12} & \multicolumn{2}{|c|}{ December 13} \\
\hline \multirow[t]{2}{*}{$\begin{array}{r}2 \\
4 \\
6 \\
8 \\
10 \\
N \\
2 \\
4 \\
6 \\
8 \\
10 \\
M\end{array}$} & $\begin{array}{c}- \\
2.28 \\
- \\
2.28 \\
- \\
2.28 \\
- \\
2.28 \\
- \\
2.28 \\
\overline{2.28}\end{array}$ & $\begin{array}{c}185 \\
\overline{185} \\
\overline{185} \\
\overline{185} \\
\overline{185} \\
\overline{185}\end{array}$ & $\begin{array}{l}2.29 \\
2.30 \\
2.30 \\
2.30 \\
2.30 \\
2.30 \\
2.30 \\
2.30 \\
2.31 \\
2.36 \\
2.45 \\
2.54\end{array}$ & $\begin{array}{l}186 \\
188 \\
188 \\
188 \\
188 \\
188 \\
188 \\
188 \\
190 \\
199 \\
215 \\
232\end{array}$ & $\begin{array}{r}2.83 \\
3.25 \\
4.20 \\
6.90 \\
17.40 \\
19.65 \\
20.65 \\
21.60 \\
22.25 \\
21.96 \\
20.88 \\
20.00\end{array}$ & $\begin{array}{r}293 \\
402 \\
720 \\
2,010 \\
19,600 \\
25,400 \\
28,200 \\
30,900 \\
32,800 \\
31,900 \\
28,900 \\
26,400\end{array}$ & \begin{tabular}{l|}
19.79 \\
20.00 \\
21.80 \\
24.00 \\
25.11 \\
26.40 \\
27.30 \\
26.99 \\
26.40 \\
24.90 \\
22.45 \\
20.35
\end{tabular} & $\begin{array}{l}25,800 \\
26,400 \\
31,400 \\
38,000 \\
41,300 \\
45,200 \\
47,900 \\
47,000 \\
45,200 \\
40,700 \\
33,400 \\
27,400\end{array}$ & $\begin{array}{l}18.56 \\
17.30 \\
16.20 \\
15.30 \\
14.45 \\
13.70 \\
13.10 \\
12.60 \\
12.10 \\
11.78 \\
11.50 \\
11.20\end{array}$ & $\begin{array}{r}22,600 \\
19,300 \\
16,700 \\
14,500 \\
12,600 \\
11,000 \\
9,800 \\
8,800 \\
7,880 \\
7,310 \\
6,860 \\
6,380\end{array}$ & $\begin{array}{r}11.00 \\
10.80 \\
10.60 \\
10.31 \\
9.95 \\
9.68 \\
9.52 \\
9.33 \\
9.16 \\
8.98 \\
8.84 \\
8.68\end{array}$ & $\begin{array}{l}6,100 \\
5,820 \\
5,540 \\
5,190 \\
4,760 \\
4,460 \\
4,300 \\
4,110 \\
3,940 \\
3,760 \\
3,640 \\
3,490\end{array}$ \\
\hline & \multicolumn{2}{|c|}{ December 14} & \multicolumn{2}{|c|}{ December 15} & \multicolumn{2}{|c|}{ December 16} & \multicolumn{2}{|c|}{ December 17} & \multicolumn{2}{|c|}{ December 18} & \multicolumn{2}{|c|}{ December 19} \\
\hline \multirow[t]{2}{*}{$\begin{array}{r}2 \\
4 \\
6 \\
8 \\
10 \\
N \\
2 \\
4 \\
6 \\
8 \\
10 \\
M\end{array}$} & $\begin{array}{l}8.55 \\
8.42 \\
8.33 \\
8.22 \\
8.10 \\
8.03 \\
7.92 \\
7.80 \\
7.70 \\
7.60 \\
7.50 \\
7.40\end{array}$ & $\begin{array}{l}3,380 \\
3,260 \\
3,180 \\
3,100 \\
3,000 \\
2,940 \\
2,860 \\
2,770 \\
2,700 \\
2,630 \\
2,560 \\
2,490\end{array}$ & $\begin{array}{c}\overline{-} \\
7.20 \\
= \\
\overline{7} \\
\overline{-} \\
\overline{6.80} \\
\overline{-} \\
6.57\end{array}$ & $\begin{array}{c}\overline{-} \\
\bar{z}, \overline{370} \\
\overline{-} \\
\overline{2}, \overline{250} \\
\overline{-} \\
2, \overline{13} 0 \\
\overline{-} \\
2, \overline{0} 00\end{array}$ & $\begin{array}{c}- \\
6.38 \\
= \\
\overline{6} \\
\overline{-} \\
6.10 \\
\overline{-} \\
5.93\end{array}$ & $\begin{array}{c}\overline{-} \\
1,900 \\
\overline{-} \\
1,830 \\
- \\
\overline{1}, \overline{7} \\
\overline{-} \\
1,660\end{array}$ & $\begin{array}{c}- \\
5.74 \\
- \\
- \\
5.67 \\
\overline{-} \\
5.56 \\
- \\
5.46\end{array}$ & $\begin{array}{c}\overline{-} \\
1, \overline{5} 60 \\
- \\
- \\
1,520 \\
- \\
\overline{1,} \\
\overline{-} \\
\overline{1}, 420\end{array}$ & $\begin{array}{c}- \\
5.38 \\
- \\
5.31 \\
- \\
5.27 \\
- \\
5.19 \\
- \\
5.16 \\
- \\
5.10\end{array}$ & $\begin{array}{c}-\overline{3} 80 \\
-\overline{3} 40 \\
1, \overline{3} \\
1, \overline{2} 0 \\
\overline{-} \\
1,290 \\
\overline{1} \overline{2} 70 \\
1, \overline{2} 40\end{array}$ & $\begin{array}{c}- \\
4.91 \\
4.88 \\
- \\
4.77 \\
\overline{4} \\
-74 \\
4.70 \\
- \\
4.60\end{array}$ & $\begin{array}{c}\overline{1}, 160 \\
\overline{1} \\
1,150 \\
\overline{-} \\
1,100 \\
\overline{-} \\
1,080 \\
1, \overline{0} \\
1, \overline{0} 00\end{array}$ \\
\hline & \multicolumn{2}{|c|}{ December 20} & \multicolumn{2}{|c|}{ December 21} & \multicolumn{2}{|c|}{ December 22} & \multicolumn{2}{|c|}{ December 23} & \multicolumn{2}{|c|}{ December 24} & \multicolumn{2}{|c|}{ December 25} \\
\hline $\begin{array}{r}2 \\
4 \\
6 \\
8 \\
10 \\
N \\
2 \\
4 \\
6 \\
8 \\
10 \\
y\end{array}$ & $\begin{array}{c}- \\
4.56 \\
- \\
4.52 \\
\overline{4.50} \\
\overline{4.44} \\
\overline{4.40} \\
\overline{4.30}\end{array}$ & $\begin{array}{c}\overline{\overline{0}} \overline{000} \\
\overline{9} \\
\overline{984} \\
\overline{9} \\
\overline{9} \\
\overline{9} 48 \\
\overline{930} \\
\overline{888}\end{array}$ & $\begin{array}{c}- \\
4.24 \\
- \\
4.20 \\
\overline{4.11} \\
- \\
4.14 \\
\overline{4.13} \\
\overline{4.16}\end{array}$ & $\begin{array}{c}\dot{863} \\
\ddot{846} \\
\ddot{808} \\
\dot{8} 1 \\
\ddot{817} \\
\dot{829}\end{array}$ & $\begin{array}{c}\overline{-} \\
4.13 \\
\overline{4.08} \\
\overline{4.07} \\
\overline{4} \\
\overline{4} 10 \\
\overline{4.20} \\
\overline{4.37}\end{array}$ & $\begin{array}{c}\overline{817} \\
\overline{796} \\
\overline{791} \\
\overline{804} \\
\overline{846} \\
\overline{917}\end{array}$ & $\begin{array}{c}- \\
4.57 \\
- \\
4.60 \\
- \\
4.44 \\
- \\
4.30 \\
- \\
4.06 \\
- \\
3.93\end{array}$ & $\begin{array}{c}\overline{1,010} \\
\overline{1} \overline{0} \\
\overline{9} \\
\overline{9} 48 \\
\overline{8} 88 \\
\overline{7} 87 \\
\overline{7} \\
\overline{7} 33\end{array}$ & $\begin{array}{c}- \\
3.94 \\
- \\
4.04 \\
- \\
4.06 \\
- \\
4.06 \\
\overline{4} .06 \\
\overline{4.11}\end{array}$ & $\begin{array}{c}7 \overline{37} \\
\overline{7} \\
\overline{7} \\
\overline{7} \\
\overline{7} \\
7 \overline{87} \\
\overline{7} \\
\overline{87} \\
808\end{array}$ & $\begin{array}{c}- \\
4.13 \\
- \\
4.10 \\
- \\
4.06 \\
- \\
4.02 \\
- \\
3.98 \\
3.96\end{array}$ & $\begin{array}{c}\overline{817} \\
\overline{804} \\
\overline{787} \\
\overline{770} \\
\overline{754} \\
\overline{745}\end{array}$ \\
\hline
\end{tabular}

Supplemental records .- Dec. $10,6: 30 \mathrm{a}_{*} \mathrm{~m}_{*}, 22.37 \mathrm{ft} ., 32,300 \mathrm{sec} . \mathrm{ft}_{*}$ 1:00 p.m., 20.95 ft., 29,100 sec. $-f t$. 
South Fork of American River near Kyburz, Calif.

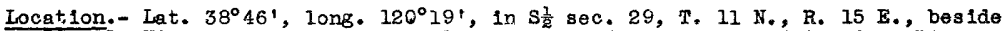
Incoln Highway, $0.5 \mathrm{mlle}$ below Sliver Fork of South Fork of American River, and 2 miles west of Kyburz, Eldorado County. Alt1tude, about 4,030 feet above mean sea level.

Drainage area.- 196 square miles.

Gage-height record. - Water-stage recorder graph.

Stage-discharge relation. - Defined by current-meter measurements below 3,900 secondfeet; extended to peak stage on basis of area-velocity study; veriffed by comparison of peak discharge and total mun-off of flood with records for other stations in American River Bas in.

Maxima.- December 1937: Discharge, 9,700 second-feet 6 a.m. Dec. 11 (gage height, 8.55 feet).

1922-November 1937: Discharge, 5,020 second-feet Mar. 25, 1928 (gage height, 7.60 feet), from rating curve extended above 2,200 second-feet.

Remarks.- Flood run-off not materially affected by artificial storage. Monthly summaries adjusted for diversion into Eldorgdo canal. Part of basic data furmlshed by Paciflc Gas \& Electric Co.

Mean dally discharge, in second-feet, November 1937 to January 1938

\begin{tabular}{|c|c|c|c|c|c|c|c|c|c|c|c|}
\hline Dey & Nov. & Dec. & Jan. & Day & Nov. & Dec. & Jan. & Day & Nov. & Dec. & Jan. \\
\hline 1 & 2.1 & 3.0 & 112 & 11 & 3.4 & 6,470 & 67 & 21 & 51 & 165 & 78 \\
2 & 2.2 & 3.0 & 121 & 12 & 2.6 & 1,260 & 64 & 22 & 2.4 & 154 & 88 \\
3 & 2.1 & 2.5 & 110 & 13 & 2.1 & 904 & 63 & 23 & 2.4 & 136 & 83 \\
4 & 2.0 & 2.2 & 104 & 14 & 4.2 & 538 & 64 & 24 & 2.5 & 144 & 74 \\
5 & 2.5 & 2.0 & 98 & 15 & 1.7 & 416 & 92 & 25 & 2.0 & 136 & 75 \\
6 & 2.4 & 4.2 & 89 & 16 & 2.6 & 322 & 78 & 26 & 1.5 & 130 & 79 \\
7 & 2.2 & 2.4 & 79 & 17 & 53 & 275 & 101 & 27 & 1.5 & 128 & 82 \\
8 & 3.1 & 1.7 & 76 & 18 & 7 & 238 & 89 & 28 & 2.2 & 117 & 82 \\
9 & 2.2 & 3.7 & 71 & 19 & 2.5 & 207 & 85 & 29 & 2.2 & 114 & 79 \\
10 & 2.1 & 2,850 & 68 & 20 & 78 & 174 & 74 & 30 & 2.2 & 110 & 67 \\
\end{tabular}

Gage height, in feet, and discharge, in secona-feet, at indicated time, 1937

\begin{tabular}{|c|c|c|c|c|c|c|c|c|c|c|c|c|}
\hline \multirow{2}{*}{ 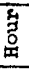 } & Feet & Sec.ft. & Feet & Sec.ft. & Feet & Sec.ft. & Feet & Sec.ft. & Feet & Sec.ft. & Feet & Sec.ft. \\
\hline & \multicolumn{2}{|c|}{ December 8} & \multicolumn{2}{|c|}{ December 9} & \multicolumn{2}{|c|}{ December 10} & \multicolumn{2}{|c|}{ December 11} & \multicolumn{2}{|c|}{ December 12} & \multicolumn{2}{|c|}{ December 13} \\
\hline $\begin{array}{r}2 \\
4 \\
6 \\
8 \\
10 \\
N \\
2 \\
4 \\
6 \\
8 \\
10 \\
4\end{array}$ & $\begin{array}{c}- \\
1.28 \\
- \\
1.29 \\
-\overline{1.20} \\
\overline{1.12} \\
\overline{1.10} \\
\overline{1.09}\end{array}$ & $\begin{array}{c}- \\
2.7 \\
- \\
2.8 \\
1.7 \\
- \\
1.1 \\
.9 \\
.9\end{array}$ & $\begin{array}{l}1.09 \\
1.08 \\
1.08 \\
1.08 \\
1.08 \\
1.08 \\
1.08 \\
1.08 \\
1.10 \\
1.16 \\
1.65 \\
2.15\end{array}$ & $\begin{array}{c}.9 \\
.8 \\
.8 \\
.8 \\
.8 \\
.8 \\
.8 \\
.8 \\
.9 \\
1.4 \\
13 \\
46\end{array}$ & $\begin{array}{l}3.90 \\
5.33 \\
6.10 \\
6.70 \\
6.65 \\
6.40 \\
6.73 \\
6.75 \\
6.60 \\
6.40 \\
6.70 \\
6.83\end{array}$ & $\begin{array}{r}506 \\
1,580 \\
2,590 \\
3,700 \\
3,600 \\
3,100 \\
3,770 \\
3,810 \\
3,490 \\
3,100 \\
3,700 \\
3,990\end{array}$ & $\begin{array}{l}7.72 \\
8.35 \\
8.55 \\
8.00 \\
7.91 \\
7.76 \\
7.51 \\
7.50 \\
7.15 \\
6.71 \\
6.38 \\
6.11\end{array}$ & $\begin{array}{l}6,420 \\
8,680 \\
9,700 \\
7,920 \\
7,670 \\
7,250 \\
6,550 \\
6,520 \\
5,550 \\
4,450 \\
3,730 \\
2,160\end{array}$ & $\begin{array}{l}.93 \\
5.80 \\
5.65 \\
5.52 \\
5.40 \\
5.30 \\
5.22 \\
5.18 \\
5.11 \\
5.00 \\
4.94 \\
4.85\end{array}$ & $\begin{array}{l}2,820 \\
2,600 \\
2,360 \\
2,160 \\
1,990 \\
1,850 \\
1,750 \\
1,690 \\
1,600 \\
1,470 \\
1,400 \\
1,300\end{array}$ & $\begin{array}{l}4.78 \\
4.70 \\
4.64 \\
4.57 \\
4.50 \\
4.45 \\
4.31 \\
4.27 \\
4.23 \\
4.19 \\
4.13 \\
4.07\end{array}$ & $\begin{array}{r}1,230 \\
1,150 \\
1,090 \\
1,020 \\
960 \\
920 \\
808 \\
779 \\
751 \\
724 \\
688 \\
652\end{array}$ \\
\hline & \multicolumn{2}{|c|}{ December 14} & \multicolumn{2}{|c|}{ December 15} & \multicolumn{2}{|c|}{ December 16} & \multicolumn{2}{|c|}{ December 17} & \multicolumn{2}{|c|}{ December 18} & \multicolumn{2}{|c|}{ December 19} \\
\hline \multirow[t]{2}{*}{$\begin{array}{r}2 \\
4 \\
6 \\
8 \\
10 \\
N \\
2 \\
4 \\
6 \\
8 \\
10 \\
M\end{array}$} & $\begin{array}{c}- \\
3.98 \\
- \\
3.90 \\
- \\
3.84 \\
3.81 \\
- \\
3.80 \\
- \\
3.77\end{array}$ & $\begin{array}{c}5 \overline{99} \\
\overline{5} \\
5 \overline{5} \\
5 \overline{2} \\
\overline{506} \\
\overline{500} \\
\overline{8} \\
484\end{array}$ & $\begin{array}{c}-.71 \\
3.71 \\
3.65 \\
-\tilde{3.60} \\
- \\
3.56 \\
- \\
3.54 \\
- \\
3.51\end{array}$ & $\begin{array}{c}4 \overline{53} \\
\overline{425} \\
4 \overline{0} 2 \\
\overline{3} \overline{85} \\
\overline{377} \\
3 \overline{6}\end{array}$ & $\begin{array}{c}5 . \\
3.46 \\
- \\
3.42 \\
- \\
3.38 \\
- \\
3.35 \\
- \\
3.33 \\
- \\
3.33\end{array}$ & $\begin{array}{c}3 \overline{45} \\
3 \overline{30} \\
\overline{3} \\
\overline{15} \\
3 \overline{0} \\
2 \overline{9} \\
2 \overline{9} 6\end{array}$ & $\begin{array}{c}- \\
z .29 \\
\vdots \\
3.25 \\
\tilde{3} \\
\tilde{3.23} \\
\tilde{3.22}\end{array}$ & $\begin{array}{c}- \\
2 \overline{8} \\
\overline{-} \\
268 \\
\overline{-} \\
262 \\
\overline{2} \\
259\end{array}$ & $\begin{array}{c}\overline{-} \\
3.19 \\
\overline{-} \\
\overline{3.13} \\
\overline{-} \\
\overline{3.12} \\
\overline{3.10}\end{array}$ & $\begin{array}{c}\overline{-} \\
249 \\
\overline{-} \\
232 \\
\overline{-} \\
229 \\
\overline{2} \\
2 \overline{2} 3\end{array}$ & $\begin{array}{c}- \\
\overline{3} \\
-06 \\
\overline{3.02} \\
\overline{-} \\
3.01 \\
= \\
3.00\end{array}$ & $\begin{array}{c}\overline{-} \\
212 \\
\overline{-} \\
201 \\
\overline{-} \\
\overline{199} \\
\overline{196}\end{array}$ \\
\hline & \multicolumn{2}{|c|}{ December 20} & \multicolumn{2}{|c|}{ December 21} & \multicolumn{2}{|c|}{ December 22} & \multicolumn{2}{|c|}{ December 23} & \multicolumn{2}{|c|}{ December 24} & \multicolumn{2}{|c|}{ December 25} \\
\hline $\begin{array}{r}2 \\
4 \\
6 \\
8 \\
10 \\
\mathbb{N} \\
2 \\
4 \\
6 \\
8 \\
10 \\
M\end{array}$ & $\begin{array}{l}2.93 \\
2.85 \\
2.85 \\
2.86 \\
2.93 \\
2.95 \\
\dot{2.95}\end{array}$ & $\begin{array}{c}\overline{179} \\
\overline{161} \\
\overline{163} \\
\overline{179} \\
\overline{184} \\
\overline{184}\end{array}$ & $\begin{array}{c}2 . \\
2.90 \\
- \\
2.87 \\
2.85 \\
2.85 \\
2.88 \\
2.88\end{array}$ & $\begin{array}{c}\overline{172} \\
\overline{165} \\
\overline{161}\end{array}$ & $\begin{array}{l}2.85 \\
2.81 \\
2.81 \\
2.78\end{array}$ & $\begin{array}{c}- \\
161 \\
- \\
152 \\
\overline{146}\end{array}$ & $\begin{array}{c}- \\
2.76 \\
- \\
2.64 \\
2.67 \\
2.74 \\
2.80 \\
2.72\end{array}$ & $\begin{array}{c}\overline{142} \\
\overline{119} \\
\overline{125} \\
\overline{138} \\
\overline{150} \\
\overline{134}\end{array}$ & $\begin{array}{c}2.69 \\
-- \\
2.71 \\
-5.81 \\
-- \\
2.91 \\
2.86 \\
2.78\end{array}$ & $\begin{array}{c}\overline{128} \\
\overline{132} \\
\overline{152} \\
\overline{174} \\
\overline{163} \\
\overline{146}\end{array}$ & $\begin{array}{c}- \\
2.71 \\
- \\
2.65 \\
- \\
2.74 \\
- \\
2.83 \\
-.79 \\
2.79 \\
2.70\end{array}$ & $\begin{array}{c}\overline{132} \\
\overline{121} \\
\overline{1} \\
138 \\
\overline{157} \\
\overline{148} \\
\overline{130}\end{array}$ \\
\hline
\end{tabular}

Supplemental records. - Dec. 10,1 a.m., $2.35 \mathrm{ft},, 66$ sec. $-\mathrm{ft}$. 
Location. - Lat. $38^{\circ} 46^{\prime}$, long. $120^{\circ} 42^{\prime}$, in SW/ sec. 25, T. 11 N., R. 11 F., 300 feet above mouth of Iowa Canyon Creek, I mile below intake of American River flume, and 3 miles northwest of Oamino, Eldorado County. Altitude, about 1,640 feet above mean sea level.

Draingge area.- 497 square miles.

Gage-he1ght record.- Water-stage recorder graph except for period 11:40 a.m. Dec. 3 to 12:40 p.m. Dec. 12. Stage graph for period 11:40 a.m. Dec. 3 to 7 a.m. Dec. 10 based on several dally readings taken from the recorder graph before it was destrojed. Stage graph for period $7 \mathrm{a.m}$. Dec. 10 to $12: 40 \mathrm{p.m}$. Dec. 12 based on floodmarks, occasional readings at a dam 1 mile above gage, and comparison with stage graphs for South Fork of American River at Coloma and Silver Oreek near Placerville.

Stage-discharge relation. - Defined by current-meter measurements below 8,000 second-feet extended to peak stage on basis of area-velocity study; verified by $A \sqrt{d}$ method, computed flow over a dam 1 mile above gage, and comparison of peak discharge and total mun-off of flood with records for other stations in American River Basin. Rating curve changed Dec. 10

Maxima.- December 1937: Discharge, 25,800 second-feet about noon Dec. 11 (gage he1ght, 25.5 feet, from floodmark).

1922-November 1937: Discharge, 24,100 second-feet (rev1sed) Mar. 25, 1928 (gage helght, 24.4 feet, from floodmark

Remarks.- Flood mun-off not terially affected by artificlal storage. American River frume diverts above station. Monthly summaries adjusted for diversion. Part of basic data furnished by Pacific Gas Blectric 00 .

Yean daily discharge, in second-feet, November 1937 to January 1938

\begin{tabular}{|c|c|c|c|c|c|c|c|c|c|c|c|}
\hline Day & Nov. & Dec. & Jan. & Day & Nov. & Dec. & Jen. & Day & Nov. & Dec. & Jan. \\
\hline $\begin{array}{r}1 \\
2 \\
3 \\
4 \\
5 \\
6 \\
7 \\
8 \\
9 \\
10\end{array}$ & $\begin{array}{r}18 \\
78 \\
94 \\
119 \\
112 \\
118 \\
114 \\
124 \\
124 \\
114\end{array}$ & $\begin{array}{r}100 \\
142 \\
112 \\
112 \\
95 \\
112 \\
125 \\
98 \\
132 \\
7,340\end{array}$ & $\begin{array}{l}341 \\
352 \\
386 \\
341 \\
319 \\
308 \\
300 \\
304 \\
252 \\
268\end{array}$ & $\begin{array}{l}11 \\
12 \\
13 \\
14 \\
15 \\
16 \\
17 \\
18 \\
19 \\
20\end{array}$ & $\begin{array}{l}164 \\
202 \\
162 \\
184 \\
192 \\
171 \\
364 \\
356 \\
205 \\
200\end{array}$ & $\begin{array}{r}18,500 \\
6,580 \\
2,640 \\
1,650 \\
1,260 \\
1,020 \\
802 \\
702 \\
630 \\
502\end{array}$ & $\begin{array}{l}252 \\
256 \\
248 \\
248 \\
386 \\
352 \\
564 \\
630 \\
532 \\
448\end{array}$ & $\begin{array}{l}21 \\
22 \\
23 \\
24 \\
25 \\
26 \\
27 \\
28 \\
29 \\
30 \\
31\end{array}$ & $\begin{array}{l}454 \\
309 \\
252 \\
338 \\
272 \\
242 \\
218 \\
160 \\
121 \\
125\end{array}$ & $\begin{array}{l}488 \\
461 \\
461 \\
398 \\
410 \\
374 \\
363 \\
374 \\
352 \\
352 \\
341 \\
\end{array}$ & $\begin{array}{l}422 \\
435 \\
448 \\
386 \\
398 \\
374 \\
386 \\
398 \\
410 \\
374 \\
532 \\
\end{array}$ \\
\hline $\begin{array}{l}\text { Mean } \\
\text { Hean } \\
\text { Run- }\end{array}$ & $\begin{array}{l}\text { month] } \\
\text { nonth } \\
\text { ef, in }\end{array}$ & $r e-f e$ & $\begin{array}{l}\text { in } \\
\text { in } \\
\text { adj }\end{array}$ & nond & $\begin{array}{l}e t \\
e t\end{array}$ & mod & & & $\begin{array}{r}190 \\
223 \\
13,280\end{array}$ & $\begin{array}{r}1,517 \\
1,610 \\
98,990\end{array}$ & $\begin{array}{r}376 \\
476 \\
29,240 \\
\end{array}$ \\
\hline
\end{tabular}

Gage height, in feet, and dscharge, in second-feet, at indicated time, 1937

\begin{tabular}{|c|c|c|c|c|c|c|c|c|c|c|c|c|}
\hline \multirow{2}{*}{$\begin{array}{l}4 \\
\text { 帘 } \\
\end{array}$} & Feet & Sec.ft. & Feet & Sec.ft. & Feet & Sec.ft. & Peet & Sec.ft. & Feet & Sec.ft. & Foet & Sec.ft. \\
\hline & \multicolumn{2}{|c|}{ December 8} & \multicolumn{2}{|c|}{ De cember 9} & \multicolumn{2}{|c|}{ December 10} & \multicolumn{2}{|c|}{ December 11} & \multicolumn{2}{|c|}{ December 12} & \multicolumn{2}{|c|}{ December 13} \\
\hline $\begin{array}{r}2 \\
4 \\
6 \\
8 \\
10 \\
N \\
2 \\
4 \\
6 \\
8 \\
10\end{array}$ & $\begin{array}{c}- \\
2.40 \\
- \\
2.16 \\
- \\
2.09 \\
- \\
2.01 \\
- \\
2.04 \\
- \\
2.20\end{array}$ & $\begin{array}{c}\overline{123} \\
\overline{96} \\
\overline{89} \\
\overline{82} \\
\overline{85} \\
\overline{100}\end{array}$ & $\begin{array}{l}2.26 \\
2.32 \\
2.36 \\
2.40 \\
2.40 \\
2.40 \\
2.40 \\
2.40 \\
2.48 \\
2.67 \\
2.89 \\
3.10\end{array}$ & $\begin{array}{l}107 \\
113 \\
118 \\
123 \\
123 \\
123 \\
123 \\
123 \\
133 \\
160 \\
194 \\
230\end{array}$ & \begin{tabular}{r|}
3.50 \\
6.00 \\
10.50 \\
14.1 \\
15.9 \\
16.0 \\
15.5 \\
14.8 \\
14.0 \\
13.3 \\
12.8 \\
12.4 \\
\end{tabular} & $\begin{array}{r}308 \\
1,230 \\
4,730 \\
9,180 \\
11,700 \\
11,800 \\
11,100 \\
10,100 \\
9,050 \\
8,140 \\
7,490 \\
6,970\end{array}$ & \begin{tabular}{|l|}
13.8 \\
16.5 \\
19.4 \\
22.5 \\
25.3 \\
25.5 \\
25.0 \\
23.2 \\
21.4 \\
19.8 \\
18.6 \\
17.3 \\
\end{tabular} & $\begin{array}{r}8,790 \\
12,500 \\
16,600 \\
21,200 \\
25,400 \\
25,800 \\
25,000 \\
22,300 \\
19,600 \\
17,200 \\
15,400 \\
13,600\end{array}$ & \begin{tabular}{|c|}
16.0 \\
14.8 \\
13.6 \\
12.6 \\
11.7 \\
11.0 \\
10.70 \\
10.35 \\
10.10 \\
9.90 \\
9.67 \\
9.45
\end{tabular} & $\begin{array}{r}11,800 \\
10,100 \\
8,530 \\
7,230 \\
6,100 \\
5,280 \\
4,950 \\
4,570 \\
4,320 \\
4,120 \\
3,890 \\
3,680\end{array}$ & $\begin{array}{l}9.20 \\
8.93 \\
8.70 \\
8.46 \\
8.27 \\
8.07 \\
7.90 \\
7.72 \\
7.56 \\
7.46 \\
7.26 \\
7.16 \\
\end{array}$ & $\begin{array}{l}3,460 \\
3,220 \\
3,040 \\
2,850 \\
2,700 \\
2,550 \\
2,430 \\
2,300 \\
2,190 \\
2,120 \\
1,990 \\
1,930\end{array}$ \\
\hline & \multicolumn{2}{|c|}{ Decomber 14} & \multicolumn{2}{|c|}{ December 15} & \multicolumn{2}{|c|}{ December 16} & \multicolumn{2}{|c|}{ December 17} & \multicolumn{2}{|c|}{ December 18} & \multicolumn{2}{|c|}{ December 19} \\
\hline \multirow[t]{2}{*}{\begin{tabular}{r|}
2 \\
4 \\
6 \\
8 \\
10 \\
1 \\
2 \\
4 \\
6 \\
8 \\
10 \\
4
\end{tabular}} & $\begin{array}{l}7.05 \\
7.06 \\
6.99 \\
6.88 \\
6.85 \\
6.82 \\
6.49 \\
6.60 \\
6.69 \\
6.51 \\
6.49 \\
6.17\end{array}$ & $\begin{array}{l}1,860 \\
1,870 \\
1,880 \\
1,760 \\
1,740 \\
1,720 \\
1,520 \\
1,590 \\
1,580 \\
1,640 \\
1,520 \\
1,330\end{array}$ & $\begin{array}{l}6.17 \\
6.16 \\
6.11 \\
6.06 \\
6.30 \\
6.27 \\
5.89 \\
6.09 \\
5.89 \\
6.00 \\
5.95 \\
5.52\end{array}$ & $\begin{array}{r}1,330 \\
1,330 \\
1,300 \\
1,270 \\
1,410 \\
1,390 \\
1,160 \\
1,280 \\
1,160 \\
1,230 \\
1,200 \\
980\end{array}$ & $\begin{array}{l}5.70 \\
5.73 \\
5.70 \\
5.70 \\
5.73 \\
5.71 \\
5.67 \\
5.64 \\
5.57 \\
5.60 \\
5.17\end{array}$ & $\begin{array}{r}1,070 \\
1,080 \\
1,070 \\
1,070 \\
1,080 \\
1,080 \\
1,060 \\
1,040 \\
1,000 \\
970 \\
811 \\
780\end{array}$ & $\begin{array}{l}5.07 \\
5.05 \\
5.03 \\
5.00 \\
5.35 \\
5.35 \\
5.20 \\
5.18 \\
5.15 \\
5.17 \\
5.04 \\
4.89\end{array}$ & $\begin{array}{l}768 \\
760 \\
752 \\
740 \\
895 \\
895 \\
824 \\
815 \\
802 \\
811 \\
756 \\
698\end{array}$ & $\begin{array}{l}4.79 \\
4.77 \\
4.76 \\
4.91 \\
5.14 \\
5.15 \\
6.13 \\
6.00 \\
4.50 \\
4.89 \\
4.84 \\
4.84\end{array}$ & $\begin{array}{l}662 \\
655 \\
658 \\
706 \\
798 \\
802 \\
793 \\
740 \\
564 \\
698 \\
680 \\
680\end{array}$ & \begin{tabular}{l|}
4.84 \\
4.84 \\
4.83 \\
4.83 \\
4.92 \\
4.84 \\
4.81 \\
4.56 \\
4.55 \\
4.76 \\
4.60 \\
4.23
\end{tabular} & $\begin{array}{l}680 \\
680 \\
677 \\
677 \\
710 \\
680 \\
670 \\
583 \\
680 \\
652 \\
596 \\
488\end{array}$ \\
\hline & \multicolumn{2}{|c|}{ December 20} & \multicolumn{2}{|c|}{ December 21} & \multicolumn{2}{|c|}{ December 22} & \multicolumn{2}{|c|}{ December 23} & \multicolumn{2}{|c|}{ December 24} & \multicolumn{2}{|c|}{ December 25} \\
\hline $\begin{array}{r}2 \\
4 \\
6 \\
8 \\
10 \\
\mathrm{~N} \\
2 \\
4 \\
6 \\
8 \\
10 \\
\mathrm{M}\end{array}$ & $\begin{array}{l}4.21 \\
4.20 \\
4.20 \\
4.35 \\
4.62 \\
4.64 \\
4.25 \\
4.35 \\
4.30 \\
4.47 \\
4.05 \\
3.91\end{array}$ & $\begin{array}{l}477 \\
474 \\
474 \\
517 \\
570 \\
610 \\
488 \\
517 \\
502 \\
554 \\
435 \\
400\end{array}$ & $\begin{array}{l}3.97 \\
4.00 \\
4.29 \\
4.30 \\
4.32 \\
4.54 \\
4.15 \\
4.29 \\
4.30 \\
4.43 \\
4.42 \\
3.86\end{array}$ & $\begin{array}{l}416 \\
422 \\
499 \\
602 \\
508 \\
577 \\
461 \\
499 \\
502 \\
542 \\
538 \\
388\end{array}$ & $\begin{array}{l}3.84 \\
3.84 \\
3.84 \\
3.88 \\
4.30 \\
4.41 \\
4.17 \\
4.18 \\
4.25 \\
4.42 \\
4.36 \\
4.07\end{array}$ & $\begin{array}{l}384 \\
384 \\
384 \\
393 \\
502 \\
535 \\
466 \\
469 \\
488 \\
538 \\
520 \\
449\end{array}$ & $\begin{array}{l}4.08 \\
4.08 \\
4.09 \\
4.24 \\
4.32 \\
4.42 \\
4.14 \\
4.19 \\
3.99 \\
4.11 \\
3.94 \\
3.67\end{array}$ & $\begin{array}{l}\mathbf{4 4 3} \\
\mathbf{4 4 3} \\
\mathbf{4 4 5} \\
\mathbf{4 8 5} \\
508 \\
538 \\
\mathbf{4 5 8} \\
\mathbf{4 7 1} \\
\mathbf{4 2 0} \\
\mathbf{4 5 1} \\
\mathbf{4 0 8} \\
\mathbf{3 4 6}\end{array}$ & $\begin{array}{l}3.58 \\
3.59 \\
3.63 \\
3.63 \\
3.76 \\
4.15 \\
4.11 \\
3.85 \\
3.89 \\
4.29 \\
4.39 \\
4.43\end{array}$ & $\begin{array}{l}326 \\
328 \\
337 \\
337 \\
365 \\
461 \\
451 \\
386 \\
396 \\
499 \\
429 \\
642\end{array}$ & $\begin{array}{l}4.33 \\
3.87 \\
3.82 \\
3.77 \\
3.75 \\
3.80 \\
3.77 \\
3.70 \\
3.68 \\
4.12 \\
4.25 \\
4.31\end{array}$ & $\begin{array}{l}511 \\
391 \\
379 \\
367 \\
363 \\
374 \\
367 \\
352 \\
348 \\
453 \\
488 \\
605\end{array}$ \\
\hline
\end{tabular}


South Fork of American River at Coloma, Calif.

Location. - Lat. $38^{\circ} 48^{\prime}$, long. $120^{\circ} 53^{\prime}$, in SW $\frac{1}{4}$ sec. 17, T. II N., R. 10 E., at highway bridge at Colome, Eldorado County, $0.6 \mathrm{mile}$ below Irish Creok. Altitude, about 740 feet above mean sea level.

Drainage area.- 635 square miles.

Gage-helght record. - Water-stage recorder graph except for period Dec. 29-30, when there was no record.

Stage-discharge relation.- Defined by current-meter megsurements below 13,200 secondfeet; extended to peak stage on basis of area-velocity study; verifled by comparison of peak discharge and total run-off of flood with records for other stations in American River Basin. Rating curve changed at peak stage.

Maxima.- December 1937: Discharge, 27,000 second-feet 2 p.m. Dec. Il (gage helght, 20.5 feet).

1929-November 1937: Discharge, 13,300 second-feet Apr. 8, 1935 (gage height, 16.85 feet), from rating curve extended above 9,400 second-feet.

Remarks.- Flood run-off not materlaliy affected by artificlal storage or diversion. Discharge for period of missing gage-height record determined from record of South Fork of American River near Camino.

Mean daily discharge, in second-feet, November 1937 to January 1938

\begin{tabular}{|c|c|c|c|c|c|c|c|c|c|c|c|}
\hline Dey & Nov. & Dec. & Jan. & Day & Nov. & Dec. & Jan. & Day & Nov. & Dec. & Jan. \\
\hline$I$ & 138 & 214 & 524 & 11 & 203 & 18,100 & 428 & $2 I$ & 565 & 688 & 662 \\
\hline 2 & 114 & 250 & 551 & 12 & 282 & 7,030 & 432 & $\begin{array}{l}21 \\
22\end{array}$ & 416 & 662 & 688 \\
\hline 3 & 148 & 235 & 569 & 13 & 212 & 3,000 & 420 & 23 & 328 & 741 & 688 \\
\hline 4 & 146 & 229 & 533 & 14 & 235 & 1,900 & 424 & 24 & 436 & 602 & 622 \\
\hline 5 & 148 & 235 & 512 & 15 & 268 & 1,500 & 647 & 25 & 360 & 632 & 602 \\
\hline 6 & 143 & 214 & 491 & 16 & 229 & 1,220 & 612 & 26 & 285 & 593 & 588 \\
\hline 7 & 146 & 235 & 465 & 17 & 440 & 1,010 & 884 & 27 & 264 & 560 & 593 \\
\hline 8 & 151 & 232 & 478 & 18 & 508 & 916 & 981 & 28 & 268 & 564 & 622 \\
\hline 9 & 156 & 235 & 436 & 19 & 313 & 824 & 854 & 29 & 217 & 560 & 714 \\
\hline 10 & 148 & 7,280 & 444 & 20 & 282 & $74 I$ & 768 & 30 & $24 I$ & 540 & 652 \\
\hline & & & & & & & & 31 & & 529 & 1,030 \\
\hline \multicolumn{9}{|c|}{ Mean monthly discharge, in second-feet... } & $\begin{array}{r}2 \\
15,4\end{array}$ & $\begin{array}{r}1,686 \\
103,700\end{array}$ & $\begin{array}{r}610 \\
37,520\end{array}$ \\
\hline
\end{tabular}

Gage helght, in feet, and discharge, in second-feet, at indicated time, 1937

\begin{tabular}{|c|c|c|c|c|c|c|c|c|c|c|c|c|}
\hline \multirow{2}{*}{$\begin{array}{l}4 \\
0 \\
0 \\
0\end{array}$} & Feet & Sec.ft. & Feet & Sec.ft. & Feet & Sec.ft. & Feet & Sec.ft. & Feet & sec.ft. & $F e \theta t$ & Sec.ft. \\
\hline & \multicolumn{2}{|c|}{ December 8} & \multicolumn{2}{|c|}{ December 9} & \multicolumn{2}{|c|}{ December 10} & \multicolumn{2}{|c|}{ December 11} & \multicolumn{2}{|c|}{ December 12} & \multicolumn{2}{|c|}{ December 13} \\
\hline \multirow[t]{2}{*}{$\begin{array}{r}2 \\
4 \\
6 \\
8 \\
10 \\
\mathrm{~N} \\
2 \\
4 \\
6 \\
8 \\
10 \\
M\end{array}$} & $\begin{array}{l}7.63 \\
7.62 \\
7.59 \\
7.49 \\
7.42 \\
7.35 \\
7.32 \\
7.37 \\
7.36 \\
7.35 \\
7.36 \\
7.38\end{array}$ & $\begin{array}{l}296 \\
292 \\
282 \\
247 \\
226 \\
206 \\
198 \\
212 \\
209 \\
206 \\
209 \\
214\end{array}$ & $\begin{array}{l}7.36 \\
7.40 \\
7.40 \\
7.40 \\
7.40 \\
7.44 \\
7.47 \\
7.50 \\
7.53 \\
7.55 \\
7.57 \\
7.59\end{array}$ & \begin{tabular}{|l|}
209 \\
220 \\
220 \\
220 \\
220 \\
232 \\
241 \\
250 \\
260 \\
268 \\
274 \\
282
\end{tabular} & $\begin{array}{r}7.60 \\
7.63 \\
8.20 \\
8.32 \\
14.25 \\
15.95 \\
16.68 \\
16.45 \\
16.17 \\
16.05 \\
15.62 \\
15.25\end{array}$ & \begin{tabular}{|r|}
285 \\
296 \\
530 \\
590 \\
7,540 \\
11,700 \\
13,700 \\
13,100 \\
12,300 \\
11,900 \\
10,800 \\
9,810 \\
\end{tabular} & $\begin{array}{l}14.95 \\
15.45 \\
16.45 \\
18.00 \\
18.98 \\
20.10 \\
20.50 \\
20.00 \\
19.15 \\
18.35 \\
17.35 \\
16.32\end{array}$ & $\begin{array}{r}9,080 \\
10,300 \\
13,100 \\
17,800 \\
21,200 \\
25,400 \\
27,000 \\
25,100 \\
22,000 \\
19,300 \\
16,200 \\
13,100\end{array}$ & $\begin{array}{l}15.60 \\
15.05 \\
14.60 \\
14.20 \\
13.83 \\
13.50 \\
13.12 \\
12.86 \\
12.63 \\
12.45 \\
12.31 \\
12.15\end{array}$ & $\begin{array}{r}11,200 \\
9,840 \\
8,760 \\
7,880 \\
7,110 \\
6,470 \\
5,780 \\
5,330 \\
4,950 \\
4,660 \\
4,440 \\
4,200\end{array}$ & $\begin{array}{l}12.03 \\
11.85 \\
11.68 \\
11.52 \\
11.37 \\
11.23 \\
11.11 \\
10.95 \\
10.82 \\
10.72 \\
10.65 \\
10.50\end{array}$ & $\begin{array}{l}4,020 \\
3,760 \\
3,530 \\
3,330 \\
3,140 \\
2,980 \\
2,830 \\
2,660 \\
2,510 \\
2,410 \\
2,340 \\
2,190\end{array}$ \\
\hline & \multicolumn{2}{|c|}{ December 14} & \multicolumn{2}{|c|}{ December 15} & \multicolumn{2}{|c|}{ December 16} & \multicolumn{2}{|c|}{ December 17} & \multicolumn{2}{|c|}{ December 18} & \multicolumn{2}{|c|}{ December 19} \\
\hline \multirow[t]{2}{*}{\begin{tabular}{r|}
2 \\
4 \\
6 \\
8 \\
10 \\
$N$ \\
2 \\
4 \\
6 \\
8 \\
10 \\
$M$ \\
\end{tabular}} & $\begin{array}{r}10.43 \\
10.36 \\
10.35 \\
10.32 \\
10.25 \\
10.17 \\
10.18 \\
10.12 \\
10.03 \\
10.03 \\
9.98 \\
9.95\end{array}$ & $\begin{array}{l}2,120 \\
2,050 \\
2,040 \\
2,010 \\
1,940 \\
1,870 \\
1,880 \\
1,830 \\
1,750 \\
1,750 \\
1,700 \\
1,680\end{array}$ & $\begin{array}{l}9.82 \\
9.73 \\
9.72 \\
9.71 \\
9.68 \\
9.66 \\
9.82 \\
9.77 \\
9.67 \\
9.69 \\
9.64 \\
9.64\end{array}$ & $\begin{array}{l}1,560 \\
1,480 \\
1,480 \\
1,470 \\
1,440 \\
1,430 \\
1,560 \\
1,520 \\
1,440 \\
1,450 \\
1,410 \\
1,410\end{array}$ & $\begin{array}{l}9.47 \\
9.36 \\
9.34 \\
9.32 \\
9.29 \\
9.27 \\
9.45 \\
9.44 \\
9.42 \\
9.38 \\
9.35 \\
9.30\end{array}$ & $\begin{array}{l}1,280 \\
1,190 \\
1,180 \\
1,160 \\
1,140 \\
1,130 \\
1,260 \\
1,250 \\
1,240 \\
1,210 \\
1,180 \\
1,150\end{array}$ & $\begin{array}{l}9.15 \\
9.05 \\
9.03 \\
9.02 \\
9.01 \\
9.00 \\
9.20 \\
9.21 \\
9.13 \\
9.11 \\
9.10 \\
9.10\end{array}$ & $\begin{array}{r}1,050 \\
981 \\
968 \\
961 \\
955 \\
948 \\
1,080 \\
1,090 \\
1,030 \\
1,020 \\
1,010 \\
1,010\end{array}$ & $\begin{array}{l}9.00 \\
8.95 \\
8.85 \\
8.84 \\
8.84 \\
8.93 \\
9.07 \\
9.08 \\
9.06 \\
9.02 \\
8.96 \\
9.00\end{array}$ & \begin{tabular}{|r|}
948 \\
916 \\
854 \\
848 \\
848 \\
903 \\
994 \\
1,000 \\
988 \\
961 \\
922 \\
948 \\
\end{tabular} & $\begin{array}{l}8.95 \\
8.74 \\
8.70 \\
8.68 \\
8.67 \\
8.66 \\
8.80 \\
8.92 \\
8.89 \\
8.74 \\
8.72 \\
8.85\end{array}$ & \begin{tabular}{|l|}
916 \\
790 \\
768 \\
757 \\
752 \\
746 \\
824 \\
897 \\
878 \\
790 \\
779 \\
854 \\
\end{tabular} \\
\hline & \multicolumn{2}{|c|}{ December 20} & \multicolumn{2}{|c|}{ December 21} & \multicolumn{2}{|c|}{ December 22} & \multicolumn{2}{|c|}{ December 23} & \multicolumn{2}{|c|}{ December 24} & \multicolumn{2}{|c|}{ December 25} \\
\hline $\begin{array}{r}2 \\
4 \\
6 \\
8 \\
10 \\
1 \\
2 \\
4 \\
6 \\
8 \\
10 \\
M\end{array}$ & $\begin{array}{l}8.77 \\
8.56 \\
8.54 \\
8.53 \\
8.53 \\
8.54 \\
8.65 \\
8.77 \\
8.63 \\
8.58 \\
8.59 \\
8.66\end{array}$ & $\begin{array}{l}807 \\
693 \\
683 \\
678 \\
678 \\
683 \\
741 \\
807 \\
730 \\
704 \\
709 \\
746\end{array}$ & $\begin{array}{l}8.55 \\
8.40 \\
8.37 \\
8.40 \\
8.50 \\
8.57 \\
8.57 \\
8.70 \\
8.60 \\
8.55 \\
8.57 \\
8.65\end{array}$ & \begin{tabular}{|l|}
688 \\
612 \\
598 \\
612 \\
662 \\
698 \\
698 \\
768 \\
714 \\
688 \\
698 \\
741
\end{tabular} & $\begin{array}{l}8.64 \\
8.50 \\
8.33 \\
8.33 \\
8.33 \\
8.34 \\
8.45 \\
8.64 \\
8.62 \\
8.65 \\
8.67 \\
8.84\end{array}$ & \begin{tabular}{|l}
736 \\
662 \\
578 \\
578 \\
578 \\
583 \\
637 \\
736 \\
725 \\
741 \\
752 \\
848
\end{tabular} & $\begin{array}{l}8.85 \\
8.65 \\
8.68 \\
8.65 \\
8.63 \\
8.60 \\
8.66 \\
8.75 \\
8.67 \\
8.58 \\
8.50 \\
8.53\end{array}$ & $\begin{array}{l}854 \\
741 \\
757 \\
741 \\
730 \\
714 \\
746 \\
796 \\
752 \\
704 \\
662 \\
678\end{array}$ & $\begin{array}{l}8.50 \\
8.36 \\
8.23 \\
8.24 \\
8.27 \\
8.28 \\
8.25 \\
8.54 \\
8.54 \\
8.40 \\
8.39 \\
8.50\end{array}$ & \begin{tabular}{|l}
662 \\
593 \\
533 \\
538 \\
551 \\
555 \\
542 \\
683 \\
683 \\
612 \\
607 \\
662
\end{tabular} & $\begin{array}{l}8.65 \\
8.68 \\
8.68 \\
8.42 \\
8.38 \\
8.35 \\
8.33 \\
8.32 \\
8.37 \\
8.30 \\
8.26 \\
8.35\end{array}$ & $\begin{array}{l}741 \\
757 \\
757 \\
622 \\
602 \\
588 \\
579 \\
574 \\
598 \\
564 \\
546 \\
588\end{array}$ \\
\hline
\end{tabular}

Supplemental records.- Dec. 10, 9 a.m., $8.45 \mathrm{ft.}, 658$ sec.-ft. 
Location. - Lat. $38^{\circ} 51^{\prime}$, long. $120^{\circ} 08^{\prime}$, in SWl sec. 29, T. 12 N., R. 17 E., I mile below main dam at Medley Lakes and 5 miles northwest of Phillips, Vade post office, Eldorado County. Altitude, about 8,100 feet above mean sea level.

Drainage area.- 6.2 square miles.

Gage-he1ght record. - Water-stage recorder graph.

Stage-discharge relation. - Affected by 1ce for period Dec. 23 to Jan. 3I. Defined by current-meter measurements below 120 second-feet; extended to peak stage.

Maxima.- December 1937: Discharge, 166 second-feet 9 a.m. Dec. 10 (gage height, 3.06 feet).

1922-November 1937: Discharge, 202 second-feet June 15, 16, 1929 (gage height, 3.42 feet).

Remarks.- Flood run-off materialiy affected by storage in Medley Lakes during storm period in December but little, if any, net retention for period Nov. 1 to Jan. 31. No record of storage. Discharge for perlod of ice effect computed on bas is of weather records. Part of basic data fumished by Pacific Gas \& Electric Co.

Mean dally discharge, in second-feet, November 1937 to January 1938

\begin{tabular}{|c|c|c|c|c|c|c|c|c|c|c|c|}
\hline Dey & Nov. & Dec. & Jan. & Day & Nov. & Dec. & Jan. & Day & Nov. & Dec. & Jan. \\
\hline 1 & 15 & 12 & - & 11 & 14 & 100 & - & $2 I$ & 13 & 32 & - \\
\hline 2 & 15 & 12 & - & 12 & 12 & 30 & - & 22 & 13 & 32 & - \\
\hline 3 & 14 & 11 & - & 13 & 11 & 25 & - & 23 & 13 & $3 I$ & - \\
\hline 4 & 14 & 10 & - & 14 & 12 & 24 & - & 24 & 13 & 31 & - \\
\hline 5 & 14 & 9 & - & 15 & 11 & 24 & - & 25 & 13 & 31 & - \\
\hline 6 & 14 & 7.5 & - & 16 & 11 & 28 & - & 26 & 13 & 30 & - \\
\hline 7 & 13 & 7 & - & 17 & 13 & 34 & - & 27 & 13 & 30 & - \\
\hline 8 & 13 & 6.5 & - & 18 & 12 & 34 & - & 28 & 13 & 30 & - \\
\hline 9 & 13 & 7 & - & 19 & 13 & 33 & - & 29 & 13 & 29 & - \\
\hline 10 & 12 & 102 & - & 20 & 14 & 32 & - & $\begin{array}{l}30 \\
31\end{array}$ & 12 & $\begin{array}{l}29 \\
29\end{array}$ & - \\
\hline $\begin{array}{l}\text { Mear } \\
\text { Run }\end{array}$ & ( & & & & & & & & $\begin{array}{r}13.0 \\
772\end{array}$ & $\begin{array}{r}28.5 \\
1,750\end{array}$ & $\begin{array}{r}25 \\
1,540\end{array}$ \\
\hline
\end{tabular}

Gage helght, in feet, and discharge, in second-feet, at indicated time, 1937

\begin{tabular}{|c|c|c|c|c|c|c|c|c|c|c|c|c|}
\hline \multirow{2}{*}{ 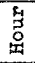 } & Feet & Sec.ft. & Fe日t & Sec.ft. & Feet & Seo.ft. & Feet & sec.ft. & Feet & Sec.ft. & Feet & Sec.ft. \\
\hline & \multicolumn{2}{|c|}{ December 8} & \multicolumn{2}{|c|}{ December 9} & \multicolumn{2}{|c|}{ December 10} & \multicolumn{2}{|c|}{ December 11} & \multicolumn{2}{|c|}{ December 12} & \multicolumn{2}{|c|}{ December 13} \\
\hline $\begin{array}{r}2 \\
4 \\
6 \\
8 \\
10 \\
\mathrm{~N} \\
2 \\
4 \\
6 \\
8 \\
10 \\
\mathrm{M}\end{array}$ & $\begin{array}{l}- \\
\overline{-} \\
\overline{-} \\
\overline{0.74} \\
\overline{-} \\
\overline{-} \\
\overline{-} \\
.73\end{array}$ & $\begin{array}{c}- \\
\overline{-} \\
- \\
- \\
6.5 \\
- \\
- \\
- \\
- \\
- \\
6.0\end{array}$ & $\begin{array}{r}0.73 \\
.72 \\
.72 \\
.72 \\
.72 \\
.72 \\
.72 \\
.74 \\
.77 \\
.84 \\
.95 \\
1.14\end{array}$ & \begin{tabular}{|c}
6 \\
6 \\
6 \\
6 \\
6 \\
6 \\
6 \\
6.5 \\
7 \\
8.5 \\
12 \\
18
\end{tabular} & $\begin{array}{l}1.53 \\
2.06 \\
2.85 \\
2.99 \\
3.00 \\
2.69 \\
2.52 \\
2.36 \\
2.24 \\
2.18 \\
2.17 \\
2.20\end{array}$ & \begin{tabular}{|r}
37 \\
74 \\
145 \\
159 \\
160 \\
129 \\
114 \\
99 \\
89 \\
83 \\
83 \\
85
\end{tabular} & $\begin{array}{l}2.30 \\
2.42 \\
2.49 \\
2.64 \\
2.84 \\
2.83 \\
2.63 \\
2.41 \\
2.10 \\
1.86 \\
1.70 \\
1.59\end{array}$ & $\begin{array}{r}94 \\
105 \\
111 \\
125 \\
144 \\
143 \\
124 \\
104 \\
77 \\
58 \\
47 \\
40\end{array}$ & $\begin{array}{c}-\overline{1.45} \\
- \\
1.39 \\
\overline{1.35} \\
\overline{1.34} \\
\overline{1.32} \\
\overline{1.31}\end{array}$ & $\begin{array}{l}\overline{32} \\
\overline{30} \\
\overline{2} \\
\overline{2} \\
\overline{27} \\
\overline{26} \\
\overline{26}\end{array}$ & $\begin{array}{l}= \\
= \\
= \\
\overline{1.30} \\
= \\
= \\
= \\
1.29\end{array}$ & $\begin{array}{l}- \\
- \\
- \\
- \\
\overline{25} \\
- \\
- \\
- \\
\overline{24}\end{array}$ \\
\hline & \multicolumn{2}{|c|}{ December 14} & \multicolumn{2}{|c|}{ December 15} & \multicolumn{2}{|c|}{ December 16} & \multicolumn{2}{|c|}{ December 17} & \multicolumn{2}{|c|}{ December 18} & \multicolumn{2}{|c|}{ December 19} \\
\hline $\begin{array}{r}2 \\
4 \\
6 \\
8 \\
10 \\
\mathbb{N} \\
2 \\
4 \\
6 \\
8 \\
10 \\
M\end{array}$ & $\begin{array}{l}\overline{-} \\
\overline{-} \\
\overline{-} \\
1.29 \\
= \\
= \\
= \\
\overline{1} \\
\overline{1}\end{array}$ & $\begin{array}{l}- \\
- \\
\overline{-} \\
\overline{24} \\
\overline{-} \\
\overline{-} \\
\overline{24}\end{array}$ & $\begin{array}{l}- \\
\overline{-} \\
\overline{-} \\
\overline{1.28} \\
= \\
\overline{-} \\
\overline{-} \\
\overline{1.28}\end{array}$ & $\begin{array}{l}- \\
- \\
= \\
\overline{24} \\
= \\
- \\
- \\
\overline{24}\end{array}$ & $\begin{array}{c}\overline{1.28} \\
- \\
1.28 \\
- \\
1.29 \\
- \\
1.44 \\
- \\
1.46 \\
\overline{1.47}\end{array}$ & $\begin{array}{l}\overline{24} \\
\overline{24} \\
\overline{24} \\
\overline{3} \\
\overline{3} \\
\overline{3} \\
\overline{34}\end{array}$ & $\begin{array}{l}- \\
- \\
- \\
- \\
- \\
1.47 \\
- \\
- \\
- \\
- \\
1.47\end{array}$ & $\begin{array}{l}- \\
- \\
- \\
- \\
\overline{34} \\
- \\
- \\
= \\
- \\
\overline{3} 4\end{array}$ & $\begin{array}{l}\bar{z} \\
\overline{-} \\
\bar{z} \\
\overline{1 .} \\
\overline{-} \\
\overline{-} \\
\overline{-} \\
\overline{-} \\
\overline{1 .}\end{array}$ & $\begin{array}{l}- \\
- \\
- \\
- \\
- \\
34 \\
- \\
- \\
- \\
- \\
\overline{33}\end{array}$ & $\begin{array}{l}\overline{-} \\
\bar{z} \\
\bar{z} \\
\overline{1 .} \\
\overline{-} \\
\overline{-} \\
\overline{-} \\
\overline{1 .} \\
\overline{1.45}\end{array}$ & $\begin{array}{l}- \\
- \\
= \\
- \\
33 \\
- \\
= \\
- \\
- \\
32\end{array}$ \\
\hline & \multicolumn{2}{|c|}{ December 20} & \multicolumn{2}{|c|}{ Decamber 21} & \multicolumn{2}{|c|}{ December 22} & \multicolumn{2}{|c|}{ December 23} & \multicolumn{2}{|c|}{ December 24} & \multicolumn{2}{|c|}{ December 25} \\
\hline $\begin{array}{r}2 \\
4 \\
6 \\
8 \\
10 \\
\mathrm{~N} \\
2 \\
4 \\
6 \\
8 \\
10 \\
M\end{array}$ & $\begin{array}{l}- \\
\overline{-} \\
\overline{-} \\
\overline{1 .} 45 \\
\overline{-} \\
\overline{-} \\
\overline{1.45}\end{array}$ & $\begin{array}{l}- \\
- \\
= \\
= \\
32 \\
= \\
- \\
- \\
- \\
32\end{array}$ & $\begin{array}{l}\overline{-} \\
\overline{-} \\
\overline{-} \\
\overline{1 .} 45 \\
\overline{-} \\
\overline{-} \\
\overline{-} \\
\overline{1.45}\end{array}$ & $\begin{array}{l}- \\
- \\
- \\
= \\
32 \\
- \\
- \\
- \\
- \\
32\end{array}$ & & & & & & & & \\
\hline
\end{tabular}

Supplemental records.- Dec. 10, 9 a.m., $3.06 \mathrm{ft.}, 166$ sec. ft. 
Location. - Lat. $38^{\circ} 40^{\prime}$, long. $120^{\circ} 08^{\prime}$, in SW $\frac{1}{4}$ sec. 32, T. 10 N., R. 17 E., 1,000 feet below S1lver Lake Dam and 3 miles southwest of Kirkwood, Amador County. Alt1tude, about 7,200 feet above mean sea level.

Dralnage area. - 14.9 square miles.

Gage-helght record. - Water-stage recorder graph.

stage-discharge relation. - Defined by current-meter measurements below 200 second-feet; axtended to peak stage on basis of area-velocity study.

Maxima.- December 1937: Discharge (regulated), 504 second-feet 3 p.m. Dec. 11 (gage height, 5.10 feet). feet).

1922-November 1937: Discharge, 374 second-feet July 1, 1932 (gage helght, 4.28

emarks. - Flood mun-off affected by storage in Silver Lake (capacity, about 4,700 acrefeet, without flashboards; 8,700 acre-feet, with flashboards). Discharge over spillway (without flashboards) began about 5 a.m. Dec. 11. Probably very 11 ttle storage In lake before Dec. 9. Peak stage and run-off of about 4,500 acre-feet must have accurred between Dec, 9 and $5 \mathrm{s.m}$. Dec. 11. Storage record for Silver Lake (1ncomplete) shows 261 acre-feet Nov, 29 and 5,231 acre-feet Dec. 14.

Mean dally discharge, in second-feet, November 1937 to January 1938

\begin{tabular}{|c|c|c|c|c|c|c|c|c|c|c|c|}
\hline Day & Nov. & Dec. & Jan. & Day & Nov. & Dec. & Jen. & Day & Nov. & Dec. & Jan. \\
\hline $\begin{array}{r}1 \\
2 \\
3 \\
4 \\
5 \\
6 \\
7 \\
8 \\
9 \\
10\end{array}$ & $\begin{array}{l}6.5 \\
5.5 \\
5 \\
4.5 \\
3.9 \\
3.0 \\
2.6 \\
2.2 \\
1.8 \\
1.4\end{array}$ & $\begin{array}{r}3.9 \\
3.3 \\
3.0 \\
2.4 \\
2.0 \\
2.4 \\
2.4 \\
2.2 \\
2.8 \\
40\end{array}$ & $\begin{array}{l}34 \\
34 \\
34 \\
33 \\
32 \\
31 \\
31 \\
30 \\
28 \\
28\end{array}$ & $\begin{array}{l}11 \\
12 \\
13 \\
14 \\
15 \\
16 \\
17 \\
18 \\
19 \\
20\end{array}$ & $\begin{array}{l}1.8 \\
2.0 \\
2.0 \\
2.0 \\
2.0 \\
2.2 \\
3.6 \\
3.6 \\
3.6 \\
4.2\end{array}$ & $\begin{array}{r}349 \\
376 \\
255 \\
156 \\
110 \\
83 \\
64 \\
55 \\
53 \\
50\end{array}$ & $\begin{array}{l}27 \\
27 \\
26 \\
26 \\
26 \\
26 \\
26 \\
26 \\
26 \\
26\end{array}$ & $\begin{array}{l}21 \\
22 \\
23 \\
24 \\
25 \\
26 \\
27 \\
28 \\
29 \\
30 \\
31\end{array}$ & $\begin{array}{l}4.8 \\
4.8 \\
4.8 \\
5 \\
5 \\
5 \\
4.8 \\
4.5 \\
4.5 \\
4.2\end{array}$ & $\begin{array}{l}46 \\
43 \\
40 \\
40 \\
39 \\
38 \\
38 \\
37 \\
36 \\
36 \\
35\end{array}$ & $\begin{array}{l}26 \\
26 \\
26 \\
25 \\
25 \\
25 \\
25 \\
25 \\
25 \\
25 \\
25\end{array}$ \\
\hline $\begin{array}{l}\text { Mes } \\
\text { Run }\end{array}$ & & & & & & & & & $\begin{array}{r}3.69 \\
220\end{array}$ & $\begin{array}{r}65.9 \\
4,050\end{array}$ & $\begin{array}{r}27.6 \\
1,700\end{array}$ \\
\hline
\end{tabular}

Gage helght, in feet, and discharge, in second-feet, at indicated time, 1937

\begin{tabular}{|c|c|c|c|c|c|c|c|c|c|c|c|c|}
\hline \multirow{2}{*}{$\begin{array}{l} \\
5 \\
3 \\
\end{array}$} & Feet & Sec.ft. & Feet & Sec.ft. & Feet & Sec.ft. & Feet & Sec.ft. & Feet & Sec.ft. & Feet & Sec.ft. \\
\hline & \multicolumn{2}{|c|}{ December 8} & \multicolumn{2}{|c|}{ December 9} & \multicolumn{2}{|c|}{ December 10} & \multicolumn{2}{|c|}{ December 11} & \multicolumn{2}{|c|}{ December 12} & \multicolumn{2}{|c|}{ December 13} \\
\hline $\begin{array}{r}2 \\
4 \\
6 \\
8 \\
10 \\
N \\
2 \\
4 \\
6 \\
8 \\
10 \\
M \\
\end{array}$ & $\begin{array}{l}\bar{z} \\
\bar{z} \\
\bar{z} \\
0.66 \\
\bar{z} \\
\bar{z} \\
\overline{.66} \\
\end{array}$ & $\begin{array}{c}= \\
- \\
= \\
2.2 \\
= \\
= \\
2.2\end{array}$ & $\begin{array}{l}-\overline{0.66} \\
.66 \\
- \\
.66 \\
.68 \\
-73 \\
- \\
.80\end{array}$ & $\begin{array}{l}2.2 \\
--2 \\
-- \\
2.2 \\
2.6 \\
-- \\
3.9 \\
6^{-}\end{array}$ & $\begin{array}{l}0.90 \\
1.02 \\
1.22 \\
1.30 \\
1.40 \\
1.49 \\
1.55 \\
1.56 \\
1.58 \\
1.62 \\
1.65 \\
1.73\end{array}$ & $\begin{array}{l}9.5 \\
15 \\
26 \\
32 \\
40 \\
47 \\
52 \\
53 \\
54 \\
58 \\
68\end{array}$ & $\begin{array}{l}1.80 \\
1.84 \\
2.70 \\
3.88 \\
4.52 \\
4.82 \\
5.00 \\
5.09 \\
5.03 \\
4.96 \\
4.87 \\
4.80\end{array}$ & $\begin{array}{r}74 \\
78 \\
162 \\
315 \\
411 \\
459 \\
488 \\
502 \\
493 \\
482 \\
467 \\
456 \\
\end{array}$ & $\begin{array}{l}4.70 \\
4.61 \\
4.52 \\
4.47 \\
4.39 \\
4.30 \\
4.22 \\
4.14 \\
4.07 \\
4.00 \\
3.92 \\
3.86\end{array}$ & $\begin{array}{l}440 \\
426 \\
411 \\
403 \\
390 \\
376 \\
363 \\
352 \\
342 \\
332 \\
321 \\
312 \\
\end{array}$ & $\begin{array}{l}- \\
3.72 \\
- \\
3.57 \\
- \\
3.44 \\
- \\
3.27 \\
- \\
3.14 \\
- \\
3.00\end{array}$ & $\begin{array}{c}2 \overline{93} \\
2 \overline{7} 2 \\
\overline{2} \\
\overline{5} 4 \\
2 \overline{3} 0 \\
\overline{2} \\
\overline{1} 3 \\
\overline{196}\end{array}$ \\
\hline & \multicolumn{2}{|c|}{ December 14} & \multicolumn{2}{|c|}{ December 15} & \multicolumn{2}{|c|}{ December 16} & \multicolumn{2}{|c|}{ December 17} & \multicolumn{2}{|c|}{ December 18} & \multicolumn{2}{|c|}{ December 19} \\
\hline $\begin{array}{r}2 \\
4 \\
6 \\
8 \\
10 \\
\mathrm{~N} \\
2 \\
4 \\
6 \\
8 \\
10 \\
\mathrm{M}\end{array}$ & $\begin{array}{c}- \\
2.87 \\
- \\
2.75 \\
- \\
2.65 \\
- \\
2.57 \\
- \\
2.48 \\
- \\
2.40\end{array}$ & $\begin{array}{c}181 \\
\overline{868} \\
\overline{156} \\
\overline{148} \\
\overline{138} \\
\overline{130}\end{array}$ & $\begin{array}{c}- \\
2.32 \\
- \\
2.25 \\
- \\
2.19 \\
- \\
2.14 \\
- \\
2.08 \\
- \\
2.03\end{array}$ & $\begin{array}{c}\overline{122} \\
\overline{115} \\
\overline{109} \\
\overline{105} \\
\overline{99} \\
\overline{95}\end{array}$ & $\begin{array}{c}- \\
1.98 \\
- \\
1.93 \\
- \\
1.88 \\
- \\
1.85 \\
- \\
1.81 \\
1.78\end{array}$ & $\begin{array}{l}\overline{90} \\
\overline{86} \\
\overline{81} \\
\overline{78} \\
\overline{75} \\
\overline{72}\end{array}$ & $\begin{array}{c}- \\
- \\
1.73 \\
\overline{-} \\
1.69 \\
\pm \\
\overline{1.65} \\
\overline{-} \\
1.62\end{array}$ & $\begin{array}{l}- \\
\overline{68} \\
\overline{-} \\
64 \\
5 \\
60 \\
\overline{-} \\
58\end{array}$ & $\begin{array}{c}- \\
\overline{1.60} \\
\vdots \\
\overline{1.59} \\
\overline{-} \\
\overline{1.57} \\
\overline{-} \\
1.57\end{array}$ & $\begin{array}{l}\overline{-} \\
56 \\
\overline{-} \\
55 \\
- \\
\overline{5} \\
\overline{-} \\
\overline{5} 4\end{array}$ & $\begin{array}{c}- \\
\overline{1.57} \\
- \\
1.56 \\
\overline{-} \\
1.54 \\
- \\
1.53\end{array}$ & $\begin{array}{l}\overline{-} \\
54 \\
\overline{-} \\
53 \\
\overline{-} \\
\overline{5} 1 \\
\overline{-} \\
\overline{50}\end{array}$ \\
\hline & \multicolumn{2}{|c|}{ December 20} & \multicolumn{2}{|c|}{ December 21} & \multicolumn{2}{|c|}{ December 22} & \multicolumn{2}{|c|}{ December 23} & \multicolumn{2}{|c|}{ December 24} & \multicolumn{2}{|c|}{ December 25} \\
\hline $\begin{array}{r}2 \\
4 \\
6 \\
8 \\
10 \\
\mathrm{~N} \\
2 \\
4 \\
6 \\
8 \\
10 \\
\mathrm{M}\end{array}$ & $\begin{array}{c}- \\
\overline{1.53} \\
- \\
\overline{1.52} \\
\overline{-} \\
\overline{1.50} \\
\overline{-} \\
\overline{1.48}\end{array}$ & $\begin{array}{l}- \\
\overline{50} \\
- \\
\overline{50} \\
- \\
\overline{48} \\
\overline{-} \\
\overline{4} 6\end{array}$ & $\begin{array}{c}= \\
= \\
= \\
\pm \\
= \\
= \\
= \\
= \\
1.46\end{array}$ & $\begin{array}{l}\bar{z} \\
= \\
\overline{4} \\
= \\
z \\
= \\
45\end{array}$ & $\begin{array}{c}= \\
= \\
= \\
1.43 \\
= \\
= \\
= \\
1.42\end{array}$ & $\begin{array}{l}= \\
= \\
= \\
42 \\
= \\
= \\
= \\
42\end{array}$ & $\begin{array}{c}\bar{z} \\
= \\
\bar{z} \\
1.40 \\
= \\
\bar{z} \\
\overline{1.40}\end{array}$ & $\begin{array}{l}= \\
= \\
= \\
40 \\
= \\
= \\
\overline{4} \\
40\end{array}$ & $\begin{array}{c}\bar{z} \\
\bar{z} \\
\bar{z} \\
1.40 \\
\bar{z} \\
\bar{z} \\
\overline{1.40}\end{array}$ & $\begin{array}{l}= \\
= \\
= \\
40 \\
= \\
= \\
= \\
40\end{array}$ & $\begin{array}{c}\overline{-} \\
\overline{-} \\
\bar{z} \\
\bar{z} \\
\overline{-} \\
\overline{1.39}\end{array}$ & $\begin{array}{l}\bar{z} \\
\overline{-} \\
\overline{39} \\
\overline{-} \\
\bar{z} \\
\overline{39}\end{array}$ \\
\hline
\end{tabular}

Supplemental records,- Dec. 11, 3 p.m., 5.10 ft., 504 sec.-ft. 


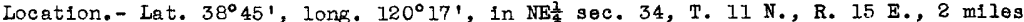
above mouth and 2 miles southeast of Kyburz, Eldorado County. Altitude, about 4,850 feet above mean sea level.

Drainage area.- 108 square miles.

Gage-helght record. - Water-stage recorder graph except for period Dec. 29 to Jan. 2 , when there was no record.

Stage-discharge relation. - Defined by current-meter measurements below 2,250 secondfeet; extended to peak stage on basis of area-velocity study; verified by comparison of peak discharge and total run-off of flood with records for other stations in American River Basin.

Maxima:- December 1937: Discharge, 5,450 second-feet 10:30 a.m. Dec. I1 (gage helght, 8.30 feet).

1924-November 1937: Discharge, 3,620 second-feet Mar. 25, 1928 (gage height, 6.54 feet), from rating curve extended above 950 second-feet.

Remarks. - Flood mun-off affected by storage in Twin Lakes and Silver Lake (combined capacity, 26,000 acre-feet). Monthly summaries adjusted for storage. Discharge for perlod of missing gage-height record based on comparison with record for South Fork of American River near Kyburz. Part of basic data furmished by Pacific Gas * Electric Co.

Mean daily discharge, in second-feet, November 1937 to January 1938

\begin{tabular}{|c|c|c|c|c|c|c|c|c|c|c|c|}
\hline Day & Nov. & Dec. & Jan. & Day & Nov. & Dec. & Jan. & Day & Nov. & Dec. & Jan. \\
\hline $\begin{array}{r}1 \\
2 \\
3 \\
4 \\
5 \\
6 \\
7 \\
8 \\
9 \\
10\end{array}$ & $\begin{array}{l}73 \\
78 \\
79 \\
78 \\
78 \\
78 \\
78 \\
84 \\
84 \\
84\end{array}$ & $\begin{array}{r}82 \\
81 \\
79 \\
81 \\
81 \\
91 \\
92 \\
89 \\
74 \\
1,330\end{array}$ & $\begin{array}{r}115 \\
112 \\
109 \\
103 \\
99 \\
93 \\
88 \\
86 \\
81 \\
79\end{array}$ & $\begin{array}{l}11 \\
12 \\
13 \\
14 \\
15 \\
16 \\
17 \\
18 \\
19 \\
20\end{array}$ & $\begin{array}{r}92 \\
86 \\
78 \\
85 \\
70 \\
70 \\
108 \\
69 \\
61 \\
105\end{array}$ & $\begin{array}{r}3,840 \\
1,470 \\
701 \\
393 \\
310 \\
250 \\
214 \\
194 \\
176 \\
161\end{array}$ & $\begin{array}{l}78 \\
75 \\
75 \\
74 \\
88 \\
85 \\
96 \\
92 \\
92 \\
86\end{array}$ & $\begin{array}{l}21 \\
22 \\
23 \\
24 \\
25 \\
26 \\
27 \\
28 \\
29 \\
30 \\
31\end{array}$ & $\begin{array}{l}91 \\
47 \\
41 \\
48 \\
43 \\
51 \\
62 \\
62 \\
61 \\
74\end{array}$ & $\begin{array}{l}156 \\
149 \\
135 \\
147 \\
142 \\
138 \\
136 \\
130 \\
126 \\
122 \\
118\end{array}$ & $\begin{array}{l}89 \\
93 \\
92 \\
86 \\
89 \\
91 \\
93 \\
95 \\
93 \\
88 \\
84\end{array}$ \\
\hline $\begin{array}{l}\text { Mean } \\
\text { Mean } \\
\text { Run- }\end{array}$ & $\begin{array}{l}\text { month } \\
\text { month } \\
\text { ff, in }\end{array}$ & $r e-f e$ & , In & on & $\begin{array}{l}\theta \theta t \\
\theta \theta t\end{array}$ & & & & $\begin{array}{r}73.3 \\
24.9 \\
1,480\end{array}$ & $\begin{array}{r}364 \\
497 \\
30,570\end{array}$ & $\begin{array}{r}90.3 \\
82.5 \\
5,070\end{array}$ \\
\hline
\end{tabular}

Gage helght, in feet, and discharge, in second-feet, at Indlcated time, 1937

\begin{tabular}{|c|c|c|c|c|c|c|c|c|c|c|c|c|}
\hline \multirow{2}{*}{ 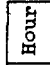 } & Feet & Sec.ft. & Feet & Sec.f't. & Feet & Sec.ft. & Feet & Sec.ft. & Feet & Sec.ft. & Feet & Sec.ft. \\
\hline & \multicolumn{2}{|c|}{ December 8} & \multicolumn{2}{|c|}{ December 9} & \multicolumn{2}{|c|}{ December 10} & \multicolumn{2}{|c|}{ December 11} & \multicolumn{2}{|c|}{ December 12} & \multicolumn{2}{|c|}{ December 13} \\
\hline \multirow[t]{2}{*}{$\begin{array}{r}2 \\
4 \\
6 \\
8 \\
10 \\
\mathrm{~N} \\
2 \\
4 \\
6 \\
8 \\
10 \\
M\end{array}$} & $\begin{array}{c}\overline{-} \\
2.09 \\
- \\
\overline{2.09} \\
= \\
\overline{2.09} \\
\overline{2.03}\end{array}$ & $\begin{array}{l}\overline{-} \\
\overline{91} \\
\overline{-} \\
\overline{91} \\
\overline{-} \\
\overline{91} \\
\overline{-} \\
\overline{82}\end{array}$ & $\begin{array}{l}2.05 \\
2.03 \\
1.98 \\
1.91 \\
1.91 \\
1.90 \\
1.90 \\
1.98 \\
1.97 \\
1.97 \\
2.01 \\
2.19\end{array}$ & $\begin{array}{r}85 \\
82 \\
75 \\
66 \\
66 \\
65 \\
65 \\
75 \\
74 \\
74 \\
79 \\
105\end{array}$ & $\begin{array}{l}3.33 \\
4.11 \\
4.50 \\
4.90 \\
5.08 \\
4.53 \\
4.87 \\
5.20 \\
5.10 \\
4.83 \\
4.80 \\
5.14\end{array}$ & $\begin{array}{r}381 \\
878 \\
1,200 \\
1,560 \\
1,740 \\
1,230 \\
1,530 \\
1,860 \\
1,760 \\
1,500 \\
1,470 \\
1,800\end{array}$ & $\begin{array}{l}5.95 \\
6.74 \\
6.70 \\
6.94 \\
8.28 \\
8.22 \\
8.01 \\
7.77 \\
7.02 \\
6.40 \\
6.00 \\
5.72\end{array}$ & $\begin{array}{l}2,640 \\
3,540 \\
3,490 \\
3,780 \\
5,420 \\
5,350 \\
5,070 \\
4,770 \\
3,870 \\
3,730 \\
2,690 \\
2,380\end{array}$ & $\begin{array}{l}5.45 \\
5.23 \\
5.05 \\
4.95 \\
4.85 \\
4.73 \\
4.64 \\
4.55 \\
4.50 \\
4.41 \\
4.34 \\
4.25\end{array}$ & \begin{tabular}{|}
2,110 \\
1,890 \\
1,710 \\
1,610 \\
1,520 \\
1,410 \\
1,330 \\
1,240 \\
1,200 \\
1,120 \\
1,060 \\
990
\end{tabular} & $\begin{array}{l}4.18 \\
4.11 \\
4.05 \\
3.96 \\
3.90 \\
3.84 \\
3.77 \\
3.74 \\
3.71 \\
3.66 \\
3.61 \\
3.55\end{array}$ & $\begin{array}{l}934 \\
878 \\
830 \\
760 \\
715 \\
673 \\
624 \\
603 \\
582 \\
550 \\
518 \\
485\end{array}$ \\
\hline & \multicolumn{2}{|c|}{ December 14} & \multicolumn{2}{|c|}{ December 15} & \multicolumn{2}{|c|}{ De cember 16} & \multicolumn{2}{|c|}{ December 17} & \multicolumn{2}{|c|}{ December 18} & \multicolumn{2}{|c|}{ December 19} \\
\hline \multirow[t]{2}{*}{$\begin{array}{r}2 \\
4 \\
6 \\
8 \\
10 \\
\mathrm{~N} \\
2 \\
4 \\
6 \\
8 \\
10 \\
\mathrm{M}\end{array}$} & $\begin{array}{c}\overline{3.46} \\
- \\
3.40 \\
\overline{3.35} \\
\overline{3.31} \\
\overline{3.30} \\
\overline{3.27}\end{array}$ & $\begin{array}{c}\overline{439} \\
\overline{4} \\
4 \overline{0} \\
\overline{389} \\
\overline{3} \\
\overline{372} \\
\overline{368} \\
\overline{357}\end{array}$ & $\begin{array}{l}- \\
3.22 \\
- \\
3.18 \\
- \\
3.13 \\
- \\
3.09 \\
- \\
3.07 \\
\tilde{3.04}\end{array}$ & $\begin{array}{c}\overline{339} \\
\overline{326} \\
\tilde{310} \\
\overline{2} \\
\overline{97} \\
2 \overline{91} \\
\overline{2} \overline{8}\end{array}$ & $\begin{array}{l}3.00 \\
- \\
2.96 \\
\overline{2.93} \\
\overline{2.90} \\
\overline{2.88} \\
\overline{-} .86\end{array}$ & \begin{tabular}{|c}
$2 \overline{70}$ \\
- \\
$2 \overline{5} 9$ \\
- \\
$2 \overline{50}$ \\
$\overline{-}$ \\
$2 \overline{4}$ \\
$\overline{237}$ \\
$\overline{2} \overline{3}$
\end{tabular} & $\begin{array}{c}- \\
2.83 \\
- \\
2.79 \\
- \\
\overline{2.76} \\
- \\
2.75\end{array}$ & $\begin{array}{c}\overline{-} \\
2 \overline{24} \\
\overline{-} \\
2 \overline{14} \\
\overline{-} \\
2 \overline{0} \\
\overline{-} \\
\overline{205}\end{array}$ & $\begin{array}{c}\overline{-} \\
2.72 \\
\overline{-} \\
2.70 \\
\overline{-} \\
2.67 \\
\overline{-} \\
2.66\end{array}$ & $\begin{array}{c}\overline{198} \\
\overline{-} \\
\overline{194} \\
\overline{-} \\
1 \overline{88} \\
\overline{-} \\
\overline{186}\end{array}$ & $\begin{array}{c}\overline{-} \\
2.64 \\
\overline{-} \\
2.61 \\
\overline{-} \\
2.59 \\
\overline{2.59}\end{array}$ & $\begin{array}{c}\overline{-} \\
1 \overline{2} \\
\overline{-} \\
\overline{176} \\
\overline{-} \\
172 \\
- \\
\overline{172}\end{array}$ \\
\hline & \multicolumn{2}{|c|}{ December 20} & \multicolumn{2}{|c|}{ December 21} & \multicolumn{2}{|c|}{ December 22} & \multicolumn{2}{|c|}{ December 23} & \multicolumn{2}{|c|}{ December 24} & \multicolumn{2}{|c|}{ December 25} \\
\hline $\begin{array}{r}2 \\
4 \\
6 \\
8 \\
10 \\
\mathrm{~N} \\
2 \\
4 \\
6 \\
8 \\
10 \\
M\end{array}$ & $\begin{array}{c}\overline{-} \\
2.55 \\
- \\
\overline{2.50} \\
= \\
\overline{2.49} \\
= \\
\overline{2.56}\end{array}$ & $\begin{array}{c}- \\
\overline{165} \\
- \\
\overline{156} \\
\overline{-} \\
\overline{154} \\
\overline{-} \\
\overline{167}\end{array}$ & $\begin{array}{c}\overline{-} \\
2.51 \\
= \\
2.48 \\
= \\
\overline{2.48} \\
= \\
2.49\end{array}$ & $\begin{array}{c}- \\
\overline{158} \\
\overline{-} \\
\overline{152} \\
\overline{-} \\
\overline{152} \\
\overline{-} \\
\overline{154}\end{array}$ & $\begin{array}{l}\overline{-} \\
2.48 \\
\bar{z} \\
\overline{2.45} \\
\bar{z} \\
\bar{z} \\
\overline{z .50}\end{array}$ & $\begin{array}{c}- \\
\overline{152} \\
- \\
\overline{147} \\
\overline{-} \\
\overline{143} \\
\overline{-} \\
. \\
.56\end{array}$ & $\begin{array}{l}\overline{2.43} \\
\overline{2.35} \\
\overline{2.35} \\
\overline{2.38} \\
\overline{2.39} \\
\overline{2.36}\end{array}$ & $\begin{array}{c}\overline{143} \\
\overline{130} \\
\overline{0} \\
1 \overline{3} 0 \\
\overline{135} \\
\overline{136} \\
\overline{132}\end{array}$ & $\begin{array}{l}-\overline{2.36} \\
\overline{2.40} \\
- \\
2.49 \\
\overline{2.55} \\
\overline{2.48} \\
\overline{2.42}\end{array}$ & $\begin{array}{c}\overline{132} \\
\overline{138} \\
\overline{154} \\
\overline{6} \\
\overline{165} \\
\overline{152} \\
\overline{142}\end{array}$ & $\begin{array}{c}2.38 \\
- \\
2.36 \\
- \\
2.45 \\
- \\
2.46 \\
- \\
2.42 \\
2.38\end{array}$ & $\begin{array}{c}\overline{135} \\
\overline{3} \\
\overline{132} \\
\overline{147} \\
\overline{149} \\
\overline{142} \\
\overline{135}\end{array}$ \\
\hline
\end{tabular}

Supplemental records.- Dec. 11, $10 \pm 30$ a.m., 8.30 ft., 5,450 sec.-ft. 
Tw In Lakes outlet near Kirkwood, Calif.

Location. - Lat. $38^{\circ} 42^{\prime}$, long. $120^{\circ} 03^{\prime}$, In swit sec. 18, T. $10 \mathrm{~N}$., R. $18 \mathrm{E} ., 500$ feet below main dam and outlet gate of Twin Lakes and 1 mile east of Kirkwood, Amador County. Alt1tude, about 7,900 feet above mean sea level.

Dralnage area. - 12.4 square miles.

Gage-helght record. - Defined by current-meter measurements for stages reached during period November to January (completely regulated).

Yaxlma.- December 1937: Outlet gates closed 8:45 a.m. Dec. 10 and flood flow completely regulated. Maximum discharge computed from increase in storage, about 2,200 secondfeet early morning Dec. 11 .

1922-November 1937: Discharge (regulated), 176 second-feet May 25-28, 1928 (gage height, 1.95 feet).

Remarks.- Flood run-off completely controlled in Tw1n Lakes (capacity, 21,200 acrefeot). No flow over Twin Iakes spll1way for perlod Nov. 1 to Jan. 31. Gain or loss in storage computed from contents at midnight determined from graph based on dally readings at $4 \mathrm{p} . \mathrm{m}$. Most of beslc data furnished by Pacific Gas \& Electric Co.

Discharge, in second-feet, and gain or loss in storage, in acre-feet, November 1937 to January 1938

\begin{tabular}{|c|c|c|c|c|c|c|c|c|c|}
\hline \multirow[b]{2}{*}{ Day } & \multicolumn{3}{|c|}{ November } & \multicolumn{3}{|c|}{ December } & \multicolumn{3}{|c|}{ January } \\
\hline & $\begin{array}{c}\text { Observed } \\
\text { d1scharge }\end{array}$ & $\begin{array}{l}\text { Gain or } \\
\text { loss in } \\
\text { storage }\end{array}$ & $\begin{array}{l}\text { Ad jus ted } \\
\text { discharge }\end{array}$ & $\begin{array}{c}\text { Observed } \\
\text { discharge }\end{array}$ & $\begin{array}{l}\text { Gain or } \\
\text { loss in } \\
\text { storage }\end{array}$ & $\begin{array}{r}\text { Ad justed } \\
\text { discharge }\end{array}$ & $\begin{array}{r}\text { Observed } \\
\text { discharge }\end{array}$ & $\begin{array}{l}\text { Gain or } \\
\text { loss } \text { in } \\
\text { storage }\end{array}$ & $\begin{array}{r}\text { Ad justed } \\
\text { discharge }\end{array}$ \\
\hline $\begin{array}{l}1 \\
2 \\
3 \\
4 \\
5\end{array}$ & $\begin{array}{l}61 \\
66 \\
66 \\
66 \\
66\end{array}$ & $\begin{array}{l}-115 \\
-125 \\
-115 \\
-141 \\
-158\end{array}$ & & $\begin{array}{l}68 \\
67 \\
69 \\
71 \\
74\end{array}$ & $\begin{array}{l}-123 \\
-123 \\
-129 \\
-145 \\
-153\end{array}$ & $* 3.0$ & $\begin{array}{l}1.4 \\
1.5 \\
1.5 \\
1.5 \\
1.5\end{array}$ & $\begin{array}{r}+9 \\
+28 \\
+19 \\
+9 \\
+29\end{array}$ & $\begin{array}{r}6 \\
16 \\
11 \\
6 \\
16\end{array}$ \\
\hline $\begin{array}{r}6 \\
7 \\
8 \\
9 \\
10\end{array}$ & $\begin{array}{l}66 \\
70 \\
72 \\
71 \\
71\end{array}$ & $\begin{array}{l}-157 \\
-139 \\
-113 \\
-137 \\
-137\end{array}$ & *1.3 & $\begin{array}{l}76 \\
76 \\
66 \\
52 \\
22\end{array}$ & $\begin{array}{r}-169 \\
-151 \\
-132 \\
-50 \\
+1,600\end{array}$ & 829 & $\begin{array}{l}1.5 \\
1.5 \\
1.5 \\
1.5 \\
1.5\end{array}$ & $\begin{array}{r}+19 \\
+9 \\
+19 \\
0 \\
+9\end{array}$ & $\begin{array}{l}11 \\
6 \\
11 \\
\frac{11}{6} .5\end{array}$ \\
\hline $\begin{array}{l}11 \\
12 \\
13 \\
14 \\
15\end{array}$ & $\begin{array}{l}71 \\
70 \\
66 \\
58 \\
54\end{array}$ & $\begin{array}{l}-112 \\
-128 \\
-118 \\
-101 \\
-102\end{array}$ & $\begin{array}{l}5.5 \\
6.5 \\
7 \\
2.6\end{array}$ & $\begin{array}{l}2.2 \\
1.0 \\
1.4 \\
1.4 \\
1.4\end{array}$ & $\begin{array}{r}+2,510 \\
+440 \\
+225 \\
+138 \\
+100\end{array}$ & $\begin{array}{r}1,270 \\
223 \\
115 \\
71 \\
52\end{array}$ & $\begin{array}{l}1.5 \\
1.5 \\
1.5 \\
1.5 \\
1.5\end{array}$ & $\begin{array}{r}+19 \\
0 \\
+10 \\
+47 \\
+56\end{array}$ & $\begin{array}{l}11 \\
1.5 \\
6.5 \\
25 \\
30\end{array}$ \\
\hline $\begin{array}{l}16 \\
17 \\
18 \\
19 \\
20\end{array}$ & $\begin{array}{l}55 \\
45 \\
40 \\
40 \\
40\end{array}$ & $\begin{array}{l}-84 \\
-50 \\
-59 \\
-67 \\
-49\end{array}$ & $\begin{array}{r}13 \\
20 \\
10 \\
6 \\
15\end{array}$ & $\begin{array}{l}1.4 \\
1.5 \\
1.4 \\
1.4 \\
1.5\end{array}$ & $\begin{array}{l}+83 \\
+74 \\
+56 \\
+46 \\
+27\end{array}$ & $\begin{array}{l}43 \\
39 \\
30 \\
25 \\
15\end{array}$ & $\begin{array}{l}1.5 \\
1.5 \\
1.5 \\
1.5 \\
1.5\end{array}$ & $\begin{array}{l}+29 \\
+66 \\
+76 \\
+38 \\
+19\end{array}$ & $\begin{array}{l}16 \\
35 \\
21 \\
25 \\
11\end{array}$ \\
\hline $\begin{array}{l}21 \\
22 \\
23 \\
24 \\
25\end{array}$ & $\begin{array}{l}25 \\
17 \\
17 \\
17 \\
26\end{array}$ & $\begin{array}{l}-41 \\
-25 \\
-17 \\
-17 \\
-50\end{array}$ & $\begin{array}{l}4.3 \\
4.4 \\
8.5 \\
8.5\end{array}$ & $\begin{array}{l}1.5 \\
1.5 \\
1.5 \\
1.4 \\
1.4\end{array}$ & $\begin{array}{l}+28 \\
+47 \\
+65 \\
+27 \\
+28\end{array}$ & $\begin{array}{l}16 \\
25 \\
34 \\
15 \\
16\end{array}$ & $\begin{array}{l}1.5 \\
1.5 \\
1.5 \\
1.5 \\
1.5\end{array}$ & $\begin{array}{r}+9 \\
+19 \\
+9 \\
+19 \\
+10\end{array}$ & $\begin{array}{c}6 \\
11 \\
6 \\
11 \\
6.5\end{array}$ \\
\hline $\begin{array}{l}26 \\
27 \\
28 \\
29 \\
30 \\
31\end{array}$ & $\begin{array}{l}40 \\
45 \\
45 \\
50 \\
68\end{array}$ & $\begin{array}{r}-58 \\
-82 \\
-100 \\
-106 \\
-123\end{array}$ & $* 2.1$ & $\begin{array}{l}1.4 \\
1.4 \\
1.1 \\
1.0 \\
1.1 \\
1.2\end{array}$ & $\begin{array}{l}+28 \\
+28 \\
+27 \\
+28 \\
+28 \\
+19\end{array}$ & $\begin{array}{l}16 \\
16 \\
15 \\
15 \\
15 \\
11\end{array}$ & $\begin{array}{l}1.5 \\
1.5 \\
1.5 \\
1.5 \\
1.5 \\
1.5\end{array}$ & $\begin{array}{r}+19 \\
+10 \\
+19 \\
0 \\
+29 \\
+105\end{array}$ & $\begin{array}{l}11 \\
6.5 \\
11 \\
1.5 \\
16 \\
54\end{array}$ \\
\hline \multirow{2}{*}{\multicolumn{7}{|c|}{ 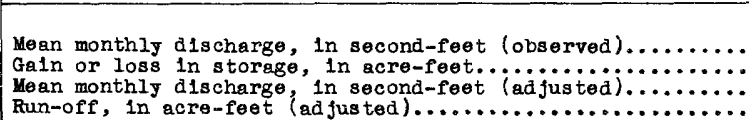 }} & November & December & January \\
\hline & & & & & & & $\begin{array}{r}52.1 \\
-2,830 \\
4.64 \\
276\end{array}$ & $\begin{array}{r}21.6 \\
+4,480 \\
94.5 \\
5,810\end{array}$ & $\begin{array}{r}1.50 \\
+728 \\
13.3 \\
820\end{array}$ \\
\hline
\end{tabular}

* Mear for the period. 
Alder Creek near Whitengll, Calif.

Location. - Lat. $38^{\circ} 45^{\prime}$, long. $120^{\circ} 22^{\prime}$, in SW $\frac{1}{4} \mathrm{sec} .36$, T. $11 \mathrm{~N} .$, R. 14 E., threequarters of a mile above mouth and 2 miles southeast of Whitehall, Eldorado County. Altitude, about 4,000 feet above mean sea level.

Drainage area.- 22.8 square miles.

Gage-helght record. - Water-stage recorder graph.

Stage-discharge relation. - Defined by current-meter measurements below 250 secondfeet; extended to peak stage on basis of area-velocity study; verifled by comparison of peak discharge and total mun-off of flood with records for other statlons in American River Basin.

Maxima.- December 1937: Discharge, 710 second-feet 9:30 a.m. Dec. I1 (gage height, 4.50 feet).

1922-November 1937: Discharge, about 2,060 second-feet Mar. 25, 1928 (gage height, 7.1 feet, from floodmark).

Remarks.- Flood min-off not affected by artificlal storage. Alder Creek feeder flume diverts immediately above station. Monthly surmaries adjusted for diversion. Part of basic data furnished by Pacific Gas \& Electric Co.

Mean daily discharge, in second-feet, November 1937 to January 1938

\begin{tabular}{|c|c|c|c|c|c|c|c|c|c|c|c|}
\hline Day & Nov. & Dec. & Jan. & Day & Nov. & Dec. & Jen. & Day & Nov. & Dec. & Jan. \\
\hline $\begin{array}{r}1 \\
2 \\
3 \\
4 \\
5 \\
6 \\
7 \\
8 \\
9 \\
10\end{array}$ & $\begin{array}{r}0.3 \\
.3 \\
.3 \\
.3 \\
.3 \\
.3 \\
.3 \\
.1 \\
.1 \\
.1\end{array}$ & $\begin{array}{r}0.5 \\
.5 \\
.5 \\
.5 \\
.5 \\
.5 \\
.5 \\
.5 \\
196\end{array}$ & $\begin{array}{l}14 \\
15 \\
16 \\
1.4 \\
13 \\
13 \\
11 \\
11 \\
10 \\
9.5\end{array}$ & $\begin{array}{l}11 \\
12 \\
13 \\
14 \\
15 \\
16 \\
17 \\
18 \\
19 \\
20\end{array}$ & $\begin{array}{r}0.6 \\
.8 \\
.5 \\
1.8 \\
1.5 \\
13.6 \\
5 \\
. .3 \\
1.6\end{array}$ & $\begin{array}{r}509 \\
262 \\
152 \\
110 \\
81 \\
63 \\
51 \\
41 \\
34 \\
29\end{array}$ & $\begin{array}{l}9 \\
8 \\
7.5 \\
8 \\
14 \\
11 \\
22 \\
20 \\
20 \\
17\end{array}$ & $\begin{array}{l}21 \\
22 \\
23 \\
24 \\
25 \\
26 \\
27 \\
28 \\
29 \\
30 \\
31\end{array}$ & $\begin{array}{r}6 \\
.8 \\
.6 \\
2.2 \\
.7 \\
.2 \\
.1 \\
.1 \\
.1 \\
.3\end{array}$ & $\begin{array}{l}26 \\
23 \\
21 \\
20 \\
18 \\
18 \\
15 \\
15 \\
14 \\
14 \\
13 \\
\end{array}$ & $\begin{array}{l}17 \\
18 \\
18 \\
15 \\
15 \\
16 \\
17 \\
18 \\
18 \\
15 \\
13 \\
\end{array}$ \\
\hline $\begin{array}{l}\text { Mean } \\
\text { Mean } \\
\text { Run- }\end{array}$ & $\begin{array}{l}\text { monthl } \\
\text { monthl } \\
\text { ff, in }\end{array}$ & $\begin{array}{l}\text { Ischa } \\
\text { Ischa } \\
\text { re fe }\end{array}$ & , in & d) & $\begin{array}{l}\text { eet } \\
\text { get }\end{array}$ & 19 & 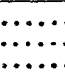 & & $\begin{array}{r}1.31 \\
3.01 \\
179\end{array}$ & $\begin{array}{r}55.8 \\
61.5 \\
3,780\end{array}$ & $\begin{array}{r}14.3 \\
21.3 \\
1,310\end{array}$ \\
\hline
\end{tabular}

Gage height, in feet, and discharge, in second-fe日t, at indicated time, 1937

\begin{tabular}{|c|c|c|c|c|c|c|c|c|c|c|c|c|}
\hline \multirow{2}{*}{ 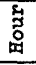 } & Feet & sec.ft. & Feet & Sec.ft. & Feet & Bec.ft. & $F \in \theta t$ & Sec.ft. & Feet & Sec.ft. & Feet & Sec.ft. \\
\hline & \multicolumn{2}{|c|}{ December 8} & \multicolumn{2}{|c|}{ December 9} & \multicolumn{2}{|c|}{ December 10} & \multicolumn{2}{|c|}{ December 11} & \multicolumn{2}{|c|}{ December 12} & \multicolumn{2}{|c|}{ December 13} \\
\hline \multirow[t]{2}{*}{$\begin{array}{r}2 \\
4 \\
6 \\
8 \\
10 \\
N \\
2 \\
4 \\
6 \\
8 \\
20 \\
1\end{array}$} & $\begin{array}{l}= \\
= \\
1.04 \\
= \\
1.04 \\
= \\
1.04 \\
= \\
1.04\end{array}$ & $\begin{array}{c}- \\
- \\
0.5 \\
- \\
- \\
.5 \\
- \\
-5 \\
- \\
- \\
.5\end{array}$ & $\begin{array}{c}- \\
1.03 \\
- \\
1.03 \\
- \\
1.03 \\
- \\
1.04 \\
- \\
1.05 \\
- \\
1.35\end{array}$ & $\begin{array}{r}-0.4 \\
-.4 \\
-.4 \\
-.4 \\
-.5 \\
-.6\end{array}$ & $\begin{array}{l}1.57 \\
2.35 \\
2.80 \\
2.87 \\
2.70 \\
2.56 \\
2.68 \\
2.69 \\
2.63 \\
2.64 \\
2.64 \\
2.87\end{array}$ & $\begin{array}{r}27 \\
154 \\
252 \\
269 \\
228 \\
197 \\
224 \\
226 \\
213 \\
215 \\
215 \\
269\end{array}$ & $\begin{array}{l}3.31 \\
3.50 \\
3.81 \\
4.30 \\
4.42 \\
4.15 \\
4.04 \\
3.97 \\
3.80 \\
3.74 \\
3.53 \\
3.35\end{array}$ & $\begin{array}{l}377 \\
426 \\
509 \\
650 \\
686 \\
605 \\
573 \\
554 \\
506 \\
489 \\
434 \\
387\end{array}$ & $\begin{array}{l}3.20 \\
3.08 \\
2.98 \\
2.90 \\
2.83 \\
2.78 \\
2.74 \\
2.70 \\
2.65 \\
2.60 \\
2.56 \\
2.52\end{array}$ & $\begin{array}{l}348 \\
319 \\
295 \\
276 \\
259 \\
247 \\
238 \\
228 \\
217 \\
206 \\
197 \\
188\end{array}$ & $\begin{array}{c}2.45 \\
- \\
2.37 \\
\vdots \\
2.32 \\
- \\
2.27 \\
2.24 \\
- \\
2.20\end{array}$ & $\begin{array}{c}\overline{174} \\
\overline{158} \\
\overline{148} \\
\overline{138} \\
\overline{132} \\
\overline{124}\end{array}$ \\
\hline & \multicolumn{2}{|c|}{ December 14} & \multicolumn{2}{|c|}{ December 15} & \multicolumn{2}{|c|}{ December 16} & \multicolumn{2}{|c|}{ December 17} & \multicolumn{2}{|c|}{ December 18} & \multicolumn{2}{|c|}{ December 19} \\
\hline \multirow[t]{2}{*}{$\begin{array}{r}2 \\
4 \\
6 \\
8 \\
10 \\
N \\
2 \\
4 \\
6 \\
8 \\
10 \\
M\end{array}$} & $\begin{array}{c}\overline{-} \\
2.15 \\
\overline{-} \\
2.11 \\
\overline{-} \\
2.08 \\
\overline{-} \\
2.04\end{array}$ & $\begin{array}{c}- \\
\overline{115} \\
\overline{-} \\
108 \\
\overline{-} \\
\overline{102} \\
\overline{-} \\
\overline{95}\end{array}$ & $\begin{array}{c}\bar{z} \\
2.00 \\
\overline{-} \\
\overline{1.96} \\
\overline{-} \\
\overline{1.93} \\
\overline{-} \\
\overline{1.90}\end{array}$ & $\begin{array}{l}- \\
88 \\
- \\
81 \\
= \\
76 \\
= \\
71\end{array}$ & $\begin{array}{l}\overline{-} \\
1.87 \\
- \\
1.85 \\
= \\
1.83 \\
- \\
\overline{1.81}\end{array}$ & $\begin{array}{l}- \\
\overline{66} \\
- \\
- \\
63 \\
- \\
\overline{60} \\
- \\
\overline{57}\end{array}$ & $\begin{array}{l}\overline{-} \\
\overline{1.79} \\
\overline{-} \\
\overline{1.77} \\
\overline{-} \\
\overline{1.76} \\
\overline{-} \\
\overline{1.74}\end{array}$ & $\begin{array}{l}\bar{z} \\
\overline{54} \\
\overline{5} \\
\overline{51} \\
\overline{4} \\
\overline{49} \\
\overline{4} \\
\overline{47}\end{array}$ & $\begin{array}{l}\overline{-} \\
1.72 \\
\overline{-} \\
\overline{1.70} \\
\overline{-} \\
\overline{1.69} \\
\overline{-} \\
\overline{1.67}\end{array}$ & $\begin{array}{l}\bar{y} \\
44 \\
\overline{41} \\
= \\
\overline{40} \\
= \\
\overline{3} 8\end{array}$ & $\begin{array}{l}\overline{-} \\
\overline{1.66} \\
\overline{-} \\
\overline{1.65} \\
\overline{-} \\
\overline{1.63} \\
\overline{-} \\
\overline{1.61}\end{array}$ & $\begin{array}{l}\overline{-} \\
\overline{37} \\
\overline{36} \\
\overline{-} \\
33 \\
\overline{31}\end{array}$ \\
\hline & \multicolumn{2}{|c|}{ December 20} & \multicolumn{2}{|c|}{ December 21} & \multicolumn{2}{|c|}{ December 22} & \multicolumn{2}{|c|}{ December 23} & \multicolumn{2}{|c|}{ December 24} & \multicolumn{2}{|c|}{ December 25} \\
\hline $\begin{array}{r}2 \\
4 \\
6 \\
8 \\
10 \\
1 \mathrm{~N} \\
2 \\
4 \\
6 \\
8 \\
10 \\
10\end{array}$ & $\begin{array}{l}- \\
\overline{1.60} \\
- \\
\overline{1.59} \\
- \\
\overline{1.58} \\
\overline{-} \\
\overline{1.57}\end{array}$ & $\begin{array}{l}- \\
\overline{30} \\
- \\
- \\
29 \\
- \\
\overline{28} \\
- \\
\overline{27}\end{array}$ & $\begin{array}{c}- \\
- \\
1.56 \\
- \\
\overline{1.55} \\
- \\
\overline{1.55} \\
\overline{-} \\
\overline{1.54}\end{array}$ & $\begin{array}{l}- \\
\overline{26} \\
- \\
- \\
26 \\
- \\
- \\
26 \\
= \\
\overline{25}\end{array}$ & $\begin{array}{c}\overline{-} \\
\overline{1.53} \\
- \\
\overline{1.51} \\
\overline{-} \\
\overline{1.51} \\
- \\
\overline{1.55}\end{array}$ & $\begin{array}{l}- \\
\overline{24} \\
- \\
\overline{2} \\
- \\
\overline{2} \\
\overline{2} \\
\overline{2}\end{array}$ & $\begin{array}{l}- \\
\overline{1.50} \\
- \\
\overline{1.51} \\
\overline{-} \\
\overline{1.50} \\
= \\
= \\
1.46\end{array}$ & $\begin{array}{l}- \\
\overline{21} \\
- \\
\overline{22} \\
\overline{-} \\
\overline{21} \\
- \\
\overline{18}\end{array}$ & $\begin{array}{l}\overline{-} \\
\overline{1.41} \\
- \\
\overline{1.55} \\
- \\
\overline{1.50} \\
= \\
\overline{1.48}\end{array}$ & $\begin{array}{l}\overline{15} \\
\overline{1} \\
\overline{26} \\
- \\
\overline{21} \\
\overline{-} \\
\overline{20}\end{array}$ & $\begin{array}{l}\overline{-} \\
1.39 \\
- \\
\overline{1.45} \\
\overline{-} \\
\overline{1.49} \\
= \\
\overline{1.45}\end{array}$ & $\begin{array}{l}- \\
= \\
= \\
13 \\
18 \\
= \\
20 \\
= \\
18\end{array}$ \\
\hline
\end{tabular}

Supplemental records.- Dec. $11,9: 30$ a.m., $4.50 \mathrm{ft.}, 710$ sec.-ft. 
Plum Oreek near Riverton, Galif.

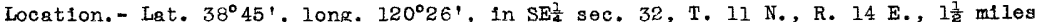
above mouth and 2 miles southeast of Riverton, Eldorado County. Altitude, about 4,100 feet above mean sea level.

Drainage srea.- 6.8 square inlles.

Gage-height record. - Water-atage recorder graph.

Stage-dlscharge relation. - Defined by current-meter measurements below 120 second-feet; extended to peak stage; verified by comparison of peak discharge with that of Alder Creek and by area-velocity study. Rating curve changed at peak stage.

Maxima.- December 1937: Discharge, 315 second-feet 7 a.m. Dec. Il (gage height, 3.10 feet).

1922-November 1937: Discharge, 635 second-feet Mar. 25, 1928 (gage height, 4.10 feet), from rating curve extended above 75 secona-feet.

Remarks. - Flood mun-off not affected by artificial storage or diversion. Part of basic Nata furnished by Pacific Gas E Electric Go.

Mean daily discharge, in second-feet, November 1937 to January 1938

\begin{tabular}{|c|c|c|c|c|c|c|c|c|c|c|c|}
\hline Day & Nov. & Dec. & Jan. & Day & Nov. & Dec. & Jan. & Day & Nov. & Dec. & Jan. \\
\hline 1 & 0.8 & 1.2 & 2.7 & 11 & 4.0 & 195 & 2.1 & 21 & 3.0 & 3.4 & 10 \\
\hline 2 & .9 & 1.2 & 3.4 & 12 & 2.1 & 75 & 2.1 & 22 & 2.4 & 3.2 & 10 \\
\hline 3 & 1.0 & 1.2 & 3.7 & 13 & 1.5 & 30 & 2.1 & 23 & 2.2 & 3.2 & 11 \\
\hline 4 & 1.0 & 1.2 & 3.2 & 14 & 2.1 & 16 & 2.0 & 24 & 3.8 & 3.0 & 9 \\
\hline 5 & 1.0 & 1.1 & 3.0 & 15 & 2.1 & 12 & 5 & 25 & 3.0 & 2.8 & 8 \\
\hline 6 & 1.0 & 1.0 & 2.8 & 16 & 2.1 & 8.5 & 4.5 & 26 & 2.4 & 2.8 & 7.5 \\
\hline 7 & 1.0 & 1.0 & 2.7 & 17 & 6.5 & 6.5 & 20 & 27 & 2.0 & 2.8 & 6.5 \\
\hline 8 & 1.0 & 1.0 & 2.6 & 18 & 3.6 & 5 & 20 & 28 & 1.7 & 2.8 & 6.5 \\
\hline 9 & 1.0 & 1.4 & 2.4 & 19 & 2.2 & 4.3 & 15 & 29 & 1.4 & 2.7 & \\
\hline 10 & 1.1 & 54 & 2.2 & 20 & 2.8 & 3.7 & 12 & 30 & 1.3 & 2.7 & 5.5 \\
\hline \multirow{2}{*}{\multicolumn{9}{|c|}{ Mean monthly discharge, in second-feet. $\ldots \ldots \ldots \ldots \ldots \ldots \ldots \ldots$}} & 2.07 & 14.6 & 6.53 \\
\hline & & & & & & & & & 123 & 897 & 402 \\
\hline
\end{tabular}

Gage height, in feet, and discharge, in second-feet, at indicated time, $193^{7}$

\begin{tabular}{|c|c|c|c|c|c|c|c|c|c|c|c|c|}
\hline \multirow{2}{*}{\begin{tabular}{|l|} 
\\
5 \\
0 \\
\end{tabular}} & Feet & sec.ft. & Feet & Sec.ft. & Feet & sec.ft. & Feet & sec.ft. & Feet & Sec.ft. & Feet & sec.ft \\
\hline & \multicolumn{2}{|c|}{ December 8} & \multicolumn{2}{|c|}{ December 9} & \multicolumn{2}{|c|}{ December 10} & \multicolumn{2}{|c|}{ December 11} & \multicolumn{2}{|c|}{ December 12} & \multicolumn{2}{|c|}{ December 13} \\
\hline 2 & - & - & 0.56 & 1.0 & 1.20 & 18 & 2.15 & 118 & 2.12 & 114 & - & - \\
\hline 4 & - & - & .56 & 1.0 & 1.75 & 66 & 2.40 & 160 & 2.02 & 100 & 1.45 & 37 \\
\hline 6 & - & - & .56 & 1.0 & 2.14 & 117 & 3. & 300 & 1. & 96 & - & - \\
\hline 8 & - & - & .56 & 1.0 & 1.92 & 86 & 3.08 & 310 & 1.90 & 83 & 1.38 & 32 \\
\hline 10 & - & - & .56 & 1.0 & 1.73 & 63 & 2.81 & 244 & 1.85 & 77 & - & - \\
\hline $\mathbb{N}$ & 0.56 & 1.0 & .56 & 1.0 & 1.64 & 53 & 2.63 & 205 & 1.79 & 70 & 1.33 & 28 \\
\hline 2 & - & - & .56 & 1.0 & 1.61 & 50 & 2.67 & 213 & 1.74 & 64 & - & - \\
\hline 4 & - & - & .57 & 1.1 & 1.54 & 43 & 2.51 & 180 & 1.69 & 59 & 1.26 & 24 \\
\hline 6 & - & - & .61 & 1.5 & 1.47 & 36 & 2.48 & 174 & 1.64 & 54 & - & - \\
\hline 8 & - & - & .66 & 2.2 & 1.47 & 36 & 2.54 & 186 & 1.62 & 52 & 1.24 & 22 \\
\hline 10 & - & - & .78 & 4.4 & 1.54 & 43 & 2. & 149 & 1.55 & 46 & - & - \\
\hline \multirow{2}{*}{ M } & .56 & 1.0 & .92 & 7.5 & 1.84 & 76 & 2.20 & 126 & 1.51 & 42 & 1.19 & 20 \\
\hline & \multicolumn{2}{|c|}{ December 14} & \multicolumn{2}{|c|}{ December 15} & \multicolumn{2}{|c|}{ December 16} & \multicolumn{2}{|c|}{ December 17} & \multicolumn{2}{|c|}{ December 18} & \multicolumn{2}{|c|}{ December 19} \\
\hline 2 & - & - & - & - & - & - & - & - & - & - & - & - \\
\hline 4 & 1.16 & 18 & 1.02 & 13 & 0.93 & 9.5 & 0.87 & 7.5 & 0.81 & 5.5 & 0.77 & 4.5 \\
\hline 6 & - & - & - & - & - & - & - & - & - & - & - & - \\
\hline 8 & - & - & - & - & - & - & - & - & - & - & - & - \\
\hline 10 & - & - & - & - & - & - & $=$ & - & - & - & - & - \\
\hline $\mathbf{N}$ & 1.10 & 16 & .99 & 12 & .90 & 8 & .85 & 6.5 & .79 & 5 & .76 & 4.3 \\
\hline & - & - & - & - & 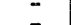 & - & & - & & - & & - \\
\hline $\begin{array}{l}4 \\
6\end{array}$ & $=$ & - & $=$ & - & 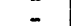 & $=$ & - & $=$ & - & $=$ & $=$ & - \\
\hline 8 & 1.06 & 14 & .96 & 10 & .88 & 7.5 & .83 & 6 & .78 & 4.8 & .75 & 4.1 \\
\hline 10 & - & - & - & - & - & - & - & - & - & - & - & - \\
\hline$M$ & - & - & - & - & - & - & - & - & - & - & - & - \\
\hline
\end{tabular}

Supplemental records.- Dec. 11, 7 a.m., $3.10 \mathrm{ft.}, 315$ sec.-ft. 


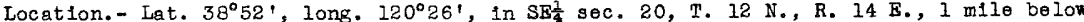
junction of North and Mldile Forks of SIlver Creek, near lower end of Union Valley, El Dorado County. Altitude, about 4,530 feet above mean sea level.

Drainage area.- 82.7 square miles.

Gage-height record.- Water-stage recorder graph except for period 8 a.m. Dec. 30 to Jan. 31, when there was no record.

Stage-discharge relation. - Defined by current-meter measurements below 3,000 second-feet extended to peak $\mathrm{stage}$ on basis of area-velocity study. Rating curve changed at peak stage.

Maxima.- December 1937: Discharge, 8,560 second-feet 10 a.m. Dec. Il (gage helght, 15.28 feet).

1924-November 1937: Discharge, 8,050 second-feet (revised) Mar. 25, 1928 (gage height, 14.7 feet, from floodmark).

Remerks. - Flood mun-off not affected by artificial storage or diversion. Discharge for period of missing gage-helght record based on range of stage indicated on recorder graph and record for Silver Creok near Placerville.

Mean daily discharge, in second-feet, November 1937 to January 1938

\begin{tabular}{|c|c|c|c|c|c|c|c|c|c|c|c|}
\hline Day & Nov. & Dec. & Jan. & Day & Nov. & DeC. & Jan. & Day & Nov. & Dec. & Jan. \\
\hline $\begin{array}{r}1 \\
2 \\
3 \\
4 \\
5 \\
6 \\
7 \\
8 \\
9 \\
10\end{array}$ & $\begin{array}{l}6.5 \\
6.5 \\
6.5 \\
6.5 \\
6.5 \\
6.5 \\
6.5 \\
7 \\
7 \\
7\end{array}$ & $\begin{array}{r}38 \\
36 \\
32 \\
32 \\
32 \\
35 \\
36 \\
38 \\
51 \\
3,840\end{array}$ & $\begin{array}{l}\bar{z} \\
\overline{-} \\
\overline{-} \\
\overline{-} \\
\overline{-} \\
\overline{-} \\
-\end{array}$ & $\begin{array}{l}11 \\
12 \\
13 \\
14 \\
15 \\
16 \\
17 \\
18 \\
19 \\
20\end{array}$ & $\begin{array}{r}17 \\
20 \\
15 \\
33 \\
25 \\
29 \\
121 \\
53 \\
42 \\
109\end{array}$ & $\begin{array}{r}5,560 \\
1,070 \\
487 \\
331 \\
285 \\
236 \\
206 \\
183 \\
158 \\
134\end{array}$ & $\begin{array}{l}- \\
- \\
= \\
= \\
= \\
= \\
-\end{array}$ & $\begin{array}{l}21 \\
22 \\
23 \\
24 \\
25 \\
26 \\
27 \\
28 \\
29 \\
30 \\
31\end{array}$ & $\begin{array}{r}121 \\
63 \\
63 \\
75 \\
55 \\
48 \\
44 \\
41 \\
40 \\
40\end{array}$ & $\begin{array}{l}128 \\
121 \\
104 \\
131 \\
121 \\
114 \\
111 \\
106 \\
104 \\
114 \\
110\end{array}$ & $\begin{array}{l}\bar{z} \\
\bar{z} \\
\bar{z} \\
\bar{z} \\
\overline{-} \\
\overline{-}\end{array}$ \\
\hline $\begin{array}{l}\text { Mean } \\
\text { Run- }\end{array}$ & $\begin{array}{l}n+h 1 \\
\text {, in }\end{array}$ & SClia & & & & & & & $\begin{array}{r}37.7 \\
2,240\end{array}$ & $\begin{array}{r}454 \\
27,940 \\
\end{array}$ & $\begin{array}{r}100 \\
6,150\end{array}$ \\
\hline
\end{tabular}

Gage height, in feet, and discharge, in second-feet, at indicated time, 1937

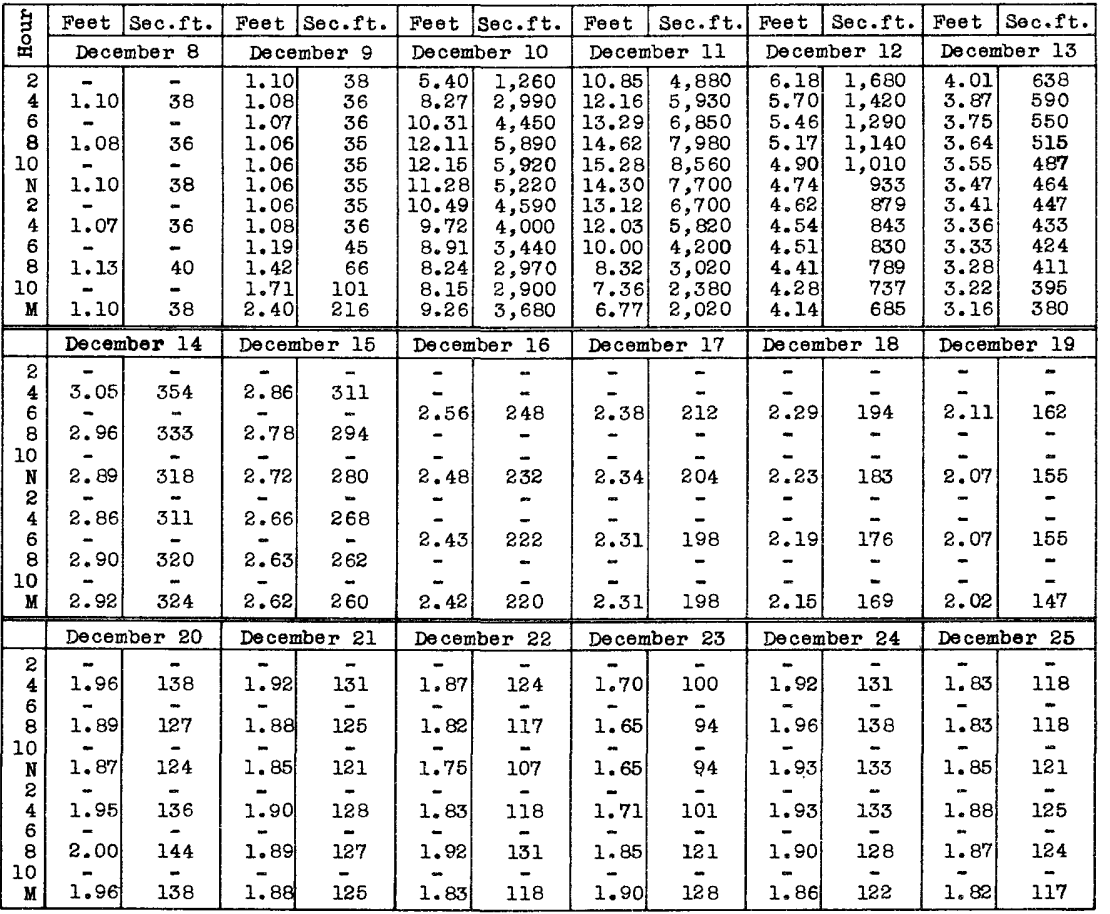


Silver Creek near Placerville, Calif.

Location.- Lat. $38^{\circ} 47^{\prime}$, long. $120^{\circ} 35^{\circ}$, in sw $\frac{2}{4}$ sec. 13, T. 11 N., R. 12 E., a quarter of a mile above mouth and $12 \mathrm{mlles}$ northeast of Placerville, Eldorado County.

Altitude, about 2,250 feet above mean sea level.

Drainase area.- 176 square miles.

Gage-he1ght record.- Water-stage recorder graph.

Stage-discharge relation.- Defined by current-meter measurements below 4,000 secondfeet; extended to peak stage with ald of area-velocity study; verifled by comparison of peak discharge and total runmoff of flood with records at other stations in American River Basin.

Max1ma.- December 1937: D1scharge, 14,600 second-feet 12:30 p.m. Dec. 11 (gage helght, 13.8 feet)

1921-November 1937: Discharge, 12,400 second-feet (revised) Mar. 25, 1928 (gage helght, 12.8 feet, present $s 1$ te and datum, from floodmarks; 18.0 feet, former site and datum, from gage-he1ght comparison).

Remarks. - Flood run-off not affected by artiflclal storage or diversion.

Mean dally discharge, in second-feet, November 1937 to January 1938

\begin{tabular}{|c|c|c|c|c|c|c|c|c|c|c|c|}
\hline Day & Nov. & Dec. & Jan. & Day & Nov. & Dec. & Jan. & Day & Nov. & Dec. & Jan. \\
\hline 1 & 34 & 90 & 208 & 11 & 53 & 9,500 & 172 & 21 & 287 & 280 & 288 \\
\hline 2 & 35 & 93 & 233 & 12 & 74 & 2,730 & 172 & 22 & 151 & 268 & 299 \\
\hline 3 & 35 & 84 & 236 & 13 & 52 & 1,160 & 172 & 23 & 134 & 246 & 329 \\
\hline 4 & 34 & 83 & 213 & 14 & 76 & 770 & 170 & 24 & 202 & 241 & 266 \\
\hline 5 & 33 & 82 & 198 & 15 & 80 & 632 & 254 & 25 & 152 & 246 & 280 \\
\hline 6 & 33 & 79 & 174 & 16 & 64 & 526 & 233 & 26 & 118 & 220 & 271 \\
\hline 7 & 32 & 82 & 176 & 17 & 237 & 450 & 407 & 27 & 109 & 218 & 274 \\
\hline 8 & 32 & 87 & 174 & 18 & 172 & 407 & 400 & 28 & 100 & 215 & 288 \\
\hline 9 & 32 & 94 & 170 & 19 & 101 & 352 & 352 & 29 & 98 & 206 & 285 \\
\hline 10 & 32 & 5,220 & 174 & 20 & 118 & 305 & 299 & $\begin{array}{l}30 \\
31\end{array}$ & 94 & 210 & 241 \\
\hline \multicolumn{9}{|c|}{ 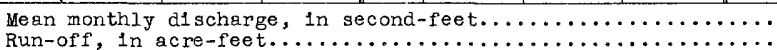 } & $\begin{array}{r}93.5 \\
5,560\end{array}$ & 50,340 & $\begin{array}{r}249 \\
15,300\end{array}$ \\
\hline
\end{tabular}

Gage height, in feet, and discharge, in second-feet, at indicated time, 1937

\begin{tabular}{|c|c|c|c|c|c|c|c|c|c|c|c|c|}
\hline \multirow{2}{*}{\begin{tabular}{l}
4 \\
\multirow{3}{3}{} \\
0 \\
0
\end{tabular}} & Feet & Sec.ft. & Feet & Sec.ft. & Feet & Sec.ft. & Feet & sec.ft. & Feet & Sec.ft. & Feet & Sec.ft. \\
\hline & \multicolumn{2}{|c|}{ December 8} & \multicolumn{2}{|c|}{ December 9} & \multicolumn{2}{|c|}{ December 10} & \multicolumn{2}{|c|}{ December 11} & \multicolumn{2}{|c|}{ December 12} & \multicolumn{2}{|c|}{ December 13} \\
\hline 2 & - & - & - & - & 3.32 & 332 & 9.40 & 6,050 & 8.40 & 4,510 & 5.66 & 1,520 \\
\hline 4 & 2.15 & 83 & 2.17 & 86 & 6.16 & 1,840 & 10.30 & 7,590 & 7.95 & 3,880 & 5.50 & 1,410 \\
\hline 6 & - & - & - & - & 8.60 & 4,810 & 11.02 & 8,890 & 7.60 & 3,420 & 5.40 & 1,340 \\
\hline 8 & 2.24 & 96 & 2.21 & 91 & 9.85 & 6,800 & 11.70 & 10,200 & 7.30 & 3,060 & 5.27 & 1,260 \\
\hline 10 & - & - & - & - & 10,45 & 7,860 & 12.35 & 11,500 & 6.90 & 2,620 & & 1,190 \\
\hline $\mathrm{N}$ & 2.23 & 94 & 2.18 & 87 & 10.60 & 8,130 & 13.70 & 14,300 & 6.62 & 2,340 & 5.05 & 1,130 \\
\hline 2 & - & - & - & - & 10.30 & 7,590 & 13.45 & 13,800 & 6.40 & 2,130 & 5.00 & 1,100 \\
\hline 4 & 2.16 & 84 & 2.18 & 87 & 9.95 & 6,960 & 12.60 & 12,000 & 6.25 & 2,000 & 4.90 & 1,040 \\
\hline 6 & - & - & - & $\tilde{0}$ & 9.52 & 6,240 & 11.70 & 10,200 & 6.11 & 1,870 & 4.82 & 992 \\
\hline 8 & 2.17 & 86 & 2.26 & 98 & 9.10 & 5,570 & 10.75 & 8,400 & 6.03 & 1,800 & 4.78 & 969 \\
\hline 10 & - & - & - & - & 8.25 & 5,040 & 9.65 & 6,460 & 5.94 & 1,730 & 75 & 952 \\
\hline \multirow{2}{*}{$\mathrm{M}$} & 2.17 & 86 & 2.56 & 149 & 8.80 & 5,110 & 8.95 & 5,340 & 5.80 & 1,620 & 4.69 & 920 \\
\hline & \multicolumn{2}{|c|}{ December 14} & \multicolumn{2}{|c|}{ December 15} & \multicolumn{2}{|c|}{ December 16} & \multicolumn{2}{|c|}{ December 17} & \multicolumn{2}{|c|}{ December 18} & \multicolumn{2}{|c|}{ December 19} \\
\hline 2 & - & - & - & - & - & - & - & - & - & - & - & - \\
\hline 4 & 4.60 & 870 & - & - & - & $\overline{-}$ & - & - & - & - & - & - \\
\hline 6 & & - & 4.20 & 676 & 3.90 & 550 & 3.67 & 461 & 3.55 & 418 & 3.39 & 363 \\
\hline 8 & 4.48 & 810 & - & - & - & - & - & - & - & - & - & - \\
\hline 10 & - & - & - & - & - & - & - & - & - & - & - & - \\
\hline $\mathbf{N}$ & 4.38 & 760 & 4.10 & 632 & 3.83 & 522 & 3.65 & 454 & 3.53 & 411 & 3.35 & 349 \\
\hline 2 & - & - & - & - & - & - & - & - & - & - & - & - \\
\hline 4 & 4.30 & 720 & - & - & - & - & - & - & - & - & - & - \\
\hline 6 & - & - & 4.00 & 590 & 3.76 & 495 & 3.60 & 436 & 3.47 & 390 & 3.31 & 335 \\
\hline 8 & 4.21 & 680 & - & - & - & - & - & - & - & - & - & - \\
\hline 10 & - & - & - & - & - & - & - & - & - & - & - & - \\
\hline \multirow[t]{2}{*}{$M$} & 4.19 & 672 & 3.94 & 566 & 3.70 & 472 & 3.56 & 422 & 3.43 & 376 & 3.28 & 326 \\
\hline & \multicolumn{2}{|c|}{ December 20} & \multicolumn{2}{|c|}{ December 21} & \multicolumn{2}{|c|}{ De cember 22} & \multicolumn{2}{|c|}{ December 23} & \multicolumn{2}{|c|}{ December 24} & \multicolumn{2}{|c|}{ December 25} \\
\hline 2 & - & - & - & - & - & - & - & - & - & - & - & - \\
\hline 4 & - & - & - & - & - & - & - & - & - & - & - & - \\
\hline 6 & 3.26 & 320 & 3.17 & 294 & 3.10 & 274 & 3.19 & 299 & 2.96 & 236 & 3.05 & 260 \\
\hline 8 & - & - & - & - & - & - & - & - & - & - & - & - \\
\hline 10 & - & - & - & - & - & - & - & - & - & - & - & - \\
\hline $\mathbf{N}$ & 3.19 & 299 & 3.13 & 282 & 3.07 & 266 & 2.96 & 236 & 2.95 & 233 & 2.96 & 236 \\
\hline 2 & - & - & - & - & - & - & - & - & - & - & - & - \\
\hline 4 & - & - & - & - & - & - & - & - & - & - & - & - \\
\hline 6 & 3.12 & 280 & 3.09 & 271 & 3.00 & 246 & 2.87 & 213 & 3.04 & 257 & 2.90 & 220 \\
\hline 8 & - & - & - & - & - & - & - & - & - & - & - & - \\
\hline 10 & - & - & - & - & - & - & - & - & - & - & - & - \\
\hline M & 3.15 & 288 & 3.10 & 274 & 3.19 & 299 & 2.90 & 220 & 3.09 & 271 & 3.02 & 252 \\
\hline
\end{tabular}

Supplemental records.-Dec. $11,12: 30$ p.m., $13.8 \mathrm{ft}, 14,600$ sec.-ft. 
South Fork of Silver Creek near Ice House, Calif.

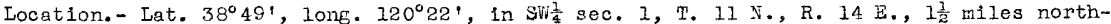
east of Ice House, Eldorado County, and 8 miles northeast of Riverton. Altitide, about 5,300 feet above mean sea level.

Drainage area.- 28.4 square miles.

Gage-height record. - Water-stage recoraer sraph.

Stage-discharge relation. - Affected by ice for periods Nov. 29 to Dec, 8, Dec, 24 to Jan. 3 , Jan. 6-9, 15-31. Defined by current-meter measurements below 550 second-feet; extended to peak stage on basis of area-velocity study; verified by comparison of peak discharge and total run-off of flood with records for other streans in American River Basin. Rating curve changed at peak stage.

Maxima.- December 1937: Discharge, 2,200 second-feet 12:30 p.m. Dec. 11 (gage height, $5 . \overline{8} 0$ feet).

1924-November 1937: Discharge, 1,620 second-feet Har. 26, 1923 (gage helght, 5.35 feet), from rating curve extended above 550 second-feet.

Remarks. - Flood mun off not affected by artiflcial storage or diversion. Discharge for periods of ice effect computed on basis of weather records and flow of nearby $s$ ineams.

Kean daily discharge, in second-feet, November 1937 to Januery 1938

\begin{tabular}{|c|c|c|c|c|c|c|c|c|c|c|c|}
\hline Day & Nov. & Dec. & Jan. & Day & Nov. & Dec, & Jan. & Day & Nov. & Dec. & Jan. \\
\hline $\begin{array}{r}1 \\
2 \\
3 \\
4 \\
5 \\
6 \\
7 \\
8 \\
9 \\
10\end{array}$ & $\begin{array}{l}1.8 \\
1.8 \\
1.8 \\
1.8 \\
1.8 \\
1.8 \\
1.8 \\
1.8 \\
1.8 \\
1.8\end{array}$ & $\begin{array}{r}9 \\
9 \\
8 \\
8 \\
8 \\
9 \\
9 \\
9 \\
12 \\
900\end{array}$ & $\begin{array}{l}20 \\
20 \\
20 \\
20 \\
20 \\
19 \\
19 \\
19 \\
19 \\
19\end{array}$ & $\begin{array}{l}11 \\
12 \\
13 \\
14 \\
15 \\
16 \\
17 \\
18 \\
19 \\
20\end{array}$ & $\begin{array}{l}3.2 \\
2.6 \\
3.5 \\
8 \\
7.5 \\
8 \\
24 \\
15 \\
12 \\
20\end{array}$ & $\begin{array}{r}1,620 \\
442 \\
149 \\
87 \\
70 \\
54 \\
47 \\
43 \\
38 \\
33\end{array}$ & $\begin{array}{l}18 \\
18 \\
17 \\
17 \\
17 \\
17 \\
17 \\
17 \\
17 \\
17\end{array}$ & $\begin{array}{l}21 \\
22 \\
23 \\
24 \\
25 \\
26 \\
27 \\
28 \\
29 \\
30 \\
31\end{array}$ & $\begin{array}{l}30 \\
22 \\
21 \\
21 \\
18 \\
16 \\
14 \\
12 \\
11 \\
10\end{array}$ & $\begin{array}{l}31 \\
30 \\
26 \\
27 \\
25 \\
24 \\
23 \\
22 \\
21 \\
20 \\
20\end{array}$ & $\begin{array}{l}16 \\
16 \\
16 \\
16 \\
16 \\
15 \\
15 \\
15 \\
15 \\
15 \\
15\end{array}$ \\
\hline \multicolumn{9}{|c|}{ 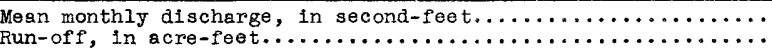 } & $\begin{array}{r}9.89 \\
589 \\
\end{array}$ & $\begin{array}{r}124 \\
7,600 \\
\end{array}$ & $\begin{array}{r}17.3 \\
1,070 \\
\end{array}$ \\
\hline
\end{tabular}

Gage height, in feet, and discharge, in scoond-feet, at indicated time, 1937

\begin{tabular}{|c|c|c|c|c|c|c|c|c|c|c|c|c|}
\hline \multirow{2}{*}{ 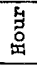 } & Feet & Sec.ft. & Feet & sec.ft. & Feet & sec.ft. & Feet & Sec.ft. & Feet & Sec.ft. & Feet & Sec.ft. \\
\hline & \multicolumn{2}{|c|}{ December 8} & \multicolumn{2}{|c|}{ December 9} & \multicolumn{2}{|c|}{ December 10} & \multicolumn{2}{|c|}{ December 11} & \multicolumn{2}{|c|}{ December 12} & \multicolumn{2}{|c|}{ December 13} \\
\hline $\begin{array}{r}2 \\
4 \\
6 \\
8 \\
10 \\
N \\
2 \\
4 \\
6 \\
8 \\
10 \\
M\end{array}$ & & & $\begin{array}{l}- \\
0.66 \\
-65 \\
-65 \\
-65 \\
.65 \\
.70 \\
.85\end{array}$ & $\begin{array}{l}\overline{12} \\
\overline{12} \\
\overline{12} \\
- \\
12 \\
\overline{12} \\
\overline{23}\end{array}$ & $\begin{array}{l}1.00 \\
1.30 \\
2.30 \\
3.50 \\
4.20 \\
4.88 \\
5.12 \\
4.93 \\
4.74 \\
4.64 \\
4.46 \\
4.38\end{array}$ & $\begin{array}{r}35 \\
59 \\
212 \\
625 \\
990 \\
1,440 \\
1,630 \\
1,470 \\
1,340 \\
1,270 \\
1,150 \\
1,100\end{array}$ & $\begin{array}{l}4.45 \\
4.58 \\
4.90 \\
5.22 \\
5.60 \\
5.78 \\
5.74 \\
5.59 \\
5.45 \\
5.02 \\
4.45 \\
4.05\end{array}$ & $\begin{array}{r}1,140 \\
1,230 \\
1,450 \\
1,710 \\
2,020 \\
2,180 \\
2,150 \\
2,010 \\
1,900 \\
1,560 \\
1,180 \\
942\end{array}$ & $\begin{array}{l}3.73 \\
3.53 \\
3.25 \\
3.05 \\
2.90 \\
2.78 \\
2.63 \\
2.51 \\
2.43 \\
2.36 \\
2.29 \\
2.21\end{array}$ & $\begin{array}{l}775 \\
634 \\
564 \\
435 \\
430 \\
339 \\
340 \\
303 \\
230 \\
262 \\
244 \\
224\end{array}$ & $\begin{array}{l}2.12 \\
2.06 \\
1.98 \\
1.92 \\
1.82 \\
1.82 \\
1.77 \\
1.73 \\
1.70 \\
1.68 \\
1.65 \\
1.65\end{array}$ & $\begin{array}{l}203 \\
189 \\
172 \\
160 \\
152 \\
142 \\
133 \\
126 \\
121 \\
118 \\
113 \\
110\end{array}$ \\
\hline & \multicolumn{2}{|c|}{ December 14} & \multicolumn{2}{|c|}{ December 15} & \multicolumn{2}{|c|}{ December 16} & \multicolumn{2}{|c|}{ Decomber 17} & \multicolumn{2}{|c|}{ December 18} & \multicolumn{2}{|c|}{ December 19} \\
\hline \multirow[t]{2}{*}{$\begin{array}{r}2 \\
4 \\
6 \\
8 \\
10 \\
\mathrm{~N} \\
2 \\
4 \\
6 \\
8 \\
10 \\
\mathrm{M} \\
\end{array}$} & $\begin{array}{l}- \\
1.57 \\
- \\
1.51 \\
- \\
1.46 \\
- \\
1.42 \\
- \\
1.40 \\
- \\
1.41\end{array}$ & $\begin{array}{c}\overline{100} \\
\overline{9} \\
\overline{8} \\
\overline{84} \\
\overline{79} \\
\overline{7} \\
\overline{7} 6 \\
\overline{7} 7\end{array}$ & $\begin{array}{c}- \\
\overline{1.40} \\
\overline{-} \\
\overline{1.35} \\
\overline{-} \\
\overline{1.30} \\
\overline{-} \\
\overline{1.29}\end{array}$ & $\begin{array}{l}- \\
\overline{76} \\
- \\
- \\
70 \\
- \\
\overline{63} \\
- \\
- \\
62\end{array}$ & $\begin{array}{l}\overline{-} \\
\overline{1.25} \\
\overline{-} \\
1.21 \\
= \\
\overline{1.19} \\
\overline{-} \\
\overline{1.18}\end{array}$ & $\begin{array}{l}- \\
\overline{5} \\
- \\
- \\
53 \\
- \\
\overline{51} \\
\overline{-} \\
\overline{50}\end{array}$ & $\begin{array}{l}- \\
\overline{1.16} \\
- \\
= \\
\bar{z} .15 \\
\overline{1.13} \\
\overline{-} \\
\overline{1.13}\end{array}$ & $\begin{array}{l}- \\
\overline{4} \\
- \\
- \\
47 \\
- \\
\overline{4} \\
= \\
= \\
45\end{array}$ & $\begin{array}{l}\overline{-} \\
1.12 \\
- \\
- \\
1.11 \\
- \\
- \\
1.09 \\
- \\
1.08\end{array}$ & $\begin{array}{l}\overline{-} \\
44 \\
- \\
\overline{43} \\
\overline{-} \\
\overline{41} \\
\overline{-} \\
\overline{40}\end{array}$ & $\begin{array}{c}\overline{-} \\
\overline{-} .06 \\
- \\
\overline{1.05} \\
\overline{-} \\
\overline{1.03} \\
- \\
\overline{-} \\
1.03\end{array}$ & $\begin{array}{l}- \\
- \\
39 \\
- \\
- \\
38 \\
- \\
- \\
36 \\
- \\
\overline{36}\end{array}$ \\
\hline & \multicolumn{2}{|c|}{ December 20} & \multicolumn{2}{|c|}{ December 21} & \multicolumn{2}{|c|}{ December 22} & \multicolumn{2}{|c|}{ December 23} & \multicolumn{2}{|c|}{ December 24} & \multicolumn{2}{|c|}{ December 25} \\
\hline $\begin{array}{r}2 \\
4 \\
6 \\
8 \\
10 \\
\mathrm{~N} \\
2 \\
4 \\
6 \\
8 \\
10 \\
\mathrm{M}\end{array}$ & $\begin{array}{l}- \\
\overline{1.01} \\
- \\
- \\
.96 \\
- \\
.97 \\
- \\
.98\end{array}$ & $\begin{array}{l}\overline{-} \\
\overline{35} \\
- \\
\overline{31} \\
\overline{-} \\
\overline{32} \\
\overline{-} \\
\overline{33}\end{array}$ & $\begin{array}{l}- \\
- \\
0.97 \\
- \\
-96 \\
- \\
-.95 \\
- \\
-.96\end{array}$ & $\begin{array}{l}\bar{z} \\
\overline{32} \\
- \\
\overline{31} \\
\overline{-} \\
\overline{30} \\
\overline{-} \\
\overline{31}\end{array}$ & $\begin{array}{l}- \\
\overline{0.95} \\
- \\
\overline{.90} \\
\overline{-} \\
.93 \\
\overline{-} \\
.96\end{array}$ & $\begin{array}{l}\overline{-} \\
\overline{30} \\
- \\
\overline{2} \\
\overline{2} \\
\overline{2} \\
29 \\
\overline{-} \\
\overline{31}\end{array}$ & $\begin{array}{l}- \\
\overline{0.87} \\
- \\
\overline{0} \\
\overline{-} \\
\overline{-} \\
\overline{-} \\
\overline{.} \\
.98\end{array}$ & $\begin{array}{l}- \\
25 \\
- \\
\overline{2} \\
- \\
\overline{-} \\
24 \\
- \\
\overline{3} 3\end{array}$ & & & & \\
\hline
\end{tabular}

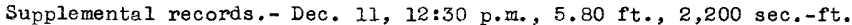


Clear Lake at Lakeport, Cal1f.

Location. - Lat. $39^{\circ} 03^{\prime}$, long. $122^{\circ} 55^{\prime}$, in $\mathrm{SE}_{4}^{\mathrm{z}} \mathrm{sec} .24$, T. $14 \mathrm{~N}$. , R. 10 W., at municipal wharf on north side of Third Street in Lakeport, Lake County. Zero of gage is

$1,318.59$ feet above mean sea level (general adjustment of 1929).

Drainage area.- 420 square miles including water surface of lake (65 square miles). Gage-helght record. - Staff gage read once dally to hundredths.

Maxima.-December 1937: Gage he1ght, 5.67 feet Dec. 16.

1913-November 1937: Gage helght, 11.12 feet Jan. 28, 1914.

January-September 1938: Gage holght, 10.25 feet Feb. 15-16.

Remarks.- Flood run-off largely controlied in lake. Basic data furnished by Clear Lake Water Co.

Gage height, in feet, November 1937 to January 1938

\begin{tabular}{|c|c|c|c|c|c|c|c|c|c|c|c|}
\hline Day & Nov. & Dec. & Jan. & Day & Nov. & Dec. & Jan. & Day & Nov. & Dec. & Jan. \\
\hline $\begin{array}{r}1 \\
2 \\
3 \\
4 \\
5 \\
6 \\
7 \\
8 \\
9 \\
10\end{array}$ & $\begin{array}{l}1.10 \\
1.10 \\
1.10 \\
1.10 \\
1.10 \\
1.10 \\
1.10 \\
1.10 \\
1.10 \\
1.10\end{array}$ & $\begin{array}{l}2.35 \\
2.35 \\
2.35 \\
2.35 \\
2.35 \\
2.35 \\
2.35 \\
2.35 \\
2.35 \\
2.80\end{array}$ & $\begin{array}{l}4.97 \\
4.97 \\
5.07 \\
5.07 \\
5.07 \\
5.07 \\
5.10 \\
5.10 \\
5.10 \\
5.15\end{array}$ & $\begin{array}{l}11 \\
12 \\
13 \\
14 \\
15 \\
16 \\
17 \\
18 \\
19 \\
20\end{array}$ & $\begin{array}{l}1.10 \\
1.17 \\
1.17 \\
1.20 \\
1.22 \\
1.40 \\
1.45 \\
1.47 \\
1.50 \\
1.70\end{array}$ & $\begin{array}{l}3.40 \\
5.35 \\
5.52 \\
5.65 \\
5.65 \\
5.67 \\
5.65 \\
5.62 \\
5.60 \\
5.50\end{array}$ & $\begin{array}{l}5.17 \\
5.20 \\
5.20 \\
5.20 \\
5.20 \\
5.27 \\
5.37 \\
5.50 \\
5.65 \\
5.72\end{array}$ & $\begin{array}{l}21 \\
22 \\
23 \\
24 \\
25 \\
26 \\
27 \\
28 \\
29 \\
30 \\
31\end{array}$ & $\begin{array}{l}1.97 \\
2.00 \\
2.07 \\
2.17 \\
2.20 \\
2.25 \\
2.27 \\
2.30 \\
2.30 \\
2.32\end{array}$ & $\begin{array}{l}5.45 \\
5.45 \\
5.45 \\
5.40 \\
5.35 \\
5.25 \\
5.17 \\
5.10 \\
5.00 \\
5.00 \\
4.97\end{array}$ & $\begin{array}{l}5.80 \\
5.87 \\
5.92 \\
5.92 \\
6.00 \\
6.00 \\
6.00 \\
6.05 \\
6.10 \\
6.20 \\
6.30\end{array}$ \\
\hline
\end{tabular}


Cache Creek at Yolo, Calif.

Location.- Lat. $38^{\circ} 43^{\prime} 30^{\prime \prime}$, Long. $121^{\circ} 48^{\prime} 25^{\prime \prime}$, in Rio Jesus Maria grant, 800 feet above highway bridge and half a mile south of Yolo, Yolo County. Altitude, about 60 feet above mean sea level.

Drainage area. 71,150 square miles (revised).

Gage-height record.- Water-stage recorder graph.

Stage-discharge relation. - Defined by current-meter measurements below 15,200 secondfeet; extended to peak stage; verified by area-velocity study. Rating curve changed at peak stage.

Maxima.- December 1937: Discharge, 19,300 second-feet 4 p.m. Dec. 11 (gage height, 29.10 feet).

1903-November 1937: Discharge observed, 21,100 second-feet Feb. 2, 1915 (gage

height, 29.8 feet, present datum, from nonrecording gage), from rating curve extended

above 12,300 second-feet.

Remarks.- Flood run-off materially affected by storage in Clear Lake.

Mean dally discharge, in second-feet, November 1937 to January 1938

\begin{tabular}{|c|c|c|c|c|c|c|c|c|c|c|c|}
\hline Day & Nov. & Dec. & Jan. & Day & Nov. & Dec. & Jan. & Day & Nov. & Dec. & Jan. \\
\hline $\begin{array}{r}1 \\
2 \\
3 \\
4 \\
5 \\
6 \\
7 \\
8 \\
9 \\
10\end{array}$ & $\begin{array}{l}0 \\
0 \\
0 \\
0 \\
0 \\
0 \\
0 \\
0 \\
0 \\
0\end{array}$ & $\begin{array}{r}57 \\
46 \\
41 \\
36 \\
33 \\
32 \\
30 \\
28 \\
29 \\
1,030\end{array}$ & $\begin{array}{l}376 \\
336 \\
316 \\
300 \\
279 \\
251 \\
223 \\
195 \\
171 \\
144\end{array}$ & $\begin{array}{l}11 \\
12 \\
13 \\
14 \\
15 \\
16 \\
17 \\
18 \\
19 \\
20\end{array}$ & $\begin{array}{r}0 \\
0 \\
0 \\
0 \\
0 \\
0 \\
10 \\
374 \\
121 \\
65\end{array}$ & $\begin{array}{r}17,300 \\
9,760 \\
3,760 \\
3,200 \\
2,680 \\
2,500 \\
2,320 \\
2,160 \\
1,990 \\
1,880\end{array}$ & $\begin{array}{r}138 \\
135 \\
132 \\
130 \\
130 \\
138 \\
465 \\
1,140 \\
890 \\
1,060\end{array}$ & $\begin{array}{l}21 \\
22 \\
23 \\
24 \\
25 \\
26 \\
27 \\
28 \\
29 \\
30 \\
31\end{array}$ & $\begin{array}{r}2,000 \\
525 \\
237 \\
262 \\
304 \\
200 \\
150 \\
115 \\
91 \\
73\end{array}$ & $\begin{array}{r}1,820 \\
1,820 \\
1,770 \\
1,770 \\
1,720 \\
1,720 \\
1,660 \\
1,600 \\
1,600 \\
1,550 \\
975\end{array}$ & $\begin{array}{l}740 \\
586 \\
510 \\
444 \\
396 \\
360 \\
332 \\
328 \\
328 \\
308 \\
996\end{array}$ \\
\hline \multicolumn{9}{|c|}{ 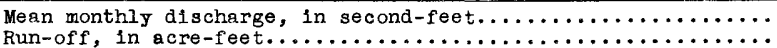 } & $\begin{array}{r}151 \\
8,980 \\
\end{array}$ & $\begin{array}{r}2,159 \\
132,700 \\
\end{array}$ & 24,350 \\
\hline
\end{tabular}

Gage height, in feet, and discharge, in second-feet, at indicated time, 1937

\begin{tabular}{|c|c|c|c|c|c|c|c|c|c|c|c|c|}
\hline \multirow{2}{*}{$\begin{array}{l}4 \\
\text { 是 } \\
\text { 足 }\end{array}$} & eet & Sec.ft. & Peet & sec.ft. & Feet & Sec.ft. & Feet & Sec.ft. & Feet & sec.ft. & Feet & Sec.ft \\
\hline & \multicolumn{2}{|c|}{ December 8} & \multicolumn{2}{|c|}{ December 9} & \multicolumn{2}{|c|}{ December 10} & \multicolumn{2}{|c|}{ December 11} & \multicolumn{2}{|c|}{ De cember 12} & \multicolumn{2}{|c|}{ December 13} \\
\hline $\begin{array}{r}2 \\
4 \\
6 \\
8 \\
10 \\
\mathrm{~N} \\
2 \\
4 \\
6 \\
8 \\
10 \\
\mathrm{M}\end{array}$ & $\begin{array}{l}- \\
\overline{1.84} \\
= \\
\overline{1.83} \\
= \\
\overline{1.82} \\
= \\
\overline{1.82}\end{array}$ & $\begin{array}{l}- \\
- \\
28 \\
- \\
- \\
28 \\
- \\
- \\
27 \\
- \\
- \\
27\end{array}$ & $\begin{array}{c}- \\
1.82 \\
- \\
1.81 \\
- \\
1.81 \\
- \\
1.86 \\
\overline{1.88} \\
\overline{2.05}\end{array}$ & $\begin{array}{l}\overline{27} \\
\overline{27} \\
\overline{27} \\
\overline{30} \\
\overline{31} \\
\overline{44}\end{array}$ & $\begin{array}{r}2.05 \\
2.11 \\
2.19 \\
2.18 \\
2.25 \\
2.37 \\
3.03 \\
5.00 \\
6.50 \\
7.63 \\
8.88 \\
10.85\end{array}$ & \begin{tabular}{|r|}
44 \\
49 \\
56 \\
55 \\
62 \\
76 \\
209 \\
1,190 \\
2,090 \\
2,770 \\
3,520 \\
4,800
\end{tabular} & & & & & & \\
\hline & \multicolumn{2}{|c|}{ December 14} & \multicolumn{2}{|c|}{ December 15} & \multicolumn{2}{|c|}{ December 16} & \multicolumn{2}{|c|}{ December 17} & \multicolumn{2}{|c|}{ December 18} & \multicolumn{2}{|c|}{ De cember 19} \\
\hline $\begin{array}{r}2 \\
4 \\
6 \\
8 \\
10 \\
\mathrm{~N} \\
2 \\
4 \\
6 \\
8 \\
10 \\
\mathrm{M}\end{array}$ & $\begin{array}{l}7.85 \\
8.80 \\
9.35 \\
8.48 \\
8.12 \\
7.98 \\
7.88 \\
7.78 \\
7.68 \\
7.61 \\
7.55 \\
7.46\end{array}$ & \begin{tabular}{|l}
3,070 \\
3,640 \\
3,970 \\
3,450 \\
3,230 \\
3,150 \\
3,090 \\
3,030 \\
2,970 \\
2,930 \\
2,890 \\
2,840
\end{tabular} & $\begin{array}{c}7.33 \\
- \\
7.22 \\
- \\
7.11 \\
- \\
7.05 \\
- \\
7.04 \\
- \\
7.04\end{array}$ & $\begin{array}{c}2, \overline{760} \\
2,690 \\
\overline{-} \\
2,630 \\
\overline{-} \\
2,590 \\
\overline{2,580} \\
2, \overline{5} 80\end{array}$ & $\begin{array}{c}- \\
\overline{6.98} \\
- \\
\overline{6.94} \\
- \\
\overline{6.86} \\
\overline{-} \\
\overline{6.79}\end{array}$ & $\begin{array}{c}\overline{-} \\
\bar{z}, 550 \\
- \\
\overline{-} \\
2,520 \\
- \\
\overline{4} \\
2,480 \\
\overline{-} \\
2, \overline{430}\end{array}$ & $\begin{array}{c}- \\
- \\
6.71 \\
- \\
- \\
6.64 \\
- \\
- \\
6.57 \\
- \\
- \\
6.51\end{array}$ & $\begin{array}{c}2, \overline{3} 90 \\
- \\
\overline{-} \\
2, \overline{3} 40 \\
\overline{-} \\
\overline{3} \\
2, \overline{3} 00 \\
- \\
- \\
2, \overline{2} 70\end{array}$ & $\begin{array}{c}- \\
- \\
6.40 \\
- \\
- \\
6.30 \\
- \\
\overline{6.22} \\
- \\
- \\
6.14\end{array}$ & $\begin{array}{c}\overline{-} \\
2, \overline{2} 10 \\
- \\
\overline{-} \\
2,160 \\
\overline{-} \\
2, \overline{110} \\
\overline{-} \\
2,070\end{array}$ & $\begin{array}{c}- \\
- \\
6.06 \\
- \\
5.99 \\
- \\
\overline{5.92} \\
- \\
5.84\end{array}$ & $\begin{array}{c}\overline{-} \\
2, \overline{0} 20 \\
- \\
\overline{-} \\
1, \overline{9} 80 \\
- \\
\overline{-} \\
1, \overline{9} 50 \\
\overline{-} \\
\overline{1,}\end{array}$ \\
\hline & \multicolumn{2}{|c|}{ December 20} & \multicolumn{2}{|c|}{ December 21} & \multicolumn{2}{|c|}{ December 22} & \multicolumn{2}{|c|}{ December 23} & \multicolumn{2}{|c|}{ December 24} & \multicolumn{2}{|c|}{ December 25} \\
\hline $\begin{array}{r}2 \\
4 \\
6 \\
8 \\
10 \\
\mathrm{~N} \\
2 \\
4 \\
6 \\
8 \\
10 \\
\mathrm{M}\end{array}$ & $\begin{array}{l}- \\
- \\
5.79 \\
- \\
\overline{5} \\
-78 \\
- \\
5.77 \\
- \\
\overline{-} \\
5.77\end{array}$ & $\begin{array}{c}\overline{-} \\
1, \overline{870} \\
- \\
\overline{-} \\
1, \overline{870} \\
- \\
\overline{-} \\
1, \overline{8} 60 \\
- \\
\overline{-} \\
1, \overline{8} 60\end{array}$ & $\begin{array}{c}- \\
- \\
5.75 \\
- \\
5.74 \\
- \\
5.73 \\
-\end{array}$ & $\begin{array}{c}- \\
\overline{-} \\
1,850 \\
- \\
\overline{-} \\
1, \overline{850} \\
- \\
\overline{-} \\
1,840 \\
- \\
\overline{-} \\
1,830\end{array}$ & $\begin{array}{l}- \\
\overline{5.69} \\
- \\
- \\
5.68 \\
- \\
\overline{5.66} \\
= \\
\overline{5.64}\end{array}$ & $\begin{array}{c}- \\
\overline{-} \\
1,820 \\
- \\
\overline{8} \\
1, \overline{8} 0 \\
- \\
- \\
1, \overline{800} \\
- \\
\overline{1}, \overline{790}\end{array}$ & $\begin{array}{c}- \\
\overline{5.61} \\
- \\
\overline{5.61} \\
- \\
\overline{5.60} \\
\overline{-} \\
5.60\end{array}$ & $\begin{array}{c}- \\
\overline{7} \\
1, \overline{7} 80 \\
\overline{-} \\
1, \overline{7} 80 \\
- \\
\overline{7} \\
1,70 \\
- \\
\overline{-} \\
1,770\end{array}$ & $\begin{array}{c}- \\
- \\
5.59 \\
- \\
- \\
5.56 \\
- \\
- \\
5.55 \\
- \\
- \\
5.53\end{array}$ & $\begin{array}{c}\overline{-} \\
1, \overline{7} 60 \\
- \\
\overline{7} \\
1, \overline{7} 0 \\
- \\
\overline{7} \\
1,740 \\
- \\
1, \overline{7} 30\end{array}$ & $\begin{array}{c}- \\
\overline{5.53} \\
- \\
- \\
5.52 \\
- \\
\overline{5.51} \\
- \\
5.50\end{array}$ & $\begin{array}{c}- \\
\overline{7} \\
1, \overline{7} 30 \\
- \\
1, \overline{7} 30 \\
- \\
\overline{7} \\
1, \bar{z} 0 \\
- \\
1, \overline{720}\end{array}$ \\
\hline
\end{tabular}


North Fork of Cache Creek near Lower Lake, Calif.

Location. - Lat. $39^{\circ} \mathrm{O} 1^{\prime}$, long. $122^{\circ} 33^{\prime}$, in $\mathrm{NE} \frac{1}{4} \mathrm{sec} .31$, T. 14 N., R. 6 W., 500 feet above Sweet Hollow Creek, 3 miles above mouth, and 7 miles northeast of Lower Lake, Lake County. Altitude, about 1,050 feet above mean sea level.

Drainage area.- 214 square miles.

Gage-height record.- Water-stage recorder graph except for period 2 a.m. Nov. 23 to 8 a.m. Dec. 16, when there was no record. Stage graph for period midnight Dec. I5 to $8 \mathrm{a} . \mathrm{m}$. Dec. 16 based on shape of stage graph for Putah Creek near Guenoc.

Stage-discharge relation.- Defined by current-meter measurements below 7,300 secondfeet; extended to peak stage on basis of area-velocity study. Rating curve changed at peak stage.

Maxima.- December 1937: Discharge, 16,000 sccond-feet about 3 a.m. Dec. 11 (gage helist, 12.98 feet).

1930-November 1937: Discharge, about 11,000 second-feet Dec. 26, 1931 (gage helight, 9.65 feet)

Remarks.- Flood mun-off not affected by artificlal storage or diversion. Discharge for period of missing gage-height record estimated from record for Putah Creek near Guenoc.

Mean da1ly discharge, in second-feet, November 1937 to January 1938

\begin{tabular}{|c|c|c|c|c|c|c|c|c|c|c|c|}
\hline Day & Nov. & Dec. & Jan. & Day & Nov. & Dec. & Jan. & Day & Nov. & Dec. & Jan. \\
\hline 1 & 0.2 & 120 & 120 & 11 & 0.4 & 8,000 & 86 & 21 & 644 & 256 & 472 \\
\hline 2 & .2 & 110 & 170 & 12 & 29 & 3,000 & 86 & 22 & 318 & 240 & 418 \\
\hline 3 & .2 & 100 & 174 & 13 & 11 & 2,000 & 86 & 23 & 700 & 222 & 365 \\
\hline 4 & .2 & 95 & 145 & 14 & 40 & 1,100 & 88 & 24 & 600 & 205 & 326 \\
\hline 5 & .2 & 90 & 132 & 15 & 136 & 750 & 114 & 25 & 400 & 198 & 294 \\
\hline 6 & .2 & 85 & 120 & 16 & 301 & 534 & 106 & 26 & 300 & 179 & 269 \\
\hline 7 & .2 & BO & 114 & 17 & 901 & 439 & 838 & 27 & 250 & 163 & 253 \\
\hline 8 & .2 & 75 & 106 & 18 & 209 & 378 & 576 & 28 & 200 & 150 & 256 \\
\hline 9 & .2 & 150 & 96 & 19 & 149 & 323 & 628 & 29 & 160 & 141 & 243 \\
\hline 10 & .3 & 9,500 & 92 & 20 & 2,210 & 280 & 580 & 30 & 130 & 134 & 222 \\
\hline & & & & & & & & 31 & & 126 & 1,060 \\
\hline \multicolumn{9}{|c|}{ 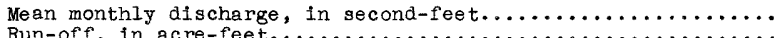 } & 256 & $\begin{array}{r}943 \\
9760\end{array}$ & $\begin{array}{r}279 \\
130\end{array}$ \\
\hline Run- & & & & 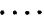 & a & & & & 15,250 & 57,960 & 17,130 \\
\hline
\end{tabular}

Gage height, in feet, and discharge, in second-feet, at indicated time, 1937

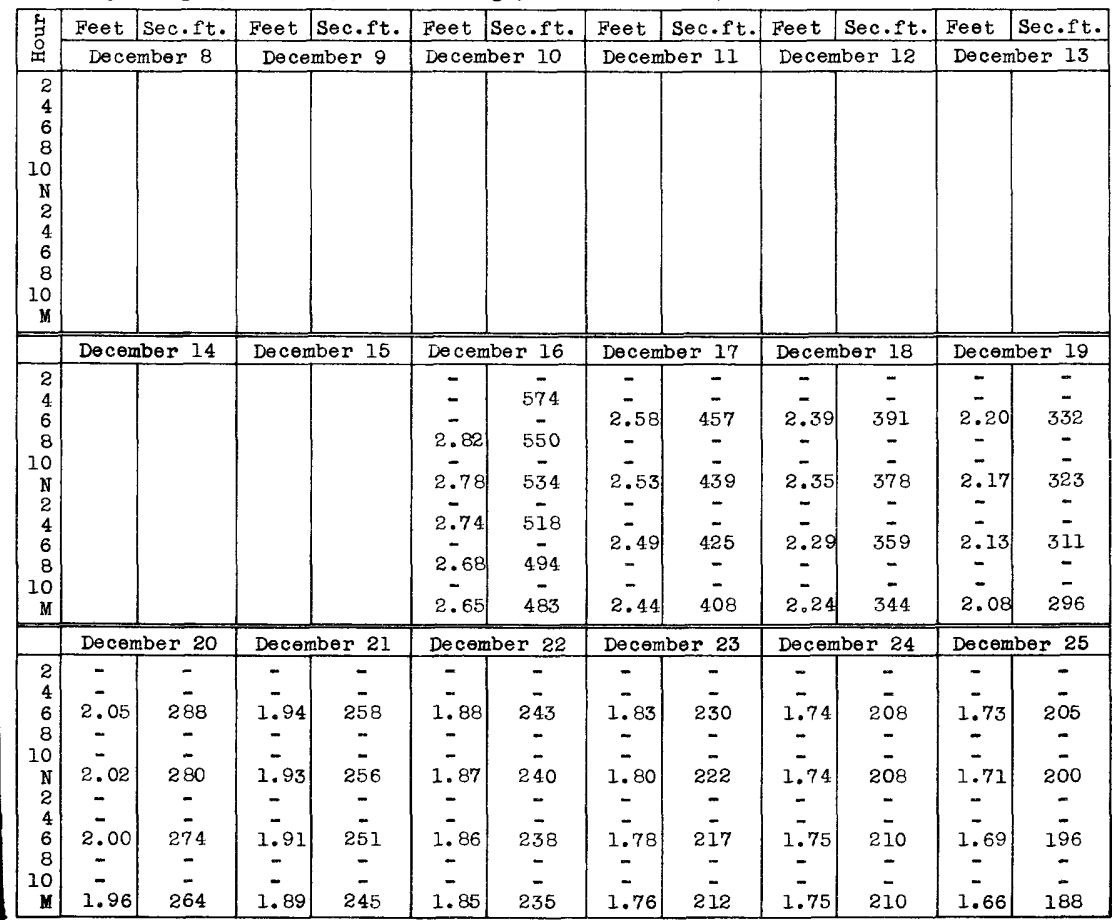

Supplemental records.- Dec. 11, about 3 a.m. $12.98 \mathrm{ft}$, 16,000 sec.-ft. 
Putah Creek near Guenoc, Calif.

Location. - Lat. $38^{\circ} 46^{\prime}$, long. $122^{\circ} 31^{\prime}$, in sec. 22, T. 11 N., R. 6 W., just above dam

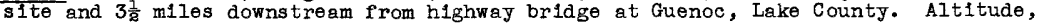
about 925 feet above mean sea level.

Drainage area. - 112 square miles.

Gage-helght record. - Water-stage recorder graph except for periods 6:30 p.m. Dec. 10 to 4:30 p.m. Dec. 11, Dec. 20 to Jan. 13, when there was no record. Stage graph for periods 6:30 p.m. Dec. 10 to 4:30 p.m. Dec. 11, Jan. 13 based on floodmarks, range of stage indicated on recorder graph, and shape of stage graph for Putah Creok near winters.

Stage-discharge relation.- Defined by current-meter measurements below 7,000 secondfeet; extended to peak stage on basis of area-velocity study. Rating curve changed at peak stage.

Maxima.- December 1937: Discharge, 24,100 second-feet about 3 a.m. Dec. II (gage helght, 22.7 feet).

1904-6, 1930-November 1937: Discharge observed, 24,600 second-feet Mar. 10, 1904 (gage height, 20.1 feet, former datum), from rating curve extended above 14,500 second-feet.

Remarks.- Flood mun-off not affected by artificial storage or diversion. Discharge for period of missing gage-height record, Dec. 21 to Jan. 12, determined f rom discharge graph based on range of stage from recorder graph and record for Putah Creek near Winters.

Mean daily discharge, in second-feet, November 1937 to January 1938

\begin{tabular}{|c|c|r|r||r|r|r|r|r|r|r|r|}
\hline Day & Nov. & Dec. & Jan. & Day & Nov. & Dec. & Jan. & Day & Nov. & Dec. & Jan. \\
\hline 1 & 2.7 & 94 & 90 & 11 & 61 & 11,600 & 75 & 21 & 811 & 180 & 461 \\
2 & 2.7 & 86 & 180 & 12 & 46 & 2,420 & 75 & 22 & 376 & 160 & 361 \\
3 & 2.8 & 79 & 180 & 13 & 13 & 1,160 & 72 & 23 & 890 & 150 & 292 \\
4 & 2.8 & 74 & 130 & 14 & 82 & 770 & 72 & 24 & 750 & 140 & 242 \\
5 & 2.7 & 68 & 90 & 15 & 97 & 558 & 90 & 25 & 366 & 130 & 212 \\
6 & 2.7 & 65 & 85 & 16 & 120 & 432 & 142 & 26 & 246 & 120 & 190 \\
7 & 2.7 & 61 & 85 & 17 & 705 & 344 & 2,400 & 27 & 184 & 110 & 176 \\
8 & 2.8 & 58 & 80 & 18 & 148 & 287 & 910 & 28 & 146 & 100 & 198 \\
9 & 2.9 & 210 & 80 & 19 & 138 & 240 & 950 & 29 & 122 & 90 & 194 \\
10 & 3.4 & 13,600 & 75 & 20 & 3,780 & 207 & 662 & 30 & 107 & 90 & 171 \\
& & &
\end{tabular}

Gage height, in feet, and discharge, in second-feet, at indicated time, 1937

\begin{tabular}{|c|c|c|c|c|c|c|c|c|c|c|c|c|}
\hline \multirow{2}{*}{ 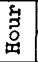 } & Feet & Sec.ft. & Feet & Sec.ft. & Feet & Sec.ft. & Feet & Sec.ft. & Feet & Sec,ft. & Feet & Sec.ft. \\
\hline & \multicolumn{2}{|c|}{ December 8} & \multicolumn{2}{|c|}{ December 9} & \multicolumn{2}{|c|}{ December 10} & \multicolumn{2}{|c|}{ December 11} & \multicolumn{2}{|c|}{ December 12} & \multicolumn{2}{|c|}{ December 13} \\
\hline $\begin{array}{r}2 \\
4 \\
6 \\
8 \\
10 \\
\mathbb{N} \\
2 \\
4 \\
6 \\
8 \\
10 \\
M\end{array}$ & $\begin{array}{c}\bar{z} \\
\overline{2.20} \\
\overline{-} \\
\overline{2.20} \\
\overline{-} \\
\overline{2.19} \\
\overline{-} \\
\overline{2.19}\end{array}$ & $\begin{array}{l}\overline{-} \\
58 \\
\bar{z} \\
58 \\
- \\
\overline{5} 7 \\
\overline{-} \\
57\end{array}$ & $\begin{array}{l}2.19 \\
2.18 \\
2.18 \\
2.19 \\
2.20 \\
2.23 \\
2.26 \\
2.30 \\
2.36 \\
2.85 \\
4.35 \\
8.40\end{array}$ & $\begin{array}{r}57 \\
56 \\
56 \\
57 \\
58 \\
61 \\
65 \\
69 \\
76 \\
148 \\
491 \\
2,700\end{array}$ & $\begin{array}{l}11.05 \\
13.30 \\
14.90 \\
15.49 \\
15.18 \\
15.14 \\
18.07 \\
21.90 \\
20.75 \\
19.70 \\
19.25 \\
19.45\end{array}$ & $\begin{array}{r}5,560 \\
8,420 \\
10,800 \\
11,700 \\
11,200 \\
11,100 \\
15,900 \\
22,600 \\
20,600 \\
18,700 \\
17,900 \\
18,300\end{array}$ & \begin{tabular}{|r|}
22.00 \\
21.25 \\
18.70 \\
17.00 \\
15.40 \\
14.20 \\
13.20 \\
12.45 \\
11.70 \\
10.95 \\
10.22 \\
9.60
\end{tabular} & $\begin{array}{r}22,800 \\
21,400 \\
17,000 \\
14,100 \\
11,500 \\
9,700 \\
8,280 \\
7,280 \\
6,340 \\
5,440 \\
4,560 \\
3,860\end{array}$ & $\begin{array}{l}9.23 \\
8.95 \\
8.68 \\
8.50 \\
8.22 \\
7.94 \\
7.67 \\
7.42 \\
7.22 \\
7.04 \\
6.87 \\
6.73\end{array}$ & $\begin{array}{l}3,480 \\
3,200 \\
2,950 \\
2,790 \\
2,560 \\
2,330 \\
2,130 \\
1,950 \\
1,810 \\
1,700 \\
1,600 \\
1,520\end{array}$ & $\begin{array}{l}6.59 \\
6.47 \\
6.34 \\
6.25 \\
6.14 \\
6.04 \\
5.95 \\
5.85 \\
5.77 \\
5.68 \\
5.60 \\
5.53\end{array}$ & $\begin{array}{l}1,430 \\
1,360 \\
1,300 \\
1,260 \\
1,200 \\
1,150 \\
1,110 \\
1,060 \\
1,030 \\
986 \\
950 \\
922\end{array}$ \\
\hline & \multicolumn{2}{|c|}{ December 14} & \multicolumn{2}{|c|}{ December 15} & \multicolumn{2}{|c|}{ December 16} & \multicolumn{2}{|c|}{ December 17} & \multicolumn{2}{|c|}{ December 18} & \multicolumn{2}{|c|}{ December 19} \\
\hline $\begin{array}{r}2 \\
4 \\
6 \\
8 \\
10 \\
\mathrm{~N} \\
2 \\
4 \\
6 \\
8 \\
10 \\
\mathrm{M}\end{array}$ & $\begin{array}{l}- \\
5.39 \\
- \\
5.27 \\
- \\
5.15 \\
- \\
5.03 \\
- \\
4.89 \\
- \\
4.80\end{array}$ & $\begin{array}{l}\overline{866} \\
\overline{818} \\
\overline{770} \\
\overline{7} \overline{6} \\
\overline{676} \\
\overline{645}\end{array}$ & 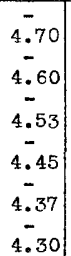 & $\begin{array}{c}6 \overline{10} \\
\overline{-} \\
5 \overline{7} \\
\overline{-} \\
5 \overline{0} \\
\overline{-} \\
5 \overline{2} \\
\overline{-} \\
4 \overline{97} \\
\overline{7} \overline{6}\end{array}$ & $\begin{array}{c}4 . \overline{25} \\
\overline{4} \\
4.18 \\
\overline{-} \\
4.12 \\
\overline{4.06} \\
\overline{4} \\
\overline{3} \\
\overline{3.95}\end{array}$ & $\begin{array}{l}4 \overline{61} \\
\overline{4} \overline{0} \\
4 \overline{24} \\
4 \overline{0} \\
\overline{395} \\
\overline{379}\end{array}$ & $\begin{array}{c}- \\
3.90 \\
- \\
3.85 \\
- \\
3.81 \\
- \\
3.77 \\
- \\
3.72 \\
- \\
3.68\end{array}$ & $\begin{array}{c}3 \overline{66} \\
\overline{354} \\
\overline{3} \\
3 \overline{4} \\
3 \overline{2} \\
\overline{3} 3 \\
\overline{314}\end{array}$ & $\begin{array}{l}- \\
3.63 \\
- \\
3.59 \\
- \\
3.56 \\
- \\
3.52 \\
- \\
3.47 \\
- \\
3.44\end{array}$ & 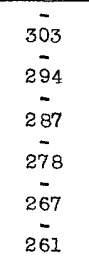 & $\begin{array}{l}- \\
3.40 \\
- \\
3.37 \\
- \\
3.34 \\
- \\
3.31 \\
- \\
3.28 \\
- \\
3.24\end{array}$ & $\begin{array}{l}2 \overline{52} \\
\overline{246} \\
\overline{240} \\
2 \overline{-} \\
2 \overline{2} \\
2 \overline{20}\end{array}$ \\
\hline & \multicolumn{2}{|c|}{ December 20} & \multicolumn{2}{|c|}{ December 21} & \multicolumn{2}{|c|}{ December 22} & \multicolumn{2}{|c|}{ December 23} & \multicolumn{2}{|c|}{ December 24} & \multicolumn{2}{|c|}{ December 25} \\
\hline $\begin{array}{r}2 \\
4 \\
6 \\
8 \\
10 \\
\mathbb{N} \\
2 \\
4 \\
6 \\
8 \\
10 \\
M\end{array}$ & $\begin{array}{c}\bar{z} \\
\overline{3.21} \\
\overline{-} \\
\overline{3.17} \\
\overline{-} \\
\overline{3.14} \\
\overline{3} \\
\overline{3.10}\end{array}$ & $\begin{array}{c}\overline{-} \\
2 \overline{14} \\
\overline{-} \\
2 \overline{07} \\
\overline{-} \\
\overline{201} \\
\overline{-} \\
\overline{194}\end{array}$ & & & & & & & & & & \\
\hline
\end{tabular}

Supplemental records.- Dec. 11, about 3 a.m., 22.7 ft., 24,100 sec.-ft. 
Location. - Lat. $38^{\circ} 3 \mathrm{I}^{\prime}$, long. $122^{\circ} 05^{\prime}$, in $\mathrm{NE}_{\frac{1}{4}}^{\frac{1}{4}}$ sec. 28, T. 8 N., R. 2 W., 6 miles west of Winters, Yolo County, and $8 \mathrm{miles}$ below Capell Creek. Altitude, about 160 feet above mean sea level.

Drainage area.- 614 square miles.

Gage-helght record. - Water-stage recorder graph.

Stage-discharge relation.- Defined by current-meter measurements below 16,700 secondfeet; extended to peak stage of 1937 on basis of area-velocity study. Rating curve changed at peak stage.

Maxlira.- December 1937: Discharge, 39,200 second-feet 8:30 a.m. Dec. Il (gage helght, 24.8 feet).

1930-November 1937: Discharge, 41,100 second-feet Feb. 4, 1937 (gage height, 25.4 feet).

1905-30: Discharge, about 60,000 second-feet Dec. 31, 1913 (gage he1ght, about 39.0 feet, from floodmarks, former site and datum, 6 miles downstream), from rating curve extended above 20,000 second-feet.

Remarks.- Flood run-off not affected by artificial storage or diversion.

Mean daily discharge, in second-feet, November 1937 to January 1938

\begin{tabular}{|c|c|c|c|c|c|c|c|c|c|c|c|}
\hline Day & Nov. & Dec. & $\operatorname{Jan}$. & Day & Nov. & Dec. & Jan. & Day & Nov. & Dec. & Jan. \\
\hline 1 & 7 & 146 & 174 & 11 & 11 & 29,300 & 132 & 21 & 3,340 & 348 & 1,100 \\
\hline$\overline{2}$ & 7 & 132 & 196 & 12 & 12 & 7,120 & 129 & 22 & 800 & 312 & 820 \\
\hline 3 & 7 & 118 & 276 & 13 & 10 & 2,730 & 125 & 23 & 593 & 296 & 664 \\
\hline 4 & 7 & 108 & 218 & 14 & 10 & 1,560 & 124 & 24 & 1,130 & 276 & 529 \\
\hline 5 & 7.5 & 100 & 188 & 15 & 10 & 1,100 & 137 & 25 & 760 & 271 & 456 \\
\hline 6 & 7.5 & 94 & 174 & 16 & 15 & 840 & 163 & 26 & 445 & 252 & 400 \\
\hline 7 & & 89 & 164 & 17 & 223 & 664 & 3,560 & 27 & 322 & 228 & 361 \\
\hline 8 & & 84 & 157 & 18 & 460 & 560 & 1,970 & 28 & 244 & 212 & 428 \\
\hline 9 & 7.5 & 88 & 147 & 19 & 188 & 470 & 2,260 & 29 & 199 & 198 & 544 \\
\hline 10 & 7 & 20,000 & 137 & 20 & 3,160 & 400 & 1,890 & 30 & 168 & 188 & 428 \\
\hline & & & & & & & & 3 & & 180 & 4,550 \\
\hline \multicolumn{9}{|c|}{ 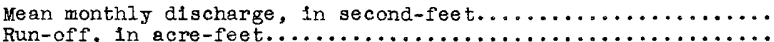 } & $\begin{array}{r}406 \\
24,140\end{array}$ & $\begin{array}{r}2,209 \\
135,800\end{array}$ & $\begin{array}{r}729 \\
44,830\end{array}$ \\
\hline
\end{tabular}

Gage height, in feet, and discharge, in second-feet, at indicated time, 1937

\begin{tabular}{|c|c|c|c|c|c|c|c|c|c|c|c|c|}
\hline \multirow{2}{*}{ 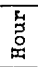 } & Feet & Sec.ft. & Feet & Sec.ft. & Feet & Sec.ft. & $F \theta \theta t$ & Sec.ft. & Feet & Sec.ft. & Feet & Sec.ft. \\
\hline & \multicolumn{2}{|c|}{ December 8} & \multicolumn{2}{|c|}{ December 9} & \multicolumn{2}{|c|}{ December 10} & \multicolumn{2}{|c|}{ December 11} & \multicolumn{2}{|c|}{ December 12} & \multicolumn{2}{|c|}{ December 13} \\
\hline \multirow[t]{2}{*}{\begin{tabular}{|r|}
2 \\
4 \\
6 \\
8 \\
10 \\
$N$ \\
2 \\
4 \\
6 \\
8 \\
10 \\
$M$ \\
\end{tabular}} & $\begin{array}{c}- \\
\overline{-} \\
\overline{-01} \\
\overline{4.00} \\
- \\
\overline{3.99} \\
- \\
\overline{3.97}\end{array}$ & $\begin{array}{l}- \\
- \\
85 \\
- \\
- \\
84 \\
- \\
- \\
83 \\
- \\
81\end{array}$ & $\begin{array}{c}-\overline{3.97} \\
- \\
3.97 \\
- \\
4.00 \\
- \\
4.06 \\
- \\
4.10 \\
- \\
4.21\end{array}$ & \begin{tabular}{|c}
$\overline{81}$ \\
$\overline{81}$ \\
$\overline{81}$ \\
$\overline{84}$ \\
$\overline{9}$ \\
$\overline{90}$ \\
$\overline{9} 4$ \\
$\overline{106}$
\end{tabular} & \begin{tabular}{|r|}
4.30 \\
4.43 \\
7.65 \\
17.00 \\
19.95 \\
20.91 \\
20.82 \\
20.57 \\
21.00 \\
23.25 \\
23.95 \\
23.50
\end{tabular} & \begin{tabular}{|r|}
116 \\
132 \\
1,100 \\
16,200 \\
24,400 \\
27,300 \\
27,100 \\
26,300 \\
27,600 \\
34,400 \\
36,400 \\
35,100
\end{tabular} & $\begin{array}{l}22.45 \\
21.95 \\
23.70 \\
24.75 \\
24.40 \\
23.53 \\
22.25 \\
20.80 \\
19.64 \\
18.40 \\
17.12 \\
15.95\end{array}$ & $\begin{array}{l}32,000 \\
30,400 \\
35,700 \\
39,000 \\
37,900 \\
35,200 \\
31,400 \\
27,000 \\
23,500 \\
19,900 \\
16,500 \\
13,500\end{array}$ & \begin{tabular}{|r|}
15.05 \\
14.41 \\
13.88 \\
13.35 \\
-13.00 \\
12.73 \\
12.47 \\
12.17 \\
11.90 \\
11.65 \\
11.36 \\
11.10
\end{tabular} & $\begin{array}{r}11,300 \\
9,900 \\
8,760 \\
7,700 \\
7,000 \\
6,510 \\
6,050 \\
5,570 \\
5,140 \\
4,740 \\
4,290 \\
3,950\end{array}$ & $\begin{array}{r}10.84 \\
10.64 \\
10.44 \\
10.24 \\
10.08 \\
9.92 \\
9.78 \\
9.63 \\
9.50 \\
9.38 \\
9.26 \\
9.16\end{array}$ & $\begin{array}{l}3,640 \\
3,410 \\
3,190 \\
2,970 \\
2,810 \\
2,650 \\
2,510 \\
2,380 \\
2,260 \\
2,150 \\
2,060 \\
1,980\end{array}$ \\
\hline & \multicolumn{2}{|c|}{ December 14} & \multicolumn{2}{|c|}{ December 15} & \multicolumn{2}{|c|}{ De cember 16} & \multicolumn{2}{|c|}{ December 17} & \multicolumn{2}{|c|}{ December 18} & \multicolumn{2}{|c|}{ December 19} \\
\hline $\begin{array}{r}2 \\
4 \\
6 \\
8 \\
10 \\
\mathrm{~N} \\
2 \\
4 \\
6 \\
8 \\
10 \\
\mathrm{M}\end{array}$ & $\begin{array}{c}- \\
8.99 \\
8.78 \\
- \\
8.61 \\
- \\
8.44 \\
- \\
8.30 \\
- \\
8.16\end{array}$ & $\begin{array}{c}1, \overline{840} \\
\overline{-} \\
1, \overline{690} \\
\overline{-} \\
1, \overline{5} 70 \\
\overline{-} \\
1,450 \\
\overline{3} \\
1, \overline{3} 70 \\
\overline{1}, \overline{2} 90\end{array}$ & $\begin{array}{c}- \\
8.03 \\
7.90 \\
- \\
7.79 \\
\overline{-} \\
\overline{-}-67 \\
7.58 \\
\overline{7.48}\end{array}$ & $\begin{array}{c}1, \overline{220} \\
\overline{-} \\
1,150 \\
\overline{-} \\
1, \overline{100} \\
1, \overline{0} 40 \\
\overline{0} \\
1,000 \\
\overline{956}\end{array}$ & $\begin{array}{c}7.38 \\
- \\
7.28 \\
- \\
7.20 \\
- \\
7.11 \\
- \\
7.05 \\
- \\
6.96\end{array}$ & $\begin{array}{c}\overline{932} \\
\overline{876} \\
\overline{840} \\
\overline{804} \\
\overline{780} \\
\overline{744}\end{array}$ & $\begin{array}{c}- \\
6.90 \\
- \\
6.83 \\
- \\
6.77 \\
- \\
6.70 \\
- \\
6.64 \\
- \\
6.59\end{array}$ & $\begin{array}{c}7 \overline{20} \\
- \\
693 \\
- \\
67 \overline{1} \\
- \\
6 \overline{4} 6 \\
\overline{624} \\
\overline{607}\end{array}$ & $\begin{array}{c}- \\
6.53 \\
- \\
6.47 \\
- \\
6.42 \\
- \\
6.36 \\
- \\
6.31 \\
- \\
6.26\end{array}$ & $\begin{array}{c}\overline{586} \\
\overline{6} \\
5 \overline{6} \\
- \\
5 \overline{50} \\
- \\
5 \overline{3} 2 \\
\overline{1} \\
5 \overline{17} \\
\overline{502}\end{array}$ & $\begin{array}{c}- \\
6.21 \\
- \\
6.18 \\
- \\
6.13 \\
- \\
6.09 \\
- \\
6.04 \\
- \\
6.00\end{array}$ & $\begin{array}{c}4 \overline{87} \\
- \\
4 \overline{7} 8 \\
- \\
4 \overline{6} 4 \\
\overline{5} \\
4 \overline{3} \\
\overline{4} \\
4 \overline{9} \\
4 \overline{2} 8\end{array}$ \\
\hline & \multicolumn{2}{|c|}{ December 20} & \multicolumn{2}{|c|}{ December 21} & \multicolumn{2}{|c|}{ December 22} & \multicolumn{2}{|c|}{ December 23} & \multicolumn{2}{|c|}{ December 24} & \multicolumn{2}{|c|}{ December 25} \\
\hline $\begin{array}{r}2 \\
4 \\
6 \\
8 \\
10 \\
1 \\
2 \\
4 \\
6 \\
8 \\
10 \\
M\end{array}$ & $\begin{array}{c}- \\
5.95 \\
- \\
5.88 \\
- \\
5.82 \\
- \\
5.78\end{array}$ & $\begin{array}{c}- \\
\overline{4} \\
= \\
- \\
3 \overline{95} \\
- \\
\overline{379} \\
\overline{-} \\
3 \overline{69}\end{array}$ & $\begin{array}{c}- \\
- \\
5.73 \\
- \\
- \\
5.69 \\
- \\
\overline{5} \\
-65 \\
\overline{-} \\
.62\end{array}$ & $\begin{array}{c}- \\
3 \overline{56} \\
- \\
- \\
346 \\
- \\
\overline{3} \\
- \\
- \\
3 \overline{2} 9\end{array}$ & $\begin{array}{c}\overrightarrow{-} \\
5.60 \\
\overline{-} \\
5.57 \\
\pm \\
5.55 \\
\overline{5} \\
5.53\end{array}$ & $\begin{array}{c}\overline{-} \\
3 \overline{24} \\
\overline{-} \\
\overline{3} \\
\overline{-} \\
\overline{3} \\
\overline{-} \\
\overline{307}\end{array}$ & $\begin{array}{c}- \\
- \\
5.51 \\
- \\
\overline{5.49} \\
- \\
\overline{5.46} \\
- \\
\overline{5.44}\end{array}$ & $\begin{array}{c}- \\
\overline{302} \\
- \\
\overline{2} \\
\overline{9} 8 \\
- \\
\overline{-} \\
\overline{9} 1 \\
- \\
\overline{2} \overline{8} 7\end{array}$ & $\begin{array}{c}- \\
- \\
5.40 \\
- \\
- \\
5.39 \\
- \\
- \\
5.38 \\
- \\
5.37\end{array}$ & $\begin{array}{c}\overline{-} \\
\overline{278} \\
\bar{z} \\
\overline{276} \\
\overline{-} \\
2 \overline{74} \\
\overline{-} \\
\overline{2} \overline{7} 1\end{array}$ & $\begin{array}{c}- \\
- \\
5.36 \\
- \\
- \\
5.37 \\
\overline{-} \\
5.38 \\
- \\
- \\
5.35\end{array}$ & $\begin{array}{c}\overline{-} \\
2 \overline{69} \\
\overline{-} \\
2 \overline{7} 1 \\
- \\
\overline{2} \\
- \\
\overline{267}\end{array}$ \\
\hline
\end{tabular}

Supplemental records.- Dec. 11, 8:30 a.m., 24.8 ft., 39,200 sec.-ft. 
Conn Creek near St. Helena, Calif.

Location.- Lat. $38^{\circ} 29^{\prime}$, long. $122^{\circ} 24^{\prime}$, in NW $\frac{2}{4} \mathrm{sec} .3$, T. 7 N., R. 5 W., a quarter of a mile upstream from highway bridge, 4 miles southeast of $\mathrm{St}$. Helena, Napa County, and

6 miles above mouth. Altitude, about 180 feet above mean sea leve?

Drainage area. -52.0 square miles.

Gage-helght record.- Water-stage recorder graph.

Stage-discharge relation.- Defined by current-meter measurements below 1,350 second-

feet; extended to peak stage. Rating curve changed on Dec. 10, 1937.

Maxima.- December 1937: Discharge, about 2,660 second-feet 4:30 a.m. Dec. 11 (gagt helght, 7.90 feet).

1930-November 1937: Discharge, about 4,600 second-feet Feb. 4, 1937 (gage height,

10.3 feet), from rating curve extended above 2,200 second-feet.

Remarks. - Flood run-off not affected by artificial storage or diversion.

Mean daily discharge, in second-feet, November 1937 to January 1938

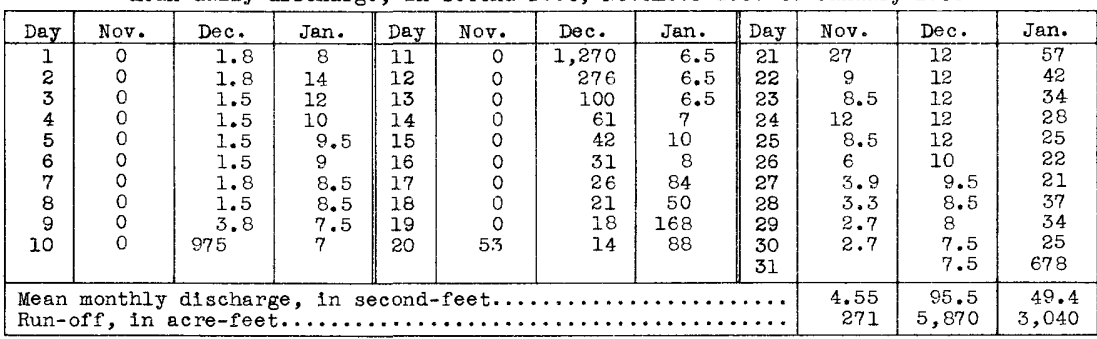

Gage height, in feet, and discharge, in second-feet, at indicated time, 1937

\begin{tabular}{|c|c|c|c|c|c|c|c|c|c|c|c|c|}
\hline \multirow{2}{*}{ 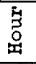 } & Feet & Sec.ft. & Feet & Sec.ft. & Feet & sec.ft. & Feet & sec.ft. & Feet & Sec.ft. & Feet & Sec.ft. \\
\hline & \multicolumn{2}{|c|}{ December 8} & \multicolumn{2}{|c|}{ December 9} & \multicolumn{2}{|c|}{ December 10} & \multicolumn{2}{|c|}{ December 11} & \multicolumn{2}{|c|}{ December 12} & \multicolumn{2}{|c|}{ December 13} \\
\hline $\begin{array}{r}2 \\
4 \\
6 \\
8 \\
10 \\
\mathrm{~N} \\
2 \\
4 \\
6 \\
8 \\
10 \\
M\end{array}$ & $\begin{array}{l}3.05 \\
3.05 \\
3.05 \\
3.05 \\
3.06 \\
3.06 \\
3.06 \\
3.07 \\
3.07 \\
3.07 \\
3.07 \\
3.07\end{array}$ & $\begin{array}{l}1.3 \\
1.3 \\
1.3 \\
1.3 \\
1.5 \\
1.5 \\
1.5 \\
1.8 \\
1.8 \\
1.8 \\
1.8 \\
1.8\end{array}$ & $\begin{array}{l}3.07 \\
3.07 \\
3.07 \\
3.07 \\
3.07 \\
3.08 \\
3.09 \\
3.10 \\
3.11 \\
3.13 \\
3.17 \\
3.24\end{array}$ & $\begin{array}{l}1.8 \\
1.8 \\
1.8 \\
1.8 \\
1.8 \\
2.2 \\
2.7 \\
3.3 \\
3.9 \\
5.5 \\
8.5 \\
16\end{array}$ & $\begin{array}{l}4.89 \\
6.01 \\
7.45 \\
6.40 \\
5.81 \\
6.17 \\
5.63 \\
5.32 \\
5.11 \\
5.22 \\
5.30 \\
5.49\end{array}$ & $\begin{array}{r}520 \\
1,170 \\
2,260 \\
1,440 \\
1,040 \\
1,280 \\
928 \\
746 \\
630 \\
691 \\
735 \\
844\end{array}$ & $\begin{array}{l}6.39 \\
7.49 \\
7.38 \\
7.58 \\
6.66 \\
6.20 \\
5.66 \\
5.35 \\
5.10 \\
4.99 \\
4.77 \\
4.60\end{array}$ & $\begin{array}{r}1,430 \\
2,290 \\
2,200 \\
2,370 \\
1,630 \\
1,300 \\
946 \\
762 \\
625 \\
570 \\
462 \\
385\end{array}$ & $\begin{array}{l}4.56 \\
4.49 \\
4.38 \\
4.61 \\
4.61 \\
4.41 \\
4.27 \\
4.16 \\
4.08 \\
4.01 \\
3.95 \\
3.91\end{array}$ & $\begin{array}{l}367 \\
336 \\
292 \\
390 \\
390 \\
304 \\
252 \\
214 \\
188 \\
167 \\
151 \\
141\end{array}$ & $\begin{array}{l}3.86 \\
3.82 \\
3.78 \\
3.75 \\
3.74 \\
3.72 \\
3.70 \\
3.67 \\
3.63 \\
3.61 \\
3.58 \\
3.56\end{array}$ & $\begin{array}{r}129 \\
120 \\
111 \\
106 \\
104 \\
100 \\
96 \\
91 \\
85 \\
82 \\
77 \\
74\end{array}$ \\
\hline & \multicolumn{2}{|c|}{ December 14} & \multicolumn{2}{|c|}{ December 15} & \multicolumn{2}{|c|}{ December 16} & \multicolumn{2}{|c|}{ December 17} & \multicolumn{2}{|c|}{ December 18} & \multicolumn{2}{|c|}{ December 19} \\
\hline $\begin{array}{r}2 \\
4 \\
6 \\
8 \\
10 \\
\mathrm{~N} \\
2 \\
4 \\
6 \\
8 \\
10 \\
\mathrm{M}\end{array}$ & $\begin{array}{l}- \\
3.52 \\
- \\
3.50 \\
- \\
3.48 \\
\overline{3.46} \\
\overline{3.42} \\
\overline{3.39}\end{array}$ & $\begin{array}{l}\overline{67} \\
\overline{6} \\
64 \\
\overline{61} \\
\overline{5} \\
\overline{5} \\
\overline{53} \\
\overline{49}\end{array}$ & $\begin{array}{c}- \\
3.36 \\
- \\
3.34 \\
- \\
3.35 \\
- \\
3.32 \\
- \\
3.29 \\
- \\
3.27\end{array}$ & $\begin{array}{l}\overline{45} \\
\overline{42} \\
\overline{44} \\
\overline{40} \\
\overline{36} \\
\overline{34}\end{array}$ & $\begin{array}{c}- \\
3.26 \\
- \\
3.24 \\
- \\
3.25 \\
- \\
3.24 \\
- \\
3.22 \\
- \\
3.21\end{array}$ & $\begin{array}{l}\overline{33} \\
\overline{3} \\
\overline{3} \\
\overline{32} \\
\overline{31} \\
\overline{29} \\
\overline{2} \\
\overline{2}\end{array}$ & $\begin{array}{c}- \\
3.19 \\
- \\
3.19 \\
- \\
3.20 \\
3.19 \\
3.16 \\
3.16\end{array}$ & $\begin{array}{l}\overline{26} \\
- \\
26 \\
\overline{27} \\
\overline{2} 6 \\
\overline{2} \\
\overline{2} 4 \\
\overline{2} 4\end{array}$ & $\begin{array}{c}- \\
3.15 \\
- \\
3.13 \\
3.13 \\
- \\
3.13 \\
- \\
3.10 \\
- \\
3.09\end{array}$ & $\begin{array}{l}\overline{23} \\
\overline{21} \\
\overline{21} \\
\overline{2} \\
\overline{2} \\
\overline{19} \\
\overline{18}\end{array}$ & $\begin{array}{c}3.08 \\
- \\
3.08 \\
- \\
3.09 \\
- \\
3.08 \\
- \\
3.07 \\
3.06\end{array}$ & $\begin{array}{l}\overline{18} \\
\overline{18} \\
\overline{18} \\
\overline{18} \\
\overline{1} \\
\overline{17} \\
\overline{16}\end{array}$ \\
\hline M & \multicolumn{2}{|c|}{ December 20} & \multicolumn{2}{|c|}{ Docember 21} & \multicolumn{2}{|c|}{ December 22} & \multicolumn{2}{|c|}{ December 23} & \multicolumn{2}{|c|}{ December 24} & \multicolumn{2}{|c|}{ December 25} \\
\hline $\begin{array}{r}2 \\
4 \\
6 \\
8 \\
10 \\
N \\
2 \\
4 \\
6 \\
8 \\
10 \\
M\end{array}$ & $\begin{array}{l}3.05 \\
\overline{3.04} \\
\overline{3.03} \\
\overline{-} \\
\overline{3.03} \\
\overline{3.01} \\
\overline{3.00}\end{array}$ & $\begin{array}{l}\overline{16} \\
\overline{15} \\
\overline{14} \\
\overline{14} \\
\overline{13} \\
\overline{12}\end{array}$ & $\begin{array}{c}- \\
3.00 \\
- \\
3.00 \\
- \\
3.01 \\
- \\
3.01 \\
- \\
2.99 \\
2.99\end{array}$ & $\begin{array}{l}\overline{12} \\
\overline{12} \\
\overline{13} \\
\overline{13} \\
\overline{13} \\
\overline{12} \\
\overline{12}\end{array}$ & $\begin{array}{c}- \\
- \\
- \\
- \\
2.98 \\
- \\
- \\
- \\
- \\
2.97\end{array}$ & $\begin{array}{l}- \\
- \\
- \\
\overline{12} \\
- \\
- \\
- \\
- \\
\overline{11}\end{array}$ & $\begin{array}{c}- \\
- \\
- \\
- \\
2.98 \\
- \\
- \\
- \\
- \\
2.97\end{array}$ & $\begin{array}{l}- \\
- \\
- \\
- \\
12 \\
- \\
- \\
- \\
- \\
\bar{I}\end{array}$ & $\begin{array}{c}- \\
2.96 \\
- \\
2.96 \\
- \\
2.96 \\
- \\
3.00 \\
- \\
3.00 \\
3.01\end{array}$ & $\begin{array}{l}\overline{10} \\
\overline{10} \\
\overline{10} \\
\overline{12} \\
\overline{12} \\
\overline{13}\end{array}$ & $\begin{array}{c}- \\
3.02 \\
- \\
3.01 \\
- \\
3.00 \\
- \\
2.97 \\
- \\
2.97\end{array}$ & $\begin{array}{l}\overline{14} \\
\overline{13} \\
\overline{12} \\
\overline{11} \\
\overline{11}\end{array}$ \\
\hline
\end{tabular}

Supplemental records.- Dec. I1, $4: 30$ a.m., $7.90 \mathrm{ft.,} 2,660$ sec.-ft. 
Lake Pilisbury at Hullville, Calif.

Location. - Lat. $39^{\circ} 24^{\prime}$, Iong. $122^{\circ} 57^{\prime}$, on line between sec. 14 and 23, T. 18 N., R. 10 W. at Scott Dam on Eel River at Hullville, Lake County, 0.3 mile below Rice Fork. Zero of gage is at mean sea level.

Draingge area. - 288 square miles.

Gage-helght record.- Gage read to tenths dally at 4 p.m. except on days for which no record is sinown.

Remarks.- Flood mun-off partly controlled in reservoir (capacity, 72,040 acre-feet at elevation of crest of spiliway, 1,900 feet; capacity increased by silde and radial gates to 93,720 acre-feet at elevation 1,910 feet). Reservolr was at spillway level at beginning of flood. Maximum elevation, 1,911.8 feet 12:30 a.m. Dec. 11 (contents, 97,980 acre-feet). See record for Eel River at Hullville. Basic data furnished by Pacific Gas \& Electric Co.

Elevation and contents, November 1937 to January 1938

\begin{tabular}{|c|c|c|c|c|c|c|}
\hline \multirow[b]{2}{*}{ Day } & \multicolumn{2}{|c|}{ November } & \multicolumn{2}{|c|}{ December } & \multicolumn{2}{|c|}{ January } \\
\hline & $\begin{array}{c}\text { Elevation } \\
\text { (feet) }\end{array}$ & $\begin{array}{l}\text { Contents } \\
\text { (acre-feet) }\end{array}$ & $\begin{array}{c}\text { Elevation } \\
\text { (feet) }\end{array}$ & $\begin{array}{l}\text { Contents } \\
(\text { acre-feet })\end{array}$ & $\begin{array}{l}\text { Elevation } \\
\text { (feet) }\end{array}$ & $\begin{array}{l}\text { Contents } \\
\text { (acre-feet) }\end{array}$ \\
\hline $\begin{array}{l}1 \\
2 \\
3 \\
4 \\
5\end{array}$ & $\begin{array}{c}1,885.4 \\
- \\
1,884.8 \\
1,884.7 \\
-\end{array}$ & $\begin{array}{c}46,140 \\
- \\
45,220 \\
45,070 \\
-\end{array}$ & $\begin{array}{l}1,900.5 \\
- \\
- \\
- \\
=\end{array}$ & $\begin{array}{l}73,050 \\
= \\
- \\
= \\
-\end{array}$ & $\begin{array}{l}1,900.3 \\
1,900.7 \\
1,900.7 \\
1,900.7 \\
1,900.6\end{array}$ & $\begin{array}{l}72,650 \\
73,460 \\
73,460 \\
73,460 \\
73,260\end{array}$ \\
\hline $\begin{array}{r}6 \\
7 \\
8 \\
9 \\
10\end{array}$ & $\begin{array}{c}- \\
- \\
1,884.6 \\
1,834.4\end{array}$ & $\begin{array}{c}- \\
- \\
44,920 \\
44,610\end{array}$ & $\begin{array}{c}- \\
\overline{-} \\
1,900.2 \\
1,908.3\end{array}$ & $\begin{array}{c}- \\
\overline{-} \\
72,450 \\
90,950\end{array}$ & $\begin{array}{l}1,900.5 \\
1,900.4 \\
1,900.3 \\
1,900.3 \\
1,900.3\end{array}$ & $\begin{array}{l}73,050 \\
72,850 \\
72,650 \\
72,650 \\
72,650\end{array}$ \\
\hline $\begin{array}{l}11 \\
12 \\
13 \\
14 \\
15\end{array}$ & $\begin{array}{l}1,886.3 \\
1,887.1 \\
1,887.2 \\
1,888.0 \\
-\end{array}$ & $\begin{array}{l}47,550 \\
48,820 \\
48,980 \\
50,270 \\
-\end{array}$ & $\begin{array}{l}1,908.9 \\
1,904.5 \\
1,902.9 \\
1,902.1 \\
1,901.7\end{array}$ & $\begin{array}{l}91,180 \\
81,390 \\
77,990 \\
76,320 \\
75,500\end{array}$ & $\begin{array}{l}1,900.3 \\
1,900.2 \\
1,900.2 \\
1,900 \cdot 2 \\
1,900.4\end{array}$ & $\begin{array}{l}72,650 \\
72,450 \\
72,450 \\
72,450 \\
72,850\end{array}$ \\
\hline $\begin{array}{l}16 \\
17 \\
18 \\
19 \\
20\end{array}$ & $\begin{array}{c}1,888.5 \\
= \\
- \\
1,399.0 \\
1,905.6\end{array}$ & $\begin{array}{l}51,090 \\
- \\
\overline{-} \\
70,060 \\
83,770\end{array}$ & $\begin{array}{l}1,901.4 \\
1,901.2 \\
1,901.0 \\
1,900.9 \\
1,900.7\end{array}$ & $\begin{array}{l}74,880 \\
74,470 \\
74,060 \\
73,860 \\
73,460\end{array}$ & $\begin{array}{l}1,900 \cdot 7 \\
1,902.7 \\
1,902 \cdot 1 \\
1,901.8 \\
1,901.5\end{array}$ & $\begin{array}{l}73,460 \\
77,570 \\
76,320 \\
75,700 \\
75,090\end{array}$ \\
\hline $\begin{array}{l}21 \\
22 \\
23 \\
24 \\
25\end{array}$ & $\begin{array}{c}1,903.7 \\
- \\
1,902.6 \\
- \\
=\end{array}$ & $\begin{array}{c}79,680 \\
- \\
77,360 \\
= \\
=\end{array}$ & $\begin{array}{l}1,900.6 \\
1,900.6 \\
1,900.7 \\
1,900.7 \\
1,900.6\end{array}$ & $\begin{array}{l}73,260 \\
73,260 \\
73,460 \\
73,460 \\
73,260\end{array}$ & $\begin{array}{l}1,901.3 \\
1,901.3 \\
1,901.2 \\
1,901 \cdot 1 \\
1,900.9\end{array}$ & $\begin{array}{l}74,680 \\
74,680 \\
74,470 \\
74,270 \\
73,860\end{array}$ \\
\hline $\begin{array}{l}26 \\
27 \\
28 \\
29 \\
30 \\
31\end{array}$ & $\begin{array}{l}- \\
- \\
-\end{array}$ & $\begin{array}{l}- \\
- \\
-\end{array}$ & $\begin{array}{l}1,900 \cdot 5 \\
1,900 \cdot 4 \\
1,900 \cdot 4 \\
1,900 \cdot 4 \\
1,900 \cdot 4 \\
1,900.3\end{array}$ & $\begin{array}{l}73,050 \\
72,850 \\
72,850 \\
72,850 \\
72,850 \\
72,650\end{array}$ & $\begin{array}{l}1,900.8 \\
1,900.8 \\
1,900.8 \\
1,900.8 \\
1,900.8 \\
1,901.7\end{array}$ & $\begin{array}{l}73,660 \\
73,660 \\
73,660 \\
73,660 \\
73,660 \\
75,500\end{array}$ \\
\hline
\end{tabular}

$1803020-39-18$ 
Eel River at Hullville, Calif.

Location. - Lat. $39^{\circ} 24^{\prime}$, long. $122^{\circ} 58^{\prime}$, in $\mathrm{NE}^{\frac{1}{4}} \mathrm{sec} .22$, T. $18 \mathrm{~N} .$, R. $10 \mathrm{~W}$, , half a mile below Scott Dam, half a mile above Soda Creek, and half a mile west of Hullville, Lake County. Altitude, about 1,800 feet above mean sea level.

Drainage area. - 289 square miles.

Gage-helght record. - Water-stage recorder graph except for periods 1:20 p.m. Dec. 1 to $4: 30$ p.m. Dec. 14,9 a.m. Dec. 17 to $10: 15$ a.m. Dec. 20, 4:15 p.m. Dec. 20 to $2: 30$ p.m. Dec. 29, and 3 p.m. Dec. 30 to 1:00 p.m. Jan. 1 , when there was no record. Stage graph for Dec. 1, 14, 17, 20, 29, 30 based on partial recorder graph and gafo readings. Peak stage obtained from floodmarks on left bank.

Stage-discharge relation. - Defined by current-meter measurements below 2,900 secondfeet; extended to peak stage on bas is of computed flows over scott Dam. Rating curve changed at peak stage.

Maxima. - December 1937: Discharge, about 38,000 second-feet about 12:30 a.m. Dec. 11 (gage height, 22.9 feet, from floodmarks).

1922-November 1937: Discharge, about 32,600 second-feet Mar. 26, 1928 (gage height, 21.0 feet, from floodinarks, present datum), from rating curve extended above 3,700 second-feet on basis of computed flow over Scott Dam.

Remarks.- Flood run-off only slightly affected by storase in Lake Pillsbury at Scott Darn. See record for Lake Pilisbury. Discharge for periods Dec. 2-13, 18-19, 21-28, and 31 determined from discharge graph based on partial stage graph, gage readings, peak stage, and record for Eel River at Van Arsdale Dam, near Potter Valley. Monthly summarles adjusted for storage. Most of basic data furnished by Pacific Gas \& Electric Co.

Mean dally discharge, in second-feet, November 1937 to January 1938

\begin{tabular}{|r|r|r|r|r|r|r|r||r|r|r|r|}
\hline Day & Nov. & Dec. & Jan. & Day & Nov. & Dec. & Jan. & Day & Nov. & Dec. & Jan. \\
\hline 1 & 174 & 393 & 459 & 11 & 46 & 29,000 & 354 & 21 & 4,500 & 630 & 1,730 \\
2 & 178 & 350 & 679 & 12 & 31 & 12,000 & 341 & 22 & 2,480 & 560 & 1,620 \\
3 & 178 & 320 & 820 & 13 & 29 & 5,800 & 325 & 23 & 2,390 & 590 & 1,530 \\
4 & 161 & 300 & 711 & 14 & 38 & 3,450 & 325 & 24 & 2,230 & 640 & 1,380 \\
5 & 66 & 280 & 572 & 15 & 34 & 2,280 & 462 & 25 & 1,610 & 640 & 1,230 \\
6 & 31 & 260 & 516 & 16 & 40 & 1,700 & 674 & 26 & 1,210 & 570 & 1,110 \\
7 & 29 & 240 & 480 & 17 & 39 & 1,380 & 3,660 & 27 & 920 & 553 & 1,040 \\
8 & 29 & 220 & 438 & 18 & 35 & 1,180 & 3,330 & 28 & 708 & 500 & 1,040 \\
9 & 55 & 280 & 401 & 19 & 91 & 1,020 & 2,580 & 29 & 572 & 462 & 1,060 \\
10 & 84 & 12,800 & 377 & 20 & 5,390 & 842 & 2,140 & 30 & 466 & 452 & 1,010 \\
&
\end{tabular}




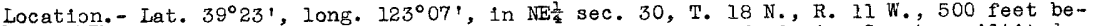
low Van Arsdale Dam and 5 miles north of Potter Valley, Mendocino County. Altitude, about 1,400 feet above mean sea level.

Drainage area.- 347 square miles.

Gage-helght record. - Water-stage recorder graph.

Stage-discharge relation. - Defined by current-meter measurements below 16,100 secondfeet; extended to peak stage on bas is of computed flow over Van Arsdale Dam. Rating curve changed at peak stage.

Maxima. - December 1937: Discharge, 39,300 second-feet 2 a.m. Dec. 11 (gage height, 30.9 feet).

1910-November 1937: Discharge, about 40,000 second-feet Mar. 26, 1928 (gage height, 27.0 feet, from floodmarks), from rating curve extended above 1,100 secondfeet on basis of computed flow over Van Arsdale Dam.

Remarks.- Flood mun-off affected by storage in Lake Plllsbury and Van Arsdale Reservoir, and by diversion to Potter Valley power house. Monthly summaries adjusted for diversion only. Part of basic data furnished by Pacific Gas \& Electric Co.

\begin{tabular}{|c|c|c|c|c|c|c|c|c|c|c|c|}
\hline Day & Nov. & Dec. & Jan. & Day & Nov. & Dec. & Jan. & Day & Nov. & Dec. & Jan. \\
\hline $\begin{array}{r}1 \\
2 \\
3 \\
4 \\
5 \\
6 \\
7 \\
8 \\
9 \\
10\end{array}$ & $\begin{array}{c}1.0 \\
1.1 \\
1.6 \\
2.6 \\
2.6 \\
80 \\
34 \\
30 \\
17 \\
2.4\end{array}$ & $\begin{array}{r}270 \\
379 \\
200 \\
166 \\
153 \\
97 \\
81 \\
66 \\
109 \\
13,300\end{array}$ & $\begin{array}{l}264 \\
494 \\
692 \\
580 \\
494 \\
427 \\
388 \\
355 \\
262 \\
295\end{array}$ & $\begin{array}{l}11 \\
12 \\
13 \\
14 \\
15 \\
16 \\
17 \\
18 \\
19 \\
20\end{array}$ & \begin{tabular}{|c|}
3.4 \\
2.3 \\
2.2 \\
2.6 \\
4.6 \\
378 \\
710 \\
204 \\
547 \\
7,100
\end{tabular} & $\begin{array}{r}31,100 \\
13,300 \\
6,610 \\
4,020 \\
2,730 \\
2,060 \\
1,560 \\
1,220 \\
997 \\
816\end{array}$ & $\begin{array}{r}276 \\
256 \\
246 \\
248 \\
379 \\
639 \\
3,880 \\
3,500 \\
2,730 \\
2,380\end{array}$ & $\begin{array}{l}21 \\
22 \\
23 \\
24 \\
25 \\
26 \\
27 \\
28 \\
29 \\
30 \\
31 \\
\end{array}$ & $\begin{array}{r}5,880 \\
2,930 \\
2,930 \\
2,670 \\
1,930 \\
1,320 \\
952 \\
728 \\
520 \\
273\end{array}$ & $\begin{array}{l}692 \\
616 \\
580 \\
461 \\
580 \\
511 \\
494 \\
324 \\
325 \\
370 \\
373 \\
\end{array}$ & $\begin{array}{r}1,830 \\
1,620 \\
1,500 \\
1,220 \\
1,020 \\
882 \\
752 \\
752 \\
794 \\
712 \\
1,920 \\
\end{array}$ \\
\hline \multicolumn{9}{|c|}{$\begin{array}{l}\text { Mean monthly discharge, ir } \\
\text { Mean monthly discharge, ir } \\
\text { Run-off, in acre-feet (ad }\end{array}$} & $\begin{array}{r}975 \\
1,106 \\
65,840 \\
\end{array}$ & $\begin{array}{r}2,728 \\
2,889 \\
177,600 \\
\end{array}$ & $\begin{array}{r}1,025 \\
1,187 \\
72,960\end{array}$ \\
\hline
\end{tabular}

Gage height, in feet, and discharge, in second-feet, at indicated time, 1937

\begin{tabular}{|c|c|c|c|c|c|c|c|c|c|c|c|c|}
\hline \multirow{2}{*}{$\begin{array}{l}9 \\
3 \\
0 \\
3\end{array}$} & Feet & Sec.rt. & Feet & Sec.ft. & Feet & Sec.ft. & Feet & sec.ft. & Feet & Sec.ft. & Feet & Sec.ft. \\
\hline & \multicolumn{2}{|c|}{ December 8} & \multicolumn{2}{|c|}{ December 9} & \multicolumn{2}{|c|}{ December 10} & \multicolumn{2}{|c|}{ December 11} & \multicolumn{2}{|c|}{ December 12} & \multicolumn{2}{|c|}{ December 13} \\
\hline $\begin{array}{r}2 \\
4 \\
6 \\
8 \\
10 \\
\mathrm{~N} \\
2 \\
4 \\
6 \\
8 \\
10 \\
\mathrm{M}\end{array}$ & $\begin{array}{l}\overline{-} \\
\overline{4.30} \\
\overline{-} \\
\overline{4.29} \\
\overline{-} \\
4.28 \\
\overline{-} \\
\overline{4.24}\end{array}$ & $\begin{array}{l}\overline{-} \\
\overline{67} \\
- \\
\overline{66} \\
- \\
\overline{64} \\
\overline{-} \\
\overline{5} 9\end{array}$ & $\begin{array}{l}4.24 \\
4.23 \\
4.22 \\
4.21 \\
4.24 \\
4.23 \\
4.24 \\
4.36 \\
4.46 \\
4.71 \\
5.19 \\
6.39\end{array}$ & \begin{tabular}{|r|}
59 \\
57 \\
56 \\
54 \\
59 \\
57 \\
59 \\
77 \\
94 \\
144 \\
259 \\
652 \\
\end{tabular} & $\begin{array}{r}7.83 \\
9.15 \\
10.61 \\
12.24 \\
13.65 \\
16.78 \\
19.10 \\
20.75 \\
22.90 \\
25.90 \\
28.95 \\
30.12\end{array}$ & \begin{tabular}{|r|}
1,200 \\
1,960 \\
3,120 \\
4,720 \\
6,340 \\
10,800 \\
14,600 \\
17,600 \\
21,700 \\
27,900 \\
34,700 \\
37,400 \\
\end{tabular} & \begin{tabular}{|l|}
30.90 \\
30.58 \\
30.30 \\
29.46 \\
28.63 \\
27.80 \\
26.82 \\
25,85 \\
24.83 \\
23.70 \\
22.79 \\
21.85
\end{tabular} & $\begin{array}{l}39,300 \\
38,500 \\
37,800 \\
35,900 \\
33,900 \\
32,100 \\
29,900 \\
27,800 \\
25,600 \\
23,300 \\
21,500 \\
19,600\end{array}$ & $\begin{array}{l}21.03 \\
20.39 \\
19.82 \\
19.22 \\
18.63 \\
18.09 \\
17.49 \\
16.95 \\
16.48 \\
16.08 \\
15.77 \\
15.45\end{array}$ & $\begin{array}{r}18,100 \\
16,900 \\
15,900 \\
14,800 \\
13,900 \\
12,900 \\
11,900 \\
11,100 \\
10,300 \\
9,690 \\
9,240 \\
8,790\end{array}$ & $\begin{array}{l}15.11 \\
14.79 \\
14.50 \\
14.18 \\
13.91 \\
13.70 \\
13.49 \\
13.30 \\
13.10 \\
12.93 \\
12.74 \\
12.58\end{array}$ & $\begin{array}{l}8,310 \\
7,870 \\
7,460 \\
7,010 \\
6,630 \\
6,380 \\
6,130 \\
5,900 \\
5,600 \\
5,460 \\
5,230 \\
5,040\end{array}$ \\
\hline & \multicolumn{2}{|c|}{ December 14} & \multicolumn{2}{|c|}{ December 15} & \multicolumn{2}{|c|}{ December 16} & \multicolumn{2}{|c|}{ December 17} & \multicolumn{2}{|c|}{ December 18} & \multicolumn{2}{|c|}{ December 19} \\
\hline $\begin{array}{r}2 \\
4 \\
6 \\
8 \\
10 \\
\mathrm{~N} \\
2 \\
4 \\
6 \\
8 \\
10 \\
\mathrm{M}\end{array}$ & $\begin{array}{c}12.24 \\
- \\
11.94 \\
11.68 \\
- \\
11.35 \\
-\overline{-} \\
11.14 \\
10.94\end{array}$ & $\begin{array}{c}\text { 4, } 630 \\
\overline{-} \\
4, \overline{2} 80 \\
\overline{-} \\
4,000 \\
\overline{-} \\
3,650 \\
\overline{3}, \overline{440} \\
3, \overline{2} 40\end{array}$ & $\begin{array}{c}- \\
10.72 \\
- \\
10.57 \\
- \\
10.40 \\
- \\
10.24 \\
- \\
10.09 \\
-\overline{-} \\
9.94\end{array}$ & $\begin{array}{c}3, \overline{020} \\
\overline{8} \\
2, \overline{8} 80 \\
\overline{2} \\
2, \overline{7} 30 \\
\overline{-} \\
2, \overline{5} 90 \\
\overline{-} \\
2,450 \\
\overline{2}, \overline{330}\end{array}$ & $\begin{array}{c}- \\
9.82 \\
- \\
9.67 \\
- \\
9.55 \\
- \\
9.43 \\
- \\
9.30 \\
- \\
9.20\end{array}$ & $\begin{array}{c}2, \overline{240} \\
\overline{2} \\
2, \overline{120} \\
\overline{2} \\
2, \overline{0} 0 \\
\overline{-} \\
1, \overline{920} \\
\overline{8} \\
1, \overline{83} 0 \\
\overline{1}, \overline{7} 60\end{array}$ & $\begin{array}{c}- \\
- \\
9.04 \\
- \\
- \\
8.89 \\
- \\
8.74 \\
- \\
8.59\end{array}$ & $\begin{array}{c}- \\
\overline{-} \\
1,650 \\
- \\
\overline{-} \\
1,550 \\
- \\
\overline{4} \\
1,460 \\
- \\
\overline{1,} \\
1,380\end{array}$ & $\begin{array}{l}\overline{-} \\
8.44 \\
= \\
8.30 \\
= \\
8.20 \\
= \\
\overline{8.08}\end{array}$ & $\begin{array}{c}- \\
\overline{-} \\
1,300 \\
- \\
- \\
1,220 \\
- \\
\overline{1} \\
1,10 \\
- \\
1, \overline{110}\end{array}$ & $\begin{array}{c}- \\
\overline{7.96} \\
- \\
\overline{7.85} \\
\vdots \\
7.76 \\
- \\
\overline{7.65}\end{array}$ & $\begin{array}{c}\overline{-} \\
1, \overline{0} 0 \\
\overline{-} \\
\overline{9} \\
\overline{-} \\
\bar{y} \\
\overline{9} \\
\overline{-} \\
\overline{9} \\
\end{array}$ \\
\hline & \multicolumn{2}{|c|}{ December 20} & \multicolumn{2}{|c|}{ December 21} & \multicolumn{2}{|c|}{ De cember 22} & \multicolumn{2}{|c|}{ December 23} & \multicolumn{2}{|c|}{ December 24} & \multicolumn{2}{|c|}{ December 25} \\
\hline $\begin{array}{r}2 \\
4 \\
6 \\
8 \\
10 \\
N \\
2 \\
4 \\
6 \\
8 \\
10 \\
M\end{array}$ & $\begin{array}{l}\overline{-} \\
7.53 \\
= \\
\overline{7.44} \\
= \\
\overline{7.37} \\
= \\
\overline{7.30}\end{array}$ & $\begin{array}{c}- \\
- \\
851 \\
- \\
- \\
812 \\
- \\
\overline{8} \\
- \\
\overline{752}\end{array}$ & $\begin{array}{c}- \\
\overline{7.23} \\
\overline{-} \\
7.16 \\
\overline{-} \\
7.10 \\
\overline{-} \\
7.05\end{array}$ & $\begin{array}{c}\overline{-} \\
\overline{724} \\
- \\
- \\
6 \overline{96} \\
- \\
- \\
672 \\
- \\
\overline{653}\end{array}$ & $\begin{array}{c}- \\
\overline{6.99} \\
- \\
\overline{6.98} \\
- \\
\overline{6.96} \\
- \\
6.91\end{array}$ & $\begin{array}{c}\overline{-} \\
\overline{630} \\
\overline{-} \\
\overline{627} \\
\overline{-} \\
6 \overline{0} \\
\overline{-} \\
\overline{0} \\
\overline{0} 2\end{array}$ & $\begin{array}{c}- \\
- \\
6.86 \\
- \\
\overline{-} \\
- \\
- \\
6.80 \\
- \\
6.79\end{array}$ & $\begin{array}{c}- \\
\overline{8} \\
\overline{-} \\
\overline{5} \\
\overline{5} 6 \\
\overline{-} \\
5 \overline{62} \\
\overline{-} \\
\overline{5}\end{array}$ & $\begin{array}{l}6.79 \\
6.80 \\
6.80 \\
6.80 \\
6.80 \\
6.81 \\
6.81 \\
6.25 \\
5.66 \\
5.67 \\
5.70 \\
6.89\end{array}$ & $\begin{array}{l}559 \\
562 \\
562 \\
562 \\
562 \\
566 \\
566 \\
385 \\
220 \\
222 \\
230 \\
594\end{array}$ & $\begin{array}{c}- \\
6.97 \\
- \\
6.90 \\
- \\
6.84 \\
- \\
6.76 \\
- \\
6.70 \\
- \\
6.65\end{array}$ & $\begin{array}{c}\overline{623} \\
\overline{5} \\
\overline{98} \\
\overline{576} \\
\overline{5} \\
\overline{4} 8 \\
\overline{5} \overline{8} \\
\overline{511}\end{array}$ \\
\hline
\end{tabular}


Iocation. - Lat. $40^{\circ} 29^{\prime}$, lone. $124^{\circ} 06^{\prime}$, in sec. 7, T. I. N., R. 1 E., at Wildwood Bridge, half a mile north of Scotis, Humbidt County. Altitude, about 50 feet above mean ser level.

Drainage area. - 3,070 square miles.

Gare-height record. - Two gase readings daily; occasional extra readings during high" stages. Graph constmuted from gage readings for periods Nov. 16-27, Dec. 10-16. Stare-discharge reletion. - Defined by current-meter measurements below 49,000 secondfeet; extended to perk stage on basis of area-velocity study.

Maxime - December 1937: Discharge, 257,000 second-feet 10:45 g.m. Dec. 1. (gage height, 55.1 feet, from gage reading).

1911-15; 1916-November 1937: Discharge observed, about 290,000 second-feet Feb. 2, 1915 (gage helght, 55.5 feet, from nonrecording gage), from rating curve extended above 114,000 second-feet.

Remarks.- Flood mun-off not materially affected by artificial storage or diversion.

Mean daily discharge, in second-feet, November 1937 to January 1938

\begin{tabular}{|c|c|c|c|c|c|c|c|c|c|c|c|}
\hline Day & Nov. & Dec. & Jan. & Day & Nov. & Dec. & Jan. & Day & Nov. & Dec. & Jan. \\
\hline 1 & 194 & 8,340 & 6,940 & 1.1. & 4,900 & 240,000 & 4,200 & 21 & 91,100 & 8,060 & 26,300 \\
\hline 2 & 203 & 7,220 & 8,060 & 12 & 11,500 & 152,000 & 3,980 & 22 & 41,000 & 7,220 & 22,800 \\
\hline 3 & 240 & 6,420 & 11,200 & 13 & 6,420 & 72,100 & 3,760 & 23 & 42,900 & 6,680 & 23,500 \\
\hline 4 & 234 & 5,640 & 9,460 & 14 & $9,1.80$ & 41,500 & 3,760 & 24 & $4.9,800$ & 6,420 & 15,700 \\
\hline 5 & 234 & 5,140 & 7,500 & 15 & 14,700 & 27,900 & 8,060 & 25 & 35,600 & 6,680 & 14,100 \\
\hline 6 & 212 & 4,900 & 6,680 & 16 & 12,500 & 20,900 & 14, & 26 & 25,100 & 940 & 12,800 \\
\hline 7 & 223 & 4,660 & 6,420 & 17 & 56,200 & 16,000 & 35 & 27 & 17,700 & 6,680 & 10,900 \\
\hline 8 & 212 & 4,420 & 5,640 & 18 & 36,500 & 13,100 & 41 & 28 & 13,700 & 6,630 & 10,300 \\
\hline 9 & 316 & 3,980 & 5, & 19 & 43,400 & 10,900 & 34 & 29 & 11,200 & 680 & $1.4,700$ \\
\hline 10 & 574 & 50,800 & 4,660 & 20 & 163,000 & 9,180 & 36,000 & 30 & 9,460 & 6,820 & 12,500 \\
\hline & & & & & & & & & & & \\
\hline \multirow{2}{*}{\multicolumn{9}{|c|}{ Mean monthly discharge, in second-feet................. }} & & 25,190 & 14,130 \\
\hline & & & & & & & & & & 1,549 & 868.9 \\
\hline
\end{tabular}

Gage height, in feet, and discharge, in second-feet, at indicated time, 1937

\begin{tabular}{|c|c|c|c|c|c|c|c|c|c|c|c|c|}
\hline \multirow{2}{*}{ 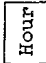 } & Feet & Sec.ft. & Feet & sec.ft. & Feet & Sec.ft. & Feet & Sec.ft. & Feet & Sec.ft. & Feet & Sec.ft. \\
\hline & \multicolumn{2}{|c|}{ December 8} & \multicolumn{2}{|c|}{ December 9} & \multicolumn{2}{|c|}{ December 10} & \multicolumn{2}{|c|}{ December 11} & \multicolumn{2}{|c|}{ December 12} & \multicolumn{2}{|c|}{ December 13} \\
\hline \multirow[t]{2}{*}{$\begin{array}{r}2 \\
4 \\
6 \\
8 \\
10 \\
\mathrm{~N} \\
2 \\
4 \\
6 \\
8 \\
10 \\
\mathrm{M}\end{array}$} & & & & & $\begin{array}{l}12.65 \\
12.75 \\
13.0 \\
13.3 \\
1.4 .5 \\
17.0 \\
21.3 \\
26.7 \\
33.25 \\
37.9 \\
42.5 \\
46.1\end{array}$ & $\begin{array}{r}4,310 \\
4,540 \\
5,140 \\
5,900 \\
9,180 \\
17,000 \\
33,800 \\
60,300 \\
99,000 \\
129,000 \\
160,000 \\
186,000\end{array}$ & $\begin{array}{l}49.0 \\
51.4 \\
53.5 \\
54.8 \\
55.1 \\
55.1 \\
55.1 \\
54.8 \\
54.3 \\
53.1 \\
51.7 \\
50.2\end{array}$ & $\begin{array}{l}208,000 \\
227,000 \\
244,000 \\
255,000 \\
257,000 \\
257,000 \\
257,000 \\
255,000 \\
251,000 \\
241,000 \\
230,000 \\
218,000\end{array}$ & $\begin{array}{l}48.7 \\
47.1 \\
45.4 \\
44.1 \\
42.7 \\
41.2 \\
39.6 \\
38.3 \\
37.0 \\
35.9 \\
34.8 \\
33.7\end{array}$ & $\begin{array}{l}206,000 \\
194,000 \\
181,000 \\
172,000 \\
162,000 \\
151,000 \\
140,000 \\
132,000 \\
123,000 \\
116,000 \\
109,000 \\
102,000\end{array}$ & $\begin{array}{l}32.7 \\
31.7 \\
30.65 \\
29.65 \\
29.0 \\
28.3 \\
27.6 \\
27.2 \\
26.7 \\
26.25 \\
25.8 \\
25.45\end{array}$ & $\begin{array}{l}95,500 \\
89,400 \\
83,100 \\
77,100 \\
73,300 \\
69,200 \\
65,300 \\
63,000 \\
60,300 \\
57,800 \\
55,500 \\
53,600\end{array}$ \\
\hline & \multicolumn{2}{|c|}{ Decomber 14} & \multicolumn{2}{|c|}{ December 15} & \multicolumn{2}{|c|}{ December 16} & \multicolumn{2}{|c|}{ December 17} & \multicolumn{2}{|c|}{ December 18} & \multicolumn{2}{|c|}{ December 19} \\
\hline $\begin{array}{r}2 \\
4 \\
6 \\
8 \\
10 \\
N \\
2 \\
4 \\
6 \\
8 \\
10 \\
M\end{array}$ & $\begin{array}{l}25.0 \\
24.65 \\
24.2 \\
23.85 \\
23.4 \\
22.85 \\
22.5 \\
22.05 \\
21.7 \\
21.5 \\
21.2 \\
21.0\end{array}$ & $\begin{array}{l}51,300 \\
49,600 \\
47,300 \\
45,600 \\
43,400 \\
40,800 \\
39,200 \\
37,100 \\
35,600 \\
34,700 \\
33,400 \\
32,500\end{array}$ & $\begin{array}{c}20.6 \\
- \\
20.45 \\
- \\
19.9 \\
19.5 \\
- \\
19.15 \\
- \\
18.8\end{array}$ & $\begin{array}{c}- \\
30,800 \\
- \\
30,100 \\
- \\
27,900 \\
2 \overline{-} 300 \\
\tilde{2} \\
24,900 \\
23,500\end{array}$ & $\begin{array}{c}18.55 \\
- \\
18.3 \\
- \\
18.0 \\
- \\
17.7 \\
- \\
17.6 \\
-\overline{-}\end{array}$ & $\begin{array}{c}22^{-}, 600 \\
- \\
21,600 \\
- \\
20,500 \\
- \\
19,400 \\
- \\
19,100 \\
18,700\end{array}$ & & & & & & \\
\hline
\end{tabular}

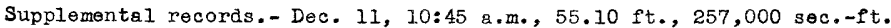


Location. - Lat. $41^{\circ} 23^{\prime}$, long. $123^{\circ} 29^{\prime}$, in $\sqrt{E} \pi_{4}$ sec. 4, T. 11 N., R. 6 E., 300 feet below mouth of Saimon River and 1 mile west of Somesbar post office, Siskiyou County. Altitude, about 450 feet above mean sea level.

Drainage area.- 8,480 square miles.

Gage-helght record.- Water-stage recorder graph.

Stage-discharge relation.- Defined by current-meter measurenents below 49,000 secondfeet; extended to peak stage on bas 1s of area-velocity study. Rating curve changed at peak stage.

Maxima.- December 1937: Discharge, 73,700 second-feet 3:30 p.m. Dec. 11 (gage helght, 32.3 feet).

1927-November 1937: Discharge, 60,300 second-feet Mar. 26, 1928 (gage helght, 27.9 feet), from rating curve extended above 49,000 second-feet on basis of area-

velocity study. Maximum stage known, about 50.8 feet Feb. 21, 1927, from floodmarks (discharge not determined).

Remarks.- Flood run-off somewhat affected by artificial storage and diversions.

Mean daily discharge, in second-feet, November 1937 to January 1938

\begin{tabular}{|c|c|c|c|c|c|c|c|c|c|c|c|}
\hline Day & Nov. & Dec. & Jan. & Day & Nov. & Dec. & Jan. & Day & Nov. & Dec. & Jan. \\
\hline $\begin{array}{r}1 \\
2 \\
3 \\
4 \\
5 \\
6 \\
7 \\
8 \\
9 \\
10\end{array}$ & $\begin{array}{l}1,900 \\
2,740 \\
2,780 \\
2,780 \\
2,780 \\
2,780 \\
2,560 \\
1,780 \\
2,360 \\
6,090\end{array}$ & $\begin{array}{r}8,160 \\
7,600 \\
7,190 \\
6,670 \\
5,300 \\
5,080 \\
5,780 \\
5,540 \\
5,540 \\
27,000\end{array}$ & $\begin{array}{r}10,300 \\
9,130 \\
8,850 \\
9,130 \\
8,850 \\
8,290 \\
7,730 \\
7,470 \\
6,820 \\
6,070\end{array}$ & $\begin{array}{l}11 \\
12 \\
13 \\
14 \\
15 \\
16 \\
17 \\
18 \\
19 \\
20\end{array}$ & $\begin{array}{r}10,000 \\
6,150 \\
6,020 \\
11,300 \\
7,880 \\
8,720 \\
12,800 \\
11,800 \\
35,500 \\
56,800\end{array}$ & $\begin{array}{r}68,600 \\
57,000 \\
33,700 \\
25,600 \\
21,000 \\
16,300 \\
13,100 \\
11,300 \\
9,410 \\
8,570\end{array}$ & $\begin{array}{r}6,560 \\
6,820 \\
6,560 \\
10,000 \\
15,800 \\
14,000 \\
14,000 \\
18,300 \\
16,600 \\
14,900\end{array}$ & $\begin{array}{l}21 \\
22 \\
23 \\
24 \\
25 \\
26 \\
27 \\
28 \\
29 \\
30 \\
31\end{array}$ & $\begin{array}{r}28,900 \\
18,500 \\
25,300 \\
21,300 \\
16,700 \\
14,600 \\
12,600 \\
10,800 \\
9,520 \\
8,720\end{array}$ & $\begin{array}{r}8,570 \\
8,290 \\
8,010 \\
8,010 \\
7,470 \\
6,430 \\
6,820 \\
8,010 \\
7,730 \\
13,700 \\
12,500\end{array}$ & $\begin{array}{l}14,300 \\
20,700 \\
21,000 \\
16,600 \\
15,500 \\
14,900 \\
13,400 \\
13,400 \\
13,400 \\
11,900 \\
11,900\end{array}$ \\
\hline & & & & & & & & & $\begin{array}{l}080 \\
900\end{array}$ & $\begin{array}{r}14,320 \\
880,600\end{array}$ & $\begin{array}{r}12,040 \\
740,200\end{array}$ \\
\hline
\end{tabular}

Gage helght, in feet, and discharge, in second-feet, at indicated time, 1937

\begin{tabular}{|c|c|c|c|c|c|c|c|c|c|c|c|c|}
\hline \multirow{2}{*}{ 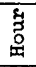 } & Feet & Sec.ft. & Feet & Sec.ft. & Feet & Sec.ft. & Feet & Sec.ft. & Feet & Sec.ft. & Feet & Sec.ft. \\
\hline & \multicolumn{2}{|c|}{ December 8} & \multicolumn{2}{|c|}{ December 9} & \multicolumn{2}{|c|}{ December 10} & \multicolumn{2}{|c|}{ December 11} & \multicolumn{2}{|c|}{ December 12} & \multicolumn{2}{|c|}{ December 13} \\
\hline \multirow[t]{2}{*}{$\begin{array}{r}2 \\
4 \\
6 \\
8 \\
10 \\
\mathrm{~N} \\
2 \\
4 \\
6 \\
8 \\
10 \\
\mathrm{H}\end{array}$} & $\begin{array}{l}7.75 \\
7.61 \\
7.50 \\
7.41 \\
7.33 \\
7.29 \\
7.83 \\
7.87 \\
7.92 \\
7.95 \\
7.86 \\
7.76\end{array}$ & $\begin{array}{l}5,660 \\
5,320 \\
5,080 \\
4,880 \\
4,710 \\
4,620 \\
5,850 \\
5,950 \\
6,070 \\
6,150 \\
5,920 \\
5,680\end{array}$ & $\begin{array}{l}7.68 \\
7.58 \\
7.47 \\
7.37 \\
7.30 \\
7.50 \\
7.86 \\
7.85 \\
7.96 \\
8.00 \\
7.94 \\
7.90\end{array}$ & $\begin{array}{l}5,490 \\
5,260 \\
5,010 \\
4,790 \\
4,640 \\
5,080 \\
5,920 \\
5,900 \\
6,180 \\
6,280 \\
6,120 \\
6,020\end{array}$ & \begin{tabular}{|r|}
7.96 \\
8.15 \\
8.55 \\
9.65 \\
11.40 \\
14.40 \\
16.60 \\
18.90 \\
21.90 \\
25.00 \\
27.40 \\
28.83
\end{tabular} & $\begin{array}{r}6,180 \\
6,670 \\
7,740 \\
10,700 \\
15,100 \\
22,900 \\
28,800 \\
35,100 \\
43,500 \\
52,200 \\
59,000 \\
63,300\end{array}$ & $\begin{array}{l}29.10 \\
29.40 \\
29.75 \\
30.00 \\
30.30 \\
31.30 \\
32.10 \\
32.28 \\
31.65 \\
30.95 \\
30.48 \\
30.30\end{array}$ & $\begin{array}{l}64,100 \\
65,000 \\
66,000 \\
66,800 \\
67,700 \\
70,700 \\
73,100 \\
73,600 \\
71,800 \\
69,600 \\
68,200 \\
67,700\end{array}$ & $\begin{array}{l}30.00 \\
29.70 \\
29.40 \\
28.70 \\
27.88 \\
27.10 \\
26.10 \\
25.25 \\
24.25 \\
23.20 \\
22.30 \\
21.60\end{array}$ & $\begin{array}{l}66,800 \\
65,900 \\
65,000 \\
62,900 \\
60,400 \\
58,100 \\
55,300 \\
52,900 \\
50,100 \\
47,200 \\
44,600 \\
42,700\end{array}$ & $\begin{array}{l}20.90 \\
20.30 \\
19.65 \\
19.15 \\
18.60 \\
18.05 \\
17.60 \\
17.30 \\
16.95 \\
16.55 \\
16.10 \\
15.75\end{array}$ & $\begin{array}{l}40,700 \\
39,000 \\
37,200 \\
35,800 \\
34,300 \\
32,700 \\
31,500 \\
30,600 \\
29,700 \\
28,500 \\
27,300 \\
26,300\end{array}$ \\
\hline & \multicolumn{2}{|c|}{ December 14} & \multicolumn{2}{|c|}{ December 15} & \multicolumn{2}{|c|}{ December 16} & \multicolumn{2}{|c|}{ December 17} & \multicolumn{2}{|c|}{ December 18} & \multicolumn{2}{|c|}{ December 19} \\
\hline \multirow[t]{2}{*}{\begin{tabular}{r|}
2 \\
4 \\
6 \\
8 \\
10 \\
$\mathrm{~N}$ \\
2 \\
4 \\
6 \\
8 \\
10 \\
$\mathrm{M}$ \\
\end{tabular}} & $\begin{array}{l}15.35 \\
15.92 \\
16.15 \\
16.00 \\
15.75 \\
15.73 \\
15.62 \\
15.45 \\
15.20 \\
14.95 \\
14.50 \\
14.20\end{array}$ & $\begin{array}{l}25,200 \\
26,800 \\
27,400 \\
27,000 \\
26,300 \\
26,200 \\
25,900 \\
25,500 \\
24,800 \\
24,100 \\
22,800 \\
22,000\end{array}$ & $\begin{array}{l}14.00 \\
13.75 \\
14.10 \\
14.25 \\
14.05 \\
14.10 \\
13.98 \\
13.85 \\
13.65 \\
13.40 \\
13.15 \\
12.75\end{array}$ & $\begin{array}{l}21,500 \\
20,800 \\
21,800 \\
22,200 \\
21,600 \\
21,800 \\
21,400 \\
21,100 \\
20,600 \\
18,900 \\
19,200 \\
18,100\end{array}$ & $\begin{array}{l}12.50 \\
12.35 \\
12.30 \\
12.75 \\
12.50 \\
12.35 \\
11.87 \\
11.82 \\
11.66 \\
11.55 \\
11.35 \\
11.15\end{array}$ & $\begin{array}{l}17,400 \\
17,000 \\
16,900 \\
18,100 \\
17,400 \\
17,000 \\
15,700 \\
15,500 \\
15,100 \\
14,700 \\
14,200 \\
13,600\end{array}$ & $\begin{array}{l}11.03 \\
10.90 \\
11.35 \\
11.35 \\
11.25 \\
11.18 \\
11.05 \\
11.00 \\
10.90 \\
10.75 \\
10.56 \\
10.45\end{array}$ & $\begin{array}{l}13,200 \\
12,800 \\
14,200 \\
14,200 \\
13,800 \\
13,600 \\
13,200 \\
13,100 \\
12,800 \\
12,400 \\
11,800 \\
11,400\end{array}$ & $\begin{array}{l}10.40 \\
10.25 \\
10.20 \\
10.40 \\
10.50 \\
10.50 \\
10.59 \\
10.58 \\
10.40 \\
10.38 \\
10.25 \\
10.15\end{array}$ & $\begin{array}{l}11,300 \\
10,800 \\
10,600 \\
11,300 \\
11,600 \\
11,600 \\
11,900 \\
11,800 \\
11,300 \\
11,200 \\
10,800 \\
10,500\end{array}$ & $\begin{array}{l}9.98 \\
9.86 \\
9.80 \\
9.76 \\
9.74 \\
9.71 \\
9.68 \\
9.63 \\
9.86 \\
9.98 \\
9.83 \\
9.71\end{array}$ & $\begin{array}{l}9,950 \\
9,590 \\
9,410 \\
9,300 \\
9,240 \\
9,160 \\
9,070 \\
8,930 \\
9,590 \\
9,950 \\
9,500 \\
9,160\end{array}$ \\
\hline & \multicolumn{2}{|c|}{ December 20} & \multicolumn{2}{|c|}{ December 21} & \multicolumn{2}{|c|}{ December 22} & \multicolumn{2}{|c|}{ December 23} & \multicolumn{2}{|c|}{ December 24} & \multicolumn{2}{|c|}{ December 25} \\
\hline $\begin{array}{r}2 \\
4 \\
6 \\
8 \\
10 \\
\mathrm{~N} \\
2 \\
4 \\
6 \\
8 \\
10 \\
\mathrm{M}\end{array}$ & $\begin{array}{l}9.64 \\
9.56 \\
9.51 \\
9.48 \\
9.45 \\
9.42 \\
9.39 \\
9.37 \\
9.34 \\
9.45 \\
9.62 \\
9.55\end{array}$ & $\begin{array}{l}8,960 \\
8,740 \\
8,600 \\
8,510 \\
8,430 \\
8,320 \\
8,260 \\
8,210 \\
8,120 \\
8,430 \\
8,900 \\
8,710\end{array}$ & $\begin{array}{l}9.43 \\
9.34 \\
9.27 \\
9.23 \\
9.68 \\
9.66 \\
9.68 \\
9.72 \\
9.72 \\
9.65 \\
9.53 \\
9.38\end{array}$ & $\begin{array}{l}8,370 \\
8,120 \\
7,930 \\
7,810 \\
9,070 \\
9,020 \\
9,070 \\
9,190 \\
9,190 \\
8,990 \\
8,650 \\
8,230\end{array}$ & $\begin{array}{l}9.23 \\
9.14 \\
9.07 \\
9.03 \\
9.48 \\
9.53 \\
9.58 \\
9.70 \\
9.68 \\
9.60 \\
9.50 \\
9.40\end{array}$ & $\begin{array}{l}7,810 \\
7,570 \\
7,390 \\
7,290 \\
8,510 \\
8,650 \\
8,790 \\
9,130 \\
9,070 \\
8,850 \\
8,570 \\
8,290\end{array}$ & $\begin{array}{l}9.26 \\
9.10 \\
9.00 \\
8.93 \\
9.48 \\
9.46 \\
9.50 \\
9.53 \\
9.50 \\
9.40 \\
9.33 \\
9.23\end{array}$ & $\begin{array}{l}7,900 \\
7,470 \\
7,210 \\
7,030 \\
8,510 \\
8,460 \\
8,570 \\
8,650 \\
8,570 \\
8,290 \\
8,090 \\
7,810\end{array}$ & $\begin{array}{l}9.10 \\
8.98 \\
8.93 \\
8.92 \\
9.45 \\
9.50 \\
9.56 \\
9.63 \\
9.61 \\
9.55 \\
9.46 \\
9.33\end{array}$ & $\begin{array}{l}7,470 \\
7,160 \\
7,030 \\
7,000 \\
8,430 \\
8,570 \\
8,740 \\
8,930 \\
8,880 \\
8,710 \\
8,460 \\
8,090\end{array}$ & $\begin{array}{l}9.18 \\
9.03 \\
8.88 \\
8.82 \\
9.28 \\
9.27 \\
9.20 \\
9.24 \\
9.30 \\
9.25 \\
9.15 \\
9.05\end{array}$ & $\begin{array}{l}7,680 \\
7,290 \\
6,900 \\
6,740 \\
7,950 \\
7,930 \\
7,730 \\
7,840 \\
8,010 \\
7,870 \\
7,600 \\
7,340\end{array}$ \\
\hline
\end{tabular}

Supplemental records.- Dec. $11,3: 30$ p.m., 32.3 ft., 73,700 sec.-ft. 
Location. - Lat. $41^{\circ} 49^{\prime}$, long. $122^{\circ} 35^{\prime}$, in $\mathrm{NE} \frac{2}{4}$ sec. 24, T. $46 \mathrm{~N}$, , R. 7 W., $0.6 \mathrm{mlle}$ above mouth and 6 miles north of Yreka, Siskiyou County. Altitude, about 2,000 feet above mean ser level.

Drainage area.- 804 square miles.

Gage-he1ght record. - Water-stage recorder graph.

Stage-discharge relation.- Defined by current-meter measurements below 570 second-feet; extended to peak stage on basis of area-velocity study; verified by slope-area computation of flood flow. Rating curve changed at peak stage.

Maxima.- December 1937: Discharge, 1,860 second-feet 4 p.m. Dec. 11 (gage height, 6.17 feet).

1933-November 1937: Discharge, 1,000 second-feet Jan. 15, 1936 (gage helght, 4.80 feet), from rating curve extended above 240 second-feet on basis of slope-area computation of flood flow.

January-September 1938: D1scharge, 1,940 second-feet 5:30 p.m. Mar. 23 (gage height, 6.24 feet).

Remarks.- Flood run-off somewhat affected by artificlal storage in Shasta River Reservoir (capacity, 72,000 acre-feet). Many 1rrigation diversions above station.

Mean dafly discharge, in second-feet, November 1937 to January 1938

\begin{tabular}{|c|c|c|c|c|c|c|c|c|c|c|c|}
\hline Day & Nov. & Dec. & Jan. & Day & Nov. & Dec. & $\operatorname{Jan}$. & Day & Nov. & Dec. & Jan. \\
\hline $\begin{array}{r}1 \\
2 \\
3 \\
4 \\
5 \\
6 \\
7 \\
8 \\
9 \\
10\end{array}$ & $\begin{array}{l}135 \\
126 \\
126 \\
126 \\
126 \\
126 \\
126 \\
124 \\
124 \\
126\end{array}$ & $\begin{array}{l}169 \\
166 \\
163 \\
160 \\
160 \\
160 \\
160 \\
160 \\
160 \\
407\end{array}$ & $\begin{array}{l}209 \\
311 \\
311 \\
295 \\
279 \\
263 \\
250 \\
234 \\
224 \\
221\end{array}$ & $\begin{array}{l}11 \\
12 \\
13 \\
14 \\
15 \\
16 \\
17 \\
18 \\
19 \\
20\end{array}$ & $\begin{array}{l}150 \\
172 \\
172 \\
169 \\
160 \\
180 \\
210 \\
186 \\
177 \\
219\end{array}$ & $\begin{array}{r}1,400 \\
1,460 \\
800 \\
488 \\
372 \\
348 \\
295 \\
266 \\
244 \\
228\end{array}$ & $\begin{array}{l}221 \\
218 \\
218 \\
240 \\
334 \\
321 \\
450 \\
411 \\
358 \\
324\end{array}$ & $\begin{array}{l}21 \\
22 \\
23 \\
24 \\
25 \\
26 \\
27 \\
28 \\
29 \\
30 \\
31\end{array}$ & $\begin{array}{l}231 \\
201 \\
338 \\
298 \\
234 \\
204 \\
189 \\
177 \\
174 \\
172\end{array}$ & $\begin{array}{l}218 \\
215 \\
212 \\
215 \\
218 \\
231 \\
276 \\
247 \\
221 \\
215 \\
215\end{array}$ & $\begin{array}{l}304 \\
317 \\
355 \\
311 \\
298 \\
288 \\
298 \\
311 \\
301 \\
282 \\
285\end{array}$ \\
\hline $\begin{array}{l}\text { Mean } \\
\text { Run- }\end{array}$ & 1 & & & & & & & & $\begin{array}{r}176 \\
10,470\end{array}$ & $\begin{array}{r}331 \\
20,330\end{array}$ & $\begin{array}{r}292 \\
17,930\end{array}$ \\
\hline
\end{tabular}

Gage helght, in feet, and discharge, in second-feet, at indicated time, 1937

\begin{tabular}{|c|c|c|c|c|c|c|c|c|c|c|c|c|}
\hline \multirow{2}{*}{ 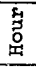 } & Feet & Sec.ft. & Feet & Sec.ft. & Feet & Sec.ft. & Feet & Sec.ft. & Feet & Sec.ft. & Feet & Sec.ft. \\
\hline & \multicolumn{2}{|c|}{ December 8} & \multicolumn{2}{|c|}{ December 9} & \multicolumn{2}{|c|}{ December 10} & \multicolumn{2}{|c|}{ December 11} & \multicolumn{2}{|c|}{ December 12} & \multicolumn{2}{|c|}{ December 13} \\
\hline $\begin{array}{r}2 \\
4 \\
6 \\
8 \\
10 \\
\mathrm{~N} \\
2 \\
4 \\
6 \\
8 \\
10 \\
\mathrm{M}\end{array}$ & $\begin{array}{c}- \\
- \\
- \\
- \\
2.83 \\
- \\
- \\
- \\
- \\
2.83\end{array}$ & $\begin{array}{c}\overline{-} \\
- \\
- \\
\overline{160} \\
\overline{-} \\
\overline{-} \\
\overline{-} \\
160\end{array}$ & $\begin{array}{l}\bar{z} \\
\bar{z} \\
\bar{z} \\
\bar{z} \\
\overline{-} \\
\overline{-} \\
\overline{2.83}\end{array}$ & $\begin{array}{c}- \\
\overline{-} \\
\overline{-} \\
\overline{160} \\
\overline{-} \\
\overline{-} \\
\overline{-} \\
\overline{163}\end{array}$ & $\begin{array}{l}2.85 \\
2.88 \\
2.90 \\
2.90 \\
2.95 \\
3.07 \\
3.21 \\
3.55 \\
4.20 \\
4.79 \\
4.97 \\
4.85\end{array}$ & $\begin{array}{r}166 \\
174 \\
180 \\
180 \\
195 \\
231 \\
275 \\
389 \\
638 \\
917 \\
1,010 \\
949\end{array}$ & $\begin{array}{l}4.89 \\
4.81 \\
5.00 \\
5.32 \\
5.40 \\
5.56 \\
6.03 \\
6.17 \\
6.11 \\
5.94 \\
5.75 \\
5.87\end{array}$ & $\begin{array}{r}971 \\
927 \\
1,030 \\
1,230 \\
1,290 \\
1,400 \\
1,760 \\
1,860 \\
1,830 \\
1,690 \\
1,540 \\
1,640\end{array}$ & $\begin{array}{l}6.15 \\
6.05 \\
5.88 \\
5.74 \\
5.65 \\
5.64 \\
5.60 \\
5.52 \\
5.42 \\
5.31 \\
5.20 \\
5.06\end{array}$ & $\begin{array}{l}1,860 \\
1,780 \\
1,640 \\
1,530 \\
1,460 \\
1,460 \\
1,430 \\
1,370 \\
1,300 \\
1,230 \\
1,150 \\
1,070\end{array}$ & $\begin{array}{c}- \\
4.85 \\
\overline{4} \\
4.59 \\
\overline{4} \\
-58 \\
4.44 \\
\overline{4.33} \\
\overline{4.21}\end{array}$ & $\begin{array}{c}\overline{940} \\
\overline{850} \\
\overline{7} \\
\overline{0} \\
7 \overline{2} 0 \\
\overline{6} \\
\overline{6} 8 \\
\overline{6} \mathbf{1 4}\end{array}$ \\
\hline & \multicolumn{2}{|c|}{ December 14} & \multicolumn{2}{|c|}{ December 15} & \multicolumn{2}{|c|}{ December 16} & \multicolumn{2}{|c|}{ December 17} & \multicolumn{2}{|c|}{ December 18} & \multicolumn{2}{|c|}{ December 19} \\
\hline $\begin{array}{r}2 \\
4 \\
6 \\
8 \\
10 \\
\mathrm{~N} \\
2 \\
4 \\
6 \\
8 \\
10 \\
\mathrm{M}\end{array}$ & $\begin{array}{c}- \\
4.10 \\
- \\
3.99 \\
- \\
3.89 \\
-7.79 \\
3.72 \\
3.68\end{array}$ & $\begin{array}{c}\overline{70} \\
- \\
5 \overline{2} 6 \\
\overline{488} \\
\overline{450} \\
\overline{4} \\
\overline{4} \overline{5} \\
\overline{411}\end{array}$ & $\begin{array}{c}- \\
3.64 \\
- \\
3.59 \\
- \\
3.56 \\
\overline{3.54} \\
- \\
3.52 \\
- \\
3.48\end{array}$ & $\begin{array}{c}\overline{396} \\
\overline{3} \\
\overline{3} 9 \\
\overline{368} \\
\overline{362} \\
\overline{355} \\
\overline{341}\end{array}$ & $\begin{array}{l}3.46 \\
3.45 \\
3.43 \\
3.42 \\
3.41 \\
3.40 \\
3.52 \\
3.79 \\
3.61 \\
3.49 \\
3.42 \\
3.40\end{array}$ & $\begin{array}{l}334 \\
331 \\
324 \\
321 \\
317 \\
314 \\
355 \\
450 \\
386 \\
345 \\
321 \\
314\end{array}$ & $\begin{array}{c}-\overline{3.36} \\
- \\
3.35 \\
- \\
3.34 \\
\overline{3.34} \\
\overline{3.35} \\
\overline{3.29}\end{array}$ & $\begin{array}{c}\overline{301} \\
\overline{2} \overline{98} \\
\overline{2} \\
\overline{9} \\
2 \overline{95} \\
\overline{2} \\
\overline{2} \\
2 \overline{7}\end{array}$ & $\begin{array}{c}- \\
- \\
- \\
- \\
3.25 \\
- \\
- \\
- \\
- \\
3.22\end{array}$ & $\begin{array}{c}\overline{-} \\
\overline{-} \\
\overline{-} \\
\overline{266} \\
\overline{-} \\
\overline{-} \\
\overline{-} \\
\overline{256}\end{array}$ & $\begin{array}{l}- \\
- \\
- \\
\overline{3.17} \\
- \\
\overline{-} \\
\overline{-} \\
\overline{3.15}\end{array}$ & $\begin{array}{c}= \\
\overline{-} \\
\overline{-} \\
\overline{240} \\
\overline{-} \\
\overline{-} \\
\overline{2} \\
\overline{2} 4\end{array}$ \\
\hline & \multicolumn{2}{|c|}{ December 20} & \multicolumn{2}{|c|}{ December 21} & \multicolumn{2}{|c|}{ December 22} & \multicolumn{2}{|c|}{ December 23} & \multicolumn{2}{|c|}{ Jecember 24} & \multicolumn{2}{|c|}{ December 25} \\
\hline $\begin{array}{r}2 \\
4 \\
6 \\
8 \\
10 \\
1 \\
2 \\
4 \\
6 \\
8 \\
10 \\
11\end{array}$ & $\begin{array}{l}- \\
- \\
- \\
- \\
3.13 \\
- \\
- \\
- \\
- \\
3.11\end{array}$ & $\begin{array}{c}- \\
- \\
- \\
\overline{2} \\
228 \\
\overline{-} \\
- \\
- \\
\overline{221}\end{array}$ & $\begin{array}{l}- \\
- \\
- \\
- \\
3.10 \\
- \\
- \\
- \\
= \\
3.09\end{array}$ & $\begin{array}{c}- \\
- \\
- \\
\overline{2} \\
218 \\
- \\
- \\
\overline{-} \\
\overline{215}\end{array}$ & $\begin{array}{l}- \\
- \\
- \\
- \\
3.09 \\
- \\
- \\
- \\
- \\
3.09\end{array}$ & $\begin{array}{c}- \\
- \\
- \\
- \\
215 \\
- \\
- \\
- \\
- \\
215\end{array}$ & $\begin{array}{l}- \\
- \\
\bar{z} \\
\overline{3.07} \\
\overline{-} \\
\overline{-} \\
\overline{-} \\
\overline{3.09}\end{array}$ & $\begin{array}{c}= \\
- \\
- \\
- \\
209 \\
- \\
- \\
- \\
- \\
215\end{array}$ & $\begin{array}{c}- \\
\overline{3.08} \\
- \\
- \\
3.09 \\
- \\
\overline{3.10} \\
- \\
3.08\end{array}$ & $\begin{array}{c}\overline{-} \\
2 \overline{12} \\
- \\
\overline{2} \\
- \\
\overline{15} \\
\overline{-} \\
\overline{2} \overline{12}\end{array}$ & $\begin{array}{l}- \\
= \\
- \\
=10 \\
= \\
= \\
= \\
= \\
3.12\end{array}$ & $\begin{array}{c}\overline{-} \\
\overline{-} \\
\overline{-} \\
218 \\
\overline{-} \\
\overline{-} \\
\overline{224}\end{array}$ \\
\hline
\end{tabular}


Salmon River at Somesbar, Cal1f.

Locet1on. - Lat. $41^{\circ} 23^{\prime}$, long. $123^{\circ} 28^{\prime}$, in NW $\frac{1}{4}$ sec. 2, T. 11 N., R. 6 E., helf a mile east

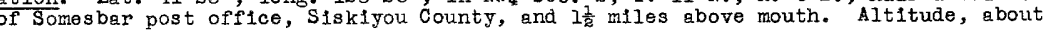
500 feet above mean sea level.

Dralnage area.- 737 squere miles.

Gage-helght record. - Water-stage recorder graph.

Stege-discharge relation. - Defined by current-meter messurements below 7,000 second-feet; extended to peak stage on basis of area-velocity study.

Maxima.- December 1937: Discharge, 27,000 second-feet 1:30 a.m. Dec. 11 (gege height, 14.80 feet).

1927-November 1937: Discherge, 21,600 second-feet Jan. 14, 1936 (gage helght, 13.0 feet), from rating curve extended above 9,200 second-feet.

Remarks. - Flood mun-off not affected by artificlel storage or diversions.

Mean dally discharge, in second-feet, November 1937 to January 1938

\begin{tabular}{|c|c|c|c|c|c|c|c|c|c|c|c|}
\hline Day & Nov. & Dec. & Jan. & Day & Nov. & Dec. & Jan. & Day & Nov. & Dec. & Jan. \\
\hline $\begin{array}{r}1 \\
2 \\
3 \\
4 \\
5 \\
6 \\
7 \\
8 \\
9 \\
10\end{array}$ & $\begin{array}{l}255 \\
235 \\
225 \\
215 \\
210 \\
215 \\
215 \\
215 \\
215 \\
441\end{array}$ & $\begin{array}{l}1,770 \\
1,590 \\
1,460 \\
1,320 \\
1,240 \\
1,180 \\
1,140 \\
1,070 \\
1,040 \\
9,890\end{array}$ & $\begin{array}{l}2,490 \\
2,420 \\
2,240 \\
2,100 \\
1,990 \\
1,880 \\
1,780 \\
1,680 \\
1,600 \\
1,530\end{array}$ & $\begin{array}{l}11 \\
12 \\
13 \\
14 \\
15 \\
16 \\
17 \\
18 \\
19 \\
20\end{array}$ & $\begin{array}{r}1,760 \\
1,070 \\
965 \\
2,200 \\
1,620 \\
2,170 \\
3,700 \\
2,810 \\
9,880 \\
17,000\end{array}$ & $\begin{array}{r}25,200 \\
13,900 \\
8,250 \\
6,040 \\
4,840 \\
4,040 \\
3,480 \\
2,950 \\
2,620 \\
2,320\end{array}$ & $\begin{array}{l}1,460 \\
1,420 \\
1,390 \\
2,430 \\
3,590 \\
3,050 \\
3,590 \\
4,150 \\
3,920 \\
3,480\end{array}$ & $\begin{array}{l}21 \\
22 \\
23 \\
24 \\
25 \\
26 \\
27 \\
28 \\
29 \\
30 \\
31\end{array}$ & $\begin{array}{l}7,750 \\
5,440 \\
8,250 \\
5,920 \\
4,500 \\
4,040 \\
3,160 \\
2,630 \\
2,250 \\
1,970\end{array}$ & $\begin{array}{l}2,100 \\
1,970 \\
1,800 \\
1,820 \\
1,680 \\
1,590 \\
1,560 \\
1,490 \\
1,450 \\
3,480 \\
2,950\end{array}$ & $\begin{array}{l}3,480 \\
6,520 \\
6,520 \\
5,080 \\
4,260 \\
3,700 \\
3,480 \\
3,370 \\
3,160 \\
2,850 \\
3,050\end{array}$ \\
\hline $\begin{array}{l}\text { Mear } \\
\text { Run- }\end{array}$ & $\begin{array}{l}\text { in } \\
\text { in }\end{array}$ & 20 & & & & & & & $\begin{array}{r}3,051 \\
181,500\end{array}$ & $\begin{array}{r}3,782 \\
232,500\end{array}$ & $\begin{array}{r}3,021 \\
185,800\end{array}$ \\
\hline
\end{tabular}

Gsge he1ght, in feet, and discharge, in second-feet, at indicated time, 1937

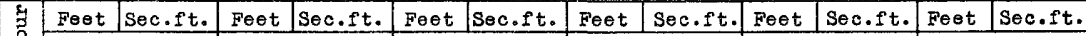

\begin{tabular}{|c|c|c|c|c|c|c|c|c|c|c|c|c|}
\hline $\begin{array}{r}\text { 届 } \\
2 \\
4 \\
6 \\
8 \\
0\end{array}$ & \multicolumn{2}{|c|}{ December 8} & \multicolumn{2}{|c|}{ December 9} & \multicolumn{2}{|c|}{ December 10} & \multicolumn{2}{|c|}{ December 11} & \multicolumn{2}{|c|}{ December 12} & \multicolumn{2}{|c|}{ December 13} \\
\hline $\begin{array}{r}2 \\
4 \\
6 \\
8 \\
10 \\
\mathrm{~N} \\
2 \\
4 \\
6 \\
8 \\
10 \\
M\end{array}$ & $\begin{array}{l}\overline{-} \\
\bar{z} \\
\overline{-} \\
4.34 \\
\bar{z} \\
\overline{-} \\
\overline{-} \\
4.32\end{array}$ & $\begin{array}{c}- \\
- \\
- \\
\overline{-} \\
1,070 \\
- \\
\overline{-} \\
\overline{-} \\
1,040\end{array}$ & $\begin{array}{c}\overline{-} \\
4.31 \\
- \\
4.30 \\
\overline{4} \\
4.30 \\
\overline{4.31} \\
\overline{4.34} \\
\overline{4.41}\end{array}$ & $\begin{array}{c}\overline{0} 030 \\
\overline{0} \\
1,020 \\
\overline{0} \\
1,020 \\
\overline{0} \\
1,030 \\
\overline{0} \\
1, \overline{0} 0 \\
1, \overline{150}\end{array}$ & $\begin{array}{r}4.50 \\
4.65 \\
5.06 \\
6.00 \\
6.59 \\
7.45 \\
8.55 \\
9.49 \\
10.86 \\
12.65 \\
14.16 \\
14.75\end{array}$ & $\begin{array}{r}1,260 \\
1,460 \\
2,090 \\
3,920 \\
5,300 \\
7,380 \\
10,100 \\
12,500 \\
16,100 \\
20,900 \\
25,100 \\
26,800\end{array}$ & $\begin{array}{l}14.76 \\
14.60 \\
14.71 \\
14.43 \\
14.24 \\
14.46 \\
14.66 \\
14.58 \\
14.12 \\
13.45 \\
12.88 \\
12.24\end{array}$ & & $\begin{array}{r}11.65 \\
11.20 \\
10.78 \\
10.42 \\
10.08 \\
9.81 \\
9.52 \\
9.26 \\
9.06 \\
8.90 \\
8.69 \\
8.50\end{array}$ & & $\begin{array}{l}8.17 \\
- \\
7.95 \\
- \\
7.71 \\
- \\
7.52 \\
- \\
7.38 \\
- \\
7.23\end{array}$ & $\begin{array}{c}9, \overline{180} \\
\overline{-} \\
8, \overline{620} \\
8, \overline{0} \\
7, \overline{5} 50 \\
7, \overline{200} \\
\overline{-} \overline{830}\end{array}$ \\
\hline & \multicolumn{2}{|c|}{ Decerber 14} & \multicolumn{2}{|c|}{ December 15} & \multicolumn{2}{|c|}{ December 16} & \multicolumn{2}{|c|}{ December 17} & \multicolumn{2}{|c|}{ December 18} & \multicolumn{2}{|c|}{ December 19} \\
\hline $\begin{array}{r}2 \\
4 \\
6 \\
8 \\
10 \\
\mathrm{~N} \\
2 \\
4 \\
6 \\
8 \\
10 \\
M\end{array}$ & $\begin{array}{c}- \\
7.09 \\
- \\
6.97 \\
- \\
6.85 \\
- \\
6.76 \\
- \\
6.66 \\
- \\
6.58\end{array}$ & $\begin{array}{c}6, \overline{500} \\
-\overline{2} 10 \\
6, \overline{-} \\
5, \overline{9} 0 \\
\overline{5}, \overline{7} 00 \\
\overline{-} \\
5,460 \\
5, \overline{270}\end{array}$ & $\begin{array}{c}- \\
6.51 \\
- \\
6.48 \\
- \\
6.41 \\
- \\
6.35 \\
- \\
6.28 \\
- \\
6.22\end{array}$ & $\begin{array}{c}5, \overline{100} \\
\overline{0} \\
5, \overline{030} \\
\overline{-} \\
4,800 \\
\overline{-} \\
4,720 \\
4, \overline{5} 60 \\
4, \overline{430}\end{array}$ & $\begin{array}{l}\overline{-} \\
6.13 \\
\overline{-} \\
6.05 \\
= \\
\overline{5.99} \\
\overline{-} \\
5.91\end{array}$ & $\begin{array}{c}- \\
\overline{-} \\
4,220 \\
- \\
\overline{0} \\
4,040 \\
- \\
\overline{-} \\
3, \overline{9} 00 \\
- \\
\overline{3}, \overline{720}\end{array}$ & $\begin{array}{l}- \\
5.84 \\
\overline{-} \\
5.78 \\
- \\
5.72 \\
\overline{5.66}\end{array}$ & $\begin{array}{c}\overline{-} \\
3, \overline{5} 70 \\
- \\
\overline{3}, \overline{440} \\
\overline{-} \\
3, \overline{300} \\
- \\
\overline{3}, \overline{180}\end{array}$ & $\begin{array}{l}- \\
- \\
5.60 \\
- \\
= \\
5.55 \\
- \\
\overline{5.50} \\
- \\
\overline{5.46}\end{array}$ & $\begin{array}{c}- \\
- \\
3, \overline{050} \\
- \\
- \\
2, \overline{950} \\
- \\
\overline{8} \\
2, \overline{850} \\
- \\
\overline{-}, \overline{780}\end{array}$ & $\begin{array}{l}\overline{-} \\
\overline{5.41} \\
\overline{-} \\
5.37 \\
\overline{-} \\
\overline{5.33} \\
\overline{-} \\
\overline{5.28}\end{array}$ & $\begin{array}{c}- \\
\overline{-} \\
2,690 \\
- \\
\overline{-} \\
2,620 \\
- \\
\overline{-} \\
2, \overline{5} 40 \\
- \\
\overline{-}, \overline{4} 60\end{array}$ \\
\hline & \multicolumn{2}{|c|}{ December 20} & \multicolumn{2}{|c|}{ December 21} & \multicolumn{2}{|c|}{ December 22} & \multicolumn{2}{|c|}{ December 23} & \multicolumn{2}{|c|}{ December 24} & \multicolumn{2}{|c|}{ December 25} \\
\hline $\begin{array}{r}2 \\
4 \\
6 \\
8 \\
10 \\
\text { N } \\
2 \\
4 \\
6 \\
8 \\
10 \\
M\end{array}$ & $\begin{array}{l}- \\
\overline{5.23} \\
\overline{-} \\
5.20 \\
\overline{-} \\
5.16 \\
- \\
\overline{5.13}\end{array}$ & $\begin{array}{c}\overline{-} \\
2, \overline{3} 70 \\
- \\
\overline{3} \\
2,0 \\
- \\
\overline{2} \\
2, \overline{2} 0 \\
\overline{-} \\
2, \overline{200}\end{array}$ & $\begin{array}{l}\overline{-} \\
\overline{5.10} \\
= \\
\overline{-} \\
\overline{-07} \\
\overline{5.04} \\
= \\
\overline{5.02}\end{array}$ & $\begin{array}{c}\overline{-} \\
2, \overline{150} \\
\overline{-} \\
2, \overline{100} \\
\overline{-} \\
2, \overline{050} \\
\overline{-} \\
2, \overline{020}\end{array}$ & $\begin{array}{l}- \\
\bar{z} \\
\overline{-} \\
\overline{4} \\
\bar{z} .99 \\
\overline{-} \\
\overline{-} \\
\overline{4} .96\end{array}$ & $\begin{array}{c}- \\
- \\
- \\
- \\
\overline{-} \\
1,970 \\
- \\
- \\
- \\
- \\
1, \overline{930}\end{array}$ & $\begin{array}{l}- \\
- \\
= \\
\overline{-} \\
4.88 \\
= \\
= \\
= \\
4.84\end{array}$ & $\begin{array}{c}- \\
- \\
- \\
\overline{-} \\
1, \overline{800} \\
- \\
- \\
\overline{-} \\
1, \overline{7} 40\end{array}$ & $\begin{array}{l}- \\
\overline{4.88} \\
- \\
\overline{-} \\
4.93 \\
- \\
\overline{4.92} \\
\overline{-} \\
\overline{4.86}\end{array}$ & $\begin{array}{c}- \\
1, \overline{800} \\
- \\
\overline{-} \\
1, \overline{8} 0 \\
\overline{-} \\
1, \overline{8} 60 \\
\overline{-} \\
1, \overline{7} 70\end{array}$ & $\begin{array}{l}\overline{-} \\
\overline{4.83} \\
\overline{-} \\
4.79 \\
\overline{-} \\
\overline{4.76} \\
\overline{-} \\
\overline{4.75}\end{array}$ & $\begin{array}{c}\overline{-} \\
1, \overline{7} 20 \\
- \\
\overline{-} \\
1,660 \\
- \\
\overline{-} \\
1, \overline{6} 0 \\
\overline{-} \\
1, \overline{6} 00\end{array}$ \\
\hline
\end{tabular}

Supplemental record.-Dec, 11, $1: 30$ a.m., 14.80 ft., 27,000 sec.-ft. 
Trinity River at Lewiston, Calif.

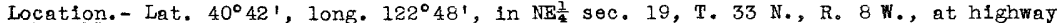
bridge at Iewiston, Trinity County, $0.8 \mathrm{mile}$ below Deadwood Creek. Zero of gage is $1,794.72$ feet above mean sea level (general adjustment of 1929).

Drainage area. - 724 square miles.

Geju-helght record. - Water-stage recorder graph.

Stage-discharge relation. - Definea by current-meter measurements below $12,400 \mathrm{second-}$ feet; extended to perk stage on basis of area-velocity study; verified by comparison of peak discharge and total mun-off of flood with records for other stations on Trinity River. Rating curve changed at peak stage.

Maxima.- December 1937: Discharge, 37,000 second-feet 1:30 a.m. Dec. 11 (gage helght, 19.90 feet)

1911-November 1937: Discharge, about 31,900 second-feet Nov. 30, 1926 (gage height, 18.3 feet, from floodmark), from rating curve extended abovo 6 , 100 secondfeet on basis of slope-area computation of 28,700 second-feet for flood of March 1928 .

Remarks. - Flood mun-off not appreciably affected by artificial storage or by diversions above stations for irrigation, power, and mining.

Wean dally discharge, in second-feet, November 1937 to January 1938

\begin{tabular}{|c|c|c|c|c|c|c|c|c|c|c|c|}
\hline Day & Nov. & Dec. & Jan. & Day & Nov. & Dec. & Jan. & Day & Nov. & Dec. & Jan. \\
\hline $\begin{array}{r}1 \\
2 \\
3 \\
4 \\
5 \\
6 \\
7 \\
8 \\
9 \\
10\end{array}$ & $\begin{array}{l}239 \\
219 \\
210 \\
207 \\
204 \\
198 \\
198 \\
195 \\
195 \\
806\end{array}$ & $\begin{array}{r}1,430 \\
1,310 \\
1,200 \\
1,120 \\
1,050 \\
996 \\
962 \\
930 \\
978 \\
14,400\end{array}$ & $\begin{array}{l}1,440 \\
1,620 \\
1,630 \\
1,530 \\
1,470 \\
1,390 \\
1,350 \\
1,290 \\
1,230 \\
1,200\end{array}$ & $\begin{array}{l}11 \\
12 \\
13 \\
14 \\
15 \\
16 \\
17 \\
18 \\
19 \\
20\end{array}$ & $\begin{array}{r}2,700 \\
1,440 \\
1,000 \\
1,280 \\
1,160 \\
2,120 \\
2,800 \\
1,850 \\
4,250 \\
20,000\end{array}$ & $\begin{array}{r}32,400 \\
15,500 \\
7,560 \\
5,240 \\
4,280 \\
3,550 \\
3,040 \\
2,630 \\
2,320 \\
2,110\end{array}$ & $\begin{array}{l}1,170 \\
1,140 \\
1,130 \\
1,290 \\
1,950 \\
2,000 \\
3,120 \\
3,120 \\
2,790 \\
2,470\end{array}$ & $\begin{array}{l}21 \\
22 \\
23 \\
24 \\
25 \\
26 \\
27 \\
28 \\
29 \\
30 \\
31\end{array}$ & $\begin{array}{r}7,610 \\
5,030 \\
10,400 \\
5,400 \\
3,560 \\
2,880 \\
2,330 \\
2,000 \\
1,750 \\
1,550\end{array}$ & $\begin{array}{l}1,930 \\
1,790 \\
1,680 \\
1,630 \\
1,530 \\
1,440 \\
1,380 \\
1,330 \\
1,270 \\
1,560 \\
1,540\end{array}$ & $\begin{array}{l}2,140 \\
2,470 \\
2,630 \\
2,320 \\
2,160 \\
2,020 \\
1,990 \\
2,110 \\
2,060 \\
1,950 \\
2,470\end{array}$ \\
\hline Pat & 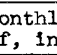 & & & & & & & & $\begin{array}{r}2, \\
166,\end{array}$ & $\begin{array}{r}3,874 \\
238,200\end{array}$ & $\begin{array}{r}1,892 \\
115,300\end{array}$ \\
\hline
\end{tabular}

Gage height, in feot, and discharge, in second-feet, at indicated time, 1937

\begin{tabular}{|c|c|c|c|c|c|c|c|c|c|c|c|c|}
\hline \multirow{2}{*}{$\begin{array}{l}4 \\
3 \\
0 \\
0 \\
0\end{array}$} & $e \theta t$ & $\theta c . f t$. & $\theta \theta t$ & Sec.ft. & Feet & $\theta c . f t$. & Feet & Sec.ft. & Feet & Sec.ft. & Feet & Sec.ft. \\
\hline & \multicolumn{2}{|c|}{ December 8} & \multicolumn{2}{|c|}{ December 9} & \multicolumn{2}{|c|}{ December 10} & \multicolumn{2}{|c|}{ December 11} & \multicolumn{2}{|c|}{ December 12} & \multicolumn{2}{|c|}{ December 13} \\
\hline $\begin{array}{r}2 \\
4 \\
6 \\
8 \\
10 \\
N \\
2 \\
4 \\
6 \\
8 \\
10 \\
M\end{array}$ & $\begin{array}{l}- \\
- \\
= \\
\overline{5.85} \\
= \\
= \\
= \\
5.82\end{array}$ & $\begin{array}{c}= \\
\bar{z} \\
\overline{-} \\
930 \\
\overline{-} \\
\overline{-} \\
\overline{-} \\
906\end{array}$ & $\begin{array}{l}5.81 \\
5.81 \\
5.81 \\
5.80 \\
5.81 \\
5.81 \\
5.83 \\
5.85 \\
5.94 \\
6.05 \\
6.19 \\
6.40\end{array}$ & \begin{tabular}{|r|}
898 \\
898 \\
898 \\
890 \\
898 \\
898 \\
914 \\
930 \\
1,000 \\
1,100 \\
1,220 \\
1,410 \\
\end{tabular} & $\begin{array}{r}6.62 \\
6.92 \\
7.42 \\
8.56 \\
10.43 \\
12.00 \\
13.63 \\
15.00 \\
16.65 \\
17.90 \\
19.11 \\
19.65\end{array}$ & $\begin{array}{r}1,620 \\
1,920 \\
2,470 \\
4,020 \\
7,370 \\
11,200 \\
15,600 \\
19,800 \\
25,500 \\
29,800 \\
34,200 \\
36,100\end{array}$ & & $\begin{array}{l}37,000 \\
35,200 \\
33,200 \\
32,300 \\
32,500 \\
33,000 \\
33,200 \\
32,600 \\
31,600 \\
30,100 \\
27,800 \\
25,100\end{array}$ & & & & $\begin{array}{l}9,400 \\
8,960 \\
8,490 \\
8,140 \\
7,800 \\
7,510 \\
7,200 \\
6,940 \\
6,710 \\
6,510 \\
6,290 \\
6,110\end{array}$ \\
\hline & \multicolumn{2}{|c|}{ December 14} & \multicolumn{2}{|c|}{ Deceraber 15} & \multicolumn{2}{|c|}{ De cember 16} & \multicolumn{2}{|c|}{ December 17} & \multicolumn{2}{|c|}{ December 18} & \multicolumn{2}{|c|}{ December 19} \\
\hline $\begin{array}{r}2 \\
4 \\
6 \\
8 \\
10 \\
N \\
2 \\
4 \\
6 \\
8 \\
10 \\
M\end{array}$ & $\begin{array}{l}9.98 \\
9.90 \\
9.83 \\
9.76 \\
9.69 \\
9.64 \\
9.58 \\
9.53 \\
9.48 \\
9.43 \\
9.40 \\
9.35\end{array}$ & $\begin{array}{l}5,7 \\
5,6 \\
5,4 \\
5,3 \\
5,2 \\
5,1 \\
5,0 \\
4, \\
4, \\
4,7 \\
4,6\end{array}$ & $\begin{array}{c}- \\
9.28 \\
- \\
9.23 \\
- \\
9.17 \\
- \\
9.10 \\
- \\
9.02 \\
- \\
8.93\end{array}$ & $\begin{array}{c}4, \overline{520} \\
\overline{4} \\
4,430 \\
\overline{3} \\
4, \overline{10} \\
\overline{1} \\
480 \\
4, \overline{0} 40 \\
3, \overline{870}\end{array}$ & $\begin{array}{l}\overline{8.86} \\
\overline{8.79} \\
\overline{8.72} \\
\overline{8.67} \\
\overline{8.62} \\
\overline{8.57}\end{array}$ & $\begin{array}{c}\overline{7} \\
3, \overline{750} \\
\overline{6} \\
3,20 \\
\overline{3}, \overline{5} 00 \\
\overline{4} \\
3, \overline{4} 10 \\
\overline{3}, \overline{320} \\
3, \overline{240}\end{array}$ & $\begin{array}{l}- \\
8.53 \\
8.48 \\
- \\
8.43 \\
- \\
8.39 \\
- \\
8.35 \\
- \\
8.32\end{array}$ & $\begin{array}{c}3, \overline{170} \\
3, \overline{0} \\
\overline{0} \\
3, \overline{0000} \\
\overline{-} \\
2, \overline{9} 30 \\
2, \overline{870} \\
2, \overline{820}\end{array}$ & $\begin{array}{l}- \\
8.28 \\
\overline{8.24} \\
- \\
8.20 \\
-\overline{16} \\
\overline{8.13} \\
\overline{8.10}\end{array}$ & $\begin{array}{c}2, \overline{7} 60 \\
\overline{-} \\
2,690 \\
\overline{6} \\
2,630 \\
\overline{-} \\
2,570 \\
\overline{-} \\
2,520 \\
2, \overline{470}\end{array}$ & $\begin{array}{l}8.07 \\
- \\
8.03 \\
- \\
8.01 \\
\overline{8.00} \\
- \\
\overline{7.96} \\
\overline{7.93}\end{array}$ & $\begin{array}{c}2, \overline{420} \\
\overline{-} \\
2, \overline{3} 60 \\
\overline{-} \\
2, \overline{3} 40 \\
\overline{-} \\
2, \overline{320} \\
2, \overline{260} \\
2, \overline{220}\end{array}$ \\
\hline & \multicolumn{2}{|c|}{ December 20} & \multicolumn{2}{|c|}{ December 21} & \multicolumn{2}{|c|}{ December 22} & \multicolumn{2}{|c|}{ December 23} & \multicolumn{2}{|c|}{ De cember 24} & \multicolumn{2}{|c|}{ December 25} \\
\hline $\begin{array}{r}2 \\
4 \\
6 \\
8 \\
10 \\
N \\
2 \\
4 \\
6 \\
8 \\
10 \\
M\end{array}$ & $\begin{array}{l}7.90 \\
= \\
7.87 \\
= \\
7.86 \\
- \\
7.83 \\
- \\
7.80 \\
= \\
7.77\end{array}$ & $\begin{array}{l}2, \overline{170} \\
\overline{-} \\
2, \overline{130} \\
\overline{-} \\
2, \overline{110} \\
2, \overline{0} 70 \\
2, \overline{030} \\
1, \overline{990}\end{array}$ & $\begin{array}{c}= \\
7.75 \\
- \\
7.73 \\
- \\
\overline{7.70} \\
\therefore \\
\overline{7.67}\end{array}$ & $\begin{array}{c}\overline{-} \\
1, \overline{9} 60 \\
- \\
\overline{-} \\
1, \overline{3} 0 \\
\overline{-} \\
1, \overline{89} \\
- \\
\overline{-} \\
1, \overline{850}\end{array}$ & $\begin{array}{l}\overline{-} \\
7.65 \\
- \\
7.63 \\
- \\
\overline{-} \\
= \\
\overline{-} \\
\overline{7.60}\end{array}$ & $1, \overline{-}$ & $\begin{array}{l}- \\
\overline{7.58} \\
= \\
\overline{7.55} \\
- \\
\overline{7.51} \\
= \\
\overline{7.48}\end{array}$ & $\begin{array}{c}- \\
\overline{-} \\
1,720 \\
- \\
\overline{-} \\
1,680 \\
\vdots \\
\overline{-} \\
1,630 \\
- \\
\overline{-} \\
1,590\end{array}$ & $\begin{array}{l}- \\
7.49 \\
- \\
\overline{7.55} \\
= \\
\overline{7.53} \\
= \\
\overline{7.46}\end{array}$ & $\begin{array}{c}- \\
\overline{-} \\
1,610 \\
- \\
\overline{-} \\
1,680 \\
- \\
\overline{-} \\
1,660 \\
-\overline{-} \\
1,570\end{array}$ & $\begin{array}{l}- \\
7.45 \\
= \\
7.43 \\
= \\
7.40 \\
= \\
7.38\end{array}$ & $\begin{array}{c}- \\
\bar{m} \\
1,560 \\
- \\
\overline{1} \\
1,530 \\
- \\
\overline{-} \\
1,490 \\
- \\
\overline{-} \\
1,470\end{array}$ \\
\hline
\end{tabular}

Supplemental records.- Dec. 11, 1:30 a.m., 19.90 ft., 37,000 sec.-ft. 
Trinity River near Burnt Ranch, Calif.

Location.- Lat. $40^{\circ} 47^{\prime}$, long, $123^{\circ} 25^{\prime}$, in sec. 29, T. 5 N., R. 7 E., 2 miles above highway bridge at Cedar Flat and $7 \mathrm{mlles}$ above Burnt Ranch, Trinity County. Zero of gage is $1,007.98$ feet above mean sea level (general adjustment of 1929).

Dralnage area.- 1,429 square miles (revised).

Gage-helght record. - Watermstage recorder graph except for period noon Dec. 11 to 4 p.m. Dec. 19, when there was no record.

Stage-d1scharge relation. - Defined by current-meter measurements below 23,800 secondfeet; extended to peak stage on basis of area-velocity study; verified by $A$ va method and comparison of peak discharge and total run-off of flood with records for other stations on Trinity River. Rating curve changed at peak stage.

Maxima.- December 1937: Discharge, 71, 800 second-feet about 2 p.m. Dec. 11 (gage height, 31.4 feet, from floodmerks on bank).

1931-Norember 1937: Dischare, 31,000 second-feet Jan. 15, 1936 (gage he1ght, 19.27 feet), from rating curve extended above 7,000 second-feet on basis of areavelocity study.

Remarks. - Flood run-off not affected by artiflcial storage; perhaps silghtly affected by regulation and di ersions above station. Discharge for period of missing gage-height record obtained from discharge graph based on peak stage, partial recorder graph, and record for Trinity River near Hoopa.

Mean da1ly dscharge, in second-feet, November 1937 to January 1938

\begin{tabular}{|c|c|c|c|c|c|c|c|c|c|c|c|}
\hline Day & Nov. & Dec. & Jan. & Day & Nov. & Dec. & Jan. & Day & Nov. & Dec. & Jan. \\
\hline $\begin{array}{r}1 \\
2 \\
3 \\
4 \\
5 \\
6 \\
7 \\
8 \\
9 \\
10\end{array}$ & $\begin{array}{l}354 \\
367 \\
347 \\
334 \\
328 \\
325 \\
316 \\
316 \\
313 \\
620\end{array}$ & $\begin{array}{l}2,650 \\
2,420 \\
2,200 \\
2,000 \\
1,850 \\
1,760 \\
1,660 \\
1,620 \\
1,530 \\
4,120\end{array}$ & $\begin{array}{l}2,720 \\
2,840 \\
3,080 \\
2,900 \\
2,780 \\
2,660 \\
2,540 \\
2,380 \\
2,270 \\
2,170\end{array}$ & $\begin{array}{l}11 \\
12 \\
13 \\
14 \\
15 \\
16 \\
17 \\
18 \\
19 \\
20\end{array}$ & $\begin{array}{r}2,720 \\
3,420 \\
1,800 \\
1,950 \\
2,150 \\
2,360 \\
6,240 \\
4,450 \\
6,560 \\
27,800\end{array}$ & $\begin{array}{r}50,400 \\
33,000 \\
19,000 \\
12,000 \\
8,500 \\
6,800 \\
5,600 \\
4,700 \\
4,000 \\
3,600\end{array}$ & $\begin{array}{l}2,120 \\
2,020 \\
1,970 \\
2,120 \\
3,210 \\
3,470 \\
5,560 \\
6,740 \\
6,230 \\
5,560\end{array}$ & $\begin{array}{l}21 \\
22 \\
23 \\
24 \\
25 \\
26 \\
27 \\
28 \\
29 \\
30 \\
31\end{array}$ & $\begin{array}{r}21,300 \\
8,830 \\
13,200 \\
11,700 \\
7,480 \\
5,900 \\
4,920 \\
4,000 \\
3,420 \\
2,960\end{array}$ & $\begin{array}{l}3,340 \\
3,080 \\
2,900 \\
2,780 \\
2,660 \\
2,490 \\
2,380 \\
2,320 \\
2,220 \\
2,720 \\
3,020\end{array}$ & $\begin{array}{l}4,760 \\
5,720 \\
6,400 \\
5,560 \\
4,920 \\
4,460 \\
4,310 \\
4,310 \\
4,310 \\
4,020 \\
4,310\end{array}$ \\
\hline Mea & & & & & & & & & $\begin{array}{r}4,893 \\
291,100\end{array}$ & $\begin{array}{r}6,426 \\
395,100\end{array}$ & $\begin{array}{r}3,820 \\
234,900\end{array}$ \\
\hline
\end{tabular}

Gage height, In feet, and discharge, in second-feet, at indicated time, 1937

\begin{tabular}{|c|c|c|c|c|c|c|c|c|c|c|c|c|}
\hline \multirow{2}{*}{ 岁 } & Feet & sec.ft. & Feet & Sec.ft. & Feet & Sec. It. & Feet & Sec.ft. & Feet & Sec.ft. & Feet & Sec.ft. \\
\hline & \multicolumn{2}{|c|}{ December 8} & \multicolumn{2}{|c|}{ December 9} & \multicolumn{2}{|c|}{ December 10} & \multicolumn{2}{|c|}{ December 11} & \multicolumn{2}{|c|}{ December 12} & \multicolumn{2}{|c|}{ December 13} \\
\hline $\begin{array}{r}2 \\
4 \\
6 \\
8 \\
10 \\
\mathrm{~N} \\
2 \\
4 \\
6 \\
8 \\
10 \\
M\end{array}$ & $\begin{array}{l}\overline{-} \\
\overline{5.49} \\
= \\
5.47 \\
\overline{-} \\
5.44 \\
\overline{5} \\
\overline{5.45}\end{array}$ & $\begin{array}{c}\overline{-} \\
1, \overline{610} \\
= \\
\overline{5} \\
1,590 \\
- \\
\overline{5} \\
1,50 \\
- \\
\overline{5} \\
1,580\end{array}$ & $\begin{array}{l}\bar{z} \\
\overline{5.41} \\
- \\
\overline{5.39} \\
- \\
\overline{5.38} \\
= \\
\overline{5.47}\end{array}$ & $\begin{array}{c}\overline{-} \\
1, \overline{540} \\
- \\
\overline{-} \\
1, \overline{520} \\
= \\
= \\
1,510 \\
- \\
\overline{-} \\
1,590\end{array}$ & $\begin{array}{r}5.47 \\
5.48 \\
5.55 \\
5.64 \\
5.75 \\
5.91 \\
6.17 \\
6.75 \\
8.45 \\
9.60 \\
11.30 \\
15.15\end{array}$ & $\begin{array}{r}1,590 \\
1,600 \\
1,660 \\
1,750 \\
1,850 \\
2,010 \\
2,280 \\
2,960 \\
5,480 \\
7,480 \\
10,900 \\
20,000\end{array}$ & $\begin{array}{c}18.00 \\
20.70 \\
22.70 \\
24.00 \\
25.76 \\
- \\
- \\
- \\
- \\
- \\
-\end{array}$ & $\begin{array}{l}27,500 \\
35,500 \\
41,700 \\
46,000 \\
52,000 \\
59,600 \\
71,800 \\
66,800 \\
60,900 \\
55,900 \\
51,400 \\
47,700\end{array}$ & & & & \\
\hline
\end{tabular}

\begin{tabular}{|c|c|c|c|c|c|c|c|c|c|c|c|c|}
\hline & \multicolumn{2}{|c|}{ December 14} & \multicolumn{2}{|c|}{ December 15} & \multicolumn{2}{|c|}{ December 16} & \multicolumn{2}{|c|}{ December 17} & \multicolumn{2}{|c|}{ December 18} & \multicolumn{2}{|c|}{ De cember 19} \\
\hline $\begin{array}{r}2 \\
4 \\
6 \\
8 \\
10 \\
N \\
2 \\
4 \\
6 \\
8 \\
10 \\
M\end{array}$ & & & & & & & & & & & $\begin{array}{l}\bar{z} \\
\bar{z} \\
\bar{z} \\
\bar{z} \\
\overline{7.55} \\
\overline{7.50} \\
\overline{7.41}\end{array}$ & $\begin{array}{l}\overline{-} \\
\overline{-} \\
\overline{-} \\
4 \\
\overline{-} \\
\overline{-} \\
\overline{-} \\
\overline{-} \\
=\end{array}$ \\
\hline & \multicolumn{2}{|c|}{ December 20} & \multicolumn{2}{|c|}{ December 21} & \multicolumn{2}{|c|}{ December 22} & \multicolumn{2}{|c|}{ December 23} & \multicolumn{2}{|c|}{ December 24} & \multicolumn{2}{|c|}{ December 25} \\
\hline $\begin{array}{r}2 \\
4 \\
6 \\
8 \\
10 \\
\mathrm{~N} \\
2 \\
4 \\
6 \\
8 \\
10 \\
\mathrm{M}\end{array}$ & $\begin{array}{l}- \\
\overline{7.36} \\
- \\
= \\
7.31 \\
= \\
7.29 \\
= \\
7.18\end{array}$ & $\begin{array}{c}- \\
3, \overline{680} \\
- \\
\overline{3}, \overline{610} \\
- \\
3, \overline{590} \\
- \\
3, \overline{440}\end{array}$ & $\begin{array}{l}- \\
\overline{7.12} \\
\overline{-} \\
7.07 \\
= \\
\overline{7.02} \\
\overline{-} \\
\overline{6.97}\end{array}$ & $\begin{array}{c}\overline{-} \\
3, \overline{3} 70 \\
- \\
\bar{z}, \overline{3} 00 \\
\overline{-} \\
3, \overline{240} \\
\overline{-} \\
\overline{3}, \overline{170}\end{array}$ & $\begin{array}{l}- \\
\overline{6.91} \\
- \\
\overline{6.91} \\
- \\
\overline{6.89} \\
\overline{-} \\
6.85\end{array}$ & $\begin{array}{c}\overline{-} \\
3,090 \\
- \\
\overline{-} \\
3,090 \\
- \\
\overline{3}, \overline{0} 0 \\
- \\
\overline{3}, 020\end{array}$ & $\begin{array}{l}- \\
6.76 \\
= \\
6.76 \\
= \\
6.69 \\
- \\
\overline{6.65}\end{array}$ & $\begin{array}{c}\overline{-} \\
2, \overline{9} 10 \\
\overline{-} \\
2, \overline{9} 10 \\
\overline{-} \\
2, \overline{830} \\
\overline{-} \\
2, \overline{7} 80\end{array}$ & $\begin{array}{l}- \\
= \\
6.61 \\
- \\
- \\
6.65 \\
- \\
\overline{6.69} \\
\overline{-} \\
\overline{6.70}\end{array}$ & $\begin{array}{c}\overline{-} \\
2, \overline{730} \\
- \\
\overline{7} \\
2, \overline{7} \\
- \\
\overline{-} \\
2, \overline{830} \\
- \\
2, \overline{840}\end{array}$ & $\begin{array}{l}- \\
\overline{6.63} \\
\overline{-} \\
6.51 \\
\overline{-} \\
\overline{6.46} \\
- \\
\overline{6.44}\end{array}$ & $\begin{array}{c}\overline{-} \\
2, \overline{7} 60 \\
= \\
\overline{-} \\
2, \overline{6} 10 \\
- \\
\overline{-} \\
2,50 \\
- \\
\overline{5}, \overline{530}\end{array}$ \\
\hline
\end{tabular}

* Hean for the day. 
Trinfty River near Hoopa, Callf.

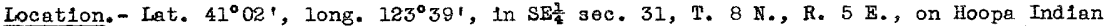
Reservation, half a mile below Campbell Creek and 2 miles southeast of Hoopa, Humboldt County. Altitude, about 315 feet above mean sea level.

Drainage area.- 2,840 square miles (revised).

Gage-helght record. - Water-stage recorder graph.

Stage-discharge relation. - Defined by current-meter measurements below 32,800 secondfeet; extended to peak stage on basis of area-velocity study; verified by $A \sqrt{d}$ method and by comparison of peak discharge and total run-off of flood with records for other stations on Trinity River. Rating curve changed at peak stage.

Maxima.- December 1937: Discharge, 105,000 sacond-feet 2 p.m. Dec. 11 (gage height, 28.70 feet).

1911-14, 1916-18, 1931-November 1937: Discharge observed, about 89,000 second-

feet Dec. 31, 1913 (gage helght, 28.1 feet, from nonrecording gage, former site and

datum, 2 miles downstream), from rating curve extended above 12,000 second-feet.

Remarks.- Flood run-off not affected by artiflelal storage or diversion.

Mean dally discharge, in second-feet, November 1937 to January 1938

\begin{tabular}{|r|c|r|c||c|r|r|r||r|r|r|r|}
\hline Day & Nov. & Dec. & Jan. & Day & Nov. & Dec. & Jan. & Day & Nov. & Dec. & \multicolumn{1}{|c|}{ Jan. } \\
\hline 1 & 641 & 5,530 & 6,300 & 11 & 3,760 & 93,400 & 4,850 & 21 & 35,900 & 7,180 & 11,900 \\
2 & 646 & 4,980 & 6,740 & 12 & 6,080 & 69,300 & 4,580 & 22 & 18,500 & 6,740 & 15,100 \\
3 & 632 & 4,480 & 6,960 & 13 & 3,720 & 39,500 & 4,490 & 23 & 22,200 & 6,300 & 17,900 \\
4 & 596 & 4,120 & 6,520 & 14 & 4,380 & 28,800 & 4,670 & 24 & 22,200 & 6,100 & 14,400 \\
5 & 582 & 3,870 & 6,300 & 15 & 5,420 & 21,400 & 6,740 & 25 & 15,200 & 5,900 & 12,200 \\
6 & 574 & 3,640 & 6,100 & 16 & 5,310 & 16,500 & 7,400 & 26 & 11,900 & 5,500 & 10,700 \\
7 & 564 & 3,430 & 5,700 & 17 & 14,900 & 12,800 & 13,100 & 27 & 9,820 & 5,500 & 9,900 \\
8 & 560 & 3,290 & 5,500 & 18 & 10,600 & 10,500 & 18,700 & 28 & 8,300 & 5,300 & 9,900 \\
9 & 560 & 3,220 & 5,210 & 19 & 16,900 & 9,120 & 16,500 & 29 & 7,050 & 5,120 & 9,640 \\
10 & 765 & 15,100 & 5,030 & 20 & 53,100 & 8,120 & 14,100 & 30 & 6,320 & 6,520 & 8,860 \\
\end{tabular}

Gage helght, in feet, and discharge, in second-feet, at indlcated time, 1937

\begin{tabular}{|c|c|c|c|c|c|c|c|c|c|c|c|c|}
\hline \multirow{2}{*}{ 芯 } & Feet & Sec.ft. & Foet & Sec.ft. & Feet & Sec.ft. & Feot & Sec.ft. & Feet & Sec.ft. & Feet & Sec.ft. \\
\hline & \multicolumn{2}{|c|}{ December 8} & \multicolumn{2}{|c|}{ December 9} & \multicolumn{2}{|c|}{ December 10} & \multicolumn{2}{|c|}{ December 11} & \multicolumn{2}{|c|}{ December 12} & \multicolumn{2}{|c|}{ December 13} \\
\hline $\begin{array}{r}2 \\
4 \\
6 \\
8 \\
10 \\
\mathbb{N} \\
2 \\
4 \\
6 \\
8 \\
10 \\
\mathrm{M}\end{array}$ & $\begin{array}{l}7.26 \\
7.26 \\
7.25 \\
7.23 \\
7.21 \\
7.20 \\
7.20 \\
7.19 \\
7.18 \\
7.17 \\
7.16 \\
7.16\end{array}$ & $\begin{array}{l}3,370 \\
3,370 \\
3,360 \\
3,330 \\
3,300 \\
3,290 \\
3,290 \\
3,280 \\
3,260 \\
3,250 \\
3,230 \\
3,230\end{array}$ & $\begin{array}{l}7.16 \\
7.15 \\
7.15 \\
7.14 \\
7.13 \\
7.12 \\
7.12 \\
7.12 \\
7.14 \\
7.16 \\
7.18 \\
7.21\end{array}$ & $\begin{array}{l}3,230 \\
3,220 \\
3,220 \\
3,210 \\
3,190 \\
3,180 \\
3,180 \\
3,180 \\
3,210 \\
3,230 \\
3,260 \\
3,300\end{array}$ & $\begin{array}{r}7.27 \\
7.40 \\
7.57 \\
7.79 \\
7.98 \\
8.35 \\
9.11 \\
11.05 \\
13.88 \\
16.93 \\
20.05 \\
22.86\end{array}$ & $\begin{array}{r}3,390 \\
3,570 \\
3,820 \\
4,180 \\
4,530 \\
5,310 \\
7,080 \\
12,000 \\
20,600 \\
33,700 \\
49,500 \\
65,800\end{array}$ & $\begin{array}{l}24.75 \\
25.46 \\
26.03 \\
26.52 \\
27.25 \\
28.05 \\
28.70 \\
28.40 \\
28.25 \\
27.89 \\
27.45 \\
27.05\end{array}$ & $\begin{array}{r}78,000 \\
82,700 \\
86,600 \\
90,000 \\
95,200 \\
101,000 \\
105,000 \\
103,000 \\
102,000 \\
99,600 \\
96,600 \\
93,800\end{array}$ & $\begin{array}{l}26.57 \\
26.05 \\
25.40 \\
24.75 \\
23.85 \\
23.05 \\
22.35 \\
21.75 \\
21.15 \\
20.65 \\
20.15 \\
19.75\end{array}$ & $\begin{array}{l}90,500 \\
86,900 \\
82,600 \\
78,400 \\
72,700 \\
67,700 \\
63,500 \\
60,000 \\
56,500 \\
53,700 \\
51,000 \\
48,900\end{array}$ & $\begin{array}{l}19.35 \\
18.95 \\
18.65 \\
18.35 \\
18.10 \\
17.85 \\
17.60 \\
17.40 \\
17.20 \\
16.95 \\
16.80 \\
16.65\end{array}$ & $\begin{array}{l}46,800 \\
44,800 \\
43,200 \\
41,800 \\
40,500 \\
39,300 \\
38,100 \\
37,100 \\
36,200 \\
35,000 \\
34,300 \\
33,600\end{array}$ \\
\hline & \multicolumn{2}{|c|}{ December 14} & \multicolumn{2}{|c|}{ December 15} & \multicolumn{2}{|c|}{ December 16} & \multicolumn{2}{|c|}{ December 17} & \multicolumn{2}{|c|}{ December 18} & \multicolumn{2}{|c|}{ December 19} \\
\hline $\begin{array}{r}2 \\
4 \\
6 \\
8 \\
10 \\
\mathbb{N} \\
2 \\
4 \\
6 \\
8 \\
10 \\
M \\
\end{array}$ & \begin{tabular}{|c|}
16.30 \\
- \\
15.93 \\
- \\
15.60 \\
- \\
15.31 \\
- \\
14.98 \\
14.70 \\
\end{tabular} & $\begin{array}{c}32,000 \\
- \\
30,300 \\
- \\
28,800 \\
27,500 \\
26,000 \\
24,800\end{array}$ & $\begin{array}{c}14.42 \\
- \\
14.15 \\
- \\
13.89 \\
- \\
13.57 \\
- \\
13.44 \\
13.24\end{array}$ & $\begin{array}{c}23,600 \\
- \\
22,400 \\
- \\
21,400 \\
20,500 \\
19,600 \\
- \\
18,800\end{array}$ & $\begin{array}{c}13.03 \\
- \\
12.80 \\
- \\
12.59 \\
- \\
12.42 \\
- \\
12.23 \\
12.01 \\
\end{array}$ & $\begin{array}{c}18,000 \\
17,200 \\
- \\
16,400 \\
15,800 \\
15,200 \\
14,400\end{array}$ & $\begin{array}{c}- \\
11.82 \\
11.66 \\
11.48\end{array}$ & $\begin{array}{c}13,800 \\
- \\
13,300 \\
- \\
12,700 \\
12,200 \\
- \\
11,800 \\
11,200\end{array}$ & $\begin{array}{c}10.88 \\
10.75 \\
- \\
10.66 \\
10.57 \\
10.52 \\
10.45\end{array}$ & $\begin{array}{c}11,000 \\
10,600 \\
- \\
10,400 \\
10,100 \\
9,960 \\
9,770\end{array}$ & $\begin{array}{c}10.33 \\
- \\
10.25 \\
- \\
10.16 \\
- \\
10.10 \\
- \\
10.02 \\
- \\
9.96\end{array}$ & $\begin{array}{c}9, \overline{4} 60 \\
9, \overline{2} 50 \\
\overline{-} \\
9, \overline{2} 0 \\
8, \overline{8} 60 \\
8, \overline{650} \\
\overline{8} \overline{5} 00\end{array}$ \\
\hline & \multicolumn{2}{|c|}{ December 20} & \multicolumn{2}{|c|}{ December 21} & \multicolumn{2}{|c|}{ December 22} & \multicolumn{2}{|c|}{ December 23} & \multicolumn{2}{|c|}{ December 24} & \multicolumn{2}{|c|}{ December 25} \\
\hline $\begin{array}{r}2 \\
4 \\
6 \\
8 \\
10 \\
\mathbb{N} \\
2 \\
4 \\
6 \\
8 \\
10 \\
M\end{array}$ & $\begin{array}{c}- \\
9.88 \\
- \\
9.78 \\
- \\
9.75 \\
- \\
9.72 \\
- \\
9.66 \\
- \\
9.61\end{array}$ & $\begin{array}{l}8, \overline{3} 10 \\
\overline{0} \\
8,070 \\
\overline{-} \overline{000} \\
7, \overline{930} \\
7, \overline{7} 80 \\
7, \overline{6} 60\end{array}$ & $\begin{array}{c}- \\
9.54 \\
- \\
9.46 \\
- \\
9.40 \\
- \\
9.36 \\
- \\
9.30 \\
\overline{9.24}\end{array}$ & $\begin{array}{l}7, \overline{500} \\
7, \overline{3} 10 \\
\overline{-} \\
7, \overline{-} \\
7, \overline{0} 90 \\
6, \overline{9} 60 \\
6, \overline{8} 30\end{array}$ & $\begin{array}{c}- \\
9.21 \\
- \\
9.17 \\
- \\
9.14 \\
-\overline{0} \\
9.13 \\
-\overline{0} \\
-11 \\
9.09\end{array}$ & $\begin{array}{l}6, \overline{7} 60 \\
6, \overline{670} \\
\overline{-} \\
6, \overline{-} \\
6, \overline{5} 90 \\
6, \overline{5} 40 \\
6, \overline{5} 00\end{array}$ & $\begin{array}{l}\overline{9.05} \\
-\overline{9.01} \\
\overline{8.96} \\
\overline{8.93} \\
\overline{8.91}\end{array}$ & $\begin{array}{l}6, \overline{4} 10 \\
6, \overline{3} 20 \\
\overline{\overline{2}} 20 \\
6, \overline{1} 60 \\
6, \overline{1} 20 \\
6, \overline{0000}\end{array}$ & $\begin{array}{c}8.84 \\
- \\
8.87 \\
- \\
8.88 \\
- \\
8.90 \\
- \\
8.97 \\
- \\
8.94\end{array}$ & $\begin{array}{l}5, \overline{980} \\
6, \overline{0} 00 \\
6, \overline{0} 60 \\
6, \overline{1} 00 \\
6, \overline{2} 40 \\
6, \overline{1} 80\end{array}$ & $\begin{array}{c}5 \\
8.91 \\
- \\
8.87 \\
- \\
8.81 \\
- \\
8.75 \\
- \\
8.71 \\
- \\
8.67\end{array}$ & $\begin{array}{c}6, \overline{120} \\
6, \overline{0} 40 \\
5, \overline{920} \\
5, \overline{800} \\
5, \overline{7} 20 \\
5, \overline{6} 40\end{array}$ \\
\hline
\end{tabular}


Owens River near Round Valley, Calif.

Location.- Lat. $37^{\circ} 26^{\prime} 25^{\prime \prime}$, long. $118^{\circ} 33^{\prime} 20^{*}$, in SEl sec. 10, T. 6 S., R. 31 E., below Sheep Bridge, 700 feet above mouth of Rock Creek and 2 miles north of Round Valley,

Inyo county. Altitude, about 4,450 feet above mean sea level.

Drainage area.- About 450 square miles.

Gage-helght record, - Water-stage recorder graph.

Stage-discharge relation. - Defined by current-meter measurements below 883 second-

feet; extended to peak stage.

Maxima.- December 1937: Discharge, 1,560 second-feet 8 p.m. Dec. 11 (gage he1ght, 4.87 feet).

1903-23, 1927-November 1937: Discharge, 1,190 second-feet June 30, 1907 (gage height, 4.0 feet).

Remarks:- Discharge at indicated time is the mean for the two-hour interval prior to the indicated hour. Recora furnished by eity of Los Angeles.

Mean dally discharge, in second-feet, November 1937 to January 1938

\begin{tabular}{|c|c|c|c|c|c|c|c|c|c|c|c|}
\hline Day & Not. & Dec. & Jan. & Day & Nov. & Doc. & Jan. & Day & Nov. & Dec. & Jan. \\
\hline $\begin{array}{r}1 \\
2 \\
3 \\
4 \\
5 \\
6 \\
7 \\
8 \\
9 \\
10\end{array}$ & $\begin{array}{l}146 \\
146 \\
146 \\
146 \\
143 \\
150 \\
148 \\
148 \\
152 \\
152\end{array}$ & $\begin{array}{l}142 \\
144 \\
146 \\
146 \\
146 \\
146 \\
146 \\
150 \\
152 \\
340\end{array}$ & $\begin{array}{l}176 \\
182 \\
178 \\
176 \\
172 \\
162 \\
160 \\
160 \\
158 \\
164\end{array}$ & $\begin{array}{l}11 \\
12 \\
13 \\
14 \\
15 \\
16 \\
17 \\
18 \\
19 \\
20\end{array}$ & $\begin{array}{l}156 \\
166 \\
166 \\
168 \\
160 \\
160 \\
166 \\
154 \\
160 \\
160\end{array}$ & $\begin{array}{l}734 \\
901 \\
491 \\
285 \\
257 \\
241 \\
227 \\
215 \\
213 \\
185\end{array}$ & $\begin{array}{l}162 \\
162 \\
152 \\
156 \\
164 \\
152 \\
166 \\
166 \\
166 \\
150\end{array}$ & $\begin{array}{l}21 \\
22 \\
23 \\
24 \\
25 \\
26 \\
27 \\
28 \\
29 \\
30 \\
31\end{array}$ & $\begin{array}{l}160 \\
160 \\
160 \\
162 \\
160 \\
156 \\
154 \\
152 \\
150 \\
144\end{array}$ & $\begin{array}{l}185 \\
181 \\
176 \\
160 \\
155 \\
157 \\
155 \\
157 \\
150 \\
160 \\
167\end{array}$ & $\begin{array}{l}150 \\
164 \\
154 \\
150 \\
150 \\
156 \\
156 \\
156 \\
154 \\
150 \\
158\end{array}$ \\
\hline \multicolumn{9}{|c|}{ 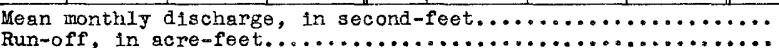 } & 9,230 & $\begin{array}{r}233 \\
14,300\end{array}$ & 9,880 \\
\hline
\end{tabular}

Gege helght, in feet, and discherge, in second-feet, at indiceted time, 1937

\begin{tabular}{|c|c|c|c|c|c|c|c|c|c|c|c|c|}
\hline \multirow{2}{*}{ รี } & Feet & Sec.ft. & $F \in e t$ & Sec.ft. & Feet & Sec.ft. & Feot & sec ft. & Feet & Sec.ft. & Feet & Sec.ft. \\
\hline & \multicolumn{2}{|c|}{ December 8} & \multicolumn{2}{|c|}{ December 9} & \multicolumn{2}{|c|}{ December 10} & \multicolumn{2}{|c|}{ December 11} & \multicolumn{2}{|c|}{ December 12} & \multicolumn{2}{|c|}{ December 13} \\
\hline \multirow[t]{2}{*}{$\begin{array}{r}2 \\
4 \\
6 \\
8 \\
10 \\
\mathbb{N} \\
2 \\
4 \\
6 \\
8 \\
10 \\
\mathbf{M}\end{array}$} & & & & & $\begin{array}{l}2.18 \\
2.19 \\
2.20 \\
2.22 \\
2.35 \\
2.40 \\
2.70 \\
3.05 \\
3.30 \\
3.40 \\
3.43 \\
3.35\end{array}$ & $\begin{array}{l}1.66 \\
168 \\
170 \\
174 \\
204 \\
216 \\
300 \\
426 \\
534 \\
577 \\
590 \\
556\end{array}$ & $\begin{array}{l}3.20 \\
3.05 \\
2.95 \\
2.92 \\
2.93 \\
3.00 \\
3.25 \\
3.65 \\
3.95 \\
4.65 \\
4.82 \\
4.65\end{array}$ & $\begin{array}{r}491 \\
426 \\
386 \\
375 \\
379 \\
405 \\
512 \\
704 \\
872 \\
1,370 \\
1,520 \\
1,370\end{array}$ & $\begin{array}{l}4.50 \\
4.20 \\
4.07 \\
4.15 \\
4.10 \\
4.00 \\
3.92 \\
3.82 \\
3.78 \\
3.76 \\
3.76 \\
3.71\end{array}$ & $\begin{array}{r}1,250 \\
1,040 \\
949 \\
1,000 \\
970 \\
900 \\
855 \\
799 \\
777 \\
766 \\
766 \\
738\end{array}$ & $\begin{array}{l}3.68 \\
3.60 \\
3.50 \\
3.40 \\
3.30 \\
3.22 \\
3.18 \\
3.08 \\
3.07 \\
3.02 \\
2.98 \\
2.97\end{array}$ & $\begin{array}{l}728 \\
683 \\
627 \\
571 \\
515 \\
471 \\
456 \\
419 \\
415 \\
396 \\
381 \\
378\end{array}$ \\
\hline & \multicolumn{2}{|c|}{ December 14} & \multicolumn{2}{|c|}{ December 15} & \multicolumn{2}{|c|}{ December 16} & \multicolumn{2}{|c|}{ December 17} & \multicolumn{2}{|c|}{ December 18} & \multicolumn{2}{|c|}{ December 19} \\
\hline $\begin{array}{r}2 \\
4 \\
6 \\
8 \\
10 \\
N \\
2 \\
4 \\
6 \\
8 \\
10 \\
4\end{array}$ & $\begin{array}{l}2.85 \\
2.80 \\
2.73 \\
2.67 \\
2.63 \\
2.60 \\
2.52 \\
2.55 \\
2.50 \\
2.57 \\
2.63 \\
2.64\end{array}$ & $\begin{array}{l}365 \\
346 \\
319 \\
297 \\
281 \\
270 \\
239 \\
251 \\
232 \\
256 \\
281 \\
285\end{array}$ & & & & & & & & & & \\
\hline
\end{tabular}


Rock Creek at Sherwin Hill, near Bishop, Cal1f.

Location. - Lat. $37^{\circ} 28^{1} 45^{n}$, long. $118^{\circ} 36^{\prime} 05^{n}$, in SW $\frac{1}{4}$ sec. 29, T. 5 S., R. 31 E., at Sherwin Hill, 3 miles above Plne Creek and 14 miles northwest of Bishop, Inyo County.

Altitude, about 4,900 feet above mean gea level.

Drainage area.- 51.7 square miles.

Gage-he1ght record. - Water-stage recorder graph.

Stage-discharge relation.- Standard rating for 6-foot improved ventur1. (Parshal1) flume. Maxima.- December 1937: Discharge, 115 second-feet 6 p.m. Dec. 11 (gage he1ght, 2.60 feet).

1922-November 1937: Discharge, 162 second-feet June 17, 1927 (gage he1ght, 3.04 feet, at former site).

Remarks.- Discharge at indicated time is the mean for the two-hour interval prior to the indicated hour. Record furnished by city of Los Angeles.

Mean de1ly discharge, in second-feet, November 1937 to January 1938

\begin{tabular}{|c|c|c|c|c|c|c|c|c|c|c|c|}
\hline Day & Nov. & Dec. & Jan. & Day & Nov. & Dec. & Jan. & Day & Nov. & Dec. & Jan. \\
\hline $\begin{array}{r}1 \\
2 \\
3 \\
4 \\
5 \\
6 \\
7 \\
8 \\
9 \\
10\end{array}$ & $\begin{array}{l}11 \\
11 \\
11 \\
10 \\
10 \\
10 \\
10 \\
10 \\
11 \\
10\end{array}$ & $\begin{array}{r}12 \\
13 \\
13 \\
13 \\
13 \\
13 \\
13 \\
12 \\
12 \\
* 44\end{array}$ & $\begin{array}{l}17 \\
16 \\
16 \\
15 \\
15 \\
14 \\
14 \\
14 \\
15 \\
15\end{array}$ & $\begin{array}{l}11 \\
12 \\
13 \\
14 \\
15 \\
16 \\
17 \\
18 \\
19 \\
20\end{array}$ & $\begin{array}{l}11 \\
10 \\
12 \\
12 \\
12 \\
12 \\
13 \\
13 \\
14 \\
14\end{array}$ & $\begin{array}{r}* 60 \\
36 \\
29 \\
24 \\
24 \\
24 \\
23 \\
22 \\
20 \\
17\end{array}$ & $\begin{array}{l}15 \\
15 \\
15 \\
15 \\
15 \\
14 \\
16 \\
15 \\
12 \\
10\end{array}$ & $\begin{array}{l}21 \\
22 \\
23 \\
24 \\
25 \\
26 \\
27 \\
28 \\
29 \\
30 \\
31\end{array}$ & $\begin{array}{l}14 \\
13 \\
13 \\
13 \\
13 \\
13 \\
13 \\
13 \\
12 \\
12\end{array}$ & $\begin{array}{l}19 \\
18 \\
16 \\
11 \\
12 \\
12 \\
13 \\
13 \\
14 \\
16 \\
17\end{array}$ & $\begin{array}{l}15 \\
16 \\
13 \\
11 \\
14 \\
14 \\
14 \\
15 \\
15 \\
10 \\
16\end{array}$ \\
\hline $\begin{array}{l}\text { Mean } \\
\text { Run- }\end{array}$ & , in & $10-1$ & 1 & & & & & & $\begin{array}{r}11.9 \\
706\end{array}$ & $\begin{array}{r}19.3 \\
1,190\end{array}$ & $\begin{array}{r}14.4 \\
885\end{array}$ \\
\hline
\end{tabular}

Gage helght, in feet, and discharge, in second-feet, at indicated time, 1937

\begin{tabular}{|c|c|c|c|c|c|c|c|c|c|c|c|c|}
\hline \multirow{2}{*}{ 密 } & Feet & Sec.ft. & Feet & Sec.ft. & Feet & Sec.ft. & Feet & Sec.ft. & Feet & Sec.ft. & Feot & sec.ft. \\
\hline & \multicolumn{2}{|c|}{ December 8} & \multicolumn{2}{|c|}{ December 9} & \multicolumn{2}{|c|}{ December 10} & \multicolumn{2}{|c|}{ December 11} & \multicolumn{2}{|c|}{ December 12} & \multicolumn{2}{|c|}{ December 13} \\
\hline $\begin{array}{r}2 \\
4 \\
6 \\
8 \\
10 \\
\mathrm{~N} \\
2 \\
4 \\
6 \\
8 \\
10 \\
\mathrm{M}\end{array}$ & & & $\begin{array}{r}0.67 \\
.67 \\
.67 \\
.65 \\
.65 \\
.65 \\
.65 \\
.65 \\
.65 \\
.66 \\
.67 \\
.72\end{array}$ & $\begin{array}{l}13 \\
13 \\
13 \\
12 \\
12 \\
12 \\
12 \\
12 \\
12 \\
12 \\
13 \\
14\end{array}$ & $\begin{array}{l}0.80 \\
.90 \\
1.35 \\
1.60 \\
1.75 \\
1.90 \\
1.80 \\
1.60 \\
1.50 \\
1.40 \\
1.30 \\
1.25\end{array}$ & $\begin{array}{l}17 \\
20 \\
39 \\
51 \\
59 \\
67 \\
61 \\
51 \\
46 \\
41 \\
36 \\
34\end{array}$ & $\begin{array}{l}1.15 \\
1.10 \\
1.07 \\
1.10 \\
1.35 \\
1.70 \\
1.90 \\
2.50 \\
2.60 \\
2.50 \\
2.05 \\
1.60\end{array}$ & $\begin{array}{r}30 \\
28 \\
31 \\
28 \\
39 \\
56 \\
67 \\
104 \\
115 \\
104 \\
75 \\
52\end{array}$ & $\begin{array}{l}1.35 \\
1.35 \\
1.40 \\
1.41 \\
1.36 \\
1.27 \\
1.23 \\
1.23 \\
1.22 \\
1.22 \\
1.20 \\
1.20\end{array}$ & $\begin{array}{l}39 \\
39 \\
41 \\
42 \\
39 \\
40 \\
33 \\
33 \\
33 \\
33 \\
32 \\
32\end{array}$ & $\begin{array}{l}1.18 \\
1.16 \\
1.14 \\
1.13 \\
1.11 \\
1.08 \\
1.00 \\
.98 \\
1.28 \\
1.09 \\
1.08 \\
1.07\end{array}$ & $\begin{array}{l}31 \\
30 \\
30 \\
29 \\
28 \\
27 \\
24 \\
23 \\
36 \\
28 \\
27 \\
27\end{array}$ \\
\hline & \multicolumn{2}{|c|}{ Decomber 14} & \multicolumn{2}{|c|}{ December 15} & \multicolumn{2}{|c|}{ De cember 16} & \multicolumn{2}{|c|}{ December 17} & \multicolumn{2}{|c|}{ December 18} & \multicolumn{2}{|c|}{ December 19} \\
\hline $\begin{array}{r}2 \\
4 \\
6 \\
8 \\
10 \\
\mathrm{~N} \\
2 \\
4 \\
6 \\
8 \\
10 \\
\mathrm{M}\end{array}$ & $\begin{array}{r}1.05 \\
1.03 \\
1.00 \\
.87 \\
.83 \\
.77 \\
.80 \\
1.05 \\
1.47 \\
1.15 \\
1.04 \\
1.02\end{array}$ & $\begin{array}{l}26 \\
25 \\
24 \\
19 \\
18 \\
16 \\
17 \\
26 \\
44 \\
30 \\
26 \\
25\end{array}$ & & & & & & & & & & \\
\hline
\end{tabular}

* Computed from b1-houriy discharge. 
Pine Creek at division box, near Bishop, Calif.

Iocation.- Lat. $37^{\circ} 24^{\prime} 55^{\prime \prime}$, long. $118^{\circ} 37^{\prime} 10^{\prime \prime}$, in NW sec. 19, T. 6 S., R. 31 E., a quarter of a mile above division box and forks of creek, 4 miles west of Round valley, and 13 miles northwest of Bishop, Inyo County. Altitude, about 5,250 feet above mean sea level.

Drainage area. - 37.9 square miles

Gage-height record.- Water-stage recorder graph.

Stage-discharge relation. - Defined by current-meter measurements.

Maxima.- December 1937: Discharge, 207 second-feet 3 p.m. Dec. il (gage he1ght, 2.88 fert).

1922-November 1937: Discherge, 350 second-feet July 21, 1936 (gage helght, 3.58 feet).

Remarks. - Discharge at indicated time is the mean for the two-hour interval prior to the indicated hour. Record furnished by city of Los Angeles.

\begin{tabular}{|c|c|c|c|c|c|c|c|c|c|c|c|}
\hline Day & Nov. & Dec. & Jan. & Day & Nov. & Dec. & Jen. & Day & Nov. & Dec. & Jan. \\
\hline $\begin{array}{r}1 \\
2 \\
3 \\
4 \\
5 \\
6 \\
7 \\
8 \\
9 \\
10\end{array}$ & $\begin{array}{l}17 \\
17 \\
17 \\
16 \\
16 \\
16 \\
16 \\
16 \\
16 \\
16\end{array}$ & $\begin{array}{r}15 \\
15 \\
15 \\
15 \\
15 \\
15 \\
16 \\
15 \\
17 \\
* 68\end{array}$ & $\begin{array}{l}22 \\
22 \\
20 \\
20 \\
19 \\
19 \\
19 \\
19 \\
19 \\
19\end{array}$ & $\begin{array}{l}11 \\
12 \\
13 \\
14 \\
15 \\
16 \\
17 \\
18 \\
19 \\
20\end{array}$ & $\begin{array}{l}16 \\
16 \\
16 \\
16 \\
16 \\
16 \\
16 \\
16 \\
16 \\
16\end{array}$ & $\begin{array}{r}* 97 \\
46 \\
34 \\
30 \\
30 \\
26 \\
25 \\
22 \\
20 \\
20\end{array}$ & $\begin{array}{l}19 \\
19 \\
19 \\
18 \\
18 \\
18 \\
19 \\
19 \\
18 \\
18\end{array}$ & $\begin{array}{l}21 \\
22 \\
23 \\
24 \\
25 \\
26 \\
27 \\
28 \\
29 \\
30 \\
31\end{array}$ & $\begin{array}{l}16 \\
16 \\
16 \\
16 \\
16 \\
16 \\
16 \\
16 \\
15 \\
15\end{array}$ & $\begin{array}{l}20 \\
19 \\
19 \\
17 \\
17 \\
16 \\
16 \\
16 \\
16 \\
19 \\
22\end{array}$ & $\begin{array}{l}18 \\
18 \\
18 \\
18 \\
18 \\
18 \\
18 \\
18 \\
19 \\
18 \\
19\end{array}$ \\
\hline $\begin{array}{l}\text { Mean } \\
\text { Run- }\end{array}$ & $\begin{array}{l}\text { nthl } \\
\text { in }\end{array}$ & & 1n & & & & & & $\begin{array}{r}16.0 \\
954\end{array}$ & $\begin{array}{r}24.3 \\
1,490\end{array}$ & $\begin{array}{r}18.9 \\
1,160\end{array}$ \\
\hline
\end{tabular}

Gage height, in feet, and dscharge, in second-feet, at indicated time, 1837

\begin{tabular}{|c|c|c|c|c|c|c|c|c|c|c|c|c|}
\hline \multirow{2}{*}{$\begin{array}{l} \\
0 \\
0 \\
0\end{array}$} & Feet & Sec.ft. & Feet & Sec.ft. & Feet & Sec.ft. & Feet & Sec.ft. & Feet & Sec.ft. & Feet & Sec.ft. \\
\hline & \multicolumn{2}{|c|}{ December 8} & \multicolumn{2}{|c|}{ December 9} & \multicolumn{2}{|c|}{ December 10} & \multicolumn{2}{|c|}{ December 11} & \multicolumn{2}{|c|}{ December 12} & \multicolumn{2}{|c|}{ December 13} \\
\hline $\begin{array}{r}2 \\
4 \\
6 \\
8 \\
10 \\
\mathrm{~N} \\
2 \\
4 \\
6 \\
8 \\
10 \\
\mathrm{M}\end{array}$ & & & $\begin{array}{l}1.09 \\
1.09 \\
1.09 \\
1.09 \\
1.09 \\
1.09 \\
1.09 \\
1.09 \\
1.10 \\
1.13 \\
1.18 \\
1.26\end{array}$ & $\begin{array}{l}16 \\
15 \\
15 \\
15 \\
15 \\
15 \\
15 \\
15 \\
16 \\
18 \\
21 \\
25\end{array}$ & $\begin{array}{l}1.86 \\
1.98 \\
2.04 \\
2.76 \\
2.30 \\
2.08 \\
1.83 \\
1.74 \\
1.68 \\
1.58 \\
1.53 \\
1.48\end{array}$ & $\begin{array}{r}62 \\
70 \\
73 \\
180 \\
76 \\
75 \\
60 \\
56 \\
51 \\
45 \\
42 \\
39\end{array}$ & $\begin{array}{l}1.48 \\
1.51 \\
1.60 \\
1.93 \\
2.65 \\
2.70 \\
2.70 \\
2.78 \\
2.30 \\
2.30 \\
2.00 \\
1.80\end{array}$ & $\begin{array}{r}39 \\
41 \\
46 \\
66 \\
155 \\
166 \\
166 \\
184 \\
88 \\
88 \\
76 \\
64\end{array}$ & $\begin{array}{l}1.77 \\
1.68 \\
1.64 \\
1.58 \\
1.56 \\
1.53 \\
1.53 \\
1.52 \\
1.50 \\
1.48 \\
1.47 \\
1.45\end{array}$ & $\begin{array}{l}56 \\
51 \\
49 \\
45 \\
44 \\
42 \\
42 \\
41 \\
40 \\
39 \\
38 \\
37\end{array}$ & $\begin{array}{c}- \\
1.43 \\
- \\
1.41 \\
- \\
1.40 \\
- \\
1.39 \\
- \\
1.37 \\
1.37\end{array}$ & $\begin{array}{l}- \\
36 \\
- \\
35 \\
- \\
34 \\
- \\
34 \\
- \\
32 \\
32\end{array}$ \\
\hline
\end{tabular}


Big Pine Creek below Ilttio Pine Creok, near Big Pine, Cal1f.

Location.- Eat. 37\%09', long. $118^{\circ} 19^{\prime}, \mathrm{N} \frac{1}{2}$ sec. 25, T. 9 S., R. 33 F., below Big P1ne

Creek power house and $2 \frac{1}{4}$ miles southwest of B1g Pine, Inyo County. Altitude, about 4,400 feet above mean sea level.

Drainage area. - 39.5 square miles.

Gage-height record. - Water-stage recorder graph.

Stage-discharge relation. - Defined by current-meter measurements.

Maxima:- Decenber 1937: Discharge, 79 second-feet 2:30 p.m. Dec. 11 (gage he1ght, 1.52 feet ).

1904-5, 1907-10: Mean da11y discharge, 268 second-feet July 10-12, 1905.

Remarks.- Discharge at indicated time is the mesn for the two-hour interval prior to

the indicated hour. Records furnished by city of Los Angeles.

Mean daliy discharge, in second-feet, November 1937 to January 1938

\begin{tabular}{|c|c|c|c|c|c|c|c|c|c|c|c|}
\hline Day & Nov. & Dec. & Jan. & Day & Nov. & Dec. & $\operatorname{Jan}$. & Day & Nov. & Dec. & Jan. \\
\hline $\begin{array}{r}1 \\
2 \\
3 \\
4 \\
5 \\
6 \\
7 \\
8 \\
9 \\
10\end{array}$ & $\begin{array}{l}16 \\
17 \\
16 \\
16 \\
16 \\
16 \\
12 \\
14 \\
9.5 \\
7.5\end{array}$ & $\begin{array}{l}3.9 \\
4.1 \\
4.3 \\
4.5 \\
4.7 \\
4.9 \\
5 \\
5.5 \\
26.5 \\
23\end{array}$ & $\begin{array}{l}14 \\
14 \\
13 \\
14 \\
13 \\
13 \\
13 \\
13 \\
12 \\
12\end{array}$ & $\begin{array}{l}11 \\
12 \\
13 \\
14 \\
15 \\
16 \\
17 \\
18 \\
19 \\
20\end{array}$ & $\begin{array}{l}8.5 \\
8.5 \\
7 \\
5 \\
4.8 \\
4.8 \\
6 \\
6 \\
6 \\
6\end{array}$ & $\begin{array}{r}* 43 \\
26 \\
21 \\
19 \\
18 \\
16 \\
15 \\
15 \\
14 \\
14\end{array}$ & $\begin{array}{l}12 \\
12 \\
12 \\
12 \\
12 \\
12 \\
12 \\
12 \\
12 \\
11\end{array}$ & $\begin{array}{l}21 \\
22 \\
23 \\
24 \\
25 \\
26 \\
27 \\
28 \\
29 \\
30 \\
31\end{array}$ & $\begin{array}{l}6 \\
6 \\
5.5 \\
5.5 \\
4.9 \\
4.9 \\
3.9 \\
3.9 \\
3.4 \\
3.9\end{array}$ & $\begin{array}{l}14 \\
14 \\
14 \\
15 \\
14 \\
13 \\
14 \\
14 \\
14 \\
14 \\
14\end{array}$ & $\begin{array}{c}12 \\
11 \\
10 \\
9 \\
10 \\
10 \\
10 \\
10 \\
11 \\
8.5 \\
11\end{array}$ \\
\hline $\begin{array}{l}\text { Mean } \\
\text { Run- }\end{array}$ & $\mathrm{f}$, in & $\theta-1$ & $\cdots$ & & & & & & $\begin{array}{r}8.35 \\
497\end{array}$ & $\begin{array}{r}13.6 \\
836\end{array}$ & $\begin{array}{r}11.7 \\
719\end{array}$ \\
\hline
\end{tabular}

Gage height, in feet, and discharge, in second-feet, at indicated time, 1937

\begin{tabular}{|c|c|c|c|c|c|c|c|c|c|c|c|c|}
\hline \multirow{2}{*}{ 啇 } & Feet & Sec.ft. & Feet & Sec.ft. & Feet & Sec.ft. & Feet & Sec.ft. & Feet & Sec.ft. & Feet & Sec.ft. \\
\hline & \multicolumn{2}{|c|}{ December 8} & \multicolumn{2}{|c|}{ December 9} & \multicolumn{2}{|c|}{ Docember 10} & \multicolumn{2}{|c|}{ December 11} & \multicolumn{2}{|c|}{ December 12} & \multicolumn{2}{|c|}{ December 13} \\
\hline \multirow[t]{2}{*}{$\begin{array}{r}2 \\
4 \\
6 \\
8 \\
10 \\
1 \\
2 \\
4 \\
6 \\
8 \\
10 \\
M\end{array}$} & & & $\begin{array}{r}0.31 \\
.31 \\
.31 \\
.31 \\
.31 \\
.31 \\
.31 \\
.31 \\
.31 \\
.35 \\
.38 \\
.37\end{array}$ & $\begin{array}{l}6 \\
6 \\
6 \\
6 \\
6 \\
6 \\
6 \\
6 \\
6 \\
7 \\
9 \\
8\end{array}$ & $\begin{array}{r}0.42 \\
.45 \\
.87 \\
.95 \\
1.00 \\
.90 \\
.78 \\
.77 \\
.75 \\
.75 \\
.72 \\
.69\end{array}$ & $\begin{array}{l}10 \\
12 \\
29 \\
33 \\
35 \\
31 \\
25 \\
25 \\
24 \\
24 \\
23 \\
22\end{array}$ & $\begin{array}{r}0.68 \\
.67 \\
.69 \\
.85 \\
1.10 \\
1.50 \\
1.50 \\
1.45 \\
1.20 \\
1.10 \\
1.05 \\
1.00\end{array}$ & $\begin{array}{l}21 \\
21 \\
22 \\
28 \\
40 \\
78 \\
78 \\
73 \\
50 \\
40 \\
35 \\
32\end{array}$ & $\begin{array}{r}0.95 \\
.90 \\
.85 \\
.82 \\
.80 \\
.78 \\
.77 \\
.81 \\
.75 \\
.75 \\
.73 \\
.72\end{array}$ & $\begin{array}{l}30 \\
31 \\
29 \\
27 \\
26 \\
25 \\
25 \\
27 \\
24 \\
24 \\
23 \\
23\end{array}$ & $\begin{array}{r}0.70 \\
.69 \\
.68 \\
.75 \\
.67 \\
.82 \\
.70 \\
.70 \\
.67 \\
.70 \\
.60 \\
.61\end{array}$ & $\begin{array}{l}22 \\
21 \\
21 \\
24 \\
21 \\
27 \\
22 \\
22 \\
21 \\
22 \\
17 \\
18\end{array}$ \\
\hline & \multicolumn{2}{|c|}{ December 14} & \multicolumn{2}{|c|}{ De cember 15} & \multicolumn{2}{|c|}{ December 16} & \multicolumn{2}{|c|}{ December 17} & \multicolumn{2}{|c|}{ December 18} & \multicolumn{2}{|c|}{ December 19} \\
\hline $\begin{array}{r}2 \\
4 \\
6 \\
8 \\
10 \\
\mathrm{~N} \\
2 \\
4 \\
6 \\
8 \\
10 \\
\mathrm{M}\end{array}$ & $\begin{array}{r}0.61 \\
.63 \\
.67 \\
.67 \\
.60 \\
.60 \\
.60 \\
.69 \\
.69 \\
.68 \\
.67 \\
.67\end{array}$ & $\begin{array}{l}18 \\
19 \\
21 \\
21 \\
17 \\
17 \\
17 \\
21 \\
21 \\
21 \\
21 \\
21\end{array}$ & & & & & & & & & & \\
\hline
\end{tabular}

Supplenental records.- Dec. 11, 2:30 p.m., $1.52 \mathrm{ft.,} 79$ sec.-ft. * Computed from bi-hourly discharge. 
Independence Creek at Independence, Cal1f.*

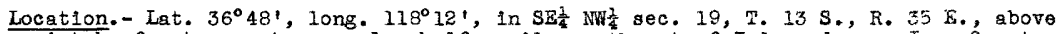
lntake for town water supply, half a mile southwest of Independence, Inyo county. Altitude, about 4,200 feet above mean sea level.

Dralnage area.- 17.6 square m1les.

Gage-helght record. - Water-stage recorder graph at combination weir and submerged orifice.

Stage-discharge relation. - Based on formulas for weir and subinerged orfflce.

Maxima.-December 1937: Discharge, 31 second-feet 6 p. m., Dec. 11 (gage he1ght, 1.96 feet).

1905-11: Daily aischarge (estimateá), 226 second-feet in June 1906.

Remarks. - In the second table gage helght and discharge given are the mean for the two-hour interval preceding the indicated hour. Record furnished by city of los

Angeles.

Mean dally discharge, in second-feet, Kovember 1937 to January 1938

\begin{tabular}{|c|c|c|c||c|c|c|c|c|c|c|c|}
\hline Day & Nov. & Dec. & Jan. & Day & Nov. & Dec. & Jan. & Day & Nov. & Dec. & Jan. \\
\hline 1 & 3.8 & 3.3 & 4.5 & 11 & 3.6 & +15 & 4.1 & 21 & 3.6 & 4.8 & 4.1 \\
2 & 3.8 & 3.3 & 4.5 & 12 & 3.6 & 10 & 3.9 & 22 & 3.6 & 4.8 & 3.8 \\
3 & 3.8 & 3.2 & 4.3 & 13 & 3.6 & 8 & 3.9 & 23 & 3.6 & 5 & 3.6 \\
4 & 3.8 & 3.1 & 4.3 & 14 & 3.6 & 7 & 3.9 & 24 & 3.4 & 4.8 & 3.8 \\
5 & 3.8 & 3.1 & 4.3 & 15 & 3.6 & 6.5 & 3.9 & 25 & 3.4 & 5.5 & 3.9 \\
6 & 3.6 & 3.1 & 4.3 & 16 & 3.6 & 6 & 3.9 & 26 & 3.4 & 8 & 3.9 \\
7 & 3.4 & 3.1 & 4.1 & 17 & 3.6 & 5.5 & 3.9 & 27 & 3.4 & 4.8 & 3.8 \\
8 & 3.4 & 3.1 & 4.1 & 18 & 3.6 & 5.5 & 3.9 & 28 & 3.3 & 4.6 & 3.6 \\
9 & 3.6 & 3.1 & 4.1 & 19 & 3.6 & 5.5 & 3.9 & 29 & 3.3 & 4.6 & 3.6 \\
10 & 3.6 & 414 & 4.1 & 20 & 3.6 & 5 & 4.1 & 30 & 3.3 & 4.6 & 3.4 \\
\end{tabular}

Gage helght, in feet, and discharge, in second-feet, at indicated time, 1937

\begin{tabular}{|c|c|c|c|c|c|c|c|c|c|c|c|c|}
\hline \multirow{2}{*}{$\begin{array}{l}8 \\
0 \\
0\end{array}$} & Feet & sec.ft. & Feot & Sec.ft. & Fert & Sec.ft. & Foot & sec.ft. & Fe日t & Sec.ft. & Feot & sec.ft. \\
\hline & \multicolumn{2}{|c|}{ December 8} & \multicolumn{2}{|c|}{ December 9} & \multicolumn{2}{|c|}{ December 10} & \multicolumn{2}{|c|}{ December 11} & \multicolumn{2}{|c|}{ December 12} & \multicolumn{2}{|c|}{ December 13} \\
\hline 2 & & & 3.83 & 3.0 & 3.43 & 11 & 3.60 & 7 & 3.20 & 16 & 3.52 & 9 \\
\hline 4 & & & 3.83 & 3.0 & 3.00 & 18 & 3.62 & 6.5 & 3.30 & 14 & 3.53 & 8.5 \\
\hline 6 & & & 3.83 & 3.0 & 2.80 & 20 & 3.62 & 6.5 & 3.40 & 12 & 3.53 & 8.6 \\
\hline 8 & & & 3.83 & 3.0 & 2.50 & 23 & 3.63 & 6.5 & 3.45 & 10 & 3.54 & 8.5 \\
\hline 10 & & & 3.83 & 3.0 & 2.15 & 26 & 3.58 & 7.6 & 3.47 & 10 & 3.6 & 8 \\
\hline 积 & & & 3.83 & 3.0 & 3.00 & 18 & 3.55 & 8 & 3.48 & 10 & 3.55 & 8 \\
\hline 2 & & & 3.83 & 3.0 & 3.30 & 14 & 3.00 & 18 & 3.49 & 9.5 & & 8 \\
\hline 4 & & & 3.83 & 3.0 & 3.42 & 11 & 2.00 & 29 & 3.50 & 9.5 & 3.5 & 8 \\
\hline 6 & & & 3.82 & 3.1 & 3.50 & 9.5 & 1.5 & 31. & 3. & & 3. & 8 \\
\hline 8 & & & 3.81 & 3.3 & 3.54 & 8.6 & 2.50 & 23 & 3.52 & 9 & 3.57 & 8 \\
\hline 10 & & & 3.77 & 3.9 & 3.67 & 8 & 2.82 & 20 & 3.53 & 8.6 & 3.57 & 8 \\
\hline M & & & 3.62 & 6.5 & 3.58 & 7.5 & 3.00 & 18 & 3.54 & 8.5 & 3.58 & 7.6 \\
\hline
\end{tabular}

* Published as Independence Creek near Independence, 1905-9, and as Little Pine Creek nesi Independence, 1910-11.

tComputed from b1-hourly dischargo. 


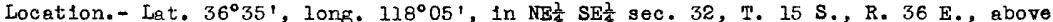
division box, at base of Alabama Hills, about $1 \frac{1}{2}$ miles southwest of Ione Pine, Inyo County. Altitude, about 4,000 feet above mean sea level.

Drainage area.- 8.5 square miles.

Gage-he1ght recora. - Water-stage recoraer graph.

Stage-discharge relation. - Standard rating for 3 foot improved ventur1 (Parshall) flume. Mexlma:- December 1937: Discharge, 41 second-feet about 4 p.m. Dec. Il (gage he1ght, 2.20 feet).

Remarks. - Discharge at indicated time is the mean for the two-hour interval prior to the

indicated hour. Record furnished by city of Los Angeles.

Mean defly discherge, in second-feet, November 1937 to January 1938

\begin{tabular}{|c|c|c|c|c|c|c|c|c|c|c|c|}
\hline Day & Nov. & Dec. & Jan. & Day & Nov. & Dec. & Jan. & Day & Nov. & Dec. & Jan. \\
\hline $\begin{array}{r}1 \\
2 \\
3 \\
4 \\
5 \\
6 \\
7 \\
8 \\
9 \\
10\end{array}$ & $\begin{array}{l}5 \\
5 \\
5 \\
5 \\
5 \\
5 \\
4.8 \\
5 \\
5 \\
5\end{array}$ & $\begin{array}{l}4.7 \\
4.7 \\
4.7 \\
4.7 \\
4.7 \\
4.6 \\
4.6 \\
4.6 \\
4.8 \\
15\end{array}$ & $\begin{array}{l}5.5 \\
5.5 \\
5.5 \\
5 \\
5 \\
5 \\
5 \\
5 \\
5 \\
5\end{array}$ & $\begin{array}{l}11 \\
12 \\
13 \\
14 \\
16 \\
16 \\
17 \\
18 \\
19 \\
20\end{array}$ & $\begin{array}{l}5 \\
5 \\
5 \\
5 \\
4.8 \\
4.8 \\
4.8 \\
4.7 \\
4.8 \\
5\end{array}$ & $\begin{array}{l}21 \\
8 \\
6.5 \\
6.5 \\
6.5 \\
6 \\
6 \\
6 \\
6 \\
6\end{array}$ & $\begin{array}{l}5 \\
5 \\
4.8 \\
4.8 \\
4.8 \\
4.8 \\
4.8 \\
4.8 \\
4.7 \\
4.6\end{array}$ & $\begin{array}{l}21 \\
22 \\
23 \\
24 \\
25 \\
26 \\
27 \\
28 \\
29 \\
30 \\
31\end{array}$ & $\begin{array}{l}5 \\
4.8 \\
4.7 \\
4.4 \\
4.4 \\
4.4 \\
4.6 \\
4.6 \\
4.7 \\
4.7\end{array}$ & $\begin{array}{l}6 \\
6 \\
6 \\
6 \\
6 \\
6 \\
5.5 \\
5.5 \\
5.5 \\
5.5 \\
5.5 \\
\end{array}$ & $\begin{array}{l}4.7 \\
4.7 \\
4.6 \\
4.6 \\
4.6 \\
4.7 \\
4.6 \\
4.6 \\
4.6 \\
4.7 \\
4.6 \\
\end{array}$ \\
\hline $\begin{array}{l}\text { Mean } \\
\text { Run- }\end{array}$ & , in & $\theta-10$ & 0 & & & & & & $\begin{array}{r}4.83 \\
288\end{array}$ & $\begin{array}{r}6.42 \\
395\end{array}$ & $\begin{array}{r}4.86 \\
299\end{array}$ \\
\hline
\end{tabular}

Gage helght, in feet, and discharge, in second-feet, at inalcated time, 1937

\begin{tabular}{|c|c|c|c|c|c|c|c|c|c|c|c|c|}
\hline \multirow{2}{*}{ 电 } & Feet & Sec.ft. & Fest & sec.ft. & Feet & Sec.ft. & Feet & sec.ft. & Peet & Sec.ft. & Feet & sec.ft. \\
\hline & \multicolumn{2}{|c|}{ December 8} & \multicolumn{2}{|c|}{ December 9} & \multicolumn{2}{|c|}{ December 10} & \multicolumn{2}{|c|}{ December 11} & \multicolumn{2}{|c|}{ December 12} & \multicolumn{2}{|c|}{ December 13} \\
\hline $\begin{array}{r}2 \\
4 \\
6 \\
8 \\
10 \\
N \\
2 \\
4 \\
6 \\
8 \\
10 \\
M\end{array}$ & & & $\begin{array}{r}0.55 \\
.55 \\
.55 \\
.55 \\
.55 \\
.56 \\
.56 \\
.55 \\
.55 \\
.55 \\
.56 \\
.64\end{array}$ & $\begin{array}{l}4.7 \\
4.7 \\
4.7 \\
4.7 \\
4.7 \\
4.8 \\
4.8 \\
4.7 \\
4.7 \\
4.7 \\
4.8 \\
6\end{array}$ & $\begin{array}{l}0.80 \\
1.00 \\
1.35 \\
1.31 \\
1.42 \\
1.22 \\
1.20 \\
1.20 \\
1.20 \\
1.21 \\
1.21 \\
1.21\end{array}$ & $\begin{array}{l}8.5 \\
12 \\
19 \\
18 \\
21 \\
16 \\
16 \\
16 \\
16 \\
16 \\
16 \\
16\end{array}$ & $\begin{array}{l}1.21 \\
1.21 \\
1.21 \\
1.21 \\
1.21 \\
1.21 \\
1.40 \\
2.20 \\
2.00 \\
1.70 \\
1.40 \\
1.20\end{array}$ & $\begin{array}{l}16 \\
16 \\
16 \\
16 \\
16 \\
16 \\
20 \\
41 \\
36 \\
28 \\
20 \\
16\end{array}$ & $\begin{array}{l}1.12 \\
.90 \\
.73 \\
.72 \\
.71 \\
.71 \\
.71 \\
.70 \\
.70 \\
.70 \\
.71 \\
.71\end{array}$ & $\begin{array}{c}14 \\
10 \\
7.5 \\
7 \\
7 \\
7 \\
7 \\
7 \\
7 \\
7 \\
7 \\
7\end{array}$ & & \\
\hline
\end{tabular}


Bridgeport Reservoir near Bridgeport, Calif.

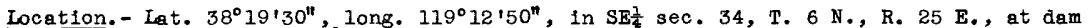

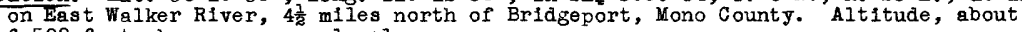
6,500 feet above mean sea level.

Gage-height record.- Gage read once daily.

Remarks. - Flood run-off completely controlled in reservoir (capacity, 42,500 acrefeet). Gage-height record and capacity table furnished by Walker River Irrigation District.

Contents, in acre-feet, November 1937 to January 1938

\begin{tabular}{|r|l|l|l||r|l|l|l||r|r|r|l|}
\hline Day & Nov. & Dec. & Jan. & Day & Nov. & Dec. & Jan. & Day & Nov. & Dec. & Jan. \\
\hline 1 & 15,470 & 18,350 & 30,120 & 11 & 16,500 & 19,330 & 32,080 & 21 & 17,060 & 27,200 & 33,860 \\
2 & 15,630 & 18,520 & 30,360 & 12 & 16,500 & 19,610 & 32,330 & 22 & 17,230 & 27,780 & 34,110 \\
3 & 15,710 & 18,700 & 30,610 & 13 & 16,580 & 19,880 & 32,460 & 23 & 17,580 & 28,010 & 34,240 \\
4 & 15,790 & 18,780 & 30,850 & 14 & 16,580 & 20,250 & 32,590 & 24 & 17,750 & 28,240 & 34,380 \\
5 & 15,870 & 18,780 & 30,970 & 15 & 16,660 & 21,600 & 32,840 & 25 & 17,920 & 28,470 & 34,510 \\
6 & 15,950 & 18,870 & 31,210 & 16 & 16,740 & 22,790 & 32,960 & 26 & 18,000 & 28,820 & 34,640 \\
7 & 16,030 & 18,960 & 31,330 & 17 & 16,740 & 24,040 & 33,090 & 27 & 18,000 & 29,160 & 34,740 \\
8 & 16,180 & 18,960 & 31,570 & 18 & 16,820 & 25,100 & 33,220 & 28 & 18,090 & 29,400 & 35,040 \\
9 & 16,260 & 19,050 & 31,700 & 19 & 16,820 & 25,980 & 33,480 & 29 & 18,090 & 29,520 & 35,170 \\
10 & 16,420 & 19,150 & 31,950 & 20 & 16,900 & 26,530 & 33,600 & 30 & 18,180 & 29,640 & 35,440 \\
& & & & & & & & 31 & & 29,880 & 35,570 \\
\hline
\end{tabular}

$1608020-39-19$ 
HUMBOLDT-CARSON SINK BASIN

Carson River at Lahontan Reservoir, Nev.

Location.- Lat. $39^{\circ} 28^{\prime}$, long. $119^{\circ} 04^{\prime}$, in SE $\frac{1}{4}$ sec. 33, T. 19 N., R. 26 E., at Lahontan Dam, Lyon County, Névada.

Drainage area.- About 1,200 square miles.

Remarks.-Flood mun-off completely regulated in Lahontan Reservolr. Elevat1on of splll-

way crest is 4,162.0 feet above mean sea level (capacity, 273, 600 acre-feet). Daily

change in storage adjusted for release and inflow to show natural run-off. All data

furnished by Trucke-Carson Irrigation District.

Storage, release, inflow, and discharge, December 1937

\begin{tabular}{|c|c|c|c|c|c|}
\hline \multirow[b]{2}{*}{ Day } & \multicolumn{3}{|c|}{ Lahontan Reservolr } & \multirow[b]{2}{*}{$\begin{array}{l}\text { Inflow from } \\
\text { Trucke } \text { Panal } \\
\text { (second-feet) }\end{array}$} & \multirow[b]{2}{*}{$\begin{array}{c}\text { Computed } \\
\text { natural mun-off } \\
(\text { second-f } \theta \theta t)\end{array}$} \\
\hline & $\begin{array}{l}\text { Contents } \\
(\operatorname{acr} \theta-f \theta \theta t)\end{array}$ & 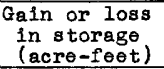 & $\begin{array}{c}\text { Release } \\
(s e c o n d-f \theta \theta t)\end{array}$ & & \\
\hline $\begin{array}{l}1 \\
2 \\
3 \\
4 \\
5\end{array}$ & $\begin{array}{l}136,422 \\
136,830 \\
137,136 \\
137,493 \\
137,901\end{array}$ & $\begin{array}{l}+469 \\
+408 \\
+306 \\
+357 \\
+408\end{array}$ & $\begin{array}{r}85 \\
87 \\
41 \\
5 \\
5\end{array}$ & $\begin{array}{l}222 \\
232 \\
192 \\
151 \\
142\end{array}$ & $\begin{array}{r}99 \\
61 \\
3 \\
34 \\
69\end{array}$ \\
\hline $\begin{array}{r}6 \\
7 \\
8 \\
9 \\
10\end{array}$ & $\begin{array}{l}138,360 \\
138,717 \\
139,074 \\
139,431 \\
139,992\end{array}$ & $\begin{array}{l}+459 \\
+357 \\
+357 \\
+357 \\
+561\end{array}$ & $\begin{array}{l}5 \\
5 \\
5 \\
5 \\
5\end{array}$ & $\begin{array}{l}136 \\
120 \\
115 \\
122 \\
216\end{array}$ & $\begin{array}{r}100 \\
65 \\
70 \\
63 \\
72\end{array}$ \\
\hline $\begin{array}{l}11 \\
12 \\
13 \\
14 \\
15\end{array}$ & $\begin{array}{l}140,920 \\
142,342 \\
145,600 \\
151,000 \\
160,818\end{array}$ & $\begin{array}{r}+928 \\
+1,422 \\
+3,258 \\
+5,400 \\
+9,818\end{array}$ & $\begin{array}{l}5 \\
5 \\
5 \\
5 \\
5\end{array}$ & $\begin{array}{l}445 \\
505 \\
480 \\
442 \\
445\end{array}$ & $\begin{array}{r}28 \\
217 \\
1,170 \\
2,290 \\
4,510\end{array}$ \\
\hline $\begin{array}{l}16 \\
17 \\
18 \\
19 \\
20\end{array}$ & $\begin{array}{l}165,733 \\
168,133 \\
170,072 \\
171,864 \\
173,336\end{array}$ & $\begin{array}{l}+4,915 \\
+2,400 \\
+1,939 \\
+1,792 \\
+1,472\end{array}$ & $\begin{array}{l}5 \\
5 \\
5 \\
5 \\
5\end{array}$ & $\begin{array}{r}109 \\
41 \\
68 \\
51 \\
59\end{array}$ & $\begin{array}{r}2,370 \\
1,170 \\
915 \\
857 \\
688\end{array}$ \\
\hline $\begin{array}{l}21 \\
22 \\
23 \\
24 \\
25\end{array}$ & $\begin{array}{l}174,808 \\
176,564 \\
177,856 \\
179,216 \\
180,304\end{array}$ & $\begin{array}{l}+1,472 \\
+1,756 \\
+1,292 \\
+1,360 \\
+1,088\end{array}$ & $\begin{array}{l}\mathbf{5} \\
\mathbf{5} \\
\mathbf{5} \\
5 \\
5\end{array}$ & $\begin{array}{l}136 \\
141 \\
134 \\
131 \\
136\end{array}$ & $\begin{array}{l}611 \\
749 \\
522 \\
560 \\
418\end{array}$ \\
\hline $\begin{array}{l}26 \\
27 \\
28 \\
29 \\
30 \\
31\end{array}$ & $\begin{array}{l}181,525 \\
182,525 \\
183,620 \\
184,600 \\
185,720 \\
186,700\end{array}$ & $\begin{array}{r}+1,221 \\
+1,000 \\
+1,095 \\
+980 \\
+1,120 \\
+980\end{array}$ & $\begin{array}{l}5 \\
5 \\
5 \\
5 \\
5 \\
3.5 \\
\end{array}$ & $\begin{array}{l}122 \\
128 \\
121 \\
138 \\
143 \\
152\end{array}$ & $\begin{array}{l}499 \\
381 \\
436 \\
361 \\
427 \\
346\end{array}$ \\
\hline \multicolumn{5}{|c|}{ 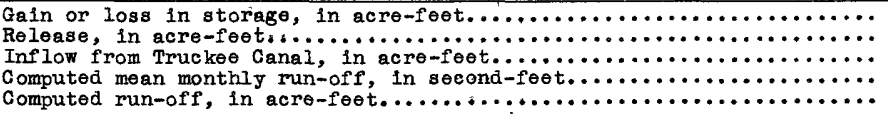 } & $\begin{array}{r}+50,747 \\
698 \\
11,450 \\
650 \\
39,990\end{array}$ \\
\hline
\end{tabular}


Lake Tahoe at Tahoe, Calif.

Location.- Lat. $39^{\circ} 05^{\prime} 55^{n}$, long. $120^{\circ} 08^{\prime} 25^{n}$, In WW sec. 7, T. 15 N., R. 17 E., near outlet of lake at Tahoe, Placer County. Zero of gage is 6,219.01 toet above mean sea level (general adjustment of 1929).

Drainage area.- 519 square milos (including water surface of lake, which $1 \mathrm{~s} 193 \mathrm{square}$ milos).

Gage-helght record. - Gage read to hundredths dally about 7 a.m.

Maxima,- December 1937: Gage helght, 4.81 feet Dec. 19.

1900-November 1937: Gage helght, 11.26 feet July 14, 15, 17, 18, 1907.

Remarks.- Flood mun-off completely controlled in lake. Se日 record for Trucke日 R1ver at Tahos. Records furniahod by Trucke日-Carson Irrigation District and H. C. Dukes, Federal water master.

Gage helght, in feet, November 1937 to January 1938

\begin{tabular}{|c|c|c|c|c|c|c|c|c|c|c|c|}
\hline Day & Hov. & Dec. & Jan. & Day & Nov. & Dec. & Jan. & Day & Nov. & Dec. & Jan. \\
\hline $\begin{array}{r}1 \\
2 \\
3 \\
4 \\
5 \\
6 \\
7 \\
8 \\
9 \\
10\end{array}$ & $\begin{array}{l}4.12 \\
4.11 \\
4.10 \\
4.10 \\
4.09 \\
4.08 \\
4.06 \\
4.04 \\
4.02 \\
3.99\end{array}$ & $\begin{array}{l}4.01 \\
4.01 \\
4.00 \\
3.99 \\
3.97 \\
3.97 \\
3.96 \\
3.95 \\
3.95 \\
4.13\end{array}$ & $\begin{array}{l}4.72 \\
4.72 \\
4.71 \\
4.70 \\
4.70 \\
4.70 \\
4.70 \\
4.68 \\
4.66 \\
4.66\end{array}$ & $\begin{array}{l}11 \\
12 \\
13 \\
14 \\
15 \\
16 \\
17 \\
18 \\
19 \\
20\end{array}$ & $\begin{array}{l}4.01 \\
4.02 \\
4.01 \\
4.00 \\
3.99 \\
3.97 \\
4.03 \\
4.04 \\
4.04 \\
4.05\end{array}$ & $\begin{array}{l}4.46 \\
4.72 \\
4.75 \\
4.77 \\
4.78 \\
4.80 \\
4.80 \\
4.80 \\
4.81 \\
4.79\end{array}$ & $\begin{array}{l}4.65 \\
4.65 \\
4.64 \\
4.63 \\
4.67 \\
4.80 \\
4.70 \\
4.71 \\
4.71 \\
4.72\end{array}$ & $\begin{array}{l}21 \\
22 \\
23 \\
24 \\
25 \\
26 \\
27 \\
28 \\
29 \\
30 \\
31\end{array}$ & $\begin{array}{l}4.08 \\
4.07 \\
4.04 \\
4.07 \\
4.06 \\
4.05 \\
4.04 \\
4.03 \\
4.02 \\
4.02\end{array}$ & $\begin{array}{l}4.77 \\
4.77 \\
4.79 \\
4.78 \\
4.77 \\
4.76 \\
4.74 \\
4.73 \\
4.72 \\
4.72 \\
4.72\end{array}$ & $\begin{array}{l}4.71 \\
4.71 \\
4.70 \\
4.70 \\
4.69 \\
4.69 \\
4.69 \\
4.70 \\
4.70 \\
4.69 \\
4.74\end{array}$ \\
\hline
\end{tabular}


Truckee River at Tahoe, Cal1f.

Location. - Lat. $39^{\circ} 09^{\prime} 55^{\prime \prime}$, long. $120^{\circ} 08^{\prime} 45^{\prime \prime}$, in NW $\frac{1}{4}$ sec. 7, T. 15 N., R. 17 E., at Tahoe, just below dam at outlet of Lake Tahoe, Placer County. Altitude, about 6,200 feet above mean sea level.

Drainage area.- 519 square miles.

Gage-he1ght record.- Water-stage recorder graph.

Waxima.- December 1937: Flood mun-off completely controlled in Lake Tahoe. 1895-96, 1900-December 1937: Discharge observed, 1,340 second-feet July 13-20, 1907.

Remarks. - Flood run-off completely controlled in Lake Tahoe. See record for Lake Tahoe. Record of daily discharge furnished by Truckee-Carson Irrigation District. Discharge records not adjusted for storage because of uncertain, but relatively large effect of evaporation.

Mean da1ly discherge, in second-feet, November 1937 to January 1938

\begin{tabular}{|r|c|c|c||r|r|r|r||r|r|r|r|}
\hline Day & Nov. & Dec. & Jan. & Day & Nov. & Dec. & Jan. & Day & Nov. & Dec. & Jan. \\
\hline 1 & 115 & 96 & 159 & 11 & 96 & 0 & 206 & 21 & 108 & 0 & 128 \\
2 & 113 & 96 & 159 & 12 & 97 & 0 & 186 & 22 & 106 & 0 & 128 \\
3 & 111 & 94 & 176 & 13 & 96 & 0 & 186 & 23 & 101 & 93 & 128 \\
4 & 111 & 93 & 186 & 14 & 94 & 0 & 170 & 24 & 106 & 159 & 128 \\
5 & 109 & 90 & 186 & 15 & 93 & 0 & 161 & 25 & 104 & 159 & 128 \\
6 & 108 & 90 & 186 & 16 & 90 & 0 & 161 & 26 & 103 & 159 & 128 \\
7 & 104 & 88 & 186 & 17 & 99 & 0 & 150 & 27 & 101 & 159 & 128 \\
8 & 101 & 87 & 186 & 18 & 101 & 0 & 128 & 28 & 99 & 159 & 128 \\
9 & 97 & 87 & 212 & 19 & 101 & 0 & 128 & 29 & 97 & 159 & 128 \\
10 & 93 & 42 & 234 & 20 & 103 & 0 & 128 & 30 & 97 & 159 & 128 \\
\end{tabular}


Truckee River at Iceland, Cal1f.

Locat1on. - Lat. $39^{\circ} 22^{\prime} 35^{n}$, Iong. $120^{\circ} 01^{\prime} 35^{n}$, in SW $\frac{1}{4} \sec , 31$, T. 18 N., R. 18 E., above dam of National Ice Co: at Iceland, Nevada County. Altitude, about 5,420 feet above mean sea level.

Dralnage area.- 937 square miles.

Gage-height record. - Water-stage recorder graph at regular station site prior to Jan. 6 ;

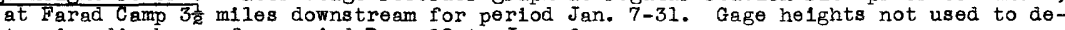
termine discharge for perlod Dec. 12 to Jan. 6.

Stage-d1scharge relation. - Defined by current-meter measurements below 4,000 secondfeet; extended to peak stage by formula for flow over Iceland Dam at Iceland station; defined by current-meter measurements below 5,000 second-feet and extended to peak stage at Farad Camp station.

Maxima.- December 1937: Discharge, 15,500 second-feet 4 p.m. Dec. 11 (gage helght, 11.59 feet), by averaging results from extensions of rating curves for stations at Iceland and Farad Camp; verifled by slope-area determination of flood flow.

1899-November 1937: Discharge observed, 15,300 second-feet Mar. 18, 1907 (gage helght, 11.5 feet, from nonrecording gage).

ingrk. - Flood run-off reduced by flov from 519 square miles stored at Lake Tahoe. Da1ly discharge est1mated for perlod Dec. 12 to Jan. 6 . Bas1c data furnished by Truckee-Carson Irrigation District and H. C. Dukes, Federal watermaster.

Mean dal1y discharge, in second-feet, November 1937 to January 1938

\begin{tabular}{|c|c|c|c|c|c|c|c|c|c|c|c|}
\hline Day & Nov. & Dec. & Jan. & Day & Nov. & Dec. & Jan. & Day & Nov. & Dec. & Jan. \\
\hline $\begin{array}{r}1 \\
2 \\
3 \\
4 \\
5 \\
6 \\
7 \\
8 \\
9 \\
10\end{array}$ & $\begin{array}{l}176 \\
172 \\
168 \\
168 \\
168 \\
164 \\
157 \\
160 \\
160 \\
157\end{array}$ & $\begin{array}{r}176 \\
187 \\
179 \\
176 \\
172 \\
172 \\
168 \\
172 \\
176 \\
4,000\end{array}$ & $\begin{array}{l}430 \\
430 \\
430 \\
430 \\
400 \\
370 \\
326 \\
390 \\
394 \\
437\end{array}$ & $\begin{array}{l}11 \\
12 \\
13 \\
14 \\
15 \\
16 \\
17 \\
18 \\
19 \\
20\end{array}$ & $\begin{array}{l}183 \\
179 \\
172 \\
191 \\
183 \\
183 \\
352 \\
275 \\
253 \\
424\end{array}$ & $\begin{array}{r}12,300 \\
7,200 \\
4,000 \\
2,400 \\
1,500 \\
1,100 \\
950 \\
800 \\
750 \\
700\end{array}$ & $\begin{array}{l}464 \\
464 \\
444 \\
444 \\
452 \\
433 \\
480 \\
429 \\
413 \\
386\end{array}$ & $\begin{array}{l}21 \\
22 \\
23 \\
24 \\
25 \\
26 \\
27 \\
28 \\
29 \\
30 \\
31\end{array}$ & $\begin{array}{l}483 \\
320 \\
285 \\
290 \\
253 \\
226 \\
217 \\
204 \\
196 \\
179\end{array}$ & $\begin{array}{l}650 \\
550 \\
500 \\
430 \\
430 \\
430 \\
430 \\
430 \\
430 \\
430 \\
430\end{array}$ & $\begin{array}{l}427 \\
421 \\
382 \\
370 \\
382 \\
340 \\
333 \\
340 \\
329 \\
296 \\
329\end{array}$ \\
\hline $\begin{array}{l}\text { Mear } \\
\text { Run- }\end{array}$ & in & & & & & & & & $\begin{array}{r}223 \\
13,290 \\
\end{array}$ & $\begin{array}{r}1,368 \\
84,130\end{array}$ & $\begin{array}{r}400 \\
24,590 \\
\end{array}$ \\
\hline
\end{tabular}

Gage he1zht, In feet, and discharge, in second-feet, at Indicated time, 1937

\begin{tabular}{|c|c|c|c|c|c|c|c|c|c|c|c|c|}
\hline \multirow{2}{*}{$\begin{array}{l}\text { 多 } \\
\text { 号 }\end{array}$} & Feet & Sec.ft. & $F \in \theta t$ & Sec.ft. & Feet & Sec.ft. & Feet & Sec.ft. & Feet & Sec.ft. & Feet & Sec.ft. \\
\hline & \multicolumn{2}{|c|}{ Decembe: 8} & \multicolumn{2}{|c|}{ December 9} & \multicolumn{2}{|c|}{ December 10} & \multicolumn{2}{|c|}{ December 11} & \multicolumn{2}{|c|}{ December 12} & \multicolumn{2}{|c|}{ December 13} \\
\hline \multirow[t]{2}{*}{\begin{tabular}{r|}
2 \\
4 \\
6 \\
8 \\
10 \\
$\mathrm{~N}$ \\
2 \\
4 \\
6 \\
8 \\
10 \\
$\mathrm{M}$ \\
\end{tabular}} & $\begin{array}{l}3.13 \\
3.14 \\
3.15 \\
3.13 \\
3.12 \\
3.11 \\
3.15 \\
3.25 \\
3.20 \\
3.17 \\
3.17 \\
3.16\end{array}$ & $\begin{array}{l}160 \\
164 \\
168 \\
160 \\
157 \\
153 \\
168 \\
208 \\
187 \\
176 \\
176 \\
172\end{array}$ & $\begin{array}{l}3.16 \\
3.15 \\
3.12 \\
3.10 \\
3.10 \\
3.18 \\
3.16 \\
3.16 \\
3.16 \\
3.20 \\
3.29 \\
3.42\end{array}$ & $\begin{array}{l}172 \\
168 \\
157 \\
149 \\
149 \\
179 \\
172 \\
172 \\
172 \\
187 \\
226 \\
285\end{array}$ & $\begin{array}{l}3.80 \\
4.80 \\
5.90 \\
6.50 \\
7.00 \\
7.30 \\
7.60 \\
7.90 \\
8.15 \\
8.35 \\
8.45 \\
8.50\end{array}$ & $\begin{array}{r}495 \\
1,220 \\
2,350 \\
3,060 \\
3,740 \\
4,200 \\
4,760 \\
5,380 \\
5,930 \\
6,370 \\
6,600 \\
6,720\end{array}$ & $\begin{array}{r}8.80 \\
9.25 \\
9.90 \\
10.35 \\
10.80 \\
11.17 \\
11.54 \\
11.59 \\
11.55 \\
11.10 \\
10.73 \\
10.25\end{array}$ & $\begin{array}{r}7,440 \\
8,610 \\
10,400 \\
11,600 \\
13,000 \\
14,100 \\
15,300 \\
15,500 \\
15,300 \\
13,900 \\
12,800 \\
11,400\end{array}$ & $\begin{array}{l}9.87 \\
9.56 \\
9.38 \\
9.16 \\
9.05 \\
8.90 \\
8.77 \\
8.68 \\
8.57 \\
8.48 \\
8.38 \\
8.30\end{array}$ & $\begin{array}{l}- \\
- \\
- \\
= \\
= \\
= \\
= \\
= \\
= \\
- \\
-\end{array}$ & $\begin{array}{l}8.22 \\
8.13 \\
8.05 \\
7.99 \\
7.94 \\
7.87 \\
7.82 \\
7.78 \\
7.75 \\
7.72 \\
7.68 \\
7.64\end{array}$ & $\begin{array}{c}- \\
\overline{-} \\
\overline{-} \\
\overline{-} \\
* 4,000 \\
\overline{-} \\
\overline{-} \\
\overline{-} \\
\overline{-} \\
-\end{array}$ \\
\hline & \multicolumn{2}{|c|}{ December 14} & \multicolumn{2}{|c|}{ December 15} & \multicolumn{2}{|c|}{ December 16} & \multicolumn{2}{|c|}{ December 17} & \multicolumn{2}{|c|}{ December 18} & \multicolumn{2}{|c|}{ December 19} \\
\hline $\begin{array}{r}2 \\
4 \\
6 \\
8 \\
10 \\
\mathrm{~N} \\
2 \\
4 \\
6 \\
8 \\
10 \\
\mathrm{M}\end{array}$ & $\begin{array}{l}7.55 \\
\overline{7.45} \\
\overline{7.4} \\
7.40 \\
\overline{7.36} \\
\overline{7.35} \\
= \\
7.32\end{array}$ & $\begin{array}{c}- \\
- \\
- \\
* 2,400 \\
\vdots \\
- \\
- \\
-\end{array}$ & $\begin{array}{l}7.30 \\
7.28 \\
7.27 \\
7.27 \\
7.26 \\
7.24 \\
7.22 \\
7.21 \\
7.20 \\
7.12 \\
6.85 \\
6.73\end{array}$ & $\begin{array}{c}\overline{-} \\
\overline{-} \\
\overline{-} \\
* 1,500 \\
\overline{-} \\
\overline{-} \\
\overline{-} \\
\overline{-} \\
-\end{array}$ & $\begin{array}{l}-\overline{6.66} \\
- \\
6.61 \\
- \\
6.58 \\
- \\
6.54 \\
- \\
6.52 \\
- \\
6.50\end{array}$ & $\begin{array}{c}\overline{-} \\
\overline{-} \\
\overline{-} \\
* 1,100 \\
\overline{-} \\
\overline{-} \\
\overline{-} \\
-\end{array}$ & $\begin{array}{c}- \\
6.45 \\
- \\
6.40 \\
- \\
6.36 \\
- \\
6.33 \\
- \\
6.34 \\
- \\
6.33\end{array}$ & $\begin{array}{l}\overline{-} \\
\overline{-} \\
\overline{-} \\
* 950 \\
- \\
- \\
- \\
- \\
-\end{array}$ & $\begin{array}{l}- \\
6.30 \\
- \\
6.29 \\
- \\
6.28 \\
- \\
6.27 \\
- \\
6.21 \\
6.26 \\
6.57\end{array}$ & $\begin{array}{l}- \\
\overline{-} \\
\overline{-} \\
\overline{8} \\
\overline{-} \\
\overline{-} \\
\overline{-} \\
- \\
-\end{array}$ & $\begin{array}{l}- \\
6.57 \\
- \\
6.49 \\
- \\
6.41 \\
- \\
6.40 \\
6.40 \\
6.35\end{array}$ & $\begin{array}{l}\overline{-} \\
= \\
- \\
\overline{-} \\
\overline{-} \\
-\end{array}$ \\
\hline & \multicolumn{2}{|c|}{ December 20} & \multicolumn{2}{|c|}{ December 21} & \multicolumn{2}{|c|}{ December 22} & \multicolumn{2}{|c|}{ December 23} & \multicolumn{2}{|c|}{ December 24} & \multicolumn{2}{|c|}{ December 25} \\
\hline $\begin{array}{r}2 \\
4 \\
6 \\
8 \\
10 \\
\mathrm{~N} \\
2 \\
4 \\
6 \\
8 \\
10 \\
\mathrm{M}\end{array}$ & $\begin{array}{c}6.26 \\
- \\
6.18 \\
- \\
6.11 \\
- \\
6.20 \\
- \\
6.17 \\
-\overline{6} 13\end{array}$ & $\begin{array}{l}= \\
= \\
= \\
=700 \\
= \\
= \\
= \\
=\end{array}$ & $\begin{array}{c}- \\
6.03 \\
- \\
5.90 \\
- \\
5.89 \\
- \\
5.96 \\
- \\
6.05 \\
6.02\end{array}$ & $\begin{array}{l}- \\
\overline{-} \\
\bar{z} \\
\overline{6} 50 \\
\overline{-} \\
\overline{-} \\
\overline{-} \\
-\end{array}$ & $\begin{array}{c}5.95 \\
- \\
5.85 \\
- \\
5.88 \\
- \\
5.93 \\
5.93 \\
5.85 \\
5.78\end{array}$ & $\begin{array}{l}- \\
- \\
- \\
\overline{-} \\
* 500 \\
\overline{-} \\
\overline{-} \\
\overline{-}\end{array}$ & $\begin{array}{c}- \\
5.62 \\
- \\
5.83 \\
- \\
5.50 \\
- \\
5.50 \\
5.56 \\
5.52\end{array}$ & $\begin{array}{l}- \\
- \\
\overline{-} \\
= \\
* 500 \\
- \\
= \\
= \\
- \\
-\end{array}$ & $\begin{array}{c}5.65 \\
5.83 \\
- \\
5.90 \\
- \\
6.05 \\
6.10 \\
6.05 \\
5.95\end{array}$ & $\begin{array}{l}- \\
- \\
- \\
- \\
\overline{4} \\
= \\
\overline{-} \\
= \\
= \\
-\end{array}$ & $\begin{array}{l}5.84 \\
5.78 \\
- \\
5.87 \\
- \\
6.02 \\
5.97 \\
5.90\end{array}$ & $\begin{array}{l}- \\
- \\
- \\
- \\
\overline{4} \\
= \\
= \\
\overline{-} \\
\overline{-} \\
\overline{-} \\
-\end{array}$ \\
\hline
\end{tabular}

* Mean for the day. 
Location. - Lat. $39^{\circ} 19^{\prime} 15^{\prime \prime}$, long. $120^{\circ} 12^{\prime} 10^{n}$, in SE⿺ sec. 16, T. 17 N., R. 16 E., $1 \mathrm{~m} 110$ below Cold Creek, $1 \frac{2}{2}$ miles southwest of Truckee, Nevada County, and 2 miles below Donner Lake. Altitude, about 5,800 feet above mean sea level.

Dralngge area. - 29.2 square miles.

Gage-helght record. - Water-stage recorder graph.

Kaxima.-December 1937: Discharge, 1,800 second-feet 2 p.m. Dec. II (gage height, 5.40 feet, Inside gage; 6.2 feet, outside gage, from floodmarks), determined by slopearea computation.

1902-15, 1928-November 1937: Discharge observed, 980 second-fest Mar. 18, 1907 (gage height, 5.5 feet, former datum, from nonrecording gage).

Remarks. - Flood run-off partly controlled by outlet gates at Donner Lake. Record of changes in storage in lake for perlod Dec. 1-11 shown below. No record subsequent to $8 \mathrm{a} . \mathrm{m}$. Dec. II; recorder destroyed. Dally discharge for period Dec. $1-11$ adfusted for changes in storage in Donner Lake. Most of basic data furnished by Trucke-Garson Irrigation District and H. C. Dukes, Federal water master.

Observed mean dally discharge, in second-feet, November 1937 to January 1938

\begin{tabular}{|c|c|r|r||r|r|r|r||r|r|r|r|}
\hline Day & Nov. & Dec. & Jan. & Day & Nov. & Dec. & Jan. & Day & Nov. & Dec. & Jan. \\
\hline 1 & 4 & 7 & 31 & 11 & 4 & 1,600 & 13 & 21 & 17 & 55 & 54 \\
2 & 4 & 7 & 32 & 12 & 4 & 980 & 12 & 22 & 12 & 43 & 54 \\
3 & 4 & 6 & 32 & 13 & 4 & 715 & 12 & 23 & 9 & 40 & 52 \\
4 & 4 & 6 & 31 & 14 & 5 & 628 & 16 & 24 & 9 & 40 & 52 \\
5 & 4 & 6 & 28 & 15 & 5 & 505 & 24 & 25 & 8 & 38 & 40 \\
6 & 4 & 7 & 20 & 16 & 5 & 243 & 31 & 26 & 7 & 34 & 15 \\
7 & 4 & 8 & 14 & 17 & 7 & 166 & 32 & 27 & 7 & 33 & 13 \\
8 & 4 & 7 & 15 & 18 & 6 & 130 & 31 & 28 & 7 & 32 & 11 \\
9 & 5 & 6 & 13 & 19 & 5 & 101 & 31 & 29 & 6 & 30 & 11 \\
10 & 5 & 366 & 13 & 20 & 9 & 78 & 41 & 30 & 6 & 30 & 12 \\
&
\end{tabular}

Contents of lake, gain or loss in storage, and daily discharge, Dec. 1-11, 1937

\begin{tabular}{|r|c|c|c|c|}
\hline \multirow{2}{*}{ Day } & \multicolumn{2}{|c|}{ Donner Lake } & \multicolumn{2}{|c|}{ Donner Creek } \\
\cline { 2 - 5 } & $\begin{array}{c}\text { Contents } \\
\text { (acre-feet) }\end{array}$ & $\begin{array}{c}\text { Gain or loss } \\
\text { (acre-feet) }\end{array}$ & $\begin{array}{c}\text { observed discharge } \\
\text { (second-feet) }\end{array}$ & $\begin{array}{c}\text { Ad justed discharge } \\
\text { (second-feet) }\end{array}$ \\
\hline 1 & 4,317 & +8 & 7 & 11 \\
2 & 4,325 & +8 & 7 & 11 \\
3 & 4,334 & +9 & 6 & 11 \\
4 & 4,342 & +8 & 6 & 6 \\
5 & 4,342 & 0 & 7 & 11 \\
6 & 4,350 & +8 & 8 & 7 \\
7 & 4,359 & +9 & 7 & 110 \\
8 & 4,359 & 0 & 6 & 1,230 \\
9 & 4,565 & +206 & 366 & 1,900 \\
10 & 6,278 & $+1,713$ & 1,600 & \\
11 & 6,870 & +592 & & \\
\hline
\end{tabular}




\section{SUMMARY OF FLOOD DISCHARGES}

In table 4 of this report are assembled the results of the determinations of maximum flood flows at existing river-measurement stations and at a few other places on streams in the basins of northern California. Table 4 gives the following information:

1. Map reference number, applicable to figures 4 to 12 on pages 13-21, to ald the reader in locating the place where the discharge was determined.

2. Name of stream and place of determination of discharge.

3. Drainage area, in square miles, tributary to the stream at the place of determination of discharge.

4. Period of record. In general, this information is given only for existing river-measurement stations and the initial fear is the first calendar year for which high water records are avallable.

5. The date of the maximum discharge previously known and 1ts magnitude in second-feet.

6. The average discharge for the 24 consecutive hours of maximum flow, total and per square mile.

7. The day, time of day, and the rate in second-feet, total and per square mile, of the maximum momentary peak discharge associated with the floods of December 1937. A notation as to the method of determination is also included.

For existing river-measurement stations the method of determination is designated "Stage-discharge relation" and is described in greater detail in the records for the respective stations.

Where the maximum discharge was not measured at a regular station, a brief reference is made to the method of determination and a discussion of each method will be found in the section of this report entitled "Determination of flood discharges."

The reader should consult the section "Records of previous floods" for possible additional references to notable floods not included in the summary table.

The basic data and computations for the determinations of discharge are filed in the San Francisco district office of the Geological Survey and may be examined there.

Figure 43 shows the maximum peak discharges of the floods of December 1937 in second-feet per square mile, as given in table 4, plotted against the corresponding drainage area. 


\begin{tabular}{|c|c|c|c|c|c|c|}
\hline 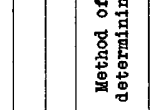 & $\bowtie \cdots$ & - & 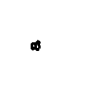 & $\cdots$ & • & $\cdots \cdots$ \\
\hline 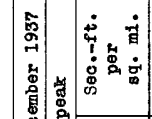 & 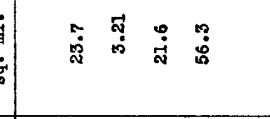 & $\stackrel{8}{\circ}$ & : & 1 , & & $\nsubseteq \tilde{\sharp}$ \\
\hline 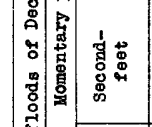 & 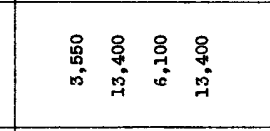 & 总 & 兽 & 悉蛋 & $\stackrel{\circ}{a}$ & 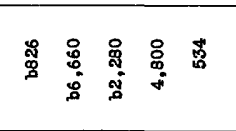 \\
\hline 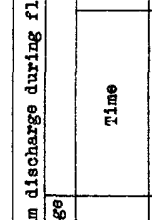 & 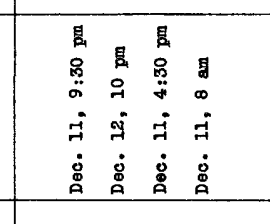 & 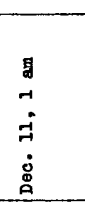 & 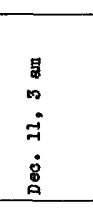 & 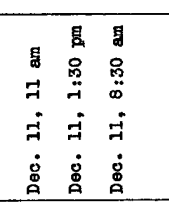 & 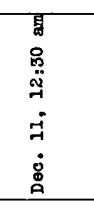 & 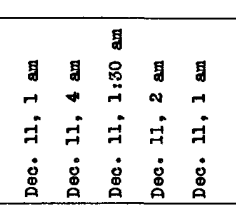 \\
\hline 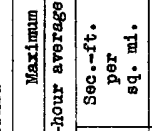 & 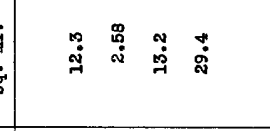 & $\stackrel{8}{9}$ & 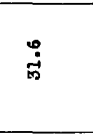 & , , & -1 & 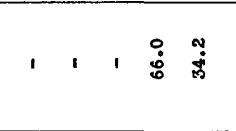 \\
\hline 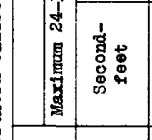 & 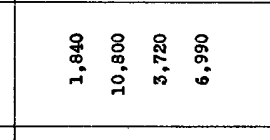 & $\stackrel{8}{8}$ & 蛋 & 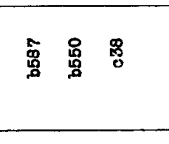 & . & 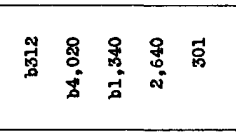 \\
\hline 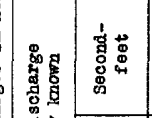 & 总 & 吇 & $\underset{8}{8}$ & 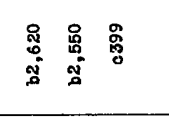 & $\stackrel{8}{2}$ & 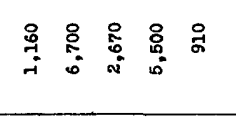 \\
\hline 竞 & 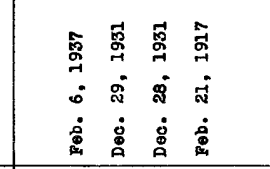 & 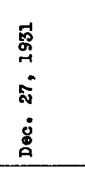 & 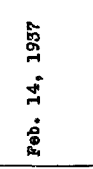 & 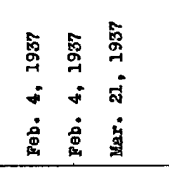 & 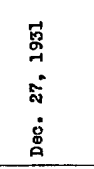 & 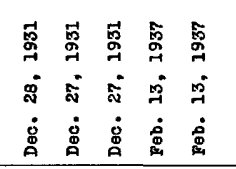 \\
\hline 总嗙 & 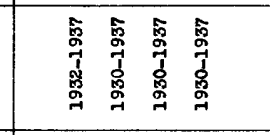 & 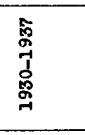 & $\stackrel{9}{g}$ & 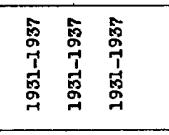 & 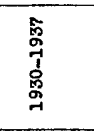 & 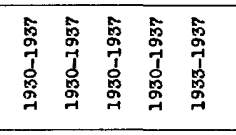 \\
\hline 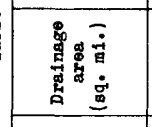 & 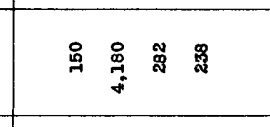 & 产 & g & 蒿 & $\overrightarrow{\dot{m}}$ & 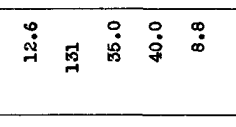 \\
\hline 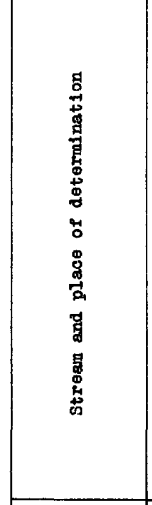 & 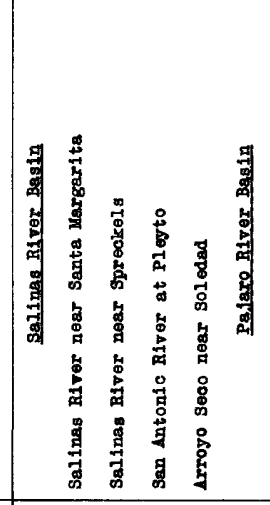 & 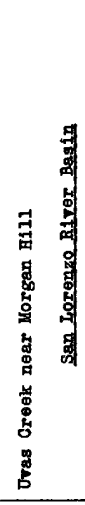 & 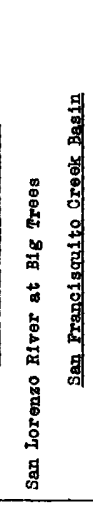 & 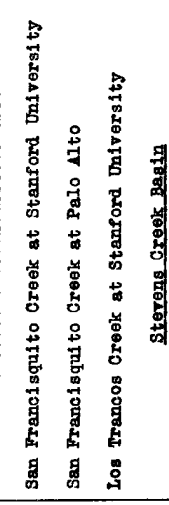 & 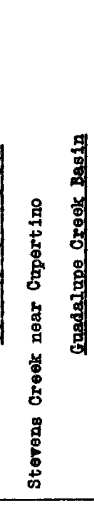 & 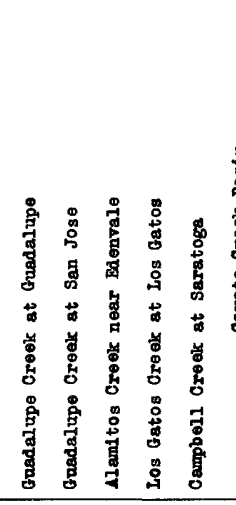 \\
\hline 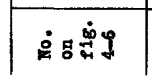 & ప ప & 密 & 8 & 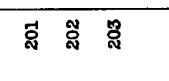 & 蛋 & $\begin{array}{lllll}8 & 8 \\
\end{array}$ \\
\hline
\end{tabular}




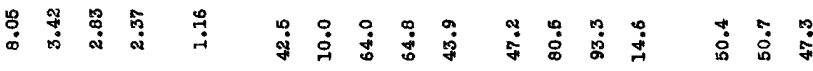

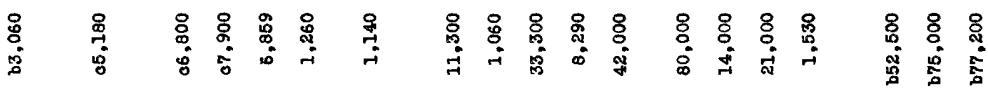

\begin{tabular}{|c|c|c|c|c|c|c|c|c|c|c|c|c|c|c|c|c|c|c|}
\hline & & & $\boldsymbol{g}$ & 寻 & & & & & & & & 量 & & & 目 & & & \\
\hline $\begin{array}{l}\mathbf{5} \\
\infty\end{array}$ & $\begin{array}{l}\text { 夏 } \\
\text { or }\end{array}$ & $\begin{array}{l}\text { 莡 } \\
\infty\end{array}$ & $\begin{array}{l}\text { 昌 } \\
\ddot{1}\end{array}$ & $\begin{array}{l}\circ \\
\stackrel{8}{\circ} \\
\stackrel{-1}{A}\end{array}$ & $\begin{array}{l}\text { 罢 } \\
\infty\end{array}$ & $\begin{array}{l}\text { 号 } \\
\text { ๙ }\end{array}$ & $\begin{array}{l}\text { 莡 } \\
0\end{array}$ & 量 & $\begin{array}{c}\text { 晏 } \\
\text { 的 }\end{array}$ & $\begin{array}{c}\text { 星 } \\
\text { m }\end{array}$ & $\begin{array}{l}\text { 量 } \\
+\end{array}$ & 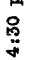 & 영 & & $\stackrel{\phi}{\ddot{\theta}}$ & 星 & 最 & $\begin{array}{l}\text { 息 } \\
2\end{array}$ \\
\hline 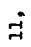 & $\stackrel{-}{\rightarrow}$ & $\underset{\rightarrow}{-i}$ & $\underset{\sim}{\stackrel{\sim}{*}}$ & $\stackrel{\vec{F}}{\sim}$ & $\underset{\sim}{\stackrel{2}{*}}$ & $\underset{7}{0}$ & $\underset{r}{-}$ & $\stackrel{-}{\rightarrow}$ & $\overrightarrow{-1}$ & 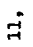 & $\stackrel{\vec{H}}{ }$ & $\vec{G}$ & $\vec{\theta}$ & $\vec{r}$ & $\stackrel{g}{-}$ & $\overrightarrow{-}$ & $\vec{g}$ & $\overrightarrow{-}$ \\
\hline$\dot{\mathscr{g}}$ & $\stackrel{\dot{\Xi}}{\stackrel{\Xi}{A}}$ & $\begin{array}{l}\dot{\Xi} \\
\stackrel{\Phi}{\circ}\end{array}$ & $\dot{\mathscr{\Xi}}$ & $\dot{\mathscr{\Xi}}$ & $\dot{\dot{\Phi}}$ & $\dot{\mathscr{\Xi}}$ & $\dot{8}$ & $\dot{\Phi}$ & $\dot{\mathscr{D}}$ & $\dot{\Phi}$ & $\dot{\Phi}$ & $\dot{\mathscr{E}}$ & $\stackrel{\dot{8}}{\stackrel{\Phi}{A}}$ & $\stackrel{\dot{\Xi}}{\circledR}$ & $\stackrel{\dot{g}}{\dot{A}}$ & $\stackrel{\dot{0}}{\stackrel{\Phi}{\circ}}$ & $\stackrel{\dot{8}}{\stackrel{\Phi}{\circ}}$ & $\dot{\dot{S}}$ \\
\hline
\end{tabular}

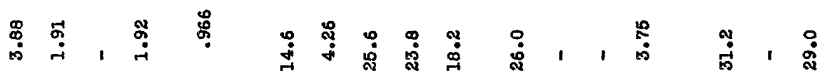

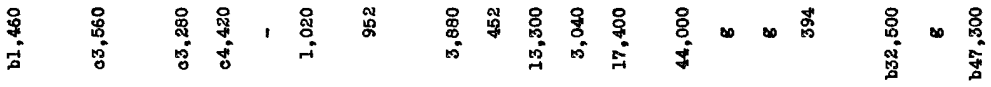

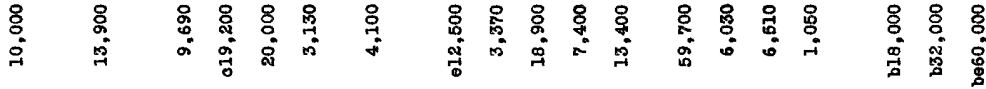

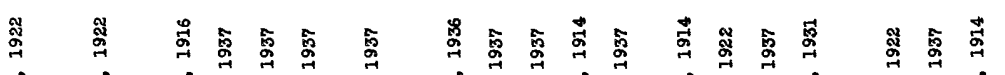

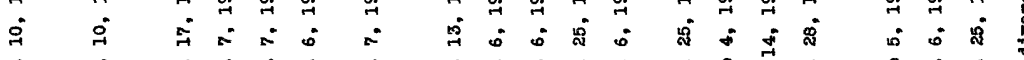

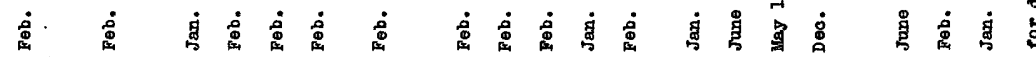

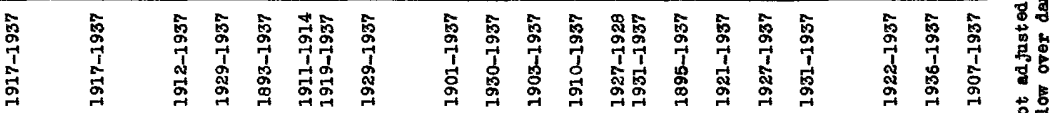
ร 


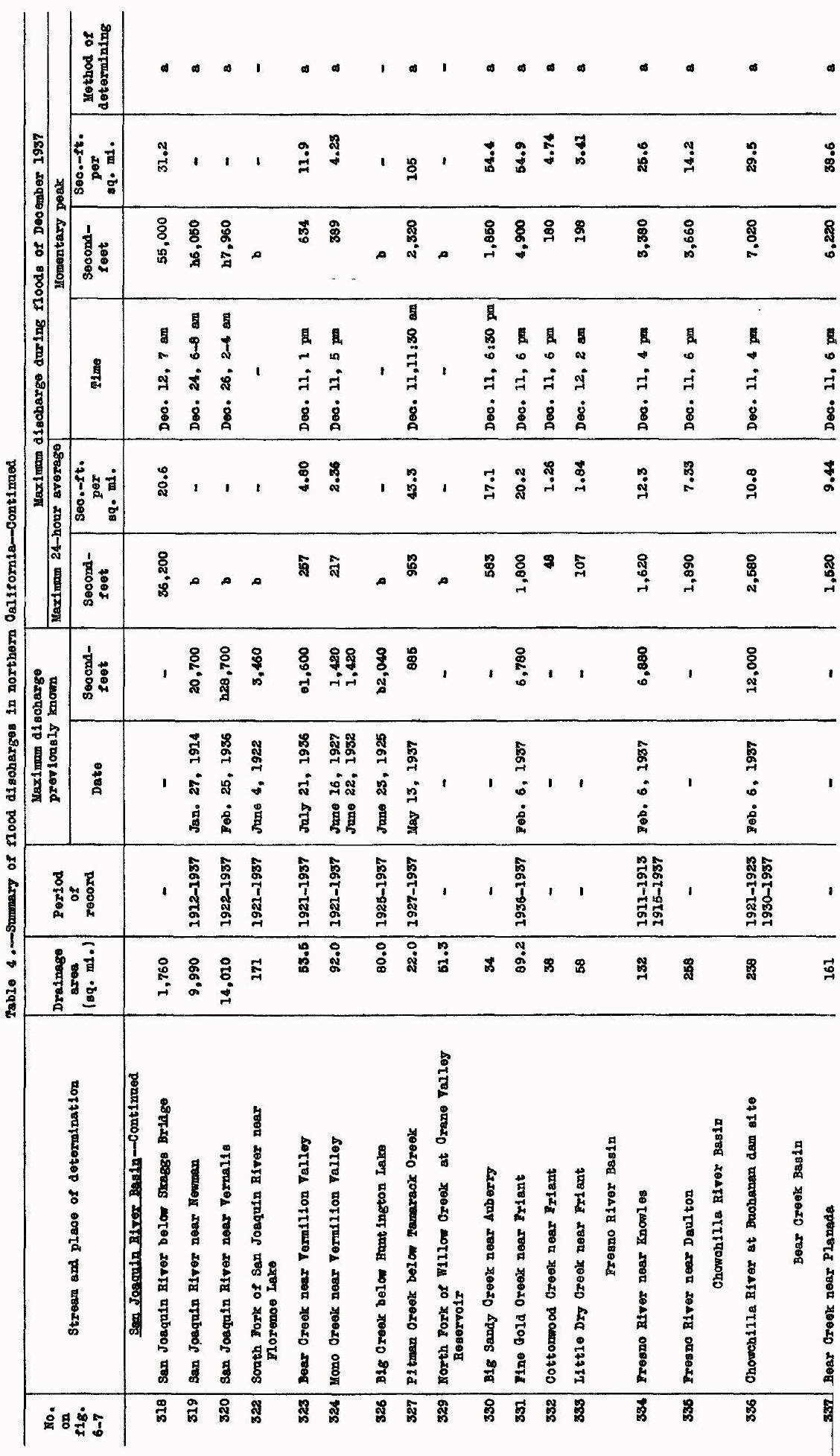




\section{氵}

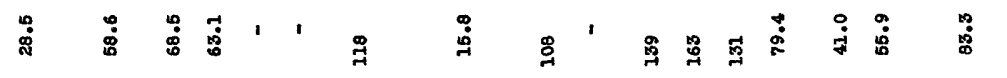

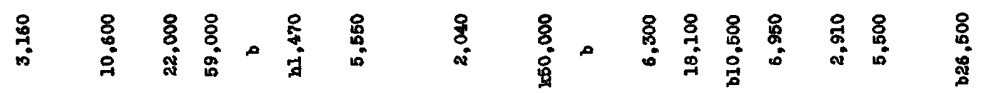

艮

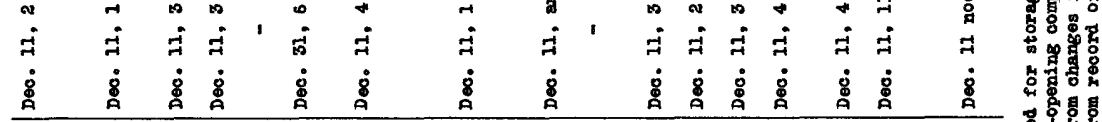

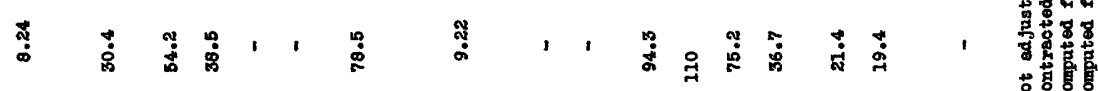

莫娤

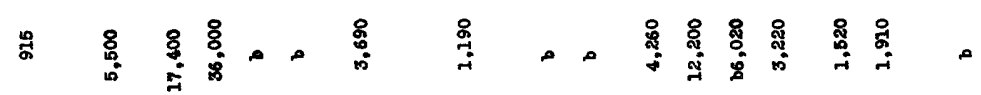

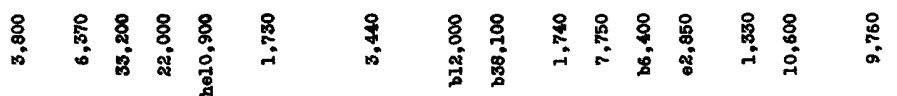

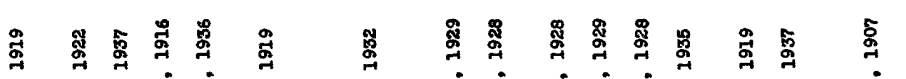

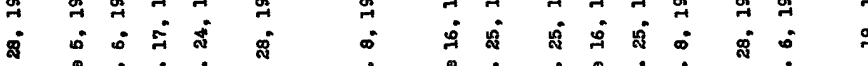

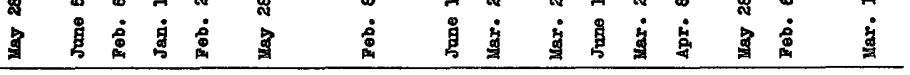

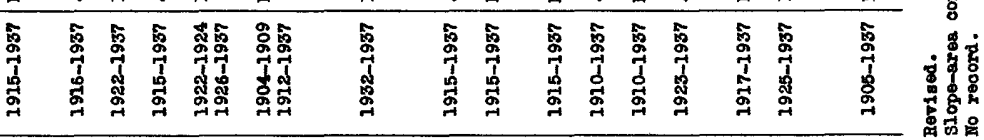

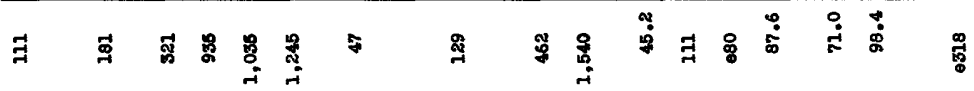

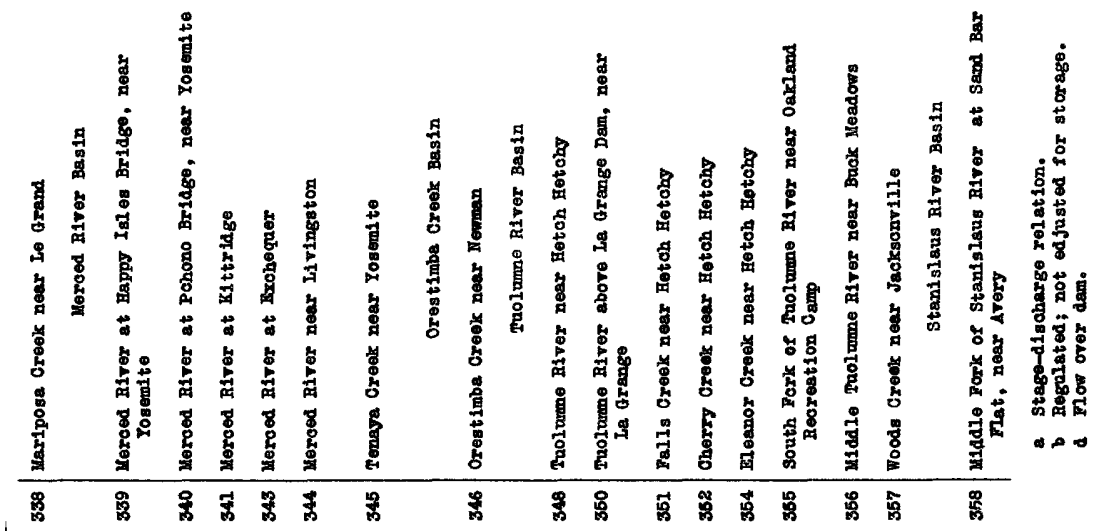




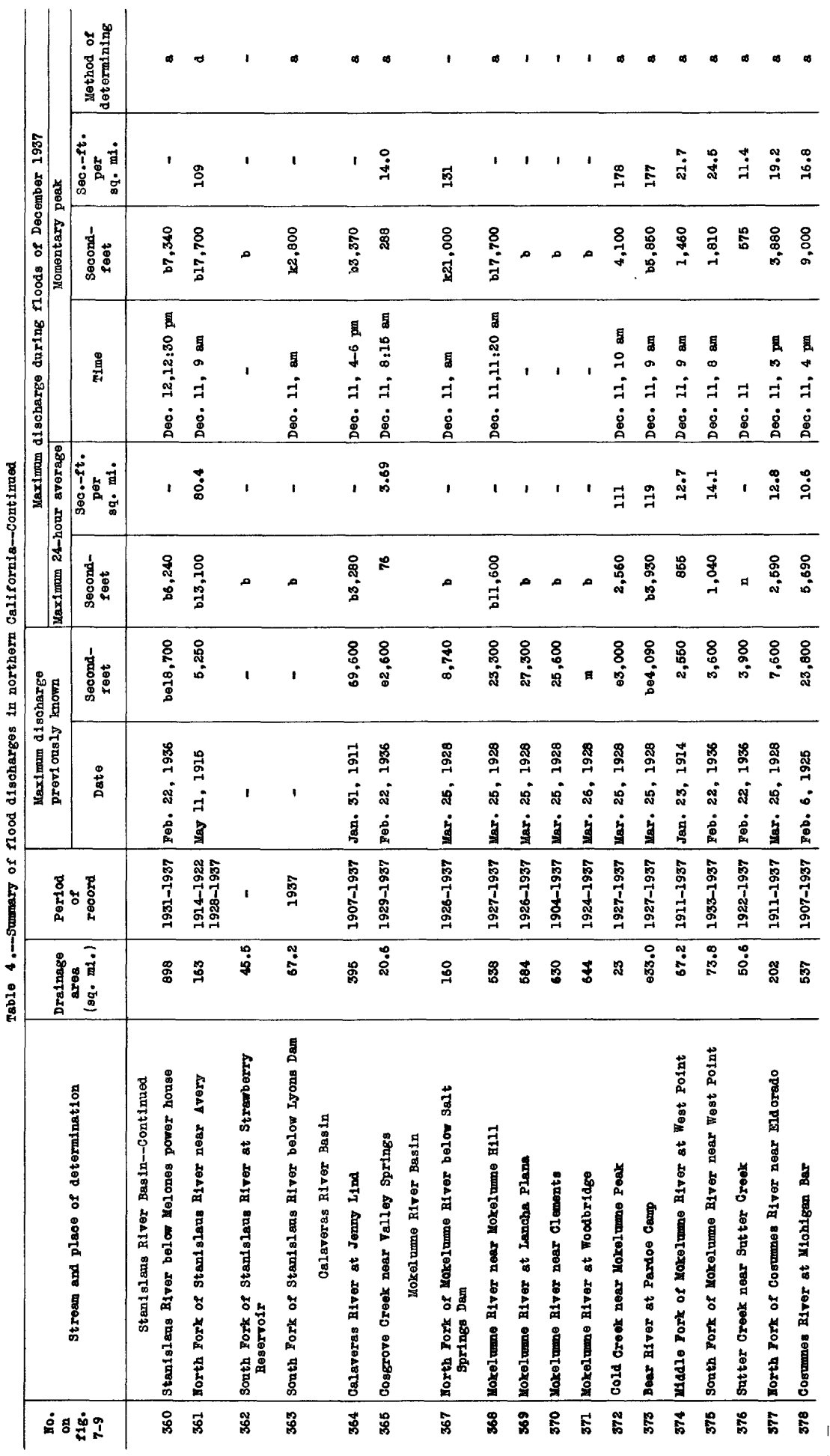




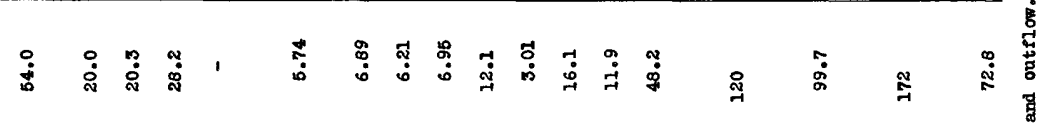

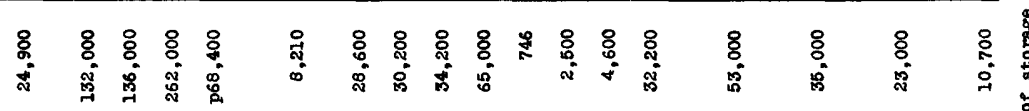

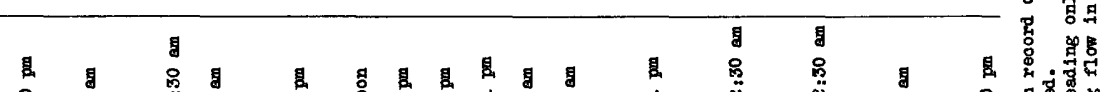

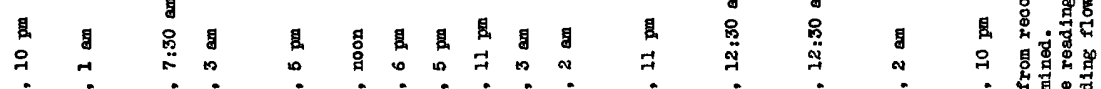
-

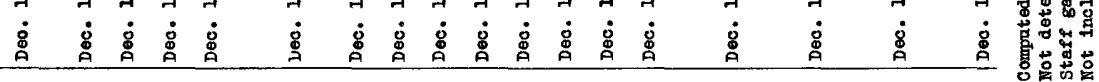

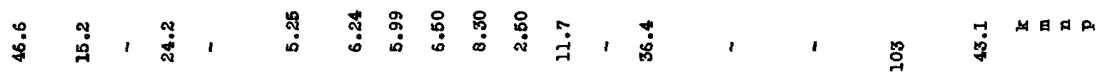

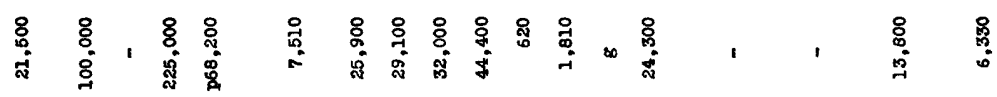

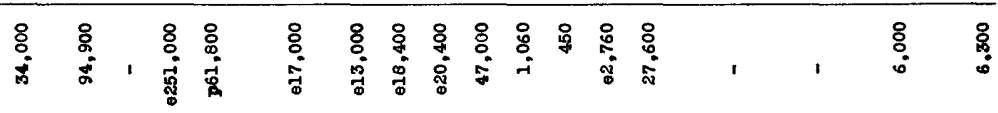

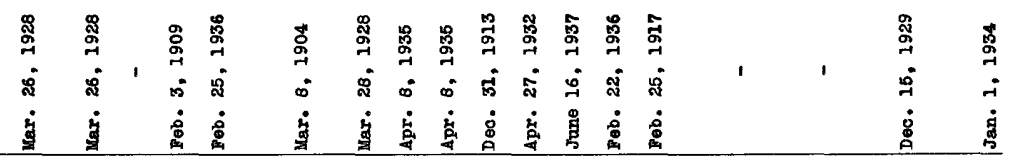

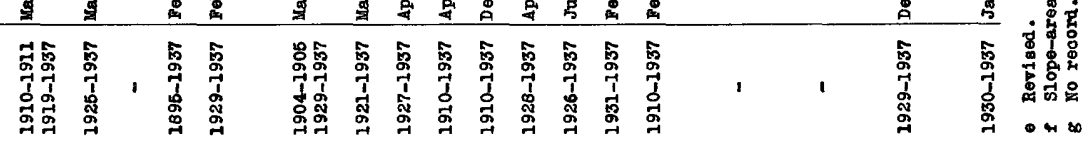

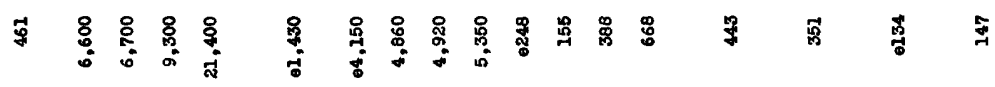

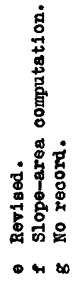

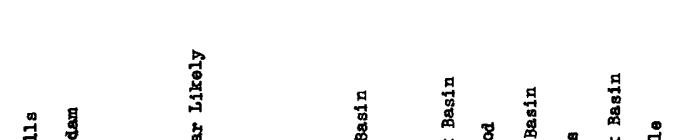




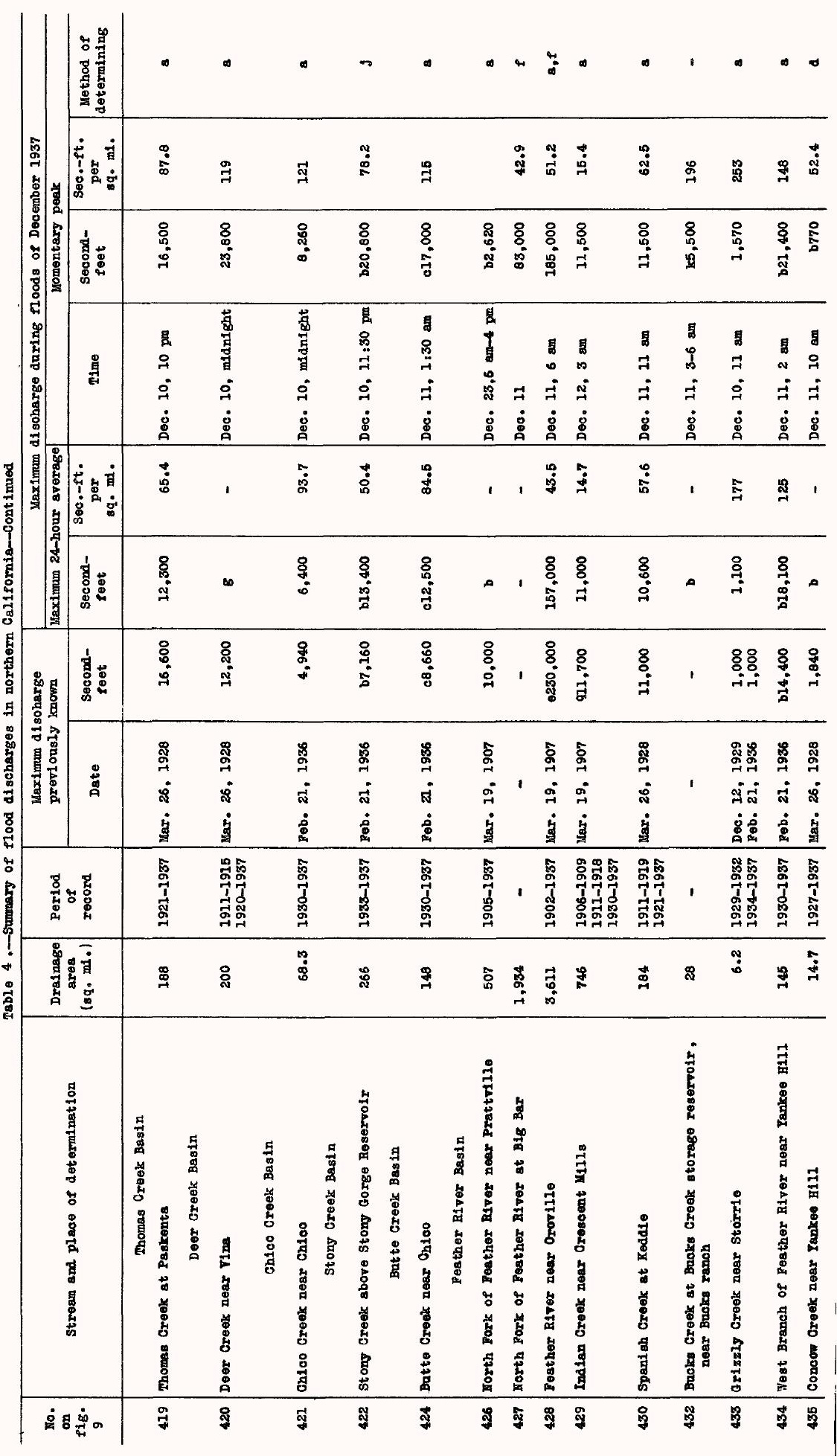




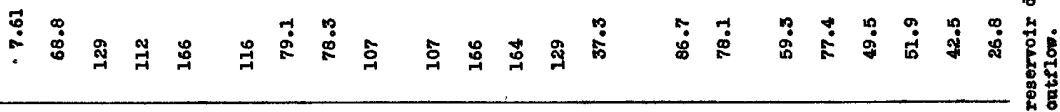

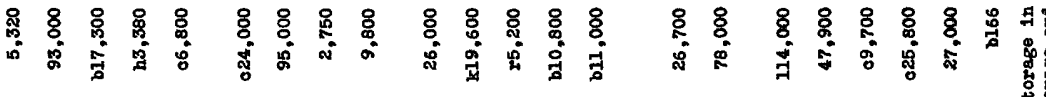

舟

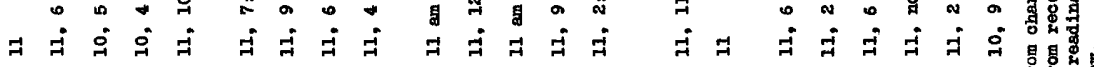
方市

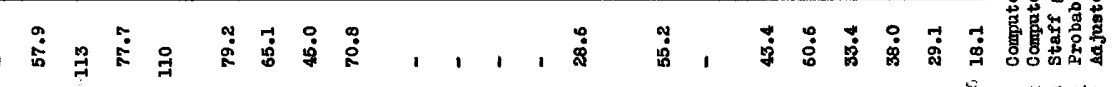

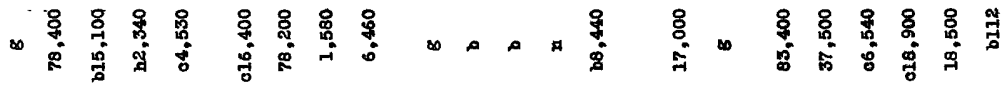

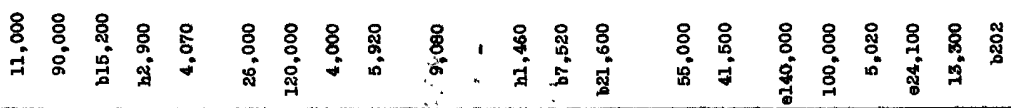

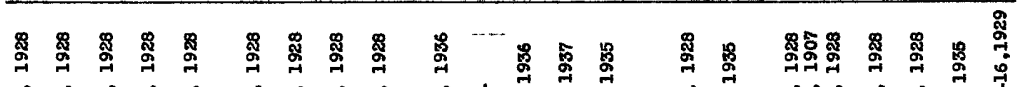

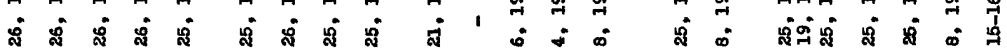

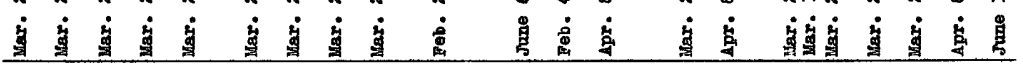

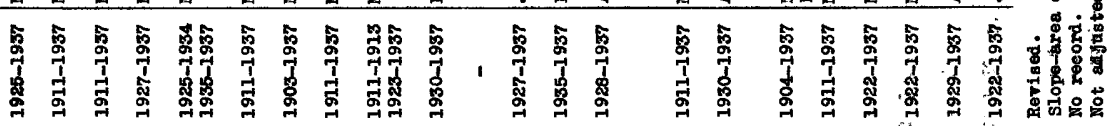

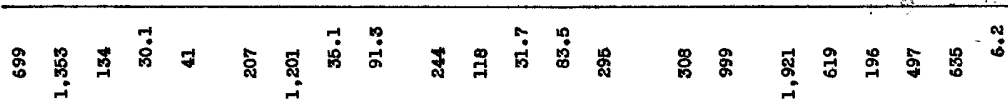

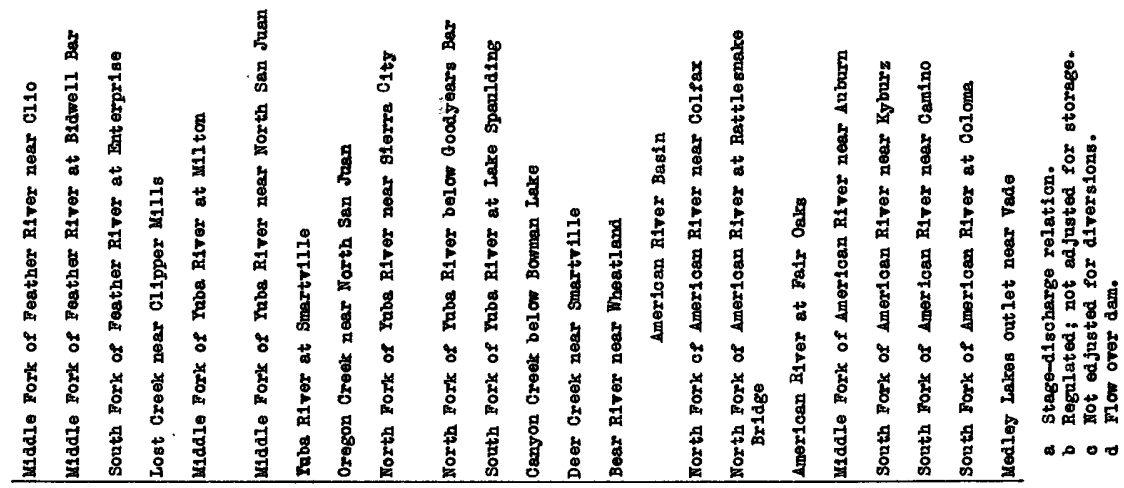




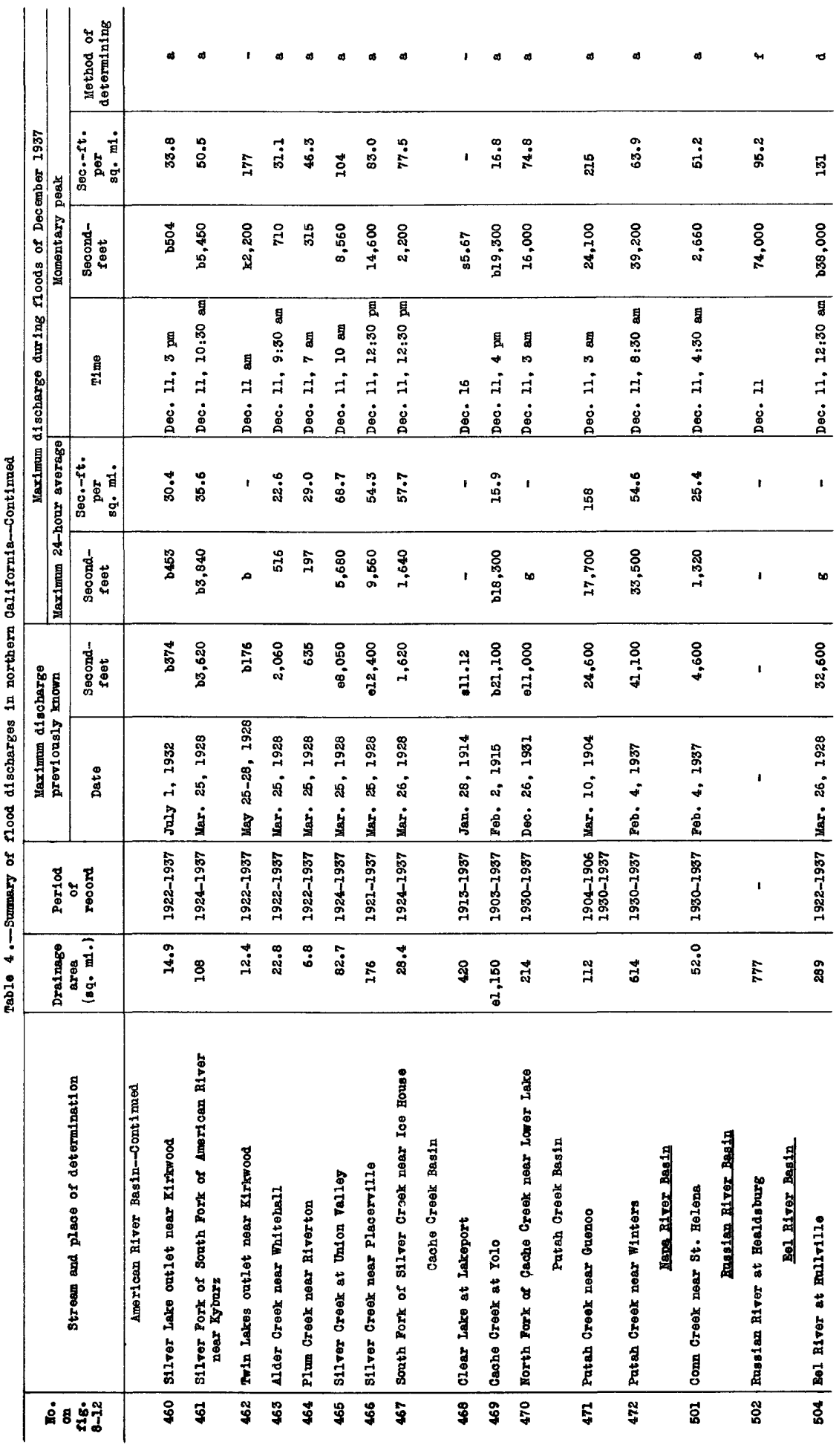




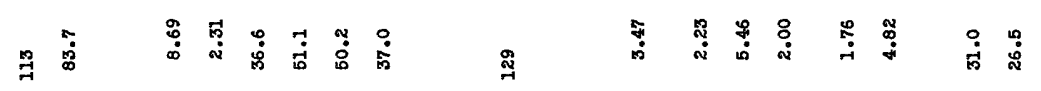

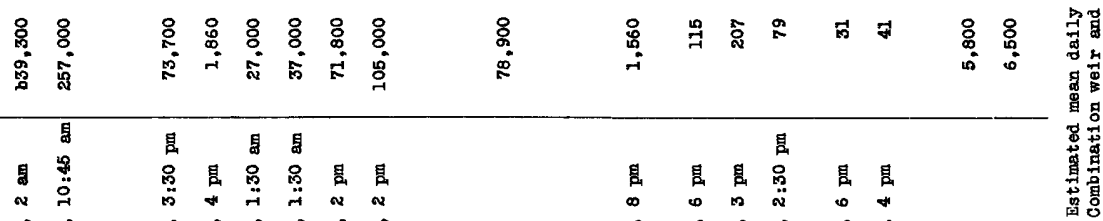

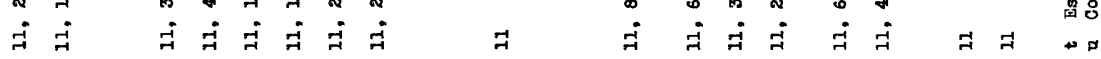

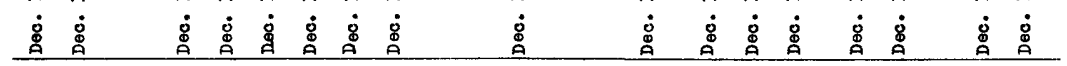

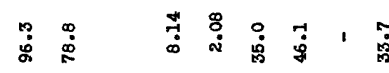

品

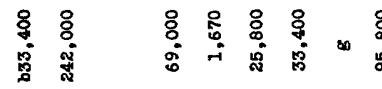

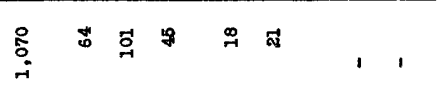

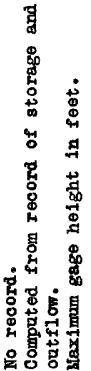

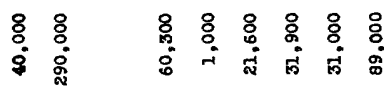

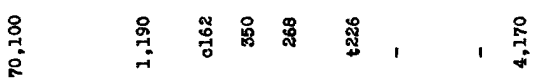
두

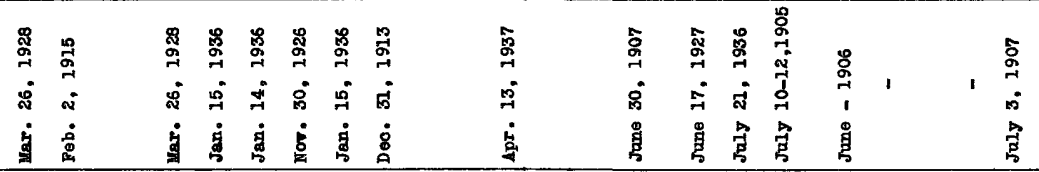

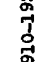

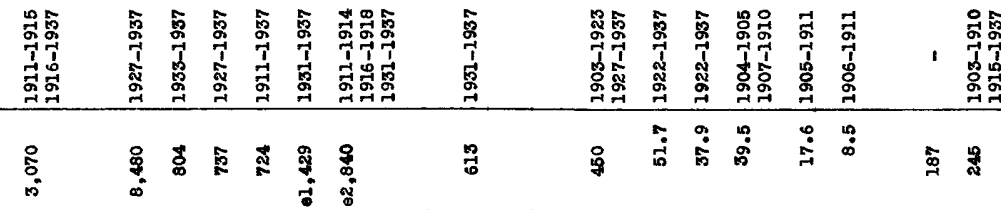

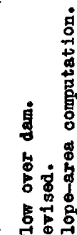

要

d 4

承

要 


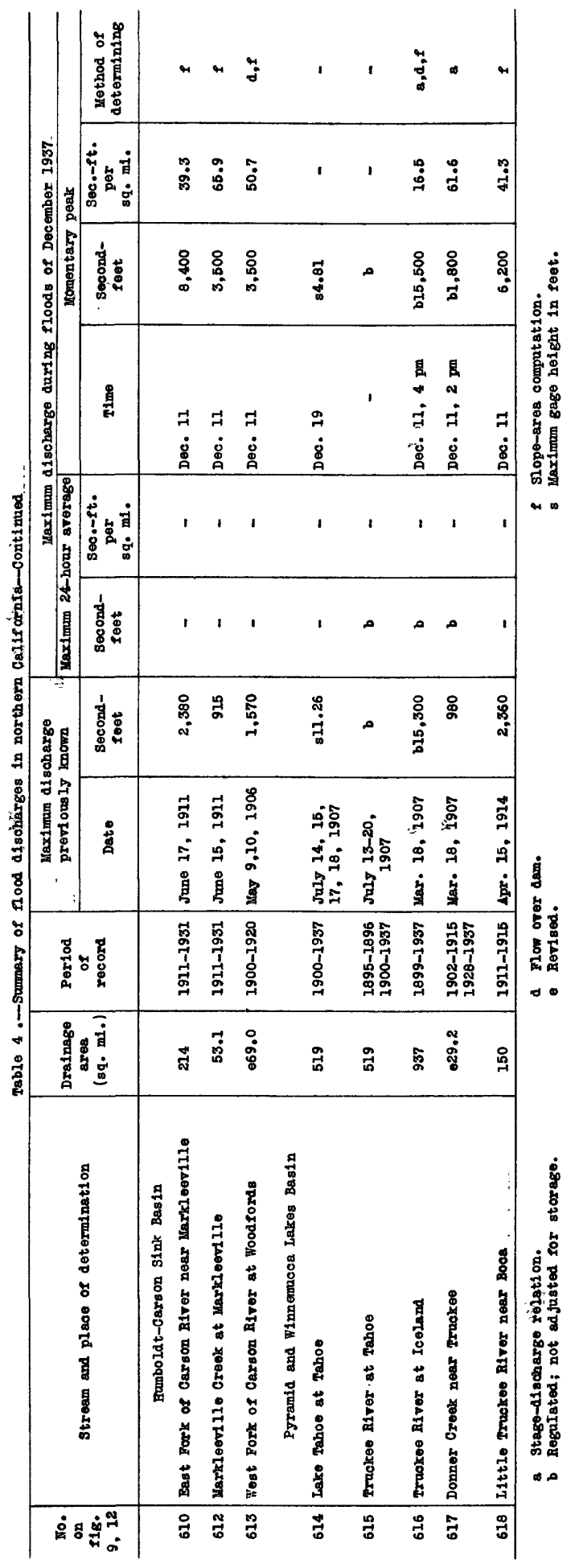




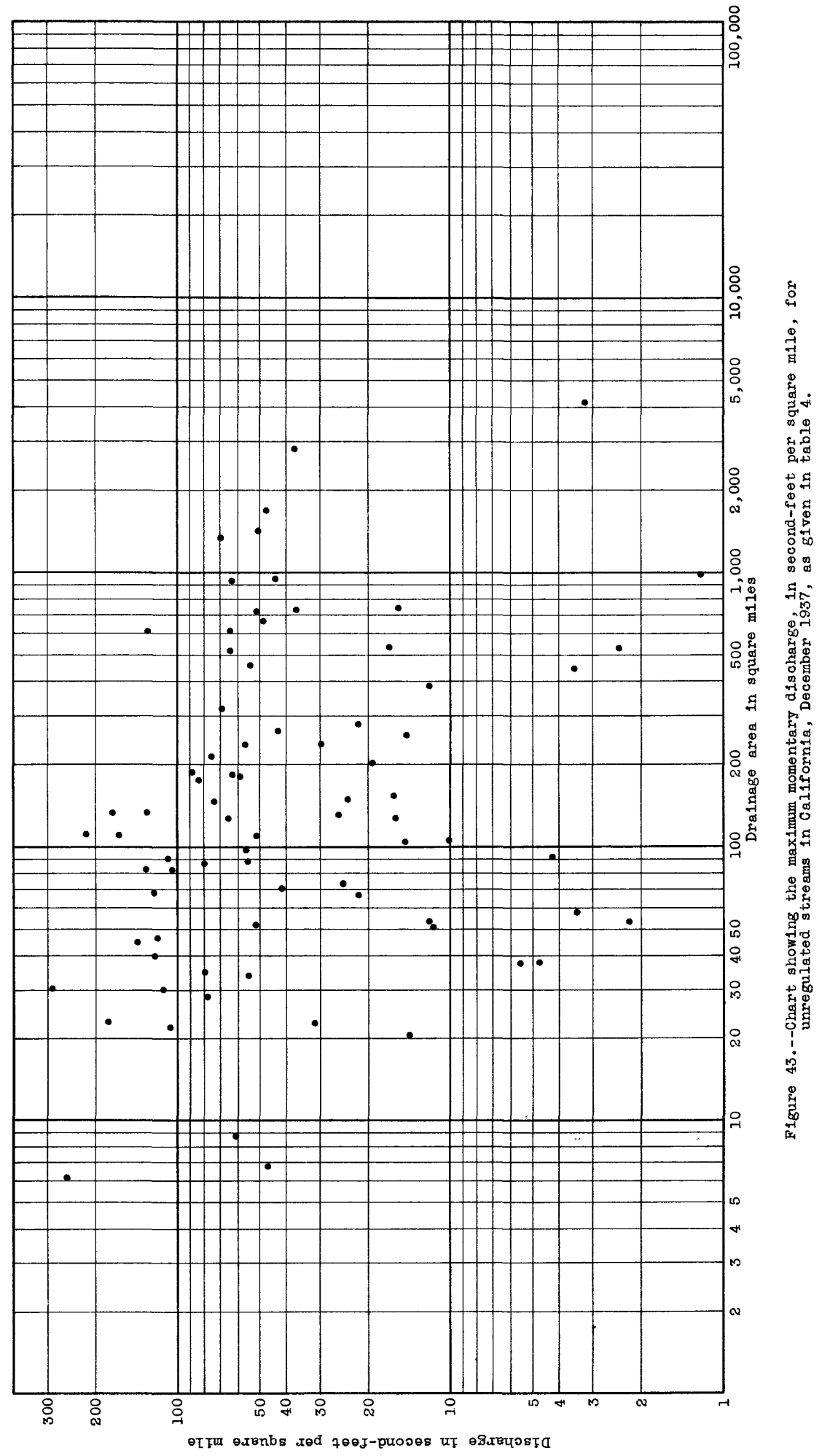




\section{STORAGE}

Run-off of many California streams is affected by storage. The effect in terms of inches in depth over various drainage areas is discussed in the section on "Rainfall and run-off studies". Basic data for practically all important storage reservolrs in northern California are given in the section on "Stages and discharges at river-measurement stations". Table 5 lists the total available storage capacity of reservolrs in northern California. (Footnotes to table 7 in the section on "Rainfall and run-off studies" explain adjustments for storage.)

Table 5.--Total available storage capacity of reservoirs in northern California, by arainage basins

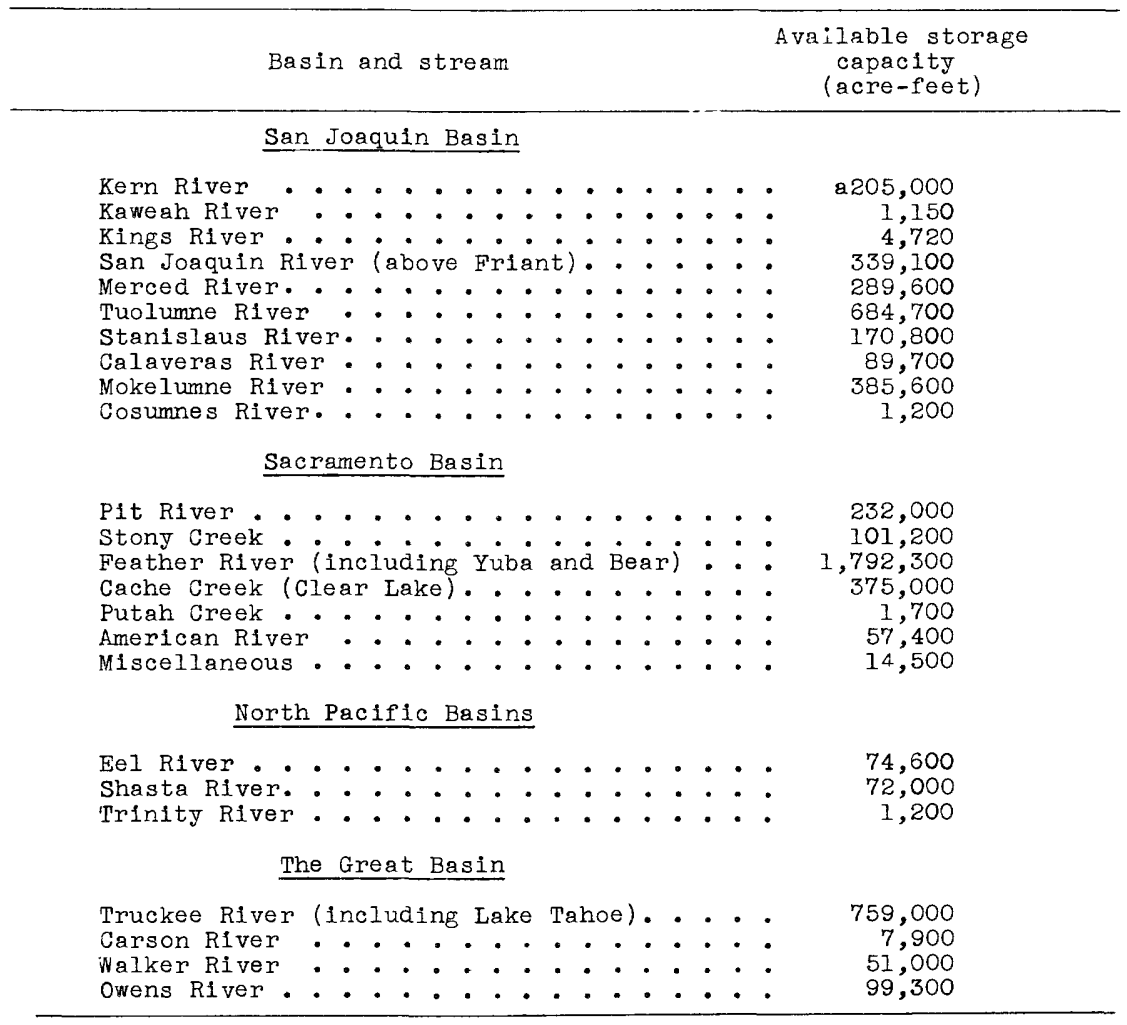

a Buena Vista Reservoir, former natural terminus of river.

Storage reservolrs in Callfornia regulate surface run-off for many purposes, including municlpal use, irrigation, hydro-electric power, flood control, navigation; replenishment of underground reservolrs at a controlled rate, assistance in salinity control near tide water, and various combinations of these uses. Some of the uses may be harmoniously combined, others are in conflict, but whatever the use some advantage 
generally accrues for flood control. Even if a reservoir is full at the time of a flood peak there will generally be some reduction in momentary maximum owing to increased channel storage in the section of the river channel occupied by the reservoir.

Daily gage height (or elevation) and daily contents for the threemonth period November 1, 1937, to January 31, 1938, are presented in this report for the following reservolrs:

San Joaquin River Basin.--Florence Lake on South Fork of San Joaquin River; Huntington Lake on Big Creek; Shaver Lake on Stevenson Creek; Lake McClure on Merced River; Hetch Hetchy Reservoir on Tholumne River; Don Pedro Reservoir on Tholumne River; Lake Eleanor on Eleanor Creek; Melones Reservoir on Stanislaus River; Salt Springs Reservoir on North Fork of Mokelumne River.

Sacramento River Basin.--Stony Gorge on Stony Creek; Lake Almanor on North Fork of Feather River; Bucks Creek Storage Reservoir on Bucks Creek; Bowman Lake on Canyon Creek; Lake Spaulding on South Fork of Yuba River.

Eel River Basin.--Lake Pillsbury on Eel River.

Less complete data are given for the following reservoirs not listed above: Clear Lake on Cache Creek; Lake Tahoe on Truckee River; Bridgeport Reservoir on East Walker River.

Data for the foregoing two groups are presented under the names of the respective reservoirs in the same order as the river-measurement stations. Some reservoir information for the flood period is also given in connection with following stream-rlow records:

San Joaquin River Bas1n.--North Fork of Willow Creek near Crane Valley Reservoir (Crane Valley Reservoir); South Fork of Stanislaus River at Strawberry Reservoir (Strawberry Reservoir); South Fork of Stanislaus River below Lyons Dam (Lyons Reservoir); Calaveras River at Jenny Lind (Hogan Reservoir); Mokelumne River at Lancha Plana (Pardee Reservoir).

Sacramento River Basin.--Concow Creek near Yankee Hill (Lake Wilenor); Twin Lakes Outlet near Kirkwood (Twin Lakes Reservoir); Silver Lake Outlet near Kirkwood (Silver Lake).

San Francisco Bay.--Alameda Creek near N1les (Calaveras Reservo1r). The Great Basin.--Carson River at Lahontan Reservoir (Lahontan Reservoir); Donner Creek near Truckee (Donner Lake). 


\section{Examples of effect of storage}

\section{San Joaquin River}

The most notable effect of storage during the flood of December 1937 was on the Iower San Joaquin River. At the river-measurement station on the San Joaquin River near Friant, there was on December 11 a momentary peak of 77,200 second-feet, by far the highest during the past 30 years of record. Friant gaging station is at the edge of the foothills, 278 miles by river upstream from Collinsville at the junction of the Sacramento and San Joaquin Rivers.

At the gaging station near Vernalis, just upstream from the effect of tide and 202 miles by river downstream from Friant, there was practically no immediate effect from the upstream flood and a very moderate and flattened peak of only 7,960 second-feet on December 26. Between the two stations the San Joaquin is joined by many tributaries, including three large streams, the Merced, Stanislaus, and Tuolumne Rivers. The remarkable reduction of the momentary peak discharge from 77,300 second-feet to 7,960 second-feet was assoclated with a similar falling-off in flood volume. The reduction was caused by a combination of natural and artificial storage. Four large reservoirs on three main tributaries were practically empty on December 9, as were many miles of channels and sloughs and many square miles of lowlands between Friant and Vernalis, hence they supplied a large volume of storage capacity to hold the flood waters.

Lake McClure on the Merced River has a capacity of 282,000 acrefeet; Melones Reservoir on the Stanislaus River, 113,000 acre-feet; Hetch Hetchy Reservoir on the Tuolumne River, 360,000 acre-feet; Don Pedro Reservoir on the Tuolumne River, 290,000 acre-feet. None of these filled during the December storm but they showed a gain in storage of 446,000 acre-feet. Many smaller reservolrs stored their proportional part of the flood.

Although the peak at Friant was by far the largest for the 30 years of record, 1t also was reduced by storage. Florence Lake, Huntington Lake, Shaver Lake, and Crane Valley Reservoir, in the headwaters of the San Joaquin, gained a total of 30,000 acre-feet during the flood period.

The eight largest reservoirs upstream from vernalis therefore detained 476,000 acre-feet of water. It appears, therefore, that very materlal contribution to flood control was furnished by the eight large reservoirs in San Joaquin River Basin, although they were built primarily 
The total avaliable artificlal storage in reservoirs upstream from Vernalis is about $1,500,000$ acre-fe日t. The natural storage avallable in channels, sloughs, and overflow areas, plus seepage loss to underground basins, is unknown in amount but without doubt was very large and was a major factor in avolding a serious flood on the lower San Joaquin. The flow past Vernalis during the perlod December 8 to 25 was only 208,000 acre-feet.

Past records show that most major storms come later in the season than the storm of December 9-13, 1937, and it is reasonable to assume that at times of floods these reservoirs would ordinarliy be at least partly full and so contribute less toward reducing the flood damage in the San Joaquin Valley.

It is now a matter of record, that the lower San Joaquin River did receive the highest water in many years during March and again in June, 1938. Many reservolrs were fllled by the midale of March, most of them were overflowing by June, and the San Joaquin River then resembled a lake for the $244 \mathrm{miles}$ from Skaggs Bridge to mouth.

Another example of effect of storage worthy of mention was at Hogan Reservolr on the Calaveras River, which has a capacity of 76,000 acrefeet. This is one of very few reservolrs in California constructed primarily for flood control, and open ports were bullt into the dam. Its effect is shown by the record at the river-measurement station on the Calaveras River at Jenny Lind. While neighboring streams were experiencing high and sharp flood peaks on December 11, the maximum at Jenny Lind was only 3,370 second-feet. The peak would have been even lower except for unregulated inflow along several miles of channel botween the reservolr and Jenny Lind. The mean discharge for December 11 was 2,040 second-feet, and for December 12, 3,100 second-feet. After adjusting for storage effect the respective mean discharges are 5,570 and 1,200 second-feet. The peak discharge, adjusted for storage, is problematical. Before construction of the reservoir there was a peak flow of 36,800 second-feet on February 6, 1925, and 17,300 second-feet was recorded on March 25, 1928. A discharge of about 69,600 second-fe日t was reported for Jamuary 31, 1911.

Reservolrs on the Mokelumne River prevented a flood of considerable size, although they were built for purposes other than flood control.

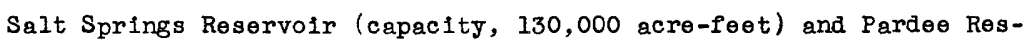
orvolr (capacity, 210,000 acre-feet) did not spill. Together, they detained 85,000 acre-feet during the flood period. Smaller reservolrs in 
the Mokelumne Basin stored some additional water. Consequently, peak discharge at the river-measurement station on the Mokelumne River near Lancha Plana was only the 2,150 second-feet released at Pardee Dam.

\section{Sacramento River}

In contrast with the fortunate situation on the Icwer San Joaquin River, serious flood conditions prevailed during December 1937 throughout the length of the Sacramento River. The ratio of available storage to volume of mun-off is much lower in the Sacramento Basin than in the San Joaquin. In addition, the antecedent period had been very wet in the northern part of the Sacramento Valley, but relatively dry in the San Joaquin.

Lake Almanor on the North Fork of Feather River gained 69,800 acrefeet during the storm period; Lake Spaulding on the South Fork of Yuba River, 31,000 acre-feet from 5 p.m. December 9 to 8 a.m. December 11, when 1t started to spill, and Bucks Creek storage reservolr on Bucks Creek, 18,100 acre-feet. These were the only instances of comparatively large storage detention. Many small reservoirs, especially in the Feather River Basin, filled and spilled during the flood period.

The total capacity of all reservolrs in the Sacramento Basin is about $2,600,000$ acre-feet, but far less than this amount was actually avallable, for three reasons. Many reservoirs were partly filled at the beginning of the December storm. Some of the "hold over" or cycllc reservolrs are never fllled by any one flood. Several reservoirs, in Pit River Basin particularly, are in areas that seldom contribute surface run-off to the Basin's main stream.

The effect of storage on each of the principal tributaries of the Sacramento River 1s summarized as follows.

On the P1t River there are 83 reservoirs w1th combined capacity of 232,000 acre-feet. However, it 1s estimated that only about 93,000 acrefeet of flood waters had been detalned at the end of the flood period, and consequently storage had relatively little effect on either the flood peak or the total flood run-off of the P1t R1ver.

The Feather R1ver, upstream from the Yuba R1ver, has 31 reservoirs with a combined capac1ty of 1,522,000 acre-feet. This includes Lake Almanor with a capacity of 1,308,000 acre-feet, wh1ch has never been fully ut1lized. It is estimated that about 80,000 acre-feet were detained above Orovilie between December 9 and 20 . The effect on the peak discharge of the Feather River was very slight. 
The Yuba River has 39 storage reservolrs with a capacity of about 256,000 acre-feet and the Bear River, five with 15,000 acre-feet. It is estimated that 82,500 acre-feet was detained on the Yuba and 7,000 on the Bear during the December storm. Storage upstream from the gaging station on Yuba River at Smartville was proportionately larger than on some of the other Sacramento tributaries and probably reduced the peak by an appreclable amount.

In Cache Creek Basin, Clear Lake with a capacity of about 375,000 acre-feet at a gage helght of 9 feet, held. 131,000 acre-feet more on December 20 than on December 10 and therefore materially affected the flow at the gaging station on Cache Creek at Yolo.

The American River has 16 reservoirs, including minor ones, with a combined capacity of about 57,000 acre-feet. It is estimated that they detained 28,000 to 30,000 acre-feet during the high water period.

The Sacramento River upstream from the Pit River has practically no storage.

Minor basins from the Pit down to the Feather have storage amounting to 114,000 acre-feet. Minor basins from the Feather to the American have reservoirs with capacities of about 1,800 acre-feet, and Putah Creek Basin about 1,700 acre-feet. The amount detained in these is problematical but was certainly small in comparison with the total flood runoff.

On December 20 there was possibly 480,000 acre-feet more in storage in artificial reservoirs in the Sacramento River Basin, than on December 10.

Run-off past Sacramento in the main channel of the Sacramento River, plus flow in Yolo by-pass December 10 to 20, was 3,100,000 acre-feet. Therefore, artificial storage was only about 15 per cent and played a small part in the results in the lower Sacramento Valley.

\section{Areas outside the Central Valley}

In Santa Clara Valley, storage on streams tributary to San Francisco Bay played an important part. During 1935 and 1936 the Santa Clara Valley Water Conservation District constmucted reservoirs on Coyote, Guadalupe, Stevens, Los Gatos, and Almaden Creeks, and Calero Reservoir, holding foothill storage supplied by a canal from Almaden Reservoir. These reservoirs were built to detain storm waters and release them at a rate slow enough to replenish natural underground storage. None of these reservoirs filled during the December flood and therefore the mun-off of 
none of the streams named approached previous flood peaks at gaging stations downstream from the reservoirs. At the end of the flood period they contained 19,200 acre-feet more than at the beginning.

In the North Pacific area, flood discharge at gaging stations was not appreciably affected by storage.

In the Great Basin area, Lake Tahoe is the outstanding storage reservoir. The gates in the dam at the outlet of the Lake were closed throughout the December storm period. Without this regulation of the runoff from 519 square miles of the Upper Truckee Basin, the flood would have been much more serious at Iceland and points farther downstream.

\section{RAINFALL AND RUN-OFF STUDIES}

\section{General discussion}

In connection with the outstanding floods of March 1936 in northeastern United States and of January 1937 in the Ohio and Mississippi Rivers, detalled analyses were made in order to develop some of the significant features of the relation between rainfall and run-off.

The results of these studies are published in Water Supply Papers 798, 799, 800, and 838. A second objective, probably of equal importance, was to use the results of the analyses, so far as practicable, in checking the accuracy or reasonableness of the basic data published in the reports and in furnishing a background of information that is useful in consideration of the deficiencies in the basic meteorologic and hydrologic data and of measures to supply them. The analyses herein, relating to the storm and floods of December 1937 in northern California, have been carried on with the same objectives in view.

As it is evident that altitude, especially along the western face of the Sierra Nevada, was a factor of major importance in affecting the magnitude of the precipitation and its occurrence as rain or snow, the drainage basins have been broken down into altitude zones and the areas in each zone determined approximately. Table 6 shows for each basin the approximate number of square miles lying above an altitude of 9,000 feet, between 7,000 and 9,000 feet, between 5,000 and 7,000 feet, and below 5,000 feet. These determinations are useful in explaining rainfall and run-off characteristics and may be of value in future studies relating to the run-off and flood potentialities of the sierra Nevada. For detail studies in any individuai basin, large scale topographic maps should be used, as the areas given in table 6 are only approximate. 
Table 6.--Dralnage areas, in square miles, between selected altitudes along western slope of the sierra Nevada

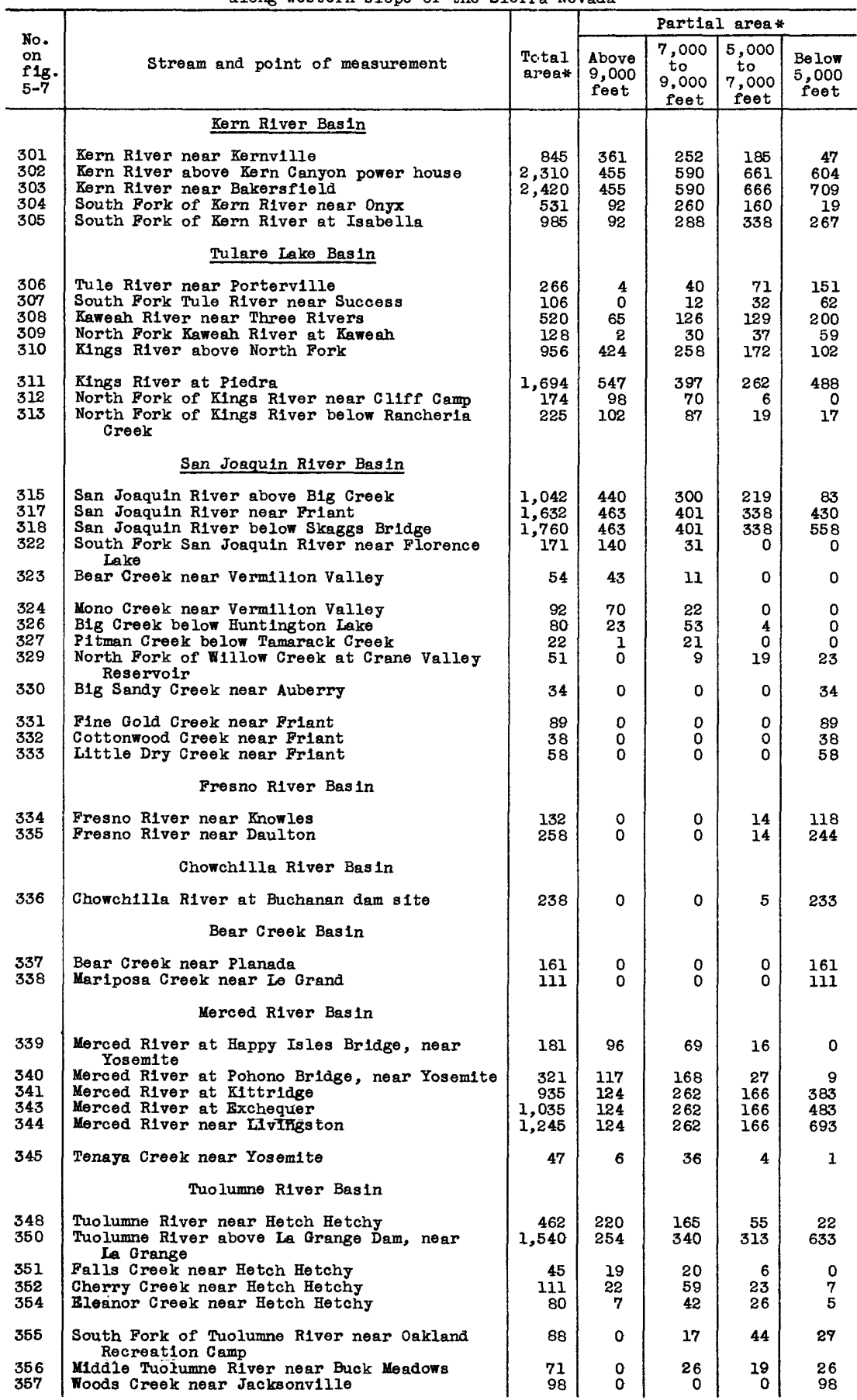

- Area given to the nearest square milo. 
Table 6.--Drainage areas in square miles between selected altitudes along western slope of the Sierra Nevada--Continued

\begin{tabular}{|c|c|c|c|c|c|c|}
\hline \multirow[b]{2}{*}{$\begin{array}{l}\text { No. } \\
\text { on } \\
\text { fig. } \\
7-9\end{array}$} & \multirow[b]{2}{*}{ Stream and point of measurement } & \multirow[b]{2}{*}{$\begin{array}{l}\text { Total } \\
\text { area* }\end{array}$} & \multicolumn{4}{|c|}{ Partial areu* } \\
\hline & & & $\begin{array}{l}\text { Above } \\
9,000 \\
\text { feet }\end{array}$ & $\begin{array}{l}7,000 \\
\text { to } \\
9,000 \\
\text { feet }\end{array}$ & $\begin{array}{l}5,000 \\
\text { to } \\
7,000 \\
\text { feet }\end{array}$ & $\begin{array}{l}\text { Be low } \\
5,000 \\
\text { feet }\end{array}$ \\
\hline & $\frac{\text { San Joaquin River Basin--Continued }}{\text { Stanislaus Rlver Bas in }}$ & & & & & \\
\hline 358 & $\begin{array}{l}\text { Middle Fork of Stanislaus River at Sand Bar } \\
\text { Flat, near Avery }\end{array}$ & 318 & 57 & 130 & 101 & 30 \\
\hline $\begin{array}{l}360 \\
361 \\
362\end{array}$ & $\begin{array}{l}\text { Stanislaus River below Melones power house } \\
\text { North Fork of Stanislaus River near Avery } \\
\text { South Fork of Stanislaus River at } \\
\text { Strawberry Reservolr }\end{array}$ & $\begin{array}{r}898 \\
163 \\
46\end{array}$ & $\begin{array}{r}63 \\
0 \\
5\end{array}$ & $\begin{array}{r}239 \\
76 \\
30\end{array}$ & $\begin{array}{r}214 \\
67 \\
11\end{array}$ & $\begin{array}{r}382 \\
20 \\
0\end{array}$ \\
\hline 363 & $\begin{array}{l}\text { South Fork of Stanislaus River below Lyons } \\
\text { Dam }\end{array}$ & 67 & 5 & 30 & 19 & 13 \\
\hline & Calaveras River Basin & & & & & \\
\hline $\begin{array}{l}364 \\
365\end{array}$ & $\begin{array}{l}\text { Calaveras River at Jenny Lind } \\
\text { Cosgrove Creek near Valiey Springs } \\
\text { Mokelumne River Basin }\end{array}$ & $\begin{array}{r}395 \\
21\end{array}$ & $\begin{array}{l}0 \\
0\end{array}$ & $\begin{array}{l}0 \\
0\end{array}$ & $\begin{array}{l}0 \\
0\end{array}$ & $\begin{array}{r}395 \\
21\end{array}$ \\
\hline 367 & $\begin{array}{l}\text { North Fork of Mokelume River below Salt } \\
\text { Springs Dam }\end{array}$ & 160 & 0 & 119 & 35 & 6 \\
\hline $\begin{array}{l}368 \\
369 \\
370 \\
371\end{array}$ & $\begin{array}{l}\text { Mokelume River near Mokelume Hill } \\
\text { Moke lume River at Lancha Plana } \\
\text { Moke Iume River near Clements } \\
\text { Moke Iumne River at Woodbridge }\end{array}$ & $\begin{array}{l}538 \\
584 \\
630 \\
644\end{array}$ & $\begin{array}{l}0 \\
0 \\
0 \\
0\end{array}$ & $\begin{array}{l}154 \\
154 \\
154 \\
154\end{array}$ & $\begin{array}{l}137 \\
137 \\
137 \\
137\end{array}$ & $\begin{array}{l}247 \\
293 \\
339 \\
353\end{array}$ \\
\hline $\begin{array}{l}372 \\
373 \\
374 \\
375 \\
376\end{array}$ & $\begin{array}{l}\text { Cold Creek near Mokelume Peak } \\
\text { Bear River at Pardoe Camp } \\
\text { Middle Fork of Mokelume River at West Point } \\
\text { South Fork of Mokelume River near West Point } \\
\text { Sutter Creek near Sutter Creek }\end{array}$ & $\begin{array}{l}23 \\
33 \\
67 \\
74 \\
51\end{array}$ & $\begin{array}{l}0 \\
0 \\
0 \\
0 \\
0\end{array}$ & $\begin{array}{r}14 \\
19 \\
0 \\
0 \\
0\end{array}$ & $\begin{array}{r}9 \\
14 \\
20 \\
20 \\
0\end{array}$ & $\begin{array}{r}0 \\
0 \\
47 \\
54 \\
51\end{array}$ \\
\hline $\begin{array}{l}377 \\
378\end{array}$ & $\begin{array}{l}\text { North Fork of Cosumes River near El Dorado } \\
\text { Cosumes River at Michigan Bar } \\
\qquad \text { Sacramento River Basin }\end{array}$ & $\begin{array}{l}202 \\
537\end{array}$ & $\begin{array}{l}0 \\
0\end{array}$ & $\begin{array}{l}4 \\
9\end{array}$ & $\begin{array}{l}46 \\
79\end{array}$ & $\begin{array}{l}152 \\
449\end{array}$ \\
\hline $\begin{array}{l}401 \\
402 \\
404\end{array}$ & $\begin{array}{l}\text { Sacramento River at Antler } \\
\text { Sacramento River at Kennett } \\
\text { Sacramento River near Red Bluff } \\
\text { P1t River Basin }\end{array}$ & $\begin{array}{l}461 \\
6,600 \\
9,300\end{array}$ & $\begin{array}{l}4 \\
9 \\
9\end{array}$ & $\begin{array}{r}7 \\
103 \\
121\end{array}$ & $\begin{array}{r}107 \\
2,308 \\
2,374\end{array}$ & $\begin{array}{r}343 \\
4,780 \\
6,796\end{array}$ \\
\hline $\begin{array}{l}406 \\
407 \\
408 \\
409 \\
410\end{array}$ & $\begin{array}{l}\text { Pit River near Canby } \\
\text { Pit River at Fali River Mills } \\
\text { Pit River below Pit No. } 4 \text { dam } \\
\text { Pit River at Big Bend } \\
\text { Pit River near Yalpom }\end{array}$ & $\begin{array}{l}1,430 \\
4,150 \\
4,860 \\
4,920 \\
5,350\end{array}$ & $\begin{array}{l}0 \\
0 \\
0 \\
0 \\
0\end{array}$ & $\begin{array}{l}77 \\
77 \\
83 \\
83 \\
83\end{array}$ & $\begin{array}{r}932 \\
1,908 \\
2,082 \\
2,082 \\
2,082\end{array}$ & $\begin{array}{l}421 \\
2,165 \\
2,695 \\
2,755 \\
3,185\end{array}$ \\
\hline $\begin{array}{l}411 \\
412 \\
413 \\
414\end{array}$ & $\begin{array}{l}\text { South Fork of Plt River near Likely } \\
\text { Hat Creek near Hat Creek } \\
\text { McCloud River near McCloud } \\
\text { McCloud River at Baird } \\
\text { Mill Creek Bas in }\end{array}$ & $\begin{array}{l}248 \\
155 \\
388 \\
668\end{array}$ & $\begin{array}{l}0 \\
0 \\
2 \\
5\end{array}$ & $\begin{array}{r}42 \\
17 \\
6 \\
13\end{array}$ & $\begin{array}{l}206 \\
101 \\
106 \\
119\end{array}$ & $\begin{array}{r}0 \\
37 \\
274 \\
531\end{array}$ \\
\hline 417 & $\begin{array}{l}\text { M111 Creek near Los Molinos } \\
\text { Deer Creek Basin }\end{array}$ & 134 & 0 & 14 & 24 & 96 \\
\hline 420 & $\begin{array}{l}\text { Deer Creek near Vina } \\
\text { Chlco Creek Basin }\end{array}$ & 200 & 0 & 0 & 44 & 156 \\
\hline 421 & $\begin{array}{l}\text { Chico Creek near Chico } \\
\text { Butte Creek Basin }\end{array}$ & 68 & 0 & 0 & 4 & 64 \\
\hline 424 & $\begin{array}{l}\text { Butte Creek near Chico } \\
\text { Feather River Basin }\end{array}$ & 148 & 0 & 0 & 47 & 101 \\
\hline $\begin{array}{l}426 \\
429 \\
429 \\
430 \\
432\end{array}$ & $\begin{array}{l}\text { North Fork of Feather River near Prattville } \\
\text { Feather River near Oroville } \\
\text { Indian Creek near Crescent Mills } \\
\text { Spanish Oreek at Keddie } \\
\text { Bucks Creek at Bucks Creek storage reservoir }\end{array}$ & $\begin{array}{r}507 \\
3,611 \\
746 \\
184 \\
28\end{array}$ & $\begin{array}{l}0 \\
0 \\
0 \\
0 \\
0\end{array}$ & $\begin{array}{r}9 \\
23 \\
0 \\
0 \\
0\end{array}$ & $\begin{array}{r}307 \\
1,907 \\
577 \\
51 \\
28\end{array}$ & $\begin{array}{r}191 \\
1,681 \\
169 \\
133 \\
0\end{array}$ \\
\hline $\begin{array}{l}433 \\
434\end{array}$ & $\begin{array}{l}\text { Grizzly Creek near Storrie } \\
\text { West Branch of Feather River near Yankee Hill }\end{array}$ & 145 & $\begin{array}{l}0 \\
0\end{array}$ & 0 & $\begin{array}{r}6 \\
46\end{array}$ & $\begin{array}{r}0 \\
99\end{array}$ \\
\hline
\end{tabular}

* Area given to the nearest square mile. 
Table 6.--Drainage areas, in square miles, between selected altitudes along western slope of the Slerra Nevada-Continued

\begin{tabular}{|c|c|c|c|c|c|c|}
\hline \multirow[b]{2}{*}{$\begin{array}{l}\text { No. } \\
\text { on } \\
\text { fig. } \\
9-12\end{array}$} & \multirow[b]{2}{*}{ Stream and point of measurement } & \multirow[b]{2}{*}{$\begin{array}{l}\text { Total } \\
\text { area* }\end{array}$} & \multicolumn{4}{|c|}{ Partial area* } \\
\hline & & & $\begin{array}{l}\text { Above } \\
9,000 \\
\text { feet }\end{array}$ & $\begin{array}{l}7,000 \\
\text { to } \\
9,000 \\
\text { feet }\end{array}$ & $\begin{array}{l}5,000 \\
\text { to } \\
7,000 \\
\text { feet }\end{array}$ & $\begin{array}{l}\text { Below } \\
5,000 \\
\text { feet }\end{array}$ \\
\hline & $\begin{array}{l}\text { Sacramento River Basin--Continued } \\
\text { Feather River Basin--Continued }\end{array}$ & & & & & \\
\hline $\begin{array}{l}435 \\
436 \\
437 \\
438 \\
439\end{array}$ & $\begin{array}{c}\text { Concow Creek near Yankee Hill } \\
\text { Middle Fork of Feather River near Clio } \\
\text { Middle Fork of Feather River at Bidwell Bar } \\
\text { South Fork of Feather River at Enterprise } \\
\text { Lost Creek near Clipper Mills } \\
\text { Yuba River Basin }\end{array}$ & $\begin{array}{r}15 \\
699 \\
1,353 \\
134 \\
30\end{array}$ & $\begin{array}{l}0 \\
0 \\
0 \\
0 \\
0\end{array}$ & $\begin{array}{r}0 \\
10 \\
10 \\
0 \\
0\end{array}$ & $\begin{array}{r}0 \\
492 \\
769 \\
61 \\
5\end{array}$ & $\begin{array}{r}15 \\
197 \\
574 \\
73 \\
25\end{array}$ \\
\hline $\begin{array}{l}440 \\
441 \\
442 \\
443 \\
444\end{array}$ & $\begin{array}{l}\text { Middle Fork of Yuba River at Milton } \\
\text { Middle Fork of Yuba River near North San Juan } \\
\text { Yuba River at Smartvilie } \\
\text { Oregon Creek near North San Juan } \\
\text { North Fork of Yuba River near Sierra City }\end{array}$ & $\begin{array}{r}41 \\
207 \\
1,201 \\
35 \\
91\end{array}$ & $\begin{array}{l}0 \\
0 \\
0 \\
0 \\
0\end{array}$ & $\begin{array}{r}14 \\
14 \\
80 \\
0 \\
16\end{array}$ & $\begin{array}{r}27 \\
79 \\
435 \\
3 \\
70\end{array}$ & $\begin{array}{r}0 \\
114 \\
686 \\
32 \\
5\end{array}$ \\
\hline $\begin{array}{l}445 \\
447 \\
449 \\
450 \\
451\end{array}$ & $\begin{array}{l}\text { North Fork of Yuba River below Goodyears Bar } \\
\text { South Fork of Yuba River at Lake Spaulding } \\
\text { Canyon Creek below Bowman Lake } \\
\text { Deer Creek near Smartville } \\
\text { Bear River near Wheatland } \\
\text { American River Basin }\end{array}$ & $\begin{array}{r}244 \\
118 \\
32 \\
84 \\
295\end{array}$ & $\begin{array}{l}0 \\
0 \\
0 \\
0 \\
0\end{array}$ & $\begin{array}{r}16 \\
50 \\
4 \\
0 \\
0\end{array}$ & $\begin{array}{r}150 \\
68 \\
28 \\
0 \\
2\end{array}$ & $\begin{array}{r}78 \\
0 \\
0 \\
84 \\
293\end{array}$ \\
\hline $\begin{array}{l}452 \\
454 \\
455 \\
456 \\
457\end{array}$ & $\begin{array}{l}\text { North Fork of American River near Colfax } \\
\text { American River at Fair Oaks } \\
\text { Middle Fork of Amerlcan River near Auburn } \\
\text { South Fork of American River near Kyburz } \\
\text { South Fork of American River near Camino }\end{array}$ & $\begin{array}{r}308 \\
1,921 \\
619 \\
196 \\
497\end{array}$ & $\begin{array}{l}0 \\
0 \\
0 \\
0 \\
5\end{array}$ & $\begin{array}{r}20 \\
242 \\
76 \\
114 \\
146\end{array}$ & $\begin{array}{r}114 \\
545 \\
242 \\
76 \\
189\end{array}$ & $\begin{array}{r}174 \\
134 \\
301 \\
6 \\
157\end{array}$ \\
\hline $\begin{array}{l}458 \\
459 \\
460 \\
461 \\
462\end{array}$ & $\begin{array}{l}\text { South Fork of American River at Coloma } \\
\text { Medley Lakes outlet near Vade } \\
\text { Silver Lake outlet near Kirkwood } \\
\text { Silver Fork of South Fork of American River } \\
\text { near Kyburz } \\
\text { Twin Lakes outlet near Klrkwood }\end{array}$ & $\begin{array}{r}635 \\
6 \\
15 \\
108 \\
12\end{array}$ & $\begin{array}{l}0 \\
0 \\
0 \\
4 \\
3\end{array}$ & $\begin{array}{r}146 \\
6 \\
15 \\
58\end{array}$ & $\begin{array}{r}189 \\
0 \\
0 \\
43\end{array}$ & $\begin{array}{r}300 \\
0 \\
0 \\
3 \\
0\end{array}$ \\
\hline $\begin{array}{l}463 \\
464 \\
465 \\
466 \\
467\end{array}$ & $\begin{array}{l}\text { Alder Creek near Whitehall } \\
\text { Plum Creek near Riverton } \\
\text { Silver Creek at Union Valley } \\
\text { Silver Creek near Placervilie } \\
\text { South Fork of Silver Creek near Ice House } \\
\text { The Great Basint } \\
\text { Owens River Basin }\end{array}$ & $\begin{array}{r}23 \\
7 \\
83 \\
176 \\
28\end{array}$ & $\begin{array}{l}0 \\
0 \\
0 \\
1 \\
1\end{array}$ & $\begin{array}{r}0 \\
0 \\
21 \\
32 \\
10\end{array}$ & $\begin{array}{r}21 \\
5 \\
49 \\
91 \\
17\end{array}$ & $\begin{array}{r}2 \\
2 \\
13 \\
52 \\
0\end{array}$ \\
\hline $\begin{array}{l}601 \\
602 \\
603 \\
604\end{array}$ & $\begin{array}{l}\text { Owens River near Round Valley } \\
\text { Rock Creek at Sherwin Hili, near Bishop } \\
\text { Pine Creek at division box, near Blshop } \\
\text { Big Plne Oreek below Little Pine Creek, near } \\
\text { Big Pine }\end{array}$ & $\begin{array}{r}450 \\
52 \\
38 \\
40\end{array}$ & $\begin{array}{l}96 \\
36 \\
30 \\
26\end{array}$ & $\begin{array}{r}264 \\
8 \\
6 \\
8\end{array}$ & $\begin{array}{r}89 \\
8 \\
2 \\
5\end{array}$ & $\begin{array}{l}1 \\
0 \\
0 \\
1\end{array}$ \\
\hline 605 & Independence Creek at Independence & 18 & 10 & 3 & 3 & 2 \\
\hline 606 & Tuttle Creek at Canyon Road, near Ione Pine & 9 & 4 & 1 & 2 & 2 \\
\hline
\end{tabular}

* Area given to the nearest square mile.

+ Eastern slope of Sierra Nevada. 
In certain respects the characteristics of the storm of December 1937 and resulting flood run-off were simple. The storm period was short and relatively isolated from antecedent and subsequent storm periods, making it possible to determine definitely the precipitation associated with the flood. There had been little precipitation for 15 days prior to December 9, and the stream discharges at the beginning of the storm consisted largely of outflow from ground water. The rise in stages was pronounced, and the recession limbs of the hydrographs were not influenced by precipitation that fell after the storm period and were influenced only in the higher Sierra Nevada by run-off from melting snow, which may have been on the ground on December 12. All the direct man-off, not artificially stored, had passed out of the basins either into the ocean or into the broad flat reaches of the Central Valley by December 20, eight days after the end of the storm.

The determination $0:$ the direct run-off resulting from the storm was, therefore, not complicated elther by a lar je ground-water flow at the beginning of the flood rise or by run-off from subsequent precipitation.

The method used in arriving at an estimate of the average precipitation in each basin is described under "Meteorologic and hydrologic conaltions". (See table 7 and figs. 13-2l for results of the determinations.) No attempt has been made to present in tabular form any estimates of the water content of the snow that may have been on the ground at the beginning of the storm and that may have contributed to the flood run-off. Comments about possible contributions from melting snow are, however, included in the discussion by drainage basins.

The records of mean dally discharge as presented in the section entitled "Stages and discharges at river-measurement stations" have been used as a basis for the determination of the direct run-off resulting from the storm.

A discharge hydrograph was constructed for the record at each rivermeasurement station for the period November 15 to December 31, 1937. The hydrograph for the Middle Fork of Feather River at Bidwell Bar (fig. 44) shows the general shape of the hydrographs at most of the river-measurement stations. 
Table 7.--Rainfall and mun-of of flood of December 1937 (Mean depth, in inches, over drainage basin)

\begin{tabular}{|c|c|c|c|c|c|c|}
\hline \multirow{2}{*}{$\begin{array}{l}\text { No. } \\
\text { on } \\
\text { fig. } \\
4-5\end{array}$} & \multirow{2}{*}{ Stream and point of measurement } & \multirow{2}{*}{$\begin{array}{l}\text { Drain- } \\
\text { age } \\
\text { area } \\
\text { (square } \\
\text { miles) } \\
2\end{array}$} & \multirow{2}{*}{$\begin{array}{l}\text { Precipi- } \\
\text { tation } \\
\text { Dec. } 9-12\end{array}$} & \multicolumn{2}{|c|}{$\begin{array}{l}\text { Direct mun-off } \\
\text { associated } \\
\text { with total } \\
\text { storm period }\end{array}$} & \multirow{2}{*}{$\begin{array}{l}\text { Col. } 3 \\
\text { minus } \\
\text { col. } 5 \\
6\end{array}$} \\
\hline & & & & $\begin{array}{c}\text { Observed } \\
4\end{array}$ & $\begin{array}{l}\text { Ad justed } \\
\text { for } \\
\text { storage } \\
5\end{array}$ & \\
\hline & Salinas River Basin & & & & & \\
\hline $\begin{array}{l}101 \\
102 \\
103 \\
104\end{array}$ & $\begin{array}{l}\text { Salinas River near SantaMargarital } \\
\text { Salinas River near Spreckels } \\
\text { San Antonio River at Pleyto } \\
\text { Arroyo Seco near Soleđad } \\
\text { Pajaro River Basin }\end{array}$ & $\begin{array}{r}150 \\
4,180 \\
282 \\
238\end{array}$ & $\begin{array}{r}3.3 \\
4.8 \\
7.7 \\
10.6\end{array}$ & $\begin{array}{l}0.5 \\
.25 \\
.9 \\
1.75\end{array}$ & $\begin{array}{l}0.5 \\
.25 \\
.9 \\
1.75\end{array}$ & $\begin{array}{l}2.8 \\
4.55 \\
6.8 \\
8.85\end{array}$ \\
\hline 105 & $\begin{array}{l}\text { Uvas Creek near Morgan H111 } \\
\text { San Lorenzo R1ver Besin }\end{array}$ & 30.2 & 18.0 & 8.9 & 8.9 & 9.1 \\
\hline 106 & $\begin{array}{l}\text { San Lorenzo River at B1g Trees } \\
\text { San Francisquito Creek Basin }\end{array}$ & 110 & 17.1 & 2.25 & 2.25 & 14.85 \\
\hline 201 & $\begin{array}{l}\text { San Francisquito Creek at } \\
\text { Stanford University }\end{array}$ & 37.7 & 6.7 & .9 & al. 3 & 5.4 \\
\hline 202 & $\begin{array}{l}\text { San Francisquito Creek at Palo } \\
\text { Alto }\end{array}$ & 38.6 & 6.6 & .8 & al.2 & 5.4 \\
\hline 203 & $\begin{array}{l}\text { Los Trancos Creek at Stanford } \\
\text { University } \\
\text { Stevens Creek Basin }\end{array}$ & 7.5 & 6.8 & .2 & b. 6 & 6.2 \\
\hline 204 & $\begin{array}{c}\text { Stevens Creek near Oupertino } \\
\text { Guadalupe Creek Basin }\end{array}$ & 18.1 & 11.2 & .3 & c1.3 & 9.9 \\
\hline $\begin{array}{l}205 \\
206 \\
207 \\
208 \\
209\end{array}$ & 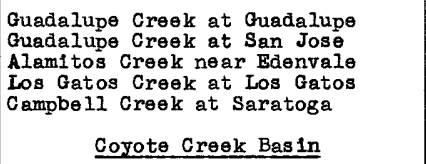 & $\begin{array}{l}12.6 \\
131 \\
35 \\
40 \\
8.8\end{array}$ & $\begin{array}{l}12.1 \\
10.9 \\
11.9 \\
14.5 \\
14.9\end{array}$ & $\begin{array}{l}1.3 \\
1.55 \\
1.9 \\
4.15 \\
2.35\end{array}$ & $\begin{array}{l}04.35 \\
\odot 2.45 \\
\mathrm{f} 4.0 \\
4.15 \\
2.35\end{array}$ & $\begin{array}{l}7.75 \\
8.45 \\
7.9 \\
10.35 \\
12.55\end{array}$ \\
\hline $\begin{array}{l}210 \\
211\end{array}$ & $\begin{array}{l}\text { Coyote Creek near Madrone } \\
\text { Coyote Creek near Bdenvale } \\
\text { Alameda Creek Bas in }\end{array}$ & $\begin{array}{l}193 \\
229\end{array}$ & $\begin{array}{l}7.2 \\
7.4\end{array}$ & $\begin{array}{l}.3 \\
.35\end{array}$ & $\begin{array}{l}81 \cdot 45 \\
81 \cdot 3\end{array}$ & $\begin{array}{l}5.75 \\
6.1\end{array}$ \\
\hline 212 & $\begin{array}{r}\text { Alameda Creek near Niles } \\
\text { Kern River Basin }\end{array}$ & 633 & 5.2 & .4 & $\mathrm{~h} .75$ & 4.45 \\
\hline $\begin{array}{l}301 \\
302\end{array}$ & $\begin{array}{l}\text { Kern River near Kernville } \\
\text { Kern River above Kern Canyon } \\
\text { power house }\end{array}$ & $\begin{array}{r}845 \\
2,310\end{array}$ & $\begin{array}{l}7.8 \\
5.3\end{array}$ & $\begin{array}{l}.4 \\
.15\end{array}$ & $\begin{array}{l}1.65 \\
\jmath .25\end{array}$ & $\begin{array}{l}7.15 \\
5.05\end{array}$ \\
\hline $\begin{array}{l}303 \\
304\end{array}$ & $\begin{array}{l}\text { Kern River near Bakersfield } \\
\text { South Fork of Kern River near } \\
\text { Onyx }\end{array}$ & $\begin{array}{r}2,420 \\
531\end{array}$ & $\begin{array}{l}5.1 \\
4.3\end{array}$ & .25 & .25 & $\begin{array}{l}4.85 \\
4.15\end{array}$ \\
\hline 305 & $\begin{array}{l}\text { South Fork of Kern River at } \\
\text { Isabella } \\
\text { Tulare Lake Basin }\end{array}$ & 985 & 3.7 & .1 & .1 & 3.6 \\
\hline $\begin{array}{l}306 \\
307\end{array}$ & $\begin{array}{l}\text { Thle River near Porterville } \\
\text { South Fork of Tule River near } \\
\text { Success }\end{array}$ & $\begin{array}{l}266 \\
106\end{array}$ & $\begin{array}{l}9.4 \\
6.7\end{array}$ & $1 . \frac{1}{.35}$ & $\frac{1.1}{.35}$ & $\begin{array}{l}8.3 \\
6.35\end{array}$ \\
\hline $\begin{array}{l}308 \\
309\end{array}$ & $\begin{array}{l}\text { Kaweah River near Three Rivers } \\
\text { North Fork of Kaweah River at } \\
\text { Kaweah }\end{array}$ & $\begin{array}{l}520 \\
128\end{array}$ & $\begin{array}{l}11.9 \\
12.4\end{array}$ & $\begin{array}{l}1.85 \\
1.6\end{array}$ & $\begin{array}{l}1.85 \\
1.6\end{array}$ & $\begin{array}{l}10.05 \\
10.80\end{array}$ \\
\hline 310 & KIngs River above North Fork & 956 & 8.1 & 1.1 & 1.1 & 7.0 \\
\hline
\end{tabular}

a Adjusted for storage in Searsville Lake plus diversions into Los Trancos and Lagunita canals.

b Adjusted for diversion into Los Trancos canal.

c Adjusted for storage in Stevens Creok Reservoir.

d Ad justed for storage in Guadalupe Creek Reservoir.

- Ad justed for storage in Calero, Almaden, Vasona, and Guadalupe Reservolrs.

$f$ Adjusted for storage in Calero and Almaden Reservoirs.

$g$ Adjusted for storage in Coyote Reservoir.

$h$ Adjusted for storage in Calaveras Reservoir plus diversions for San

Francisco water supply.

1 Ad justed for flow through Kern River No. 3 canal.

$f$ Adjusted for flow through Kerm Canyon power house. 
Table 7.--Rainfall and mun-off of flood of December 1937--Continued (Mean depth, in Inches, over dralnage basin)

\begin{tabular}{|c|c|c|c|c|c|c|}
\hline \multirow{2}{*}{$\begin{array}{l}\text { No. } \\
\text { on } \\
\text { fig. } \\
5-7\end{array}$} & \multirow{2}{*}{ Stream and point of measurement } & \multirow{2}{*}{$\begin{array}{l}\text { Drain- } \\
\text { age } \\
\text { area } \\
\text { (square } \\
\text { miles) } \\
2\end{array}$} & \multirow{2}{*}{$\begin{array}{l}\text { Prec1p1- } \\
\text { tat1on } \\
\text { Dec. } 9-12\end{array}$} & \multicolumn{2}{|c|}{$\begin{array}{l}\text { Direct mun-off } \\
\text { assoc lated } \\
\text { with total } \\
\text { storm period }\end{array}$} & \multirow{2}{*}{$\begin{array}{l}\text { Col. } 3 \\
\text { mimus } \\
\text { col. } 5 \\
6\end{array}$} \\
\hline & & & & $\begin{array}{l}\text { Observed } \\
\qquad 4\end{array}$ & $\begin{array}{l}\text { Ad justed } \\
\text { for } \\
\text { storage } \\
5\end{array}$ & \\
\hline & Tulare Lake Bas1n--Continued & & & & & \\
\hline $\begin{array}{l}311 \\
312\end{array}$ & $\begin{array}{l}\text { Kings River at Pledra } \\
\text { North Fork of Kings R1ver near } \\
\text { Cliff Camp }\end{array}$ & $\begin{array}{r}1,694 \\
174\end{array}$ & $\begin{array}{r}9.7 \\
13.4\end{array}$ & $\begin{array}{c}1.5 \\
-\end{array}$ & 1.5 & $\begin{array}{l}8.2 \\
-\end{array}$ \\
\hline 313 & $\begin{array}{l}\text { North Fork of Kings River below } \\
\text { Rancheria Creek }\end{array}$ & 225 & 13.2 & - & - & - \\
\hline 314 & $\begin{array}{c}\text { Los Gatos Creek near Coglinga } \\
\text { San Joaquin River Basin }\end{array}$ & 105 & 4.2 & .15 & .15 & 4.05 \\
\hline $\begin{array}{l}315 \\
317 \\
318\end{array}$ & $\begin{array}{l}\text { San Joaquin River above Blg Creek } \\
\text { San Joaquin River near Friant } \\
\text { San Jogquin River below Skaggs } \\
\text { Brldge }\end{array}$ & $\begin{array}{l}1,042 \\
1,632 \\
1,760\end{array}$ & $\begin{array}{l}8.8 \\
9.3 \\
9.0\end{array}$ & $\begin{array}{l}1.85 \\
1.6 \\
1.15\end{array}$ & $\begin{array}{l}\mathrm{k} 2 \cdot 05 \\
\mathrm{ml} \cdot 85 \\
\mathrm{ml} \cdot 45\end{array}$ & $\begin{array}{l}6.75 \\
7.45 \\
7.55\end{array}$ \\
\hline 322 & $\begin{array}{l}\text { South Fork of San Joaquin R1ver } \\
\text { near Florence Lake }\end{array}$ & 171 & 8.4 & 0 & $\mathrm{n} 1.15$ & 7.25 \\
\hline $\begin{array}{l}323 \\
324 \\
326 \\
327 \\
329\end{array}$ & $\begin{array}{l}\text { Bear Creek near Vermillion Valley } \\
\text { Mono Creek near Vermililon Valley } \\
\text { B1g Creek below Hunt1ngton Lake } \\
\text { P1tman Creek below Tamarack Creek } \\
\text { North Fork of Willow Creek at } \\
\text { Crane Valley Reservolr }\end{array}$ & $\begin{array}{l}54 \\
92 \\
80 \\
22 \\
51\end{array}$ & $\begin{array}{r}6.4 \\
6.0 \\
9.9 \\
12.7 \\
15.5\end{array}$ & $\begin{array}{l}.45 \\
0.4 \\
2.35 \\
-\end{array}$ & $\begin{array}{l}.45 \\
.4 \\
03.05 \\
2.35 \\
\text { p. } 0\end{array}$ & $\begin{array}{l}5.95 \\
5.6 \\
6.85 \\
10.35 \\
12.5\end{array}$ \\
\hline $\begin{array}{l}330 \\
331 \\
332 \\
333\end{array}$ & $\begin{array}{l}\text { B1g Sandy Creek near Auberry } \\
\text { Fine Gold Creek near Frlant } \\
\text { Cottonwoad Creek near Friant } \\
\text { Little Dry Creek near Friant } \\
\text { Fresno River Basin }\end{array}$ & $\begin{array}{l}34 \\
89 \\
38 \\
58\end{array}$ & $\begin{array}{l}8.7 \\
8.4 \\
4.4 \\
6.3\end{array}$ & $\begin{array}{r}.85 \\
1.05 \\
.05 \\
.1\end{array}$ & $\begin{array}{r}.85 \\
1.05 \\
.05 \\
.1\end{array}$ & $\begin{array}{l}7.85 \\
7.35 \\
4.35 \\
6.2\end{array}$ \\
\hline $\begin{array}{l}334 \\
335\end{array}$ & $\begin{array}{l}\text { Fresno River near Knowles } \\
\text { Fresno R1ver near Daulton } \\
\text { Chowchilia River Basin }\end{array}$ & $\begin{array}{l}132 \\
258\end{array}$ & $\begin{array}{r}11.0 \\
8.7\end{array}$ & $\begin{array}{l}.75 \\
.45\end{array}$ & $\begin{array}{l}.75 \\
.45\end{array}$ & $\begin{array}{r}10.25 \\
8.25\end{array}$ \\
\hline 336 & $\begin{array}{c}\text { Chowchilla River at Buchanan } \\
\text { dam s1te } \\
\text { Bear Creek Basin }\end{array}$ & 238 & 7.7 & 0.65 & 0.65 & 7.05 \\
\hline $\begin{array}{l}337 \\
338\end{array}$ & $\begin{array}{l}\text { Bear Creek near Planada } \\
\text { Mariposa Creek near Le Grand } \\
\text { Merced Rlver Basin }\end{array}$ & $\begin{array}{l}161 \\
111\end{array}$ & $\begin{array}{l}3.8 \\
5.5\end{array}$ &. .45 & $\begin{array}{l}.45 \\
.4\end{array}$ & $\begin{array}{l}3.35 \\
5.1\end{array}$ \\
\hline 339 & $\begin{array}{l}\text { Merced River at Happy Isles } \\
\text { Bridge }\end{array}$ & 181 & 12.1 & 2.0 & 2.0 & 10.1 \\
\hline 340 & $\begin{array}{l}\text { Merced River at Pohono Bridge, } \\
\text { near Yosemite }\end{array}$ & 321 & 12.2 & 3.55 & 3.55 & 8.65 \\
\hline $\begin{array}{l}341 \\
345\end{array}$ & $\begin{array}{l}\text { Merced River at Kittridge } \\
\text { Tenaya Creek near Yosemite } \\
\text { Orestimba Creek Basin }\end{array}$ & $\begin{array}{r}935 \\
47\end{array}$ & $\begin{array}{l}11.7 \\
12.7\end{array}$ & $\begin{array}{l}2.25 \\
4.95\end{array}$ & $\begin{array}{l}2.25 \\
4.95\end{array}$ & $\begin{array}{l}9.45 \\
7.75\end{array}$ \\
\hline 346 & $\begin{array}{c}\text { Orest imba Creek near Newman } \\
\text { Tholumne River Basin }\end{array}$ & 129 & 4.7 & .4 & .4 & 4.3 \\
\hline $\begin{array}{l}348 \\
350\end{array}$ & $\begin{array}{l}\text { Tuolumne River near Hetch Hetchy } \\
\text { Tuolumme River above La Grange } \\
\text { Dam, near Le Grange }\end{array}$ & $\begin{array}{r}462 \\
1,540\end{array}$ & $\begin{array}{r}10.0 \\
9.5\end{array}$ & .45 & $\begin{array}{l}\mathrm{q} 3.3 \\
\mathrm{r} 3.4\end{array}$ & $\begin{array}{l}6.7 \\
6.1\end{array}$ \\
\hline $\begin{array}{l}351 \\
352 \\
354\end{array}$ & $\begin{array}{l}\text { Falis Creek near Hetch Hetchy } \\
\text { Cherry Creek near Hetch Hetchy } \\
\text { Eleanor Creek near Hetch Hetchy }\end{array}$ & $\begin{array}{l}45 \cdot 2 \\
111 \\
80\end{array}$ & $\begin{array}{l}11 \cdot 4 \\
11.8 \\
12.9\end{array}$ & $\begin{array}{l}6.75 \\
9.05 \\
4.6\end{array}$ & $\begin{array}{r}6.75 \\
9.05 \\
89.6\end{array}$ & $\begin{array}{l}4.65 \\
2.75 \\
3.3\end{array}$ \\
\hline
\end{tabular}
at outlet.

$k$ Adjusted for storage in Florence Lake Reservolr and flow of Ward tunnel

$m$ Adfusted for storage in Florence Lake, Shaver Lake, Huntington Lake, and

Crane Valley Reservolr.

$n$ Adjusted for storage in Florence Lake Reservolr plus diversion to Ward tunnel at intake.

- Adjusted for storage in Huntington Lake and for diversions.

p Adjusted for storage in Crane Valley Reservolr and for diversions.

q Adjusted for storage in Hetch Hetchy Reservoir.

$r$ Adjusted for storage in Don Pedro, Hetch Hetchy, and Eleanor Feservolra, but not for some negligible diversions.

a Adjusted for storage in Lake Eleanor. 
Table 7.--Rainfall and mun-off of flood of December 1937--Cont1nued (Mean depth, in inches, over drainage basin)

\begin{tabular}{|c|c|c|c|c|c|c|}
\hline \multirow{2}{*}{$\begin{array}{l}\text { No. } \\
\text { on } \\
\text { flg. }\end{array}$} & \multirow{2}{*}{\multicolumn{2}{|c|}{ Stream and point of measurement $\mid \begin{array}{c}\text { Drain- } \\
\text { age } \\
\text { area } \\
\text { (square } \\
\text { miles) }\end{array}$}} & \multirow{2}{*}{$\begin{array}{l}\text { Precipi- } \\
\text { tation } \\
\text { Dec. } 9-12\end{array}$} & \multicolumn{2}{|c|}{$\begin{array}{l}\text { Direct mun-off } \\
\text { associated. } \\
\text { with total. } \\
\text { storm period }\end{array}$} & \multirow{2}{*}{$\begin{array}{l}\text { Col. } 3 \\
\text { minus } \\
\text { col. } 5 \\
6\end{array}$} \\
\hline & & & & $\begin{array}{l}\text { Observed } \\
\qquad 4\end{array}$ & $\begin{array}{l}\text { Ad justed } \\
\text { for } \\
\text { atorage } \\
5\end{array}$ & \\
\hline & $\begin{array}{l}\text { San Joaquin River Bas1n--Continued } \\
\text { Tuolumne River Basin--Continued }\end{array}$ & & & & & \\
\hline 355 & $\begin{array}{l}\text { South Fork of Tuolumne River } \\
\text { near Oakland Recreation Camp }\end{array}$ & 88 & 11.1 & 1.9 & 1.9 & 9.2 \\
\hline 356 & $\begin{array}{l}\text { M1ddle Tuolumne R1ver near Buck } \\
\text { Meadows }\end{array}$ & 71 & 10.9 & 1.3 & 1.3 & 9.6 \\
\hline 357 & $\begin{array}{c}\text { Woods Creek near Jacksonvilie } \\
\text { Stanislaus River Basin }\end{array}$ & 98 & 6.4 & 1.0 & 1.0 & 5.4 \\
\hline 358 & $\begin{array}{l}\text { Middle Fork of Stanislaus River } \\
\text { at Sand Bar Flat, near Avery }\end{array}$ & 318 & 9.3 & 3.8 & $t 4.3$ & 5.0 \\
\hline 360 & $\begin{array}{l}\text { Stanislaus River below Melones } \\
\text { power house }\end{array}$ & 898 & 9.4 & 1.0 & u. 3.4 & 6.0 \\
\hline 361 & $\begin{array}{l}\text { North Fork of Stanislaus River } \\
\text { near Avery }\end{array}$ & 163 & 9.8 & 5.05 & v6.0 & 3.8 \\
\hline 362 & $\begin{array}{c}\text { South Fork of Stanislaus River } \\
\text { at Strawberry Reservolr }\end{array}$ & 45.5 & 11.4 & - & พ5.25 & 6.15 \\
\hline 363 & $\begin{array}{c}\text { South Fork of Stanis laus River } \\
\text { below Lyons Dam } \\
\text { Calaveras River Basin }\end{array}$ & 67 & 11.1 & .45 & $x 5.65$ & 5.45 \\
\hline $\begin{array}{l}364 \\
365\end{array}$ & $\begin{array}{l}\text { Calaveras River at Jenny IInd } \\
\text { Cosgrove Creek near Valiey } \\
\text { Springs } \\
\text { Mokelume River Basin }\end{array}$ & $\begin{array}{l}395 \\
20.6\end{array}$ & $\begin{array}{l}6.0 \\
3.6\end{array}$ & $\begin{array}{l}.75 \\
.25\end{array}$ & $\begin{array}{r}y .75 \\
.25\end{array}$ & $\begin{array}{l}5.25 \\
3.35\end{array}$ \\
\hline 367 & $\begin{array}{l}\text { North Fork of Mokelumne River } \\
\text { below } S_{2} \text { lt } S p r i n g s \text { Dam }\end{array}$ & 160 & 7.9 & 0.6 & z9.35 & -1.45 \\
\hline 368 & $\begin{array}{l}\text { Mokelumne RIver near Mokelumne } \\
\text { H1II }\end{array}$ & 538 & 8.6 & 1.25 & 293.85 & 4.75 \\
\hline $\begin{array}{l}369 \\
370 \\
371 \\
372 \\
373 \\
374\end{array}$ & $\begin{array}{l}\text { Mokelumne River at Lancha Plana } \\
\text { Mokelumne River near Clements } \\
\text { Mokelumne River at Woodbridge } \\
\text { Cold Creek near Mokelumne Peak } \\
\text { Bear River at Pardoe Camp } \\
\text { Middle Fork of Hokelumne River } \\
\text { at Vest Point }\end{array}$ & $\begin{array}{r}584 \\
630 \\
644 \\
23 \\
33 \\
67\end{array}$ & $\begin{array}{l}8.2 \\
7.8 \\
7.7 \\
9.2 \\
9.4 \\
9.1\end{array}$ & $\begin{array}{r}.5 \\
.5 \\
.45 \\
7.35 \\
5.9 \\
.8\end{array}$ & $\begin{array}{r}a b 3.65 \\
\operatorname{ab3} .35 \\
\operatorname{ac} 3.25 \\
7.35 \\
\operatorname{ad} 9.65 \\
.8\end{array}$ & $\begin{array}{r}4.55 \\
4.45 \\
4.45 \\
1.85 \\
-0.25 \\
8.3\end{array}$ \\
\hline 375 & $\begin{array}{l}\text { South Fork of Mokelumne River } \\
\text { near West Point }\end{array}$ & 74 & 10.0 & .85 & .85 & 9.15 \\
\hline $\begin{array}{l}376 \\
377\end{array}$ & $\begin{array}{l}\text { Sutter Creek near Sutter Creek } \\
\text { North Fork of Cosumnes River } \\
\text { near El Dorado }\end{array}$ & $\begin{array}{r}51 \\
202\end{array}$ & $\begin{array}{l}5.5 \\
8.3\end{array}$ &. .45 & .95 & $\begin{array}{l}5.05 \\
7.4\end{array}$ \\
\hline 378 & Cosumnes River at Michigan Bar & 537 & 7.0 & .8 & .8 & 6.2 \\
\hline
\end{tabular}

$t$ Adjusted for storage in Rellef Reservolr on basis of an estimate that 60 percent of reservolr capacity was filled during period Dec. 9-20. Not adjusted for small inflow in Philadelphia ditch.

$u$ Adjusted for storage in Melones Reservolr plus 60 percent of combined capac1ties of Relief, North Fork, Big Dam, Upper Strawberry, Strawberry Lake, Herring Creek, and Lyons Reservolrs.

$v$ Adjusted on basis of an estimated change in storage amounting to 60 percent of the capacities of Union, Silver Valley, Splcer Meadow, and Hunters Reservolrs. Utica Reservolr was full at the beginning of the storm.

W Oomputed from change in storage in Strawberry Reservoir for period Dec. 8-18. $x$ Adjusted for diversions in Tuolumne and Philadelphia ditches and observed storage in Lyons and Strawberry Lake Reservolrs plus 60 percent of capac1ty of Big Dam, Upper Strawberry, and Herring Creek Reservolrs.

y Hogan Reservoir detalned some mun-off and reduced peak but did not change total mun-off.

$\mathrm{z}$ Adjusted for observed storage in Salt Springs Reservolr, estimated storage in Blue Lake, Lower Blue, Meadow, and Twin Lake Reservolrs, and diversion to Tiger Creek power house conduit.

a. Adjusted for observed storage in Salt Springs Reservoir, estimated storage in 4 small reservolrs, and total capacity of Bear River Reservoir.

ab Adjusted for observed atorage In Salt Springs and Pardee Reservolra, diversions to East Bay Municipal Jt1lity District aqueduct, estimated storage in 4 small reservolrs, and capacity of Bear River Reservolr.

ac Same as ab. Flow in Woodbridge canal negligible for this period.

ad Adjusted for storage capacity of Bear River Reservolr. 
Table 7.--Rainfall and run-off of flood of December 1937--Continued (Mean depth, in Inches, over dralnage basin)

\begin{tabular}{|c|c|c|c|c|c|c|}
\hline \multirow{2}{*}{$\begin{array}{l}\text { No. } \\
\text { on } \\
\text { fig. } \\
8-9\end{array}$} & \multirow{2}{*}{\multicolumn{2}{|c|}{ Stream and point of measurement $\mid \begin{array}{c}\text { Drain- } \\
\text { age } \\
\text { area } \\
\text { (square } \\
\text { m1les) } \\
1\end{array}$}} & \multirow{2}{*}{$\begin{array}{c}\text { Prec1p1- } \\
\text { tation } \\
\text { Dec. } 9-12\end{array}$} & \multicolumn{2}{|c|}{$\begin{array}{c}\text { Direct mun-off } \\
\text { assoclated } \\
\text { w1th total } \\
\text { storm period }\end{array}$} & \multirow{2}{*}{$\begin{array}{l}\text { Col. } 3 \\
\text { minus } \\
\text { col. } 5 \\
6\end{array}$} \\
\hline & & & & $\begin{array}{c}\text { Observed } \\
4\end{array}$ & $\begin{array}{l}\text { Ad justed } \\
\text { for } \\
\text { storage } \\
5\end{array}$ & \\
\hline & Sacramento River Bas in & & & & & \\
\hline $\begin{array}{l}401 \\
402 \\
404\end{array}$ & $\begin{array}{l}\text { Sacramento River at Antler } \\
\text { Sacramento River at Kennett } \\
\text { Sacramento River near Fed Blufr } \\
\text { P1t River Basin }\end{array}$ & $\begin{array}{r}461 \\
6,600 \\
0,300\end{array}$ & $\begin{array}{l}8.3 \\
6.3 \\
6.7\end{array}$ & $\begin{array}{l}4.45 \\
1.9 \\
2.5\end{array}$ & $\begin{array}{r}4.45 \\
\operatorname{ae} 2.15 \\
\operatorname{af} 2.7\end{array}$ & $\begin{array}{l}3.85 \\
4.15 \\
4.0\end{array}$ \\
\hline $\begin{array}{l}406 \\
407 \\
408 \\
409 \\
410 \\
411\end{array}$ & 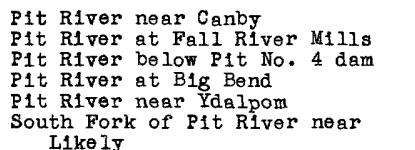 & $\begin{array}{r}1,430 \\
4,150 \\
4,860 \\
4,920 \\
5,350 \\
248\end{array}$ & $\begin{array}{l}4.6 \\
4.9 \\
5.1 \\
5.1 \\
5.7 \\
3.4\end{array}$ & $\begin{array}{r}.9 \\
.8 \\
.8 \\
.95 \\
1.4 \\
.25\end{array}$ & $\begin{array}{l}\operatorname{ag} 1.9 \\
\operatorname{ah1} 1.2 \\
\text { a } 11.15 \\
\text { a } 11.3 \\
\text { a } 11.70 \\
\text { a j2.35 }\end{array}$ & $\begin{array}{l}2.7 \\
3.7 \\
3.95 \\
3.8 \\
4.0 \\
1.05\end{array}$ \\
\hline $\begin{array}{l}412 \\
413 \\
414\end{array}$ & $\begin{array}{l}\text { Hat Creek near Hat Creek } \\
\text { MeCloud River near McCloud } \\
\text { McCloud R1ver at Balrd } \\
\text { M111 Creek Basin }\end{array}$ & $\begin{array}{l}155 \\
388 \\
668\end{array}$ & $\begin{array}{l}6.8 \\
7.0 \\
8.3\end{array}$ & $\begin{array}{l}.65 \\
1.0 \\
3.15\end{array}$ & $\begin{array}{l}.65 \\
1.0 \\
3.15\end{array}$ & $\begin{array}{l}6.15 \\
6.0 \\
5.15\end{array}$ \\
\hline 417 & $\begin{array}{c}\text { M111 Creek near Los Molinos } \\
\text { Elder Creek Basin }\end{array}$ & 134 & 13.5 & 6.8 & 6.8 & 6.7 \\
\hline 418 & $\begin{array}{c}\text { Elder Creek near Henlejville } \\
\text { Thomas Creek Basin }\end{array}$ & 147 & 4.8 & 2.75 & 2.75 & 2.05 \\
\hline 419 & $\begin{array}{r}\text { Thomas Creek at Paskenta } \\
\text { Deer Creek Basin }\end{array}$ & 188 & 5.8 & 5.05 & 5.05 & .75 \\
\hline 420 & $\begin{array}{l}\text { Deer Creek near Vina } \\
\text { Chico Creek Basin }\end{array}$ & 200 & 14.2 & - & - & - \\
\hline 421 & $\begin{array}{l}\text { Chico Creek near Chico } \\
\text { Stony Creek Basin }\end{array}$ & 68 & 14.2 & 6.75 & 6.75 & 7.45 \\
\hline 422 & $\begin{array}{l}\text { Stony Creek above Stony Gorge } \\
\text { Reservoir } \\
\text { Butte Creek Basin }\end{array}$ & 266 & 7.0 & 4.2 & ak4. 8 & $2 \cdot 2$ \\
\hline 424 & $\begin{array}{l}\text { Butte Creek near Chico } \\
\text { Feather River Basin }\end{array}$ & 148 & 15.0 & 6.3 & am6.05 & 8.95 \\
\hline 426 & $\begin{array}{l}\text { North Fork of Feather River } \\
\text { near Prattv1lie }\end{array}$ & 507 & 7.1 & - & an3.1 & 4.0 \\
\hline $\begin{array}{l}428 \\
429 \\
430 \\
432\end{array}$ & $\begin{array}{l}\text { Feather River near Oroville } \\
\text { Indlan Creek near Crescent Mills } \\
\text { Spanish Creek at Keddle } \\
\text { Bucks Creek at Bucks Creek } \\
\text { storage reservolr }\end{array}$ & $\begin{array}{r}3,611 \\
746 \\
184 \\
28\end{array}$ & $\begin{array}{r}9.8 \\
5.9 \\
11.2 \\
18.2\end{array}$ & $\begin{array}{l}3.55 \\
1.65 \\
4.1 \\
-\end{array}$ & $\begin{array}{r}\text { a03.95 } \\
1.65 \\
4.1 \\
\text { ap } 12.6\end{array}$ & $\begin{array}{l}5.85 \\
4.25 \\
7.1 \\
5.6\end{array}$ \\
\hline $\begin{array}{l}433 \\
434\end{array}$ & $\begin{array}{l}\text { Grizzly Creek near Storrie } \\
\text { West Branch of Feather River } \\
\text { near Yankee Hill }\end{array}$ & $145^{6.2}$ & $\begin{array}{l}19.5 \\
15.0\end{array}$ & $\begin{array}{r}12.5 \\
8.7\end{array}$ & $\begin{array}{r}12.5 \\
\mathrm{aq} 9.7\end{array}$ & $\begin{array}{l}7.0 \\
5.3\end{array}$ \\
\hline
\end{tabular}

ae Adjusted for an estimated storage of 92,880 acre-feet in P1t River Bas1n. on Battlo Creok

ag Adjuated on basis of fragmentary records and est1mated storage in West Valley and Blg Sage Reservolrs, Tule Lake, and other reservolrs for a total of 78,500 acre-feet.

ah Same as ag plus 10,000 acre-feet additional storage.

a Same as ah plus storage in Lake Britton.

aj Adjusted for estimated storage in West Valley Reservo1r and Tule Lake.

ak Ad Justed for storage in East Park Reservolr.

am Ad justed for diversion from West Branch of Feather River.

an Adjusted for storage in Lake Almanor.

ao Adjusted for storage in Lake Almanor, Butt Valley and Bucks Creok

Reservolrs, and Lake Wilenor.

ap Computed from changes in storage in Bucks Creek Reservolrs.

aq Adjusted for storage in Lake Wilenor, estimated storage in 3 small reservolrs, and for diversions in Spring Valley ditch and Miocene canal. 
Table 7.--Rainfal1 and run-off of flood of December 1937--Continued (Mean depth, in inches, over drainage basin)

\begin{tabular}{|c|c|c|c|c|c|c|}
\hline \multirow{2}{*}{$\begin{array}{l}\text { No. } \\
\text { on } \\
\text { f1g. } \\
9\end{array}$} & \multirow{2}{*}{ Stream and point of measurement } & \multirow{2}{*}{$\begin{array}{l}\text { Drain- } \\
\text { age } \\
\text { area } \\
\text { (square } \\
\text { miles) } \\
2 \\
\end{array}$} & \multirow{2}{*}{$\begin{array}{l}\text { Precipi- } \\
\text { tation } \\
\text { Dec. } 9-12\end{array}$} & \multicolumn{2}{|c|}{$\begin{array}{l}\text { Direct man-off } \\
\text { associated } \\
\text { with total } \\
\text { storm perlod }\end{array}$} & \multirow{2}{*}{$\begin{array}{r}\text { Col. } 3 \\
\text { minus } \\
\text { col. } 5 \\
6 \\
\end{array}$} \\
\hline & & & & $\begin{array}{c}\text { Observed } \\
4 \\
\end{array}$ & $\begin{array}{l}\text { Ad justed } \\
\text { for } \\
\text { storege } \\
5\end{array}$ & \\
\hline & $\begin{array}{l}\text { Secramento River Basin--Continued } \\
\text { Feather River Basin--Continued }\end{array}$ & & & & & \\
\hline $\begin{array}{l}435 \\
436\end{array}$ & $\begin{array}{l}\text { Concow Creek near Yankee Hill } \\
\text { Middle Fork of Feather River }\end{array}$ & $\begin{array}{l}14.7 \\
699\end{array}$ & $\begin{array}{r}11.0 \\
6.6\end{array}$ & 2.4 & $\operatorname{er} 6.65$ & 4.35 \\
\hline 437 & $\begin{array}{l}\text { Middle Fork of Feather River at } \\
\text { Bldwell Bar }\end{array}$ & 1,353 & 10.8 & 4.35 & as 4.35 & 6.45 \\
\hline 438 & $\begin{array}{l}\text { South Fork of Feather River at } \\
\text { Enterprise }\end{array}$ & 134 & 18.2 & 7.85 & 7.85 & 10.35 \\
\hline 439 & $\begin{array}{c}\text { Lost Creek neer Clipper Mills } \\
\text { Yuba River Basin }\end{array}$ & 30.1 & 19.1 & 6.2 & 6.2 & 12.9 \\
\hline 440 & $\begin{array}{l}\text { Middle Fork of Yuba River at } \\
\text { Milton }\end{array}$ & 41 & 13.0 & 6.2 & at7. 65 & 5.35 \\
\hline 441 & $\begin{array}{l}\text { Middle Fork of Yuba River near } \\
\text { North San Juan }\end{array}$ & 207 & 11.5 & 5.25 & at5. 6 & 5.9 \\
\hline $\begin{array}{l}442 \\
443 \\
444\end{array}$ & $\begin{array}{l}\text { Yuba River at Smartville } \\
\text { Oregon Creek near North San Juan } \\
\text { Nortin Fork of Yuba River near } \\
\text { Sierra City }\end{array}$ & $\begin{array}{l}1,201 \\
35.1 \\
91\end{array}$ & $\begin{array}{l}12.4 \\
10.4 \\
13.3\end{array}$ & $\begin{array}{l}4.75 \\
3.75 \\
5.0\end{array}$ & $\begin{array}{l}\operatorname{au} 6.0 \\
3.75 \\
5.0\end{array}$ & $\begin{array}{l}6.4 \\
6.65 \\
8.3\end{array}$ \\
\hline 447 & $\begin{array}{l}\text { South Fork of Yuba RIver at Lake } \\
\text { Spaulding }\end{array}$ & 118 & 12.8 & - & av 12.2 & .6 \\
\hline $\begin{array}{l}449 \\
450 \\
451\end{array}$ & $\begin{array}{l}\text { Canyon Creek below Bowman Lake } \\
\text { Deer Creek near Smartville } \\
\text { Bear River near Wheatlend }\end{array}$ & $\begin{array}{l}31.7 \\
84 \\
295\end{array}$ & $\begin{array}{r}13.5 \\
9.8 \\
8.8\end{array}$ & $7 \cdot \frac{-}{1.9}$ & $\begin{array}{r}\operatorname{aw} 11.9 \\
7.1 \\
\operatorname{ax} 2.35\end{array}$ & $\begin{array}{l}1.6 \\
2.7 \\
6.45\end{array}$ \\
\hline & American River Besin & & & & & \\
\hline 452 & $\begin{array}{l}\text { North Fork of American River } \\
\text { near Colfax }\end{array}$ & 308 & 10.3 & 4.3 & ey 4.55 & 5.75 \\
\hline $\begin{array}{l}454 \\
455\end{array}$ & $\begin{array}{l}\text { Amerlcan River at Fair Oaks } \\
\text { Middle Fork of American River } \\
\text { near Auburn }\end{array}$ & $\begin{array}{r}1,921 \\
618\end{array}$ & $\begin{array}{r}9.0 \\
10.3\end{array}$ & $\begin{array}{l}3.2 \\
4.7\end{array}$ & $\begin{array}{l}\mathrm{az} 3.5 \\
\mathrm{ba} 4.8\end{array}$ & $\begin{array}{l}5.5 \\
5.5\end{array}$ \\
\hline 456 & $\begin{array}{l}\text { South Fork of American River } \\
\text { near Kyburz }\end{array}$ & 196 & 9.5 & 2.5 & bb3. 6 & 5.9 \\
\hline 457 & $\begin{array}{l}\text { South Fork of American River } \\
\text { near Camino }\end{array}$ & 497 & 9.7 & 2.85 & $\mathrm{bc} 3.35$ & 6.35 \\
\hline 458 & $\begin{array}{l}\text { South Fork of American River at } \\
\text { Coloma }\end{array}$ & 635 & 9.2 & 2.2 & bd2. 6 & 6.6 \\
\hline $\begin{array}{l}459 \\
460 \\
461\end{array}$ & $\begin{array}{l}\text { Medley Lakes outlet near Vade } \\
\text { Silver Lake outlet near Kirkwood } \\
\text { Silver Fork of South Fork of } \\
\text { American River near Kyburz }\end{array}$ & $\begin{array}{r}6.2 \\
14.9 \\
108\end{array}$ & $\begin{array}{l}8.8 \\
9.5\end{array}$ & $\begin{array}{l}-2 \\
2.2 \\
2.65\end{array}$ & $\begin{array}{l}\text { be } \overline{8} .85 \\
b f 4.65\end{array}$ & $\begin{array}{c}- \\
-.05 \\
4.85\end{array}$ \\
\hline $\begin{array}{l}462 \\
463 \\
464 \\
465 \\
466 \\
467\end{array}$ & $\begin{array}{l}\text { Twin Lakes out let near Kirkwood } \\
\text { Alder Creek near Whitehall } \\
\text { Plum Creek near Riverton } \\
\text { Silver Creek at Union Valley } \\
\text { Silver Creek near Placervilie } \\
\text { South Fork of Silver Creek near } \\
\text { Ice House }\end{array}$ & $\begin{array}{c}12.4 \\
22.8 \\
6.8 \\
83 \\
176 \\
28.4\end{array}$ & $\begin{array}{r}8.2 \\
10.4 \\
10.1 \\
10.3 \\
10.0 \\
10.1\end{array}$ & $\begin{array}{l}- \\
2.25 \\
2.0 \\
5.1 \\
4.15 \\
4.25\end{array}$ & $\begin{array}{c}\text { bg7. } 9 \\
2.25 \\
2.0 \\
5.1 \\
4.15 \\
4.25\end{array}$ & $\begin{array}{l}.3 \\
8.15 \\
8.1 \\
5.2 \\
5.85 \\
5.85\end{array}$ \\
\hline
\end{tabular}

ar Adusted for storage in Lake wilenor.

as Ad justed for estimated storage in 13 small reservoirs amounting to 10,400 acre-feet.

et Adjusted for diversion to Milton-Bowman tunnel.

au Ad fusted for storagein Lake Spaulding, Bowman Lake, and Bullards Bar

Reservoir, end for estimated storage in French Lake and Lake Fordyce.

av Computed from storage, inflow, and release at Lake Spaulding.

aw Computed from storage in Bowman Lake minus diversion in Milton-Bowman tunnel plus diversion in Bowman-Spaulding canal minus mun-off from 6 square miles above French Lake, which did not overflow.

ax Adjusted for storage estimated as 50 percent of the capacity of Comble and Camp Far West Reservolrs, amounting to 14,000 acre-feet.

ay Adjusted for storage estimated as 50 percent of the capacity of Lake

Velley and two smaller reservolrs.

az Adjusted for storage estimated as 50 percent of the capacity of 14 small reservolrs, including Twin Lakes.

$\mathrm{ba}$ Ad fusted for storage estimated as 50 percent of the capacity of Loon Lake. $\mathrm{bb}$ Ad justed for storage, partiy estimated, in Twin and Silver Lakes plus diversion in Eldoredo cenal.

bc Adjusted for storage, partly estimated, in Twin and Silver Lakes plus 30 percent (estimated) of the capacity of Medley Lakes plus diversion in American River flume.

bd Same as bc plus 1,000 acre-feet (estimated) between Camino and Coloma.

be Adjusted for storage in Silver Lake.

bf Adjusted for estimated storage in Twin and Silver Lakes.

bg computed from storage in Twin Lakes. 
Table 7.--Rainfall and mun-off of flood of December 1937--Cont1nued (Mean depth, in inches, over drainage basin)

\begin{tabular}{|c|c|c|c|c|c|c|}
\hline \multirow{2}{*}{$\begin{array}{l}\text { No. } \\
\text { on } \\
\text { fig. } \\
9-12\end{array}$} & \multirow{2}{*}{ Stream and point of measurement } & \multirow{2}{*}{$\begin{array}{c}\text { Drain- } \\
\text { age } \\
\text { area } \\
\text { (square } \\
\text { miles) } \\
2\end{array}$} & \multirow{2}{*}{$\begin{array}{l}\text { Prec1p1- } \\
\text { tation } \\
\text { Dec. } 9-12\end{array}$} & \multicolumn{2}{|c|}{$\begin{array}{l}\text { Direct run-off } \\
\text { assoclated } \\
\text { with total } \\
\text { storm period }\end{array}$} & \multirow{2}{*}{$\begin{array}{l}\text { Col. } 3 \\
\text { mimus } \\
\text { col. } 5 \\
6\end{array}$} \\
\hline & & & & $\begin{array}{l}\text { Observed } \\
4 \\
\end{array}$ & $\begin{array}{l}\text { Ad justed } \\
\text { for } \\
\text { storage } \\
5\end{array}$ & \\
\hline & $\begin{array}{c}\text { Sacramento R1ver Basin--Continued } \\
\text { Cache Creek Basin }\end{array}$ & & & & & \\
\hline $\begin{array}{l}469 \\
470\end{array}$ & $\begin{array}{l}\text { Cache Creek at Yolo } \\
\text { North Fork of Cache Creek near } \\
\text { Lower Lake } \\
\qquad \text { Putah Creek Bas In }\end{array}$ & $\begin{array}{r}1,150 \\
214\end{array}$ & $\begin{array}{l}7.3 \\
7.3\end{array}$ & $\begin{array}{l}1.45 \\
4.15\end{array}$ & $\begin{array}{r}\text { bh3. } 6 \\
4.15\end{array}$ & $\begin{array}{l}3.3 \\
3.15\end{array}$ \\
\hline $\begin{array}{l}471 \\
472\end{array}$ & $\begin{array}{l}\text { Putah Creek near Guenoc } \\
\text { Putah Creek near Winters } \\
\text { Napa Creek Bas 1n }\end{array}$ & $\begin{array}{l}112 \\
614\end{array}$ & $\begin{array}{r}14.1 \\
8.4\end{array}$ & $\begin{array}{l}9.7 \\
3.7\end{array}$ & $\begin{array}{l}9.7 \\
3.7\end{array}$ & $\begin{array}{l}4.4 \\
4.7\end{array}$ \\
\hline 501 & $\begin{array}{c}\text { Conn Creek near St. Helena } \\
\text { Eel R1ver Basin }\end{array}$ & 52 & 8.1 & 1.95 & 1.95 & 6.15 \\
\hline $\begin{array}{l}504 \\
505 \\
506\end{array}$ & $\begin{array}{l}\text { Eel River at Hullville } \\
\text { Eel R1ver at Van Arsdale Dam } \\
\text { Eel R1ver at Scotia } \\
\text { Klamath River Basin }\end{array}$ & $\begin{array}{r}289 \\
347 \\
3,070\end{array}$ & $\begin{array}{r}11.8 \\
11.6 \\
9.9\end{array}$ & $\begin{array}{l}8.65 \\
7.8 \\
7.3\end{array}$ & $\begin{array}{l}b \neq 8.7 \\
b j 8.05 \\
b j 7.35\end{array}$ & $\begin{array}{l}3.1 \\
3.55 \\
2.55\end{array}$ \\
\hline $\begin{array}{l}507 \\
508 \\
509 \\
510 \\
511 \\
512\end{array}$ & $\begin{array}{l}\text { Klamath River at Somesbar } \\
\text { Shasta River near Yreka } \\
\text { Salmon River at Somesbar } \\
\text { Trinity River at Lewiston } \\
\text { Trinity River near Burnt Ranch } \\
\text { Trinity River near Hoopa } \\
\text { The Great Basin } \\
\text { Owens Lake Basin }\end{array}$ & $\begin{array}{r}8,480 \\
804 \\
737 \\
724 \\
1,429 \\
2,840\end{array}$ & $\begin{array}{l}\overline{4.4} \\
5.8 \\
6.4 \\
6.3 \\
6.6\end{array}$ & $\begin{array}{l}1.05 \\
.2 \\
3.55 \\
4.15 \\
3.65 \\
3.75\end{array}$ & $\begin{array}{r}\text { bk }- \\
\text { bmo.35 } \\
3.55 \\
4.15 \\
\mathbf{3 . 6 5} \\
\mathbf{3 . 7 5}\end{array}$ & $\begin{array}{l}4.05 \\
2.25 \\
2.25 \\
2.65 \\
2.85\end{array}$ \\
\hline $\begin{array}{l}601 \\
602\end{array}$ & $\begin{array}{l}\text { Owens River near Round Valley } \\
\text { Rock Creek at Sherwin Hill, near } \\
\text { Blshop }\end{array}$ & $\begin{array}{l}450 \\
51.7\end{array}$ & $\begin{array}{l}4.0 \\
4.6\end{array}$ & .2 & .2 & $\begin{array}{l}3.8 \\
4.45\end{array}$ \\
\hline 603 & $\begin{array}{l}\text { Pine Creek at division box, near } \\
\text { Bishop }\end{array}$ & 37.9 & 5.5 & .25 & .25 & 5.25 \\
\hline 604 & $\begin{array}{l}\text { Big Plne Creek below Iittle Pine } \\
\text { Creek, near Big Pine }\end{array}$ & 39.5 & 5.4 & .1 & .1 & 5.3 \\
\hline $\begin{array}{l}605 \\
606\end{array}$ & $\begin{array}{l}\text { Independence Creek near Big Pine } \\
\text { Tuttle Creek at Canjon Road } \\
\text { Carson River Basin }\end{array}$ & $\begin{array}{r}17.6 \\
8.5\end{array}$ & $\begin{array}{l}5.0 \\
3.1\end{array}$ & .11 & .15 & $\begin{array}{l}4.9 \\
2.95\end{array}$ \\
\hline 611 & $\begin{array}{l}\text { Carson River at Lahonton } \\
\text { Reservoir }\end{array}$ & 1,200 & - & - & bn. 45 & - \\
\hline $\begin{array}{l}613 \\
616 \\
617\end{array}$ & $\begin{array}{l}\text { Pyramid and Winemucea Lake Basins } \\
\text { Pmickee River at Tahoe } \\
\text { Trickee River at Iceland } \\
\text { Donner Creek near Truckee }\end{array}$ & $\begin{array}{r}519 \\
937 \\
30\end{array}$ & $\begin{array}{r}6.8 \\
7.2 \\
10.5\end{array}$ & $\begin{array}{l}- \\
1.25 \\
6.7\end{array}$ & $\overline{-}$ & $\overline{-}$ \\
\hline
\end{tabular}

bh Adjusted for storage (estimated) in Clear Lake.

bi Adjusted for storage in Lake P111sbury.

bj Adjusted for storage in Lake P1llsbury and for diversion to Potter Valley power house.

bk No attempt made to determine natural mun-off

bm Ad justed for storage in Lake Dwinneli.

bn Adjusted for atorage in Lahonton Reservolr. 
Stream flow on December 8 (point A, fig. 44) was low and, because there had been little or no antecedent precipitation since November 24, consisted largely of outflow from ground water. On December 9 , the water-stage recorder indicated increases in stage and discharge culminating in a peak (B) occurring generally between 10 a.m. December 10 and $4 \mathrm{p} . \mathrm{m}$. December 11. The peak was followed by a decline in stage

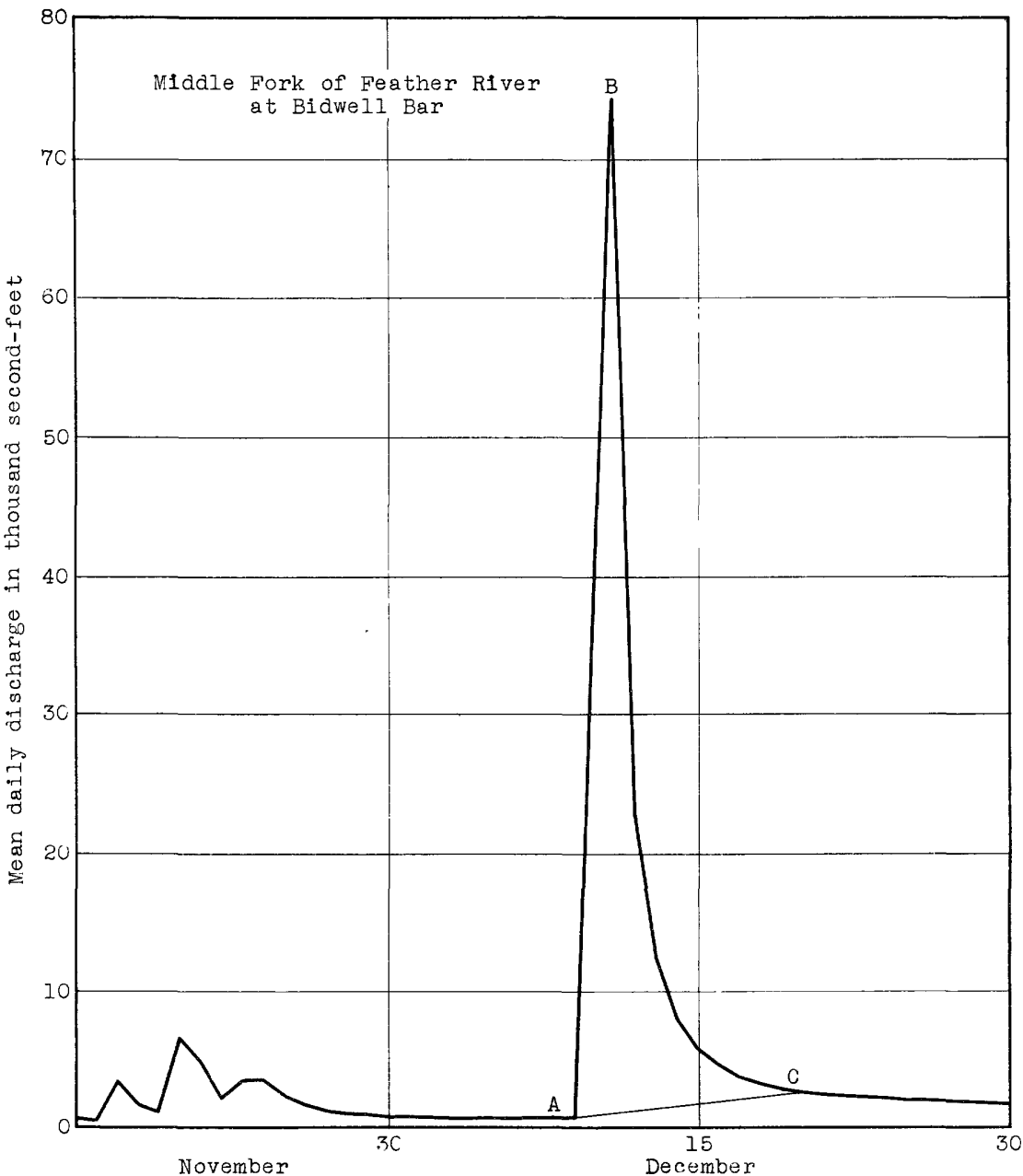

Figure 44.--Method of analysis used in determining direct run-off associated with the storm period December 8-13, 1937.

which continuec without interruption until about December 20, when practically all of the direct mu-off assoclated with the flood had passed the gaging station. The flow represented by that portion of the hydrograph from (B) to (C) represents, to a very considerable extent, water draining out of the channel system as a result of the large direct inflow into the channel systems, lasting from about noon December 
The total area under the hydrograph represents the direct run-off resulting from the storm precipitation plus the stream flow that would have been maintained from antecedent sources had there been no increment of direct run-off ofter point (A).

The Increase in stream flow directly attributable to the rain and melting snow has been estimated by making an approximation of the position $(A-C)$ of the graph of ground-water flow plus surface run-off from antecedent precipitation, which in this example is negligible, and by assuming that the area above that line represents the increment in stream flow resulting from the direct run-off associated with the precipitation that occurred after December 8. The area above Iine A-C is belleved to include essentially all the surface run-off resulting from the storm precipitation, and may include some ground water originating from the current storm and discharged into stream channels with a promptness that approached that of the surface run-off. The results of these analyses, expressed in inches of depth over the drainage basins, are shown in table 7 and in figure 45. It is evident that these estimates of direct run-off are somewhat less than the total measured flow by reason of the exclusion of the flow maintained from antecedent sources, an amount generally less than 10 percent of the total run-off. Other investigators, of course, might estimate such maintained flow differently. Such differences in judgment, however, would result in differences that would be relatively small in relation to the magnitude of the flood run-off as a whole.

For river basins where there was artificial storage or diversion, the run-off records were adjusted for the effect of the storage or diversions, and the adjusted run-off as well as the observed run-off was expressed in inches of depth over the drainage area and are listed in table 7. The difference between these two represents the total net storage or diversions during the flood period December 9 to 20 . In many of the smaller basins, where the quantity of water stored or diverted was a large part of and in some instances equal to the entire flow, the adjusted run-off estimates may not represent the natural runoff as closely as the data given for those basins where there were no complications due to storage or diversion.

At those river-messurement stations where the observed stresm flow represents essentially natural-flow conditions unaffected by artificlal storage, there were determined (a) the direct run-off expressed in inches over the area for the maximum 24-hour average discharge; (b) the 


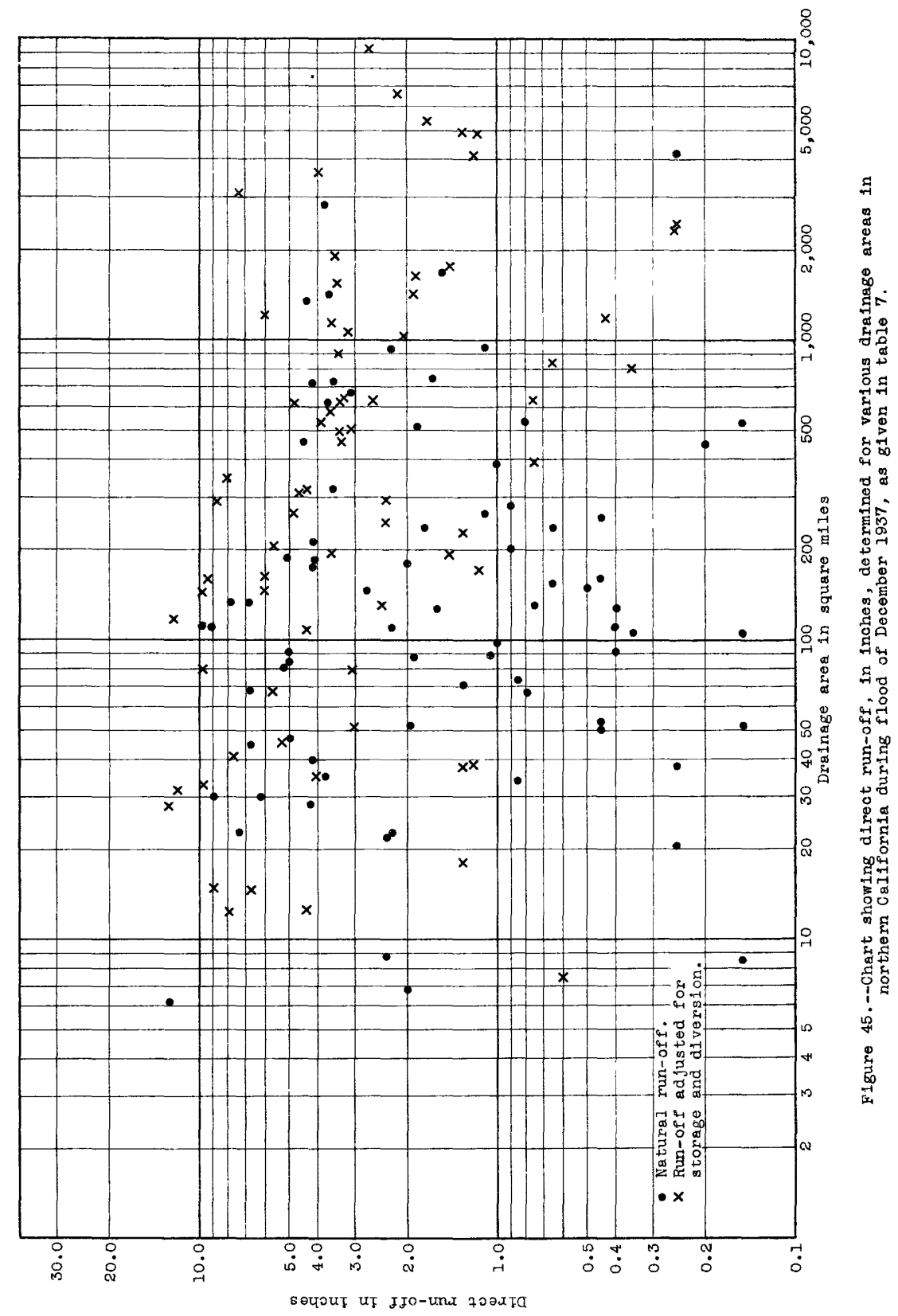


ratio in percentage between the direct run-off during the 24 hours of greatest flow and the total direct run-off for the flood period; (c) the date and time of occurrence of the momentary peak discharge, the time being generally to the nearest hour, but in a few instances, to the nearest 15 minutes; and (d) the ratio in percentage between the momentary peak discharge and the maximum 24-hour average discharge. The results of the se determinations are shown in table 8 .

The data relating to rainfall and run-off and the flood characteristics as summarized in tables 7 and 8 are essentially basic in that they are all directly derived from observations of rainfall and run-off. Engineers and hydrologists will readily appreciate, however, the approximations that may have been necessary with respect to some of the individual items. Moreover, the analyses of the records are complicated by conditions which, although present in other areas where similar studies have been made, were not so pronounced as those that exist in that part of California embraced within this flood study. These conditions relate largely to the lack of uniformity in the topographic, edaphic, and biologic characteristics of the various drainage basins. For example, a typical basin on the west slope of the Sierra Nevada is tilted steeply from headwater to the valley floor and may include a range in altitude of 10,000 or 12,000 feet. It crosses a series of zones differing in precipitation, temperature, cover, and soil. To a considerable extent similar conditions apply to most of the river basins discussed herein. These conditions may materially affect the interpretation of the results. Although the basic data are necessarily collected by basins, the basins themselves may or may not be natural divisions for the study of precipitation, run-off, or residuals, and basins grouped herein on the basis of similar run-off characteristics may not necessarily have similar inherent characteristics in other important respects.

Because of large differences in altitude and topography, the rainfall, snowfall, and temperature data are applicable to relatively restricted areas near the places of observation. The restricted application of the observed data affects the accuracy of the isohyetal maps from which the precipitation values given in table 7 were obtained and also makes uncertain the delineation of the line of demarcation between areas where the precipitation took the form of rain or snow. 
Table 8.--Run-off characteristics

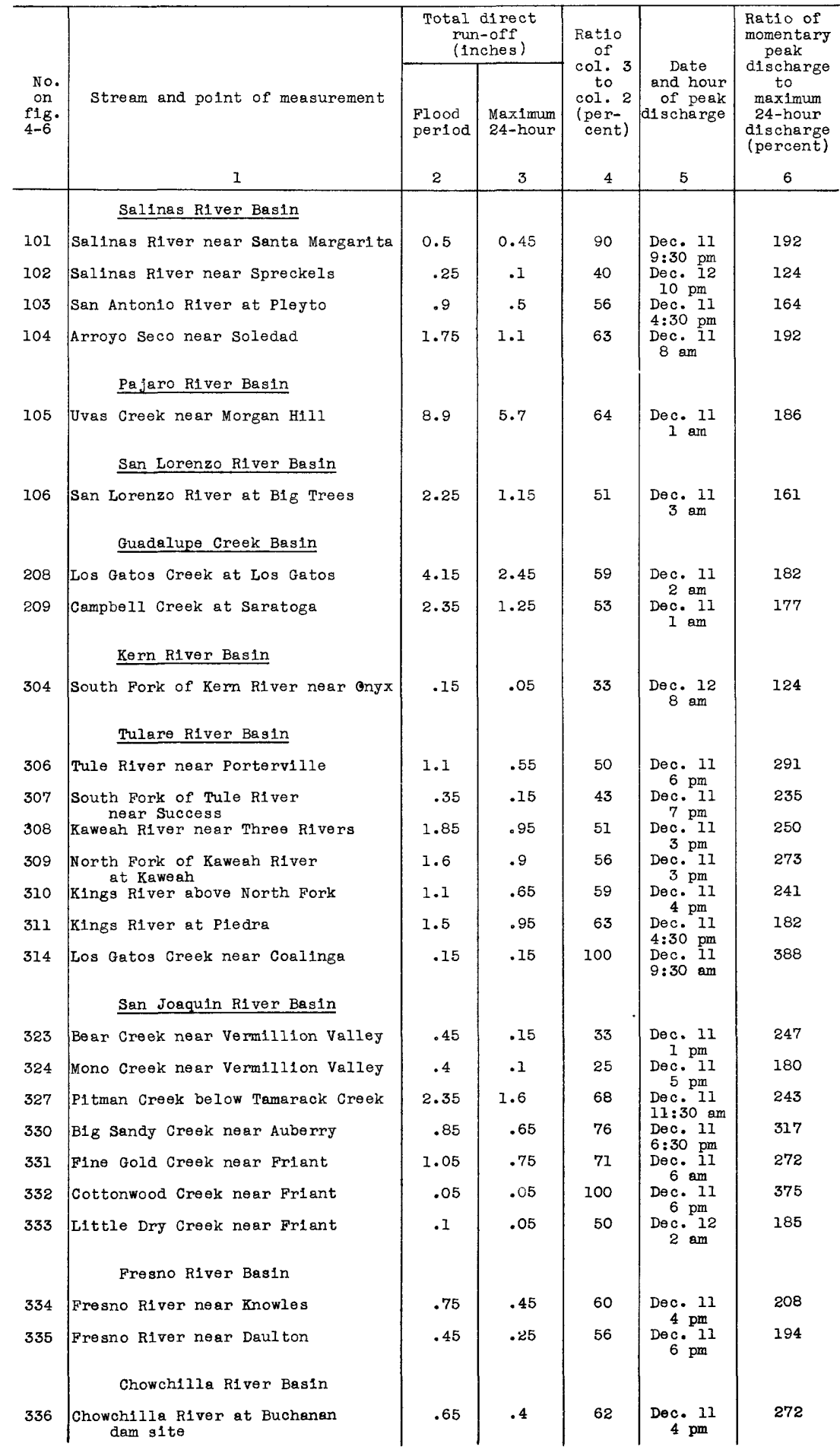


Table 8.--Run-off characteristics--Continued

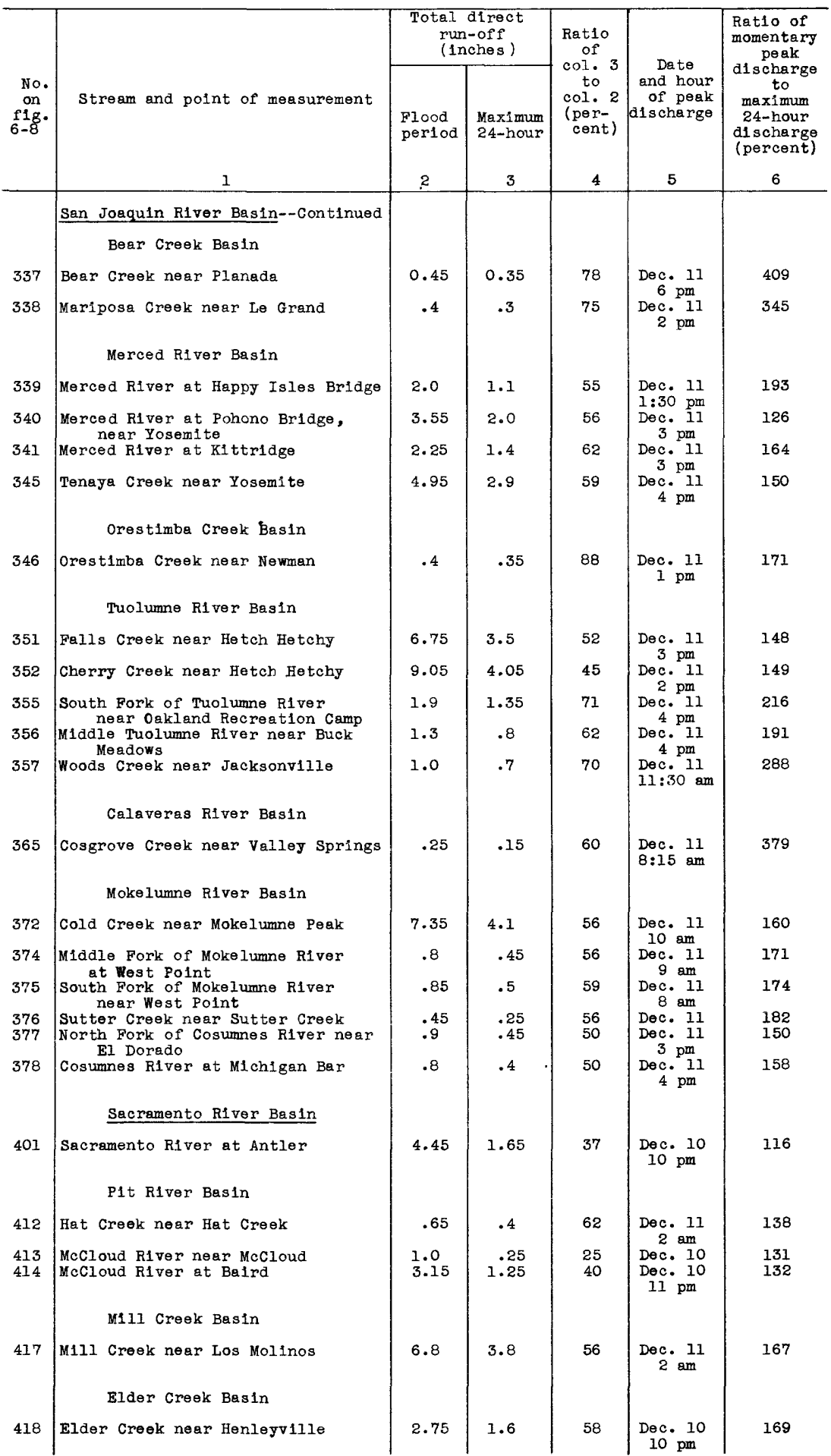


Table 8.--Run-off characteristics-Continued

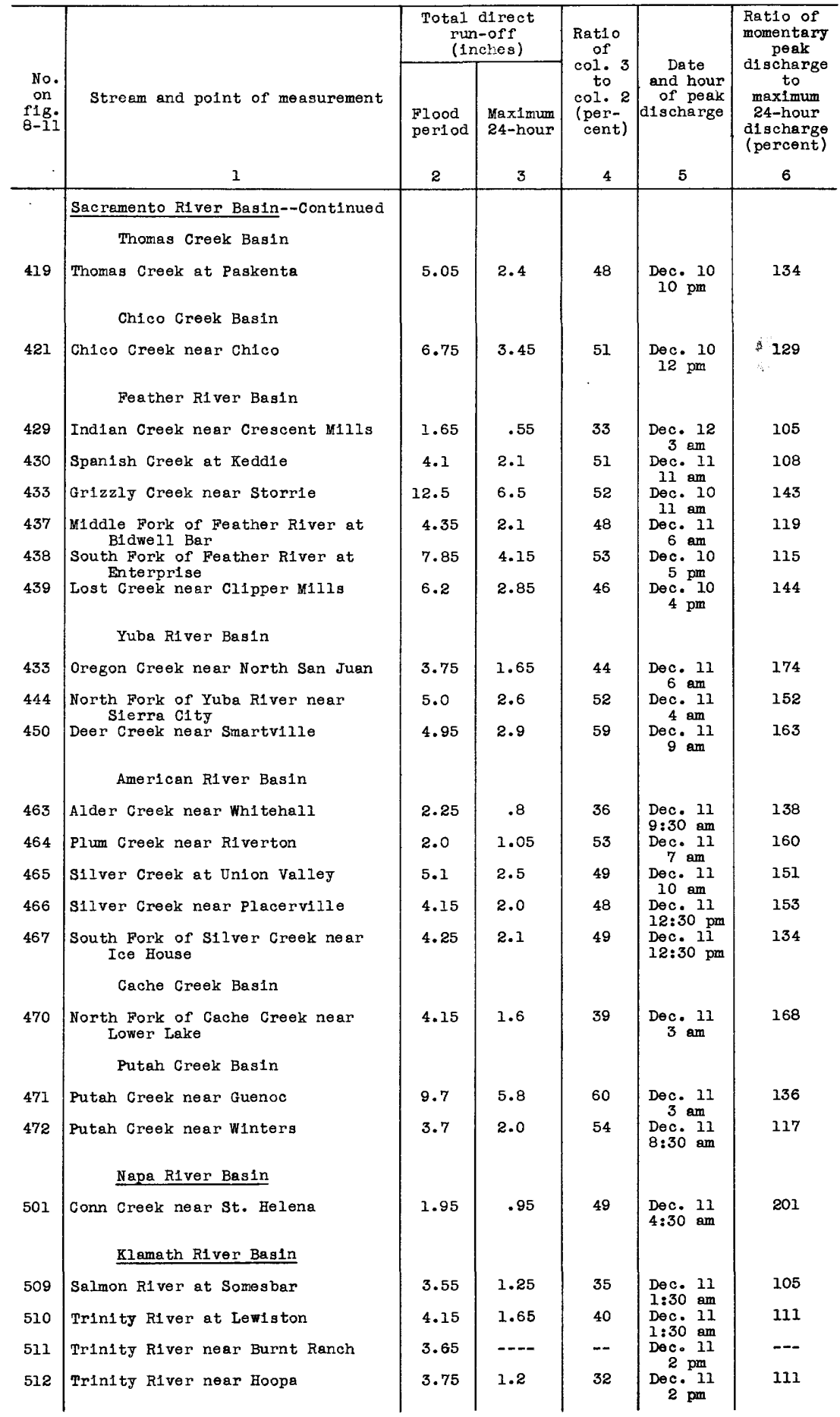


Table 8.--Run-off characteristics--Continued

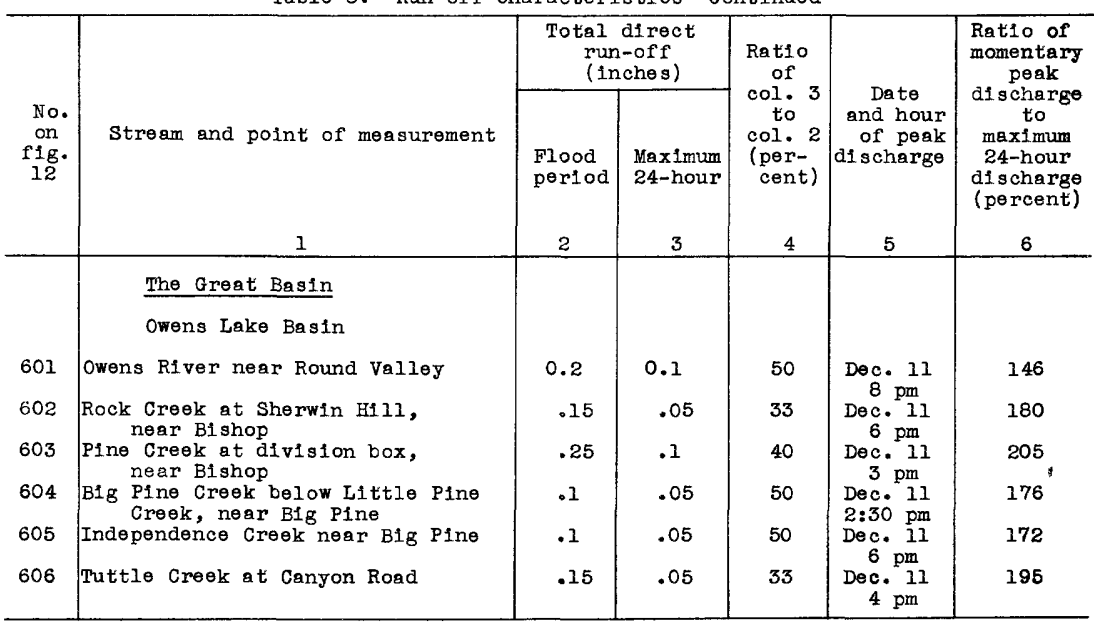


The run-off values in tables 7 and 8 , being expressed in inches over the drainage basins, are significant for comparison only if the entire basin contributed direct run-off. The analyses of the mu-off records indicate that there was little contribution to the stream flow in those parts of basins lying at altitudes of about 9,000 feet or more, or from those parts of the basins where the total storm precipitation was less than about 5 inches and in some areas about 8 inches. In basins where either or both of these conditions exist, the run-off values in table 7 are not satisfactorily comparable unless adjusted to the areas lying below the 9,000 foot contour or having at least 5 inches of precipitation. To a limited extent, these adjustments have been included in the descriptive text relating to each basin. For many basins, inconsistencies in the mun-off values disappear when the run-off is expressed in depth in inches over the approximate net contributing area. For reasons given, similar adjustments are necessary in the residuals or differences between rainfall and direct mun-off. The interpretation of the data is also complicated by the fact that, in a very considerable part of the area, the indicated differences between rainfall and run-off are so large that they become insensitive as an index of possible discrepancies in the basic data. Considerable error might exist in either the rainfall or the run-off values without a negative residual being shown. Such a negative residual would be an indication of error, unless runoff was affected by melting snow from previous storms. In some of the basins, the adjustments for artificial storage and diversion greatly exceed the measured stream flow, and therefore errors in the stagecapacity tables of storage reservolrs or in the estimates of storage where no records are avallable may affect the run-off figures in table 7. Many of the basic rainfall and run-off cata in table 7, which appear inconsistent, may reflect actual basin characteristics rather than errors in observations. To a limited extent the apparent inconsistencies are discussed by individual basins.

\section{Direct run-off}

The run-off in table 7 is the total direct mu-off during the flood period December 9 to 20 expressed in inches over the drainage areas. The hydrographs given in the section "Stages and discharges at river-measurement stations" (figs. 31 to 4l) show, for selected river-measurement stations, the distribution of the run-off with respect to time after it had reached the river channels. For consideration 
of problems relating to the retention and storage of water, either in reservoirs or through the medium of land use practices, a knowledge of the total flood mu-off is of major importance. The effect of mun-off in bullding up channel storage in the lower reaches of principal river systems and in overflowing and submerging natural flood plains is also of direct interest in flood-control studies. The degree to which the flood run-off is concentrated with respect to time is of paramount importance in studies relating to the capacities of spillways, by-passes, bridge openings, or channels designed to carry momentary peak discharges, and is a measure of the dynamic destructive force of stream flow. When the observed run-off is adjusted for channel storage and thus synchronized more clearly with the precipitation, it furnishes information of immediate value in problems relating to direct surface run-off before it reaches stream channels.

As is to be expected, the areas from which there was high run-off coincide with the areas in which the precipitation was the greatest. The adjusted total direct flood run-off was generally in excess of 8 inches, and was in excess of 12 inches from three basing where the storm rainfall averaged from 12 to 18 inches, and where there were maxima in excess of 20 inches at individual places.

Analyses of the run-off of major floods in the United States (including the floods of March 1913, which were extreme on the Miami River In Ohio; the floods of March 1936, which embraced all of the northeastern United States from Virginia to Maine; the great Ohio and Mississlppi River floods of January 1937; and certain other floods caused by intense local storms) indicate that, over a considerable part of the country, the direct run-off during a flood period has ranged between 8 and 10 inches. The character of the storms associated with these floods has varied greatly, between short intense storms for small drainage basins and widely extended general rainfall covering many days and marked by several comparatively intense storm periods. Similarly, the flood rises varied from sharp peaks for small basins to relatively flat rises extending over many days for the largest basins. By comparison, therefore, with standards elsewhere in the country, extreme flood conditions seemingly prevalled during December 1937 in those basins in California where the total direct run-off was 8 inches or more.

The areas in which the adjusted total direct flood run-off exceeded 10 inches (see table 7) include the drainage basins of Bucks Creek and Grizzly Creek in the Feather RIver Basin, and the South Fork of the Yuba 
River and Canyon Creek in the Yuba River Basin. Drainage basins in which the adjusted direct run-off was between 8 and 10 inches include those of Uvas Creek, Upper Putah Creek, and the Eel River above Hullville and above Van Arsdale Dam, draining parts of the Coast Ranges, Eleanor Creek and Cherry Creek in the Tuolumne River Basin, the North Fork of the Mokelumne River, the West Branch of the Feather River, the Bear River above Pardoe Camp, and Silver Lake, draining parts of the Sierras. In parts of the Pit River Basin downstream from Big Bend, including Squaw Creek and possibly the area tributary to the lower McCloud River, the direct run-off also apparently exceeded 8 inches. The run-off in parts of the drainage basins immediately adjacent to the basins just mentioned probably also exceeded 8 inches. In addition, drainage basins in which river-measurement stations were inoperative or were not being maintained during the flood period, such as the basins of the Russian River, the Smith River, Grindstone Creek, the North Fork of the Kings River, and possibly others, may have experienced flood run-off of more than 8 inches.

Areas in which the adjusted total direct flood run-off was between 6 and 8 inches include those upstream from river-measurement stations on Falls Creek in the Tuolumne River Basin; the North Fork of the Stanislaus River; Cold Creek in the Mokelumne River Basin; Concow Creek, Lost Creek, and the South Fork of the Feather River in the Feather River Basin; the Middle Fork of the Yuba River at Milton, and Deer Creek near Smartville in the Yuba River Basin; Twin Lakes outlet in the American River Basin; Mill Creek; Chico Creek; Butte Creek; and the Eel River at Scotia.

It seems evident that in all the basins mentioned above the water avallable for run-off exceeded the capacity of the basins to retain or absorb water by an amount sufficient to produce flood run-off comparable with the run-off during great floods elsewhere in the United States. Many other basins from which the flood run-off was less than 6 inches appear to $\mathrm{fall}$ into three more or less well defined groups.

One group includes basins where the storm rainfall and the direct run-off were relatively low, yet where momentary peak discharges reached on December 10 or 11 have not been equalled or exceeded during the period of record which in many cases exceeds 20 jears. The storm precipitation in December 1937 averaged less than 7 inches over the basin, the total adjusted direct run-off was generally less than 2 inches, and yet the momentary peak discharge on December 10 or 11 was considerably more than 
has been recorded since the river-measurement stations have been in operation at the following places: P1t River at Fall River M1lls, P1t R1ver below Pit No. 4 dam, PIt River at Ydalpom, and Hat Creek near Hat Creek. The basins upstream from these points of measurement are underlain in part by lava, drainage at many places is poorly defined, and some of the areas have no visible outlets to stream channels. The Upper Pit River country is normally an area of low rainfall. By comparison with the floods of other regions, neither the total mun-off nor the momentary peak discharge during December 1937 can be considered as elther a medium or a large flood. However, on the basis of the flood history of these streams as disclosed by the stream-flow records, the records of December 1937 are a measure of large floods for these particular basins.

The second group of basins includes those in which the storm precipitation was greater than that which took place over some basins where the run-off was in excess of 6 inches and no snow was involved, yet by reason of a high retentive and absorptive capacity during the storm period the run-off was relatively small. In the basins of the following rivers the average storm precipitation was 10 inches or more but the adjusted total direct run-off was generally less than 3 inches: San Lorenzo River, Guadalupe Creek (at San Jose), Campbell Creek, Stevens Creek, Fresno Rlver, Arroyo Seco, South Fork of Mokelumne RIver, Plum Creek, and Alder Creek. Other peak discharges of record in these basins have materially exceeded the peak discharge during December 1937, and the other maxima on San Lorenzo Creek, Campbell Creek, Arroyo Seco, and the Fresno River resulted from storms of less intensity than that of December 1937. (See table 9 on pp. 337-339.) Brief analysis seems to indicate that the large residual shown for many of these basins during December 1937 does not necessarily reflect a high retentive and absorptive capacity during all storms.

The third group of basins includes those where by reason of high altitudes and low temperature some of the precipitation fell as snow that did not contribute immediately to the flood run-off, and also those basins in which there was snow on the ground at the beginning of the storm period that did not melt materially and perhaps actually retained some of the rainfal1. The net effect was that direct surface run-off took place in only a part of these dreinage areas. Consequently, for basins in this group, a high storm precipitation is indicated, but the run-off expressed in inches over their areas as a whole is low and not indicative of run-off contributions from those parts of basins where 
no snow wás involved. Typical basins of this type include the upper Merced, Kings, and Kaweah Rivers. In parts of these basins, although the total run-off was low, it was concentrated with respect to time ana momentary peaks greatly exceeded prior peaks of record. The unusualIy high peak discharge in these basins as compared to all other peaks of record would seem to be a measure of the unusual character of the storm of December 1937 with respect to rain at high altitudes.

On the other hand, some of the smaller basins like Bear and Mono Creeks near Vermilion Valley are at such high altitudes that neither their total run-off nor the momentary peak discharges approached those for floods from melting snow in the spring and early summer.

Based on observations of run-off, precipitation, snow, and the relation between these factors and altitude, a generalized map (fig. 46) has been prepared showing areas from which the direct mun-off during the flood period in December was greater than 8 inches, between 4 and 8 inches, between half an inch and 4 inches, and less than half an inch. In preparing this generalized map an attempt was made to balance areas above and below lines of equal run-off so that mean mun-of for a given basin equals the measured run-off. In areas where the run-off was not measured, the lines of equal run-off are based to a large extent on precipitation and on general relations between rainfall and run-off observed in adjacent areas. There is also shown in figure 46 the approximate location of the 9,000-foot contour which for the December storm and flood represents approximately the upper limit of the area in much of the sierra Nevada that contributed materially to the flood run-off. As indicated in this figure, areas in which there were 8 inches or more of direct run-off include most of the headwater basins of the Eel River and Putah Creek and parts of the Russian River Basin in the northern Coast Ranges; Uvas Creek Basin in the Santa Cruz Mountains area; Squaw Creek and adjacent areas tributary to the lower Pit River and headwater areas of Mill, Deer, Chico and Butte Creeks; the West Branch, South Fork, and lower parts of the North and Middle Forks of the Feather River; the South Fork of the Yuba River; parts of the North and South Forks of the American River; and parts of the headwater areas in the Mokelumne, Stanislaus and Tuolumne River Basins. Areas in which there was less than about half an inch of direct run-off include all the San Joaquin Valley floor and adjacent foothill areas, the western half of the central sacramento and all of the lower sacramento Valley, much of the area immediately tributary to San Francisco Bay, and most of the drainage areas on the eastern 


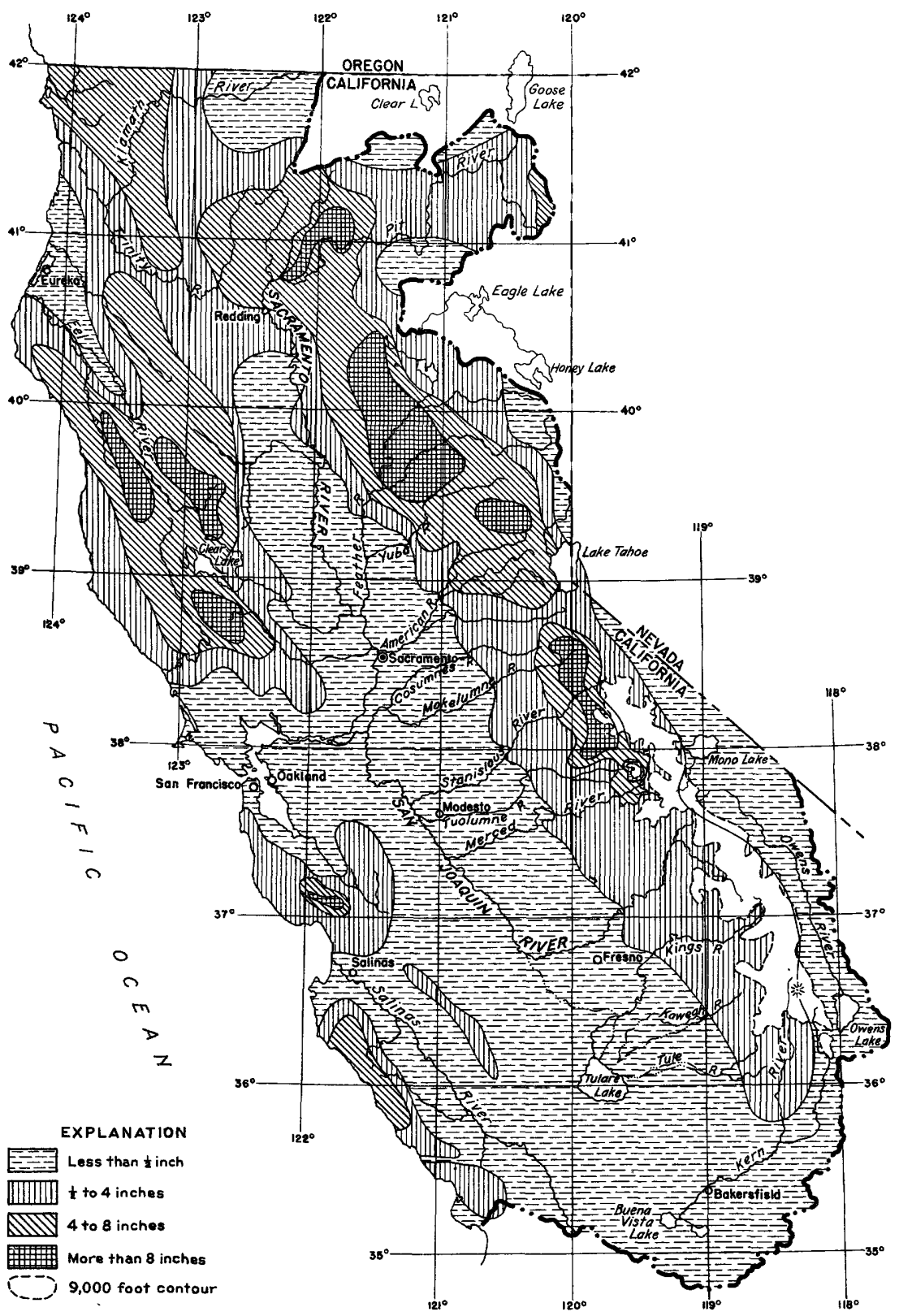

$20 \quad 0 \quad 20 \quad 40 \quad 60 \quad 80 \quad 100$ MIles

Figure 46.--Map showing areas of equal mun-off in northern California during floods of December 1937. 
slopes of the Sierra Nevada. The storm covered about 109,000 square miles. The areal extent of the run-off was approximately as follows:

\begin{tabular}{l|c}
\hline $\begin{array}{c}\text { Run-off } \\
\text { (Inches) }\end{array}$ & $\begin{array}{c}\text { Tributary area } \\
\text { (square miles) }\end{array}$ \\
\hline Little or none & $1 / 3,900$ \\
Less than $1 / 2$ & 56,400 \\
$1 / 2$ to 4 & 28,300 \\
4 to 8 & 16,400 \\
More than 8 & 3,800 \\
\hline
\end{tabular}

If It is assumed that above an altitude of 9,000 feet there was little if any run-off.

of the 56,400 square miles where the direct run-off was less than half an Inch, about 35,000 square miles are located in the Central Valley and foothill area tributary to the San Joaquin and Sacramento Rivers and Tulare and Buena Vista Lakes. The question arises: to what extent may this great area be considered as one that will rarely, if ever, contribute large amounts of flood run-off to the San Joaquin and Sacramento Rivers? Local areas may be subject to the cloudburst type of storm with resultant intense run-off from relatively small areas. However, the area would seem to be so located with respect to the Pacific Ocean and mountain ranges as to be more immune to widespread occurrence of heavy rainfall than much of the area in the Coast Ranges and the Sierra Nevada. Moreover, the topographic and edaphic conditions in much of the area are conducive to a relatively high absorptive capacity, at least at the beginning of the rainy season. On the other hand, storms such as those in February 1936 and February 1937 did occur in foothill areas with resultant large flood run-off.

During the flood of December 1937, there were 44,700 square miles from which the run-off was between half an inch and 8 inches; of this area, 28,300 square miles had less than 4 inches and 16,400 square miles had between 4 and 8 inches. How subject are these areas to flood runoff greater than took place during December 1937 ? Consideration should be given especially to the flood-producing potentialities of the areas in which the run-off during the flood of December 1937 was between 4 and 8 inches with a view to determining whether, by reason of their altitude and topography, these areas may be subject to storm precipitation of a magnitude that would produce run-off considerably in excess of that during December 1937. Relatively little is known about the absorptive capacity of much of these areas under different storm 
conditions, but in general their absorptive capacity under normal conditions is probably less than that of the valley floor, which is composed largely of alluvium. In the absence of specific information to the contrary, it would appear that much of the 16,400 square miles from which there was between 8 and 4 inches run-off during the December storm must be regarded as subject to run-off considerably in excess of the peaks of 1937. During the flood of December 1937, the 9,000-foot contour was about the upper limit of appreciable run-off, but there is considerable evidence that the heavy rain extended above the 9,000-foot altitude in the headwaters of the Tuolumne River, notably in Cherry, Eleanor, and Fall Creek Basins. Matthes $6 /$ states:

Owing to low alr temperatures all the year round... but a small proportion of the snowpack in the Alpine zone is transformed into meltwater. . . Above altitudes of 11,000 to 12,000 feet, according to latitude, melt-water is so scanty that it forms no channel-making streams or streamlets. Above 13,000 feet the snow-fields yield but small trickles that do not reach the valley below.

It would appear that the area between altitudes of 9,000 and 11,000 feet may at times contribute flood run-off to some extent. On the other hand, as discussed herein, the abnormally high temperatures prevailing during the storm of December 1937 had the effect of raising the altitude of the rainfall limit to only about 9,000 feet.

The flood-producing potentialities of the high Sierra Nevada offer a field for an interesting study of snow in relation to flood mun-off. Because of their high altitudes, many of the snow fields in the Sierra Nevada, especially in the southern part, are apparentiy not subject to unusually high winter temperatures and to the accompanying warm winds of the Chinook type, which occur in the Pacific northwest and which result in the release of large volumes of water in sharp and violent floods similar to those from rain storms of high intensity. However, the runoff from the higher snow fields of the Sierra Nevada is influenced by the seasonal trends of temperature. The higher spring temperatures, either with or without rain, release large amounts of water which may or may not produce major flood stages in tributaries of the San Joaquin River, depending upon the abnormality of the temperature, but which may accumulate, as during May and June, 1938, in the channel of the lower San Joaquin and result in major flood stages and long continued occupancy of the natural flood plains.

6) Matthes, F. E., Evaporation and runoff from snow in the Alpine zone of our western mountains, Am. Geophys. Union Trans., pt. 3, August 1938 , p. 662 . 
If rain falis on snow there is a tendency for some retention, the amount depending on the associated temperatures and the depth of the snow and its water content. However, an analysis of winter and spring floods in the San Joaquin River Basin may show that during Iong continued periods of rain associated with high temperatures, snow cover, even at the higher altitudes, may constitute a distinct flood hazard. In the basins draining the northern parts of the Sierra Nevada there is relatively less area of high altitude than in the southern basins. Therefore, snow fields on the western slopes tributary to the Sacramento River are subject to higher temperatures and more precipitation in the form of rain, and hence constitute a greater flood hazard than snow fields on higher slopes tributary to the San Joaquin River.

Although the rains of December 1937 produced widespread floods of high intensity, a brief analysis indicates that, in many basins, the run-off of some prior floods which were associated with melting snow exceeded the run-off during the December flood, even though the degree of concentration and the momentary peak discharge may have been less. The floods of March 1928 in parts of the Sacramento River basin are an example of this type of flood. The direct run-off in some of the basins, especially of the American and Feather Rivers, was larger than the direct run-off during the flood of December 1937. The flood period in March 1928 was generally longer than that in 1937, and mun-off was less concentrated with respect to time.

\section{Residuals}

If the run-off and the precipitation records are correct and there was no snow on the ground at the beginning of the storm period, the differences between the run-off and precipitation, herein called residuals, represent the amount of water that was retained in the basin in the form of snow or as surface storage and absorption, or was transpired and evaporated during the flood period. Negative residuals are clearly indicative of errors in basic data. Unusually large or unusually small residuals represent either unusual basin characteristics or possibilities of error in basic data. Generally, the residuals, if properly interpreted, should represent relative measures of the absorptive capacity of the various drainage basins during the December storm.

Analysis of the rainfall and run-off values in table 7 aiscloses only three drainage basins - the North Fork of the Mokelumne River (above 
Salt Springs Dam), the Bear River (above Pardoe Camp in the Mokelumne River Basin), and Silver Lake outlet (near Kirkwood in the American River Basin) - where negative residuals are indicated. All these basins are at an altitude above 5,000 feet, and the flood run-off may have been augmented by snow on the ground at the beginning of the flood period or affected by inaccuracies in the large storage adjustments that were made to determine the natural run-off. In six other basins upstream from river-measurement stations on Cold Creek near Mokelumne Peak, the South Fork of the Pit River near Likely, Thomas Creek near Paskenta, the South Fork of the Yuba River at Lake Spaulding, Canyon Creek below Bowman Dam, and Twin Lakes outlet near Kirkwood - the residuals are less than 2 inches and possible sources of discrepancies in results are indicated as follows. In three of the basins, large storage adjustments were necessary, and in all basins except Thomas Creek near Paskenta snow melt may have contributed to the flood runoff. Thomas Creek Basin lies on the eastern slopes of the northern Coast Ranges where there is a decided sparsity of rain gages and where it appears that the isohyetals indicate less storm rainfall than actually occurred.

On the other extreme, residuals in four areas upstream from rivermeasurement stations on San Lorenzo River at Big Trees, Campbell Creek at Saratoga, North Fork of Willow Creek at Crane Valley Reservoir, and Lost Creek near Clipper M1Ils, exceed 12 inches; and the residual in San Lorenzo Creek Basin is nearly 15 inches. The Lost Creek Basin is small and lies mostly below an altitude of 5,000 feet in the Feather River Basin, and there is a possibility that less rain fell in the basin than is indicated by the 1sohyetals as drawn. For the basin of the North Fork of Willow Creek there was a large adjustment for storage and diversions. The other two basins are on the slopes of the southern Coast Ranges, where it is belleved that the positions of the isohyetals are well fixed by supplemental precipitation records. Los Gatos Creek Basin (Santa Clara County), also draining a part of the Coast Ranges, has a high residual of 10.35 inches. It $1 \mathrm{~s}$ belleved that the direct run-off from these basins has been determined with reasonable accuracy. These high values may be due in part to the highly shattered condition of the underlying bed rock, and to some extent may be indicative of a tendency of areas in the southern Coast Ranges, as well as in much of the semidesert and foothill areas of the southern Central Valley, to absorb 
large quantities of water, at least during the first period of heavy rains in the early winter. This view seems to be supported in part by the fact that residuals in excess of 8 inches are indicated in the basins, in addition to those already named, upstream from gaging stations on Uvas Creek near Morgan H1ll, Stevens Creek near Cupertino, Guadalupe Creek at San Jose, and Arroyo Seco near Soledad, all in the Coast Ranges, and for parts of the Tule, Mokelumne, Kaweah, and Fresno River Basins, tributary to the southern part of the Central Valley. In all these areas, the precipitation was generally in excess of 10 inches, and the residual values indicated in table 7 may approach the maximum capacity of these areas to absorb water under conditions similar to those prevalling during the storm of December 1937. During the period December 9 to 12 the residuals were more a measure of total rainfall than of infiltration capacity in parts of the Salinas, San Francisquito, Guadalupe, Coyote, Alameda, Lower Kern, Los Gatos (near Coalinga), lower San Joaquin, Chowchilia, Bear, Orestimba, Lower Tuolumne, Stanislaus, Calaveras, and lower Mokelumne Basins.

Considering the basins in the northern part of the Central Valley and in the northern Coast Range, it is evident that during the December storm, at least, their absorptive capacity was materially less than that in the southern basins described.

In the upper Sacramento, Pit, McCloud, Putah, Elder, Stony, Cache, Eel, Shasta, and Trinity Basins, the residuals are consistently less than 5.0 inches. It has been pointed out in the discussion of antecedent rainfall that during November 1937, there was generally in relation to normal an excess of rain in the northern part of the area and a deficiency in the southern part. To antecedent conditions may therefore be ascribed some and perhaps a major part of the differences in the absorptive capacities as measured by the residuals, except in basins where lava formations are a major influence.

Interpretation of the residuals for basins in the higher parts of the Slerra Nevada is uncertain because of snow and relatively sparse rainfall data. In parts of the upper Kings, San Joaquin, Tuolumne, Feather, Yuba, and American River Basins residuals of 6 to 8 inches are indicated. However, as shown in table 7 the residuals for the larger number of basing range between 4 and 6 inches. In the absence of other information, it may be concluded that the average retention in much of the higher Slerra country was between 4 and 6 inches during the flood period in December, and that, other things being equal, residuals of 
less than 4 to 6 inches may indicate contributions to run-off from snow on the ground at the beginning of the storm period, and higher residuals may indicate either an over-estimate of the rainfall or retention of water in the form of snow on the ground at the end of the period studied.

It may be of interest to point out that during the storm of March 9 to 22, 1936, residuals of less than 3 inches were indicated for nearly all river basins in Virginia, Maryland, Pennsylvania, New York, and New England. For the storm of December 1937 in California residuals as small as 3 inches are the exception, not the rule.

\section{Comparison of rainfall and run-off conditions during floods of record}

A study has been made of the rainfall and run-off conditions during the highest flocds of record for those basins in which there is no large artificial storage, for the purpose of comparison with conditions prior to and during the December flood. The study is of preliminary character and largely qualitative rather than quantitative. Instead of preparing a detailed rainfall map for each of the storms which have resulted in the major floods herein considered, the precipitation data concerning major floods were assembled for all avallable rainfall stations and ratios were determined between the precipitation during the storm of December 1937, used as a standard, and the previous or subsequent large storms. The results of these comparisons are shown in table 9, which includes symbols and explanatory footnotes to classify the characteristics of the precipitation. A more detalled explanation of some of the symbols than appears in the table follows.

When the precipltation was within 10 percent of that which occurred during the storm of Deceinber 1937 the symbol (c) is used. When the precipitation was within 10 to 25 percent, plus or minus, of that of December 1937 the symbol (b) is used to signify that the difference was plus and (d) to signify that the difference was minus. In a similar manner the symbol (a) indicates that the precipitation was more than 25 percent greater than that which occurred during the December storm, and (e) that the precipitation was more than 25 percent smaller. The symbol $(\mathrm{k})$ is used to indicate that there was substantial contribution of melting snow to the flood run-off, and symbol (1) to indicate small contributions. When there was an accumulation of snow during the storm period the symbol (n) indicates light accumulation and symbol (o) heavy accumulation. Most of the storms analyzed were apparently of longer duration than the storm of December 1937. When the duration was 
Table 9.--Comparison of floods of December 1937 with other floods, for unregulated streams

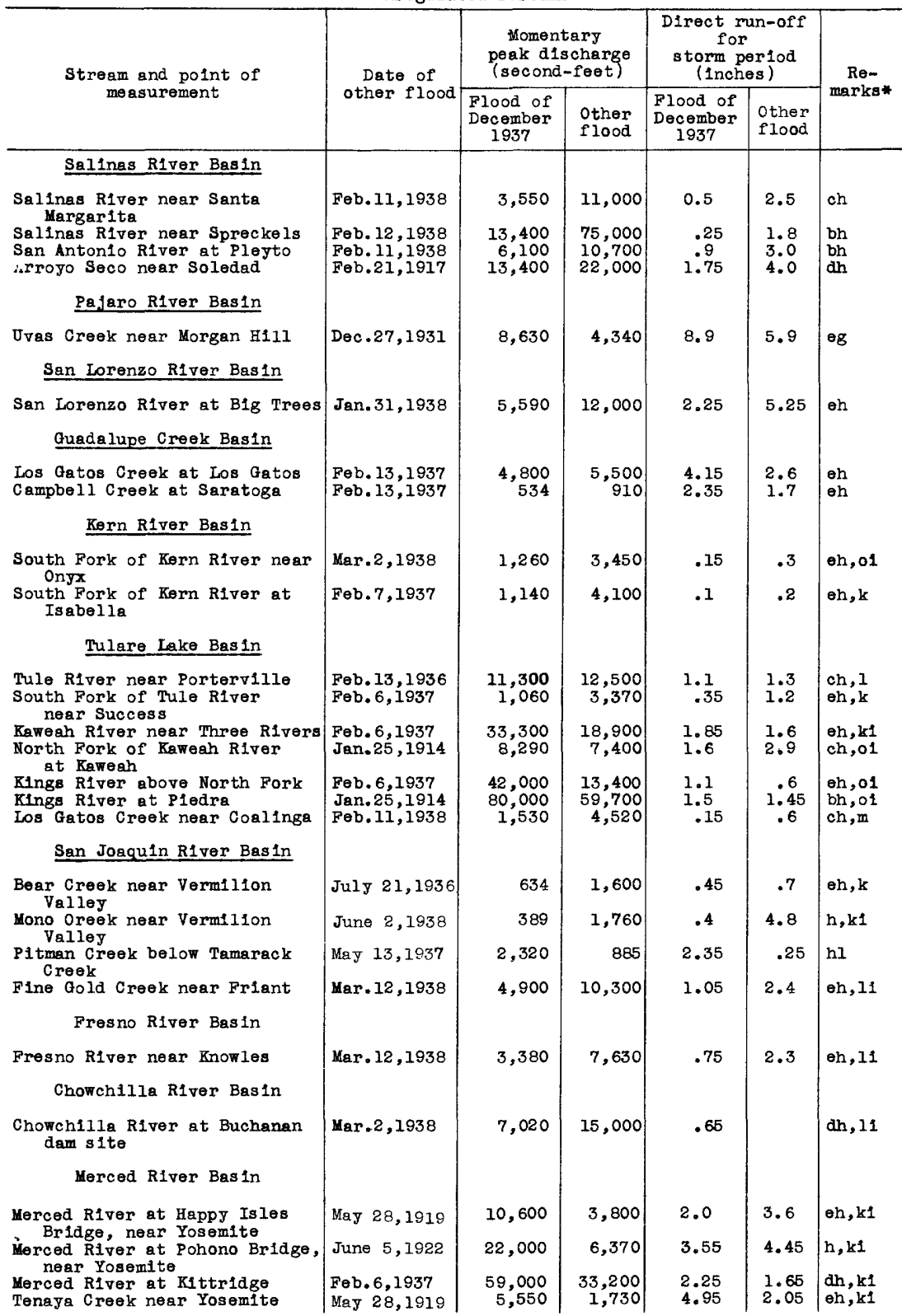

* Remarks refer to amount of water available for mun-off during other flood as compared with amount available during flood of December 1937. Key letters explained below:

a Much more precipitation.

f Short storm. $k$ Large snow contribution.

b slightly more precipitation. \& prolonged storm.

c Precipitation about same

d Slightig less precipitation.

Large amount of ante-

cedent precipitation.

1 small snow contribution.

Huch less precipitation.

1 At high altitudes. Ho snow contribution.

Light snow accumalation.

$f$ At low altitudes. 
Table 9.--Comparis on of floods of December 1937 with other floods, for unregulated streams--Continued

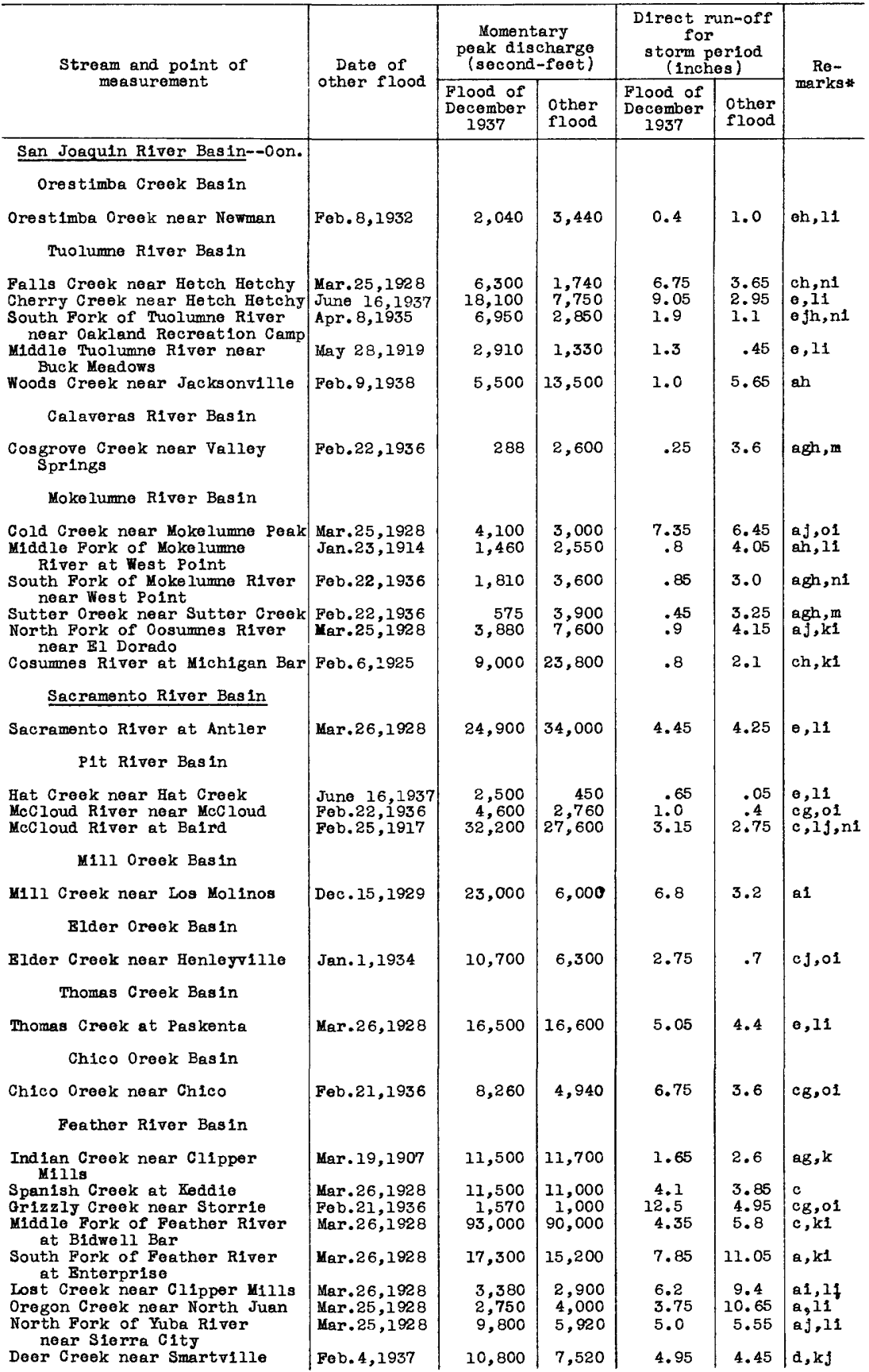

Deor Crook near Smartville

* Remarks refor to amount of water available for mun-off during other flood as compared with amount avallable durlng flood of December 1937. Koy letters explained

a Much more precipitation. f Short storm.

b Slightly more precipitation. $g$ Prolonged storm.

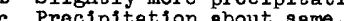

d Precipitation about samo.

3 Prolonged storm. 1

Large amount of ante- m cedent precipitation. n

Large snow contribution.

- Much less precipitation.

1 At high altitudes. Small snow contribution. No snow contribution. No snow contribution. 
Table 9.--Comparison of floods of December 1937 with other floods, for unregulated streams--Continued

\begin{tabular}{|c|c|c|c|c|c|c|}
\hline \multirow{2}{*}{$\begin{array}{l}\text { Stream and point of } \\
\text { measurement }\end{array}$} & \multirow{2}{*}{$\begin{array}{l}\text { Date of } \\
\text { other flood }\end{array}$} & \multicolumn{2}{|c|}{$\begin{array}{l}\text { Momentary } \\
\text { peak discharge } \\
\text { (second-feet) }\end{array}$} & \multicolumn{2}{|c|}{$\begin{array}{l}\text { Direct mun-off } \\
\text { for } \\
\text { storm perlod } \\
\text { (1 nches) }\end{array}$} & \multirow{2}{*}{ Rerks* } \\
\hline & & $\begin{array}{c}\text { Flood of } \\
\text { December } \\
1937\end{array}$ & $\begin{array}{l}\text { other } \\
\text { flood }\end{array}$ & $\begin{array}{l}\text { Flood of } \\
\text { December } \\
1937\end{array}$ & $\begin{array}{l}\text { other } \\
\text { flood }\end{array}$ & \\
\hline$\frac{\text { Sacramento River Basin--Con. }}{\text { American River Basin }}$ & & & & & & \\
\hline $\begin{array}{l}\text { Alder Creek near Whitehali } \\
\text { PIum Creek near Riverton } \\
\text { Silver Creek at Union Valley } \\
\text { Silver Creek near Placervilie } \\
\text { South Fork of Silver Creek } \\
\text { near Ice House } \\
\text { Cache Creek Basin }\end{array}$ & $\begin{array}{l}\text { Mar.25, } 1928 \\
\text { Mar.25, } 1928 \\
\text { Mar.25, } 1928 \\
\text { Mar.25, } 1928 \\
\text { Mar.26, } 1928\end{array}$ & $\begin{array}{r}710 \\
315 \\
8,560 \\
14,600 \\
2,200\end{array}$ & $\begin{array}{r}2,060 \\
635 \\
8,050 \\
12,400 \\
1,620\end{array}$ & $\begin{array}{l}2.25 \\
2.0 \\
5.1 \\
4.15 \\
4.25\end{array}$ & $\begin{array}{l}7.15 \\
- \\
4.55\end{array}$ & $\begin{array}{l}\text { aj, of } \\
\text { aj,k } \\
\text { aj, of } \\
\text { aj,oi } \\
\text { aj, nit }\end{array}$ \\
\hline $\begin{array}{l}\text { North Fork of Cache Creek } \\
\text { near Lower Lake } \\
\text { Putah Creek Basin }\end{array}$ & Dec.26,1931 & 16,000 & 11,000 & 4.15 & 2.35 & 0,11 \\
\hline $\begin{array}{l}\text { Putah Creek near Guenoc } \\
\text { Putah Creek near Winters } \\
\text { Napa River Basin }\end{array}$ & $\begin{array}{l}\text { Mar. } 10,1904 \\
\text { Feb. 4, 1937 }\end{array}$ & $\begin{array}{l}24,100 \\
39,200\end{array}$ & $\begin{array}{l}24,600 \\
41,100\end{array}$ & $\begin{array}{l}9.7 \\
3.7\end{array}$ & $\begin{array}{l}8.85 \\
2.0\end{array}$ & $\mathrm{~d}^{-}$ \\
\hline $\begin{array}{c}\text { Conn Creek near St. Helena } \\
\text { Kamath River Bas In }\end{array}$ & Feb. 4, 1937 & 2,660 & 4,600 & 1.95 & 1.5 & $d$ \\
\hline $\begin{array}{l}\text { SaImon River at Somesbar } \\
\text { Trinity River at Lewiston } \\
\text { Trinity River near Burnt Ranch } \\
\text { Trinity River near Hoopa } \\
\qquad \text { Smith River Basin }\end{array}$ & $\begin{array}{l}\text { Jan. } 14,1936 \\
\text { Nov. 30,1926 } \\
\text { Jan. 15,1936 } \\
\text { Dec.31, } 1913\end{array}$ & $\begin{array}{r}27,000 \\
37,000 \\
71,800 \\
105,000\end{array}$ & $\begin{array}{l}21,600 \\
31,900 \\
31,000 \\
89,000\end{array}$ & $\begin{array}{l}3.55 \\
4.15 \\
3.65 \\
3.75\end{array}$ & $\begin{array}{l}3.55 \\
4.55 \\
1.75 \\
4.55\end{array}$ & $\begin{array}{l}\mathrm{ag}, 01 \\
\mathrm{ag}, \mathrm{m} \\
\mathrm{ag}, 01 \\
\mathrm{ag}, 1\end{array}$ \\
\hline $\begin{array}{l}\text { Smith River near Crescent City } \\
\text { The Great Basin } \\
\text { Owens Lake Basin }\end{array}$ & Apr.13,1937 & 78,900 & 70,100 & - & 9.1 & d \\
\hline $\begin{array}{l}\text { Owens River near Round Valley } \\
\text { Rock Oreek at Sherwin Hill, } \\
\text { near Blshop } \\
\text { Pine Creek at division box, } \\
\text { near Blshop }\end{array}$ & $\begin{array}{ll}\text { June } & 30,1907 \\
\text { June } & 17,1927 \\
\text { July } 21,1936\end{array}$ & $\begin{array}{r}1,560 \\
115 \\
207\end{array}$ & $\begin{array}{r}1,190 \\
162 \\
350\end{array}$ & $\begin{array}{l}.2 \\
.15 \\
.25\end{array}$ & $\begin{array}{l}.3 \\
.5 \\
.45\end{array}$ & $\begin{array}{l}\mathrm{ki} \\
e, \mathrm{k} i \\
e, \mathrm{k} 1\end{array}$ \\
\hline
\end{tabular}

* Remarks refer to amount of water avallable for mun-off during other flood as compared with amount avaliable during flood of December 1937. Key letters explainea below:
a Much more precipitation.
b Silghtiy more precipitation.
Precipitation about same.
d Silghtiy less precipitation.
- Much less precipitation.
$f$ Short storm.
$g$ Prolonged storm.
h Large amount of ante- cedent precipitation. 1 At high altitudes. f At low altitudes.

k Large snow contribution.
I Smali snow contribution.
m No snow contribution.
n Light snow accumilation.
- Heavy snow accumulation. 
much longer the symbol (g) is used, and where shorter the symbol ( $f$ ). If no indicating time length is given it may be inferred that the duration was somewhat longer than for the storm of December 1937.

The amount of antecedent rainfall seems to be a very influential factor in Calfornia floods. The great majority of floods which exceeded that of December 1937 were preceded by more precipitation, although the actual flood-producing precipitation may have been less.

Some of the earlier maxima are not based on recording-gage records and the accuracy of the momentary peaks may not approach that of the more recent records.

Analysis indicates that, in six basins where apparently no snow was involved, storms of less rainfall produced larger peaks than were recorded during December 1937. These basins drain parts of the Coast Ranges and are upstream from gaging stations located on Arroyo Seco near Soledad, the San Lorenzo River at Big Trees, Los Gatos Creek at Los Gatos, Campbell Creek at Saratoga, Putah Creek near Winters, and Conn Creek near St. Helena. All the highest peaks occurred later in the rainy season than the flood of December 1937 and were preceded by much more precipitation. On Arroyo Seco and the San Lorenzo River the maximum peaks were accompanied also by a greater total direct run-off than occurred during December 1937. At the other four gaging stations the total direct run-off associated with the storm of February 1937 was less than in December 1937.

If floods are considered in basins where snow was involved, storms of less rainfall produced higher peaks than in December 1937 in 19 basins, and produced more direct run-off in 12 basins. In nearly all of these floods there was more antecedent precipitation and the storm period was longer than in December 1937.

In general it may be said that, with the exception of a few floods due wholly or primarily to melting snow, the floods that exceeded those of December 1937 were associated with storms that were more prolonged or that had more antecedent precipitation.

In comparison with floods of the eastern part of the United States, it seems evident that in semi-arid regions the avallable absorptive capacity of the basin at the time of the flood may be a major determining influence, whereas in more humid regions the avallable absorptive capacity is likely to be subject to less variation due to regularly recurring rainfalls and the maximum floods are associated very commonly with maximum storm precipitation. 


\section{Run-off characteristics}

In the area covered by this report there are approximately 250 river-measurement stations at which continuous records of stage and discharge are obtained. However, as a result of artificial storage for 1rrigation, power, municipal water supplies, and flood prevention, and of diversions of water upstream from some of the gaging stations, the observed discharge represents natural flow conditions at only about 81 river-measurement stations.

The hydrographs of the flow at these 81 stations have been anaIyzed to show the characteristics of the natural run-off during the floods of December 1937. Where groups of basins had similar run-off characteristics, it has been assumed that some general deductions could be drawn.

An important characteristic of flood run-off is the degree to which 1t is concentrated with respect to time. For basin-wide storms not assoclated with snow, Sherman 7 presented the 1dea that surface run-off from rainfalis occurring within the same time interval will produce similar hydrographs whose ordinates will very with the volume of surface run-off. The studies by Bernard, $\frac{8}{\text { Hoyt, }} \stackrel{9 / \text { Snyder, }}{10 /}$ the Corps of Engineers, U. S. Army, and others, have substantiated the general 1dea. It would appear that if, during an isolated storm such as occurred during December 1937, the storm characteristics were similar over the affected area, the degree to which the man-off was concentrated with respect to time may be related largely to inherent basin characteristics, except in those basins where snow was involved. Concentration is usually evaluated in the form of a ratio between discharge for a short interval of time and discharge for a relatively long interval of time. Some investigators have chosen the ratio between the average discharge for the calendar day of greatest flow and the average discharge for the perlod of flood run-off (both computed above a base representing contribution from ground water and surface run-off from antecedent precipitation). Others have used the ratio between momentary peak discharge and discharge for the highest calendar day (with or without

7) Sherman, L. K., Stream flow from rainfall by the unit graph method: Eng. News-Record, vol. 108, pp. 500-501, 1932.

8 Bernard, M. M., An approach to determinate stream flow: Am. Soc. C1vil Eng. Trans., vol. 100, pp. 347-362, 1935.

$9 /$ Hoyt, W. G. and others, Studies of relations of rainfali and runoff in the United States: U. S. Geol. Survey Water-Supply Paper 772, 1936. 
correction for ground-water contribution). It may be readily appreciated that any ratio involving the calendar day is not desirable because it is only by accident that the average discharge for the highest calendar day will colncide with that for the maximum 24-hour discharge.

In this report two separate measures of the concentration are used. The first is the ratio between the run-off during the 24 hours of greatest discharge and the total direct run-off during the storm period. This ratio is listed in table 8 , column 4 .

The second ratio computed is that between the momentary peak discharge and the maximum 24-hour discharge. This ratio is I1sted in table 8, column 6 .

For the 81 unregulated streams listed in table 8 for which complete data are avallable, the ratio between the mun-off during the 24 hours of greatest discharge and the total direct mun-off during the storm period will be discussed first. It is realized that, because of the relatively small size of many of the basins and the extreme flashiness of the runoff, the 24-hour period is too long for any except very general comparisons.

As indicated in table 8 , column 4 , in 12 of the basins less than 40 percent of the total run-off occurred during the 24 hours of greatest discharge. In 14 other basins the ratios of concentration were between 40 and 49 percent. In 33 basins, the largest number for any one group, between 50 and 59 percent of the total run-off occurred during a 24-hour interval. In 11 basins, ratios were between 60 and 69 percent, and in anly 10 basins were the ratios 70 percent or more.

An examination of the grouping of the stations with respect to the degree of concentration of the flood run-off indicates that in general those basins in which less than 50 percent of the total direct run-off occurred during 24 hours fall into two groups. One group, including the upper Kern River, Bear, Mono, Indian, Cherry, and Silver Creeks, and the Middle Feather River drains parts of the high Slerras where melting snow may have contributed to the mun-off. The other group includes some streams in the Klamath and upper Sacramento River Basing where there was but little contribution to the run-off from melting snow.

Basins in which there was an unusually high concentration of flood run-off with respect to time - that is, in which 70 percent or more of the total run-off cucurred during a 24-hour period - are located principally in the semi-arid and lower foothizl areas where the stream flow is not well sustained and the flood run-off takes place following periods 
of high rainfall intensity as a sudden and flashy peak of relatively small volume but with a high maximum rate. Such basins include the areas upstream from the river-measurement stations on Orestimba Creek, Los Gatos Creek near Coalinga, the Salinas RIver near Santa Margarita, Woods Creek, Fine Gold Creek, Cottonwood Creek, Big Sandy Creek, Bear Creek near Planada, Mariposa Creek, and the South Fork of the Tuolumne River. The basins seem to group between these limits with some degree of consistency. Those that drain the upper foothills, including the Fresno, Chowchilla, lower Kings, Middle Tuolumne, and others, had concentration ratios of 60 to 69 percent. The largest group includes basins situated largely on the higher slopes of the Slerra Nevada where between 50 and 59 percent of the total run-off occurred during a 24-hour period. In many of these basins there may have been snow on the ground, but the effect was apparently not such as to produce a low concentration ratio.

Salinas River near Santa Margarita, Los Gatos Creek near Coalinga, Cottonwood Creek near Friant, and Orestimba Creek near Newman show particularly high concentration ratios.

In view of the large number of basins where natural run-off characteristics could not be determined because of regulation, the relations indicated in table 8 , column 4 , are subject to modification on a basis of detalled studies of other floods and through the use of time intervals shorter than 24 hours.

In the area studied, most of the basins with natural flow conditions are small and have relatively little channel storage. Flood run-off appears at the river-measurement stations soon after the time when rainfall Intensity exceeds the infiltration capacity, and crest stages occur almost simultaneously over the individual basins. This is in contrast to many large river systems where wide channels and overflow areas provide channel storage which retards and reduces the flood crest.

In 68 of the 81 basins in table 8 the momentary peak stages were on December 11, and their times were about equally divided between forenoon and afternoon. In nine basins, the peaks were on December 10, seven beIng late in the afternoon or at night. On four streams, the peaks were on December 12. During the late afternoon and night of December 10, there were peak stages in the northern part of the Sacramento River Basin. Durlng the morning of December 11, there were peak stages throughout the northern Slerra Nevadas and areas near San Francisco Bay. In the southern Sierra Nevadas, in general, peak stages were reached during the 
afternoon and evening of December 11. The times of occurrence of the crest, stages may be indicative of the progress of the most intense part of the storm, when allowance is made for the elapsed time between the falling of the rain and its observed appearance as run-off. It should not be overlooked that because of antecedent precipitation, there would be a tendency for the run-off to be earlier in the northern part of the area than in the southern part, and this may be reflected in the later occurrence of peak stages in much of the San Joaquin River Basin. At many of the stations there were two peaks, but generally the second peak reached the higher stage. With time of occurrence of the maximum peak stages so nearly simultaneous, no correlation with basin characteristics has been attempted.

\section{Characteristics of peak discharge}

In connection with the study of the magnitude and frequency of floods In the United States, the Advisory Committee on Flood Protection Data, appointed by the American Society of Civil Engineers, suggested that significant and valuable information would be developed by investigating the magnitude of the maximum 24-hour flows, independent of coincidence with the calendar day, and by determining the relation between the maximum 24-hour flow and the momentary peak discharge. In that study 690

flood events were tabulated, but the data did not respond to general analysis. Nevertheless, it was suggested that "not only the seasonal influence but also the wide varlety of soll molsture, directions of storm movement, duration and distribution of rainfali on a given river system, influence of thaws, and shape of drainage basin may be reflected in the relative values". 12/

The influences upon the shape of the flood crest, as outlined above, may be classifled as follows: first, those that relate to the particular meteorologic and hydrologic conditions attending a specific storm, and second, those that are peculiar to each basin.

In table 4 (see pp. 288-298) there are given in second-feet the momentary peak discharge and the maximum 24-hour average discharge, independent of the calendar day. In table 8, column 6, (see pp. 321-324) is shown the ratio between momentary peak discharge and the maximum 24hour average discharge for 81 unregulated streams. These ratios range

11/ Jarvis, C. S., and others, Floods in the United States magnitude and frequency: 'U. S. Geol. Survey Water-Supply Paper 771, 1936. 
all the way from 105 percent for Indian Creek at Crescent Mills, in the Feather River Basin, influenced by channel storage, to 409 percent for Bear Creek near Planada with little, if any, channel storage. Ten basins had ratios of less than 125 percent, and 20 basins had ratios exceeding 200 percent. The largest grouping had ratios between 125 and 200 percent. As between basins where the discharge for the 24 hours of greatest flow was only slightly less than the momentary peak discharge and basins where the momentary peak discharge was between two and three times greater than the maximum 24-hour average discharge, differences in basin characteristics are, in general, pronounced. Among the large number of basins where the momentary peak was from 125 to 200 percent of the maximum 24-hour average discharge, correlation with basin characteristics is difficult. Snow was involved in many of the basins that fall in this grouping, and delayed run-off therefrom probably had an effect on the ratio. In general, low ratios prevail in those basins in which there were known to be large amounts of channel storage, and storage in swamps and lakes, or where lava is present as in the Feather, Klamath, and Pit River Basins. High ratios are indicated in much of the semi-arid and foothill areas where flash floods of short duration follow closely periods of heavy rainfall intensity, with little flow prior to the beginning of the sharp flood rise and rapid recession following the peak.

The range in amount of total direct mu-off from unregulated streams is from 0.05 inch on Cotionwood Creek to 12.5 inches on Grizzly Creek. Cottonwood Creek is a small tributary of the San Joaquin River lylng wholly in the low foothill area where precipitation was light, the antecedent period was dry, and the absorptive capacity of a large part of the basin was probably not reached. Grizzly Creek is a high Sierra basin in a region where the rainfall was heavy, the antecedent period was wet, and the run-off was augmented by the melting of snow which was already on the ground at the beginning of the storm.

The total direct run-off for each of the river-measurement stations listed in table 7 (see pp. 311-316) has been plotted, as shown In figure 45 (see p. 319), and the scattered points are evidence of the great variety of conditions that were in effect on the different stream basins. Cottonwood Creek and Grizzly Creek, cited in the preceding paragraph, represent opposite extremes. It should also be kept in mind that Cottonwood Creek and Grizzly Creek Basins are sufficiently small and compact to be subject to practically unfform conditions over their $1603120-39-23$ 
respective areas. On the contrary, most of the basins, as mentioned elsewhere in this report, are subject to great variations in altitude, preclpitation, temperature, cover, gradient, and soll, so that run-off is the resultant of many variable influences.

As also stated previously, analyses of the run-off of major floods In the central and eastern parts of the United States Indicate that the direct run-off of such floods has rarely exceeded 10 inches, and has generally been between 8 and 10 inches. Figure 45 seems to indicate that for the floods here studied many of the results conform more or less closely to these limits.

The method of plotting results used in figure 45 disregards basin dfferences and, like some other studies in this report, produces results that have a composite character. The method has the advantage of showing actual and natural behavior of stream flow. It may be that detalled analysis of the long-time rainfall and run-off records by large and small basins will show run-off characteristics more comprehensively, and perhaps more accurately for extensive areas, than can be shown by the synthetic development of ralnfall-run-off experfences on relatively small experimental areas:

\section{Basin characteristics}

In this section neighboring stream basins have been grouped for convenience in description and in discussion of rainfall and run-off. The grouping, and the order of discussion, are not exactly the same as used in the annual water-supply papers of the Geological survey but are most suitable to a study of the hydrology associated with the storm of December 1937.

The word "basin" is used at many places in this report to refer to the area upstream from the gaging station at which the run-off is measured. Therefore, under this usage the reference is to the entire basin of any given stream only when the gaging station is located near the mouth. Few basins in Calffornia are subject to unfform conditions over their whole areas. On the contrary, most basins possess widely varying altitudes and stream gradients, and cross different zones of precipitation, temperature, cover, and soll, so that the run-off is the resultant of the action of many variable influences.

Key maps (figs. 47 to 70) show the relative location of each group of basins. A brief description is included for each basin for which complete run-off data are avallable in order to give the reader a general 
idea of the shape, size, altitude, slope, and geologic formation. Basins for which run-off data are incomplete are not described. It is recognized that the nature and extent of forest and other vegetative cover is one factor in the relation between rainfall and run-off. As the stream basins show great variation in this feature it is considered beyond the scope of this report to describe cover conditions $13 /$ in the individual basins or to make a study of the probable effect upon mu-off.

Streams in the area covered by this report may bo classified approximately into four groups in accordance with different hydrologic characteristics. Such a classification can be of only the most general nature because, as explained previously, most California streams and their drainage basins are subject to great variations in climate, topography, and geology. The examples given are considered typical. Many streams contain characteristics of two or more groups and no attempt has been made to put every stream arbitrarily into some group.

\section{High sierra type}

A stream may be sald to have characteristics of a "typical High Sierra stream" when it has its source in long-lived or perpetual snow banks, or glaciers, near the crest of the Sierra Nevada, and when a large proportion of the precipitation over its basin accumulates in the form of snow. As a result it will be a perennial stream even though its lower reaches may be in foothill or valiey areas that receive no rain from May to october. Its run-off will depend to a large extent upon the depth and water content of the snow pack and upon the rapidity with which the snow melts.

The discharge hydrograph will be characterized by a diurnal fluctuation that will make periodic appearances in March and will usually become continuous in April. The diurnal variation will increase in amplitude until the peak of the snow run-off is reached in late May or June. At that time the discharge corresponding to the warmest part of the day may bs two or three times the discharge at the low point corresponding to the night period when the least melting occurs. After that time the fluctuation gradually decreases.

A typical High sierra stream may be subject to flood run-off at any time from November to June, owing to storms such as those of Mareh 1928 or December 193\%. Occasionally summer thunder storms, which are 
common to the High Sierra from June to August, will cover sufficient area and be of long enough duration to cause a very large peak discharge on one or more tributaries. In discussing and comparing discharge and runoff from High Sierra streamg it is important to know the distribution of the drainage area upstream from the river-measurement station with respect to altitude. A tributary that has a basin wholly above 7,000 feet will obviously have a different type of discharge than the main stream which is normally measured at the base of the foothills. The maximum 24-hour average discharge for the tributary would occur during the time of greatest snow run-off. That for the main stream would more 1ikely be due to heavy rainfall plus snow melt at lower altitudes.

When rivers such as the San Joaquin are classified as High Sierra streams it is understood that they are considered from a point upstream from man-made works that may change their nature.

Rivers that may be considered to belong to the High sierra group are the Kaweah, Kings, San Joaquin, Merced, Tuolumne, Stanislaus, Mokelumne, American, and probably the Feather and Yuba. The Kern River at the extreme south end of the sierras has distinctive characteristics but is.also one of this group. On the east side of the Sierra Nevada, the group includes such rivers as the Truckee, Carson, Walker, and Owens, although they are in a region of much less precipitation than the rivers on the west side. Headwater tributaries of all the streams named would also belong to the group.

Midslope type

Streams of this type are those that head moderately high in the Sierra Nevada, but whose basins have relatively small percentages of their areas at high altitudes and therefore do not accumulate a snow pack that lasts until summer. They may show very large daily fluctuations during April and May when the snow at lower elevations is melting fast.

Streams in this group would ordinarily have both their highest momentary peaks and maximum 24-hour average discharge caused by heavy rain storms augmented by some melting snow. Their summer flow may be very low and may even become zero in the lower reaches during a dry season.

Streanis that may be considered to belong to this group are the Tule, South Fork of the Tule, Fresno, Cosumnes, North Fork of the Cosumnes, West Branch of the Feather, and Bear Rivers, also Plum, 
Alder, and Spanish Creeks. Mill Creek and Deer Creek (near Vina) come nearer to this type than to any other, although they are at the north end of the Sierra Nevada and their summer flow is relatively large owing to perennial springs and underground storage in lava fields.

Foothill type

In this group are streams that are usually torrential in character and intermittent and that depend almost entirely on rain for their munoff. Their basins are in semi-arid regions on which no rain may fall from May to October, or even for longer periods, and the streams may have no surface flow for many months in some years. The slopes of the basins are flatter than those in the preceding groups, and run-off is largely dependent upon the absorptive condition of the soll of the basin, which in turn may be determined largely by the amount of recent antecedent rainfall.

Streams of this type are: the Salinas River and its tributaries, Uvas Creek, Los Gatos Creek (near Coalinga), Fine Gold Creek, the Chowchilla River, Orestimba Creek, Woods Creek, Cosgrove Creek, Sutter Creek, Elder Creek, North Fork of Cache Creek, Putah Creek, and Conn Creek.

\section{Miscellaneous group}

The fourth group, denoted the miscellaneous group, is not marked by common characteristics, to any great extent, but constitutes a classification for streams that fall outside the preceding three groups. It includes streams that originate around Mount Shasta or in the Siskiyou and Klamath mountains and in the Coast Ranges between the Smith River on the north and San Francisco Bay on the south. The Trinity and Salmon Rivers, in that area, have many characteristics of the High Sierra type but are in a region of considerably greater rainfall.

The fourth group also includes the short coastal streams south of San Francisco Bay, originating on the westernmost slope of the Coast Ranges. San Lorenzo River (Santa Cruz County) is the only one in that area discussed in this report. 


\section{Southern Pacific basins}

Topographically the Salinas Basin is a long narrow valley (fig. 47), walled in by steep mountain slopes which have been greatly eroded and

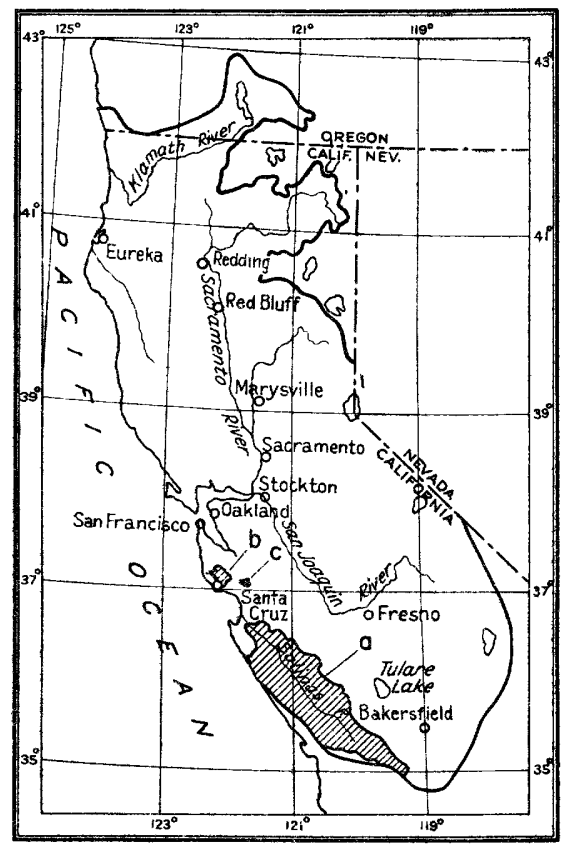

Figure 47.--Key map showing location of southern Pacific basins:

(a) Salinas River, (b) San Lorenzo River, (c) Uvas Creek. dissected by stream action. There is a broad mesa or elevated plain along the southeast side. The crests of the encircling mountains range in altitude from 2,500 to 4,000 feet above sea level.

The Salinas River flows about 150 miles northwestward and for most of the distance is in a broad, flat, alluvial valley. Most of the water comes from the Arroyo Seco and the San Antonio and Nacimiento Rivers, on the west. San Lorenzo Creek and the Estrella River, on the east, are intermittent streams that carry extremely heavy loads of sediments during flashy floods. Soda Lake Basin does not drain

Into the Salinas River. The base gaging station is near Spreckels, a few miles upstream from the mouth, at an altitude of about 50 feet above sea level.

The Salinas River is of the footh111 type of stream, as described in the introduction to this section.

The basin is composed of a wide variety of granitic and sedimentary rocks. Except in the headwater area the bed of the valley is alluvium.

Uvas Creek, in the Pajaro Basin, rises on the south side of Loma Prieta Mountain (altitude, 3,800 feet), flows southeastward, and drops in about 10 miles to an altitude of 390 feet at the gaging station. The basin is about one and a half times as long as it is wide and is underlain largely by sandstone, chert, limestone, and serpentine. Uvas Creek is a foothill type of stream. 
The San Lorenzo River drains a coastal basin about 16 miles long by 8 miles wide, has several large tributaries, is bounded on the west and east by ranges about 2,000 feet high, and flows in a southerly direction through a steep canyon. The basin is underlain by a mixture of greatly shattered sedimentary and granitic formations. The river flows parallel to a fault line. The gaging station is at an altitude of 150 feet. This stream is classified in the miscellaneous group. It is a perennial stream and is in a region of heavier precipitation than the foothill type. Precipitation is always in the form of rain and is at times torrential.

Twenty-nine rainfall stations in the Salinas, San Lorenzo, and Pajaro River Basins and about an equal number in adjacent territory define the lines of equal rainfall with a fair degree of accuracy. The precipitation stations are largely in the valleys, only a few being maintained in the hills where rainfall during the December storm was heaviest. There was no snow on the ground before the storm and no snow fell during it.

The observed mun-off from $a l l$ the basins is essentially natural. Except at the Salinas River near Spreckels, above which there are considerable channel storage, flat slopes, and high absorptive capacity, meteorologic conditions were soon reflected at the gaging stations. The direct run-off, in inches, above the various gaging stations was (table 7, see pp. 311-316) 2.25 for the San Lorenzo River, 8.9 for Uvas Creek, 0.5 for the Salinas River near Santa Margarita, 0.9 for the San Antonio River, 1.75 for Arroyo Seco, and 0.25 for the Salinas River near Spreckels. The run-off was generally less than 0.5 inch over the greater part of the Salinas River Basin.

San Lorenzo River and Uvas Creek Basins received excessive amounts of rain, but from only the Uvas Creek Basin was the flood run-off unusually high.

Indicated residuals between rainfall and run-off range from 2.8 inches in the upper Salinas River Basin to 14.85 inches in the San Lorenzo River Basin. It is probable that in the lower part of the Salinas River Basin there was insufficient rain to utilize or exceed the absorptive capacity of the basin. The ability of the San Lorenzo River Basin to absorb rain during the December storm was apparently very great, as indicated by the large residual.

There are no recording precipitation stations in the southern Paciflc area. However, the river and creek gage-height graphs show that the storm traveled generally in a southeast direction. The 
water-stage recorder graphs for Uvas Creek and San Lorenzo RIver show an inftial peak about $6 \mathrm{a} . \mathrm{m}$. on December 10 and the highest peak about $2 \mathrm{a} \cdot \mathrm{m}$. on December 11. The Arroyo Seco had a large Inflow into the stream channel on December 10 and the highest peak at 8 a.m. on December 11. The San Antonio RIver at Pleytc began to flow about noon on December 10 and reached the peak about $4 \mathrm{p} . \mathrm{m}$. on the following day. The Salinas River near Santa Margarita did not begin to rise unt1l 8 a.m. on December 11 and reached 1 ts peak about $10 \mathrm{p} . \mathrm{m}$. on the same day. The peak did not pass Spreckels until $10 \mathrm{p} \cdot \mathrm{m}$. on December 12.

The ratios of the momentary peak flow to the mean during the 24 hours of highest flow were generally high and ranged from 161 to 192 percent on the smaller basins. On the 4,180 square miles of the Salinas Basin above Spreckels this ratio was only 124 percent. The ratios between the run-off durling the 24 hours of highest flow and the total storm run-off ranged from 40 percent for the Sallnas Basin as a whole to 90 percent for the 150 square miles upstream from the gaging station near Santa Margarita.

The momentary peak discharge and the total direct flood run-off of Uvas Creek greatly exceeded those for the previous maximum flood of record on December 27, 1931. Peaks at other river-measurement stations In the southern Paclfic area did not approach record discharges, although the precipitation during the storm of December 1937 was generally as great as or greater than that which occurred during the storms that produced previous maximum peaks of record. However, the previous peaks occurred later in the season when the absorptive capacities were probably much less than at the beginning of the rainy period in December 1937. It appears that if the storm of December 1937 had occurred later In the rainy season, the run-off would have been considerably greater. The precipitation in the storms in January, February, and March 1938 fell upon ground more fully moistened than in December 1937 and, as a consequence, new records for peak discharge and for total direct flood run-off were established for the river-measurement stations on the Salinas River near Santa Margarita and at Spreckels, on the San Antonlo River at Pleyto, and on the San Lorenzo River at Blg Trees. 
Los Gatos Creek Basin (near Coalinga) and Orestimba Creek Basin

Los Gatos and Orestimba Creeks are short, torrential, intermittent streams which drain the eastern slopes of the Coast Ranges and flow out

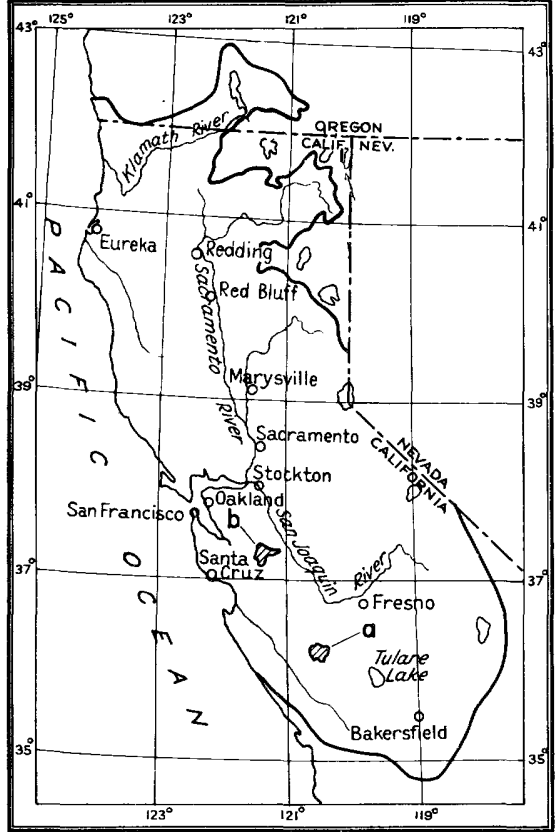

Figure 48.--Key map showing location of (a) Los Gatos Creek Basin

(near Coalinga) and (b) Orestimba creek Basin. onto alluvial fans on the western side of the San Joaquin Valley. Most of the run-off sinks into these fans. These streams are examples of the foothill type. (See fig. 48 for location.)

Los Gatos Creek drains an approximately square area and has three main tributaries that originate on the south slopes of San Benito Mountain. The mountain rises to an altitude of more than 5,000 feet and is composed of serpentine and other intrusive rocks. The three main tributaries of Los Gatos Creek flow through formations of marine sediment for most of the 14 miles above the gaging station,

and drop from altitudes of 3,000, 4,000, and 5,000 feet, respectively, down to an altitude of 1,000 feet at the gaging station.

Orestimba Creek drains a triangular area which is about $18 \mathrm{miles}$ long and which has a watershed line that follows the crest of the Diablo Range for about $15 \mathrm{miles}$. The tributary from the north rises at an altitude of about 3,000 feet and the main tributary from the south rises at an altitude of about 2,000 feet, whereas the gaging station is at an altitude of 190 feet. The headwater area is underlain by sedimentary and metamorphic rocks, the midsection lies in marine sediments, and just upstream from the gaging station the channel is cut in alluvium.

There are no rainfall stations in either basin and the lines representing equal rainfall in these areas are not well defined.

There was no snow on either drainage basin before the storm and none fell during the storm. The observed flow from both streams is not affected by artificial storage. 
The run-off for both streams (see table 7, pp. 311-316) was very small, being only 0.4 inch for Orestimba Creek and 0.15 inch for Los Gatos Creek. These basins are in an area of low precipitation, and the precipitation during the storm was comparatively light. The differences between rainfall and direct run-off were slightly greater than 4 inches in each basin and probably do not reflect their greatest absorptive capacities. The ratios between the momentary peak flow and the average for the 24 hours of highest flow were very high, reaching 388 percent for Los Gatos Creek, indicating a type of flashy run-off perhaps to be expected from small semi-arid basins where there is no sustained flow. In Orestimba Creek basin the ratio was 171 percent. The ratios between the run-off during the 24 hours of highest flow and the total run-off for the storm were also very high, being 88 and 100 percent on Orestimbs and Los Gatos Creeks, respectively. These ratios were 89 and 87 percent, respectively, before the component figures of the ratios were rounded off to the nearest half-tenth of an inch. Run-off began on both creeks on the morning of December 11 and the peaks were reached about noon on the same day.

The momentary peak discharge on Los Gatos Creek exceeded the previous peak of record but was itself greatly exceeded when the rains of the storm of February 11, 1938, fell upon ground previously moistened.

The highest records on Orestimba Creek both for momentary peak and total direct run-off occurred in connection with the storm of February 8, 1932. Although the storm of 1932 apparently produced less rainfall than that of 1937, the rainfall from the former fell upon more moist ground and possibly was augmented by melting snow in the higher parts of the basin.

\section{Kern River Basin}

The Kern River Basin, the largest stream basin in the Sierra tributary to the San Joaquin Valley, occupies the southeast end of that valley and differs from any of the other tributary basins in that its main axis lies north and south instead of east and west. The basin, which is long and comparatively narrow, lies west of the main sierra divide, but is east of the secondary parallel crest, called the Great Western Divide, which separates this basin from the basins of the Kaweah and Tule Rivers and the southern foothill streams on the west. (See figure 49.) It is separated from the Kings River Basin on the north by a cross range about 15 miles in length, known as the Kings-Kern Divide. The Kern River 
and its main tributary, the South Fork, rise in numerous small glacial lakes at the north end of the basin among very high peaks and flow south-

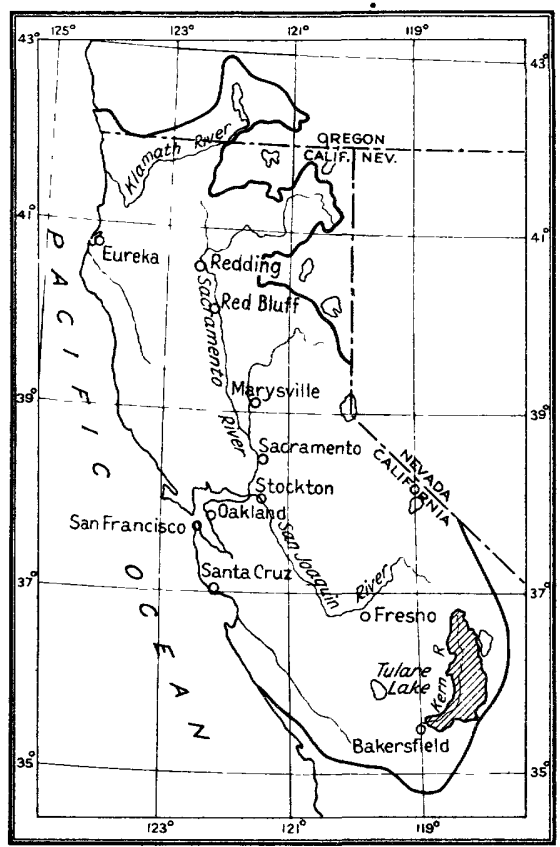

Figure 49.--Key map showing location of Kern River Basin. ward for many miles. About 70 percent of the basin upstream from Bakersfield is at an altitude of more than 5,000 feet. It is a High Sierra river, although in a region of less precipitation than the High Sierra rivers to the north.

The basin of the South Fork of the Kern River upstream from the gaging station near Onyx is about 50 miles long and increases in width southward, from about 6 miles in the headwater area to about 18 miles near the mouth. The headwaters are at an altitude of about 10,500 feet and the gaging station is at 2,900 feet. The basin is charac-

terized by low, flat, and irregular hills, separated by meadows. Granitic rocks are predominant, but there are also limestones, slates, and schists in the basin. Between the upper and lower gaging stations, near onyx and at Isabella, the river flows for 18 miles on alluvilu at flat slopes. In this reach the floods are much affected by channel or ground-water storage. This intermediate area drains granitic rocks but the rainfall is normally low and the contribution to the flow of the river is small. The run-off of the South Fork is much less than that of the main branch, and the peak of the snowmelt normally comes earlier than from the Sierra streams to the north. The part of the basin of the Kern River upstream from the gaging station near Kernville is about 55 miles long and averages about $18 \mathrm{miles}$ in width. From the headwaters in the north, at an altitude of about 13,000 feet, the river flows in an almost straight line southward through a deep canyon, with a steep slope to the gaging station at an altitude of about 3,550 feet. The upper part of the basin is characterized by high glaciated peaks and ridges and by deep 
metamorphic rocks, but the river flows on alluvium for about $10 \mathrm{miles}$ above and below the junction with the South Fork at Isabella. Downstream from Isabella the river again flows through a canyon over granitic rocks, then through marine sediments along the edge of the foothills, and finally through alluvium for the last few miles above the gaging station near Bakersfield, which is at an altitude of about 470 feet.

Lines of equal precipitation in the Kern River Basin have been based on five records in the southern part of the basin and on scattered records in adjoining basins to the east and west, which may not be closely indicative of the precipitation in the headwater areas. As indicated by the isohyetals (see fig. 14, p. 46), the precipitation during the storm period, December 9 to 13, is assumed to have decreased from a total of 12 inches along the upper portions of the higher mountain areas lying between the headwaters of the upper Kern and Kaweah River Basins to about 4 inches along the eastern boundary and to less than 2 inches along the southern part of the basin. There was probably some snow on the ground on December 9 in the headwater areas, but the small total run-off indicates that there was little contribution from melting snow to the flood run-off.

An analysis of the direct run-off, as measured at five places within the basin, indicates that practically all of the stream flow at the gaging station on the Kern River near Bakersfield originated in the area above Kernville and in the South Fork of the Kern River above Onyx. These basins have a combined area of nearly 1,400 square miles, of which 95 percent lies above an altitude of 5,000 feet, 70 percent above 7,000 feet, and 33 percent above 9,000 feet. Based on the isohyetals as drawn, the storm precipitation over the drainage area above Kernville averaged 7.8 inches and above onyx 4.3 inches. The total direct run-off was 0.65 and $0.15 \mathrm{inch}$, respectively. If it is assumed that the area above 9,000 feet did not contribute direct run-off to the stream channels because the precipitation had the form of snow, the total direct run-off from the contributing areas below 9,000 feet was 1.15 inches above Kernville and 0.2 inch above onyx. In the absence of exact information as to the precipitation and run-off for the higher altitudes, it seems reasonable to assume that the representative run-off from the area which actually contributed may lie somewhere between 0.035 and 1.15 inches for the basin above Kernville and 0.15 and 0.2 inch for the basin above Onyx. From a study of differences in the measured stream flow, there was apperently 
The maximum 24-hour direct run-off from the South Fork of the Kern River above Onyx was 0.05 inch, or 33 percent of the total direct runoff. This relatively low ratio may indicate some run-off from melting snow. The ratio between the morentary peak flow and the mean for the 24 hours of highest flow was 124 percent.

The determinations of the magnitude of the precipication seen consistent insofar as rainfall is concerned. There may have been more precipitation in the headwater areas than is shown by the isohyetals, but if so, it apparently was in the form of snow and did not contribute materially to the flood run-off.

The heavy rainfall began to be reflected in the staze of the South Fork of the Kern River near Onyx on the morning of December 10 and high flows continued during all of that day and the next. The first of two small peaks came about midnight of December II, and the second and higher one came about 8 a.m. on December 12 .

None of the momentary peak discharges at the river-measurentent stations on the South Fork of the Kern River and on the Kern River near Kernville approached the highest peaks on record. However, on March 2 , 1938, a new peak of record was established on the South Fork of the Kerm River near onyx. All the peaks of record probably resulted from less total precipitation than in Deceinber 1937, but they occurred later in the rainy season after absorptive capacity of the ground had been considerably utilized. Also run-off from melting snow may have been a large factor associated with some of the storms that brought the record peaks. In these basins, as in many others, the storm of December 1937 undoubtedly would have produced greater peaks and more total run-off if there had been preceding rains to moisten the soil.

Tule and Kaweah River Basins

The Iule River rises at an altitude of about 9,300 feet above sea level near the top of the Great Western Divide, which is a secondary crest rougihly paralleling the crest of the Sierra Nevada. The river flows westward and southwestward, and during flood periods reaches Tulare Lake. (See fig. 50.)

The eastern two-thirds of the basin is an eroded mountain region whose rather steep slopes have been carved by the action of primary and secondary stream systems. The western third is a refion of rounded foothills. Granitic and metamorphic rocks predominate in the basin. 
The basin upstream froin the gaging station (altitude, 580 feet) is approximately triangular in shape, is about $24 \mathrm{miles}$ long, and its water-

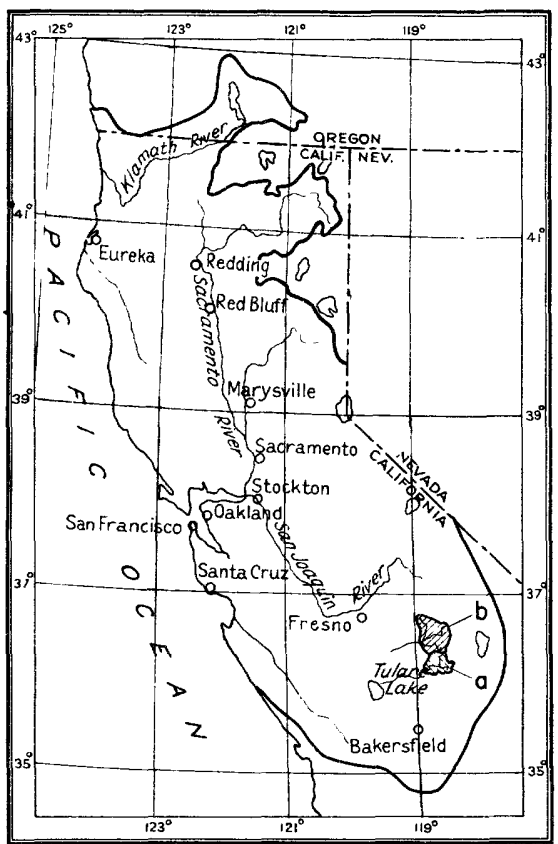

Figure 50.--Key map showing location of (a) Tule and (b) Kaweah River Basins. shed line follows the Sierra crest for 18 miles. About 43 percent of the basin is above an altitude of 5,000 feet. It is classed as a midslope stream. The South Fork of the Tule River is not included in the basin upstream from the gaging station on the main river. The South Fork originates at an altitude of about 8,000 feet and flows generally westward. The gaging station, at an altitude of 750 feet, is about 16 miles from the source and about 5 miles upstream from the junction with the Tule River. About 40 percent of the basin upstream from the gaging station is at an al-

titude of more than 5,000 feet. Both granitic and metamorphic rocks are found in its basin. It is of the midslope type of Sierra Nevada stream.

The Kaweah River rises in Lion Lake, at altitude of 10,900 feet above sea level, and follows a general southwestward course. During flood periods it reaches Tulare Lake through various channels across its ancient delta. The upper parts of the basin are very rugged and contain many domes and ridges, interspersed between upland meadows and small glacial lakes. Granitic rocks predominate in the headwater areas, and there are some limestone and schist in the lower portions. The river and main tributaries have fairly well developed canyons and moderately steep slopes. The basin upstream from the gaging station near Three Rivers (altitude, 620 feet) is about 22 miles long and borders the crest of the Great Western Divide for about 20 miles. The average altitude of the basin is much higher than that of the Tule River Basin, 62 percent of its area being above an altitude of 5,000 feet. The Kaweah River is a typical High sierra river. 
The lines of equal precipitation are fairly well defined by observations in the Tule River Basin, excluding the South Fork, and in the Kaweah River Basin, excluding the North Fork. In the higher parts of the basins the isohyetals are based largely on observations near Springville (14.68 inches; altitude, 4,050 feet), Giant Forest (16.28 inches; altitude, $\dot{6}, 300$ feet), and General Grant National Park (15.10 inches; alt:tude, 6,775 feet). The isohyetals have been constructed on the assumption that these observations indicate the precipitations that may have occurred over relatively small areas and that there was a reduction in the amount of rainfall at higher altitudes.

The observed run-off at all four gaging stations is not affected by artificial storage. The total storm precipitation was in excess of 11 inches in the Kaweah River Basin and it is probable that nearly all of the drainaje area contributed direct run-off during the storm period. The lower parts of the Tule River Basin and the South Fork of the Tule River Basir had less than 5 inches of rainfall and probably contributed but little to the flood run-of'. The direct run-off (table 7, pp. 311-316) from the four areas was 0.35 inch for the South Fork of the Tule, 1.1 inches for the Tule, 1.85 inches for the Kaweah, and 1.6 inches sor the North Fork of the Kaweah River Basins.

On the assumption that there was no direct run-off from the areas above an altitude of 9,000 feet and that there was negligible contribution from those areas in the Tule and South Fork of the Tule River Basins where the precipitation was less then 5 inches, the adjusted direct run-off would be 0.35 inch for the South Fork of the Tule, 1.15 inches for the Tule, 2.15 inches for the Kaweah, and 1.6 inches for the North Fork of the Kaweah River Basins. The differences for those basins between adjusted rainfall and adjusted run-off are 7.45 inches, 9.95 inches, 9.95 inches, and 10.8 inches respectively.

The total direct run-off during the 24 hours of greatest flow ranged from 0.15 inch in the south Fork of the Tule River Basin to 0.95 inch in the Kaweah River Basin and the degree of concentration of run-off, as expressed by the ratio between the maximum 24-hour run-off and the total run-iff during the flood period ranged from 43 percent to 56 percent. The momentary peak discharge was from 2.35 to nearly 3 times greater than the average discharge for the 24 hours of greatest flow. The recording rain gage at Fresno indicated heavy rain during the afternoon of December 9 and a few hours of lighter rain in the forenoon of December 10. Then there was a heavy rain in the forenoon of Decenber 11 
with a maximum intensity about $7 \mathrm{a} \cdot \mathrm{m}$., and a short sharp peak of great intensity between 4 and $5 \mathrm{p} . \mathrm{m}$. on the same day. These periods of high rainfall were reflected in high flow during the whole forenoon of December 10, followed by a recession during the afternoon of that day and the early morning hours of the next day. Then there was a second and higher peak between 4 and $7 \mathrm{p} . \mathrm{m}$. on December 11 at all four stations.

Momentary peak discharges on the Kaweah River near Three Rivers and the North Fork of the Kaweah River at Kaweah in December 1937 exceeded the previous peaks of record on those streams, whereas the momentary peaks on the Tule River near Porterville and on the South Fork of the Tule River near Success did not exceed the highest peaks on record. The total direct run-off for the storm reached a new record only at the gagine station on the Kaweah River.

Kings River Basin

The Kings River has its source in many small glacial lakes at altitudes of 12,000 feet and more, near the crest of the Sierra Nevada. (See figure 51 for location of the basin.) The topography is very rough and irregular, beinz characterized by sharp peaks and ridges, precipitous canyons, and granite domes. Many small lakes and meadows are scattered through the upper part of the basin. The midale portion is the most rugged area in the entire Sierra Nevada. The canyon of the main river below the junction of the Middle and South Forks is more than 5,000 feet deep, and thus is one of the deepest canyons in the continental United States. Nearly all the tributaries also run in deep canyons cut through solid granite, and those on the South Fork and the Middle Fork (Tehipite Valley) are noted for their resemblance to Yosemite valley. The basin is largely underlain by granitic rocks, but a broad belt of metamorphic rocks traverses the area from northwest to southeast, crossing in the vicinity of the junction of the Middle and South Forks. The Kings River is a typical High Sierra river. During flood perlods the river reaches Tulare Lake. The basin upstream from Piedra has a radial distance of about 40 miles to the north and 60 miles to the east. The altitude at this gaging station is about 500 feet, but 71 percent of the basin is above 5,000 feet.

The portion of the basin upstream from the gaging station located on the main stream just above the mouth of the North Fork, is fanshaped with a radial distance of 32 to 40 miles. The gaging station is at an altitude of 1,020 feet, and 89 percent of the basin is above 5,000 
The highest precipitation stations within the Kings River Basin and also the placas where the greatest precipitation was recorded are cliff

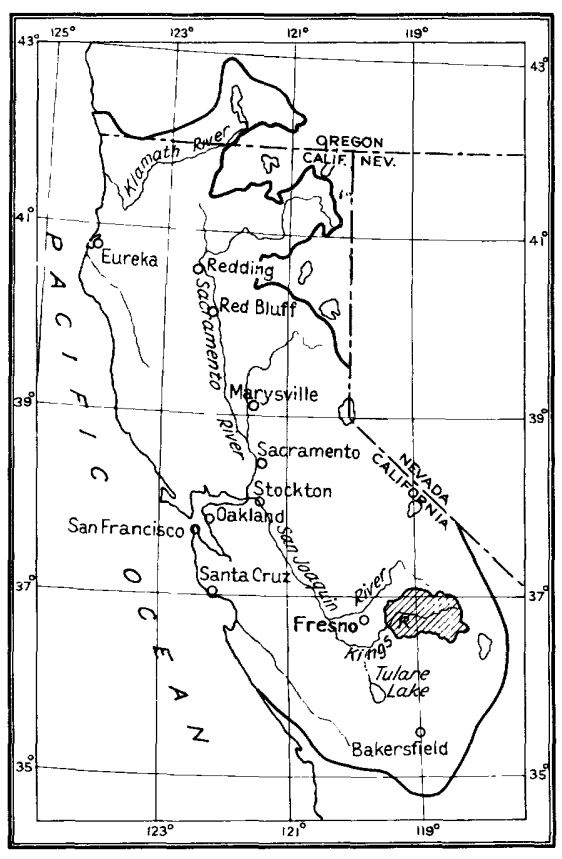

F1gure 51.--Key map showing location of Kings River Basin

Camp (altitude, 6,150 feet) and General Grant National Park (altitude, 6,775 feet) where the total precipitation was 12.19 inches and 15.10 inches, respectively. Half of the Kings River Basin upstream from Pledra lies at an altitude above 7,000 feet and 30 percent lies at an altitude above 9,000 feet. In this large high area between Cliff Camp, General Grant National Park, and the eastern boundary of the basin, there is little, if any, basic information that will definiteIy locate the isohyetals, and the computed precipitation may not be indicative of actual conditions.

No complete record showing the distribution of the precipitation with respect to time is available within the basin. At the experimental station of the United States Forest Service in the Big Creek area near Trimmer, where the total storm precipitation was somewhat more than 12 inches, partial failure of recording apparatus made it impossible to determine accurately the maximum intensities. The partial precipitation record and also the recording graphs of river stages indicate that there were two periods of great rainfall intensity about 12 hours apart, and that probably the period of maximum intensity was during the last storm period, during the morning of December 11. The peak discharge on the King s River at Piedra was reached between 4 and $4: 30 \mathrm{p} \cdot \mathrm{m}$.

River-measurement stations of the San Joaquin Light \& Power Corporation on the North Fork of the Kings River at Cliff Camp and below Rancheria Creek, and on Dinkey Creek did not operate during the entire flood period as a result of fallure of the water-stage recorders caused by over-topping or other difficulties. 
In these areas the storm precipitation may have exceeded the 12 to 14 inches indicated by the isohyetals. As indicated by differences in the flow of the Kings River above the North Fork and at Pledra, the total direct run-off in inches from the intermediate areas of the North Fork, Dinkey Creek, and a small foothill area was about twice that of the Kings River above the mouth of the North Fork.

There is very little artificial storage within the basin and the observed records represent natural flow. The direct run-off (table 7 , pp. 311-316) for the Kings River Basin above the North Fork was 1.1 inches; for the Kings River above Pledra, 1.5 inches; and for the intermediate area, about 2 inches. If 1 t is assumed that there was a negligible contribution to the run-off from areas lying above 9,000 feet, the direct mun-off below 9,000 feet would be 1.95 inches for the area above the North Fork and 2.25 inches for the entire basin above Pledra.

The differences between rainfall and direct run-off are 7.0 inches and 8.2 inches for the Kings River above the North Fork and at Piedra, respectively. These differences do not indicate that there was any material contribution to the run-off from snow on the ground prior to the storm. In fact, the low run-off values, expressed in inches over the area, may indicate an over-estimation of the area that actually contributed flood run-off, and the high residuals may indicate that some of the precipitation fell as snow that did not melt. Assuming no run-off above 9,000 feet, the adjusted average precipitation would be 11.1 and 11.4 inches, the adjusted run-off would be 1.95 and 2.25 inches, and thus the adjusted residual would be 9.15 inches in each instance for the areas on the Kings River above the North Fork and above Piedra. Somewhat more than 60 percent of the total run-off passed the rivermeasurement stations during the 24-hour period of greatest flow. This high ratio signifies that there may have been but little run-off from melting snow during the flood period. The peak discharge of the Kings River above the mouth of the North Fork was 2.41 times the maximum 24hour average and at Piedra 1.82 times the maximum 24-hour average.

Momentary peak discharge and total direct run-off from the Kings River above the North Fork and the Kings River at Pledra exceeded the previous record. At Pledra there was slightly more precipitation in the storm of January 1914 than in December 1937 and it fell on ground previously moistened. However, there was heavy snow at an altitude of about 6,000 feet at the beginning of the storm of 1914, and the snow 
Iine lowered about 2,000 feet in altitude during the storm, making the amount of precipitation available in the form of water approximately equal to that in 1937 .

Upper San Joaquin River Basin

The San Joaquin River rises in the High Sierra south of Yosemite National Park and flows southwestward to the trough of the San Joaquin Valley, whence it takes a northwestward course to its mouth. (See figure 52.) Near the headwaters numerous small glacial lakes and smooth bare domes and ridges bear testimony to the former presence of great glaciers, and near the highest peaks small glaciers still exist. The region between the crest and the edge of the valley is cut into canyons by many long perennial streams. About 68 percent of the area upstream from Skaggs Bridge is above an altitude of 5,000 feet. Downstream from Skaggs Bridge the river becomes a winding stream of flat oradient. Nuch of the area in the lower valley is subject to overflow.

The South Fork of the San Joaquin River, Bear Creek, and Mono Creek all rise in glacial lakelets along the crest of the Sierra Nevada at altitudes of 11,000 to 12,000 feet and flow in a general westerly direction. They are typical High sierra streams. The gaging stations are at altitudes of $7,200,7,400$ and 7,400 feet, respectively. Florence Lake reservoir is on the South Fork, just upstream from the gaging station.

There are metamorphic formations in each basin, but granitic rocks are predominant. Each basin has several small tributaries, but the South Fork has two main branches which unite half-way from the source to the gaging station.

Big Creek and Pitman Creek rise at altitudes between 9,000 and 10,000 feet, and flow in a general westerly direction among granitic rocks. The gaging stations are at altitudes of 6,600 and 7,100 feet, respectively. They are small High Sierra streams. Huntington Lake reservoir is in the Big Creek Basin.

The basin of the North Fork of Willow Creek, upstream from the gaging station below Crane Valley Reservoir, is approximately rectangular in shape and extends about 12 miles north and south and about 5 miles east and west. Granitic rocks predominate in the basin, but quartzite, limestone, slate, and schist are found around Crane Valley Reservoir. The longer of the two main branches rises at an altitude of about 8,000 feet. The run-off is measured at an altitude of about 2,900 feet. 
The two upper branches of Fine Gold Creek rise at an altitude of about 4,000 feet and flow in a general southerly direction. The gaging

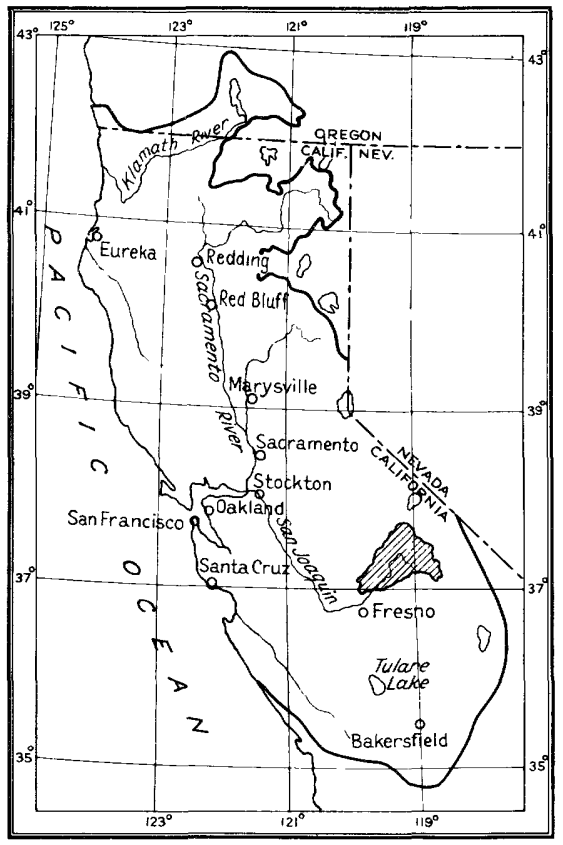

Figure 52.--Key map showing location of upper San Joaquin River Basin. station is at an altitude of about 680 feet. It is a typical foothill stream. Formations are similar to those in the Willow Creek Basin and granite predominates. Big Sandy, Cottonwood, and Little Dry Creeks have small basins tributary to the San Joaquin River in the vicinity of Friant. They may be considered foothill streams. Cottonwood and Little Dry Creeks rise at altitudes between 1,000 and 2,000 feet, and each drops to about 360 feet at the gaging stations, whereas Big Sandy Creek rises at about 4,000 feet and drops to 1,300 feet at the gaging

station. Granite predominates in all three basins.

The San Joaquin River Basin upstream from the gaging station near Friant, which contains all the previously mentioned basins, is shaped approximately like an equilateral triangle, about 55 miles on a side, with one side following the crest of the Sierra Nevada. The intermediate area not included in previously mentioned basins is underlain by granitic and volcanic rocks. The gaging station near friant is at an altitude of 315 feet. Four large reservoirs - Florence, Huntington, and Shaver Lakes, and Crane Valley Reservoir - are in the basin upstream from Friant. Between the gaging stations near Friant and at Skaggs Bridge the San Joaquin River flows over sedimentary rock formations for about 10 miles and over alluvium on the valley floor for about 20 miles.

The San Joaquin River, considered as a whole from any point upstream from Skaggs Bridge, clearly falls into the class of High Sierra rivers. Downstream from that point its nature is changed by works of man.

There are 15 precipitation records in the San Joaquin Basin upstream 
the area, and here the lines of equal rainfall are well defined. The only precipitation stations at notably high altitudes are those at Florence Lake (altitude, 7,400 feet) and Huntington Lake (altitude, 7,000 feet). There are also records at an altitude of about 5,400 feet at Shaver Lake and Central Camp. There are no precipitation data in areas with altitudes above 9,000 feet. Such areas comprise 42 percent of the drainage area of the San Joaquin River above Big Creek and about 80 percent of the drainage area above the river-measurement stations on Bear Creek, Mono Creek, and the South Fork of the San Joaquin River near Florence Lake. Records at Bishop Creek, Lake Sabrina, South Lake, Gem Lake, and Ellery Lake are of considerable aid, although they are on the eastern slope of the Sierra Nevada. In the high altitudes and in the northwest two-thirds of the basin the lines of equal rainfall are poorly defined.

Prior to the storm in December there was no snow on the ground at Huntington Lake or Florence Lake, but there was 12 inches of snow at Kaiser Pass (altitude, 9,300 feet) on November 30, some of which probably diseppeared by December 9. At the beginning of the storm there was no snow on the eastern slope of the Sierra Nevada at South Lake (alt1tude, 9,620 feet), Lake Sabrina (altitude, 9,100 feet), Bishop Creek (altitude, 8,390 feet), and Gem Lake (altitude, 9,120 feet). As nearly as can be determined, all the precipitation was in the form of rain on December 9, 10, and 11 up to an altitude of 8,500 feet, a mixture of rain and snow between altitudes of 8,500 and 9,000 feet, and mostly snow above an altitude of 9,000 feet. On December 12, the last day of the storm, an inch of snow fell at Huntington Lake, and $5 \frac{1}{2}$ inches of wet snow fell at Florence Lake. There was probably an accumulation of snow at Kalser Pass during the storm, as 19 inches remained on December 19. On the eastern slope of the Sierra Nevada, at South Lake 6 inches of snow fell on December 10, 5 inches on the 11th, and 5 inches on the 12th; at Lake Sabrina half an inch fell on the $9 \mathrm{th}, 2$ inches on the 11th, and 6 inches on the 12th; at Bishop Creek, 2 inches fell on the 11 th, and 1 inch on the 12th; at Gem Lake, 7 inches were on the ground on December 12. All this snow was very wet.

The observed run-off of Bear, Mono, Pitman, and Fine Gold Creeks is unregulated. The run-off of the South Fork of the San Josquin River near Florence Lake and the San Joaquin above Big Creek is affected by artificial storage in Florence Lake and by diversion to Ward tunnel. This storage and diversion amounted during the flood period to 1.15 
inches over the basin of the South Fork of the San Joaquin above the gaging station near Florence Lake and 0.2 inch over the basin of San Joaquin above Big Creek. The mun-off of Big Creek below Huntington Lake was affected by storage in Huntington Lake and diversion into and out of the basin. The net total of this storage and diversion amounted to 3.05 inches. The run-off of the North Fork of Willow Creek at Crane Valley Reservoir was affected by storage in the reservolr and by some diversions, all of which amounted to 3.0 inches. The run-off of the San Joaquin River near Friant was affected by storage in Florence Lake, Shaver Lake, Huntington Lake, and Crane Valley Reservoir, amounting to 0.25 inch over the drainage area. The observed run-off from the abovementioned basins has been adjusted on the basis of changes of storage in the reservoirs to show natural mun-off. (See table 7, cols. 4, 5.)

The adjusted total run-off, in inches, from the drainage areas upstream from the gaging stations on the San Joaquin River above Big Creek, Mono Creek, Bear Creek, and the South Fork of the San Joaquin River near Florence Lake were $2.05,0.40,0.45$, and 1.15 inches, respectively. If It is assumed that the area above an altitude of 9,000 feet did not contribute to the stream flow, the run-off, in inches, from the areas below 9,000 feet would be $3.55,1.6,2.35$ and 6.45 inches, respectively. These latter figures are more consistent and are believed to represent more nearly the conditions existing during the storm.

The differences between rainfall and run-off range from 5.6 and 5.85 inches on Mono and Bear Creeks to 10.35 and 12.5 inches on Pitman Creek and the North Fork of Willow Creek. On the assumption that there was no run-off above 9,000 feet, the residuals for Mono and Bear Creeks are about 5.0 and 4.2 inches respectively. The residuals for the North Fork of Willow Creek and for Pltman Creek appear to be large. However, there was a residual of 7.35 inches for the Fine Gold Creek Basin where the precipitation was less than that in either the Willow or the Pitman Creek Basin by more than 4 inches.

There are four recording rain gages in the basin above Friant one each at $0^{\prime} \mathrm{Neals}$ and at Bass Lake and two at North Fork. All of them indicated (fig. 27, p. 62) continous rainfall of high intensity during the afternoon and evening of December 9 and the morning of the 10th. There was one peak in the rainfall rates just before midnight, and another about $4 \mathrm{a} . \mathrm{m}$. on the $10 \mathrm{th}$. This heavy rain produced moderate rises on the San Joaquin River above Big Creek and on Fine Gold Creek. Bear, Mono, and Pltman Creeks rose only slightly. There was another 
rainfall of short duration but of the highest recorded intensity between 2 and $3 \mathrm{p} . \mathrm{m}$. on the 11 th. P1tman Creek reached 1 ts highest stage at noon on the 11 th, and the San Joaquin River above Big Creek and Fine Gold Creek reached their maximum stages at 4 and 6 p.m., respectively, on December 11. Bear and Mono Creeks were highest in the aftemoon of December 11, but they did not reach extreme stages. The snow cover at these high altitudes was apparently heavy enough so that it absorbed most of the precipitation that fell as rain. The ratios between the run-off during the 24 hours of highest flow and the total mun-off for the storm are $33,25,68$, and 71 percent for Bear, Mono, Pitman, and Fine Golc Creeks, respectively. The low ratios for Bear and Mono Creeks probably indicate the influence of snow in the basins. Ratios between the rates of flow at the momentary peak and for the 24 hours of highest flow are $247,180,243$, and 272 percent, respectively, for the same streams.

The momentary peak and total direct mun-off for Pitman Creek greatIy exceeded the previous records, but subsequent highest peaks of record were established on Fine Gold Creek and Mono Creek in 1938. The peak on Pitman Creek on May 13, 1937, and the peaks on Mono Creek in 1927 and 1938 resulted from melting snow and not from direct precipitation.

Fresno and Chowchilla River, Mariposa and Bear Creek Basins

The Fresno and the Chowchilla Rivers and Mariposa and Bear Creeks all rise among foothills or low mountains, part way up the western slope of the Sierra Nevada, and flow southwestward. (See fig. 53.) The Fresro River belongs to the midslope type of Sierra streams. The others belong to the foothili group.

One branch of the Fresno River rises at an altitude of about 8,000 feet and the other at about 6,000 feet. Both flow in a general southwesterly direction half-way to the gaging station, then unite and flow southward. The gaging station near Knowles is at an altitude of about 1,140 feet. Only a few square miles of the drainage area are at an altitude of more than 5,000 feet. The basin is about 18 miles long, 12 miles wide in the middle, and 6 miles wide at the upper and lower ends. Granitic rocks predominate, but limestone, slate, and schist are in the area. The drainage area between the gaging stations near knowles and near Daulton is about 20 miles long and 6 miles wide, although the airlines distance between the stations is only about 12 miles. The altitude of the lower gaging station is about 390 feet. The rocks in this 
The five branches of the Chowchilla River rise at altitudes ranging from 2,000 to 4,000 feet, and the gaging station is at an altitude of

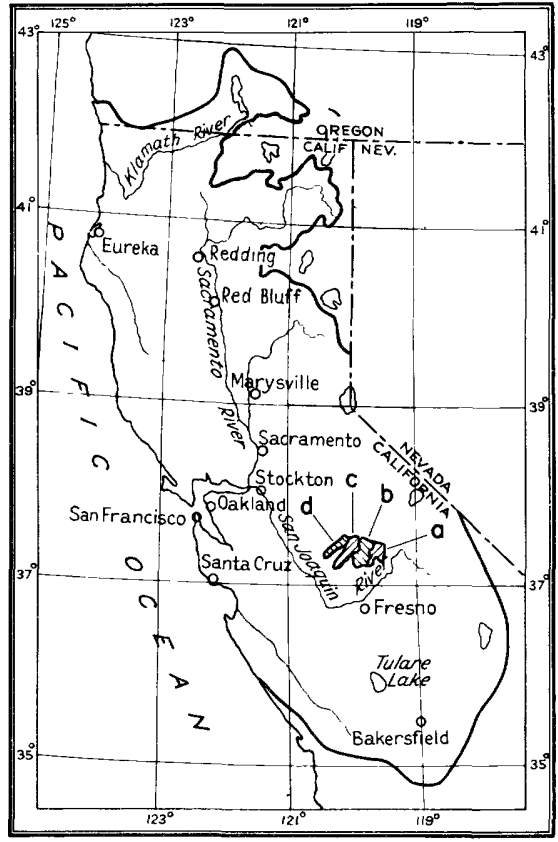

Figure 53.-- Key map showing location of (a) Fresno River, (b) Chowchilla River, (c) Mariposa Creek, and (d) Bear Creek Basins. about 390 feet. The length of the basin is about 24 miles to the gaging station, and the width is 10 to 12 miles. The geologic formations are similar to those in the Fresno River Basin, but the lower end of the stream above the station flows through slate formations.

Mariposa and Bear Creeks rise at an altitude of about 2,000 feet and flow in a general southwesterly direction. The gaging stations are on the floor of the San Joaquin Valley. Mariposa Creek Basin, upstream from the gaging station, is about 24 miles long and 2 to 8 miles wide, whereas Bear Creek Basin is about 20 miles long and 10 miles wide. Both basins contain granitic rocks and a variety of metamorphic rocks, but Mariposa Creek flows among non-marine sediments for several miles upstream from the gaging station, whereas for the lower 5 miles Bear Creek flows over alluvium.

Although there are no precipitation stations in the Fresno or Chowchilla River Basins and only one each in the Mariposa and Bear Creek Basins, it is belleved that precipitation records in adjacent basins may be fairly indicative of precipitation within the four basins mentioned. There was no snow in these drainage areas during the storm period.

The total precipitation over the areas ranged from 2.5 to 14 inches. The precipitstion record at the San Joaquin Experimental Station of the United States Forest Service near O'Neals (fig. 27, p. 62) should be fairly indicative of the distribution of the storm rainfall with respect to time in the headwater areas. At o'Neals the precipitation fell in two principal storms, lasting from noon December 9 to about 7 a.m. December 10 and from $6 \mathrm{p.m}$. December 10 to $8 \mathrm{p} \cdot \mathrm{m}$. December 11 , with 
maximum intensities during the aftermoon of December 11. The maximum stage was recorded on December 11 at $2 \mathrm{p} . \mathrm{m}$. at the Mariposa Creek gaging station, at 4 p.m. at the Fresno and Chowchilla Rivers gaging stations, and at $6 \mathrm{p.m}$. at the Bear Creek gaging station.

The total direct surface run-off from these basins was very small in comparison with other basins herein considered, being 0.75 inch from the Fresno River near Knowles, 0.65 from the Chowchlila River, 0.4 Inch from Marlposa Creek, and 0.45 inch from Bear Creek. The difference between ralnfall and mun-off, assuming that all of the dralnage area was contributing, was 10.25 inches in the Fresno and 7.05 inches in the Chowchilla River Basins, 5.1 inches in the Marlposa and 3.35 inches in the Bear Creek Basins. The low residual in the Chowchllia River, Marlposa Creek, and Bear Creek Basins probably Indicates that there was an amount of rain insufficient to utilize all their absorptive capacity. Assuming that there was run-off only from areas having total storm precipitation of more than 5 inches, the mean preclpitation on such areas would be 8.35 Inches for the Chowchilla River, 7.1 1nches on Mariposa Creek, and 5.95 inches on Bear Creek. The mun-off adjusted for corresponding areas would be $0.8,0.75$, and 2.3 inches, and the corresponding residuals would be $7.55,6.35$, and 3.65 Inches, respectively. Examination of these figures suggests that the indicated precipitation on Bear Creek Basin may be lower than the actual and that the area above the 5-inch isohyetal should be larger.

There is no material storage in these basins and the observed flow at the river-measurement stations represents natural mun-offo The maximum run-off durling a 24-hour perlod was 0.451 nch for the Fresno and 0.4 Inch for the Chowchilla River, 0.3 inch for Mariposa and 0.35 Inch for Bear Creek. These run-offs represent about 61 percent of the total runoff from the Fresno and Chowchilla River Basins and about 76 percent of the total run-off from Mariposa and Bear Creek Basins. Ratios between the momentary peak discharge and the maximum 24-hour averages are 208, 272,345 , and 409 percent for the Fresno and Chowchllia Rivers, and Mariposa and Bear Creeks, respectively.

The momentary peak discharges of the Fresno and Chowchilia Rivers did not equal the previous peaks of record, but new maxima were estab11shed on each in March 1938.

There was much less rain during the storm of March 12, 1938, on the Fresno Basin and slightly less rain during the storm of March 2, 1938, on the Chowchilia Basin than durling the storm of December 1937. However, 
the storm of March 1938 occurred toward the end of the rainy season and there was apparently much less capacity for absorption than during December 1937.

Merced River Basin

The Merced River drains a part of the western slope of the Sierra, but touches the crest of the Sierra only at Mount Lyell (altitude, 13,090 feet) which is common to the upper San Joaquin Basin on the south, the Tuolumne Basin on the north, and the Great Basin on the east. The river has its sources in numerous small glacial lakes at altitudes of 10,000 feet and above. It flows in a general southwesterly course and joins the lower San Joaquin River on the floor of the Great Valley. The mountainous portion of the basin is about 65 miles long and 20 to 25 miles wide. (See fig. 54.)

The outstanding topographic feature is Yosemite Valley, less than a mile wide and about 7 miles long. The almost flat valley floor (altitude, about 3,900 feet) is margined by cliffs that rise almost vertically 2,000 to 3,000 feet. In the upper basin are other smaller valleys, but the surrounding topography is very rough and broken and is characterized by jagged peaks, precipitous walls, and bare granite domes. In parts of the basin there are large areas of massive, ice-smoothed gran1te. Although the percentage of rainfall that muns off from such areas must be high, there is a compensating effect in the talus slopes, mountain meadows, and lakes found nearby.

of the part of the basin upstream from the gaging station at Exchequer, 53 percent is above an altitude of 5,000 feet. The Merced River and its headwater tributaries are typical High Sierra streams.

The basin upstream from Yosemite Valley is underlain almost entirely by granitic rocks. The floor of Yosemite Valley consists of glacial deposits and alluvium. Downstream there is a mixture of granitic, metamorphic, and sedimentary rocks.

Lake McClure, an artificial storage reservoir, occupies the channel of the Merced River for most of the distance between the gaging stations at Kittridge and at Exchequer.

Lines of equal rainfall in the Merced River Basin (fig. 16) are based on observations at Yosemite (altitude, 3,983 feet) with some weight given to the observations at Ellery Lake (altitude, 9,600 feet) and Gem Lake (altitude, 9,120 feet) lying in Mono Lake Basin east of the divide. 
may be considerably in error. In the absence of snow observations, it is assumed that above an altitude of 9,000 feet all of the precipitation

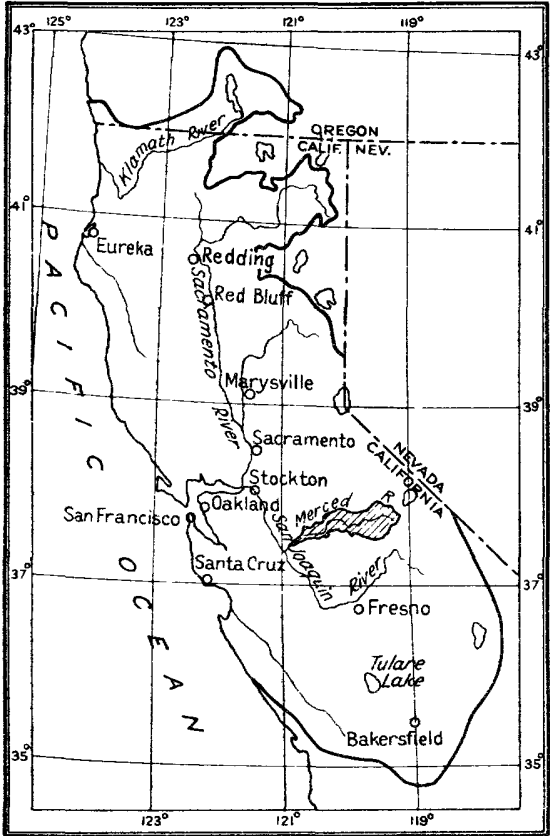

Figure 54.--Key map showing location of Merced River Basin. took the form of snow, and that between 7,500 and 9,000 feet there was snow on the ground prior to the storm period. Some or all of the snow at the lower altitudes probably melted during the flood. The precipitation was partly as snow on December 9 and 12, but largely as rain on December 10 and 11. About 90 percent of the Merced drainage basin above Yosemite lies at an altitude above 7,000 feet, and 10 percent of the area lies above 9,000 feet. The observed flow at the river-measurement stations upstream from Kittridge was essentially natural. Practi-

cally all of the direct mun-off was impounded in Lake Mcclure, downstrear from Kittridge.

Probably somewhat more than 12 inches of precipitation fell over each of the headwater basins. There was, however, considerable variation in the total direct run-off during the flood period expressed in inches over the drainage basins. The indicated amounts (table 7, see pp. 311-316) were 2.0 inches for the Merced River above Happy Isles, 4.95 for Tenaya Creek, 3.55 inches for the Merced River above Pohono Bridge, and about 5.95 inches for the area between Happy Isles Bridge and Pohono Bridge. If 1 is is assumed that the area above an altitude of 9,000 feet was essentially non-contributing, the total direct run-off in Inches for the parts of the basins below 9,000 feet would be 4.2 inches for the Merced River above Happy Isles Bridge, 5.55 Inches for Tenaya Creek Basin, and 5.2 inches for the Merced River above Pohono Bridge. These run-off values are more consistent, although considerably less, than the higher mu-off values indicated in the upper 
Using these adjusted run-off values and revised precipitation over the contributing area, the difference between rainfali and run.off would be about $9.3,7.6$, and 8.3 inches for basins above the Happy Isles Bridge, Pohono Bridge, and Tenaya Creek gaging stations, respectively. These relatively high residuals indicate that there was apparently little contribution to run-off from snow, which may have been on the ground prior to the storm period, and suggests the possibility that part of the indicated precipitation had the form of snow and remained on the ground. Based on differences betweem the stream flow at Pohono Bridge and that at kittridge, the direct run-off for the intervening area was 1.6 inches and the residual 9.85 inches, the results being comparable with those for the adjacent basins of the South and Middie Forks of the Tuolumne River. The maximum peak stages in the headwater areas were between $1: 30$ and $4: 00 \mathrm{p} . \mathrm{m}$. On December 11. On an average, 60 percent of the total mun-off was during the 24-hour period of maximum flow. The instantaneous peak discharge was 50 to 90 percent greater than the mean of the 24-hour maximum discharge, except at Pohono Bridge, where 1t was only 26 percent greater. The latter figure probably reflects the effect of the channel and overflow storage in Yosemite Valley, where about half the valley floor was inundated.

The momentary peak discharges for the flood of December 1937 greatiy exceeded the previous maxima for the Merced River at Happy Isles Bridge, the Merced River at Pohono Bridge, and Tenaya Creek near Yosemite. (See table 9, p. 337.) The total direct run-off for the storm was also greater for the flood in December 1937 than for the previous largest flood on the Merced River at Kittridge and on Tenaya Creek near Yosemite. The total direct run-off for the flood of December 1937 was less than that for the previous high flood for the Merced River at Happy Isles Bridge and Pohono Bridge, but the previous floods at these gaging stations were due mostly to melting snow in May and June.

Tuolumne River Basin

The Tuolumne River has its source in Lyell, Maclure, and other glaciers and in extensive snow fields and snow drifts on the upper portions of the Sierra Nevada. It flows westward through upland meadows and then through a deep canyon nearly 80 miles long cut in solid granite. The upper part of this canyon, 3,000 to 4,000 feet deep, is one of the notable topographic features of the State and is known as the Grand 
Canyon of the Tuolumne. At the lower end of the Grand Canyon is Hetch Hetchy Valley, which is smaller than Yosemite Valley but in every other

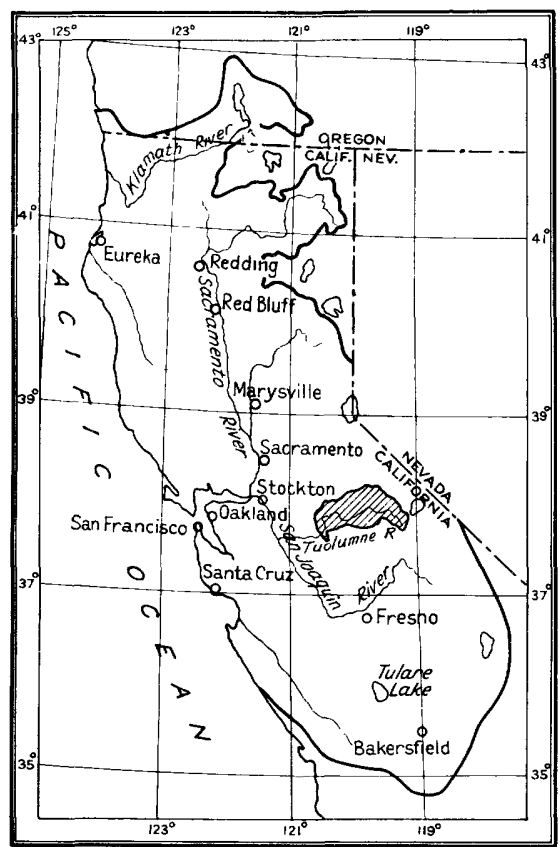

Figure 55.--Key map showing location of Tuolumne River Basin. way greatly resembles 1 . Hetch Hetchy Reservoir now occupies the floor of the valley. Finally the river passes through the lower canyon, through Don Pedro Reservoir, and into the San Joaquin Valley, which it enters near La Grange. (See f1g. 55.)

Typical features of the basin are large areas of bare glaclated granite and rugged domes and cliffs. The granite formation typical of this and many other sierra basins does not necessarily mean that they are lacking in absorptive capacity. Meadows, lakes, and glacial deposits are numerous.

The granite contains many cracks, and many of the cliffs have extensive talus slopes at their feet. Limestone is present in the lower part of the basin.

The Tuolumne River Basin, considered as a whole upstream from the base river-measurement station near La Grange (altitude, 330 feet), is roughly trapezoldal in shape and lies on the western slope of the slerra Nevada. It has a width of more than 40 miles along the crest and a length of about $70 \mathrm{miles}$ from the crest to La Grange. About 59 percent of the area upstream from La Grange is above an altitude of 5,000 feet. The Tuolumne River and its headwater tributaries are typical High Slerra streams.

Cherry Creek and its tributary, Eleanor Creek, are alike in many respects. The Cherry Creek gaging station is upstream from the junction with Eleanor Creek and measures the flow from a basin about 20 miles long, ranging in altitude from 9,500 to 4,800 feet. The Eleanor Creek gaging station is just downstream from Lake Eleanor, and the basin above it is also about $20 \mathrm{miles}$ long and ranges in altitude from 10,000 to 
4,600 feet. The geology of these basins is practically the same as that of the upper Tuolumne River Basin.

The basins of the Middle Tuolumne River and the South Fork of the Tuolumne River, upstream from their respective gaging stations, are about 25 and 20 miles long, and 5 to 6 miles wide at the widest parts. Each stream rises at an altitude of about 8,000 feet and flows westward without important tributaries. Each gaging station is 2,800 feet above sea level. The basins are almost exclusively underlain by granitic rock, but the South Fork flows over metamorphic formations for a few miles upstream from the gaging station. These two streams do not originate at the sierra crest. They are of the midslope type of sierra streams. About two-thirds of the basin areas are over 5,000 feet in altitude and a very small portion is over 7,000 feet.

Woods Creek is a characteristically foothill type of stream with three principal branches. It flows in a generally southerly direction among various formations that include granite and metamorphic rocks. It heads at an altitude of about 2,000 feet and the gaging station is at 645 feet.

The only precipitation observations in the headwater areas are those at Hetch Hetchy (altitude, 3,530 feet) and Lake Eleanor (altitude, 4,600 feet). From 60 to 84 percent of the Tuolumne River, and of Falls, Cherry, and Eleanor Creek Basins upstream from Hetch Hetchy are above an altitude of 7,000 feet, and from 10 to 50 percent of these basins Ile above 9,000 feet.

In view of the scarcity of observations, the lines of equal rainfall In the headwater areas are subject to error.

There was no snow on the ground at Lake Eleanor and at Hetch Hetchy prior to the storm period, and all of the precipitation had the form of rain. It is assumed that precipltation fell as snow above an altitude of 9,000 feet, and as rain and snow between 7,500 and 9,000 feet altitude.

Durlng the flood perlod the observed discharge of Falls Creek, Cherry Creek, the Middle and South Forks of the Tuolumne RIver, and Woods Creek was essentialiy natural. The flow of the Tuolumne River at Hetch Hetchy was materlaliy modifled by storage in Hetch Hetchy Reservolr, amounting to 2.85 inches over the area; of Eleanor Creek by storage in Lake Eleanor, amounting to 5.05 inches; and of the Tuolumne River near La Grange by storage in Don Pedro Reservolr, in addition to that in Hetch Hetchy Reservoir and Lake Eleanor, amounting to a total 
equivalent to 3.0 inches over the drainage area. The natural mun-off for the flood period has been determined by adjusting the observed runoff for changes in storage in the above-mentioned reservoirs.

The adjusted total direct run-off expressed in inches over the drainage areas is (table 7 , pp. $311-316$ ) $3.3,6.75,4.05$, and 9.6 inches for the basins of the Tuolumne River near Hetch Hetchy, Falls Creek, Cherry Creek, and Eleanor Creek upstream from the river-measurement stations. If it is assumed that the run-off from the area above 9,000 feet did not contribute greatly to the stream flow, the flood run-off expressed in inches over the area below 9,000 feet would be 6.3 , $10.7,12.0$, and 10.6 , respective1y.

The indicated differences between rainfall and mu-off for the four upper stations, assuming the entire area was contributing, range from 2.75 to 6.7 inches. On the assumption that there was no material contribution to the stream flow from areas above 9,000 feet, the differ ences range from about 0.3 to 2.3 inches for the basins of Falls, Eleanor, and Cherry Creeks, to 4.8 Inches for the upper Tuolumne River Basin. These values would indicate that there was either a substantial contribution from melt of antecedent snow or more rain than is indicated by the isohyetals. Although some of the headwater areas of the South and Middle Forks are at an altitude of more than $r, 000$ feet and the lines of equal rainfall (fig. 16, p. 48) show about the same total precipitation as for other headwater areas, the total direct run-off is only 1.9 inches for the South Fork of the Tuolumne River and 1.3 inches for the Middle Tuolumne River, with indicated differences between rainfall and run-off of 9.2 and 9.6 inches, respect1vely. These differences compare favorably with those for adjacent arainage areas to the south and indicate considerably less run-off and considerably more difference between rainfall and run-off than for the higher sierra areas. In Woods creek Basin there was probably little direct run-off. In the lower part of the basin, where the precipitation was less than 5 inches, the indicated total direct man-off of 1.0 inch is probably somewhat less than the actual amount from the contributing areas.

There were no recording precipitation stations within the basin, but the graphs of river stages indicate that the precipitation was marked by two storm peaks about 12 hours apart, the period of maximum intensity being probably during the moming of December 11 . In the basins at high altitudes the maximum stages were between 2 and $4 \mathrm{p} . \mathrm{m}$. 
In the Woods Creek area the maximum stage was at 11:30 a.m. In the high basins the maximum peak discharge wss about 50 percent greater than the average for the 24 hours of maximum run-off; in the South Fork and Middle Tuolumne, twice as large; and in the Woods Creek area three times as large. The ratio for Woods creek is typical of that for the lower foothill areas where the precipitation rate materially exceeded the infiltration rate for only a short time, causing high intensity of mun-off for a portion of the 24-hour period of maximum run-off and a relatively low flow for the remainder of that period. From 45 to 71 percent of the total direct run-off was during a 24-hour period.

The momentary peak discharges and total direct storm run-off for Falls Creek, Cherry Creek, the South Fork of the Tuolumne River, and the Middle Tuolumne River greatly exceeded the previous record.

The momentary peak on Woods Creek was only about half the previous peak of record. A new record peak was subsequently established on February 9, 1938, when direct run-off was also much greater and resulted from much more precipitation on wetter ground.

\section{Stanislaus River Basin}

The Stanislaus River drains a basin on the western slope of the Sierra Nevada, which ranges in width from about $20 \mathrm{miles}$ along the crest of the Sierra to 10 miles near the lower end, and is about 55 miles long from the crest to the base gaging station below Melones power house. The river has its source in small glacial lakes at altitudes close to 9,000 feet, in rough and broken country. The three main branches flow southwestward in well developed canyons from 500 to 2,000 feet deep. They are typical High Sierra streams. About 57 percent of the area upstream from the base gaging station (altitude, about 500 feet) is at an altitude of more than 5,000 feet. (See fig. 56.)

The three main branches, referred to gaging stations, are the North Fork of the Stanislaus River near Avery, the Middle Fork of the Stanislaus River at Sand Bar Flat near Avery, and the South Fork of the Stanislaus River below Lyons Dam. The flow of the South Fork was measured also at the dam for Strawberry Reservoir, about 12 miles upstream from Lyons Dam. Granitic rocks and andesite are prevalent in the upper basins, but volcanic formations are also found. The downstream portion of the basin includes similar rocks, and also a variety of metamorphic rocks.

Lines of equal rainfall (fig. 16, p. 48) are fairly well defined 
by precipitation observations in the Stanislaus River Basin except in the headwater areas where the isohyetals are based on observations

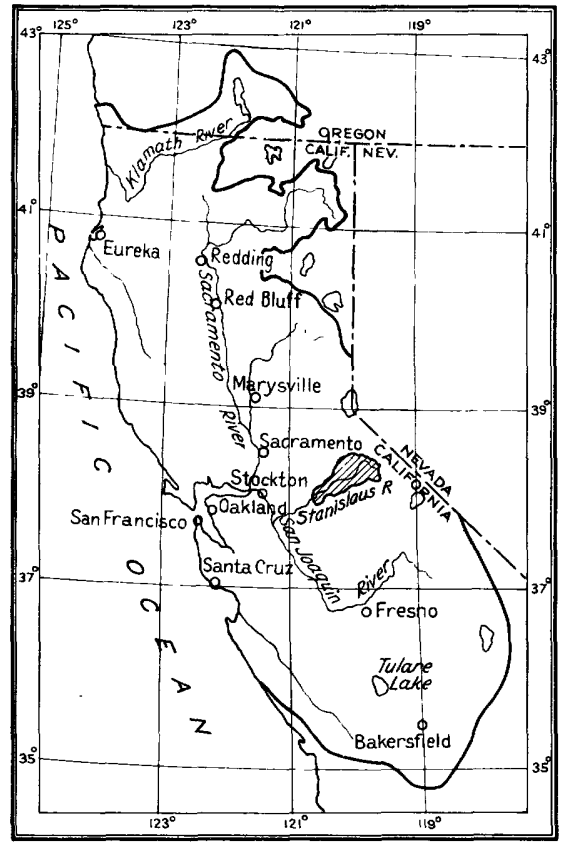

Figure 56.--Key map showing location of Stanislaus River Basin. only at Lake Alpine (altitude, 7,500 feet), Strawberry (alt1tude, 5,720 feet), Spring Gap (altitude, 4,875 feet), and Sand Bar Flat (altitude, 4,875 feet). About 10 percent of the area upstream from Melones is above an altitude of 9,000 feet and 35 percent is above 7,000 feet. Up to an altitude of 5,600 feet there was no snow on the ground at the beginning of the storm, and all of the precipitation on December 9, 10, and 11 had the form of rain, but snow was associated with the rain on December 12.

Above an altitude of 7,500 feet there was considerable snow on the ground, as indicated by the record at Lake Alpine of 13 inches on the ground on November 30. At these altitudes a portion of the precipitation on December 9 and 12 had the form of snow, although it appears that most of the precipitation on December 10 and 11 was rain.

The flow at all the river-measurement stations in the Stanislaus River Basin is modified by storage; that in the Middle Fork Basin by storage in Relief Reservoir, amounting to 0.5 inch over the arainage area; in the North Fork Basin by storage in Union, Silver Valley, Spicer Meadows, and Utica Reservoirs, amounting to 0.95 inch; in the South Fork by Lyons and Strawberry Reservoirs, amounting to 5.2 inches over the area above the lower station; and in the main stream by additional storage in Melones Reservoir for a total retalned storage amounting to 2.4 inches over the drainage area. These estimates of storage have been based on observations at the larger reservoirs, Melones, Lyons, and Strawberry, and on estimated values for Relief Reservoir and all the smaller reservolis, the total capacity of which 
comprises but a small part of the total.

The adjusted direct run-off (table 7, see pp. 311-316) for the Middle Fork of the Stanislaus River Basin above Sand Bar Flat was 4.3 inches, compared to almost 6 inches for the North and South Forks. It is possible that the differences result from inadequate adjustments for storage.

Melting snow may have contributed to the run-off of the Middle and North Forks of the Stanislaus River. The indicated differences between rainfall and run-off of 5.0 inches and 3.8 inches, respectively, would be increased somewhat if the total amount of water available for runoff (rainfall plus water content of the snow cover) were taken into account, making them more in conformity with the 5.45 inches for the South Fork and 6.0 inches for the Stanislaus River Basin as a whole.

Because of the necessary large adjustments for storage, no attempt was made to determine the natural maximum run-off during a 24-hour period or to determine the degree to which the natural run-off was concentrated with respect to time.

Calaveras River Basin

The basin of the Calaveras River upstream from the gaging station at Jenny Lind is about 36 miles long and 16 miles wide at the middle. (See fig. 57.) Only a very small part of the basin is above an altitude of 4,000 feet. There are six branches that rise at altitudes ranging from 3,000 to 5,000 feet along the lower western slope of the Sierra Nevada. The gaging station is at an altitude of about 220 feet. The geologic formations include granitic rocks, andesite, and metamorphic rocks in the headwater regions, and a variety of metamorphic rocks in the lower region. As the headwaters of the Calaveras River do not reach the higher slopes of the Sierra Nevada and as most of the basin is below an altitude of 4,000 feet, snowfall is an unimportant factor and the stream has the hydrologic characteristics of foothill streams.

Cosgrove Creek Basin is a very small area among low foothills and is a part of the Calaveras Basin. The hebdwaters originate at an alt1tude of about 1,200 feet and the gaging station is about 580 feet above sea level. The flow of the stream is very flashy, in common with all foothill streams. The geologic formations are extremely varied and include most of those listed for the Calaveras River, and also some sedimentary rocks. 
All of the Calaveras River drainage basin is at an altitude of less than 5,000 feet. There was apparently no snow on the ground prior to

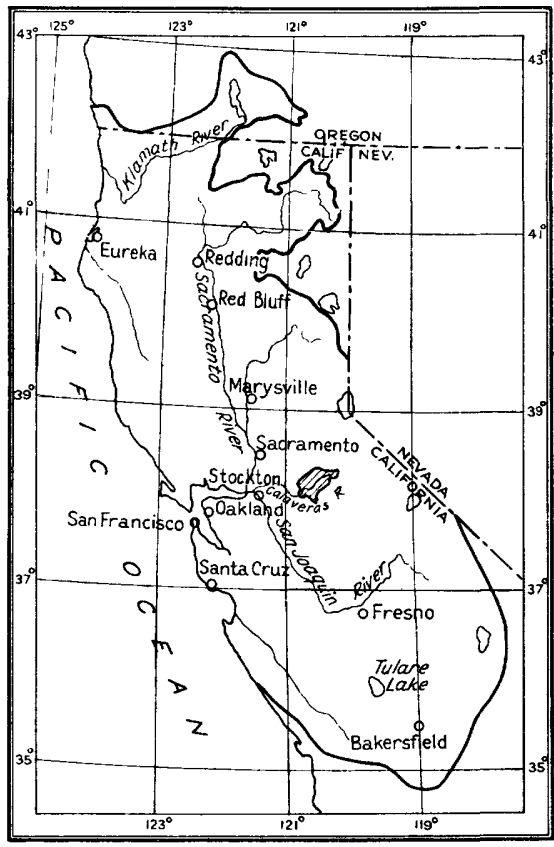

Figure 57.--Key map showing location of Calaveras River Basin. the storm period and all of the precipitation during the storm period had the form of rain. The total precipitation ranged from 9 to 14 inches. As indicated by the recording precipitation gage at Fricot City, the precipitation was nearly continuous from 1 a.m. December 9 to $8 \mathrm{p} . \mathrm{m}$. December 11 followed by showers between $4 \mathrm{a} \cdot \mathrm{m}$. and $8 \mathrm{a} \cdot \mathrm{m}$. December 12. Maximum intensities during the storm were reached early on the morning of December 11 .

At Cosgrove Creek near Valley Springs, where the flow was unaffected by storage but upstream from which the total rainfall was less than 4 inches,

there was no appreciable run-off unt1l morning of December 11 when the creek rose rapidly to its peak stage at 8:15 a.m., about 2 hours after the maximum rain intensity of 0.84 inch per hour at Fricot City and of 0.36 Inch per hour at Fiddletown. The flow of the Calaveras River at Jenny Lind was materially modifled by storage in Hogan Reservoir. Instead of a major peak stage and a large concentration of flow on December 11, the discliarge was spread comparatively uniformly over a period of three days. Little storage was retained in Hogan Reservoir at the end of the flood period, and the total observed direct run-off approximates natural-flow conditions. In Cosgrove Creek Basin, where the flow was not affected by storage, 60 percent of the total direct mun-off was durIng a 24-hour period and the instantaneous peak was 3.79 times the maximum discharge in a 24-hour period.

The indicated difference between rainfall and run-off was 3.35 Inches for the Cosgrove Creek Basin and 5.25 inches for the Calaveras River Basin as a whole. It is evident that, except for a short period during the morning of December 11, the greater part of the precipitation 
in Cosgrove creek Basin fell at intensities very little more than the capacity of the basin to absorb it. A similar condition probably existed in the lower portions of the Calaveras River Basin where the precipitation was less than 5 inches. Assuming no run-off below the 5-inch isohyetal, the precipitation for the net area in the Calaveras River Basin would be 7.55 inches, the adjusted run-off 1.4 inches, and the residual 6.35 inches.

The momentary peak and the total direct run-off for the storm for Cosgrove Creek near Valley Springs did not approach the record for the storm of February 22, 1936. The storm in 1936 produced much greater precipitation in this locality than the storm of December 1937, was more prolonged, and occurred later in the rainy season after other storms had partly utilized the absorptive capacity of the ground. There was no snow in either storm.

Cosumnes River and Sutter Creek Basins

The headwaters of the Cosumnes River rise at altitudes of about 7,000 feet on the western slope of the Slerra Nevada and flow in a westerly direction. The basin upstream from the gaging station (altitude, 190 feet) is about 45 miles long. (See fig. 58.) Only about a sixth of the Cosumnes Basin is above 5,000 feet, and the basin is separated from the crest of the Sierra by the American and Mokelumne Rivers. It is of the midslope type of Sierra Nevada rivers. The basin contains granitic rock, andesite, quartzite, Iimestone, slate, and shale.

The North Fork of the Cosumnes River Basin is simllar to that just described. The basin upstream from the gaging station (altitude, 910 feet) is about 33 miles long.

Sutter Creek is essentally a single stream that rises at an altitude of about 4,000 feet and flows southwestward. The basin upstream from the gaging station (altitude, 1,100 feet) is about 18 miles long, and has the characteristics of a foothill creek. The upper basin contains andesite, and the lower portion is underlain by quartzite, 1imestone, slate, and shale.

In these two basins, which are part of the Mokelumne River Basin, precipitation for the storm is fairly well defined up to 8 or 9 inches by observations within and adjacent to the basins. The nearest recording precipitation gages are at Sacramento and Fiddletown (fig. 26) where the storm perlod extended from about $6 \mathrm{p} . \mathrm{m}$. December 9 to $7 \mathrm{p} . \mathrm{m}$.

December 11, the period of maximum intensity being between 4 and 5 a.m. 
December 11. All of the Sutter Creek drainage basin and 84 percent of the Cosumnes River basin above Michigan Bar are below an altitude of

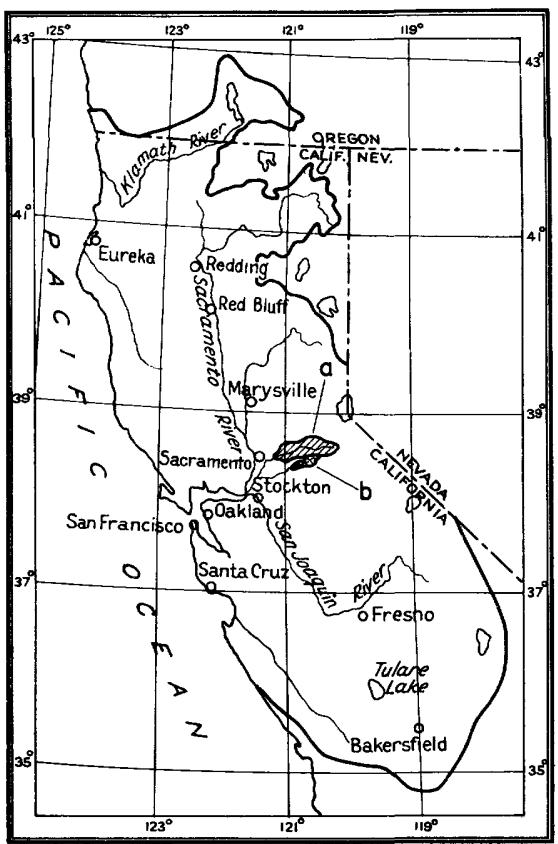

Figure 58.--Key map showing location of (a) Cosumnes River and (b) Sutter Creek Basins.
5,000 feet and 98 percent of the area is below 7,000 feet. Observations indicate that there was probably no snow on the ground prior to the storm period and that practically all of the flood-producing precipitation had the form of rain.

As there is no storage or diversion, the observed streamflow records represent natural flow conditions. Continuous records show pronounced increases in the river stage at noon December 10 and noon December 11 and crest stages between 3 and 4 p.m. December 11, thus reflecting two periods of high intensity in precipitation.

The direct run-off during the flood period was 0.9 inch over the basin of the North Fork of Cosumnes River above El Dorado, 0.7 inch over the area between EI Dorado and Michigan Bar, and 0.8 inch from all the drainage basin above Michigan Bar. The average precipitation over the basin was about 7.0 inches, leaving a difference between rainfall and munoff of 6.2 inches. Of the total direct mun-off about 50 percent flowed past Michigan Bar during the 24-hour period of greatest flow, ending at noon on December 12. The instantaneous peak discharge was about 50 percent greater than the average for the 24 hours of greatest flow. In the Sutter Creek Basin the storm precipitation averaged only about 5.5 inches and the storm run-off was but 0.45 inch.

In all probability there was little direct mun-off in the lower part of the basin where the total storm precipitation was less than 5 inches and the actual run-off.from the contributing area was probably somewhat greater than is indicated by the rate of 0.45 inch for the areas as a whole. On this assumption, the precipitation for the area within the 5inch isohyetal would be 7.9 inches, the adjusted run-off for the 
corresponding area, 1.05 inches, and the residual, 6.85 inches.

Ne1ther the momentary peak discharges nor the total direct run-off for the flood of December 1937 approached those resulting from previous floods of record on Sutter Creek, the North Fork of the Cosumnes River, and the Cosumnes River. This was as expected, Inasmuch as the larger floods were the result either of very much more rain, or of about the same amount of rain augmented by melting snow or falling upon ground that had already received sufficient recent precipitation to utilize the absorptive capacity to a considerable degree.

Mokelumne River Basin

The Mokelumne River Basin, on the western slopes of the Sierra Nevada, is about 85 miles long from the crest of the sierra to the downstream gaging station at Woodbridge (altitude, 30 feet). It has a width of about $20 \mathrm{miles}$ along the crest and of only 2 to 5 miles in the lower half. (See fig. 59.) The source of the river is in glacial lakelets at altitudes between 8,000 and 9,000 feet, and the course is generally in a southwesterly direction. The main branch, the North Frrk, has cut a deep canyon, a part of which is now occupied by Salt Springs Reservoir. The upper part of the basin is marked by parallel ridges separated by canyons, and the lower part is a rolling, hilly region. Nearly half of the area upstream from the gaging station at Woodbridge is above an altitude of 5,000 feet, and 54 percent of the basin upstream from the gaging station near Mokelumne Hill is above an altitude of 5,000 feet.

The river channel for most of the distance between the gaging stations near Mokelume Hill and at Lanche Plane is filled by Pardee Reservolro

The North Fork of the Mokelumne River is clearly a High Sierra river. The Mokelumne River as a whole is in the same classification as far downstream as the gaging station near Mokelumne Hill. Below that point its character is affected by control and diversions.

Granitic rocks and andesite predominate in the upstream areas. Iimestone, shale, and slate are found in the lower portions, and alluvium containing gravel, sand, silt, and clay mark the area downstream from Clements.

Bear River and Cold Creek rise at altitudes of about 9,000 to 10,000 feet and flow in a southwesterly direction. The gaging stations, at altitudes of 5,650 and 6,000 feet respectively, are 10 and 8 miles downstream from the headwaters. The high altitude of these small basins 
causes snowfall to be the prevaliing form of precipitation and gives them hydrologic characteristics different from the nearby South and

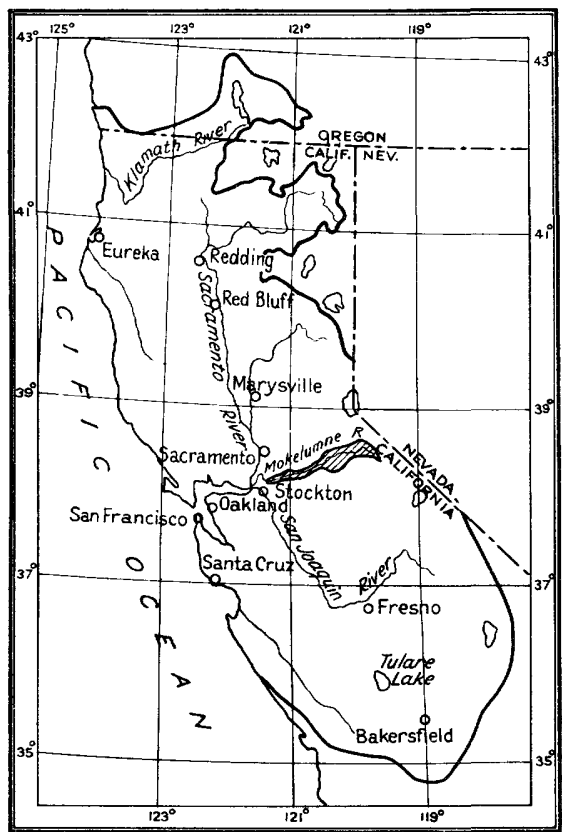

Figure 59.--Key map showing location of Mokelumne River Basin.
Midale Forks of the Mokelumne River.

The South and Middle Fork Basins upstream from the geging stations are each about 20 miles long and 6 miles wide at the widest place. Each of these streams has two main branches, rises at an altitude of around 7,000 feet, and flows in a westerly direction. The gaging stations are at g.l titude of 2,500 and 2,000 feet respectively. The streams are relatively much smaller than the North Fork and may be classed with the midslope type streams, but have some characteristics of foothill creeks.

The isohyetals for the

Mokelumne River Basin (fig. 16, p. 48) seem fairly well defined by observations. The high precipitation indicated in the headwaters of the Middle and South Forks of the Mokelumne River Basin is predicated on the high precipitation recorded at Big Trees (altitude, 4,700 feet). The indicated precipitation in the other high headwater areas is based largely on observations at Salt Springs (altitude, 3,600 feet), Lake Alpine (altitude, 7,500 feet), and Twin Lakes (altitude, 7,920 feet).

It would appear that the se three stations should indicate the precipitation in the upper basins with a fair degree of accuracy. Somewhat more than 290 square miles of the Mokelumne River Basin lies above an altitude of 7,000 feet and 150 square miles lies above 9,000 feet.

On the basis of observations at Lake Alpine and Twin Lakes there was possibly 5 to 8 inches of snow prior to the storm over a considerable part of the drainage basing of the North Fork of the Mokelumne River upstream from the gaging station below Salt Springs, Cold Creek, and the Bear River and some of the precipitation on December 9, 11, and 12 may have had the form of snow. Recording precipitation records at Fiddletown 
and Fricot C1ty (figs. 26 and 27, see pp. 61, 62) should show the distribution of the precipitation within these basins. The tendency for the precipltation to be marked by two periods of heavy intensity is indicated by declded increases in river stage early in the mornings of December 10 and 11. There was some decrease in stage after the first period of heavy intensity and before the second.

At only three of the river-measurement stations is the flow essentalliy unaffected by artificial storage - those on Cold creek and on the Middle and South Forks of the Mokelumne River. The flow at the other gaging stations is modifled by storage in several reservolrs, at the largest of which (Salt Springs and Pardee) records of storage are avallable. At the smaller reservoirs, Blue Lake, Lower Blue Lake, Meadow Lake, Twin Lake, and Bear, the total capacity of which is but a small part of the total, no records of storage are available. The storage retained above or diverted around the gaging stations amounted to 8.75 inches for the North Fork of the Mokelumne River below Salt Springs Dam, 2.6 inches for the Mokelumne River near Mokelumne Hill, 3.I5 inches for Lancha Plana, 2.85 inches for Clements, 2.8 inches for Woodbridge, and 3.75 inches for the Bear River at Pardoe Camp.

The rainfall and mun-of relations seem falrly consistent in areas where there was no snow. The total residuals (table 7, see pp. 3II-3l6) were 7.75 inches, 8.3 inches, and 9.15 inches respectively in the areas between Salt Springs Dam and Mokelumne Hill, and in the Middle and South Fork Basins.

In the North Fork of the Mokelumne River Basin upstream from the gaging station below Salt Springs Dam and in the Bear River Basin the indicated direct mun-off is somewhat more than the computed rainfall. In both of these areas large storage adjustments were made, and the direct run-off values shown in table 7 may be in error.

In Cold Creek Basin, where the observed mun-off represents natural flow conditions, the indicated direct mun-off is 7.35 inches as compared to adjusted values of over 9 inches in adjacent basins. The indicated differences between rainfall and mun-off was nearly 2 inches in Cold Creek Basin, and there may have been a contribution to the flood mun-off of I to 2 inches resulting from melting snow. Based on the total amount of water avallable for run-off the indicated residual would be between 3 and 4 inches.

In besins where natural flow conditions prevalled, the peak stages were reached December 11 between 8 and 10 a.m. about 2 hours after the 
period of heaviest rainfall intensity at Fricot City and about 6 hours before the end of the storm period. Between 56 and 59 percent of the total direct mun-off was during a 24-hour period and the peak discharge was between 60 and 74 percent greater than the mean for the 24 hours of greatest discharge.

The momentary peak discharge and the total direct run-off for the flood exceeded all previous records on Cold Creek, but did not approach previous records on the Middle and South Forks of Mokelumne River. These results are in keeping with the characteristics of the storm of December 1937, notable for extremely heavy rainfall at altitudes of 3,000 to 7,000 feet and above, and relatively light rainfall in the lower areas. The gaging station on Cold Creek is at an altitude of about 6,000 feet.

The larger former floods on the Middle and South Forks of the Mokelumne River were caused by heavier rainfall following preliminary storms which had lessened the absorptive capacity of the basins.

\section{Upper Sacramento River and McCloud River Basins}

The upper Sacramento River Basin as treated herein includes the area that drains into the Sacramento River upstream from the base gaging station near Red Bluff except the Plt River Basin. (See fig. 60.) The part of the basin upstream from the junction with the Pit River is very much smaller in area and in volumne of stream flow than the Pit River Basin. The McCloud River flows into the Pit River downstream from Ydalpom and a few miles upstream from the confluence with the Sacramento and is similar to the Pit River in many respects。 A large area in the upper McCloud River Basin is occupied by volcanic formations that regulate the water supply. The McCloud is probably the least flashy of the large rivers in California. The summer flow is particularly well sustained.

The basin of the McCloud River upstream from the gaging station near McCloud (altitude, 2,750 feet) is roughly a square which is about 20 miles long on each side and the northwest corner of which occupies the slope of Mount Shasta (altitude, 14,161 feet). Springs in the lava formation southeast of Mount Shasta are large and steady contributors, and additional flow comes from the southern and eastern slopes of the mountain through Cold and Ash Creeks. Almost the entire basin upstream from McCloud is underlain by volcanic rocks. Mud and Squaw Valley Creeks also rise on the southern slope of the mountain in similar volcanic formations 
and flow southward to contribute to the main river downstream from the gaging station near McCloud and upstream from the gaging station at

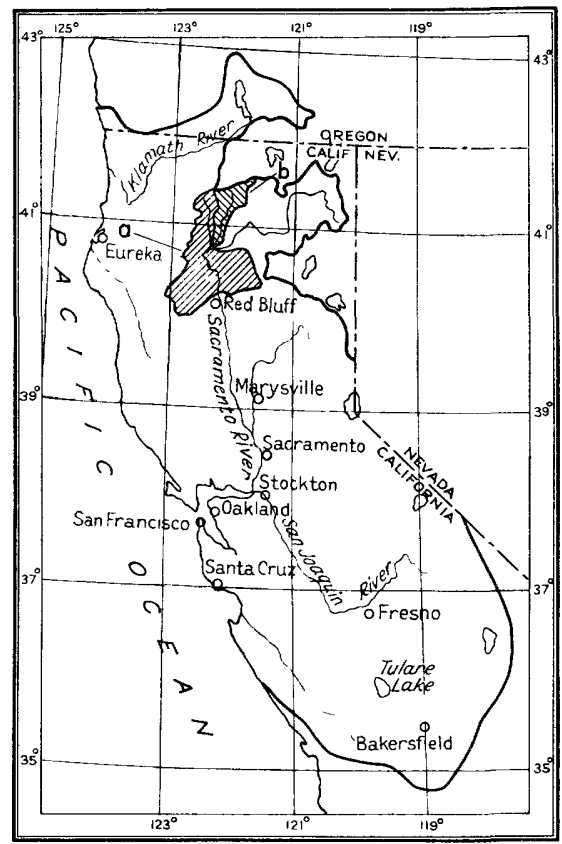

Figure 60.--Key map showing location of (a) upper Sacramento River and

(b) McCloud River Basins.
Baird (altitude, 700 feet). The area between these gaging stations is about 45 miles long and has a maximum width of 12 miles in the middle. During the summer, mud flows associated with the recession of glaciers come from the slopes of Mount Shasta. The lower part of the basin is underlain by marine sediments and to a lesser extent by volcanic and granitic formations. About 30 percent of the area upstream from the upper gaging station is above an altitude of 5,000 feet whereas only a few square miles of the intermediate area is above 5,000 feet.

The basin of the Sacramento River upstream from the gaging station at Antler (altitude, 934 feet) is about 35 miles long and 15 miles wide. One comer drains the southwestern slopes of Mount Shasta and is underlain by formations similar to those of the upper MeCloud Basin. About 25 percent of the area is above an altitude of 5,000 feet. The lower part of the basin is underlain by metamorphic formations and granite. The small intermediate area downstream from the gaging stations or the Pit River near Ydalpom, the McCloud River at Baird, and the Sacramento River at Antler and upstream from the gaging station at Kennett (altitude, 618 feet) is underlain by a wide variety of formations.

The large drainage area between the gaging station at Kennett and the one near Red Bluff (altitude, 250 feet) is 70 to 80 miles from east to west and 25 to 35 miles from north to south. This area is notable for its large contribution to the run-off of the sacramento River during periods of winter rain. Cow, Battle, and Cottonwood Creeks are the most important tributaries in this reach. Battle creek drains the western slope of Lassen Peak and Cow Creek rises at an altitude of about 6,000 
feet, but most of this area is in the foothills or in the valley. Although there are some volcanic materials in the headwaters of Cow and Battle Creeks, various sedimentary formations occupy most of the area. Alluvium is very prominent along the branches of Cow Creek and along the Sacramento River between Redding and the mouth of Cottonwood Creek.

The upper Sacramento, McCloud, and Pit River Basins have peculiarities, as described, that put them into the miscellaneous group of streams.

The precipitation map is comparatively well defined for the Sacramento River Basin above Antler and Kennett by rainfall stations at Mount Shasta Clty, Dunsmuir, Vollmer's ranch, Bayles, and Kennett. Isohyetals in the McCloud River Basin are based on one record at McCloud and those in adjacent basins. Twenty to twenty-five percent of the area upstream from Baird and Antler is above an altitude of 5,000 feet and without precipitation records. Lines of equal rainfall are not well defined in the McCloud River Basin upstream from McCloud.

Except on small areas on Mount Shasta and Lassen Peak, there was no snow on the ground at the beginning of the storm and no snow fell during the storm. There was about 8 feet of snow at Lake Helen (altitude, 8,300 feet) on the slopes of Lassen Peak at the end of November, and this was reported to have been reduced to about 5 feet of slush during the rains in December. Probably the snow absorbed the rain above altitudes of about 8,500 to 9,000 feet and there was $11 t$ tle run-off above these altitudes. There probably was snow ranging from a few inches to a few feet in depth between altitudes of 6,500 and 8,000 feet which melted and ran off during the December storm. The area between these altitude limits, however, amounts to only a few square miles around Lassen Peak and was even smaller around Mount Shasta.

The observed discharge during the flood period was essentialiy natural on the Sacramento River at Antler, the Mccloud River near McCloud, and the MCCloud River at Baird. The run-off at the river-measurement station on the Sacramento River at Kennett was adjusted for a considerable amount of storage on the Pit River, and the mun-off for the Sacramento near Red Bluff was adjusted for additional storage in reservoirs on Battle Creek. The total adjustment for storage amounted to 0.25 inch above Kennett and 0.20 inch above Red BIuff.

The adjusted total direct mun-off expressed in inches over the drainage areas is (table 7 , see pp. 311-316) 4.45, 2.15, 2.7, 1.0, and 3.15 for the areas above Antler, Kennett, Red Bluff, McCloud, and Baird, respectively. The low run-off on the upper McCloud River Basin was 
probably due to a combination of large absorption in very porous lava beds and slightly lower precipitation than occurred over the other headwater areas. The intermediate area between the Sacramento River gaging stations at Kennett and Red Bluff produced a mun-off of about 4.0 inches. The residuals seem consistent in these basins. In the upper McCloud River Basin, which is composed of large areas underlain by lava beds, the residual was 6.0 inches. Other residuals were 5.15 for the McCloud River at Baird, 3.85 for the Sacramento River at Antler, 4.15 for the Sacramento River at Kennett, 4.0 for the Sacramento near Red Bluff, and about 3.7 for the area between Kennett and Red Bluff. The precipitation in these areas during November 1937 was much larger than that in the southern part of the Central Valley.

Recording-gage precipitation records at Mount Shasta City and Vollmer's ranch in the basin above Antler (fig. 26, p. 61) indicate continuous rainfall from about 9 a.m. December 9 to $4 \mathrm{p} . \mathrm{m}$. December 11 , high intensities being recorded in the forenoon and afternoon of December 10 and the forenoon of December 11. The Mccloud River at Baird and the Sacramento River at Antler show peak mun-off about four hours after the peak precipitation of the afternoon of December 10, and neither shows any appreciable rise until midnight December 9 following 15 to 16 hours of continuous rain. Most of the precipitation of December 9 apparently was absorbed. Feak stages were reached at $10 \mathrm{p}$. m. on December 10 at Antler, and at 11 p.m. on December 10 at Baird, and a second peak of considerable magnitude was recorded in the afternoon of December 11, following a period of high rainfall intensity at about $10 \mathrm{a} \cdot \mathrm{m}$.

The ratios between the run-off during the 24 hours of greatest flow and the total storm mun-off are 37 percent for Antler, 25 percent for the McCloud River near McCloud, and 40 percent for the McCloud River at Baird. Corresponding ratios between the maximum momentary discharge and the maximum 24-hour average discharge are 116, 131 , and 132 percent, respectively.

At the three river-measurement stations in this area where the flow is not regulated, the Sacramento River at Antler, and the McCloud River near McCloud and at Balrd, the total direct run-off for the flood was higher, and, except at the Antler station, the momentary peak discharge was higher than for previously recorded floods. At Antler the momentary peak of March 26, 1928, remains as the maximum of record. Melting snow contributed to that flood. 
Pit River Basin

The P1t River upstream from the base gaging station near Ydalpom drains an area of 5,350 square miles, not including the Goose Lake Basin

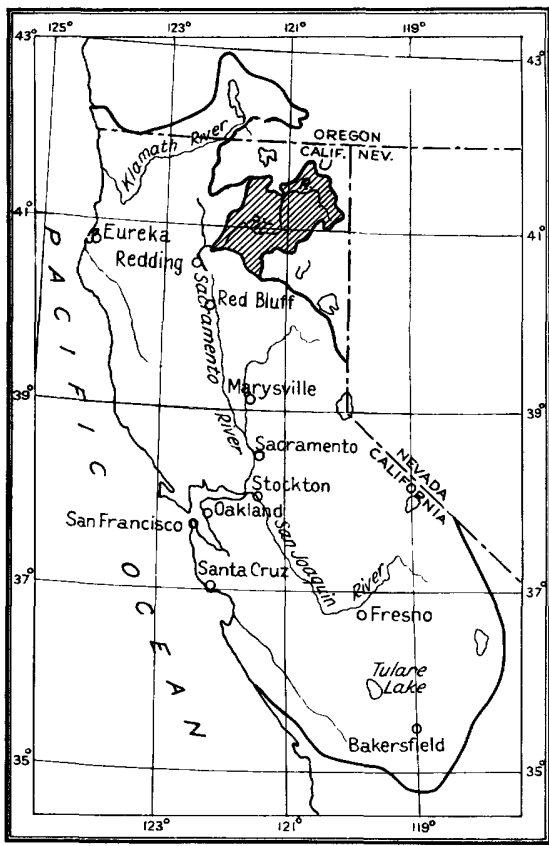

F1gure 61.--Key map showing location of P1t River Basin. which does not now drain into the P1t River. (See fig. 61.)

The P1t River rises near the easterm border of California in the Warner Mountains, which reach an altitude of 9,900 feet, and flows generally westward to the gaging station which is near Ydalpom at about an altitude of 735 feet. Twofifths of the area is at an altitude of more than 5,000 feet; for the most part it is underlain by lava beds in the north and consists of numerous meadow valleys, flat and marshy, in the south. The area also contalns many volcanic buttes and peaks, of which Lassen Peak is the most conspicuous.

The P1t River Basin is noted for 1ts large springs l4/ and for the marked regulating effect of the volcanfc formations upon stream flow. The lava flelds act as great underground storage basins that reduce flood flows and increase ary season flows. Because of the uncertainly in locatIng watershed lines, discharges expressed in second-feet per square mile may have little significance. The vagueness of drainage boundaries and the large time lag between rainfall and its appearance as mu-off caused by underground storage, render it difflcult or impracticable to formulate relations between precipitation and mun-off. It is probable that storage in lava beds holds over from season to season and that the effect of elther an extremely dry or an extremely wet season may extend over several years.

14/ Melnzer, 0. E., Large springs of the United States: U. S. Geol. Surve Water-Supply Paper 557, pp. 55-62, 1927. 
The North and South Forks of the Pit River head in the Warner Mountains. The gaging station on the South Fork near Likely is about 4,680 feet above sea level, and the gaging station near Canby below the junction of the Forks is about 4,300 feet. This whole area is underlain by volcanic rocks, but andesite is more common in the Warner Mountains and basalt and other types in the large, relatively flat plain the center of which is near Alturas.

Most of the large area between the gaging stations near Canby and Fall River Mills (altitude, 3,235 feet) is very flat, and the drainage boundaries on the sides of the basin are very indefinite. Volcanic andesite and basalt are predominant, but there are large areas of alluvium around Bleber and Fall River Mills.

The area between the gaging stations at Fall River Mills and below Pit No. 4 dam (altitude, 2,345 felt), which includes the area upstream from the Hat Creek gaging station (altitude, 4,500 feet), also contains volcanic plateaus, although the river flows in a canyon in this reach. Headwater areas of Hat Creek around Lassen Peak contain volcanic ash and porous lava, but most of the area is underlain by other volcanic material such as andesite, rhyolite, and basalt. Drainage areas are not well defined in parts of this region.

The small area between the gaging stations below P1t No. 4 dam and at Big Bend (altitude, 1,700 feet) is chiefly underlain by volcanic rocks, but there is a small amount of marine sediments along the river near Big Bend. This reach of the river is in a deep canyon.

The intermediate area below the Big Bend gaging station and above the Ydalpom station forms a crude triangle about 25 or 30 miles on a side. Part of this area is above an altitude of 5,000 feet, and the surface is very rough and irregular. In general, the part of the drainage area to the southeast of the river is underlain principally by volcanic rocks and to a lesser extent by marine sediments and granite, whereas the main river and Squaw Creek, the important tributary from the west, flow through areas of more dense metamorphic rocks. The Pit River is in the miscellaneous group of streams. (See p. 349.)

The precipitation map of the Pit River Basin is defined by nine rainfall stations in the basin and by a few stations in adjacent basins. About 40 percent of the entire basin lies above an altitude of 5,000 feet. The percentage increases toward the headwaters to 65 percent near Canby and 100 percent for the South Fork of the Pit River basin above Likely. A small percentage lies above 7,000 feet. 
With the exception of the heavy snow cover around Mount Lassen in the headwaters of Hat Creek, there was very little snow on the ground below an altitude of 5,000 feet at the beginning of the December storm and apparently only a few inches over most of the area above an altitude of 6,000 feet. Indications are that nearly all of this snow melted and ran off during the early part of the storm. A slight amount of snow fell at the higher altitudes during the last hours of the storm. The lower fringe of the snow pack around Lassen Peak may have melted and run off, but the general effect was probably for the deep snow blanket on the peak to absorb the rain without producing run-off.

In the PIt River Basin only the gaging station on Hat Creek shows natural run-off. Observed mu-off at the other river-measurement stations was adjusted for estimated and observed storage in the reservoirs as follows: The South Fork of the Pit River near Likely for storage in West Valley and Tule Lake reservoirs; the Pit River near Canby for BIg Sage Reservoir and other small reservolrs in addition to those on the South Fork; the Pit River at Fall River Mills for 10,000 acre-feet in addition to that above Canby; the Pit River below Pit No. 4 dam for Lake Britton in addition to that above Fall River Mills; and the PIt River at $\mathrm{BIg}$ Bend and year Ydalpom for the same storage as at P1t No. 4 dam.

The results of adjusted direct mun-off in inches (table 7 , see pp. 311-316) from the drainage areas above the stations near Likely, Canby, Fall River Mills, Pit No. 4 dam, Big Bend, and Ydalpom are 2.35, $1.9,1.2,1.15,1.3$, and 1.7 , respectively, of which it is estimated that $2.1,1.0,0.4,0.35,0.35$, and 0.3 inches, respectively, were held in the storage reservolis during the flood period. The decrease in runoff downstream as far as Pit No. 4 dam is probably due mostly to large areas contributing relatively little or no flow, the percentage of such area being especially high upstream from the Fall River Mills gaging station. Natural run-off for Hat Creek has the low value of 0.65 inch. The surface drainage in the Hat Creek Basin is poorly defined, the lava is exceptionally porous, and it is probable that comparatively little of the area contributes to the surface run-off. Therefore the result stated has little significance.

There was a storm center of considerable magnitude below Big Bend, as indicated by the precipitation record of 14.77 inches at Montgomery Creek and by the large inflow into Pit River between Big Bend and Ydalpom. For this intermediate area the average storm rainfall was about 
12.0 inches, the direct run-off 8.4 inches, and the residual 3.6 inches. The residuals in the basin range from 1.05 inches for the gaging station near likely to 4.0 inches for the station near Ydalpom.

A recording precipitation gage at Redding shows almost continuous rain from 9 a.m. December 9 to $1 \mathrm{p} . \mathrm{m}$. December 11, greatest intensities being reached between 9 and $10 \mathrm{a} \cdot \mathrm{m}$. and between 5 and $6 \mathrm{p} \cdot \mathrm{m}$. December 10 . (See fig. 26, p. 61.) These latter periods apparently correspond to discharge peaks on Hat Creek at 7 p.m. December 10 and 2 a.m. December 11. The flow of Hat Creek showed no rise for about 16 hours after the storm began. The ratio of the run-off during the 24-hours of highest flow to the total run-off for the storm is 62 percent, and the ratio between the maximum peak flow and the maximum 24-hour average flow is 138 percent.

Hat Creek is notable for its relatively steady, spring-fed flow, and from the beginning of record in 1926 until December 1937 there had been no record of a flood on the stream. For reasons stated in the basin description, the peak run-off per square mile or the total direct flood run-off in inches has little significance in this area. The momentary peak discharge of 2,500 second-feet on December 11, 1937, is considered remarkably high when the past record of this stream and the characteristics of its basin are considered.

M111, Deer, Chico, and Butte Creek, and Bear River Basins

M111, Deer, Chico, and Butte Creeks and the Bear River all have long narrow basins that head at fairly high altitudes on the western side of the Slerra Nevada and flow in a southwesterly direction to the sacramento Valley. (See fig. 62.) The first four streams, in their relatively sudden approach to the floor of the valley, have the common characteristics of deep canyons cut down through old lava flows.

Mill and Deer Creeks are very similar, although Mill Creek rises on the slopes of Lassen Peak (altitude, 10,453 feet) and Deer Creek originates at an altitude of about 5,000 feet in the broad Deer Creek Meadows which are fed from an adjacent drainge area having altitudes as high as 7,000 feet. The gaging station on Mill Creek is at an altitude of about 420 feet and that on Deer Creek about 480 feet. Mill Creek Basin upstream from the gaging station is about 40 miles long and has a width of about 4 miles at 1 ts upper end, whereas Deer Creek Basin is only 35 miles long but is about 8 miles wide at the upper end. The upper part of each basin is underlain by volcanic materials such as rhyolite and andesite, whereas the lower parts are underlain by sedimentary materials. 
Chico and Butte Creek Basins are very much allke. Butte Creek Basin upstream from the gaging station is a little over 30 miles long

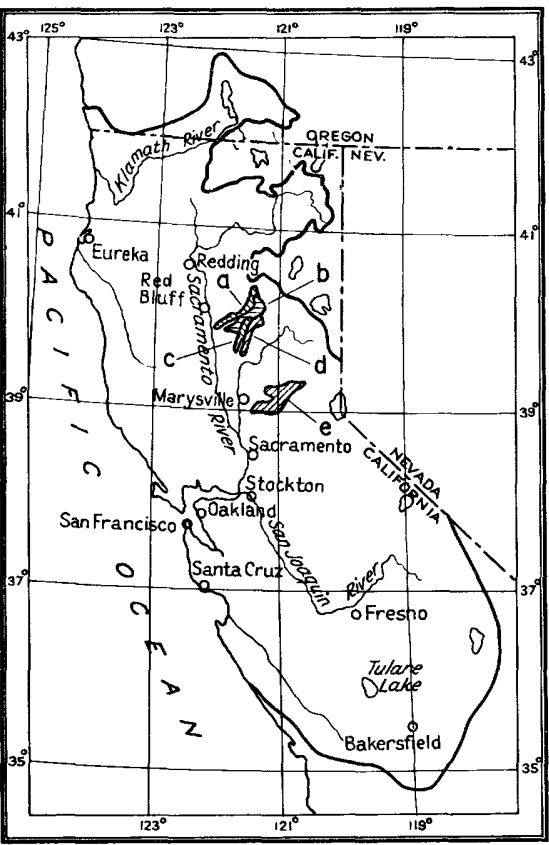

Figure 62.--Key map showing location of (a) Mill Creek, (b) Deer Creek, (c) Chico Creek, (d) Butte Creek, and (e) Bear River Basins. and Chico Creek Basin a little less, but each is only 2 to 5 miles wide. Butte Creek rises at an altitude of about 6,000 feet and Chico Creek at about 5,000 feet. The gaging stations are about 350 and 400 feet, respectively, above sea level. Both streams originate in volcanic material, and flow on marine sediments through most of their length.

The Bear River Basin has characteristics quite different from the four basins just described. The Bear River originates at an altitude of only a little more than 5,000 feet, and nearly all of the drainage area is below 5,000 feet. The gaging station is on the main valley floor at an altitude of about 85 feet. The basin is about 45 miles long and 10 miles wide in the middle, and narrows at the ends. The basin materials vary greatly, but metamorphic rocks are most common. In the lower reaches the bed is filled with debris resulting from hydraulic mining in the headwaters. The Bear River is called a beheaded stream, the South Fork of Yuba RIver having stolen its ancient headwaters. It belongs to the midslope type of streans. (See p. 348.)

There are only three rainfall stations in these minor basins, all located on the east side of the sacramento valley, but there are enough stations in adjacent basins to define the precipitation map comparatively we11.

There was no snow on the ground at the beginning of the storm and none fell during the storm, except on 6 square miles in the headwaters of M11l Creek on the slopes of Lassen Peak. In this small area there was heavy snow above an altitude of about 8,000 feet, which probably absorbed all the rain. A narrow fringe of snow between 7,000 and 6,000 $1603(1020)-3 !-2 t$ 
feet probably contributed some direct mun-off.

The observed discharge on Mill Creek and Chico Creek is natural. The record on Deer Creek is incomplete, as the gaging station was destroyed by the flood. The run-off on Bear River was adjusted on the assumption that storage in Combie and Camp Far West Reservoirs occupied 50 percent of their capacity. Such storage arrounted to 0.45 inch over the area. The run-off of Butte Creek was adjusted for diversions received from the Feather River Basin.

The adjusted total direct run-off in inches over these basins (table 7, see pp. 3ll-316) is 6.8, 6.75, and 2.35 for Mill Creek, Chico Creek, and the Bear River, respectively. The run-off for the Bear River is low because a considerable part of its drainage area is on the valley floor in a region that received comparatively little rainfall. The direct run-off from headwater areas of Deer, Butte, Battle, Antelope, and Cow Creeks probably equalled or exceeded the observed mun-off from Mill and Chico Creeks.

Residuals for Mills Creek, Chico Creek, and the Bear River are fairly consistent at $6.7,7.45$, and 6.45 inches, respectively.

The rain gage at Redding recorded almost continuous precipitation from 9 a.m. December 9 to noon December 11, and there were periods of especially high intensity about $9 \mathrm{a} . \mathrm{m}$. and $5 \mathrm{p} . \mathrm{m}$. December 10 . These peaks were reflected in a rapid increase in the stages of Mill and Chico Creeks at about 2 p.m. December 10 and peaks at midnight on December 10 for Chico Creek and 2 a.m. on December 11 for Mill Creek. Neither Mill Creek nor Chico Creek showed any appreciable rise in stage until 8 p.m. December 9 after it had been raining at Redding for about 10 hours at an average rate of about 0.2 inch per hour. The ratio between the peak flow and the maximum 24-hour flow is 167 percent for Mill Creek and 129 percent for Chico Creek. Mill Creek also had a greater concentration of mun-off in the 24 hours of greatest flow in relation to the mun-off of the entire storm, the ratio being 56 percent compared with 51 percent for Chico Creek.

Mill and Chico Creeks are the only streams of this group with complete records of the flood run-off unaffected by storage or diversions. Both the momentary peak discharges and the total direct run-offs for the flood period greatly exceeded previous records.

It appears probable that the storm of December 1929 brought much more precipitation to the Mill Creek area, over a seven-day period, than the storm of December 1937. However, the period preceding the storm in 
1929 was much drier than the corresponding period in 1937. This appears to be one more confirmation of the probability, previously mentioned, that antecedent conditions are very important and may be more influential than basin characteristics.

Elder, Thomas, Stony, Cache, and Putah Creek Basins

Elder, Thomas, Stony, Cache, and Putah Creeks all rise on the easterm slope of the coast Ranges at altitudes of 4,000 to 8,000 feet and flow in a general easterly direction. (See fig. 63.) The gaging stations are on the west side of the Sacranento Valley. Unless artificially regulated, these streams go wholly or nearly dry in the summer and fall, and are subject to flashy flords in the winter and spring.

One of the two main branches of Elder Creek rises at an altitude of about 7,000 feet. The main stream generally flows in a easterly direction. The gaging station on the floor of the valley is at an altitude of about 310 feet. The basin is about 27 miles long above the station and 8 miles wide near the upper end, and narrows near the gaging station. Most of the basin is at relatively low altitude. It is a very flashy stream of the foothill type. (see p. 349.)

Thomas Creek rises at a similar elevation, but a much larger proportion of the drainage area is at comparatively high altitudes and the gaging station is at a little higher altitude on the edge of the foothills. The basin is about 25 miles long and 12 miles wide near the middle. At times snowfall is a factor in the stream's behavior. Geological conditions at the headwaters of both Thomas and Elder Creeks are unmapped, but the region contains sedimentary rocks and both streams cross bands of sedimentary material of various kinds.

The four upper branches of Stony Creek rise at altitudes ranging from 4,000 to 6,000 feet near the crest of the Coast Ranges, and flow eastward out of the hills and then northward through a broad valley. The basin upstream from the gaging station is roughly a square of about 16 miles on each side, and is only a small part of Stony Creek Basin. The formations are chlefly sedimentary but there is granitic rock in some of the headwater area.

The three main branches of the North Fork of Cache Creek rise at altitudes of about 4,000 to 5,000 feet and flow eastward and southward. The gaging station is at an altitude of about 1,050 feet. The basin is roughly diamond-shaped, its major axis being 25 miles in length and 1 ts minor axis 15 miles. Almost the entire basin is underlain by 
sedimentary formations. It is a foothill type of creek.

Clear Lake, which is surrounded by hills, is the principal topo-

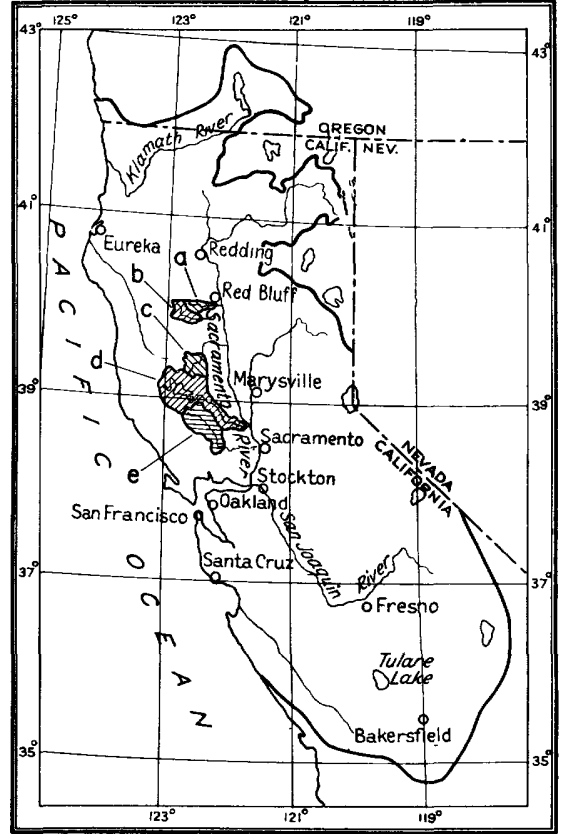

FIgure 63.--Key map showing location of (a) Elder Creek, (b) Thomas Creek, (c) Stony Creek, (d) Cache Creek, and (e) Putah Creek Basins. graphic feature of upper Cache

Creek. The area in Cache

Creek Basin upstream from the gaging station at Yolo includes, in addition to the North Fork Basin, a 40-mile strip along the divide on the west, 2,000 to 3,000 feet high, a flat district around the margin of Clear Lake, and a 40-mile strip of low valley land. The whole basin upstream from Yolo is about 80 miles long and about 35 miles wide near the upper end. The basin is underlain by sedimentary formations, alluvium, and Iimited amounts of volcanic material.

Putah Creek Basin is long and narrow. Several branches rise along the east side of the

Coast Ranges at altitudes of 3,000 to 5,000 feet and converge a few miles west of the gaging station near Guenoc which is at an altitude of about 925 feet. The basin upstream from Guenoc, which is only about $16 \mathrm{miles}$ Iong and 10 miles wide, is in an area that has heavy precipitation. It is underlain mostly by sedimentary rocks, but there is volcanic material in the mountains and alluvium in the downstream valleys. Some of the intermediate drainage area downstream from Guenoc and upstream from the gaging station near winters (altitude, about 160 feet) is as high as 2,000 feet, but a large part is under 1,000 feet in the valleys near Pope Valley and Monticello. Various kinds of sedimentary formations predominate. Putah Creek is a foothill type of stream. (See p. 349.)

There are no precipitation stations in Elder, Thomas, or the North Fork of Cache Creek Basins and the Ilnes of equal rainfall are therefore poorly defined by stations in adjacent basins. Two precipitation stations in Stony Creek Basin above Stony Gorge Reservoir tend to fix the position of the isohyetals, but the locations are indefinite in the 
higher altitudes. A systematic search was made for supplemental precipitation data in the Putah Creek Basin, and the rainfall map is considered well defined in that basin and for Cache Creek Basin, except for the North Fork.

There were probably patches of snow in small areas lying above 6,500 feet in the Coast Ranges, but in general there was little, if any, contribution from snow melt.

The run-off is natural for Elder and Thomas Creeks and North Fork of Cache Creek and at the two gaging stations on Putah Creek. The mun-off of Cache Creek at Yolo is materialy affected by storage in Clear Lake, amounting to about 2.15 inches over the drainage area; and on Stony Creek above Stony Gorge Reservoir by storage in East Park Reservoir, amounting to 0.6 inch over the drainage area. The observed run-offs at the latter two gaging stations were adjusted to show natural run-off. The adjusted total run-off in inches from the drainage basins (see table 7, pp. 311316) is 2.75 for Elder Creek, 5.05 for Thomas Creek, 4.8 for Stony Creek, 4.15 for North Fork of Cache Creek, 3.6 for Cache Creek at Yolo, 9.7 for Putah Creek near Guenoc, and 3.7 for Putah Creek near Winters. The lower parts of Elder and Putah Creek Basins recelved less than 5 inches of rainfall, and the run-off from the contributing areas in these basins was In excess of the indicated rates for their entire areas.

The area upstream from Putah Creek near Guenoc had much heavier rainfall and mu-off than did nelghboring areas.

The difference between rainfall and run-off, in inches, is 2.05 for Elder Creek, 0.75 for Thomas Creek, 2.2 for Stony Creek, 3.15 for North Fork of Cache Creek, 3.3 for Cache Creek at Yolo, 4.4 for Putah Creek near Guenoc, and 4.7 for Putah Creek near Winters. The low residuals for Thomas Creek, Elder Creek, and Stony Creek probably indicate that there was more rain in these areas than is shown by the lines of equal rainfall.

There are no recording gages in these basins, but the one at Redding may be falrly indicative of conditions on Elder and Thomas Creeks and the one at sacramento may be indicative of the rainfall distribution in Cache and Putah Creek Basins. The rain fell at maximum intensity between 5 and 6 p.m. December 10 at Redding and maximum peaks were reached on Elder and Thomas Creeks at $10 \mathrm{p.m}$. on that date. At Sacramento, as is generally true for much of the southern storm area, there were two periods of heavy rainfall intensity, one in the forenoon of December 10 and the other during the early hours of December 11. (See fig. 36, p. 61.) These periods 
were followed by double peaks of almost equal magnitude on Cache and Putah Creeks.

The ratios between the momentary peak discharge and the discharge during the 24 hours of greatest flow range from 117 percent for Putah Creek near Winters to about 168 percent for Elder Creek and North Fork of Cache creek. The lower ratio at Winters probably reflects the smoothing of the peak by channel storage. Ratios between the mu-off during the 24 hours of greatest flow and the total run-off for the storm range from 40 to 60 percent.

The momentary peak discharges and total direct mu-off for the storm period were the highest on record for Elder Creek and the North Fork of Cache Creek. Previous momentary peaks were slightly higher than those for December 1937 on Thomas Creek, Putah Creek near Guenoc, and Putah Creek near Winters. However, the total direct mun-off for the storm in 1937 was probably a maximum of record at all three measuring points.

Feather River Basin

The Feather River Bas in upstream from the base gaging station near Oroville is a large fan-shaped area having a radial distance of 70 to 80 miles from the gaging station to the north and east perimeter along the crest of the Sierra. The distance around the perimeter is about 110 miles. (See fig. 64.) The crest of the sierra in this region is lower and not as well defined as it is to the south, and the North and Middle Forkg of the Feather River flow through high and relatively flat valleys in their upper reaches before they enter deep canyons in the middle reaches. About 53 percent of the basin upstream from Oroville is above an altitude of 5,000 feet. There is a rather sharp line of demarcation muning near Doyle, Susanville, Westwood, Almanor, Caribou, Sterling City, and Oroville between the greatly varied granites, andesites, and metamorphic rocks to the south and the more recent volcanics, andesite, rhyolite, and sediments to the north.

There are two significant characteristics of the Feather River Basin. One is the regulating action upon stream flow of the volcanic formations in the northern part of the basin. In this respect it resembles the Pit River Basin where areas of lava act as huge underground reservolrs, reducing flood flows and augmenting dry season discharge. The other characteristic is the sharp distinction between the relatively low water-yleld of the upper areas such as the Sierra, Indian, and 
Geneser Valleys, and the high yield of the intermediate areas further downstream. There are two reasons for the marked differences the re-

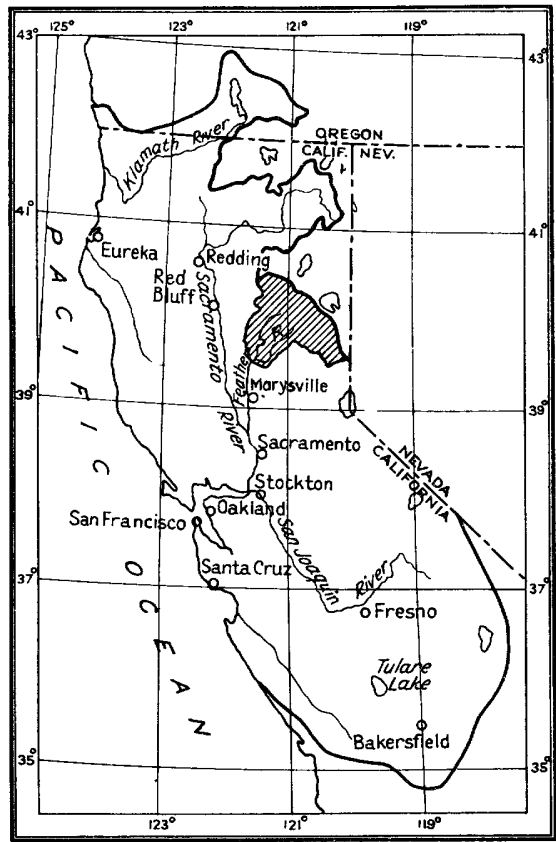

Figure 64.--Key map showing location of Feather River Basin. duced precipitation in the upper valleys, which are east of the high ridges through which the Feather River and its branches have cut deep canyons; and the increased seepage, evaporation, and other losses where streams flow through flat alluvial valleys. Although the Feather River has its own peculiar characteristics, it resombles the High Sierra type of streams in many respects.

The South Fork of the Feather River rises at an altitude of about 7,000 feet and flows about 30 miles through a narrow basin. The gaging station is at an altitude of about

550 feet. Iost Creek is tributary to South Fork, and has a narrow basin about 11 miles long which descends from an altitude of more than 5,000 feet at the head to 3,050 feet at the gaging station. The geologic formations are rather varied in this area. Granite is most prominent, particularly in the Lost Creek Basin, but there are also volcanic materials.

About half of the area of the Middle Fork is at altitudes between 5,000 and 7,000 feet, and the rest ranges from 5,000 feet down to 290 feet at the gaging station. A prominent feature is the large amount of comparatively flat terrain just below 5,000 feet in the Slerra Valley, a mountain meadow. The Slerra Valley and the surrounding country are very dry in summer. The western part of the basin is a crescent-shaped area about 50 miles long and 6 to 15 miles wide, and the river flows in a canyon. Granitic rocks and andesite volcanics are more prevalent than metamorphic rocks. Indian Creek Basin, which is about 40 miles long and 25 miles across, ranges in altitude from about 8,000 feet along the divide on the north and east to 3,500 feet at the gaging station. A 
over 5,000 feet. The stream has a flat gradient, especially in the swampy Indian Valley. Granite and andesite are most prevalent in the headwater areas, but there are large patches of metamorphic rocks and auriferous gravels as well as numerous small areas of various formations in the western end, and the stream flows over alluvium for several miles in Indian and Genesee Valleys.

Spanish Creek Basin also is relatively flat; it ranges in altitude from about 7,000 feet on some of the surrounding hills to 3,250 feet at the gaging station, and two-thirds of the area is below 5,000 feet. The two main branches flow 12 and 15 miles from the east and west, respectively, unite, and flow northward a few miles to the gaging station. The stream may be considered as of the midslope type. (See p. 348.) Metamorphic rocks occupy most of the area, but the stream flows through several large patches of alluvium.

The North Fork of the Feather River Basin upstream from the gaging station near Prattville has altitudes of about 5,500 to 10,453 feet (Mount Lassen) along the north side and of 4,380 feet at the gaging station. There are many perennial springs in the headwater area, which also contains the large Lake Almanor and Mount Meadows Reservoirs. For the Ereater part of 1ts course the North Fork flows through a deep canyon, and most of the tributaries are short streams that drain precipitous slopes. Most of the area is underlain by more recent volcanic andesite, rhyolite, and basalt, but there is alluvium around Mount Meadows Reservolr. There are several fault lines north of Lake Almanor.

Grizzly and Bucks Oreek Basins are two small areas lying between altitudes of 7,000 and 5,000 feet. The Bucks Creek Bas In, a large portion of which is occupled by Bucks Creek storage reservolr, is underlain almost entirely by granite, whereas Grizzly Creek Basin contalns mostly metamorphic rocks and only a minor amount of granite.

The basin of the West Branch of the Feather River upstream from the gaging station $1 \mathrm{~s}$ about $27 \mathrm{miles}$ long and 3 to $7 \mathrm{miles}$ wide. It ranges In altitude from about 6,000 feet at the headwaters to 1,100 feet at the gaging station. Basalt and metamorphic rocks are most common. It is a midslope type stream. Concow Creek flows into West Branch of Feather River and has a very small drainage area which ranges in altitude from about 4,000 feet in the upper part to 1,850 feet at the gaging station. Granite and metamorphic rocks are most common.

The Intermediate area in the basin of the North Fork of Feather River between all these tributary basins and the base gaging station 
near Oroville is about $50 \mathrm{miles}$ long from north to south and 10 to 20 miles wide. The altitude ranges from about 7,000 feet at the peaks to 182 feet at the gaging station. Granite and metamorphic rocks are most common.

The lines of equal rainfall ( $\mathrm{fig} .17, \mathrm{p} .49$ ) in Feather River Basin are well defined by 22 rainfall stations above Oroville and by some in adjacent basins. About half the basin is above an altitude of 5,000 feet. However, only two of the rainfall stations are above an altitude of 5,000 feet, which may cause some inaccuracies in the location of the isohyetals in headwater areas.

Snow data in the basin are meagre. There was heavy snow on a few square miles around Mount Lassen in the drainage of the North Fork of the Feather River near Prattville; the lower fringe of this snow melted. The heavier snow at highest altitudes probably absorbed all the rain that fell. A small part of the area upstream from the Middle Fork of the Feather River near Clio is above 7,000 feet, and it is presumed that in this and adjacent areas snow conditions were similar to those at Soda Springs (altitude, 6,752 feet), where there was 13 inches of snow on the ground on December 8, 13 inches on the 9 th, 10 inches on the 10th, a trace on the 11th, 8 inches on the 12th, and 7 inches on December 13. At Soda Springs, 13 inches of snow melted and ran off during the storm, and 8 inches of new snow fell during the last phases of the storm. At the beginning of the storm the snow generally ranged in depth from a trace to about 1 foot at altitudes of 6,000 to 7,000 feet. A considerable part of the North Fork of the Feather River Basin above Prattville and small parts of the drainage areas of Spanish Creek, Indian Creek, and the Middle Fork of the Feather River near Clio are within these limits, and there was probably contribution to the flood mun-off from melting snow.

The observed discharge is essentially unregulated at the river-

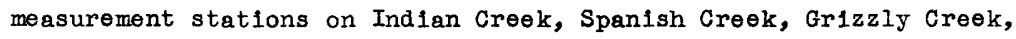
Lost Creek, the Middle Fork of the Feather River at Bidwell Bar, and the South Fork of the Feather River near Enterprise. The flow on the North Fork of the Feather River near Prattville is controlled at Almenor Dam. The record for Bucks Creek is derived from storage records in Bucks Creek storage and diversion reservoirs. Flow on the West Branch of the Feather River near Yankee Hill was materially modified by storage in Lake Wilenor and in smaller reservoirs and by diversions into Spring Valley ditch and Miocene canal, amounting to 2.0 inches during 
the storm. The flow of Concow Creek was modifled by storage in Lake Wlienor, amounting to 4.25 inches; and that of the Feather River near Oroville, by storage in five large reservoirs having a total retention during the storm equivalent to 0.40 inch over the area. The observed mun-off has been adjusted to give natural mun-off. Changes in storage on Lost Creek and in the South Fork of the Feather River Bas in above Enterprise were so small that run-off was assumed to be natural. No detalled mun-off data for the flood period are avallable for the station on the Middle Fork of the Feather River near Clio.

At the gaging station on the Feather River near Oroville the water-stage recorder was overtopped at the peak, and the record is therefore incomplete.

The indicated direct run-off in inches (see table 3, pp. 311-316) was 1.65 for Indian Creek, 4.1 for Spanish Creek, 12.5 for Grizzly Creek, 6.2 for Lost Creek, 7.85 for the South Fork of the Feather River near Enterprise, and 4.35 for the Middle Fork of the Feather River at Bidwell Bar. The run-off adjusted for storage is 12.6 inches for Bucks Creek, 9.7 for the West Branch of the Feather River, 6.65 for Concow Creek, 3.1 for the North Fork of the Feather River near Prattville, and 3.95 for the Feather River near Oroville. There was probably a limited contribution from melting snow in the basin above Prattville and in some of the others. The result for Indlan Creek reflects the comparatively low rainfall of less than 6 inches. The indicated mun-offs for Grizzly and Bucks Creeks exceed those for any drainage basin for which complete records of these floods are avallable. Lack of information to determine accurately the drainage area for Grizzly Creek casts some doubt upon the run-off values expressed in inches over the area. The adjusted values for Bucks Creek, however, support the high value for Grizzly Creek.

Differences between rainfall and run-off range from 4.0 inches for the North Fork of the Feather River near Prattville to 12.9 inches for Lost Creek. All but Lost Creek and South Fork of Feather River near Enterprise show less than 7.1 inches.

There are no recording rainfall gages in or near the Feather River Basin. The gage-height graphs of the natural flow stations seem to indicate that the precipitation was generally continuous throughout the storm period. With the exception of those on Indian Creek, all the peak stages occurred between noon December 10 and noon December 11. The ratios between the rate of flow at the peak and the maximum 24-hour 
average flow are very low for Indlan Creek, Spanish Creek, Mlddle Fork of the Feather Rlver, and South Fork of the Feather River, ranging from 105 percent to 119 percent. The small dralnage areas on Grizzly Creek and Lost Creek show ratios of 143 and 144 percent, respectively. The ratios between the run-off during the 24 hours of greatest flow and the total storm run-off were close to 50 percent, except that for Indian Creek which was 33 percent. The flow of Indlan Creek responded comparatively slowly to the storm rainfall, the crest stage not being reached unt1l $2 \mathrm{p} . \mathrm{m}$. December 12 , whereas the crest stages on most of the other streams occurred on December 11. The delayed run-off and lower ratios for Indlan Creek are probably related to the flat meadows above the point of measurement, which act as natural detention reservoirs that smooth the peaks and delay the run-off.

The momentary peak discharges during December $1: 37$ exceeded previous high peaks at all gaging stations in the Feather RIver Basin except those with records going back to the flood of March 1907. There seems little doubt that the flood of 1907 was the largest in the Feather River Basin thus far in this century.

\section{Yuba River Basin}

The basin of the Yuba River upstream from the base gaging station at Smartville is fan-shaped, and has a radial distance of 45 to $52 \mathrm{mlles}$ from Smartvilie and an outer periphery of about $50 \mathrm{miles}, 30 \mathrm{miles}$ of which is along the 7,000 to 8,000-foot crest of the Sierra Nevada. (See f1g. 65.) The topography 1s rugged and mountalnous, and about 43 percent of the area is above an alt1tude of 5,000 feet. The tributaries have cut deep canyons, whlch head well up in the mountains. There are perennial springs in parts of the basin and many small glacial lakes at higher altitudes. In the lower reaches of the river the stream bed is filled with debris from hydraulic mining washed down from upper parts of the bas in.

The headwaters of the South Fork of the Yuba R1ver are measured at gaging stations on the South Fork at Lake Spaulding, and on Canyon Creek below Bowman Dam. The former stream rises at an altitude of about 8,000 feet on the crest of the Slerra Nevada and drops to around 5,200 feet at the gaging station; the latter rises at about 7,000 feet and drops to about 5,100 feet at the gaging station. Glaclal deposits, andesites, grantte, granodiorite, metamorphic rocks, and lesser amounts of basalt, 
limestone, slate, and shale are some of the varied formations in the areas.

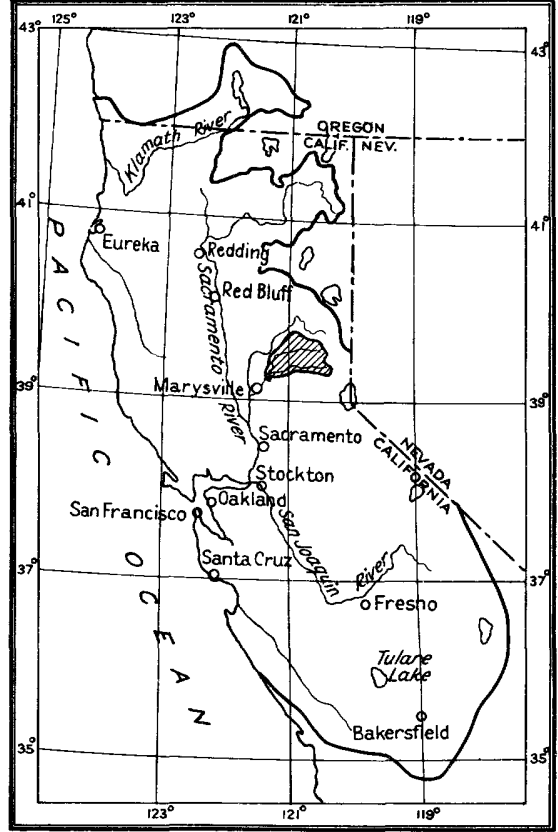

Figure 65.--Key map showing location of Yuba River Basin.
The Middle Fork of the Yuba River heads along the crest of the Sierra Nevada at an altitude of a little more than 7,000 feet and drops to about 5,700 feet at the gaging station near Milton. Glacial deposits, andesite, and metamorphic rocks are among the varled formations. Oregon Creek, which has a basin 15 miles long and 2 miles wide, is also tributary to the Middle Fork. This stream rises at an altitude of about 5,000 feet and drops to about 1,500 feet at the gaging station. The exposed formations include andesite, metamorphic rocks, ser-

pentine, and some granodiorite. The basin of the Middle Fork upstream from the gaging station near North San Juan, which includes the two areas just mentioned, is about $35 \mathrm{mlles}$ long and 4 to $7 \mathrm{miles}$ wide. The altitude at the gage is about 1,400 feet. Geologic formations include all the types found in the upper basins.

The North Fork of the Yuba River rises at about 7,000 feet and, in about $14 \mathrm{miles,}$ drops to an altitude of about 4,100 feet at the gaging station near Sierra City. Most of the basin is underlain by granodiorite, glacial deposits, and andesite. The Yuba River and its higher tributaries have the characteristics of a High Sierra stream. (See p. 347.)

Deer Creek arains a basin about 28 miles long and 3 to 5 miles wide which heads at an altitude of about 4,000 feet and arops to about 500 feet at the gaging station near Smartville. It can be classed as a foothill stream, although snowfall may be a factor at times.

The drainage area between the previously mentioned gaging stations and the base gaging station at Smartville is V-shaped, has legs 35 to 
45 miles long, and reaches altitudes as high as 7,000 feet. Formations include all of the types enumerated for the tributary basins, except glacial deposits.

There are ten precipitation stations in the Yuba River Basin. Three of these, including the important station at Soda Springs (altitude, 6,752 feet) are above an altitude of 5,000 feet. The greater part of the area above Smartville is below an altitude of 5,000 feet, 36 percent is between 5,000 and 7,000 feet, and 7 percent is above 7,000 feet. The topography is more complex than that of the basins to the north, and the lines of equal rainfall are probably not as well defined as in areas where the conditions are more uniform.

The snow depth at Soda Springs was 13 inches on December 8,13 inches on December 9, 10 inches on December 10, a trace on December 11, 8 inches on December 12, and 7 inches on December 13. There was no snow on the ground on December 9 at Lake Spaulding (altitude, 5,075 feet), and only a trace at Bowman Dam (altitude, 5,347 feet). There was, however, an inch of snow at each place after the storm on December 12. From these and other data it is assumed that all precipitation in this basin was in the form of rain during the early days of the storm and turned to snow at altitudes above 5,000 feet during the last part of the storm period. It is concluded that there was snow on the ground at the beginning of the storm, ranging in depth from a trace at an altitude of about 5,500 feet to a few Inches at 6,000 feet, and about a foot at 7,000 feet. Much of this snow probably melted during December 9 and 10 , and contributed to the run-off.

The observed discharge at the river-measurement stations on Deer Creek near Smartville, Oregon Creek near North San Juan, and the North Fork of the Yuba River near Sierra City is essentially natural. The observed direct run-off at the following stations was adjusted for artificial storage and diversions: at the Middle Fork of the Yuba River near North San Juan and near Milton for diversions to M1lton-Bowman tunnel, amounting to 1.55 inches on the area above Milton and 0.35 inch on the area above North San Juan; the South Fork of the Yuba River at Lake Spaulding for storage in Lake Spaulding, Fordyce Reservoir, and other reservolrs; Canyon Creek below Bowmen Dam for storage in Bowman Lake, minus inflow from Milton-Bowman tunnel, plus diversions into Bowman-Spaulding canal, and for some storage in French Lake; and the Yuba River near Smartville for storage at Bullards Bar Reservoir, 
Fordyce Lake, French Lake, Lake Spaulding, and Bowman Lake, amounting to 1.3 inches over the drainage area.

The total direct mun-off, in inches, for the flood periods (see table $7, \mathrm{pp} .311-316)$ is 5.0 inches for the area upstream from the gaging station on the North Fork of the Yuba River near Sierra City, 11.9 inches for Canyon Creek, 12.2 inches for the South Fork of the Yuba River at Lake Spaulding, 3.75 inches for Oregon Creek, 5.6 inches for the Middle Fork of the Yuba River near North San Juan, 7.1 inches for Deer Creek near Smartville, 7.65 inches for the Middle Fork of the Yuba River at Milton, and 6.0 inches for the Yuba River at Smartville. The high run-off for Canyon Creek and the South Fork of the Yuba River at Lake Spaulding are probably partly due to snow melt.

The residuals range from 8.3 inches for the area of the North Fork upstream from Sierra City to 1.6 for Canyon Creek and 0.6 for the area of the South Fork above Lake Spaulding. The latter two figures are obviously low and it is probable that the rainfall map in this area would show more rain if there were additional data in the higher altitudes. However, the reason may be found in contribution from melting snow, as previousiy mentioned.

There are no recording precipitation gages in the basins where the run-off was essentialiy natural, but Oregon Creek shows a flrst peak in rainfall at 7 a.m. December 10, the main peak at 6 a.m. December 11 , and a third peak at noon December 11. The North Fork of the Yuba River near Sierra City shows the first peak at noon December 10, and the main peak at $4 \mathrm{a} \cdot \mathrm{m}$. December 11. Precipitation that caused the third peak on Oregon Creek may have fallen as snow above Sierra City. The run-off during the 24 hours of greatest flow was 44 percent of the total runoff for Oregon Creek and 52 percent for the area of the North Fork above Sierra City. Near Sierra City the flow during the main peak was about 50 percent greater than the maximum 24-hour average flow and on Oregon Creek about 75 percent greater.

of the three basins where the mun-off is natural, two, the North Fork of Yuba River near Sierra City and Deer Creek near Smartville, had highest momentary peak discharges for their periods of record. On the third, Oregon Creek, the storm in 1837 seemed considerably less severe than the storm in 1928 and the peak in 1928 is still the maximum. It is possible that in that basin melting snow was a larger factor in 1928 than in 1937 . 
Amorican River Basin

The American River Basin, upstream from the base gaging station at Fair Oaks, is triangular in shape, is about $65 \mathrm{miles}$ long, and has a

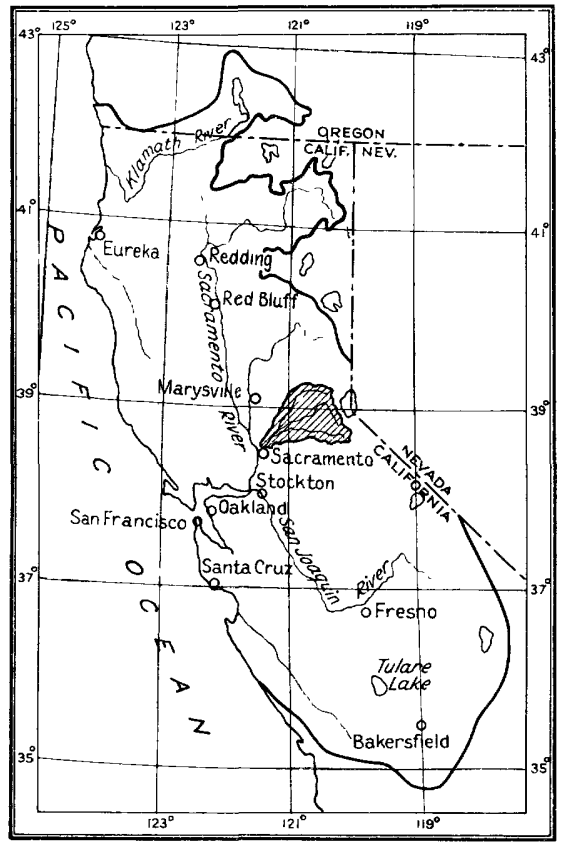

Figure 66.--Key map showing location of American River Basin. maximam width of 50 miles along the crest of the Sierra Nevada. (See fig. 66.) The American River is formed by the union of the South, Middle, and North Forks, which flow in deep canyons down the western slope of the Sierra. A few miles upstream from Fair Oaks the river emerges from its canyon and flows over cobble bars. In the lower reaches the river beu is practically filled with debris that was started downstream by early hyaraulic mining operations.

About 41 percent of the basin is above an altitude of 5,000 feet and 13 percent is

over 7,000 feet. The river is classed with the High Sierra streans. Generally speakjng, the American River Basin will have a greater depth of snowpack, at like elevations, than the Sierra basins near the southern end of the Sierras.

Granite and andesite predominate in the upstream portion of the basin. Quartzite, Iimestone, shale, slate, and glacial deposits are common in the lower areas.

The American River Basin contains many subdivisions, but the area upstream from each gajing station is not described in detail. A brief description of the outstanding features of some of the smaller basins follows.

Silver Creek, 8 tributary of the South Fork of the American River, rises at an altitude of about 9,000 feet and flows westward. The basin upstream from the gaging station (altitude, 2,250 feet) near Placerville is about 22 miles long and 10 miles wide, and 18 percent of it is above 
an altitude of 7,000 feet. Of the basin upstream from South Fork of Silver Creek near Ice House, 39 percent is above 7,000 feet.

Plum and Aldel Creeks are in two small basins tributary to the South Fork of the American River but at lower altitudes than Silver Creek. Both basins lie between altitudes of 4,000 and 7,000 feet. They flow northwestward between steep ridges that shut out a part of the sunlight and some of the rain from the southwest. They belong to the midslope type of streams. (See p. 348.)

There are 11 precipitation stations in the American River Basin, but only one, Twin Lakes (altitude, 7,920 feet), is above 5,000 feet, and the stations are otherwise poorly distributed. There may be considerable inaccuracy in the lines of equal rainfall at high altitudes.

The snow on the ground at Twin Lakes was reported as 8 inches on December 8 and 8 inches on December 12, but the original 8 inches melted and ran off on December 9 and 10 and was replaced durine the closing nours of the storm. Reports indicate that there was about 2 feet of snow on Echo Sumit at the beginning of the storm and not more than 2 feet at Desolation Valley (altitude, 8,200 feet). Any snow cover greater than about 2 feet would probably have had a tendency to absorb rain rather than to contribute to the run-off. Estimates of the United States Weather Bureau place the snow cover at 12 inches between altitudes of 6,500 and 7,500 feet. The melting of the snow would contribute about 2 or 3 inches to the mun-off. There must have been some snow on the area between altitudes of 5,500 and 6,500 feet. It is assumed that all precipitation in this area was rain on December 9 and 10, except that there were a few hours of snow during the last hours of the storm at the higher elevations.

Alder Creek, Plum Creek, and the three stations on Silver Creek show natural discharge. The flow at the other river-measurement stations was materially modifled by storage in reservoirs as follows: the flow on the North Fork of the American near Colfax by the contents of three reservoirs amounting to 0.25 inch over the drainage area; the Middle Fork of the American River by storage estimated as 50 percent of the capacity of Loon Lake, amounting to 0.1 inch over the area; the Silver Fork of the South Fork of the American River by storage in Twin Lakes and Silver Lake amounting to 1.7 inches; the South Fork of the American River near Kyburz by the last items and by diversions to El Dorado canal, the total adjustment amounting to 1.1 inches; the South Fork of the American River near Camino by the last items plus diversion to the American River flume, 
totaling 0.5 inch; the South Fork of the American River at Coloma by the last items plus some small storage, amounting to 0.2 inch; and the American River at Fair Oaks by 14 reservoirs with a net retention during the flood period amounting to 0.3 inch over the drainage area. The discharge at Silver Lake outlet and Twin Lakes outlet is controlled and the observed run-off has been adjusted to give natural run-off based on observations of changes of storage in the lakes.

The adjusted total direct run-off expressed in inches over the drainage areas (see table 7 ) varied from 8.85 and 7.9 above Silver Lake outlet and Twin Lakes outlet to 2.25 and 2.0 on Alder Creek and Plum Creek. The two higher figures include some run-off from snow. The low run-off on Alder and Plum Creeks is explained by the basin characteristics previously cited and by the probability that rainfall in those local areas was less than indicated by the general isohyetals.

Differences between rainfall and run-off range from 8.15 to 8.1 inches on Alder and Plum Creeks to 0.30 and 0.05 inches above Twin and Silver Lake outlets. The difference is largely explained by the drainage basin characteristics, but the negative value for silver Lake outlet indicates an error probably either in the adjustment for storage or in drawing the isohyetals. All the other run-offs and residuals in the American River drainage appear reasonably consistent.

There are recording rainfall gages at Georgetown in this basin and at Fiddletown just to the south. Both of these records show high rainfall Intensities in the early morning hours of December 10 and also on December 11, although Georgetown had the highest peak on December 10 and Fiddletown on December 11. These high intensities seem to correspond to the peaks about noon on December 10 and on December 11 in the gage-height graphs at the three gaging stations on Silver Creek. Peaks on the short drainage areas on Alder and Plum Creeks occurred three or four hours after the highest rainfall intensities. The second peak was the higher on all five of the streams where the run-off is unaffected by storage. The ratios between the greater of the peak flows and the maximum 24-hour average flow range from 134 percent on the South Fork of Silver Creek to 160 percent on Plum Creek. The ratios between the run-off during the 24 hours of greatest flow and the total run-off for the storm are very nearly 50 percent for all the streams having natural flow, except that for Alder Creek, which is 36 percent.

of the five basins with unregulated flow in this area, the momentary peak discharges in two, Alder Creek and Plum Creek, were much lower than the peaks of March 1928. At the three gaging stations on Silver Creek 
the peaks in December 1937 were moderately higher than those of March 1928.

The storm in 1928 was unusually heavy in the lower altitudes of some of the Sierra basins, such as PIum and Alder Creek Basins, and was accompanied by considerable contribution from melting snow at low and intermediate altitudes. The storm in 1937 was relatively less severe at the lower altitudes and probably was not augmented by melting snow in basins such as those of Plum and Alder Creeks.

\section{Northern Pacific basins}

The northern Pacific basins for which data are given in this report are those of the Russian, Eel, Klamath, and Smith Rivers, and three tributaries of the Klamath, the Shasta, Salmon, and Trinity Rivers. (See fig. 67.) They belong to the miscellaneous group of streams. (See p. 349.)

The Klamath River heads far to the northeast, in southern Oregon. The others drain parts of the California Coast Ranges, a region subject to heavy precipitation. The northern Pacific basins, including those not mentioned herein, Jield more than one-third of all the run-off in the State.

The three main branches of the Eel River rise at altitudes of about 5,000 to 6,000 feet, 15 to 20 miles to the north, south, and east of the gaging station at Hullville, just downstream from Lake Pillsbury (altitude, about 1,800 feet). The intermediate drainage area between the gaging stations at Hullville and below Van Arsdale Dam is very small. The river drops about 400 feet in the intervening 8 miles. The tributary drainage area downstream from the Van Arsdale gaging station and upstream from the gaging station at scotia is about 90 miles long, is 50 miles wide in the middle, and narrows as it approaches Scotia. Most of the water comes from tributaries draining mountains 5,000 to 6,000 feet high along the Coast Ranges, and the river flows generally northwestward. The gaging station at Scotia Is at an altitude of about 50 feet. The rocks of this region are nearly all sedimentary.

The Shasta River Basin is roughly 25 miles square. The river rises on the north slopes of Mount Shasta and moderately high mountalns to the east, and flows northward through the broad alluvial Shasta Valley and then through several miles of canyon to the junct1on w1th the Klamath River. The gaging station is at an altitude of 
about 2,000 feet. The rocks on the east side of the river are mostly volcanic; those on the south are chiefly volcanic, grenitic, and meta-

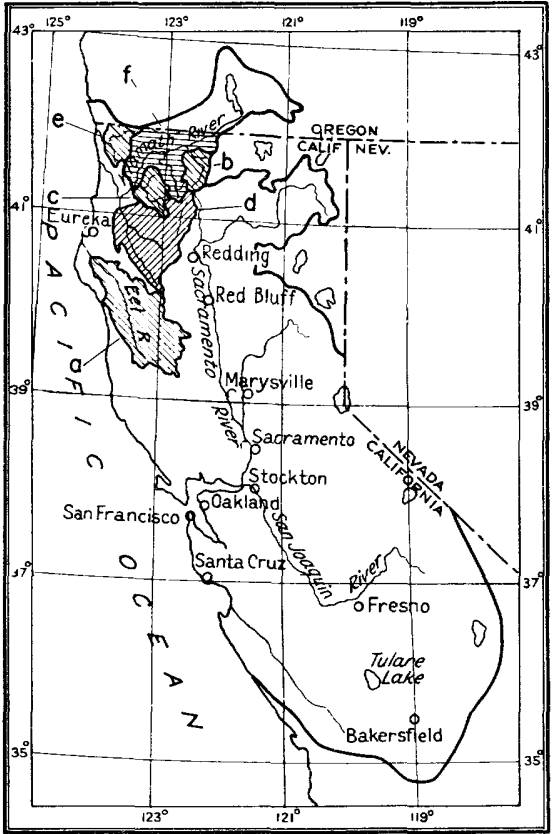

Figure 67.--Key map showing location of icrthern Pacific basins:

(a) Eel River, (b) Shasta River, (c) Salmon River, (d) Trinity

River, (e) Smith River, (f)

Klamath River between Copco and Somesbar. morphic; and those on the west are largely limestone. Large springs are found in the volcanic areas. There may be corresponding losses at other places. Discharge expressed in second-feet per square mile has little meaning in the Shasta Basin because of undefined limits of surface drainage and lava beds.

The Selmon River and its main branches rise along one of the crests of the coast Range at about 6,000 feet and f'low in a westerly direction. The gaging station near the nouth is at an altitude of about. 500 feet. Salmon River flow: into the Klamath just upstresm from the gaging station on thie Klamath. It drains a mountain area that is subject to heavy snowfall. In winter, and it has many characteristics of a High Sierra river. Whis regior is mostly unmapped geologically, but it probably contains a great variety of formations.

The Trinity River Basin includes some of the roughest and least populated mountain areas in California. Some of the mountain peaks are more than 8,000 feet above sea level. The river rises at an altitude of about 7,000 feet about 20 miles west of Mount Shasta, and flows southwestward for about 60 miles and then generally northwestward for about 70 miles to its junction with the Klamath River. There are three gaging stations on the river, one at Lewiston (altituile, about 1,800 feet), one near Burnt Ranch (altitude, 1,010 feet), and one near Hoopa (altitude, 315 feet). The geological formations vary widily and include granite, metamorphic and sedimentary rocks, and alluviun. 
Branches of the Smith RIver rise at altitudes of about 5,000 feet along 40 miles of the crest of the westernmost Coast Range, and converge a short distance upstream from the gaging station, which is at an altitude of a few hundred feet. This is a region of very heavy rainfall and little snow, and the river is extremely responsive to storms. It may have the highest average discharge per square mile of any basin in California.

On the Russian River the only information avallable is the momentary peak discharge. A description of the basin is therefore not given.

The flow of the Klamath River at Somesbar is controlled to such an extent by upper Klamath Lake, by other storage reservolrs, and by power plants that no attempt has been made to adjust the observed run-off. A description of the basin is not given.

There are about 30 precipitation records in the northern Pacific and adjacent basins. However, these records are very unequally distributed among the basins, and there are no avallable records in the upstream portion of the Eel, Salmon and Trinity Basins. In general there are no records at high altitudes along the crests of the Coast Ranges. Therefore the isohyetal lines as drawn are subject to error.

Snow data are scarce, but the information avallable in records of the United States Forpst Service indicates that there were patches of snow on the shaded slopes on the comparatively small areas above an altitude of 6,500 feet. This small amount undoubtedly melted on December 9 and 10, but added very little to the mun-off.

The observed run-off at the three river-measurement stations on the Trinity River and at the Salmon River station is natural. Flow at some of the other stations is materially affected by storage in reservolrs and diversion: the Eel River at Hullville by retained storage in Lake Pillsbury, amounting to 0.05 inch over the drainage area; the Eel River at Van Arsdale Dam and at Scotia by storage in Lake P1llsbury and Van Arsdale Reservoir and by diversions to the Potter Valley power house, amounting to 0.25 inch on the upper area and 0.05 inch on the whole area above Scotia; and the Shasta River near Yreka by storage in Shasta Reservoir, amounting to 1.65 inches over the area. The run-off at these stations has been adjusted to show natural mun-off.

Indicated direct run-off in inches of the natural flow streams (see table 7, pp. 311-316) was 3.55 for the Salmon River, and 4.15, 3.65, and 3.75 for the Trinity River at Lewiston, Burnt Ranch, and near Hoopa, respectively. 
The record of stage on the Smith River is incomplete, owing to stopping of the water-stage recorder. The momentary peak run-off was 129 second-feet per square mile, although the only nearby rainfall records indicsted not to exceed 4 or 5 inches of rain.

The run-off adjusted for storage amounts to $8.7,8.05$, and 7.35 inches for the Eel River at Hullville, below Van Arsdale Dam, and at Scotia, respectively, and 0.35 inch on the Shasta River near Yreka. The storm was evidently not so heavy in the northern end of the State, generally, although the Smith River had a very high momentary peak.

Differences between rainfall and run-off range from 2.25 for the Trinity River at Lewiston and the Salmon River to 4.05 inches for the Shasta River near Yreka.

A recording rainfall gage at Eureks registered high intersities atout noon December 10, noon December 11, and about 8 p.m. December 11. Gage-height graphs at stations on the Salmon River at Somesbar and the Trinity River at Lewiston showed pesks about midnight December 10, but high stages continued during December 11. The peak occurred at noon December ll at the lower gaging station on the Trinity River.

The ratios between the momentary peak discharge and maximum 24hour average flow are very low, averaging about 110 percent. Ratios between the run-off during the 24 hours of highest flow and the total mun-off for the storm range from 32 to 40 percent. At 811 of the four river-messurement stations where flow is unregulated the momentary peak discharges were the highest on record.

\section{San Francisco Bay basins}

The San Francisco Bay basins as discussed here include those of San Francisquito, Stevens, Guadalupe, Campbell, Coyote, and Alameda Creeks, and also of Conn Creek in Napa River Basin. (See fig. 68.) They resemble the foothill type of streams. (See p. 349。)

Alameda Creek is the largest stream draining into the southern part of San Francisco Bay, and has a basin about 50 miles long and 10 to 20 miles wide. The long lateral tributaries from the south, which drain from sedimentary formations at altitudes of 3,000 to 4,000 feet, are the most important. Most of the laterals from the north flow through a brosd sedimentary valley, but there are some volcanic rocks interbedded with the sediments. The gaging station is at an altitude of about 100 feet. 
Calaveras Reservoir is on Calaveras Creek, a tributary of Alameda Creek.

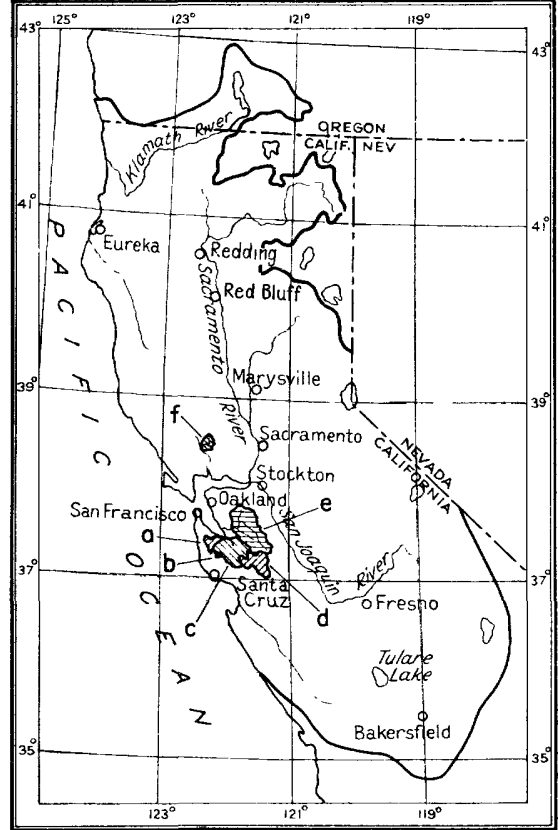

Figure 68.--Key map showing location of San Francisco Bay basins:

(a) San Francisquito Creek, (b) Stevens Creek, (c) Guadalupe Creek, (d) Coyote Creek, (e) Alameda Creek, (f) Conn Creek.
Cornte Creek and its tributaries rise on the southern slope of Mount Hamilton anc flow southward for about 15 miles, draining sedimentary formations at altitudes of 3,000 to 4,000 feet. There the creek turns northwestward and flows in a canyon along the Ify yward fault line until it passes out of the hills near the upper gaging station near Madrone into the flat Sarita Clara Valley. It then flows in a comparatively flat chanrel between hills on the east and an alluvial valley on the west, and finally thrugh a flat delta to the bay. The downstream gaging station near Edenvale is 190

feet above sea level.

Alamitos, Guadalupe, and Los Gatos Creeks rise on the north slopes of Loma Prieta Mountain at altitudes of more than 3,000 feet, and flow generally northward 4 to 10 miles through sedimentary formations. The gaging stations are at the edge of the hills at altitudes between 200 and 360 feet. From here the streams flow through channels cut in alluvium. Guadalupe and Los Gatos Creeks unite immediately upstream from the gaging station in San Jose.

Campbell and Stevens Creeks drain sedimentary and serpentine rock formations as they drop from altitudes between 2,000 and 3,000 feet to sea level. The gaging stations are at altitudes of 400 or 500 feet at the edge of the hills, 5 to 6 miles from the headwaters.

San Francisquito Creek and its tributary, Los Trancos Creek, rise on a 2,000-foot ridge southwest of Stanford University, and drop nearly to sea level in a few miles. The gaging stations are a few miles from the source at altitudes of 120 and 160 feet. The upper basins contain a 
variety of sedimentary formations, which are probably badly shattered, and the stream courses seem to have a relation to the San Andreas fault. San Francisquito Creek flows for about 4 miles between the upstream and downstream gaging stations in a channel cut in alluvium higher than the bordering areas.

Conn Creek, In Napa County on the north side of San Francisco Bay, originates in hills some 2,000 feet above sea level. It takes a general southeasterly course and, in times of flood, unites with Napa River (tributary to San Pablo Bay, an arm of San Francisco Bay). The gaging station is at the edge of the foothills and is about 180 feet above sea level. The basin contains a variety of sedimentary, intrusive, and volcanic formations.

Rainfall data are more plentiful around San Francisco Bay than in any other locality in northern California. There are 23 rainfall stations within this drainage area and numerous other stations in adjacent territory. A great majority of these gages are unofficial, being maintained by private individuals or quasi-public institutions. Most of the records collected are at points in the valleys, and few data are available at the higher altitudes where the precipitation was generally heavy. Lines of equal rainfall are believed to be fairly well defined, however, in spite of the steep gradients of variation in precipitation.

There was no snow on the ground at the beginning of the storm, and none fell during the storm.

Basins in which the run-off is natural are those of Conn Creek, Los Gatos Creek, and Campbell Creek. The observed run-off from the other basins has been adjusted for storage. The flow of Los Trancos Creek was adjusted for diversions to Los Trancos canal, such adjustment amounting to 0.4 inch over the drainage area. San Francisquito Creek at Stanford and at $\mathrm{Palo}$ Alto were adjusted for storage in Searsville Lake and for diversions to Los Trancos and Lagunita canals, amounting to 0.4 inch for each station. Stevens and Guadalupe Creeks were adjusted for Stevens and Guadalupe Reservoirs, amounting to 1.0 and 3.05 inches, respectively. Alamitos Creek was adjusted for storage in Calero and Almaden Reservoirs, totaling 2.1 inches. Guadalupe Creek at San Jose was adjusted for storage in Calero, Almaden, Vasona, and Guadlupe Reservoirs, totaling 0.9 inch. Coyote Creek near Madrone and at Edenvale was adjusted for storage in Coyote Reservoir, amounting to 1.15 inches on the upper drainage area and 0.95 inch on the lower. Alameda Creek was 
adjusted for storage in Calaveras Reservoir and diversions for San Franclsco water supply amounting to 0.35 inch over the drainage area.

The adjusted run-off in inches (see table 7, pp. 311-316) ranges from 0.6 and 0.75 on Los Trancos and Alameda Creeks to 4.15 and 4.35 on Los Gatos and Guadalupe Creeks at Guadalupe, respectively. The precipitation was definitely lighter on the northern basins in this group and exceeded their absorptive capacity by comparatively small amounts. There were centers of heavy precipitation along the divide between the coast and the bay drainage area from Saratoga Gap to and south of Loma Prieta, a large mountain on which lie the headwater areas of Los Gatos, Guadalupe, Alamitos, and Uvas Creeks. The rainfall was much lighter on the second range of hills, which is drained by Alameda and Coyote Creeks.

The differences between rainfall and run-off are generally high. This is particularly true of Stevens, Campbell, and Los Gatos Creek Basins in which residuals of between 10 and 12 inches are indicated. These values are partially substantiated by the extremely high value of 14.85 inches for San Lorenzo River, just over the ridge, and 9.1 inches for Uvas Creek, to the south.

The recording rain gage (see fig. 27, po 62) at San Francisco may be indicative of the distribution of the storm precipitation in the San Francisco Bay and Santa Cruz Mountain areas, although the total amount recorded is much less than that in much of the area. The precipitation of greatest intensity, about $10 \mathrm{a} . \mathrm{m}$. December 9 , is not reflected in discharge peaks at any of the stream-measurement stations. Later periods of high intensity at about $2 \mathrm{p.m}$. on the loth and the early morning of the 11 th seem to be reflected in peaks on Conn and Los Gatos Creeks at 6 a.m. on the loth and in the morning of the lith. A short, sharp storm about $6 \mathrm{a} . \mathrm{m}$. on December 12 must have been local to San Francisco, there being no effect on the run-off of Los Gatos Creek and only a slight effect on Conn Creek.

The ratios between the flow at the momentary peaks and the maximum 24-hour average flows are high, as is to be expected on short creeks with high gradients and draining steep hills, like Los Gatos, Campbell, and Conn; these ratios were 182, 177, and 201 percent, respectively. The ratios between the highest 24-hour run-off and the total run-off for the storm range from 49 to 59 percent.

Maximum momentary peaks on Los Gatos, Campbe11, and Conn Creeks were considerably lower than the peaks of February 1937. However, total direct 
run-off during the storm of December 1937 exceeded the total direct muoff of the February storm. This behavior is apparently accounted for by the double peak and the broader hydrograph of the flood of December 1937.

\author{
Owens Lake basins
}

The streams in Owens Lake Basin discussed in this report are Owens River and Rock, Pine, Big Pine, Independence, and Tuttle Creeks, (See fig. 69.)

The Owens River rises along the crest of the Sierra Nevada immediateIy east of the headwaters of the San Joaquin River around Mount Lye11, and the smaller streams on the west side of Owens Valley rise along this crest between Mount Lyell and Mount Whitney. The sources are small glaciers or snow banks that lie on the shady side of the peaks and crests. The streams emerge from the mouths of the canyons at the eastern base of the Sierra upon talus slopes and detrital cones, and cross a broad alluvial plain. In this belt of debris the streams lose a large amount of water, part of which reappears in springs in the valley.

The large underground water storage in Owens Valley is directly related to the small surface run-off and to the porous surface that characterizes both the detrital cones and the lava fields. Parts of the Owens Basin are non-contributing to surface run-off, owing to their volcanic (lava) formation. This region is semi-arid, desert in parts, on the lower western slopes of the Sierra Nevada and Coast ranges. The streams in Owens Valley, to an even greater extent than streams on the west side of the Sierra Nevada, depend upon melting of winter snows for run-off. It therefore is evident that these streams do not show and can not be expected to show either a large surface discharge per square mile or a large total run-off for a given storm. As in the Pit River Basin, discharge per square mile has little significance.

The Owens River upstream from the gaging station near Round Valley has a basin roughly 25 miles long and 18 miles wide, in which the two main tributaries rise at altitudes of 8,000 to 12,000 feet, flow eastward to unite in Long Valley at about 6,800 feet, and then flow southward through a comparatively flat valley. The gaging station is at an altitude of 4,450 feet. Almost the whole basin is at an altitude of more than 5,000 feet. The headwater areas on the escarpment of the sierra Nevada contain chiefly metamorphic rocks and granite overlain locally by volcanic deposits. The middle and lower parts of the basin are alluvium and an old lake bed. The upper part of Owens Valley and the 
volcanlc rock fields at its head are traversed by a network of small

faults. There are numerous hot springs in the region west of Long Valley.

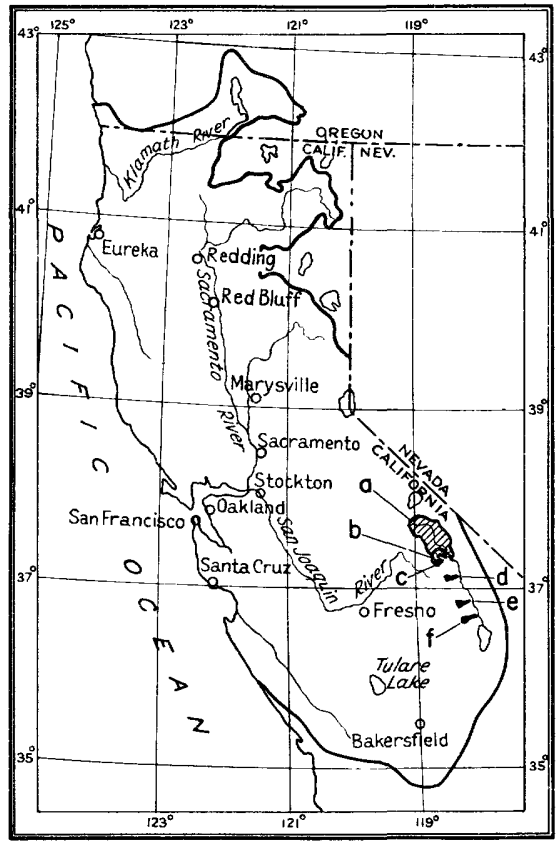

Figure 69.--Key map showing location of Owens Lake basins:

(a) Owens River upstream from Round Valley, (b) Rock Creek, (c) Pine Creek, (d) Big Pine Creek, (e) Independence Creek, (f) Thutle Creek.
Rock Creek and Pine Creek rise at very high altitudes of about 11,000 to 12,000 feet on the granitic escarpment of the Sierra Nevada, and drop sharply for a few miles in a northeasterly direction, Rock Creek among glacial deposits, and Pine Creek among metamorphic rocks, moraines, and terrace deposits. Pine Creek has a particularly high proportion of its area at high altitudes, and is associated with a fault line in its middle course. The grging station on Rock Creek is at an altitude of about 4,900 feet, and the station on Pine Creek is at about 5,250 feet.

Big Pine Creek heads in a row of small glaciers, of which Palisade Glacier is the largest, at an altitude of about 12,500 feet, and drops sharply eastward through glacial and terrace deposits. The gaging station is at an altitude of about 4,200 feet. The length from source to gaging station is only about 10 miles.

Independence and Tuttle Creeks also rise at very high altitudes on the granitic escarpment and plunge eastward for a few miles before reaching comparatively gentle slopes on terrace deposits. The gaging stations are at altitudes of about 4,000 feet.

The only rainfall records available in the Owens Basin are those at Blg Pine Creek power house No. 3, and the only ones avallable In Big Pine Creek Basin are those at Crooked Creek. However, there are about 12 nearby rainfall stations that help to define the lines of equal rainfall in the dralnage areas of Owens River and Rock, Pine, Big Pine, Independence and Tuttle Creeks with a fair degree of accuracy. The extremely steep 
slopes of these basins add to the difficulties of definition of the rainfall. The records at Ellery Lake (altitude, 9,600 feet), Gem Lake (altitude, 9,120 feet), Bishop Creek (altitude, 9,390 feet), Lake Sabrina (altitude, 9,100 feet), and South Lake (altitude, 9,620 feet) were very useful in defining the precipitation at high altitudes. Most of the other rainfall stations are located along the Owens River.

With the exception of 1 inch at Gem Lake, there was practically no snow at any of the five high precipitation stations at the beginning of the storm on December 9. The following new snow was reported: at Ellery Lake, 2 inches on December 9, 17 inches on the 10th, 4 inches on the IIth, and 3 inches on the 12th, the accumulation on the 12th being 20 Inches; at Gem Lake, an accumulation of 7 inches on December 12; at Bishop Creek, 2 inches on the IIth, and one inch on the 12th; at Lake Sabrina, $1 / 2$ inch on December 9,2 inches on the 11 th, and 6 inches on the 12th, the accumulation on the 12 th being 7 inches; at South Lake, a trace on December 9, 6 inches on the 10th, 5 inches on the 11 th, and 5 inches on the 12th, the accumulation on December 12 being 12 inches. The water content of the snow added up to 6.43 inches at Ellery Lake, 0.92 inch at Lake Sabrina, and 5.95 inches at South Lake. As the total precipitation during the storm was reported to be 6.84 inches at Ellery Lake, 4.66 at Gem Lake, 6.75 at Bishop Creek, 8.72 at Lake Sabrina, and 5.40 at South Lake, it is obvious that almost all of the precipitation was snow above an altitude of 9,500 feet, and partly snow and partly rain at 9,000 feet, at which altitude there was no run-off. At Lundy Lake (altitude, 7,760 feet), 2 inches of snow was reported on December 12, but this was gone on December 14. From this record and that at Bishop Creek, it would seem that at an altitude of 8,500 feet the precipitation fell as rain during December 9 and 10 and changed to snow on the last days of the storm, and that practically all the precipitation was rain below about 7,500 feet.

Run-off was unregulated at all the six stream-measurement stations In this area, and amounted to 0.2 inch over the drainage area on the Owens River, 0.15 inch on Rock Creek, 0.25 inch on Pine Creek, 0.1 inch on Big Pine Creek, 0.1 inch on Independence Creek, and 0.15 inch on Tuttle creek. Assuming that only the area below 9,000 feet contributed, these figures would be $0.25,0.45,1.1,0.25,0.15$, and 0.25 respective1y. The Pine Creek Basin has a particularly high percentage of its area above an altitude of 9,000 feet. 
The differences between precipitation and mu-off were 3.8 inches for the Owens River, 4.45 for Rock Creek, 5.25 for Pine Creek, 5.3 for Blg Pine Creek, 4.9 for Independence Creek, and 2.95 for Tuttle Creek. These values seem consistent. Assuming that only the area below 9,000 feet contributed and using the precipitation for this area, the respective residuals would be $3.55,3.35,4.1,4.55,4.25$, and 2.35 Inches.

Ratios between the run-off during the 24 hours of highest flow and for the entire storm range from 25 to 53 percent. Ratios between the momentary peak discharge and the maximum 24-hour average discharge range from 146 percent on Owens River to 205 percent on Pine Creek. Both sets of ratios are consistent.

There are no recording rainfall records avaliable in this region, but all the stream-stage records show rises beginning in the early momIng of December 10, and all the streams except the Owens River near Round Valley reached low peaks in the forenoon of the same day. The Owens River reached the first peak just before midnight. After a 12 to 14hour recession, a second rise started, and the five smaller streams reached a higher peak in the afternoon of December 11. The Owens River reached its higher peak at $10 \mathrm{p.m}$. the same evening.

The momentary peak of 1,560 second feet on the Owens River exceeded the previous peak of 1,190 second feet on June 30, 1907. The momentary peaks of 115 and 207 second feet on Rock and Pine Creeks did not exceed the previous record peaks of 162 and 350 second feet on June 17, 1927, and JuIy 21, 1936, respectively.

\section{Truckee RIver Basin}

Truckee River has its source in Lake Tahoe, the dominating feature of the basin. The lake, which has a surface area of about 193 square miles, occupies part of an elongated valley between the steep east front of the Sierra Nevada and the west front of the Carson Range. Glacial lakes occupy small valleys along the east front of the slerra, at altitudes of more than 9,000 feet, and are drained by small streams entering Lake Tahoe. The gaging station on the upper Truckee River is immediately downstream from the lake outlet, at an altitude of about 6,200 feet above sea level. (See fig. 70.)

The Slerra Nevada and Carson Ranges are made up chiefly of granitic rocks, and the Sierra has been extensively glaclated. Volcanic rocks, alluvium, and glacial deposits occupy the valley tract. 
The tributaries of Donner Creek rise at about 7,000 feet near Donner Summit, in granite, and rlow eastward through glacial Donner

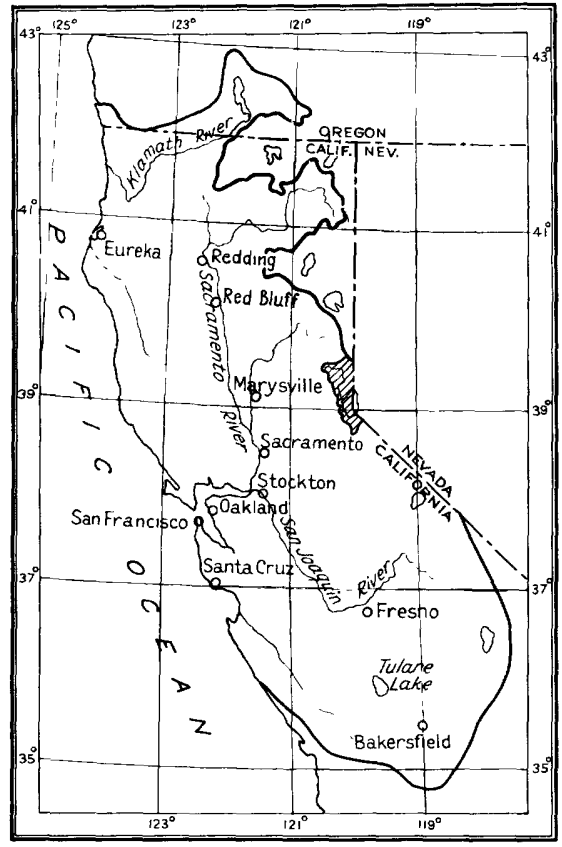

Figure 70.--Key map showing location of Truckee River Basin (California part.)
Lake. The gaging station

is not far from the confluence of tile creek with Truckee River and is at an altitude of about 5,800 feet。

The intermediate drainage area between the Truckee River gaging stations at Tahoe and Iceland is about 22 miles long from north to south and 18 miles wide from east to west. The mountains are composed mostly of volcanic material, and there are considerable amounts of glacial deposits in the valleys. After leaving Lake Takoe, the Truckee River flows northward to the junetion with Donner Creek, then northeastward past the Iceland gaging station, at an altitude of about 5,420 feet, and finaliy northward and northwestward and discharges into Pyramid and Winnemucca lakes.

There are four rainfall stations in the Truckee River basin upstream from Iceland, and some in adjacent territory, but the Iines of equal rainfall are poorly defined. The steep rainfall gradient and the rapid change in altitude add to this uncertainty.

A considerable part of the drainage area along the western side of the basin is above 7,000 feet. Snow conditions at soda springs were probably typical of the high area. At Soda Springs (altitude, 6,752 feet) there were 13 inches of snow on the ground on December 8 , 13 inches on the 9 th, 10 inches on the 10th, a trace on the 11 th, 8 inches on the $12 t h$, and 7 inches on December 13 th. The orlginal 13 inches of snow melted and ran off during the early days of the storm and was followed by a lighter cover during the closing hours of the storm. There was probably some snow at all altitudes above 6,000 feet at the beginning of the storm. 
Run-off at all three gaging stations is controlled by large lake storage upstream: the two Truckee River stations by Lake Tahoe, and Donner Creek by Donner Lake. Storage quantities in these lakes were relatively so large and uncertain that no attempt has been made to adjust the observed flow for storage in order to compute the total flood run-off.

\section{FLOOD CRESTS}

Various agencies of the Federal and State governments, together with public-service and other companies, obtained records of the crest stages reached by the San Joaquin and Sacramento Rivers during December 1937. Some of the records were obtained at regular rivermeasurement stations for which additional data appear in this report. Other records are at places for which only the crest stage is available. All these records of crest stages for the two rivers have been assembled in table 10, which shows both the gage height in feet and the altitude above mean sea level.

The profile of crest stages on the San Joaquin River is shown graphicilly in figure 71 and for the Sacramento River in figure 72. For comparison, the profile of crest stages in the San Joaquin River during the flood of March 1938 is shown in figure 74 on page 492.

It should be noted that the table and graphs show the absence, rather than the presence, of a peak on the lower San Joaquin River in December 1937. The "peak" that reached the Geological Survey gaging station near Newman on December 24, 1937, was only 6,050 second-feet, and the small rise that appeared at the Vernalis gaging station on December 26 had little relation to the record peak that passed the Friant gaging station on December 11. 
Table 10.--Flood-crest stages

Stream and gaglng station

\section{San Jogquin River}

Frlant, U. S. Geological Survey gage, $1 \mathrm{mlle}$ upstream from Cottonwood Creek

Skaggs Bridge, Southern California Ed1son Co. gage 2 miles downstream from bridge, near Herndon Gravelly Ford, M1ller \& Lux gage, 150 feet downstream from Intake of Graveliy Ford canal

Whitehouse, M1ller \& Lux gage, 400 feet upstream from head of Lone W1llow Slough

Mendota Dam, M1Iler \& Lux gage, 25 feet upstream from dam

Flrebaugh, Miller \& Lux gage, highway bridge

Temple Slough, Miller \& Lux gage, headgate of slough

Santa R1ta Bridge, Miller \& Lux gage

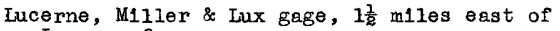
Lucerno farm

Chamberlain Slough, State Division of Water Resources gage, $6 \frac{3}{2}$ miles west of El Nido

Turner Island Bridge, State Division of Water Resources gege, 1 mile downstream from Turner ranch

Fremont Rosd bridge, State Division of Water Resources gage, 5 miles northeast of Gustine

Newman, U. S. Geolog1cal Survey gage, 300 feet downstream from mouth of Merced River

Grayson, c1ty of San Franc1sco gage, La1rd Slough, I골 miles east of Grayson

Tuolumne River, c1ty of San Franc1sco gage, on Tuolumne River, 2,000 feet upstream from junction with San Jogquin River

Vernal1s, U. S. Geological Survey gage, 3 miles downstream from mouth of Stanislaus R1ver

Lathrop, U. S. Weather Bureau gage

\section{Sacramento R1ver}

Antler, U. S. Geologlcal Survey gege, right bank, 0.2 mile downstream from highway bridge

Kennett, U. S. Geological Survey gage, highwey bridge

Kesw1ck, U. S. Geologlcal Survey gege, left bank, $0.5 \mathrm{mile}$ downstreem from Spring Creek

Red Bluff, U. S. Geological Survey gage, left bank, 4 miles upstream from Red Bluff

Red Bluff, U. S. Weather Bureau gage, bridge

Hamilton City, U. S. Weather Bureau gage, Glanel11 Brldge

Ord's Ferry, State Division of Water Resources gage, right bank, ferry crossing

Butte City, U. S. Geologlcal Survey gage, left bank, $0.2 \mathrm{mile}$ downstream from highway bridge

Moulton Break, State Division of Water Resources gage, right bank, Gordon's pump house

Colusa, State D1vision of Water Resources gage, we1r

Colusa, U. S. Geologlcal Survey gage, right bank, highway bridge

Merldian, Sacramento Northern Ry. gage, brlage

Tisdale weir, State D1vision of Water Resources gage, pumping plant, 1,000 feet downstream from we1r

Wilkins Slough, J. S. Geologlcal Survey gage, right bank, 1,500 feet downstream from pumping plant of reclamation distriot No. 108

Knights Landing, U. S. Geological Survey gage, left bank, just above Southern Pac1fic Co. bridge

Fremont weir, Corps of Engineers, U. S. Army, gage, upstream end

Fremont weir, Corps of Engineers, U. S. Army, gage, downstream end

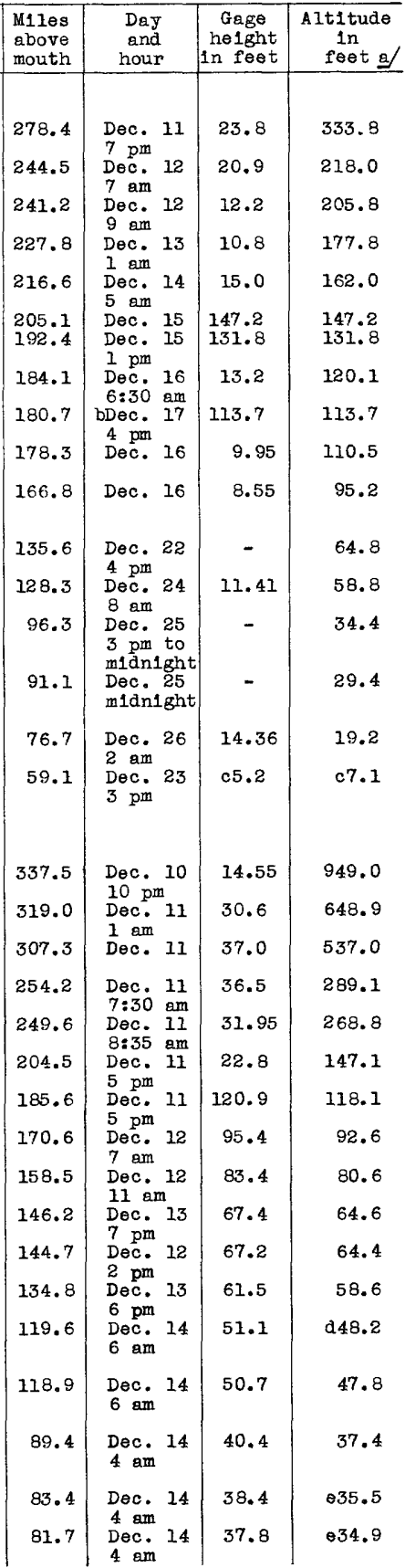

a Above mean sea level.

b Gage helght practicaliy unchanged, Dec. 16 and 17 .

c Probably affected by tide.

d Elevation of crest of we1r, 39.4 feet.

e Elevetion of crest of ve1r, 30.6 feet. 
Table 10.--Flood-crest stages--Continued

\begin{tabular}{|c|c|c|c|c|}
\hline Stream and gaging station & $\begin{array}{l}\text { Miles } \\
\text { above } \\
\text { mouth }\end{array}$ & $\begin{array}{l}\text { Day } \\
\text { and } \\
\text { hour }\end{array}$ & $\begin{array}{c}\text { Gage } \\
\text { hoight } \\
\text { in feot }\end{array}$ & $\begin{array}{c}\text { Altitude } \\
\text { in } \\
\text { feet a }\end{array}$ \\
\hline 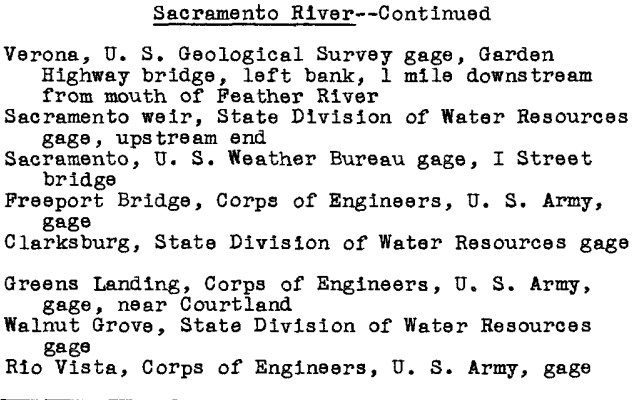 & $\begin{array}{l}78.7 \\
63.5 \\
59.4 \\
46.6 \\
42.2 \\
34.5 \\
26.6 \\
12.5\end{array}$ & $\begin{array}{l}\text { Dec. } 14 \\
3 \text { am } \\
\text { Dec. } 12 \\
3 \text { am } \\
\text { Dec. } 12 \\
2 \text { am } \\
\text { Dec. } 12 \\
3 \text { am } \\
\text { Dec. } 12 \\
3 \text { am } \\
\text { Dec. } 12 \\
3 \text { am } \\
\text { - } \\
\text { Dec. } 16 \\
1 \text { pm }\end{array}$ & $\begin{array}{l}38.23 \\
31.4 \\
27.7 \\
23.3 \\
21.2 \\
18.8 \\
12.7\end{array}$ & $\begin{array}{r}35.3 \\
128.4 \\
27.8 \\
20.3 \\
18.2 \\
15.8 \\
9.7\end{array}$ \\
\hline
\end{tabular}

a Above mean sea level.

$f$ Elevation of crest of weir, 22.0 feet. 


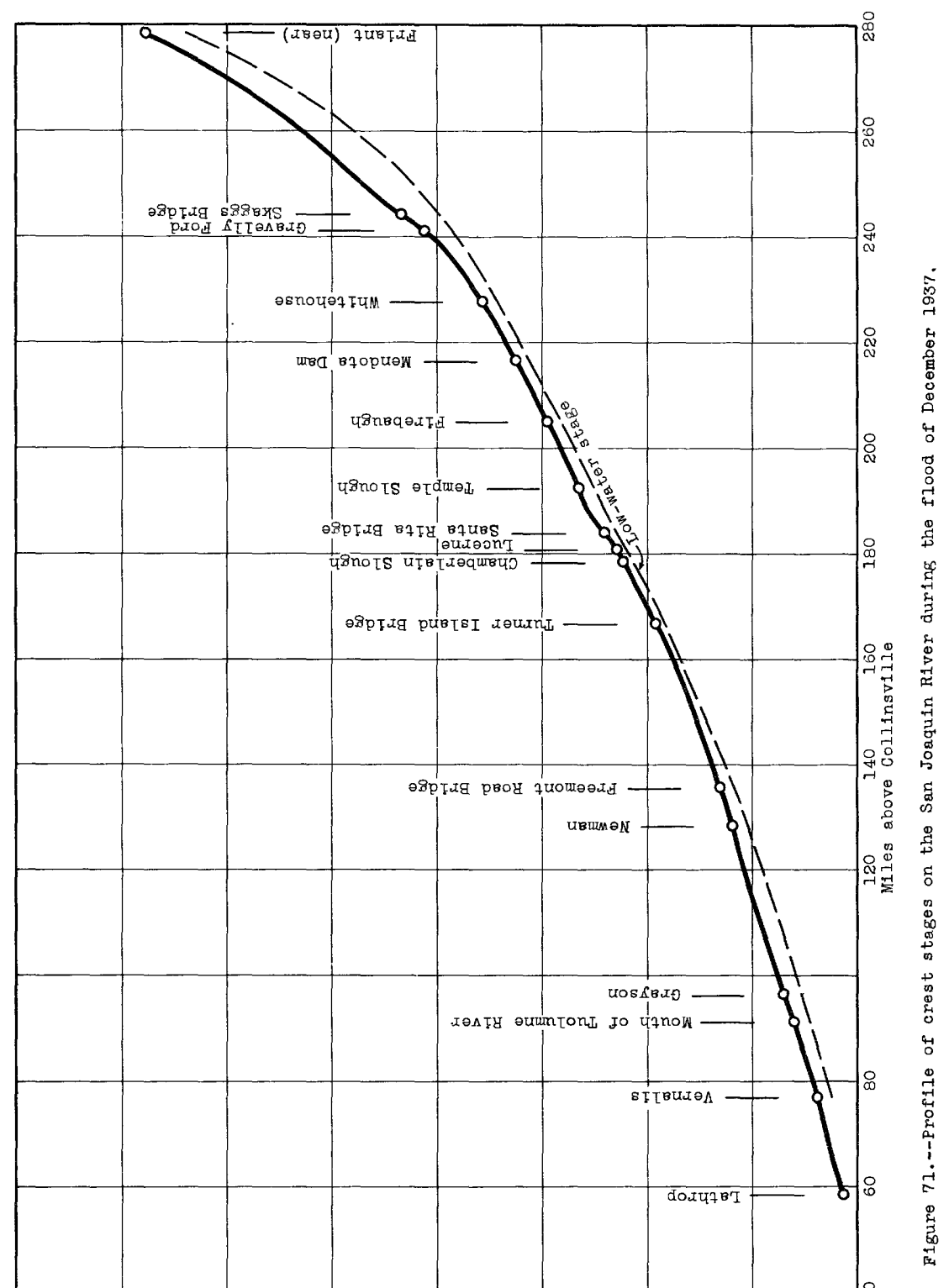




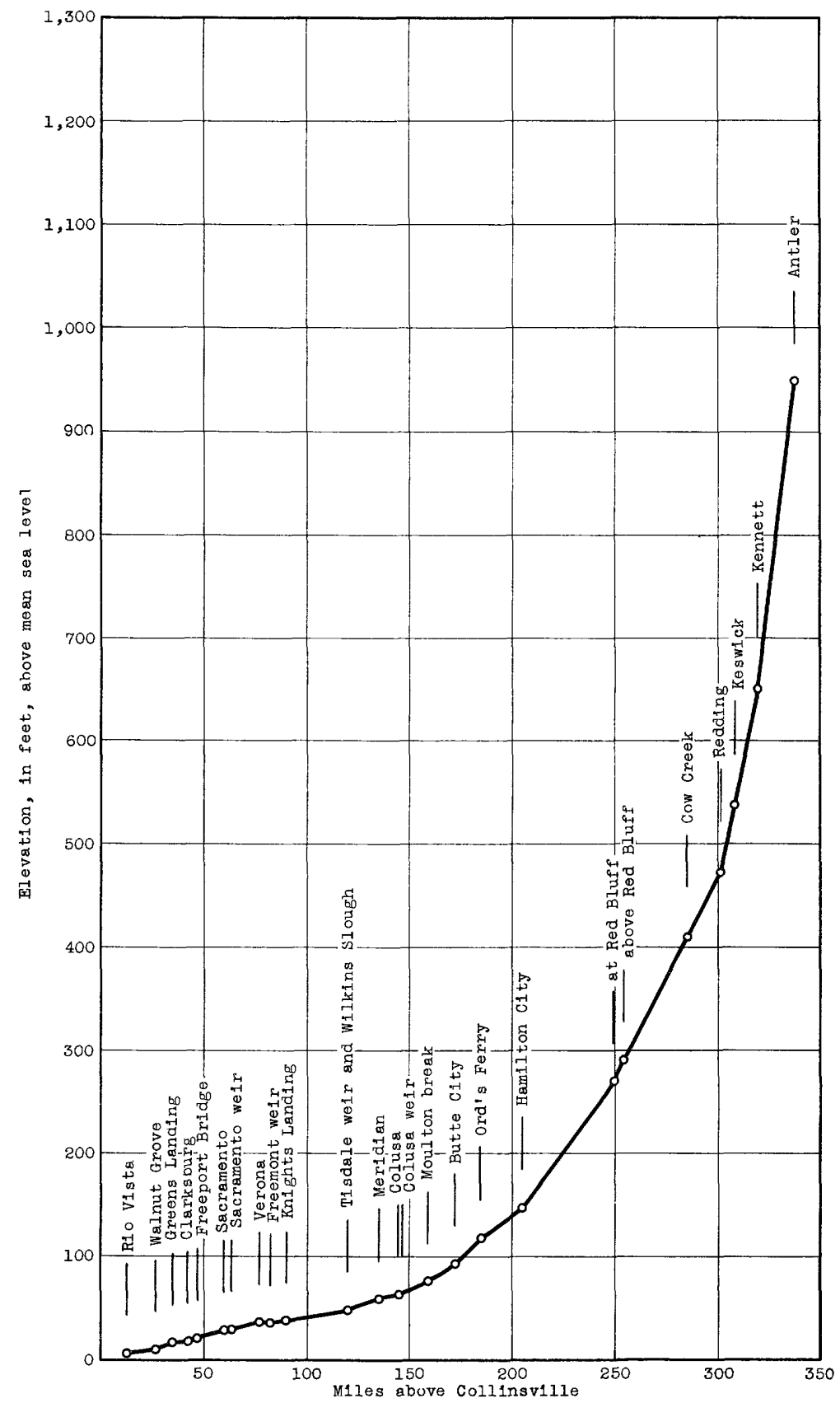

Figure 72.--Profile of crest stages on the Sacramento River during the flood of December 1937. 
Information is very meager about floods in northern California prior to about 1850, when extensive settlement of the state began. There were several great floods in the region between 1850 and about 1890, the time when systematic records of stream flow began. With regard to those floods, authentic data are available on the rainfall conditions and crest stages in some localities. The data are supplemented by accounts in local histories and newspapers, which give much general information on the duration and areal extent of the largest floods. From 1890 to 1907 flood data on the larger rivers have been published in watersupply papers of the Geological Survey, and since 1907 the published records have continuously increased in comprehensiveness and accuracy.

Comprehensive and reliable comparisons of the magnitude of early floods cannot be made, because of complicated and variable artificial conditions and the lack of complete data. Mining, reclamation, flood protection, and other works have greatly altered the regimen of the rivers and at some places to such an extent that the crest stages of recent minor floods were higher than those of early major floods. $15 /$ Comparisons of available flood data for some streams are shown in tables 11 to 17 .

Further on in this chapter detailed information about floods is given for each major stream basin, or group of basins.

\section{Sources of information}

Some of the principal sources of published information about previous floods are the newspapers, the county histories and other historical writings, and the Federal, State, and private reports describing floods or flood control problems. Of these sources the newspapers generally have the most detailed descriptive accounts of the early floods and the special reports generally have the most specific data. In addition, it is possible in many cases to obtain eye-witness accounts of previous floods from local residents, sometimes supplemented by wellauthenticated high-water marks. Many of these eje-witness accounts are not specific as to dates but may be verified by newspaper reports.

15. Discussions of changes in conditions of several California streams due to artificial causes are published in $U$. S. Geol. Survey Prof. Paper 105, Water-Supply and Irrigation Papers 17, 18, and 19, several reports of the Corps of Engineers, U. S. Army, and reports and publications of the state of California. 
It is not practicable to give in this report detailed references to all sources of information of former floods. More specific data about sources than are here supplied are available in the files of the San Francisco district office of the Geological Survey.

\section{Newspapers}

There is given below a partial list of the newspapers consulted to obtain descriptions of the floods that are discussed in this report. These are grouped according to the basins to which the local news was related, although the State-wide accounts found in newspapers of the principal cities were the only news sources consulted for some localities and floods. The papers are listed, alphabetically by cities, with the latest names and places of publication. Many of them have had various names, and a few were published at other places in the earlier years. The clties are in California unless otherwise designated.

San Francisco Bay basins.--Napa Daily Register, Napa; San Francisco Chronicle, San Francisco.

Kern River Basin.--Bakersfield Californian, Bakersfield.

Tulare Lake Basin.--Fresno Expositor, Fresno; Fresno Morning Republican, Fresno; Visalia Delta, Visalia.

San Joaquin River Basin.--Mariposa Gazette, Mariposa; Stockton Morning Independent, Stockton.

Sacramento River Basin.--Folsom Telegraph, Folsom; Marysville AppealDemocrat, Marysville; Red Bluff Beacon, Red Bluff; Red Bluff Sentinel, Red Bluff; Tehama County People's Cause, Red Bluff; Sacramento Bee, Sacramento; Dally Sacramento Placer Times, Sacramento; Sacramento Dally Union, Sacramento.

Northern Pacif1c basins.--Del Norte Record, Crescent C1ty; Humboldt Standard, Eureka; Humboldt Times, Eureka; Healdsburg Enterprise, Healdsburg; Russian River Flag, Healdsburg; Sonoma County Tribune, Healdsburg; Trinity Journal, Weaverville.

Great Basin.- Esmeralda Union, Aurora, Nevada; Carson City AppealNews, Carson City, Nevada; Gold Hill Daily News, Gold Hill, Nevada; Inyo Independent, Independence.

In addition to accounts in these newspapers, a collection of miscellaneous news clippings was reviewed at the Bancroft Library, University of California, Berkeley. This collection is assembled in a volume called "California Floods", and covers the period 1861-1879. Another collection 
of news clippings at this library is assembled in a volume called "Sacramento River Floods of 1878 and 1881 ".

Detalled information about the issues available and the locations of these and other newspapers is given in "American Newspapers 1821-1936, A Union List of Files Available in the United States and Canada", edited by Winifred Gregory and published by the H. W. Wilson Co., New York, 1937. The most complete files in Northern California are those of the California State Library, Sacramento, and of the Bancroft Library, University of California, Berkeley. Some newspapers are available only in local collections such as those of the publisher's, or of the city and county libraries.

\section{Histories}

The following list of histories includes those that were found to be most complete and apparently most accurate in their accounts of early floods. Although county histories were found not to be a very satisfactory source of flood information, they furnished some valuable fragmentary data that were not obtainable elsewhere.

History of Fresno County, Calif., Lilboume Alsip Winchell, under the editorial supervision of Ben R. Walker, published by A. H. Cawston, Fresno, 1933.

History of Kern County, Calif., by Wallace M. Morgan and others, published by Historic Record Co., Los Angeles, 1914.

History of Sacramento County, Calif., Thompson \& West, Oakland, Calif., 1879.

History of Siskiyou County, Calif., D. J. Stewart \& Co., Oakland, Calif., 1881 .

History of Stanislaus County, Calif., by L. C. Branch and others, published by Wallace W. Elliott \& Co., San Francisco, Calif., 1881。

Illustrated atlas and history of Yolo County, published by De Pue \& Co., San Francisco, Calif., 1879.

\section{Miscellaneous reports}

The following list records some of the miscellaneous reports that

were consulted, with a brief statement of the flood information obtained.

Annual Report of the Surveyor-General of California for the year 1862. Cortains special reports from several county surveyors, listing flood heights above low water in 1862 at a few places in the Central Valley.

Engineers Report on the Northern Boundary of Swamp Land District No. 2; B. F. Leet, Engineer, and George H. Goddard, Consulting Engineer; Sacramento, Calif., May 13, 1862. (Part of this report is published in the Sacramento Union of May 16, 1862.)

Contains high-water elevations and areas of cross-sections for the flood of January 10, 1862, at several points on the American River from Folsom to Sacramento. 
Report of the State Engineer to the Legislature of the State of Cal1fornia - Session of 1880. Part III; Sacramento, Califo, 1880. Presents high-water elevations for $1878-79$ at a number of points in the Yuba River Basin and for 1861-62 on the South Fork of Yuba River at Edwards Bridge. Detailed descriptions of the channel conditions are given.

Report of the Chief of Engineers, U. S. Army, 1882. Appendix MM. Contains miscellaneous high-water elevations of the floods of 1879-80, and comparisons with the flood of 1861-62 on the cosumnes, Calaveras, Stanislaus, and Tuolumne Rivers. Compares the floods of 1861-62 and 1881 on the Feather River at and near Oroville.

Physical Data and Statistics of California; compiled in the State Engineering Department of California. Wm. Ham. Hall, C. E., State Engineer; Sacramento, Calif., 1886.

Presents many early meteorological records, and monthly and yearly stream flow data for the period 1878-84.

Report of the Chief of Engineers, U. S. Army, 1891. Appendix VV. Lists data on the high water of 1861-62, for the South Fork of Yuba River at Edwards Bridge. Maximum and minimum gage heights for the Feather and Yuba Rivers near Marysville are given for the years 1881-89, and gage heights are listed for several days during the high-water period March-May 1890. The peak stages of Apr11 1853 and December 1889 for the Feather River at Nicolaus are referred to the low-water plane. Damages in the lower Sacramento Basin caused by the floods of 1889-90 are discussed. Detalled descriptions of channel conditions are given for the Feather, Yuba, Bear, and American Rivers, and for the large tributaries of the lower San Joaquin River.

Report of the Commissioner of Public Works to the Governor of California; Sacramento, Calif., 1895.

Contains graphs of rainfall at Red Bluff, October 1877 to June 1887, and October 1887 to June 1894; and at Sacramento, October 1861 to June 1862; October 1877 to June 1887; and October 1887 to June 1894. Stage-graphs for the Sacramento River at Red Bluff are given for most of the winter months during the period December 1878 to August 1894, excepting the seasons of $1888-89$ and 1889-90. Stagegraphs for the Sacramento River at Sacramento are given for the periods September 1849 to August 1862; and September 1874 to November 1894. Miscellaneous high-water elevations are listed for points in the Sacramento River Basin and on the lower San Joaquin River, especlally for the years 1878 and 1879. References are given to sources of information about the channel dimensions and water surface elevations of many rivers of the Central Valley.

Report of the Commissioner of Public Works to the Governor of California, 1895-1896; Sacramento, Calif., 1896.

Contains a list of maximum and minimum gage heights on the San Joaquin River near Lathrop, for the years 1879-94 and the high-water gage height of 1895. The flood profile of the Sacramento River from Cache Slough to Collinsville is given for 1896, and is compared with flood profiles for 1878 and 1879 .

\section{Summary of outstanding floods}

The following summary of the most outstanding and wide-spread floods for the period 1861 to 1907 affords a brief general description of the $1 \mathrm{r}$ magnitude and areal extent. Unless otherwise stated, the observations refer to foothill localities on streams tributary to the great central Valley and to places near the mouths of the coastal streams. 
of large floods, and for the prolonged and widespread inundation in the San Joaquin and Sacramento Valleys. During the period December 7-9, 1861, exceptionally high or record-breaking stages were observed in the Klamath River Basin, and large floods were reported throughout the Sacramento River Basin. During the latter part of December 1861, moderate or large floods occurred from the Kern River to the upper Sacramento River Basin, and on some of the coastal streams.

In the period January 10-11, 1862, extremely high or record-breaking stages were observed on the larger streams in the San Joaquin and Sacramento Valleys, on coastal streams from the Salinas to Eel River, and on streams in the Great Basin from the Walker to the Truckee River.

In the period January 12-18, floods occurred several times on foothill streams in the San Joaquin Valley and, about January 18, in the Kerm and Tulare Lake Basins, and probably in the South Pacific Basins. There was another important flood period, January 22-24, in the Sacramento and lower San Joaquin River Basins. The peak discharges of the lower San Joaquin and Sacramento Rivers in January 1862 appear to have been the greatest since early in the nineteenth century。

Floods of $1867-68$

The floods of 1867-68 were especially severe on streams in the Sierra Nevada in the southern part of the Central Valley. Peak stages in this region in the period December 24-26 were generally the highest of record. There were floods of great magnitude also on the main tributaries of the lower San Joaquin and Sacramento Rivers, where the crest stages at many points approached or equalled those of 1861-62. Floods also occurred in the Great Basin from the Truckee River south to the Walker River, and possibly as far as the Owens River. Apparently at some points in the Walker and Carson River Basins the floods were the greatest of which there is knowledge. High stages were observed several times during December 1867 on the foothill streams of the Sierra Nevada, and moderate or large floods occurred during the latter part of this month on streams in the upper Sacramento River Basin and on some of the coastal streams.

Floods of 1881

The floods in 1881 were outstanding in the upper part of the Sacramento River Valley. The Sacramento River upstream from Cow Creek reached 
early in February the highest stage of which there is record. Floods of considerable magnitude occurred throughout the Sacramento River Basin from January 30 to February 4. Peak stages along the lower Feather and Sacramento Rivers equalled or exceeded those of 1861-62, but the maximum discharges probably were less. There were notable floods at some points in the San Joaquin River Basin and on coastal streams from San Francisco Bay north to the Smith River. The peak stage of 1881 on the Klamath River at Weitchpec, although considerably below that of 1861 , was one of the highest known.

Floods of $1889-90$

The winter season of $1889-90$ was remarkable for the exceptionally heavy and widespread precipitation which produced floods of considerable importance throughout northern California in January and February 1890 , and moderate floods at other times from December 1889 to May 1890. The floods of January and February were especially heavy on coastal streams from the Salinas River north to the Smith River. Several of these rivers were reported to have been, during the first part of February, the highest since 1861-62. The crests near the mouths of the Klamath and Smith Rivers were about the same as the record peaks of 1861-62. The peak discharges from streams of the Sierra Nevada were, in general, not very great. In this region the season was unusual because of exceptionally low temperatures and heavy snowfall at high altitudes resulting in very high stages owing to ice and snow gorges at some places.

Floods of 1907

The flood season of 1907 was one of the most outstanding for which fairly adequate stream-flow data are available. During the period March 18-21, major floods occurred on the main tributaries of the lower San Joaquin River, in the Sacramento River Basin, on many of the coastal streams, and on the Truckee River in the Great Basin. The peak stages on some of the larger tributaries of the lower San Joaquin and Sacramento Rivers were possibly the highest since 1867-68, but in general were lower than the record peaks of 1861-62. Exceptionally high stages on the Trinity, Eel, and Russian Rivers were reported, and moderate floods occurred in the basins tributary to San Francisco Bay, and southward to the Salinas River Basin. 


\section{Southern Pacific basins}

Floods of 1861-62.--A flood of major proportions occurred on Salinas River during the winter season of 1861-62. According to Juan Arajo, resident near Paso Robles since 1855, the channel, which prior to 1862 was narrow and meandering, was widened considerably in places by this flood. From statements of Charles Bardin, a witness of the flood of 1862 near Salinas, the height of the flood referred to the datum of the gage at the present river-measurement station near Spreckels was recently determined as about 31 feet, or about 5 feet higher than the stage of any other known flood at this point. The river overflowed beyond the channel and practically covered the site of the present town of Salinas.

In 1861-62 the Pajaro River at the present railroad crossing upstream from Watsonville reached a stage about 15 feet above the peak stage of 1937,32 feet above the high water of 1932, and 26.5 feet above the high water of 1900. The stages for 1862, 1900, and 1932 were reported at a public hearing conducted by the Corps of Engineers, U. S. Army. It was also brought out at this hearing that the Pajaro River channel was wider in 1870 than in 1862. The date of the maximum of 1862 was probably January 1I, but major floods also occurred between January 17 and 24 .

There were major floods on Soquel Creek and the San Lorenzo River on January 11, 1862. The overflow from Soquel Creek destroyed several buildings in the town of Soquel, and the flood on the San Lorenzo River destroyed buildings at Santa Cruz. It was noted that the great quantity of rain kept the San Lorenzo River at high stage for two weeks after January 11. There was another major rise on streams in this vicinity during the latter part of this period.

Floods of 1867 and subsequent floods.--It appears from newspaper accounts and statements of residents that notable floods occurred on the Salinas River in the periods 1867-68, 1878, 1879, 1880, 1881, 1884, 1889-90, 1907, 1911, and 1913-14. Residents near Santa Margarita in the upper part of the basin mention the floods of 1881, 1889-90, and 1911 as especially large. At Paso Robles the flood of 1913-14 was described by residents as the highest observed in recent years until 1938. It washed out the highway bridge at Paso Robles and the railroad bridge 12 miles downstream. 
At the gaging station at Spreckels on the lower river the peak of 1911 reached a stage of 26.1 feet as compared with stages of 25.2 in 1914 and 25.0 in 1938. Mr. Charles L. Pioda, who has studied these floods in the lower Salinas Basin, found that the flood of 1914 was higher than that of 1911 at many places. The magnitude of these and earlier floods cannot be closely compared from the relation of the stages at this point, as it is probable that channel changes have tended to lower the flood profiles.

In the Pajaro River Basin stages resulting in overflow occurred near Watsonville in the years 1890, 1894, 1907, 1909, 1911, 1914, 1915, 1916, 1922, 1927, 1931, 1933, and 1937. This record, furnished by the City Engineer, probably included some minor floods. Outstanding floods occurred in the period 1913-14, when five inundations were noted at Watsonville, and possibly in 1911 when very high stages were recorded in adjacent basins. Uvas Creek flooded the city of Gilroy in 1913-14.

Newspaper accounts mention floods of considerable size on the San Lorenzo River in 1869, 1890, 1895, and 1907, and floods probably occurred in other years when there were major floods in the San Francisco Bay and Pajaro River Basins. The San Lorenzo River at Santa Cruz was said to have been the highest since 1862 on February 10, 1869. Another major flood was that of January 25, 1890, called "the highest ever known" in a newspaper dispatch from Santa Cruz. Again in January 1895 there was a flood of such magnitude that railroad tracks were washed out at points between Santa Cruz and Boulder Creek. The San Lorenzo River was at flood stages several times between March 19 and 25, 1907, causing damage to or loss of bridges along its channel, and damage to buildings in Santa Cruz。

\section{San Francisco Bay basins}

Early floods.--Severe storms near San Francisco during the period 1787-1820 are listed in a history of California by Theodore E. Hittell. Heavy rains in January and February 1819 caused floods that changed the courses of many streams. Another series of storms, which probably caused floods, was that of December 1798 and January 1799 , which was reported to have lasted for 28 days.

Floods of $1849-50$.--Reference to the flood season of $1849-50$ was made in a history of Santa Clara County published in 1881. Julius Martin of Gilroy, a pioneer of 1843, was cited as authority for the 
statement that there were heavy rains from November 1849 to April 1850 , which culminated in an inundation in Santa Clara Valley that remained for weeks. Another account stated thet there was an extensive flood in Napa Valley during this season.

Flood of 1852-53.--During the flood of 1852-53 a bridge on the Napa River at Napa was washed out. The river overflowed into the town, and flooded all lowlands in Napa County.

Floods of 1861-62.--Part of the town of Napa was flooded on December 8, 1861, and several houses were washed away. Again on December 28 part of the town was flooded. Exceptionally severe floods occurred throughout the San Francisco Bay basins on January 11, 1862. The towns of AIvarado, San Leandro, Napa, and Pacheco were flooded. The floods of January 1862 destroyed many bridges and mills in San Mateo and Santa Clare Counties.

Flood of 1867.--Heavy rains occurred throughout this drainage area in December 1867. It is said that on December 31 Petaluma Creek at Petaluma was the highest since the town was settled. Railroad tracks and buildings were flooded.

Flood of 1869.--It is recorded in a history of Santa Clara County that Los Gatos and Guadalupe Creeks overflowed in San Jose and caused the greatest flood known since settlement of the town by Americans. Newspaper accounts state that water covered the valley in every direction from San Jose, February 9-10. Floods of considerable proportions also occurred at this time in the Napa Valley, where rallroad tracks were washed out below Calistoga and below Napa.

Floods of 1871.--There was also a flood in San Jose from overflow of Los Gatos and Guadalupe Creeks in December 1871. It is noted in the historical account that widening and improvement of the channels has lessened the flood hazard since that date.

Floods of 1874 and $1878 .-A$ history of Sonoma County records that there were floods in November 1874 caused by excessive rains. January 1878 was also 11 sted as a perlod of unusual and damaging floods.

Floods of 1879.--Floods on the Napa River at Napa, about March 5-8, 1879, were called the greatest since 1862, and possibly approached or exceeded the floods of that year. Parts of the town were flooded and several houses washed away.

Floods of 1881.--The floods on the Napa River and Petaluma Creek on January 31,1881 , were sald to have exceeded any other known. A 
stone bridge was destroyed and the railroad bridge at Napa was damaged. Floods of 1889-90.--Precipitation for the winter season 1889-90 was the greatest of record at many points in the San Francisco Bay region. There were floods on January 24-25, apparently nearly as high as any known. The Napa River at Napa was reported to have been on January 24 only a foot below the record height of 1881 , and the flood in the Santa Clara Valley near San Jose was said to have been the greatest since 1862. An observer of the flood of 1890 at Mountain View near San Jose stated recently that it has not since been equalled. Bridges were destroyed at several points in the San Francisco Bay region, railroad tracks were washed out, towns and farms were flooded, and at least two persons were drowned.

Floods of 1892 to $1906 .--S t r e a m-f l o w$ records on Alameda Creek began in 1891. There was a flood of great magnitude on November 30, 1892, which possibly has not been exceeded since. Mean daily discharge at Niles Dam for this date is listed as 16,200 second-feet, the highest for the period of record at this station, and higher than any daily discharge recorded at nearby comparable stations since 1900. Moderate floods occurred in January and February 1894, November 1900, March 1903, and January 1906; and an outstanding flood, January 18, 1895, indicated by a mean daily discharge of 10,900 second-feet at N1les Dam. On the Napa River at Napa there was a flood of considerable magnitude on January 21-22, 1895, noted as the second within 3 weeks at that point. The stream-flow record for Coyote Creek near Madrone, started in 1902, shows a high peak discharge of 15,000 second-feet on March 31, 1903, exceeded only in March 1911 for the periods of record 1902-12, and 1916-38. Moderate peaks were recorded in January and December 1906.

Flood of 1907.--There were floods on streams in the Santa Clara Valley on March 19 and 23, 1907, those of March 19 on Los Gatos Creek and adjacent streams apparently were especially severe. Railroad bridges were washed out and farm lands were damaged in that region. There was a moderate peak on Coyote Creek near Madrone on March 19, and floods on Alameda Creek, March 19 and 23, of the same magnitude as those of 1895. Country adjacent to San Jose was flooded on both days, especlally from overflow of Guadalupe Creek.

Floods of 1909.--There were floods on Alameda and Coyote Creeks on January 21, 1909, of the same magnitude as those of 1907.

Flood of 1911.--There was another flood on Alameda Creek March 7, 1911, which was about the same magnitude as that of 1892. The maximum 
recorded discharge at the gaging station on Coyote Creek near Madrone was in 1911, probably on March 7. This gaging station has been operated since 1902, except for the period 1913-15.

Floods of 1914 and subsequent floods.--Several floods have occurred on streams in Santa Clara Valley since 1911. Alameda Creek reached high stages on January 25, 1914, February 25, 1917, February 10, 1919, and February 10, 1922. Storage on this creek has affected the flood discharges since 1916. There were moderate floods on Coyote Creek near Madrone on February 21, 1917, February 10, 1919, Febmuary 10, 1922 , February 13, 1927, and December 28, 1931. Since 1934 some flood waters have been impounded in a reservoir.

\section{Kern River Basin}

Floods of 1861 and 1862 .--There was a notable flood on the Kern River about December 25, 1861, which resulted in a change in the channel at the site of the present city of Bakersfield, and flooded all but the higher knolls in that vicinity. A prolonged flood period followed the initial rise. Definite information is lacking as to the stage the river reached in its foothill channel, or the dates of the peak stages, but it is probable that there were other floods about the middle of January 1862, when the rivers in Tulare Lake Basin and in southern California reached their peak stages.

Flood of 1867.--The greatest flood on the Kem River of which there 1s knowledge lasted from about December 25, 1867, to January 1, 1868. Cedar logs believed to have been deposited by this flood were recently found by the Corps of Engineer, U. S. Army, in the rocky canyon two miles downstream from Falrview (13 miles upstream from Kernville). These logs and other evidences of the early flood were about 13 feet above the highest of recent flood marks, which were about 10 feet above low water and which probably were left by the flood of February 1937. The river at Kernville was reported to have been at an extremely high stage for a period of three days in December 1867, and at 1ts peak to have covered practically the entire site of the present town of Kernville. The South Fork of the Kem River overflowed the lowlands in South Fork Valley between Onyx and Isabella, keeping ranchers from their homes for four days. According to information from the Corps of Engineers, U. S. Army, drift logs were found at a height of about 40 feet above the high-water line of February 1937 on the Kern River, in 
a narrow rock canyon two miles downstream from the South Fork of Kern River. Drift marks of this early flood still exist at several places in this canyon. At the same place the peak of February 1937 was about 30 feet above present low water. Near Borel power house, about 9 miles downstream from the South Fork of the Kern River, several drift logs and fragments were found about 25 feet above the high-water line of February 1937, which was about 23 feet above low water. Many of the logs and pieces of wood were of cedar and redwood, and must have been carried down from the high mountains. Local residents believe that these floodmarks In Kern Canyon were undoubtedly left by the flood of 1867. As reported to the Corps of Engineers, U. S. Army, by an eye witness of the flood of 1867 on the Kern River at Rio Bravo ranch, $3 / 4$ mile below Cottonwood Creek, the flood stage in 1867 was 6.4 feet above that of February 1937. The peak stage of 1937 was about 16 feet above low water at this ranch. The flood profile in 1937 may have been modified by the present bridge, the floor of which was submerged in 1937. In 1867 the Kern River overflowed beyond 1ts channel for a considerable distance, near the present site of Bakersfield, and was reported to have covered knolls not flooded In 1861-62. A remarkable feature of the flood of 1867 was the large quantities of logs carried down from the mountains and deposited on the overflowed lands near Kernville and Bakersfield. Saw mills were established at Kernville and Bakersfield to cut these logs into lumber. Trees along the channel near Kernville were said to have been entirely washed away by the flood of 1867 , from which fact it was inferred that the flood was the greatest for a long period. The flood of 1867 on the Kern River was certainly much greater than any that have occurred aince that time.

Flood of $1890 .--T h e$ Kern River near Bakersfleld was reported to have been the highest on January 26, 1890, since 1867-68. The flood apparently was not of major importance, although structures were damaged on the river at Kernville and near Bakersfield.

Flood of 1893.-There was a flood on the Kern River at Bakersfield on February 10, 1893, which, according to a Bakersfield nowspaper, was the first of importance since the flood season of 1867-68. According to this account, the flood of 1893 did not quite reach a place in Bakersfield which had been flooded to a depth of 2 feet in 1867-68. Residents along the Kern River downstream from Kernville, who witnessed the flood of 1893, describe it as having been several feet below the floodmarks of the early flood, but much higher than the floods of 1916 
and 1937. From the best information available the flood stage in 1893 at the moluth of the South Fork of the Kern River was about 4 feet above the peak of February 1937, which was about 11.5 feet above low water. The flood of 1893 was of comparatively brief duration, but it caused extensive flooding of farm lands along the lower Kern River and washed out rallroad tracks near Bakersfield. In general, the flood of 1893 on the Kern River was not as great as that of 1867 , but appears to have exceeded any other since 1867 .

Floods of 1909 and subsequent floods.-Floods occurred on the Kern River in January 1909, January 1914, January 1916, and February 1937. The flood of 1909 was of minor proportions and resulted in comparatively little damage, although it was relatively high on the upper river. The floods of January 1914, January 1916, and February 1937 were about the same magnitude, and all caused considerable property damage along the lower river. Highways, farm lands, and homes were flooded by the overflow from the river. (See table 11 for a comparison of floods in Kern River and Tulare Lake Basins from 1867 to 1938.)

\section{Tulare Lake Basin}

Floods of 1861 and 1862 .- The first heavy storm of the season occurred on December $23-25,1861$. It was reported that there was a flood on the White River and a damaging flood on the Tule River which overflowed farms to a depth of several feet. The Kaweah and Kings Rivers apparently did not reach exceptionally high stages.

Then on January 11, 1862, there was an exceptionally great flood, which probably has since been equalled or exceeded only in December 1867. The flood followed a general storm, which resulted in record-breaking stages on tributaries of the lower San Joaquin and Sacramento Rivers. The town of Visalia, an early settlement in the lower Kaweah River Basin, was flooded on Main Street to a depth of about 2 feet on January 11. The town was again flooded to about the same depth on January 17-18, and the water again rose on January 20 to a stage slightly greater than on either of the previous dates. This information serves chiefly to establish the dates of the larger floods, but because of the probable variable influence of extensive overflow below the foothills, it indicates only very roughly their magnitude. The lowlands along the tributaries of Tulare Lake were probably flooded continuously from January 11 unt1l about the end of the month. It is not clear, from the contemporary accounts, when the maximum stages occurred in the foothills. It is probable, however, 


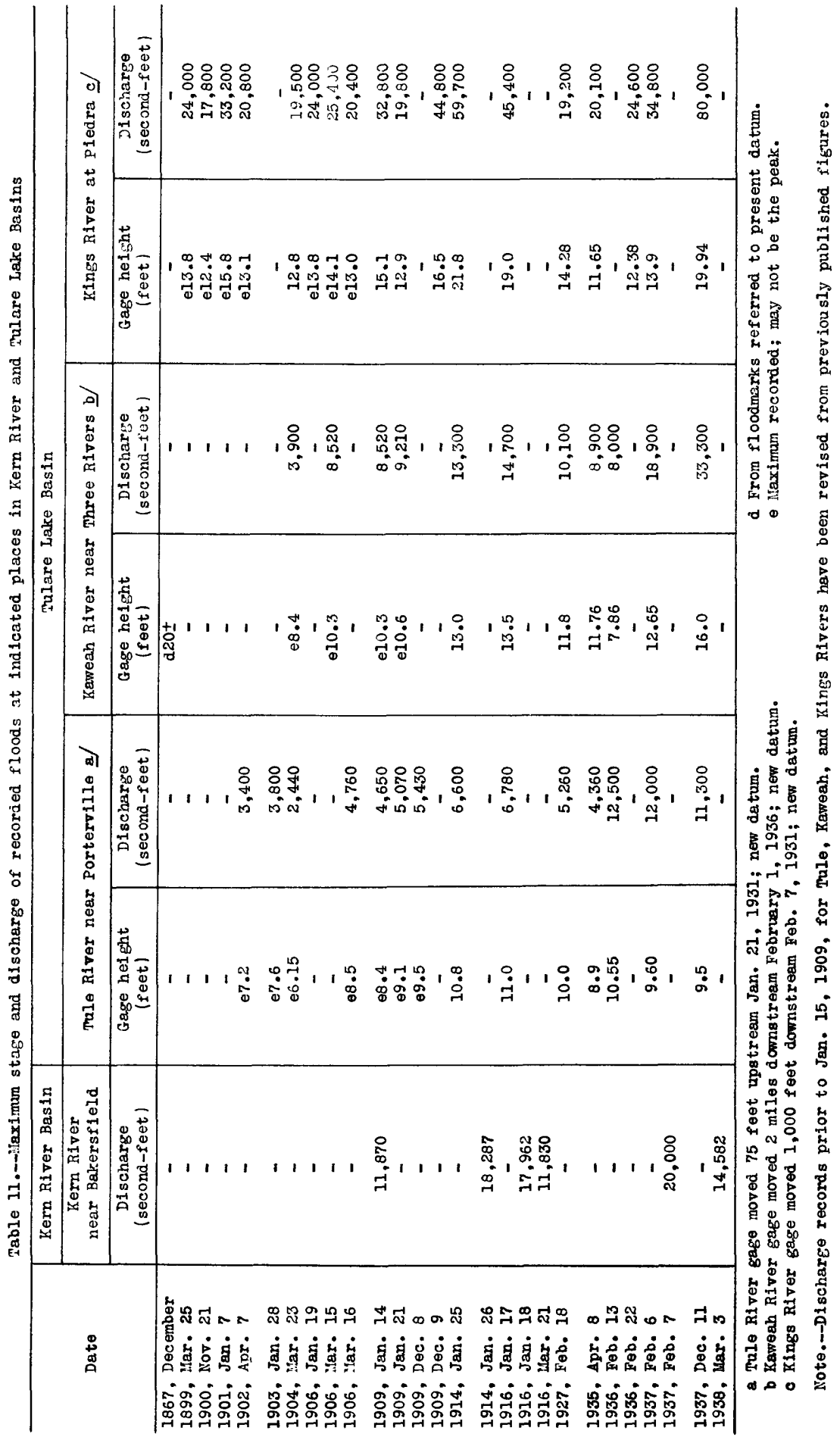


that the Kings River reached its greatest stage on January 11, the day when the highest stage was observed on the adjacent San Joaquin River. The Wite River and Poso Creek, in the southeastern part of Tulare Lake Basin, were reported to have been at their highest on January 18. During these flocds, the Tule Rlver changed its channel for a considerable distance downstream from the foothills. From the number of large trees washed down from the mountains by the floods on the Kings, Kaweah, Tule, and White Rivers it was inferred by the settlers that this was the greatest flood for many years.

Flood of 1867.--Following an exceptionally heavy rain in the period December 21-25, 1867, which extended throughout northern California, there were major floods on all the main tributaries of Tulare Lake. The town of Visalia was partly flooded by water from the Kaweah River on December 23, and by December 24 the flood stage in the town had exceeded the record of 1862 by 4 inches. After receding about 2 feet, the water again rose to about the same stage on December 26. The stage of the Kaweah River in its channel downstream from the foothills was reported to have exceeded the stage in 1862 by 2 feet. As determined by the position of the redwood and cedar logs deposited by this flood, the maximum stage on the Kaweah River near Three Rivers referred to the datum of the present gage was about 20.0 feet. So far as known, this stage has not since been approached, except in December 1937 when the peak stage was 16.0 feet.

Descriptions of the flood of 1867 on Kings River do not given a definite comparison with the flood of 1862. A settlement known as Scottsburg on the Kings River, near the present town of Centervilie, was flooded in 1862. The town, rebuilt at a new site, was destroyed by the flood of 1867. From this fact it appears that the later flood was at least as severe as that of 1862 , and probably reached a greater height. From reliable accounts by an eye-witness of the flood of 1867, the Kings River reached a stage about 3 feet greater than in 1937 at a point one mile downstream from Piedra. At Pine Flat dam site on Kings River, about three miles upstream from Pledra, it was recently determined from the position of cedar and other drift logs deposited along the channel that a previous flood had exceeded that of 1937 by at least 7 feet. The rise in December 1937 was about 18 feet above low water. From statements of ranchers who settled in this vicinity about 1875 it is believed that these logs were deposited either in 1862 or in 1867. An outstanding characteristic of the flocd of 1867 on the Kings and Kaweah Rivers, as 
well as on the Kern and upper San Joaquin RIvers, was the tremendous quantity of timber brought down from the Sierra and deposited on the plains. That there were exceptionally heavy storms in the Slerra Nevada In December 1867 is indicated by the record precipitation of 12.19 Inches measured at Camp Independence in Owens Valley, east of the headwaters of the Kaweah R1ver. From the meagre reports avallable it is probable that the Tule and White Rivers and Deer and Poso Creeks reached exceptionally high stages in December 1867. Newspaper accounts stated that the Tule River was higher than in 1862. Downstream from the foothills it flooded farm lands and, as in 1862, cut a new channel for a portion of lts course. The low lands between the Tule and Kern Rivers were described as having been almost completely flooded.

In general, the flond of 1867 in Tulare Lake Bas in was the greatest of which there is knowledge. In 1868 Tulare Lake reached about the same helght as in 1862-63 when 1t overflowed to the north into the San Joaquin River.

Floods of 1875 and subsequent floods.--Floods occurred in the Tulare Lake Basin in the years 1875, 1879, 1884, 1893, 1906, 1914, and 1916. Historical writings mention high water at Visalia in 1875 and 1879 as having flooded parts of the clty. The floods were undoubtedly of minor proportions in Tulare Lake Basin. The State Engineer in 1886 lists the high water of 1879 on Kings River near Kingsburg as only 6.7 feet above the low water of 1878, as compared with the helght of 17.3 feet in 1867-68 at the same place.

In 1884 there was a prolonged season of high water that caused much damage to the farms in the lowlands. There is no information avallable as to peak stages of the rivers during this period. The state records of stream flow for this season, l1sted in Water-Supply Paper 299, show very high snow run-off on the Kings, Kaweah, and Tule Rivers.

There were floods in the northern part of the Tulare Lake Basin on Jamuary 25-27, 1886. Judging from later comparisons, the KIngs RIver did not reach an extremely high stage at this time, although there was an extensive Inundation in the city of Fresno from streams in that vicinity.

There were floods of considerable proportions in the Kaweah and Kings R1ver Basins in January 1890. Overflow from the Kaweah R1ver caused damage in Visalia where it was reported that boats were used on Main Street. Rallroad tracks were washed out in the vicinity of Visalia. About January 25, 1890, the Kings RIver reached a stage reported to have been the highest since 1867-68, although it may have been exceeded in 
1914 and 1937 at footh111 points. The crest at the ra1lroad bridge near Kingsburg was reported in a Fresno newspaper as 16 feet above low water, exceeding by 2.5 feet any since construction of the bridge. This stage possibly is comparable with the peak stage of 1867-68 which was 17.3 feet above low-water of 1878 as mentioned above. The stage of 1890 probably was referred to the same gage datum used by the state Englneer at this raliroad bridge, from 1878 to 1884, as described in Water-Supply Paper 299. The relative helghts of the crests at this point, however, do not necessarily indicate, even roughly, the relative heights of the crests in the foothill channel.

A flood occurred on the Kaweah and Tule Rivers on February 9, 1893. Bridges and roads were washed out or damaged in the Kaweah River Basin and 1t was reported that the Kaweah River was higher than it had been for 20 years. Evidently the rainfall was especially heavy in the southern part of Tulare Lake Basin, where the Tule Rlver was sald to have been as high as in 1867. Highway and rallroad brldges were washed out, and parts of the clty of Porterville were flooded. The helght of this flood on Tule River is not known at a point that would be comparable with recent recorded peak stages. The flood of 1893 was of brlef duration and in general does not rank as a major one throughout the Tulare Lake Basin. The gage helght on the Kings River at Kingsburg on February 10, 1893, was 11.5 feet, not an exceptionally high stage.

Visalla was flooded by the Kaweah River in March 1906 and again in June 1906. The flood in June followed unusually high flows from melting snow. At the helght of this flood the water in the town was about 1 foot deep on Main Street, apparently 1 or 2 feet below the height of 1867. The floods on streams in the Tulare Lake Basin were of minor proportions. For a comparison of this flood with later peak stages in this basin see table 11 .

On January 25, 1914, stages were recorded on the Kings River at Pledra and on the Kaweah River near Three Rivers that were considerably higher than any others that have occurred since the establishment of the river-measurement atations. A resident on the Kings River at Trimmer reported in 1914 that the flood of that year had exceeded by 3 feet any others that had occurred since the season of 1867-68, when the Kings RIver at that point was 6 feet higher than in 1914. The flood of 1914 caused considerable damage to roads and farm lands along the Kings River. An exceptional feature of this flood was the high precipitation in the Sierra Nevada. A total precipitation of 22 inches was reported 
for the storm period at Hume Lake in the upper Kings River Basin. In the southern part of Tulare Lake Basin the floods were not of major proportions.

A flood similar to that of 1914 occurred on January 17, 1916, in the Tulare Lake Basin. The stages were higher than in $191 \leqslant$ on the Kaweah River near Three Rivers and on the Tule River near Porterville, but were not exceptional. On the Kings River at Piedra the peak in 1916, although lower than in 1914, was among the highest recorded at that station.

See table 11 for a comparison of floods in Kern River and Tulare Lake Basins during the period 1867 to 1938.

\section{San Joaquin River Basin}

Floods of 1847 and $1852,--T h e$ earliest flood mentioned in historical accounts of the settlement of the San Joaquin River Basin is that of January 1847. It was reported that the Stanislaus River, at a point about $1 \frac{1}{2}$ miles upstream from its mouth, overflowed the country for miles beyond its channel, and that the San Joaquin River near the mouth of the Stanislaus River was about 3 miles wide at the crest of the flood. Apparently this flood did not attract much attention at other places in the basin and was prolably of minor magnitude. As in the Sacramento River Basin, the extent of overflow in the lower reaches of these rivers in the early days scarcely gives any indication of the discharge, as the minor floods would have spread, in many places, beyond the normal channels almost as far as the major ones. Brief mention is made of a flood in 1852 that inundated parts of Stockton and was considered the highest known flood in the lower San Joaquin River Basin until 1862. Rainfal1 and run-off in the foothilis of the Sierra Nevada were reported to have been excessive.

Floods of 1861-62.--At the time of the first flood of the winter season of 1861-62 in the Sacramento River Basin on December 9, the San Joaquin River and its lower tributaries, with the possible exception of the Cosumes River, did not rise to extremely high stages.

The first exceptionally high run-off from the tributary basins of the lower San Joaquin River occurred on December 26, 1861, when according to reports, the Mokelurne River slightly exceeded its previous record of 1852 and the Merced River was at about the flood stages of 1849 and 1852-53. The storm that caused the flood of December 26 was general from the Kern River to the upper Sacramento River. During this 
storm, snow fell continuously in the upper basin of the stanislaus River, so it is probable that the heaviest run-off was from comparatively low altitudes in the Sierra Nevada. Foothill creeks were extremely high, and frequent rains during the latter part of December 1861 prolonged the flood conditions in the lower San Joaquin Valley. Stockton was first flooded on December 26, and by December 28 the surrounding country was inundated for many miles.

The upper San Joaquin River and 211 of its important tributaries reached record-breaking stages on January 11, 1862. The heavy rainstorm that caused this flood was general throughout northern California, as was also the preceding snowfall on January 5. It was reported that in the upper Mokelumne River Basin, at an altitude of about 9,000 feet, there was 18 feet of snow on the ground preceding the storm. Rain fell from January 9 to 11 and the snow settled to a depth of 15 feet. At Big Trees in the Stanislaus River Basin (altitude, about 5,000 feet) the snow, which was reported to have been $3 \frac{1}{2}$ feet deep preceding the storm, all melted. The flood of January 11 on the upper San Joaquin River at old Millertown, upstream from Friant, was determined by the Fresno County Surveyor to have been 26 feet above low water. This rise was several feet higher than ever known before, but it was exceeded by several feet in 1867. At this same place on December 11, 1937, the river reached a stage about 21 feet above low water.

According to the Mariposa Gazette, the Merced River near Kittridge on January 11, 1862, exceeded the record height of December 1861 by about 10 feet. Mariposa Creek was reported as being very high for two weeks before and after January 11, but apparently the highest stage was reached about that date. It was said that the whole country about lower Mariposa Creek and the Fresno and Chowchilia Rivers, as seen from the foothills, was one vast sheet of water. Reports about the Merced River were too vague to permit the determination of the stage of the 1862 flood at most locations that would afford a comparison with recent flood stages. Reported stages reached in 1862 at points upstream and dowstream from Kittridge are in general much greater than the stage of the flood of 1937 at Kittridge. It is believed that the flood of 1862 was higher than that of 1937 at Kittridge, but probably was not as high as the flood of 1937 in the Yosemite Valley. The Merced River, downstream from the mouth of its canyon, flooded the town of Snelling on January 11, 1862, and the channel was widened and changed considerably by the flood. 
On the Tuolume River at Branch's Ferry, about 4 miles below La Grange, the crest stage on January 10, 1862, was about 30 feet above low water and about 7 feet above the previous record in 1852. Near the La Grange dam site on the Tuolume River above La Grange, high-water marks of the flood of 1862 were found by Wagoner. 16/ From the flood profile thus determined he computed the peak discharge of 1862 as 130,000 second-feet. Most of the flood water of the Tuolumne River in December 1937 was impounded in reservolrs upstream from La Grange, so a comparison with the flood of 1862 cannot readily be made.

The Stanislaus River at Knights Ferry, after flooding part of the town on January 10, 1862, and washing away bulldings and the bridge, rose to its greatest height on January 11 and washed away almost the entire business part of the town, which was later rebuilt on higher ground. This flood was said to have been 12 feet higher than any previously known. Its crest was recently determined by the Corps of Engineers, U. S. Army, as 33 feet gage height, referred to the datum of the former gaging station at Knights Ferry, compared with a peak stage of 27 feet on March 19, 1907, and 26 feet on January 31, 1911. In December 1937 reservoirs impounded most of the flood water.

In 1862 the Mokelumne River near Mokelume Hill reached a maximum stage corresponding to about 23.4 feet at the present river-measurement station, as determined from a mark polnted out by Mr. C. F. Kelton, whose grandfather observed the flood. The crest stage of 1907 , possibly the greatest since 1867, was observed by Mr. Kelton at a point that corresponds to a gage helght of 20.3 feet. The maximum stage since the establishment of the gaging station in 1927 was 16.1 feet on March 25, 1928. The discharge corresponding to the latter stage was 23,300 second-feet.

After the peak stage of January 11, 1862, there were frequent storms that resulted in almost incredible amounts of rain in the period January 12-23 in parts of the Sierra Nevada tributary to the San Joaquin Basin. A total of 21 inches of rain was reported to have fallen from January 12 to 23 at Mariposa, and 30 Inches from January 14 to 23 at Sonora.

Newspapers of Stockton and Mariposa stated that the Stanislaus River equalled its flood of January 11 during this period, and that the Tuolume and Merced Rivers exceeded the records of January 10 and 
11. The earlier floods of the season destroyed nearly all of the bridges, mills, and other structures along the channels. On January 17 the water rose in stockton about half a foot above its previous record of January 11; on January 23 it slightly exceeded this mark; and on January 24 it established a record for the season. The flood helght of January 24, 1862, was determined by the San Joaquin County Surveyor to have been 12.1 feet above low tide of December 3, 1862, at Stockton, and 3.5 feet above the flood of 1852 . He reported that the San Joaquin River west of Lathrop, on January 24, 1862, was 12 feet above the summer low tides and 5 feet above the highest water of 1852 .

The magnitude of the flood of 1862 on the upper San Joaquin River has probably been exceeded only in 1867. The floods in 1862 on the main tributaries, including the Merced, Tuolume, Stanislaus, and Mokelume Rivers, were undoubtedly major floods and were equalled, if at all, only in 1867. An outstanding feature of the floods of 1861-62 on these tributaries was that record-breaking stages were reached two or three times during the season. The flood period of 1861-62 in the lower San Joaquin River Basin was probably the greatest of which there is definite knowledge.

Floods of 1867 and 1868.--On December 11, 1867, the Merced River at Snelling reached its highest stage since 1862, owing to heavy rains during the previous week. On the same day the Mokelumne River overflowed its banks near Woodbridge and reached a stage described as 2 feet below the record of 1862 .

In the period December 21-25, 1867, an extremely severe storm, which was general throughout northern California, caused the upper San Joaquin River to reach a record-breaking stage on December 24, 1867 . Near Temperance Flat, about 12 miles upstream from Friant, the stage as recently determined from floodmarks was about 19 feet higher than that of December 1937, which was about 33 feet above low water. At Millerton, then the county seat, the water rose to a point on the court-house, identified by ege witnesses, 12 feet above the floodmark of 1937, which was about 21 feet above low water. News accounts stated that the flood of 1867 exceeded that of 1862 by 10 feet in Millerton, and that many buildings were destroyed. On the San Joaquin River about 15 miles downstream from the present town of Friant, the flood of 1867 was reported to have been 6 feet higher than in 1862. On January 2, 1868, the flood stage on the San Joaquin River near Newman, as observed in a bullding st111 standing, was 21.7 feet (datum of present gage). The 
highest stage noted since 1868 was 19.8 feet in 1886. At very high stages the river overflows beyond the channel for a considerable distance. The known stages at Newman are tabulated in table 12.

The Merced River in its foothill channel reached a peak on December 24, 1867, sald to have been higher than ever seen before. The Merced River did not again flood the tow of Sneliing, as in 1862, although according to the local newspaper the river was 2 feet higher than In 1862. The Tuolume and Stanislaus River were reported to have slightly exceeded their record stages of 1862 on December 26, 1867 . Houses were washed away at Knights Ferry on the Stanislaus River. The Mokelume River was reported variously to have been within 4 inches of the stage of 1862, or to have exceeded 1t, on December 26, 1867. These accounts presumably refer to the lower Mokelumne River. The maximum in 1867 at Mokelumne Hill was reported to have been 3 feet lower than in 1862 and roughly at the same height as was reached in 1907.

The San Joaquin at Kasson's Landing, downstream from the present gaglng station near Vernalis, was said to have risen on December 24, 1867, to within 1.5 feet of the stage of 1862. On December 26, the Tuolumne, Stanislaus, and Mokelumne RIvers reached the ir peaks, and on January 2,1868 , the San Joaquin RIver near Newman reached 1ts maximum stage. On January 11, 1868, the San Joaquin River was falling rapidly and, upstream from the Stanislaus River, was within its banks. A map published by the State Engineer In 1886 lists the high water of 1867-68 at Durham's Ferry on the San Joaquin River as 1.8 feet lower than in 1862 .

The flood of 1867-68 was one of major importance throughout the San Joaquin River Basin. In the foothills the flood on the main river exceeded conslderably any other known flood, and was probably higher than any known flood at all points upstream from the mouth of the Merced RIver. The San Joaquin RIver downstream from the mouth of the Stanislaus River was not as high in 1867-68 as in 1861-62. Flood stages of the lower river for this early period cannot be compared with those of recent floods, because of extensive changes in the channel. It is probable, however, that the peak discharge of the lower San Joaquin River has not been equalied since 1868 .

Floods from 1869 to $1878 .--A$ flood of considerable proportions occurred in the lower part of the San Joaquin Basin about February 10-11, 1869, at the time of the large floods in the San Francisco Bay area. The city of Stockton was partly flooded, mainly from the Calaveras 
Fiver, which was said to have been the highest known to that date.

Historical writings mention a flood on the Mokelumne, Stanislaus, and Tuolumne Rivers in the winter of 1871-72. The accounts state that there was comparatively little damage.

A disastrous flood occurred on Sutter and Jackson Creeks on February 16 or 17,1878 . It was said that several persons were drowned in Jackson, and that buildings and bridges were destroyed. The streets of Woodbridge were flooded by the Mokelumne River. Streams had been high for several weeks preceding the flood of 1878 in the lower San Joaquin Basin, and the peak resulted from an intense, brief rainfall in the foothills. Important floods also occurred in Woodbridge in 1862,1868 , and 1872 .

Flood of 1881.--The flood of 1881 was apparently not disastrous In the San Joaquin Valley, although major floods occurred in the northern part of the State in January and February 1881. The State records of stream-flow show that there may have been an exceptionally high peak In January 1881 on the San Joaquin River near the present town of Friant. News accounts state that the heaviest rainfall since 1867 occurred at Mariposa about the end of January 1881, and that mining equipment was damaged by the flood on the Merced River that resulted from this storm. Other accounts state that bridges, dams, and levees in Stanislaus County in the lower San Joaquin Basin were not damaged by the flood in 1881. An extensive flood was observed in the country adjacent to the lower Mokelumne River, and may have been caused by overflow from the Sacramento River. Historical writings, however, do not mention the flood in 1881 as outstanding in the San Joaquin Valley, and in general it probably was not of great importance.

Floods of 1884 to 1904.--Floods occurred in March 1884, JanuaryFebruary 1886, and during the seasons 1889-90 and 1892-93. There is little definite information, but 1t appears that exceptionally high stages on the Sierra Nevada streams were reached at various $t$ imes during this period. Outstanding peaks observed on the lower San Joaquin River at the railway crossing near Lathrop, March 11, 1884, January 27, 1886, and May 30, 1890, were roughly 16 feet above low water, about the same height as on February 6, 1881. This stage was exceeded during several years after 18:0, indicating that channel changes probably had an increasing effect on the flood profiles.

The town of Hill's Ferry on the San Joaquin River near the present town of Newman was flooded to a considerable depth in February 1886 . As 
determined from a floodmark pointed out by an eye witness, this flood was 1.9 feet lower than the record flood of 1867 . According to the person who observed the flood of 1886, it has not been equalled since. Tributaries of the lower San Joaquin River from the Stanlslaus to the Cosumes River were reported to have been at exceptionally high stages about the end of January 1886.

Large floods occurred throughout the San Joaquin River Basin during the latter part of January 1890. The upper San Joaquin River possibly reached an extremely high stage. The Merced, Stanislaus, Tuolumne, and Mokelumne Rivers were at dangerously high stages, and some of the foothill tributaries of these rivers were said to have been the highest known. Several towns were flooded and railroad and highway structures washed out. The maximum stage of the season, however, was reached, at least on the lower San Joaquin, during the snow run-off period in May 1890.

The few stream flow records avallable indicate that there were no extremely high floods from 1895 to 1907. Farm lands adjacent to lower Mokelumne River were reported to have been flooded in 1904 to the greatest extent since 1881. The flood, however, was attributed to a rush of water from overflow of the Sacramento River. The records for tributaries of the lower San Joaquin River indicate that only moderately high flows occurred in February and March 1904.

Flood of 1907.--The flood of March 1907 was outstanding in the San Joaquin River Basin. Only a moderate rise on the upper river was observed during this flood, but there were exceptionally high stages on the large tributaries in the lower part of the basin. From the Merced to the Mokelumne River the peak stages occurred on March 19 and were followed by high stages for several days. The San Joaquin River downstream from Mendota was at or above flood stage from March 19 to about the end of the month. A description of the flood of 1907 is given in the transactions of the American Society of Civil Engineers (vol. 61, p. 281, 1908), and there is a brief discussion of this flood and attendant weather conditions in Bulletin 43 of the United States Weather Bureau.

Floods of 1909.--There were moderate rises on the upper San Joaquin River and its tributaries from the Merced to the Mokelume Rivers on January 14 and 15, 1909, and again on January 21. The peak stages were not exceptionally high except on the Calaveras River which, on January 21 , overflowed near Bellota and flooded parts of Stockton and adjacent lands. The lower San Joaquin River reached a stage of 19 feet at Lathrop on January 23 and 24 , which was about the same stage as occurred in 1907. 
The flood of 1909 is discussed in Bulletin 43 of the United States Weather Bureau.

Flood of 1911.--The flood of 1911 was the greatest that has occurred in the lower San Joaquin Valley in recent times. During this flood the upper San Joaquin River near Friant reached high stages on January 30 and 31. (See table 12.) The flood was relatively higher downstream, and near Newman at the mouth of the Merced River the peak stage of 1911 has not been equalled since. High stages were reached on January 30 and 31 on the Calaveras, Mokelumne, Stanislaus, Tholumne, and Merced Rivers. The floods on these tributaries combined to raise the San Joaquin River at Lathrop to a record-breaking stage of 22 feet on February 1 . It was estimated that 75,000 acres of land were flooded from the overflow of the San Joaquin, Mokelumne, and Calaveras Rivers. Extensive reclamation works and other improvements affecting the capacity of the channel make It impossible to estimate from the flood heights the relative magnitude of the flood flows in the lower San Joaquin Basin. For a discussion of the flood of 1911 and attendant weather conditions see the report entitled "Flood problems of Calaveras River", published by the Department of Engineering, State of California, and Bulletin 43 of the United States Weather Bureau.

Floods of 1914 and subsequent floods.--The San Joaquin River near Friant attained a peak on January 25, 1914, which was not exceeded unt11 December 1937. On the upper river this flood was probably the greatest for a long period prior to 1914 but was much lower than the recordbreaking flood of 1867 . The Tuolume RIver nearly equalled its record of 1911, but the Stanislaus and Calaveras Rivers reached only moderately high peaks. The San Joaquin River near Newman reached a peak on January 27, 1914, which was not exceeded unt11 1938, but which was cons1derably lower than the reported peaks of 1868, 1886, and 1911. In 1914 the lower San Joaquin River at Lathrop reached its crest on January 27 at a stage that was about the same as the peaks of 1907 and 1909, but considerably below the record stage of 1911.

See table 12 for a comparison of floods at certain localities in the San Joaquin River Basin during the period 1867 to 1938. 
Table 12.--Maximum stage and discharge of recorded floods at indicated places on San Joaquin and Trolume Rivers

\begin{tabular}{|c|c|c|c|c|c|c|}
\hline \multirow{3}{*}{ Date } & \multicolumn{4}{|c|}{ San Joaquin River-- } & \multicolumn{2}{|c|}{ Tuolunne River-- } \\
\hline & \multicolumn{2}{|c|}{ near Frlant a } & \multicolumn{2}{|c|}{ near Newman } & \multicolumn{2}{|c|}{$\begin{array}{l}\text { above La Grange Dam } \\
\text { noar La Grange b/ }\end{array}$} \\
\hline & Gage helght & $\begin{array}{l}\text { Discharge } \\
\text { (sec.-ft.) }\end{array}$ & Gage he 1 ght & $\begin{array}{l}\text { Discharge } \\
(\text { sec.-ft. })\end{array}$ & $\begin{array}{c}\text { Gage height } \\
\text { (feet) }\end{array}$ & $\begin{array}{l}\text { Discharge } \\
(s e c \cdot-f t \cdot)\end{array}$ \\
\hline $\begin{array}{l}1867-8 \\
1886, \text { February } \\
1899 \text {, Mar. } 25 \\
1901 \text {, Feb. } 19 \\
1906 \text {, Mar. } 24\end{array}$ & $\begin{array}{l}- \\
\overline{-} \\
-\end{array}$ & $\begin{array}{l}- \\
- \\
- \\
-\end{array}$ & $\begin{array}{c}c 21.7 \\
c 19.8 \\
- \\
-\end{array}$ & $\begin{array}{l}- \\
- \\
- \\
-\end{array}$ & $\begin{array}{l}\overline{-} \\
\bar{d} \overline{2} .5 \\
\mathrm{~d} 11.7 \\
\mathrm{~d} 12.45\end{array}$ & $\begin{array}{l}\overline{-} \\
\overline{-} \overline{6}, 800 \\
02 \overline{2}, 500 \\
026,200\end{array}$ \\
\hline $\begin{array}{l}1907, \text { Mar. } 19 \\
1909, \text { Jan. } 14 \\
1909, \text { Dec. } 9 \\
1909, \text { Dec. } 31 \\
1911, \text { Jan. } 31\end{array}$ & $\begin{array}{l}\text { dis. } 0 \\
\overline{-} \\
\text { d } 1 \overline{5} .3 \\
\text { d18.0 }\end{array}$ & $\begin{array}{l}26,800 \\
\overline{-} \\
37,900 \\
38,800\end{array}$ & $\begin{array}{l}- \\
\overline{-} \\
\overline{-}\end{array}$ & $\begin{array}{l}\overline{-} \\
\bar{z} \\
\overline{-}\end{array}$ & $\begin{array}{c}\mathrm{d} 15.75 \\
\mathrm{~d} 9.5 \\
\mathrm{~d} 8.1 \\
- \\
\mathrm{d} 16.45\end{array}$ & $\begin{array}{c}850,400 \\
26,500 \\
20,900 \\
- \\
60,300\end{array}$ \\
\hline $\begin{array}{l}1911 \\
1914, \text { Jan. } 25 \\
1914, \text { Jan. } 27 \\
1916, \text { Feb. } 6 \\
1917, \text { Feb. } 21\end{array}$ & $\begin{array}{l}2 \overline{1} .72 \\
\overline{-} \\
-\end{array}$ & $\begin{array}{c}54,000 \\
- \\
-\end{array}$ & 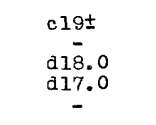 & $\begin{array}{c}- \\
20,700 \\
18,200 \\
-\end{array}$ & $\begin{array}{l}\overline{16.0} \\
\overline{-} \\
\overline{2} \overline{7} .6\end{array}$ & $\begin{array}{c}\overline{57,900} \\
\bar{z} \\
\overline{-} \\
e 3 \overline{3}, 800\end{array}$ \\
\hline $\begin{array}{l}\text { 1918, Mar. } 7 \\
1928, \text { Mar. } 25 \\
1928, \text { Mar. } 31 \\
1935, \text { Apr. } 8 \\
1935 \text {, Apr. } 18\end{array}$ & $\begin{array}{l}1 \overline{2.35} \\
\overline{13} .16 \\
-\end{array}$ & $\begin{array}{l}- \\
13,100 \\
15,700 \\
-\end{array}$ & $\underset{\overline{14} .95}{\bar{m} .02}$ & $\begin{array}{l}- \\
\overline{4,500} \\
\overline{8,820}\end{array}$ & $\begin{array}{l}22.47 \\
- \\
- \\
-\end{array}$ & $\begin{array}{l}23,300 \\
- \\
- \\
-\end{array}$ \\
\hline $\begin{array}{l}1936, \text { Feb. } 22 \\
1936, \text { Feb. } 26 \\
1937 \text {, Feb. } 6 \\
1937 \text {, Feb. } 20 \\
1937 \text {. Dec. } 11\end{array}$ & $\begin{array}{c}15.7 \\
- \\
18.2 \\
\overline{23} .8\end{array}$ & $\begin{array}{l}25,000 \\
- \\
36,400 \\
77,200\end{array}$ & $\begin{array}{c}\overline{16 .} .80 \\
\overline{15 .} .96 \\
-\end{array}$ & $\begin{array}{l}14 \overline{,}, 400 \\
12,800\end{array}$ & $\begin{array}{l}- \\
\overline{-} \\
-\end{array}$ & $\begin{array}{l}- \\
\overline{-} \\
-\end{array}$ \\
\hline $\begin{array}{l}\text { 1938, Mar. } 2 \\
1938, \text { Mar. } 7\end{array}$ & $\begin{array}{l}18.95 \\
-\end{array}$ & 41,400 & $\overline{18.50}$ & $\mathrm{f33,000}$ & - & - \\
\hline
\end{tabular}

a Record prior to Nov. 9. 1913, obtained at former site, 2 miles upstream.

b Record prior to Apr. 1, 1908, obtained at gage at bridge below La Grange Dam;

record from Apr. 1, 1908, to Mar. 18, 1915, obtained at La Grange Dam; record subsequent to Mar. 18, 1915, obtained at present s1te, $3 \frac{1}{2}$ miles upstream from La Grange Dam.

Storage on Tuolumine River began in Lake Eleanor in June 1918, in Don Pedro Reservolr in November 1922, and in Hetch Hetchy Reservoir in May 1923.

c Observed in a building 500 feet upstream and referred to gage datum.

d Maximum recorded; may not be the peak.

o Supersedes previously published discharge. Prior to 1909 , discharge records also include diversions not previously included, to make all entries comparable.

$f$ Adjusted for measured flow in by-pass channels around gage; discharge records for previous years were not adjusted. 


\section{Sacramento River Basin}

Floods from 1825 to 1847 --County histories and journals of pioneers mention floods in the lower Sacramento River Basin during the seasons 1825-26, 1839-40, and in the year 1847. The flood of 1839-40 was experienced by the pioneer settler John A. Sutter, who described the country as a vast expanse of water. His small boat was delayed for • several weeks in making the trip between his fort at the site of the present city of Sacramento and the base of supplies at Yerba Buena, now San Francisco. This flood was evidently of considerable duration, but the widespread flooding of the lowlands does not necessarily indicate that it was of extreme magnitude. Until levees were constructed even minor floods would have spread far beyond the channel of the lower Sacramento River. Histories of the early settlements state that the Indians recalled the flood of $1825-26$ as an outstanding one, and that they had knowledge of a great flood, supposed to have occurred about the beginning of the nineteenth century, which caused thousands of deaths.

Floods of 1850.--The first flood on the lower Sacramento River of which there are fairly accurate descriptions is that of January 1850. The city of Sacramento was flooded on January 10 for a distance of a mile back from the Embarcadero. Newspaper accounts state that most of the houses were flooded, and that many were washed from their foundations. Some loss of life was caused by this flood, and there was great damage to provisions and other property. Lowlands west of the Sacramento River were flooded, but without great damage. The maximum stage at Sacramento on January 10 has been determined as 20.2 feet, referred to a datum that is at about mean sea level. Subsequent reference to the stage of the Sacramento River at Sacramento refer to this same datum. (See list of flood stages at Sacramento on page 469.)

An eye witness 17 / of the flood of 1850 wrote as follows under date of January 10, 1850:

This morning I went upon the foretop of a store-ship anchored near our steamer, to take a survey of an entire city under water. I could not discover a single speck of land in sight, except a little spot of a few feet on the levee near our boat. The boatmen were navigating the streets in whale boats in every direction.

Further on he stated:

-. the valley, for the width of several miles, and in length for more than a hundred miles, was an unbroken sea of waters. 
On February 23, 1850, a Sacramento newspaper stated that there were accounts from all quarters of tremendous floods and continued rains. Again in April there was another flood at Sacramento "within a foot of the great inundation".

The few available precipitation records support the conclusion that the season of 1849-50 must have been one of heavy mun-off. However, the floods of 1850 were exceeded at Sacramento in 1852 , and greatly exceeded in 1862 .

Floods of 1852 and 1853.--The flood of 1852 on the Sacramento River Is described in a Red Bluff newspaper of 1861 as the highest known to the oldest residents prior to December 1861 . As reported in this account, the crest stage of 1852 was only slightly exceeded on December 8, 1861.

The lower Sacramento River and its tributary, the American River, reached high stages after a prolonged rain that began on March 5, 1852 . The city of Sacramento was flooded during the period March 7-11, chiefly from overflow of the American River east of the city. The Sacramento River at Sacramento was not extremely high during this flood, reaching a gage-height of only 18 feet.

On December 31, 1852, after a short, sharp rise of the American River that flooded the city on December 19, the Sacramento River reached a gage-height of 21.7 at Sacramento, higher than any previously observed. The clty was reported to have been completely flooded on January 1, 1853 , but rapid recession followed the peak. The brief duration of the flood in Sacramento suggests that it was due mainly to overflow from the American River which remains at flood stages for relatively brief periods. The lowlands of the Sacramento River downstream from Colusa were flooded, and it was reported that all places along the right bank of the river were under water except the Indian mounds, and that thousands of cattle were drowned. The flood had subsided by the end of January 1853.

There was a flood at the function of the Yuba and Feather Rivers on March 28, 1853, which was said to have been 8 inches higher than that of the preceding January. It was noted that this was the fourth and last flood of the season at that place. The Sacramento River at Sacramento rose from a low stage on March 25 to 19.4 feet on April 3.

Floods of 1861 and $1862 .--A$ series of floods occurred in December 1861 and January 1862, which months constitute the greatest flood period in the history of California. At Red Bluff the first flood on the Sacramento River occurred on December 8, 1861, when, it was reported, there was a rapid rise from a comparatively low stage to a height probably of 
about 28 feet, as determined by comparison with the record flood of January 1862. The tributary cleeks in the vicinity of Red Bluff were not notably high, the greatest rise being in the mountain regions in the northern part of the basin. On December 23, 1861, after a two-day storm, the river at Red Bluff was at bank-full stage, and on December 28 and 29, 1861, another hard rain caused tributaries upstream from Red Bluff to rise to very high stages. Cottonwood Creek was reported to have been higher than ever before known. The Sacramento River at Red Bluff apparently did not reach exceptionally high stages during either of these storms. On January 10, 1862, after a rainstorm that had been preceded on January 5 by a snowfall of 8 inches at Red Bluff, the Sacramento River had the second notable flood of the season, described as being within 1.5 feet of the flood of December 8, 1861 . Cottonwood Creek was reported to have exceeded its previous record by 3 feet. Again on January 15 and 17 there were snowstorms at Red Bluff, followed by a heavy rain that began on January 19. After a gradual rise of several days the river reached on January 23 a record height of 29 feet, which according to Bulletin 43 of the United States Weather Bureau was the highest stage at Red Bluff until February 4, 1881. The storm that caused the flood of December 8, 1861, on the upper Sacramento River was general throughout the Sacramento River Basin. The lower Sacramento River and its tributaries, the Feather, Yuba, Bear, and American Rivers, rose from high stages on December 7 to flood crests on December 9. The American River at Folsom was described as having exceeded the flood of 1852 by 8 feet on the latter date, and it is probable that the other tributaries were correspondingly high. Overflow from the American River, east of Sacramento, flooded that city on December 9, causing loss of life and much destruction of property. The lower Sacramento River continued to rise until December 14, flooding considerable areas in the lowlands downstream from Colusa. After the river gradually subsided from a gage height of 22.0 feet on December 13 to 18.8 feet on December 23, there was a second rise to about 22.2 feet at Sacramento on December 25, and after another subsidence there was a rise to 22.6 feet on December 27 and 31 . A notable feature of this flood period in the lower Sacramento Valley was the prolonged high stages that existed from December 13, 1861, to about the first of Febmary 1862. During this period there was an outstanding storm, general throughout central California, beginning on January 8, that caused record floods on several of the rivers in the Sierra Nevada on January 10 
and II. The American River at Folsom attained a stage considerably greater than any other known, except possibly that of 1867. At all of the lower points on the Feather, Yuba, Bear, and American Rivers, the flood stages were much greater than had been previously observed.

The Sacramento R1ver at Sacramento reached a stage of 24.0 feet on January 11, 1862, which was the highest of record to that time, and caused additional loss of life and destruction of property. Many of the reports published during this period describe the lower Sacramento Valley as one vast sea of water. Thousands of cattle were drowned or died from starvation in the overflowed regions, and many ranch buildings were destroyed.

Throughout the month of January the lower Sacramento River was at flood stage, ranging in height from about 21 to 24 feet. There was a fourth notable rise of the tributaries in the Sierra Nevada on January 22, although the floods of the Yuba River at Marysvilie and probably also of the American River at Folsom were lower than the floods of December 9 , 1861, and of January 1I, 1862. The lower Sacramento River did not reach its former record, and by the end of January it was receding gradually. Another minor rise occurred about the end of February on the American River, causing another fiood in Sacramento. The Sacramento River at Sacramento reached a height of about 21 feet on March 2,1862 .

The known stages for the floods of 1861-62 in the Sacramento River Basin are given in tables $13-15$ and in the list on page 469.

Floods of 1867 and 1868.-- In December 1867 the storms that resulted in the record-breaking floods in the San Joaquin River Basin also caused floods in the lower Sacramento Valley. Streams of the Sacramento River Basin upstream from Red BIuff probably did not reach exceptionally high stages, although floods on the Sacramento River upstream from the Pit River and on Cow Creek were reported. An outstanding feature of this flood period in the lower Sacramento River Basin was the extremely heavy precipitation reported for December 1867. At Nevada City, in the Yuba River Basin, 4l.95 inches of rain was measured in that month. Heavy storms occurred in the periods December 8-9, 17-18, and 21-25, 1867, and from December 29, 1867, to January 2, 1868, and were followed by excessive mun-off from the foothills. Foothili tributaries of the Yuba and American Rivers were reported to have reached record stages on December 22, 23, and 25. The American River near Sacramento was higher on December 24, 1867, than during the flood of January 10, 1862, and by December 26 it was at its crest, reported variousiy to have been 2 to 
Table 13.--Maximum stage and discharge of recorded floods at indicated places on Sacramento and Pit Rivers

\begin{tabular}{|c|c|c|c|c|c|c|c|}
\hline \multirow{3}{*}{ Date } & \multicolumn{5}{|c|}{ Sacramento River-- } & \multirow{2}{*}{\multicolumn{2}{|c|}{$\frac{\text { P1t River-- }}{\text { near Ydalpom } g /}$}} \\
\hline & \multicolumn{2}{|c|}{ at Kennett } & \multicolumn{2}{|c|}{ near Red Bluff } & \multirow{2}{*}{\begin{tabular}{|c|} 
at Red Bluff \\
$\begin{array}{c}\text { Gage } \\
\text { height } c / \\
\text { (feot) }\end{array}$
\end{tabular}} & & \\
\hline & $\begin{array}{c}\text { Gage } \\
\text { height b } \\
(\text { feet })\end{array}$ & $\begin{array}{l}\text { Discharge } \\
\text { (sec.-ft.) }\end{array}$ & $\begin{array}{c}\text { Gage } \\
\text { height } \\
\text { (feet) }\end{array}$ & $\begin{array}{l}\text { Discharge } \\
\text { (sec.-ft.) }\end{array}$ & & $\begin{array}{c}\text { Gage } \\
\text { height } \\
\text { (feet) }\end{array}$ & $\begin{array}{l}\text { Discharge } \\
\text { (sec.-ft.) }\end{array}$ \\
\hline $\begin{array}{l}1862, \text { Jan. } 23 \\
1881, \text { Feb. } 4 \\
1896, \text { Jan. } 27 \\
1900, \text { Jan. } 3 \\
1902, \text { Feb. } 10\end{array}$ & $\overline{-}$ & $\begin{array}{l}\bar{z} \\
\overline{-}\end{array}$ & $\begin{array}{c}\overline{-} \\
\overline{-} \\
\text { e23.6 }\end{array}$ & $\begin{array}{c}\overline{-} \\
\overline{-} \\
140,000\end{array}$ & $\begin{array}{r}29 \\
29.5 \\
e 24.1 \\
e 24.7 \\
\theta 24.7\end{array}$ & $\begin{array}{r}\text { d28士 } \\
\overline{-} \\
\overline{-}\end{array}$ & $\begin{array}{l}\overline{-} \\
\overline{-}\end{array}$ \\
\hline $\begin{array}{l}1902, \text { Feb. } 24 \\
1902, \text { Nov. } 10 \\
1903, \text { Jan. } 25 \\
1903, \text { Nov. } 22 \\
1904, \text { Feb. } 16\end{array}$ & $\begin{array}{l}- \\
\overline{-} \\
-\end{array}$ & $\begin{array}{l}\overline{-} \\
\overline{-}\end{array}$ & $\begin{array}{l}\text { e } 24.8 \\
\text { e } 21.4 \\
\text { e } 22.8 \\
\text { e } 21.5 \\
\text { e } 31.0\end{array}$ & $\begin{array}{r}151,000 \\
118,000 \\
131,000 \\
119,000 \\
1207,000\end{array}$ & $\begin{array}{l}\text { e24.7 } \\
\text { e23.3 } \\
\text { e24.4 } \\
\text { e24.5 } \\
\text { e28.2 }\end{array}$ & $\begin{array}{l}\overline{-} \\
\overline{-}\end{array}$ & $\begin{array}{l}\overline{-} \\
\overline{-}\end{array}$ \\
\hline $\begin{array}{l}\text { 1905, Jan. } 23 \\
1906, \text { Mar. } 31 \\
1906, \text { Apr. } 1 \\
1907, \text { Feb. } 2 \\
1907, \text { Feb. } 4\end{array}$ & $\begin{array}{c}\overline{-} \\
\overline{-} \\
-\end{array}$ & $\begin{array}{l}- \\
\overline{-} \\
\overline{-}\end{array}$ & $\begin{array}{c}e 20.3 \\
e 23.4 \\
- \\
\text { e23. }\end{array}$ & $\begin{array}{c}108,000 \\
137,000 \\
- \\
13 \overline{4}, 000\end{array}$ & $\begin{array}{l}\text { e } 24.5 \\
\text { e } 25.5 \\
\text { e } 25.5 \\
\text { e } 24.4\end{array}$ & $\begin{array}{l}\overline{-} \\
\overline{-} \\
\overline{-}\end{array}$ & $\begin{array}{l}\overline{-} \\
\overline{-} \\
-\end{array}$ \\
\hline $\begin{array}{l}\text { 1907, Mar. } 20 \\
1909 \text {, Jan. } 16 \\
1909, \text { Jan. } 21 \\
1909, \text { Feb. } 3 \\
1911, \text { Mar. } 7\end{array}$ & $\begin{array}{r}35.2 \\
\text { e } 34.5 \\
\text { e } 32.0 \\
\text { e } 34.5 \\
\text { e19.0 }\end{array}$ & $\begin{array}{l}= \\
= \\
=\end{array}$ & $\begin{array}{l}\text { e } 29.4 \\
\text { e } 28.4 \\
\text { e } 27.1 \\
\text { e } 35.2 \\
\text { e22.7 }\end{array}$ & $\begin{array}{r}f 191,000 \\
181,000 \\
f 168,000 \\
f 252,000 \\
130,000\end{array}$ & $\begin{array}{l}\text { e26.8 } \\
\text { e27.9 } \\
\text { e26.0 } \\
\text { e30.5 } \\
\text { e25.5 }\end{array}$ & $\begin{array}{c}- \\
- \\
013.3\end{array}$ & $\begin{array}{c}\overline{-} \\
\overline{-} \\
20,600\end{array}$ \\
\hline $\begin{array}{l}\text { 1913, Dec. } 31 \\
1914, \text { Jan. } 1 \\
1914, \text { Jan. } 2 \\
1915, \text { Feb. } 2 \\
1916, \text { Feb. } 10\end{array}$ & $\begin{array}{l}\text { e28.6 } \\
-\overline{7} .0 \\
\text { e } 31.5 \\
\text { e } 23.0\end{array}$ & $\begin{array}{l}\overline{-} \\
\overline{-} \\
-\end{array}$ & $\begin{array}{l}\text { e } \overline{\overline{7}} .6 \\
\text { e } \overline{3} \overline{4} .0 \\
-\end{array}$ & $\begin{array}{l}f 17 \overline{3}, 000 \\
-\overline{9}, 000 \\
-\end{array}$ & $\begin{array}{l}e 28.0 \\
e 29.0 \\
e 30.4 \\
-\end{array}$ & $\begin{array}{c}\text { e20.7 } \\
\overline{-} \\
\text { e17. } \\
\text { e18.9 }\end{array}$ & $\begin{array}{c}47,000 \\
- \\
- \\
33,900 \\
40,300\end{array}$ \\
\hline $\begin{array}{l}\text { 1916, Feb. } 11 \\
1926, \text { Feb. } 4 \\
1926, \text { Feb. } 5 \\
1927 \text {, Feb. } 21 \\
1928, \text { Mar. } 26\end{array}$ & $\begin{array}{l}1 \overline{9} .5 \\
\overline{4} .66 \\
25.1\end{array}$ & $\begin{array}{l}- \\
66,000 \\
- \\
92,800 \\
94,900\end{array}$ & $\begin{array}{l}e 19.4 \\
- \\
20.5 \\
26.0 \\
-\end{array}$ & $\begin{array}{r}101,000 \\
- \\
110,000 \\
+152,000 \\
-\end{array}$ & $\begin{array}{l}\text { e24.0 } \\
\text { e } \overline{3} .5 \\
\text { e } 26.5 \\
-\end{array}$ & $\begin{array}{l}14.75 \\
-\overline{-} \\
20.8 \\
18.5\end{array}$ & $\begin{array}{l}26,000 \\
- \\
45,700 \\
37,800\end{array}$ \\
\hline $\begin{array}{l}\text { 1928, Mar. } 27 \\
1935, \text { Apr. } 7 \\
1935, \text { Apr. } 8 \\
1936, \text { Jan. } 15 \\
1936, \text { Feb. } 21\end{array}$ & $\begin{array}{l}\overline{15.65} \\
\overline{-} \\
2 \overline{3} .3\end{array}$ & $\begin{array}{c}47,000 \\
- \\
- \\
85,500\end{array}$ & $\begin{array}{c}26.1 \\
= \\
=\end{array}$ & $\begin{array}{c}f 153,000 \\
- \\
- \\
-\end{array}$ & $\begin{array}{c}\text { e26.9 } \\
\overline{\bar{c}} .6 \\
-\end{array}$ & $\begin{array}{c}- \\
\overline{16.00} \\
18.5 \\
-\end{array}$ & $\begin{array}{c}- \\
- \\
29,400 \\
37,900 \\
-\end{array}$ \\
\hline $\begin{array}{l}\text { 1936, Feb. } 22 \\
1937 \text {, Dec. } 10 \\
1937 \text {, Dec. } 11\end{array}$ & $\overline{30.6}$ & $\begin{array}{c}\overline{-} \\
132,000\end{array}$ & $\begin{array}{l}24.5 \\
3 \overline{6} .5\end{array}$ & $\begin{array}{l}133,000 \\
26 \overline{2}, 000\end{array}$ & $\overline{32.0}$ & 24.2 & 65,000 \\
\hline
\end{tabular}

a Records prior to 1924 from staff gage, 400 feet downstream from present gage; gage heights prior to 1924 adjusted to present datum by adding 2.50 feet to staff-gage readings.

b Records prior to 1926 furnished by U. S. Weather Bureau and adjusted to datum of present U. S. Geological Survey, which is 2.00 feet lower.

c Records furnished by U. S. Weather Bureau.

d From floodmark referred to present datum.

- Maximum recorded; may not be the peak.

f Supersedes discharge previously published.

$1603020-39-30$ 


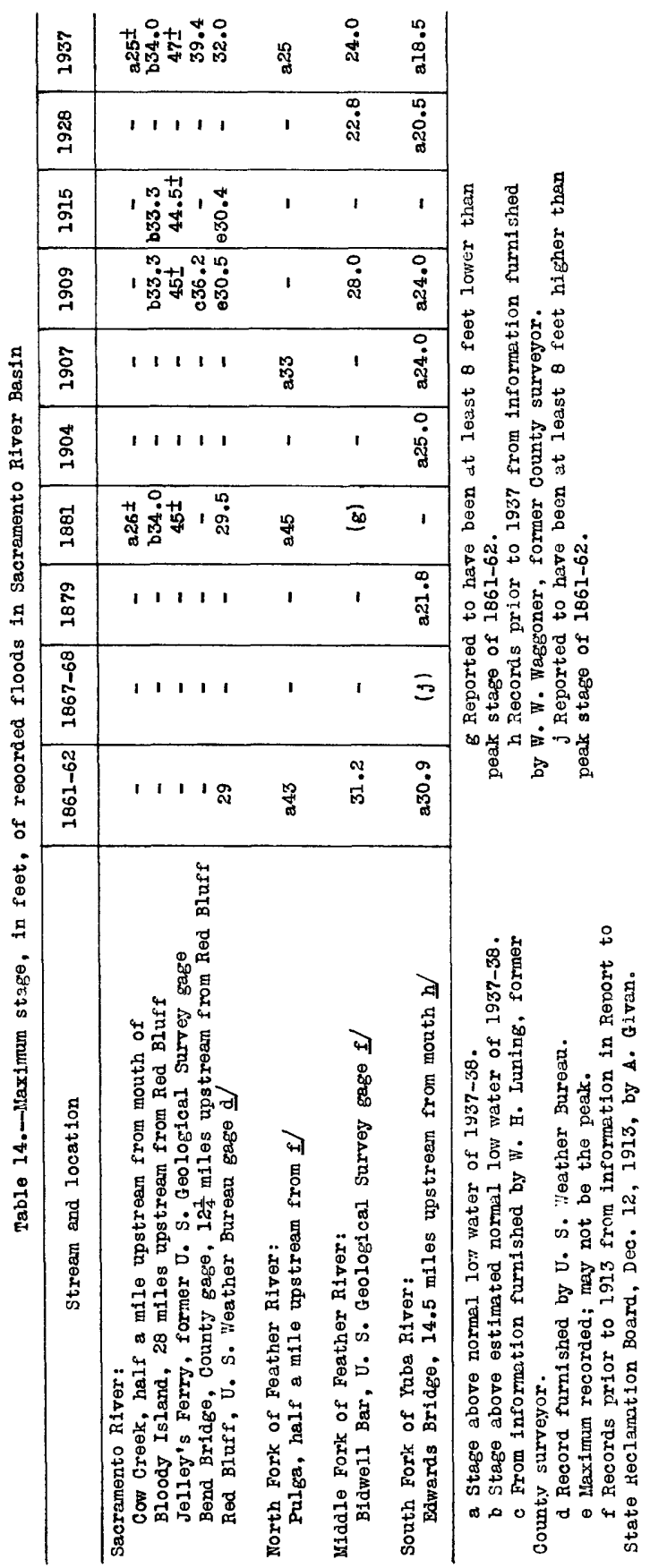


Table 15.--Maximum stage and discharge of recorded floods at indicated places on Feather, Yuba, and American Rivers

\begin{tabular}{|c|c|c|c|c|c|c|c|}
\hline \multirow{3}{*}{\multicolumn{2}{|c|}{ Date }} & \multirow{2}{*}{\multicolumn{2}{|c|}{$\frac{\text { Feather River-- }}{\text { at 0roville }}$}} & \multirow{3}{*}{$\begin{array}{l}\text { Yuba River-- } \\
\text { at Smartville } \\
\begin{array}{c}\text { Discharge } \\
\text { (sec.-ft.) }\end{array}\end{array}$} & \multicolumn{3}{|c|}{ American River-- } \\
\hline & & & & & \multirow{2}{*}{$\frac{\text { at Folsom }}{\begin{array}{c}\text { Gage } \\
\text { hejght b/ } \\
\text { (feet) }\end{array}}$} & \multicolumn{2}{|c|}{ at Fair Oaks } \\
\hline & & $\begin{array}{c}\text { Gage } \\
\text { helght a } \\
\text { (feet) }\end{array}$ & $\begin{array}{l}\text { Discharge } \\
(s e c-f t .)\end{array}$ & & & $\begin{array}{l}\text { Gage } \\
\text { helght } c \\
(f \theta e t)\end{array}$ & $\begin{array}{l}\text { Discharge } \\
(s \theta c .-f t .)\end{array}$ \\
\hline $\begin{array}{l}1862, \\
1879, \\
1881, \\
1881, \\
1883,\end{array}$ & $\begin{array}{l}\text { Jan. } 10 \\
\text { Feb. } 12 \\
\text { Jan. } 30 \\
\text { February } \\
\text { Mar. } 29\end{array}$ & $\begin{array}{c}\mathrm{f} 1 \overline{1.7} \\
\mathrm{f} \\
=\end{array}$ & $\begin{array}{l}\overline{-} \\
\overline{-}\end{array}$ & $\begin{array}{l}\bar{z} \\
\bar{z}\end{array}$ & $\begin{array}{l}042 \\
\mathrm{f24} .0 \\
\mathrm{f} 23.5 \\
- \\
\mathrm{f} 19.7\end{array}$ & $\begin{array}{l}e 39^{ \pm} \\
- \\
= \\
=\end{array}$ & $\begin{array}{l}\overline{-} \\
- \\
\overline{-} \\
-\end{array}$ \\
\hline $\begin{array}{l}1884, \\
1884, \\
1885, \\
1886, \\
1904,\end{array}$ & $\begin{array}{l}\text { Mar. } 9 \\
\text { Dec. } 23 \\
\text { Dec. } 25 \\
\text { Jan. } 24 \\
\text { Feb. } 22\end{array}$ & $\begin{array}{c}f 13.0 \\
f 13.8 \\
f 15.7 \\
f 15.1 \\
.\end{array}$ & $\begin{array}{l}- \\
\overline{-} \\
=\end{array}$ & $\begin{array}{c}\overline{-} \\
\overline{-} \\
59,800\end{array}$ & $\begin{array}{c}\mathrm{f} 26.0 \\
- \\
\mathrm{f} 23.8 \\
\mathrm{f} 29.0 \\
=\end{array}$ & $\begin{array}{l}- \\
\overline{-} \\
\overline{-}\end{array}$ & $\begin{array}{l}- \\
\overline{-} \\
-\end{array}$ \\
\hline $\begin{array}{l}1904, \\
1907, \\
1909, \\
1909, \\
1909,\end{array}$ & $\begin{array}{l}\text { Feb. } 24 \\
\text { Mar. } 19 \\
\text { Jan. } 14 \\
\text { Jan. } 15 \\
\text { Jan. } 16\end{array}$ & $\begin{array}{c}\mathrm{f} 19.5 \\
28.2 \\
- \\
\mathrm{f}\end{array}$ & $\begin{array}{c}106,000 \\
8230,000 \\
- \\
- \\
8180,000\end{array}$ & $\begin{array}{c}59,900 \\
100,000 \\
- \\
111,000 \\
-\end{array}$ & $\begin{array}{c}- \\
\text { f26.8 } \\
\text { f24.5 } \\
= \\
-\end{array}$ & $\begin{array}{l}- \\
\mathrm{f} 31.4 \\
\mathrm{f} 27.7 \\
- \\
-\end{array}$ & $\begin{array}{c}8140,000 \\
101,000 \\
= \\
=\end{array}$ \\
\hline $\begin{array}{l}1911, \\
1913, \\
1914, \\
1914, \\
1915,\end{array}$ & $\begin{array}{l}\text { Jan. } 31 \\
\text { Dec. } 31 \\
\text { Jan. } 1 \\
\text { Jan. } 25 \\
\text { May } 11\end{array}$ & $\begin{array}{c}2 \overline{0} .5 \\
= \\
\overline{16.3}\end{array}$ & $\begin{array}{c}\text { g12i, } 000 \\
- \\
\text { g8ī, } 400\end{array}$ & $\begin{array}{c}39,000 \\
61,200 \\
- \\
- \\
-\end{array}$ & $\begin{array}{c}- \\
\bar{f} \\
\overline{-} \\
-\end{array}$ & $\begin{array}{l}\text { f22.9 } \\
- \\
\text { f21. } 7 \\
- \\
=\end{array}$ & $\begin{array}{l}82,000 \\
\overline{74,100} \\
=\end{array}$ \\
\hline $\begin{array}{l}1915, \\
1917, \\
1919, \\
1925, \\
1927,\end{array}$ & $\begin{array}{l}\text { May } 12 \\
\text { Feb. } 25 \\
\text { Feb. } 11 \\
\text { Feb. } 6 \\
\text { Feb. } 21\end{array}$ & $\begin{array}{l}\overline{16.15} \\
\overline{-} \\
18.34\end{array}$ & $\begin{array}{c}\overline{-} \\
\mathrm{g} 80,400 \\
- \\
\bar{g} 9 \overline{4}, 000\end{array}$ & $\begin{array}{l}46,500 \\
45,800 \\
29,400 \\
43,800 \\
49,000\end{array}$ & $\begin{array}{c}- \\
\text { f15.4 } \\
f 17.2 \\
- \\
-\end{array}$ & $\begin{array}{l}- \\
20.4 \\
26.0 \\
=\end{array}$ & $\begin{array}{l}\overline{-} \\
\overline{67}, 500 \\
99,500 \\
-\end{array}$ \\
\hline $\begin{array}{l}1928, \\
1928, \\
1935, \\
1936, \\
1937,\end{array}$ & $\begin{array}{l}\text { Mar. } 25 \\
\text { Mar. } 26 \\
\text { Apr. } 8 \\
\text { Feb. } 22 \\
\text { Dec. } 11\end{array}$ & $\begin{array}{c}\text { n2 } \overline{6} .5 \\
- \\
\text { n2 }\end{array}$ & $\begin{array}{c}-\overline{8} 185,000 \\
j 58,600 \\
- \\
\jmath 185,000\end{array}$ & $\begin{array}{r}120,000 \\
41,200 \\
44,500 \\
95,000\end{array}$ & $\begin{array}{c}+26.8 \\
- \\
f 18.8 \\
- \\
23.9\end{array}$ & $\begin{array}{l}31.45 \\
- \\
20.73 \\
20.7 \\
29.06\end{array}$ & $\begin{array}{r}\mathbf{8} 140,000 \\
50,900 \\
58,300 \\
114,000\end{array}$ \\
\hline
\end{tabular}

a Referred to datum of U. S. Weather Bureau gage.

b Record furnished by U. S. Weather Bureau. Prlor to 1907 gage was located 1,000 feet upstream from present gage (high-water gage heights not comparable with subsequent records).

c Datum lowered 1.00 foot in 1930; all gage helghts adjusted to present datum.

d Recent investigation indicates that flood crest of 1862 was about 33 feet at present site.

e From reported floodmark; verifled by comparison with flood crests of 1862 and 1907 at other points.

$f$ Maximum recorded; may not be the peak.

g Supersedes discharge previously published.

h Gage helght outside of well.

$f$ At station 5 miles upstream. 
5 feet above the record of 1862 at different places near Sacramento. The flood profile of the American River at Sacramento was undoubtediy raised by channel constrictions made after 1862. The levees protecting Sacramento were ralsed after the flood of 1862 and the city has not been serlously flooded since that time. The American River at Folsom on December 26 was reported in news accounts from Folsom to have been as hlgh as, or slightly higher than, the record peak of 1862. It was also reported that on the same date the South Fork of the American River near 1ts mouth rose to within a few inches of the peak of 1862. The North and South Forks of the Yuba River were reported to have exceeded the stage of 1862. The Feather River at Oroville was considerably below the flood crest of 1862 but, according to varying reports, downstream from the mouth of the Yuba River 1t equalled or exceeded the crest of 1862 . The flood profiles of the lower Feather and Yuba Rivers had probably been raised somewhat by the deposition of mining debris in the channels since 1862. Cache and Putah Creeks, tributaries of the Sacramento River from the Coast Ranges, were reported to have been at unusual stages on December 22, 1867. Either on this date or about December 31, Cache Creek reached the highest stage since 1853, and Putah Creek was higher than ever before known. On December 26, 1867, the Sacramento River at Sacramento rose to a stage of 24.1 feet, which was about the same as its previous crest of January 1862 .

The tributaries of the lower Sacramento River again rose to high stages on December 31, 1867, or on January 1, 1868, but did not equal the flood stages of December 26. The Yuba River at Marysville was reported to have risen on January 1 to within a few inches of its peak of December 26. The American River at Folsom on December 31, 1867, it was said, lacked 6.5 feet of reaching its previous peak. The American River at Brighton, near Sacramento, was reported to have attained on January 1 , 1868, a helght some 2 feet below its previous record. Cache Creek near Yolo was again at overflow stage. The Sacramento River at Sacramento rose to 23.4 feet on January 1, 1868. It was reported that during the flood of 1867-68 the peak at Maine Prairle, in the flood basin below Sacramento, was very close to that of 1862 .

Floods of 1878.--The Sacramento River at Red Bluff reached a flood height of about 26 feet above low water on January 17, 1878, the highest stage since January 1862. Rainfall for the period January 14 to 16 was 9.40 inches at Red Bluff. Tributaries in the vicinity of Red Bluff, Including Read, Grasshopper, Dibble, and Cottonwood Creeks, were at very 
high stages, and washed out or damaged railway trestles and highway bridges. Cache and Putah Creeks reached notably high stages. Continued rains resulted in prolonged inundation of the lowlands on the west side of the river from Colusa to Knights Landing.

On January 28, 1878, after minor rises on January 22 and 25 to stages of about 20.5 feet above low water, the Sacramento River at Red BIuff reached a stage of 25.5 feet. Elder, Thomas, and Stony Creeks were at extremely high stages and flooded the lowlands for miles beyond their channels. The relative magnitudes of the floods on these creeks cannot be determined from the information a vailable, but the actual magnitudes were apparently great.

The Sacramento River at Sacramento on February 1, 1878, reached a gage height of 25.2 feet, the highest stage known at that point up to that time, but at Maine Prairie the stage was about 2 feet lower than in 1862. As a result of a break in the levee below Sacramento, the south part of the city and adjacent lands were flooded. Lowlands upstream from Knights Landing and at other places along the lower river were inundated during the entire month of February. On February 19, Knights Landing was partially flooded when the levees protecting the town were overtopped. On February 20 the Sacramento River at Sacramento again exceeded the previous record, rising to 26.0 feet. As previously mentioned, continued levee building tended to raise the flood profile at Sacramento. Several breaks in the levees above and below the c1ty caused flooding of the lowlands west of the river. Cache and Putah Creeks were again at exceptionally high stages, causing extensive overflow and damage to railroad structures, but streams in the upper Sacramento River Basin were not at exceptionally high stages.

Floods of 1881.--The Sacramento River at Red Bluff reached on January 14-15, 1881, a stage of about 24 feet. Th1s rise was followed by high stages on the lower Sacramento River, and it was reported that there were numerous breaks in the levees.

On January 30, after a three-day storm that extended throughout the Sacramento River Basin, the river attained a stage of about 25 feet at Red Bluff. The storm that caused this rise was followed almost immediately by another general storm. The Sacramento River at Red Bluff, already at a high stage on January 31 , continued to rise and reached a peak of 29.5 feet (present datum of the gage of the United States Weather Bureau) on February 4, the highest known to that date. An exceptional feature of this flood was the prolonged period of high stages 
preceding the peak. At the present river-measurement station on the Pit River near Ydalpom the floodmark of 1881, as pointed out by an eye witness, was found to be about 4 feet above the peak of 1937 . This witness said that the flood of 1881 had been described to him as the greatest for at least 30 years prior to and including that year. He stated also that the flood in 1937 was the highest since 1881. The Sacramento River immediately upstream from the mouth of Cow Creok attained in 1881 a stage that is considered by local residents to have been the highest since the settlement of this region in about 1850. A cedar drift $10 \mathrm{~g}$, which is a high-water mark of the flood of 1881 at this point, was reached but not disturbed by the flood of 1937. Cow Creek was at a notably high stage in 1881 and washed out bridges and roads, but the flood of that year was considerably exceeded by the one in 1937, when the creek was at the highest stage known to local residents. Cottonwood Creek was reported not to have been exceptionally high in 1881. On the Sacramento River at Bloody Island, near the junction with Cottonwood and Battle Creeks, the floods of 1881 and 1937 were at about the same stage; at Jelley's Ferry the stage of 1881 was exceeded in 1937; and at Red Bluff the stage of 1881 was exceeded by 2.5 feet in 1937 .

There were notable floods on the Feather, Yuba, and American Rivers in the perlod January 30-31, 1881. The Feather and Yuba Rivers near Marysville were reported to have risen higher than ever before known, although the Feather River at Oroville did not exceed its previous record stage unt1l Febmary 4. The relatively high stages along the lower channels of these rivers were undoubtedly due in part to changed channel conditions that resulted from mining activities and reclamation work. The American River at Folsom was reported to have reached a stage of 23.5 feet on January 30 , not an exceptionally high stage. The Sacramento River at sacramento reached a flood stage of about 26 feet on January 31 .

Beginning on February 2 the Feather and Yuba Rivers rose gradually to the highest stages of the year on February 4. The Feather River at Oroville exceeded thi record stage of 1862 by about half a foot, but It was reported that at Longs Bar, upstream from Oroville, the crest was several feet below that of 1862 . The relatively high stage at Oroville was attributed to deposition of mining debris in the channel since 1862. On the Middle Fork of the Feather River at Bidwell Bar, where flood stages are more nearly comparable, the stage of 1881 was reported to have been 8 feet below the record stage of 1862 . On the North Fork of 
the Feather River near Pulga the crest in 1881 was about 2 feet higher than that in 1862, both floods being considerably higher than any other floods observed at that place. The American River apparently did not attain a second notably high stage.

The Sacramento River at Sacramento, which was at high stages since January 31, established a new record stage of 26.5 feet on February 4. Several breaks occurred in the levees on both sides of the river downstream from Sacramento during this period. Rallroad tracks in the lower Sacramento River Basin were submerged and washed out at several places. At Maine Prairie the peak stage was the same as that in 1862 .

Floods of 1886.--There were moderate floods in this bas in in January 1886. Maximum stages on the tributaries of the lower Sacramento River, occurring about January 24, probably were the highest during the period 1882-88. On some of these tributaries, notably the American River and Cache Creek, the floods apparentiy were of considerable proportions, and resulted in overflow of farm lands and railroad tracks. The maximum reached on the Sacramento River at Sacramento was 25.6 feet on January 28, the highest between 1882 and 1888.

Floods of 1889-90.--The winter of 1889-90 was notable for the prolonged rainy season, which produced damaging floods in the Sacramento River Basin in December 1889 and in January, February, and March 1890. The Sacramento River reached flood stages from Tehama to Sacramento on December 12, 1889. The peak stages at Colusa and Sacramento on this date were the highest yet observed. The storm was evidently very general throughout the lower Sacramento River Basin, but caused only a minor rise on the main river at Red Bluff. The crests at Colusa and Sacramento were higher than they would have been if no reclamation work had been done along the rivers. There were many breaks in the levees from Colusa downstream, and considerable damage was done to grain lands. A large break on the right bank below Sacramento about December 12 probably helped to reduce subsequent flood stages at Sacramento. By December 21 the river downstream from Sacramento was rapidiy receding.

On January 25, 1890, tributaries of the Sacramento River were again at high stages. The American River at Folsom was reported to have reached on this date a gage-height of 30 feet, possibly not the crest. This stage probably is comparable with the readings at the former Weather Bureau gage site given in table 15. Stony, Cache, and Putah Creeks were at extremely high stages on January 24 or 25 . Stony and 
residents, and there was a considerable overflow from Cache Creek near Yolo, which flooded farms and caused washouts along the rallroad. The lower Sacramento River reached only a moderately high crest about January 31.

In February 1890 there was a flood on the upper Sacramento River that resulted in the greatest rise of the season at Red Bluff, the river reaching a stage of about 26.5 feet on February 4. The Sacramento River at Redding washed out part of a highway bridge constructed about 1885 . The lower Sacramento River, at a fairly high stage since January, reached another moderate crest about February 11. The stage at Sacramento was above 21 feet for most of the period from February to June. Again in March 1890 there was a prolonged period of high water on the upper Sacramento River, although the peak stages at Red Bluff were not exceptionally high. Stony Creek and possibly other tributaries from the Coast Ranges were at flood stage on March 5, 1890. The lower Feather River on about March 7 apparently reached its highest stage of the season. The crest on the Sacramento River at Sacramento on March 11 was about 2.5 feet below the maximum of December 12. The peak of 1889 at Sacramento exceeded that of 1881, chiefly because of changed channel conditions, but the maximum at Maine Prairie during 1889-90 was roughly 3 feet lower than the record helghts of 1881 and 1861-62.

The season of 1889-90 was featured by an exceptionally heavy snowfall in the mountains, and the snow run-off period was one of the heaviest and longest of record. Lowlands in the lower Sacramento River Bas In were flooded for many weeks.

Floods of 1891 to 1903.--There were no outstanding general floods in the Sacramento River Basin from 1891 until 1904, although the Sacramento River at Sacramento reached high stages in 1891, 1892, 1893, 1895, 1896, 1900, 1901, 1902, and 1903. The maximum during this period occurred on December 27, 1892, when there was a crest at Sacramento higher than in December 1889. The crest in the flood basin at Maine Prairie for the season of 1892-93, however, was about 2 feet lower than that in 1889-90. At Red Bluff the Sacramento River was at or above a stage of 25 feet from about December 24 to 27, 1892. This flood in the Sacramento Valley followed a heavy rainfall, December 22-25, which evidently extended to the eastern slope of the sierra, causing a flood in the Carson River Basin. The flood of January 1895, which was particularly severe on some of the coastal streams, also appears to have been of major proportions on Cache Creek, January 22-23. The crest at Rumsey 
was stated to have been 2 feet higher, and that at Capay, 10 inches higher than ever known. In the lower part of the basin there was an extensive inundation of farm lands, destruction of bridges, and damage to railroad rights of way.

Floods of 1904.--The Sacramento River at Kennett was reported in a newspaper dispatch to have reached on February 15, 1904, a peak stage of 23 feet, the highest yet observed at that comparatively recent settlement. Cottonwood and Clear Creeks, tributaries between Kennett and Red Bluff, were said to have been higher than ever before known, and on February 16 the river at Red Bluff reached a stage of 28.2 feet, which was reported to have been the highest since February 1881. From February 15 to the end of March the flood period was almost continuous in the lower Sacramento River Basin. During this time there were several rises on the Sacramento River near Red Bluff. There was a severe flood on the Pit River at Alturas about March 10, when it was reported that boats were rowed through the main part of the town.

For a discussion of the flood of 1904 reference is made to WaterSupply Paper 147. In general, it was considered to have been the most destructive flood in the history of the lower sacramento valley up to that time, but it was belleved that the peak discharge of the lower Sacramento River had been much greater in 1862. Exceptionally high stages were reached only on tributaries of the upper sacramento River.

Flood of 1907.--In March 1907 there was a very destructive flood In the Sacramento River Basin.18/ The flood was caused by a severe rain in the period March 16-20, and was preceded and followed by a period of comparatively high run-off.

Exceptionally high stages were reached on streams throughout the basin. On the Feather River at Oroville the flood height was the greatest ever observed, although it was believed that the flood profile at that place had been raised since 1862 by deposition of mining debris. On the American River at Folsom and Fair Oaks the peak of March 19 was exceeded in 1862 and possibly also in 1867. A report by A. Givan and C. E. Grunsky to the State Reclamation Board lists the flood profile of 1862 as about 7.5 feet above the high water of 1907 at Fair Oaks, and 4.0 feet above the high water of 1907 near M11ls, where the river has a

18/ The flood of 1907 is discussed in the following publications: Clapp, W. B., Murphy, E. C., and Martin, W. F., The flood of March, 1907, in the Sacramento and San Joaquin River Basins, California: Am. Soc. Civil Eng. Trans., vol. 61, p. 281, 1908. Taylor, N. R., The rivers and floods of the Sacramento and San Joaquin watersheds: Buil. 43, U. S. Weather Bur. 1913. 
w1de overflow. From Investigations near folsom it seems probable that the peak of 1907 at the present gage at Folsom was about 6 feet below that of 1862 .

Flood of 1909.--In the period January 14-27, 1909, there were floods at several places in the Sacramento River Valley from Red Bluff to the mouth of the Sacramento River. The flood of 1909, in general, was belleved to have been as great as that of 1907 . The Sacramento River had reached high stages at Red Bluff by the perlod January 7-10. Again on January 17 the river was at a very high stage, and on February 3 it reached the highest stage theretofore observed at Red Bluff, which has since been exceeded only by the record-breaking stage of December 11,1937 .

The lower river at Sacramento reached the maximum stage of record on January 17, and exceptionally high stages were recorded between January 14 and 19 on nearly all of the main tributaries of the river. Flood conditions prevalled unt1l January 27 in the lower basin, and were followed again by damaging floods during the first part of February.

The floods of 1909 are discussed In Bulletin 43 of the United States Weather Bureau. They are the most disastrous of any of which there is an authent1c account, although it is belleved that the flood discharge from the Sacramento River Basin in 1862 was probably far in excess of that in the floods of elther 1907 or 1909.

Flood of 1911.--A minor flood occurred in the Sacramento Valley In March 1911. Sacramento RIver near Red Bluff reached a high stage on March 7, and Stony, Cache, and Putah Creeks had high peak stages on March 6 or 7, 1911. The Feather, Amerlcan, and lower Sacramento R1vers did not reach exceptionally high stages. Damaging floods were confined mainly to the lowlands on the west side of the Sacramento River downstream from Colusa, and were the result of heavy run-off from the foothills of the Coast Ranges.

Flood of 1913-14.--On December 31, 1913, and during the first week of January 1914, high stages were recorded on some of the tributarles of the upper Sacramento River. The Sacramento River at Red Bluff, although not rising to the flood crests of 1881 and 1909 , was at a very high stage for three days after December 31, and there was an outstanding peak of 29 feet on January 1, 1914. Putah Creek at Winters attained a record-breaking peak on December 31, 1913. The main tributaries of the lower Sacramento River did not reach exceptionally high stages during 
this perlod, and the flood was of little importance in the lower basin. During the latter part of January 1914 there was a prolonged period of high water on the Sacramento River near Red Bluff and on nearly all of its downstream tributaries. High stages were recorded on the Feather and American Rivers on January 25, at the time that notable floods were observed In the San Joaquin RIver and Tulare Lake Basins. The floods on the main tributaries of the Sacramento River were of small magnitude but, occurring at a time of prolonged high water, caused the Sacramento River at Sacramento to rise to a stage of 27.8 feet on January 27 , the highest since 1909.

Flood of 1915.--On February 2, 1915, the upper Sacramento River reached a helght at Kennett of 29.5 feet (datum of United States Weather Bureau) which, although not as high as the floods of 1907 and 1909 , has not been exceeded since. The crest stage at Red Bluff almost equalled that of 1909. The discharge of Cache Creek at Yolo on February 2, 1915, was the greatest of record, and that of Putah Creek at Winters was exceptionally high, although considerably less than the record flood of 1913. The Feather and American Rivers did not reach notably high stages and the flood was of little importance on the lower Sacramento River.

Flood of 1928.--H1gh stages were recorded on several streams of the Sacramento Basin In 1916, 1917, 1919, 1925, 1926, and 1927, but few of these were exceptionally high, and no general or outstanding floods occurred. In March 1928 there was a severe flood in the Feather and American River Basins and moderate floods throughout the Sacramento River Basin. A notable feature of the flood of 1928 was that it occurred during a relatively dry season and was preceded and followed by comparatively low stages, whereas most of the important floods in this basin have occurred during seasons of heavy precipitation. The flood of 1928 occurred during a period (March 22-28) of heavy precipitation in the Slerra Nevada. Temperatures were unusually high and the rainfall was especially heavy in the period March 24-25 at altitudes up to 7,000 feet. On March 25 the American River at Falr 0aks equalled its maximum recorded discharge of March 19, 1907, and the Feather River at Oroville was exceptionally high. The Sacramento River at Sacramento on March 26 nearly reached 1ts record stage of 1909 , mainly as a result of the run-off from the American River. The greatest damage during the flood of 1928 was from overflow of the American River near Sacramento. Several thousand acres, Including the town of North Sacramento, were flooded. 
For a record of stage associated with the flood of 1928 reference is made to a publication of the State of California, Department of Public Works, entitled "Stream flow data for flood season of $1928^{n}$.

Table 13 on page 457 gives a comparison of floods at two points on the Sacramento River and on Pit River near Ydalpom from 1862 to 1937.

Table 14 on page 458 furnishes a comparison of floods at several points on the Sacramento River during the period 1861 to 1937 . Similar information is given, for the Feather, Yuba, and American Rivers, in table 15 on page 459.

Table 16 shows a comparison of floods on Stony, Cache, and Putah Creeks for the period 1904 to 1937.

Table 16.--Maximum stage and discharge of recorded floods at indicated places on Stony, Cache, and Putah Creeks

\begin{tabular}{|c|c|c|c|c|c|}
\hline \multirow{2}{*}{ Date } & \multirow{2}{*}{$\begin{array}{c}\begin{array}{c}\text { Stony Creek } \\
\text { at } \\
\text { St. Johna }\end{array} \\
\begin{array}{c}\text { Gage } \\
\text { height } \\
\text { (feet) }\end{array}\end{array}$} & \multicolumn{2}{|c|}{$\begin{array}{c}\text { Cache Creek } \\
\text { at } \\
\text { Yolo }\end{array}$} & \multicolumn{2}{|c|}{$\begin{array}{c}\text { Putah Creek } \\
\text { near } \\
\text { Winters }\end{array}$} \\
\hline & & $\begin{array}{c}\text { Gage } \\
\text { he lght } \\
\text { (feet) }\end{array}$ & $\begin{array}{l}\text { Discharge } \\
(\mathrm{sec} .-\mathrm{ft} .)\end{array}$ & $\begin{array}{l}\text { Gage } \\
\text { heisht } \\
\text { (feet) }\end{array}$ & $\begin{array}{l}\text { Discharge } \\
(\mathrm{sec} . \mathrm{ft})\end{array}$ \\
\hline $\begin{array}{l}\text { 1904, Mar. } 10 \\
1907, \operatorname{Mar} .19 \\
1909, \text { Jan. } 8 \\
1909, \text { Jan. } 26 \\
1909, \text { Feb. } 3\end{array}$ & $\begin{array}{c}1 \overline{3} .2 \\
\bar{d} \overline{1 .} .0 \\
-\end{array}$ & $\begin{array}{l}30.2 \\
= \\
\overline{2} \\
\overline{9} .8\end{array}$ & $\begin{array}{c}\overline{-} \\
\overline{-} \\
20, \overline{800}\end{array}$ & $\begin{array}{l}2 \overline{9} .0 \\
27.5 \\
=\end{array}$ & $\begin{array}{c}37, \overline{0} \\
33,400 \\
= \\
=\end{array}$ \\
\hline $\begin{array}{l}\text { 1909, Feb. } 4 \\
1911, \text { Mar. } 7 \\
1913, \text { Dec. } 31 \\
1914, \text { Jan: } 1 \\
1914, \text { Feb. } 21\end{array}$ & $\begin{array}{c}12.6 \\
- \\
\overline{0} \\
10.0 \\
\mathrm{~d} 10.3\end{array}$ & $\begin{array}{l}\overline{2} \overline{.} .8 \\
29.4 \\
-\end{array}$ & $\begin{array}{c}20, \overline{800} \\
20,500 \\
- \\
-\end{array}$ & $\begin{array}{l}\overline{-} \\
39.0 \\
=\end{array}$ & $\begin{array}{c}\overline{-} \\
60,000 \\
- \\
=\end{array}$ \\
\hline $\begin{array}{l}\text { 1915, Feb. } 2 \\
1916, \text { Jan. } 3 \\
1917, \text { Feb. } 24 \\
1917, \text { Feb: } 25 \\
1921, \text { Jan. } 30\end{array}$ & $\begin{array}{l}d 11.5 \\
d 10.0\end{array}$ & $\begin{array}{c}29.8 \\
28.9 \\
-\overline{7} .2 \\
26.3\end{array}$ & $\begin{array}{c}21,100 \\
20,300 \\
= \\
18,800 \\
18,000\end{array}$ & $\begin{array}{l}30.0 \\
35.0 \\
29.0 \\
2 \overrightarrow{29.2}\end{array}$ & $\begin{array}{c}40,400 \\
53,300 \\
37,300 \\
- \\
33,500\end{array}$ \\
\hline $\begin{array}{l}\text { 1925, Feb. } 11 \\
1925, \text { Feb. } 12 \\
1927, \text { Feb. } 18 \\
1927, \text { Apr. } 2 \\
1928, \text { Mar. } 27\end{array}$ & $\begin{array}{l}\overline{-} \\
\bar{d} \overline{7} .6\end{array}$ & $\begin{array}{l}\overline{2} .7 \\
24.8 \\
\overline{2} .3\end{array}$ & $\begin{array}{l}18, \overline{400} \\
17,200 \\
= \\
15, \overline{100}\end{array}$ & $\begin{array}{l}35.1 \\
\overline{-} \\
\overline{2} .2 \\
31.0\end{array}$ & $\begin{array}{c}53,600 \\
- \\
- \\
31,300 \\
34,700\end{array}$ \\
\hline $\begin{array}{l}\text { 1931, Dec. } 27 \\
1935, \text { Mar. } 6 \\
1936, \text { Feb. } 21 \\
1937, \text { Feb. } 4 \\
1937, \text { Dec. } 10\end{array}$ & $\begin{array}{l}\overline{-} \\
\overline{12} .0\end{array}$ & $\begin{array}{l}- \\
\overline{-} \\
-\end{array}$ & $\begin{array}{l}- \\
\overline{-} \\
-\end{array}$ & $\begin{array}{l}21.8 \\
23.2 \\
22.85 \\
25.4 \\
-\end{array}$ & $\begin{array}{c}30,000 \\
34,200 \\
33,000 \\
41,100 \\
=\end{array}$ \\
\hline 1937. Dec. 11 & - & 29.1 & 19,300 & 24.8 & 39,200 \\
\hline
\end{tabular}

a Record furnished by U. S. Weather Bureau.

b Records prior to June 1930 are for former Geological Survey gage at winters, 6 miles downstream.

c Gage datum lowered 2.0 feet in 1.30; gage heights prior to 1930 adjusted to present datum.

d Maximum recorded; may not be the peak. 
Table 17 is a list of maximum annual stages observed on Sacramento River at Sacramento from 1849 to 1938 . The record for periods $1849-79$ and 1889-91, was taken from Commissioner of Public Works Report, State of California, 1894-95; the entire record from 1849 to 1929 was compiled and furnished by Department of Public Works, State of Calipornia. Record for the period 1930-38 was furnished by United States Weather Bureau.

The zero of present Weather Bureau gage is 0.12 foot above mean sea level. All stages given in the table are presumably referred to the present Weather Bureau gage datum.

These data are to be used with caution. The stage is often not a true indication of discharge or the magnitude of a flood since it has been affected by building of levees, bypasses, and overflow channels. The data should not be used or quoted except with proper qualification.

Table 17.--Maximum annual stage, in feet, on the Sacramento River at Sacramento from 1849 to 1938

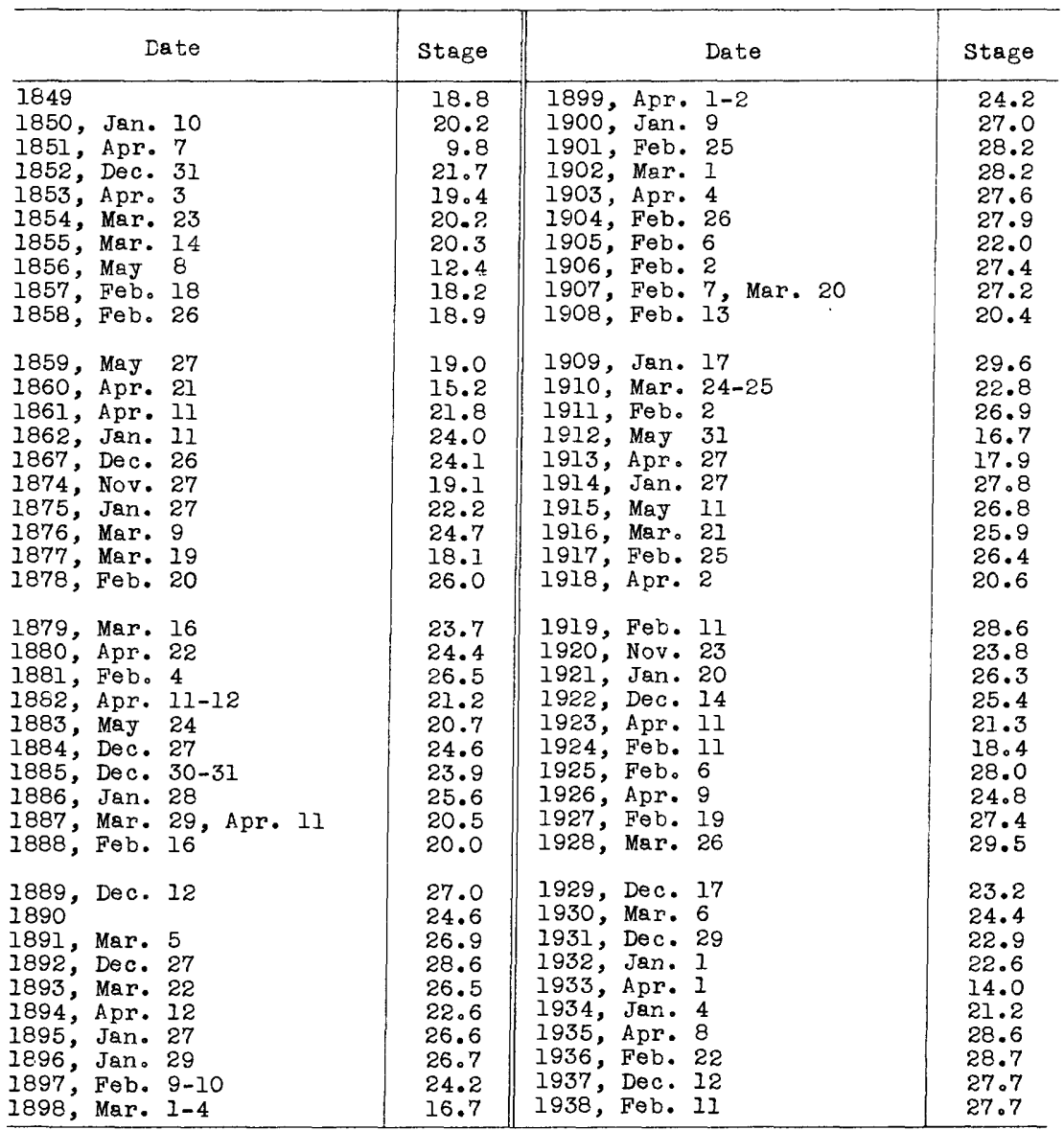




\section{Russian River Basin}

Floods of 1861-62.--The Russian River near Guerneville, after rising to flood stages in December 1861, reached a stage in January 1862 which, so far as known, has not been equalled since.

Floods from 1867 to 1881.--Floods occurred on the lower Russian River in 1867, 1871, 1878, 1879, and 1881. During January and February 1878 the river between Ukiah and Healdsburg reached flood stages several times, the highest being near Healdsburg on February 21, 1878. There was an outstanding flood during the first part of March 1879, reported to have been the highest at Ukiah for eleven years. Disastrous floods occurred on coastal streams west of the Russian River, which were, at some points, the highest known to old inhabltants. Another flood on January 30, 1881, was noted at Guerneville as the third in three years in that city. The peak stage was reported in a news account as 41 feet 8 inches above low-water. This flood probably was somewhat lower than those of 1878 and 1879.

Flood of 1890.--A major flood occurred on January 24-25, 1890, which evidently was nearly the highest known at many points along the river. The crest at Ukiah was said to have been the highest for 20 years, and that at cloversdale, the highest for 40 years. The river changed 1 ts course upstream from Geyserville, destroying a portion of the rallroad. In Alexander Valley, upstream from Healdsburg, the water was reported to have overtopped the highway bridge by 5 feet, and apparently it was about 6 feet above the floodmark of 1878 at that place. The river at Healdsburg in the period January 24-25 was described in the Healdsburg Enterprise as the highest for 25 years. It was stated that a resident who had kept a record of the height of the river for that period had found the 1890 peak to be $2 \frac{1}{2}$ feet higher than any other. Another account stated that the river at Healdsburg was higher than ever before known, even surpassing the peak of 1862. Downstream at Guerneville the crest on February 25 was reported to have been within 9 inches of the flood of 1879, and higher than any between 1880 and 1889.

Floods from 1893 to 1937 --Floods of considerable magnitude have been recorded by residents along the river at different times subsequent to 1890. Outstanding floods were reported for the years 1893, 1895, 1907 , 1914, 1915, and 1937, and 1t is possible that floods of similar magnitude have also occurred in other years. An observer of the flood of 1895 at Guerneville stated that it was the highest flood of which he had 
knowledge during the period 1885-1939. Newspaper accounts, January 23-24, 1895, describe this flood at Healdsburg and at Guerneville as the greatest for a long period prior to 1895 - evidently it was considered higher than the flood of 1890 at these points. For a comparison of maximum stages on the Russian River near Guerneville see table 18. Several of the listed stages are so nearly the same that it would be misleading to make exact comparisons, especially as channel changes may have affected the flood profiles.

\section{Eel River Basin}

Flood of 1852.--The flood of 1852 on the lower Eel River was apparently one of the greatest known. At the time of the flood of 1890 residents mentioned that of 1852 as having been outstanding.

Floods of 1861-62.-Floods occurred on the lower Eel River during the latter part of November and the first part of December, on December 22, 1861, and on January 11, 1862. Residents along the lower Eel River stated at the time of the January flood that the crest was a foot higher than ever known, and about eighteen inches higher than the previous record of the season. At the time of the great flood of 1915 old residents at Metropolitan, on the river 4 miles below Scotia, recalled that of 1862 as having been higher.

Floods of 1877, 1878, and 1879.--There were floods during the season of 1877-78, and a major flood on the lower Eel River about March 6, 1879. Accounts indicate that the crest heights in 1879 from Scotia to the mouth were the highest for at least about 12 years, and probably were nearly as high as any known. Major floods occurred at upper points in the Eel River Basin, on the Van Duzen River, and on the Mad River, north of the Eel River Basin.

Floods of 1881.--An outstanding flood occurred on the Eel River, January 12-15, 1881, as described in the Humboldt Times of January 14 and 15. The crests on the lower river, on its tributary, the Van Duzen, and on the adjacent Mad River apparently were somewhat higher than those in 1879. It is probable that other floods occurred on the Eel River later in January and in February, when the rivers to the north and south reached their highest crests.

Floods of 1890.--There was a flood on the Eel River on February 3 , 1890, and another about the first of March 1890. From newspaper accounts it appears that the two floods had about the same stage and that the stage was somewhat lower than that of 1881 . 


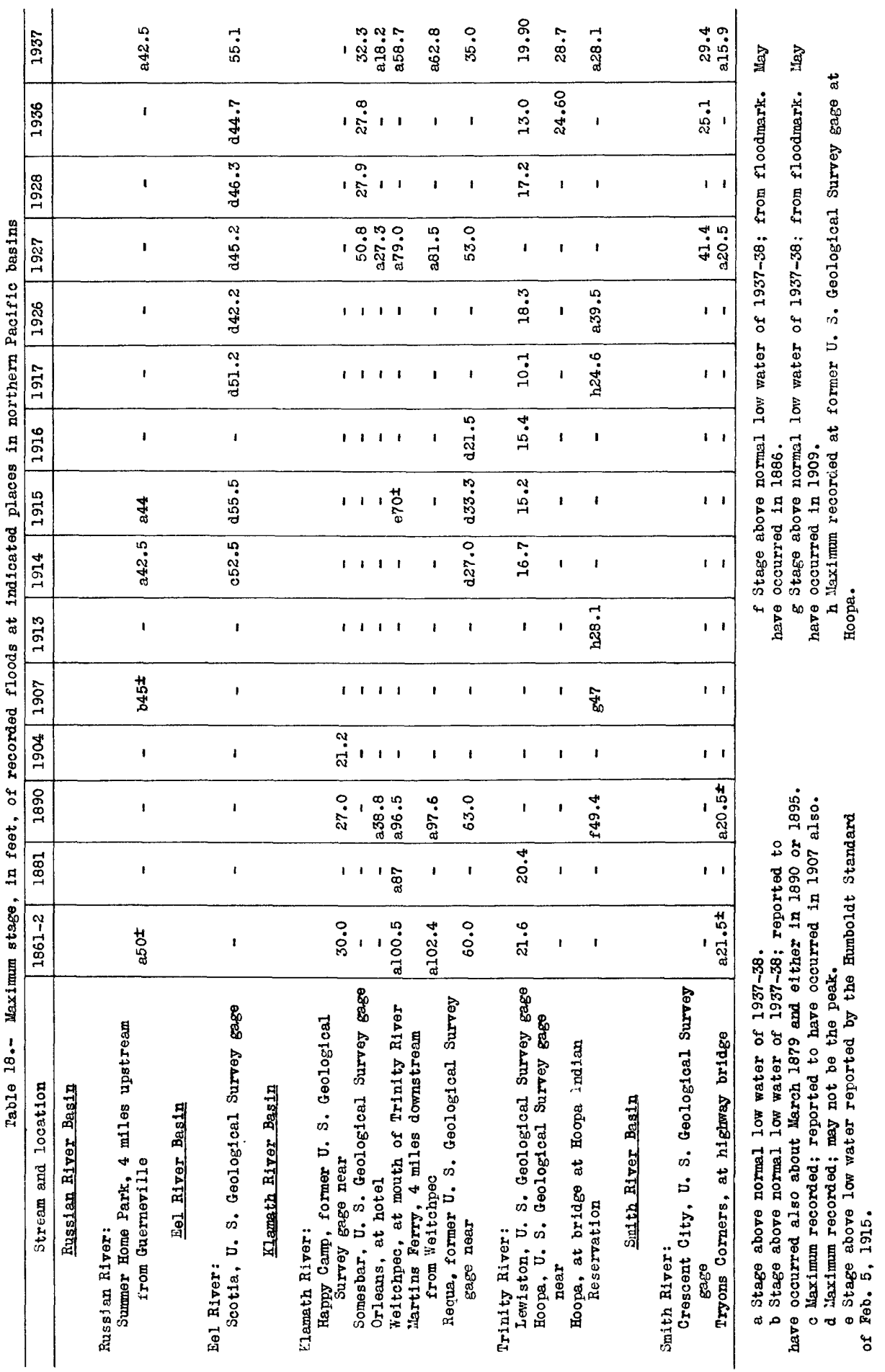


Flood of 1907.--It was reported that on March 18, 1907, the Ee1 River at places downstream from Scotia was the highest known for 30 years. The peak stage at Scotia was roughly established by comparisons with the flood of 1914 at Scotia, Rio De11, and Rohnerville, where the two floods were reported to have reached about the same stage. (See table 18.)

Flood of 1913-14.--A flood that reached its highest stages on December 31, 1913, and January 1, 1914, followed a period of several days of warm rainfall. For comparison with later floods see table 18. Flood of 1915.--On February 2, 1915, the Eel River from Scotia to Loleta rose to its highest recorded stage, possibly exceeded only in 1862. At Shively, 10 miles upstream from Scotia, the peak of 1915 was described as 14 inches above that of 1907 . It was 3 feet higher than the peak of 1914 at Scotia, and was reported as 18 inches higher at Fortuna, 12 miles downstream. Homes and ranch buildings along the lower river were flooded.

The peak of 1915 at Scotia has not been exceeded since, but was nearly equalled in December 1937. The latter flood was variously described as from 8 inches lower to 3 feet higher than that of 1915 at other points along the river. The two floods may be classified as approximately of the same magnitude.

Floods of 1917-37.--An outstanding flood occurred at Scotia on February 25, 1917, and minor floods were recorded in 1926, 1927, 1928, and 1936.

For a comparison of floods on Eel River from 1861 to 1937 see table 18.

\section{Klamath River Basin}

Floods of 1852-53.--The first large floods in the Klamath River Basin after the settlement of the country are mentioned in a history of Siskiyou County. During the season of $1852-53$ there were four floods, which washed out the few bridges that had been built and caused damage in the settlements of Scotts Bar, on the Scott River, and in Yreka, on Yreka Creek.

Floods of 1861-62.--A flood of great magnitude occurred about December 8,1861 . Rainfall had been heavy throughout November, and the rains at the end of that month were extremely heavy. On November 30 the Shasta and Scott Rivers flooded large tracts of land. On December 7 and 8, these rivers and their tributaries were at flood stages that evidently 
were higher than the previous rises. Buildings were washed away or damaged at Yreka, Etna, and Fort Jones. AIong the SaImon and Trinity Rivers, the water washed out bridges, mills, and mining equipment. The main Klamath River from Happy Camp downstream to the Trinity River reached stages that have not been equalled since. A suspension bridge across the river near Martins Ferry, downstream from the mouth of the Trinity River, described as 98 feet above the river, was washed out. The peak of 1861 at Martins Ferry was recently determined to have been about 102 feet above the low water of 1937-38.

There was a third flood on December 22 which, according to a history of Siskiyou County, was the final one of the season of 1861-62. This third flood was apparently of lesser magnitude at least in the upper part of the basin. Based upon the history of this flood season in other basins, it is possible that there were floods again in January 1862 on the lower Klamath River.

Flood of 1864.--A flood described as "nearly as great as that of 1861" occurred in the Scott River Basin on December 26, 1864. Precipitation in the Scott River Valley for the month of December exceeded the large amount measured during December 1861. The flood was probably of little importance on the main Klamath River.

Flood of 1867.--Floods occurred in the Shasta and Scott River Basins in December 1867. The Klamath River near the junctions with these tributaries was described as approaching the record flood of 1861 . The flood of 1867 on other tributaries and on the lower Klamath River evidently was of much less magnitude.

Floods of 1881.--After a heavy rainfall, the Klamath River near the Shasta and Scott Rivers was at a stage on January 14, I881, that was described in a historical account as equalling that of 1861 . The tributaries washed out bridges and caused extensive damage to farms and roads.

During the first part of February these rivers were again at flood stages, described as even higher than in January. The upper Trinity River at Lewiston nearly equalled its peak of 1861. The Klamath River downstream from the Trinity River was reported to have been highest in February since 1861, but was considerably below that record peak.

Floods of 1890.--On February 3-4, 1890, the Klamath River from Happy Camp to below Weitchpec reached stages nearly as high as those in 1861, and the river from BIue Creek to its mouth reached record-breaking. stages, which were somewhat above those in the flood of 1861 . On the 
upper Trinity River at Lewiston the flood did not attract attention. The season of 1889-90 was notable for the quantities of snow deposited In the mountains of northern California, and for the exceptionally heavy rainfall at lower altitudes.

Floods of 1904--Floods in the Shasta and Scott River Basins on February 22, 1904, were described as the greatest since 1861. The Scott River washed out a bridge at Scotts Bar and flooded Fort Jones. As in the Sacramento River Basin, these floods evidently were relatively high on the smaller streams of the basin. The Klamath River at Happy Camp reached only a moderately high stage, as compared with those of 1890 and 1861. Its peak of February 22 was slightly exceeded again on March 8 , 1904.

Floods of 1914 and subsequent years.--The lower Klamath River was reported to have been on January 1, 1914, at the highest stage for a number of years, but the flood apparently did not do much damage.

In February 1915 the Klamath RIver at Weitchpec probably exceeded the rise of 1914 and possibly was at its highest since 1890. Mining structures along the lower river were damaged.

The Klamath River near Requa reached an exceptionally high stage on February 19-20, 1927. The flood was falrly high at We1tchpec and higher at Somes Bar than at any time since. It was apparently of much less magnitude in the upper part of the Klamath Basin. On the upper Trinity River at Lewiston it was lower than a previous rise in the same season.

Floods occurred on the Klamath River in 1928, 1936, and 1937 . These were moderate floods, except at upper points in the basin. For a comparison of floods during the period 1861 to 1.937 see table 18 .

\section{Smith River Basin}

Flood of 1861.--The flood of December 1861 damaged farms in the Smith River Valley and carried down great quantities of timber. There is little definite information but, so far as known, this flood has not been equalled since.

Flood of 1881.--The Smith River reached an exceptionally high stage in February 1881.

Flood of 1890.--A flood on the Smith River below the mouth of the Middle Fork on February 3, 1890, almost equalled the flood of 1861, as determined by the depth of water in a ranch house. An account of this 
flood period in Grescent city mentioned the occurrence of rain throughout January and of heavy snows in the mountains, followed by general rains from January 29 to February 3 . It was believed that the snowfall in this basin during the winter of $1889-90$ was the heaviest since settlement of the country. As in the Klamath River Basin, the flood run-off in 1890 probably came chiefly from the lower altitudes.

Flood of 1927--A flood of great magnitude occurred on the lower Smith River in the period February 19-20, 1927, and resulted in considerable overflow of the lowlands. This flood was of about the same magnitude as those in 1890 and 1861, and was much greater than the recent floods of 1936 and 1937 .

For a comparison of floods during the period 1861 to 1937 , see table 18.

\section{Major streams from the Sierra Nevada tributary to the Great Basin}

Floods of 1861-62.--Pioneer accounts furnish information about floods of the winter season of 1861-62 on the Owens River and other major streams of the Sierra Nevada tributary to the Great Basin. It is stated that there was rain or snowfall on each of 54 consecutive days after December 24, 1861. Creeks became impassable and the Owens River at overflow stages was from one-fourth to one mile wide in places. The level of Owens Lake was reported to have been raised 12 feet by the flood waters.

In the Walker Lake Basin there was a rainstorm that combined with melting snow to cause heavy run-off during the period January 8-11, 1862 . At Aurora, Nevada, in the Bodie Creek Basin tributary to the East Walker River, several buildings were destroyed by the flood of January 11, and there was reported loss of life on nearby Bodie Creek.

There were floods in the Carson River Basin in December 1861 at the time of the first large floods of this season in the lower sacramento River Basin. The greatest run-off, however, evidently took place from January 9 to 12,1862 , as a result of the general warm rainfall. There was a disastrous flood on the Carson River at the towns of Emplre and Dayton, Nevada, where several persons were reported to have been drowned, and a number of buildings were washed away. Water in Empire was said to have been from 6 to 8 feet deep. The flood at Dayton and on the river downstream was called the greatest known to that time.

Severe floods also occurred north of the Carson River Basin in January 1862. Washoe Lake was described as appearing to be twice its usual size. There was an extensive inundation in the steamboat Creak Basin, 
tributary to the Truckee River.

Floods of 1867-68.--Floods similar to those of 1861-62 occurred in December 1867. At Independence, in the Owens River Basin, preclpitation during this month was greater than the total for any of the 50 seasons after 1867-68 for which complete records have been obtained.

In the Walker Lake Basin there were storms on December 8 and 9 , and almost continuously from December 16 to 31 . The East Walker River was said to have been higher than ever before known, and it washed out or destroyed farm buildings along its channel. There were also damaging floods on the West Walker River and In the upper Carson River Basin.

The Carson River flooded the towns of Empire and Dayton on December 24, 1867, and was at flood stage for several days, reaching a height at Empire on December 26 reported to have been within 2 feet of the maximum stage of 1861-62. Floods on local tributaries occurred on December 23, 25 , and 31 .

The Truckee River was reported to have overflowed beyond its channel for miles on December 26, 1867, flooding many ranches. This account preeumably refers to places near present Reno, Nevada, in Truckee Meadows, which were described on January 1, 1868, as having been flooded for the 10 days preceding. Bridges on the main river and on its tributaries were washed out.

Flood of 1886.--A notable flood occurred in the Truckee River Basin near Reno during January 23-24, 1886, as the result of heavy rainfall. Rallroad tracks were washed out at several points.

Floods of 1889-90.--The season of 1889-90 was featured by the great amount of snow deposited in the Sierra Nevada and throughout the Walker, Carson, and Truckee River Basins. At many points in this region the precipitation was probably the greatest since 1867-68.

The rainstorm of January 25, which caused floods in central California, extended into the Great Basin, and although the mun-off evidently was not extremely heavy, there were exceptionally high stages as a result of ice gorges at several points. Damaging floods were noted especlally on the Owens RIver at Lone Pine and near Independence, on the East Fork of the Carson River, and on the Carson River near Genoa, Nevada. The floods in the Carson River Basin at this time resulted chiefly from ice gorges, and were followed during the first part of February 1890 by floods on the lower Carson River after a period of warm weather that caused release of the lce dams and melting of snow. The lower part of Emplre was flooded on February 6, and mills along the 
river were put out of operation by the high water.

There were floods again during the first part of May 1890, caused by heavy snows in the Walker, Carson, and Truckee River Basins. The Truckee River near Reno was reported to have been higher about May 8 than for many years, and its overflow covered a number of ranches. Stream-flow records for the Truckee River near Boca, California, show that the mean discharge for May 1890, which was 5,275 second-feet, was greater than the maximum daily discharge for most of the seasons during the period of record, 1899-1937, at comparable stations downstream. The maximum daily discharge during May 1890 was 7,172 second-feet. Corresponding records for May 1890 show somewhat greater mean and maximum discharges at V1sta, Nevada, below Truckee Meadows.

Flood of 1892 --On the East Fork of the Carson River near Gardnerville there was on December 25, 1892 a peak discharge estimated as 5,540 second-feet, which is the maximum recorded for the periods of record: 1890-93, 1900-06, 1908-10, 1917, 1924-29, and 1935-37; but which was considerably exceeded in December 1937 by an estimated peak discharge of 11,000 second-feet.

Flood of 1907.--The flood of March 18-19, 1907, was one of the greatest, from the Owens to the Truckee River Basin, for which quantitative information is avallable. There were moderate floods on the Owens River near Big Plne, California, on the East Walker River near Yerington, Nevada, and on the Carson River near Empire, Nevada, and a major flood on the Truckee River。

The mean daily discharge of the Truckee River at Iceland, California, about 4 miles downstream from Boca, on March 18, 1907, was 15,300 secondfeet, which, for the perlod of record 1899-1938, was relatively closely approached only in March 1928 and December 1937. There were extensive washouts of the railroad along the Truckee River near Floriston, Cal1fornia, and Verd1, Nevada. The flood of 1907 was called in a news dispatch from Reno the highest in Nevada for 37 years. The peak discharge of the Truckee River at Iceland in 1907 apparently was considerably more than that of 1890, and probably was somewhat higher than those in 1928 and 1937 .

Floods of 1914.--There were floods of considerable magnitude from the Owens to the Truckee River Basin during January 23-27, 1914, notably at lower points on the rivers. The Owens River near Big Pine reached a peak discharge of about 3,220 second-feet on January 26, the highest for the period of record, 1906-38. The Carson River near Empire had on 
January 23, 1914, a maximum recorded discharge of 5,160 second-feet, the highest for the period, 1900-22. This flow was nearly equalled again during January 26-27, 1914. The Carson River near Fort Churchill, Nevada, reached a peak discharge of 6,150 second-feet on January 26 , 1914, the highest for the period of record, 1911-37. Heavy run-off caused extensive washouts on several of the railroad lines at lower points in the basins, but run-off from the high mountains was comperatively small. The peak discharge of the Truckee River at Reno during this season was 7,520 second-feet on December 31, 1913, apparently considerably higher than that during the January flood.

Flood of 1928.--In March 1928 there was an outstanding flood on Truckee River at Iceland, with a mean discharge of 12,000 second-feet on March 25, and of 11,000 second-feet on March 26. This is comparable with the mean discharge of 12,300 second-feet on December 11, 1937, when there was a peak discharge of 15,500 second-feet. There were moderate floods in thé Carson River Basin during March 1928, and only minor rises on streams in the Walker and Owens River Basins.

\section{RECORDS OF FLOODS IN 1938}

The floods of December 1937 in northern California were forerunners of other notable floods in California, especially those of March 1938 in southern California on which a separate report (Water-Supply Paper 844, Floods of March 1938 in southern Cal1formia) has been made.

A series of storms passed over northern California during January, February, and March 1938. During those months momentary peak discharges higher than those of December 1937, and in fact the highest on record, occurred at 14 river-messurement stations. Three were in the Salinas River Basin, one in a coastal basin, one in the Kern, elght in the San Joaquin, and one in the Klamath River Basin. Later, during the period of snow run-off early in June 1938, Mono Creek (San Joqquin R1ver Basin) reached the highest peak discharge on record. Of the 15 maxima of record, only two, those on the South Fork of the Kern River near Onyx and on the Chowchilla River, were associated with the storm of March 2 , 1938, which caused major floods in southern Califormia.

For 11 of the 15 streams that experlenced maximum peak discharge, gage heights and discharge for bi-hourly perlods during the flood, and also mean daily discharge for a 25-day period Including the flood, are given in this chapter. The 11 are: Salinas River near Santa Margarita, 
River at Blg Trees, South Fork of Kern River near Onyx, Los Gatos Creek near Coalinga, Mono Creek near Vermilion Valley, Fresno River near Knowles, Merced River near Livingston, Woods Creek near Jacksonville, and Shasta River near Yreka.

At three of the 15 river-measurement stations - San Joaquin River near Newman, San Joaquin River near Vernalis, Fine Cold Creek near Friant - mean daily discharge only for the month of March 1938 is given herein. The floods at the first two stations of this group rose and fell so gradually and were so prolonged that bi-hourly records do not add information of special significance. On Fine Gold Creek bi-hourly data are not given because the water-stage records are incomplete.

At the fifteenth gaging station, Chowchilla River at Buchanan dam site, there is no record for the period March 2-31, and neither bihourly or da1ly discharge data are given. The peak gage height, probably on March 2, was determined from floodmarks, and the corresponding discharge was computed as 15,000 second-feet (gage height, 14.4 feet). The mean monthly discharge for March 1938 was estimated to be 2,000 secondfeet.

During February and March 1938, and also during June 1938, serious flood conditions prevailed on the lower San Joaquin River and considerable damage was done to farm lands and homes.

This is in strong contrast to the situation during December 1937 when there was no flood on the San Joaquin downstream from the Merced River, because of storage in reservoirs on the principal tributaries and storage in the natural channels and overflow areas downstream from Mendota. The reservolrs upstream from Vernalis, which stored large volumes of water during the flood of December 1937, were Hetch Hetchy and Don Pedro on the Tuolumne River, Lake McClure on the Merced River, and Melones on the Stanislaus River. By February 11 these reservoirs were filled sufficiently so that large volumes of water were passing down the three rivers, and the natural channels and lower overflow areas of the San Joaquin were also filled. The San Joaquin River also recelved some flood flow from the Kings River through Fresno by-pass (Fresno Slough). The record of discharge of Fresno by-pass for the period January 1 to July 31,1938 , is included in this section.

On figure 73 are shown the graphs of stage at various river-stage stations on the San Joaquin River for the period March 1-20, 1938 . This may be compared with figure 42 on page 96 which shows similar data. 


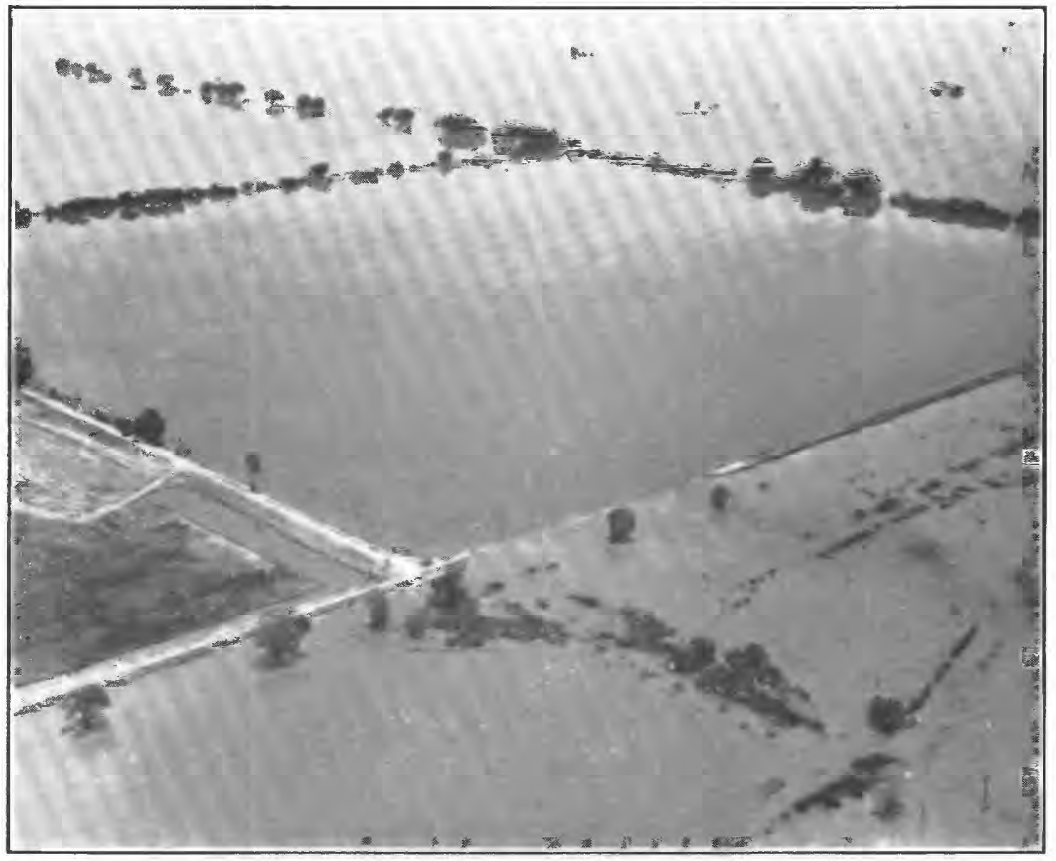

A. NORTHEAST END OF TULARE LAKE.

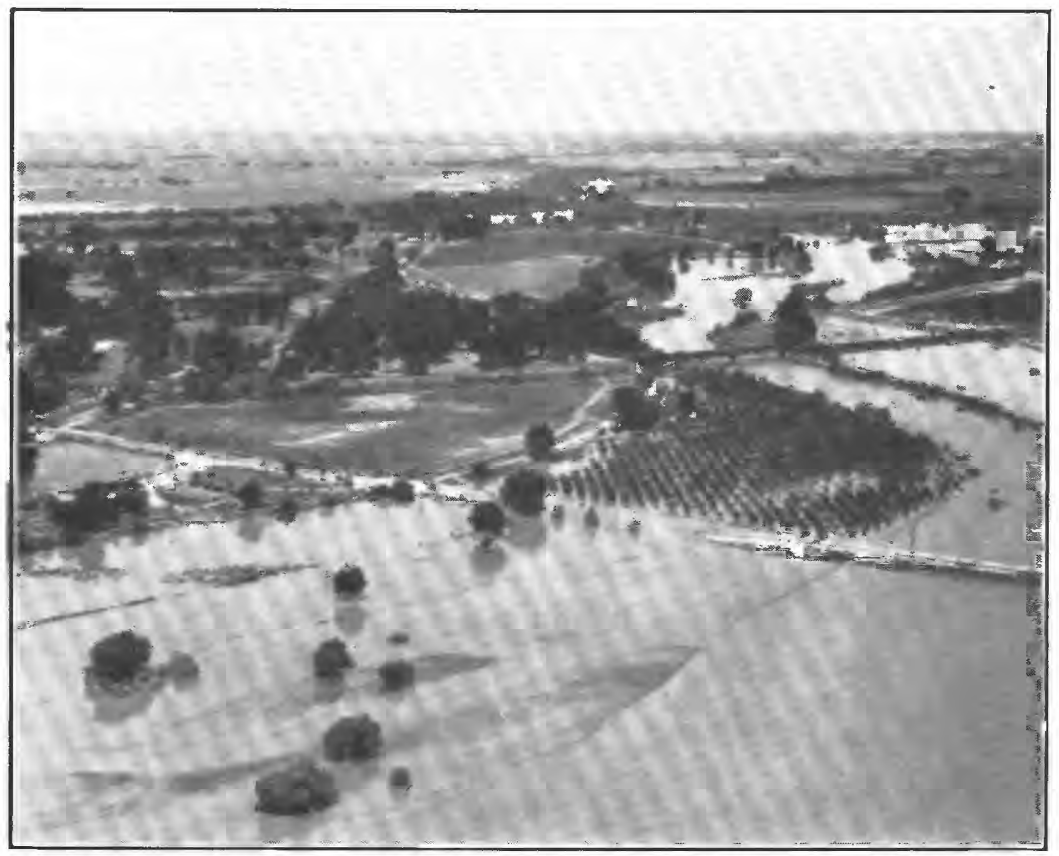

B. AGRICULTC'RAL LA VDS NEAR LATON ON FRESNO-HANFORD HIGHWAY FLOODED BY OVERFLOW FROM KINGS RIVER. 

On flgure 74 is shown a profile of crest stages on the San Joaquin River during the flood of March 1938. See figure 71 for a similar graph for the flood of December 1937.

Tulare Lake rose substantially during the floods of December 1937 , but was affected to a greater extent by the floods of February and March 1938 and experienced very serious overflow conditions in the period of the summer snow melt. Daily gage heights for Tulare Lake for the period, May 1937 to September 1938, are given in this section. Views of high water of June 1938 in Tulare Lake Basin are shown on plate 13. 
Salinas River near Santa Margarita, Cal1f.

Location.- See page 97.

Maxima.- February 1938: Discharge, about 11,000 second-feet 10 a.m. Feb. 11 (gage helght, 17.0 feet). feet).

1932-January 1938: Discharge, 7,260 second-feet Feb. 6, 1937 (gage height, 14.35

Mean daily discharge, in second-feet, 1938

\begin{tabular}{|c|c||r|r||r|r||r|r||c||c|}
\hline Day & February & Day & February & Day & February & Day & February & Day & February \\
\hline 1 & 485 & 6 & 154 & 11 & 7,190 & 16 & 536 & 21 & 241 \\
2 & 329 & 7 & 99 & 12 & 1,730 & 17 & 408 & 22 & 215 \\
3 & 1,670 & 8 & 75 & 13 & 569 & 18 & 571 & 23 & 197 \\
4 & 732 & 9 & 315 & 14 & 1,700 & 19 & 476 & 24 & 184 \\
5 & 312 & 10 & 881 & 15 & 815 & 20 & 288 & 25 & 172 \\
\hline
\end{tabular}

Gage height, in feet, and discharge, in second-feet, at indicated time, 1938

\begin{tabular}{|c|c|c|c|c|c|c|c|c|c|c|c|c|}
\hline \multirow{2}{*}{$\begin{array}{l}0 \\
0 \\
0 \\
\end{array}$} & Feet & sec.ft. & Feet & Sec.ft. & Fe日t & Sec.ft. & Feet & Sec.ft. & Feet & Sec.ft. & Feet & Sec.ft. \\
\hline & \multicolumn{2}{|c|}{ February 8} & \multicolumn{2}{|c|}{ February 9} & \multicolumn{2}{|c|}{ February 10} & \multicolumn{2}{|c|}{ Febmuary 11} & \multicolumn{2}{|c|}{ February 12} & \multicolumn{2}{|c|}{ February 13} \\
\hline $\begin{array}{r}2 \\
4 \\
6 \\
8 \\
10 \\
18 \\
2 \\
4 \\
6 \\
8 \\
10 \\
4\end{array}$ & $\begin{array}{l}4.60 \\
4.58 \\
4.57 \\
4.56 \\
4.55 \\
4.54 \\
4.52 \\
4.52 \\
4.51 \\
4.51 \\
4.51 \\
4.52\end{array}$ & $\begin{array}{l}82 \\
80 \\
78 \\
77 \\
76 \\
75 \\
72 \\
72 \\
71 \\
71 \\
71 \\
72\end{array}$ & $\begin{array}{l}4.58 \\
4.65 \\
4.95 \\
5.46 \\
5.40 \\
5.35 \\
5.50 \\
5.95 \\
6.50 \\
6.38 \\
6.28 \\
6.33\end{array}$ & $\begin{array}{r}80 \\
89 \\
140 \\
259 \\
242 \\
229 \\
270 \\
412 \\
625 \\
577 \\
537 \\
557\end{array}$ & $\begin{array}{r}6.40 \\
6.36 \\
6.26 \\
6.10 \\
5.95 \\
5.88 \\
5.78 \\
5.81 \\
6.25 \\
7.65 \\
9.80 \\
11.13\end{array}$ & $\begin{array}{r}585 \\
569 \\
529 \\
465 \\
412 \\
388 \\
354 \\
364 \\
525 \\
1,210 \\
2,890 \\
4,190\end{array}$ & $\begin{array}{r}12.55 \\
12.95 \\
13.30 \\
14.90 \\
17.00 \\
16.56 \\
15.90 \\
14.45 \\
13.05 \\
11.72 \\
10.80 \\
9.95\end{array}$ & $\begin{array}{r}5,700 \\
6,140 \\
6,560 \\
8,480 \\
11,000 \\
10,500 \\
9,740 \\
8,140 \\
6,600 \\
5,240 \\
4,320 \\
3,560\end{array}$ & $\begin{array}{l}9.22 \\
8.60 \\
8.25 \\
8.05 \\
7.74 \\
7.39 \\
7.05 \\
6.82 \\
6.59 \\
6.38 \\
6.22 \\
6.10\end{array}$ & $\begin{array}{r}2,940 \\
2,440 \\
2,200 \\
2,060 \\
1,840 \\
1,590 \\
1,380 \\
1,240 \\
1,100 \\
980 \\
900 \\
840\end{array}$ & $\begin{array}{l}5.97 \\
5.84 \\
5.74 \\
5.63 \\
5.56 \\
5.46 \\
5.43 \\
5.35 \\
5.29 \\
5.25 \\
5.22 \\
5.31\end{array}$ & $\begin{array}{l}775 \\
713 \\
668 \\
618 \\
487 \\
544 \\
532 \\
500 \\
476 \\
460 \\
448 \\
484\end{array}$ \\
\hline
\end{tabular}

Salinas River near Spreckels, $C_{a l 1 f}$

Location.- See page 98.

Paxima:- February 1938: Discharge, about 75,000 second-feet 6830 a.m. Feb. 12 (gage heIght, 25.0 fe日t).

1930-Jamary 1938: Discharge, about 42,100 second-feet Dec. 29, 1931 (gage he1ght, 20.40 feet).

Mean daily discharge, in second-feet, 1938

\begin{tabular}{|c|c|r|r||r|r|r|r|r|r|}
\hline Day & Pebruary & Day & February & Day & February & Day & February & Day & February \\
\hline 1 & 1,730 & 6 & 8,520 & 11 & 44,800 & 16 & 11,900 & 21 & 6,700 \\
2 & 7,180 & 7 & 5,740 & 12 & 69,900 & 17 & 8,780 & 22 & 5,500 \\
3 & 6,700 & 8 & 4,310 & 13 & 31,500 & 18 & 7,310 & 23 & 4,620 \\
4 & 16,600 & 9 & 3,700 & 14 & 17,200 & 19 & 7,100 & 24 & 3,680 \\
5 & 14,900 & 10 & 7,720 & 15 & 20,700 & 20 & 8,990 & 25 & 2,960 \\
\hline
\end{tabular}

Gage helght, In feet, and discharge, in second-feet, at Indicated t1me, 1938

\begin{tabular}{|c|c|c|c|c|c|c|c|c|c|c|c|c|}
\hline \multirow{2}{*}{ 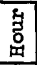 } & Feet & Bec.ft. & Feet & Sec.ft. & Feet & sec.ft. & Feet & Sec.ft. & Feet & Sec.ft. & Feet & Sec.ft. \\
\hline & \multicolumn{2}{|c|}{ Febmuary 9} & \multicolumn{2}{|c|}{ Pebruary 10} & \multicolumn{2}{|c|}{ Pebruary 11} & \multicolumn{2}{|c|}{ February 12} & \multicolumn{2}{|c|}{ February 13} & \multicolumn{2}{|c|}{ February 14} \\
\hline $\begin{array}{r}2 \\
4 \\
6 \\
8 \\
10 \\
1 \\
2 \\
4 \\
6 \\
8 \\
10 \\
4\end{array}$ & $\begin{array}{l}8.57 \\
8.47 \\
8.50 \\
8.45 \\
8.45 \\
8.51 \\
8.50 \\
8.49 \\
8.45 \\
8.36 \\
8.35 \\
8.38\end{array}$ & $\begin{array}{l}3,770 \\
3,670 \\
3,700 \\
3,650 \\
3,650 \\
3,710 \\
3,700 \\
3,690 \\
3,650 \\
3,660 \\
3,550 \\
3,680\end{array}$ & $\begin{array}{r}8.80 \\
9.70 \\
10.35 \\
10.77 \\
10.92 \\
11.00 \\
11.05 \\
11.19 \\
11.60 \\
12.20 \\
13.20 \\
14.40\end{array}$ & $\begin{array}{r}4,080 \\
5,210 \\
6,200 \\
6,910 \\
7,160 \\
7,300 \\
7,400 \\
7,680 \\
8,500 \\
9,800 \\
12,400 \\
16,300\end{array}$ & $\begin{array}{l}15.60 \\
16.54 \\
17.18 \\
17.70 \\
18.60 \\
20.52 \\
21.90 \\
23.05 \\
23.56 \\
23.72 \\
23.69 \\
23.83\end{array}$ & $\begin{array}{l}21,100 \\
25,300 \\
28,400 \\
31,000 \\
35,500 \\
46,100 \\
54,400 \\
61,800 \\
65,100 \\
66,200 \\
66,000 \\
66,900\end{array}$ & $\begin{array}{l}24.28 \\
23.74 \\
24.99 \\
24.97 \\
24.90 \\
24.72 \\
24.52 \\
24.33 \\
23.86 \\
23.07 \\
22.10 \\
21.15\end{array}$ & $\begin{array}{l}70,000 \\
73,200 \\
74,900 \\
74,800 \\
74,500 \\
73,500 \\
72,400 \\
71,400 \\
68,800 \\
64,600 \\
59,500 \\
54,800\end{array}$ & $\begin{array}{l}19.90 \\
18.56 \\
17.45 \\
16.60 \\
15.83 \\
15.16 \\
14.54 \\
14.07 \\
13.60 \\
13.00 \\
12.55 \\
12.25\end{array}$ & $\begin{array}{l}48,700 \\
42,700 \\
37,900 \\
34,500 \\
31,600 \\
29,100 \\
26,900 \\
25,200 \\
23,700 \\
21,700 \\
20,400 \\
19,500\end{array}$ & $\begin{array}{l}11.88 \\
11.64 \\
11.36 \\
11.22 \\
11.16 \\
11.18 \\
11.20 \\
11.23 \\
11.24 \\
11.25 \\
11.32 \\
11.64\end{array}$ & $\begin{array}{l}18,700 \\
17,900 \\
17,100 \\
16,800 \\
16,600 \\
16,700 \\
16,700 \\
16,800 \\
16,800 \\
16,800 \\
17,000 \\
17,900\end{array}$ \\
\hline
\end{tabular}


San Antonio River at Pleyto, Calif.

Location.- See page 99.

Maxima.- February 1938: Discharge, 10,700 second-fe日t 7 a.m. Feb. II (gage height, 5.10 feet).

1930-Jamuary 1937: Discharge, 7,460 second-feet Dec. 28, 1931 (gage he1ght, 4.55 feet).

Mean daily discharge, in second-feet, 1938

\begin{tabular}{|c|c||c|c||c|c||c|c||c|c|}
\hline Day & February & Day & February & Day & February & Day & February & Day & Fobruary \\
\hline 1 & 922 & 6 & 778 & 11 & 9,200 & 16 & 1,460 & 21 & 824 \\
2 & 667 & 7 & 612 & 12 & 3,740 & 17 & 1,110 & 22 & 749 \\
3 & 3,130 & 8 & 524 & 13 & 1,980 & 18 & 1,170 & 23 & 678 \\
4 & 1,830 & 9 & 1,330 & 14 & 4,650 & 19 & 1,290 & 24 & 585 \\
5 & 1,040 & 10 & 5,670 & 15 & 2,200 & 20 & 920 & 25 & 515 \\
\hline
\end{tabular}

Gage height, in feet, and discharge, in second-feet, at indicated time, 1938

\begin{tabular}{|c|c|c|c|c|c|c|c|c|c|c|c|c|}
\hline \multirow{2}{*}{$\begin{array}{l}5 \\
\text { 号 }\end{array}$} & \multicolumn{2}{|c|}{ Feet Sec.ft. } & \multicolumn{2}{|c|}{ Feet Sec.ft. } & \multicolumn{2}{|c|}{ Feet Sec.ft. } & \multicolumn{2}{|c|}{ Feet Sec.ft. } & \multicolumn{2}{|c|}{ Feet Sec.ft. } & \multicolumn{2}{|c|}{ Feet Sec.ft. } \\
\hline & \multicolumn{2}{|c|}{ February 9} & \multicolumn{2}{|c|}{ February 10} & \multicolumn{2}{|c|}{ February 11} & \multicolumn{2}{|c|}{ Febmuary 12} & \multicolumn{2}{|c|}{ Febmuary 13} & \multicolumn{2}{|c|}{ Febmuary 14} \\
\hline $\begin{array}{r}2 \\
4 \\
6 \\
8 \\
10 \\
\mathrm{~N} \\
2 \\
4 \\
6 \\
8 \\
10 \\
\mathbf{4}\end{array}$ & $\begin{array}{l}1.94 \\
2.00 \\
2.05 \\
2.06 \\
2.15 \\
2.42 \\
2.55 \\
2.63 \\
2.79 \\
3.45 \\
3.90 \\
3.74\end{array}$ & $\begin{array}{r}524 \\
560 \\
592 \\
5,98 \\
660 \\
868 \\
990 \\
1,070 \\
1,260 \\
2,600 \\
4,200 \\
3,560\end{array}$ & $\begin{array}{l}3.50 \\
3.38 \\
3.36 \\
3.55 \\
4.00 \\
4.45 \\
4.48 \\
4.70 \\
4.60 \\
4.66 \\
4.79 \\
4.71\end{array}$ & $\begin{array}{l}2,750 \\
2,400 \\
2,350 \\
2,900 \\
4,650 \\
6,920 \\
7,090 \\
8,300 \\
7,750 \\
8,080 \\
8,840 \\
8,360\end{array}$ & $\begin{array}{l}4.88 \\
5.03 \\
4.94 \\
5.00 \\
4.91 \\
4.92 \\
4.95 \\
4.85 \\
4.84 \\
4.66 \\
4.55 \\
4.35\end{array}$ & $\begin{array}{r}9,380 \\
10,300 \\
9,740 \\
10,100 \\
9,560 \\
9,620 \\
9,800 \\
9,200 \\
9,140 \\
8,080 \\
7,480 \\
6,380\end{array}$ & $\begin{array}{l}4.18 \\
4.08 \\
3.98 \\
3.90 \\
3.80 \\
3.72 \\
3.65 \\
3.56 \\
3.50 \\
3.45 \\
3.40 \\
3.35\end{array}$ & $\begin{array}{l}5,500 \\
5,010 \\
4,560 \\
4,200 \\
3,800 \\
3,480 \\
3,220 \\
2,930 \\
2,750 \\
2,600 \\
2,450 \\
2,320\end{array}$ & $\begin{array}{l}3.30 \\
3.26 \\
3.21 \\
3.17 \\
3.12 \\
3.11 \\
3.10 \\
3.11 \\
3.15 \\
3.24 \\
3.30 \\
3.45\end{array}$ & $\begin{array}{l}2,200 \\
2,100 \\
1,980 \\
1,900 \\
1,800 \\
1,780 \\
1,760 \\
1,780 \\
1,860 \\
2,060 \\
2,200 \\
2,600\end{array}$ & & \\
\hline
\end{tabular}

San Lorenzo River at Big Trees, Calif.

Location.- See page 102.

Maxima.- Jamuary 1938: Discharge, 12,000 second-feet 3 p.m. Jan. 31 (gage helght, 16.8 feet, from drift marks outside of well; 16.3 feet inside of well, affected by drawdown).

1936-December 1937: Discharge, 8,700 second-feet Feb. 14, 1937 (gage he1ght, 14. I feet, from floodmarks).

Mean da1ly discharge, in second-feet, 1838

\begin{tabular}{|c|c||c|c||r|r||r|r||r|r|}
\hline Day & Jamary & Day & January & Day & February & Day & February & Day & February \\
\hline 22 & 96 & 27 & 69 & 1 & 2,590 & 6 & 1,100 & 11 & 2,320 \\
23 & 87 & 28 & 104 & 2 & 1,520 & 7 & 748 & 12 & 1,550 \\
24 & 79 & 29 & 140 & 3 & 2,320 & 8 & 574 & 13 & 2,720 \\
25 & 74 & 30 & 116 & 4 & 1,950 & 9 & 1,090 & 14 & 2,970 \\
26 & 71 & 31 & 4,850 & 5 & 1,280 & 10 & 1,650 & 15 & 1,350 \\
\hline
\end{tabular}

Gage height, in feet, and discharge, in second-feet, at indicated t1me, 1938

\begin{tabular}{|c|c|c|c|c|c|c|c|c|c|c|c|c|}
\hline \multirow{2}{*}{$\begin{array}{l}\text { 岁 } \\
\text { 号 }\end{array}$} & Feet & Sec.ft. & Peet & Sec.ft. & Feet & Sec.ft. & Feot & Sec.ft: & Feet & Sec.rt. & Feet & Sec.ft. \\
\hline & \multicolumn{2}{|c|}{ Jamuary 31} & \multicolumn{2}{|c|}{ Fobruary 1} & \multicolumn{2}{|c|}{ Fobruary 2} & \multicolumn{2}{|c|}{ February 3} & \multicolumn{2}{|c|}{ February 4} & \multicolumn{2}{|c|}{ February 5} \\
\hline $\begin{array}{r}2 \\
4 \\
6 \\
8 \\
10 \\
7 \\
2 \\
4 \\
6 \\
8 \\
10 \\
4\end{array}$ & $\begin{array}{r}2.30 \\
2.37 \\
2.71 \\
5.60 \\
10.00 \\
13.32 \\
16.00 \\
16.15 \\
13.53 \\
11.90 \\
10.90 \\
10.10\end{array}$ & $\begin{array}{r}106 \\
116 \\
168 \\
1,040 \\
3,800 \\
7,610 \\
11,550 \\
11,800 \\
8,340 \\
6,390 \\
5,300 \\
4,500\end{array}$ & $\begin{array}{l}9.72 \\
9.38 \\
9.15 \\
8.54 \\
8.18 \\
7.70 \\
7.32 \\
7.06 \\
6.86 \\
6.61 \\
6.36 \\
6.18\end{array}$ & $\begin{array}{l}4,120 \\
3,780 \\
3,580 \\
3,030 \\
2,700 \\
2,320 \\
2,030 \\
1,870 \\
1,750 \\
1,600 \\
1,480 \\
1,390\end{array}$ & $\begin{array}{l}6.05 \\
5.90 \\
5.78 \\
5.60 \\
5.45 \\
5.35 \\
5.38 \\
5.70 \\
6.50 \\
7.35 \\
8.40 \\
9.55\end{array}$ & $\begin{array}{l}1,330 \\
1,260 \\
1,210 \\
1,120 \\
1,060 \\
1,020 \\
1,030 \\
1,170 \\
1,550 \\
2,060 \\
2,900 \\
3,950\end{array}$ & $\begin{array}{l}9.00 \\
8.55 \\
8.10 \\
7.88 \\
7.62 \\
7.65 \\
7.50 \\
7.30 \\
7.10 \\
6.85 \\
6.58 \\
6.80\end{array}$ & $\begin{array}{l}3,4 \\
3,0 \\
2,6 \\
2,4 \\
2,2 \\
2,2 \\
2,1 \\
2,0 \\
1,8 \\
1,7 \\
1,5 \\
1,7\end{array}$ & $\begin{array}{l}7.25 \\
7.80 \\
8.15 \\
7.90 \\
7.62 \\
7.32 \\
7.08 \\
6.85 \\
6.60 \\
6.36 \\
6.25 \\
6.07\end{array}$ & $\begin{array}{l}1,980 \\
2,400 \\
2,680 \\
2,480 \\
2,260 \\
2,030 \\
1,880 \\
1,740 \\
1,600 \\
1,480 \\
1,420 \\
1,340\end{array}$ & $\begin{array}{l}5.90 \\
5.80 \\
5.65 \\
5.55 \\
5.50 \\
5.50 \\
5.75 \\
6.17 \\
6.35 \\
6.55 \\
6.50 \\
6.35\end{array}$ & $\begin{array}{l}1,260 \\
1,220 \\
1,150 \\
1,100 \\
1,080 \\
1,080 \\
1,190 \\
1,380 \\
1,480 \\
1,580 \\
1,550 \\
1,480\end{array}$ \\
\hline
\end{tabular}


South Fork of Kom River near Onyx, Calif.

Location.- See page 119.

Maxima.; March 1938: Discharge, 3,450 second-feet 6 p.m. Mar. 2 (gage he1ght, 6.69 feet).

19i1-14, 1919-Febmary 1938: D1scharge, 3,130 second-feet Feb. 6, 1937 (gage helght, 6.50 feet).

Mean daily discharge, in second-ieet, 1938

\begin{tabular}{|c|c||c|c||r|r||r|r|r|r||r|}
\hline Day & February & Day & Febmary & Day & March & Day & March & Day & March \\
\hline 19 & 67 & 24 & 112 & 1 & 430 & 6 & 331 & 11 & 226 \\
20 & 77 & 25 & 107 & 2 & 1,710 & 7 & 289 & 12 & 540 \\
21 & 82 & 26 & 103 & 3 & 1,100 & 8 & 266 & 13 & 531 \\
22 & 94 & 27 & 110 & 4 & 580 & 9 & 232 & 14 & 373 \\
23 & 105 & 28 & 176 & 5 & 407 & 10 & 217 & 15 & 334 \\
\hline
\end{tabular}

Gage height, in feet, and discharge, in second-feet, at indicated time, 1938

\begin{tabular}{|c|c|c|c|c|c|c|c|c|c|c|c|c|}
\hline \multirow{2}{*}{$\begin{array}{l}8 \\
3 \\
0 \\
0\end{array}$} & Feet & Sec.ft. & Feet & Sec.ft. & Feet & Sec.ft. & Feet & Sec.ft. & Feet & Sec.ft. & Feet & Sec.ft. \\
\hline & \multicolumn{2}{|c|}{ February 28} & \multicolumn{2}{|c|}{ March 1} & \multicolumn{2}{|c|}{$\operatorname{March} 2$} & \multicolumn{2}{|c|}{ March 3} & \multicolumn{2}{|c|}{ March 4} & \multicolumn{2}{|c|}{ March 5} \\
\hline $\begin{array}{r}2 \\
4 \\
6 \\
8 \\
10 \\
N \\
2 \\
4 \\
6 \\
8 \\
10 \\
M\end{array}$ & $\begin{array}{l}2.20 \\
2.23 \\
2.28 \\
2.34 \\
2.42 \\
2.54 \\
2.52 \\
2.54 \\
2.57 \\
2.67 \\
2.76 \\
2.91\end{array}$ & \begin{tabular}{|l}
114 \\
120 \\
130 \\
143 \\
161 \\
190 \\
185 \\
190 \\
198 \\
225 \\
250 \\
294
\end{tabular} & $\begin{array}{l}3.28 \\
3.64 \\
3.58 \\
3.55 \\
3.45 \\
3.31 \\
3.20 \\
3.14 \\
3.15 \\
3.14 \\
3.13 \\
3.11\end{array}$ & \begin{tabular}{|l}
423 \\
585 \\
555 \\
540 \\
492 \\
434 \\
393 \\
372 \\
376 \\
372 \\
368 \\
362
\end{tabular} & $\begin{array}{l}3.12 \\
3.25 \\
3.51 \\
3.98 \\
4.63 \\
5.05 \\
6.28 \\
6.65 \\
6.69 \\
6.30 \\
5.78 \\
5.39\end{array}$ & $\begin{array}{r}365 \\
412 \\
520 \\
764 \\
1,140 \\
1,480 \\
2,880 \\
3,380 \\
3,450 \\
2,940 \\
2,360 \\
1,950\end{array}$ & $\begin{array}{l}5.03 \\
4.79 \\
4.67 \\
4.52 \\
4.39 \\
4.27 \\
4.20 \\
4.16 \\
4.07 \\
3.99 \\
3.91 \\
3.83\end{array}$ & \begin{tabular}{|r}
1,610 \\
1,390 \\
1,300 \\
1,180 \\
1,090 \\
1,010 \\
965 \\
939 \\
882 \\
834 \\
790 \\
746
\end{tabular} & $\begin{array}{l}3.76 \\
3.68 \\
3.63 \\
3.56 \\
3.50 \\
3.45 \\
3.42 \\
3.38 \\
3.37 \\
3.35 \\
3.32 \\
3.28\end{array}$ & $\begin{array}{l}710 \\
670 \\
645 \\
610 \\
580 \\
558 \\
544 \\
526 \\
522 \\
513 \\
500 \\
482\end{array}$ & $\begin{array}{l}3.25 \\
3.21 \\
3.16 \\
3.13 \\
3.08 \\
3.04 \\
3.04 \\
3.03 \\
3.02 \\
3.01 \\
3.00 \\
2.98\end{array}$ & \begin{tabular}{|l}
470 \\
452 \\
432 \\
419 \\
399 \\
384 \\
384 \\
380 \\
377 \\
373 \\
369 \\
362
\end{tabular} \\
\hline
\end{tabular}

Los Gatos Creek near Coalinga, Calif.

Location.- See page 131.

Maxima.- February 1938: D1scharge, about 4,520 second-feet 3 a.m. Feb. 11, (gage helght, 8.0 feet, from floodmarks on banks; 6.23 feet, inslde of well, affected by ârawdown).

1931-Jamuary 1938: Discharge, about 1,530 second-feet Dec. 11, 1937 (gage helght, 5.1 feet, from floodmarks on bank; 4.58 feet, inside of well, affected by drawdown).

Mean dally discharge, in second-feet, 1938

\begin{tabular}{|c|c||c|c||c|c||c|c||c|c|}
\hline Day & February & Day & February & Day & February & Day & February & Day & February \\
\hline 1 & 220 & 6 & 80 & 11 & 1,170 & 16 & 95 & 21 & 48 \\
2 & 88 & 7 & 53 & 12 & 219 & 17 & 75 & 22 & 43 \\
3 & 296 & 8 & 38 & 13 & 127 & 18 & 77 & 23 & 40 \\
4 & 194 & 9 & 227 & 14 & 206 & 19 & 72 & 24 & 38 \\
5 & 117 & 10 & 386 & 15 & 131 & 20 & 54 & 25 & 35 \\
\hline
\end{tabular}

Gage height, in feet, and discharge, in second-feet, at indicated time, 1938

\begin{tabular}{|c|c|c|c|c|c|c|c|c|c|c|c|c|}
\hline \multirow{2}{*}{\begin{tabular}{l}
$\xi$ \\
\multirow{3}{3}{} \\
0 \\
西
\end{tabular}} & Feet & Sec.ft. & Feet & Sec.ft. & Feet & Sec.ft. & Feet & Sec.ft. & Feet & Sec.ft. & Feet & Sec.ft. \\
\hline & \multicolumn{2}{|c|}{ February 9} & \multicolumn{2}{|c|}{ February 10} & \multicolumn{2}{|c|}{ February 11} & \multicolumn{2}{|c|}{ February 12} & \multicolumn{2}{|c|}{ February 13} & \multicolumn{2}{|c|}{ February 14} \\
\hline $\begin{array}{r}2 \\
4 \\
6 \\
8 \\
10 \\
\mathrm{~N} \\
2 \\
4 \\
6 \\
8 \\
10 \\
\mathbf{M}\end{array}$ & $\begin{array}{r}0.95 \\
.96 \\
1.20 \\
1.81 \\
1.82 \\
1.80 \\
1.77 \\
1.92 \\
2.30 \\
2.28 \\
2.23 \\
2.12\end{array}$ & $\begin{array}{r}37 \\
38 \\
84 \\
233 \\
236 \\
230 \\
220 \\
265 \\
404 \\
394 \\
374 \\
332\end{array}$ & $\begin{array}{l}1.95 \\
1.74 \\
1.64 \\
1.55 \\
1.51 \\
1.54 \\
1.68 \\
1.95 \\
3.51 \\
3.55 \\
3.55 \\
3.28\end{array}$ & \begin{tabular}{|l|}
274 \\
214 \\
188 \\
165 \\
155 \\
162 \\
198 \\
274 \\
816 \\
840 \\
840 \\
679 \\
\end{tabular} & $\begin{array}{l}3.55 \\
5.95 \\
5.80 \\
4.20 \\
3.25 \\
2.23 \\
2.43 \\
2.65 \\
2.65 \\
2.58 \\
2.42 \\
2.23\end{array}$ & $\begin{array}{r}840 \\
3,890 \\
3,590 \\
1,390 \\
748 \\
320 \\
390 \\
470 \\
470 \\
443 \\
387 \\
320\end{array}$ & $\begin{array}{l}2.10 \\
2.01 \\
1.96 \\
1.94 \\
1.94 \\
1.94 \\
1.87 \\
1.81 \\
1.76 \\
1.72 \\
1.69 \\
1.65\end{array}$ & $\begin{array}{l}280 \\
253 \\
239 \\
233 \\
233 \\
233 \\
214 \\
199 \\
186 \\
177 \\
170 \\
160\end{array}$ & $\begin{array}{l}1.62 \\
1.58 \\
1.56 \\
1.54 \\
1.51 \\
1.48 \\
1.46 \\
1.45 \\
1.44 \\
1.44 \\
1.44 \\
1.48\end{array}$ & $\begin{array}{l}154 \\
145 \\
140 \\
136 \\
129 \\
123 \\
119 \\
116 \\
114 \\
114 \\
114 \\
123\end{array}$ & & \\
\hline
\end{tabular}


Location.- Staff gage, lat. $36^{\circ} 05^{\prime}$, long. $119^{\circ} 44^{\prime}$, at SW corner sec. 31, T. 21 S., R. $21 \mathrm{E}, 12 \mathrm{miles}$ southeast of Stratford.

Records available.- May 1937 to September 1938. March 1906 to September 1920 (1ncomplete) at several other sites.

Extremes.- Maximum stage recorded during period May 1937 to September $1938,195.5$ feet June 5, 1938. Maximum amount in storage, about 1, 160,000 acre-feet, June 30 , 1938. 1906-38: Maximum stage probably occurred June 21, 1907 (gage helght, 14.0 feet, former site and datum); lake dry or practically so for parts of 1906, 1914, 1916, $1919,1920-22,1924-36$, and 1937.

Remarks. - Tulare Lake receives water from Kings, Kaweah, and Tule Rivers during highwater periods and occasionally from Kern River, Deer Creek, and several small intermittent streams. Its boundaries have been greatly altered in recent years by the construction of levees and other reclamation work. Water reached lake from tributaries about Feb. 10, 1937, for first time since April 1923, and lake attained a stage of 192.3 feet June 16,1937 (contents about 420,000 acre-feet). It then receded until Dec. 14, 1937, when it began to recelve flow from flood of Dec. Il. It continued to rise slowly through March 1938, with occasional perlods of falling stage due to breaking of levees. The spring rise began about Apr. 15, 1938, and continued to the peak stage of June 5 , 1938 .

The amount of water in storage continued to increase, due to more levee breaks, until June 30, 1938. Gage-height record furnished by Tulare Lake reclamation district No. 749 .

Gage height, in feet, 1937-38

1937

\begin{tabular}{|c|c|c|c|c|c|c|c|c|c|c|c|}
\hline Day & May & June & JuIy & Aug. & Sept. & Day & May & June & July & Aug. & Sept. \\
\hline $\begin{array}{l}1 \\
2 \\
3 \\
4 \\
5\end{array}$ & $\begin{array}{l}- \\
\overline{-} \\
-\end{array}$ & $\begin{array}{l}190.4 \\
190.7 \\
191.0 \\
191.2 \\
191.3\end{array}$ & $\begin{array}{l}191.8 \\
191.8 \\
191.7 \\
191.7 \\
191.6\end{array}$ & $\begin{array}{l}189.5 \\
189.4 \\
189.3 \\
189.2 \\
189.2\end{array}$ & $\begin{array}{l}186.9 \\
186.8 \\
186.8 \\
186.7 \\
186.7\end{array}$ & $\begin{array}{l}16 \\
17 \\
18 \\
19 \\
20\end{array}$ & $\begin{array}{l}187.1 \\
187.4 \\
187.8 \\
188.4 \\
189.0\end{array}$ & $\begin{array}{l}192.3 \\
192.2 \\
192.2 \\
192.2 \\
192.2\end{array}$ & $\begin{array}{l}190.9 \\
190.8 \\
190.7 \\
190.7 \\
190.6\end{array}$ & $\begin{array}{l}188.2 \\
188.1 \\
188.0 \\
187.9 \\
187.8\end{array}$ & $\begin{array}{l}186.3 \\
186.3 \\
186.2 \\
186.2 \\
186.2\end{array}$ \\
\hline $\begin{array}{r}6 \\
7 \\
8 \\
9 \\
10\end{array}$ & $\begin{array}{c}\overline{-} \\
\overline{-} \\
186.0\end{array}$ & $\begin{array}{l}191.4 \\
191.6 \\
191.8 \\
191.8 \\
192.0\end{array}$ & $\begin{array}{l}191.6 \\
191.5 \\
191.5 \\
191.4 \\
191.3\end{array}$ & $\begin{array}{l}189.1 \\
189.0 \\
188.9 \\
188.8 \\
188.7\end{array}$ & $\begin{array}{l}186.6 \\
186.6 \\
186.5 \\
186.5 \\
186.4\end{array}$ & $\begin{array}{l}21 \\
22 \\
23 \\
24 \\
25\end{array}$ & $\begin{array}{l}189.2 \\
189.4 \\
189.6 \\
189.8 \\
190.0\end{array}$ & $\begin{array}{l}192.2 \\
192.2 \\
192.1 \\
192.1 \\
192.1\end{array}$ & $\begin{array}{l}190.6 \\
190.5 \\
190.4 \\
190.3 \\
190.2\end{array}$ & $\begin{array}{l}187.7 \\
187.6 \\
187.5 \\
187.5 \\
187.4\end{array}$ & $\begin{array}{l}186.1 \\
186.1 \\
186.1 \\
186.0 \\
186.0\end{array}$ \\
\hline $\begin{array}{l}11 \\
12 \\
13 \\
14 \\
15\end{array}$ & $\begin{array}{l}186.1 \\
186.4 \\
186.5 \\
186.6 \\
186.8\end{array}$ & $\begin{array}{l}192.1 \\
192.2 \\
192.2 \\
192.2 \\
192.2\end{array}$ & $\begin{array}{l}191.2 \\
191.2 \\
191.1 \\
191.0 \\
191.0\end{array}$ & $\begin{array}{l}188.6 \\
188.5 \\
188.4 \\
188.4 \\
188.3\end{array}$ & $\begin{array}{l}186.4 \\
186.4 \\
186.4 \\
186.4 \\
186.3\end{array}$ & $\begin{array}{l}26 \\
27 \\
28 \\
29 \\
30 \\
31\end{array}$ & $\begin{array}{l}190.2 \\
190.6 \\
190.9 \\
191.0 \\
191.2 \\
190.4\end{array}$ & $\begin{array}{l}192.1 \\
192.0 \\
192.0 \\
191.9 \\
191.9\end{array}$ & $\begin{array}{l}190.1 \\
190.0 \\
190.0 \\
189.8 \\
189.7 \\
189.6\end{array}$ & $\begin{array}{l}187.3 \\
187.2 \\
187.2 \\
187.1 \\
187.0 \\
187.0\end{array}$ & $\begin{array}{c}186.1 \\
186.1 \\
186.1 \\
186.1 \\
186.2 \\
\ldots\end{array}$ \\
\hline
\end{tabular}

$1937-38$

\begin{tabular}{|c|c|c|c|c|c|c|c|c|c|c|c|c|}
\hline Day & oct. & Nov. & Dec. & Jan. & Feb. & Mar. & Apr. & May & June & JuIy & Aug. & Sept. \\
\hline $\begin{array}{l}1 \\
2 \\
3 \\
4 \\
5\end{array}$ & $\begin{array}{c}18 \overline{6} .2 \\
- \\
186.2 \\
186.2\end{array}$ & $\begin{array}{c}- \\
186.2 \\
186.2 \\
186.2 \\
-\end{array}$ & $\begin{array}{c}186.0 \\
- \\
- \\
-\end{array}$ & $\begin{array}{c}186.9 \\
- \\
186.9 \\
186.9 \\
186.9\end{array}$ & $\begin{array}{l}- \\
\overline{-} \\
-\end{array}$ & $\begin{array}{l}188.3 \\
188.3 \\
188.5 \\
188.6 \\
188.9\end{array}$ & $\begin{array}{l}193.4 \\
193.1 \\
192.9 \\
192.7 \\
192.6\end{array}$ & $\begin{array}{l}192.6 \\
192.3 \\
192.1 \\
192.1 \\
192.2\end{array}$ & $\begin{array}{r}195.1 \\
195.2 \\
195.3 \\
195.4 \\
* 195.5\end{array}$ & $\begin{array}{l}193.0 \\
193.0 \\
193.0 \\
193.0 \\
193.0\end{array}$ & $\begin{array}{l}192.2 \\
192.2 \\
192.2 \\
192.2 \\
192.1\end{array}$ & $\begin{array}{l}191.4 \\
191.4 \\
191.3 \\
191.3 \\
191.3\end{array}$ \\
\hline $\begin{array}{r}6 \\
7 \\
8 \\
9 \\
10\end{array}$ & $\begin{array}{c}186.2 \\
186.2 \\
- \\
- \\
186.2\end{array}$ & $\begin{array}{c}- \\
186.2 \\
186.1 \\
186.1 \\
186.1\end{array}$ & $\begin{array}{c}- \\
18 \overline{5} . \\
18 \overline{6} .0\end{array}$ & $\begin{array}{c}186.9 \\
186.9 \\
186.9 \\
- \\
186.9\end{array}$ & $\begin{array}{c}187.4 \\
- \\
18 \overline{7} .5 \\
- \\
18 \overline{7} .7\end{array}$ & $\begin{array}{l}189.2 \\
189.6 \\
190.0 \\
190.3 \\
190.5\end{array}$ & $\begin{array}{l}192.5 \\
192.5 \\
192.6 \\
192.6 \\
192.6\end{array}$ & $\begin{array}{l}192.2 \\
192.2 \\
192.3 \\
192.4 \\
192.4\end{array}$ & $\begin{array}{r}195.3 \\
* 195.1 \\
194.6 \\
* 194.2 \\
193.7\end{array}$ & $\begin{array}{l}193.0 \\
193.0 \\
193.0 \\
192.9 \\
192.9\end{array}$ & $\begin{array}{l}192.1 \\
192.1 \\
192.0 \\
192.0 \\
192.0\end{array}$ & $\begin{array}{l}191.2 \\
191.2 \\
191.2 \\
191.2 \\
191.2\end{array}$ \\
\hline $\begin{array}{l}11 \\
12 \\
13 \\
14 \\
15\end{array}$ & $\begin{array}{c}186.3 \\
- \\
- \\
186.3 \\
186.4\end{array}$ & $\begin{array}{l}186.1 \\
186.1 \\
186.1 \\
186.1 \\
186.1\end{array}$ & $\begin{array}{c}186.0 \\
- \\
186.0 \\
186.2 \\
186.4\end{array}$ & $\begin{array}{l}187.0 \\
187.0 \\
187.0 \\
187.0 \\
187.1\end{array}$ & $\begin{array}{r}187.8 \\
187.9 \\
\$ 187.9 \\
188.2 \\
188.3\end{array}$ & $\begin{array}{l}190.7 \\
190.9 \\
191.0 \\
191.2 \\
191.5\end{array}$ & $\begin{array}{l}192.6 \\
192.6 \\
192.6 \\
192.6 \\
192.6\end{array}$ & $\begin{array}{l}192.5 \\
192.5 \\
192.5 \\
192.6 \\
192.8\end{array}$ & $\begin{array}{r}193.3 \\
\# 193.1 \\
193.0 \\
192.8 \\
192.8\end{array}$ & $\begin{array}{l}192.9 \\
192 \cdot 9 \\
192 \cdot 8 \\
192 \cdot 8 \\
192 \cdot 8\end{array}$ & $\begin{array}{l}192.0 \\
191.9 \\
191.9 \\
191.9 \\
191.8\end{array}$ & $\begin{array}{l}191.1 \\
191 \cdot 1 \\
191 \cdot 1 \\
191 \cdot 1 \\
191 \cdot 1\end{array}$ \\
\hline $\begin{array}{l}16 \\
17 \\
18 \\
19 \\
20\end{array}$ & $\begin{array}{c}- \\
186.4 \\
186.4 \\
- \\
186.4\end{array}$ & $\begin{array}{l}186.1 \\
186.0 \\
186.0 \\
186.0 \\
186.0\end{array}$ & $\begin{array}{c}186.6 \\
186.7 \\
186.8 \\
- \\
186.8\end{array}$ & $\begin{array}{l}187.1 \\
187.1 \\
187.1 \\
187.1 \\
187.1\end{array}$ & $\begin{array}{l}188.5 \\
188.6 \\
188.7 \\
188.5 \\
188.4\end{array}$ & $\begin{array}{l}191 \cdot 8 \\
192 \cdot 1 \\
192 \cdot 3 \\
192 \cdot 8 \\
192.9\end{array}$ & $\begin{array}{l}192.7 \\
192.7 \\
192.7 \\
192.8 \\
192.8\end{array}$ & $\begin{array}{l}192.9 \\
193.0 \\
193.2 \\
193.4 \\
193.6\end{array}$ & $\begin{array}{l}192.7 \\
192.8 \\
192.8 \\
192.8 \\
192.9\end{array}$ & $\begin{array}{l}192.8 \\
192.7 \\
192.7 \\
192.7 \\
192.7\end{array}$ & $\begin{array}{l}191.8 \\
191.8 \\
191.8 \\
191.8 \\
191.7\end{array}$ & $\begin{array}{l}191.1 \\
191.0 \\
191.0 \\
191.0 \\
191.0\end{array}$ \\
\hline $\begin{array}{l}21 \\
22 \\
23 \\
24 \\
25\end{array}$ & $\begin{array}{c}186.3 \\
186.3 \\
186.3 \\
= \\
186.3\end{array}$ & $\begin{array}{l}186.0 \\
186.0 \\
186.0 \\
186.0 \\
186.0\end{array}$ & $\begin{array}{c}186.9 \\
186.9 \\
186.9 \\
186.9 \\
-\end{array}$ & $\begin{array}{l}187.1 \\
187.1 \\
187.1 \\
187.1 \\
187.1\end{array}$ & $\begin{array}{c}188.4 \\
- \\
188.2 \\
188.2 \\
188.2\end{array}$ & $\begin{array}{l}193.1 \\
193.3 \\
193.5 \\
193.6 \\
193.7\end{array}$ & $\begin{array}{r}192.8 \\
192.8 \\
192.9 \\
\# 193.0 \\
193.0\end{array}$ & $\begin{array}{l}193.8 \\
194.0 \\
194.2 \\
194.4 \\
194.5\end{array}$ & $\begin{array}{l}192.9 \\
192.9 \\
192.9 \\
192.9 \\
193.0\end{array}$ & $\begin{array}{l}192.7 \\
192.6 \\
192.6 \\
192.6 \\
192.5\end{array}$ & $\begin{array}{l}191.7 \\
191.7 \\
191.6 \\
191.6 \\
191.6\end{array}$ & $\begin{array}{l}191.0 \\
191.0 \\
191.0 \\
191.0 \\
191.0\end{array}$ \\
\hline $\begin{array}{l}26 \\
27 \\
28 \\
29 \\
30 \\
31\end{array}$ & $\begin{array}{c}186.3 \\
186.3 \\
186.2 \\
= \\
186.2\end{array}$ & $\begin{array}{c}186.0 \\
186.0 \\
186.0 \\
186.0 \\
186.0 \\
-\end{array}$ & $\begin{array}{l}186.9 \\
186.9 \\
186.9 \\
186.9 \\
186.9 \\
186.9\end{array}$ & $\begin{array}{c}187.1 \\
187.1 \\
- \\
- \\
-\end{array}$ & $\begin{array}{c}188.2 \\
188.2 \\
188.2 \\
- \\
- \\
-\end{array}$ & $\begin{array}{r}* 193.8 \\
193.7 \\
193.7 \\
193.8 \\
* 193.9 \\
193.7\end{array}$ & $\begin{array}{c}192.9 \\
192.8 \\
192.9 \\
* 193.0 \\
192.9 \\
-\end{array}$ & $\begin{array}{r}194.5 \\
* 194.6 \\
194.7 \\
194.8 \\
194.9 \\
195.0\end{array}$ & $\begin{array}{c}193.0 \\
193.0 \\
193.0 \\
193.0 \\
193.0 \\
-\end{array}$ & $\begin{array}{l}192.5 \\
192.4 \\
192.4 \\
192.4 \\
192.3 \\
192.3\end{array}$ & $\begin{array}{l}191.5 \\
191.5 \\
191.5 \\
191.5 \\
191.4 \\
191.4\end{array}$ & $\begin{array}{c}190.9 \\
190.9 \\
190.9 \\
190.9 \\
190.9 \\
-\end{array}$ \\
\hline
\end{tabular}


Kings River, during flood periods, flows into Tulare Lake but also contributes some water to the San Joaquin River by way of Fresno Slough and Fresno by-pass which joins the San Joaquin River near Mendota. Data furnished by C. L. Kaupke, water master, Kings River Water Association. (See No. 31la on figure 6 and p. 128.)

Daily discharge, in second-feet, January to July 1938

\begin{tabular}{|c|c|c|c|c|c|c|c|}
\hline Day & January & February & March & Aprell & May & June & July \\
\hline $\begin{array}{l}1 \\
2 \\
3 \\
4 \\
5\end{array}$ & $\begin{array}{l}590 \\
570 \\
455 \\
445 \\
510\end{array}$ & $\begin{array}{r}280 \\
210 \\
410 \\
960 \\
1,080\end{array}$ & $\begin{array}{l}1,345 \\
1,380 \\
1,750 \\
2,380 \\
3,380\end{array}$ & $\begin{array}{l}2,170 \\
2,085 \\
1,960 \\
1,815 \\
1,630\end{array}$ & $\begin{array}{l}2,700 \\
2,730 \\
2,590 \\
2,310 \\
2,100\end{array}$ & $\begin{array}{l}4,230 \\
4,190 \\
4,400 \\
4,710 \\
4,940\end{array}$ & $\begin{array}{l}2,655 \\
1,600 \\
1,470 \\
1,580 \\
1,650\end{array}$ \\
\hline $\begin{array}{r}6 \\
7 \\
8 \\
9 \\
10\end{array}$ & $\begin{array}{l}505 \\
360 \\
355 \\
345 \\
290\end{array}$ & $\begin{array}{l}1,470 \\
1,680 \\
1,490 \\
1,235 \\
1,045\end{array}$ & $\begin{array}{l}3,930 \\
3,730 \\
3,250 \\
2,940 \\
2,790\end{array}$ & $\begin{array}{l}1,595 \\
1,695 \\
1,820 \\
1,635 \\
1,410\end{array}$ & $\begin{array}{l}1,670 \\
1,535 \\
1,565 \\
1,615 \\
1,710\end{array}$ & $\begin{array}{l}5,100 \\
5,230 \\
5,120 \\
4,830 \\
4,480\end{array}$ & $\begin{array}{r}1,430 \\
1,005 \\
265 \\
385 \\
530\end{array}$ \\
\hline $\begin{array}{l}11 \\
12 \\
13 \\
14 \\
15\end{array}$ & $\begin{array}{l}270 \\
220 \\
180 \\
145 \\
130\end{array}$ & $\begin{array}{l}1,025 \\
1,600 \\
1,880 \\
2,455 \\
2,860\end{array}$ & $\begin{array}{l}2,750 \\
2,600 \\
2,500 \\
2,540 \\
3,170\end{array}$ & $\begin{array}{r}1,275 \\
1,225 \\
1,075 \\
965 \\
1,275\end{array}$ & $\begin{array}{l}1,820 \\
1,950 \\
2,190 \\
2,660 \\
2,990\end{array}$ & $\begin{array}{l}4,300 \\
4,250 \\
4,120 \\
3,950 \\
3,500\end{array}$ & $\begin{array}{r}540 \\
315 \\
105 \\
45 \\
0\end{array}$ \\
\hline $\begin{array}{l}16 \\
17 \\
18 \\
19 \\
20\end{array}$ & $\begin{array}{l}145 \\
145 \\
410 \\
465 \\
480\end{array}$ & $\begin{array}{l}2,540 \\
2,410 \\
2,295 \\
2,100 \\
1,900\end{array}$ & $\begin{array}{l}3,630 \\
3,380 \\
3,050 \\
2,935 \\
2,880\end{array}$ & $\begin{array}{r}1,310 \\
1,050 \\
980 \\
1,035 \\
1,310\end{array}$ & $\begin{array}{l}3,450 \\
4,150 \\
4,680 \\
4,700 \\
4,280\end{array}$ & $\begin{array}{l}3,065 \\
2,920 \\
3,110 \\
3,350 \\
3,490\end{array}$ & $\begin{array}{l}0 \\
0 \\
0 \\
0 \\
0\end{array}$ \\
\hline $\begin{array}{l}21 \\
22 \\
23 \\
24 \\
25\end{array}$ & $\begin{array}{l}485 \\
490 \\
400 \\
310 \\
265\end{array}$ & $\begin{array}{l}1,950 \\
2,310 \\
2,235 \\
1,905 \\
1,710\end{array}$ & $\begin{array}{l}2,770 \\
2,680 \\
2,650 \\
2,610 \\
2,535\end{array}$ & $\begin{array}{l}1,740 \\
2,090 \\
2,410 \\
2,580 \\
2,740\end{array}$ & $\begin{array}{l}4,010 \\
3,720 \\
3,335 \\
2,975 \\
2,890\end{array}$ & $\begin{array}{l}3,290 \\
2,880 \\
2,330 \\
1,900 \\
2,020\end{array}$ & $\begin{array}{l}0 \\
0 \\
0 \\
0 \\
0\end{array}$ \\
\hline $\begin{array}{l}26 \\
27 \\
28 \\
29 \\
30 \\
31\end{array}$ & $\begin{array}{r}185 \\
75 \\
45 \\
40 \\
40 \\
145\end{array}$ & $\begin{array}{c}1,550 \\
1,470 \\
1,380 \\
= \\
= \\
-\end{array}$ & $\begin{array}{l}2,490 \\
2,580 \\
2,500 \\
2,375 \\
2,300 \\
2,235\end{array}$ & $\begin{array}{c}2,840 \\
2,940 \\
2,980 \\
2,810 \\
2,710 \\
-\end{array}$ & $\begin{array}{l}3,110 \\
3,600 \\
3,900 \\
4,210 \\
4,360 \\
4,360\end{array}$ & $\begin{array}{c}2,435 \\
2,850 \\
3,050 \\
3,080 \\
3,040 \\
-\end{array}$ & $\begin{array}{l}0 \\
0 \\
0 \\
0 \\
0 \\
0\end{array}$ \\
\hline
\end{tabular}

Monthly discharge, January to July 1938

\begin{tabular}{|c|c|c|}
\hline Month & $\frac{\text { Moan }}{(\text { second-feet })}$ & $\begin{array}{l}\text { Run-off in } \\
\text { acre-feet }\end{array}$ \\
\hline 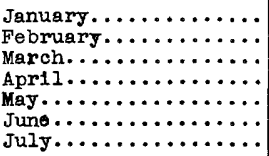 & $\begin{array}{r}306 \\
1,623 \\
2,711 \\
1,838 \\
3,028 \\
3,672 \\
438\end{array}$ & $\begin{array}{r}18,800 \\
89,961 \\
166,390 \\
109,207 \\
185,853 \\
218,117 \\
26,878\end{array}$ \\
\hline
\end{tabular}


San Joaquin River near Newman, Calif.

Locat101.- See page 136.

Maxima..- Merch 1938: D1scharge, 33,000 second-feet 12:30 a.m. Mar. 7 (gage he1ght, 18.51) feet).

1')12-February 1938: Discharge observed (unregulated), 20,700 second-feet (ma1n chaniel only) Jan. 27, 1914 (gege helght, 18.0 feet).

Mean da11y discharge, in second-feet, Februery to Apr11 1938

\begin{tabular}{|c|c|c|c|c|c|c|c|c|c|c|c|}
\hline Day & $P e b$ & Mer. & Apr. & Day & Feb. & Mer. & Apr. & Dey & Feb. & Mar. & Apr. \\
\hline $\begin{array}{r}1 \\
2 \\
3 \\
4 \\
5 \\
6 \\
7 \\
8 \\
9 \\
10\end{array}$ & $\begin{array}{l}3,560 \\
1,840 \\
1,930 \\
5,380 \\
3,550 \\
7,420 \\
3,080 \\
3,450 \\
7,010 \\
7,690\end{array}$ & $\begin{array}{l}10,800 \\
11,300 \\
13,300 \\
16,800 \\
22,100 \\
31,700 \\
33,000 \\
31,700 \\
30,400 \\
28,100\end{array}$ & $\begin{array}{l}15,000 \\
14,100 \\
13,000 \\
12,300 \\
11,600 \\
11,300 \\
11,600 \\
11,100 \\
11,100 \\
10,500\end{array}$ & $\begin{array}{l}11 \\
12 \\
13 \\
14 \\
15 \\
16 \\
17 \\
18 \\
19 \\
20\end{array}$ & $\begin{array}{l}14, \\
20, \\
23, \\
23, \\
24, \\
24, \\
24, \\
22, \\
21,\end{array}$ & $\begin{array}{l}27,100 \\
27,100 \\
26,100 \\
25,200 \\
25,200 \\
27,100 \\
29,200 \\
28,100 \\
28,100 \\
27,100\end{array}$ & $\begin{array}{r}10,300 \\
10,500 \\
10,300 \\
10,100 \\
10,100 \\
9,880 \\
9,880 \\
9,690 \\
9,510 \\
10,100\end{array}$ & $\begin{array}{l}21 \\
22 \\
23 \\
24 \\
25 \\
26 \\
27 \\
28 \\
29 \\
30 \\
31\end{array}$ & $\begin{array}{l}20,800 \\
19,500 \\
17,800 \\
15,400 \\
14,100 \\
13,000 \\
11,900 \\
11,300\end{array}$ & $\begin{array}{l}5,200 \\
4,400 \\
3,600 \\
2,100 \\
0,800 \\
0,100 \\
0,100 \\
0,100 \\
9,500 \\
7,300 \\
5,800\end{array}$ & $\begin{array}{l}10,800 \\
11,100 \\
10,800 \\
10,800 \\
11,300 \\
11,900 \\
13,000 \\
13,700 \\
14,500 \\
14,500\end{array}$ \\
\hline & & & & & & & 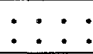 & & $\begin{array}{r}14,350 \\
797\end{array}$ & $\begin{array}{r}23,500 \\
1,445\end{array}$ & $\begin{array}{r}11,480 \\
683\end{array}$ \\
\hline
\end{tabular}

Sen Joaquin River near Vernalis, Calif.

Locet1on. - See page 137.

Mex1ma:- March 1938: Discherge, 51,200 second-feet 1 a.m. Mer. 16 (gege helght, 26.64 Ie日t).

1922-Februery 1938: D1scharge, 28,700 second-feet Feb. 25, 1936 lgege height, 25.57 feet).

Mean dally discherge, In second-feet, February to April 1938

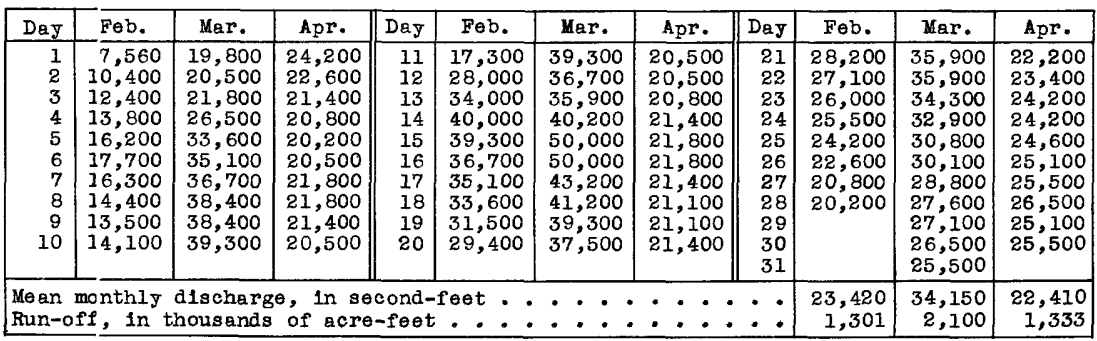


Mono Creek near Vermilion Valley, Calif.

Location. - See page 141.

Maxima.- June 1938: Discharge, 1,760 second-feet 10:30 p.m. June 2 (gage height, 8.62 feet).

1921-May 1938: Discharge, 1,420 second-feet June 16, 1927 (gage he 1ght, 8.09 feet), June 22, 1932 (gage height, 8.10 feet).

Mean daily discharge, in second-feet, 1938

\begin{tabular}{|c|c|c|c|c|c|c|c|c|c|}
\hline Day & May & Day & May & Day & June & Day & June & Day & June \\
\hline $\begin{array}{l}22 \\
23 \\
24 \\
25 \\
26\end{array}$ & $\begin{array}{l}446 \\
570 \\
712 \\
828 \\
910\end{array}$ & $\begin{array}{l}27 \\
28 \\
29 \\
30 \\
31\end{array}$ & $\begin{array}{r}1,030 \\
1,030 \\
970 \\
1,060 \\
1,210\end{array}$ & $\begin{array}{l}1 \\
2 \\
3 \\
4 \\
5\end{array}$ & $\begin{array}{l}1,410 \\
1,520 \\
1,550 \\
1,520 \\
1,410\end{array}$ & $\begin{array}{r}6 \\
7 \\
8 \\
9 \\
10\end{array}$ & $\begin{array}{l}1,380 \\
1,380 \\
1,340 \\
1,410 \\
1,340\end{array}$ & $\begin{array}{l}11 \\
12 \\
13 \\
14 \\
15\end{array}$ & $\begin{array}{r}1,270 \\
1,030 \\
800 \\
828 \\
1,000 \\
\end{array}$ \\
\hline
\end{tabular}

Gage height, in feet, and discharge, in second-feet, at indicated time, 1938

\begin{tabular}{|c|c|c|c|c|c|c|c|c|c|c|c|c|}
\hline \multirow{2}{*}{ 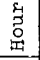 } & Feet & Sec,ft. & Feet & Sec.ft. & Feet & sec.ft. & Feet & Sec.ft. & Feet & sec.ft. & Feet & Sec.ft. \\
\hline & \multicolumn{2}{|c|}{ June 1} & \multicolumn{2}{|c|}{ June 2} & \multicolumn{2}{|c|}{ June 3} & \multicolumn{2}{|c|}{ June 4} & \multicolumn{2}{|c|}{ June 5} & \multicolumn{2}{|c|}{ June 6} \\
\hline $\begin{array}{r}2 \\
4 \\
6 \\
8 \\
10 \\
\mathrm{~N} \\
2 \\
4 \\
6 \\
8 \\
10 \\
\mathrm{M}\end{array}$ & $\begin{array}{l}8.16 \\
8.11 \\
8.02 \\
7.95 \\
7.85 \\
7.77 \\
7.74 \\
7.85 \\
8.15 \\
8.44 \\
8.56 \\
8.59\end{array}$ & $\begin{array}{l}1,450 \\
1,420 \\
1,350 \\
1,300 \\
1,240 \\
1,190 \\
1,170 \\
1,240 \\
1,440 \\
1,650 \\
1,730 \\
1,750\end{array}$ & $\begin{array}{l}8.51 \\
8.39 \\
8.27 \\
8.15 \\
8.04 \\
7.94 \\
7.92 \\
8.05 \\
8.30 \\
8.49 \\
8.61 \\
8.60\end{array}$ & $\begin{array}{l}1,700 \\
1,610 \\
1,530 \\
1,440 \\
1,370 \\
1,300 \\
1,280 \\
1,380 \\
1,550 \\
1,680 \\
1,760 \\
1,760\end{array}$ & $\begin{array}{l}8.55 \\
8.44 \\
8.33 \\
8.22 \\
8.11 \\
8.00 \\
8.01 \\
8.11 \\
8.27 \\
8.41 \\
8.47 \\
8.47\end{array}$ & $\begin{array}{l}1,720 \\
1,650 \\
1,570 \\
1,490 \\
1,420 \\
1,340 \\
1,350 \\
1,420 \\
1,530 \\
1,630 \\
1,670 \\
1,670\end{array}$ & $\begin{array}{l}8.42 \\
8.34 \\
8.26 \\
8.16 \\
8.07 \\
7.98 \\
7.98 \\
8.18 \\
8.34 \\
8.40 \\
8.41 \\
8.38\end{array}$ & $\begin{array}{l}1,630 \\
1,580 \\
1,520 \\
1,450 \\
1,390 \\
1,330 \\
1,330 \\
1,470 \\
1,580 \\
1,620 \\
1,630 \\
1,610\end{array}$ & & & & \\
\hline
\end{tabular}

Fine Gold Creek near Friant, Calif.

Location.- See page 148 .

Maxima.- March 1938: Discharge, 10,300 second-feet about 9 p.m. Mar. 12 (gage he1ght, 20.4 feet, from floodmarks).

1936-February 1938: Discharge, 6,780 second-feet Feb. 6, 1937 (gage helght, 16. 45 feet).

Mean dally discharge, in second-feet, 1938

\begin{tabular}{|c|c|c|c|c|c|c|c|c|c|c|c|}
\hline \multicolumn{12}{|c|}{ Mar. } \\
\hline $\begin{array}{r}1 \\
2 \\
3 \\
4 \\
5 \\
6 \\
7 \\
8 \\
9 \\
10\end{array}$ & $\begin{array}{l}524 \\
274 \\
738 \\
808 \\
452 \\
237 \\
174 \\
154 \\
440 \\
270\end{array}$ & $\begin{array}{r}1,100 \\
3,200 \\
3,000 \\
1,510 \\
780 \\
603 \\
500 \\
1,040 \\
580 \\
452\end{array}$ & $\begin{array}{l}142 \\
137 \\
131 \\
133 \\
306 \\
174 \\
152 \\
138 \\
133 \\
133\end{array}$ & $\begin{array}{l}11 \\
12 \\
13 \\
14 \\
15 \\
16 \\
17 \\
18 \\
19 \\
20\end{array}$ & $\begin{array}{r}3,950 \\
1,320 \\
616 \\
1,140 \\
603 \\
428 \\
306 \\
350 \\
792 \\
361\end{array}$ & $\begin{array}{r}405 \\
2,460 \\
3,200 \\
1,200 \\
800 \\
650 \\
615 \\
430 \\
305 \\
567\end{array}$ & $\begin{array}{l}133 \\
134 \\
194 \\
164 \\
143 \\
137 \\
131 \\
121 \\
118 \\
114\end{array}$ & $\begin{array}{l}21 \\
22 \\
23 \\
24 \\
25 \\
26 \\
27 \\
28 \\
29 \\
30 \\
31\end{array}$ & $\begin{array}{l}282 \\
237 \\
201 \\
192 \\
174 \\
170 \\
157 \\
210\end{array}$ & $\begin{array}{l}385 \\
240 \\
206 \\
447 \\
255 \\
185 \\
170 \\
177 \\
170 \\
154 \\
149\end{array}$ & $\begin{array}{l}109 \\
107 \\
103 \\
107 \\
186 \\
133 \\
117 \\
109 \\
109 \\
114\end{array}$ \\
\hline \multicolumn{11}{|c|}{ 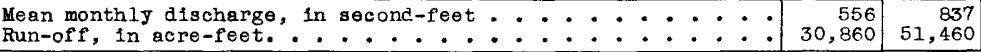 } & 8,260 \\
\hline
\end{tabular}


Fresno River near Knowles, Cal1f.

Locat1on. - See page 151.

Maxima.- March 1938: Discharge, 7,630 decond-feet 5 p.m. Mar. 12 (gage he1ght, 8.67 feet).

1911-13, 1915-February 1938: D1scharge, 6,880 second-feet Feb. 6, 1937 (gage helght, 8.16 feet).

Mean daily discharge, in second-feet, 1938

\begin{tabular}{|r|r||r|r||r|r||r|r|r||r||r|}
\hline Day & March & Day & March & Day & March & Day & March & Day & March \\
\hline 1 & 1,270 & 6 & 814 & 11 & 638 & 16 & 1,090 & 21 & & 736 \\
2 & 3,280 & 7 & 694 & 12 & 2,890 & 17 & 1,020 & 22 & 604 \\
3 & 2,670 & 8 & 1,140 & 13 & 4,020 & 18 & 766 & 23 & 552 \\
4 & 1,590 & 9 & 743 & 14 & 1,570 & 19 & 680 & 24 & 1,050 \\
5 & 1,050 & 10 & 617 & 15 & 1,140 & 20 & 998 & 25 & 687 \\
\hline
\end{tabular}

Gage height, in feet, and discharge, in second-feet, at indicated time, 1938

\begin{tabular}{|c|c|c|c|c|c|c|c|c|c|c|c|c|}
\hline \multirow{2}{*}{$\begin{array}{l}5 \\
5 \\
0 \\
0 \\
\text { 足 }\end{array}$} & Feet & Sec.ft. & Feet & Sec.ft. & Feet & Sec.ft. & Feet & Sec.ft. & Feet & Sec.ft. & Feet & Sec.ft. \\
\hline & \multicolumn{2}{|c|}{ March 11} & \multicolumn{2}{|c|}{ March 12} & \multicolumn{2}{|c|}{ March 13} & \multicolumn{2}{|c|}{ March 14} & \multicolumn{2}{|c|}{ March 15} & \multicolumn{2}{|c|}{ March 16} \\
\hline \begin{tabular}{r|}
2 \\
4 \\
6 \\
8 \\
10 \\
$\mathrm{~N}$ \\
2 \\
4 \\
6 \\
8 \\
10 \\
$\mathrm{M}$
\end{tabular} & $\begin{array}{l}2.66 \\
2.65 \\
2.64 \\
2.63 \\
2.62 \\
2.62 \\
2.62 \\
2.70 \\
2.78 \\
2.90 \\
3.13 \\
3.29\end{array}$ & $\begin{array}{r}584 \\
578 \\
571 \\
564 \\
558 \\
558 \\
558 \\
610 \\
666 \\
750 \\
934 \\
1,060\end{array}$ & $\begin{array}{l}3.41 \\
3.54 \\
3.65 \\
3.77 \\
3.87 \\
3.98 \\
4.16 \\
5.00 \\
6.82 \\
7.10 \\
7.70 \\
6.90\end{array}$ & $\begin{array}{l}1,170 \\
1,290 \\
1,380 \\
1,490 \\
1,590 \\
1,700 \\
1,880 \\
2,720 \\
4,930 \\
5,320 \\
6,160 \\
5,040\end{array}$ & $\begin{array}{l}6.33 \\
7.67 \\
8.00 \\
7.15 \\
6.15 \\
5.80 \\
5.82 \\
5.50 \\
5.19 \\
4.90 \\
4.65 \\
4.41\end{array}$ & $\begin{array}{l}4,270 \\
6,120 \\
6,580 \\
5,390 \\
4,040 \\
3,620 \\
3,640 \\
3,270 \\
2,930 \\
2,620 \\
2,370 \\
2,130\end{array}$ & $\begin{array}{l}4.25 \\
4.11 \\
4.02 \\
3.95 \\
3.87 \\
3.82 \\
3.75 \\
3.70 \\
3.67 \\
3.65 \\
3.62 \\
3.60\end{array}$ & $\begin{array}{l}1,970 \\
1,830 \\
1,740 \\
1,670 \\
1,590 \\
1,540 \\
1,480 \\
1,430 \\
1,400 \\
1,380 \\
1,360 \\
1,340\end{array}$ & & & & \\
\hline
\end{tabular}

Merced River near Ilvingston, Calif.

Location. - See page 161.

Maxima.- February 1938: Discharge, 11,100 second-feet 11 p.m. Feb. 12 (gage he1ght, 19. 44 feet).

1922-24, 1926-January 1938: Discharge, 10,900 second-feet (rev1sed) Feb. 24, 1936 (gage height, 19.24 feet).

Mean daily discharge, in second-feet, 1938

\begin{tabular}{|r|c||r|c||c|c||c|c||c|c|}
\hline Day & February & Day & February & Day & February & Day & February & Day & February \\
\hline 1 & 2,020 & 6 & 1,760 & 11 & 3,830 & 16 & 7,080 & 21 & 5,370 \\
2 & 1,720 & 7 & 1,610 & 12 & 8,950 & 17 & 6,450 & 22 & 4,060 \\
3 & 846 & 8 & 1,540 & 13 & 9,570 & 18 & 5,890 & 23 & 2,530 \\
4 & 1,760 & 9 & 1,610 & 14 & 7,650 & 19 & 5,510 & 24 & 2,130 \\
5 & 2,140 & 10 & 2,420 & 15 & 8,150 & 20 & 5,440 & 25 & 2,000 \\
\hline
\end{tabular}

Gage helght, in feet, and discharge, in second-feet, at indicated time, 1938

\begin{tabular}{|r|r|c|c|c|c|c|c|c|c|c|c|c|}
\hline$\xi$ & Feet & Sec.ft. & Feet & Sec.ft. & Feet & Sec.ft. & Feet & Sec.ft. & Feet & Sec.ft. & Feet & Sec.ft. \\
\cline { 2 - 10 } & \multicolumn{2}{|c|}{ February 9 } & \multicolumn{2}{|c|}{ February 10 } & February 11 & February 12 & \multicolumn{2}{|c|}{ February 13} & February 14 \\
\hline 2 & 5.18 & 1,250 & 7.10 & 1,950 & 8.14 & 2,360 & 15.10 & 6,540 & 19.33 & 11,000 & 16.69 & 8,040 \\
4 & 5.40 & 1,330 & 7.94 & 2,280 & 8.85 & 2,640 & 15.40 & 6,810 & 19.12 & 10,800 & 16.55 & 7,900 \\
6 & 5.80 & 1,470 & 8.54 & 2,520 & 9.58 & 2,960 & 15.85 & 7,220 & 18.85 & 10,500 & 16.43 & 7,780 \\
8 & 6.14 & 1,590 & 8.81 & 2,620 & 10.21 & 3,270 & 16.30 & 7,650 & 18.56 & 10,100 & 16.34 & 7,690 \\
10 & 6.38 & 1,680 & 8.84 & 2,640 & 10.60 & 3,480 & 17.00 & 8,350 & 18.26 & 9,760 & 16.20 & 7,550 \\
N & 6.54 & 1,740 & 8.80 & 2,620 & 10.85 & 3,620 & 17.72 & 9,140 & 17.97 & 9,420 & 16.09 & 7,440 \\
2 & 6.62 & 1,770 & 8.81 & 2,620 & 11.16 & 3,800 & 18.35 & 9,870 & 17.72 & 9,140 & 15.99 & 7,340 \\
4 & 6.68 & 1,790 & 8.79 & 2,620 & 11.79 & 4,170 & 18.83 & 10,400 & 17.50 & 8,900 & 15.95 & 7,300 \\
6 & 6.68 & 1,790 & 8.66 & 2,560 & 12.62 & 4,700 & 19.14 & 10,800 & 17.30 & 8,680 & 15.99 & 7,340 \\
8 & 6.54 & 1,740 & 8.37 & 2,450 & 13.38 & 5,220 & 19.33 & 11,000 & 17.13 & 8,490 & 16.10 & 7,450 \\
10 & 6.33 & 1,660 & 8.02 & 2,310 & 14.14 & 5,760 & 19.43 & 11,100 & 16.96 & 8,310 & 16.26 & 7,610 \\
M & 6.46 & 1,710 & 7.85 & 2,240 & 14.69 & 6,200 & 19.43 & 11,100 & 16.82 & 8,170 & 16.45 & 7,800 \\
\hline
\end{tabular}


Woods Creek near Jacksonvi11e, Cal1t.

Location.- See page 174.

Maxima.- February 1938: Discharge, 13,500 second-feet 8 p.m. Feb. 9 (gage helght, 10.5 feet).

1925-January 1938: Discharge, 10,600 second-feet Feb. 6, 1937 (gage helght, 9.12 feet).

Mean dally discharge, in second-feet, 1938

\begin{tabular}{|c|c||r|c||c|c||r|r||c||c|}
\hline Day & February & Day & February & Day & February & Day & February & Day & February \\
\hline 1 & 1,460 & 6 & 248 & 11 & 5,440 & 16 & 366 & 21 & 192 \\
2 & 414 & 7 & 178 & 12 & 1,220 & 17 & 279 & 22 & 190 \\
3 & 2,280 & 8 & 142 & 13 & 530 & 18 & 252 & 23 & 180 \\
4 & 1,190 & 9 & 3,160 & 14 & 1,180 & 19 & 418 & 24 & 170 \\
5 & 476 & 10 & 5,250 & 15 & 566 & 20 & 232 & 25 & 160 \\
\hline
\end{tabular}

Gage height, In feet, and discharge, in second-feet, at Indicated time, 1938

\begin{tabular}{|r|r|c|r|r|r|r|r|r|r|r|r|r|}
\hline \multirow{2}{*}{$\begin{array}{c}\xi \\
\text { 孚 }\end{array}$} & Feet & Sec.ft. & Feet & Sec.ft. & Feet & Sec.ft. & Feet & Sec.ft. & Feet & Sec.ft. & Feet & Sec.ft. \\
\hline 2 & 1.44 & 153 & 1.51 & 168 & 5.21 & 2,800 & 7.00 & 5,300 & 4.45 & 2,000 & 2.59 & 686 \\
4 & 1.41 & 146 & 1.60 & 190 & 4.48 & 2,030 & 7.13 & 5,560 & 4.18 & 1,740 & 2.46 & 634 \\
6 & 1.41 & 146 & 1.82 & 245 & 4.59 & 2,140 & 6.90 & 5,150 & 3.91 & 1,510 & 2.34 & 586 \\
8 & 1.40 & 144 & 2.35 & 395 & 6.37 & 4,360 & 7.57 & 6,440 & 3.61 & 1,270 & 2.24 & 546 \\
10 & 1.39 & 142 & 2.88 & 582 & 7.62 & 6,540 & 8.09 & 7,480 & 3.35 & 1,090 & 2.18 & 522 \\
N & 1.38 & 140 & 3.05 & 650 & 8.19 & 7,680 & 8.02 & 7,340 & 3.18 & 988 & 2.08 & 482 \\
2 & 1.37 & 138 & 2.80 & 550 & 7.93 & 7,160 & 8.13 & 7,560 & 3.12 & 952 & 2.04 & 466 \\
4 & 1.36 & 136 & 3.76 & 980 & 8.59 & 8,580 & 7.32 & 6,940 & 3.16 & 976 & 2.00 & 450 \\
6 & 1.36 & 136 & 9.61 & 10,500 & 8.40 & 8,100 & 6.59 & 4,680 & 3.17 & 982 & 1.96 & 436 \\
8 & 1.36 & 136 & 10.50 & 13,500 & 7.38 & 6,060 & 5.69 & 3,380 & 3.15 & 970 & 1.95 & 432 \\
10 & 1.41 & 146 & 8.22 & 7,740 & 6.34 & 4,310 & 5.13 & 2,710 & 2.94 & 860 & 2.03 & 462 \\
$\mathbf{M}$ & 1.47 & 159 & 6.65 & 4,780 & 6.04 & 3,870 & 4.75 & 2,300 & 2.76 & 770 & 2.58 & 682 \\
\hline
\end{tabular}

Shasta RIver near Yreka, Oal1f.

Location. - See page 270.

MaxIma.- March 1938: Discharge, 1,940 second-feet 5:30 p.m. Mar. 23 (gage he1ght, 6.24 foet).

1933-February 1938: Discharge, 1,860 second-feet 4 p.m. Dec. 11, 1937 (gage height, 6.17 feet).

Mean dally discharge, in secondmfeet, 1938

\begin{tabular}{|r|c||r|r||r|r||r|r||r|r|}
\hline Day & March & Day & March & Day & March & Day & March & Day & March \\
\hline 7 & 477 & 12 & 382 & 17 & 511 & 22 & 530 & 27 & 750 \\
8 & 447 & 13 & 443 & 18 & 496 & 23 & 1,470 & 28 & 725 \\
9 & 422 & 14 & 454 & 19 & 500 & 24 & 1,260 & 29 & 655 \\
10 & 400 & 15 & 432 & 20 & 570 & 25 & 970 & 30 & 610 \\
11 & 382 & 16 & 500 & 21 & 550 & 26 & 800 & 31 & $\mathbf{5 7 0}$ \\
\hline
\end{tabular}

Gage helght, In feet, and discharge, in second-feet, at Indicated time, 1938

\begin{tabular}{|c|c|c|c|c|c|c|c|c|c|c|c|c|}
\hline \multirow{2}{*}{ 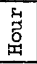 } & Feet & Sec.et. & Feet & sec.ft. & Foet & Sec.ft. & Feet & sec.ft. & Feet & Sec.ft. & Feet & Sec.et. \\
\hline & \multicolumn{2}{|c|}{ March 22} & \multicolumn{2}{|c|}{ March 23} & \multicolumn{2}{|c|}{ March 24} & \multicolumn{2}{|c|}{ March 25} & \multicolumn{2}{|c|}{ March 26} & \multicolumn{2}{|c|}{ Karch 27} \\
\hline $\begin{array}{r}2 \\
4 \\
6 \\
8 \\
10 \\
\mathrm{~N} \\
2 \\
4 \\
6 \\
8 \\
10 \\
\mathrm{H}\end{array}$ & $\begin{array}{l}3.95 \\
3.95 \\
3.95 \\
3.95 \\
3.95 \\
3.95 \\
3.96 \\
3.97 \\
4.08 \\
4.11 \\
4.13 \\
4.24\end{array}$ & $\begin{array}{l}511 \\
511 \\
511 \\
511 \\
511 \\
511 \\
515 \\
519 \\
562 \\
574 \\
582 \\
628\end{array}$ & $\begin{array}{l}4.45 \\
4.70 \\
5.08 \\
5.54 \\
5.84 \\
5.95 \\
6.08 \\
6.18 \\
6.22 \\
6.13 \\
5.98 \\
5.82\end{array}$ & $\begin{array}{r}725 \\
855 \\
1,080 \\
1,390 \\
1,610 \\
1,700 \\
1,800 \\
1,880 \\
1,920 \\
1,840 \\
1,720 \\
1,600\end{array}$ & $\begin{array}{l}5.66 \\
5.54 \\
5.45 \\
5.37 \\
5.32 \\
5.28 \\
5.29 \\
5.31 \\
5.30 \\
5.27 \\
5.22 \\
5.16\end{array}$ & $\begin{array}{l}1,470 \\
1,390 \\
1,320 \\
1,270 \\
1,230 \\
1,210 \\
1,210 \\
1,230 \\
1,220 \\
1,200 \\
1,160 \\
1,130\end{array}$ & $\begin{array}{l}5.09 \\
5.03 \\
4.99 \\
4.94 \\
4.88 \\
4.85 \\
4.81 \\
4.78 \\
4.76 \\
4.74 \\
4.72 \\
4.71\end{array}$ & $\begin{array}{r}1,080 \\
1,050 \\
1,020 \\
994 \\
958 \\
940 \\
916 \\
899 \\
888 \\
877 \\
866 \\
860\end{array}$ & & & & \\
\hline
\end{tabular}




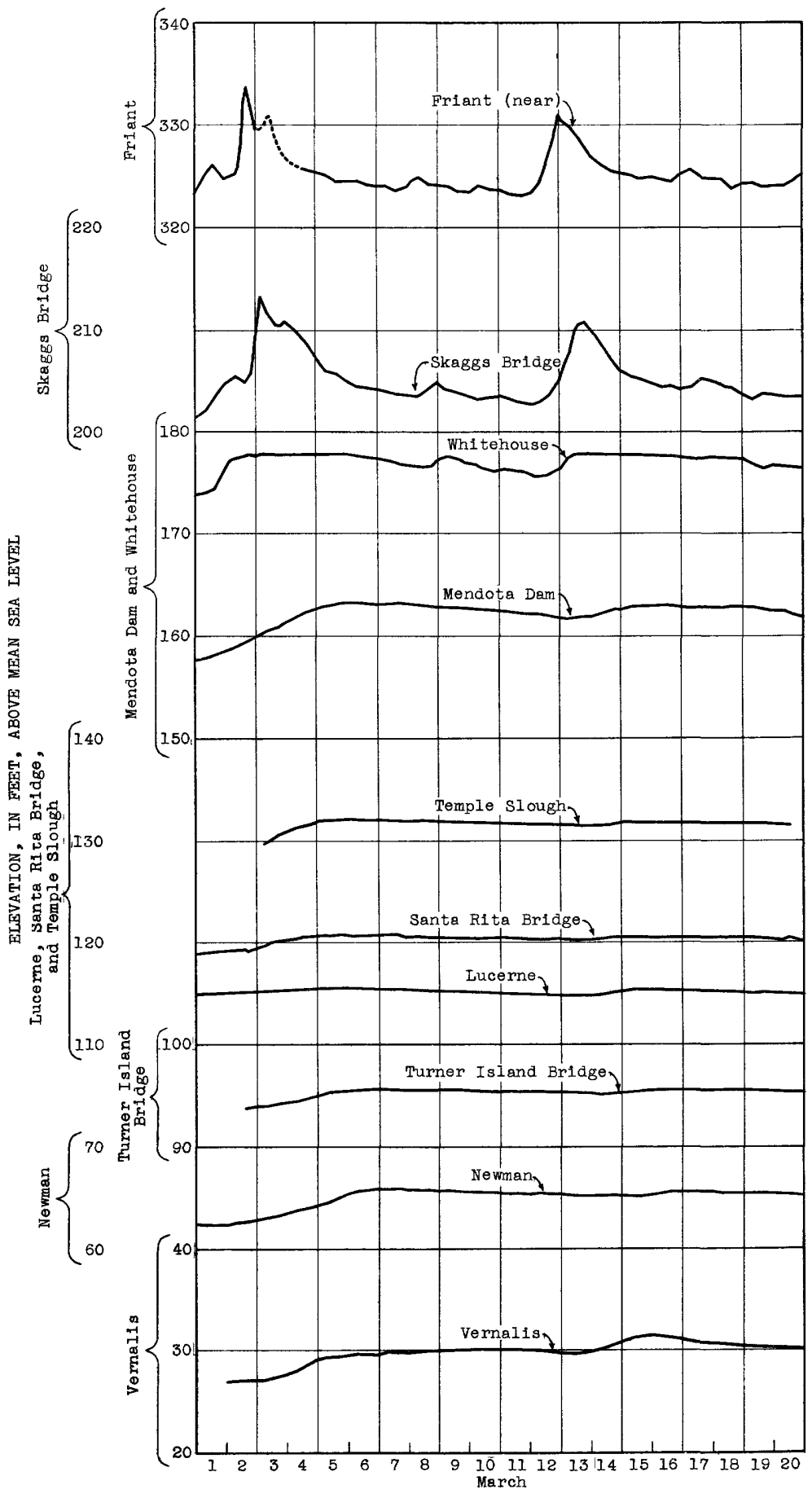




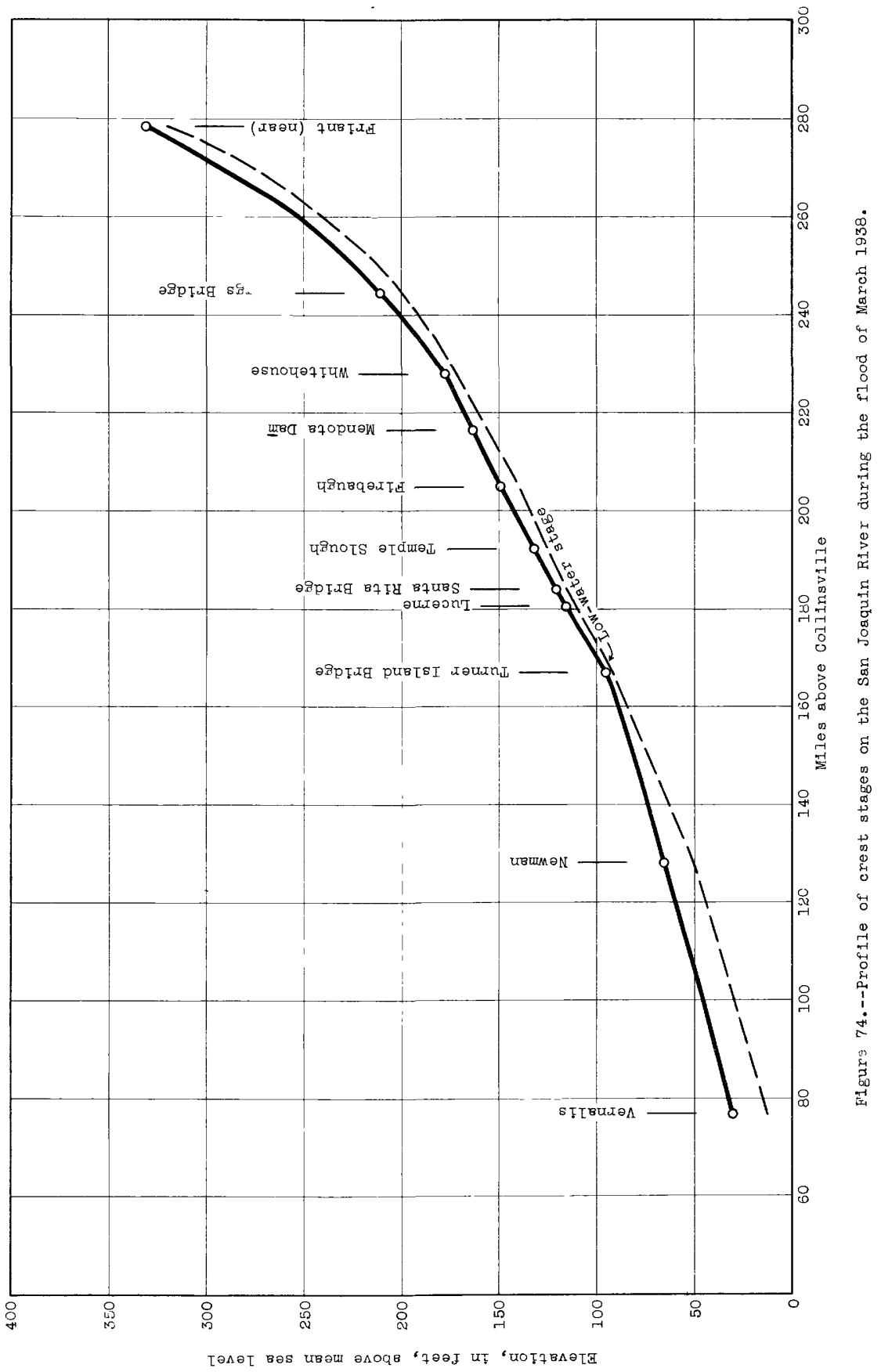


Abstract . . . . . : : : : : :

Administration and personnel ....

A lameda Creok near Niles......

Alameda Creek Basin, rainfail and run-off in........

stage and discharge records in .

Alamitos Creok near Edenvale . . .

Alder Creek near Whitehal1 . . . .

American R1ver at Fair Oaks

maximum stages and discharges on. Middle Fork of, near Auburn .... North Fork of, near Colfax . . . South Fork of, at Coloma.: : : South Fork of, near Camino . . . South Fork of, near Kyburz American River Basin, rainfail and mun-off in... 309, 315

Anderson, Calif., scene of flooded

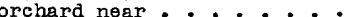

Antler, Sacramento River at : : : Arroyo Seco near Soledad . . . . .

Auberry, Big Sandy Creek near

Auburn, Middle Fork of American River North Fork of Stanisiaus River near.............

Baird, McCloud River at

Bear Creok near Planada

near Vermilion Valley

scene of damaged highwey bridge on

Bear Creok Basin, ralnfall and runoff in........ $307,312,32$

Bear River at Pardoe Camp . . . . near Wheatland ${ }^{*}$ 'F ${ }^{*}{ }^{*}$ Ferther

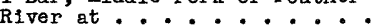

Big Bend, Pit River at: : : : : :

B1g Creek below Huntington Lake :

Blg Creek, Florence lake near . : :

Huntington Lake near ........

San Joaquin River above . . . .

Shaver Lake near. . . : : :

Big Pine Creek below Littie Pine Creok, near Big PIne...

Bib Sandy Creek near Auberry ... .

B1g Tre日s, San Lorenzo River at
B1shop, PIne Creek at division box near.

Rock Creek at Sherwin Hili near.

Bowman Lake, Canyon Creek below . . near Granitevilie

Bridgeport Reservolr near Bridgeport

Buchanan dam site, Chowchilla River at Buck Meadows, Middle Tuolumne River near

Bucks Creok at Bucks Creok storage reservolr .

Bucks Creok storage reservoir near Bucks ranch $\dot{0} \cdot \dot{0} \cdot-\dot{0}$ ranch, Bucks Creok storage reservoir near.

Burnt Remen Rring River ne

Butto Greok rainfall and mun-off in ... : :308,314

Cache Creek at Yolo

maximum tope...

North Fork of, near Lower lake. Cache Creok Basin, rainfall and runoff in $316,323,339$

Calaveras River at Jenny Lind ... 181, 182 Calaveras River Bas1n, rainfal1 and mun-off in.... 308, 313, 322, 338

Camino, South Fork of American

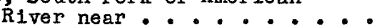

Campbel1 Creek at Saratoga: : : Canby, Pit River near . . . . Canyon Creek below Bowman Lake. Carson River at Lahontan Reservolr. Nev. ...........

205

468
Page

Carson River Basin, rainfall and 316

4-5 Cherry Creek near Hetch Hetchy . . . 169

114 Chester, Calif., scene of flood damage .......... . pl. 1,B 311 Chleo, But te creek near: : . . 218

-115 Chico Creok near Chico ..... 215

109 Chico Crook Basin, rainfall and run-

254 off in . - . 308, 314, 323, 338

245 Chowch111a River at Buchanan dam

459 site ........... 153

245 Chowchilla River Basin, rainfail and

244 run-off in . . . 307, 312, 321, 337

249 Clear Lake at Lakeport: . ... . . 259

248 Clements, Mokelume River near : : : 188

247 cliff Camp, North Fork of Kings

252 River near 129

C110, Middle Fork of Feather R1ver near 229

Cl1pper Mills, Lost Creek near . . 232

Coalinga, Los Gatos Creok near . . 131, 484

1. 3,B Cold Creek near Mokelumne Peak .. 190

197 Colfax, North Fork of American River

100 near *.*.*.*. *.*. 244

147 Coloma, South Fork of American River

249

Concow Creek near Yankes Hill... 228

Conn Creok near St. Felena : : : 264

178 Cosgrove Creek near Valley springs: 183

Cosumes River at Michigan Bar . - 196

210 North Fork of, near El Dorado . . * 195

118 Cottonwood Creek near Friant . . . 149

154 Coyote Creek near Edenvale . : . : 113

140 near Madrone . . . . . . . . 112

, B Coyote Creek Bas in, rainfall and runoff in .......... . 311

stage and discharge records in $.112-113$

191 Crane Valley Reservolr, North Fork

of Willow Creek at . . . . 146

230 Crescent Mills, Indian Creek near : $\quad 222$

143 Daulton, Fresno River near . . . 152

138 Deer Creek near Smartville:. . . 242

142 near Vina............. 214

132 Doer Crook Basin, rainfail and run-

145 off in .................. 308, 314

Donner Creek near Truckee... . . 286

278 Don Pedro Reservoir near La Grange . 166

147 Downlevilie, scene of flood damage in pl. 4

Edenvale, Alamitos Creek near . . 109

277 Covote Creek near ....... 113

276 Eel River at Hullville . . . . . 266

241 at Scot1a...:. : 268

240 at Van Arsdaie Dam, near Potter

281 Valley ......... 267

153 Eel River Basin, rainfali and run- 316 off in :

173 stage and discharge records in $\cdot 265-268$

225 Elder Creek Basin, rainfall and mun-

off in ........ . 314, 322, 338

224 E1 Dorado, North Fork of Cosumes River near 195

24 Eleanor Creok near Hetch Hetchy . . 171

73 Elk Creek, Stony Gorge Reservolr near 217

18 Emigrant Gap, Lake Spaulaing noar . . 238

1.8 Enterprise, South Fork of Feather

Exchequer at ن́ciure : * : : 231

260 Merced River at.......... 160

Fair Oaks, American River at * : : 245

Fal1 River u111s, Pit R1ver at: : : 203

Feather River, maximum stages and - 459

discharges on
de Fork of, at Bidweil Bar : : $\quad 459$

Middle Fork of, near Cllo...: 229

248 near Orov1110?........... 221

111 North Fork of, near Prattvilie: : 220

202 South Fork of, at Enterprise 241 West Branch of, near Yankes H111.
231

Feather River Basin, rainfall and

282 run-off in. 308-309, 314-315, 323, 338 
Feather River Basin--Cont inued

scenes of flood damage in

Fine Gold Creek near Friant

Flood discharges, determination of: $\cdot 148,488$

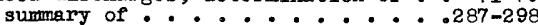

Floods, crest stages of, on Sacra-

mento River ...... 422-424, 426

on San Joaquin River: : 422-423, 425

determination of discharges of, from rating curves

from slope-area 72-74

general discussion of :.: : 71-72

over dams ........: $74-75$

through contracted openings: : $77-79$

general features of the ..... 6-21

miscellaneous stages of, on San

Joaquin River * - *. . 95

previous, in Kern River Basin: $437-440$

in Sacramento River Basin . . 453-470

in San Francisco Bay basins . . 434-437

in San Joaquin River Basin . : 444-453

in southern Pacific basins . . 433, 434

in Tulare Lake Basin... . . .439-444

records of, in 1938 ... . . 479-490

stage and discharge records of . . 79-286

summary of outstanding ..... . .430-433

Florence Lake near Big Creek. . . . 138

Florence Lake, South Fork of San

Joaquin River near . . . . . 139

Fresno by-pass, Fresno County : : 128, 486

Fresno River near Daulton - - : - ir 152

near knowles . . . . . . . 151, 489

Fresno River Basin, rainfall and mun-off in : $307,312,321,337$

Friant, Cottonwood creek near . : 149

Fine Gold Creek near . . : : i48, 488

Itttle Dry Creek near . . . . . 150

San Joaquin River near ... . .

Gerber, Calif., flood scene near . . pl. 6 G1lroy, Calif., flood scene in . : pl. 9, Great Basin, rainfall and run-off in the Grizzly Creek near Storrie . . - . 226 Guadalupe Creek at Guadalupe . : : at San Jose

Guadalupe Crook Bas in, roinfoil and mun-off in...... $311,321,337$

stage and discharge records in . .107-111

Guenoc, Putah Creek near...... 262

Happy Isles Bridge, near Yosemite, Merced River at

Hat Creok near Hat Creek : : :

pl. 10 Henleyvilie, Elder Creek near . . - 212

Hetch Hetchy, Cherry Creek near . :

Eleanor Creok near .........

Falls Creek near ..........

Lake Eleanor near . . . . . .

Tuolume River near . : : : .

Hetch Hetchy Reservoir at Hetch Hetchy Hoopa, Trinity River near . . . . Hulivilie, Eel River at . : . .

Lake Pilisbury at :.: : : : Humboldt-Carson Sink Basin, stage and discharge records in.... Huntington Lake, B1g Creek below . . Huntington Lake near BIg Creek . : Hydrologic conditions :. . . . :

Ice House, South Fork of S1lver Creek near . . . . .

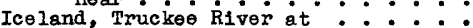
Independence Creek at Independence. Indian Creek near Crescent M111s. . Introduction ${ }^{\prime}$.

Kaweah River near Three Rivers....

North Fork of, at Kaweah . :

scenes at river-measurement station

on ............. pl.

Kedale, Spanish Creok at : : : : Kennett, Sacramento River at.... Kerckhoff power house, San Joaquín River below . . . .

Kern Canyon power house, Kern River above ............

143
142

$22-71$
258

285

279

222
2
120

124

125

- 12

198

133

117

Kern River above Kern Canyon power

house ................. 117

near Bakersfield : : . 118

near Kernville........... 116

South Fork of, at Isabeila: : : 120

South Fork of, near Onyx . . . 119, 484

Kern River Basin, previous floods in .437-439 stage and discharge records in . . 116-120 rainfell and run-off $31 i, 321,337,354-357$

Kernville, Kern River near.... 116 Kings County, Tulare Lake in: : : i24, 485

Kings River above North Fork . . . . 126

at Pledra ............ 127

North Fork of, below Rancheria

Creok ........ 130

near cliff camp. . 128

Kirkwood, Silver Lake outiet near. : 251

Twin Lakes outlet near . . . . . 253

Kittridge, Merced River at..... 158

Klamath River at Somesbar ${ }_{\text {Klamath River Basin, rainfail and run- }}$

of in in.?. . . . . . . 316, 323, 339

stage and discharge records in . 269-274

Knowles, Fresno River near . . . 151, 489

Kyburz, Silver Fork of South Fork of American River near -

South Fork of American River near. : 247

Jacksonville, Woods Creek near . . 174, 490 Jenny Lind, Calaveras River at : : 181, 182

Ia Grange, Don Pedro Reservolr near.

Tuolumine River above La Grange Dam near :

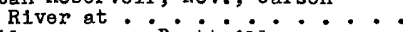

Lake Almanor near Prattvilile . . .

Lake Eleanor near Hetch Hetchy . .

Lake McClure at Exchequer . : - :

Lakeport, Clear Lake at . . . . .

Lake spaulding neax Emigrant Gap. .

Lake Spaulding, South Fork of Yuba

Tahoe at Tahoo : : : :

Lake Tahoe at Tahoe :

Lewiston, Trinity River at:.: : : 27

Iikely, South Fork of Pit River near : 207

Lisbon, Yolo by-pass at ...... 201

Ifttle Dry Creek near Friant . . . 150

Livingston, Merced River near. . . 161, 489

Lone Pino, Tuttle Creek at Canyon Road, near........... 280

Los Gatos Creek at Los Gatos... 110

near Coslinga ...... 131, 484

Los Molinos, Mill Creek near: : : : 211

Los Trancos Creek at Stanford

University ....... 105

Lost Creek near Clipper Mills.... 232

Lower Lake, North Fork of Cache Creek

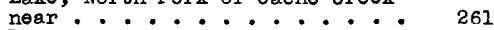

Lyons Dam, South Fork of Stanisiaus River below ........

McCloud River at Baird . . . . . . 210

near McCloud........... 209

Madrone, Coyote Creek near

Meriposa Creak near Lo Grand .... 155

Marysvilie, Calif., flood scene north of ............ 3, A

Medley Lakes outlet near vade

Melones power house, Stanislaus River below house, Stanislaus River

Melones Reservoir at Meiones Dam : : $\quad 176$

Merced River at Exchequer ... . . 160

at Happy Isles Bridge, near

Yosemite...?........

at kittridge : : *.:. . 158

at Pohono Bridge, near Yosemite : : 157

flood scene of, near Briceburg . . pl. 2

near Livingston ..... 161, 489

Merced River Basin, rainfoi and

mun-off in .307, 312, 322, 337, 370-372

Meteorologic conditions :. - . $22-71$

Middlo Tuolume River near Buck

196

Meadows .... . . . .

173 
M111 Creek Basin, rainfall and minoff in . 308, 314, 322, 338, 392-393

Milton, Middle Fork of Yuba River at.

Mokelumne Peak, Cold Creek near. .

Mokelume River at Lancha Plana:. : at Woodbridge .......... near Clements ........ near Moke lume Hill . . . . Midale Fork of, at West Polnt . North Fork of, below Salt Springs

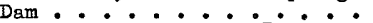

South Fork of, near West Point.

Mokelume River Basin, ralnfall and run-off in.308, 313, 322, 338, 383-385

Mono Creek near Vermilion Valiey .141, 488

Morgan Hill, Uvas Creek near....

Napa River Basin, rainfall and runoff in ....... 316, 323, 339

stage and discharge records in . 264

Newman, Orestimba Creek near . . . 163

San Joaquin River near . . : : 136, 487

Niles, Alameda Creek near . . . 114, 115

North Fork, Kings River above... 126

North San Juan, Middle Fork of Yubs R1ver near .........

Oregon Creek near : : : : : :

Oakland Recreation Camp, South Fork of Tholume River near . . Onyx, South Fork of Kern Riven 172 Oregon Creek near North San Juan 119,484 Orestimba Creek near Newman ..... 163 Orestimba Creek Basin, rainfali and run-off in $-312,322,338,353-354$ Oroville, Feather River near ... 221

Owens Lake Basin, rainfall and munoff in ? $309,316,324,339,417$ stage and discharge records in . $.275-280$

Owens River near Round Valley . . : 275

Pajaro River Basin, rainfal1 and runoff in . . 311, 321, 337, 350-352 stage and discharge records in .. 101 Palo Alto, San Francisquito Creek at. 104 Pardoe Camp, Bear Rlver at ....

Paskenta, Thomas Creek at . . . .

amintstration and

Pledra, Kings River at ....... 127

Pine Creek at division box, near Blshop ...........

P1tman Creek below Tamarack Creek .

Pit River at Big Bend........ at Fal1 River M111s: : : : : below P1t No. 4 dam ....... maximum stages and discharges of. near Canby ............ near Yalpom . . : : . . .

South Fork of, near Likely ...

P1t River Basin, rainfall and runoff in . 308, 314, 322, 338, 389-392

Placerville, Silver Creek near : . 257

Planada, Bear Creek near ... . - 154

Pleyto, San Anton1o River at. . . 99,483

Plum Creek near Riverton . . . . 255

Pohono Bridge, near Yosemite; Merced River at . $\cdot . \cdot . \cdot . \cdot$

Porterville, Tule River near: :

Potter Valley, Eel River at Van Arsdale Dam near - : - : -

Prattville, Lake Almanor near :

Precipltation, duration of

general features of .... . . :

Isohyetal maps of : : : : : : : :

records of

studies of

Putah Creek, maximum stages and discharges on ... . . . . .

near Guenoc ............

near Vinters . . . . . . . .

Putah Creek Basin, rainfali and runoff in . . . $316,323,339$

Pyramid and Winnemucea Lakes Basin, stage and discharge records in.283-286

Pyramid Lake Basin, rainfall and run-off in .........
Rancheria Creek, North Fork of

Kings River below ..... . 130

Red Bluff, Sacramento R1ver near : - 199

R1verton, Plum Creek near . . . . 255

Rock Creek at Sherwin Hill, near

Blshop ........... 276

Round Valley, Owens River near . . 275

Run-off. See Rainfall and run-off

Russian River, flood scenes on... pl. 10

Rainfall. See Preclpitation; Rainfail and run-off studies

Rainfall and run-off studies . . .306-422 comparison of conditions during

floods of record......336-340 general discussion of :.: : 306 results of, in Alameda Creek

Bas In .......... 311

In American River Basin. ' ${ }^{\circ}$ is 309 ,

In Bear Creek Basin . . .307, 312, 322

In Butte Creek Basin . . . . 308, 314

In Cache Creek Basin . . .316, 323, 339

In Calaveras River Basin $3 i 3,322,338$

In Carson River Basin ... 316

In Chico Creek Bas in $308,314,323,338$

in Chowchilla River Basin 307 ,

In Coyote Creek Basin .... 312, 321, 337

In Deer Creek Basin . . . 308, 314

in Eel River Bas in..... 316

In Elder Creek Bas in. $.314,322,338$

In Feather River Basin: : 308-309,

$314-315,323,338$

3i2, 321, 337

in Great Basin . . 309, 316, 324, 339

in Guadalupe Creek Basin 311, 321, 337

In Kern River Basin - $311,321,337,354-357$

In Klamath River Basin - $316,323,339$

In Merced River Basin: 312 , 322, 337

In M111 Creek Basin. 308, 314, 322, 338

in Mokelumne River Basin.? 308 ,

In Napa River Basin $313,322,338$

In Orestimba Creok Basin .316, 323, 339

$322,338,353$

In Owens River Basin 309, 316, 324, 339

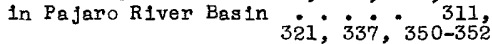

In P1t River Basin. 308, 314, 322, 338

in Putah Creek Bas in 316, 323, 339

In Pyramid and Winemuces Lake

In Sacramento River Basin : 308-309, $314-316,322-323,338-339$

In Salinas River Basin $321,337,350-352$

In San Francisquito Creek Basin. 311

in San Joaquin River Bas in . 307-308, $312-313,321-322,337-338$

In San Lorenzo River Bas In $:$ 311, $321,337,350-352$

in Smith River Basin... . . 339

in Stanislaus River Basin: 308,313

in Stevens Creek Basin ... . . 311

in Stony Creek Basin . : 314

in Thomes Creek Basin. : $314,323,338$

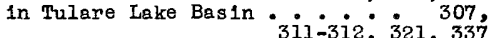

In Tuolumne River Bas in 307 ,

In Yuba River Basin. $\begin{array}{r}312-313,322,338 \\ . .309,315,323\end{array}$

Sacramento River at Antler . . . . 197

at Kennett.: : : : : : 198

at Sacramento and Yólo by-pass at

Issbon 201

at Verona ............. 200

crest stages on : : : $422-424,426$

effect of storage on ...... 304

flood scenes near Gerber: . : pl. 6

flood scenes on ...... pl: 5

maximum stages and discharges of : ${ }_{457}$

near Red Bluff......... : 199

Sacramento River Basin, maximum

stages of recorded floods in . 458 
Sacramento River Basinm-Continued previous floods in ...... 453-469 rainfall and mun-off in $308-309,314-316$ $322-323,338-339$

stage and discharge records of . .197-263 Sacramento Valley, flood scenes in. -pl. 9, A St. Helena, Conn Creok near.- : : 1,264 Salinas River noar Santa Margarita 99,482

Salinas River Basin, rainfall and mun-off in $.311,321,337,350-352$ stage and discharge records in . . 97-100 Salmon River at Somesbar .... 271

Salt Springs Dam, North Fork of Mokelume River below

Salt springs Reservolr near West Point 184 San Antonio River at Ployto... . 99,483 Sand Bar Flat, near Avery, Middle Fork of Stanislaus River at.

San Francisco Bay basins, provious floods in.........434-437 rainfall and mun-off in . . . . 413-417

San Franc1squito Crook at Palo Alto. 104 at Stanford University ..... 103

San Francisquito Crook Basin, rainfall and mun-off in.?...

stage and discharge records in :.103-105

San Joaquin Rivor above Big Crook . : 132

below Kerckhoff power house. . . 133

below Skaggs Bridge.: : : : : 132

crest stages on : * : : $422-423,425$

maximum stages and discharges of. - 452

miscollanoous flood stages on - : i 95

near Frlant . . . . - : i34, 487

near Newman : * : : : : : : 136, 487

South Fork of, near Firince Lake: 139

San Jokquin Rivor Basin, previous

floods in.........444-453

rainfall and mun-off in ... 307-308, $312-313,321-322,337-338$

stage and discharge records in . .132-196 San Joaquin valley, flood scenes in: pl. 11

San Jose, Guadalupe Creөk at . . . 108

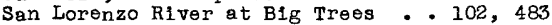

San Lorenzo River Basin, rainfali

and run-off in. $311,321,337,350-352$

stage and discharge records in . - 102

Santa Margarita, Salinas River near .97, 482

Saratoga, Campbell Creek at ..... 111

Scotia, Eel River at : * : : : : 270,498

Shasta River near Yroka : : : 270,490

Shaver Lake near Big Crosk Creek at C1ty, North Fork of Yuba River

Silver Creok at Union valiéy : : :

near Placervilio : : : . : :

South Fork of, near Ic $\dot{\theta}$ Housi : :

Silver Lake outlet near Kirkwood .

Skaggs Bridge, San Joaquin RIver below.

Slope-area observations, computation of flow from ........

Smartvilie, Deer Creek near. : :

Yuba River at..............

Smith River Basin, rainfal1 and runoff in . . . . . . . . .

Snow, relation of, to floods . . Soledad, Arroyo Séco near..... Somesbar, Klamath River at .....

Salmon River at .........

Southern Pacific basins, provious floods in........ 433, 434

rainfall and mun-off in : : : $350-353$

Spanish Creek at Keddie... . . 223

Spreckels, Salinas River near... .98, 482

Stanford Unfversity, Los Trancos Creok at * - * - * - •

San Francisquito creek

Stanislaus River below Melones power house de Fork of, at Sand Bar Flat,

North Fork of, near Avery: : :

South Fork of, at Strawbery

Reservolr "beiow Ljons Dam :
South Fork of,

256
257
258

258

135
Stanislaus River Basin, rainfall

Page and run-off in ..... 308, 313

Stevens Crook near Cupertino . . . 106

Stevens Creek Basin, rainfall and run-off in *. *.*. . 311

stage and discharge records in 106

Stony Creek above Stony Gorge

Reservolr......... 216

maximum stages and discharge on . 468

stony Creek Basin, rainfall and

run-off in ........ 314

Stony Gorgo Reservoir near Eik Croek. 217

Stony Creek above... . . . . 216

storage, $\theta$ ffects of, on mun-off: . .300-306

on Secramento River.....304-306

on Sar Joaquin River ... . . 302-304

outside tho Central Vailey . : .305-306

Storrio, Grizzly Crook noar .... 226

Strawborry Reservolr, South Fork of Stanislaus River at.....

Success, South Fork of Tule River

near . * - * *....

Sutter Croek near sutter Crook . .

Tahoo, Lake Tahoo at ........ 283

Truckee River at . : : : : : 284

Tamarack Crook, P1tman Creok below. - 144

Temperature, relation of, to floods . 56-65

Tenaya Creok near Yosem1te.... 162

Thomas Croek at Paskenta .... . 213

Thomas Creok Basin, rainfail and mun-off in?............. 323, 338

Threo Rivers, Kaweah River near. 124

Trinity River at Lewiston...: : 272

near Burnt Ranch ........ 273

noar Hoopa . . . . . . . . . 274

Truckeo, Donner Creok near ... . 286

Truckeo River at Icoland ..... 285

at Tahoe . . . . . . . . . 284

Tulare Lake in Kings county : : : i21, 485

Tulare Lake Basin, flood scene in

June 1938 ......... pl. 13

previous floods in ... . . 437-440

rainfall and run-off in : $307,311-312$

321,337

stage and discharge records in . .121-131

Tule River near Porterville..... 122

South Fork of, near Success: . - 123

Tuolumne River above La Grange Dam, near la Grange .... 167

maximum stages and discharge of . 452

neer Hetch Hetchy . ....... 165

South Fork of, near Oakland

Recreation Camp.......

Tuolume River Basin, rainfall and run-off in : $307,312-313,322,338$

Tuttle Creek at Canyon Road, noar

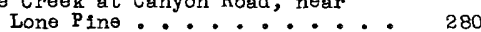

75 Vade, Medley Lakes outlet near $\cdot \dot{*} \cdot$

$\begin{array}{lll}242 & \text { Valley Springs, Cosgrove Creek near : } & 183 \\ 235 & \text { Van Arsdale Dam, Eel River at . . : } & 267\end{array}$

Vermilion Valley, Bear Creek near. 140

339 Mono Creek near....... 141, 488

65-71 Vernal1s, San Joaquin River near.: 137, 487

100 Verona, Sacramento RIver at..: : 200

269 Vina, Deer Creek near...: 214

Walker Lake Basin, stage and discharge in ......... 281

West Polnt, Middie Fork of Mokelumne

River at ........... 192

Salt Springs Reservolr near... 184

South Fork of Mokelume River near. 193

105 Wheatland, Bear River near : : : : : 243
103 Whitehall, Alder Creek near : : 254

Willow Creek, North Fork of, at .146

Winemucca Lakes Basin, Pyramid and; ca Lakes Basin, Pyramid and,

stage and dscherge records in 316

$\begin{array}{ll}\text { Winters, Putah Creek near . : : : : } & 263 \\ \text { Toodbridge, Mokelume RIver at : } & 189\end{array}$

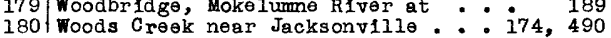




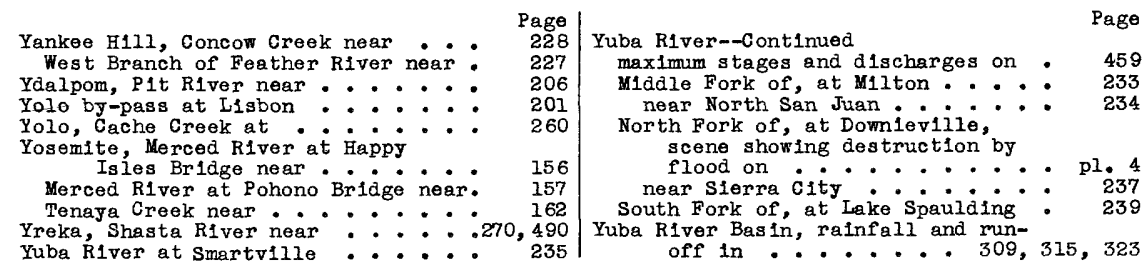




